QL

535.1

L8X

ENT 


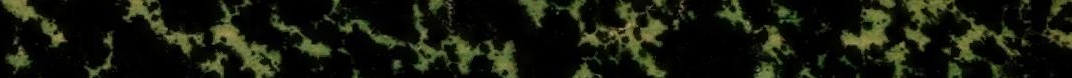

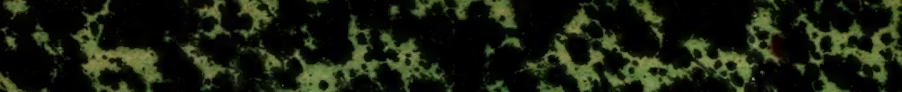

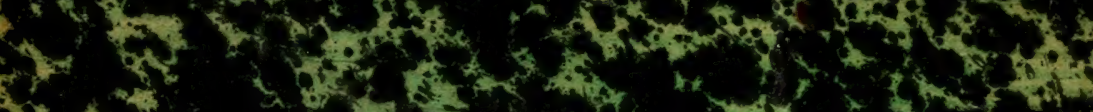

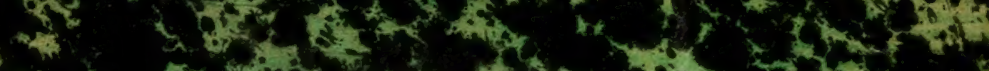

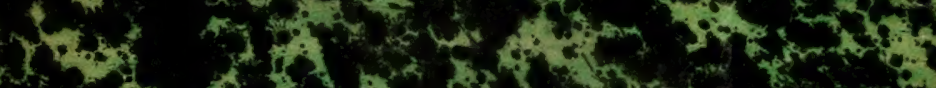

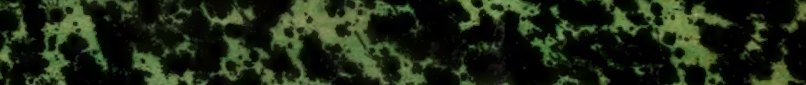

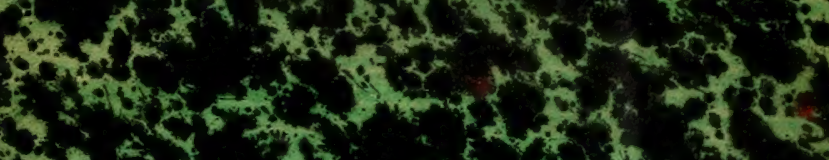

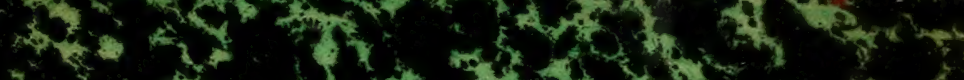

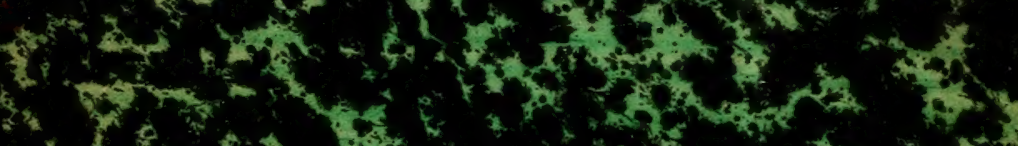
t.

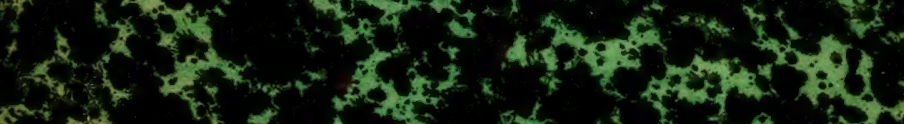

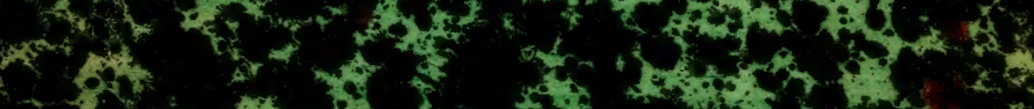

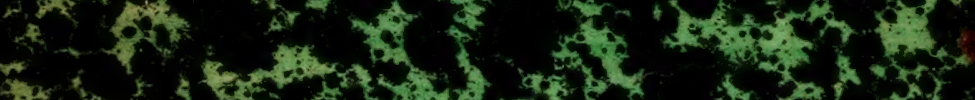

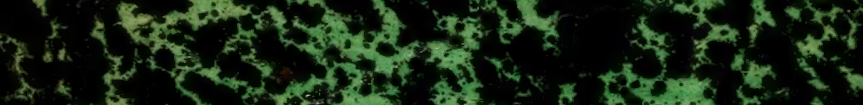

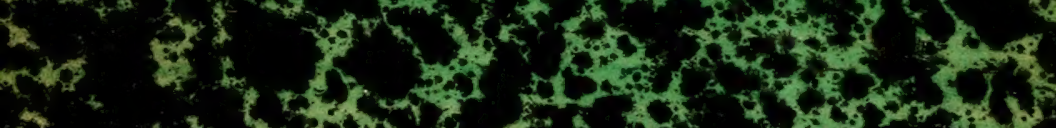

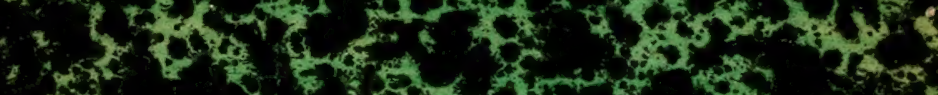

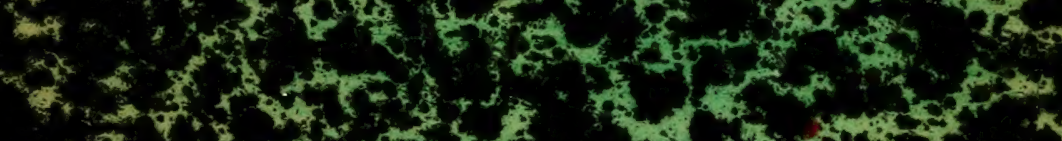

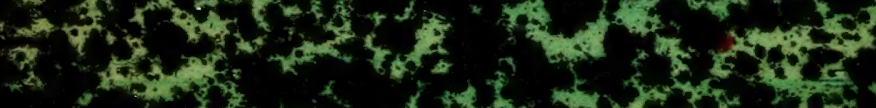

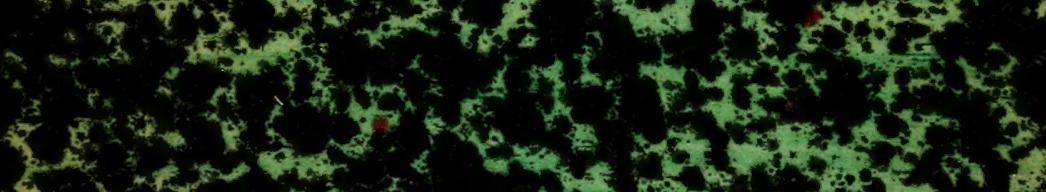
4

. te (1) st

co

(t)

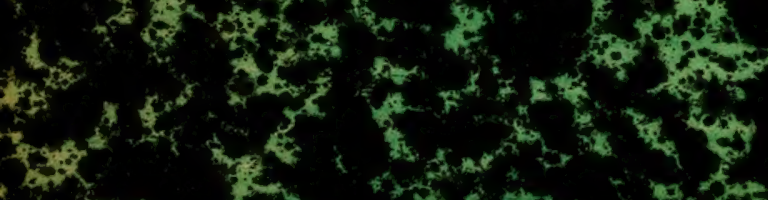
1.5. 
Published in Berliner Ent.Ztsch., as follows:

1. $\mathrm{v}, 1861,307-359$

2. vi, 1862, 185-282

3. vii, 1863, 1-55

4. vii, 1863, 275-3?6

5. viii, 1864, 49-99

6. ix, 1865, 187-186

7. $\mathrm{x}, 1866,1-54$

8. xiii, $1869,1-52$

9. xiii, 1869, 129-186

10. xvi, 1872, 49-119

I have penciled the original pagination all through. JMA.

ation all through. Jila.
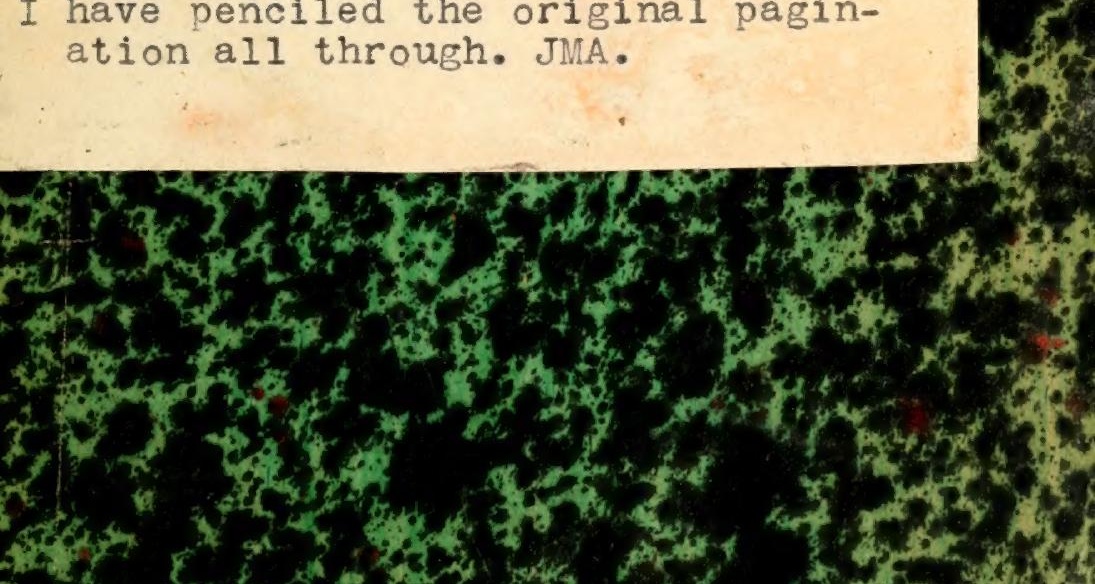

ReGine' Thuch $^{3} 1-43,50$

A. L. MELANDER

From the Library of

J. M. ALDRICH 




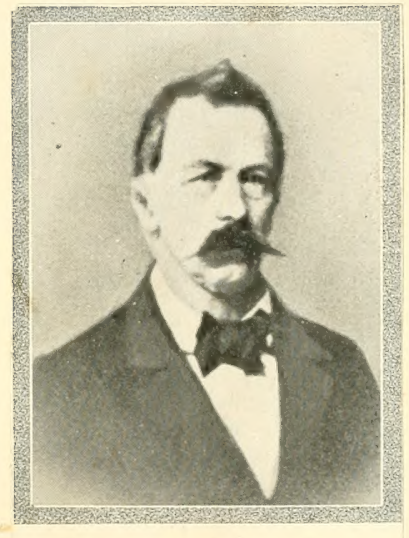

H. Loew. 


\section{Diptera}

\section{Americae septentrionalis indigena.}

Descripsit

H. I 0 e w. $5 \times x_{0}$. 64 .

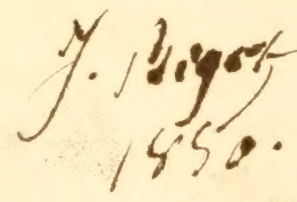

Berolini.

Typis A. W. Schadii.

1861 . 


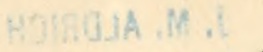

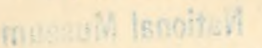

(4) notanthenth

farity

- it. 2 ?

atid

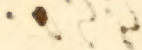



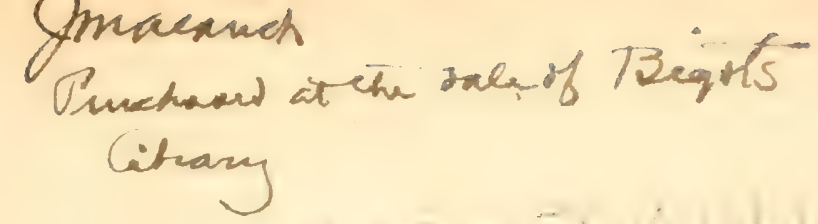

\section{Diptera Americae septentrionalis indigena.}

Descripsit

II. I, o e w.

Centuria prima.

1. Tanypus pinguis.

2. - favicinctus.

$3 . \quad$ - tricolor.

1. Ceralopogon trinialis.

$5 . \quad$ - argentatus.

6. - bimaculatus.

7 - albiventris.

\$. - setulosus.

$9 . \quad$ - opacus.

10. - longipennis.

11. plebejus.

$12 . \quad$ rufus.

13. - festivus.

14. Dilophus longiceps.

15. - serotinus.

16. Arthropeas americana.

17. Chysopila velutina.

18. - foeda.

19. - rolundipennis.

20. Leplis terminalis.

21. - hirta.

22. - scapularis.

23. Brachystoma serrulata.

24. Syneches rufus.

25. - pusillus.

26. Syndyas dorsulis.

27. polita.

28. Empis obesa.

29. - sordida.

30. - pallidre.
31. Eimpis poeciloptera.

32 - armipes.

3:3. - labiata.

31. - varipes.

35. Pachymeria pudica.

36. Rhamphomyia dimidiala.

37. - laevigata.

$38 . \quad$ longicauda.

39 - fumose.

40. - pulchra.

41 - glabra.

42. - sellata.

43. - grucilis.

44 - pulla.

45.

46.

47.

$4 \mathrm{~s}$.

49.

50.

51.

52.

5.3.

54.

55.

56.

57.

5.

5 !).

60. debilis.

longipennis.

longicornis.

gilvipes.

pectinata.

luctifera.

corvine.

brevis.

clavigera.

priapulus.

angustipennis.

conjuncta.

vara.

- sordida.

crussinervis.

limbate. 
61. Rhamphomyia lituratu.

62.

63.

64.

65.

66.

67.

68. Tropidia mamillata.

69. Tetanocera triangularis.

$70 . \quad$ rolundicornis.

71. Sciomyza luclifera.

72. Trypeta alba.

73. - albidipennis.

74. - Vernoniae.

75. Pallopteru superba.

76. Sapromyza compedila.

77.

fraterna.

78.

79. quadrilineala.

80.

\$1. Sapromyza cincta.

82. Pachycerina verticales.

83. Iantania variegata.

84.

opaca.

\&5.

86. - obscura.

87. - muscaria.

88. - manuleata.

89. - femoralis.

90. - trivilluta.

91. Discocerina orbitalis.

92. - simplex.

93. - leucoprocta.

94. Hydrellia formosa.

95. Philygria opposila.

$96 . \quad$ - debilis.

97. Parydra abbrevialse.

98. Scatella obsoleta.

99. Milichia picla.

100. Diastala pulchra.

1. Tanypus pinguis nov. sp. ․ Niger, nilidus; alae cinereo-hyalinae, nudae, venis crassioribus obscure fuscis; halteres albidi; pedes antici piceo-nigri, femorum basi fluvá; pedes posteriores favi, summo tibiarum apice tarsorumque dimidio apicali nigris. Long. corp. $1 \frac{2}{3}$ lin., Long. al. $1 \frac{7}{1} \frac{7}{2}$ lin.

Tanypo nervoso simillimus, sed antennarum basi flavâ halıeribusque albidis certo distinctus. - Ex piceo niger, nitidus. Palpi fusci. Facies et frons sordide ferrugineae. Anlennae fuscae, scapo et infumis flagelli articulis flavis. Plcurae ferruginae; pectus flavum. Pedes antici ex piceo nigri. coxis femorumque triente basali flavis; pedes intermedii flavi, tibiarum basi infuscati. tihiarum apice tarsorumque dimidio apicali inde ab articuli primi apice ex fusco nigris; pedes postici flavi, tibiarum apice tarsorumque dimidio apicali inde ab articuli secundi apice ex fusco nigris. Halleres ex flavo albidi. Alae cinereo-hyalinae, nudae, venis subtilioribus pallide fuscis, validioribus obscure fuscis. (New York; Edwards.) 
2. Tanypus flavicinctus nov. sp. б. Piceo-niger, nilidus, segmentis abdominalibus singrulis in basi favis; alae hyalinae, mulue, venis crassioribus fuscis; halleres albidi; pedes favi, tibiarum anticarum posticarumque apice tursonumque omnium dimidio apicali nigris - Long. corp. $1 \frac{1}{2}$ lin., Long. al. $1 \frac{1}{3}$ liu.

Ex pireos nizer, nitens. Palpi flavi; facies flava. Antennae obscure fuscae, pilis fuscis penicillatac. Pleurae ferrugineae. Basis scgmenforum abdominalium anteriorum continue et lalius, posterio. rum interupte et anguslius flava. Forceps analis obtusus, segmento septimo aequalis. Pedes flavi, apice tibiarum anticarum latius, posticarum angustius nigro, tarsis anticis inde ab primi, posterioribus ab articuli secundi apice nigris. Alae nudae, hyalinac, vix dilutissime cinerascentes, venis tenuioribus testaceis, validioribus fuscis. - (Penusylvania.)

3. Tanypus tricolor nov. sp. 오. Flavescens, thoracis vittis ex rufo ferrugineis. fusco marginalis, abdominis nigri basi segrmentorumque singulorum margine postico flavis; pedes nigro-anmulati; alae hyalinae, mudae, venis longitudinalibus pallidis, transversalibus e.t nigro fuscis et fusco limbatis. - Jong. corp. $1 \frac{3}{4}$ lin., Long. al. $1 \frac{5}{6} \mathrm{lin}$.

Caput pallidissime flavescens. Palpi fusci. Antennae breviusculae, fuscae, scapo dilute flavo. Thoracis maculae humcrales et pleurae pallide flavescentes; viltae dorsales confluentes. ex rufo ferrugineae, fusco marginatae. Scutellum fuscum, villulà medià flavà. Metanotum ex fusco nigrum. Pectus ferrugineum. Primum abro. minis segincntum totum flavum; secundum flavum, basi fuscà se. gmenta relípua nigra, postico singulorum margine flavo. Pedes flavi, nigro-annulati; annulus femorum medius latior, sed obsoletus, apicalis angustior et distinclus; tibiarum anumli distincli, alter sub. basalis lalissimus, alter apicalis angustus. Tarsi antici inde ex articuli primi apice nigri; tarsorum posteriorum articuli primi in apice, articuli reliqui toli nigri. Halleres pallide flavicantes. Alae hyalinae, nudae, venis longitudinalibus flavicantibus. t:ansversis ex nigro fuscis et fusco limbatis. - (New York; Eilwards.)

4. Ceratopogon trivialis nov. sp. O. Ater mitidus, fromte halterumque rapitulo concoloribus, pedibus luteis. tibiis et tursis omnibus femorumque postirorum dimidio apicali obscurioribus: femora antica non incrassata, sublus spinosa: ultimus larsorum arliculus parvus: simplex, non spinosus, unguiculis minulis subuequa- 
libns armatis: alne mudae, cinereae, venis anterioribus fuscis, cellularum submarginulium secundá triplane fere primae longiludinem aequante. - Long. corp. 1 s lin., Long. al. 2 lin.

Ater, nitidus. Frons angustissima, concolor. Facies ferruginea aut obscure picea. Antennarum scapus ochraceus aut ferrugineus; flagellum teute, nigro-fuscum, articulis inferioribus plerumque ex parle teslaceis. Palpi obscure testacei, apicen versus nigro-fusci. Thorax totus ater, nitidissimus; scutellum thoraci concolor. Abdo. men atrum. minus nitens quam thorax. basi interdum piceâ. Pedes anteriores lniei, tibiis tarsisque fuscis, busi tamen borum luteâ; pedes postici nigri, femorum triente basali luteo tarsisque fuscis; in speciminibus immaturis color fuscus in sordide luteum, niger in fuscum abit. Femora antica non incrassata, subtus spinosa; ultimus farsorum articulus simplex. minutus, non spinosus, unguiculis minutis subaequalibus armatus. Halterum capitulum nigrum. peduncolus lufrus. Alae nudac, ex fusco cinereac, venis pallide fuscis; cellularum suimarginalium secunda triplam fere primae longitudinem aequans. - (Washinglon: Osten-Sacken)

5. Ceratopogon argentatus nov. sp. ‥ Aler, nitidus, abromine candido micante, pedibus anterioribus luleis, genibus tibiarumque brsi nigris ant fuscis, pedibus postiris nigris, femorum anmalo subapicali tibiarumque apice lnteis; femora omnia simplicia. inernia: ultimus tarsorum albidorum articulus niger, subtus spinosus: unguiculi tarsonum anticorum subcequales, posteriorum valde inuequales: alae uudae, venis anterioribus fuscis, cellulá submarginali secundá quadruplam primae longtiudinem fere excedente. Long. corp. $\frac{5}{5}$ lin., Long. al $1 \frac{1}{1} \frac{1}{2}$ lin.

Aler, nitidus. Oculi in fronte contigui. Antennarum scapus ex luteo rufus aut ferrugineus, flagellum tenue, fuscum articulis inferioribus teslaceis. Facies ex luteo rufa. Palpi concolores, articulo ultimo nigro. Thorax ater, nitidus. Scutellum thoraci concolor. Abdomen candido-micans. Pedes anteriores lutei aut ex rufo lutei, genibus tibiarumque basi fuscis aut nigris; pedes postici nigri, aunulo femorum subapicali ex luteo rufo tibiarumque apice luteo. Femora omnia simplicia, non spinosa. Tarsi omnes albidi, articulo ultimo longo, aut fusco aut nigro, subtus spinoso; unguiculi tarsorum anticorum mediocres subaequales; tarsornm posteriorum unguiculus exterior mediocris, interior minntissimus. IIalterum eapifulum nigrum, pedunculus loteus. Alae nudae, cinereo-hyalinae, venis an. terioribus crassis, fuscis, cellulà submarginali secundà quadruplam 
primac longiludinem aut aequante aut nonnihil superante. - ( Wa. shington; Oslen-Sacken).

Nota. Heteromyia fasciata Say nisi eadem. certe vicina huic speciei videtur. quâ de re, quibus occasio est. adeant Sayi descriptionem, quam ipse inspicere non potui.

6. C'eratopoggon bimaculatus nov. sp. ․ Ater, nilidus, antennamum scapo, facie, palpis, pectore cum coxis pedibusgue flavis, femorum posticurum annulo nigro; femora simplicia, non spinosu: tarsorum articulus ultimus incrussalus; alue mudae, cellulis submarginalibus duabus maculisque duabus nigricumibus. - Long. corp. $1 \frac{1}{3}$ lin., lang. al. $1 \frac{1}{6}$ lin.

Gracilis, ater, nitidus. Frons latiuscula, afra, nitida. Antennarum scajus laete flavus; llagellum tenuissimum nigrum, arliculis inferioribus lomgioribus quam in congeneribus plesisque. Facies flava; palpi concolores. Thoras aler, nitidus; pleurarum pars superior atra, inferior flava, vitta candido-micante ornata. Seulellum el abdomen nigra. Pedes flavi, femoribus omnibus rectis, tenuibus, simplicibus, non spinosis, posticis annulo subapicali nigro cinclis. Tarsorum articulus quartus brevis, nigricans; articulus quintus infuscatus, in tarsis anticis incrassatus et unguiculis aerualibus armatus, in tarsis posterioribus non incrassatus et unguiculis inaequalibus praedilus. Halteres albi. Alae nudae, cinerascentes. maculis dua. bus uigricantibus subcostalibus pictae; cellula submargiualis secunda quadıuplam primae longiludinem aequat. - (Washington; OstenSacken.)

7. Ceratopogon albinentris nov. sp. O. Mer, nilidus, antemnarum scrupo et flagelli dimidio basali, hallerum perlunculo, abdomine et primis tribus tarsorum arlirulis albis; femorre simplicia, inermia: alne nudae, albidae, celludi submarginali unica perlongá. - Long. corp. $1 \frac{1}{2}$ lin, l.ong. al. $1 \frac{2}{3}$ lin.

Frons ansusta. atra. Anlenuarum scapus ex luleo albidus; dimidium flagelli basale albirlum, apicale nigrum. Facies ferruginea; palpi fusci. Thorax tolus afer, nitidus: sculellum comoolor. Abdomen albun. Pedes atri, tribus primis tarsorum articulis albis; fe. mora ommia simplicia. non syinosa; ultimus farsmom articulus sublus spinosus, mguieulis minutis subacqualibus amalus. Halierum capilulum nigrun. pedunculus albus. Alat nudae, albidae, venis anterioribus pallidissine lutescentibus. cellulì submarginali unich, alae apicem fere altingente. - (Georgia; Osten-Sacken.) 
S. Ceratopogon setulosus nov. sp. I ct $\sigma^{\top}$. Albidus. opacus, thorace fusco albido-pollinoso, punclis et maculis obscurioribus picto, pedibus nigro-cingulutis: femora ommia simplicia, prope apicem setigera: ultimus tarsorum arliculus non selosus, unguiculis minutis aeyualibus; alae nudae, subcinerascentes, venis ommibns concoloribus, cellulá submarginali mnicá longá. - Long. corp. I- liu., long. al. $1 \div$ lin.

Caput ex ferrngineo fuscum. Antennarum scapus fuscus aul ferrugineus: flagellum mediocre fuscum, articulis inferioribus subglo. bosis pallidis, summo singulorum apice nigro; penicillum antenuale maris colore pallide orichalcen micans. Thorax fuscus, opacus, in dorso albido.pollinosus, relictis vittâ mediâ duplicatâ et vittâ utrinque laterali obscurioribus, illâ postice, hâc antice valde abbreviatâ. Sculclum Inlenm. Ablomen albidım, interdum subfuscum. Coxae ex nigro fuscae. Femora omnia prope apicem setulis rigidis praedita; libiae posticac in latere superiore seligerae. In femoribus anlicis basis, annulus subapiralis et extremus apex. in femoribus intermediis basis ef apes nigri smnt; femora postica nigra annulo medio latissimo albido cingunfur. Tibiae albidae, anticarum annulo subbasali, basi posteriorum et extremo omuium apice nigris. Tarsi albili, extremo articulorum singulorum apice nigro, arliculo ultimo inermi, unguiculis aequalibus minutis armato. Halteres albidi. Alae nudae, hyalinae. subcincrascentes, cellulâ submarginali unicâ longâ. - (Washington; Osten-Sarken.)

9. Ceralopogon oparus nov. sp. T. I’allide fuscus, opacus, pectore pedibusque pallide testaceis, tarsis udversus apicem nigris; femora omnia simplicia, non setigera; ultimus tarsorm artimulus simplet, ungniculis minutis aequalibus armatus; alae nudae, cinereo infumatae, oprecae, celluli sulmarginali unira. - Long. corp. $\frac{3}{4}$ lin., Long. al. I lin.

Pallide fuscus, obsolcte cinereo-pollinosus, opacus. Antennae fuscar. inferioribus llagelli arliculis subglobosis, pallidis. Palpi sordide tristacri. Pedes simplices, pallide tesiacei. breviter et subtiliter pubcscentes, femoribus omnibus incrmibus; ultims farsorum articulus simplex, unguiculis minutis aequalibrs. Malleres reliquo corpori concolores. Alae nudae, cinercac, opacae, adversus costam et basim limpidiores, cellulì submarginali unicâ. simplici. - (Washington: Osten-Sacken.) 
10. Ceralopogon longipennis nov. sp. ․ Fusrus, opacus, dorso thoracis albido-pollinoso, punctis fuscis adsperso; pedes nigro el luteo varii, larsis albidis; femora anlica recurvv, femora omnia subtus spimulosa; ultimus tarsorum articulus spinosus, unguiculis magnis subaequalibus armatus; alae albidae, venis anterioribus lutescentibus, cellulà submarginali secunda fere guadruplam primae congifudinem aequante. - Long. corp. 2 lin., Long. al. $2 \frac{1}{4}$ lin.

Fuscus, opacus. Oculi in fronte contigui. Antennarum scapus ferrugineus, rarius ex luter feriugineus; flagellum tenue, fusco-nigrum, articulorum inferiorum basi teslaceâ. Facies fusca. Palpi fusco-nigri. Thoracis dorsum leviter albido-pollinosum, punctis dispersis et vittâ mediâ duplice postice abbreviatâ obscurioribus. Scutellum ferrugineum. Abdomen fuscum ant fusco-nigrum, polline tenui albido obsoleto, in speciminibus obscuris fere nullo tectum. Femora antica recurva, subtus spinulosa, nigra, annulo subapicali luleo; tibiae anlicae aul tolae nigrae, aut in basi luteae. Femora posteriora subtus spinulosa, nigra, basi et annulo subapicali luteis; tibiae posteriores aut totae nigrae, aut ex fusco lutene, basi et apice nigris. Tarsi albidi, summo articulorum siugulorum apice nigro, arliculo ultimo aut pallide fusco ant nigio, sublus setoso, unguiculis permagnis subaequalibus armato. Halteres a!bi. Alae nudae, albicantes, venis anterioribus lutescentibus, cellulâ submarginali secundì perlongà, fere quadruplam primae longitudinem aequiparante. - (Penusylvania; Oslen-Sacken.)

11. Ceratoporon plebejus nov. sp. T. Ater, antennarum scupo, ventre pedibusque luteis; alue mudae, hyalinae, nenis anterioribus obscure fuscis cellulisque subnarginalibus durbus: femora antiru valde incrassala et sublus spinosa; ullimus tarsorm arliculus simplex. unguiculis minutis requelibus. - Long. corp. $1 \frac{1}{1}$ lin.. bong. al. I lin.

Aler, nitidus. Frons angusta, alı. Antemnarum scajus flavus, flagellum teuuc abseure fuscum. Facies ferruginea. Palpi sordide lulei. Thorax lotus ater, nilens, pleurarum maculi subalari obsolele albo-micante. Sculellum atrum, nitidum. Abdomen alrum, imâ basi et ventre lulescentibus. Coxarum apex et pedes llaving genibus et ultimo tarsormu articulo atris; femora anlica valde incrassala, sublus nigro-spinosa; ullimus tarsorum arliculus minulus, simplex, subtus non spinosus, unguiculis minulis subaequalibus armalus. Alae nudae. hyalinae. venis anlerioribus nigro-fuscis. cellulis submargina- 
libus duabus, secundâ duplam primae longitudinem aequante. (Pennsylvania; Osten-Sacken.)

12. Ceratopogon rufus nov. sp. 오. Ex rufo flavus, antennarum flagello. metanolo, abdomine, femorum apice tibiisque posticis obscuris; alae nudae, hyalinae, venis anterioribus fuscis cellulisque submarginalibus duabus; femora antica incrassata, subtus spinosa; ultimus tarsorum articulus simplex, unguiculis minutis

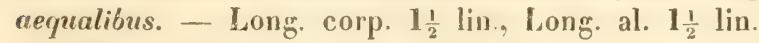

Ex rufo flavus, nitidus, capite toto et antennarum scapo concoloribus, antennarum flagello tenui, nigro-fusco. Palpi apicem versus nigricantes. Thorax tolus ex flavo rufus, nitidus, maculâ pleurarum subhumerali absolete albomicante. Scutellum thoraci concolor. Melanolum fusconigrum, nitidum. Abdominis color adversus basim in flavum, adversus apicen in fuscum mutatur. Pedes ex rufo flavi, apice femorum anteriorum anguste, posticorum late nigro; femora antica incrassata, subtus nigro-spinosa; tibiae posticae reliquis obscuriores, annulo subbasali latissimo et summo apice nigro-fuscis; ultimus tarsorum articulus mediocris, simples, subtus non spinosus, unguiculis minutis subaequalibus armatus. Alae nudae, byalinae, venis anterioribus fuscis, cellulis snbmarginalibus duabus, secundâ duplam primac longitudinem aequante aut paullo exce. dente. - (Pennsylvania; Osten-Sacken.)

13. Ceralopogon festivus nov. sp. $\delta$ et 오. Rufus, nigro-varius: alae nudae, hyalinae, maculis duabus nigricantibus, primấ minulá, secundấ permágna, ornatae; femora antica maxime incrassata, sublus spinosa; tibine anticue arcualae.

б" penicillum antennale orichalceum, abdomen rufo et fusco annulatum.

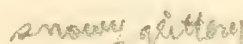

of abdomen niveo fmicans, tarsi postici longissimi. unguiculo unico permagno.

Long. corp. ठ大 $1 \frac{7}{12}$, ㅇ $1 \frac{1}{1} \frac{1}{2}-2$ lin., Long. al. $1 \frac{5}{6}-1 \frac{1}{2}$ lin.

Rufus, nigro-varius, nilidus. Caput ex flavo rufum. Scapus antennarum capiti concolor; flagellum tenue, dimidio basali pallide leslaceo, apicali fusco; penicillum aulcmale maris colore orichalci micans. Palpi nigri, basi rufeseente. Thorax rufus, nilidus, subtiliter transverse aciculatus. villis tribus atris ornatus, medià postice, lateralibus antice abbreviatis. omnibus inferdum diffluentibus. Pleurar rufae, interdum fusco-maculatac. Seculclum ex flavo rufum. Abdiomen maris rufum, annulo segmentorum singulorum nigro-fusco, 
segmento ultimo toto nigro, appendicibus analibus flavis; abdomen foeminae candido-micans. Femora antica crassissima, sublus nigrospinosa; tibiae anticae arcualae, ex rufo fuscae, apice acuto; femora media tenuia, recta; femora postica valga, dimidio apicali crassiore; tibiae posteriores fuscae, apice rufescente; tarsi ex albo flavescentes, articulo ultimo simplici, subtus non seloso; tarsi postici foeminae valde elongati, tenues, ungniculo perlongo unico; reliqui foeminae tarsi larsique maris omnes unguiculis duobus minutis subaequalibus armati. Alae nudae, hyalinae, venis plerisque fuscis, maculis duabus nigricantibus ornatae, maculâ primâ minutâ in angulo axillari sitâ, maculà secundâ permagnâ costae contiguâ et maculam hyalínam, pone cellulas submarginales sitam includente; cellula submarginalis secunda triplam primae longitudinem aequiparat. - (Pennsylvania; Oslen-Sacken.)

14. Dilophus longiceps nov. sp. $\sigma^{7}$ et 오. Caput elongatum; pecten prothoracis anterior non interruptus; tibiae anticae spi$n$ is mediis et apicalibus armatae; alae albicantes. stigmate fusco. - Long. corp. $\frac{5}{6}$ lin., Long. al. $\frac{1}{1} \frac{1}{2}$ lin.

M as: Tolus nigerrimus, nilidus, pilis albidis vestitus. Capitis pars, quae aute oculos sila est, elongata, cylindrica. Halterum nigrorum pedunculus pallidior. Pubes totius corporis pallida Alae albicantes, stigmate angusto fisco, venis anterioribus pallide fuscanis, posterioribus albidis.

Foemina: Caput nigrum, valde elongatum. Thorax niger, nitidissimus, prothoracis marginibus lateralibus late testaceo-rufis, pleuris testaceis. Pedes testacei, trochanteribus, tibiis tarsisque fuscis, femoribus anticis valde incrassalis. Halterum nigrorum pedunculus pallidior. Alae albidae, flavedine quàdam levissime tinctae, stigmate angusto fusco, venis anterioribus pallide fuscanis, posterioribus subalbidis. - (Illinois; Osten-Sacken.)

15. Dilophus serolinus nov. sp. ठ et 오. Anterior pro thoracis pecten non interruptus; tibiae anticae spinis mediis et apicalibus armatae: alae nigrae, prope marginem anticim obscuriores.

бँ totus niger, nilidus, albido-pilosus.

I nigra, thorace toto, coxis femoribusque rufis.

Long. corp. 3-3 $3 \frac{1}{6}$ lin., Long. al. $2 \frac{3}{4}-3 \frac{5}{12}$ lin.

Mas: Nigerrimus, nitidus, pube totius fere corporis flavido-albi, oculorum, segmentorum abdominalium ultimorum, libiarum tarsorumque nigricante. Halteres nigri. Alae fusco-nigrae, adversus mar- 
ginem anticum obscuriores, stigmate magno atro, venis validissimis fuscis.

Foemina: Caput totum nigrum, non magis quam in Dilophis plerisque elongatum. Thorax totus rufus, marginibus prothoracis lateralibus et anteriore, villà inaequali ab alarum basi ad prothoracem ductâ scutelloque piceis. Abdomen nigrum, nitidum, pube brevi pallidà instructum. Pedes rufi, trochanteribus piceo-nigris, tibiis tarsisque nigris; summus femorum apex, tibiae et tarsi nigro pubescentes. Halteres nigri. Alae fusco-nigrae, adversus marginem anticum obscuriores, stigmate magno alro, venis validissimis fuscis. - (Illinois, Osten-Sacken.)

16. Arthropeas americana nov. sp. 오. Ex rufo teslacea, frontis parte superiore viltisque tribus dorsalibus, latissimis, confluentibus, nigris, abdomine obsolete fusco-fasciato, alis fulve. scentibus, nigro variis. - Long. corp. $4 \frac{1}{2}$ lin., Long. al. $4 \frac{1}{2}$ lin.

Ex rufo testacea, brevissime pilosa. Frons nigra, prope antennas rufa. Occiput nigrum. In thoracis dorso vittae tres latissimae nigrae, per lineas flavido-pollinosas separatae. Scutellum cum reliquo corpore concolor. Abdominis segmenta singula fasciấ fuscâ basali, latissimâ, sed obsoletâ ornantur. Pedes fulvi, tarsorum apice fusco. Halteres rufo-testacei. Alae fulvescentes, triente apicali, limbo posteriore lato el liturì (posteriorem cellulae basalis primae partem cellulanque basalem sccundan tegente) nigricantibus, margine postico ipso dilutius fulvescente. - (Noth Wiskonsin.)

Observatio. Ab Arthrop. sibiricâ, ad quem prope accedil, frontis margine anteriore el facie rufo-testaceis, alis nou albicantibus, sed fulvescentibus et colore nigro latius pictis. fronte denique foeminae latiore diversa est. -

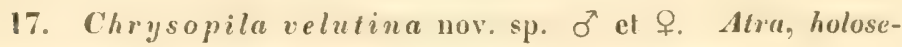
riceu, antennis palpisque concoloribus, tibiis tarsisque sordicle albis, alis atris, cellularum posteriorum discis elutis.

ठै copite, thorace ef abdoninis apice pilis nigris, veliguo abdomine pilis lutescrntibus ravioribus vestitis.

- tolo conpore brevissime nigro-piloso.

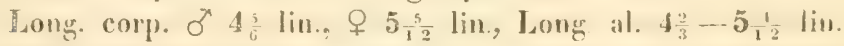

Pili lutescentes in maris abdomine longiores. sine ullo nilore. Summus femormm nigrorum apex testaceus. apex tarsorum fuscus. llalteres atri. Alae locminae obseuriores quan man is of celluamm poskeriorun discis distinctius elulis. (Illinois; Osten-Sacken) 
18. Chrysopila foeda nov. sp. ot et $q$. Sordide fuscu, opaca, pilis pallidissime sublutescentibus opacis parce vestita, tibiis tarsisque sordide testaceis, alis modice latis, cinereis, cellula costali fuscâ venisque omnibus fusco-limbatis. - Long. corp. $\sigma^{\top} 4$ lin., 우 6 lin. Long. al. $4 \frac{2}{3}-5 \frac{1}{1} \frac{1}{2}$ lin.

Obesa, sordide nigro-fusca, opaca. Oculi maris fronte lineari separati. Frons foeminae fusca, parte superiore obscuriore et bre. viter nigro-pilosà. Antennae nigrae. Palpi nigri, albido-pilosi. Thoracis dorsum et scutcllum pilis pallidissime flavescentibus, in margine illius laterali confertioribus vestita. Pili in abdomine nigro rariores, pallidissime flavescentes, ad marginem segmentorum singulorum posticum frequenliores. Femora nigro-fusca, summo apice testaceo; tibiac sordide, sed dilute testaceae; tarsi fusci, basi late testaceâ. Pedunculus hallerum fuscorum sordide testaceus. Alae angustiores, cinereae, cellulâ costali limbisque venarum omnium et marginis lotius fuscis. - (Illinois; Osten-Sacken.)

19. Chrysopila rolundipennis nov. sp. O. Testracea, pallide pilosa, alis lalissimis, rotundato ovalis, hyalinis, stigmate brevi, pallide fusco. - Long. corp. $2 \frac{1}{4}$ lin., Long. al. $2 \frac{1}{2}$ lin.

Pallide testacea, pilis pallide flavis rarioribusque nigris vestita. Caput pallide fuscum, occipite et facie albido-pollinosis; antennae testaceae; palpi-fusci. Pleurae cum metanoto dilute flavae. Abdomen subfuscum, apice et ventre flavis. Pedes pallide flavescentes, tarsis apicem versus fuscis. Ialteres dilute flavescentes. Alae latissimae, rolundato.ovatae, hyalinae, apice vix levissime cinerascente, venis ex flavo ferrugineis et stigmate brevi pallide fusco. - (Georgia, Gerhard.)

20. Leptis terminalis nov. sp. $\sigma^{\pi}$. Flava, capile et thoracis dorso (eaceptis marginibus) cinereis, tribus ultimis abdominis lutei segmentis in angulis anterioribus nigro-notatis, coxis unticis tolis, posterioribus aut totis aut maximá ex parte flavis, alis lutescentibis, immaculatis. - Long. corp. $4 \frac{1}{6}-4 \frac{1}{3}$ lin., Long. al. $4 \frac{1}{6}-$ $4 \div \frac{1}{2}$ lin.

Capul obscure cinereum, albido-pollinosum. Antennae flavac, articulo primo et selà totâ nigris. Facies et inferior occipitis pars albido-pilosae, margo verticalis nigro-pilosulus. Palpi flavi, pallide pilosi; proboscis palpis concolor. Thoracis dorsum nigro-pilosum, cinereum, callo humerali, vittà laterali el margine postico flavesecntibus. Pleurae flavo et cinereo maculatae, polline albo indutae. 
Scutellum flavım, nigro-pilosum. Abdomen lutcum, segmenforum trium ultimorum angulis anticis nigris; venter flavus, duobus ultimis segmentis atris, antepenultimi lateribus late nigris. Coxae flavae, posteriores in latere anteriore saepe infuscatae. Trochanleres nigri. Pedes flavi, dimidio femorum posticorum apicali, tibiarum posticarum apice tarsisıue omnibus fuscis, farsorum anteriorum basi flavâ. Alae lulescentes, apice levissime cinerascente, stigmate elongato, pallide fusco. - (New York; Kennicot.)

21. Leptis hirta nov. sp. ठ. Flava, capite thoraceque cinereis, abdominis pilis longis, in marginibus lateralibus pallidis, in reliquo abdomine nigris, maculá segmenti primi et fasciis sequentium subaequalibus atris, coxis anticis pallide flavescentibus alis $l u-$ tescentibus immaculatis. - Long. corp. $4 \frac{1}{12}$ lin., Long. al. $4 \frac{1}{1} \frac{1}{2}$ lin.

Caput obscure cinereum, albido-pilosum. Antennae flavae, articulis duobus primis et selâ tołà nigris. Facies et inferior occipitis pars albido-pilosae; margo verticalis brevissime nigro-pilosulus. Palpi graciles, flavi, pallide-pilosi; proboseis palpis concolor. Thorax nigro-pilosns, cinereus, callo humerali, vittâ laterali, margine postico pleurarumque maculis flavis. Scutellum flavum. Abdomen saturate flavum; pili abdominis longiores quam in reliquis speciebus, in tergo nigri, in marginibus pallidi; in segmento primo macula media subquadrata atrí cernitur; reliqua segmenta sin. gula fasciâ basali atrâ ornata sunt, fasciâ secundi utrinque valde abbreviati, tertii subintegrî, relifquorum fasciis integris, ultimorum postice emarginatis; venter flavus, duobus ultimis segmentis et antepenultimi lateribus late nigris. Coxae anticae totae flavae, posticae cinereae. Pedes flavi, liturâ femorum posticorum, apice libiarum posticarum tarsisque omnibus, exceptâ anteriorum basi, fuscis. Alae lulescentes, apice levissime cinerascente, stigmate elongato pallidissime fusco. - (Illinois; Osten-Sacken.)

22. Leptis scapularis nov. sp. J et 오 Flava, capite el thoracis dorso cintreis, ubdomine brevissime nigroppiloso, cingulis segmentorum singulornm basalibus atris subaequalibus, coxis anlicis lotis pallide favescentibus, alis lutescentibus immaculatis.

of pleuris cinereis, callo humerali favescente, palpis flavis in busi juscis.

I pleuris, callo humerali et villi llowacis laterali palpisque (olis Mavis.

Long. corp. of $3 \frac{7}{12}$, \& $3 \frac{1}{1} \frac{1}{2}$ lint, Long. al. $3 \frac{7}{12}-33_{6}^{5}$ lin. 
Caput cinercum, albido-pilosum. Antennac flavae, articulo primo in foeminâ, articulis duolıs primis in mare nigris, setae nigrae basi flavâ. Palpi graciles, pallide pilosi, in mare adversus basim fusci. Proboscis palpis concolor. Thorax maris lofus obseure cinereus. callo humerali flavescente; thorax foeminae llavus, florsi vittis tribus latissimis confluentibus nigro-rinereis, plenris cinereomaculatis. Pili in thoracis dorso breves, nigrie. Scutellum rt abdomen flava; abdominis segmentum primum immaculalum, reliqua fasciis basalibus atris, in mare aequalibus, in foeminâ postice emarginatis picta. Pili abdominis perbreves, in tergo nigri, in lateribus pallidi. Venter flavus, tribus ultimis segmentis in mare, quatuor vel quinque ultimis in foeminâ nigris. Coxae anticae in ulroque sexu pallirle flavescentes; coxae posteriores in mare totre cinereae, in foeminâ flavescunt. Pedes pallide flavi, annulo fenorum posticorum Iatissimo subapicali, tibiarum posticarum apice tarsisque ommibus fuscis. basi tarsorum anteriorum panllo dilutiore. Alae lulesentes, apice subcinerascente, stigmate elongato pallide fusco. - (Illinois; Osten-Sacken.)

23. Brachystoma serrulata nov. sp. ․ Capite thoraceque atris, abdomine obscure luteo, adversus apicem ex nigro piceo, pedibus flavis, alis ex luleo cinerascenibus, basim versus valde ungustatis, venae longitudinalis terticue ramulo anteriore ante alae marginem cum vená longitudinali tertia conjuncto. - Long. corp. $1 \frac{2}{3}$ liu., Jong. al. $2 \frac{5}{1} \frac{5}{2}$ lin.

Caput atrum, nitidum, fronte superius dilatatî. Facies anğustissima, albido-pollinosa; antennae desunt. Proboscis flava. Thorax cum scutello ater, nitidus, pleuris tenuiler albido-pollinosis. Abdomen elongatum. cylindricum, ex piceo sordirle huteum. basi et apice obscurioribus; venter luteus; ultimnm abdominis segmentum non inflatum, integrum, dimidio superiore cum inferiore in unum connato, margine postico pilis brevibus albidis densissime ciliato. Coxae et pedes pallide flavescentes, femorum posteriorum liturâ anticâ tibiisque posticis fere totis badiis, tarsorum omnium articulis duobus ultimis nigro-fuscis, articulis praccedentibus tarsorum anticorum fuscis, tarsorum intermediorum badiis; femora posteriora inermia, femora antica in apicali lateris inferioris parte spinulis brevissimis atris serrulata. Halteres flavi. Alae basim versus valde angustalae, ex luteo cinerascentes, venis validis ex luteo fuscis; ramulus venae longitudinalis tertiae anterior ante alae marginem cum venâ longitudinali terlià conjungitur. (Georgia; Gerhard). 
24. Syneches rufus nov. sp. ㅇ. Rufus, alis subhyalinis, maculá costali nigrâ. - Long. corp. 2 lin., Long. al. $2 \frac{1}{12}$ lin.

Paulo major quam Synech. simplex Walk., Synech. lhoracico Say aequalis et affinis. Ex ochraceo rufus, opacus, antennis. proboscide, palpis, halteribus pedibusque conconcoloribus, tibiis posicis plerunque, femoribus posticis et anticis interdum fuscis. Color abdominis in fuscum vergit. Alae subhyalinae dilutissime ex luteo cinerascentes, cellulà costali distinctius lutescente; vena longitudiualis secunda cos!am, a quâ late distat. oblique petit; ultra finem venae longitudinalis primae macula rotundata nigra, satis magna a costâ usque ad venam longiludinalem secundam extenditur. (Chicago. New York: Edwards.)

25. Syneches pusillus nov. sp. б et 오. Ex nigro fuscus, antennis halteribusque concoloribus, abdomine nigro, pedibus pallide flavis, fusco variis, alis cinerascentibus, immaculatis. - Long. corp. $1 \frac{5}{12}$ lin., Long. al. $1 \frac{1}{2}$ lin.

Minulus, ex nigro fuscus, opacus. Proboscis flava. Antennae ex nigro fuscae, articulis duobus primis haud raro pallidioribus. Abdomen nigrum, opacum, margine segmentorum singulorum postico anguste et obsolete cinereo pollinoso. Pedes flavescentes, fusco varii; in speciminibus pallidioribus dimidium basale femorum omnium, femorum posticorum apex, annulus tibiarum posticarum subapicalis, annulus tarsorum posticorum intermedius et ultimus tarsorum posticorum articulus colore fusco suffunduntur; in speciminibus obscuris femora omnia et tota tibiaeque omnes praeter apicem et infimam basim colore ex fusco nigro tinguntur. Ilalteres ex fusco nigri, petiolo pallidiore. Alae ex fusco dilute cinerascentes, immaculatae, venis pallide fuscis, rarius lulescentibus; vena longitudinalis secunda in costam, a quâ modice distat, arcuatim ducitur. (Chicago; New York; Eilwards.)

26. Syndyas dorsalis nov. sp. ㅇ. Atru, nilida, summo rbdominis dorso opaco, tomento fusco vestito, alis pure hyalinis, melatarso postico valde incrassato. - Long. corp. $1 \frac{2}{3}$ lin., Long. al. $1 \frac{5}{12}$ lin.

Tola atra, nitida, antennis, proboscide, palpis pedibusque concoloribus; abdomen opacum, tomento fusco vestitum, lateribus et ventre tamen nitidis. Thoracis dorsum pube brerissimâ, abdomen pube longiore albidâ vestitum; setulae thoracis et scutelli nigrae Pedes nigro-pilosi, tibiis posticis crassis, valde clavatis et metatarso 
postico valde inerassato. Halteres nigri. Alae limpidac, venis pallidissime fuscis, secundo costae dimidio nigricante. - (New York; Edwards.)

27. Syndyas polita nov. sp. ㅇ․ Alra, nilida, abdomine non opaco, alis ea cinereo hyalinis, melalarso postico molice incrassalo. - Long corp. $1 \frac{2}{3}$ lin., Long. al. $1 \frac{5}{12}$ lin.

Tota atra, nilida, antennis, proboscide, palpis, abdomine pedibusque concoloribus. Thoracis dorsum pube brevissimâ, abdomen pube longiore sordide albidà vestitum; setulae thoracis et sculelli nigrae. Pedes nigro-pilosi, tibiis posticis crassis, modice clavatis, metatarso postico modice incrassato. Halleres nigri. Alae lıyalinae, subcinerascentes, cellulae marginais dimidio apicali distinctius cinerascente, venis obscure fuscis, apicali costae parte nigrâ. - (Carolina; Zimmermann.)

28. Empis obesa nov. sp. ơ. Cinerea, opaca, thorace quadrivittato, pedibus baliis, apicem versus nigris; proboscis longissima; oculi contigui; hypopygium tumidum, filamento rentrali rrassissimo, supero; alae infusculae. venae longitudinalis tertiae ramulo anteriore valde obliquo - Long. corp. $1 \frac{1}{2}$ lin., Long. al. $1 \frac{1}{6}$ lin.

Cinerea, opaca. Oculi configui. Proboscis tenuis, corpori fere aequalis. Palpi flavi. Antennae nigrae. Thoracis dorsum nigro quadrivillatum, pube tenui albidà pilisque nigris paullo longioribus consitum. Margo scutelli nigro-setosus. Abdomen albido-pilosum. Hypopygium magnum, tumidum, ascendens; lamellae oblusae in apice, superae totae badiac; filamentum centrale superum, crassissimum. Cosae cinereae, in apice ipso badise, pilis pallidis setisquo nonnullis nigris vestilae. Pedes tenues, simplices, balii, nigro-pilosi; tibiae anteriores in apice, posticae practer basim ubique ex fusco nigrae; tarsi nigri. Halteres lutei. Alae infuscatae, venis et stigmate obscure fuscis, cellula discoidali mediocri, anteriore veuae lon. gitudinalis tertiae ramulo valde obliquo. - (Massachusets; Scudrier.)

29. Empis sordida nov. sp. ơ. Cervina, opaca, thorace quadriviltato, abdomine pullide flavescente, fusco-fasciato, coxis pedibusque ex favo pallide testaceis; oculi distantes; hypopygium par. vum, clavatum. lamellis mediis ascendentibus, filamento centrali abscondito; alae dilutissime sulfuscae, stigmate absolelo. - Long. corp. $1 \frac{3}{4}$ lin.. Long. al. $1 \frac{2}{3}$ lin.

Pallide cervina, opaca. Caput cinereum. Proboscis duplice 
capilis longiludine brevior. Antennarum articuli duo basales fusci. terminalis niger. Oculi distantes. Thoracis dorsum fusco-quadrivittatum, pilis paucis nigris praeditum. Abdomen pallide flavescens. nitidum, basi segmentorum singulorum fuscâ. Hypopygium concolor, parvum, clavalum, clausum, lamellis mediis ascendentibus, oblongo-ovatis, brevissime pubescentibus. Coxae ex flavo pallide testaceae, nigro pilosae. Pedes longi, graciles, ex flavo testacei. nigro-pilosi; tibiarum apex fuscus; tarsi antici exceptâ basi nigri; tarsorum posteriorum articuli ultimi nigri. Halteres flavescentes. Alae longae, subhyalinae, dilutissime ex fusco cinerascentes, stigmate obsoleto, venis fuscis - (Distr. Columbia; Osten-Sacken.)

30. Empis pallida nov. sp. $\delta$. Flava, thorace opaco, abdomine nitente, ultimo tarsorum arliculo toto, reliquis articulis in apice nigris; oculi distantes; hypopygium parvum, clavatum, lamellis mediis ascendentibus. filamento centrali suboperto; alae hyalinae ex luteo subcinerascentes, stigmate subobsoleto. - Long. corp. 2 lin., Long. al. $2 \frac{11}{12}$ lin.

Tota flava. Caput concolor. Oculi distantes. Proboscis capite multo longior. Antennae longae, tenues, articulis duobus primis flavis, tertio practer basim nigro, stylo terminali gracili. Thorax opacus, rare nigro-pilosus. Abdomen nitidum, pilis longioribus lutescentibus convestitum. Hypopygium parvum, clavatum, lamellis mediis oblongo-ovatis, ascendentibus, breviter pubescentibus. Coxae flavae, nigro-pilosae. Pedes longi, graciles, flavi, nigro-pilosi; ultimi tarsorum articuli toti, reliqui in apice nigri. Halteres flavi. Alae magnae, hyalinae, ex luteo dilute cinerascentes, stigmate pallide lutescente, subobsoleto, venis luteis. - (New York; Edwards.)

31. Empis poeciloptera nov. sp. ㅇ․ Flava, thorace opaco, abdomine nitido, antennarum tarsorumque apice nigris; alae hyalinae, ex luteo subcinerascentes, venis transversis fusco-limbatis. Long. corp. $2 \frac{1}{12}$ lin., Long. al. $2 \frac{7}{12}$ lin.

Flava, nigro-pilosa. Caput flavum. Proboscis flava, duplicem capitis longiludinem aequiparans. Antennae longae, graciles, flavae, superiore arliculi tertii margine et apice nigris. Thorax opacus. Abdomen nilidum. Pedes longi, graciles, pallide flavi, tarsorum apice nigro. Halteres flavi. Alae longae, ex luteo subcinerascentes, venis fuscis; venae transversales fusco-limbatae; anterior venae longitudinalis tertiac ramulus cum venâ longitudinali secundâ per venulam transversam conjunctus. - (New York; Edwards.) 
32. Empis armipes nov. sp. J et + . Flava, thorare univillalo, abdomine fusco, marginibus segmentorum singulorum laterulubus et postico flavis, tarsis apicem versus fusco-nigris; tertius antennarum articulus elongatus, niger; alae longae, ex fusco cinerascentes.

$\sigma$ hypopygium parvum porrectum, lamellis inferis acutis, filamento centrali suboperto; poplites pedum posticorum dentibus validis obtusis armati.

ㅇ pedes simplices.

Long. corp. '2 $\frac{1}{2}$ lin., Long. al. $2 \frac{2}{3}$ lin.

Mas: Flavus, breviler nigropilosus. Oculi distantes. Probosris flava, capite longior. Palpi flavi. Duo primi antennarum articuli ex flavo fusci; articulus tertius niger, longus, e basi latâ valde attenuatus; stylus terminalis longus Thorax opacus, vittâ uniế fuscâ, utrinque abbrevialâ, inlerdum obsoletâ. Abdomen nifidum, fuscum, marginibus segmentorum singulorum lateralibus et postico flavis. Venter flavus. Hypopygium parvum, porreclum; lamellac mediae et inferae flavae; flilamentum centrale subopertum. Pedes longi, graciles, flavi, tarsis inde ab articuli primi apice fusco-nigris; pedes postici in poplitibus dentibus nonnullis validis obtusis. partim majoribus et nigropilosis. partim minoribus ef nudis armati. Halteres flavi. Alae longae, ex fusco cinerascentes, stigmate subobsoleto fusciore, venis fuscis.

Foemina: Mari simillima; pedes postici simplices; pili tibiarum tarcorumque breviores et rariores quam in mare. - (New York.)

33. Empis labiata nov. sp. б et ㅇ. Atra, alis nigris, cellulá sulmarginali lalá, venae longitudinalis tertiae ramulo anteriore subperpendiculari. vená longitudinali quarıá incompletá; palpi flavi; labium tenue, labellis filiformibus valde elongatis.

$\sigma$ hypopygio porrecto nigro, lamellis inferis incurvis, apicem versus pallidis.

Of femoribus posterioribus utrinque, tibiis posterioribus superne squamato-ciliatis.

Long. $\operatorname{corp.} 1 \frac{1}{2}-1 \frac{2}{3}$ lin., Long. al. '2 lin.

Mas: Ater. Oculi contigui. Proboscis longa, tenuis; labium tenuissimum, labellis filiformibus, stipiti aequalibus. Palpi flavi. An. tennae nigrae. Thorax polline raro cinerascens, modice nitens. Abdomen nitidum. Hypopygium mediocre, porrectum, atrum; lamellae inferae incurvac, breviler pubescentes et apicem versus pallescentes. Pedes nigri vel ex fusco nigri, longi, graciles, pilis et se- 
tis nigris, metalarsis omnibus elongatis. Halteres fusci vel nigricantes, capitulo supra pallido. Alae ex fusco nigrae, stigmate et venis obscurioribus; vena longitudinalis tertia crassa, paullo pone sùmmum alae apicen marginem attingens. ramulo anteriore rectâ ad marginem ascendente; vena longitudinalis quarta incompleta.

Foemina: Alarum apex latior quam in mare; vena longitudinalis tertia longius post alae apicen excurrens; cellula discoidalis paullo major; pedes brevius pilosi, posteriorum tamen femoribus et tibiis utrinque squamato-ciliatis - (Distr. Columbia; Osten-Sacken.)

34. Empis varipes nov. sp. $\sigma^{7}$ et $q$. Capite, thorace et scutello cinereis, opacis, abdomine atvo, nirido, basi hutê, pedibus luteis, nigro vel fusco annulatis. femorilus infra nigro-spinulosis, halteribus albis.

$\sigma^{7}$ hypopygio minutissimo. immerso, filamento centrali infero, leviter arcuato, alis albicantibus, venis concoloribus.

ㅇ alis non albicantibus, venis subfuscis.

Long. corp. 1 $\frac{1}{3}-1 \frac{2}{3}$ lin. Long al. $1 \frac{3}{4}-2 \frac{1}{12}$ lin.

Gibba, capite, thorace et scutello einereis, opacis. Proboscis capite longior, lutea, slipite labii nigro. Antennarum articuli duo primi ex nigro fusci. tertius niger. Thorax nigro-pilosus. Abdomen atrum, nitidissimum, pilis pallidis perpaucis et valde tenuibus praeditum, basi et ventre luteis. Hypopygium maris minutissimum, immersum, atrum, filamento centrali infero, leviter areuato Coxae anticae luteae, posteriores ex cinerco fuscae. Pedes, lutei, femorum posteriorum annulo subapicali latissimo atro, tibiarum posticarum annulo subbasali latissimo fusco, interdum obsoleto, libiarum omnium apice fusco; femora omnia infra nigro-spinulosa. Halteres albi. Alae maris longiores quam foeminae, albicantes. venis concoloribus, secundo tamen costae dimidio et venae longitudinalis tertiae apice nigricantibus; alae foeminae pure hyalinae, non albicantes. vix levissime cinerasenles. venis fuscis. - (Pennsylvania; Osten-Sacken.)

35. Pachymeria pudira nov. sp. $\delta$ et ${ }^{\circ}$. Cinerea. opaca, breviter nigro-pilosa, thorace quadrivittalo, abdomine atro, nitido, supra subnudo: basi et margine laterali pallide pubescentibus, segmento ultimo segmentorumque praecedentium maculis lateralibus albido-pollinosis: alae hyalinae. levissime tantum subcinerascentes.

of abdominis maculne laterales cinereae parvae; hypopygii appendices superae minalue, Iumidae. ex fusco flavae. brevissime albopubescentes. 
maculae abdominis laterales cinereae permagnae.

Long. corp. $2 \frac{1}{3}-2 \frac{1}{2}$ lin., Long. al. $2 \frac{1}{2}-2 \frac{3}{6}$ lin.

Caput obscure cinereum. Oculi maris distantes. Antennae nigrae, articulis duobus primis cinerascentibus, interdum ex parte fuscis. Proboscis perlonga. Thorax fusco quadrivitlatus, pilis nigris brevibus et raris vestilus. Abdomen breve, latum. atrum, nitidum, sub. nudum, pilis tenuibus pallidis in basi et basali marginis lateralis parte longioribus; segmentum abdominale ultimum fere totum albido-pollinosum; segmenla praecedentia utrinque maculâ albido-pollinosât, in foemiıâ permagnâ, in mare minore et posticum segmenti marginem non attingente notala. Hypopygium maris parvum; appendices superae ex lamellis in corpora minuta, tumida, ovata, ex fusco flava, brevissime et subtilissime pubescentia mutatae sunt; filamentum centrale absconditum. Coxae ex cinereo fuscae, apicem versus badiae; femora nigra, apice badio, interdum tota badia, infra liturâ magnà nigrâ variegata; tibiae ex flavo testaccae, basi plerumque late badiâ; tarsi ex flavo testacei, articulo ullimo nigro. Halteres albidi. Alae dilutissime cinerascentes, venis fuscis. - (Distr. Columbia; Osten-Sacken.)

36. Rhamphomyia dimidiata nov. sp. ठ'. Opaca, fusca, palpis, abdomine, coxis pedibusque ochraceis, tibiarum posticarum dimidio basali tarsisque praeter basim fuscis, alis hyalinis, stigmate fusco, subobsoleto. - Long. corp. $2_{\frac{1}{2}}^{\frac{5}{2}}$ lin., Long. al. $2_{2}^{\frac{1}{2}}$ lin.

Caput ex nigro fuscum, antennis brevibus, concoloribus; oculi contigni; proboscis capiti aequalis, fusca; palpi ochracei. Thorax tolus cum scutello obscure fuscus, opacus, breviler nigro-pilosus. Abdomen ochraceum, lamellis hypopygii brevibus concoloribus, flavo-pilosum. Coxae ochraceae, rare nigro-pilosae. Pedes ochracei, tibiarum posticarum dimidio basali, tarsis anticis totis et reliquis apicem versus fuscis; femora postica incrassata. Halteres lutei. Alae hyalinae, dilutissime cinerascentes, venis fuscis, prope basim luteis; cellula discoidalis mediocris; stigma subobsoletum pallide fuscum. - (Maryland; Osten-Sacken.)

37. Rhamphomyia laevigata nov. sp. ․ Atra, nitens, abdomine ex fusco atro, femoribus tibiisque squamato-ciliatis, halteribus albidis, alis longis ex. fusco nigsis, basi fluvescente, sligmate obscuriore, subobsoleio - Long. corp. $2 !$ lin., Long. al. $2 \frac{2}{3}$ lin.

Atra, nitida. Caput concolor; antenuae graciles, nigrae, articulis duobus ultimis in basi lutescentibus; proboscis nigra, longitu- 
dinem capitis modice excedens. Pili nigri in nilido thoracis dorso rari et breves; pleurae polline albido cinereae. Abdomen ex fusco atrum, nigro-pilosum. Pedes ex fusco atri, femoribus et tibiis squamalo-ciliatis. Halteres albidi. Alae longae, ex fusco nigrae; venae obscure fuscae, in basi alarum flavescente flavae; stigma subobsoletum, obscurius nigricaus. - (Nebraska.)

Nota: A Rhamphom. longicaudâ, cui affinis, diversâ corporis picturâ et primo tarsorum poslicorum articulo non ciliato facile distinguitur.

38. Rhamphomyia longicauda nov. sp. ఠ et ㅇ․ Gracilis, alra, nitida, thoracis margine laterali et maculá posticâ, sculello et confuentibus pleurarum maculis flavo-testaceis, abdomine fusconigro; antennae elongatae nigrae; coxae flavae; alae ex fusco nigrae.

ठ' pedes longi, graciles, fluvi, femoribus posticis apicem versus tibiisque anterioribus pallide fuscis, tibiis posticis tarsisque omnibus obscure fuscis; lamellue hypopygii superiores permagnue, elongatae, ereclae, integrae, pallide fuscae.

ㅇ pedes nigro-fusci, femorum basi fluvâ, metalarsis posticis, tibiis femoribusque omnibus compressis, nigro-plumalis.

Long. corp. $3-3 \frac{1}{6}$ lin., Long. al. $3 \frac{5}{1} \frac{5}{2}-3 \frac{3}{4}$ lin.

Mas: Caput nigrum, oculis in fronte contiguis; antennae nigrae, elongatae, articulo tertio tenui, longe subulato; facies nigra; proboscis capiti vix aequalis, nigra; palpi concolores. Thoracis dorsum atrum, nitidum, rare nigro-setosum, margine laterali pallide flavotestaceo, maculà poslicâ magnâ obscurius testaceâ, interdum obsoletâ. 1)iscus scutelli testacei fuscus. Metanolum ex fusco testaceum. Pleurae uigro el teslaceo variegatae. Tegularum cilia fusca; pili ante halleres nigricantes. Abdomen elongalum fuscum, segmenti ultimi margine infero dilatatato et pilis longis obscure fuscis cilialo. Lamellae hypopygii superiores pallide fuscae, permagnae, elongatae, erectae, integrae, breviter pubescentes, apice obtuso; lamellae inferiores obscure fuscae, mediocres, oblique descendentes, integrae, in apice pilis obscure fuscis barbatae. Coxae pallide flavae, trochanteribus lineolâ apicali atrâ notatis. Pedes elongati, tenues, flavi, fusco-pilosi; pedum anteriorum femora apicem versus paullo obscuriora, tibiae pallide fuscae, tarsi obscure fusci; femora pedum posticorum apicem versus distincte fusca, tibiae obscure fuscae, tarsi nigro-fusci; metatarsi anteriores articulis tribus sequentibus, postici quatuor sequentibus simul sumplis aequales. Halteres fusci, pedun- 
culo testaceo. Alae longae, modice latae, fusco-nigrae, ad costam obscuriores, venâ longitudinali terliâ finem versus incurvâ, cellulâ discoidali mediocri. oblongâ.

Foemina. Frons lata, atra, nitida. Abdomen colore nigriore tinclum quam in mare, segmentis ultimis lenuibus, elongatis. Coxae flavae. Pedes fusci, femoribus anlicis plerumque badiis, femorum omnium basi semper flavå; metatarsi postici, libiae el femora omuia valde compressa, lata, squamulis longis nigris pennata. - (Distr. Columbia; Osten-Sacken).

39. Rhamphomyia fumosu nov. sp. ठ․ Gracilis, atra, uitida, humeris, thoracis angulis posticis scutellique angulis lateralibus testaceis, pleuris fuscis, prope coxas testaceis; ablomen fuscum; lamellue hypopygii superiores ingentes, elongatue, erectae, integrue, pallide fuscae; lamellae inferiores mediocres subrotundae, obscure fuscae, in margine apicali incisae et pilis nigris ciliatae; coxae flavae; pedes longi, graciles, flavi, femoribus posticis apicem versus libiisque anterioribus pallide fuscis, tibiis postiris tarsisque omnibus obscure fuscis: alae ex fusco nigrae. - L,ong. corp. 3 lin., Long. al. $3 \frac{2}{3}$ lin.

Speciei praceedenti tam similis, ut piclurâ corporis aegre distinguatur. Lamellae hypopygii longiores quam in illà, inferiores rolundatae et in margine postico incisae sunt, unde superne lobum rotundatum et infra dentem habent. - (New York.)

40. Rhamphomyia pulchra nov. sp. Q. Gracilis, thorace rufo, vittâ laterali latissimâ, maculà humerali et linế medià po. stice abbreviatâ nigris, abdomine halteribusque fuscis, ventre, pectore, coxis pedibusque flavis, femorum posticorum dimidio apicali, tibiis posticis tarsisque anterionibus nigro-fuscis, articulo tarsorum posticorum terminali nigro, alis latiusculis, ex fusco-nigris. - Long. corp. $2 \frac{1}{1 \frac{1}{2}}$ lin, Long. al. $3 \frac{1}{3}$ lin.

Caput alrum, nitidum, fronte modice latâ. Antennac graciles, articulis duobus primis flavis, superne infuscatis, articulo tertio tenui, longe subulato. nigro, basi flava. Thoracis dorsum rufum, nifidum, rare nigro-setulosum, lineâ mediâ postice abbreviatí. utriuque maculâ humerali et vittâ latissimâ laterali nigris. Scutellum fuscum. Metanotum ex fusco testaceum, ulringue nigrum Pleurac fuscae, margine supero nigro vel nigro-fusco. Cilia tegularum ni. gricantia, pili ante halteres nigri. Abdomen nigro-fuscum. Cosae flavae, trochanteribus lineolả trausversà alrâ notalis. Pedes flavi, 
dimidio femorum posticorum apicali, tibiis posticis tarsisque anterioribus nigro-fuscis, tarsis posticis pallidissime flavescentibus, articulo ultimo nigro. Halteres nigro-fusci, pedunculo testaceo. Alae latiusculae, obscure fusco-nigrae, venâ longitudinali lertiâ apicem versus incurvà. - (New - York.)

41. Rhamphomyia glabra nov. sp. ․ Flava, antennarum apice, thoracis linế mediâ abbreviatâ et linể uirinque laterali subobsoletâ nigris, abdomine, tibiis posticis praeter apicem tarsisque totis fuscis, alis magnis ex fusco nigris. - Long. corp. 3 lin. Long. al. $3 \frac{5}{1 \frac{5}{2}}$ lin.

Caput nigrum, haud raro ex parte, rarius tolum flavum. Frons modice lata. Antennae elongatae, articulo tertio longe subulato, flavae, apicem versus nigrae. Proboscis capite lougior, nigra, labio fusco. Thoracis dorsum ex rufo flavum, nitidum, rare nigro-pilosum, lineâ medià postice abbreviatâ nigrâ et utrinque lineâ laterali obsoletiore nigro-fuscâ ornatum. Scutellum thoraci concolor; pleurae flavae. Abdomen fuscum, ventre flavo. Coxae flavae, trochanteribus lineolồ apicali atrâ signatis. Pedes flavi, nigro-pilosi; tibiae posticae basi et apice exceptis fuscae; tarsi antici fusci, basi articuli primi plerumque flavâ; duo ultimi tarsorum posteriorum articuli obscure fusci, praecedentes flavi, in apice tamen obscure fusci. Halteres fusci, pedunculo flavo. Tegularum cilia fusca, pili ante halteres nigro-fusci. Alae magnae, ex fusco nigrae, venâ longitudinali tertiâ apicem versus incurvâ. - (Virginia, Illinois; OstenSacken.)

42. Rhamphomyia sellata nov. sp. $\delta$. Gracilis, pallide flava, capite, thoracis maculà dorsali permagnâ et ultimo abdominis segmento nigris, tarsis excepta basi fuscis; alis longis, cinereohyalinis, stigmate fusco, venâ longitudinali tertiâ modice incurvâ. - Long. corp. $2 \frac{1}{6}$ lin., Long. al. $2 \frac{1}{1} \frac{1}{2}$ lin.

Caput nigrum, oculis fronte angustâ separatis; proboscis pallide flava, labro fusco. Antennae nigrae, articulo secundo fusco, tertio longe subulato. Thoracis dorsum nitidum, rare nigro-pilosum, maculâ permagnâa atrâ postice in vittam latiusculam, quae posticum thoracis marginem attingit, productâ et utrinque prope alae basim puncto nigro. Scutellum et metanotum flava; pleurae pallide flavae; pili ante balteres et in tegularum margine nigri. Abdomen nigropilosum, flavum, segmentorum singulorum margine postico paullo obscuriore, segmento ultimo brevi, fusco-nigro. Hypopygium breve, 
porrectum; lamellae superae flavae, mediocres, obtusae; lamellae intermediae angustae, sublanceolatae, prominentes, fuscae; lamellae inferae flavae, superis subaequales. Coxae pallide flavae, trochanteribus.lineolâ apicali atrâ notatis. Pedes pallide flavi, pilis brevibus nigricantibus el setulis raris nigris vestiti; tarsi fusci, basi arliculi primi in anterioribus, in posticis vero articulo primo fere toto et articuli secundi basi sordide Mavis. Alae hyalinae, ex luteo subcincrascentes, limbo apicali paullo obscuriore, stigmate fusco, venis tenuioribus lutescentibus, venis validioribus subfuscis, venâ longitudinali tertiâ modice tantum incurvà. - (Distr. Columbia; Osten Sacken.)

43. Rhamphomyia gracilis nov. sp. ఠ et ㅇ․ Gracilis, atra, nilida, antennis, proboscide et palpis concoloribus, coxis flavis, pedibus obscurius flavis, gracilibus, breviler nigro-pilosulis et rare nigro-setosis, tibiis posticis tarsisque omnibus fuscis; alae hyalinae leviler cinerascentes, venis crassiusculis et stigmate elongato obscure fuscis.

б alae praeter stigma immaculatae, hypopygium parvum porrectum.

우 alue prope apicem maculis duabus nigricantibus ornalae.

Long. corp. 3 lin., Long. al. $2{ }_{6}^{5}$ lin.

Mas: Caput atrum, oculis contiguis; occiput tenuiter albidopollinosum; facies polline confertiore cinerascens. Antennae atrae, longiusculae, tenues, articulo tertio angusto, acuto. Thorax ater, nitidus, subnudus, pilis albis et setis nigris raris. Scutellum et metanotum thoraci concolora; pleurae niveo-pollinosae. Abdomen tenue, atrum, nitidum, hypopygio concolore, minuto, porrecto. Coxae flavae, albido-micantes, trochanteribus lineolà apicali atrâ ornatis. Pedes elongati tenues, obscurius flavi vel ex flavo badii, pube brevi atrâ et selulis raris atris vestiti, in femorum intermediorum latere inferiore confertius nigro-setulosi; femorum posticorum tibiarumque anticarum apices et tibiae posticae praeter apicem nigro-fuscae; tarsi longi, nigro-fusci, basi articuli primi ex badio flavâ. Halteres pallide flavi. Alae hyalinae, subcinerascentes, basi dilute sublutescente; venae crassiusculae, obscure fuscae, in alae basi lutescentes; vena longitudinalis tertia apicem versus modice incurva; stigna angustum, clongatum, nigro-fuscum.

Foemina: Praeter alas maculatas mari simillima. Frons lata, alra, nitida. Pollen faciei rarius quam in mare. Alac paullo magis cinerasecntes, prope apicem maculis duabus nigris, alterâ an- 
gustiore in cellulà submarginali, alterà latiore in cellularum poste. riorum primâ. Tarsorum articulus primus in basi plerumque dilıtius et latius flavus quam in mare. - (Pennsylvania; Osten-Sacken.)

44. Rhamphomyia pulla nov. sp. ठ. Ex nigro cinerea, coxis et tertio antennarum artirulo concoloribus, duobus primis antennarum articulis pedibusque obscure flavis, tibiarum posticarum apice nigro, tarsis praeter basim ex fusco nigris; alae subhyalinae apicem versus dilute cinerascentes, stigmate fusco. - Long. corp. $2 \frac{1}{1} \frac{1}{2}$ lin., Long. al. 3 lin.

Caput nigrum, oculis contiguis, occipite obscure cinereo, prope verticem nigro-setoso. Antennae subelongatae, articulis duobus primis flavis, articulo tertio angusto nigro, stylo terminali brevi. Proboscis nigra, capite paullo longior. Thoracis dorsum lineis duabus nigris perspicuis et interjectâ lineâ mediâ obsoletiore notalum, pilis setisque nigris rarioribus praditum. Scutellum et metanotum thoraci concolora. Pleurae nigro-cinereae et nigro-pilosae Abdomen nigrum, nitidum. Hypopygium mediocre, porrectum, apertum; lamellae superae ex nigro-fuscae, minulae, breviter pubescentes; lamellae intermediae paullo majores, nigrae et pilis longis nigris vestitae; lamellae inferae deformes; filamentum centrale distinctum. Coxae anticae prope basim nigrae. apicem versus badiae; coxae posteriores nigrae. Pedes ralidiusculi, obscure flavi, breviter nigropilosi; summus femorum posteriorum apex puncto nigro notatus, apex tibiarum posticarum ex fusco niger; tarsi ex fusco nigri, anteriorum tamen articulo primo praeter apicem articulorumque duorum sequentium basi flavis, posticorum imâ tantum basi flavà. Hal. teres albi. Alae mediocres, hyalinae, dilute lutescentes, in dimidio apicali obsolelissime subcinerascentes. venis fuscis, prope basim luteis, stigmate angusto. obscure fusco, cellulâ discoidalì minutâ. (Connecticut; Norton.)

45. Rhamphomyia debilis nov. sp. $\sigma^{7}$ et 9 . Capile, thorace scutelloque cinereis, abdomine livido, palpis, proboscide, duobus primis untennarum articulis, coxis pedibusque luteis; halteres pallide flavescentes; cellula alarum discoidalis mediocris, stigma mugnum, obsoletum.

ठ oculi conligui; hypopygium luteum, porrectum, lamellis inferis longioribus, acutis, filamento centrali concolore, tenui; alae hyalinae, stigmate pallide lutescente.

I alae pallide fuscae, stigmate obscuriore.

Long. corp. $2 \frac{1}{1} \frac{1}{2}$ lin., Long. al. $2 \frac{1}{2}$ lin. 
Mas: Caput cinereum, oculis contiguis. Proboscis cum palpis flava, capiti aequalis. Duo primi antennarum articuli flavi; articulus tertius niger, acutus, stylo terminali concolore, mediocri. Thorax cinereus, pilis nigris raris et tenuibus vestitus. Scutellum cum thorace concolor. Abdomen lividum, ventre luteo; pili abdominis pallidi et rari. Hypopygium luteum, porrectum; lamellae superae breves, obtusae, lividae, breviter pubescentes; lamellae mediae lineares, apicem versus nigricantes, breviter pilosae; lamellae inferae longiores, acutae, in margine inferiore et in apice pilis longioribus instructae, in secundả marginis superioris parte nigrae et breviter nigro-ciliatae; filamentum centrale tenue, luteum. Coxae luteae, pilis nigris, validioribus, raris. Pedes graciles, lutei, tarsis apicem versus modice infuscalis, articulo ultimo ex fusco nigro. Pubes pedum mediocris, nigricans, ex parte fusca vel subfusca. Halteres pallide flavescentes. Alae hyalinae, dilutissime subcinerascentes, venis lutescentibus, stigmate obsoleto, magno, pallide lutescente, cellulâ discoidali mediocri.

Foemina. Pili totius corporis multo breviores; color farsorum plerumque obseurius fuscus; alae paullo latiores, pallide fuscae, stigmate obsoleto, modice obscuriore. In reliquis mari simillima. (Saskatchevan; Kennicot.)

46. Rhamphomyia longipennis n.sp. ठ大. Cinerea, proboscide, palpis antennisque nigris, coxis pedibusque pallide testaceis, femoribus libiisque apicem versus fuscis, tarsis totis ex fusco nigris, pilis thoracis brevibus nigris, pilis abdominis et tibiarum posticarum longis, pallide favescentibus; hypopygium mediocre, porrectum, obtusum, in apice breviter atro-barbatum, filamento centrali infero; alae cinerascentes, stigmate paullo obscuriore, cellulâ discoidali mediocri. - Long. corp. $1 \frac{5}{6}$ lin., Long. al. $2 \frac{1}{4}$ lin.

Cinerea, opaca. Caput concolor, oculis late distantibus. Longitudo proboscidis nigrae capitis longitudinem modice superat. Palpi minuti, nigri. Antennae nigrae, articulo tertio angusto, stylo terminali brevissimo. Thorax cinereus, pilis nigris raris et brevibus instructus; scutellum concolor. Abdomen ex cinereo nigrum, pilis longioribus flavescentibus vestitum. Hypopygium mediocre, colore abdominis tinctum, porrectum, obtusum, in apice pilis brevibus atris barbatum; filamentum centrale atrum, inferum, arcualum. Color coxarum et pedum sordide testaceus, adversus coxarum basim et adversus apicem femorum et tibiarum fuscus, in tarsis ex fusco niger. Pubes flavescens tibiarum posticarum perlonga. Halteres albidi. 
Alae longiusculae, cinerascentes, stignate obsoleto paullo saturatius cinereo, cellulà discoidali, mediocri. (Distr. Columbia; Osten-Sacken.)

47. Rhamphomyia longicornis nov. sp. ठ大 et \&. Ex cinereo nigra, nigro-pilosa, proboscide, palpis antennisque nigris, thorace trivilialo, pedibus badiis, larsis nigris, femoribus tibiisque apicem versus plerumque fuscis, femoribus infra nigro-setulosis; halteres sordicle fusci; alae cinereae, venis crassis et stigmate angusto fuscis, cellulâ discoidali mediocri.

c) oculi distantes; hypopygium ex cincreo nigrum, globosum, porrectum, lamellis parvis, obtusis, breviter nigro-pilosis, basi filament $i$ centralis crassissimâ, apice abscondito.

ㅇ praeter ordinaria sexus discrimina mari simillima, pilis $10-$ tius corporis tamen brevioribus pilisque abdominis plerisque subfuscis.

Long. corp. $2 \frac{1}{2}$ lin., Long. al. $2 \frac{1}{2}-2 \frac{3}{6}$ lin.

I as: Ex cinereo niger, totus nigro-pilosus. Caput concolor; oculi distantes; proboscis nigra, capite modice longior; palpi nigri; antennae nigrae, longae, graciles, articulo tertio angusto, stylo terminali crassiusculo. Thoracis opaci dorsum vitlis tribus fuscis notatum, vittulâ incompletâ obsoletiore utrinque prope marginem adjectâ. Abdomen modice nitens, nigro-pilosum. Hypopygium concolor, globosum, porrectum; lamellae parvae, obtusae, breviter nigropilosae; filamentum centrale badium, basi crassissimâ, apice abscondito. Coxae ex cinereo nigrae, nigro-pilosae. Pedes badii, femoribus tibiisque apicem versus obscure fuscis, tarsis totis ex fusco nigris. Halteres sordide fusci. Alae cinereae, venis validis et stigmate angusto fuscis, cellulâ discoidali mediocri, truncatâ.

Foemina: Mari persimilis, sed pilis totius corporis brevioribus pilisque abdominis plerisque subfuscis diversa. Coxae interdum badiae, basi tantummodo nigrâ, et femorum tibiarumque apex non fuscus. Cellula discoidalis plerumque minus truncata quam in mase. (Distr. Columbia; Osten.Sacken.)

45. Rhamphomyia gilvipes nov. sp. $\delta$ et ․ Cinerea, opaca, subnuda, thorace trivillato, palpis, coxis, pedibusque saturate flavis, proboscide, antennis tarsisque nigris; halleres flavi; alae dilute subfuscue, venis validis fuscis, stigmate obsoleto subfusco, cellulâ discoidali mediocri.

ऽ hypopygium parvum, reflexum, clausum, filamenti centralis crassissimi apice abscondito.

․ femora postica fusco-liturata.

Long. corp. $2_{6}^{5}$ lin., Long. al. $2_{6}^{5}$ liu. 
Cinerea. opaca, subnuda; proboscis nigra vel fusea, capite longior; palpi flavi; antennae longae, graciles, nigrae, articulo lertio angus!o, stylo terminali validiusculo; oculi maris distantes. Thoracis dorsum fusco trivittalum, adjectâ utrinque viltulà laterali abbreviatâ fuscâ; pili thoracis nigri, rari, brevissimi. Abdomen pilis raris, brevibus, tenuibus, ex flavo albidis convestitum Hypopygium maris mediocre, reflexum, clausum, lamellis obtusis breviter pubescentibus, filamenti centralis crassissimi basi inopertâ, apice incluso. Coxae saturate flavae, pilis flavescentibus vestitae. Pedes validiusculi, saturate flavi, tarsis omnibus exceptâ articuli primi basi nigris; femora postica subincrassata et in foeminâ superne fusco-liturala, femora omnia subtus nigro-setulosa Halteres flavi. Alae ex cinereo dilute subfuscae, venis crassis obscure fuscis, stigmate obsoleło subfusco, cellulâ discoidali mediocri. - (New York; Edwards.)

49. Rhamphomyia pectinata nov. sp. §. Nitida, tota atra, nigro-pilosa; proboscis brevis; oculi contigui; tibiae posticae setis nigris pectinatae; alae nigricantes, basi sublutescente, stigmate ex fusco nigro; hypopygium minutissimum, porrectum, filamento centrali abscondito. - Long. corp. $2 \frac{1}{2}$ lin., Long. al. $2 \frac{7}{\frac{1}{2}}$ lin.

Atra, nitida, nigro-pilosa, thorace polline raro cinerascente obsoletissime sublineato, abdomine leviter fusco-pollinoso. Proboscis nigra, capite paullo longior. Palpi minuti, nigri. Antennae nigrae, articulo tertio angusto, stylo terminali tenui. Oculi contigui. Pili in thoracis dorso rari, in abdomine confertiores. Hypopygium minutissimum, porrectum, atrum, aigro-pilosum, filamento centrali incluso. Pedes graciles, tibiis intermediis nigro-selosis, tibiis posticis utrinque setis nigris pectinalis. Halteres nigri. Alae ex fusco nigricantes, stigmate ex fusco nigro, cellulà discoidali mediocri. (Iist. Columbia; Osten-Sacken.)

50. Rhamphomyia luctifera nov. sp. $\delta$. Tola atra, nigro-pilosa, thorace modice nitente, abdomine opaco; proboscis brevis; oculi contigui; tibiae intermediae setis duabus validis armatae; alae totae nigrae, sligmate obsoleto paullo obscuriore, cellula discoidali mediocri; hypopygium mediocre, porrectum, breviter nigropilosum, filamenti centralis atri apice abscondito. - Long. corp. 2 lin., Long. al. 2 lin.

Tota atra. Proboscis nigra, capiti fere aequalis. Palpi minuti, nigri. Antennae nigrae, stylo terminali tenui. Oculi contigui. Thoracis dorsum modice nitens, pilis tenuissimis nigris et polline obso- 
leto subfusco vestilum. Abdomen opacum, margine laterali tamen nitido. Hypopygium mediocre, porrectum, obtusum, lamellis nigropubescentibus; filamentum centrale atrum, crassiusculum, breve, basi inopertâ, apice incluso. Pedes graciles, nigro-pilosi; tibiae intermediae setis duabus validis armatae. Halteres sordide nigricantes. Alae nigrae, stigmate paullo obscuriore et cellulà discoidali mediocri. (New York; Edwards.)

51. Rhamphomyia cervina nov. sp. ‥ Tota atra, dense, sed breviter nigro-pilosa, thorace polline albido subcinerascenle, abdomine subnitido, femoribus posterioribus libiisque posticis utrinque, libiis intermediis superne squamalo-ciliatis; alae obscure nigricantes, basi subfuscà, stigmate ex fusco nigro, cellulà discoidali brevi, latissimâ. - Long. corp. $2 \frac{1}{1} \frac{1}{2}$ lin., Long. al. $2 \frac{1}{\frac{1}{2}}$ lin.

Tota atra. Proboscis nigra, capitis longitudinem modice excedens. Palpi nigri. Antennae nigrae, articuli tertii basi subdilatatâ, stylo terminali minutissino. Thoracis dorsum polline tenui albicante subcinerascens, pilis brevibus nigris crebre consitum. Abdomen subnilens. Pedes nigro-pilosi, femoribus poslerioribus tibiisque posticis utrinque, tibiis intermediis superne squamato-ciliatis. Halteres nigri, pedunculo fusco. Alae obscure nigricantes, basi subfuseâ, stigmate ex fusco nigro; cellula discoidalis brevis, sed latissima. - (New York; Edwards.)

Nota, A foeminâ Rhamphomyiae brevis alis nigrioribus tibiisque intermediis distinctius squamato-ciliatis differt.

52. Rhamphomyia brevis nov. sp. ot et 8 . Tola alra, dense, sed breviter nigro-pilosa, thorace polline albido subcinerascente, alarum stigmate ex fusco nigro, cellulâ discoidali brevi, lalissimâ.

ठౌ oculi contigui; alae dilute subfuscae; hypopygiun atrum, parvum, porrectum, nigropilosum, filamento centrali atro, tenuissimo, arcuato.

ㅇ alae fuscae; tibiae posticae et femora posteriora squamatociliata, tibiae intermediae superne pilis vix dilatatis ciliatae.

Long. corp. $2 \frac{1}{1} \frac{1}{2}-2 \frac{1}{4}$ lin., Long. al. $2 \frac{1}{12}-2 \frac{1}{4}$ lin.

Breviuscula, tota atra. Oculi maris contigui. Proboscis nigra, capitis longitudinem modice excedens. Palpi nigri. Antennae nigrae, articuli tertii basi subdilatatâ, stylo terminali tenui. Thoracis dorsum polline tenui albicante subcinerascens, pilis brevibus nigris crebre consitum. Abdomen subnitens. Hypopygium maris atrum, par- 
vum, porrectum, lamellis nigro-pilosis, filamento atro, tenuissimo, arcuato. Pedes nigro-pilosi, maris metatarsus posticus et tibiae posteriores nigro-setosae; foeminae tibiae posticae et femora posteriora utrinque squamato-ciliata, tibiae intermediae superne pilis vix dilatatis ciliatae. Halteres nigri. Alae maris ex cinereo dilute subfuscae; alae foeminae subfuscae; in utroque sexu basis alarum pallidior, stigma ex fusco nigrum, cellula discoidalis brevis, sed latissima. - (Distr. Columbia; Osten - Sacken.)

53. Rhamphomyia clavigera nov. sp. 万. Tola ex cinereo nigra, opaca, nigropilosa; oculi contigui; proboscis capiti subaequalis; hypopygium apertum, lamellis superis tenuibus, breviter nigro-pubescentibus, lamellis inferis ex nigro fuscis, longissimis, porrectis, nigro-pilosis, filamento centrali tenuissimo, infero, apicem versus arcualo; alae subcinerascentes, stigmate fusco. - Long. corp. $1 \frac{5}{6}$ lin, Long. al. $1 \frac{5}{6}$ lin.

Ex cinereo nigra, opaca, nigro-pilosa. Oculi contigui. Proboscis nigra, capiti subaequalis. Palpi nigri. Antenuae nigrae, stylo terminali tenui. Pili nigri in thoracis dorso mediocres et rariores, in abdomine breviores et frequentiores. Hypopygium nigrum, apertum; lamellae superae parvae, horizontales, breviter nigro-pubescentes, lamellae inferae ex nigro fuscae, perlongae, porrectae, pilis longis nigris instructae; filamentum centrale inferum, tenue, apicen versus arcuatum. Pedes nigro-pilosi; tibiac posteriores setıs paucis armatae; metatarsus posticus subincrassatus. Halteres nigri. Alae subcinerascentes, stigmate fusco, cellulà discoidali mediocri. - (New York.)

54. Rhamphomyia priapulus nov.sp. ơ. Ex cinereo nigra, opaca, nigro-pilosa; oculi contigui; proboscis capite modice longior; hypopygium nigrum, maximum, apertum, lamellis superis crassis, ascendentibus, nigro-pubescentibus, lamellis inferis ex nigro fuscis, longissimis, porrectis, nigro-pilosis, filamento centrali tenuissimo, arcuato; halleres albidi; alue cinerascentes, sligmate obsoleto, cellulà discoidali mediocri. - Long. corp. $1 \frac{1}{2}$ lin., Long. al. $1 \frac{3}{4} \mathrm{lin}$.

Ex ciuereo nigra, opaca, nigropilosa. Oculi contigui. Proboscis nigra, crassa, capitis longitudinem modice excedens. Palpi nigri. Antennae nigrae, stylo terminali tenui. Pili nigri in thoracis dorso mediocres et rariores, in abdomine frequentiores et prope marginem segmentorum singulorum posticum longiores, quam in specicbus affiubus esse solent. Hypopygium ingens, apertum; lamellae superae 
crassae, ascendentes, nitidae, nigrae, breviter nigro-pubescentes; lamellae inferae perlongae, porrectae, basi atrâ, apice fusco, margine nigro-piloso; filamentum centrale tenuissimum, arcuatum. Pedes nigro-pilosi. Halteres sordide albi. Alae angustae, cinerascentes; stigma obsoletum ex cinereo subfuscum; cellula discoidalis mediocris. - (Maryland; Osten-Sacken.)

55. Rhamphomyiu angustipennis nov. sp. ठ’. Atra, nitida, nigro-pilosa; oculi contigui; thoracis dorsum polline albo raro subviltatum; hypopygium perparvum porrectum, lamellis parvis breviter pubescenlibus, superis subrecurvis, aculiusculis, inferis oblusis, filamento centrali abscondilo; halteres albidi; alarum dimidium basale limpidum, dimidium apicale ex cineren nigricans, sligma ex fusco nigrum. - Long. corp. $2 \frac{1}{6}$ lin., Long. al. $2 \frac{5}{12}$ lin.

Atra, nitida. Oculi contigui. Proboscis nigra, apicem versus plerumque fusca, eapiti aequalis. Palpi nigri. Antennae nigrae, articulo tertio adversus apicem valde altenuato. Thoracis pars anterior polline raro albido subviltata, pars posterior tota polline minus raro tecta. Pili thoracis nigri, rari, breves et tenues Abdo. men nigro-pilosum, pilis in anteriore marginis lateralis et ventris parte tamen pallide lutescentibus. Hypopygium atrum, minutum, porrectum; lamellae parvae, superae subrecurvae et brevissime pubescentes, inferae obtusae; filamentum centrale absconditum. Pedes nigro-pilosi, metalarso poslico validiusculo. Halteres albidi. Alae angustae, dimidio basali hyalino, dimidio apicali ex cinereo nigricante, stigmate ex fusco nigro, cellulâ discoidali majusculâ. (New York.)

56. Rhamphomyia conjuncta nov. sp. ठ大. Obscure cinerea, opaca, thorace obsolete biviltato; oculi late distantes; hypopy. gium parvum, lamellis obtusis, filamento centrali arcuato; metatarsi antici modice incrassati; halleres sordide albidi; alae subcinerascen. tes, stigmale fusco, venâ intercalari ex anteriore cellulae discoidalis angulo natâ. - Long. corp. $1 \frac{1}{1} \frac{1}{2}$ lin., Long. al. $1 \frac{1}{1} \frac{1}{2}$ lin.

Obscure cinerea, opaca. Oculi late distantes. Proboscis nigra, capite paullo longior. Palpi nigri. Antennae nigrae. Thoracis dorsnm vittis duabus obscurioribus obsoletis pictum, parce nigro-pilosum. Abdomen pilis flavescentibus vestilum. Hypopygium parvum; lamellac obtusae, superae subnudae, inferae flavo-pilosae; filamentum centrale tenue, arcuatum. Pili pedum plerique flavescentes, reliqui fusci aut nigricantes; metalarsus anticus distincle, sed modice in- 
crassalus; tibiae posticae supra prope apicem pilis longis consitae. Halteres sordide albidi. Alae subcinerascentes, venis et sligmate ex nigro fuscis; vena intercalaris ex anteriore cellulae discoidalis angulo oritur. - (Distr. Columbia; Osten-Sacken.)

57. Rhamphomyia vara nov. sp. $\sigma^{7}$ et 오. Cinerea, opaca, thorace obsolete bivittato, palpis flavis, proboscide, antennis pedibusque nigris, genibus testaceis; halteres albidi; alue longae, rinerascentes, basi sublutescente, venis validis obscure fuscis, sligmate subfusco, cellula discoidali mediocri.

o oculi subcontigui; pedes postici vari; hypopygium parvum, ascendens, obtusum, filamento centrali crasso, subarcuato.

ㅇ. frons anterior profunde sulcata; pedes postici non vari.

Long. corp. $2 \frac{1}{4}-2 \frac{7}{1} \frac{7}{2}$ lin., Long. al. $2 \frac{7}{1} \frac{7}{2}-2 \frac{5}{6}$ lin.

Mas: Cinereus, opacus. Oculi subcontigui. Proboscis nigra. capile longior. Palpi flavi. Antenuae nigrae. Thorax obsolete bivittatus; pili thoracis breves, subtiles, plerique pallidi, reliqui nigri. Scutelli margo nigro-setosus. Abdomen pilis longis pallide lutescenlibus vel sordide albidis vestitum. Hypopygium parvum ascendens, lamellis obtusis, inferis breviter pilosis, filamento centrali crasso, subarcuatim ascendente. Coxae pilis pallide lutescentibus instructae. Pedes longi, nigri, genibus testaceis; femora postica vara; tibiae posticae subclavalae, varae Halteres albidi. Alae longae, anguslae, cinerascentes, basi dilutissime sublutescente; venae crassac, obscure fuscae; stigma dilutius fuscum; cellula discoidalis mediocris.

Foemina: Mari simillima; pilis tolius corporis brevioribus, pedibus posticis simplicibus, non varis, fronte anticà profunde sulcatà. - (Nebrasca.)

58. Rhamphomyia sordida nov. sp. Ђ. Cinerea. opaca, thorace trivitlato. perlibus subfusris, femoribus supra tibiisyue apicem versus ex nigro fuscis, tarsis totis nigris; oculi distantes; hypopygium parvum, ascendens, lamellis ob/usis, filamento centrali abscondito; halteres albidi; alae subcinerasrentes, venis obscure fuscis, sligmate obsoleto, cellulâ discoidali mediocri. - Long. corp. $2 !$ lin.. Long. al. 21 lin.

Cinerea, opaca. Proboscis nigra. capite forsitan longior. Palpi fusci. Antennae nigrae. Oculi late dislantes. Villac thoracis obscuriores tres; pili thoracis nigri, breves et rari. Pili abdominis minus rari, longiores, dilute lutescentes. IIy popygium nigrum, parvum, asceudens; lamellae obtusae, pilis brevibus pallide lutescentibus 
vestitae; filamentum centrale absconditum. Pedes subfusci, femoribus superne tibiisque adversus apicem ex nigro fuscis, tarsis totis nigris. Pili pedum nigri, in superiore tibiarum posticarum et metatarsi postici latere longiores et magis conferti. Halteres albidi. Alae leviter subcinerascentes, venis validis fuscis; stigma obsoletum; cellula discoidalis mediocris, sed paullo major quam in specie praecedente. - (Distr. Columbia; Osten-Sacken.)

59. Rhamphomyia crassinervis nov. sp. ․ Cinerea, opaca, thorace trivittato, vitta mediâ angustiore, proboscide, palpis, antennis perlibusque nigris, imâ femorum basi genibusque testaceis; halteres sordide albidi; alae angustae, subcinerascentes, venis obscure fuscis, sligmale subfusco, cellulâ discoidali magnâ. - Long. corp. $2 \frac{1}{4}$ lin., Long al $2 \frac{1}{4}$ lin.

Cinerea, opaca. Proboscis nigra, capite paullo longior. Palpi nigri. Antennae nigrae, graciles. Thoracis dorsum pilis paucis, brevibus, nigris vestitum, obscure trivittafum, vittâ mediâ angusliore. Abdomen nudiuseulum, pilis minutis, plerisque pallide lutescentibus. Pedes longi, nigri, breviter nigro-pilosi, femorum basi genibusque testaceis. Halteres sordide albidi. Alae subcinerascentes, imâ basi lutescente, venis crassis obscure fuscis, stigmale subfusco, cellulâ discoidali magnâ. - (New York.)

Nota: Speciei praecedenti similis, sed palpis nigris, pedibus obscurioribus femoribusque posticis gracilioribus nimis discrepat, quam ut pro foeminâ illius haberi possit.

60. Rhamphomyia limbata nov. sp. $\delta$ et ㅇ․ Aut obscure cinerea aut allida, viltis thoracis quatuor obscurioribus, coxis pedibusque nigris; antennae breves, nigrae; proboscis crassissima, capite paullo longior; alae subhyalinae, venis validis et stigmate fuscis.

б ex fusco cinereus; hypopygium magnum, erectum, lamellis mediis majoribus, in margine apicali nigro-pilosis, filamento conIrali arcuato; halteres fusci; alarum cellula discoidalis mediocris.

은 thorax ex cinereo albidus, abdomen candidum; cellula discoidalis permagnu, alae marginem fere allingens, cellularum posteriosum secunda et tertia confluentes; halteres sordide albidi.

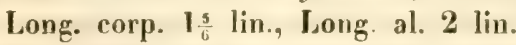

Mas: Ex nigro cinereus, opacus, humeris, pleuris lateribustrue abdominis purius cinereis. Oculi late distantes; antennae breves, nigrae, articulo tertio latiusculo, stylo terminali tenui, parvo; palpi 
nigri; proboscis nigra, crassissima, capili aequalis aut paullo longior. Villae thoracis qualuor dorsales obsoletae, fuscae. Caput, thoracis dorsum el sculellum nigro-pilosa. Abdominis pili longiores pallide subfusci. Hypopygium magnum, erectum, nigrum; lamellae superae oblongae; lamellae inlermediae latiores, oblusae, in margine apicali pilis longis nigris vestitae; lamellate inferae minutae, vigro pilosae; filamentum ceutrale longum, arcuatim ascendens. Pedes nigri, confertius nigro-pilosi, metalarso antico modice incrassato. Halteres sordide nigri. Alae hyalinae, dilut cinerascentes, venis et sligmale obscure fuscis, cellulà discoidali mediocri.

Foemina: Ex albo cinerea, thorace vittis quatuor obscurioribus signalo, abdomine candido-micante et pilis pallidis brevissimis rare vestilo. Pedes breviler pilosi. Halteres sordide albidi. Alae hyalinac, dilute cinerascenles, venis et stigmate obscure fuscis, marginis postiri dimidio apicali cinereo-limbato; cellula discoidalis maxima, alae marginem. fere allingens; cellula posterior secunda ininula, cum tertiâ in unam confluens. - (Disir. Columbia; Osten-Sacken.)

61. Rhamphomyia lilurala nov. sp. of et 9 . Aut cinerea, aut albida, breviler pilosa, coxis pedibusque sordide testaceis, tarsis ex nigro fuscis; antennae breves nigrae; pruboscis crassissima, capite paullo longior; halteres albi; alae ex fusco cinereae, venis vulidis fuscis, stigmate angustissimo fusco.

o' thorax ex albo cinereus, abdomen obscurius cinereum; hypopyginm magnum, ascendens, lamellis oblusis, filamenlo centrali arruato; alae simplices, celluli discoidali mediocri; tibice posticae et metalarsi postici dense fusco-pilosi.

o thorax ex cinereo albilus, abdomen candidum; alarum apex strigis duabus cinereis pictus; cellula discoidalis permagna, alae marginem fere allingens.

Long. corp. $1 \frac{5}{6}-2$ lin., Lang. al. $2 \frac{1}{2}-2 \frac{1}{6}$ liu.

Mas: Cinereus, capite, scutello et thorace ex albido cinereis. Oculi hate distantes. Antemae nigrae, breves, articulo tertio latiusculo, slylo terminali minuto. Palpi minuli, nigri. Proboscis fusca, crassissina, capite paullo longior. Pili thoracis nigri, breves, rari. Scutelli setulae apicales duae, nigrae. Abdomen obscure cineream, pilis pallide luteis rare veslitum. Hypopygium ex cinereo nigrum, magnum, clausum, ascendens, lamellis ololusis, superioribus in margine apicali breviler nigro-pilosis, filamento centrali nigro, arcuato. Cosac lestaceac, subnudac. Pedes sordide testacei, femorum omnium apicibus tibiisque anticis practer basim fuscis, tarsis omnibus 
ex fusco nigris; pubes fusca in supero libiarum posticarum el metatarsorum poslicorum latere conferta et longa; metalarsus anticus subincrassatus. Halteres albidi. Alae ex fusco cinereae, venis validis fuscis, cellulâ discoidali mediocri, stigmate angustissimo, fusco.

Foemina: Capite, thorace et scutello ex cinereo albidis. abdomine candido-micante. Pedes simplices, nec metatarso antico sub. incrassato, nec tibiis et metatarsis posticis pube longà vestitis. Alarum apex strigis duabus cinereis, alterì in cellulâ submarginali, alterâ in cellulâ posteriore primît, variegalus; cellula discoidalis maxima, alae marginem prope altingens; cellula posterior secunda cum tertiâ in unam conjuncta. I land; Osten-Sackeu.)

Nota. Non me errasse puto hanc foeminam cum mare conjungendo; si vero erraverim, mari aliud nomen eligendum erit.

62. Rhamphomyia leucoptera nov. sp. 万’. Tola nigra, polline albo cinerea, alis halleribusque niveis, proboscide capili aequali, metatarso postico incrassalo. - Long. corp. $1 \frac{1}{2}$ lin., Long. al. $1 \frac{1}{2}$ lin.

Caput nigrum, oculis contiguis, proboscide brevi, capiti sub. aequali. Antemae breves, nigrae, articulo tertio latiusculo. Thorax polline albido cincreus, pilis selulisque rarissimis nigris praeditus. Scutellum et melanotum concolora. Abdomen polline densissimo albicans, pilis rarioribus uigris vestitum. Hypogygium mediocre, porrectum, aperlum, lamellis superis mediocribus acutis, intermediis majoribus oblusis, inferis minutissimis subobsoletis, filamento medio arcuatim ascendente et e basi crassâ valde allenuato. Pedes nigri, graciles, nigro-pilosi, tibiarum tarsorumque pilis longioribus et validioribus; tibiae posticae subclavatae; metatarsus posticus incrassatus, oblongo-ovatus. Halteres nivei. Alae niveae, venis concoloribus, costâ tamen totî venisque tribus primis apicem versus obscure fuscis. - (Distr. Columbia; Osten-Sacken.)

63. Rhamphomyia pusio nov. sp. ठ大. Atra, thorace pedibusque nitidis, abdomine opaco; antennae brevissimae; proboscis capiti aequalis; halleres albidi; alae albae, venis concoloribus, secundo costae dimidio et venae longitudinalis terliae apice nigricantibus; pili minuti thoracis nigricantes, pili abdominis et pedum pallide subfusci, in tibiis el melalursis poslicis longiores; hypopygium mediocre, crassiusculum, ascendens, - Long. corp. $\frac{1}{1} \frac{1}{2}$ lin., Long. al. $1 \mathrm{lin}$. 
Atra: caput concolor, oculis in mare subcontignis Antennae nigrae, brevissimac. articulo tertio ovato, latiusculo, slylo terminali minutissimo, subobsoleto. Proboscis capiti afqualis. Thorax nitidus, pilis raris et brevissimis nigris vestitus. Scutellum nitidum, setulis aliquot nigris in margine apicali praeditum. Abdomen opacum, pilis raris, minutis, pallide subfuscis obsitum. Hypopygium mediocre. atrum, nitidum. ascendens. lamellis obtusis, subnudis, filamento centrali abscondito. Pedes atri, breviusculi, metatarso postico subincrassato; pili pedum subfusci, certo situ albicantes, rari et breves, in tibiis et metatarsis posticis longiores. Halteres albidi, pedunculo nigricante. Alae albae, stigmate obsoleto venisque concoloribus, costae dimidio secundo et venae longitudinalis tertiae apice nigricantibus, cellulî discoidali mediocri, laliusculâ. - (Maryland: Osteu-Sacken.)

64. Rhamphomyia nana nov. sp. J et 오. Atra. nitida, thorace pedibusque nigro-pilosis; proboscis rapilis longitudinem non excedens: halleres albi; cellula discoirfalis mediorris.

o lamellae hypopygii parve, obtusae. ascendentes: filamentum rentrale tenue. arcuatum; metatarsus posticus modice incrassatus; alae cinerene, basi pallidissime flavescente, stigmale nigro.

\& pedes intermedii in femoribus utringue et in tibiis superne, pedes postici et in femoribus et in tibiis utrinque squamato-ciliati.

Jong. corp $1 \frac{1}{6}$ lin., Long. al. $1 \frac{1}{6}$ lin.

Atra, nitida, antennis, palpis et proboscide concoloribus. Oculi maris contigui: proboscis capili fere aequalis, tenuior in mare quam in foeminâ. Thorax pilis nigris parce convestitus. Pili abdominis pallide subfusci. Hypopysium maris alrum, nitidum, ascendens, lamellis parvis, obtusis. breviter pubescentibus, filamento centrali tenui, arcuato. Pedes nigri et nigro-pilosi, in speciminibus immaturis ex nigro fusci, genibus summis pallidioribus; postica maris femora infra pilos validiores. tibiae et metafarsi modice incrassati supra setas nonnullas inaequales gerunt; intermedii foeminae pedes tibias superne el femora utrinque squamato-ciliata, pedes postici et tibias et femora utrinque squamato-ciliata habent. Halteres albi. Alae maris cinerascentes, basi dilutissime subflavescente, stigmate nigro; alae foeminae latiores, Lotae nigrae, sligmate obscuro; cellula discoidalis in utroque sexu mediocris. - (Maryland; (Nilen-Sacken.)

Nota. Saepe venula transversa adventicia basim cellulae posterioris secundae transgreditur. 
65. Rhamphomyia umbilicala nov. sp. \&. Ex nigro cinerea. alis albido-hyalinis, venne longitudinalis quartae segmento ultimo valde abbreviato, punctum insigne atrum dissecante. - Long. corp. $\frac{1}{12}-1$ lin.. Long. al. $1 \frac{1}{1} \frac{1}{2}$ lin.

Ex nigro rincrea, interdum nigricans. Caput nigrun, antennis, proboscide palpisque concoloribus, fronte tomento albido-cinereo vestitâ. Thoracis dorsum et abdomen pilis albidis. tenuibus et raris tecta. Pedes graciles. subtiliter pubescentes, nigri, metalarsorum posticorum basi pallidiore, tribus ultimis tarsorum articulis brevibus; in sperimibus immaturis pedes multo pallidores esse solent. Halteres albi. Alae albido-hyalinae, interdum leviler subcinerascentes, venis sordide albidis, ullimo venae longiludinalis quartae segmento valde abbreviato et punctum insigne nigrum gerente. - (Mesieo, Pennsylvania: Osten-Sacken.)

66. Rhamphomyia ungulata nov. sp. $\sigma^{7}$. Albido-cinerea. breviler albo-pubescens, abdomine niveo-pollinoso. hypopygio parvo sub ventrem deflexo. halteribus alisque albis. venâ longitudinali quartá nonnihil abbreviatâ. pedibus nigricantibus, tarsorum anteriorum articulis intermediis albis. tarsis posterioribus albis, apicem versus nigris, unguiculis longis ef tenuilus, pulvillis anguslatis, elongatis et eleganter ciliatis. - Long. corp. 1 $\frac{1}{12}$ lin., Long. al. 1! lin.

Es albo cinerea, breviter albo-pubescens. Caput nigrum, oculis per frontem angustissimam sejunctis. Antennae nigrae, arliculo tertio subulato. Proboscis nigro-fusea, capite longior. Thoracis dorsum et scutellum polline albo resita; abilomen dense niveo-pollinosum. Hypops gium parvum. nigricans, deflexum. Pedes nigricantes; tar. sorum anticorum arliculus primus niger, secundus albus, tertius albidus, quartus nigricans. quinlus denique niger; tarsi posteriores albi, articulo ultimo nigro. Unguiculi longi, tenues, albidi; pulvilli elongali, angusti, albidi, pulchre albido-ciliati. Halteres albi, pedunculo nigricante. Alae albae. venis concoloribus, secundo costae dimilio sulfusco. venâ longitudinali quartâ prope alae marginem à̉. ruptî. - (Hesivo.)

67. Rhamphomyia soccata nov. sp. $\sigma^{\circ}$. Nigra, breviter albo-pubescens, thorace obsolele, abdomine perspicue cinerasrente, hy. popygio paren non deflexo, halleribus albis, alis hyalinis, venis albidis. costá fuscâ. venâ longiludinali quartâ abbreviatá, pedibus nigricantibus, farsorum anticorum arliculis intermediis praeter api- 
cem albidis, tarsorum posteriorum arliculis primis albis, sequentibus fuscis, ullimo nigro, unguiculis longis validiusculis, pulvillis longis, subangustalis el eleganter ciliatis. - Long. corp. $1 \frac{1}{1 \frac{1}{2}}$ lin., Long al. $1 \frac{1}{4}$ lin.

Nigra, breviter albido-pubescens. Caput nigrum, oculis per frontem angustissimam separatis. Antennae nigrae, articulo tertio subulato. Proboscis nigra, capite multo longior. Thoracis dorsum et scutellum polline rarissimo albido obsolete subcinerascunt. Abdomen atrum opacum, oblique inspectum cinerascens. Hypopygium nigrum, parvum. porrectum, lamellis obtusis. Pedes nigricantes, albido pubescentes; tarsi antici nigricantes, articulorum intermediorum basi sordide albidâ; tarsorum intermediorum articuli duo primi albi, summo lamen apice nigro, duo sequentes fusci, ultius niger; tarsorum posticorum articuli tres primi albi in apice nigri, articulus quartus fuscus, quintus niger. Unguiculi longi, validiusculi, incurvi, albidi, in apice nigri. Pulvilli elongati, modice angustati, albidi, pulchre albido ciliati. Alae hyalinae, non albidae nisi adversus luminis radium visae, venis albidis, anlerioribus subflavescentibus, costâ totâ obscure fuscà; vena longiludinalis quarta abbreviala longius ab alae margine desinit quam in specie praecedente. (Missisippi; Schaum.)

68. Tropidia mamillata nov. sp. $\delta$. Aeneo-nigra, sculelli margine, fasciis abdominis duabus inlerruptis, libiis tarsisque test ceis, antennis ochraceis; femora postica sublus apophysi subbasali mamillat â armata; tibiae posticae crassae, arcuatae. - Long. corp. 4 lin., Long. al. 3 lin

Facies carinata, polline ex ciuerco albo micans. Antennae lacte ochraceae. Thoracis dorsum ex nigro aeneum, uitidum. Scutelli aeneo-nigri margo testaceus. Pleurae cinereo-polliuosae. Abdomen adversus basim nigrum, adversus apicem fuscum, fasciis duabus interruptis testaceis. Femora atra, summo apice testaceo; femora postica in latere inferiore prope basim apophysi validâ mammiformi armata. Tibiae anteriores simplices, ex testaceo flavae; tibiae posti. cae dilatatae, arcuatae, fuscu-nigrae, basi et latere superiore testaceis, apice in dentem producto. Tarsi ex testaceo flavi, articulo penultimo nigro, articulo ultimo aut in posticis tantum aut in om. nibus fusco. Halteres albidi. Alae ex cinereo hyalinae, stigmate flavo. - (Illinois.) 
69. Tetanocera triangularis nov. sp. ठ. Glandicolor, thorace bilineato, frontis opacae vittulis lateralibus laevigatis, subobsoletis, fossula medià distinctâ, non dilatala, subtriangulá, antenuarum setá pilis longis, rarioribus, nigris plumali, alis lulescentibus, unicoloribus, venis transversis fusco-limbalis, posteriore subvectâ. - Long. corp. $3 \frac{1}{12}$ lin., Long. al. $3 \frac{1}{6}$ lin.

Occiput flavum, maculâ pernagnâ candidâ ornatum. Frons flávissima, tota opaca. vittulis lateralibus ordinariis lacvigatis, angustis, subobsoletis, fossulà mediâ distinctà, laevigatâ, non dilatatà. valde abbreviafâ, subtriangulâ. Antennae breviusculae ochraceae, articulo tertio longitudinem praecedentium simul sumptorum paullo excedente. adversus apicem ferrugineo, setâ pilis nigris. Inngis, sed rarioribus plumatâ. Facies albomicans, immaculata. Thoracis dorsum lineis duabus obscurioribus. valde approximatis pictum. Abdomen unicolor. Pedes lutei, articulis ultimis tarsorum anticorum tribus, intermediorum unico, posticorum duobus nigricantihus. femoribus poslicis maris sublus nigro-selosis. Alae lutescentes, unicolores, marginibus anteriore et apicali non obscurioribus. venis transrersis fuscolimbatis, posteriore subrectì. - (English River; Kennicot.)

Nota. Simillima Tet. sylvaticae Meig., sed Tet unicolori Loew propior: ab illà frontis fossulâ meliâ valłe abbreviatâ et margine antico non laevigato. ab hâc. quam magnitudine superat, thorace lineato frontisque fossulî angustiore et minus obsoletâ distinguitur.

70. Tetanocera rotuncicornis wov. sp. ó et 우. Ex helvo glandicolor, frontis opacae vittulis lateralibus ordinariis sublaevigatis, distinctis, fossula medià requali usque ad anteriorem frontis marginem producti. antennarum articulo tertio orato. superius non exciso, setâ pilis nigris longis. sed ruris plumatí, alis hutescentibus, costae dimidio secundo el apice anguste fusris. venis iransversis fusco-limbatis, posteriore subrecta. - Long. corp. $2 \frac{5}{1} \frac{1}{2}-$ 3 lin.. Long. al. $2 \frac{1}{2}-3$ lin.

Occiput flavum. maculâ cordatâ alho-micante ornatum. Frons flavissima, tota opaca, vittulis lateralibus ordinariis laevigatis, latioribus. fossulâ meciâ laevigatâ, aequali, integrâ. Autennae breves, ochraceae, articulo tertio ovato, superius non exciso, setâ pilis nigris. longis. sed raris plumatà. Thoracis dorsum lineis quatuor obscurioribus pictum. intermedis integris. lateralibus interruptis, ommibus haud raro obsoletis. Abdomen uniculor, vilta laterali obseu. riore. in mate plerumque obsoletâ. Pedes lutei, ultimis tarsorum 
arliculis nigris, femoribus posticis in mare subtus nigro-setosis. Alae Iutescentes, marginis costalis dimidio secundo dilutius, margine apicali saluratius infuscato, venis transversis fusco-limbatis. posteriore subrecti el subperpendiculari. - (Euglish liver: Kennicot.)

Nota. Interdum venulac adrenticiae e posieriore venae longitu. dinalis quartae latere prodeunt.

71. Sciomyza luctifera nov. sp. o'. Nigra. thorace cinerco, facie albi, antennis et fronte fulvis, coxis anticis albis, pedibus nigris. tarsis posterioribus sordide albis, alis nigricantibus, margine costali nigro-limbato. - Long. corp. $1 \frac{1}{2}$ lin.. Long. al. $1 \frac{1}{t}$ lin.

Miuna, nigra. Facies, genae et iuferior occipitis pars albae. Antemua et frons fulsae, vittis hujus lateralibus. antice abbreviatis, et triangulo ocellari cum superiore occipitis parte cinereis. Thorax obscure cinereus, nigro-pilosus. Pedes antici atri. coxis albis. can. dido-micantibus; pedes posteriores nigri, trochanteribus tarsisque sordide albidis, horum apice nigro. Alae mediocres. nigricantes, ad costam latius vigro-marginatae. - (Pennsylvania: Osten-Sacken.)

Nota: In speciminibus junioribus pedum intermediorum color niger in fuscum vergit.

72. Trypeta alba nov. sp. ơ et 4 . Albida. alis concoloribus immaculatis, fronte, pleuris, scutello segmentorumque abdominalium singulorum margine postico pallide sulphureis. facie cum antennis. pedibus et terebrí obscurius flavis. - Long. corp. $1 \frac{1}{2}-2$ lin., Long. al. $1 \frac{3}{4}-1_{6}^{5}$ lin.

Antemne mediocres, articuli tertii ublongi apice rotundato, sela brevissime puberulà. Oculi magni. subrotundi: grenae mediocres. Oris apertura mediocris rotundata, proboscide non geniculata palpisque brevibus Scutellum planum, quadrisetosum. Terebra focminae depressa. ex ferrugineo hara. Iribus ultimis abdominis semmeutis simul sumplis longior. Alarum albidarum venae omnes pallidissimae et, ¿siepta longiludinali prima. nudae; posterior cellulae analis angulus acutus. - (Pennsylrania; cum duabus sequeutibus ef Tryp. obliquà Say ab Osten-Saclienio in Vernoniac specie capta.)

73. Trypela albidipennis nov. sp. o et + . lisro-rinerea, thoracis darso abbicante, capile. thoracis villei laterali scutelloyue sulphureis, alarum albidarum stigmate fusco, terebri fueminue atra. - Long. corp. $2-2 \frac{1}{3}$ lin. Long. al. $2 \frac{2}{6}-2 \frac{1}{4}$ lin. 
Antennae mediocres, ex ferrugineo flavae, articuli tertii apice rolundato, setâ subnudâ. Oculi magni et subrotundi; genae mediocres; proboscis non geniculata palpique breves. - Thoracis dorsum albido-pollinosum, pube brevi albidâ setisque nigris pracditum; scutellum quadrisetosum. - Abdomen nigro-pilosum. Terebra foeminae depressa, atra, nigro-pilosa, tribus ultimis abdominis segmentis simul sumptis paullo longior. - Pedes fusco-nigri, trochanleribus, genibus, tibiarum apice tarsisque ex flavo ferrugineis. Alae albidae, stigmate fusco, venis omnious, exceplâ longitudinali primâ, nudis, in parte alarum basali pallide havis, in reliquâ alâ fuscis. - (Yeunsylvania; Osten-Sacken.)

74. Trypeta Vernoniae nov. sp. ठำ Helva, metunoto nigro, capite, thoracis vittà laterali, superiore pleurarum parte et scutello pallidius, antennis, terebrâ pedibusque obscurius flavis; alarum dimidio apicali fasciis tribus fuscis subreticulato, primâ incompleta et obsoletiore, secundá integrà, tertia postice abbreviata. Long. corp. $2 \frac{1}{\frac{1}{2}}-2 \frac{1}{2}$ lin., Long. al $2 \frac{1}{1}-2 \frac{1}{6}$ lin.

Caput flavum, orbità oculorum angustissimâ albo-micante. Autennae ochraceae, articulo teıtio oblongo, setâ subnudà. Oris apertura majuscula, rotundata, proboscide non geniculatâ palpisque mediocribus. Oculi magni, oblongi. Thoracis dorsum pube brevi albidà sefisque pallidissime fuscis vestitum. Scutellum planum, quadrisetosum. Melanolum nigrum, albido-polinosum. Abdomen ex helvo luleum, pilis in margine abdominis laterali et in segmentis ultimis nigris, reliquis pallidis. Terebra foemiuae ochracea, nitida, subdepressa, tribus ultimis abdominis segmentis simul sumptis aequalis, pilis teueris nigricantibus vestita. Pedes toti fulvescentes. Alae subhyalinae, per fascias tres transversas irregulares maculasque aliquot minutas apicales fusco subreticulatae; fascia prima postice valde abbreviata a stigmatis basi obscura oblique ad venam transversam median descendit et haud raro obsolescit, relicto veutilae transversae limbo obscuro; fascia secunda angusta est ct rectâ a coslà usque ad marginem posteriorem extenditur; fascia tertia inaequalis et postice abbreviata cum maculis costalibus cohaeret. Vena longitudinalis prima setigera, reliquae nudae. - (Pennsylvania; OstenSacken.)

75. Palloptera superla nov. sp. ठ' et $Q$. Flava, segmenlis abdominalibus singulis serie murlorum nigrorum prope marginem postirum notatis; alae longae, vilti costali latissima et fa. 
sciâ trunsversâ connexis nigro-fuscis. lin., Long. al. $3-3 \frac{1}{3}$ lin.

- Long. corp. $2 \frac{5}{1}-2 \frac{7}{12}$

Inter majores sui generis. Flava. Frons laetius flava, opara. Antennae pallide flavae, articulo tertio ovato, setâ breviter plumalâ. Thorax unicolor, raro lineis obscurioribus obsolete pictus. Sculellum convexum. Abdominis segmenta singula in margine posilico serie punctorum nigrorum ornata. Hypopygium maris globosum. Pleurae et pedes pallide flavescentes. Alae subhyalinae, villâ costali latissimâ, sed paullo angustiore quam est dimidia ala, et fasciâ latâ, veuam transversam posteriorem includeute nigro-fuscis. - (Pennsylvania; Osten Sacken.)

76. Sapromyza compedita nov. sp. $ర$ et 오. Flavescens, antennis, proboscide et palpis concoloribus; ulae lulescentes, viltà subapicali plerumque interruptâ et maculà apicali nigricantibus; se-

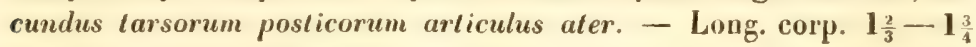
liu., Long. al. $2-2 \frac{1}{12}$ lin.

Subopaca, tola flava, colore thoracis et scutelli nomuihil in rufescentem, colore pedum magis in pallide flavum vergente. Frons laetius flava, sine ullo nitore. Tertius antennarum articulus breviter ovatus; seta fusca breviter pubescens. Scutellum planum. Lamellae hypopygii permagni in apice nigro-pilosae. Pedes flavescentes; tarsi graciliores quam in plerisque Sapromyzis, secundo posticorum articulo atro, in mare dilatato, in foeminâ simplice. Alae Intescentes, venis transversis nigro-limbatis; venae transversae posteriori maculae dnae, quarum altera in venâ longitudinali tertiâ siła est, altera apicem venae longitudinalis secundae tegit, oppositae sunt, quae inter se et cum venae transversae posterioris limbo confluentes fasciam transversalem formant; apex alae maculam magnam ex duabus connatam habet. (Pennsylvania; Osten-Sacken.)

77. Sapromyza fraterna nov. sp. $\sigma^{7}$ et 오. Flava, anten. nis palpisque concoloribus, ultimo tarsorum posteriorum articulo superne fusco; alae lutescentes, venis transversis nigro-limbatis, venâ longitudinali terliá punctis tribus, secundâ et quartâ utrâque puncto unico apicali notatis. - Long. corp. $1 \frac{5}{6}-2$ lin., Long. al. $1 \div \frac{1}{2}-$ $2 \frac{1}{1 \frac{1}{2}}$ lin.

Flava, modice nitens. Caput opacum, fronte laetius flavâ, facic albicante. Antennae flavae, articulo tertio ovato, setî nigrả brevi. ter plumatà. Sculcllum subplanum. Нурору⿻̆丶n maris majusculum. Pedes pallide flavi, articulo tarsorum posteriorum terminali 
superne fusco. Alae lutescentes; venae transversae nigro limbatae, limbo ordinariae antice dilatato; venarum longitudinalium secunda, terlia et quarla singulae puncto apicali nigro notatae, adjectis in terliâ punctis duobus, per quae ultimum hujus venae segmentum in tres partes subaequales dividitur. (Pennsylvania; Osten Sacken.)

Nola. Sapr, philadelphicae Macq. similis, sed punctis venae tertiae tribus, non duobus diversa, similior Sapr. notatae Fall., cui eadem omnino alarum pictura, sed femora maris hujus subtus nigro-sctosa, Sapr. fraternae nuda sunt.

78. Sapromyza quadrilinéuta wov. sp. ठ et 오. Cinerea, opaca, thoracis lineis qualuor longiludinalibus fuscis, scutello et abdomine pallide luteis, illo adversus basim cinereo, hoc quatuor macularum fuscarum seriebus picto; pedes favescentes annulis fuscis, saepe obsoletis ornati; alue lutescentes. - Long. corp. $1 \frac{1}{2}$ lin, Long. al. $1 \frac{3}{4}$ lin.

Minula, cinerea, opaca Caput ex flavo albidum, lincis frontis duabus longitudinalibus fuscis. Antennae pallide luteae, articulo lertio rotundato-ovato, setâ obscurâ breviter nigro-pubescente. Clypeus proninulus. Oris apertura magna; palpi minuti atri. Thoracis dorsum cinereum, lineis quatuor fuscis pictum, humeris plerumyue flavescentibus. Pleurae cinereae. Scutellum subplanum, paIlide lulescens, fusco-bimaculatum et adversus basim in speciminibus plerisque cinerascens. Abdomen breve, pallide lutescens, quatuor macularum fuscarum seriebus piclum. Hypopygium maris mediocre, crassissimum, abdomini concolor aut magis rufescens. - Peles pallide lutescentes annulis fuscis haud raro obsoletis ornantur, annulo lamen tibiarum posticarum subbasali semper conspicuo. - (Penusyívauia; Osten-Sacken.)

79. Sapromyza bispina nov. sp. ठ et \&. Flava, antennis palpisque concoloribus, antennarum sefa nigri breviter pubescente, alis lutescentibus, venis transversis nigris. - Long. corp. 1 $\frac{2}{3}-2 \frac{1}{1} \frac{1}{2}$ lin., Long. al $1 \mathbf{1}_{6}^{5}-2$ lis.

Tula flava. Caput opacum, fronte et antennis flavis, harum ariculo tertio ovato, breviter nigro-pubescente. Faries adversus oris aperturam recedens, clypeo non prominenle. Thoracis dorsum et sculellum planum modiee nitent, colore ex flavo nomnilil in rufescenten vergente. Abiomen pallide flavescens, subopacum. Maris hypopy gium magnum, lamellis duabus apicalibus rolundatis, nigropilosis praeditum segnentumque ventrale ultimum dilatalum el utrin- 
que dente uagno el valido armatum. Pedes pallide flavi, extremo tantum apice articuli terminalis tarsorum posteriorum nigro. Alac lutescentes, venis transversis nigris. - (Nebraska.)

Nota. Sapr. bispina a Sapr. rorida Fall. margine frontis anleriore magis proiuberante et venis alarum transversis nigris diversa, a specie sequente iisdem nolis et segmento abdominali maris ultimo dentibus duobus validis armato distinguilur.

80. Sapromyza tenuispina nov. sp. $\delta$ et + . Flava, antennis palpisque concoloribus, antennarum selá nigrá adversus basim pallida, breviter pubescente, alis lulescentibus. - Long. corp. $1 \frac{3}{4}$ lin., Long. al. $1 \frac{5}{6}$ lin.

Tota flava. Caput opacum. fronte et antennis laetius flavis, illus margine antico magis prominente quan in specie praecedente, harum articulo tertio ovato. setâ nigrâ, adversus basim pallidà, breviter nigro-pubescente. Facies adversus oris aperturam recedens, clypeo non prominente. Thoracis dorsum et scutellum planum subopaca. colore ex flavo nonuhil in rufescentem vergente tiucta. Abdomen pallide flavescens, subopacum. Maris hypopygium magnum lamellis duabus apicalibus minutis rotundatis el breviter nigro-pilosis praeditum segmentumque ventris ultimum utrinque spinulà tenui armatum. Pedes pallide flavi. Alae hutescentes, venis transversis concoloribus. - (Nebraska.)

1. Sapromyza cincta nov.sp. 오. Flava, antennarum palporumque apice, puncto verticis minulo. segmentorumque abdominalinm singulorum margine postico atris, alis ex luteo pallidissime

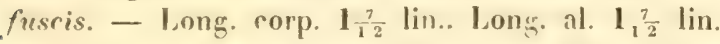

Ex rufo flava, nitens. Frons lata, tota nitens. Antennac flavae, articuli tertii dimidio apicali atro, sela pilis longis nigris plumati. Oculi rotundi; genae latiusculae el facies pailide flavescenles, opacae. Clypeus prominulus; palpi tenues, atri. Sculellum subplanum. Segmentorum abdominalium singulorum uargo posterior fasciâ aequali atrà limbatus. Pedes pallide flavi. Alac colore dilulissimo ex luteo in fuscum vergente tinclae. - (Cuba; Richl.)

82. Pachycerina verlicalis nov. sp. ㅇ․ Ex rufo flara, uilida, maculi frontis verticali palpisque atris, seli antennur tum densissime nigro-plumosti, alis dilutissime ex fusco lutescentibus. Long. corp. $1 \frac{1}{3}$ lin., Long. al. $1 \frac{1}{3}$ lin.

Ex rufu llava, nitida. Frons latissima, tota nitida, puncto ver- 
ticali magno alro, ocellos includente. Antennae flavae; articulus tertius elongatus, sublinearis, in apice et margine inferiore plerumque fuscus aut niger; seta atra, densissime atro-plumosa Clypeus subprominens; palpi lati, atri. Oculi subrotundi; genae latiusculae. Abdomen cum reliquo corpore concolor, segmentorum singulorum margine postico interdum fusco, rarius totum fuscum. Pedes flavi, tarsis anticis fuscis; in speciminibus obscurioribus tibiae anticae et ultimi tarsorum posteriorum articuli colorem magis in fuscum vergentem habent. - (Florida; Osten-Sacken.)

83. Lauxania variegata nov. sp. ㅇ․ Mellea, tota nitens, punctis frontis duobus anterioribus et uno verticali, faciei convexae maculis tribus, viltis duabus thoracis, pleurarum viltâ superiore el maculâ mediâ, femorum anticorum annulo subapicali, tibiis tarsisque anticis atris; alae cinereae, limbo costae lato, apicis totius limbo latissimo fuscis. - Long. corp. $2 \frac{1}{2}$ lin., Long. al. 2 lin.

Mellea, tota nitens. Frons plana, prope marginem anteriorem punctis duobus atris, in vertice puncto misuto atro, ocellos includenle signata. Facies valde convexa, maculis tribus atris, mediâ oblongo-ovalâ, lateralibus oblique descendentibus, cuneatis. Oculi oblongi; genae latissimae. Duo primi autcunarum arliculi mellei; tertius in specinine descripto deest. Thoracis dorsum vittas duas late distantes, postice abbrevialas, nigras habet. In pleuris vitta atra superior et macula media aterrima et velutina conspiciuntur. Scutellum majusculum, subplanum. Pedes paullo pallidiores quam reliquum corpus, femoribus anticis annulum subapicalem atrum gerentibus, tibiis tarsisque anticis totis atris; tibiarum posteriorum color apicem versus in fuscum vergens, tarsorum posteriorum apex fuscus. Alae ex luteo cinereae, limbo costae lato, totius apicis latissimo, ullimum alae trientem fere totum explente, fuscis. - (Cuba, Riehl.)

84. Lausania opaca nov. sp. ơ et + . Atra, thorace et scutello plano albo-pollinosis, illo viltis tribus obscurioribus distinctissimis picto; antennarum articulus primus secundi longitudinem prope aequat, terlins elongalus, linearis, selá obscurâ pilis mediocrilus plumalá; facies modice convexa, tota albo-pollinosa, opaca; halteres pedesque nigri, genibus tarsisque posterioribus sordide albicrintibus; alae lutescentes, imâ busi obsoletissime nigricante. Long. corp. $1 \frac{1}{2}-1 \frac{2}{3}$ lin., Long. al. $1 \frac{2}{3}-1 \frac{3}{4}$ lin.

Atra. Frons atra, opaca, a latere tola polline albo vestita videlur, desuper visa viltam median colore atro, prope marginem au- 
teriorem in ferrngineum vergente pictam villasque laterales cinereas latissimas refert. Antennae graciles; articuli duo primi ex rufo ferruginei. primus paullo brevior quam secundus; articulus tertius elongatus. linearis, ater, basi articulis praecedentibus roncolore; seta pilis mediocribus plumala, obscura, basi lutescente Facies modice convexa, subcarinata, tota albo-polliuoso, opaca. Proboscis nigricans; palpi atri. Thoracis dorsum albo-pollinosum, opacum, vittis tribus laevigatis atris, mediâ angustâ, lateralibus latissimis. Pleurae alrac, nitidae, maculis duabus albo-pollinosis. Sculellum planum, albo-pollinosum, opacum. Pedes atri, genibus tarsisque posterioribus sordide albidis. Ilalteres nigri, pedunculo lutescente. Alae lutescentes, imà basi obsoletissime nigricante. - (Florida; Osten-Sacken.)

85. Lnuxania gracilipes nov. sp. o ct f. Alru, nilida, thoracis dorso leviter pollinoso, scutello velutino, tevtio antenuarum artimulo oblongo-orato, selà obscurá pilis nigris plumatá, pedibus albis, femoribus nigris, alis lutescentibus, basi conrolore. - Long corp. $1{ }_{6}^{5}$ lin., Long. al. $1 \frac{7}{12}$ lin

Frons atra, nitida. vitta mediâ brevi velutinâ. Aulennae cs luteo rufae, articulis duobus primis brevibus, tertio oblongo-ovato. apicem versus fusco, setâ obseurâ, pilis longissimis plumatâ. Fa. cies modice convexa, atra, nitens, orbilis latis candido micantilius Prohoscis nigra; palpi atri. Thoracis dorsum polline cinereo, adversus marginem posteriorem albicante vestilum modice nilet. Plenrac albo-pollinosae. Seutellum planum, velutionn, alrum, prope ba. sim polline albido oblectum. Ahdomen nitidum. P'edes grariles, albi. primo coxarum articulo femoribusque, excepto tamen horum apice, atris. Jalleres albidi. Alae lutescentes, basi concolore. (Pennsylvania; Osten-Sacken.)

56. Lauxania obscura nov. sp. o’ el t. Alra, capite, thorace scutelloque opacis, abdomine nitido, frontis margine antico antennarumque basi ex ferrugineo sufis, berlio andennarum arliculn praeter brsim nigro-fusco, ouato. seti nigricante pilis mediocribus plumutâ, pedibus atris, tarsis posticis dilute lutescentilus, haltermm pedunculo luteo, copilulo nigro, alis lutescentibus, imâ basi nigri.

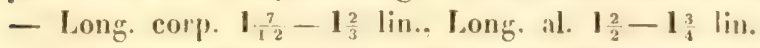

Laux. Iongipenni Fbr. affinis, sed fronte mimus latâ, facie breviore et minus convexâ, abdomine denique nitido distincla. Atra. Frons modice lala, alra. opaci, margine asteriore ex ferruginco rufo; 
vittac frontis laterales antice valde abbreviatae, obsolete albido-pollinosae; orbita oculorum frontalis antice angustissima, alba. Duo primi antennarum articuli breves, ex ferrugineo rufi aut flavi; articulus tertius ovatus, ater. triente basali articulis praecedentibus concolore; seta obscura, pilis mediocribus plumata. Facies brevis, subplana, albo-pollinosa, opraca. Proboscis nigra, palpi atri. Thoracis dorsum polline tenui albido opacum, vittis quatuor obscurioribus obsoletissimis. Scutellum planum, thoraci concolor. Pleurae atrae, modice nitentes. Abdomen atrum. valde nitidum. Pedes atri, tarsis posterioribus sordide albidis, tibiis interdum ex fusco nigris. Halteres nigri. pedunculo sordide lutescente. Alae lutescentes. basi nigrâ. - (English River; Kennicot. - Pennsylvania; Osten-Sacken.)

87. Lauxania muscaria nov. sp. ․․ Atra, nitida, non pollinosn, colore thoracis ef scutelli convexi nonnihil in chalybeum, colore abdominis magis in olivaceum vergente, antennarum lutearum articulo tertio ovato. setâ fuscâ pilis longis plumatâ, pedibus anticis tolis nigris, posteriorum sordide lutescentium femoribus fusconigris, alis totis lutescentibus. - Long. corp. $\mathbf{1}_{5}^{5}$ lin. Long. al. $15 \operatorname{lin}$.

Nilida, atra, colore capitis, thoracis et scutelli convexi modice in chalybeum, colore abdominis distinctius in olivaceum vergente. Frons nitida, non pollinosa, viltis lateralibus laetius resplendentibus. Antennae ex luteo rufae, articulis duobus primis brevibus, tertio oblongo-ovato: setâ obscurâ, pilis longis plumatâ. Facies modice convexa, atra, nitida, orbilis non albo-pollinosis. Proboscis nigra; palpi alri. Thoracis dorsum et scutellum nilida, sine ullo pollinis vestigio; pleurae concolores, interdum ex parte badiac. Abdomen nitidum. Pedes nigri, genibus omnium posteriunque tibiis et tarsis pallidissime testaceis aut sordide albidis. Halteres dilute flavescentes. Alae lutescentes, basi concolore. - (Cuba; Poey.)

88. Lauxania manuleat a nov. sp. ठ. Atra, nitens, tertio antennarum articulo lineari, elongato, setâ albidâ pilis longis plumatâ, pedibus pallide fluvis, anticorum libiis primoque larsorum articulo atris, articulis qualuor sequentibus candidis, alis infumatis. - Jong corp. $1 \frac{5}{6}$ lin., Long. al. $\mathbf{1}_{1^{\frac{1}{2}}}$ lin.

Gracilis. atra, nitida, thorace et scutello plano tenuiter aibido. pollinosis, pleurarum polline candido magis conspicuo. - Frons lata, aterrima, velutina, margine verticali vittisque lateralibus nilidissimis. Antennae graciles, articulis duobus primis luteis, tertio 
clongalo, lincari, alro, setâ albidti pilis longis plumatì. Facies valde convexa, atra, nitidissima, acneo iesplendens, orbità oculorum angustissimâ, candido-pollinosâ. Proboscis nigra; palpi atri. Pedes pallide flavescentes, anticorum coxis posteriorumque tibiis et tarsis albicanlibus, femorum anticorum apice, tibiis antiris totis et primo tarsorum anticorum articulo primo atris, arliculis quatuor sequentibus et articuli primi apice candidis. Halteres albili. Alarum dimidium costale lutescens, dimidium posterius cum apice toto infuscatum. - (Penusylvania; (Isten.Sacken.)

89. Lauxania femoralis nov. sp. 오 Atra nitens, leviler albo.pollinosa. scutelli apice nigerrimo, velutino. tertio antennarum articulo lineari, elongato, sela albidâ pilis longis plumatà, pedibus albis, femoribus nigris, alis lutescentibus. - Long. corp. $1 \frac{1}{1} \frac{1}{3}$ lin... Long. al. $1_{\frac{7}{2}}^{\frac{7}{2}}$ lin.

Gracilis. atra, nitida. thorace tenuiter albido-pollinoso, vittî mediâ obscuriore obsoletissimâ: pleurae candido-pollinosae Sculellım planum, ex fusco-atrum. velutinum, prope basim subnitidum el obsolete albido-pollinosum. Frons lata, aterrima, velutina, margine verticali vittisque lateralibus nitidissimis. Antennarum gracilium articulis duobus primis ex rufo luleis, tertio elongato, lineari. atro, setì albida pilis longis plumati. Facies convexa. alra. nitidissima; orbita oculorum angustissima, candido-pollinosa. Proboscis nigra; palpi atri. Pedes albi, primo coxarum articulo femoribusque atris. Halteres albidi. Alae lutescentes, basi concolore. - (Georgia.)

90. Lauxania trivittala nov. sp. ․ Alra. thorace et srutello plano albo-pallinosis, illo vitlis tribus abscurioribus distinctissimis picto; antennarum articulus primus secundo paullo longior, terlius elongatus, linearis, setâ pallidâ pilis mediorribus plumatâ: facies valde comvexa, nilidu, lineà mediâ tenui maculisque duabus lateralibnes albo-pollinosis; halleres et pedes nigri, genibus tarsisque posterioribus sordide albicantibus; alae lutescentes, imâ basi distincte nigrâ. - Long. corp. $1 \frac{1}{3}$ lin, Long. al. $1 \frac{1}{2}$ lin.

Atra. Frons atra modice nitet el praeter orbitam angustissimam fere nullum pollinis albi vestigium prabet; desuper visa viltam nediam atram et utrimque prope marginem anteriorem maculam atram polline candido circumscriptam exhibet. Antennar graciles; duo primi articuli ex rufo lutei, primus panllo longior quam secundus; arliculus terlius elongalus, linearis, aler. basi articulis pracedentibus concolore; seta antennarum pallida. pilis mediocribus 
plumata. Facies valúe convexa, atra, nilida, lineâ medià angustâ et maculà utrimque laterali albo-pollinosis, illà saepe obsulelâ. Proboscis nigricans; palpi atri. Thoracis dorsum polline albo opacum, viltis tribus laevigatis atris, mediâ angustâ, lateralibus latissimis piclum. Pleurae atrae, nitidae, maculis duabus albo-pollinosis. Scutellum planum, polline albo upacum. Abdomen nitidum. Pedes atri, genibus tarsisque posterioribus sordide albidis, horum apice nigro. Halteres nigri, pedunculo sordide luteo. Alae lutescentes, imâ basi distincte nigricante. - (Georgia.)

91. Discocerina orbilalis nov. sp. $\sigma^{7}$. Cinerea, opaca, colore thoracis magis in ochraceum, abdominis in nigrum vergente, untennis rufis, oculorum orbila candida, alis hyalinis, segmento costali secundo tertii longitudinem modice superante. - Long. corp. $\frac{3}{4}$ lin., Long. al. ${ }_{6}^{5}$ lin.

Caput obscure cincreum, opacum, orbitâ oculorum listiusculì, infra oculos non dilatalâ, candidà. Facies latiuscula, dimidio superiore distincte carinato, inferiore convexo, setulis utrinque circiter sex, quae ab orbitis magis quam in Diseocerinis plerisque distant. Geuae modice angustae. Anteunae rufesccules, articulu terlio obscuriore. In thoracis dorso et in sculello color cinereus in ochat ceum transit; pleurae canescunt. Abdomen reliquo corpore obscurius, apicem versus nigrun, non sinc omni niloris vestigio. Femora nigra, polline albo canescentia; tibiae el tarsi flavescentes, illarum annulo latissimo et summo horum apice fuscis. Halteres albi. Alac pure hyalinae, secundo costae segmento tertiun longiludine paullo superante. - (Washington; Osten-Sacken.)

92. Discocerina simplex nov. sp. Cinerea, opaca, antenuis nigris, setis faciei utrinque duabus, genis latioribus, larsis favescentibus, upicem versus nigris, alis hyalinis. - Loug. corp. ${ }_{6}^{5}$ $\frac{1}{1} \frac{1}{2}$ lin., Long. al. 1 lin.

Jiscocerinae lacteipenni similis, sed autenuis nigris, setis faciei paucioribus et alio modo dispositis, alis denique vix albicantibus facillime dignota. - Cinerea, opaca. Frons latiuscula, reliquo corpore paulo obscurior, utrinque lineâ longitudinali impressa; lunula frontalis angustissima, albido-pollinosa. Antennae nigrae, puncto albido - pollino:o in superiore articuli secundi latere, setâ pilis quatuor aut quinque longis pectinatâ. Facies molice lata. gibba, dimidio superiore distincte carinato, inferiore conveso, ad oris aperturam recedente. Setae in facie utrimque binae, oculis approxima. 
lae. Orbila oculorum angustissima infra oculos valde dilatatur. Genae latiores quam in Discocerinis plerisque. Color cinereus in thoracis dorso nonnihil flaveseit, in abdominis dorso, praesertim apicem versus, distinctius in canum abit. Pedes reliquo corpori concolores polline albo canescunt; tarsi anteriores flavescentes apicem versus nigricant; tarsi postici toti obscuri. Halteres albi. Alae hyalinae, sordide subalbicantes, vení costali non incrassatà. - (Maryland; Osten-Sacken.)

93. Discocerina leucoprocta nov. sp. ㅇ. Cinerea, abdominis atri segmento ultimo niveo, alis hyalinis. - ILong. corp. $\frac{3}{4}$ lin., long. al. ${ }_{6}^{5}$ lin.

Frons ex fusco cinerea, opaca. Antennac rufae, articulo tertio fusco, setâ pilis quinque sexve longis pectinatì. Facies ex flavo alba, dimidio superiore carinato, inferiore convexo et utrinque setulis tribus validis armato. Geuae angustae el orbita oculorum lola albidae. Thoracis dorsum nigro-cinereum, opacum, breviter nigro-pilosum. Pleurae albo-pollinosae. Scutellum thoraci concolor. Abdomen atrum, opacum, segmento ultimo breviore, candido-micante. Coxae anticae nigrac, albo-snicantes, summo apice tlavescente; trochanteres flavi; femora nigra, polline albo cincrascentia, summo apice flavo; tibiac anticae et posticae nigrae, basi et apice flavis, intermediae totae flavescentes, ommes in latere superiore albomicantes; tarsi flavi, articulo terminali nigricante. Alae hyalinae, segmenti costalis secundi longitudine sesquialteran tertii longitudinem subacquante. - (Maryland; Osten-Sacken.)

94. Hydrellia formosa nov. sp. ․ Arra, thoracis dorso, abdominis apice marginibusque nitidis, fronte, thoracis maculi laterali permagna scutelloque aterrimis, opacis, facie, puncto frontali pleurarumque villi superiore candidis, femoribus nigris, tibiis tarsisque pallidis, alis cinereo-hyalinis. - Long. corp. $\frac{2}{3}$ lin, Long. al. $\frac{3}{4}$ lin.

Facies modice convexa, non carinala, candidissima. Genae angustissimae, atrae. Frons et superior occipitis pars aterrimae, velulinac. puncto frontali candidissimo insigni. Antennae nigrae, arliculo tertio rufo, superius nigro-marginato, selít pilis raris nigris pectinati. Thoracis dorsum nitidissimum, utrimque macula lalerali permagnâ, alerrimâ. velutinà ornatum. Scuiellum aterrimum, opacum, margine angusto cincrascente. Pleurac atrac, villâ latissimâ. superiore, candida Abdomen nigrum. opacmm. dimidio apieali mar- 
ginibusque lateralibus nitidissimis. Femora atra; tibiae et tarsi pallide flavescentes, illarum latere superiore candido micante, horum articulo terminali atro. Halteres pallide citrini. Alae cinereo-hyalinae, segmento costali secundo tertii longitudinem modice superante, venâ longitudinali tertiâ summum apicem attingente, venâ transversâ posteriore inter basim et alae apicem mediâ. - (Pennsylvania; Osten-Sacken.)

Nota. Philygriae pictae Fall. affinibusque valde similem pubes oculorum brevissima et densissima Hydrelliam vere esse demonstrat.

95. Philygria opposita nov. sp. $ð$. Ex cinereo fusca, abdomine atro nitido, alarum venis longitudinalibus secundâ, terliâ et quartâ nigro-punctatis, venis transversis late nigro-limbatis. Long. corp. $\frac{5}{6}-1$ lin., Long. al. $1 \frac{1}{12}$ lin.

Ex cinereo fusca, opaca. Triangulo ocellari maximo concolore, a reliquâ fronte obsoletius separato. Antennarum articuli duo primi nigri, tertius niger, basi et dimidio apicali sordide rufis. Facies angusta nigra, albido-pollinosa, parte medià inferius flavescente. Orbitae oculorum faciales angustae, albo-micantes. Thoracis dorsum obscurum, ex cinereo fuscum, lineis obscurioribus angustissimis obsoletis. Pleurae obscure cinercae. Scutellum thoraci concolor. Abdomen atrum, nitidissimum, maculâ basali maximâ obscure cinereâ, opacâ, posteriorem segmenti secundi marginem non attingente. Pedes ex flavo-ferruginei, ultimo farsorum articulo atro, femorum basi interdum fuscâ. Alae cinereo-hyalinae, venis nigris; e venis longitudinalibus secundî, tertiâ et quartà venulae brevissimae adventiciae nigro-marginatae prodleunt et e venâ quidem tertiâ venulae quatuor, quae exceptâ ultimâ totidem venulis e venâ secundâ natis opponuntur; ultimum venae quartac segmentum venulas plerumque duas enittit; venae transversac ordinariae nigro latius cinguntur. Segmentum costae secundum fere duplam tertii longitudinem aequat. - (Pennsylvania; Osten-Sacken).

Nota. Philygr. opposita a Philygr. punclalo-nervosâ Fall., cui valde similis est, colore corporis fusciore, facie magis angustatâ, antennis pedibusque obscurioribus. majore abdominis parte atrâ et punctorum in alis numero minore dillert; orbitae oculorum faciales, quac mullo angustiores quan in Philygr. punclato nervosâ sunt. Phitygriam opposilan merito distingui aperte demonstrant. 
96. Philygria debilis nov. sp. $\sigma^{7}$. Nigro-cinerea, opaca, antennis totis nigris, fronte atvâ, opacì, triangulo ocellari maximo, nigro-cinereo, ullimo abdominis segmento atro, nitido, pedibus obscuris, genibus, tibiarum anteriorum apice tursisque favescentibus, horum apice nigro, alis cincreo-hyclinis, circa venas transversales infuscatas limpidioribus. - Long. corp. $\frac{7}{12}$ lin.. Long. al. $\frac{3}{4}$ lin.

Nigro-cinerea, opaca. In fronte atrâ utrinque linea marginalis alba angustissima et triangulum ocellare permagnum nigro-cinereum conspiciuntur. Antennae totac nigrae. Facies flavicans, orbitâ angustâ albidâ. Thoracis dorsum lineis angustis obsoletissimis ornatum. Abdomen thorace paullo obscurius et minus opacum, segmento ultimo atro, laevigato. Pedes nigricantes, genibus tibiarumque anteriorum apice flavescentibus. tibiis posticis aut totis nigricantibus, aut annulo angusto pallidiore obsoletissimo signatis, tarsorum flavescentium articulis ultimis nigricantibus. Halteres sordide albi, capitulo paullo obscuriore. Alae cinereo-hyalinae, circa venas transversas infuscatas limpidiores, segmento costali secundo duplam ferme tertii longitudinem attingente. - (Pennsylvania; Osten-Sacken.)

Nota. A Philygr. femoratâ Stenh., cui simillima, antennis totis nigris, trianguli ocellaris angulo anteriore nimus obtuso et segmento costali secundo perspicue longiore differt.

97. Parydra abbreviata nov. sp. $\delta$. Minuta, antennis $1 i$ biisque ferrugineis; alae infuscctae guttis aliquot hyalinis distinctissimis ornatae segmento costae tertio secundi longitudinem paullo excedente, renis longitudinalibus tertia et quartâ distincte divergentibus. - Long. corp. ${ }_{6}^{5}$ lin., Long. al. ${ }_{6}^{5}$ lin.

Olivacea. Antennae obscure ferrugineae, arliculis duobus primis et superiore tertii margine nigris; seta tota superius breviter pubescens. Facies modice declivis, utrinque sctâ ordinarià peristomio non magis quam in congeneribus plerisque approximatâ. Genae angustae. Scutellum non tuberculatum. Perles nigri, genibus, tibiis tarsorumque basi ferrugineis; pollen albo-micans, quale in tibiis specicrum affinium conspicitur, in hâe non adest. Alae breviusculae, distincle infuscatae guttis septem majoribus hyalinis ornantur; vena longitudinalis secunda vix brevissime appendieulata, tertia el quarta adversus apicem divergentes; segmenti costalis secundi longiludo ad tertii longiludinem prope accedit. - Pennsylvania; Osten Sacken). 
98. Scatella obsoleta nov. sp. ㅇ. Opaca, capile toto, scutello pleurisque ex flavo, pectore et abdomine ex cano cinereis, antennis pedibusque nigris; alue hyalinae, dilule cinerascentes, gultis limpidioribus quinque obsoletissimis. - Long. corp. $\frac{5}{6}$ lin., Long. al. 1 lin.

Caput totum flavo-cinereum, antennis nigris, facie valde fornicałâ, peristomio pilis mediocribus ciliato. Thorax capiti concolor, pectore subglauco. Scutellum flavo-cinereum. Abdomen ex cano cinereum, subglaucum, opacum. Pedes toti nigri, leviter albo-pollinosi. Halteres sordide flavi, pedunculo fusco. Alae hyalinac, dilutissime cinerascentes, gutlis quinque valde obsoletis limpidioribus signatae, venis transversis uon infuscatis; segmentum costale secundum triplicem tertii longitudinem superat. - (Washington; OstenSacken.)

99. Milichia picta nov. sp. ठð. Ex cinereo albida, punctis fuscis adspersa, fronte, antennis, palpis pedibusque flavis, tibiis nigro-annulatis, alis cinereo-hyalinis, fusco-reticulatis. - Long. corp. $2 \frac{1}{6}$ lin., Long. al. $2 \frac{1}{6}$ lin.

Ex cincreo albida, opaca. Frons ochracea, rare nigro-pilosula, utrimque vittâ albidâ, setas tres validas in punctis nigris gerente ornata; triangulum ocellare albicans, elongatum, obsoletissimum; lunula frontalis albo-pollinosa, lineâ mediâ dissecta. Antennae ochraceae, breves, articulo tertio rotundato, in margine apicali pilis aliquot nigris minutis praedito, setâ subulatâ, distincte biarticulatâ, brevissime pubescente, in dimidio basali albidâ, in apicali atra. Facies et genae albo-pollinosae, posteriore harum dimidio flavicante et nigro-piloso. Margo oris lateralis nigro-setosus. Palpi ochracei, nigro-pilosi; proboscis lutea. Thoracis dorsum pilis brevibus nigris et setis validis, in series quatuor longitudinales dispositis vestitum, illis e punctis fuscis minutissimis, his e punclis magnis surgentibus. Pleurarum dimidium superius albo-pollinosum, inferius fusco-testaceum. Scutellum maculis obsoletissimis pallide fuscis variegatum et praeter setas qualuor marginales nudum. Abdomen nigro-pilosum, punctis minutis fuscis adspersum macularumque fuscarum seriebus quatuor ornatum. Pedes testacei, breves, validi, femoribus posticis incrassatis; femora antica in latere posteriore, femora posteriora in anteriore latere maculâ subapicaii nigrâ signata; tibiae annulo medio latiore et altero apicali angustiore nigris cinctae; tarsorum postico. rum articulus primus praeter apicem niger. Halleres flavi. Alae latac, cinereo-hyalinac, fusco-reticulatae. - (Georgia.) 
100. Diastatu pulchra nov. sp. of et . Nigru. fronte antemisque fulvis, facie albida, pedibus tuteis, alis nigris, ad costam et apicem dilutioribus. maculis quinque albido-hyalinis. - Long. corp. 1! lin., Long. al. 1 $\frac{1}{2}$ lin.

Nigra. Frons fulva, triangulo ocellari vittulisque verticis lateralibus fuscis. Antennae fulvae, articuli tertii margine supcriore et apice plerumque fuscis, setâ plumatâ nigrâ. Facies albida; genac angustissimae. Occiput nigrum, cinereo-pollinosum. Thoracis dorsum tenuiter fusco-pruinosum, subnitidum; pleurac distinctius albido-pollinosae. Abdomen atrum, nitidum, segmentorum anteriorum singulorum margine postico albido-pruinoso, segmento primo interdum toto fusco. Pedes lutei aut ex fusco lutei. Halteres albidi. Alae nigrae, ad costam et in apice paullo dilutiores, maculis quinque albido-hyalinis ornatae; macula prima inter cellulas basales et venulam transversam mediam sita in fasciolam extenditur; macula secunda ex tribus congesta a venà longitudinali secundâ usque in cellulam discoidalem descendit; maculae tertia et quarta reliquis minores in cellularum posteriorum secundâ et tertiâ siłae sunt; macula quinta quadrangularis et omnium maxima a venâ longiludinali quartâ ultra venan longitudinalem tertiam producta est. - (Pennsylvania: Osten-Sacken.) 



\section{Diptera Americae septentrionalis indigena.}

Descripsit

H. L $\quad \boldsymbol{o} \quad \boldsymbol{e} w$.

Centuria se cunda.

1. Corelhra trivitlata.

2. Simulium quadrivillalum.

3. Leptis ochracea.

4. - costala.

5. Bolbomyia nana.

6. Leptogaster badius.

7. - pictipes.

8. - varipes.

$9 . \quad$ murinus.

$10 . \quad$ - testaceus.

11. - incisuralis.

12. - favillaceus.

13. - obscuripes.

14. - tenuipes.

15. - flavipes.

16. Brachystoma binummus.

17. nigrimana.

18. Syneches albonotatus.

19. Empis barbata.

20. - nuda.

21. - spectabilis.

22. Pachymeria brevis.

23. Rhamphomyia villata.

24.

25.

26.

27.

28.

29.

30.
31. Rhamphomyia impedita.

32. - exigua

33. - unimaculata.

34. Hilara umbrosa.

35. - femorata.

36. velutina.

37. - unicolor.

38. - nigriventris.

39. - triviltata.

40. - mutabilis.

41. - brevipila.

42. - atra.

43. - leucoptera.

44. - gracilis.

45. - basulis.

46. Cyrtoma halteralis.

47. - longipes.

45. - pilipes.

49. Clinocera simplex.

50. - lineata.

51. Itemerodromia valida.

52. - obsoleta.

5.3. notala.

54. - scapularis.

$55 . \quad$ - defecta

$56 . \quad$ viltate.

57. Drapet is pubescens.

58. Stilpon varipes.

59. Dolichopus albicilialus.

60. - socius. 
61. Dolichopus fulvipes.

62. - prceustus.

63. - setosus.

61. Tachylrechus angustipennis.

65. Chrysolus cornutus.

65 . - picticornis.

67. Hydrophores parvus.

65. Synрусииs nodalus.

69. P'silopus melampus.

70 . - dimidialus.

71. - tener.

72. Lispe sociabilis.

73. Trypeta sarcinata.

74. - atra.

75. - geminala.

76. - timida.

77. - abstersa.

78. - finalis.

79. Laurania albovillala.

80. Scoliosentra helvala.
81. Anorostoma marginata.

82. Blepharoptera pubescens.

83. armipes.

S4. tristis.

85. Allophyla laevis.

86. Helomyza apicalis.

87. - assimilis.

S8 - plumale.

89. - lalericia.

90. - longipennis.

91. Diplocentra helva.

92. Psilopa nobilis.

93. Amiota humeralis.

94 . - leucostoma.

95. Drosophila dimidiata.

96. - amoena.

97. - tripunctuta.

98. - adustu.

99. - ampelophila.

100. - punctulata.

1. Corethra trivittata nov. sp. ठ大. Pallide flavescens, vitIis thoracis tribus, melanoto, abdominis fasciis, annulis femorum upicali tibiarumque altero basali, altero apicali ex fusco nigris, alis cinereo maculatis. - Long. corp. $2 \frac{1}{6}$ lin., Long. al. $2 \frac{1}{2}$ lin.

Dilutissime flavescens, pilis longis, plerisque subfuscis vestita. Antennae nigro annulatae, pilis confertis subfuscis verticillatae. Thoracis dor'sum nigro trivittatum, villâ medià geminâ postice, lateralibus antice valde abbrevialis Sculclli latera fusca. Vetanotum ex nigro fuscum. Abdomen fusco fascialum. Pedes pallide flavi, inde ab apice artiruli farsalis primi pallide subfusci, annulis femorum apicali, tibiarum duobus (altero basali, altero apicali) nigricantibus. Alae maculis aliquot parvis ex nigro cinereis variegatae. (Maine; OstenSacken.)

2. Simulium quadrivittatum nov. sp. Atrum, opacum, thorace villis quatuor allis ornalo, halleribus fawis, tibiis tarsisque posterioribus albido-ringulatis, alis hyalinis. - Long. corp. ${ }_{6}^{5}$ lin., Long. al. ${ }_{6}^{5} \mathrm{lin}$. 
Atrum, opacum. Antennae fucac. Thoracis dorsum lineis quatuor longitudinalibus et margine postico albo-pollinosis. Scutellum immaculatum. Pleurarum maculae el metanotum albo-pollinosa. Pedes ex fusco nigri, pedum anticorum genibus et imà metalarsi basi, pedum posteriorum annulo tiliarum basali, metalarso practer apicem articulisque larsorum duobms sequentibus in basi albidis. IIalteres flavi. Alae pure hyalinae, venis crassioribus lestaceis. - (Cuba; Gundlach.)

3. Leptis ochracea nov. sp. \&. Ochracea, immaculata, thorace nitido, capite nigro, albido-pollinoso, antennis, palpis et proboscide favis, tarsis fuscis, alarum upice el venume trunsversulium, marginis postici venarumque in marginem posticum excurrentium limbis fuscis. - Long. corp. $4 \div$ lin., Long. al. 4 lin.

Ochracea. Caput nigrum, polline albido cinereum. Antennae flavac, selâ terminali fuscâ. Palpi flavi, pilis pallidis hirli. Proboscis ochracea. Thoracis dorsum et scutellum nitida, sine ullo vil. tarum vestigio. Pleurae flavae. Abdomeu minus nitens, immaculalum. Pedes flavi; femorum anticorum apex late infuscatus; libiac anticae pallide flavescentes, triente apicali infuscalo; tibiae posticae plerunque apicem versus, interdum lotae infuscatae; larsi ex nigro fusci, basi intermediorum pallidì. IIalteres flavi, capilulo infuscato. Alae lutescentes, costam versus ochraceac, stigmate subfusco; apex, limbi venarum transversalium venarumque, quae in marginem posticum exeunt, denique tenuior marginis postici limbus fusci. - (New York; Edwards.)

4. Leptis costata nov. sp. ot et ㅇ. Luter, antennis, proboscide palpisque concoloribus, thorace fusco trivillato, in mare praeler humeros et dimidium pleurarum superins cineven, abdomine trifuriam nigro-maculato, alis ex fusco cinereis, cellulî costali lu-

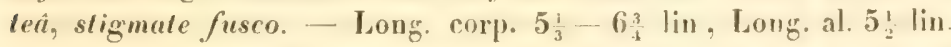

Caput nigricans, facie et occipite polline pallido cincreis, oculis maris contiguis, fronte focminae es fusco cinerea. Antennac dilule luteae, articulo primo paulo obscuriore, setì terminali niggrâ. Palpi flavi, pallide pilosi. Proboscis dilute lulea. Thorax foeminac lutens, maris cinereus, humeris tamen pleurarumpue dimidio superiore dilute luteis; in utroque sexu villae tres latissimae fuscac adsunt. quarum media linei pallidit dissecatur. Scutellum luteum, prope basim ex nigro fuscum. Abdomen maris luteum, segmentis singulis nigro trimaculatis, maculis lateralibus segmentorum ultimorum obsoletio- 
ribus. Abdomen foeminae similiter pictum, sed maculis segmentorum, lateralibus multo obsoletioribus. Pedes antici testacei, femorum tibiarumque dimidio apicali subfusco, tarsis ex nigro fuscis; pedes postici loti ex nigro fusci. Alae ex fusco cinereae, cellulâ coslali et liturâ ab alae basi ad cellulae submarginalis primae basim ductâ luteis, stigmate fusco. - (California; Agassiz.)

5. Bolbomyia nana nov. sp. ․ Nigra, opaca, antennis palpis, proboscide halteribusque concoloribus, pedibus ex fusco nigris, alis nigricantibus. - Long. corp. $1 \frac{1}{1 \frac{1}{2}}$ lin., Long. al. $1 \frac{1}{3}$ lin.

Nigra, opaca, polline rarissimo obscure cinereo aspersa, frontis thoracisque pilis nigris, raris et brevibus, abdomine subnudo. Proboscis et palpi nigri. Pedes ex fusco nigri, brevissime pubescentes. Halleres nigri. Alae ex nigro cinereae, adversus costam obscuriores, sligmate nigricante; cellula submarginalis secunda perlonga, apicem versus dilatata; cellula discoidalis subtrigona, oblique truncata; cellula posterior secunda breviter pedunculata; cellula analis clausa. (Washington; Osten-Sacken.)

6. Leptogaster badius nov. sp. ㅇ. Badius, nitens, alarum hyalinarum triente basali subfusco, cellulâ submarginali secundâ apicem versus angustatâ, cellularum posteriorum secundâ non elongotâ, quartà longe pedunculatâ. - Long. corp. $6 \frac{\mathrm{r}}{2}-7$ lin., Long. al. $4 \frac{2}{3}-5$ lin.

Badius, nitidus. Antennae angustae, fulvae, articulis basalibus obscurioribus. Facies alba; pili mystacis albi. Thoracis dorsum interdum vittis tribus abbreviatis nigris variegalum, nitidum, triente postico subopaco, margine laterali albido-pollinoso. Plenrae fuscae, albido pollinosac. Abdomen obscure badium s. fuscum, fasciis segmenlorum singulorum mediis ex fusco nigris obsoletioribus, apicem versus plerumque ex nigro fuscum. Femora obscure badia s. fusca, anteriora annulo subapicali, postica basi, annulisque duobus (altero subapicali, altero apicali) ex flavo dilute badiis. Tibiae luteae, in latere anteriore lineâ fuscâ piclae, posticae apicem versus fuscae. Tarsi badii. articulo primo praeter apicem et imâ articulorum sequentium basi flavis. Halteres fusci, pedunculo pallidiore. Alae hyalinae, Iriente basali dilute subfusco, venis nigris; cellula submarginalis secunda brevis, apicem versus angustior; cellula posterior secunda non elongata, basi subtruncati; cellula posterior quarta longe pedunculata.

- (Illinois; Kennicot.) 
7. Leptogaster pictipes nov. sp. ऊ. Niger, abdomine pallide annulalo, antennis favis, apicem versus nigris, pedibus posticis albo, fulvo et nigro annulatis, empodio manifesto, alis hyalinis, cellulurum posteriorum secundâ non elongralì. quarlâ subsessili. - Long. corp. $3 \frac{1}{3}$ lin., Long. al. $2 \frac{5}{1} \frac{1}{2}$ lin.

Leptogastro annulato similis, sed empodio non obsoleto. Facies alba, mystace concolore. Antenuae flavae, apicem versus fuscae. Frons obscure cinerea. Thorax niger, albo-pollinosus, opicus, vitti mediâ duplicatâ vittisque lateralibus latissimis obscurioribus. Abdomen ex fusco nigrum, subopacum, fascià segmentortum singnlorum posticà albidà, forcipe validiusculo, atro. Pedes albidi; femora anteriora apicem versus flavicantia; triens femorum posticorum apicalis valde incrassatus, ex nigro fuscus, annulo subapicali fulvo ornalus; tibiac posticae apicem versus inscrassalae, triente basali subfusco, medio albido, apicali obscure fuseo anuulo medio dilutiore, fulvescente; tarsi anteriores apicem versus dilute badii, tarsi postici subfusci, articulo primo tanen albido. Halleres nigri, pedunculo albido. Alae hyalinae, venis ex fusco nigris; cellula posterior secunda non elongata, basi oblique truncatâ et basi cellulae submarginalis secundae oppositî; cellula posterior quarta subsessilis. - (Illinois; Le Baron. )

8. Leptogaster varipes nov. sp. ㅇ. Niger, abdomine pallide annulato, antennis nigris, pedibus posticis fubo el nigro annulatis, empodio manifesto, alis subhyalinis, cellularum posteriorum secundâ non elongatâ, quartâ subsessili. - Long. corp. $3 \frac{3}{3}$ lin., Lons. al. $1 \frac{5}{12}$ lin.

Facies alba, mystace concolore. Antennae nigrae. Thorax niger, dorso viltis tribus fusco-pollinosis confluentibus obscuro, in marginibus lateralibus et postico albo-pollinoso. Pleurae albo-pollinosae. Abdomen nigrum, subopacum, fasciâ segmentorum singulorum posticà ex flavo sordide albida, in segmentis posterioribus obsoletiore. Pedes anteriores subfulvi, tibiarum intermediarum lincâ longitudinali fuscâ; femora postica pallide flavescentia, trienlis ullimi crassissimi dimidio primo ex nigro fusco, secundo fulvo; tibiae posticae apicem versus valde incrassatae, dimidio basali flavo, anmulo medio ex nigro fusco, apice fulvo; tarsi postici obscure fusci, articulo primo praeter apicem albido. Empodium mediocre. Halterum capitulum fuscum, pedınculus albidus. Alac hyalinae, subcinerascentes, venis nigris; cellula posterior secunda non elongala, basi oblique 
truncatâ et basi cellulae submarginalis secundae oppositâ; cellula poslerior quarta subsessilis - (District Columbia; Osten-Sacken.)

9. Leptogaster murinus nov. sp. ․ Validiusculus, ex cinereo fuscus, opacus, abdomine non anmulato, antennis nigris, pedibus flavis, tibiarum posticarum dimidio apicali nigro, alis ex cineveo subhyalinis, cellularum posteriorum primi valde elongat â. quarta breviter pedunculatâ. - Long. corp. $6 \frac{1}{4}$ lin., Long. al. 4 lin.

Facies albida, mystace albo. Antennae nigrae. Thoracis dor'sum ex cinereo fuscum, opacum. Pleurae albo-pollinosae. Abdomen ex cinereo fuscum, subopacum, adversus marginem lateralem cineras. cens, non annulalum. Pedes flavi; femora postica lineâ fuscâ picta, apicem versus modice incrassata; tibiae posticae validae, dimidio apicali ex nigro fusco; tarsi anteriores apicem versus obscure fusci; tarsi postici obscure fusci, articulo primo practer apicem articulorumque sequentium singulorum basi flavis. Empodium magnum. Halterum capitulım nigrum, pedunculus albidıs. Alae subhyalinae, cinerascentes, venis validis ex nigro fuscis; rellula submarginalis secunda pedunculo aequalis; cellularum postriorum secunda valde elongata, quarta breviter pedunculata; cellula analis apicem versus subangustata. - (Nebraska.)

10. Leptogaster testaceus nov. sp. 오 Ex rufo lestaceus, nilidus, colore abdominis in badium vergente, pedibus subfulvis, alis hyalinis, sublutescentibus, cellularum posteriorum secunda elongatd, quartá pedunculatâ. - Long. corp. $5 \frac{3}{4}$ lin., Long. al. $4 \frac{1}{4}$ lin.

Facies albida, mystace flavescente. Duo primi antennarum articuli fulvi (articulus terlius in specimine descripto deest). Frons cinerea. Thoracis dorsum ex fulvo rufum, nitidum. limbo laterali et triente postico polline flavo opacis. Pleurae flavo-pollinosae. Color abdominis in badium vergens. Pedes graciles, fulvi, tarsis apicem versus obscurioribus; femora postica apicem versus modice incrassała. Alae hyaliuae, sublutescentes, costâ flavî, venis fuscis; crllula sulomarginalis secunda pedunculo duplo longior; cellularum posteriorum prima modice elongata, quarta breviter pedunculata; cellula analis apicem versus anguslata. - (New-York; Calverly.)

11. Leptogaster incisuralis nov. sp. $\delta$. Thorace latericio, albido-pollinoso, dorsi maculà maxima viltis compositâ, scutello pleurarumque parte inferâ nigris, abdomine ex fusco luteo, nigroannulato. pedibus sordide flavis. femorum posticorum annulo obso- 
leto tibiarumque posticarum apice fuscis, alis hyalinis. rellularnm posteriorum secundi modice elongati, quarti breviter pedunculati. Long. corp. $6 \frac{2}{3}$ lin., Long. al $33_{6}^{5}$ lin.

Facies alba, mystace concolore. Antenuae fulvac, slylo terminali fusco. Thoras latericius, albido-pollinosus, villis dorsi lribus latissinis, in maculam permagnam nigram conflurntibus. Scutcllum nigrum. Pleurae latericias. infra nigrae, tofae albido-yollinosac. Abdomen tenue, longum, ex fuseo luteum, segmento prino segmento. rumpue sequentium singulorum margine postico nigris, segmentorum lriums ullimorum villâ medià nigricante. Pedes sordide flavi, fomormm posticorum anumlo subapicali obsoleto tibiarumpue posticarum apice fuscis, summo articuli tarsorum ultimi apice nigro. Ilalleres subflavescentes, capitulo paulo obscuriore. Alic hyalinae, sublulescenles, costá flavâ, venis fuscis; cellula submarginalis secunda duplicem pedunculi longiludinem acqual; cellularum posteriorum secunda modice elongata, quarla pedunculata; cellula analis apicem versus subangustala. - (Illinois; Kennicol.)

12. Leptogaster favillaceus nov. sp. ․․ Ex cinereo,fuscus, opacus, abdominis segmentis secundo, tertio et quarlo luteo annulatis, antennis ex nigro fuscis, articulo secundo et infimé ter. tii basi testaceis, perlibus ex fusco testaceis, macula femorum posticorum subapicali tibiarmmque posticarum apice fuscis, alis ex ci. neveo hyalinis, cellularum posticarum secundi valde elongati. quarti

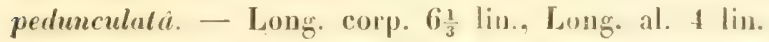

Facies alba, myslace concolore. Antemae ex nigro fuscac, articulo secundo praeler summum apicem et infima articuli terlii basi testaceis. Thoracis dorsum opacum, folum ex fusco cincreum. villis tribus obsoletis obscurioribus. Pleurac albido-pollimosae. Abdomen ex fusco cinereum, subopacum; segmenla secundum, tertium et quartum singula annulo subapicali sordide luteo cingmnlur. Pedes es fusco testacei, femoribus posticis apicem versus modice incrassalis et supra maculâ fuscâ nolalis; apex tibiarum posticarum fuscus. Mlac ex cincreo hyalinae, costâ fuscì, venis ex fusco nigris; cellula sub. marginalis secunda duplicem pedunculi longiludinem superal: cellularum posticarum secunda valde elongafa. quata pedunculata; cellula analis apicem versus nec angustata, nec dilatala. - (Connec. ticut; Norton).

13. Leptogaster obscuripes nov. sp. o’. Niger, nitidus, humeris plerumque mufis, antemnis nigris, pedibus temubus, mavima 
ex parte fuscis, femoribus posterioribus anle apicem annulo subfulvo ornatis, alis brevibus ex cinereo hyalinis, cellulâ submarginali secundâ brevi, cellularum posteriorum secundâ valde elongat $\hat{a}$, quartấ pedunculatâ. - Long. corp. $1 \frac{1}{12}$ lin., Long. al. $2 \frac{5}{6}$ lin.

Facies albida, mystace concolore. Antennae totae nigrae. Thoracis dorsum atrum, nitidum, nıargine laterali angustius, postico latius albido-pollinosis; humeri plerumque rufi, rarius badii. Pleurae albo pollinosae. Abdomen tenue, atrum, nitidum, margine laterali testaceo. Pedes antici ex fulvo testacei, femorum apice tibiarumque lineâ longitudinali anticâ ex nigro fuscis. Pedes intermedii eandem picturam habent, adiecto tamen femorum annulo medio latissimo ex nigro fusco. Pedes postici tenues, fusci, femorum annulo subapicali fulvescente tibiarumque lineâ longitudinali superâ testaceâ. Alac breves, ex cinereo hyalinae, margine apicali paulo obscuriore, venis nigris; cellula submarginalis secunda quam pedunculus paulo longior; cellularum posteriorum secunda valde elongata, quarta pedunculata; cellula analis apicem versus angustata. - (Cuba; Gundlach.)

Nota. Variat polline in dorsi margine et in pleuris ex albo subflavicante.

14. Leptogaster tenuipes nov. sp. Ј'. Badius, subopacacus, vittis thoracis tribus confluentibus atris, abdomine apicem versus fusco, antennis nigris, pedibus gracilibus, dilutissime testaceis, femoribus tibiisque fusco lineatis, alis hyalinis. cellulâ submarginali secundâ pedunculo aequali, cellularum posteriorum secundá valde elongatâ, quartâ pedunculata. - Long. corp. $4 \frac{2}{3}$ lin., Long. al. $3 \frac{1}{6}$ lin.

Facies alba, mystace concolore. Antennae nigrae, articulis duobus primis fuscis. Thorax ex rufo badius, polline albido subopacus, vittis tribus dorsalibus atris in maculam permagnam atram connatis. Abdomen ex fusco badium, apicem versus obscure fuscum. Pedes graciles, dilutissime testacei, antico femorum tibiarumque latere fusco, primis tarsorum articulis in apice, sequentibus totis ex nigro fuscis; femora poslica apicem versus paulo crassiora, tibiae posticae lenues. Alae hyalinae, venis ex nigro fuscis; cellula submarginalis secunda peduneulo aequalis; cellularum posticarum secunda valde elongata, quarta pedunculata; cellula analis apicem versus non angustata. -

Nota. Foeminam abdomine toto obscure fusco et triente basali alarum infuscato diversam. Leptogastri tenuipedis, cui in reliquis simillima est, foeminam esse suspicor. (District Columbia; Osten-Sacken.) 
15. Leptogaster flavipes nov. sp. ․ Ex fusco cinereus, opucus, antennis pedibusque flavis, thoracis dorso nigro-bilinento, segment is abdominis anterioribus favo annulatis, alis hyalinis, cetlulà submarginali secundà duplicem perhunculi longitudinem superante, cellularum posteriorum secundà elongat $i$, quarlâ breviler pedunculatâ. - Long. corp. $4 \frac{1}{1} \overline{2}$ lin., Long. al. 3 lin.

Facies alba, mystace concolore. Antennae laete flavae, slylo terminali nigro. Thoracis dorsum ex fusco cinereum, vittâ mediâ lineis duabus atris postice abbreviatis compositâ, angulis posticis pallide flavis. Pleurae albo-pollinosae. Abdomen ex fusco cinereum, subopacum; segmentorum secundi, tertii et quarti margines laterales et annuli singulorum duo incompleti flavi. Pedes laele flavi. Hae hyalinae, costâ festaceâ, venis fuscis; cellulac submarginalis secumdae longitudo duplicem pedunculi longitudinem excedit; cellularum posteriorum secunda elongata, quarta breviter pedunculata; cellula analis apicem versus non angustala. - (Nebraska.)

16. Brachystoma binummus nov. sp. $\sigma$. Atra, primis duobus antennarum articulis, ventre pedibusque pallide flavicantibus, femorum posticorum dimidio apicali tibiisque posticis fuscis, articulis tarsorum omnium duobus ultimis atris, anticorum dilutalis et singulis infra puncto argenteo notatis. - Jong. corp. $1 \frac{1}{2}$ lin., Long. al. $2 \frac{5}{12}$ lin.

Caput atrum, nitidum, fronte prope antennas angustiore. Primi duo antennarum articuli dilutissime flavescentes, articulus tertius niger, setâ terminali concolore. Facies angustissima, linearis, allıpollinosa. Proboscis pallide flava. Thorax ater, nitidus, nudus, angulis posticis obsolete fuscis, pleurarum dimidio inferiore albo-pollinoso. Scutellum atrum. Abdomen atrum, nitidum, nudum. Venter dilute flavescens. Hypopygium globosum, atrum, in apice fasciculo pilorum pallide flavicantium crecto instructum. Coxale et pedes gra. ciles, pallidissime flavicantes. Femora antica prope apicen infra spinulis minutissimis alris serrulata; femora intermedia reliquis paulo crassiora, vara, prope basim infra pilis albidis rarioribus, anle apicem postice confertissimis praedita; femora postica tenuia, dimidio apirali infuseato. Tibiae anticae simplices; dimidium tibiarum intermediarum basale subfuscum, apicale praerupte incrassatum et pilis longis pallide flavicantibus hirtum: tibiae posticae curvae, fuscae, extremo apice dilutiore. Tres primi farsorum anticorum articuli longiludine de. crescentes, flavi, duo ultimi atri, dilatati, utrinque breviter nigropilosi, uterque infra puncto argenteo ornatus, ultimus maior; tar- 
sorum intermediurum arliculi tres primi flavi, duo ultimi alri; tarsi postici arliculum ultimum alrum, penultimum es fusco nigrum, reliquos flaros habent. Halteres albi. Alae longae, angustae. cuneatae. subciue. rascentes. stigmate obsoleto, margine postico pilis longis ex parie reflexis ciliato; venae longitudinalis tertiae ramus anterior venam longitudinalem secundam petit; cellula basalis prima duabus ullimis multo bresior. - (District Columbia; Osten-Sacken.)

Nota Brachyst. serrulalae marem esse crederem, nisi tarsorum anticorum articulis tribus primis flavis, cellulà basali primâ breviore et cellulae analis apice longius ab alae margine remolo diversa esset.

17. Brachystoma nigrimana nov. sp. ठ. Atra, nitida, antennis concoloribus. ventre pallide faro, pedibus simplicibus, anterioribus pallide flacicantibus, tarsis tamen nigris, posticis fuscis, femorum basi genibusque pallidissime favicantibus. - Long. corp. $1 \frac{1}{3}$ lin., Long. al. $1 \frac{1}{1} \frac{1}{2}$ lin.

Caput atrum, nitidum, fronte antice angustiore. Antennae nigrae. Facies angustissima, linearis, albo pollinosa. Proboscis pallide flaricans. Thoras ater. nitidus, nudus, inferiore pleurarum dimidio albo-pollinoso. Scutellum et abdomen atra; venter flavus. Hypoprgium subglobosum atrum, in apice pilis nonnullis erectis, pallide flavicantibus instructum. Coxae et pedes graciles, dilutissime flavicantes. Femora antica prope apicern infra spinulis minutissimis atris scrulata; femora intermedia reliquis non crassiora, saturatius flavicantia; fimora postica praeter basim et summum apicen fusca. Tibiae anteriores apicem versus saluratius flavicantes, posticae fuscae. prope apicem infra pallidae. Tarsi anteriores nigri, poslici ex nigro fusci, apice nigro. Alae cineráscentes, angustae, cuneatae, stigmate obsoleto. ciliis marginis postici non reflexis; venae longitudinalis tertiae ramus anterior venam longitudinalem secundam pelens, cellulam submarginalem primam claudit; cellulae tres basales subaequales. (Illinois; Le Baron.)

Noła. Cum Brachystomâ serrulatà et binummo genus novum, Brachystomae proximum, cellulì submarginali primà clausâ distinctum, constituit, cui nomen Blepharoproctae proponendum videtur. 
18. Synerhes albonolatus nov. sp. ․ Niger, opares. therace maculis albo-pollinosis ornato, predibus atris, tarsis piceis. alis cinereis. stigmale obsoleto subfusco. - Long. sorp. $1 \frac{3}{4}$ lïn, Long al '2 lin.

Caput nigrum, proboscide el antennis concoloribus. Thopas niger, opacus; a lalere seapula cum partibus. quae adiacent, et ma. cula cuneata ante scutellum polline candido indutae cernuntus: desuper videnti adhuc lineae dua albae. late dislantes et postice abbrevialae apparent. Pleurae polline raro albido aspersie, abdomen polline fusco. Pedes atri, nilidi, larsis piceis, apicem versus nigris. Alase obscure cinereac, venis nigris, stigmate sububsoleto, dilut: fusco. - (District Columbia; Osten-Sachen.)

19. Empis barbata. nov. sp. ठ․ I'alida. nigra. pulpis pedibusque badiis. farie nigrobarbali. proboscide longissimâ. pedibus fuscis. - Long. corp. $4_{2}^{1}$ lin.. Lons al. 5 lin.

Caput nigrum, pilis longis nigris hirtum. Oculi magni, sub. contigui. Antennarum nigrarum arliculi duo primi pilis Jongis nigris vestiti. Facies pilis nigris babala. Palpi magni, badii, nigropilosi Proboscis longissima, basi valde inerassatâ. Thuracis dorsum nigrum, opacum, nigro-pilosum, viltis tribus cinereo-pollinosis, media angustâ, lateralibus lalis. Plemrae nigrae, polline ex luleo cinereo tectae, praeter fasciculum pilorum nigrorum ante halteres nudac. Abdomen nigrun subnilidum. latera versus polline eincreo opacum. pilis longis nigris praeditum. Hypopgium parrum. nigro-pilısum. lamellis inferis ma-nis, ovatis. filamento centrali brevi, subulato. Pedes badii. nigropilosi, extremo tibiarmm apice larsisque nigris. metatarso famen praeler apicem articulurumque proxime sequenlium basi hadiis. Alae longae. apicem rersus subangustalae, fuscac. cellulà costali ferrugincì. - (California; Agassiz.)

20. Emp is nuda, nov. sp. ठ大. Cincrea. submuda. orulis distantibus, antennis clongatis nigris. thora:e fusco guatrivillato. hypopygio mediocri pedibusque gracilibus fluris. tarsis ex fusco nigris. alis subhyalinis, venis crassiussulis ex fusco nigris. celluli discoidali medincri. - Long corp. 25 lin. Long al. 3 lin.

Pallide cinerea. opaca. nudiuscula Oculi distintes. Antennac elongatae, tenues, nigrae. Proboscis mediocris. Thoracis dorsm subuudum, setulis nigris rarissimis aspersum. fusen quadrivillatum, vittis intermediis postice, lateralibus utrinque abbreviatis. Pleurac cinereae. praeter setulas duas nigras ante halleres prorsus nudan 
Abdomen ex fusco cinereum, margine segmentorum singulorum postico ex albo cinerascente. Hypopygium parvum, ex testaceo flavum, rare nigro-pilosum, lamellis oblongo-ovatis, filamenti centralis basi crassissimâ, apice operto. Coxae pallide flavae, anticae praeter selulas aliquol apicales nudae. Pedes graciles, saturatius fl: vi, annulo femorum posticorum apicali angustissimo tarsisque ex fusco nigris, horum basi tibiarumque apice dilutius fuscis; trochanteres postici infra spinulis nigris armati; pili nigri in femoribus hrevissimi, in tibiis intermediis longiores, in tibiis posticis superne elongati. Alae cinerascentes, stigmate obsoleto pallide subfusco, venis validis fuscis. - (Illinois; Le Baron.)

21. Empis spectabilis, nov. sp. \&. Murina, opaca, nigropilosa, thorace quadrivillato, coxis pedibusque rufis, femoribus posterioribus infru nigro-spinosis; proboscis fere duplicem capitis longitudinem aequans; antennae nigrae; halteres flavi; alae ex fusco ferrugineae, cellulâ discoidali brevi, obliquâ. - Long. corp. $3 \frac{1}{2}$ lin., Long. al. $3 \frac{1}{3}$ lin.

Muriva, opaca, breviter nigro-pilosa. Caput cinereum. Longifudo proboscidis fere duplicem capitis longitudinem aequiparat. Palpi flavi. Antennae magnae, articulis duobus primis obscure badiis et nigro-pilosis, articulo tertio nigro, stylo apicali valido. Thorax fusco quadriviltatus, vittis lateralibus valde abbreviatis. Coxae ex badio rufae, basim versus cinerascentes, nigro-pilosae. Pedes rufi, extremo femorum apice et apice articulorum tarsalium singulorum nigris, ultimo tarsorun articulo toto nigro; femora postica modice incrassata, intermedia et postica subtus nigro-spinulosa. Halteres flavescentes. Alae ex fusco ferrugineae, cellulâ costali ex ochraceo ferrugineâ, venis obscure fuscis, stigmate dilutius fusco; cellula discoifalis brevis; anterior venae longitudinalis tertiae ramulus ardue ascendens. - (Maryland; Osten-Sacken.)

22. Pachymeria brevis, nov. sp. ठ․ Nigra, nigro-pilosa, oculis distantibus, thoracis dorso cinereo, obsolete vitlato, coxis nigricantibus, pedibus badiis, hypopygio minuto, compresso, nigro, filamento centrali infero, arcuato, pallido. - Long. corp. $2 \frac{1}{12}$ lin., Long. al. $2 \frac{1}{2}$ lin.

Caput nigrum, polline pallido cinereum, occipite nigro-piloso. Oculi distantes. Antennae nigrae. Thoracis dorsum polline pallido cinereum, obsoletissime subviltatum, pilis rigidis selisque nigris hirtum. Scutellum thoraci concolor, setis quatuor marginalibus 
nigris instructum. Pleurae nigrae, cinereo pollinosae et nigro-pilosae. Abdomen latiusculum, subdepressum, nigrum et nigro-pilosum. Нypopygium parvum, compressum, nigrum, lamellis inferis ovatis, filamento centrali pallide flavo, infero, arcuato. Coxae nigrae, cinereopollinosae, nigro-pilosae. Alae cinerascentes, venis fuscis. - (Districl Columbia; Osten-Sacken.)

23. Rhamphomyia vittata, nov. sp. $\delta$ et ㅇ. Flava, nitida, thoracis villis duabus atris, abdomine nigro-vario, alis ex luteo cinerascentibus, stigmate et limbo apicali fuscis. - Long. corp. $2 \frac{3}{1}$ lin., Loug. al. '2 ${ }_{6}^{5}$ lin.

Flava, nitida. Capul nigrum. Antennae nigrae, lenues, artienlo secundo fusco, articulo tertio in slylum longum, a stylo terminali obsolete separatum, attenuato. Proboscis pallida, capite paulo longior. Thoracis dorsum pilis selulisque rarissimis nigris praedilum villisque duabus latis integris atris ornatum. Scutellum thoraci concolor. Pleurae pallide flavae. Abdomen exceptả basi nigrum, marginibus segmentorum anticis interdum pallidis; segmentum quintum maris magnum, subtumidum, flavum, segmentum sextum abbreviatum, nigrum. Hypopygium parvum, lamellis superis majoribus flavis, inferis linearibus, filamento centrali operto. Pedes graciles, breviter pubescentes, llavi, tarsis praeter basim ex fusco nigris, femoribus in summo apice puncto nigro notatis. Alae maris ex luteo dilutissime cinerascentes, foeminae ex luteo salurate cinereac, limbo apicis fusco in foeminâ magis repando quam in mare, stigmale ex nigro fusco. - (Illinois; Le Baron.)

24. Rhamphomyia testacea, nov. sp. ㅇ. Testacea, opaca, antennis pedibusque concoloribus, femoribus, tibiis metatarsisque omnibus fusco squamato ciliatis, alis fuscis. - Long. corp. $2 \frac{2}{3}$ lin., Long. al. $3 \frac{1}{12}$ lin.

Testacea, subopaca. Caput nigrum, polline pallido cinereum. Antennae breves, ex fusco testaceae, articulo tertio lato, acuminato, stylo terminali brevi, tenui. Proboscis valida, capite paulo longior. Thoracis dorsum opacum, pilis brevibus selisque aliquot nigris. Scutellum thoraci concolor, selis quatuor instructum. Pleurae supra coxas anticas et ante halteres nigro-pilosae, praeterea nudac. Abdomen subnitidum, pilis nigris brevibus et raris vestilum. Pedes testacei; femora antica infra, femora posteriora et tibiae onnes utrinque, metatarsi omnes supra squamis longis fuscis ciliata. Ilalteres sordide flavi. Alae ex ferrugineo fuscae, limbo costali obsc1l- 
riore, basi et cellulà costali ex ferrugineo testaceis, cellulâ discoidali parvâ - (Illinois; Le Baron.)

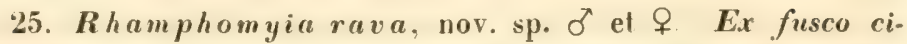
nerea, thorace fusco-trilineato, antennis angustis, mediocribus, nigris, articulis duobus primis plerumque fuscis, stylo terminali brevi, palpis. coxis pedibisque ex testuceo flavis, alis ex ferrugineo fuscis, stigmate nullo. - Long. corp. $4-4 \frac{1}{2}$ lin., Long. al. $3{ }_{6}^{5}-4$ lin.

Ex fusco cinerea, opaca. Caput concolor, facie laliusculà pol. line pallidiore obtectà Oculi maris subcontigui; antennae mediocres, anguslae, nigrae, articulis duobus primis plerumque totis fuscis, stylo terminali brevi. Palpi flavi, interdum sublestacei; proboscis mediocris. Thoracis dorsum fusco trilineatnm, pilis et setis mediocribus non confertis hirtum. Scutellum thoraci concolor, setis marginis inaequalibus nigris. Pleurae cinereae, pilis ante halteres tenuioribus pallidis, validioribus nigris. Abdomen foeminae ex fusco cincreum, brevissime pubescens, pilis plerisque pallidis. Abdomen maris obscurius, pilis longioribus vestitum, tenuioribus pallidis, va lidioribus nigris Hypopygium mediocre, porrectum, lamellis magnis ex flavo testaceis, infra nigro-pilosis, filamento centrali infero, subarcuato, flavo, basim versus valde incrassato, apice tenui operto. Coxae ex flavo testaceá, setis nigris.pilisque pallidis vestitae. Pedes ex testaceo flavi, femoribus in summo apice nigro-nolatis, tarsis apicem versus fuscis, pilis setulisque nigris, brevibus, sed rigidis. Alae ex ferrugineo fuscae, stigmate nullo, sed cellulae marginalis basi obscuriore. - (Illinois; Le Baron.)

26. Rhamphomyia mutabilis, nov. sp. O’ et 오 Antennis nigris, proboscide brevi, pedibus flavo et nigro variis, halleribus albis, alis hyalinis, stigmate dilutissime subfusco.

of Olscure rinereus, abdomine nigro, fronte et facie aequalibus angustis, hypopygio nigro, filamento centrali concolore, per anfractus ascondente.

\& Ex cinereo albicans, postico segmentorum abdominalium margine albo.

Long. corp. $2 \frac{1}{6}-2 \frac{1}{3}$ lin., Long. al. $2 \frac{1}{6}-2 \frac{1}{4}$ lin.

Mas: Obscure cinereus, opacus, abdomine nigro. Caput concolor, pilis in superiore occipitis dimidio nigris, in inferiore subfuscis. Oculi distantes; frons angusta. polline albido cincrea. Anlennae mediocres, nigrae, stylo terminali brevi. Facies angustissima, fronti aequalis, nigra, albido-pollinosa. Proboscis capiti subaequalis. 
Thoracis dorsum subobsolete nigro trilinealum. pilis setisque nigris rarioribus convestilum. Sculellum ex nigro cinereum, setis quatuon praedilum. Pleurae cinereae, fasciculo pilorum ante halteres nigro. Abdomen nigrum opacum, marginibus segmentorum posticis cine. rascentibus, pilis raris plerisque nigris. Venter polline alho cinerens. Hypopygium parvum, ringens, lamellis nigris, pube superiorum brevi longisque inferiorum pilis nigris, filamento centrali ex uigro fusco, anfractuoso. Coxae anticae ex flavo testaceae, pusleriores vigrae. in summo tantum apice testacene. Femora ex teslaceo flava, anteriora apicem versus infuscata, postica in dimidio apicali ex fusco nigra; tibiae nigrae, omnes in basi et anticae supra flavae; larsi nigri. Ilalteres albi. Alae hyalinae, venac longitudinalis primac apice subincrassato nigro, stigmate dilutissime subfusco.

Focmina: Albido-cinerea, opaca. Caput concolor, fronte et facie modice latis. Lineae thoracis obscuriores obsoletissimae. Scutellum et pleurae thoraci concolores. Abdomen albicans, posticis segmentorum marginitus albis, pilis nigris brevioribus quam in mare. Coxae intermediae praeter basim et posticae in apice latius ex flavo testaceae. Color pedum flavus magis propagalus quam in mare, obscurus dilutior, ila ut quod in illo fuseum est, in hac subfuscum sit, quod nigrum, obscure fuscum. Alae subalbicantes, venae longitudinalis primae fine minus valido et stigmate etiam pallidiore. (Illinois; Le Baron.)

27. Rhamphomyia aperta, nov. sp. ․ Obscuve cinerea. pube thoracis nigricante, abdominis pullida, pedibus e.t nigro fuscis, halteribus sordide albidis, alis dilatatis fuscis, celluela discoidali aperlá. - Long. corp. $1 \frac{5}{12}$ lin., Long. al. $1 \frac{5}{6}$ lin.

Obscure cinerea, opaca. Frons latissima. Antennae breves, latac, articulis duobus prinis obscure fuscis, tertio nigro, slylo terminali brevissimo. Proboscis capite paulo longior. Thoracis dorsum pilis nigricantibus hirtum. Pili ante halteres pallidi. Abdonen ex nigro cinereum, pilis brevibus pallidis. Pedes ex nigro sordide fusci, breviter pubescentes. Halteres sordide albidi. Alae dilalablate fuscae, stigmate paulo obscuriore, celuala discoidali cum cellulâ posteriore secundâ in unam conjunctà. - (Illinois; Le Baron.)

28. Rhamphomyia frontalis, nor. sp. $\delta$. E.r nigro rinerea, opaca, oculis distantibus, fronte adversus verticem dilatali, antennis nigris, facie angustissimi, proboscide quam crepul breviore, hypopygio nigro, infra pilis longis flavicantibus ciliato, pedibus ex 
nigro fuscis, alis cinereis, stigmate subfusco. - Long corp. $1 \frac{1}{2}$ lin., Long. al. $1 \frac{7}{1 \frac{2}{2}}$ lin.

Parva, ex nigro cinerea, opaca. Caput ex fusco nigrum, opacum, oculis latius quam in speciebus reliquis dislantibus, fronte verticem versus satis dilatatå. Antennae mediocres, latiusculae, nigrae, stylo terminali brevi. Proboscis capite brevior. Thoracis dorsum polline subfusco opacum, ex nigro cinereum, lineis tribus obsoletissimis nigris, pilis setulisque nigricantibus hirtum. Scutellum thoraci concolor. Pili ante halteres pallidi. Abdomen cinereum, pilis brevibus pallidis vestitum Hypopygium ringens, lamellis nigris, inferioribus latis, apice truncato, margine infero pilis longis flavicantibus ciliato, filamento centrali nigro, tenui, arcuato. Pedes ex nigro fusci vel nigricantes, breviler pubescentes, pilis tibiarum posticarum longioribus. Halteres sordide albidi. Alae ex cinereo hyalinae, venis nigris, stigmate subfusco. - (Illinois; Le Baron.)

29. Rhamphomyia polita nov. sp. ठ'. Alra, nitida, antennis, pedibus et hypopygio parvo concoloribus, oculis contiguis, halteribus albis, alis ex nigro cinereis, in apice nigricantibus, in basi sordide albicantibus. - Long. corp. 13 lin., Long. al. 2 lin.

Atra, nitida. Oculi contigui. Antennae longiusculae, angustae, nigrae, stylo terminali brevi. Proboscis nigra, capite brevior. Thoracis dorsum pilis setisque raris nigris hirtum. Scutelli setae quatuor marginales. Fasciculus pilorum nigrorum ante halteres. Abdomen nigro-pilosum. Lamellae hypopygii nigrae, parvae, nigro-pilosae; filamentum centrale pallide flavum, inferum, tenue, arcuatum. Pedes toti atri, graciles, nigro-pilosi; tibiae intermediae supra setis duabus, posticae compluribus instructae. Alae ex nigro cinereae, apicem versus nigricantes, in imâ basi sordide albicantes, stigmale perlongo fusco. - (Illinois; Be Baron)

30. Rhamphomyia lugens nov. sp. \&. Atra, nitida, antennis pedibusque concoloribus, pedibus longis nigris, intermedionum femoribus infra et tibiis supra, posticorum tibiis femoribusque utrinque squamato - ciliatis, halteribus albis, alarum nigrarum imâ basi albidá. - Long. corp. $1 \frac{7}{12}$ lin., Long. al. $2 \frac{1}{1 \frac{1}{2}}$ lin.

Atra, nitida. Antennae nigrae, mediocres, angustae, stylo terminali brevi. Proboscis nigra, capite paulo longior. Thoracis dorsum nigro-pilosum, praeter vittas Ires polline albo leviter aspersum. Pili ante halteres nigri. Abdomen angustum, atrum, nigro-pilosum. Pedes longi, ex fusco nigri, antici breviter nigro-pilosi; pedum inter- 
mediorum femora supra nigro-pilosa, infra squamis angustis ex nigro fuscis ciliata, tibiae supra squamulis angustissimis ciliatae, infra pilosae; pedum posticorum femora et tibiae utrinque squamato-ciliatae, squamulis tibiarum inferis praecipue prope apicem angustissimis. Halteres albi, pedunculo obscuriore. Tegulae sordide albidae, nigro limbatae et pilis nigris ciliatae. Alae ex fusco nigrae, stigmate paulo obscuriore, in imà basi subalbicantes. - (California; Agassiz.)

31. Rhamphomyia impedita nov. sp. ठ․ Atra. subopaca, antennis, halteribus pedibusque concoloribus, metatarso postico glo-

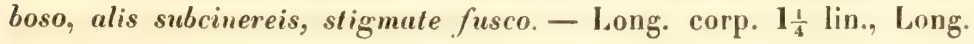
al. $1 \frac{1}{2}$ lin.

Atra, subopaca. Oculi contigui. Antennae breves, nigrae, stylo terminali minuto. Proboscis capite brevior. Pili in thoracis dorso et ante halteres nigri. Pedes nigri, nigro-pilosi, metatarso postico crassissimo, globoso. Halteres nigri. Alae subcinerascentes, costà venisque anterioribus nigris, reliquis et stigmate subfuscis. - (Illi. nois; Le Baron.)

Nota. A Rhamph. nanâ, cui similis, halteribus nigris et meta. larso postico multo crassiore distinguitur. A Rhamph. exiguâ iisdem notis et alis cinerascentibus differt.

32. Rhamphomyia exigua nov. sp. đ'. Nigra, subnitida, thorace pedibusque nigro-pilosis, metatarso postico modice incrassato, proboscide quam caput breviore, halleribus albis, alis hyalinis. stigmate obsoletissimo. - Long. corp. $1 \frac{5}{1} \frac{5}{2}$ lin., Long. al. $1 \frac{2}{3}$ lin.

Simillima Rhamphom. nanae. Nigra, subnitida, antennis, proboscide et palpis concoloribus. (tculi maris contigui. Proboscis capite paulo brevior. Thorax pilis nigris rarioribus hirtus; abdomen subopacum, pilis dilutissime subfuscis. Hypopygium alrum, nitidum, ascendens, lamellis parvis, obtusis, breviter pubescentibus, filamento centrali tenui, arcuato. Pedes nigri, in speciminibus immaturis ex nigro fusci, genibus summis pallidioribus, tibiae pedum posticorum et metatarsi modice incrassati supra setulas aliquot inaequales gerunt. Halteres albi. Alae hyalinae, basi ex flavo albicante, stigmate obsoletissimo. - (Illinois; Le Baron.)

Nota. Foeminas possideo mari descripto simillimas, nec nisi pedibus simplicibus et alis subcinerascentibus diversas.

33. Rhamphomyia unimaculata nov. sp. F. Ex nigyo cinerea, $p$ ilis brevibus rarissimis albis aspersa, genilus hulteribusgue 
albidis, alis hyulinis, ullimo venue longitudinalis quarlae segmento abbreviato, maculam nigram dissecante. - Long. corp. $1 \frac{1}{4}$ lin., Long. al. $\frac{1}{3}$ lin.

Rhamph. umbilicatae affinis, sed venâ longitudinali quartâ minus abbreviatâ, maculam maiorem nigram dissecante diversa. Ex nigro cinerea, pilis rarissimis brevibus albis vestita. Caput nigrum, antennis, proboscide palpisque concoloribus. Abdomen nigrum. Pedes graciles, subtilissime pubescentes, ex cinereo nigri, genibus sordide albidis, ultimis tarsorum articulis brevibus. Halteres albi. Alae hyalinae, venis plerisque sordide albicanlibus, longitudinali tertiâ et ultimo costae dimidio nigricantibus; segmentum venae longitudinalis quartae ultimum abbreviatum maculam nigram dissecat. - (Illinois; Le Baron.)

34. Hilara umbrosa nov. sp. ․ Nigra, subopaca, primis duobues antennarum articulis rufis, supra fuscis. pedibus pallide testaceis, tibiis posticis tarsisque omnibus ex nigro fuscis, halterum capitulo nigro, alis cinereis, in dimidio apicali obscurioribus, stigmate nigricante. - Loug. corp. $2 \frac{1}{3}$ lin., Long. al. $2 \frac{1}{1} \frac{1}{2}$ lin.

Inter maiores. Caput nigrum, praeter frontem polline albicante cinerascens. Primi duo antennarum articuli rufi, supra fusci, tertius niger. Palpi ex fusco testacei. Thoracis dorsum polline raro subcinerascens, confertius nigro-pilosum. Abdomen thoraci concolor, breviter nigro-pilosum. Coxae et pedes dilute testacei, tibiis posticis tarsisque omnibus ex nigro cinereis. Alae cinereae, in dimidio apicali obscuriores, stigmate nigricante. - (Illinois; Le Baron )

35. II ilara femorata nov. sp. ఠ et 9 . Atra, nitida, fronte opacî, antennis, palpis halleribusque nigris, genibus tarsisque ex fusco testaceis, femoribus anticis utrinsque sexus et antico maris metatarso incrassatis, alis hyalinis, stigmate obsolelissimo. - Long. corp. $1 \frac{1}{3}$ lin., Long. al. $1 \frac{7}{\frac{1}{2}}$ lin.

Caput atrum, opacum, antennis palpisque nigris. Thorax et abdomen atra, nitida, brevissime pubescentia. Pedes nigri, genibus, tibiarum anticarum apice tarsisque anticis ex fusco testaceis, tarsis posterioribus plerumque fuseis, interdum pallidioribus; femora antica in utroque sexu valde incrassata, metatarsus maris anticus crassus. Halteres nigri. Alae hyaliuae, venis fuscis, stigmate cinerascente obsoletissimo. - (Maryland; Osten-Sacken.) 


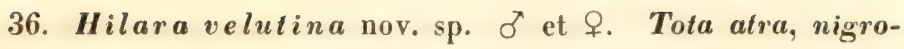
pilosa, capite thoraceque velutinis, abdomine pedibusque modice nitentibus, alis ex cinereo nigricantibus, stigmate saluratius nigricante, antico maris metatarso incrassato. - Long. corp. $1 \frac{1}{2}$ lin., Long. al. $1 \frac{2}{3}$ lin.

Tota alra. Caput velutinum, nigro-pilosum, antennis palpisifue concoloribus. Thorax opacus, velutinus, nigro-pilosus. Scutellum modice nitens. Abdomen cum scutello concolor, nigro-pilosum. Pedes toti nigri, breviler nigro-pilosi, antico maris metatarso oblongo, incrassato. Alae ex cinereo nigricantes, stigmate ex fusco nigro. - (I)istrict Columbia; Osten-Sacken.)

37. Hilara unicolor nov, sp. $\sigma^{\star}$. Ex nigro cinerea, confertius nigro-pilosa, abdomine ex cinereo nigro, antennis, palpis, halteribus pedibusque totis nigris, antico maris metatarso incrassato, alis dilute cinerascentibus, stigmate nigro. - Long. corp. $1 \frac{1}{2}$ lin., Long. al. $1 \frac{2}{3}$ lin.

Caput nigrum, nigro-pilosum, occipite ex nigro cinereo, antennis palpisque nigris, proboscide brevissimâ. Thorax ex nigro cinereus, opacus, pilis confertioribus nigris hirtus. Scutellum thoraci concolor. Abdomen ex cinereo nigrum, opacum, nigro-pilosum Pedes toti nigri, breviter nigro-pilosi, tibiis posticis pilis aliquot longioribus instructis; metatarsus anticus incrassatus. Halteres nigri. Alae dilute cinerascentes, stigmate nigro. - (Maryland; OstenSacken.)

38. Hilara nigriventris nov. sp. $\delta$ et ․ Ex nigro cinerea, opaca, conferlius nigro-pilosa, abdomine nigro, nitido, palpis testaceis, antennis, halteribus pedibusque nigris, coxis anticis prater basim, femorum anticorum basi et genibus extremis ex flavo testaceis, antico maris melalarso incrassato, alis dilutissime cinerascentibus, stigmate nigro. - Long. corp. $1 \frac{1}{3}$ lin., Long. al. $1 \frac{1}{2}$ lin.

Caput nigrum, nigro-pilosum, antennis concoloribus, occipite cinereo. Palpi ex flavo testacei, basi fuscà. Proboscis capiti sub. aequalis. Thorax ex nigro cinereus, confertius nigro-pilosus. Scutellum thoraci concolor. Abdomen nígrum, nitidum, nigro-pilosum. Coxae anticae ex flavo lestaceae, basi fuscâ, posticae plerumque totae nigrae, inlerdum in apice teslaceae. Pedes nigri, breviler nigro-pilosi, femorum anticorum basi genibusque extremis semper ex flavo testaceis, femorum intermediorum basi rarius testacea; anticus maris metalarsus oblongus, incrassatus. Alae dilulissime cinerascentes, stigmate nigro. - (Pennsylvania; Osten-Sacken.) 
39. Hilara trivittata nov. sp. ठ․ Ex nigro cinerea, subopaca, capite atro, frontis triangulo antico cineveo, antennis palpisque nigris, thoracis vittis tribus ex nigro fuscis, pedibus nigris, genibus flavis, metatarso antico maris incrassato, halteribus ex fusco luteis, fusco maculatis, alis ex cinereo hyalinis, stigmate fusco. Loug. corp. $2 \frac{1}{6}$ lin., Long. al. $2 \frac{1}{4}$ lin.

Ex nigro cinerea, subopaca. Caput atrum, antico frontis triangulo maiore quam in reliquis speciebus et facie cinerascentibus. Antennae nigrae. Palpi nigri, subcinerascentes. Proboscis capite paulo brevior. Thoracis dorsum polline ex fusco cinereo opacum, vitlis lribus subintegris fuscis, pilis nigricantibus brevissimis convestitum. Scutelium et pleurae concolores. Abdomen polline ex cinereo fusco subopacum, pilis pallidissime subfuscis hirtum. Pedes nigri, brevissime pilosi. Alae ex cinereo hyalinae, stigmate ex nigro fusco. - (Illinois Le Baron.)

40. Hilara mutabilis nov. sp. ․․ Nigra, antennis, palpis halteribusque concoloribus, thorace nigro-piloso, cinereo-pollinoso, viltis tribus atvis, pedibus nigris, genibus flavis, alis ex nigro cinereis, stigmate nigro. - Long. corp. $1 \frac{1}{12}$ lin., Long. al. $1 \frac{5}{12}$ lin.

Nigra. Caput atrum, antennis palpisque nigris, proboscide quam caput paulo breviore. Thoracis dorsum pilis longioribus nigris hirtum et polline cinereo tectum, ita ut a latere visum fotum cinerenm. desuper inspectum vittis tribus atris, mediâ integrâ, lateralibus postice valde abbreviatis notalum appareat. Scutellum thoraci concolor. Abdomen nigrum subnitidum, rare nigro-pilosum. Pedes nigri, breviter nigro-pilosi, genibus summis flavis. Halteres nigri. Alae ex nigro cinereae, stigmale nigro. - (Illinois; Le Baron.)

41. II ilara brevipila nov. sp. Ђ. Nigra, breviter pilosa, antennis, halteribus pedibusque concoloribus, genibus testaceis, antico maris metatarso incrassato, palpis testaceis, thorace et abdomine polline pallido subcinerascentibus, alis hyalinis, stigmate fusco. - Long. corp. $2 \frac{1}{1 \frac{2}{2}}$ lin, Long. al, 2 lin.

Nigra, subopaca. Caput atrum, occipite polline albido cinerascente. Antennae vigrae. Palpi ex flavo testacei. Proboscis capile brevior. Thoracis dorsum polline tenui albido subcinerascens, vittis łuabus nigrioribus approximatis obsoletis, pilis brevibus nigricantibus hirtum. Scutellum thoraci concolor. Abdomen nigrum, subnitidum, obsoletissime cinereo-pollinosum, nigro-pilosum. Pedes nigri, genibus ex flavo testaceis, breviter nig!o-pilosi, pedum anticorum 
posticorumque tibiis ef metatarsis supra pilis panlo longioribus instructis, antico maris metatarso incrassato. Halteres nigri. Alae hyalinae, stigmate ex nigro fusco. - (Illinois; Le Baron.)

42. Hilara atra nov. sp. ठ․ Atra. nitida, antennis, palpis, halleribus pedibusque concoloribus, nigro-pilosu. tibiis anticis et metatarso antico valde incrassuto supra pilos longiores gerentibus, alis subcinereis, stigmate nigro. - Long. corp. $1 \frac{1}{6}$ lin., Long. al. $1 \frac{1}{2}$ lin.

Atra. nitida. Caput atrum, nigro-pilosum, antennis palpisque nigris; proboscis capite brevior. Thoracis dorsum atrum, nitidum, vix levissime cinereo pruinosum, pilis longioribus nigris hirtum. Scutellum thoraci concolor. Abdomen atrum. nitidum, nigro-pilosum, hypopygio nonnihil elongato concolore. Halteres nigri. Pedes toli nigri, breviter nigro-pilosi, tibiis anticis et melatarso antico valde incrassato supra pilos longiores gerentibus. Alae subcinereae, stigmate ex fusco-nigro. - (Illinois; Le Baron.)

43. Hilara leucoptera nov. sp. +. Nigra, subnitida, polline albido cinerascens, antennis palpisque nigris, pedibus fuscis, genibus halteribusque sordide albidis, alis albicantibus, venis pallidis, cellulâ submarginali secunda brevi. - Long. corp. $1 \frac{1}{4}$ lin., Long. al. $1 \frac{1}{2} \operatorname{lin}$.

Nigra, modice nitens. Caput atrum, occipite polline albido cinerascente. Antennae nigrae, articulis duobus primis ex fusco nigris. Palpi nigri. Proboscis capite paulo longior. Thoracis dorsum polline tenui albido subcinerascens, pilis nigricantibus hirtum. Scutellum thoraci concolor. Abdomen nigrum Pedes fusci, in speciminibus maluris verisimiliter nigri, genibus sordide albidis. Malteres albidi. Alae hyalinae, albicantes, venis anticis dilute lutescentibus, reliquis sordide albidis, stigmate obsoletissimo; venəe longitudinalis tertiae ramus anterior ardue ascendens: cellula submarginalis secunda perbrevis. - (Florida; Osten-Sacken.)

44. Hilara gracilis nov. sp. $\sigma^{\nearrow}$ et $q$. Cinerea, nigro-pilosa, abdomine nigro, antennis halleribusque nigris, palpis pedibusque testaceis, tibiis infuscatis, tarsis ex fusco nigris. antico maris metatarso modice incrassato, alis ex cinereo hyalinis, stigmate ex nigro fusco. - Long. corp. $1 \frac{1}{2}$ lin. Long. al. $1 \frac{3}{4}$ lin.

Caput nigrum. occipite cinereo. Antennae nigrac. Palpi ex testaceo flavi. Proboscis capili aequalis vel subaequalis. Thorax cinereus, opacus, non vittatus. pilis nigris hirtus. Sculellum tho- 
raci concolor. Abdomen nigrum, modice nitens, nigro-pilosum, obsolete cinereo-pollinosum. Pedes testacei vel ex fusco testacei; tibiae fuscae, anteriorum basi tamen plerumque testaceâ; tarsi ex fusco nigri, metatarso antico maris oblongo, incrassato, pilis longioribus non instructo. Halteres nigri. Alae ex cinereo hyalinae, stigmate ex nigro fusco. - (Pennsylvania; Osten-Sacken.)

45. Hilara basalis nov. sp. $\sigma^{\circ}$. Nigra, nigro-pilosa, antennis concoloribus, thorace subcinerascente, abdominis basi halteribusque ex fusco testaceis, palpis pedibusque ex flavo testaceis, tarsis praeter basim fuscis, tibiis anticis et metatarso antico valde incrassato supra pilos aliquot longiores gerentibus, alis cinereis, stigmate ex nigro fusco. - Long. corp. $1 \frac{2}{3}$ lin., Jong. al. $1 \frac{1}{1} \frac{1}{2}$ lin.

Nigra, subuitida. Caput atrum, occipite subcinerascente. Antennae nigrae. Palpi ex flavo teslacei. Proboscis capite brevior. Thoracis dorsum polline tenuissimo albido subcinerascens, nigro-pilosum. Scutellum thoraci concolor. Abdominis dimidium basale testaceum vel ex fusco testaceum, apicale nigrum, obsoletissime cinereo-pollinosum. Pedes ex testaceo flavi, tarsis praeter basim fuscis, primo anticorum articulo valde incrassato; tibiae anticae et metatarsus anticus supra pilos aliquot longiores uigricantes habent. Halteres ex testaceo fusci. Alae cinereae, stigmate ex nigro-fusco. - (Illinois; Le Baron.)

46. Cyrtoma halteralis nov. sp. $\delta$ et 오. Nigra, halteribus albidis, tibiis posticis apicem versus paulo crassioribus. - Long. corp. $1_{\frac{1}{1}}$ lin., Long. al. $1 \frac{1}{1} \frac{1}{2}$ lin.

Tota nigra, modice nitens. Pili thoracis et scutelli aut omnes aut plerique nigri, abdominis sordide albidi. Tibiae posticae in utroque sexu apicem versus nonnihil incrassatae. Halteres sordide albidi. Alae ex cinereo subfuscae, stigmate saturatius fusco. - (District Columbia; Osten-Sacken.)

47. Cyrtoma longipes nov. sp. $\delta$ et + . Atra, modice nitens, pedibus elongatis concoloribus, halteribus nigris, alis nigrican. tibus. - Long. corp. $1 \frac{1}{3}$ lin., Long. al. $1 \frac{1}{3}$ lin.

Tota atra, nitens. Pili thoracis et scutelli nigri. Abdomen supra pilis nigris, in lateribus et infra pallidis vestitum; abdomen maris supra opacum. Pedes longiores et graciliores quam in reliquis speciebus, modice pilosi, tibiis posticis apicem versus nonnihil incrassatis. Halteres ex fusco nigri. Alae nigricantes. - (Illinois; Le Baron.) 
48. Cyrtoma pilipes nov. sp. ㅇ․ Atra, nilens, pedibus vulidiusculis valde pilosis, halteribus nigris, alis nigricantibus. - Long. corp. $1_{\frac{5}{1} \frac{5}{2}}$ lin., Long. al. $1 \frac{5}{12}$ lin.

Atra, nitens. Pili thoracis et seutelli omnes, abdominis plerique nigri. Pedes validiores quam in speciebus pracedentilus et confertius nigro-pilosi, tibiis posticis erassiusculis, apicem versus nonnihil incrassatis. Halteres nigri. Alae nigricantes. - (Illinois; Le Baron.)

49. Clinocera simplex nov. sp. ठ' et + . Ex olivaceo cinerea, facie, pleuris et ventre albido-pollinosis, antennis, palpis, halteribus pedibusque nigris, alis cinereis, setulis costalibus minutissimis, stigmate obsoleto, pallidissime subfusco. - Long. corp. $2 \frac{1}{6}$ lin., Long. al. $2 \frac{1}{3}$ lin.

Ex olivaceo cinerea, opaca. Caput nigrum, albido pollinosum, vittâ frontali et maculâ magnâ occipitali ex cinereo olivaceis. Antennae nigrae. Genae latae. Palpi nigri. Thorax ex cinereo olivaceus, scutello, metanoto pleurisque albido-pollinosis. Abdomen ex olivaceo cinereum, ventre albido-pollinoso. Hypopygium maris reflexum, abdomini concolor. Pedes tenues, nigri, breviler nigropilosi, apicalibus femorum setulis nullis, empodio pulvillis acruali. Halteres ex fusco nigri, pedunculo pallidiore. Alae cinereae, stigmate obsoleto, oblongo, dilutissime subfusco, renis duabus primis fuscis, reliquis nigris, setulis costae minutissimis, venâ longitudinali secundâ rectâ, cellulâ submarginali secundà brevi, cellulae discoidalis apice acuto, cellulâ posteriore secundâ cuneiformi et venâ longitudinali sextâ nullà. - (Hudson's Bay Territory.)

50. Clinocera lineata nov. sp. Q. Ex olivaceo nigra, tribus thoracis lineis atris, pedibus flavis, alis ex cinereo fuscis, venulâ transversá inter costam et venam longitudinalem secundam positâ. setulis costae nullis. - Long. corp. 1 lin, Long. al. $1 \frac{1}{3}$ lin.

Ex olivaceo nigra, subopaca. Antennae nigrae; genae mediocres et facies albo-pollinosae; palpi nigri. In thoracis dorso vittae duae niteutes, lineâ atrâ separatae et utrinque lincâ nigrầ margi . natae. Scutellum thoraci concolor; pleurarum dimidium inferius polline albido tectum. Abdomen subnitidum. Pedes graciles, nudiusculi, coxarum basi plerumque, genibus, summo tibiarum apice et ultimis tarsorum arliculis semper fuscis; selulac in femorum apice nullae adsunt; emporlium minutum pulvillis aequale; unguiculi minuti. Halteres obscure fusci. Alac ex cinereo fuscae, venis ex 
nigro fuscis, setulis costae nullis; vena longitudinalis secunda ante apicem venulam transversam ad alae costam mittit; vena longiludinalis tertia undulata, ramo anteriore minus decumbente quam in reliquis speciebus; punctum decolor in extremo cellulae discoidalis apice. - (Pennsylvania; Osten-Sacken.)

Nota. Inter genera Clinoceram et Ardopteram media, capitis formà orisque conformatione Clinocerae propinquior videtur.

51. Hemerodromia valida nov. sp. ․ Cinerea, pedibus halleribusque saturate flavis, alarum cellulà discoidali quadrangula, cellulâ posteriore secundâ quam pedunculus multo breviore, cellulâ anali oblique truncat $\hat{a}$, stigmate dilute subfusco. - Long. corp. 2 lin., Long. al. $2 \frac{2}{3}$ lin.

Valida, tota cinerea. Facies albo-pollinosa. Vittae in thoracis dorso duae angustae paulo obscuriores. Pedes saturate flavi, apice tarsorum posteriorum fusco, femoribus anticis valde incrassatis. Halteres sordide flavi. Alae hyalinae, venis plerisque fuscis, stigmate ex flavo subfusco; cellula basilis prima paulo longior quam secunda; cellula discoidalis oblonga, quadrangula; cellula posterior secunda pedunculo mullo longior; cellula analis completa, oblique truncata. - (Hudsons Bay Territory.)

Nota. Simillima Hemerodromiae Frigelii, a quâ cellulâ anali obliquius truncałâ distiucta videtur.

52. Hemerodromia obsolela nov. sp. ․ Albida, supra subfusca, thoracis marginibus et metanoto nigris, alis hyalinis, cellulà discoidali quarlrangulia, cellulâ posteriore secundá quam pedunculus paulo breviore, cellulâ anali completâ, stigmate obsoletissimo, sublutescente. - Long. corp. $1 \frac{3}{4}$ lin., Long. al. 2 lin.

Caput nigrum, occipite et vertice polline albido cinerascentibus, fronte et facie candido-micantibus. Antennae totae albae. Thoracis dorsum ex fusco testaceum, albido pollinosum, marginibus late nigricantibus. Scutellum ex fusco nigricans; metanotum nigrum, albido-pollinosum. Pleurae albo-pollinosae, dimidio superiore nigricante, inferiore albido vel ex albo dilute flavicante. Abdomen fuscum vel nigricans, segmentorum singulorum fasciâ interruptà posticà pallidâ. Venter albidus. Pedes albidi, femoribus anticis valde incrassatis, ultimis duobus tarsorum posteriorum articulis nigris. Alae prorsus hyalinae, stigmate obsoletissimo, dilutissime subflavicante; cellula hasalis prima longior quam secunda; cellula discoidalis oblonga, 
quadrangula; cellula posterior secunda pedunculo paulo brevior; cellula analis completa. - (Illinois; Le Baron.)

53. Hemerodromia notata nov. sp. ․ Albida, thoracis fusco-testarei viltâ medià, scutello, metanoto et abdomine nigris, alis hyalinis, cellulà discoidali quadrangula, cellulá posteriove secundá quan pedunculus longiore. cellulâ anali completâ, stigmate rotundo alro - long. corp. $1 \frac{7}{12}$ lin, Long. al. $1 \frac{3}{4}$ lin.

Caput nigrum, albo-pollinosum, facie candido-micante. Antennae tota albae. Thoracis dorsum ex fusco testaceum, albido-pollinosum. vittà mediâ latâ et marginibus lateralibus extremis nigris. Scutellum et metanotum nigra. Pleurae albidae. dimidio superiore paulo obscuriore. Abdomen nigrum, marginibus segmentorum singulorum poslicis et ventre albidis. Pedes albidi, femoribus anticis valde incrassatis ultimo tarsorum posticorum articulo nigro. Alae hyalinae, stigmate rotundo nigro; cellula basalis prima longior quam secunda; cellula discoidalis oblonga, quadrangula; cellula posterior secunda pedunculo longior; cellula analis complefa. - (Illinois; Le Baron.)

54. Hemerodromia scapularis nov. sp. ठ et + Atra, nitida, humeris vel testaceis vel fuscis, raro atris, abdomine nigro et albo vario, antennis, proboscide, halteribus pedibusque albis, alis hyalinis, cellulis discoidali et basali secundà in unam connatis, cellulâ posteriore secundà sessili, celluli anali completa., stigmate nullo. - Long. corp. $1 \frac{5}{12}$ lin., Long. al. $1 \frac{7}{12} \operatorname{lin}$.

Caput atrum, nitidum, facie angustâ candido-micante. Antennae totae et proboscis albae. Thorax ater, nitidus. sculello pleurisque concoloribus, humeris plerumque testaceis, interdum fuscis, raro atris. Abdomen maris plerumque fere totum atrum, hypopygio concolore, interdum segmentis basalibus albis; abdomen focminae album, apice atro, terebrâ ensiformi flavicante, in basi et apice late atrà. Pedes albi, raro flavicantes; femora antica posterioribus paulo crassiora; duo ultimi tarsorum articuli fusci vel nigri. Alae hyalinae, stigmate nullo; vena longitudinalis secunda hrevis; cellula discoidalis cum cellulâ basali secundâ in unam coniuncla nervulos tres alae marginem petentes emittit, ita ut cellula posterior secunda pedunculata non sil; cellula analis completa. - (Maryland, Maine. Pennsylvania; Osten-Sarken.) 
55. Hemerodromia defecta nov. sp. $\sigma$. Albida, apice hypopygii et ultimis tarsorum articulis subfusris, alis hyalinis, cellulá basuli primâ quam secunda longiore, cellulá discoidali nullâ, rellulâ anali completâ, stigmate obscuro. - Long. corp. $1 \frac{1}{2}$ lin., Long. al. $1 \frac{2}{3}$ lin.

Albida, thorace et abdomine dilute flavescentibus; caput nigrum, occipite et vertice polline albido subcinerascentibus, fronte et facie candido-micantibus; antennae totae et proboscis albae. Apex hypopygii infuscatus. Pedes albidi, ultimis duobus tarsorum articulis subfuscis, femoribus anticis valde incrassatis. Alae hyalinae, stigmate obsoletissimo, dilutissime subflavescente; cellula basalis prima longior quam secunda; cellula analis completa. - (District Columbia; OstenSacken.)

Nota. Mas descriplus immaturus est.

56. Hemerodromia vittata nov. sp. ठ et \&. Albida, thoracis viltâ latâ, scutello, metanoto et abdomine nigris, alis hyalinis, cellulâ basali secundâ quam prima mullo longiore, cellulis di-

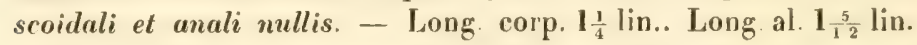

Albida. Caput nigrum, albo-pollinosum, fronte et facie candidomicantibus; antennac totae et proboscis albae. Thorax dilute flavicans vel subtestaceus, vittâ latâ nigrâ, in speciminibus iunioribus interdum obsoletâ. Scutellum et metanotum nigra, in immaturis fusca. Abdomen nigrum, segmento ultimo foeminae plerumque, maris raro albido, hypopygio maris et brevi foeminae terebrâ atris. Venter albidus. Pedes albidi, articulis tarsorum duobus ultimis vel infuseatis vel nigris, femoribus anticis valde incrassatis. Alae hyalinae, stigmate, cellulâ discoidali et cellulâ anali prorsus nullis; cellula basalis secunda multo longior quam prima; cellula posterior secunda pedunculo aequalis. - (District Columbia; Osten-Sacken)

57. Drapetis pubescens nov. sp. ․ Atra, nitida, abdomine fusco, pleuris pedibusque pallidissime flavicantibus, antennis flavis, articulo tertio subfusco. - Long. corp. 1 lin. Long. al. $1 \frac{1}{6}$ lin.

Drapetidi flavipedi Macq. similis. Capnt atrum, nitidum, pube verticis fuscà. Antennae sordide flavicantes, articulo tertio et setâ subfuscis. Palpi ex nigro fusci. Thoracis dorsum atrum nitidum, pube albicante brevi et confertâ vestitum. Pleurae dilutissime flavescentes triente summo fusco, nigro-maculato Abdomen ex nigro fuscum, nitidum, pube pallidå brevissimà; basis abdominis haud raro flavescens; terebra foeminae longior quam in speciebus plerisque, 
subrecurva, nigra apice badio. Pedes albidi, breviter albido-pubescentes, tibiis posticis supra pilos paulo validiores gerentibus. Halteres fusci. Alae ex cinereo hyalinae, triente basali subinfuscato, venà longitudinali quartâ subarcuatâ, cellulis basalibus aequalibus. (New-York; Edwards.)

55. Stilpon varipes nov. sp. ․ Ater, abdomine testaceo, halleribus fuscis, alis infuscatis, costae segmentis secundo et tertio subaequalibus. - Long. corp. $\frac{5}{6}$ lin, Long. al. 1 lin.

Caput nigrum, facie allo-pollinosâ; antennarum basis flava, articulus tertius obscure fuscus; palpi flavi. Thorax ater, nitidus; scutellum thoraci concolor. Abdomen testaceum vel latericium, apicem versus infuscatum. Pedes flavi; femora antica valde incrassata, minus tamen crassa quam in Europae speciebus; femorum intermediorum apex posticorumque dimidium apicale fusca; tibiae anteriores praeter basim infuscatae, posticae in apice paulo incrassato fuscae; iarsi subfusci, articulo primo fusco, ullimo nigro; metatarsus posticus subincrassatus. Halteres ex nigro fusci, pedunculo testaceo. Alae cinercae, venis fuscis, venâ longiludinali primâ et primo costie segmento testaceis, primo venae longitudinalis quartae dimidio decolore, venis omnibus praeter secundum quartae dimidum et quintae apicem latissime subfusco limbatis, costae perspicue puberulae segmentis secundo et tertio subaequalibus. - (Pennsylvania; OstenSacken.)

59. Dolichopus albiciliatus nov. sp. ․ Obscure viridis, nitens, pedum nigronum tibiis, excepto tamen posticarum apice, tarsorumque anteriorum basi flavis, facie albat, riliis oculorum inferioribus albis, tegularum ciliis nigris. - Long. corp. $2 \frac{1}{3}$ lin., Long. al. $2 \frac{1}{3} \operatorname{lin}$.

Facies latiuscula, alba. Antennae nigrae, articulo tertio brevi. Frons obscure viridis, nitida. Inferiora oculorum cilia alba. Femora nigra, viridi micantia, apice extremo luteo, postica infra pilis nigris longioribus quam in speciebus confunibus vestita, ita ut in mare ciliata esse suspicari liceat; tibiae flavae. posticarum apice nigro. Tarsi anteriores inde ab articuli primi apice nigri; tarsi postici toli nigri. articulo primo setis paucis armato. Tegularum cilia nigra. Alae ex cinereo hyalinae. - (Hlinois; Le Baron.)

60 Dolichopus sorius nov. sp. ఫ. Aeneo-viridis, nilidus. facie albâ, antennarum nigrarum articulo primo subtus rufo, ciliis 
oculorum inferioribus albis, tegularum ciliis pallide flavicantibus, pedibus flavis, coxis anticis conroloribus, tarsis anticis inde ab articuli primi apice, apice tibiarum posticarum tarsisque posticis tolis nigris. - Long. corp. 2 lin., Long. al. 2 lin.

Viridis, nitens. Facies alba. Antennae nigrae, articulo primo infra rufo, articulo terlio ovato, apice non rotundato. Frons viridis, nitens. Oculorum cilia inferiora alba Lamellae hypopygii albae, mediocres, ovatae, angustissime nigro marginatae. Coxae anticae pallide flavicantes, pube subtilissimâ albâ vestitae; coxae posteriores nigricantes, in apice pallide flavescentes. Pedes pallide flavi; femora postica infra subnuda; apex tibiarum posticarum niger; tarsi anteriores inde ab articuli primi apice nigri, terminali tamen anticorum articulo dilute ferrogineo; tarsi postici toti nigri. Cilia tegularum navescentia. Alae hyalinae, venâ longitudinali quartâ non fractâ. (Illinois; Le Baron.)

61. Dolichopus fulvipes nov. sp. ठౌ. Viridis, nilidus, facie aureâ, antennis fulvis, articulo terlio praeter basim nigro, ciliis oculorum inferioribus flavis, tegularum ciliis nigris, coxis anlicis pedibusque fulvis, tibiarum intermediarum apice albo. - Long. corp. $2 \frac{2}{3}$ lin., Long. al. $2 \frac{7}{2}$ lin.

Viridis, nitidus. Facies angusta, aurea. Antennae fulvae, articulo tertio praeter basim nigro, elliptico, apice non rotundato. Frons viridis. Cilia oculornm inferiora flava. Lamellae hypopygii parvae, albidae, angustissime nigro limbatac, margine apicali circinato. Coxae anticae fulvae, nigro-pilosae. Pedes validiusculi, fulvi; tibiarum intermediarum apex supra tumidus, albus. Tarsi simplices, anteriores inde ab arliculi primi apice nigri, basi lamen articuli secundi pallidiore, poslici toti nigri. Cilia tegularum nigra. Alae cinereo-hyalinae in margine postico ante angulum axillarem sinu lato excisae, venae longitudinalis quartae segmento ultimo non fracto. - (Illinois; Le Baron.)

62. Dolichopus praeustus nov. sp. $\delta$. Aeneo-viridis, nilens, farie ex cinereo ochracea, antennis nigris, ciliis oculorum inferioribus albidis, tegularum ciliis nigris, pedibus testaceis, liturâ femorum anteriorum infer $\hat{a}$, femorum posticorum apice, tarsis anterioribus inde ab articuli primi apice tarsisque posticis totis cum tibiarum posticarum apice nigris, alarum ex cinereo hyalinarum apice nigro. - Long. corp. $2 \frac{5}{12}$ lin. Long. al. $2 \frac{5}{12}$ lin.

Aeneo-viridis, nitidus. Facies ex cinereo ochracea.

Antennae 
totae nigrae, articulo tertio brevi. Frons viridis, modice nitens. Cilia oculorum inferiora albida. Lamellae hypopygii mediocres, latae, nigro limbatae. Coxae nigricantes, in apice testaceae, anticac polline ex albo cinereo tectae nigro-pilosae. Pedes testacei; femora anteriora infra nigro liturata, posteriora in apice nigra; apex tiliarum posticarum niger, supra foveolatus; tarsi simplices, anteriores inde ab articuli primi apice, postici toti nigri Alae cinereo-hyalinae extrumo apice nigro, venâ longitudinali quartâ subrectâ. - (Illinois; Le Baron.)

63. Dolichopus setosus nov. sp. Ђ. Viridis, nitidus, $f a-$ cie et inferioribus oculorum ciliis albis, antennis et riliis tegularum nigris, coxis anticis pedibusque favis, tarsis anterioribus inde ab articuli primi apice tarsisque poslicis totis cum libiarum postirarum apice nigris; femora postica pilis flavis ciliata; libiae posticae setis longis armatae; alarum venu longitudinalis quarta non fracta. Long. corp. $2 \frac{2}{3}$ lin., Long. al. $2_{6}^{5}$ lir.

Viridis, nitens. Facies angusta alba. Antennae nigrae, infero articuli primi margine subfusco, articulo tertio elliptico, apice non rolundato. Frons obscure viridis, nonnibil nitens. Inferiora oculorum cilia albida. Lamellae hypopygii mediocres, latae, rotundatae, albae, nigro limbatae. Coxae anticae dilute flavescentes, albo-pollinosae, prope apicem el prope marginem interiorem pilis minutis nigris vestitae; coxae posteriores nigricantes, in apice flavesrentes. Pedes pallide flavi; femora postica infra pilis flavicantibus ciliata; tibiarum posticarum setae longiores quam in congeneribus plerisque, apex niger; tarsi anteriores inde ab articuli primi apice, postici toti nigri. Alae ex cinereo hyalinae, costâ ubi venam longitudinalem primam excipit incrassatâ, venâ longitudinali quartà non fractâ. - (Massachusetts; Le Baron.)

64. Tachytrechus angustipennis nov. sp. 万. Antennis peclibusque tolis nigris, alis maris immarulatis. - Long. corp. $2 \frac{1}{2}$ lin., Long. al. $2 \frac{1}{4}$ lin.

Viridis, subopacus. Facies pallide ochracea. Anlennae tolae nigrae. Frons polline dilute ochraceo opaca. Cilia oculorum laleralia et infera alba. Thoracis dorsum polline dilute ochraceo tectum, lineis duabus mediis, vittulis punctisque fuscis variegatum. Abdomen viride, polline albido subtessellalum. Iypopygium nigrum. lamellis parvis, rotundalis, nigricanlibus, brevi!er pilosis. Coxae nigrae, polline ex flavo albido tectae, anticae pilis sublilissimis albidis sctulisque 
aliquot nigris vestitae. Pedes nigri, viridi micantes, tarsis simplicibus; femora postica antice setam ab apice satis remotam, tibiae posticae praeter setas ordinarias supra setas tres compresso-dilatatas gerunt. Cilia tegularum nigra. Alae angustae, ex cinereo hyalinae, dimidio cellulae marginalis apicali et venae transversalis limbo obscurioribus, primo costae segmento incrassato. - (District Columbia; OstenSacken.)

65. Chrysotus cornutus nov. sp. ठ․ Obscure viridis, modire nitens, antennarum nigrarum arliculo tertio elongato, orulis infra antennas contiguis, tegularum ciliis femoribusque nigris, $t i$. biis testaceis, tarsis anticis inde ab articuli primi apice, posticis tolis fuscis. - Long. corp. $\frac{1}{1} \frac{1}{2}$ lin., Long. al. 1 lin.

Obscure viridis, modice nitens, fronte concolore. Oculi infra contigui. Antennae nigrae, articulo tertio elongato, setâ apicali. Cilia tegularum nigra. Femora nigra, extremo apice testaceo; tibiae pallide testaceae, posticarum åpice ex fusco nigro; tarsi anteriores inde ab articuli primi apice, postici toti ex nigro fusci. Alae ex cinereo hyalinae, venis nigris, transversà posteriore brevi, ante mediam alam sitâ. - (Illinois; Le Baron.)

66. Chrysotus picticornis nov. sp. $ð$. Minutus, viridiueneus, modice nilens, oculis infra antennas contiguis, primo antennarum articulo rufo, coxis anticis pedibusque flavis. - Long. corp. $\frac{2}{3}$ lin., Long. al. $\frac{3}{4}$ lin.

Valde minutus, viridi-aeneus, modice nitens. Oculi infra contigui. Antennae nigrae, articulo primo rufo, tertio parvo, subobliquo, setâ apicali. Coxae anticae et pedes flavi, femorum posticorum apice tarsisque inde ab articuli primi apice fuscis. Alae ex cinereo hyalinae, venis fusco-nigris. - (Illinois; Le Baron.)

67. Hydrophorus parvus nov. sp. ठ大. Olivaceo-aeneus, thorace et scutello cupreo splendentibus, abdomine virescente, femoribus tibiisque viridibus, tarsis nigris, polline faciei ex fusco ochraceo, pleurarum polline albo, venis alarum ex nigro cinerascentium nigris, longitudinalibus tertiâ et quartâ perfecte parallelis. - Long. corp. $1 \frac{1}{6}$ lin., Long. al. $1 \frac{1}{2}$ lin.

Ab Hydrophora piratâ, cui colore simillimus, corpore multo minore, alis magis nigricantibus venisque longiludinalibus tertiâ et quartà perfecte parallelis differt. Facies polline conferto, ex fusco ochraceo opaca; palpi nigri. Cilia oculorum supera nigra, infera 
alba. Pili abdominis brevissimi, nigri. Coxae ex nigro virescentes, antice pube brevi pallidà vestitae. Femora obscure viridia, antica infra brevissime spinulosa, adiectis spinulis duabus tribusve longioribus prope basim. Tibiae femoribus concolores, anticae infra brevissime spinulosae. Tarsi nigri. Halteres nigri. Alac ex uigro cinereae sive dilute nigricanles, venis omnibus et totis nigris; vena transversa posterior perpendicularis, limbo obscuriore nullo. - (Illinois; Le Baron.)

68. Sympyrnus nodatus nov. sp. $\delta^{7}$ et ․ Cinereus, fronte obscuriore, margine primi antennarum articuli infero, fasciâ abdominis basali maculisque lateralibus, ventre et perlibus flavicantibus, femorum posticorum apice nigro. Mas setam antennalem capitulo apicali minuto instructam et secundum tarsorum intermediorum articulum nonnihil dilatatum habet; in foeminâ et seta antennalis et tarsi simplices. - Long corp. $1 \frac{1}{6}-1 \frac{1}{4}$ lin., Long. al. $1 \frac{1}{4}-1 \frac{6}{1} \frac{6}{2}$ lin.

Facies maris valde angusta, polline albo tecta; facies foeminae multo latior, polline rariore albido ex nigro cinerea. Antennac nigrae, articulo primo infra flavescente; seta antennarum in foeminâ simplex, in mare capitulo minutissimo terminata Thoracis dorsum ex fusco cinereum, opacum, non lineatum. Abdomen aeneo-nigrum, fasciâ latissimâ segmenti secundi, maculis lateralibus segmenti tertii fere connatis, segmenti quarti minoribus flavis. Appendices hypopygii minutae, nigrae. Coxae et pedes pallide flavescentes, femorum posticorum apice nigro. Tarsorum anticorum articuli duo primi in mare pallide flavescentes, sequentes nigri, articulus primus brevissimus, secundus elongatus; tarsorum intermediorum articulus primus elongatus, flavescens, apice tamen nigro, articuli sequentes toti nigri, tertius tribus sequentibus simul sumptis aequalis, apicem versus dilatatus. Tarsi anteriores foeminae simplices, apicem versus nigricantes, articulis decrescentibus. Tarsi postici utriusque sexus simplices, articulo primo flavo, sequentibus nigris, articulo secundo reliquis longiore, tertio et quarto simul sumptis aequali. Alae ex cinereo hyalinae, venis longiludinalibus tertiâ et quartì parallelis, venâ transversâ posteriore perpendiculari. - (Illinois; Le Baron)

69. Psilopus melampus nov. sp. $\sigma$ et 9 . Viridis, saepe ex chalybeo viridis, nilidus, facie nudâ, alarum fasciis duabus nigricantibus antice conjunctis et postice abbreviatis, pedibus totis nigris.

o abdomen fasciis aequalibus nigris ornatum; halteres ex fusco 
nigri; primus tarsorum anticorum articulus setis nigris armalus, articuli duo sequentes non abbreviali.

을 nigrae abdominis fasciae anguslae, subobsoletae; halterum capitulum flavum.

$$
\text { Jong. corp. } 2-2 \frac{1}{2} \text { lin, Long al } 2 \frac{5}{12}-2 \frac{7}{12} \text { lin. }
$$

Viridis, nitidus, haud raro ex chalybeo viridis, proboscide, palpis, antennis pedibusque nigris. Faciei nuda, tenuiter albido-pollinosa. Fasciae segmentorum abdominalium singulorum basales nigrae in mare latae et aequales, in foeminâ angustae et obsolefae. Hypopygium nigrum, appendicibus minulis concoloribus. Femora infra pilis per. longis, plerisque albidis, apici proximis nigris vestitae; tibiae anticae postice setis quatuor vel quinque, in foeminâ brevioribus armatae; tibiae intermediae maris, superne pilis ordinariis paullo longioribus obsolete subciliatae, setas paucas et modice longas gerunl. Tarsi utriusque sexus simplices; primus anticorum articulus in mare setis sex vel septem satis longis, in foeminâ selulis totidem valde minutis armatus; primus tarsorum intermediorum articulus in mare antice ef superne pilis minutissimis obsoletissime subciliatus. Halteres maris ex fusco nigri, foeminae flavi, pedunculo tamen obscuriore. Tegulae nigro-marginatae et nigro-ciliatae. Alae hyalinae, fasciis duabus nigricantibus, antice coniunclis et postice abbreviatis; pictae, vena transversa posterior modice obliqua. - (Mexico.)

70. Psilopus dimidiatus nov. sp. $ठ$. Nitidissimus, capite thoraceque violaceis, abdomine viridi; pedes simplices, graciles, femoribus nigris, tibiis favis, tarsis fuscis; alae ex fusco nigrae, triente marginali et margine postico hyalinis. - Long. corp. 2 lin., Long. al. $2 \frac{1}{3}$ lin.

Caput violaceum, fronte praeter setas ordinarias et facie albopollinosà nudis; antennae parvae, nigrae, articulo secundo brevissime nigropiloso; seta antennarum dorsalis, mediocris. Color thoracis violaceus, adversus marginem posticum in chalybeum vergens. Scutellum chalybeum. Pleurae ex viridi nigrae, albo-pollinosae. Abdomen viride, nitidissimum, setis in margine segmentorum singulorum postico mediocribus. Hypopygium parvum. Coxae ex fusco nigrae. albo-pollinosae, anticae pilis et selis albidis vestitae; femora gracilia, subnuda, ex fusco nigra, summo tamen apice flavo; tibiae tenues, flavae, brevissime nigro-pilosae, pilis intermediarum erectioribus; larsi tenues, simplices, fusci, anteriores tibiis multo longioresCilia tegularum nigra. Alae ex fusco nigrae, triente apicali, mar- 
gine postico et angulo axillari hyalinis, costâ subciliatâ, vena Iransversâ posteriore valde obliquâ. - (Nexico; Collect. Winth.)

71. Psilopus tener nov. sp. $\sigma$ et \&. Laete viridis. proboscide, palpis, primis duobus antennarum articulis, pleurarum margine postico, abdominis basi, coxis pedibusque fluvis, ciliis tegularum albicantibus, alarum venâ transversâ posteriore valde obliquâ.

c' femora antica setulis subtribus armata; appendices hypopygii mrijusculae, flavae.

I femora antica setis quatuor validis armata.

Long. corp. $1 \frac{1}{1} \frac{1}{2}-2$ lin., Long. al. $2 \frac{1}{2}$ lin.

Laete viridis, modice nilens. Proboscis flava, palpi flavi, setulis aliquot nigris armati. Facies lata, nuda, albo-pollinosa. Antennae parvae, articuli duo primi flavi, setulis secundi nigricantibus brevissinis; articulus tertius minutus, nigricans, interdum pallidior; seta antennarum mediocris. Frons praeter setas ordinarias nuda, plerumque laete caerulea. Thoracis dorsum viride, interdum caeruleum, setas paucas gerens. Scutellum viride aut violaceum, setis duabus praeditum. Abdomen laete viride, basi in foeminâ semper, in mare plerumque flavâ, setulis ordinariis in margine segmentorum singulorum postico minutis. Hypopygium maris nigricans, appendicibus flavis maioribus. Coxae flavae, pilis setulisque tenuibus albis vestilae. Pedes nudiusculi, gracillimi, flavi. Femora antica infra prope basim in mare setulis tribus, in foeminâ setis quatuor flavis armata. Tarsi anteriores tibiis multo longiores, filiformes; tarsi postici tibiis aequales. Tegularum cilia albida. Alae longiusculae, angustae, basim versus attenuatae, cinereo-hyalinae, venis anterioribus flavis, postedioribus subfuscis; venae longitudinalis tertiae ramus anterior valde decumbens, modice arcuatus; vena transversa posterior ab alae margine remola, valde obliqua; basis alarum maris infra spinam aduncam nigram habet. - (Pennsylvania; Collect. Winth.)

72. Lispe sociabilis nov. sp. ర大 et 우. Nigricans, facie sordide ochraceá, abdomine trifariam albo maculato, femoribus posticis elongatis, setâ inferâ unicâ.

б palpi ingentes, nudi, pallide favi, candido micantes; tarsorum articuli basales plerumque fusci, metatarsus anticus articulis duobus sequentibus simul sumptis paullo brevior.

I palpi magni, breviter nigro-pubescentes, saturate flavi, albomicantes; tarsi nigri, metatarsus anticus articulis tribus sequenti. bus simul sumptis aequalis.

Long. corp. $2 \frac{2}{3}-3 \frac{1}{\frac{1}{2}}$ lin., Long. al. $2 \frac{2}{3}-2 \frac{3}{3}$ lit. 
Lispae tentaculatae simillima. Nigricans; facies polline opaco sordide ochraceo vestita, utrinque setâ mystacinâ validâ setulisque aliquol minoribus armata. Palpi maris ingentes, praeter marginem inferum nudi, pallide flavi, breviter nigro-pubescentes, albo-micantes. Thoracis dorsum polline tenui cinerascente vestitum, lineis tribus nigrioribus obsoletissimis. Abdomen ex fusco nigrum; segmentum primum albo-pollinosum, segmenta reliqua singula utrinque macula candidâ, margini anlico contiguâ, ornata; segmenta secundum et terlium singula insuper maculâ mediâ, in illo maiore, albicante, margine postico contiguâ; segmentum quintum maris ex fusco nigrum, foeminae absconditum. Pedes nigri. nigro-pilosi; femora antica superne et subtus seriatim nigro-setosa; femora intermedia apicem versus altennata, in dimidio apicali subtus nigro-setosa; femora postica longa, subtus pone dimidium setam unicam ferentia. Tibiae anticae simplicrs. in apice setosae; tibiae intermediae maris longiores et tenuiores quam foeminae, in apice setas aliquot geruut, praeter quas seta exlerior in mediis foeminae tibiis adest; tibiae posticae et maris et foeminae setis duabus, alterâ mediâ, alterâ subapicali, armatae. Tarsi foeminae nigri, simplices; primus omnium articulus articulis tribus sequentibus simul sumptis aequalis. Tarsi maris plerumque fusei apicem versus nigri, articulis primis saepe ferrugineis, raro toli nigri: metatarsus anticus articulis duobus sequentibus simul sumplis paullo brevior. Tegulae albae. Alae ex cinereo hyalinae, venis anterioribus subfuscis, posterioribus ex nigro-fuscis, venis longitudinalibus tertiâ et quartà apicem versus parallelis. - (Illinois, Distr. Columbia; Osten-Sacken.)

73. Trypeta sarcinata nov. sp. 오. Luten, dorso thoraris cinerascente punctis aliquot majusculis atris picto, scutello tumido, atro, bimammato, alarum fasciis quinque valde obliquis ex luteo fuscis, venis transversis valde approximatis. - Long. corp. $3 \frac{1}{4}$ lin. Loug. al. $3 \frac{1}{1} \bar{z}$ lin.

Ex affinibus Trypetae multifascialae. Caput magnum, flavum; frons lata; antennae flavae; facies modice concava; genae latiusculae, puncto obscuro, oculis contiguo notatae; oris apertura latior quam longior; proboscis et palpi breves. Thoracis dorsum cinerascens in disco puncta sex atra, opaca, in margine laterali maculas aliquot alras, nilidas habet. Sculellum tumidum, atrum, nitidum, lineâ medià Inteâ. depressâ, ita ut ex mammis duabus connalum appareat. Abdomen luteum, immaculatum; terebra abdomini concolor, qualuor ultimis segmentis simul sumplis longior. Pedes lulei. Alae fasciis 
quinque valde obliquis, ex luteo fuscis variegatae, fasciis tribus primis ad costam coniunctis, duabus ultimis a praecedentibus separatis, sed in anteriore alae dimidio in unam comnatis; venae transversae valde approximatae. - (Carolina; Zimmermann.)

74. Trypeta atra nov sp. $\sigma^{\top}$ et 오. Aterrima, nitida, capite, femorum apice, tibiis tarsisque favis, scutello tumido, alarum albido-hyalinarum macula basali fasciisque tribus latissimis ex fusro nigris, fasciis dubus primis antice conjunctis, postice late divergentibus, fascia apicali ab illis stparalâ. - Long. corp $1 \frac{5}{1 \frac{5}{2}}-1 \frac{1}{2}$ lin., Long. al. $1 \frac{1}{2}-1 \frac{7}{12} \operatorname{lin}$.

A Trypetâ polità, cui simillima, fasciis alarum non cinerco limbatis primisque duabus magis divergentibus, femoribus denique praeter apicem nigris differt. - Frons fulva, setis lateralibus utrinque duabus. Antennae flavae, basi setae incrassatâ. Facies albida. Genae albidae, maculi infra oculos ex fusco badiâ. Palpi breves, lati, pallide flavescentes, albido-pilosuli. Proboscis brevis. Thoracis dorsum atrum, laevigatum, setis ordinariis nigris setulisque raris albidis vestitum. Scutellum tumidum, atrum, laevigalum, setis quatuor praeditum. Abdomen breve, atrum, nitidum, pilis rigidis in segmentorum singulorum margine postico nigris, in reliqu". abdomine albis praeditum. Terebra atra, nigro-pilosa, conica, non compressa, tribus ultimis abdominis segmentis simul sunptis paullo longior. Pedes ex ferrugineo flavi, femoribus excepto lamen apice atris. Alae ex albido hyalinae, maculà magnà basali fasciisque tribus latissimis ex fusco nigris. non cincreo limbatis; fasciae duae primae antice coniunctae, a fascià tertiâ anguste separatae postice valde divergunt. - (NewYork; Collect. Winth.)

Trypelam in Brasiliâ degentem, et atrae et politae simillimam, hic describere liceat.

Trypeta nigerrima nov. sp. 오. Atra, nitida, lateralibus thoracis maculis utrinque binis velutinis, pleuris et fasciis aldominis albidopollinosis, capile flavo, pedibus ex ferrugineo flavis, femoribus posterioribus ex fusco nigris, alis hyalinis, maculì mugnù basuli fasciisque tribus latissimis, in margine antico connatis, nigris. - Long. corp. 2 lin, Long. al. $2, \frac{1}{2}$ lin.

Atra, nitida. Caput pallide flavescens, fronte obscurius flavà, selis frontalibus nigris. Antennae llavae, majusculae; articulus tertius oblongus, angulo antico acuto; seta subnuda, tenuis, basim versus non incrassata. Facies subplana, margine oris antico prominente Oruli ublongi Grnar: latiusculae, albido-pilosae, maculà subfuscâ notatae. () đí apurlura parva, 
75. Trypeta geminata nov. sp. ㅇ. Ex luteo cinerea, capite, thoracis margine laterali, scutello, abdominis dimidio basali, femorum apice, libiis tarsisque flavis, pleuris, metanoto, abdominis maculis et apice, terebrá femoribusque ex nigro fuscis; alae praeter basim fuscae, limpido gullatae, gultulis disci minutis rarissimis, gullis marginis postici majoribus, anguli axillaris confertioribus, maculis denique duabus costalibus trigonis limpidis. - Long. corp. 2 lin., Long. al. $2 \frac{1}{3}$ lin.

Caput pallide flavum. Frons lata, setis ordinariis subfuscis. Anteunae obscure flavae, articnli tertii angulo apicali subacuto, setà basim versus incrassatå. Facies modice concava. Oris apertura roI unda, proboscide brevi, non geniculatâ. Thoracis dorsum ex luteo cinereum, margine laterali flavo, setis ordinariis fuscis, pilis confertis prope humeros nigris, in reliquo thorace pallidissime flavescentibus. Pleurae ex nigro fuscae, pilis plerisque nigris. Metanotum ex nigro fuscum. Abdomen flavum quatuor macularum nigricantium seriebus notatum, maculis singulis in posterioribus segmentis maioribus et ita confluentibus, ut dimidium abdominis posterius fere totum colore nigro-fusco pictum sit; pili abdominis pallidissime subflavescentes, in maculis obscuris nigricantes. Terebra ex fusco nigra, depressa, duobus ultimis abdominis segmentis simul sumptis multo brevior.

rotundata; palpi latiusculi, pallide flavi, albo-pilosuli; proboscis brevis, non geniculata, fusca. Thoracis dorsum atrum, nitidum, praeter latera armeo splendens, maculis lateralibus utrinque duabus aterrimis velutinis, suturâ flavâ separatis notatum, setis ordinariis nigris et praeter vittas lalissimas denudatas pilis rigidis flavicantibus vestitum. Scutellum tumidum, atrum, nitidum, setis quatuor armatum. Netanotum atrum, fasciâ albo-pollinosâ ornatum. Pleurae álbido-pollinosae et albo-pilosae, puncto humerali et striolâ marginis superi atris opacis. Abdomen atrum, nigropilosum, pilis tamen segmenti ultimi plerisque albis; segmenta singula prater ultimum in margine postico albido-pollinosa. Terebra depressa, atra, tribus ultimis abdominis segmentis simul sumptis aequalis. Pedes ex ferrugineo flavi, femoribus posterioribus praeter imam basin et prae. ter apicem ex fusco nigris. Alae latiusculae, hyalinae, subalbicantes, maculà basali magna fasciisque tribus ad costam conjunctis nigris; fascia prima reliquis latior a stigmate ad venae longitudinalis sextae apicem ducta, secunda a stigmate per venas transversas ad marginem posticum decurrens, tertia inde a stigmate costam et apicem alae cingens, sed ita ut inter ipsum alae marginem et fasciam spatium angustum hyalinum, in cellulà submarginali nonuihil dilatatum et puncto nigro notatum, interjectum sit. Venae transversae approximatae, subobliquae; vena longitudinalis tertia setulis minutissimis armata. - (Brasilia; Collect. Winth.) 
Femora ex fusco nigra, antica selis longis nigris praedita; summus femorum apex, tibiae et tarsi flavi. Alae fuscae, limpido guttulatac. basi sublimpidâ; gutla maior in cellulae costalis apice, in stigmatis apice guttula minuta et pone stigma maculae duae costales trigonae. strigula fuscâ seiunctae conspiciuntur; discus alae gutlulis raris mịnu. tissimis aspersus; in angulo axillari et in cellulae posterioris terliae parte quae adiacel guttae confertiores, in marginis postici dimidio apicali guttae quatuor vel quinque maiores adsunt; summus alae apex angustissime limpido marginatus; vena longitudinalis terlia setulis praedita. - (Pennsylvania; Coll. Winth.)

76. Trypeta timida nov. sp. ठ大. Lutea, metanoto pleurisque ex nigro fuscis, alis nigro-reticulatis, in apice radiatis, gutlis disci pancissimis, pone venulam transversam unicâ, stigmate nigro prope apicem strigulam flavam includente, vená longitudinali tertia nudâ. - Long. corp. 2 lin., Long. al. $1 \frac{1}{1} \frac{1}{2}$ lin.

Cum Trypetâ bellâ et similibus cognata. Lutea; caput flarum. mediâ occipitis parte cinereâ. Frontis angustae setae ordinarite validae, pallide subfuscae. Antennae flavae, mediocres, setâ tenui subnudà. Facies concava, oris margine antico ascendente. Palpi breves. flavi; proboscis concolor, brevis, non geniculata. In thoracis durso vitta latissima media, obsolete subcinerascens cernilur; setae validae. subfuscae; tria setarum paria in medio thorace. Scutellum setis quatuor instructum. Pleurae obscure fuscae, polline albido cincrascentes, margine tamen supero et maculà subalari luteis. Melanolum pleuris concolor. Abdomen luteum, pilis lutescentibus setisurue ex luteo subfuscis vestitum. Pedes lutei, femorum anticorum selis pallide lutescentibus. Alae hyalinae, nigro-reliculatae, apice quinqueradiato; in disco inter venas longiludinales tertiam ef quartam guttae duae, altera ante, altera pone venulam transversam invenjunlur: in cellulâ discoidali guttae duac, infra venulam transversam et ad posticum cellulae marginem positae, adsunt; cellularum posteriorum tertiat guttâ basali gultisque quinque subapicalibus ornatur; in angulo axillari guftae quatuor obsoletiores exstant; sligma nigrum prope apicem strigulam flavam includit; pone stigma strigulae costales limpidae duae cuneatae, a radiis apicalibus alae longe distantes, strigulî nigrì separatae; vena longitudinalis tertia nuda. - (Mexico; Coll. Winlh.)

77. Trypeta abstersa nov. sp. ․ Ex luteo cinerea. capite, pleuris, scutello pedibusque flavis, abdomine obsrure luteo. pilis setulisque pallidis vestito, terebrâ brevi lutea, alarum dimidio basali 
obsolete cinereo retirulato, dimidio apicali maculà magnâ nigrâ, gutlulam costalem includente, radiosque duos ad costam, tres ad apicem et tres ad marginem posticum emittente, ornato, proboscide non geniculat $\hat{a}$. - Long. corp. $1 \frac{2}{3}-1 \frac{3}{4}$ lin., Long. al. $1 \frac{7}{1} \frac{1}{2}$ lin.

Ex affinibus Trypetae stellatae. - Caput flavum, antennis con. coloribus, setis ordinariis pallide fuscis, pilis omnibus albicantibus. Oris apertura magna, margine antico acuto. Proboscis brevis, non geniculata. Thorax ex luteo pallide cinereus, humeris, scutello pleurisque flavis, setis ordinariis pallide subfuscis, pilis omnibus albidis. Abdomen obscure luteum, apicem versus obsolete cinerascens, pilis setulisque omnibus albidis. Terebra lutea, duobus ultimis abdominis segmentis simul sumptis paullo brevior. Pedes flavi. Alae hyalinae; dimidium basale totum obsolete cincreo reticulatum; in dimidio apicali macula magna nigra ceruitur, guttulam costalem includens, radios duos obliquos ad costam, radios tres ad apicem et alteros tres ad marginem posticum emiltens. - (Amer. boreal.; Coll. Winth.)

78. Trypeta finalis nov. sp. $\sigma^{\top}$ et 9 . Obscure cinerea, capite pedibusque flavis, proboscide non geniculata, alis nigro reliculatis, fasciâ obliquâ a stigmate per venas transversas ad posticum alae marginem ductâ, maculâ subapicali costae contiguâ et maculâ minore apicali non reticulut is, stigmatis nigri basi dilute flavescente, venâ longitudinali tertiâ nudâ. - Long. corp. ' $z-2 \frac{3}{4}$ lin., Long. al. $2-2 \frac{1}{3}$ lin.

Obscure cinerea. Caput flavum, occipite fere toto fusco. Frons laetius flava, modice lata, selis ordinariis nigris. Antennae ex ferrugineo flavae, mediocres, antico articuli tertii angulo obtuso, selâ brevissime puberulà, basim versus paullo incrassatâ. Facies concava. Oculi rolundi; genae modice latae. Oris apertura magna, subrotunda, proboscide non geniculatâ palpisque brevibus. Thorax cinereus, polline et pilis brevissinis pallide flavescentibus, setis ordinariis nigris. Scutellum selis quatuor praeditum, cinereum, extremo apice flavo. Abdomen thoraci concolor, pilis pallide flavescentibus vestitum, margine segmenti ultimi, praecedentibus singulis longioris postico nigrosetoso. Terebra duobus ultimis abdominis segmentis simul sumptis nounihil longior, rufa, basi el apice nigris. Pedes ex rufo flavi. Alae longiusculae, hyalinae, colore ex fusco nigro reticulatae; gutlis limpidis fere omnibus maiusculis, confertis sed non confluentibus; fascia a sligmate oblique per venas transversas ad marginem posticum ducla, macula subapicalis costae contigua et macula minor in ipso alae apice sita guttis nullis perlusae; stigma nigrum, basi sublim- 
pidå pallide flavescente; vena longitudinalis tertia nuda. - (California; Agassiz.)

79. Lauxania albovittata nov. sp. +. Atra. opace, facie, frontis lateribus, thoracis vitlis scutellique margine albo-pollinosis; antennae fuscae, setâ pilis longis plumati: alue pallide subfusrae, adversus costam paullo obscuriores. - Loung. corp. $1 \frac{1}{2}-$ $1 \frac{7}{12}$ lin., Long. al. $1 \frac{1}{2}-1 \frac{7}{1 \frac{7}{2}}$ lin.

Alra, opaca. Frons declivis, utrinque vittà albo-pollinosì o1. nalá, viltâ mediâ obsoletiore fuscâ dividitur. Intennae ex rufo sul,fuscae, articulo tertio oblongo, setà nigrât pilis longis plumatì. Facies planiuscula, albo-pollinosa; clypeus modice prominens. Occiput albo-pollinosum. Thoracis dorsum aterrimum. opacum. vitlis quatuor integris polline albo oblectis ornatum. Seutelli atri margo albo-pollinosus. Pleurae atrae, viltis duabus albo-pollimosis variegatac. Abdomen nigrum, polline tenuissimo cinereo tectum, apicem versus subnitidum. Pedes alri. tibiarum basi albat. tarsis sordide al. bidis, apicem versus nigricantihus. Halteres albi. Alac dilule subfuscae. costam versus paullo obsruriores, basi concolore. - (Cuba; Gundlach.)

80. Scoliocentra helvola nov. sp. or et 7 . Pallide flara. marginibus segmentorum abdominalium posticis nigricuntibus. apicibus venarum longitudinalium. quae in alue apicem excurrunt. et venû transversâ posteriore fusco limbatis. - Long. corp. $4 \frac{1}{2}-5$ lin., Long. al. $4 \frac{1}{6}-4 \frac{1}{2}$ lin.

Pallide flava. Antennae luteae, setà tenui. elongatâ. brevissine puberulà. Oculi subrotundi, mediocres. Facies recedens. anlico, oris margine subobsoleto, setâ mystacinâ utrinque unicâ. T'horaris dorsum plerumque reliquo corpore paulo obscurius, selis infermediis in unare mullo subtilioribus quam in foeminat. Sculellum nudum Pleurarum dimidium inferius pilosmm, superius nudum. pilis tamen nonnullis minutis supra coxas anticas aspersum. Segmenta abolominis singula. primo tamen utriusque sexus et ullimo maris exceptis. postice nigro marginatis. Iypopygium parvum. Pedes toti pallide flavi. Alae lutescentes, venà transversì posteriore venarumpue in alae apicem excurrentium singularum fue distinctissime fusco limbatis. - (Illinois; Osten-Sacken.)

81. Anorostoma marginata nov. sp. J et q. Helra. rapite praeter frontem pedibusque totis pallide favis, alis dilute hel- 
volis, costâ, apice venisque transversis fusco limbatis. - Long. corp. $25-3$ lin., Long. al. $2 \frac{2}{3}-2 \frac{5}{6}$ lin.

Helva, opaca. Caput dilute flavescens, fronte luteâ. Facies infra valde recedens. Genae latissimae, subbnccatae. Oris apertura minuta, margine antico obsoleto, setà mystacinà utrinque unicâ, mediocri. Palpi parvi, pallide flavescentes. Oculi parvi, transverse ovati. Antennae parvae, subfulvac, articulo tertio subrotundo, setâ breviter puberulâ. Thoracis dorsum plerumque punctis sex octove fuscis, selas ordinarias ferentibus variegatum. Scutellum praeter setas ordinarias nudum. Pleurae obsolete subvitlalae et ante alas setam gerentes, praeterea nudae. Abdomen unicolor, hypopygio maris globoso. Pedes flavi, nitidi, pilis et setis nigris hirti, femoribus anticis posticisque crassioribus, praesertim in mare. Alae dilute helvolae, coslae dinidio secundo, apice venisque transversis fusco limbalis; setulae costales validae; vena transversa minor pone venae longitudinalis primae finem sita. - (English River; Kennicot.)

82. Blepharoptera pubescens nov. sp. ․ Ferruginea, fronte antennisque fulvescentibus, setâ antennarum subnudâ, thorace fusco villato, pleuris totis confertim nigro-pubescentibus, alis immaculatis. - Long. corp. $2 \frac{5}{6}$ lin., Long. al. 3! lin.

Ex fusco ferruginea, polline tenui subcinerascens. Frons fulva, antice lutea, triangulo verticali marginibusque lateralibus albido pollinosis. Antennae subfulvae, articulo tertio rotundo, maiusculo, setà longâ, tenui, subnudâ. Oculi rotundi; genae mediocres; seta mystacina utrinque unica valida. Thoracis dorsum viltis duabus angustis et lineâ interiectà mediâ, postice abbreviatâ fuscis. Scutellum praeter setas ordinarias nudum. Pleurae totae pube confertâ nigrâ vestitae. Abdomen ex fusco nigricans, apice ferrugineo, polline pallido cinerascens. Pedes ferruginei, tarsis ex nigro fuscis. Alae immaculatae, ex fusco cinereae, venis ex ferrugineo fuscis. (Massachusets; Scudder.)

83. Blepharoptera armipes nov. sp. ठ' et 9 . Cinerea, capite peditusque pallide favis, antennis fuscis, alis subhyalinis, setulis costae validis.

ऽ hypopygio flavo, femoribus posticis ante apicem pectinem setis circiler novem validissimis constructum ferentibus.

오 abdominis apice flavo, pedibus simplicibus.

Long. corp. $2 \frac{1}{2}-2 \frac{5}{6}$ lin., Long. al. $2 \frac{3}{6}-3$ lin.

Cinerea. Caput pallide flavescens, fronte obscuriore, superiore 
occipitis dimidio et vertice cinereis Antennae fuscae, articulis duobus primis plerumque ex fusco luteis, interdum luteis, articulo tertio rotundo, mediocri, setâ longâ, subnudà. Oculi rotundi, maiusculi; genae mediocres; seta mystacina utrinque unica valida. Thoracis dorsum immaculatum, praeter selas ordinarias rare nigro-pilosum. Scutellum subnudum, cinereum, margine pallide flavo, aut totum pallide flavom. Superius pleurarum dimidium nudum Abdomen cinereum, segmentis sexto et septimo in foeminà, hypopygio in mare pallide flavis. Pedes pallide flavi, tarsis p!erumque distincte iufuscatis, apicem versus interdum ex fusco nigris; pedes foeminae simplices; femora maris postica infra pectine e setis circiter novem va. lidis constructo armata, intermedia infra breviter spinulosa. Alae subhylinae, ex luteo subcinerascentes, immaculatae, setulis costalibus validis. - (Hudsons Bay Territory.)

84. Blepharoptera tristis nov. sp. ㅇ. Minuta, ex nigro cinerea, capile flavo, antennis ex fusco nigvis, setâ brevi subnudá, pedibus nigris, alis ex cinereo hyalinis, setulis costae raris et pau. cis. - Long. corp. $1 \frac{2}{3}$ lin., Long. al. $1 \frac{3}{4}$ lin.

Ex nigro cinerea. Caput flavum, occipite et vertice ex nigro cinereis. Antennae ex fusco nigrae, arliculis duobus primis fuscis. tertio rotundo, setà brevi, subnudâ. Oculi maiusculi rotundi; genae mediocres; facies infra recedens, setâ mystacinâ utrinque unicà mediocri. Pleurae et scutellum praeter setas ordinarias nuda. Pedes toti nigri. Halteres dilute flavescentes. Alae ex cinereo hyalinae. stigmate dilutissime subfusco, venis nigricautibus, selulis costae raris et parvis. - (Winnipeg; Kennicot.)

85. Allophyla laevis nov. sp. o et ㅇ Flava, nitida, antennis concoloribus, articulo tertio tamen in foemina infuscato, ultimo tarsorum articulo nigro, alis subhyalinis, immaculatis. - Long. corp. 2 lin., Jong. al. $2 \frac{1}{2}$ lin.

Flava, nitens. Frons laetius flava, opaca, superius utrinque laevigata. Antennae flavae, articulo tertio ovato, in foeminâ infuscalo, setî pilosâ. Oculi maiusculi rotundi. Genae angustae, albidae. Facies albida, setà mystacinâ utrinque unicâ tenui. Srulellum praeter sctas ordinarias nudum. Superius pleurarum dimidium omnino nudum, inferius rare pilosum. Pedes pallide flavi, extremo tarsorum articulo nigro tibiarunque posticarum apice interdum nigricante. Alae subhyalinae, ex luteo dilutissime subcinerascentes, venà transversâ 
posteriore obsoletissime subfusco limbatâ, setulis costae mediorribus, raris. - (English River; Kennicut.)

Nota. Allophylae nigricorni Meig. valde propinqua, vix nisi antennarum colore diver'sa.

86. Helomyza apicalis nov. sp. ㅇ. Flava, venis transversis venarumque longitudinalium apicibus distincte fusco limbatis, pleurarum dimidio superiore pilis aliquot minutis asperso, setâ antennarum breviter pubescente. - Long. corp. 3 lin., Long. al. $3 \frac{1}{1 \frac{1}{2}}$ lin.

Flava, opaca, colore thoracis et scutelli magis in latericium vergeute. Frons laetius flava. Antennae subfulvae, articulo tertio ovato, setâ breviter pubescente. Oculi maiusculi, subrolundi; genae mediocres; seta mystacina utrinque unica mediocris. Thoraris dorsum punctis minulissimis fuscis aspersum, punctis paulo maioribus subfuscis setarum intermediarum basim cingentibus. Scutellum praeter latera nudum. Pleurae subvittatae, in dimidio superiore pilos aliquot minutos gerentes. Margines segmentorum abdominalium singulorum postici nigricantes. Pedes lutescentes, fenorum posticorum apice tibiarumque omnium basi subfuscis, tibiarum apice fusco, ultimis tarsorum articulis nigris. Alae hyalinae, ex cinereo subfuscae, venarum longitudinalium apicibus venisque transversis distincte fusco limbatis, setulis costae mediocribus. - (District Columbia; OstenSacken.)

87. Helomyza assimilis nov. sp. ठౌ. Flava, costá, venis transversis apicibusque venarum longitudinalium distincte fusco limbatis, pleurarum dimidio superiore pilis nonnullis minutis asperso

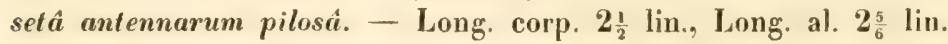

Flava, opaca, colore thoracis et sculelli magis in latericium vergente. Frons laetius flava. Antennae subfulvae, articulo tertio ovato, selà pilis longioribus hirtâ. Oculi mediocres, subrotundi; genae mediocres; sela mystacina utrinque unica mediocris. Thoracis dorsum punctis minutissimis fuscis aspersum, punctis in quibus setae mediae positae sunt maioribus. Scutellum pilosum. Plenrae subviltatae, in dimidio superiore pilos nonnullos minutos gerentes. Margo segmentorun abdominalium singulorum posticus plerumque nigricans, media abdominis segmenta interdum tota nigricantia. Pedes lutescentes, tibiarum posteriorum annulo subbasali obsoletissimo omniumque apice subfuscis, ultimis tarsorum articulis nigris. Alae ex fusco cinereae, costà, venarum longitudinalium apicibus venisque trans- 
versis distincte fusco-limbatis, selulis costae mediocribus. -- (Hudsons Bay Territory.)

Nota. Praecedenti valde similis, sed setâ antennarum pilis multo longioribus vestilâ certo distincta; ab Helom. nemorum, cui etiam similior, non differt nisi pilis setae antennalis paulo bre. vioribus et pallidiore totius corporis colore.

88. II elomyza plumata nov. sp. O et 오. Flava, venis transversis apiribusque venarum longitudinalium anguste fusco limbatis, pleurarum dimidio superiore omnino nudo, sculello rare piloso, apicem versus denudato, setâ antennarum pilis perlongis phumatâ. long. corp. $2 \frac{1}{6}-3$ lin., Long. al. $2 \frac{5}{1} \frac{5}{2}-3 \frac{1}{6}$ lin.

Flava, opaca, colore frontis, thoracis et scutclli plerumque magis in latericium vergente. Antennae sulphureae, articulo tertio ovato, setâ pilis longis plumalà. Oculi mediocres, rolundi; genae latiusculae; seta mystacina utrinque unica mediocris. Thoracis dorsum punctis minulissimis fuscis aspersum, punctis setas ordinarias ferentibus paulo maioribus. Scutelli dimidium basale rare pilosum, apicale nudum. Pleurae obsolete subvillatae, dimidio superiore plane nudo. Margo segmentorum abdominalium singulorum poslicus nigricaus Pedes pallide tlavescentes, tarsis apicem versus infuscatis. Alae subhyalinae, ex luteo cinerascentes, venis transversis venarumque longiludiralium apicibus anguste fusco limbatis, setulis costae rarioribus, mediocribus. - (New-York; Osten-Sacken.)

89. Helomyza latericia nov. sp. ot et . Flava, venis transversis venarumque longitudinalinm apicibus fusco limbatis, pleurarum dimidio superiore nuelo, scutello toto piloso, antennarum setâ pilis longis plumatâ. - Long. corp. $2 \frac{5}{1 \frac{1}{2}}-2 \frac{1}{2}$ lin., Long. al. $2 \frac{1}{2}-$ $2 \frac{7}{12}$ lin.

Flava, opaca, colore frontis, thoracis et scutelli plerumque magis in latericium vergente. Antennae fulvae, articulo tertio ovato, setî pilis longis plumatà. Oculi magni, ovali; genae angusfae; seta mystacina utrinque unica validior. Thoracis dorsum punctis minutissimis fuscis aspersum, punctis selas ordinarias ferenlibus paulo maioribus. Scutellum tolum pilosum. Plenrarnm dimidium superius omnino mudun. Margo segmenlorum abdominalium singulorum posticus niger. Pedes pallide flavi, extremo femorum posticorum apice fusco-notato, tribus ultimis tarsorum articulis nigris. Alae subhyalinae, ex luteo subfuscae, venis transversis venarumque longi- 
Indinalium apicibus fusco limbatis, setulis costae mediocribus. (Connecticut; Norton.)

Nota. Ad Helom. flavam Meig. prope accedit, sed quam illa maior est et thoracis dorsum atomis fuscis aspersum habet. Ab Helom. assimilis Meig. speciminibus immaturis, quibus colore similis est, venâ transversâ posteriore minus obliquâ distinguitur. - Helom. latericiam Helom. quinquepunctalam, a Sayo descriptam, esse crederem, nisi auctor antennas "quinquepunctatae" suae colore ex rufo fusco tinctas esse affirmaret. - Ab Helom. plumatâ haec nostra Helom. latericia oculis maioribus ovatis, genis angustioribus et scutello toto piloso differt.

90. Helomyza longipennis nov. sp. $ఠ$ et 오. Flava, alis subhyalinis, venis transversis angusle fusco-limbatis, pleurarum dimidio superiore, praeler pilos minulos tres quatuorve ante suturam, omnino nudo, dimidio inferiore, praeter pilos ordinarios nigros, pube tenuissimâ albidà vestito, setâ antennarum plumatâ. Long. corp. $3-33_{6}^{1}$ lin., Long. al. $3 \frac{2}{2}-3 \frac{1}{1} \frac{1}{2}$ lin.

Flava, opaca, colore frontis, thoracis et scutelli saepe magis in latericium vergente. Antennae fulvae, articulo terlio ovato, setâ pilis brevioribus quam in speciebus praecedentibus plumatâ. Oculi mediocres, rotundi; genae laliusculae; seta mystacina utrinque unica validiuscula. Thoracis dorsum punclis subfuscis, propter parvitatem obsoletissimis aspersum, punctis setas ordinarias ferentibus distinctioribus. Scutellum totum pilis rarjoribus vestitum. Pleurarum dimidium superius, praeter pilos minutos tres quatuorve ante suturam positos, nudum; dimidium inferius pube subtili pallidà pilisque ordinariis nigris vestitum. Segmentorum abdominalium singulorum margo posticus plerumque nigricans, interdum latius niger. Pedes pallide flavi, tarsis apicem versus infuscatis, rarius articulis tribus ultimis ex fusco nigris. Alae maiusculae, subbyalinae, ex luteo cinerascentes, venis transversis anguste fusco-limbatis. - (New-York; Osten-Sacken.)

Noła. A Meigenii Helom. olente, cui propinqua, setâ antennarum plumatâ separatur.

91. Diplocentra helva nov. sp. $\delta$ et 오. Helva, facie albidâ, abdominis lineâ mediá et vittâ utrinque laterali maculis segmentorum singulorum angulatis compositâ fuscis, lateralibus thoracis marginibus praeter setas nudis. pleuris subnudis, alis ex luteo 
subfuscis, venâ transversâ posteriore fusco limbatâ. - Long. corp. $2_{6}^{5}-3$ lin., Long. al. $3-3 \frac{1}{6}$ lin.

Helva. Frons lutea, triangulo ocellari et viltis setas ferentibus polline pallide ochraceo tectis. Antennae luteae, articulo tertio interdum subfusco. Facies ex flavo albida, setis mystacinis minutis. Palpi flavi. Thoracis dorsum pilis validis scabrum, margine laterali praeter setas nudo; breves pleurarum pili rarissimi. Abdominis segmentum secundum utrinque maculam ovatam, sequentia singula vittulam mediam postice abbreviatam et utrinque maculam angulatam habent, ita ut abdomen fusco trivittatum sil; anguli laterales antici singuli segmentorum nigri. Pedes pallide flavescentes. Alae ex luleo subfuscae, venâ transversâ posteriore anguste fusco-limbatà, venis longiludiualibus secundâ, tertià et quarłâ apicem versus divergentibus. - (North Red River; Kennicot.)

92. Psilopa nobilis nov.sp. $\sigma^{7}$. Nigro-viridis, fronte alrâ, puncto frontali albo, primis duobus antennarum articulis nigris, tertio rufo, facie pallide ochracea, femoribus nigris, tibiis tarsisque flavis, hypopygio albido, perlongo. - Long. corp. $1 \frac{1}{3}$ lin., Long. al. $1 \frac{5}{12} \operatorname{lin}$.

Frons atra, opaca, supra antennas puncto albo ornata. Dno primi antennarum articuli nigri, tertius rufus, angulo apicali subacuto. Facies angusta, pallide ochracea. Genae angustissimae. Palpi flavi. Thoracis dorsum et scutellum nigro-viridia, modice nitida. Abdomen aeneo-nigrum, latera versus albo-pollinosun, s gmento ultimo chalybescente. Hypopygium perlongum, theca albidâ, pene nigro. Pedes flavi, femoribus praeter apicem nigris. Halleres sulphurei. Alae limpidae. - (Distr. Columbia; Osten.Sacken.)

93. Amiota humeralis nov. sp. ㅇ. Atra, nitida, facie totû, humeris et maculâ subalari niveis, pedibus pallide flavis. - L Long. corp. $1 \frac{1}{2}$ lin., Long. al. $1 \frac{1}{2}$ lin.

Simillima Amiotae alboguttatae Wahlb, sed robustior et facie totâ niveâ distincta. - Atra, nitida, breviter ferrugineo-pilosa. Frontis dimidium superius nigricans, inferius sordide albicans. Anteunae fuscae. Genae angustissimae, pallide flavae. Clypeus niger. Humeri nivei. Pleurae sub alarum basi maculâ nivea orualae. Pedes pallide flavi. Alae subhyalinae, venis longitudinalibus tertiâ et quarlả apicem versus convergentibus. - (District Columbia; Osten-Sacken.) 
94. Amiota leucostoma nov. sp. ․ Ex ferrugineo rufa, facie, humeris pleurarumque maculá subalari candidis, abdominis apice segmentorumque praecedentium singulorum dimidio basali atris. - Long. corp. $1 \frac{7}{1} \frac{7}{2}$ lin., Long. al. $1 \frac{2}{3}$ lin.

Frons ex ferrugineo rufa, opaca. Antennarum articuli duo primi fronti concolores, tertius fuscus. Facies candida. Thoracis dorsum ex ferrugineo rufum, subnitidum, polline tenuissimo flavicante aspersum; humeri candidi. Sculellum magnum thoraci concolor. Pleurae ex ferrugineo rufae, sub alis maculâ candidà ornatae. Abdomen latiusculum, apice tumido, segmentis duobus ultimis totis, duorum praecedentium dimidio basali et secundi maculis lateralibus atris. Pedes pallide flavicantes. Halteres albi. Alae lutescentes, immaculatac, venis longitudinalibus tertiâ ef quartâ convergentibus. - (Pennsylvania; Osten-Sacken.)

95. Drosophila dimidiata nov. sp. ․ Supra atra, infra alba, abdomine albo et atro variegato, alis subcinereis, puncto costali atro. - Long. sorp. 1 lin., Long. al. $1 \frac{1}{6}$ lin.

Frons atra, praeter triangulum ocellare et praeter vittulas a verticis lateribus decurrentes opaca. Antennae nigrae. Facies cum clypeo atra, dimidio superiore ex fusco nigro. Occiput atrum; proboscis et genae albae. Thoracis dorsum atrum, nitidum; scutellum concolor, sed opacum. Pectus album. Abdominis segmentum primum maximà ex parte nigrum; segmenta tria sequentia alba, margine laterali et fasciâ singulorum posticâ late interruptâ atris; segmenta duo ultima alba, nigro trimaculata. Pedes albi. Halterum pedunculus albidus, capilulum nigrum. Alae ex flavo subcinerascentes, in apice segmenti costalis primi puncto atro notatae. (Illinois; Le Baron.)

96. Drosophila amoena nov. sp. o et 오. Rufescens, ab. domine alro, pectore pedibusque dilutissime flavicantibus, alis subhyalinis, maculis duabus transversis fuscis, alterâ discoidali majore, alterá subapicali minore, apice ipso albo. - Long. corp $1 \frac{1}{4}$ lin., Long. al. $1 \frac{1}{2}$ lin.

Frons flava, margine laterali albido-pollinoso. Antennae flavae, articulo tertio saepe subinfuscato. Genae angustae et facies albo. pollinosae. Thoracis dorsum et scutellum rufescentia, modice nitida; plearae paulo pallidiores. Abdonen angustum, alrum, nitidum, basi tamen refescente. Pedes pallidissime flavicanles. Halteres albidi. Alae ex cinereo subhyalinae, apice albo, maculis duabus transversis fuscis, alterâ discoidali majore, alterâ subpicali minore, sub- 
fasciałae, venis longitudinalibus terlià et quartâ modice convergentibus. - (District Columbia; Osten-Sacken.)

97. Drosophila tripunctata nov.sp. ․ Pallide testacea, infra sordide albida, tertio antennarum articulo subfusco, segmentorum abdominalium marginibus poslicis atris, alarum venis transversis apicibusque venarum longitudinalium anguste nigro limbatis - Long. corp. $1_{\frac{1}{1}}^{\frac{1}{2}}$ lin., Long. al. $1 \frac{1}{3}$ lin.

Pallidissime testacea. Frons flava, opaca. Antennarum articuli duo primi flavescentes, tertius subfuscus. Seta antennarum radiis longissimis plumala. Facies nasuta. Abdominis segmenta singula praeter ultimum fasciâ posticâ atrâ marginata, quae in segmentis posticis in lineam longitudinalem mediam dilaiatur. Pleurae et pedes ex flavo sordide albicantes. Alae ex luteo cinereae, venis Iransversis venarumque longitudinalium apicibus anguste nigro limbatis, ita ut in margine apicali puncla tria minuta nigra conspiciantur; venae longitudinales tertia et quarta parallelae. - (Washington; OstenSacken.)

98. Drosophila adusta nov. sp. ठ大 et P. Pallide testacea, saepe subbadia, thoracis viltis duabus latissimis et limbo laterali albido-pollinosis, abdominis apice atro, alis subcinereis, maculà api-

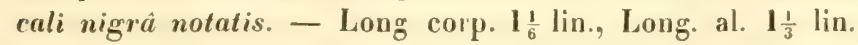

Drosophilae graminum Fall. similis et affinis. Frons flava, limbo laterali lato albido-pollinoso. Antennae pallide testaceae, articulis duobus primis interdum supra et articulo tertio in basi subfuscis. Facies alba; setulae mystacinae et quae in palporum apice cernuntur validiusculae. Color thoracis et scutelli in immaturis testaceus, in maturis subbadius; in thoracis dorso vittae duae latissimae et margines laterales polline albo teguntur, ita ut vitlae tres obscuriores, aequales et integrae appareant. Pleurae pallide flavicantes. Abdomen pallide testaceun, segmento ultimo atro, segmento penultimo plerumque, praesertim in mare, utrinque maculá permagnâ atrâ variegato; in speciminibus quibusdam masculis ultima tria abdominis segmenta fere tota alra. Pedes dilutissime llavicantes, larsis anticis et extremo posteriormu apice subfuscis. Alae ex luteo subcinerascentes, maculâ minutà nigrî̀. in venae longitudiualis terliae fine sità; venae longiludiuales tertia et quarta parallelae. - (Washington; Osten-Sacken.)

99. Drosophila ampelophila nov. sp. O et + . Ex favo mefescens, antennis pallidis, abdomine nigro-fascialo, segmentis ul- 
timis duobus in mare, ultimo in foeminâ atris, puncto apicali atvo in antico maris metalarso, alis omnino immaculatis. - Long. corp. $\frac{3}{4}-\frac{5}{6}$ lin. Long. al. $\frac{5}{6}-\frac{1}{1} \frac{1}{2}$ lin.

Frons flava, opaca. Antennae pallide flavae, articulo tertio nonnumquam subfusco. Facies nasuta, flava, setulis mystacinis utrinque compluribus validiusculis, praesertim in foeminâ. Thoracis dorsum ex flavo rufescens, unicolor, modice nitens. Scutellum thoraci concolor. Pleurae pallidiores. Abdomen ex flavo rufescens; segmenta singula fasciâ posticâ nigrâ, in mediis segmentis nonnibil dilatałâ cingunlur; duo ultima segmenta in mare atra, in foeminâ ultimum alrum sive obscure fuscum. Pedes flavescentes; metatarsus maris anticus in apice supra tuberculum minutum atrum habet. Alae breves, latiusculae, ex cinereo sublutescentes, prorsus immaculatae, venis transversis inter se non remotis. - (Cuba; Poey.)

Nota. Drosophila ampelophila in Europae regionibus meridianis frequentissima nec Europae mediae plane aliena etiam in meridianis Africae partibus habitat.

100. Drosophila punctulata nov.sp. $\sigma^{7}$ et 9 . Fusca. thorace cinerascente, opaco, punctis fuscis asperso, fasciâ basali segmentorum abdominalium singulorum interruptá pallidá, alis subcinereis, immaculatis. - Long. corp. $1 \frac{1}{3}-1 \frac{5}{12}$ lin., Long. al. $1 \frac{1}{2}$ lin.

Frons fusca, opaca, Iriangulo ocellari magno vittulisque a verticis lateribus decurrentibus cinereo-pollinosis et obsolete fusco maculatis, margine antico subalbicante. Antennarum articuli duo primi testacei, supra infuscati, articulus terlius fuscus. Facies nasuta, carinâ ipsâ sulcatà. Genae unediocres. Thoracis dorsum polline cinereo opacum, punctis confertis fuscis aspersum. Scutellum thoraci concolor, practer puncta setas ordinarias ferentia impunctatum. Pleurae fuscac. Abdomen saturatius fuscum, subnilidum, segmentis singulis iu basi fasciâ interruptâ pallidà variegatis, adiectâ in speciminibus quibusdam lineâ pallidâ longitudinali. Pedes dilutissime testacei, femoribus anticis, femorum posteriorum apice tibiarumque posteriorum basi saepe subfuscis. Alae ex cinereo sublutescentes, immaculatac, segmenti costalis primi apice nigro, venis transversis non longe inter se distantibus, venis longiludinalibus tertiâ et quartâ apicem versus parallelis. (Cuba; Poey.) 


\section{Diptera Americae septentrionalis indigena.}

Descripsit

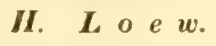

C e nt uriatertia.

1. Dixa marginata.

2. - terna.

3. - centralis.

4. notata.

5. - fusca.

6. Rhachicerus obscuripennis.

7. - varipes.

8. Xylophagus lugens.

9. Sicbula pallipes.

10. Nemotehes crassus.

11. unicolor.

12. - canadensis.

13. - acutirostris.

14. Oxycera centralis.

15. - unifascialu.

16. I'achygaster pulcher.

17. Leptis dimidiata.

18. Phthiria sulphurea.

19. - notata.

20. Sericomyia chalcopyga.

21. Sphegina lobala.

22. - rufiventris.

23. - infuscate.

24. Baccha lugens.

25. - capilata.

26. - obscuricornis.

27. - rognala.
28. Empis picta.

29. - poplitea.

30. - leplogastra.

31. Rhamphomyia incompleta.

32. Hilara macroptera.

33. - lutea.

34. Synampholera bicolor.

35. Phoneutisca bimaculata.

36. Platypalpus discifer.

37. - debilis.

38. - mesogrammus.

39. Cordylura terminalis.

40. - bimaculata.

41. adusta.

42. pleuritica.

43. - confusa.

44. - setosa.

45. - angustifrons.

46. - flavipes.

47. - cincta.

45. - cornula.

49. - gilvipes.

50. Hydromyza confluens.

51. Scoliocentra fraterna.

52. Blepharoptere lutcu.

5.3. - lencostoma.

51. Palloptera terminalis. 
55. Palloptera jucunda.

56. Supromyza rolundicornis.

57. umbrosa.

58. sticlica.

59. Dirastata eluta.

60. Drosophila terminalis.

61. Crassiseta formosa.

62. - costata.

63. - nigriceps.

61. - longula.

65. - nigricornis.

66. Gaurax festivus.

67. Hippelates nobilis.

68. - plebejus.

69. Oscinis pallipes.

70. - nudiuscula.

71. - flaviceps.

72. - dorsalis.

73. - umbrosa.

74. - alriceps.

75. - hirla.

76. - decipiens.

77. - longipes.
78. Oscinis subvillata.

79. - variabilis.

80. - trigramma.

81. Siphonella cinerea.

S2. Chlorops fossulala.

8.3. - sulphurea.

84. - sanguinolenta.

S5. - eucera.

86. - variceps.

87. - trivialis.

88. - - pubescens.

89. - crocol $\alpha$.

90. - obscuricornis

91. - melanocera.

92. - grata.

93. - unicolor.

94. - quinquepunclata.

95. - Sallbergii.

96. - producta.

97. - versicolor.

98. Odontocera dorsalis.

99. Phytomyza Ilicis.

100.

Clemalidis.

1. Dixa marginata nov. sp. \&. Pallide fava, villis thoracis rufescentibus, abdomine sordide subfusco, alis angustis, in dimidio anteriore fuscis, in posteriore cinereis, in venae pacnullimae

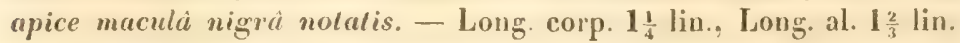

Caput flavum, proboseide palpisque pallidioribus. Antennae ni. gricantes, scapo et imâ flagelli basi flavis. Thorax flavus, solitis dorsi viltis rufescentibus, rufo in ferrngineum vergente circumseriptis, plemris obsolete fusco-maculalis. Scutellum flavum, ferugineobivitlatum. Abdomen sordide subfuscum, ventre dilute flaveseente. Pedes flavi, summo femorum apice nigro. Hallerum capilulum ex fusco nigrum. Alae angustae, ex fusco cinereae, dimidio :nteriore fusco, venis tamen apici propinquioribus cinereo-limbatis, cellulì costali interiore sublimpidâ, exteriore obscure fuscâ, celluli marginali luteâ, postico alac margine in renac pacultima fine macula minutî nigrâ nolato. - (District Columhia: Osten-Sarken.) 
2. Dixa terna nov. sp. $\sigma$. Capite cum antennis et palpis nigro, horum basi et proboscide favis, thorace cum scutello flavo, solitis dorsi viltis atris, opacis, villâ pleurarum latissimâ nigri, melanolo nigricante, abdomine ex fusco nigro, halleribus pedibusque pallide flavis, alis ex cinereo hyalinis, immaculatis. - I.ong. corp. $1 \frac{1}{4}-1 \frac{1}{3}$ lin., Long. al. $1 \frac{2}{3}-1 \frac{3}{4}$ lin.

Caput nigrum, antennis totis palpisque concoloribus, horum basi et proboscide flavis. Thorax flavus, subopacus, vittis tribus atris, opacis pleurarumque vittâ latissimâ nigrâ. Scutellum thoraci concolor; metanotum nigricans. Abdomen ex fusco nigrum, forcipe magno concolore, articulo terminali flavo. Pedes flavescentes. cxtremo femorum libiarumque apice fusco vel nigro, tarsis fuscis. Halteres ex albo flavicantes. Alae ex cinereo hyalinae, venis fuscis; veuae primae finis bạsi alae quam inilium tertiae propinquior; furculae anterioris pedunculus perbrevis; venula transversa media umbrâ vix obsolelissimâ circumfusa. - (New-York; Osten-Sacken.)

Nota. A Dixâ recenti Walk. vitlâ pleurarum latissimâ nigrầ differt.

3. Dixa centralis nov. sp. ठ大. Tota ex fusco nigra, tho. racis dorso praeter viltas solitas atras flavo, halteribus pedibusque sordide flavicantibus, coxarum basi, femorum tibiarumque apice tarsisgue ex fusco nigris, alis hyalinis subcinerascentibus, coeruleo et violaceo splendentibus, venis obscure đuscis, venulà transversá mediâ et pedunculi anterioris busi late fusco-limbatis. - Long. corp. $1 \frac{1}{3}$ lin., Long. al. $1 \frac{3}{4}$ lin.

Caput nigrum, antennis, proboscide palpisque concoloribus. Thorax niger, pleuris, scutello et metanoto concoloribus, dorso praeter vitlas solitas atras pallide flavo. Abdomen ex fusco nigrum, hypopygio concolore. Pedes flavescentes, coxarum basi, femorum tibiarumque apice et tarsis ex fusco nigris. Alae hyalinae, subcinerascentes, colore coeruleo et violaceo resplendentes, venis obsenre fuscis; vena prima ubi tertia oritur in costam excurrens; furculate an. terioris pedunculus quam furcula ipsa vix brevior; furculae secundae pedunculus longitudinem furculae valde excedens; vena transversa media et basis pedunculi anterioris late fusco-limbatae. (New.York; Osten-Sacken.)

Nota. Num species hic descripta Dixa nova Walkeri sit, ex im. perfectâ descriptione hujus dijudicare nequeo. 
4. Dixa notata nov. sp. ㅇ․ Capile cum antennis et palpis nigro, horum basi et proboscide flavis, thorace cum sculello flavo, solilis dorsi villis atris opacis, lotâ pleurarum villà nigrâ, metanoto nigricante, abdomine fusco, halteribus pedibusque pallide favis, alis ex cinereo hyalinis, venula transver'â mediâ subfusco-limbatâ. - Long. corp. $1 \frac{1}{3}$ lin., Long. al. $1 \frac{3}{4}$ lin.

Caput nigrum, antennis tolis palpisque concoloribus, basi lmorum et proboscide flavis. Thorax flavus, subopacus, vittis tribus atris opacis, pleurarum vittâ latissimâ nigrà. Scutellum thoraci concolor'; metanotum nigricans. Abdomen obscure fuscum. Pedes llavescentes, summo femorum tibiarumque apice fusco vel nigro. tarsis fuscis. Halteres ex albo flavicantes. Alae ex cinereo hyalinac, venis fuscis; venae primae finis basi alae quam initium tertiae propinquior; furculae anterioris pedunculus mediocris; venula trans. versa media subfusco-limbata, ita ut macula dislincla appareat. (Maryland; Osten-Sacken.)

Nota. IIane Dix. ternae focminam esse judicarem, nisi furculae anterioris pedunculus in omnibus hujus speciminibus longior quam illius esset.

5. Dix a fusca nov. sp. $\sigma^{7}$ et ․ Tota obscure fusca, peclore infimo, coxis, femorum hallerumgue basi semper, metanolo el scutello interdum dilute flavicantibus, alis ex fusco dilute cinereis, im-

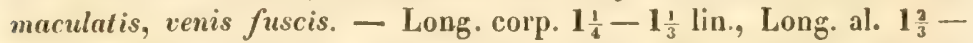
$1 \frac{3}{4} \operatorname{lin}$.

Caput nigrum, antennis, proboscide palpisque concoloribus. Thorax ex nigro fuscus, subnitens, scutello et metanoto in nonmullis, pleurarum parte inferiore in speciminibus omnibus pallide flavicantibus. Abdomen ex nigro fuscum, basi ventris pallidâ. Coxae dilute flavescentes. Pedes fusci vel subfusci, femoribus basim versus pallide flavescentibus. Halterum pedunculus subflavescens, capitulum ex nigro fuscum. Alae subhyalinae, ex fusco diluto cinerascenles, immaculatae; venae fuscae; finis primae basi secundae oppositus; furcula anterior duplicem pedunculi longitudinem paulo superans, posterior quam pedunculus multo brevior. - (New-York; Osten-Sacken.)

6. Rhachicerus obscuripennis nov. sp. ơ et . Ex nigro piccus, abdomine nigro, antennis in utroyue sexu pectinatis, pedibus favis, posticorum femoribus praeter basim tibiarumque apicem nigris, alis nigro-nebulosis, foeminae quam maris obscurioribus. -

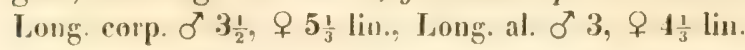


Mas. Caput atrum, nitidum, fronle supra antenuas albo-polli. nosâ. Articuli antennarum nigrarum, nisi fallor, viginti et septem, arliculi flagelli infra appendicibus perlongis ochraceis instructi. Palpi flavi. Proboseis nigra. Thorax subnudus, ex piceo niger, humeris, villis dorsi sublateralibus maculisque pleurarum piceis. Sculellum lhoraci concolor. Abdomen nigrum, pube brevi ex ferrugineo fuscî, in segmentis posticis nigrâ praeditum. Coxae posteriores subfuscae; coxac anticae pedesque pallide flavi, femoribus posticis praeler basim et apicale tibiarum posticarum dimidium ex piceo nigricantibus. IJalleres flavi. Alae cinerascentes, cellulis costalibus et marginalihus, venarum transversalium limbis et apice alae nigro-infumalis.

Foemina. Similis mari, sed obscurior et major, antennis bre. vius pectinatis, flagelli appendiculis quinque primis ochraceis, reliquis nigris, pube abdominis nigrå breviore, femoribus anterioribus plermmque badiis et alis quam maris multo obscurioribus. - (Illinois; Osten-Sacken.)

Nota. A Rhachicero ruficolli Hal. thorace obscuriore, femoribus tibiisque pedum posticorum magnâ ex parte nigricantibus, alis obseurioribus et antennis in utroque sexu pectinatis facile di. stinguitur.

7. Rhachicerus varipes nov. sp. $\sigma$ el 오. Niger, humeris et laterali thoracis margine testaceis vel piceis, antennis nigris, maris pectinatis, foeminae simplicibus, pedibus nigris, tibiis anticis totis, intermediis praeler apicem, posticisque in basi albis, metatarsis omnibus albis, in apice nigris, alis nigro-nebulosis. - Long. corp. đ' 3 , \& $3 \frac{3}{4}$ lin., Long. al. ơ 3 , ㅇ $3 \frac{1}{3}$ lin.

Il as. Caput nigrum, nitidum, occipite et anticâ frontis fasciâ cinereis, opacis. Antennae ex fusco nigrae, flagello infra perlongis arliculorum singulorum appendicibus pectinato. Thorax sordide testaccus, disco dorsi nigro, pleurarum maculis piceis. Scutellum nigrum, margine sordide testaceo. Abdomen nigrum, postico segmentorum singulorum margine angustissimo albido, triente postico pube albidâ, brevi sed confertâ veslito. Coxae piceae. Pedes nigricantes, interdum picei; tibiae auticae totac, intermediac praeter apicem, posticae in basi albae; metalarsi omnes, apice excepto, albi; calcaria tibiarum anteriorum alba, posticarum nigra. Alae ex cincreo subhyalinae, cellulae costalis apice, celluli marginali practer basim, venarum transversalium limbis el apicali alarum triente toto nigro-iufumalis.

Focmina. Major quam mas el obscurior. Antennac simpli- 
ces. Thorax praeter humeros et anticum marginem niger, pleuris coxisque ex piceo nigris. Pedes albo et nigro varii. Alae multo obscuriores quam maris, cellulis costalibus totis nigricantibus. (Cuba; Gundlach).

8. Xylophagus lugens nov. sp. ․ Totus ater, antennis, palpis pedibusyue concoloribus, thorace cinereo linealo, trochanteribus, genibus et imâ tarsorum basi dilute testaceis, apicali alarum dimidio nigro-maculalo. - Long. corp. 5 lin., Long. al. $4 \frac{1}{3}$ lin.

Totus ater. Occiput et superius frontis dimidium opaca; antennae et palpi atri; proboscis ex fusco nigra. Thoracis dorsum cinerco-pollinosum, ita ut capite lumini adverso lineae tres albidae, a lumine averso vittulac duae late distantes et postice valde abbrevialae appareant. Scutellum nigrum, praeter margines cinereo-pollinosum. Abdomen alrum, nilidum. Pedes atri, coxis anticis totis coxarumque postcriorum apice, trochanteribus, imâ femorum basi, genibus tarsorumque basi dilule testaceis vel ex albido flavicantibus. Halleres sordide flavicantes. Alarum dimidium basale subhyalinum, cellulis costali totâ et apicali praeter maculam subapicalem dilute fuliginosis, dimidio apicali nigro, discis cellularum subhyalinis. (Illinois.)

9. Śubula pallipes nov. sp. $\sigma^{7}$ et ․ Nigra, antennarum lateribus adversis prope basim, palpis, proboscide, lineâ thoyacis laterali, sculello, coxis pedibusque, halteribus marginibusque posticis segmentorum abdominalium singulorum favis, alis immaculatis. Long. corp. $2-3$ lin., Long. al. $2 \frac{1}{3}-2 \frac{1}{1} \frac{1}{2}$ lin

Nigra, pube brevi, in capite et thoracis dorso paulo confertiore, albidà vestita. Antennae nigrae, primo laterum adversorum dimidio flivo. Proboscis cum palpis flava. Vitlula thoracis lateralis flava, inde ab humero usque ad basim alarum pertinens. Sculellum flavum, angulis extremis nigris. Abdomen nigrum, maculâ basali segmentorumque singulorum marginibus posticis flavis. Hypopygium maris flavum. Venter aut tolus flavus, aut piceus, posticis segmentorum marginibus flavis latis, aut nigrum, marginibus flavis angustis. Coxae pedesque flavi, extremo femorum posticorum apice nigro, tarsorum apice subinfuscato. Alae subhyalinae, venis ex luteo fuscis. - (Illinois, Wisconsin; Osten-Sacken.)

Nota. Subulae marginatae valde affinis et similis, sed antennarum, coxarum tarsorumque colore dislincta. 
10. Nemotelus crassus nov. sp. ․ Pbesus, ex viridi ater, subaeneus, fronte immaculati, antennis nigris, arliculi secundi apice testaceo, laterali thoracis lined, genibus, libiis anticis larsisque omnibus dilute favescentibus. - Long. corp. $2 \frac{1}{2}$ lin., Long. al. 2 liin.

Crassinsculus. nudus, nilidissimus, ex viridi aler, colore in anleviore fronlis parte et in facie in chalybenin magis quam in viridem vergonte. Frons lata, immaculata. Antemate nigrae, arliculi secundi apice ex fusco flavo vel testaceo. Facies in conum majusculum aculum producla. Laleralis thoracis linea dilute flavescens. temossima. Femora atra, apice tamen flavescente; libiac anticas tofac, posteriores in basi latius et in apire angustius flavescentes, parle iulorjecti alrâ; tarsi dilule flavescentes. Halleres albi. Alac albidac, venis temuioribus concoloribus, validioribus, ex albo dilutissime lavescentibus, cellula sulimarginali concolore opaci. - (RhodeIsland )

Nola. Corporis partes, quae in hoc el duobus sequentibus flitvicaut, in vivis allas esse suspicor.

11. Nemotelus unicolor nov. sp. Y. Nudus, nilidus, ater: antannis concoloribus, fronte immaculata, laterali thoracis lineid temissima flavicante. femoribus yraeter apicem flarescentem aris, tibiis anterioribus subfuscis, posticis atris, basi et extremo omminm apice flavescentibus. - Jong. corp. $1 \frac{3}{4}$ lin.. long. al. $1 \frac{2}{3}$ lin.

Nudus, nitidus, ater. Frons immaculata. Antemae nigrae. Facies in conum majusculum acufum producta. Isateralis thoracis linea dilute flaveseens, tenuissima. Tibiac posticae el femora atra. apice horum illarumgue basi el apice flavescentibus; tibiac anteriores subfuscac, in basi Jatius. in apice angustius flavescentes. interdum totae dilute flavescentes; larsorum flavescentium articulis duobus ultimis nommmquam infuseatis. IIalteres albidi. Alac albidac. venis validioribus dilutissime subflavescentibus. - (Illinois; Le Baron.)

12. Nemotelus cancelensis nov. sp. of et Q. Prube lrevi albidi restitus, nilens. ex viridi niger, suluenens, anlennis nigries, laterali thoracis lined angustissima, femornm apice, libiis praeler medium posticorum annulum tarsisque favescentibus;

o oculis contiguis, antico frontis triangulo flavescente, furcie acuminuli

of fronte lala, atrinque puncto flarescente, interdum subobsoleto notati., facie aculit.

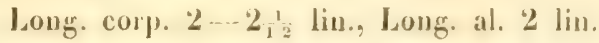


Pube albidâ brevi et subtili vestitus, nitens, ex viridi niger, subaenescens. Caput concolor. Oculi maris contigui, oculi foeminae in fronte late sejuncti. Maris triangulum frontale anterius supra dilute flavescens, foeminae frons utrinque puncto laterali dilute flavescente notata. Facies maris in conum mediocrem acuminatum, foeminae in subacutum producta. Lateralis thoracis linea ex albo flavescens, tenuissima. Abdomen lineâ tenui sordide flavescente, interdum obsoletâ marginatum. Femora nigra, in apice flava; tibiae flavae, posticae annulo nigro circumcinctae; larsi flavi, articulis ultimis haud raro infuscalis vel nigricantibus. Halteres albi. Alae albidae, venis validioribus dilute flavescentibus, cellulâ submarginali plerumque concolore. - (Hudsons Bay Territory, Fort Resolution; Kennicot.)

13. Nemotelus acutirostris nov. sp. ㅇ. Niger, nitens, pube tenui allidâ vestitus, fronte utringue puncto albo notat $\hat{a}, f a-$ cie in conum perlongum acutissimum product $\hat{a}$, laterali thoracis li$n e \hat{A}$, margine abdominis tribusque macularum paribus albis, pedibus albidis, basali femorum dimidio nigro. - Long. corp. $1 \frac{1}{2}$ lin., Long. al. $1 \frac{1}{2}$ lin.

Niger, nitens, pube brevi et subtili albâ vestitus. Caput concolor, fronte utrinque puncto albo notatâ, facie in conum perlongum acutissimum, supra plerumque fuscum productâ. Antennae nigrae, primis duobus articulis fuscis, rarius ex fusco testaceis. Thoracis punctum humerale et linea lateralis tenuissima alba. Margo abdominis albus, segmenta secundum, tertium et quartum singula maculis duabus oblongis albis, margini postico contiguis variegala. Venter plerumque albus, interdum limbo laterali segmentisque posticis tolis fuscis vel nigricantibus. Pedes albidi, femoribus plerumque praeter apicem atris, interdum eliam in basi sordide albicantibus; tibiae posteriores, basi et apice tamen exceptis, haud raro subinfuscatac. Alae albidae, venis validioribus dilute flavescentibus. (Cuba; Gundlach.)

14. Oxycera centralis nov. sp. ㅇ․ Atra, nitida, antennis nigris, facie, genis et inferâ orbitae oculorum posticae parte albomicantibus, proboscide, frontis maculis duabus obliguis duabusque orbitae posticae elongatis, thoracis lineis duabus dorsalibus abbreviatis, maculá submarginali et striâ laterali, maculis abdominis sex (lateralibus utrinque binis, unâ discoidali et unâ apicali) laele flavis, pedilus sordide favis, femoribus ultra dimidium, tibiarum po- 
sticarum annulo larsisque adversus apicem nigris. - Long. corp. $2 \frac{1}{2}$ lin., Long. al. $2 \frac{7}{2} \frac{7}{2}$ lin.

Atra, nitida. Caput concolor. Facies utrinque vitti laterali albo-micante, in frontem mediocriter, in orbitam posticam longe ascendente ornalur. Antennae nigrae. In anteriore frontis latissimae parte maculae duae obliquae, prope ocellos puncta duo minulissima flava discernuntur. Postica oculorum orbita lata, superiore marginis postici et inferiore antici dimidio flavis. Proboscis flava. In thoracis dorso lineae duae poslice abbreviatae, macula sublateralis lineaque lateralis utrinque, anguli denique postici flavi sunt. Scutellum flavun, imâ basi angulisque lateralibus atris. Pleurae immaculatae. Tertium abdominis segmentum utrinque maculam marginalem ovatam, aliam in disco subovalam margini antico approximatam flavas habet; segmentum quartum utrinque maculâ flavâ pictum; ultinum abdominis segmentum maculâ flavâ terminali majusculà ornatum. Venter tolus ater. Femora atra, apicali anticorum dimidio, posticorum triente ex ochraceo flavis; tibiae ex ochraceo flavae, medio posticarum annulo flavo, anterioribus interdum obsolete ct imperfecte nigro-annulatis; tarsi anteriores ex fusco nigri, basi flavescente; tarsorum posticorum dimidium basale flavescens, apicale nigrum. Halterum capitulum ex flavo virescens. Alae hyalinae, venis validioribus et stigmate ochraceis. -- (Red River; Kellnicot.)

15. Oxycera unifasciata nov. sp. ㅇ. Alra, nitida, antennis ex rufo favis, faciei marginibus lateralibus albo-micantibus, villis frontalibus duabus, orbilâ oculorum posticâ, viltis thoracis dorsulibus quutuor et unâ utrinque marginali, sculello, pleurarum maculis duabus, abdominis basi, fasciâ media, maculis marginalibus utrinque duabus et maculà uné apicali, pedibus denique tolis fla-

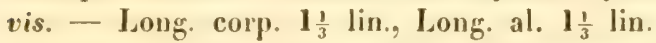

Atra, nitida. Frons viltis duabus angustis flavis ornata. Macula verticis et orbita oculorum postica flavac. Proboscis cum palpis et antennae ex rufo flavae. Facies utrinque vilta albomicante marginata et puncto medio didymo flavo-notala. Thoracis dorsum flaro-ruadrivitlatum, vittis intermediis postice modice abbrevialis, exterioribus integris. Vitta marginalis dorsi angusta et maculac in posteriore pleurarum dimidio duae flavac. Abdominis basis et apex, fascia aequalis media el maculae marginales ovatae utringue duae flavae. Venter niger. Coxac nigrae; pedes toli flavi. Alac hyalinae, stigmale venisque validioribus ex ochraceo flavescenlibus. venâ 
longitudinali primâ paulo obscuriore. - (Pennsylvania; OstenSacken.)

16. Pachygaster pulcher nov. sp. $\delta$ et 오. Ater, halleribus pedibusque albis, femoribus praeler apicem atris, antennis dilute flavicantibus, latere interiore articuli tertii fusco-maculato.

$\sigma$ oculis conliguis, orbilis oculom facialibus anguslissimis, candido-pollinosis, alis subcinereis, venis validioribus subfuscis.

우 oculis distantibus, front is dimidio anteriore orbitisque faciulibus latis candido-pollinosis, thoracis dorso et scutello breviter subaureo-lomentosis, alis subhyalinis, venis validioribus lutescentibus.

Long. corp. ơ $1 \frac{1}{4}$, ㅇ $1 \frac{1}{2}$ lin., Long. al. ơ $1 \frac{1}{3}$, 오 $1 \frac{1}{2}$ liu.

Mas. Ater, modice nileus, abdominis disco opaco. Oculi contrgui. Facies angusla, orbilis oculorum angustissimis, candido-pollinosis. Partes oris atrae, proboscidis apice subfusco. Antennae parvae, dilute ochraceae, latere interiore articuli terlii fusco-maculato. Coxae nigrae, trochanteribus sordide albidis. Pedes albi, femoribus praeter apicem atris. IIalleres albi, puncto capituli nigricante. Alae subcinereae, venis validioribus subfuscis.

Foemina. Latior, robustior et magis opaca. Oculi separali. Frontis modice latae dimidium anterius impressum, candido pollinosum. Orbitae oculorum faciales latae, candido-pollinosae. Partes oris et antennae ut maris, tertio tamen harum articulo majore. Thoracis dorsum et scutellum pube brevissimâ, confertâ, subaureà vestila, subopaca. Pleurarum fasciola perpendicularis candido-pubescens. Praeter femorum apicem plerumque etiam basis albical. Alae subliyalinae, venis validioribus lutescentibus, raro dilute subfuscis. - Variat antennis albidis et pube thoracis et scutelli candidâ. - (District Columbia; Osten-Sacken.)

17. Leplis dimidiala nov. sp. o". Nigra, segmentis abdominalibus secundo terlioque et margine postico quarti testaceis, tibiis tarsisque fuscis, alis ex cinereo subfuscis, stigmate fusco. Long. corp. $3 \frac{1}{3}$ lin., Long, al. $3 \frac{1}{2}$ lin.

Nigra, antennis, proboscide palpisque concoloribus, supra nigropilosa, infra pilis sordide albicantibus vestita. Oculi conligui. Pulpi nigro-pilosi. Segmenta abdominis sccundum et tertium tota teslacea, segmentum quartum postice testaceo - marginalun. Tibiae ex testaceo fuscae, apicem versus obscuriores; tarsi fusci. Halteres flivicantes. Alae ex cinereo dilute subfuscae, stigmate fusco, venis ex nigro fuscis. - (Silka; Sahlberg.) 
18. Phthiria sulphurea nov. sp. ‥ Dilute flava, vitlis thoracis paulo obscurioribus, obsolelis, antennis palpisque ex fusco ferrugineis, proboscide tarsisque praeler basim fuscis, alis ex cinereo hyalinis, venae anxiliaris fine venisque transversalibus omnibus anguste nigro limbalis, cellulà posteriore tertiâ appendiculatâ. - Long. corp. $1 \frac{7}{4}$ lin., Long. al. $2 \frac{3}{4}$ lin.

Dilute flava, opaca, pube pallidâ brevi, in specimine descripto valde detrita. Obsoleta frontis vilta paulo obscurior. Antennae ex fusco ochraceae, articulis duobus primis brevibus, supra pallide flavis, articulo tertio praecedentibus latiore. Palpi ex fusco ochracei. Proboscis fusca, in basi ochracea. Pedes flavi, tibiarum apice vix levissime infuscalo, tarsis practer basion fuscis. Alae ex cinereo hyalinae, venis ex fusco nigris, costà et venà primà fuscis, omnibus in imâ alarum basi flavis; cellula posterior teria appendiculala, venulâ adventiciâ in cellulam discoidalem directì; apex renac auxiliaris, venulae transversae omues et anterior venae tertiae ramulus in basi anguste nigro-limbata; cellula basalis prima, ubi vena secunda oritur, puncto nigro notala. - (New Jersey; Glover.)

Nota. Phthir. punctipennis Walk. obscurior quam Phthir. sulphurea est et secundum costae dimidium fusco-limbatum habet.

19. Phthiria notata nov. sp. 오. Dilute favescens, viltis thorucis tribus latissimis at disco scutelli rufis, fronte, facie, villis thoracis lateralibus pleurisque nigro-maculatis, tarsis praeler basim ex fusco nigris, alis magnis, hyalinis. - Long. corp. '2 $2 \frac{3}{4}$ lin., Long. al. $3 \frac{1}{12}$ lin.

Modice nilens, pube brevi et rarâ, maximà ex parte nigrâ ve. stita. Caput pallide flavum; frons praeter margines laterales paulo saturatius tiucla, postice punclo verticali, antice utrinque maculâ minulà, oculis propinquâ et lineolà mediâ nigris picla. Facies utrinque maculis duabus, alterâ supra alteram positâ, variegata, maculà superiore ex parte rufà, inferiore totâ atrâ. Autennac ochraceae, apicen versus subfuscae, arliculis duobus primis minutis, terlio elongato, lineari, praecedentibus non latiore. In thoracis dorso villae tres latissimae, postice confluenles rufae adsunt, quae lineis duabus ex albo flavicanlibus, tenuibus et postice abbreviatis scparantur; vittae laterales prope humeros nigro-maculatie sunt; dorsi margo lateralis ex albo flavescit. Scutellum supra rufum, margiue lale ex albo subflavescenle. Pleurac vitlis quatuor, dilute flavicantibus et rufis alternis variegalae sunt, vitlá rufä medià nigro-maculatí. Ab. domen flavum, naculà basali marginibusque segmenlorum singulorum 
posticis praeler latera angustissime nigris. Venter dilute flavus, lateralibus segmentorum omnium marginibus nigris, segmentis quatuor primis puncto medio nigro notatis. Pedes flavi, tibiis apicem versus subinfuscatis, tarsis praeler basim ex fusco nigris. Alae magnae, ex cinereo hyalinae, immaculatae, venis tenuibus nigris, primo costae dimidio et venis auxiliari et longitudinali primâ luteis. - (California; Agassiz.)

20. Sericomyia chalcopyga nov. sp. ㅇ. Nigra, scutello ex nigro piceo, abdomine opaco, segmentorum terlii et quarli marginibus posticis segmentoque quinto toto nitidis, fasciis segmentorum secundi, tertii et quarti flavis, aequalibus, interruptis, pedibus lutescentibus, femoribus prueter apicem tarsorumque articulis ultimis nigris, anteriore alarum dimidio fusco. - Long. corp. $5 \frac{1}{3}-6 \frac{1}{3}$ lin., Loug. al. $5 \frac{1}{4}-6 \frac{1}{4}$ lin.

A Sericomyiâ boreali, cui simillima, fasciis nitidis segmentorum abdominalium tertii et quarti, margines posticos tangentibus, distinclissimis, illâ nigrâ, bac cum segmento quinto nigro-viridi distinguitur. Segnenta ventralia anguste flavo-marginata. Alarum dimidium anterius fuscum, posterius ex fusco cinereum. - (Sitka; Sablberg.)

21. Sphegina lobata nov. sp. ఠ’ et + . Atra, nitida, antenris luteis, humeris maculisque lateralibus dorsi testaceis, pedibus albidis, nigro-variis, alis dilule subfuscis. - Long. corp. $3 \frac{1}{6}$ lin., Long. al. $2 \frac{3}{4}$ lin.

Mas. Caput nigrum, facie fere totâ albidâ. Oculi separati; frons aeçualis; antennae luteae, setâ subfuscâ. Thorax ater nilidus, humeris maculisque lateralibus dorsi testaceis. Scutellum et abdomen atra, nitida, fascià basali segmenti abdominalis tertii flavâ, angulis anticis et margine postico segmenti quarti testaceis. Hypopygium globosum, atrum. Segmenti ventralis ultimi angulus sinister in lobum magnum ex fusco testaceum productus. Coxae et pedes albicantes; femorum posticorum dinidium apicale, summo apice tamen excepto, atrum; tibiarum posticarum dimidium basale fuscum, apex imperfecte nigro-annulatus; articuli ultimi duo tarsorum anlicorum atri; tarsorum posticorum articuli primus et ultimi duo alri, interjecti subfusci. Alac subfuseae, sligmate paulo obscuriore, angulo apicali cellulac posterioris primae recto.

Focm. Mari simillima. Frons paulo latior; facies supra latius nigricans. Dimidium apicale abdoninis valde dilatalum, maculis segmentorum tertii et quarti binis anticis, magnis, testaceis, subobso- 
letis, segmento quinto sordide albo. Ultimi duo tarsorum anteriorum articuli nigricantes; tarsi postici nigri, articulis intermediis paulo dilutioribus. - (Mittelstaaten.)

22. Sphegina rufiventris nov. sp. ․ Rufa, fronte, occipite, thoracisque dorso fere tolo semper, scutello, pleuris abdominisque basi interdum nigris, tertio antenuarum articulo praeceden. tibus obscuriore, fusco vel nigro, pedibus anterioribus flavescentibus, tarsorum apice nigro, pedibus posticis ex badio rufis, tibiarum apice tarsisque ex nigro fuscis, intermedieis horum articulis plerumque dilutioribus. - Long. corp. $3 \frac{1}{6}$ lin., Long. al. $2 \frac{3}{6}$ lin.

Species valde variabilis. Rufa, thoracis dorso praeter humeros et angulos posticos semper nigro, interdum thorace fere toto nigro. Frons nigra, aequalis. Facies flavescens, supra subnigricans. Occiput nigrum. Tertius antennarum articulus fuscus vel niger, praecedentibus obscurior. Scutellum interdum rufum, sacpius piceum, raro nigrum. Abdomen rufum. nitidum, basi saepe nigrå, dimidio apicali quam in Spheginà lobatí minus lato. Pedes anteriores flavescentes, ultimis duobus tarsorum articulis nigris; pedes postici ex badio ruf, femoribus tibiisque in basi flavis, tibiarum apice tarsisque ex fusco nigris, intermediis horum articulis saepe dilutioribus. Alae subhyalinae vel apicem versus subfuscae, angulo apicali cellulae posterioris primae recto. - (New York; Osten-Sacken.)

Nota. A specie praecedente praeter colorem corporis abdominis segmentis ultimis minus latis femoribusque posticis mints incrassatis differt.

23. Sphegina infuscat a nov. sp. ot et 9 . Capite cum antennis, thorace et scutello atris, alis magnis subfuscis, abdomine pedibusque maris fuscis, foeminae ex rufo testaceis. - Long. corp. $2, \frac{7}{2}-3$ lin., Long. al. $3-3 \frac{1}{3}$ lin.

Caput alrum, opacum, fronte maris quam foeminac angusliore pilisque nigris longioribus vestitâ. Thorax ex fusco ater, dorsi pube tenui, in mare longiore et multo obscuriore quam in foeminå. Scutellum et metanotum thoraci concolora. Abdomen brevius quam in speciebus Europae indigenis et basim versus attenuatum, im mare fuscum, in foeminâ ex rufo testaceum vel latericium. Coxac fuscac. apice anticarum foeminac ex rulo testaceo. Pedes maris fusci, focminae ex rufo testacei. Alae magnae, dilute infuseatac, stigmate elongato fuseo, angulo cellulae posterioris primae apicali aculo. (Silka; Sahlberg.) 
24. Baccha lugens nov. sp. ठ'. Nigro-aenea, abdomine atro, opaco, basi antennarum, facie praeter latera, femoribus anterioribus, apice tamen excepto, femorumque posticorum basi flavis, alarum venis lalissime nigro-limbatis. - Long. corp. 5 lin., Long. al. $4 \frac{1}{4}$ lin.

Frons nigro-aenea, nigro-pilosa, supra antennas flavo-maculata. Primi duo antenuarum articuli flavi, nigro-pilosi; articulus tertius ater. Facies flava, lateribus obscuris, polline flavicante opacis. Thoracis dorsum et scutellum nigro-aenea, modice nitida, colore scutelli nonnihil in testaceo-aeneum vergente, pleurarum dimidio inferiore albido-pollinoso. Abdomen atrum, opacum, apicem versus non clavatum, basi segmentorumque singulorum marginibus apicalibus nitidis, fuscis, segmento ultimo toto nitido, ex nigro subviolaceo. Pedes nigri, femoribus anterioribus praeler apicem, femorum posticorum tibiarumque anteriorum basi flavis vel flavo-testaceis. Halteres sordide albidi, capitulo nigro-maculato. Alae subcinerascentes; venae omnes praeter ramulum anteriorum quartae limbis nigris latis. simis, prope costam inter se confluentibus marginatae. - (New Wiskonsin; Osten-Sacken.)

25. Baccha capitata nov. sp. $\sigma^{7}$. Ex fusco ochracea, opaca, nudiuscula, capite, thoracis viltis, pleurarum maculis, scutello fasciisque abdominis laete flavis, femoribus posticis tibiarumque posticarum dimidio apicali fuscis, alarum limbo costali latiusculo, sub-

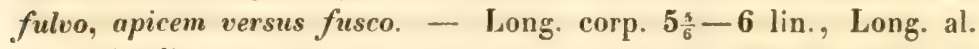
$5 \frac{1}{12}-5 \frac{1}{6}$ lin.

Caput magnum, laete flavum, lunulâ frontali ex fusco ochraceâ, fusco-circumscriptâ. Antennae obscure ochraceae, articulo tertio ovato. Tuberculum faciei obscure ochraceum Occiput nigricans, albido-pollinosum, polline orbilarum tamen laete flavo. Thoracis dorsum ex fusco ochraceum, opacum, vittis laete flavis quatuor pictum, intermediis postice acutis et modice abbreviatis, lateralibus late interruptis. Scutellum laete flavum, apicem versus plerumque ex fusco ochraceum. Pleurae maculis lacte flavis, obscure ochraceis et fuscis variegatae. Segmentum primum abdominis flavum, fasciả posticâ ex fusco ochraceả; reliquum abdomen ex fusco ochraceum, pube ochraceâ, adversus abdominis apicem confertiore vestitum; segmentum secundum in basi flavescit, tertium fasciam basalem latiusculam laete flavam habet, in quarti basi fascia angusta saturatius flava cernitur. Pedes ochracei, femoribus posticis practer basim et apicem tibiarumque posticarum dimidio apicali fuscis. Alae 
hyalinae, limbo costae latiusculo, ex ochraceo subfulro, apicem versus fusco. - (Cuba; Gundlach.)

26. Baccha obscuricornis nov. sp. T. Aeneo-nigra, capite toto concolore, antennis atris, plenris testaceis, abdomine ex nigro fusco, fasciis basalibus segmentorum tertii, quarti et interdum quinti flavis; alae subhyalinae, margine apicali et stigmate infumatis, basi hujus nigrâ. - Long. corp. $3 \frac{1}{3}$ lin., Long. al. $3 \frac{1}{6}$ lin.

Bacchae elongatae valde similis. Caput aeneo-nigrum, fronte fere totâ et facie practer tuberculum polline albo rariore, occipite confertiore aspersis. Antennae lotae atrae. Thoracis dorsum el scutellum aeneo-nigra. Pleurae pallidissime testaceae, vel supra flavae et infra subfuscae. Abdomen tenue, ex nigro-fuscum, aenescens, basi plerumque aeneo-nigrâ; segmentorum tertium et quartum semper. quintum plerumque fasciâ basali flavâ cingilur. Pedes flavi vel dilute testacei, posticorum femoribus prope apicem, tibiis tarsisque fere totis subfuscis. Alae subhyalinae, leviter cinerascentes, venis ex fusco nigris; venulae transversae obsolete fumido-limbalae; stigma elongatum fumidum, maculâ basali nigrâ; alae margo apicalis et marginis postici dimidium apicale fumido-limbata. -.. (Sitka; Sahlberg.)

Nota. A Bacchâ elongatâ fronte minus aequali et antennis totis atris differt.

27. Baccha $\operatorname{cog}$ nata nov. sp. ㅇ. Ex nigro aener, capile concolore, dimidio inferiore faciei antennisque tamen flavis, humeris pleurisque favicantibus, abdomine ex nigro aeneo, fasciis basalibus segmentorum tertii et quarti, interdum etiam quinti flavis: alae subhyalinae, margine apicali et stigmate infumatis, basi hujus nigrâ. - Long. corp. $3 \frac{1}{3}$ lin., Long. al. $3 !$ lin.

Simillima speciei praecedenti. Caput aeneo-nigrum, inferiors: faciei dimidio flavo; frons practer villam mediam et facies praeter tuberculum polline albido rariore, occiput confertiore aspersa. Antennac totae ochraceae. Thoracis dorsum ex nigro acneum. humeris tamen dilute flavicantibus. Pleurae dilute flavieantes vel sublestaceae, iufra obscure aenescentes. Scutellum thoraci concolor. Abdomen tenue, nigro-aeneum, apicem versus ex fuseo acneum; segmentorum ferlinm et quartum semper. quintum plerumque lascia basali flavà cingilur. Pedes flavi vel dilute testacci, posticorum ficmoribus prope apicem, tibiis et farsis fere tolis dilute subfuscis. Alae subhyalinae, leviter cinerascentes, venis ex fusco nigris; venu. 
lae transversae nigro-limbatae; stigma elongatum fumidum, maculâ basali nigrå; margo apicalis alae fumido limbatus. - (New Wiskonsin; Osten-Sacken.)

\section{= spiloterew Wrets}

28. Empis picta nov. sp. ठ․ Ex cinereo nigra, abdomine pedibusque ex fusco nigris, femoribus tibiarumgue basi ex flavo testaceis, alis subfuscis, fusco variegatis, venae longitudinalis secundae apice recurvo, anteriore tertiae ramulo rectâ ascendente, quartâ incomplet $\hat{a}$, appendiculatâ. - Long. corp. $2 \frac{1}{1 \frac{1}{2}}$ lin., Long. al. $2 \frac{5}{1 \frac{5}{2}}$ lin.

Caput nigrum, occipite cinerascente. Oculi in fronte contigui. Antennae nigrae, mediocres, articulo tertio acuminato, stylo terminali longiusculo. Palpi nigri. Proboscis badia, duplicem capitis longitudinem excedens, labio profunde bipartito. Thorax et scutellum ex cinereo nigra, nigro-pilosa. Abdomen ex fusco nigrum, modice nitens, nigro-pilosum; hypopygium crassiusculum, subglobosum, clausum, lamellis superioribus brevibus, obscure badiis, filamento centrali abscondito. Coxae ex fusco nigrae. Femora ex flavo testacea, in summo apice puncto nigro notata; tibiae anteriores in basi testaceae, apicem versus ex nigro fuscae; tibiae posticae ex fusco nigrae, basi tantum testaceâ; tarsi ex fusco nigri, imâ artículorum singulorum basi anguste testaceâ; pedes toti pilis longis nigris vestiti. Halterum capitulum infuscatum. Alae dilute fuscae, venis validiusculis obscure fuscis, apice longitudinalis secundae recurvo, anteriore tertiae ramulo rectâ ascendente, quartâ abbreviatâ et prope apicem inferius ramulo adventicio furcatâ; stigma ovale fuscum; venulae Iransversae, adventicia venae quartae appendicula et costa inter venae terliae ramulos fusco-limbatae; cellula discoidalis lata. - (Mexico.)

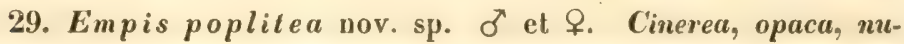
diuscula, antennis nigris, thorace fuśco quadriviltato, pedibus rufis, tarsis ex fusco nigris, alis hyalinis, cinerascentibus, venis validis, obscure fuscis, stigmate dilute luteo, subobsoleto.

ठั poplites pustici apophysibus nigro-barbatis instructi.

우 pedes simplices.

Long. corp. $2 \frac{7}{\frac{7}{2}}$ lin., Long. al. $3 \frac{1}{6}-3 \frac{7}{\frac{7}{2}}$ lin.

Cinerea, opaca, pilis setulisque omnibus brevibus, nigris. Caput concolor, nigro - pilosum, oculis maris separatis. Antennae nigrae, mediocres, articulo tertio elongato et apicem versus valde attenuato. Palpi minutissimi, leslacei. Proboscis valida, nigra, supra badia, duplicem fere capitis longitudinem aequiparans. Thoracis dor- 
sum fusco quadrivilatum. Hypopygium maris minutum. subimmersum, clausum, lamellis superioribus parvis, ex cinereo nigris, inferioribus minulis, testaceis, filamento centrali abscondilo. Coxac ex nigro cinereae. Pedes rufi, rare nigro-pilosi. tibiarum tarsorumque pilis longioribus et paulo confertioribus; extremus femorum apex puncto nigro nolalus; tibiarum apex nigricans; tarsi nigri. basi articuli primi plerumque obscure rufâ; poslici maris poplites apophysibus tribus validis instructi. unâ in femorum apice, duabus in tibiarum basi. Halteres sordide lutescentes. Alae longiusculae. venis validis fuscis, stigmale dilule lutescente. subobsoleto. - (Sitka; Sablberg.)

30. Empis leptogastra nov. sp. ‥ Flava, nitida, capite, thoracis linề mediâ, fasciis abdominis latiusculis, femorum posticorum annulo medio, tibiarum posticarum apice tarsisque ommibus nigris, alis ex cinereo hyalinis. - Long corp. $2 \frac{1}{3}$ lin.. Long. al. $2 \frac{1}{3} \operatorname{lin}$.

Tenuis, flava, nitida, nudiuscula. Caput nigrum, facie ef fronte angustissimá concoloribus; antennae tenues, elongatae, articulo tertio nigro, praccedentibus fuscis. Proboscis capite paulo longior, tenuis, flava. Thoracis dorsum lineà longitudinali nigrâ dimidiafum. Abdomen fasciis segmentorum singulorum basalibus atris, per lineam atram conjunctis variegatum, segmento ultimo toto atro. Perles rare pilosuli, lenues, femoribus posticis apicem versus incrassalis et infra nigro-spinosis: femorum posticorum apex et annulus medius, triens tibiarum posticarum apicalis larsique ommes nigri. Capitulum halterum infuscatum. Alae longiusculae, subanguslac, ex cinerco hvalinae, venis ex fusco nigris, longitudinali tertia apicem versus loniler incurvâ, ramulo anlico reclâ ascendente. - (Distr. Colmmbia: OstenSacken.)

31. Rhamphomyia incompleta nov. sp. ․ Nigricans, subopaca, primis duobus tarsomm arliculis prueter apicem halteribusque albidis, alis ex cinereo subhyalinis, celluli discoidali aperlit. - Long. corp. $1 \frac{1}{4}-1 \frac{2}{3}$ lin., Long. al. $1 \frac{1}{3}-1_{\frac{1}{2}}^{\frac{3}{2}}$ lin.

Nigricans, subopaca. Frons latiuscula, nigra, rare nigro-pilosa. Antennae breves, articulo tertio lato. stylo terminali tenui. Proboscis nigra, tenuis, capile paulo longior. Thoracis dorsum et seutellum pilis raris albidis hirla. pedes et abdomen brevissime albido puberula. Duo primi tarsorm articuli practer apicem albi. Halteres albidi. Alae mediocres, ex cinereo subhyalinar. stigmalo mullo. 
cellulâ discoidali incompletâ. ita ut inde a venulà transversâ medià usque ad venam intercalarem aperta sit. - (District Columbia: Osten-Sacken).

32. Hilara macroptera nov. sp. б. Obscure cinerea, opaca. antennis proboscide abdomineque nigris, pilis longis nigris rarionibus vestita, halleribus pedilusque pallide flavis. tibiarum dimidio apicali tarsisfre nigris, pedum anticorum libiis metatarsisque supra pilos perlongos nigros gerentibus, alis permagnis cinereo-hyaliris. - Long. corp. $1 \frac{1}{3}$ lin. Long. al. 2 lin.

Obscure cincrea, opaca. Caput concolor, nigro-pilosum. Anlennae nigrae, articulis primis duobus ex nigro fuscis. Palpi ex fuseo nigri, pilis aliquot longioribus nigris instructi. Proboscis nigra, crassiuscula, capite brevior. Thoracis dorsum non vittatum. pilis nigris longioribus praeditum. Abdomen nigrum, opacum, nigropilosum. Pedes pallide flavi, nigro-pilosi, apicali tibiarum dimidio tarsisque lotis nigris; anticus maris melatarsus modice incrassatus et tibiae anticae supra pilis perlongis nigris hirtae. Halteres flavescentes. Alae permagnae. distincte cinerascentes, subhyalinae. in basi dilute flavescentes. venis ex luteo subfuscis , in basi pallide flavis, stigmate elongato cinereo, obsoletissimo. - (District Columbia; Osten-Sacken.)

33. Hilara lutea nov. sp. ơ et ㅇ․ Lutea, opaca, breviter et rare nigro-pilosula: capile abdominisque fasciis nigricantibus, alis subhyalinis, ex cinereo dilute lutescentibus, antico maris metatarso modice incrassato. - Long. $1 \frac{1}{\frac{1}{2}}-1 \frac{5}{1 \frac{2}{2}}$ lin., Long. al. 2 lin.

Lutea, opaca, pilis nigris, brevibus et raris vestita. Caput nigricans, polline albido cinerascens. Antennarum articnli basales fusci (articulus tertius deest). Palpi lutei; proboscis nigra, crassa, capite paulo brevior. Pleurae maculis cinerascentibus obsolete variegalac. Abdomen fasciis segmentorum singulorum basalibus nigricantibus cingulatum. Pedes reliquo corpore dilutiores. extremo tarsorum apice fusco et antico maris metatarso modice incrassato. Halteres dilute lutescentes. Alae subhyalinae, ex cinereo dilute lntescentes, venis luteis, posticis subfuscescentibus. Iongitudinali secundà apicem versus recurvâ, anteriore tertiae ramulo oblique ascendente. - (District Columbia; Osten-Sacken )

34. Synamphotera bicolor nov. sp. ठ et 오. Nigra, duobus primis antennarum articulis. proboscide. palpis. humeris, pleu- 
rarum maculis, coxis pedibusque flavescentibus, alis hyalinis, renis lutescentibus, longitudinali tertiâ simplice. - Long. corp. $1 \frac{1}{2}$ lin.. Long. al. 2 lin.

Nigra. Frons rare cinereo-pollinosa. Primi duo antennarum articuli pallide flavescentes, tertius longus, acuminatus, niger; seta terminalis concolor, quam articulus tertius brevior. Proboscis subincurva, flavescens; palpi oblongi, concolores. Thoracis dorsum polline rarissimo ex nigro obsolete subcinerascente; humeri lutescentes; pleurae luteo-maculatae, interdum tolae luteae. Scutelli margo in spcciminibus plerisque lutescens. Abdomen nigrum. Hуроруgium maris concolor, tumidum, reflexum, lamellis superis minutis, oblongo-ovatis, flavis. Pedes et coxae dilute flavescentes, summo tarsorum apice infuscato. Alae vix obsoletissime ex cinereo sublutescentes, venis luteis, tertiâ simplice. - (Sitka, Sahlberg.)

Nota. Tertio antennarum articulo setâque antennali longioribus ei venât alarum longitudinali tertià simplice a Synamphoterî pallidà differt, quae tertium antennarum articulum setamque antennalem breves et venam longitudinalem tertiam furcalam habet. - Synamphotera cum Hemerodromia et Phyllodromia partibus oris, cum Sciodromiâ et Ardopterâ pedum formâ ac figurâ convenit, ita ut inter utrasque quasi media appareat. -

35. Phoneutisca bimaculata nov. sp. \&. Atra, nitida. palpis elongatis halteribusque albis, genibus anterioribus semper. tarsis posterioribus in basi plerumque testaceis, alis cinereis maculâ costali nigrâ pictis, venis fuscis, secundae apice abrupte recurvo. terlia et quartà approximatis et parallelis. - Long. corp. $\frac{11}{1} \frac{1}{2}$ lin.. Long. al. 1: lin.

Atra, nitida. Antennae nigrae, articulo tertio ovato, selà sub. dorsali concolore. Palpi albi, angusti, proboscidi aequales. Proboscis nigra, recta, subperpendicularis. Pedes atri, postici anterioribus longiores el graciliores; femora anteriora modice incrassata; genua anteriora testacea; tarsi posteriores in imâ basi plerumque léstacei vel fusci. Halteres albi. Alae cinereac, maculâ costali nigria. finem venae secundae abrupte recurvum includente; venae validae. obscure fuscae, tertia et quarta approximatae, parallelac, leniter sub. recurvae; cellula analis nulla. - (Silka, Sahlberg).

Nola. Phoneutisea a Tachypezî differt setâ antennarum sub. dorsali, venac secundae apice abruple recurvo, ita nt serundum costae segmentum tertio brevius sit. femoribusque anticis mi 
nus incrassatis; a Drapetide proboscide tenuiore rectâ et palpis elongatis anguslis distinguitur.

36. Plalypalpus discifer nov. sp. $\sigma^{\top}$ et 오. Ater, nilidus. thoracis dorso, scutello et melanoto polline luteo, occipite pleurisque polline albido opacis, antennis praeter apicem, palpis pedibusque flavis;

o' tarsis anticis totis albidis et confertim albido pilosulis; Iarsis intermediis atris, articulo primo depresso, in patellam dilatato; tarsis poslicis apicem versus nigris:

우 tarsis omnilus simplicibus, apicem versus nigris.

Long. corp. 1 $\frac{1}{3}$ lin., Long. al. $2 \frac{1}{12}$ lin.

Ater, nilidus. Frons et occiput polline albido cincrea. Antennae parvae, ochraceae, apice articuli terlii nigro. Facies albopollinosa. Palpi mediocres, ochracei. Thoracis dorsum, scutellum et metanolum polline luteo opaca. Pleurae albido-pollinosae, maculà magnà inferâ atrâ, nilidissimà. Pedes flavi, femoribus intermediis valde incrassatis et infra nigro-spinulosis; tibiae intermediae incurvae, infra nigro-spinulosae, dente apicali nigro armatae. Tarsi foeminae simplices, anticorum articulis primis quatuor in apice nigricantibus, ultimo nigro, posteriorum arliculis primis tribus in apice nigricantibus, reliquis totis nigris. Antici maris tarsi paulo validiores quam foeminae, ex flavescente albidi, coufertim albido-pilosuli; tarsi intermedii atri, articulo primo in patellam ovatam, utrinque pilis nigris breviter ciliatam depresso; tarsi poslici simplices, articulis primis tribus in apice, sequentibus totis nigris. Halleres albidi. Alae subinfuscatae, priore costae dimidio et venà longitudinali primâ praeter apicem lutescentibus, venis reliquis validis, ex nigro fuscis, venis longitudinalibus tertià el quartâ apicem versus convergentibus, cellulầ anali completâ. - (District Columbia; Osten-Sacken.)

37. Platypalpus debilis nov. sp. ㅇ. P'arvus, rapite, tho. race scutelloque cinereis, opacis, abdomine atro nitido, antennarum articulis basalibus flavis, terminali et setä nigris, perlibus flavis, omnibus tarsorum articulis in apice nigris, alis hyalinis, venis luteis, longitudinalibus tertiâ et quar/á subparallelis, cellulâ anali incompleti. - Long. corp. ${ }_{6}^{5}$ lin., Jong. al. $1 \frac{1}{6}$ lin.

Caput cinerenm, facie albâ. Antennarum articuli basales flavi, terminalis niger, setá concolore. Palpi albicantes; proboscis atrı. Thoracis Jorsum, scutellum et metanotum polline lutescente cinerea, opaca; pleurae polline albido teclae. macula infera lacvigatà nili- 
dissimâ, atrâ. Abdomcu atrum, nitidum. Pedes flavi, femoribus intermediis modice incrassatis, apicali tibiarum intermediarum dente mediocri, extremo articulorum tarsalium apice nigro. Halteres dilute flavescentes Alac hyalinae, venis luteis, longitudinalibus tertia et quartâ apicem versus subparallelis, priore sextac dimidio obsolelo. ita ut cellula analis late aperta sit. - (District Columbia; UstenSacken).

35. Platypalpus mesogrammus nov. sp. o' el ․․ Flueres, nitidus, antennis, palpis et proboscide, apice hujus tamen excepto, concoloribus, capite nigro, medici thoracis rufescent is villit. scutell" praeter angulos laterales abdomineque atris, nitidis. alis hyrlinis. venis longitudinalibus tertiâ et querla paralielis. - Long. corp. $\frac{3}{4}-\frac{5}{6}$ lin., Long. al. $1 \frac{5}{1} \frac{5}{2}$ lin.

Flavus, nilidus, thoracis dorso magis rufescente. Caput nigrum. facie albo-pollinosâ. Antemnae flavae, setâ fuscâ. Proboscis cum palpis flava, apice tamen nigro. Thoracis vilta lata, sculcllum practer angulos laterales et abdomen atra, nitida; venter plerumque albicans. interdum sordide nigricans. Pedes pallide flavi, femoribus intermediis valde incrassatis, apicali tibiarum intermediarum dente minulissimo, ultimo tarsortum articulo subfuseo. Halleres dilulissime llavicantes. Alae hyalinae, venis fuscis, transversis contiguis vel subcon. tiguis, longiludinalibus tertiâ et quartâ adversus finem rectis et patrallelis. - (District Columbia; Osten-Sacken).

39. Cordylura terminalis nov. sp. F. Nitida, atru, pediunes concoloribus, fronte, pleuris coxisque candido-pollinosis, antennis nigris, interno articuli terlii latere apiceque secundi ex fusco flavis. setà phumata, facie hallevibusque albiclis, apicali alarum hyalinurum: triente nigricante. - Long. corp. $2 \frac{7}{2}$ lin., Long. al. $2 \frac{5}{12}$ lin.

Alra, nitida, pilis brevibus selisque raris nigris vestila. Capul concolor, facie albida, fronte oculornmque orbità posteriore candidopollinosis; antenuae breves, ex lusco nigrae, interno articuli tertii latere ex ochraceo fuseo, apice articuli secundi llavo, setâ pilis longis plumatâ. Thorax, scutellum et abdomen alra, nilida, pleuris candidopollinosis. Coxae anticac nigricantes, postcriores nigrae, omnes candido-pollinusate. Trochanteres dilute testacei. Fentora atra, nitida. summo apice llavo; tibiac aulicate ex nigro fuscac, posteriores nigrac, imâ omnium basi flavicaule: larsi nigri, basi articuli primi plerum. que testacea. Tegulae halleresque albirantes. Alas subhyalinac, di lute havicantes, lriente apicali nigricante, venis hasin lersus luleis. apiecm versus ex fusco nigris. - (Penusylvania) 
40. Cordylura bimaculata Loew. $\sigma$ et 오 Atra, nitida, fronte pleurisque candido-pollinosis, coxis omnibus pedibusque anticis albidis, pedibus posterioribus praeter femorum basim atris, alis nigro-biplagiatis. - Long. corp. $3 \frac{1}{2}-3 \frac{5}{6}$ lin., Long. al. $2 \frac{1}{1} \frac{1}{2}-3$ lin.

Synon. Cordylura bimaculata Loew, Wien. Ent. Monatsch. IV. 80.

Atra, nilidissima. Caput concolor, fronte candido-pollinosâ, facic albidà, angustissimâ oculorum orbitâ foeminae atrå. Antennae maris albae, foeminae fuscae vel nigro-fuscae, breves, setâ pilis longis plumatà. Proboscis crassa, infra flava, in foeminå saepe obscurior. Palpi maris albi, foeminae fusci vel nigro-fusci. Thorax ater, nitidus in mare villâ mediâ candido.pollinosâ ornatus; pleurae praeter plagam magnam subalarem polline candido indutae. Scutellum et abdomen thoraci concolora. Hypopygium parvum, atrum, nigro-pilosum. Coxae omnes albidae. Pedes graciles; antici albidi, tibiis supra in mare subfuscis, in foeminâ fuscis, tarsis in mare fuscis et infra nigro-punctatis, in foeminâ nigris; pedes posteriores atri, femorum basi albidâ, genibus flavis, tarsis maris fuscis, foeminae nigris. Halteres albidi. Alae hyalinae, apice late nigro, venis transversis approximatis, nigro circumfusis. - (Illinois; Wisconsin).

Nota. Variat colore pedum nigro in ferrugineum mutato.

41. Cordylura adusla nov. sp. $\sigma^{7}$. Gracilis, alra, nitida, capile praeter superius occipitis dimidium, viltâ thoracis dorsali, pleuris prceeter maculam oblongam subalarem, coxis pedibusque pallide fluvicantibus, femorum posticorum apice, tibiis posticis tarsisque omnibus ex nigro fuscis, alis hyalinis in apice subinfuscalis. Long. corp. $2 \frac{5}{1 \frac{5}{2}}$ lin., Long. al. $2 \frac{1}{6}$ lin.

Caput pallide flavum, maculà parvâ ocellos includente et superiore occipitis dimidio atris. Antennae breves, dilute flavae, setâ nigricante breviter pilosâ. Proboscis et palpi cum capite concolores. Thoracis dorsum atrum, nitidum, vittâ mediâ flavâ. Scutellum et metanolum atra, nitida. Pleurae dilute flavescentes, maculâ oblongâ subalari atrà. Abdomen tenue, atrum, nitidum, breviter nigro-pilosum, hypopygio parvo concolore. Pedes graciles, ex albo flavicantes, femorum posticorum apice, tibiis posticis praeter basim tarsisque omnibus fuscis vel ex nigro fuscis, femoribus intermedis infra nigrospinulosis. Alae hyalinae, apice late subinfuscato, veuulâ transversâ posteriore umbrâ vix levissimâ circumscriplâ. - (New Jersey; Osten. Sacken.) 
12. Cordylura pleurilica nov. sp. ․ Alra, nitida, capite cum antennis. proboscide et palpis (vertice lamen et superiore occipitis dimidio exceptis), pedibus tolis halleribusque pallide flavicantibus. alarum hyalinarum apice infuscato, veni transversi pusteriore' obsuletius subfusco-limbati. seti antennarum nigra, pilis long is plumata. - Long. corp. $3 \frac{1}{2}$ lin., Long. al. $2 \frac{5}{6}$ lin.

Caput dilute llavum, antemnis hrevibus ef proboseide concolorihus, vertice et superiore occipitis dimidio atris, facie palpisqute albidis. sctì antemarum nignti, pilis longis plumatâ. Thora. ater, nilidus. pleuris practer maculam oblongan subalarem pallide flaviannlibus. Scutellum, melanotum el abdomen atra, nilida. Pedes cum coxis llavi. femorum posticorum apice subfusco, pilis pallidis. selis plerisrue nigris. Tegulac albidat, halleres ex albo flaveseentes. Alac hyalinae, ex luteo subcincrascenles, costà ochraceà, venis réliquis ex uigro fuscis, in basi alarun lavicantibus; apex alae et angustus venae transversae posterioris limbus subiufuscati. - English River. Kennicot).

43. Cordylura confusa nov. sp. o’ el ․․ Ex cimereo nigra. opaca, antennis medivoribus nigris, setà pilis longis plumeti. facié genisque albidis, palpis, tibies larsisque testaceis, tarsis anticis infru nigro-punctatis, alis ex luteo cinereis. - Long. corp. $33_{1}^{5}-1_{2}^{1}$ liu., Jong. al. $3 \frac{5}{12}-3 \frac{1}{2}$ lin.

Ex cinereo nigra, opaca. Caput nigrum, polline albido cintreum, fronte anticà aurantiacit. facie geuisque albidis. Anlennic: mediocres, nigrae, articulo tertio latiusculo, seti concolore pilis longis plumala. Proboscis atra; palpi testacei, summo apice in foeminâ dislinctius quam in mare infuseato. 'Thoracis dorsum reliqun, corpore minus opacum, humeris vittaque media polline confortiore albieantibus. Hypopygium majusculum, nigrum, lanellis inleris ma. snis, ovalis. Femoria ex cinereo nigra. summo apice teslaceo Ti biae et larsi testacei, larsi anlici infra nigro-punclati. Selac lolius corporis nigrae; inferius ocejpitis dimidium. pleurae ef lemoral pilis pallidis, in mare quam in foemina longioribus vestila; abdo men foeminae fere tolum nigro-pilosmm; abdomen maris ultra dimi. dium pallide pilosum; femora supra, tibiace tarsique toti nigro-pilosí, pilis aliquol pallidis inlermivlis. Alac ex luteo cinereae, immaculatae, venis luteis, in alae apicem el in matginem posticum exenrrentibus finem versus fuscis. - (Iludsous Bay Territory, Forl lic. solution; Kinnicol).

Nola. Cordyl. pubcrac simillima, sed pauto robustior. maghis 
opaca, confertius pilosa et dilutiore palporum colore facile distincta.

44. Cordylura setosa Loew. o' et ㅇ. Atra, nilida, fronte pleurisque candido-pollinosis, maculà hujus anticâ uurantiacĥ, facie albâ, basalibus antennarum articulis duobus flavis, terlio nigro, set $\hat{\imath}$ pilis longis plumutâ, palpis, coxis anticis pedibusque ex mufo testa-

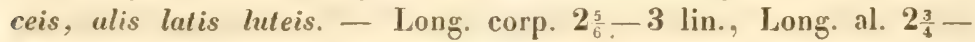
$2 \frac{5}{6}$ lin.

Synon. Cordylura setosa Loew, Wien. Ent. Honatschr. IV. 81.

Atra, nitida, pilis brevibus setisque omnibus nigris. Caput atrum. occipite et fronte candido-pollinosis, bujus parte antennis contiguâ colore aurantiaco tinctâ. Antennae mediocres, articulis duobus primis saturate flavis, tertio atro, setâ concolore pilis longis plumatâ. Facies albida; genae maris subfuscae, foeminae nigrae, albo-micantes. Proboscis picea; palpi testacei. Coxae anticae dilutissime flavotestaceae, pilis brevibus albidis setisque aliquot nigris vestitae; coxae posteriores fuscae vel ex fusco nigrae. Pedes toti ex rufo testacei, tarsis paulo obscurioribus. Halteres flavicaules. Alae satis latae, lutescentes, venis saturatius luteis. - (Distr. Columbia; Osten-Sacken.)

45. Cordylura angustifrons nov. sp. ठ'. Cinerea, opacu. viltâ frontali aurantiacâ, primis duobus antennarum articulis, pro. boscide, palpis, ultimo abdominis segmento, hypopygio pedibusque flavis, tertio antennarum articulo praeter basim atro, setâ pilis longis plumata, femoribus anticis supra nigro-lituratis, alis lulescentibus. venis concoloribus. - Long. corp. $3 \frac{1}{2}$ lin., Long. al. $3 !$ lin.

Cinerea, opaca. Vitta fronlis aurantiaca, vertex et occiput praeter marginem inferum cinerea; frons modice lata, antice angustior; antennae mediocres, articulis duobus primis flavis, tertio atro, in basi tamen flavo, setâ concolore, pilis longis plumatâ. Facies et genae albidae. Proboscis ex flavo testacea; palpi dilute flavicantes. Thoracis dorsum ex luteo cinereum, opacum, lineis duabus paulo obscurioribus, postice valde abbrevialis, obsolelissimis. Scutellum concolor. Pleurae polline albidiore indutae. Abdomen ex luteo cinereum, opacum, segmento ultimo et hypopygio majusculo luteis, segmento paeunltimo utrinque obsoletius luteo-maculato. Coxae anticae ex albo dilute flavicantes, postcriores flavae; pedes flavi, femoribus ralidis, anticis supra nigro-lituratis. Pili longi in inferiore occipitis dimidio, in pleuris, coxis, femoribus, tibiis et abdomine dilute flavicantes, in hoc nigris intermixti; femora supra, tibiae et 
tarsi pilis brevibus nigris vestita; setae omnes nigrae. Alae immaculatae, luteolae, adversus costam el basim saturatius lutescentes, venis luteis. - (Wisconsin.)

46. Cordylura flavipes nov. sp. ठ大. Cinerea, opaca, vithi frontis aurantiacâ, proboscide, palpis, hypopygio pedibusque totis pallide flavis, primis duobus antennarum articulis subfuscis, secundi apice flavo, articulo tertio tolo nigro, setâ pilis longis plumata, alis sublutescentibus, venis luteis. - Long. corp. $2 \frac{2}{3}$ lin., Long. al. $2 ! \operatorname{lin}$.

Praecedenti simillima, sed fronte aequali, articulis antennarum primis duobus obscurioribus, articulo tertio toto nigro diversa. Cinerea, opaca. Frontis pars superior et superius occipilis dimidium cinerea. Frons aequalis, viltâ aurantiacâ picta. Antennae breves, articulis primis duobus ex flavo subfuscis, secundo supra nigricaute, in apice flavo albo-micante, articulo terlio brevi, toto nigro, setâ concolore pilis longis plumata. Facies, genae et inferior occipitis pars albidae. Proboscis flavescens; palpi ex flavo albidi. Thoracis dorsum vix obsoletissime sublineatum. Hypopygium pallide flavum; ultima duo abdominis segmenta ex flavo cinerea, praecedentibus fere concolora. Coxae et pedes toti dilute flavescentes, femoribus minus validis, quam in specie praecedente, anticis non lituratis. Pili mediocres in inferiore occipitis dimidio, in pleuris, coxis ef femoribus ex llaro subalbidi, in abdominis basi et lateribus pilis nigris intermixti; pili abdominis praeter basim et latera nigri; femora supra, tibiac et larsi breviter nigro-pilosa; setae omnes nigrae. Alae sublutescentes, immaculatae, venis luteis. - (Wisconsin).

47. Cordylura cincta nov. sp. $\sigma$. Cinerea, opaca, pilis selisque nigris, vilt $\hat{\imath}$ fronlali favà, facie genisque albidis, anternis majusculis nigris, articuli secundi apice et basi tertii flavis, selti nudâ, palpis albis, ex basi tenuissimâ admodum dilatatis, coxis cinereis, pedibus faris, femoribus validis, unnulo medio nigricunte latissimo, sed imperfecto cingulatis, alis subcinereis, renis luteis. Long. corp. 3 lin, Long. al. 3 lin.

Cinerea, opaca, pilis setisque praeter pubem in occipitis dimidio inferiore nigris. Margines fronlis laterales, verfex el oceiput concolora; vitta frontalis llava; orbitac frontalis pars anterior et orbitit facialis flavicantes; facies el genae albidac. Antenuae majusculae, nigrae. articuli secundi apice et tertii basi llavis, seti nigra nudit. Palpi albi, ex basi anguslissimâ maximopere dilatali. Proboscis nigra. 
Thoracis dorsum nou lineatum. Pleurae cum coxis, scutellum et metanotum concolora. Pedes flavi; femora valida maculis duabus nigricantibus, alterà superà, alterù inferâ, in annulum latum subconfluentibus ornata. Alae subcinerascentes, venis luteis. - (District Columbia, Osten-Sacken.)

Nota. Abdomen speciminis descripti nimis laesum, quam ut adcuratiorem ejus descriptionem facere possim.

48. Cordylura cornuta nov. sp. ‥ Obscure cinevea, opaca, occipite, frontis marginibus et triangulo verticali concoloribus, villi frontali supra fuscâ, infra aurantiaca, facie, genis palpisque albidis, proboscide antennisque elongatis nigris. seta harum breviter pubescente, ultimo abdominis segmento testaceo, pedibus ex luteo testaceis, alis luteis, venis concoloribus. - Long. corp. $2 \frac{1}{2}$ lin., Loug. al. $2 \frac{1}{2} \operatorname{lin}$.

Obscure cinerea, opaca, pilis brevibus setisque omnibus nigris. Triangulum verticale, margines frontis laterales et occiput praeler marginem inferum cinerea; vitia frontalis aurantiaca, supra obscure fusca. Facies et genae albidae. Antennae elongalae, nigrae, ariiculi secundi apice flavo, setâ breviter pilosâ. Thoracis dorsum non lineatum. Ultimum abdominis segmentum compressum, sordide testaceum. Coxae et pedes ex rufo testacei; extremus femorum posteriorum apex niger; tarsorum anticorum articulus ullimus, intermediorum articuli ultimi duo tarsique postici toti nigri. - Alae lutescentes, venis luteis. - (Euglish River, Kennicot).

19. Cordylura gilvipes nov. sp. ㅇ. Nudiuscula, anguslu, tomento luteo opaca, occipite, vertice lateribusque frontis concoloribus, villa frontali aurantiacâ, facie genisque flavicantibus, albidopollinosis, antennis longiusculis nigris, articulo secundo praeter basim flavo, palpis dilute flavescentibus, coxis anticis pedibusque tolis luteis, alis longis, angustis, sublutescentibus, venis luteis, adversus apicem alarum fuscis. - Long. corp. 3 lin., Long. al. $2 \frac{1}{1} \frac{1}{2}$ liu.

Angusta, nudiuscula, opaca, nigro totius corporis colore polline confertissimo luteo obtecto. Vertex, froutis margines laterales et occiput concolora; vitta frontalis aurantiaca. Autennae longiusculae. nigrae, articulo secundo praeter basim flavo, setà nigrâ, nudà. Fa cies et geuae flavicautes, albido-pollinosac. Setae mystacinae utriuque complures. Palpi dilutissime lutescentes. Proboseis nigra. Thoracis dorsum non linealum, selis plerisque solito brevioribus. Ullimum abdominis segmentum non compressum, praecedentibus con- 
color. Coxae posteriores nigrae, polline luteo vestitae; coxae an ticae et pedes lutei. Alae longae, angustae, sublutescentes, venis luteis, in apicen et marginem posticum excurrentibus finem versus fuscis. - (English River, Kennicot).

Nota. Cordyl. gilvipes propinquior Scatophagis est quam reliquae sui generis species.

50. Hydromyza confluens nov. sp. ठ大. Ex cinereo nigricans, opaca, nudiuscula, abdomine glaucescente, fronte super antennas, orbitis oculorum facialibus, genibus tarsorumyue basi rufis, facie dilute flavescente, palpis ex rufo flavis, alis ex cinereo nigricantibus, cellulì basali secundá cum discoidali in unam conjuncti. - Long. corp. $2 \frac{1}{2}$ lin., Long. al. $2 \frac{1}{6}$ lin.

Ex cinereo nigrieans, opaca, setis pilisque brevibus, rigidis, nigris. Caput nigrum, vertice et occipite polline pallido cinerascentibus, fronte prope antennas nigras orbitâque oculorum faciali rufis, facie dilutissime flavescente, genis palpisque ex rulo flavis; setae mystacinae parvae. Humeri, margines laterales thoracis angulique postici cinerei. Pleurae superius polline subfusco, inferius subalbido vestitae. Abdomen glaucescens, segmento quinto turrito. Pedes nigri, cinereo-pollinosi, trochanteribus, genibus tarsorunque basi rufis. Halteres rufi. Alae ex cinereo nigricantes; venis validis nigris, Lerliâ et quartâ finem versus subconvergentibus, cellulis discoidali et basalium secundâ confluentibus. - (English River; Kennicot).

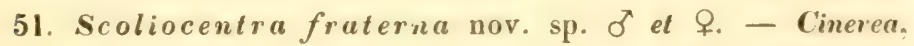
opaca, pube confertà longiore setisque nigris vestila, capite cum antennis et palpis ex ochraceo rufo, dimidio anteriore frontis flavo, humeris, scutello et abdomine ex testaceo mifis, pleuris totis conferlim nigro-pubescentibus, rufo-et cinereo-variegalis, pedibus ex bulio rufis, tarsis anticis tibiis subaequalibus, alis dilute subfuscis, setulis costae mediacribus. - Long. corp. $2 \frac{1}{2}-2 \frac{2}{3}$ lin., Long. al. 3$3 \frac{1}{4} \operatorname{lin}$.

Cinerea, opaca, praeter setas ordinarias pube confertâ nigrii longiusculâ vestita. Caput ex ochraceo rufum, dimidio superiore occipitis paulo obscuriore. Frontis latae dimidium anterius flavum. Antennae ex ochraceo rufae, articulo tertio rolundo, seta atrì. longì. tenui, subnudà. Facies recedens et genae latae polline tenui albido aspersae. Seta mystacina utriuque unica. Palpi ex ochraceo ruli. latiusculi. Oculi rolundi. Thoracis dorsum cinereun opacum. immaculatum, nigro-pubescens, humeris angulisque posticis ex testa- 
ceo rufis. Scutellum ex testaceo rufum, praeter selas solitas nudum. Metanotum nigricans. Pleurae totae confertim nigro-pubescentes, setà supra coxas intermedias unicâ mediocri, maculis rufis et obscure cinereis variegatae. Abdomen ex tesiaceo rufum, hy popygio maris parvo. Pedes ex badio rufi, femoribus tibiisque confertim nigro-pilosulis, tarsis apicem versus fuscis. Alae longae, dilute subfuscae, setulis costae mediocribus validiusculis. - (Sitka; Sahlberg).

Nota. Simillima Scoliocentrae spectabili, quae tamen major et gracilior quam nostra species est et tarsos multo longiores habel.

52. Blepharoplera lutea nov. sp. ठ et 우. - Tota ochracen, opaca, tarsis apicem versus subfuscis, setâ antennarum subnudâ, setâ mystacinâ utrinque unâ, validâ, pleurarum dimidio superiore scutelloque praeter setas solitas nudis, femoribus omnibus validis, hypopygio maris parvo, alis subcinerascentibus, setulis costue minutis. - Long. corp. $1 \frac{5}{6}$ lin, Long. al. $1 \frac{1}{1} \frac{1}{2}$ lin.

Ex affinibus Blepharopt. inseriplae et crassipedis. Tota ochracea, opaca. Antennae concolores, articulis primis duobus brevissimis, articulo terlio majusculo rolundo, setâ tenui nigricante, subnudà. Oculi subrotundi. Genae latiusculae. Seta mystacina utrinque unica, valida. Dimidiun superius pleurarum prorsus nudum; supra coxas intermedias sela unica. Abdominis segmenta subaequalia, intermedia interdum, marginibus posticis tamen exceptis, fusca vel nigra. Hypopygium maris parvum, concolor. Coxae et pectus inter coxas nigro-pilosa. Pedes ochracci, femoribus validis, tarsis apicem versus subfuscis. Alae ex luteo subcinerascentes, venis dilute subfuscis, adversus apicem et marginem posticum fuscis, setulis coslae parvis. - (Sitka; Sahlberg).

53. Blepharoptera leucostoma nov. sp. $\sigma^{7}$ et 오. Ochracea, opaca, vertice, occipite, thoracis dorso praeter humeros et praeter angulos posticos, melanoto pleurarumque fascià latissimá cinereis, facie genisque candido-pollinosis, set î mystacinâ ulvinque unicì valida, dimidio superiore pleurarum scutelloque praeter setas sulitas mudis, femoribus omnibus validis, hypopygio maris parvo, alis subcinerascentibus, setulis costae parvis. - Long. corp. $1 \frac{1}{1} \frac{1}{2}$ lin., Long. al. 2 lin.

Ochracea, opaca. Caput concolor, oceipitis dimidio superiore, triangulo ocellari lateribusque verticis cinereis, lunula frontali, facic genisque candido-pollinosis; orbilae fronlales angustissime albidopollinosae. Autennae obscure cinerene, articulis primis duobus bre- 
vibus, tertio majusculo rolundo, selà tenui nigricante, subnudâ. Seta mystacina utrinque unica, valida. Oculi rotundi. Genae latiusculae. Thoracis dorsum opacum, practer humeros ochraces cinereum. Pleu. rac ochraceae, fasciì latissimâ cinereâ, interdum fere totae obscure cinercae, dimidio superiore prorsus nudo, seti supra coxas intermedias unà. Scutellum praeter selas solitas nudum. Metanotum cinereum. Segnenta abdominalia subaequalia, intermedia interdum praeler margines poslicos fusca. Hypopygium maris parvum, concolor. Coxae et pectus inter coxas nigro-pilosa. Pedes ochracei, femorihus validis, larsis apicem versus fuscis. Alac subcinerascentes, venis subfuscis, adversus apicem et marginem posticum ex nigro fuscis, setulis costae parvis. - (Sitka; Sahlberg).

54. Palloptera terminalis nov. sp. $\sigma^{7}$ et ․ Cinerea, opaca, capite, scutello, abdomine, coxis pedibusque flavis; alis subhyalinis, venâ auxiliari et vená longiludinali primâ praeter basim nigricantibus; alae apice ipso venarumque ibi excurrentium apicibus anguste nigro-marginatis, venâ transversâ posteriore anguste et dilute nigro-limbalda. - Long. corp. $1 \frac{2}{3}-1_{6}^{5}$ lin., Long. al. $2 \frac{1}{3}-2 \frac{3}{4}$ lin.

Pallopterae ustulatae valde similis. Cinerea, opaca. Caput flavum, antennis, proboscide palpisque concoloribus; maculà occipitali et puncto ocellari nigris. Thorax tofus cinereus, opacus, callo humerali subtestaceo. Scutellum flavum. Abdomen flavum, segmentis intermediis praeter margines singulorum posticos saepe fuscis. Coxae flavae. Pedes concolores, extremo tarsorum apice fuseo vel ex fusco nigro. Halteres flavicantes. Alae subhyalinae, in basi dilute flavescentes; vena auxiliaris et vena longitudinalis prima praeter basim ex fusco nigrac, cellulà interjectâ concolore; apex venae longitudinalis secundae longius, apices venarum longiludinalium tertiae et quartae brevius nigro-limbali, limbis omnium cum limbo an. gusto concolore, alae apicem cingente conjunctis; renulae transversae mediae limbo obscuriore nullo, posterioris angusto, dilute nigricante. - (Silka; Sablberg).

55. Pallopleva jucunda nov. sp. $\sigma^{\top}$ et . Tola flava, alis hyalinis, apice, cellulae marginalis dimidio secundo, venularum transversalium limbis venisque auxiliari et longitudinali prima ex fusco nigris. - Long. corp. 1 $\frac{3}{4}-1 \frac{5}{6}$ lin.. Long. al. $2 \frac{1}{2}-2 \frac{2}{3} \operatorname{lin}$

Tola flava, nigro-pilosa. Dimidium anterius frontis sublumidum. Hypopygium maris majusculum, globosum. Alae hyalinae; vena anxiliaris et vena longitudinalis prima cum areolâ interjectî et apice 
cellulae costalis summo ex fusco nigrae; venula transversa media anguste, posterior late fusco-nigro limbatae; margo costalis inde a cellulae marginalis dimidio et apex alae late fusco-nigro limbati. (Sitka; Sahlberg).

Nota. Pallopterae arcuatae valde affinis, sed major; venâ auxiliari et venâ longitudinali primâ ex fusco nigris venulisque transversis latius distantibus ab illâ diversa

56. Sapromyza rotundicornis nov. sp. ㅇ. Flava, palpis antennisque concoloribus, articulo tertio harum rolundo, setá brevissime pubescente, segmentis abdominis ultimis tribus singulis atrobipunctatis. - Long. corp. 1! lin., Long. al. $1 \frac{3}{4}$ lin.

Ex ochraceo flava. Antennae concolores, articulo tertio rotundo, setà subfuscâ brevissime pubescente. Proboscis et palpi flavi. Scutellum subplanum. Segmenta ultima tria abdominis singula atrobipunctata, punctis antepaenultimi reliquis minoribus. Pedes toti flavi. Alae dilute sublutescentes, venis luteis. - (Sitka; Sahlberg.)

57. Sapromyza umbrosa nov. sp. ठ․ Flavescens, fronte, thorace scutelloque subfusco vittatis, abdomine subfusco, tibiis postevioribus prope basim nigro-annulatis, alis ex fusco cinereis, dimidio anteriore fere toto venularumque transversalium limbis obscure fuscis. - Long. corp. $1 \frac{1}{4}$ lin., Long. al. $1 \frac{1}{2}$ lin.

Ex testaceo flavescens, opaca. Caput flavum, vittâ frontali sub. fuscâ, per triangulum ocellare elongatum dissectà, orbilâ oculorum faciali prope antennas puncto nigro pictâ, infra pilosâ, pilo supremo reliquis longiore, setulam mystacinam meutiente. Antennae ochraceae, breves, articulo tertio rotundo, setâ breviter pubescente. Thoracis dorsum vittis angustis subfuscis quatuor et lineà mediầ obsoletiore variegatum. Scutellum subfusco-bivittatum. Pleurae subfusco obsolete maculatae. Abdomen sordide fuscum, in vivâ verisimiliter testaceum. Pedes flavescentes, femoribus anticis adversus basim nigricantibus tibiisque posterioribus prope basim annulo imperfecto nigro cinctis. Alae ex fusco cinereae, limbo costae latissimo fusco, inde a venae auxiliaris fine usque ad apicem alae pertinente et in parte apicali usque ad venam quarlam dilalato, venulis transversis fusco-marginatis. - (District Columbia; Osten-Sacken.)

58. Sapromyza sticlica nov. sp. ․ Opaca, capile, thorare sculelloque cinereis, punctis maculisque nigris aspersu, abdomine nigro, maculis punclisque cinereis variegalo: alae latae, ma- 
melis nigris, confertis et confuentibus pictae, maculâ apicali gutlis

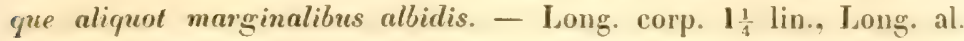
$1 \frac{1}{2} \operatorname{lin}$.

Tola opaca. Caput ex flavo cinereum: vitla frontalis fusca; setar frontales et verlicales e punctis nigris ortae; orbita facialis nigro-punctata. Antennac breves, articulo tertio rolundo, in Iatere exteriore puncto nigro notato. Thoracis dorsum cinereum. lineis duabus, maculis aliquot punclisque ex fusco nigris pictum. Pleurae ex fusco nigrae, cinereo-maculatae. Scutellum ex flavo cinereum, angulis lateralibus vitlulisque duabus ex fusco nigris. Abdomen ex fusco nigrum, maculis punctisque cinereis aspersum. Pedes dilute flavescentes. annulis femorum duobus latissimis tibiarumque annulo basali nigris. Halterum capitulum nigrum. Alae latae, dilute subfuscae. maculis' nigris confertissimis, inter se confluentibus variegatae, maculà apicali gutlisque circiter undecim (quinque costae, marginis postici sex) albidis. - (District Columbia; Osten-Sacken.)

59. Diastatce eluta nov. sp. ठ. Ex fusco cinerea, ópaca. capite praeter occiput ochraceo, abdomine nigro nitido, pedibus obscure testaceis, alis dilute subcinerascentibus, apice cinereo-nebuloso. cellula costali venularumque transversalium limbis latissimis nigris. Long. corp. 1 $1 \frac{1}{4}-1 \frac{1}{3}$ lin., Long. al. $1 \frac{1}{2}-1 \frac{7}{12}$ lin.

Caput ochraceum, occipite nigricante, cinereo-pollinoso. Antennae ochraceas, colore articuli tertii interdum in fuscum vergente; facies et genac albido-pollinosae. Palpi obscure ochracei. Thoracis dorsum ex fusco cinereum, opacum. Scutellum concolor. Pleurae et metanotum nigra, cinereo-pollinosa. Abdomen nigrum, nilidum, obsoletissime fusco-pollinosum. polline in marginibus posticis segmentorum singulorum non dilutiore. Coxae ex testaceo fuscae; pedes obscure testacei. Alae dilute subcinerascentes, apice cinereonebuloso, cellulà costali fere tolà. strigulà cellulae marginalis prope apicem venae primae sitâ limbisque latissimis venarum transversalium nigris: plagae duae, altera inter limbos venularum interjecta altera trans venulae posterioris limbum sita, quam reliquae alae partes limpidiores. - (Sitka; Sahlberg.)

Nota. Multis notis cum Diaslalí nebulosi congruit, sed abdomine nitidiore. marginibus posticis segmenforum singulorum polline pallidiore non aspersis, alis non cinereis, sed dilute subcinerascentibus plagisque duabus limpidis non albicantibus obsoletioribusque ab illà distincla. 
60. Drosophila terminalis nov. sp. $\delta$. Pallide testacen, metanoto nigricante, abdomine praeter latera fusco, ultimis duobus segmentis atris, alis subcinereis maculâ upicali nigrâ notatis. Long. corp. $1 \frac{1}{3}-1 \frac{5}{12}$ lin., Long al. $1 \frac{7}{1} \frac{7}{2}-1 \frac{2}{3}$ lin.

Frons flava, limbis lateralibus leviter albo-pollinosis. Antennae dilulius flavae. Facies ex albo flavescens; setae myslacinae et quae in palporum apice exstant validiusculae. Color thoracis et scutelli dilute testaceus, metanoti nigricans; vittae dorsales albido-pollinosae duae obsoletissimae; in speciminibus quibusdam linea media fusca apparet. Pleurae flavae vel testaceae, dimidio superiore interdum subfusco. Abdomen praeter latera dilute testacea ex nigro fuscum, segmentis ultimis duobus atris. Pedes flavescentes. Alae ex luteo subcinerascentes, maculâ minutâ nigrâ in venae tertiae fine; venae longitudinales tertia et quarta parallelae. - (Sitka; Sahlberg.)

Nota. A Dros. arlustâ distinguitur corpore majore, facie minus albà, thoracis vittis dorsalibus obsoletissimis, metanoto nigricante setulisque femorum anticorum longioribus.

61. Crassiseta formosa nov. sp. ㅇ. Atra, modice nilens; caput, occipile tamen et triangulo verticali exceptis, rufum; abdomen rufum, marginibus et apice fuscis; pedes flavo et rubido varii,

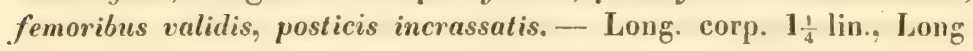
al. $I_{\frac{1}{2}}^{\frac{5}{2}}$ lin.

Caput ex ochraceo rufum, occipite et triangulo verticali permagno atris, nitidis. Antennae cum capite concolores, articulo tertio subovato, supra plerumque fusco, setâ compresso-dilatatâ, breviter pubescente, nigrâ. Palpi ochracei. Thorax ater, nitidus, dorso punclis exsculptis scabriusculo. Scutellum planum, scabriusculum, dentibus marginalibus minutis. Abdomen rubidum, segmentis posticis totis et praecedentium marginibus lateralibus obscure fuscis; maculae mediae fuscae in primis duobus segmentis rarius adsunt. Coxac dilute flavae. Pedes validi, dilute flavi, femorum anteriorum dimidio apicali, femoribus posticis praeter basim, tibiis anticis posticisque, tibiarum intermediarum basi, tarsis anticis posteriorumque articulo ultimo rubidis, colore tibiarum anticarum posticarumque et tarsorum anticorum pleruinque in badium vergente. Femora anteriora valida, postica valde incrassata. Alae hyalinae, levissime subcinerascentes, venis subfuscis. - (District Columbia; Osten-Sacken.)

Nota. Prima duo abdominis segmenta inter se connala in hace et in sequentibus Oscinidarum speciebus pro singulis numeravi. 
62. Crassisetu costata nov. sp. ․ Atra, nitida. capite favo, triangulo verlicali, interdum etiam maculi faciei atris; ilentes scutelli distincli; antennae ochraceae, setà compresso-dilatata. breviter pubescente; pedes ex rufo flavi, anticorum tibiis et tarsis posticorumque tibiis ex fusco nigris (in speciminibus immaluris multo dilutioribus); secundum costae segmentum distincte incrassatum. Long. cosp. $1 \frac{1}{6}$ lin., Long. al. $1 \frac{1}{4} \mathrm{lin.}$

Atra, nitida. Caput flavum, occipite nigro, maculà faciei mediâ et triangulo verticali permagno, ab oculis separato atris, nitidis; occiput atrum; genae ex nigro fuscae. Antennae ex flavo ochraceae. articulo tertio subrotundo, supra fusco, setà dilatato-compressà, breviter pubescente, nigrâ. Clypeus et proboscidis genu atra, nilida; palpi flavi. Thoracis dorsum et scutellum ut in plerisque punctis exsculplis scabriuscula et minus splendida; dentes scutelli plani distincti. Abdomen nitidissimum, ventre plerumque sordide rufescente. Coxae et pedes flavi, femorum colore magis in rufum vergente, tibiis anticis tolis, posticis praeter basim et apicem tarsisque anticis ex fusco nigris. Alae ex cincreo hyalinae, venis fuscis, costae segmento secundo quam in speciebus sequentibus crassiore. - (District Columbia; Osten-Sacken.)

Nota. Mire colore variat, ut Crassiselae solent. Specimina immatura caput totum flavum habent, superiore occipitis dimidio trianguloque verticali exceptis; pleurae ex rufo testaceac sunt, pedum anticorum tibiae et tarsi colore dilate subfusco tingunlur et tibiae posticae annulum fuscum gerunt.

63. Crassiseta nigriceps nov. sp. Q. Atra, nitida, capile concolore, abdominis busi teslacei; dentes scutelli subobsoleti; antennae ochraceue. sela compresso-dilatati, breviter jubescente; pedes ex rufo flavi, libiis tarsisque anticorum, posticorum femoribus praeter basim et tibiis ex fusco nigris; secundum costae segmentum nom incrassatum. - Long. corp. 1 liu., Long. al. $1_{i j}^{\prime}$ lin.

Atra, nitida. Caput alrum, occipite subnitido. triangulo verticali permagno, nitidissimo, supra ab oculis anguste disjunclo, infra ad anticum usque frontis marginem perlinente. Anlemac ex rufo ochraceac, articulo lertio ovato, supra fusco, selí dilatato-compressit. breviter pubescente, alrì. Thoracis dorsum et sculellum planum punctis exsculplis scabriuscula et minus nitida; dentes scutelli valde minuti. Abdomen nitidum, alrum, in basi sordide tastaceum vel lutescens; veuler dilute lutescens, apicem versus obseurior. Coxar. el pedes flavi, colore femorum magis in rufum vergente; perlum an- 
ticorum tibiae et farsi, posticorum femora praeter basim et tibiae ex fusco nigrae. Alae ex cinereo hyalinae venis subfuscis. secundo costae segmento non incrassato. - (Pennsylvania.)

64. Crassiseta longula nov. sp. ㅇ. Alra, triangulo verlicali, thorace et scutello subnitidis, abdomine nitidissimo; scutellum planum, dentibus obsoletissimis vel nullis; margo frontis anticus et primi antennarum articuli ex ochraceo rufi; pedes ex rufo flavifemoribus omnibus adversus apicem, tibiis anticis posticisque, tarsis denique anticis ex nigro fuscis; secundum cosiae segmentum non incrassatum. - Long. corp. $1 \frac{1}{12}$ lin., Long. al. $1 \frac{1}{6}$ lin.

Atra. Caput coneolor, occipite et triangulo verticali permagno minus nitentibus quam in reliquis speciebus, frontis margine antico ex ochraceo rufo, colore faciei ex nigro in piceum vergente. Antennarum articuli primi duo ex ochraceo rufi, tertius ex nigro fuscus, in basi cum praecedentibus concolor' seta modice compressa. nigro-pubescens. Palpi ex fusco nigri. Thoracis dorsum et scutellum punctis confertis exsculptis scabra, modice nitentia; scutellum planum, dentibus obsoletissimis vel nullis. Abdomen atrum nitidissimum. Coxae et pedes ex rufo flavescentes; femora anteriora supra fusco liturata, postica praeter basim ex nigro fusca; tibiae anticae et posticae, basi tamen exceptâ, ex nigro fuscae; tarsi antici toti extremusque posteriorum apex ex nigro fusci. Alae hyalinae, dilutissime subcinerascentes, venis subfuscis, secundo costae segmento non incrassato. (District Columbia; Osten-Sacken.)

65. Crassiseta nigricornis nov. sp. $ठ$. Nitida, alra, capile et antennis concoloribus; dentes scutelli convexiusculi nulli; pedes ex testrceo lutei, femorum apice, tibiis tarsisque ex fusco nigris; secundum costae segmentum non incrassalum. - Long. corp. 1 lin., Long. al. $1 \frac{1}{6}$ lin.

Atra, nitida, nigro-pilosula. Caput atrum, opacum, occipite nitido, triangulo verticali nitidissimo, maximo, supra oculis subcontiguo, infra usque ad anticum frontis marginem perlinente. Antennae totae atrae, setâ concolore, minus quam in duabus praecedentibus compressâ, sed pube paulo longiore vestitâ. Thorax et scutellum convexiusculum nitidissima, punctis exsculptis nullis; dentes in matgine scutelli nulli. Coxae et pedes ex testaceo lutei, femorum liturâ superiore obsoletiore et extremo apice, tibiis tarsisque omnibus ubique ex fusco nigris. Alae hyalinae, leviter subcinerascentes, secundo costae segmento non incrassato. - (Louisiana; Schaum.) 
66. Guuraxfestivus nov. sp. ơ. I'allide flavus, albo-pilosus, thoracis dorso mufescente, tertio anlennarum articulo, margine frontis supero, occipite, dorsalibus thoracis maculis, pleurarum strigulâ, halterum capitulo, metanoto abdomineque atris; pedes albi, femoribus posticis tibiisque posterioribus atro-lituratis. - Long. corp. $\frac{5}{6}$ lin., Long. al. $\frac{3}{6}$ lin.

Caput lacte flavum; triangulum verticale concolor, margine supero tamen atro, nitido; arliculi antennarun primi duo breves, flavi, articulus tertius suspensus, reniformis, praeter basim flavam ater, pube albâ confertim vestitus; seta subapicalis breviter sed distincte plumata. Facies angusta, excavata; setula mystacina albida utrinque una; laterales oris margines albido-pilosi. Oculi majusculi, subrotundi, pilis albidis aspersi; genae angustissimae. Occiput atrum, margine infero tamen flavo. Thoracis dorsum rufescens, nitidum, albido-pilosum; in medio dorso prope marginem anticum adest macula didyma atra, quae cum maculâ majore atrâ, margini postico appositâ el tridentalà, per lineam atram conjungitur; prope latera dorsi macula humeralis et vittula atrae cernuntur. Pleurae flavae strigulà mediâ alıâ notantur. Scutellum breve, subconvexum, laete flavum, albida-pilosum. Metanotum et abdomen atra, vitida. Pedes albi, albo-pilosi; femora poslica supra lituram mediam, postice maculam subapicalen atras habent; tibiae intermediae prope apicem utrinque liturâ atrà ornantur, posticae utrinque liturâ mediâ. Pedunculus halterum albus, capitulum atrum. Alae latae, distincte infuscatae, adversus basim el marginem posticum cinereae, venis subfuscis, longitudinali quarti prope apicem in alae marginem excurrente, transversà posteriore obliquâ. - (Pennsylvania.)

Nofa. Gaurax, qui Oscininis adnumerandus est, a reliquis horum generibus nolis sequentibus distinguitur: 1) antennarum articulo terlio suspenso, majusculo, reniformi, valde pubescente, setâ subterminali plumatâ; 2) facie angustâ excavatâ genisque angustissimis; 3) pube oculorum solito longiore, 4) alis latis.

67. II ippelates nobilis nov. sp. \&. Lx, fusco cinerens, opacus, cupile et antennis flaris, triangulo rerlicali cinereo, opaco, vittuli atri nilida diviso, pectore alvo nitido, primis duobus abulominis segmentis albidis, reliquis atris, nilidis, albo-marginatis; pedes ex albo flavicantes, femoribus tibiisque posticomem annulo medio latissimo nigro ornatis. - Long. corp. 1 $\frac{1}{4}$ lin., Long. al. $1 \frac{1}{3}$ lin.

Caput flavum, colore frontis in ochraceum vergente; triangulum verticale breve, ex fusco cinereum, opacum, villulì medià atrâ ni- 
tidà divisum. Antennae ochraceae, breves, arliculo tertio majusculo rotundo, setâ ex ochraceo subfuscâ, tenui, breviter pubescente. Palpi ex albo flavicantes. Clypeus angustus ater. Occiput nigrum. orbitit tenui albicante, margine infero flavicante. Thoracis dorsum ex fusco dilutissimo cinereum, opacum, subtiliter scabriusculum, vittis tribus depressis, confertius punctatis. Scutellum planum thoraci concolor. Pleurae supra cum dorso concolores, infra atrae el nilidac. Prima duo abdominis segmenta ex flavicanti albida, sequentia tria atra, nitida, marginibus singulorum postiris et abdominis apice albidis. Venter totus albidus. Coxae et pedes dilute flavescenles, femoribus tibiisque posticorum annulo medio latissimo nigro ornatis; tibiae intermediae calcare mediocri recto, posticae ingenti arcuato armatae. Alae hyalinae, obsoletissime ex cinereo sublutescentes, venis luteis, longitudinalibus tertiâ et quarlâ rectis et parullelis. (Illinois.)

Nota. Hippelates calcaribus tibiarum posticarum ingentibus a reliquis Oscinidarum generibus diversus, praeterea totius corporis formâ ac figurâ cum Oscin. pumilionis et affinibus, quas auctores quidam cum Siphonellis veris conjungęre solent, congruit.

68. Hippelates plebejus nov. sp. ․ Ex fusco cinereus, opacus, capite et anternis flavis, Iriangulo verticali cinereo, opaco, integro, pectore cinereo, abdomine ex fusco nigro, nilido, basi, apicalibus segmentorum singulorum marginibus et apice ex albo sordide flavicantibus; pedes flavicantes, femoribus posticis praeter basim et apicem dilutissime subfuscis. - Long. corp. 1 lin., Long. al. 1 lin.

Caput flavum, fronte ochraceâ; triangúlum verticale ex fusco cinereum, opacum, vittulà nitidâ nullâ. Antennae ochraceae, breves, articulo tertio majusculo, rotundo, infuscato, setâ fuscâ, tenui, breviter pubescente. Palpi flavi; clypcus anguslus ater. Occipul nigrum, orbitâ oculorum angustâ ex cinereo albicante, margine infero flavo. Thoracis dorsum ex dilutissime fusco cinereum, opacum, subtilissime scabriusculum, viltis tribus depressis, confertius punctulatis, humeris ochraceis. Scutellum planum, scabriusculum, thoraci concolor, margine tamen ochraceo. Pleurae totae cinereae. Abdomen ex fusco atrum, nitidum, segmento basali flavicante, posticis reliquo. rum singulorum marginibus et extremo abdominis apice ex flavicanti sordide albidis; venter tolus dilute flavescens. Coxae el pedes flavescentes, femoribus posticis praeter basim et apicem obsoletissime. 
subfuscis; libiac intermediae calcare mediocri recto, poslicae ingenti arcuato armatac. Alae hyalinae, ex obsolele cinereo sublutescentes, venis luteis, longiludinalibus tertiâ et quartâ rectis et parallelis. (District Columbiat; Osten-Sacken.)

69. Oscinis pallipes nov. sp. +. Atra. mudiuscula, nitidissima, fronte prater triangulum verlicale, antennis prueter marginem arliculi terfii stuperum, ablominis busi priorigne ventris dimi. dio, coxis, pedibus haltcribusque ex albo dilutissime favicantibus; alae hyalinae, venis pallidis, longitudinalibus tertici et quarlâ perfecte parallelis. - Long. corp. $i^{\frac{7}{2}}$ lin., Long. al. $\frac{2}{3}$ lin.

Nudiuscula, atra, nilidissima. Frons dilute flavescens, triangulo verticali atro. nitido, permagno, supra cum oculis contiguo, infra frontis marginem non attingente. Antennae breves, dilutissime flavescenles, articuli tertii marginibus supero el apicali fuscis, setâ teunissimi concolore. apicem versus subfuseâ, brevissime pubescente. Facies latiuscula, brevis excavala, nigricans, polline cineraseente sparsa, orbitis oculorum angustissimis flavicantibus. Genae angustae, ex nigro fuscae. Proboseis nigricans. Sculellum modice convexum. Abdominis basis el prins ventris dimidium dilulissime lavescentia. Coxae ef pedes ex albo dilutissime flavescentes. Halteres concolores. Alac pure hyalinae, venis pallidis, Jongiludinalibus teriat et quartâ parallelis, costâ dilute subfuscâ. - (Cuba; (iundlach.)

70. Oscin is nudiuscula nov. sp. ơ. Arre. mudiuscule, nitidissima. fronte praeter trianguhum vertirale, antennarum articulis primis dubus et tortii basi, halleribus, coxis perlibusque dilute flavicantibus, fomoribus intermediis praeter apicem nigris; alue cinerene, venis fuscis, longinudinalibus tertiâ el quevtâ apicem versus subdirergentibus. - Long. corp. $\frac{2}{3}$ lin., Long. al. $\frac{3}{4}$ lin.

Nudiuscula, atra, nitidissima. Frons flava, triangulo verticali alro, nilido, mediorri, supra oculis subconligno. Anleunac breves, dilute flavae, articulo tertio practer basiu ex uigro fusco, selit fuscâ distincte pubescente. Facies angusta, nigricans, cincreo pollinosa. Genac anguslissinae, lineares, nigrae. Scutellum modice convexum. Basis abdominis fusca. Cosac el pedes dilute llavescentes, femoribus intermedis practer apicem atris. Inalleres dilute flaveseentes. Alac cinereac, venis ob-eure luscis, longiludinalibus terlia el quarti apicem versus levissime divergentibus. - (Georgia.)

Nola. Pracedenti valde similis, a quà, practer fenurum intermediormu picluram, triangulo vertieali minore, selit anlcunarum 
obscuriore, minus tenui et magis pubescente, facie genisque multo angustioribus et alarum obscuriorum venis fuscis distinguitur.

71. Oscinis flaviceps nov. sp. ‥ Alra, nitidissinu, nula, capite cum antennis dilutissime flavo, occipite et triangulo verticali atris, nitidis; pedes favi, femoribus tibiisque posticorum fusco lituratis; alae hyalinae, venis longitudinalibus tertiâ et quartâ rectis et parallelis. - Long. corp. 1 lin., Long. al. $1 \frac{1}{1 \frac{1}{2}}$ lin.

Caput dilutissime flavum, fronte subtumidà, facie perpendiculari, pilis mystacinis minutissimis pallidis. Triangulum verlicale mediocre, ad mediam usque frontem pertinens, supra valde latum, atrum, nitidum Occiput exceptis marginibus lateralibus et infero atrum. Antennae parvae concolores, arliculis primis duobus mivutis, tertio rotundo, setá tenuissimâ subnudâ. Proboscis dilute flava; palpi concolores. Clypeus indistinctus. Thorax, scutellum convexiusculum et abdomen ex viridi atra, nilidissima, nudiuscula, basi abdominis sordide lutescente. Coxae flavae; pedes sordide flavi, femoribus tibiisque posticorum utrinque fusco lituratis. Alae hyalinae, venis ex luteo subfuscis, longitudinalibus tertià et quartà rectis et parallelis. - (Cuba; Gundlach.)

72. Oscinis dorsalis nov. sp. F. Flava, pedibus concoloribus, thoracis maculà dorsali maximâ postice dentatâ, scutello, metanoto, abdominis dimidio apicali pleurarumque strigulâ atris, nitidis, ultimo antennarum articulo nigro. - Long. corp. $\frac{5}{6}$ lin., Long. al. $\frac{11}{1} \frac{1}{2}$ lin.

Caput flavum, triangulo verticali obscuriore nullo, puncto ocellos includente et occipitis fasciâ transversâ latissimâ atris. Antennae mediocres, articulis primis duobus lutescentibus, tertio nigro, setâ concolore in basi flavicante, breviter pubescente. Facies breviuscula, nonnihil recedens. Proboseis flava; palpi concolores. Thorax flavus, dorso praeter margines laterales et posticun per maculam permasnam atram, postice dentalam completo. Scutellum convexiusculum, atrum, nitidum. Metathorax concolor. Pleurae strigulâ longitudinali ałrâ notatae. Prima duo abdominis segmenta dilute flava, lateralibus secundi marginibus atris, nitidis; segmenta sequentia tota atra, quinti lateribus flavicantibus. Coxae et pedes ex albo llavicantes, apice femorum intermediorum subfusco, posticorum fusco-maculato. Alac hyalinae, venis subfuscis, Jongitudinalibus tertiâ et quartâ rectis et parallelis. - (Pennsylvania.) 
73. Oscinis umbrosa nov. sp. ․ Nudiuscula, nitidissima. atra, capite cum antennis et cum oris partibus concolore, opaco, triangulo verticali tamen nitido, coxis pedibusque flavis; alae subfuscae, adversus marginem posticum cinerene, venis longitudinalibus tertid et quarli apicem versus modice divergentibus. - Long. corp. $\frac{1}{12}$ lin., Jong. al. $\frac{1}{1} \frac{1}{2}$ lin.

Nudiuscula, nitidissima, atrí. Caput concolor, opacum, triangulo verticali magno nitidissimo, supra cum ocellis contiguo, infra frontis marginem prope atlingente. Antennae atrae, articulis primis duobus brevissimis, tertio orbiculari majusculo, setâ concolore validiusculâ, distincle pubescente. Facies modice lata, brevis, concava. Partes oris alıae. Genae lineares, angustae. Sculellum convexum. Coxae et pedes flavi. Halteres concolores. Alac subfuscae, adversus marginem posticum rinereac, venis ex nigro fuseis, longitudinalibus tertià el quartâ finem versus nomnihil divergentibus. - (Peunsylvania.)

74. Uscinis atriceps nov. sp. б et + . Gracilis, nitidissima, nigro-viridis, capite cum antennis et partibus oris atro, opaco, triangulo verticali tamen nitido, coxis pedibusque dilute favicantibus; alae ex fusco cinereae, venis ex fusco nigris, longitudinalibus tertiá et quarlâ subparallelis. - Long. corp. $\frac{1}{1} \frac{1}{2}$ lin., Long. al. $\frac{1}{1} \frac{1}{2}$ lin.

Gracilis, angusta, nitidissima, nigro-viridis. Caput atrum, opacum, triangulo frontali magno, nitidissimo, supra oculis contiguo, infra uon ad frontis marginem usque pertinente. Autennac atrae, articulis primis duobus brevissimis, tertio orbiculari, setà tenui concolore, brevissime pubescente. Genae lineares, angustissimae. Scutellum convexum. Coxae et pedes toli dilute flavicantes. Halteres concolores. Alae dilule fusco-cinereae, venis ex nigro fuscis, longitudinalibus tertia el quarta apicem versus rectis et subparallelis. (Pennsylvania)

Nota. Ab Oscin, atricorni Zett., cui simillima, corporis staturâ. tertio antennarum articulo palpisque minoribus, venis denique longitudinalibus tertià et quartâ minus adcurate parallelis rere distincta videtur.

75. Oscinis hirta nov. sp. ठ'. Nigra, modice nitens, setulis nigris in cupite. thorace et scutello lomgioribus quam in reliquis speciebus, antico frontis margine el antennis flavis, his supra nigro-marginatis, facie et genis albidis, coxis, dimidio priore femorum tibiarumpue basi semper. extreme tibiarum apice larsorumpue 
basi saepe luteis; scutellum convexum setis quatuor praeditum; alae cinereae, venis ex nigro fuscis, longitudinalibus tertiâ et quartâ parallelis. - Long. corp. $1 \frac{1}{6}$ lin., Long. al. $1 \frac{3}{4}$ lin.

Nigra, modice nitens, setulis capitis, thoracis et scutelli validiusculis et longioribus quam in reliquis speciebus. Caput parvum, nigrum: frons opaca, margine antico flavo, triangulo verlicali nitido, mediocri, lato, infra obtuso. Antennae mediocres, flavae, articulis primis duobus brevissimis, tertio rotundo, supra nigro-marginato, setâ tenui distincte pubescente. Facies quam frons angustior, sordide albida vel subflavescens, setis mystacinis utrinque binis, validiusculis, nigris. Genae mediocres albidae. Clypeus utrinque strigulà nigrâ notatus; palpi flavescentes. Thorax niger, polline raro cinereo aspersus, modice nitens. Scutellum convexum, setis nigris quatuor. Abdomen nigrum, hypopygio concolore majusculo, globoso. Coxae lufeccentes vel testaceae; pedes ex fusco nigri, dimidio basali femorum tibiarumque basi semper, extremo tibiarum apice tarsorumque basi saepe lutescentibus vel testaceis. Halteres sordide albidi. Alae cinerascentes, venis ex nigro fuscis, longiludinalibus tertiâ et quartà parallelis. (IIlinois.)

Nota. Specimina immatura pedes multo dilntius pictos habent.

76. Oscinis decipiens nov. sp. \%. Nigra, nitida, capile praeter occiput et triangulum verlicale flavescente, antennis orhraceis, setâ nigrâ, validiusculâ, sed non incrassatâ, distincte nigropubescente. pedibus testcceis, femoribus magnat ex parte fuscis; thoracis dorsum rare punclatum, viltis duabus depressis, confertius punctatis; scutellum planum, scabrum. - Long. corp. 1 lin., Long. al. 1 lin.

Praeter setam antennalem non incrassatam formâ ac figurâ totius corporis cum Crassisetis congrua, prae reliquis Crassisetae cornutae simillima. - Nigra, nitens. Caput flavescens, occipite tamen nigro. Triangulum verticale mediocre, atrum, nitens. Antennae breves, ochraceae, articulis basalibus interdum subfuscis. marginibus basali et supero articuli tertii plerumque fuscis; seta validiuscula, sed non incrassata, nigra et distincte nigro-pubescens. Genae mediocres. Clypeus utrinque nigro notatus; proboscis pallide flava; palpi concolores. Thorax tolus ater, nitidus, dorsi punctis raris vittisque duabus depressis, confertius punclatis. Scutellum planum, scabrum, subopacum. Abdomen atrum, nitidum. Coxae anticae testaceae, posteriores piceae. Pedes testacei, femoribus plerumque omnibus praeter apicem et basim piceis vel fuscis, libiis (intermediis tamen ex- 
ceptis) non raro fusco-lituratis, tarsis apicem versus fuscis. Halleres dilute flavicantes. Alae ex lutco dilute cinereae. venis testaceis vel subfuscis, longitudinalibus tertiâ ef quartâ parallelis. - (Silka; Sahlberg.)

77. Oscinis longipes nov. sp. Ot et ㅇ. Gracillima, nudiuscula, nitidissima, atra, antennis, facie et oris partibus concoloribus opacis, pedibus clongatis allidis, femorum apice, tibiis anlicis tolis posticisque nigris; alae tonginsculae cinercae. - Long. corp. 1 $1 \frac{1}{12}$ lin., Long al. 1-1 $\frac{1}{12}$ lin.

Elongata, angusta, nudiuscula, atra, nitida. Caput concolor opacum, triangulo verlicali nitido, frontem modice latam totam explente; facies angusta, brevis. concava, infra cinereo-pollinosa; genae lineares, angustissimae, nigrae, subcinerascentes. Palpi atri; proboscis concolor. Thoracis dorsum polline cinereo rarissimo aspersum. nitidum. Scutellum convexum concolor. Pleurae et abdomen nitidissima. Pedes elongati, graciles, albidi, femorum omnium apice, tibiis anticis pusticisque, harum tamen basi excepti, tarsisque praeter basale intermediorum dimidium nigris. Halteres albidi. Alae longiusculae, adversus basim anguslatae, cincreae, venis ex nigro fuscis. Iongitudinalibus tertiâ et quartà apicem versus distincte divergentilus, apice terliae leviter recurvo. - (District Columbia; OstenSacken.)

Nota. A congeneribus corporis gracilitate pedumque longitudine differt; Osc. atricorni Zett. quam reliquis similior.

78. Oscinis subvittata nov. sp. ơ et . . Gracilis, supra atra, thorace scutelloque scaberrimis, abdomine laevigato, infra flava; caput flavum, margine supero antennarum, triangulo verticali et occipite atris; alae cinerascentes, vittà medià subfuscá. - Long. corp. $1 \frac{3}{4}-3 \frac{5}{5}$ lin., Long. al. $1 \frac{1}{2}-1 \frac{7}{12}$ lin.

Gracilis, atra. Caput ex albo flavicans, occipite atro, fronte saturate flavâ, triangulo verticali mediocri, supra ab oculis distante, ante ocellos profunde foveolato, nitido, atro. Antennae magnae. articulis basalibus duobus brevibus, ochraceis, articulo terlio breviter ovato, ex flavo albido, supra alro-marginato; seta albida, pube concolore longiusculâ vestita. Facies recedens, subplana, supra subtiliter carinata, albo-pollinosa. Genac angustae, concolores. Prohoscis flava; clypeus concolor; palpi maris flavi, foeminac atri. Thoracis dorsum atrum, bisulcalum, scaberimum, modice nilens. Scutellum planum, scabrum, thoraci concolor. Melanolum alrum. Pleurae flavae, supra 
rufescentes. Abdomen longum, tenue, atrum, nitidum. Venter dilute flavus. Pedes graciles, flavi, extremo apice tarsorum nigro. Halteres albi. Alae dilute cinerascentes vittâ mediâ subfuscâ, venis obscure fuscis, longifudinalibus tertiâ et quartâ valde divergentibus.

- (Washington, Osten-Sacken.)

79. Oscinis variabilis nov. sp. o et 9 . Atra, nitidissima, capile, antennis et oris partibus concoloribus opacis, triangulo frontali tamen nilido; pedles atri, tibiarum apice tarsisque praeter apicem dilute flavicantibus; halleres flavicanites; alae cinereae, venis longitudinalibus tertia et quartâ parallelis. - Long. corp. $\frac{1}{2}-\frac{7}{12}$ lin., Long. al. $\frac{7}{1 \frac{7}{2}}-\frac{2}{3}$ lin.

Oscini Frit simillima, sed purius atra et magis nitens. Caput atrum, opacum, antennis mediocribus et partibus oris concoloribus; triangulum verticale nitidissimum, magnum, supra cum oculis contiguum, infra frontis marginem non attingens. Facies subangusta, brevis, mediocriter excavata. Genae lineares angustissimae. Scutellum convexum. Coxae et femora atra, extremo apice horum interdum flavescente; tibiae basim versus atrae, apicem versus flavescentes; tarsi dilute flavescentes, in apice nigri. Halteres subflavescentes. Alac cinereae, venis nigris, longitudinalibus tertiâ et quartâ parallelis. - (District Columbia; Osten-Sacken.)

Nota. Tibiis fere totis flavis variat.

80. Oscinis trigramma nov. sp. $\sigma^{7}$. Latiuscula, nigricans, subopaca, triangulo verticali, thoracis vittis quatuor et scutello plano obscure cinereis, opacis; pedes sulflavicantes, femoribus praeter apicem nigricantibus, tibiis obsolete, sed late subnigro annulatis; alae subcinereae, venis longiludinalibus tertiâ et quartâ parallelis. - Long. corp. $\frac{7}{12}$ lin., Long. al. $\frac{7}{12}$ lin.

Ex affinibus Oscinis pumilionis. Latiuscula, nigricans, subopaca. Frons nigra, opaca, margine antico flavo, marginibus lateralibus anguste cinerascentibus, triangulo verticali brevi, obscure cinereo, opaco. Antennae breves, lutescentes, articulo tertio latissime fusco-marginato. Facies brevis, quam frons angustior, subalbicans; genae angustac concolores. Clypeus ex fusco niger; palpi flavicantes. In thoracis dorso vittae quatuor aequales, postice subabbreviatae, obscure cinereae, opacae lineaeque interjectae tres ex nigro fuscae adsunt. Scutellum planum, obscure cinereum, opacum. Abdomen nigrum, subopacum. Coxae et pedes subllavicantes; femora intermedia obsoletius, reliqua distinctius nigricantia, apice omnium pallido; tibiae praeter basim et apicem obsoletissime nigricanles; summus 
tarsorum apex ex fusco niger. Halteres subflavicantes. Alae dilute cinereae, venis ex nigro fuscis, longitudinalibus terlia et quartå parallelis. - (District Columbia. Osten-Sacken.)

Nota. Pedum color in speciminibus maturis obscurior esse, quam in specimine descripto, videtur.

81. Siphonella cinerea nov. sp. \&. Cimerea, opaca, abdomine nigricante, basi praeter maculam mediam et apice albidis; caput albicans, fronte et antennis favis, apice hurum fusco, triangulo verticali cinereo, opaco; pedes sordide albidi, femoribus apice excepto nigris, tibiis posterioribus nigro-cingulatis: alue hyalinae. Long. corp. $\frac{3}{4}$ lin., Long. al. ${ }_{6}^{5}$ lin.

Cinerea, opaca. Caput albidum, occipite nigro, triangulo verticali brevi, obscure cinereo, opaco, fronte et antennis flavis, articulo tertio harum praeter basim fusco, setâ tenui. breviter pubescente. Genae latiusculae. Oris apertura longior quam latior, proboscide geniculatâ, perlongâ, atrì, palpis tenuibus, elongatis, albis. Scutellum planum, thoraci concolor. Coxae anticae sordide albicantes, posteriores nigricantes. Femora nigricantia, apice omnium subalbido; tibiae sordide albicantes, intermediae obsolete subnigro cingulalae, posticae annulo latissimo nigro praedilae: tarsi sordide albidi in extremo apice nigricantes. Halteres albidi. Alae pure hyalinae, costầ subfuscà, venis pallidioribus, longiludinalibus tertiâ et quartà parallelis. - (Florida, Osten-Sacken).

82. Chlorops fossulata nov. sp. $\sigma^{7}$. Alra, nitida. fronte, praeter triangulum verticale, fossulì medià excavalum, ex nigro fusch, opaci, untennis tarsisque rufis, halteribus albis; alae ex cinereo hyalinae, venis fuscis, ultimo quartae segmento tenui. - Long. corp. $1 \frac{1}{1} \frac{1}{2}-1 \frac{1}{6}$ lin., Long. al. $\frac{1}{1} \frac{1}{2}-1$ lin.

Nigra, nitida, pube totius corporis brevi. Triangulum verticale magnum, fossulà mediâ latiusculâ excavalum, anticum frontis marginem prope attingens. Frons praeter triangulum opaca, fusca, adversus marginem anticum nigra. Antennae mediocres, rufae, margine articuli tertii fusco, setâ concolore, apicem versus subfuscâ, brevissime pubescente. Facies perpendicularis, nigra, subcinerascens. Genae angustissimae concolores. Thoracis dorsum punctis minutissimis exsculptis subscabrum, modice nitens. Scutellum convexum. scabriusculum, thoraci concolor. Abdomen totum atrum. Pedes atri, genibus testaceis, extremo tibiarum apice tarsisque rufis. IIalteres albi. Alae cinereae, venis obscure fuscis, longitudinalibus ter- 
tiâ et quartá apicem versus divergentibus, ultimo quartae segmento valde attenuato. - (Cuba, Gundlach).

Nota. Colore corporis similior Oscinibus quam Chloropibus sed propter segmenli costalis quarti tcunilatem his adnumeranda.

83. Chlorops sulphurea nov. sp. ․ Pallide fava, tertio antennarum arliculo cum setâ, triangulo verticali praeter latera et praeler angulos superos, villis dorsalibus solitis tribus strigulisque lateralibus, maculis minutis pleurarum duabus vel unicâ, melanoto, maculis duabus in bnsi abdominis prope latera segmentorumque marginibus anticis nigris; tarsi antici plerumyne toti posteriorumgue arliculi ultimi duo vel tres nigri. - Iong. corp. $1_{\frac{1}{1}}^{\frac{1}{2}}$ lin., ILong. al. 15 liu.

Pallide flava, vix uitens. Caput concolor, opacum, fronte subtumida paulo saturatius flavà. Triangulum verticale mediocre, supra ab oculis separitum, infra acutum, nitidum, praeter latera et angulos superos atrum. Macula occipitalis atra supera, subquadrata, ab oculis late separata. Antennae parvae, articulis primis duobus flavis, tertio rotundo, atro, setâ concolore brevissime pubescente. Facies lata, fronti aequalis; genae latissimae. Proboscis flava; clypeus et palpi concolores. Vittac thoracis solitae latiusculae, nigrae, cinereo-pollinosae, media subintegra, laterales antice abbreviatae; strigulae supra alas sitae distinctae, cum vittis concolores; punctum humerale nullum. Sculellum dilute flavum vel albicans, convexum, praeter setulas marginales pilis aliquot minutis nigris aspersum. Metanolum alrum. Pleurarum maculae atrae minulae duae vel unica. Abdominis segmenta singula in basi nigro-fasciati, secundum utrinque maculầ minutà atrâ nolatum. Pedes flavi, tarsis anticis plerumque totis posteriorumque articulis ultimis duobus vel tribus nigris. Halteres albidi. Alae subcinerascentes, venis obscure fuscis, longiludinalibus tertiâ et quartâ divergentibus, tertià subrectî, ultimo segmento quartae attenuato. - (English River, Kennicot).

84. Chlorops sunguinolenta nov. sp. ठ'. Dilute sanguinea, thoracis dorso cinerascente, opaco, villis tribus ex fusco cinereis; antennarum articulis duobus primis fuscis, articulo terlio magno, ovato, ochraceo, in apice alro; facie alba, nigro quadristrigata, palpis majusculis atris, metanoto pleurarumque maculis ex piceo nigris, pedibus piceo et testaceo variegalis. - Long. corp. $1 \frac{1}{2}$ lin., Long. al. $1 \frac{5}{12}$ lin.

Caput magum, album, facie perpendiculari, strigulis nigrican- 
tibus quatuor, infra abbreviatis piclâ. Frons latissima, sordide ochracea, opaca; triangulum verticale mediocre, supra cum oculis non contigurm, cinereo-pollinosum, opacum. punclo ocellari, marginibus lateralibus et angulo antico atris et nitidis. Occiput infra album, supra ex sanguineo subfuscum, vitlulis duabus tenuibus fuscis. Genae latissimae, albae. Margo oris lateralis fuscus; clypeus niger; proboseis flava; palpi majusculi atri. Antennarum articuli primi duo ex nigro fusci, margine extremo secundi tamen ochraceo; articulus tertius magnus, ovatus. supra distincte excisus, basim versus ochraceus, apicem versus ater; setac articulus primus ochraceus, secundus albus, pube paulo longiore albidâ instructus. Thoracis dorsum ex sanguineo cinereum, opacum, vittis solitis strigulisque supra alas ex fusco cinereis. Scutellum thoraci concolor, pilis nigris minutis et raris praeditum. Pleurae sanguineae, maculis ex piceo atris variegatae. Metanotum ex piceo atrum, nitidum.. Abdomen fuscum, colore basis marginumque lateralium in sanguineum vergente, extremo apice sordide albido. Pedes piceo et testaceo varii. Alae subcinereae. venis ex nigro fuscis, longiludinalibus tertiâ et quartâ subparallelis. - (Carolina.)

$$
\text { inthracephacga }
$$

85. Chlorops eucera nov. sp. ơ et ㅇ. Flava, modice nitens, palpis, triangulo verticali toto, thoracis vittis strigulisque, metanoto, pleurarum maculis abdomineque praeter margines atris; antennae magnae, articulo tertio ovato, setâ albâ et distincle albo-pubescente. - Long. corp. $1 \frac{1}{6}$ lis., Long. al. $1 \frac{1}{4}$ lin.

Flava. modice nitens Capul concolor, maculâ occipitali atrâ, superâ, quadralâ. Triangulum verticale atrum, nitidissimum, mediocre, marginibus lateralibus convexis, angulo infero breviler acuminato. Antennae majusculae; arliculi prini duo breves, fusci, secundi marginibus infero et apicali rufis; articulus terlius ovatus, basim versus ex ochraceo rufus, apicem versus ater; articulus primus setae flavus, secundus albus, pube albidà longiusculà ef confertì vestitus. Facies lata, fronti aequalis, lineolis duabus obsolele nigricantibus, infra valde abbeviatis. Clypens utrinque punctum nigrum gerens; proboscis flava; palpi majnsculi atri. Thoracis villae satis latae. et strigulae supra alas atrae, polline cinerascente teclae. subopacae; vitla media postice. lalerales antice abbreviatac. Callus humeralis nigro-notatus. Scutellum modice convexum, praeter selulas marginales pilis nomnullis nigris instructum. Metanotum atrum nitidum. Pleurarum maculae ex fusco atrae, uninutac. Abdomen marginibus et apice exceptis nigrum. Venter flavus. Coxae el pedes 
flavi, femoribus omnibus tibiisque anticis et posticis fuseo vel nigro lituratis; tarsi antici plerumque toti reliquorumque articuli ultimi duo vel tres nigri. Halteres albidi. Alae cinereae, venis obscure fuscis, longitudinalibus tertiâ et quartâ valde divergentibus, tertiâ levissime subrecurvà, ultimo segmento quartae modice attenuato. (District Columbia; Osten-Sacken.)

$$
\text { chlouphs }
$$

86. Chlorops variceps nov. sp. ठำ $\mathrm{et}$. Obesa, nudiuscula. flava, vitlis thoracis latis, pleurarum maculis magnis, metanoto el abdomine praeter margines laterales el praeter margines posticos segmentorum singulorum atris; triangulum frontale permagnum, punctatum, ante ocellos subsulcatum, flavum, angulis superis, puncto ocellari et linể mediâ ex fusco nigris; pedes badii, femorum apice, tibiarum basi et apice primisque tarsorum articulis subochraceis. - Long. corp. $1 \frac{1}{3}$ lin., Long. al. $1 \frac{1}{3}$ lin.

Obesa, nudiuscula, nitida, flava. Caput latum, flavum; occiput praeter margines nigrum. Triangulum verticale permagnum, supra ab oculis sejunctum, infra marginem frontis adpropinquans, punctatum, ante ocellos obsolete fossulatum vel sulcatum, flavum, angulis superis, puncto ocellari et plerumque etiam lineâ mediâ obscurioribus, fuscis vel ex fusco nigris. Antennarum articuli primi duo breves, ochracei vel ferruginei; articulus tertius rotundus, dimidio basali ochraceo vel rufo, apicali nigro; seta nigra, brevissime pubescens. Facies supra recedens, infra rectâ demissa. Genae mediocres. Clypeus utrinque nigro-strigatus; palpi flavi. Thoracis dorsum obsoletissime bisulcatum, vittis atris tribus, adjectis strigulis supra alas solitis; vitta media latissima, postice valde abbreviata, interdum per lineolas tres fuscas cum margine postico dorsi conjuncta; vittae laterales cuneatae, antice modice abbreviatae, postice subintegrae; callus humeralis puncto nigro notatus. Scutellum pla. num. Metanotum alrum. Pleurae maculis magnis atris variegatae. Abdomen atrum, marginibus lateralibus totis, posticis segmentorum singulorum marginibus, apice et ventre flavis. Pedes plerumque badii, femorum apice, tibiarum basi et apice, articulis tarsorum posteriorum primis tribus anticorumque solo primo ex badio ochraceis; pedes toti in speciminibus junioribus colore multo dilutiore pieti. Halteres albi. Alae cinerascentes, venis subfuscis vel fuscis, longitudinalibus tertiâ et quartâ divergentibus, tertiâ subcurvâ, quarlâ et quintâ apicem versus valde attenuatis. - (Pennsylvania; OstenSacken ) 
87. Chlorops trivialis nov. sp. $\sigma^{\top}$ el $q$. Laele flava, nudiuscula, triangulo verticali praeter angulos superos, thoracis vittis tribus integris, pleurarum maculis plerumgue guatuor, metanoto et abdomine atris, margine laterali hujus, segmenti paenultimi margine postico et ullimi apice flavis; antennarum basis flava, articulus tertius vel tolus vel ex parte niger; proboscis et palpi flave-

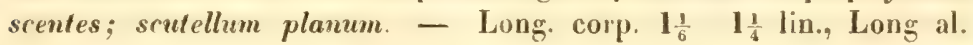
$1 \frac{1}{4}-1 \frac{1}{3} \operatorname{lin}$.

Laete flava, nudiuscula, nilens. Caput concolor; triangulum verticale longum, modice latun, supra ab oculis discretum, infra usque ad frontis marginem pertinens, praeter angulos superos flavos atrum, nitidum, plerumque violaceo-splendens. Antennac majusculae, articulo tertio subrotundo, aut in dimidio apicali ant toto nigro; seta nigricans, brevissime pubescens. Clypeus utrinque strigulâ nigrâ notatus. Proboscis flava; palpi concolores. Genae modice latae. Occipitis macula supera atra cum triangulo verticali plerumque connexa. Thoracis dorsum obsoletissime bisulcatum, vitlis atris tribus, latis, aequalibus; vitta media interdum poslice acuminata aut abbreviata, vittae laterales nonnumquam in angulos scutelli productae. Pleurarum dimidium inferius atro quadrimaculatum. Scutellum planum, praeter setulas apicales duas nudum. Metanotum atrum, nitidum. Abdomen ex fusco atrum, marginibus lateralibus, segmenti paenultimi margine postico et dimidio ultimi secundo semper, maculis segmentorum sinŁulorum lateralibus saepe flavis. Pedes flavi, tarsis anticis plerumque totis, haud raro praeler articulum primum fuscis vel subfuscis. Alae byalinae, obsoletissime subcinerascentes, venis fuscis, longitudinalibus lertiâ et quartâ modice diver ţentibus, tertiâ rectâ, ultimo quarlae segmento tenui. - (District Columbia; Osten-Sacken.)

$$
\text { chlowops }
$$

88. Chlorops pubescens nov. sp. ․ Flava, pube longiore quam congeneres plerique vestitae, palporum apice, tertio antennarum articulo cum basi selue, triangulo fronluli mediocri, sed valde acuminato, thoracis villis modice latis tribus et metanoto atvis, annulo tibiarum posticarum tarsisque, basi tamen horum excepta, ex fusconigris. - Long corp. $1 \frac{1}{3}$ lin., Long. al. $1 \frac{1}{3}$ lin.

Ex luteo tlava, pube nigricante longiore quam Chloropes pleraeque vestita. Caput flavum, mediocre, margine antico frontis acuto; triangulum verticale atrum, nilidum, mediocre, supra ab oculis latius distans, infra admodum acuminatum, ita ut lineâ tenui marginem frontis prope attingat. Occiput flavum, maculà atrâ superà, cum trian- 


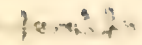

gulo verticali cohaerente. Antennae majusculae; articuli primi doo breves, flavi; articulus tertius rotundus, ater; seta albicans, breviter pubescens, basi atrô, incrassatâ. Genae subangustae. Proboscis flava; clypeus concolor; palpi atri. Thoracis dorsum non sulcatum, vittis atris tribus modice latis, mediâ postice valde abbreviatâ, lateralibus utrinque subabbreviatis, supra alarum basim strigulâ atrå. Scutellum convexum, nigro-pubescens. Metanotum atrum. Pleurae immaculatae. Abdomen quam reliquum corpus obscurius, colore disci in ferrugineum vergente Tibiae posticae late fusco-annulatae; tarsi antici fere toti, reliqui praeter basim ex fusco nigri. Alae subcinereae, venis ex nigro fuscis, longitudinalibus tertiâ el quartâ distincte divergentibus, tertià rectà, ullimo quartae segmento modice allenuato. - (Florida; Osten-Sacken).

$$
\text { oheorops }
$$

89. Chlorops crocota nov. sp. ․ Saturate flwa, subopaca, puberula, palporum apice, articulo tertio antennarum, triangulo verticali mediocri praeter angulos superos, viltulis duabus occipitis, vittis thoracis tribus cum puncto humerali et striguld laterali utrinque, metanoto, pleurarum maculis abdominisque incisuris alris, femoribus omnibus tibiisque posticis nigro-lituratis, scutello convexo, halteribus flavis. - Long. corp. $1 \frac{1}{3}$ lin., Long. al. $3 \frac{1}{3}$ lin.

Saturate flava, nigro-puberula, subopaca. Caput concolor, occipite alro bivittato. Triangulum verticale mediocre, valde acuminatum, ante ocellos foveolatum, praeter angulos superos flavos atrum et nitidum. Articuli primi duo antennarum ex ochraceo fusci; arliculus tertius rotundus, ater, setâ nigrâ, breviter pubescente. Genae latae. Proboscis flava; palpi praeter apicem atrum concolores: clypeus utrinque atro-maculatus. Thoracis dorsum viltis tribus strigulisque lateralibus nigris variegatum, vittầ mediâ postice, lateralibus antice abbreviatis; callus humeralis puncto nigro'notatus. Scutellum convexum, pilis minutis nigris rare aspersum. Melanotum atrum. Pleurae maculis atris quatuor vel quinque variegalae, $\mathrm{Ab}$ domen flavum, fasciis segmentorum singulorum basalibus alris, in medio abdomine dilatatis, ita ut eum segmentorum fasciis posticis nigris conjungantur. Pedes flavi, femoribus omnibus tibiisque posticis nigro-lituratis, tarsis apicem versus ex fusco nigricanlibus. Halteres flavi. Alae cinerascentes, venis ex nigro fuscis, longitudinalibus terliâ et quarlà valde divergentibus. - (Pennsylvania).

Nota. Chloropi pubescenti similis, sed practer picturam articulo tertio antennarum minore, setâ totâ nigrâ et in basi miuns crassit genisque multo latioribus ab illâ distincla. 
90. Chlorops obscuricornis nov. sp. J. Laete fava, nitens, clypeo, antennis praeter basim ex fusco nigricantem, macula occipitali, solitis thoracis vittis strigulisque, puncto humerali, maculis pleurarum et metanoto atris, abdomine praeter margines et maculas laterales nigro, tarsis anticis praeter basim, posterioribus in apice ex fusco nigris; alae ex fusco cinereae, venis ex fusco nigris, validis, longitudinalibus tertiâ et quartâ divergentibus, tertià rectâ, segmento ultimo quartae vix allenuato. - Long. corp. $1 \frac{1}{4}$ lin., Long. al. $1 \frac{1}{6}$ lin.

Laete flava, nitens. Caput flavum, occipitis dimidio superiore praeter margines laterales atro. Triangulum verticale mediocre, praeter margines laterales et angulos superos atrum, nitidum. Antennarum articuli primi duo breves, ex ferrugineo nigri; articulus tertius rotundus, ater, setâ concolore, brevissime pubescente. Genae mediocres. Clypeus totus ater; proboscis flava; palpi concolores. Thoracis dorsum modice nitens, obsoletissime bisulcatum, vittis solitis tribus strigulisque lateralibus atris, vittâ mediâ postice, lateralibus antice abbreviatis; callus humeralis puncto nigro notatus. Scutellum convexum, pilis minutis nigris aspersum. Metanotum atrum. Pleurarum maculae atrae plerumque quinque vel sex. Abdomen fere totum nigrum, marginibus, apice ef ventre semper, maculis lateralibus segmentorum saepe flavis. Pedes flavi, tarsis anticis praeter basim, posterioribus in apice extremo ex fusco nigris. Halteres albidi. Alae ex fusco cinereae, venis ex nigro fuscis, validis, Iongitudinalibus tertiâ et quartâ divergentibus, tertiâ rectâ. segmento ultimo quartae levissime attenuato. - (Washington; Osten-Sacken).

Nota. Chloropi melanocerae valde similis, clypeo atro, palpis flavis, alis brevioribus obscurioribusque, venis validioribus. femoribus denique immaculatis distinguitur.

$$
\text { cheoroins }
$$

91. Chlorops melanocera nov. sp. ․ Flava. palpis, antennis totis, triangulo verticali mediocri, thoracis vittis tribus latissimis et strigulâ utrinque supraalari, pleurarum maculis subquatuor, melanoto, tarsorumque apice atris, abdomine supra nigro, femoribus omnibus tibiisyue posterioribus nigro subannulatis; scutellum convexum; alarum venae longitudinales tertia et quarta divergentes. -

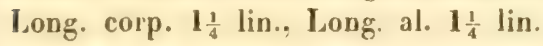

Laete flava. Caput mediocre concolor; triangulum verticale mediocre, supra ab oculis anguste sejunctum, infra acutum et usque ad mediam frontem pertinens, totum atrum, laevigatum nitidissimum: dimidium superius occipitis praeter margines laterales atrum, niti- 
dum. Antennac breves, tolae atrac, articulo tertio orbiculari, sclit concolore, breviler pulvesecnte. Genae mediocres. Proboscis flava: clypeus concolor: palpi alri, basi lamen flavâ. Thoracis dorsum modice nitens, obsoletisime bisulcalum, viltis tribus latissimis atris, medià integrà, lateralibus subintegris, puncto humerali et viltulâ supra alas utrinque adjcetis. Scutellum convexum, pilis minutis nigris sparsum. Metanolum atrum. Pleurarum maculae subquatuor alrae. Abdominis dorsum fre tolum nigrum adversus margines flavum, ventre toto flavo. Pedes flavi; femora onnia prope apicem maculis nigris imperfecte subannulata; tibiae posteriores annulis subnigricantibus obsoleioribus instructae; tarsi antici praeter basim, reliqui in apice nigri. Halteres albidi. Alae hyalinae, subcinerascentes, venis nigris, longiludinalibus tertiâ et quartâ distincte divergentibus, tertiâ rectâ. - (District Columbia; Osten-Sacken).

chloropisca

92. Chlorops grata nov. sp. o et ㅇ. Laete flava, nitidre, antennarum magnarum margine supero, triangulo frontali perlongo, thoracis dorso praeter limbos laterales, metanolo, pleurarum maculis et abdomine atris, basi, segmentorum singulorum maculis lateralibus et apice hujus flavis. - Long. corp. $1 \frac{1}{3}$ lin., Long. al. $1 \frac{1}{4} \operatorname{lin}$.

Laete flava, valde nitens. Caput majusculum, concolor, margine antico frontis acutiusculo; triangulum verticale perlongum, angustum, supra ab oculis separatum, infra marginem frontis altingens, atrum, nitidissimum, violaceo et chalybeo spleudens. Occiput flavum. maculâ superâ atrâ, cum triangulo verticali conjunctâ. Antennae magnae, infra flavae. supra atrae, articulo secundo obliquo, articulo tcrtio breviler ovato, setâ obscurâ, breviter pubescente. Genae latiusculae. Proboscis flava, palpis concoloribus; clypeus utrinque puncto nigro notalus. Thoracis dorsum obsoletissime bisulcatum, practer limbos laterales totum atrum, rarius atro per lineas obsoletas flavas in viltas solitas dissecto. Scutellum planum. praeter setulas apicales duas nudum. Pleurae plerumque maculâ unicâ, rarius tribus vel quatuor atris notatae. Metanotum atrum. Abdominis dorsum atrum, basi, maculis lateralibus transversis, segmenti paenultimi margine postico et ultimi apice flavis. Pedes plerumque toti flavi, raro articulis tarsorum anticorum ultimis quatuor subfuscis. Halteres albicantes. Alae hyalinae, venis subfuseis vel nigricantibus, longitudinalibus tertià et quartâ distincte divergentibus, tertiâ rectâ, ullimo quartae segmento subtili. - (Pennsvivania; Osten-Sacken). 


\section{Cheoroth \\ Americae septentrionalis.}

93. Chlorops unicolor nov. sp. 우. Tola flava, supra rufescens, puncto verticali et antennarum articulo tertio praeter basim atris, venis longitudinalibus alarum tertià et quarti aliquantulum divergentibus. - Long. corp. $1 \frac{1}{3}$ lin., Long. al. $1 \frac{1}{3}$ lin.

Tota flava, supra rufescens. Caput mediocre. frontis margine antico mediocriter producto, acuto; triangulum verticale concolor, planum, permagnum, supra cum oculis subconliguum, infra frontis marginem prope attingens, fossulà mediâ nullà. Ocelli puncto atro inclusi. Antennae concolores, breves, articulo tertio mediocri, suborbiculari, praeter basim atro. Genae mediocres. Proboscis llava; clypeus et palpi concolores. Thoracis dorsum subrufescens. leviler bisulcatum, vittis distinctis nullis. Sculellum suhconvexum. Pleurae supra rufescentes, immaculatae. Abdomen praeter poslicos segmentorum singulorum margines subrufescens. Pedes pallide llavi. Alae hyalinae, obsolete subcinerascentes, venis longitudinalibus tertià et quartâ subparallelis, tertiâ rectà. - (Missisippi; Schaum.)

$$
\text { cheorops }
$$

94. Chlorops quinquepunclata nov. sp. T. Tola flava. triangulo verticali permagno concolore, villis thoracis rufescentibus, puncto verticali punctisque singulis humerorum et pleurarum atris. - Long. corp. $1 \frac{1}{3}$ lin., Long. al. $1 \frac{1}{3}$ lin.

Tota flava. Caput majusculum, paulo laetius flavum; triangulum verticale concolor, maximum, supra cum oculis contiguum, infra usque ad anticum frontis narginem pertinens, per fossulam longitudinalem dimidiatum. Ocelli puncto atro inclusi. Antennae flavae, arliculo tertio subrotundo, setà breviter pubescente. Genae latissimae. Proboscis llava; palpi et elypeus concolores. Thoracis dorsum vittis tribus rufescentibus variegatum, medià postice valde. lateralibus utrinque modice abbreviatis, striolà supra alas subbadià utrinque adjectà; callus humeralis puncto alro notatus. Scutellum subplanum. Metanotum rufescens. Pleurarum punclum medium atrum. Abdominis basis utrinque puncto minuto subfusco picta. Alae hyalinae, venis subfuscis, longiludinalibus lerliâ et quarlà apicem versus levissime divergentibus, tertià rectâ. - (Vebraska.)

$$
\text { cheoropo }
$$

95. Chlorops sahlbergii nov. sp. . Flara, modice nitens. clypeo, antennamm articulo tertio. triangulo verticali. villis thoraris solitis tribus strigulisyue supra alas, melanoto pleurarum,pue maculis tribus atris, abdomine praeter margines ex nigro fusco, larsis anticis plerumque fere totis, posterioribus upiceme rersus fuscis. interdum femoribus anticis posticisque fusco-lituratis et libies po- 
sticis fusco-annulatis; triangulum verticale prope margines laterales et in angulo antico sublilissime rugulosum. - Long. corp. $1 \frac{2}{3}$ lin., Long. al. $1_{4}^{3}$ lin.

Flava, modice nitens. Caput concolor, maculâ occipitali alrâ, superâ, cum triangulo verticali cohaerente, adversus orbitam mediam dilatatâ. Triangulum verticale mediocre, subaequilaterale, tolum atrum et nitidum, prope margines laterales et in angulo antico subtilissime rugulosum, lineâ impressâ mediâ nullâ. Antennae breves, articulis primis duobus ex ochraceo vel ex nigro fuscis, articulo tertio parvo, rotundo, atro, sełâ concolore breviter nigro-pubescente. Clypeus angustus, tolus ex fusco niger; proboseis flava; palpi concolores. Genae mediocres sive latiusculae. Vittae atrae thoracis latiusculae. media postice valde, laterales utrinq̨ue modice abbreviatae; strigulae laterales concolores; callus humeralis interdum fusco notatus. Scutellum convexum, nigro-pilosulum. Metanotum atrum. Pleurae atro trimaculatae, maculis duabus inferis magnis. Abdomen praeter unargines laterales et extremum apicem ex nigro fuscum. Coxae flavae. Pedes concolores, tarsis anticis plerumque fere totis, posterioribus apicem versus ex nigro fuscis; femora antica et postica interdum fusco - liturata et libiae posticae fusco-annulatae. Halteres ex flavo albicantes. Alae dilute subcinereae, venis subfuscis, anticis obscurioribus, tertiâ et quarıâ divergentibus, segmento ultimo quartae et apice quintae attenuatis. - (Sitka; Sahlberg.)

$$
\text { hemops }
$$

96. Chlorops producta nov. sp. $\delta$. Flava, antennis, triangulo verticali, maximâ occipitis parte, thoracis vittis tribus strigulisque lateralibus solitis, puncto humerali, pleurarum maculis, metanolo, abdominis fasciis, femorum omnium tibiarumque posticarum lituris tarsorumque apice atris vel nigris; oris cuvitas longior quam latior, margine antico distincle producto; proboscis elongata, geniculata, dilule fava; palpi concolores. - Long. corp. $1 \frac{1}{3}$ lin., Long. al. $1 \frac{5}{12}$ lin.

Flava, modice nitens. Caput concolor, occipite praeter margines laterales et inferum atro. Frons modice lata, triangulo verticali mediocri, supra ab oculis separato, infra acuto, atro, modice nitido. Anlennae breves, at ticulis primis duobus ex fusco nigris, articulo tertio rolundo. alro, setâ concolore breviter pubescente. Facies concava, infra valde producta. Genae mediocres. Oris cavitas longior quam latior; proboscis elongata, geniculata, dilute flava; palpi concolores. Vittae atrae thoracis latae, media integra, laterales utrinque nonnihil abhreviatae, antice usque ad callum hu- 
meralem, punctum nigrum gerentem, pertinentes; slrigulae supraalares tenues. Scutellum convexum, pilosulum. Netanotum atrum. Pleurae maculis atris plerumque tribus variegatie. inferis majoribus. Coxae et pedes flavicantes, femoribus omnibus et tibiis posticis nigro vel fusco lituratis, femoribus interdum praeter basim et apicem ex fusco nigris, tarsis finem versus fuscis. IIalteres ex albo flavicantes. Alae subcinereae, venis testaceis vel subfuscis, longiludinalibus tertià el quaıtâ valde divergentibus, ultimo segmento quartae sublili. - (Silka; Sahlberg.)

$$
\text { Siptotaza }
$$

97. Chlorops versicolor nov. sp. $\delta$ et 오. Rufescens, cupile pleurarumque vitla pallide flavis, thoracis dorso opaco, villis duabus cinereis, vittâ interjectâ mediâ et scutello ex cinereo fuscis, abdomine ex cinereo nigricante, alarum venis longitudinalibus secundâ el tertia valde recurvis, venulis transversis valde approximalis; antenue longae, ex ochraceo rufae, articulis primis duobus supra nigris, tertio ovato, in apice alro, selâ albà. - Long. corp. 1: lin., Long. al. $1 \frac{1}{3}$ lin.

Corpuris picturâ valde varians, pleromque rufescens. Caput pallide havum, facie quam frons paulo angustiore genisque mediocribus albis. Triangulum verticale majusculum, subaequilaterale, laevigatum, atrum, obsolete violaceo resplendens. Occiput maculam mediam cum triangulo verticali cohaerentem et fasciam transversam atras habet, ila ut supra ulrinque macula flava, selulam lateralem verticis ferens, supersit. Antennac longiusculae, arliculo terlio ovato, supra vix levissime exciso, plerumque ex ochraceo rufae, articulis primis duobus supra nigris, tertio in apice vigro, interdum praeter basim articuli tertii totac nigrae; seta antennarum alba, basim versus flava, pube longiore albâ hirta. Clypeus ater, nitidus; proboscis flava; palpi concolores. Thoracis dorsum opacum, humeris et marginibus lateralibus rufescentibus, disci vittis tribus latissinis integris, medià ex cinereo fuscâ sive murinâ, latcralibus cinereis, plerumque cum illâ contiguis, in speciminibus junioribus tamen ope linearum angustarum rufescentium vel flavescentium ab illâ separatis. Scutellum plinnum, cum viltâ mediâ thoracis concolor. Melanolum nigrum. Pleurae rufescentes, villâ longiludinali medià flavà, in speciminibus maturis maculis duabus vel tribus nigris variegatae. Abdomen ex muriuo nigricans, subopacum. Coxae et pedes rufescentes, anticorum libiis et tarsis tolis, posteriorum larsis, basi tamen exceptâ, nigris. Halteres albi. Alac hyalinae, levinsime subeinerascentes, venis fuscis, secundâ et segmento ultimo quartac dilutiori- 
bus; venae longitudinales secunda et tertia arcuatim recurvae, venulac transversae admodum approximatae, segmentun ullimum venae quartae valde attenuatum. - (Washington; Osten-Sacken.)

Nota. Chlor. versicolor cum similibus proprium genus ore setulis mystacinis minutis instructo, antennis longiusculis, venis longitudiualibus secundå et tertiâ arcuation recurvis venulisque transversis valule approximatis insigne conslituit, cui nomen Diplotoxae propono.

98. Odontocera dorsalis nov. sp. + . Cinerea, opaca, cupite, thoracis marginibus lateralibus et maculà posticá, sculelli mo. cula media, pleuris hulteribusque flavis, abdomine nigro, nitido, segmentis singulis angustissime, ultimo tamen paulo latius flavo-marginatis, pedibus fluvis, femoribus supra obsoletissime subfuscis, tibiis supra fuscis, tarsis totis ex nigro fuscis. - Long. corp. 1 lin.. Long. al. 1! lis.

Odontocerac acuticorni similis, sed major. Caput dilute flarvum, proboscide et palpis concoloribus, fronte laetius flavâ. Primi duo antennarum articuli flavi, tertius ater et quam in Odont. acuticorni panlo major, setâ concolore. Macula ocellos includens nigra. Occiput pricter maculas verticis laterales flavas nigrum. Thoracis dorsum cinereum, opacum, limbis lateralibus et maculâ oblongî cum margine postico contiguâ, laełe flavis; callus humeralis nigro notalus. Pleurae laete flavae, maculis obscure cinereis variegatae. Scutellum flavum, lateribus ex cinereo fuscis. Abdomen ex fusco nigrum. nitens, marginibus posticis segmentorum singulorum angustissimis, segmenti ultimi tamen paulo latiore, flavis. Coxae flavae. Pedes concolores, femoribus supra obsoletissime subfuscis, libiis supra fuscis. larsis totis ex nigro fuscis. Halteres laete flavi. Alae cincrascentes, venis ex luteo subfuscis. - (Distr. Columbia; OstenSacken.)

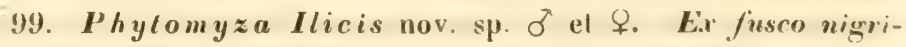
cans, thorace et scutello cinereis. oparis, facie abirante, antemis palpisque atris, proboscide. puncto humerali et ima alarum subcine. rascentium basi dilutissime flavicantibus, halterilus albidis. pedibus ex fusco nigricantibus, genibus, libiis anticis tarsorumque basi suepe ex fusro testaceis. - Long. corp. $\frac{2}{3}-\frac{3}{4}$ lin., Long. al. $\frac{1}{1} \frac{1}{2}-1$ lin.

Capul nigrum, opacum, fronte supra latiore ex cinereo nigrí; anlennic atrae, selí concolore. Facies albicaus, subcarinata Pro. boscis dilutissime flavicans; palpi atri. Thorax cinereus, opacus. 
puncto humerali obsolete flavicante. Seutellum thoraci concolor. Abdomen ex fusco nigricans, modice nitens, margine postico segmenti ultimi anguste albido. Pedes ex fusco nigri, genibus extremis testaceis; in speciminibus junioribus color tibiarum anticarmm of larsurnm in testaceum veruil. Halleres albidi, interdum subflaresentes. Alae levissime subcinerascentes, ima basi subflavicante, renis fuiris. cellulis basalibus omni!bus perfectis. primâ quam secunda paulo longiore. - (Dislr. Columbia; Osten-Sacken.)

Nota. Larva subcutanea in foliis Ilicis opacae degit.

100. Phytomyza Clematidis nov. sp. $\delta$. Nitida, atra, antennis palpisque concoloribus, proboscide, imá alarum cinerascentium basi halteribusque laete favis. genibus, libiis anticis totis posterionumque apice et tarsis ex testaceo flavicantibus, ultimo horum articulo nigricante. - Long. corp. $\frac{7}{12}$ lin., Long. al. $\frac{5}{6}$ lin.

Atra, nitida, nigro-pilosa. Caput concolor, praeter dimidium superius orbitarum frontalium opacum; antennae atrac, setâ concolore; facics carinata. in lateribus albido - pollinosa. Proboscis laele flava; palpi atri. Margo posticus ultimi abdominis segmenti flavus. Pede's alri, genibus, tibiis auticis posteriorumque apice et larsis omnibus ex testaceo flivicantibus. ultimo horum articulo nigricante. Halleres laete flavi. Hae dilute cinerascentes, imâ basi flavâ, venis (x nį̣o fuscis, cellulis bisalibus omnibus perfectis, primâ quam serunda paulo longiore. - (Distr. Columbia; Osten-Sacken.)

Nota. Larvae in foliis Clematidis cuniculos agunt. 



\title{
Diptera Americae septentrionalis indigena.
}

\author{
Descripsit
}

\author{
H. L $\quad$ o $e$ e $w$.
}

\author{
Centuria quarta.
}

1. Holorusia rubiginosa.

2. Tipula apicalis.

3. - tessellata.

4. - septentrionalis.

5. - longiventris.

6. - fasciata.

7. - fragilis.

8. - suspecta.

9. - ignobilis.

10. - fallax.

11. - grata.

12. - discolor.

13. - subfasciata.

14. serla.

15. balioptera.

16. pallida.

17. - versicolor.

18. hebes.

19. - angustipennis.

20 - appendiculata.

21. validu.

22. - speciosa.

23. - submaculata.

24. cincta.

25. - casta.

26. - infuscata.

-27 . - eluta.
28. Tipula strepens.

29. - bella.

30. - caloptera.

31. - umbrosa.

32. Pachyrrhina incurva.

33. - pedunculata.

34. - punctum.

35. - unifasciala.

36. - abbreviata.

$37 . \quad-\quad$ suturalis.

$38 . \quad$ - circumscripla.

$39 . \quad$ - eucera.

40. - polymera.

41. - tenuis.

42. Slygeropis sordida.

43. Blepharoptera capitata.

44. Metoponia similis.

45. - obscuriventris.

46. Bombylius haemorrhoicus.

47. - pulchellus.

48. - validus.

$49 . \quad$ - alriceps.

50. - ravus.

51. Systoechus candidulus.

52. - vulgaris.

53. Lordotus gibbus.

54. Geron calvus. 
55. Geron subauralus.

56. Systropus macer.

57. Temnocera megacephala.

58. Orthoneura pictipennis.

59. Chrysogaster latus.

60. - nigripes.

61. Triglyphus pubescens.

$62 . \quad$ modestus.

63. Paragus dimidiatus.

64. - angustifrons.

65. Chilosia capillata.

66. - comosa.

67. - cyanescens.

68. - plumata.

69. - leucoparea.

70. - pallipes.

71. - tristis.

72. Chrysochlamys buccala.

73. Helophilus latifrons.

74.

75.

76.

77. obscurus. obsoletus. integer. laelus.
78. Helophilus divisus.

79. hamalus.

80. Pterallastes thoracicus.

81.

82. Didea fuscipes.

8.3. Doros flavipes.

84. - aequalis.

85. Hyalomyia triangulifera.

86. Xysta didyma.

87. Himantostoma sugens.

88. Cislogaster divisa.

89. Trichopoda radiata.

90. Irifasciata.

91. Wahlbergia brevipennis.

92. Heteroneura spectabilis.

93. - latifrons.

94. Anthophilina terminalis.

95. - tenuis.

$96 . \quad$ - variegata.

97. Ischnomyia vittala.

98. Hyadina gravida.

99. Scatella sejuncta.

100. Parydra varia.

1. Holorusia rubiginosa nov. sp. ơ et + . Opaca, thorace fusco vel ferrugineo, obsolete viltalo, abdomine rubiginoso, alis fuscis, tribus ultimis antennarum articulis quam praecedentes multo tenuioribus. - Long. corp. $11-16 \frac{1}{2}$ lin.. Long. al. $12-17$ lin.

Caput ferrugineum, fronte et occipite cinerascentibus. Primus antennarum articulus ferrugineus, reliqui subochracei; ultimi tres tlagelli articuli breviores et multo tenuiores quam praecedentes, primus cylindricus, reliqui semiglobosi, supra breviter setulosi. Palpi ferruginei, apicem versus nigri. Collare albidum, supra fuscum vel ferrugineum. Thorax totus fuscus, rarius ferrugineus; vittae ordinariae paulo obscuriores, obsoletae. Scutellum et metanotum immaculata. Pleurae supra villam lividam, infra latiorem albidam ha bent. Abdomen ferrugineum vel rubiginosum, lateralibus segmentorum marginibus pallidis. Hypopygium parvum, concolor, lamellis superis pallidis obtusis. Terebra parva, acuta. Pedes ex luteo fusci; 
femoribus apicem versus nigris. Unguiculi maris infra unidentali, focminae simplices. Alae totae ex ferrugineo fuscae, stigmate paulo obscuriore. - (California; Agassiz.)

Nota. Holorusia venae secundae segmentum ultimum valde arcuatum habet, ita ut in decursu medio venam lertian fere attingat, inde ad costam resurgens. Venula transversa, venam primam cum secundâ conjungens, obsolescit, iła ut cellularum marginalium interna cum anticâ coalescat; articuli antennarum breves, setulis nullis nisi minutis instructi; reliqua ut in Tipulis. Praeter speciem, quam supra descripsi, Holorusias quasdam javanas vidi. -

2. Tipula apicalis nov. sp. ㅇ. Intea, viltis tribus thoracis et unicâ abrlominis, fuscis; alae lulescentes, fasciâ subupicali latissimâ albicante, apice ipso nigro. - Long. corp. $7 \frac{1}{2}$ lin., Long. al. $7 \frac{1}{3}$ lin.

Lutea. Frons et occiput obsolete fusco-viltata. Antennarum scapus et primi flagelli articuli concolores, reliqui fusci. Palpi ex luteo subfusci. Thoracis dorsum opacum, vittis tribus fuscis, polline lutescente conspersis. Scutellum el metanotum immaculata. Abdomen luteum, vittâ mediâ, lineis lateralibus subobsoletis et apice fuscis. Terebra fusca, apicem versus lutea, acuta. Femorum apex niger. Alae lutescentes, cellulâ costali luteâ, stigmate ex fusco luteo, fasciâ latà subapicali albidâ, apice ipso nigro. - (Maine; OstenSacken.)

3. Tipula tessellata no7. sp. 오. Alae totae albido. et nigro-subtessellatae, maculâ obscurâ insigni in cellularum basalium initio: terebra infra serrulata. - Long. corp. $11 \frac{2}{3}-12$ liu.. I.ong. al. $8 \frac{5}{6}$ lin.

Obscure cinerea. Caput concolor, rostro obscure ferrugineo. Antennarum articulus primus subferrugineus, secundus et tertius flavi, sequentes tres vel quatuor flavi, basi tamen atrâ, reliqui toti nigri. Palpi fusci, apicem versus nigri. Ordinariae thoracis villae quam reliquum dorsum paulo obscuriores, fusco-marginatae, media yer linearm fuscam, antice coarctalan divisa. Scutellum et metanotưn concolora, lineâ medià subobsoletâ fuscâ. Pleurae cincreae. Abdomen ex fusco cinereum, vitlâ mediâ lineisque lateralibus paulo obscurioribus obsolelis, marginibus lateralibus albidis. Terebra fusca. lamellis superioribus infra serrulatis, apicem rersus recurvis. Pedes fusci, tibiis subfuseis. Alac totae albido- et nigro-subtessellatae, cel- 
lulâ posteriore quartâ fere totâ albidâ; macula nigricans cellularum basalium initium explet. - (Labrador; Schneider.)

4. Tipula septentrionalis nov. sp. $ठ$. Alae maculatue, maculâ obscurâ insigni in cellularum basalium inilio. maculis albidis margini postico contiguis nullis. - Long. corp. $8 \frac{1}{2}$ lin., Lang. al. 9 lin.

Caput cinereum. Seapus antennarum luteus; primus flagelli articulus concolor, cylindricus; reliqui articuli breviusculi, infra excisi, basi incrassalâ singulorum atrâ, dimidio apicali obscure ferrugineo vel fusco. Rostrum ferrugineum, supra leviter cinerascens. Palpi subfusci, basim versus sordide testacei, apicem versus nigri. Thorax cinereus; vittae ordinariae concolores, fusco-marginatae, media per lineam fuscam, antice coarelatam divisa. Scutellum et metanotum concolora. lineâ medià obsoletissimâ subfuscâ. Pleurae cínereae. Abdomen latericium, apicen versus fuscum, villà medià lineisque lateralibus fuscis. Hypopygium parvum, ex latericio fuscum, lamellis superis parvis luteolis. Pedes ex luteo ferruginei, femorum apice subfusco. Alae cinereae, maculis albidis et nigricantibus variegalae; macula nigricans conspicua cellularum basalium initium explet. Cellulae posteriores, praeter basim albidam primae et quarlae, immaculatae; maculae albidae margini postico contiguae omnino nullac. - (Labrador; Schneider.)

5. Tipula longiventris nov. sp. $\sigma^{\nearrow}$ et 오. Alue ex fusco cinereae, totae albido- et nigro-maculatae, maculà obscurci insigni in cellularum basalium initio: antennae tolae favae, eleganter nigroannulatae; abdomen foeminae perlongum. - Long. corp. $\delta 7 \frac{2}{3}$, 오 $13 \frac{3}{4}-14$ lin., Long. al. $9 \frac{1}{4}-10$ lin.

Caput cinereum, lineâ frontali fuscâ. Antennae flavae; arículi flagelli, primo vel primis tamen exceptis, in basi atri. ultimus totus ater, omnes in mare infra leviler excisi et multo longiores quam in foeminà. Rostrum ferugineum, supra leviter cinerascens. Palpi nigri, adversus basim fusci. Thorax ex cervino cinerascens, vitlis ordinariis cinereis, obsoletius subfusco-marginatis, medià per lineam fusiformem, antice valde altenuatam, ex cervino cineream divisà. Scutellum et metanotum concolora vel dilutiora. lineà medià sub. fuscâ obsoletâ. Abdomen ex luteo latericium. apicem versus subfuscum, lineis laleralibus fuscis, plerumque distinctis, medià plerumque obsolelissimà vel nullà. Hypopygium parvum subfuscum. apicem versus pallidum, lamellis superis minutis, pallidis. Abdomen 
foeminae valde elongatum, terebrâ tcstaceà, lamellis superioribus ex nigro fuscis, latiusculis, rectis, in utroque margine serrulatis. Femorum apex ex fusco niger. Alae ex fusco cinereae, totae maculis albidis maculisque aliquot nigris variegatac; macula nigricans ccllularunı basalium initium explet; alia cum stigmale conjungilur, ila ut gutlula pellucida, ad stigmalis basim adposita appareat. - (Illinois; Osten-Sacken.)

6. Tipula fasciata nov. sp. $\sigma^{\top}$. Rostrum breviusculum; thorax cervinus, vittis fuscis, lateralibus distinctis, mediấ obsolelissimà; alae maculis nigricantibus raris albidisque obsoletis variegalae, dimidio basali subimmaculato; abdomen pallidum, nigro-fascialum. Long. corp. $4 \frac{7}{12}$ lin., Long. al. $5 \frac{1}{2}$ lin.

Caput ex cinereo cervinum. Rostrum breviusculum, luteum, lateribus fuscis. Palpi fusci, basi apiceque articuli tertii et articulo ultimo toto albicantibus. Antemna longiusculae, graciles; scapus pallidus, extremo articuli prini apice nigricante; primus flagelli articulus cylindricus, dimidio basali nigro, apicali pallido; articuli sequentes lutei, ultimi subfusci, basi omnium incrassatà, atrà. Collare flavescens. Thoracis dorsum ex cinereo cervinum, vitlis lateralibus distinctissimis fuscis, mediâ obsoletissimà. Sculellua pallidum, angulis fuscis. Metanotum subfuscum, lineâ medià pallidâ. Pleurac pallidae, maculis nigris biviltatae. Abdomen pallidum, segmentis ullimis duobus, reliquorum singulorum fascià posticâ lateribusque secundi nigris. Iypopygium majusculum, pallidum, infra selis duabus instructum, lamellis superis nigro-marginalis. Pedes ..... Alae ex luteo subcinerascentes, in triente apicali maculis nonnullis nigrocinereis obsoletius variegatae, ceteroquin subimmaculatae, maculis albicantibus omnibus subobsoletis; stigma ex fusco nigrum. - (Sharon Springs; Osten-Sacken.)

7. Tipula fragilis nov. sp. $\sigma^{7}$. Cinerascens, abdomine testaceo, thoracis villis tribus fuscis, media divisi, parlibus singulis yuem villae laterales mullo angustioribus; alae cinereae, maculis nigricuntibus submullis, albicantibus compluribus rariegralae, maculi nigricante in cellularnm Lasalinm initio mulla, maculis albicantibus in postico alurum margine tribus. - Long. corp. $1 \frac{1}{3}$ lin., Long. al $5 \frac{1}{2} \operatorname{lin}$.

Capul ex cervino cinereum, rostro mediocri luteo, lateribus fuscis. Antennat tenues, longiusculac, seapo flavo. flagello tolo nigro, articulis simplicibus. Palpi maximit ex parte fusci. Thorax ex 
cervino cinereus, pleuris dilutioribus; ordinariae thoracis vittae fuscae, laierales integrae, media antice obsoleta, per vittaın cineream in partes vittis lateralibus mullo angustiores dissecta. Scutellum et metanotum immaculata. Abdomen testaceum vel lutescens, marginibus lateralibus et ultimis segmeutis plerumque subfuscis. Нуроpygium dilute lutescens, infra subcarinalum, nigrum. Pedes gracillimi, femorum apice nigro. Alae cinereae, stigmate ex nigro fusco, praeter trientem apicalem maculis circiter sex albidis, tribus marginis postici totidemque disci, variegatae, maculis nigricantibus subnullis. - (Maine.)

8. Tipula suspecta nov. sp. 우 Cinerascens, abdomine testaceo, thoracis vitlis tribus fuscis, mediâ in partes villis lateralibus non angustiores divisâ; alae cinereae, maculis nigricuntibus subnullis, albicantibus compluribus variegatae, maculâ nigricante in cellularum basalium initio nullâ, maculis albicantibus in postico alarum margine tribus. - Long. corp. $6 \frac{1}{2}$ lin., Long. al. $6 \frac{5}{12}$ lin.

Praecedenti persimilis, sed singulis vitlae dorsalis mediae par tibus multo latioribus diversa; foemina forsitan illius. - (District Columbia; Osten-Sacken.)

9. Tipula ignobilis nov. sp. \&. Cinerascens, thoracis vittis fuscis immarginatis, mediâ divisâ, abdomine (in specimine descripto) livido; alae cinereae, maculis aliquot albidis variegatae, stigmate fusco, cellulis posterioribus dilutioribus, sed praeter subalbidam primae basim immaculatis, maculis albidis in postico alarum margine nullis. - Long. corp. 6 lin., Long. al. $6 \frac{1}{2}$ lin.

Caput cinereum, fronte angustâ non lineatà. Scapus antennarum et primus flagelli articulus flavus, articuli reliqui ex nigro fusci, imâ basi nigrâ. Rostrum ferrugineum; palpi ex ferrugineo obscure fusci. Thorax albido-cinereus, vitlis fuscis immarginalis, mediâ per lineam albicantem, antice subduplicatam dissectâ. Abdomen in specimine descripto lividum, utrinque obsolete fusco-vittatun. Terebra testacea, lamellis superis angustis, rectis, acutis. Femorum apex ex fusco niger. Alae cinereae, maculis aliquol majusculis sub. albidis variegatae; stigma subfuscum; cellulae posteriores paulo dilutius tinctae, sed praeter subalbidam primae basim immaculatae; maculae albidae in postico alarum margine nullae. - (Distr. Columbia; Osten-Sacken.) 
10. Tipula fallax nov. sp. ð. Sublestacea, thoracis ex cervino cinerei villis incomplet is abdominisque villis lateralibus fuscis; alce subfuscae, maculis fuscis aliguot albidisque compluribus variegalae, maculâ obscurâ insigni in cellularum basalium inilio nullâ, cellulis posterioribus omnibus albido-maculatis, cellularum axillarium margine immaculato; apex hypopygii appendiculis duabus pendulis, supra ungulatis, infra subulatis instructus. - Long. corp. $5 \frac{2}{3}$ lin., Long. al. $7 \frac{2}{3} \mathrm{lin}$.

Caput lutescens, vertice et occipite cinerascentibus. Scapus antennarum lutescens, flagellum tenue nigrum, articulis simplicibus. basi singulorun permodice incrassatâ, imâ inferorum basi interdum lutescente. Rostrum luteum, utrinque fusco lineatum. Palpi ex nigro fusci, apicem versus lutei. Thorax ex cervino cinerascens, marginibus dorsi pleurisque dilutioribus; vittae ordinariae cinereae, marginibus mediae lateralibus et lateralium anticis fuscis. Scutellum et metanotum immaculata. Abdomen pallide luteolum vel subtestaceum, utrinque vittå latiusculà fuscâ, per margines segmentorum singulorum posticos interruptà. Hypopygium magnum, concolor, basi et lamellâ superà subfuscis, appendiculis duabus apicalibus pendulis, supra spinà incurvâ ungulatis, infra in filum subulatum productis. Femorum apex niger. Alae ex cinereo subfuscae, maculis aliquot et stigmate saturatioribus, tolae maculis albidis variegatae; macula obscura in cellularum basalium initio nulla nec ullae albidae in margine cellularum axillarium; cellulae posteriores omnes albido-maculatae, prima praeter basim et maculan median fere tota albida. (California; Agassiz.)

Nota. Tipulis gratae ef hebati simillima, ab illâ hypopygio appendicibus pendulis instructo, $a b$ hae appendicibus minoribus antennisque non annulatis, ab utrâque cellulis posterioribus omnibus perspicue albido-maculatis distinguitur.

11. Tipula grala nov. sp. $\sigma^{7}$ et 9 . Subtestacea, villis thoracis ex cervino cinereis subcompletis, fusco-marginatis, villis abdominis tribus obsoletis subfuscis; alae subfuscae, maculis fuscis aliquot albidisque compluribus variegatae, maculá obscura insigni in cellularum basalium initio nullâ, cellulâ posteriore primâ fere toli et basi quartae albidis, reliquis immaculutis vel subimmaculatis, cellularum axillarium margine immaculato; hypopygium appendiculis

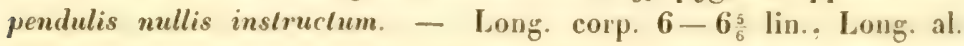
$7 \mathrm{lin}$.

A Tipula fallace. cui simillima est, antennis brevioribus, viltis 
thoracis minus incompletis fuscioribusque, vittâ abdominis mediâ distinctiore alarumque cellulis posterioribus rarius maculatis differt. Cellula posterior prima praeter basim et maculam mediam plerumque fere tota albida; cellulae posteriores reliquae praeter quartae basim plerumque immaculatae, rarius submaculatae. Hypopygium hypopygio Tipulae fallacis simile, sed appendicibus pendulis distitutum; terebra picea, lamellis superioribus rectis, tenuibus, testaceis. - (District Columbia; Osten-Sacken.)

12. Tipula discolor nov. sp. ㅇ. Thorax cinereus, vittis concoloribus, subfusco-marginalis, media integrâ; abdomen testaceum, nigro-trivitlatum; alae ex fusco cinereae maculis nigricanlibus subnullis, albidis compluribus variegatae, maculis nec obscurâ in cellularum basalium initio. nec albidis in postico alarum margine, cellulis posterioribus praeter basim albidam primae et quarlae immaculatis. - Long. corp. $9 \frac{3}{4}$ lin., Long. al. 8 lin.

Caput dilute cinereum. Rostrum ex luteo ferrugineum, lateribus obscurioribus. Palpi ferruginei, apicem versus ex fusco nigri. Antennae mediocres, scapo primisque flagelli articulis luteis, sequentibus subfuscis et in basi nigris, reliquis totis nigris. Thorax cinerascens, viltis latis cinereis, mediâ integrâ, omnibus subtiliter sub. fusco-marginatis. Scutellum flavescens; inetanotum dilute cinereum. Abdomen testaceum vel latericium, nigro trivittalum, vittâ mediâ lateralibus latiore. Terebra badia, lamellis superioribus rectis, acutis. Femorum apex subfuscus. Alae ex fusco cinereae, maculis nigricantibus subnullis, sed albidis compluribus variegatae; stigma ex nigro fuscum; macula obscura in cellularum basalium initio nulla et maculae nullae albicantes in postico alarum margine; cellularum posteriorum prima et quarta in basi albicantes, reliquae immaculatae. - (Massachusets; Scudder.)

13. Tipula subfasciata nov. sp. $\sigma^{7}$. Cinerea, vittis thoracis paulo obscurioribus subobsoletis, mediá divisâ, abdomine latericio, fusco-trivittato (?); alae angustae, ex nigro cinereae, maculis majusculis albidis variegatae, maculâ obscurâ insigni in cellularum basalium initio nullâ nullisque albidis in postico alarum margine, cellularum posteriorum primâ praeter basim et maculam mediam ere $t o t \hat{a}$, quartâ praeter apicem albidis. - Long. corp. $5 \frac{1}{2}$ (!) lin.. Jong. al. $7 \mathrm{lin}$.

Caput cinereum. Rostrum fuscum, lateribus ex nigro fuscis, in speciminibus immaturis totum luteum. Palpi ex fusco nigri. An- 
tennae mediocres, scapo luteo, flagello nigro, articulis simplicibus. primo nonnumquam luteo. Thorax ciuereus, dorsi margiuibus, pleuris. scutello et metanoto albidioribus, immaculatis; vitlae dorsales paulo obscuriores, cinereae, inmarginatac, partibus mediae per lineam cineream dissectae aequalibus. Abdomen latericium, fusco Irivittatum, imá basi cinerề, in utroque specimine descripto mutilatum. Femorum apex fuscus. Alae angustae, ex nigro cinereac, maculis aliquot majusculis albidis variegafac; stigma nigricans; macula obscura insignis in cellularum basalium initio nulla et maculae albidae nullae in postico alae margine; cellula posterior quarta praeter apicem tota albida, ita ut fascia angulata albida postice nounihil abbreviata appareat; cellula posterior prima praeter basin, maculam mediam et apicem extremum albida, colore albido tamen adversus cellulae apicem minus puro. - (English River; Kennicot.)

14. Tipula serta nov. sp. $ఠ$ et + . Thorax cervinus, vittis ex cervino subfuscis, fusco-marginatis, media per lineam cineream tenuem dissectâ; alae subfuscae, maculis subquatuor albidis variegatae, cellulis posterioribus praeter albidam primae et quartae basim immaculatis. - Long. corp. $\delta 7 \frac{1}{4}$, $\& 8 \frac{5}{0}$ lin., Long. al. $7 \frac{1}{4}-7 \frac{1}{3}$ lin.

Ex luteo testacea. Caput ex cervino cinereum, rostro luteo, late. ribus fuscis. Palpi ex fusco nigri, basi plerumque luteâ. Antennarum scapus luteus; articuli flagelli mediocres, primus cylindricus, plerum. que luteus; reliqui plerumque nigri, saepe praeter basim nigram subfusci, in mare infra profunde excisi, in foeminâ subsimplices. Thoracis dorsum ex ochraceo cervinum, vittis ex cervino fuscis, saturatius marginatis, medià per lineam subochraceam vel cinera. scentem dissectà. Scutellum sordide lutescens, immaculatum; melanotum cinereum; pleurae subalbicantes. Abdomen ex luteo testaceum vel sublatericium. vittis tribus fuscis, mediâ plerumque perspicuâ, lateralibus saepe obsoletissimis. Hypopygium parrum lamellis superioribus minutissimis, infra lamella minutå triangulâ, in apice bidentatâ instructum. Terebra badia, recta, lamellis superioribus acutis. Femora apicem versus subfusca. Alae subfuscae, adversus costam lutescentes, maculis subquatuor albidis variegatae: stigma fuscum; cellularum posteriorum prima et quarta in basi fere semper albicantes. reliquae immaculatae; margo cellularum axillarium immaculatus. - (English River, Wimnipeg; Kennicot. Massachusets: Scudder.) 
15. Tipula balioptera, nov. sp. ठ․ Thorax ex cevino cinereus, viltis cinereis obscure fusco-marginatis, mediù per viltulam obscure fuscam subfusiformem et lineolam pallidam dissecta: alre subfuscae, maculis subqualuor albidis variegatae, cellulis posterioribus praeter albidam primae et quarlae basim immaculatis. - Long corp. $6 \frac{5}{6}$ lin. Long. al. $7 \frac{3}{4}$ lin.

Ex luteo teslacea. Caput cinereum, rostro lnteo supra cinerascente. Palpi ex fusco nigri, basi luleà. Antennae luteae, primo flagelli articulo cylindrico, sequentibus infra excisis, basi singulorum nigrâ, inferorum basi lamen haud raro concolore. Thoracis dorsum ex cinereo cervinum, viltis cinereis fusco-marginalis; villa media per vittulam subfusiformem, e lineis duabus obscure fuscis et interjeçâ pallidà compositam dividitur. Pleurae subalbicantes. Scutellum lutescens; metanotum cinerascens. Abdomen ex luteo testaceum vel sublatericium, vittis tribus aequalibus ex nigro fuscis. Hypopygium parvum, lamellis superioribus parvis ovatis, quam in Tipulâ sertâ majoribus et multo latioribus, lamellâ inferì non instructum. Apex femorum fuscus. Alae subfuscae, adversus costam sublutescentes, maculis subquatuor albidis variegatae; macula minuta in venae secundae basi et stigma fusca; cellularum posteriorum prima et quarta in basi plerumque albicautes, reliquae semper immaculatae. - (English River; Kenuicot.)

Nota. A praecedente hypopygio lamellâ inferâ destiluto, antennis luteis nigro-annulatis, vittac dorsalis mediae formâ ac figurâ et basi venae secundae distinctius fusco-marginatâ differt.

16. Tipula pallida nov. sp. ð et + . Dilute ochracea, villis thoracis saturatius ochraceis vel ex ochraceo subfuscis, immarginatis, mediâ divisâ, abdominis lineis lateralibus fuscis obsoletis vel nullis; alue cinereae, maculis subquatuor albidis absolete variegatae, stigmate fusco, cellularum posteriorrum primâ et quarta in basi albicantibus, reliquis et cellularum axillarium margine immaculatis. -

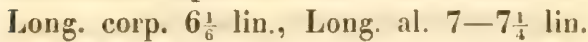

Dilute ochracea. Caput concolor, occipite et vertice cinerascentibus. Scapus antennarum dilute ochraceus; flagellum fuscum. articulis singulis in mare longioribus et infra excisis, in foeminâ brevioribus et simplicibus, articulo primo tamen in utroque sexu cylindrico et dilute ochraceo; in nuper exclusis antennae interdum fere totae pallide ochraceae reperiuntur. Viltae thoracis paulo saturatius ochraceae, raro subfuscae, marginibus obscurioribus nullis. Scutellum, metanotum et abdomen concolora, hujus lineis lateralibus 
fuscis obsoletis, saepius nullis. Iypopygium mediocre, concolor, fusco-maculatum, lamellis superioribus omnium minutissimis. Terebra brevis, lamellis superioribus latiusculis. aculis. Femorum apex dilute subfuscus. Alae cinereae, apice paulo obscuriore, adversus costam dilute lutescentes, maculis albidis subquatuor obsolelius variegatae; stigma fuscum; cellularum posteriorum prima et quarta in basi albicantes, reliquae cellularumque axillarium margo immaculati. - (Massachusets; Scudder.)

17. Tipula versicolor nov. sp. 오. Thoracis dorsum ex cinereo dilute ochraceum, viltis ex ochraceo fuscis, immarginatis, mediâ divisâ; abdomen aurantiacum. nigro trivittatum; alae subfuscae, stigmate obscuriore, maculis albidis subquatuor variegatae, cellularum posteriorum primâ et quartâ in basi albicantibus, reliquis immaculalis, margine cellularum axillarium immaculato. Long. corp. $7_{\frac{2}{3}}^{2}$ lin., Long. al. $8 \frac{1}{1} \frac{1}{2}$ lin.

Caput ex cinereo subochraceum, rostro palpisque luteis, his apicem versus nigricantibus. Antennae .... Thoracis dorsum ex cinereo dilute ochraceum, vittis ordinariis ex ochraceo fuscis, immarginatis, mediâ per lineam dilute ochraceam dissectâ. Abdomen aurantiacum, vittis tribus ex fusco nigris, lateralibus tenuibus, mediâ latiusculâ. Terebra brevis, lamellis superioribus acutis. Femorum apex niger. Alae subfuscae, adversus coslam lutescentes, maculis subquatuor albidis variegatae; stigma ex luteo fuscum, apicem versus saluratius fuscum; cellularum posteriorum prima et quarta in basi albicantes, reliquae immaculatae; margo cellularum axillarium immaculatus. - (Illinois.)

18. Tipula hebes nov. sp. $\delta$ et $ᄋ$. Pallida, antennis nigroannulatis, thoracis dorso ex fusco ochraceo, viltis concoloribus fuscomarginatis. Alae latiusculae ex lnteo dilute subfuscae. maculis aliquot fuscis albidisque pluribus variegratae, masula obscura majore in cellularum basalium initio nullû, cellulis posterioribus praeter albidam primae basim cellularumque axillarium margine immarulalis. - Long. corp. $\sigma^{7} 6_{6}^{1}$, \& $77_{0}^{5}-8$ lin., Long. al. $7-7_{6}^{5}$ lin.

Tipulac fallaci et gratae similis, ab utrâque praeter hypopygii forman antennis nigro-annulatis et alis latioribus rariusque albidomaculatis facile distincta. Pallida vel dilute ocbracea. Caput concolor, vertice subcinerascente. Antennae ochraceae, articulis flagelli in utroque sexu simplicibus, basi singulorum atrå. Rostrum lıteum, lateribus obscurioribus. Palpi ochracei vel ex fusco ochracei, basi 
plerumque fuscâ. Thoracis dorsum ex fusco ochraceum; viltae concolores fusco-marginalae; margines vitlarum lateralium subaequales. vittae mediae postice atlenuati, antice dilatali el maculâ ex fuseo ochraceâ subinterrupli. Plcurae serie macularum fuscarum notatae. Abdomen adversus apicem saepe dilute subfuscum. Hypopygium permagnum concolor, infra pilis fulvis breviter barbatum, in apice appendicibus duabus magnis pendulis instructum. Terebra testacea, lamellis superis rectis, tenuibus, acutis. Femorum apex fuscus. Alae latiusculae ex luteo dilute subfuscac, adversus costam lutescentes, maculis saturatioribus paucis, albidis pluribus variegatae: basis venae secundae fusco-marginala; stigma fuscum; cellularum posteriorum prima in basi albicans, reliquae immaculatae; maculac albidae in postico alarum margine nullae; venulae transversales alarum basi proximae infuscatae, sed macula obscura major in cellularum basalium initio nulla. - (Connecticut; Norton. Illinois, Maine; Asten-Sacken.)

19. Tipula angustipennis nov. sp. ఠ et . Obesa, pedibus validis, fronte latiusculà; alae foeminae breviores quam maris, ex cinereo fuscae, sligmate nigro, maculis aliquot albicantibus variegatae, cellulis posterioribus omnibus et postico alarum margine immaculatis. - Long. corp. $\sigma^{7} 7-7 \frac{1}{3}$, \& $10 \frac{3}{4}$ lin. Long. al. $\sigma^{7} 8$, \& $6_{6}^{5} \operatorname{lin}$.

Caput obscure cinereum, rostro concolore, in immaturis infra obscure testaceo, fronte latâ. Palpi ex fusco nigri. Antennae nigrae, basi articuli primi et articulo secundo in plerisque, articulis duobus primis et dimidio basali tertii in multis speciminibus ex rufo flavis; mas articulos flagelli praeter primum in basi incrassatos, foemina simplices habet. Thoracis dorsum ex cinereo sordide ochraceum, vittis ex cinereo fuscis, mediâ per lineam cineream dissectâ, omnibus aequaliter nigro-marginatis. Abdomen latericium, nigro trivittatum, vittis lateralibus angustis plerumque interruptis, interdum obsoletis. Hypopygium majusculum, pallidum, adversus basim subinfuscatum. Terebra fusca, lamellis superis angustis, rectis, acutis. Femora apicem versus fusca. Alae paulo angustiores quam in speciebus cognatis, ex cinereo fuscae, stigmate nigro maculisque tribus albicantibus variegatae, maculâ primâ cellulis anali et axillarium primae communi, secundâ discoidali, tertiâ ultra stigma ad costam sitâ. Cellulae posteriores praeter albidam primae basim et cellula discoidalis immaculatae. - (Massachusets; Scudder. Winnipeg; Keunicot.) 
Nota. Tipulam possideo masculan corporis picturâ et figurâ hypopygii mari Tipulae angustipemis simillimam, sed thorace minus lato et basi cellulae discoidalis albidâ diversam; utrum species distincta an Tipulae angustipeunis varietas sit ex specimine mutilato dijudicare nequeo.

20. Tipula appendiculata nov. sp. б. Thoracis dorsum obscure cinereum, villis concoloribus jusco-marginatis, subconfluenlibus; abdomen ex fusco latevicium, nigro-villatum, hypopygio magno fusco, in upice luteo, appendicibus duabus magnis pendulis pruedito; alae angustae, ex cinerco hyalinae, obsoletissime albido maculatuc, sligmate fusco, cellulis posterioribus praeter albidam primae basim et margine alarum postico immaculatis. - Long. corp. $3 \frac{3}{4}$ lin., L. 011 . al. $5 \frac{1}{2}$ lin.

Caput cinereum, viltulâ frontali fusiformi fuscà. Scapus anteunarum flavus, flagellum nigrum, articulis simplicibus. Rostrum luteum, lateribus obsemris. Palpi nigri, apicem versus ochracei. Thoracis dorsum ex fusco obscure cinereum, vittis concoloribus sub. conllucntibus, medià integrà omnibus fusco-margiuatis, marginibus laleralium aequalibus, mediae antice latioribus. Scutellum et pleurac concolora. Pleurae pallido et cinereo variegalae. Abdomen latericium vel ex fusco latericium, vittâ mediâ nigrì. Hypopygium magnum, fuscum, apice luteo, appendicibus duabus magnis concoloribus pendulis instruclo. Pedes graciles, femorum apice fusco. Alae angustae, ex cinereo hyalinae, maculis tribns subalbidis perobsoletis variegalae, stigmate fusco, cellulis posterioribus praeter albidam primae basim et postico alarum margine immaculatis. - (Satkalchevan; Kennicot.)

21. Tipula valida nov. sp. O. Ex luteo cinerascens, villis thoracis sub/uscis immarginatis, medit divist. abdomine luteo, nigrotriviltato, margine laterali pallido; alae ex luteo dilute subfuscue,

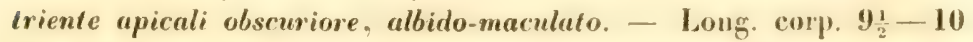
lin. Long. al. $10_{6}^{5}-11 \div \frac{1}{2}$ lin.

Ex luteo cinerascens, immatura dilute ochrascens. Capul eoncolor. vertice cinerascente. Rostrum ex ferrugineo ochraceum. palfis concoloribus, apicem versus nigricantibus: antennae ex rulo ochraceac, adversus apicem paulo obscuriores, arliculis flagelli pracles inferos in ima basi nigris. Thoracis dorsum ex luteo cincrascens vel subochraceum, villis subfuscis immarginatis, media per villam dilutiorem, antice allenualam dissecta. Abdomen luteum. villis tri. 
bus et segmento ultimo fusco-nigris, viltis laleralibus nonnumquam interruptis, marginibus lateralibus et margine segmentorum singulorum postico albicantibus. Terebra mediocris, utrinque apophysi basali instructa, lamellis superis acutis, subincurvis. Femorum apex niger. Alae ex luteo subfuscae, triente apicali saturatins infuscato. stigmate fusco; stigma utrinque maculà albidâ includitur et fascia albida subintegra cum venâ intercalari in posticum alae marginem excurrit; cellulae posterioris tertiae basis plerumque maculâ albâ notatur. - (Massachusets; Scudder. Illinois; Osten-Sacken.)

22. Tiprala speciosa nov. sp. $\delta$. Dilute ochracea, villis thoracis obsoletissimis concoloribus; alae lutecte. triente upiculi infuscato et absoletissime albido-maculato, basi venue secundae fuscolimbata. - Long. corp. $8 \frac{1}{3}$ lin., Long. al. $9 \frac{1}{2}$ lin.

Dilute ochracea. Caput concolor, fronte et vertice cinerascentibus. Antennae laete ochraceae, flagelli articulis in basi atris, infra non excisis, primo tamen toto ochraceo et ultimo toto atro. Palpi perlongi, dilute ochracei. Ordinariae thoracis vittae concolores, obsoletissimae. Abdomen saepe utrinque obsolete subfusco-lineatum. Hypopygium magnum, margine apicali lamellae infimae exciso et pilis sordide ochraceis barbato, lamellâ supremâ bipartitâ fuscâ, forcipe dextrâ sinistram Iongitudine multo superanle. Femorum apex fuscus. Alae luteae, triente apicali infuscato, stigmate et maculà minutâ, in basi venae secundae sitâ fuscis; stigma ulrinque maculâ subalbidà includitur et fascia albida subintegra cum venà intercalarí in posticum alae marginem excurrit. - (Illinois; Osten-Sacken.)

23. Tipula submaculata nov. sp. ㅇ. Dilute ochracea, vittis thoracis obsoletissimis concoloribus; alae lutescentes, triente apicali dilute subinfuscato, obsolete albido-maculato, basi venae secundae subfusco-notatâ. - Long. corp. $7 \frac{1}{4}-8$ lin., Long. al. $8 \frac{1}{4}$ lin.

Praecedenti valde similis, sed multo minor. Alae dilutius lutescentes, triente apicali dilute subinfuscato; stigma et punctum in imâ venae secundae basi subfusca; fascia subalbida imperfecta, in basi cellulae posterioris quartae desinens. Ultima duo abdominis segmenta fusca. Terebra longa, lamellis superis rectis, acutis. Femorum apex dilulissime subfuscus. In reliquis notis cum Tipulâ speciosâ congrua. - (Massachusets; Scudder.)

24. Tipula cincta nov. sp. $\sigma$. Cinerea, vittis thoracis e.t nigro fuscis, mediâ per lineam nigram dissectâ, omnibus nigro- 
marginatis; abclomen fuscum, margine postico segmentorum singulorum flaso; alue dilute subfiscae, apice paulo saluratius infuscato. stigmate fusco. - Jong. cosp. 4 lin., Jong. al. 6 lin.

Caput cinerenm, rostro concolore, lateribus tamen interdum fuscis. Frons lata. Palpi nigri. Antennae nigrae, primo scapi arliculo cinereo, articulis flagelli simplicibus, primo sequentibus aefuali. Thoracis dorsum cinercum, villis nigro-fuscis, mediâ per lineam nigram lissectâ, marginibus ommium nigris. Sculellum luteolum; metanotum cineriscens; pleurae albicantes. Abdomen fuscum, marginibus lateralibus, postico segmentorum singulorum margine et ventre flavis. Hypopygium majusculum, fuscum, infra rufum. lamellis superioribus pallidis, falcatis. Femora apicem versus fusca. Alac angust:e, aequaliter ef dilute subfuscae, in apice paulo saturatius inluseatac; stigna fuscum. - (District Columbia; OstenSacken.)

25. 'Tipula custa nov. sp. $\delta$. Helva, capite thoraceque albido.pollinosis, dorso hujus subcinerascente, villis cinereis subfuscomarginatis, medici per lineam cineream divisti; abdomen fusco-vittutum; alae subfiescae, obsolete dilutius viltatae, apice non infuscato. celluli costali et stigmate fuscis. - Iong. corp. $6{ }_{6}^{5}$ lin. I. Iong. al. $7 \frac{3}{4}-8 \operatorname{lin}$.

Helva, capite el thorace polliuc albido cineraseentibus, pleuris albicautibus. Scapus aulennarum helvus, primus flagelli articulus concolor, cyliudricus, reliqui ex fusco nigri. inferi tamen praeter basim nigram haud raro dilutius tincti. Palpi ex ochraceo ferruginei. Thoracis dorsum ex albo cinerascens, villis ex fusco cinereis, subfusco-margiuatis, mediâ per lineam albido-cineream, utrinque fusco-matginatam, inferdum imperfectam divisa. Vilta abdominis helvi fusca vel subfusca, angusla, inlerdum subobsolela. Ilypopysium concolor, minufum, compressum, lamellis appendicibusque ommibus minutis. Femora apicem versus fusea. Alac subfuscac, rellularum basalium primí marginibusque secundae paulo limpidioribus, cellulà costali el stigmate fuscis. - (Pennsylvania.)

26. Tipula infuscala nov. sp. T. Cinever, villis thoracis ex fusco cinereis, fusco-marginatis, medicimperfecte divisa; abdomen obscure testucenm, linề media fusci, murgine segmentorum singulorm postico: nltimis srgmentis tolis el terebrae basi ex fusco cinereis, opucis; alae aequaliter subficsae, apice concolore, celluli

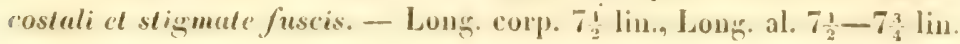


Caput cinereum, rostro ferrugineo, supra cinerascente. Palpi ex ochraceo fusci, apicem versus nigri. Primus antennarum articulus ex rufo fuscus, cinerascens, articulus secundus rufus; llagellum nigrum, articulo basali rufo. Thoracis dorsum cinereum, villis ex cinereo fuscis, obscurius marginatis, mediâ imperfecte divisâ. Pleurae ex albo cinereae. Abdomen obscure testaceum, marginibus segmentorum singulorum posticis, marginibus lateralibus, segmentis ultimis totis et basi terebrae ex cinereo fuscis, opacis, vittâ medià anguslâ fuscâ. Lamellae terebrae ex rufo testaceae, superae acutae et subincurvae. Alae subfuscae apice concolore, cellulà basali primâ sub. dilutiore, cellulà costali et stigmate fuscis. - (New York; OstenSacken.)

Nota. Tipulae helvae proxima, sed toto corpore obscuriore alarumque colore magis aequali diversa.

27. Tipula eluta nov. sp. ․ Antennarum flagellum obscure ochraceum, apicem versus infuscatum, basi articulorum singulorum atra; alae vittatae, limbis venae quintae angusto el costue lato fuscis, viltâ mediấ per cellularum posteriorum primam usque ad extremum alae apicem pertinente et maculâ minutâ ad stigmat is basim sil â subhyalinis, cellulis posterioribus praeter primam cellulisque axillaribus et anali ex cinereo dilute subfuscis. - Long. corp. 7 lin., Long. al. $7 \frac{1}{4}$ lin.

Caput ex fusco ochraceum, fronte et occipite subcinereis. Rostrum concolor, lateribus obscurioribus. Palpi subfusci. Scapus antennarum ex fusco ochraceus; flagellum obscure ochraceum, apicem versus fuscum, articulorum singulorum basi atrâ. Thoracis dorsum ex fusco ochraceum, vittis paulo obscurioribus subobsolelis, mediâ per lineam fuscam dissectâ. Vittae abdominis duae latae subfuscae, margines laterales et postici segmentorum singulorum pallidi. Extremus femorum apex subfuscus. Alae vitlalae, limbis venae quintae anguste et costae late fuscis, vittâ mediâ per cellulam discoidalem et cellularum posteriorum primam in alae apicem excurrente et maculâ ad stigmatis basim sitâ subhyalinis, cellulis posterioribus praeter primam cellulisque anali et axillaribus ex cinereo dilute fuscis. (District Columbia; Osten-Sacken.)

Nota. A Tipulâ tricolore Fabro, cui similis, cellulà basali primâ minus infuscatâ et vitlâ hyalinâ usque ad apicem alae pertinente distinguitur. 


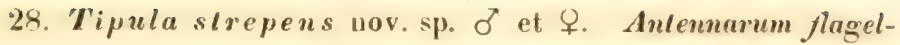
lum totum laete ochraceum, basi arliculorum singulorum alri; alae villatce, limbis venue yuintae anguste et costae latius fuscis, villa media inde a basi cellulae basalis secundae per cellulas posteriores usque ad extremum alae apicem pertinente albido-hyalini, maculit ad stigmatis basim sitâ lutescente, cellutis anali et axillaribus ex cinereo subfusris, adversus basim albido-hyalinis. - I.ong. corp. б 7, 의 9. lin, Jong. al. $9 \frac{3}{4} \ldots 10 \mathrm{lin}$.

Caput cincreum, roslro palpi-que ochraceis, apice horum fusco. Antennae tolae laete ochraceae. basi articulorum flagelli singulorum atrâ. Thoracis dorsum cinerema, vitis cincreis fusco-marginatis, mediâ per liuean obscure fuscam divișà specimina immatura thoracis dorsum helvum, viltas ex ochraceo fuscas habent. Abdomen sublalericiun, viltis duabus latis fuscis lineisque transversis concoloribus prope marginem segmentorum singulorum posticum sitis. Alae viltatae, limbis venae quinlae anguste el costae latius fuscis, villà medià albo-hyalinâ inde a cellulae basalis sccuudae basi per cellulas posteriores usque ad extremum alae apicem ductà; cellulâ costalis ex fusco lutea; macula ad sligmalis basim sila lutescens; cellulae discoidalis dimidium apicale et cellulac posterioris primac basale fusca; cellulae posteriores reliquae in dimidio basali albidae, in apicali fusco-cinereae; cellulae axillares et analis ex fusco cinereae, adversus basim subluyalinae. - (New York.)

\section{Tipula bella nov. sp. ơ et ㅇ. Anlennarum flagellum} obscure ochraceum, apicem versus infuscafum, basi articulorum singulorum atrâ; alae vitlatae, limbis venae quintae anguste, costae latius ex fusco nigris, villa media albido-hyalina per cellularum posterionum primam usque ad extremum alae apicem pertinente. cellulis posterioribus reliquis cellulisque anali et axilluribus cinereis, omnibus vel plerisque basim versus albido-hyalinis. - Long. corp. ð $6 \frac{1}{4}-6 \frac{1}{3}$, 우 $8-8 \frac{1}{6}$ lin. Long. al. $7 \frac{1}{4}-7 \frac{5}{6}$ lin.

Caput cinereum, rostro luteo, palpis fuscis. Scapus antennarum plerumque fuscus, articulo secundo interdum dilutius picto; flagellum saturate ochraceum, apicen versus subfuscum vel fuscum, basi arliculorum singulorum alri. Thoracis dorsum cincreum vel ex albo cinereum. interdum ex fusco ochraceum, villis subobsolelis paulu obseurioribus, imperfecte sublisico vel fusco marginalis, media per lineam fuscam divisi. Abdomen ex cinereo sublatericium, villis duabus latis fuscis. Iypopygium parvum, compressum. Femorum apes ex fusco niger. Alac villatae, limbis venae quinlac anguste et co- 
stae latius ex fusco nigris, vittâ medià albido-hyalinâ per cellulam discoidalem et cellularum posteriorum primam ad extremum usque apicem alae pertinente; limbus costae inaequalis, ante basim venae secundae et ante stigmatis basim excisus, pone sligma plerumque elutus; cellulae discoidalis et posteriorum prima totae albido-hyalinae; cellularum posteriorum secunda parva, plesumque perparva, quarta et quinta in basi albidae; cellulae axillares et analis in dimidio basali albido-hyalinae, in apicali cinereae. - Connecticul; Norton. District Columbia; Osten-Sacken.)

30. Tipula caloptera nov. sp. ठ大 et + . Antennavum flagellum obscure ochraceum, apicem versus infuscalum, basi articulorum singulorum atrà; alae villatae, limbis venae quintae anguste, costae late fuscis, vilta media albo-hyalina inde a cellulae basalis secundae dimidio per cellulas posteriores usque ad extremum alue apicem perlinente, maculá ad stigmatis basim silá lutescente, cellulis, anali et axillaribus subfuscis. - Long. corp. $\sigma^{7} 8 \frac{3}{4}$, \& $12 \frac{2}{3}-12 \frac{3}{4}$ lin. Long. al. 11-14 lin.

Caput cinereum, rostro palpisque obscure ochraceis. apice horum fusco. Antennarum arliculus primus ex ochraceo ferrugineus, secundus plerumque fuscus; flagellum obscure ochraceum, apicen versus subfuscum, basi articulorum singulorum atrâ. Thoracis dorsum helvum vel ex ochraceo fuscum, vittis paulo obscurioribus fusco-marginatis, mediâ per lineam latan obscure fuscam dissectâ. Abdomen sublatericium, vitlis duabus latissimis fuscis lineisque transversis concoloribus ante margines segmentorum singulorum posticos sitis. Hypopygium parvum, compressum. Femorum apex fuscus. Alae vitlatae, limbis venae quintae anguste et costae late fuscis, vittà mediâ albo-hyalinà inde a dimidio cellulae basalis secundae per cellulas posteriores usque ad apicem alac ductâ; cellula costalis ex luteo fusca; macula ad stigmatis basim sita lutescens; dimidium cellulae discoidalis apicale et cellulae posterioris primae apicale fusca; cellulae posteriores reliquae in basi albo-hyalinae, in apice $\mathrm{ex}$ cinereo fuscae; cellularum axillarium et analis dimidium basale albidohyalinum, dimidium apicale ex cinereo subfuscum; vena longitudinalis septima anguste fusco-limbata. - (Rhode Island.)

31. Tipula umbrosu nov. sp. ऊ. Subfusca, pleuris, coris, femorum basi, ventre, hypopygio parvo antennisque dilutioribus, his nigro-annulatis, vill is thoracis fuscis, media divisí; alae uequaliter subfuscae, stigmate concolore, venis fuscis, maculà lunatâ albida subobsoletâ. - Long. corp. $6 \frac{1}{3}$ lin. Long. al. $7 \frac{2}{3}$ lin. 
Caput subfuscum, verticis occipitisyue colore in cinereum vergente. Antennae ex luteo subfuscae, longiusculac, basi arliculorum llagelli singnhornm nigrâ. Palpi fusci. Thoracis dorsum dilute sub. fuscum, viltis ordinaris fuscis, medià per linean dilute subfuscam aeyualiter divisi. Color femotum, scutelli el metanoli in helvum vergens. Abdomen subfuscum, marginibus lateralibus el marginc postico segmentorm singulorum pallidis. Hypopygium parvum. basi subfusei. appendicibus pallidis. Pedes subfusci. femorum apice fusco, basi pallidi. Alac aequaliter subfuscae, sligmate concolore, venis fuscis, maculâ lunalâ albidâ parvà. subobsoletì. - (Louisiana; Sehauı.)

32. Pachyrrhina incurva nov. sp. ठ. Macula nigra occipitis parva; thorax nigro-villatus, viltis lateralibus antice incurvis; scutellum et metanotum nigro-unicittata; alae cinereo-hyalinae, limbo upicali distincle nigricante el stigmate parvo nigro. - Isong. corp. $5 \frac{1}{4}$ lin., Long. al. $5 \frac{1}{2}$ lin.

Flava. Occiput opacum, maculấ parvâ nigrâ, nitidà. Primus antennarum articulus favus, apicem versus fuscus, sccundus subfuscus; flagelli articuli nigri, primus paulo longior quam secundus et inlerdum praeter apicem fuscus, sequentes infra levissime excisi. Punctum nigrum inter antennas nullum. Rostrum plerumque supra fusco-vittatum. Palpi pallidi, articulo primo et apice saepe subfuseis. Collare flavum, lateribus fuscis. Thoracis vittae nigrae: villae laterales antice cum maculâ opacâ niggrà confluunt, ila ut incurvac appareant; margo lateralis ante alas lineoli brevi nigricante nolatus. Metanofum et scutellum villâ nigrâ picla. Pleurae maculis ochraceis vel ex fusco ochraceis variegatae. Primum abdominis segmentum praeter margines nigrum; segmenta sequentia singula maculam poslicam nigram subtrigonam habent, secuudum practerea mediam; segmentum septimum et oclavum tota nigra; hypopygium ochriceum. Femora apicem versus nigra. Halteres pallidi, capitulo praeter apicem fusco. Alae cinereo-hyalinae, venis ex nigro fuscis, limbo apicali distincte nigricanle, sligmate parvo nigro, cellulâ posteriore secundâ brevissime pedunculatâ, rarius sessili. - (District Columbia; Osten-Sacken.)

Nota. Variat vittae dorsalis mediae marginibus vittarumque la. teralium dimidio posteriore fuscis.

33. I'achyrehina pedunrulat " nov. sp. Q. Macula nigra uccipilis magna; thorax nigro-vittalus; villis lateralibus antice non 
incurvis; scutellum et metanotum nigro-univiltala; alae cineveohyalinae, stigmate nigro-fusco. - Long. corp. 85. lin., Long. al. $6 \frac{1}{2}$ lin.

Flava. Occiput opacun, maculà maguâ uigrâ, vilidà. Primus antennarum articulus flavus, secundus ex ochraceo subfuscus, reliqui nigri. Inter antennas punctum minulum nigrum cernitur. Rostrum plerumque supra fusco-viltatum. Palpi pallidi, articulo primo et apice subfuscis. Thoracis vittae nigrae, laterales antice non incurvae; margo lateralis ante alas liturâ nigrâ notatus. Pleurae maculis ex fusco ochraccis variegatae. Primum abdominis segmentum nigrum; reliqua singula maculam magnam nigram habent et secundum practerea fasciam nigram. Femora apicem versus fusci. Halleres pallidi, capitulo praeter apicem fusco. Alise cinereo-hyalinac, venis fuscis, limbo apicali summo levissime uigricante, stigmate mediocri ex fusco nigro, cellulà posteriore secundà pedunculatà. - (Saskatchevan; Kennicot.)

34. Pachyrrhina punctum nov. sp. ㅇ. Occiput opecum, immaculatum; antennarum flagellum praeter basim nigricans; villae thoracis ex fusco nigrae, puncto atro insigni vittis lateralibus anlice adjecto. - Long. corp. $7 \frac{1}{2}$ lin., Long. al. $6 \frac{1}{2}$ lin.

Occiput opacum, immaculatum, prope collum polline albido aspersum. Scapus antennarum et inferi flagelli articuli flavi, reliqui ex fusco nigricantes. Rostrum supra fuscum. Palpi pallidi, ex parte subfusci. Collare flavum. Thoracis vittae solitae ex fusco ochraceae, marginibus adversis subtilissime ferrugineis, maculà parvâ atrâ, opacâ vittarum lateralium initio infra adjectâ; suturae transversalis sulci laterales et posticus colore atro picti. Scutellum et metanotum non vittata. Pleurae maculis subochraceis obsoletissime variegatae. Abdominis segmenta ultima duo immaculata, praecedentia quinque singula maculâ posticâ nigrâ subtrigonà, secunduu praeterea maculâ minore anlicâ notantur'; in segmento primo fasciola nigra adest. Femora in extremo apice dilute subfusca. Halteres pallidi, capitulo infra subfusco. Alae paulo latiores quam in reliquis speciebus plerisque, sublutescentes, stigmate ex nigro fusco. cellulâ posteriore secundâ sessili, basi modice tantum angustałà. (Illinois; Osten-Sacken.)

35. Pachyrrhina unifasciata nov. sp. ․ Caput praeter frontis latera nitidum; thoracis villae ex fusco ochraceae; alae cinereo-hyalina, nigricuntibus venarum transversalium limbis fasciam trunsversam efficientibus. - Long. corp. $7 \frac{1}{2}$ lin., Long. al. $6 \frac{1}{3} \mathrm{lin}$. 
Capul praeler frontis latera nitidum. occipite immaculato. Frons puncta duo nigra, superis oculorum angulis contigna et villulam fuscam obsoletiorem ostendit. Anfennarum seapus et primi flagelli articuli flavi, reliqui nigri. Latera rostri subfusca. Primi tres pal. porum arliculi pallidi. apicem versus fusci, arliculu quarlus niger. Villae thoracis ex fusco ochraceae. laterales antice non incurvae. postice prope alas fusco-notitac. Scutellum el metanotum flava, lateribus ex fusco ochraceis. Pleurac supra ex ochraceo subfuscae, albido-pollinosae, infra flavae. Segmenta abdominalia primum et nIlimum immaculala, paenultimum subinmaculatum. reliqua singula maculá posticà nigrà, Irigonî praedita, secundum praeterea maculà minore anticâ. Femorum apex subito niger. Halleres pallidi, capitulo infra nigro. Alae cinereo-hyalinac. leviter sublutescontes. stigmate ex fusco nigro, venis transversis distincte subnigro-limbatis, cellula posteriore primå duabusque praecedentibus subnigro-lituratis. cellulâ posteriore secundà pedunculatâ. - (District Columbia; OstenSacken.)

36. Pachyrrhina abbreviala nov. sp. ․ Occiput opacum, macula nitida concolore; antennae fluvae. flagelli articulis in basi atris; villae thoracis ochraceae. sutura latera versats atra; abdomen nigro-muculatum; alae hyalinae, apice infuscalo, stigmate subfusco. - Long. corp. $5 \frac{1}{3}$ lin., Long. al. $5 \frac{1}{4}$ lin.

Occipitis opaci macula nitida concolor vel subochracea, mediocris, modice acula. Antenmae flavae, basi articulorum flagelli sin. gulorum atrâ, primi tamen concolore. Palpi pallidi. Ordinariae thoracis vittae ex ochraceo badiae, marginibus adversis subtilissime ferrugineis; vitlae laterales latae, antice usque ad lateralem thoracis marginem decurrentes; sutura adversus latera atra et in maculam atram excurrens. Scutellum et metanotum ochracea, lateribus flavis. Pleurae maculis ochraceis variegatae. Abdomen trifariam nigro-macu. latum, maculis mediis majoribus subtrigonis, lateralibns minutis, in ultimis tribus segmentis nullis. Lamellae inferiores terebrae per. breves, oblusae. Extremus femorum apex subfuscus. Alae hyalinae, vix levissime ex cinereo sublutescentes, cellulâ costali concolore, stigmate subfusco, apice alae infuscato. cellulâ posteriore secuudà pedunculatâ. - (Missisippi; Schaum.)

37. Pachyrrhina suturalis nov. sp. ․ Occiput oparum. macula nitida concolore, modice aruti; antenuce flave, flagelli articulis in basi atris; vittae thoracis ochracere. sutura atra; abdo- 
men immaculatnm; alae ex fusco cinereae, stigmate subfusco. Long. corp. 5 lin., Long. al. $5 \frac{1}{4}$ lin.

Occipitis opaci macula nitida concolor, mediocris, modice acuta. Antennae flavae, basi articulorum singulorum flagelli atrâ, primi tamen semper et secundi interdum flavâ. Palpi pallidi, apicem versus subfusei. Ordinariae thoracis vittae ochraceae, marginibus adversis subtilissime ferrugineis, angulis anticis vittae mediae et maculâ initio vittarum lateralium infra appositâ fuscis, nitidis; sutura thoracis atra. Scutellum et metanotum ex flavo ochracea, lateribus flavis. Pleurae maculis ochraceis variegatae. Abdomen immaculatum. Extremus femorum apex ex fusco niger. Halleres pallidi, capitulo infra subfusco. Alae ex fusco cinereae, obsoletissime sublutescentes, cellulâ costali et stigmate dilute subfuscis. - (Georgia; Osten-Sacken.)

Nota. Pachyrrhinam quandam in Floridâ captam accepi, maculis fuscis in thoracis dorso vix obsoletissimis et cellulà posteriore secundà pedunculatâ praeditam; quae utrum varietas Pachyrrhinae suturalis, an species distincta sit, ex specimine mutilato dijudicare nequeo.

38. Pachyrrhina circumscripta nov. sp. ㅇ․ Occipitis opaci macula nitida ochracea, antice fusca et valde acuta; antennae flavae, flagelli arliculis in basi atris; vitlae thoracis ochraceae, marginibus adversis ferrugineis; sutura thoracis ferruginea; abdomen ....; alae ex cinereo sublutescentes, stigmate subfusco. - I Long. corp. 6 lin., Long. al. $6 \frac{1}{6}$ lin.

Pachyrrhinae suturali simillima, sed maculâ occipitali angustiore, acutiore et antice fuscå, lateribus collaribus fuscis et transversà thoracis suturâ ferrugineâ diversa. Alae paulo dilutiores et magis lutescentes; maculae viltis thoracis lateralibus adjectae in specimine descripto nullae. - (Cuba; Riehl.)

39. Pachyrrhina eucera nov. sp. $\delta$ et ․ Occiput immaculatum, totum nitidum; antennae maris articulis 19, foeminne 15 instructae, articulis flagelli nigris in basi flavis; vittae thoracis ochraceae; alae luteae, stigmale ex fusco luteo. - Long. corp. $7 \frac{1}{3}-9 \frac{1}{3}$ lin., Long. al. $7 \frac{1}{6}-9$ lin.

Flava. Occiput immaculatum, totum nitidum. Scapus antennarum flavus, flagellum nigrum, articulo primo praeter apicem reliquorumque singulorum basi flavis; antennae maris 19-articulatae, primo flagelli articulo cylindrico, valde elongato, reliquis infra pro- 
funde excisis; antennae foeminae 15-articulatae, breviores, articulis flagelli infra non excisis. Palpi flavi. Vittae thoracis pallide ochracese, interdum subobsoletae, raro subfuscae. Scutellum et metanotum nec fasciata. nec maculata. Pleurae maculis ochraceis obsolete variegalae. Abdomen supra lineam fuscam, utrinque in margine laterali seriem strigularum atrarum, infra seriem punctorum nigrorum habet. Hypopygium maris flavum, infra pilis llavis barbatum. Extremus femorum apex subfuscus vel fuscus. Halteres pallidi, capitulo saepe dilute subfusco. Alae magnae, luteae, stigmate ex fusco lutco, cellulât posteriore secundâ sessili. - (New York, Illinois, District Columbia; Osten-Sarken.)

Nota. Qui Nephrotomas a Pachyrrhinis separandas esse censet, hanc speciem et sequentem inter Nephrotomas recte collocabit.

40. Pachyrrhina polymera nov. sp. ot et 9 . Occiput totum nilidum, immaculatum; antennae maris arliculis 16, foeminae articulis 14 instructae, flagelli articulis nigris in basi favis; vittae thoracis ochraceae; alae lutescentes, apice nigricante, stigmate ex nigro fusco. - Long. corp. $5 \frac{3}{1}-7 \frac{5}{6}$ lin., Long. al. $6 \frac{1}{2}-7$ lin.

Flava. Occiput immaculatum, totum modice nitens. Scapus antennarum flavus, flagellum nigrum, articulo primo praeter apicem reliquorumque singulorum basi flavis; antennae maris $\mathbf{1 6}$-articulatae, primo flagelli articulo cylindrico, elongato, reliquis infra excisis; antennae foeminae 14-articulatae, breviores, articulis flagelli infra non excisis. Palpi flavi. Vittae thoracis ochraceae vel ex fusco ochraceae; supra alas ad suturam punctum nigrum. Scutellum et metanotum nec maculata, nec vitlata. Pleurae maculis ochraceis obsolete variegatae. Abdomen supra lineam subfuscam obsoletissimam vel nullam, utrinque in margine laterali seriem strigularum nigrarum hahet; segmentum ultimum in utroque sexu nigrum. Hypopygium maris ochraceum, infra pilis flavis barbatum, lamiuâ supremâ nigrâ. Extremus femorum apex fuscus. Halteres flavi, capitulo infra subfusco. Alae lutescentes, apice nigricante, stigmate ex nigro fusco, cellulâ posteriore secundâ subsessili. - (Illinois; Osten-Sacken.)

41. Pachyrrhina tenuis nov. sp. O’ et $\%$. Occipul opacum, immaculatum; antennoe utrinsque sexus aequales, primis tribus arlirulis favis, reliquis nigricuntibus. in ima basi tamen pallidis; thorax opacus, vittis obsoletissimis ochraceis; alae ex luteo subhyalinae, venis et margine costali huteis. - Iong. corp. of $5 \frac{2}{3}$, of $8 \frac{1}{4}$ lin., Long. al. $6 \frac{1}{4}-6 \frac{1}{1} \frac{1}{2}$ lin. 
Flava. Caput concolor, opacum, occipite immaculato. Latera rostri fusca vel ferruginea. Palpi nigri, apicem versus ferruginei. Antennae utriusque sexus aequales: scapi articuli flavi; articuli flagelli simplices, primus flavus, reliqui ex fusco nigri, iınâ singulorum basi tamen pallidà. Thoracis dorsum opacum, vittis ordinariis obsoletissimis ochraceis. Abdomen utrinque serie strigularum nigrarum pictum; series strigularum nigrarum in ventre unica. Hypopygium maris parvum; terebrae lamellae superae acutae, subincurvae. Pedes gracillimi, femorum apice concolore. Alae ex luteo subhyalinae, venis omnibus, stigmate et margine costali luteis; cellula posterior secunda plerumque breviter pedunculata. - (Sharon Springs; OstenSacken.)

42. Stygeropis sordida nov. sp. ․ Ex fusco nigricans, rostro toto nigro, antennarum apice valde altenuato. empodio conspicuo. - Long. corp. $5 \frac{1}{\frac{1}{2}}$ lin., Long. al. 5 lin.

Stygeropidi pubescenti similior quam Stygerop. Dianae. Ex fusco nigricans, opaca. Capul concolor, rostro toto palpisque concoloribus. Antennae nigrae, primo flagelli articulo in basi interdum obscure rufescente, articulis ultimis tribus tenuibus. Collare per lineam incisam in partes duas aequales divisum. Vittac thoracis ex fusco nigrae, subobsoletae, media per lineam dilutiorem divisa. Abdominis margines laterales segmentorumque singulorum margines postici pallescentes. Terebra mediocris, lamellis superis angustis, subrectis, acutis, praeler basim fuscis. Empodium conspicuum. Femorum apex subfuscus. Alae cinereae, stigmate sublutescente, maculà lunatâ albidâ obsoletissimâ. - (Winnipeg.)

Nota. Nomen Prionocerae rejiciendum in Stygeropidem mulavi. Stygerop. sordida a Stygerop. Dianâ rostro toto nigro, a Słygerop. pubescente antennis gracilioribus adversus apicem valde attenuatis et empodio majore differt.

43. Blepharoknera capitata nov. sp. $\sigma^{7}$ et 오. Cinerea, fasciis abdominis fuscis, interdum obsoletis, pedibus flavescentibus. ultimo tarsorum arliculo infra non exciso. - Long. corp. 1 $\frac{2}{3}-2 !$ lin., long. al. $2 \frac{1}{2}-3 \frac{2}{3}$ lin.

Color corporis variabilis, plerumque cinereus. Facies latiuscula, polline albido aspersa. Rostrum flavum, palporum basi concolore. apice nigro. Thoracis dorsum cinereum, plerumque glaucescens. vittâ mediâ subfuscâ, postice abbreviatâ. Scutellum thoraci concolor. Pleurae interdum tolac pallidae, saepius ex parte glauce- 
scentes vel ex glauco cinereae. Abdomen cinereum, subglaucum, dimidio posteriore segmentorum singulorum fusco, margine postico tamen cincrascenle. Venter tolus flavus aut segmentorum singulorum basi nigricante. Pedes flavescentes, apicem versus subtestacei, ultimo tarsorum articulo infra uon exciso. Alae hyalinae, venis ut in Blepharopterí fisciatâ Westwo directis. - (District Columbia; Osten-Sacken.)

44. Metoponia similis nov. sp. б. Ex nigro viridis, nitida, abdomine dilute testaceo, marginibus lateralibus late segmentorumque singulorum marginibus posticis anguste fuscis, cellula discoidali minutâ. - Long. corp. $2 \frac{1}{2}$ lin., Long. al. $2 \frac{1}{\frac{1}{2}}$ lin.

Facies et triangulum fronlale albo-pollinosa. Antennac nigrae, articulo primo fusco. secundo et basi tertii flavicantibus. Thoracis dorsum et scutellum ex nigro viridia, nitida, albo-pubescentia. humeris angulisque posticis illius piceis; pleurae ex viridi nigricantes, vittâ albido-pollinosâ. Abdomen ex flavo testaceum, late fusco-limbatum segmentorumque singulorum margine postico anguste fusco. Pedes flavescentes, tibis anticis posticisque praeter basim subfuscis, farsis anticis lotis, intermediis inde ab arliculi secundi posticisque ab tertii apice ex fusco vigris. Alac cinerascentes, stigmate fusco, cellulâ discoidali quam Metoponiae fuscilarsis Say multo minore.(New York; Schaum.)

45. Metoponia obscuriventris nov. sp. P. Nigra, abdomine concolore. thoracis dorso sculelloque obsolete subvirescentibus, pedibus fusco et testaceo variis, cellulá discoidali parvâ. - Long. corp. 2 lin., Long. al. 2 lin.

Caput atrum nitidum, fronte angustiore quam Metoponiae fuscitarsis Say. Antennae nigrae, articulo secundo et basi tertii rufis. Thoracis dorsum et scutellum nigra, obsolete virescentia et pube brevissimâ albidâ vestita; pleurae nigrae, obsoletissime virescentia, vittâ albo-pollinosâ. Abdomen tolum nigrunínitidum. Pedes lusci, Irochanteribus, femorum apice tibiarumque basi ex flavo testaceis, tarsorum postcriorum articulis primis qualuor flavicantibus, ultimis duobus obscure fuscis. Halteres fusci. Alae obscure cinereae, stigmate fusco. cellulâ discoidali majore quam in specie praecedente, minore tamen quam in Metoponiâ fuscitarsi Say. - (I)istrict Columbia; Osten-Sacken.)

Nota. Metoponiae cujusdam foemina ex Sibiria allata ab hac nostrâ Metoponiâ obscuriventri non differt, nisi thoracis scu- 
tellique colore purius nigro, cellulac discoidalis figurâ minus ovatâ, pedibus obscurioribus tarsorumque posteriorum apice la. tius ex fusco nigro.

46. Bombylius hamorrhoicus nov. sp. $\sigma^{7}$. Ater, atropilosus, ano fulvopiloso. - Long. corp. $4 \frac{3}{4}$ lit.. Long. al. $5 \frac{5}{12}$ lin.

Bombylio anali Fabr. similis, formâ ac figurâ cellularum margini alarum postico conlignarum Bomb. rufo Oliv. et ferrugineo Fabr. affinis. Tolus ater, opacus, atro-pilosus, pilis occipitis et thoracis brevibus, pilis ani confertis ex rufo fulvis. Oculi contigui. Primi duo antennarum arliculi nigro-pilosi, tertius sululatus. Tegulae nigrae. Alae angustae, lyyalinae, imâ basi atrâ, cellulâ submarginali secundâ cellulisque posterioribus secundâ el terliâ aequirlibus, venulâ transversâ mediâ a cellulae discoidalis fine paulo lon. gius quam a basi remotâ. -- (Cuba, Riehl.)

47. Bombylius pulchellus nov. sp. o et 오. Fuscus, pilis in occipile el in lateralibus thoracis marginibus albidis, maculis alarum fuscis, fascias subquatuor efficientibus. - Long. corp. 23-3 lin., Jong. al: $3 \frac{1}{1} \frac{1}{2}-3 \frac{1}{3}$ lin.

Ex affinibus Bombylii pieti Panz. Niger, opacus, pilis ex fusco cervinis vestitus, in abdominis disco confertioribus et decumbentibus. Oculi maris contigui, foeminac late separati. Antennae ob. scure testaceae vel subfuscae, articulo tertio latiusculo, valde acuminato, primo nigro-piloso. Mystax tenuis, pilis externis nigris, internis ex fusco cervinis. Proboscis corpore paulo brevior. Mas occiput totum, foemina latera occipilis albo-pilosa habet. Thoracis margines laterales et anguli postici confertim albido-pilosi. Pedes flavescentes, femoribus ultimisque tarsorum articulis dilute subfuscis. Alae hyalinae adversus costam fuscae et maculis fuscis, fascias subquatuor efficientibus eleganler piclae; cellula margininalis apicem versus dilatatur et venula transversa media prope cellulae discoidalis finem sita est. - (Illinois; Osten-Sacken.)

48. Bombylius validus nov. sp. $\sigma^{\top}$ et . Ater, opacus, flavopilosus, pilts verticis, frontis, antennarum, faciei, pectoris ventrisque nigris, pedibus testaceis, alis subfusris, adversus costam el basim saturatius fuscis. - Long. cosp. $4 \frac{1}{2}-6$ lin., Long. al. $6-7 \frac{1}{3}$ lin.

Ater, opacus, pilis saturate llavis confertim vestitus. Caput nigrum, prope oris aperturam plerumque obscure testaceum, pilis verticis, frontis et faciei atris, pilis occipitis brevibus et saturate flavis, 
menti paulo longioribus et dilutius flavis. Oculi maris contigui, foeminae per frontem modice latam separati. Antennae nigrae, artirulis primis duobus nigro-pilosis. Proboscis corpore paulo brevior. In thoracis abdominisque dorso et in scutello pili omnes flavi; prothoracis metathoracisque epimera in utroque sexu flavo-pilosa, epimera metathoracis in mare nigro-pilosa, in foeminâ pilis flavis crebrioribus nigrisque rarioribus vestita. Pili pectoris coxarumque plerique nigri. Pedes lutei, colore fernorum saepe in testaceúm vergente, tarsis apicen versus fuscis. Halterum capitulum fuscum, summo tamen apice albicanle. Alae magnae, subfuscae, adversus costam et hasim suluratius fuscae, venis ex fusco ferrugineis, venulâ transversâ mediâ cellulae discoidalis basi quam apici propiore. (Illinois, Virginia; Osten-Sacken.)

49. Bombylius atriceps nov. sp. ơ et + . Ater, subopacus. margine oris pedibusque luteis, supra flavo-pilosus, marginibus segmentorum abdominalium singulorum posticis nigro-pilosis, infra albo-pilosus, alis hyalinis adversus costam et basim ex nigro fuscis. termino fuscedinis elulo. - Long. corp. $3 \frac{2}{3}$ lin, Long. al. $4 \frac{1}{2}$ lin.

Mas: Ater; caput concolor, nitidum, margine oris luteo. Oculi conligui. Pili verticis, frontis, antennarum ef faciei nigri, intimi tamen mystacis pili flavi. Occiput breviter flavo-pilosum; mentum pilis altis hirlum. Proboscis corpore paulo brevior. Thorax opacus, flavo-pilosus, infra pilis albis vestitus. Scutellum subnitidum, flavo-pilosum, pilis aliquot marginalibus nigris. Abdomen subnitidum. supra flavo-pilosum, marginibus segmentorum singulorum posticis nigro-pilosis. Venter albo-pilosus. Pedes dilute lutei, tarsis apicem versus fuscis, femorum basi albo-pilosâ. Halterum capitulum flavun. infra fuscum. Alac ex cineren hyalinae, adversus costam et basim ex nigro fuscac, fuscedinis termino eluto, reclo, venulâ transversâ mediâ ante cellulam discoidalem mediam positâ.

Foemina: Oculi separati; frous atra, nilida, infra aureo-tomentosa. Posterior thoracis pars, sculolium et abdomen tomento aureo lecta; in reliquis cum mare congrua. - (Florida, Virginia; Osten-Sacken.)

Nota. Bomb. atriceps a Bomb. mexicano Wied., cui simillinus est, maryinibus segmentorum abdominalium posticis nigro-pilosis facile distinguilur.

50. Bombylius ravus nov. sp. ㅇ․ Nigricans. opacus, albopilosus, pilis in posteriore thoracis dimidio. scutello et abdominis 
disco brevioribus, decumbentibus ef colore in ravum rergente tinctis vestitus, thoracis limbo poslico, scutello marginibusque posticis segmentorum abdominalium singulorum pilis longioribus nigris instructis, pedibus flavicantibus, alis hyalinis, - Long. corp. $3 \frac{1}{2}$ lin.. Long. al. $3 \frac{2}{3}$ lin.

Nigricans, opacus, albido-pilosus. In vertice, in primis antennarum articulis et in summo mystacis margine pili aliqnot nigri cernuntur, reliquis capitis pilis omnibus allsis. Antennae tenues, nigrae. Thoracis margines laterales et anticus pilis candido-micantibus teguntur; reliquum thoracis dorsum, sculellum et abdomen pilos paulo breviores decumbenles et colore ex albido in ravum vergente tinclos habent. Prope posticum thoracis marginem, in scutello et in marginibus segmentorum abdominalium singulorum posticis pili longiores nigri conspiciuntur. Plenrae, pectus et venter pilos albos gerunt. Pedes dilute flavicantes, tomento albido induti, tarsorum apice fusco. femorum basi nigricante, albo-pilosâ. Alae hyalinae, venis fuscis, primâ totâ, tertiâ et quintâ prope basim dilute ferrugineis; venula transversalis media a cellulae discoidalis apice longius distat quam a basi. - (Mexico.)

51. Systoechus candidulus nov. sp. 万. Nigricans, opacus, sculelli apire ferrugineo, capile praeter scciput et mentum nigropiloso, reliquo corpore toto confertim albo-piloso, pedibus luteis, femoribus basim versus luteis, atis hyalinis. - Iong. corp. $3 \frac{1}{4}-3 \frac{2}{3}$ lin., Long. al. $3 \frac{1}{2}-3 \frac{5}{6}$ lin.

Nigricans, opacus, apice scutelli ferrugineo. Caput parvum. atrum; superius faciei dimidium polline dilute cinerascente rare aspersum; pili verticis, frontis, antennarum et faciei atri; reliquum corpus pilis confertis albis hirtum. Proboscis tenuis, capite et thorace simul sumptis longior. Pedes graciles, dilute lutei, femorum anteriorum dimidio basali nigro, femoribus posticis adversus basim nigris, femoribus omnibus prope basim albo-pilosis. Alae hyalinae. basi sublutescente. - (Wisconsin; Osten-Sacken.)

52. Sysloechus vulgaris nov. sp. $\sigma^{\top}$ et . Nigricans, scutello praeter basim ferrugineo. flavo-pilosus, capile praeler mentum et occiput nigro-piloso, pedibus flivis setulas ferrugineas gerentibus. femoribus basim versus plerumque nigris, alis hyalinis. - Lon: corp. $3 \frac{1}{4}-3 \frac{2}{3}$ lin., Long. al. $3 \frac{1}{2}-3 \frac{5}{6}$ lin.

Nigricans, flavo-pilosus, pilis nigris in thorace, scutello et abdomine omnino nullis. Caput nigro-pilosum, occipite tamen con- 
fertim flavo-piloso et mento pilis dilutius flavis vestito; pili breviores flavi nigris in mystace immixti. Oculi maris anguste separati; frons focminae latissima, infra maculam permagnam geminam, atram ct nitidam gerens. Pedes flavi, tarsis inde ab articuli primi aut secundi apice ex fusen nigris. femoribus basim versus plerumyue nigris, setulis omnibus dilute ferrugineis vel sordide ochraceis. Alae Lyalinae basi lutescente. - (Nebraska; Osten-Sacken.)

Nola. Bombylium solitum Walk. Systoechum quidem esse suspicor, Systoecho valgari nostro similem, sed pedibus nigrosetosis et apice tibiarum piceo diversum.

53 Lordotus gibbus nov. sp. ․ Niger. opacus, pilis confertis subaureis hirlus, secundo antennarum articulo pedibusque ochraceis, alis hyalinis, adversus costum et basim dihue ochraceis. Long. corp. 5 lin., Long. al. $4 \frac{1}{2}$ lin.

Niger, opacus, pilis confertis subaureis hirtus, obscurioribus in toto corpore omnino nullis. Frons modice lata. Antenuae tenues, nigrae, articulis primis duobus eylindricis, secundo praeter basim luteo vel ochraceo, dimidiam primi longitudinem paulo superante, tertio subulato. Mystax densus. Proboscis nigra quam tibia anlica paulo longior. Thorax valde convexus. Abdomen cylindricum, crassum. Pedes ex luteo ochracei, larsis praeter basim ex fusco nigris, femóribus in inà basi nigricantibus; tibiarum tarsorumque setulae nigrae, rigidae; femorum sefae longiores, tenuiores, Inteae. Halteres dilute lntescentes. Alae basim versus non angustatae, hyalinae, adversus costan et basim dilute ochraceac, venis colore saturatius ochraceo tinclis, costâ ipsì lamen nigrà; apex cellulae marginalis dilatatus; vena longiludinalis tertia ramulum anteriorem propo alae matginem eniltit, ita ut cellularum submarginalium prima solito longior, tertia vero angustior sit; cellula basalis prima perlonga, venulà lransversâ a basi cellulae discoidalis duplo longius guam a fine distante. - (Matamoras.)

Nota. Lordofus sic ut Sobarus et Platamodes, quibus proxime affinis est, cellulas submargiuales tres et cellulam posteriorem primau apertam habet; ab illo alis basim versus non angustatis, ab hoc primo antemarum articulo non incrassato, ab utroque corpore subeylindrico couvexissimo cellulisque alarum submarginali primà et basali primâ longioribus dillerl.

51. Geron calvus nov. sp. F. Temuis, opacus, er nigro fusrus, thorace distincte cinereo-viltato. supra pilis ravis et tomento 
rarissimo favicantibus, infra pilis albidis praedilus, pedibus flavis, tarsis praeter basim femorumque apice nigris, vamulo anderiore venae tertiae decumbente. - Long. corp. '2 lin.. Jong. al. $2 \frac{1}{12}$ lin.

Gracilior et pilis brevioribus rarioribusque praeditus quan reliquae species, ex nigro fuscus, opacus. Frous angusta, aequalis. Antennae nigrae, articulo-primo cinerascente, secundi apice sordide testaceo. Facies, mentum et occiput albido.pilosa, vertex nigro-pilosus. Thoracis dorsum cincreum, vittis duabus fuscis postice confluentibus maculâque utrinque suprahumerali fuscâ, pilis raris flavicantibus vestitum. Scutellum thoraci concolor. Pleurae ex albo cinereae, rare albo-pilosulae. Abdomen fuscum, pilis brevioribus decumbentibus flavis longioribusque erectis albicanlibus rare vestitum, in apice pilis nonnullis nigris instructum. Venter flavus, apicem versus ex fusco cinereus, totus albo-pilosus. Pedes flavi, tibiis praeter basim ex fusco nigris, femorum anteriorum dimidio apicali, posticorum triente apicali nigris. Halteres flavi, capitulo supra fusco. Alae dilutissime fuscescentes, cellulâ sligmaticali paulo saturatiore, ramulo venae tertiae auteriore decumbente. - (New York.)

55. Geroi subauratus nov. sp. б’ et $\&$. Opacus, ater, supra pilis lutescentibus et tomento tenui subaureo vestitus, infra pilos squamulasque candidas gerens, mystace candido, brevibus antennarum pilis nigris, ramulo anteriove venulce tertiae arduo. - Long. corp. $1 \frac{3}{4}-2 \frac{1}{2}$ lin., Long. al. $1 \frac{3}{4}-2 \frac{5}{12}$ lin.

Mas: Ater, opacus. Oculi contigni; frons et facies candidopilosae. Antennae nigrae, articulis primis duobus breviter nigro-pilosis; pili verticis nigri, occipitis lutescentes, menti albidi. Thoracis dorsum et scutellum aira, opaca, pilis lutescentibus et tomento rarissimo subaureo vestita. Pleurae pilis albidis et tomento candido instructae. Abdomen alrum, opacum, pilis lutescentibus et tomento brevissimo subaureo rare aspersum, lateribus et ventre dilute cinereis, pilis albidis el tomento candido praeditis. Pedes nigri, tibiis interdum piceis. Halteres flavi. Alae hyalinae, leviter cinerascentes, cellulâ stigmaticali dilute subfuscâ, ramulo anteriore venae tertiae ardue ascendente.

Foem.: Frons modice lata, atra, marginibus lateralibus angustis et triente infero albidis, supra tomento subaureo, infra candido aspersa. Pili totius corporis breviores et tomentum subaureum in thoracis dorso, scutello abdomineque confertius quam in marc. - (Pennsylvania; Osten-Sacken.) 
Nota. Magnitudine valde varial; specinina minora supra pilis dilulius sublutescentibus vestita vidi.

56. systropus macer nov. sp. of el $q$. Niger, thorace non villato, abdomine medio rufo. - Long. corp. 5-6 lin., Long. al. $3 \frac{1}{6}-4$ lin.

Niger, opacus. Uculi utriusque sexus contigui. Autennae concolores, capite lhorareque simul sumptis longiores, articulo terlio longiludinem fere duplicem secundi allingente. Frous et faciei pars snprema nigrae, albo-micantes; margines oris albidi. Thoracis dorsum non vittatum, puncto utrinque humerali punclisque angulorum posticorum albidis. Pleurae nisrae, subtilissime candido-puberulae, epimeris prothoracis fere tolis albis. Segmenla abdominis intermedia rufa; basis colore nigro in rufum diluto tincta; segmenta ultima tria athi. Cosae anticae rufae, intermediae rufo et nigro variae, posticae totae nigrae. Pedes nigri, femoribus anticis rufis, superne et apicem versus nigris, summo apice albido; libiae et melatarsi pedum anticorum in latere postico lineam alban vel albidam habent. Alac obscure cincreate, imà basi, cellulis costalibus et maculâ in venae secundac basi silà ex nigro fuscis. - (Wisconsin, Pennsylvania; Osten-Sackeu.)

Nota. Cum Systropo foenoidi in multis rebus convenit, thoracis vero dorso non viltato segmentisque abdominis ultimis tribus semper alris diflert.

57. Temnocera megacephala nov. sp. ․ Lutea. capite permagno sordide luteo, thoracis villis duabus obsoletioribus nigellis, abdomine praeter imam segmentorum singulorum basim fusco, pectore ventrisque villa interrupla nigris, antennis ochraceis, pedibus ex ochraceo luteis, alis hyalinis, venis transversis costaeque dimidio secundo nigro-limbatis. - Long. corp. $6 \frac{1}{2}$ lin., Long. al. $6 \frac{7}{13} \operatorname{lin}$.

Brevis, lata, lutea. Caput permagnum latum sordide luteum, fronle et facie breviter nigro-pubescentibus, pube oculorum brevissimà subalbidà, occipilis genarumque dilute luteolâ: facies modice producta, tuberculo ordinario fere nullo. Antentae ochraceae, breviusculac, articulo tertio supra exciso. In dorso thoracis viltae duae obsoletiores nigellac. late dislantes adsunt. Sculellum tolum luteum. Thoracis dorsum et sculellum praeter margines pilis brevibus nigris, in marginibus pallidis aspersal, selis nullis instructa. Pleurac supra luteae, infra nigrae. Abdomen lalum, subluscum, imâ tamen segueu- 
torum singulorum basi luteâ et pilis pallidis vestitâ. Venter dilute luteus, brevissime pallide pilosus, vittâ mediâ interruptâ nigrâ et nigro-pilosâ. Coxae et trochanteres nigri; pedes ex ochraceo lutei, pallide pilosi, tarsorum apice obscure fuseo. Alae hyalinae, apicali costae dimidio colore ex cinereo nigro late marginato, venis transversis colore saturatius nigro-limbata. - (California; Agassiz)

58. Orthoneura pictipennis nov. sp. $\sigma^{\top}$ et 9 . Aeneo-viridis, antennis linearibus, oculis unicoloribus, alis fusco-nebulosis, sligmale limbisque venarum transversalium fuscis. - Long. corp. $2 \frac{2}{3}-$ 3 lin., Long. al. $2 \frac{1}{4}-2 \frac{1}{3}$ lin.

Caput viridi-aeneum; antennae lineares, nigrae, articulis primis duobus et basi tertii infra rufescentibus. Facies albido-pilosula, subtiliter transverse rugulosa, supra ulrinque maculan triangulam albido-pollinosam gerens, tuberculo nullo, peristomio subito producto. Frons foeminae tola transverse rugosa, lineâ mediâ longitudinali exsculptâ. Thoracis dorsum modice nitens, subtilissime punctulatum. vittis quatuor, lateralibus antice, intermedis postice abbreriatis, co. lore omnium in speciminibus aeneis purpureo, in virescentibus pyritoso. Scutellum planum, subtiliter et inaequaliter transverse ru gulosum. Abdominis discus subcaesius et modice nitens, margines nitidi viridi-aenei vel cuprei. Pedes aeneo-nigri, genibus, basi et apice tibiarum primisque duobus larsorum articulis rufis. Tegulae albae. Halteres dilute flavicantes. Alae cinereae cellulis discoidali et posteriorum primâ liturâ fuscâ notatis, narginali et submarginali infuscatis, stigmate venarumque transversalium limbis fuscis. (New York.)

Nota. Affinis est Orthoneurae hieroglyphica Big., sed oculis unicoloribus, stigmate fusco alisque apicem versus infuscatis ab illâ diversa.

59. Chrysogaster latus nov. sp. f. Aeneo-niger, nitidus, pedibus totis concoloribus; antennae mediocres, nigrae, articulo tertio rolundo, piceo: latera frontis infra transverse rugosa; alae sublutescentes, stigmate et venis luteis. - Long. corp. $3 \frac{1}{4}$ lin., Long. al. $2 \frac{3}{4} \operatorname{lin}$.

Aeneo-niger, laevigatus, nitidus, pilis brevissimis albidis rare. aspersus. Frons lata, lateribus infra transverse rugosis. Antennac mediocres, articulo tertio subrotundo fusco, selâ concolore. Tuberculum faciei nullum; peristomium valde productum. Abdomen la. tum, nitidum, postico segmenti ultimi margine integro. Pedes toti 
aeneo-nigri. Halteres et togulae lutescentes. Alae adversus costam dilute sublutescentes, venis et stigmate luteis. - (English River; Kennicot.)

60. Chrysogaster uigripes uov. sp. ऊ. Obscure aeneo. viridis. Thoracis dorso abdominisque disco opacis, antennis parvis testaceis, pedibus viridi-nigris, alis nigricantibus. - Long. corp. $3-3 \frac{1}{1} \frac{1}{2}$ lin. Long. al. $2 \frac{2}{3}-2 \frac{3}{4}$ lin.

Caput ex chalybeo obscure aeneo-viride, nitidum; iuberculum faciei parvum; peristominm permodice productum. Antennae parvae, articulis primis duobus fuscis vel fusco-nigris. articulo tertio ovato, testaceo, seta subfuscà Triangulum frontale permagnum. convexum, fossulat longiludinali exsculplum. Thoracis dorsum nigrum, opacum, atumis virescentibus. latera versus in vithulas congestis aspersum. Scutellum viride, asperulum. subnitidum. Abdominis diseus niger, opacus; margines aeneo-virides, nitidi. Pedes toti ex viridi nigri. Tegulae dilute subnigricantes. Halterum pedunculus lutescens. capilulum nigrum. Alae subnigricantes, adversus basim et marginem posticum dilutiores, stigmate infuscalo. (New York.)

61. Triglyphus pubescens nov. sp. $\sigma^{7}$. Nigroviridis, pube longiusculd dilute lutesrente vestilus, tibiis posticis nigro-pilosis, genibus, tibiarum anteriorum basi tarsisque praeter apicem et praeter articulum anticarum posticarumque primun favescentibus. - Long. corp. 2 lin., Long. al. $1_{6}^{5}$ lin.

Nigro - viridis, nitidus, tolus pube longiusculâ vestitus. Pubes faciei albida, frontis prope antennas dilutissime lutescens, in angulo frontis supero et in vertice nigra. Antennae longiusculae nigrae, articulo tertio oblongo, infra obscure rufescente. Pubes thoracis et scutelli majusculi lutescens. Pubes abdominis quam thoracis dilutior, adversus anum albicans. in posticis segmentorum secundi et tertii marginibus nigra. Pedes ex viridi atri, pallide pubescentes, libiis posticis tamen supra nigro - pilosis. Genua tibiarumque anteriorum basis dilute lutescentia: tarsi antici nigri, articulo primo practer basim nigram fusco, articulo secundo sordide luteo; tarsi intermedii dilute lutei. arliculo lerlio subfusco, ultimis duobus nigris; tarsi postici nigri, articuli prini modice incrassali apice articulisque sequentibus duobus dilute luteis. Tegulae albae. Halteres dilute flavescenles. Alae cinereo-hyalinae, stigmate subfusco, vonì spuria praeter nodum subobsoletà. - (Wisconsin.) 
62. Triglyphus modeslus nov. sp. ․ Ex nigro chalybescens, pube brevi albà vestilus, libiis posticis allo-pilosulis, genibus, tibiarum bnsi tarsisque praeter apicem et praeter arliculum anticorum posticorumque primum dilute lutescentibus. - Long. corp. $2 \frac{2}{3}$ lin., Long. al. $2 \frac{1}{3}$ lin.

Ex nigro chalybescens, modice nitens, pube brevi albidà vestitus, lineis dorsalibus quatuor obscurioribus admodum obsoletis. Frons laliuscula, nitida, maculis utrinque binis triangulis albido-pollinosis, pube longiusculà, in dimidio inferiore et in vertice albâ, in dimidio superiore nigrâ. Antennae longiusculae nigrae, arliculo tertio oblongo-ovato, infra obscure rufescente. Thoracis dorsum et scutellum subplanum breviter albo-pubescentia. Abdomen subtilissime punclulatum, nilidum, breviter albo-pubescens. Pedes nigri, albidopubescentes tibiisque posticis supra albo-pilosulis. Genua, ima tibiarum posticarum basis tibiarumque anteriorum dimidium basale dilute lutescentia; tarsorum anticorum articulus primus fuscus apice lutescente, secundus totus dilute luteus, reliqui nigri; tarsorum intermediorum articuli primi duo dilute lulescentes, tertius subfuscus, reliqui duo nigri; primus tarsorum posticorum articulus modice incrassalus niger, apice tamen luteo, articulus secundus dilute luteus, tertius paulo obscurior, sequentes nigri. Tegulae albae. Halteres dilute flavicantes. Alae hyalinae, stigmate subfusco; uodus venae spuriae in specimiue descripto cum venà longitudinali tertiâ per venulan transversam adventiciam conjungitur. - (New York.)

63. Faragus dimidiatus nov. sp. ठ el ․ Nigro-viridis, nitidus, scutcllo toto concolore, facie flavicante modice project $\hat{a}$, in utroque sexu nigro-viltata, pedibus flavo et ochraceo variis, basali femorum dimidio atro, tribus ultimis abdominis segmentis in mare ex ochraceo rufis, alis hyalinis, stigmate dilutissime subfusco. Long. corp. 1 $\frac{1}{2}-2$ lin. Long. al. $1 \frac{3}{4}-1 \frac{1}{1} \frac{1}{2}$ lin.

Simillimus Paragi tibialis Fall. varietati, quam Meigenius Paragum haemorrhoidalem appeliavit, sed triangulo verticali minus lato, facie minus projeclà et pube totius corporis aliquantulo breviore distinclus. Terlius antennarum arliculus infra sordide rufescens. Abdomen foeminae totum nigro-viride, maris bicolor, primis duohus segmentis nigro-viridibus, sequentibus ex ochraceo rufis. - (District Columbia; Osten-Sacken.)

Nota. Pictura abdominis Paragi tibialis valde variabilis dubitalionem mili movel, num in Parago dimidialo minus variabilis sit. 
64. Paragus angustifrons nov. sp. f. Viridi-niger, nitens, facie permodice projecti, ex chrelybeo nigri, utrinque flavomarginati, fronte valde angusta, apice scutelli testaceo; pedes flavo et ochraceo varii. femorum dimidio brsali nigro. libiarum posticarum upice et metatarso postico fuscis; alce hyalinae, stigmate luteo. Long. corp. 2 lin., Isong. al. 2 lin.

Caput ex chalybeo nigrum, nitidum; frons angusta, immaculata; facies subperpendicularis, infra pernodice projecta, utrinque flavidomarginata. Antennae nigrae, articulo tertio infra sordide rufescente; pubes facici albida, frontis nigricans, verticis luteola. Thoracis dorsum pube brevissimà sublutescente vestitum. antice obsolele cinereo bilineatum. Scutellum thoraci concolor, extremo apice tamen testaceo. Abdomeu totum ex viridi nigrum, albido-pubescens. Pedes flavo ef ochraceo varii, femoribus practer apicem posticorum et praeter anteriorum dimidium apicale nigris, libiarum posticarum apice et metalarso postico fuscis. Alae hyalinae, stigmate luteo. - (Virginia.)

65. Chilosia capillata nov. sp. ठ․ Aeneo-viridis, pube longiusculà dilutissime lutescente vestila; oculi nudi; antennae nigrae, articulo secundo toto et basi tertii rufis, setà subnudâ: in margine scutelli setae nigrae nullae; abdominis segmenta secundum et lerlium prater angulos anticos opara, atra; pedes lutei, femoribus nigris. - Long. corp. $3 \frac{1}{2}$ lin., l,ong. al. $3 \frac{1}{4}$ lin.

Aeneo-viridis, nilida, pube totius corporis longiusculà, dilutissime sublutescente, menti, pleurarum abdominisque albidâ, verticis subnigricante. Facies atra, praeter tuberculum satis projectum leviter pollinosa, supra valde excavata. Antennae mediocres, articulo primo nigro, secundo rufo, tertio subrotundo, in basi rufo, in apice nigro; seta antennalis nigra, subnuda. Seulellum setis marginalibus nigris destilutum, ante marginem impressum. Abdominis segmenta secundum et tertium practer angulos anticos alra, opaca, sed pubes abdominis omnis pallida, in marginibus lateralibus el ventre albida. Pedes lutei, femoribus practer apicem nigris, tibiis posticis obsolete subfusco-annulatis, metatarso postico ultimisque tribus tarsorum articulis fuscis. Tegulae sublutescentes; halteres lutei. Alae ex cinereo hyalinae, venis luteis, adversus apicem alae obscure fuscis, stignate luteo. - (District Columbia; Osten-Sacken.)

66. Chilosia comosa nov. sp. ơ. Aeneo-viridis, pube longiusculâ, dilutissime lulescente vestita; oculi mudi; frons el facies 
solito latiores; antennae obscure rufae, seta subnuda; selae nigrae in margine scutelli nullae; pedes nigri, genibus et basi apiceque tibiarum ex rufo luteis. - Long. corp. 3 lin., Long. al. 25 lin.

Tola aeneu-viridis, fasciis atris in abdomine nullis, pube lon. giusculà dilutissime lulescente restita. Frons et lacies latiores quam in speciebus plerisque, practer tuberculum facialem satis projectum leviter pollinosac. Autennae mediocres, articulo primo nigro, sequentibus obscure rufis. setâ nigrâ subnudà. Scutelluun convexinsculum, setis marginalibus nigris destitulum. Abdomen lotum nitidum. Pedes nigri, genibus tibiarumque basi et apice ex luteo rufis. Alae cinereo-hyalinae, sligmate venisque luleis, his tanen adrersus apicem alarum et costâ fuscis. - (Euglish River, Winnipeš; Ken. nicot.)

67. Chilosia cyanescens nov. sp. $\delta$. Nigro-cyanea, oculis nudis, antennis ochraceis, seld pilis longis phumata, scutelli margine nigro-seloso, pedibus nigris, genibus, tibiurum basi el apice tarsisque anterioribus prueter arliculum ultimum luteis. - Long. corp. $3 \frac{1}{2}$ lin., long. al. $33_{6}^{5}$ lin.

Nigro-eyanea, nitida, pube thoracis et seutelli nigrì, abdominis albidà. Pili fromtis et verticis nigri. Antemna parvae, ex rufo ochraceae, articulo tertio ovalo, selâ nigrì, pilis longis plumatà. Facies lola atra, praeter tuberculum modice projectum leviter pollinosa. Margo scutelli nigro-setosus, infra albido-pilosus. Abdomen totum nitidum. Femora atra, apice luteo; tibiae anteriores lutear. atro-annulatae, posticae atrae, basi latius et apice anguslius luteis: tarsi anteriores dilute lutei, articulo terminali nigro; tarsi postici nigri. articulis paenultimo el antepaenultimo ex fusco luteis. Tegulae albidac; halleres lalescentes. capilulo supra nigro. Alae longiusculae, ex luteo dilutissime subfuscae, basim versus sublutescentes, venis in basi luteis, in apice subfuscis; stigma dilule lutescens. (Illinois.).

68. Chilosic plumata nov. sp. P. Nigro-cyanea, oculis nudis, antennis orldruceis. setâ pilis longis plumati. luberculo faciei testaceo, postico scutelli margine nigro-setoso. pedibus anterioribus luteis, posticis nigris, femorum tamen tibiarnmque busi el apice luteis. - Long. corp. $3 \frac{2}{3}$ lin., Long. al. 4 lin.

Nigro-cyanea, nitida, pube futius corporis brevi, thoracis et seutelli nigrâ, abdominis albidà. Frons angusta, plana. supra antennas fossulata. Antennae mediocres. ex rufo ochraceae. articulo tertio 
ovalo, setâ nigrà, pilis longis plumatà. Facies atra, leviter pollinosa, fuberculo morlice projecto el peristomio antico ex luteo testaceis. Margo seutelli nigro-setosus. Abdomen lolum nitidum. Pc. des anteriores lntei, articulo farsorum terminali nigro, inlermedin. rmm femoribus tibiisque subfusco-lituratis; pedes postici nigri, femoribus libiisque in basi et in apice lnteis, tarsorum articulis tertio et quarto ex fusco luteis. Tegulae albidae; halteres dilute lutescentes. capitulo toto concolore. Alae lyyalinae, basim versus sublutescentes, venis dimidii basalis luteis. apicalis fuscis: sligma dilutissime lutescens. - (Virginia.)

69. Chilosia leucoparea nov. sp. ․ Nigra: oculi nudi, anlennae rufae, setâ brevissime puberulà: faries inf rre utrinque pallida: humeri pallidi; scutelli margo testaceus. nigro-setosus: pedes lutei, femoribus praeler apicem nigris. - Long. corp. 3! lin. Long. al. 3 lin.

Nigra. modice nilens, pube tolius corporis rarissuli el perhrevi. in abdominis disco et apice nigricante. in reliquo corpore al. bicante; pili verticis paulo longiones nigri. Frons angusta, plana. Antennac totae rufae, articulo tertio rolundalo-ovato, setâ nigrì. brevissime puberulâ. Facies atra, nitida. supra valde excavata, infra utrinque pallida; tuberculum faciale majusculum, obtusum. Thoracis dorsum et scutellam scabriuscula, humeris pallidis, margine scutelli sordide testaceo. Abdomen aequale, subtilissime punctulatum, nitidum. Pedes lulescentes, femoribus praeter apicem nigris, tibiis metalarsisque posticis subfuscis, in basi lamen et apice lutescentibus. Halteres albiçantes; tegulae albae. Alae subhyalinae, ex cinereo leviter sublutesentes, basi limpidiore, stigmate saturatius lutescente. - (Carolina: Zimmermann.)

70. Chilosia pallipes nov sp. ․ Nigro-viridis; oculi nudi: antenua ex ferrugineo rufae, pube selae nigrae longiussula; facies infra utrinque luteo morulata: humeri hutei; scutellum luteum, setis marginalibus nigris instructum; pedes lutei. femoribus postiris prater basim et apicem nigris, annulo tibiarum posticarum, metatarso postico el ullimo tarsorum omnium articulo fuscis. - Long. corp. $2 \frac{7}{12}$ lin. Long. al. $2 \frac{2}{3}$ lin.

Obscure aeneo-viridis, nitida, pube totius corporis breviusculi dilute lutescente, pleurarum albidiore, disci abdominis obscuriore; pili verticis modice longiores nigricantes. Frons modice lata, nitida. subconvexa, supra antennas fossulata. Antennac parvac. ex ferrugi- 
neo rufac, articulo tertio rotundato-ovalo; seta antennalis nigra. pube longiuscula confertim vestita. Facies atra, nitida, supra valde excavala, infra utrinque maculâ magnà lutescente notata; tuberculum faciale majusculum, subobtusum. Humeri dilute lutescentes. Scutellum lulescens, margine basali nigro, apicali setis nigris praedito. Abdomen subaequale, nitidum. Pedes lutei, femoribus posticis praeter trientem basalem et apicem nigris, tibiis posticis fusco. vel subfusco-annulatis, metatarso postico et ultimo tarsorum omnium articulo fuscis. Alae ex cinereo hyalinae, stigmate luteo. - (District Columbia; Osten-Sacken.)

71. Chilosia tristis nov. sp. Q et $\sigma^{7}$. Nigro-viridis. oculis nudis, pube setae antennalis longiusculti, scutelli margine nigro-setoso, pedibus nigris, tibiarum basi et extremo apice lutescentibus.

o pilis longinsculis vestitus, scutello toto concolore, abdominis segmentis secundo et tertio praeter angulos anticos atris et opacis. alis dilutissime subinfuscatis.

\& pube brevi vestila, maculis duabus faciei testaceis, sculelli margine plerumque piceo, abdomine toto nitido, alis ex cinereo hyalinis.

Long. corp. $3 \frac{1}{1} \frac{1}{2}-3 \frac{3}{4}$ lin., Long. al. $3-3 \frac{1}{2}$ lin.

Mas: Pili frontis et verticis nigri. Antennae parvae, articulis primis duobus nigris, tertio subrotundo, ferragiseo vel ex ferrugineo rufescente; seta antennalis pube longiusculâ instructa. Pili in thoracis dorso plerique nigri, reliqui lutescentes, in scutello nigri rariores quam lutei. Pleurae albido-pilosae, pilis tamen infra alas nigris. Abdomen nigrum; segmenta secundum et tertium opaca, angulis anticis obscure viridibus, nitidis; segmentum ultimum totum viride et nitidum. Pubes abdominis lutescens, in posticis segmentorum secundi, tertii et quarti marginibus atra. Pedes nigri, femorum apiçe, tibiarum basi et extremo apice, interdum primis etiam tarso. rum intermediorum articulis luteis. Tegulae albidae; halteres flavicantes. Alae dilutissime subinfuscatae, stigmate ex luteo subfusco.

Foemina: Pube brevi dilutissime lutescente, in pleuris et abdominis marginibus albidâ, in fronte modice latâ et in disco abdominis obscuriore vestita. Tertius anteunarum articulus quam maris paulo major. Facies utrinque maculâ testaceâ notata. Scutelli margo plerumque piceus. Abdomen totum nitidum. Tibiarum basis latius lutea quam in mare et primi tarsorum intermediorum articuli fere semper lutei. Alae ex cinereo hyalinae. - (Red River: Kennicot.) 
Noła. A Chilosia plumuliferâ tuberculo tariei magis projecto e! acutiore maculisque facialibus foeminae acgre distinguitur.

72. Chrysochlamys buccata nov. sp. ․ Aenescens. scutello testaceo; frons nigra, fuscii media orhraceo-pollinosä; anten. nue supra nigrae, infra rufae. setä rufá; genae nigro-vitlatae; pedes ochacei, femorum anteriorum dimidio basali nigro. - Jong. corp. $3 \frac{7}{12}$ lin., Long. al. $3 \frac{5}{1 \frac{2}{2}}$ lin.

Aeneo-nigra, subvirens, nitida. Frons atra. nitida, breviter nigro-pubescens, per fasciam latiusculam ochraceo-pollinosam dimidiata. Antennae majusculae, articulo primo atro, sequentibus supra nigris. infra rufis; sela autennalis rufa, nuda. Facies ex testaceo flaya. su. pra valde concava et ochraceo - pollinosa, infra buccala, tuberculo magno obluso subiufuscato genisque per vittulam nigram a facie se. paratis. Thoracis dorsum pube brevi lutescente vestitum, marginibus lateralibus vittisque duabus aequalibus cinereo pollinosis. Scutellum testaceum, angulis lateralibus nigricantibus, pube lutescente brevi, setis marginalibus nigris. Abdonen nitidum, breviter luteopubescens, posticis segmentorum secundi et tertii fasciis atris, opacis. Pedes ochracei, femorum anteriorum dimidio basali tarsorumque omnium apice nigris, tibiis anticis practer basim el apicem femorunque posticorum basi dilute subinfuscalis. Alae ax cinereo hyalinae, adversus basim lutescentes, cellulâ costali et stigmate luteis, basi venae longiludinalis tertiae veuulisque transversis disci ni. gro-limbatis. - (Virginia.)

73. Helophilus latifrons nov. sp. б’ et + Ex affinibus Helophili trivithati; villá faciei modice projectae testared, antennis nigris, fasciis abdominis latis, primá interruptâ, reliquis integris vel subintegris, fronte maris latiore quam in reliquis speciebus. Jong. corp. $4 \frac{5}{6}-5 \frac{1}{2}$ lin., Long. al. $4 \frac{1}{4}-1 \frac{1}{3}$ lin.

Simillimus Helophilo trivitłato. Faciei modice projectae vitta testacea. Antennae piceo-niğrac. setâ ochraceâ. Frons maris latior, quam in reliquis speciebus. Abdominis fascia prima latissima, interrupta; fascia secunda maris lata, integra vel subinterrupla, macula basali nigrì interjectí, foeminac mediocris, biarcuata; fascia tertia maris mediocris, angulata, ochrascens, foeminae angusta, biarcuata. cinerascens. Ilypopygium maris plerumque flavum: ultimum segmentum abdominis foeminae fasciâ angustâ cinereâ pictum. Pedes antici flavi, femorum basi, extremo tibiarum apice tarsisque nigris; pedes intermedii llavi, femorum basi larsorumque apice nigris; pe- 
des postici nigri, apice femorum tibiarumque basi flavis. Alae hyalinae, stigmate dilute lutescente. - (Nebraska.)

74. Helophilus obscurus nov. sp. ㅇ․ Ex. Helophili penduli affinibus: alro el fano varius. viltâ faciei atrâ, tertio antennarum arliculo rufo, intermediis thoracis villis angustis, fasciis flavis abdominis mediocribus, omnibus interruplis. - Long. corp. $4 \frac{1}{1} \frac{1}{2}$ lin., Long. al. $4 \frac{1}{2}$ lin.

Atro el flavo varius. Faciei satis projectac vilta latiuscula et genae atrac. Primi duo aufennarum articuli ex fusco nigri, tertius rufus, margine supero ohscuro. Thoracis dorsum flavo quadrivittafum. vitlis intermediis tenuibus. Scutellum ex flavo lestaceum. Ab. domen atrum, opacum, posticis segmenlorum singulorum marginibus subnitidis; fasciae quatuor flavae interruplae, prinae mediocres, ultimae angustae. Femora nigra, apice anferiorum ef subapicali posticorum annulo luteis; pedum anticorum tibiae et tarsi desunt; intermediorum tibiae et metatarsi lutei, reliqui farsorum arliculi nigri: pedum posticorum libiae nigrae, hasi luteâ el annulo medio badio, tarsi toti nigri. Alae cinereo-hyalinae, adversus costam dilutissime subinfuscatac, stigmate subfuseo. - (Carolina, Zimmermann.)

75. Helophilus obsoletus nov. sp. ㅇ. Ex "ffinibus Heloghili versicoloris; lineis duabus dorsalibus lutco-pollinosis, obsoletis, fasciis abdominis mediocribus, primis duabus interruptis, pedibus luteis, femoribus posticis nigro-maculatis, tarsis posticis cum tibiarum apice nigris. - Long. corp. $4 \frac{1}{3}$ lin, Long. al. $3 \frac{1}{2}$ lin.

Heloph. versicolori et frutetorum simillimus. Viltae seu potius lineae dorsales duae luleo-pollinosae, obsoletae. Margo basalis scutelli niger. Fasciac luteae abdominis mediocres, prima latius et secunda anguslius inlerruptae, tertia inlegra; segmenta singula, primo tamen excepto, marginem posicum luteum et maculam triangulam curn margine postico contiguam labent. Pedes lutei, colore posticorum saturatiore; femora antica prope basim maculas duas minutas nigras, femora postisa in latere postico maculam magnam nigram habent; libiae posticae prope basim annulum obsoletiorem subfuscum et apicem ex nigro fuscum gerunt; tarsi postici toti nigri. Pubes totius corporis paulo longior quam foeminarum specierum sequenlium. - (Hudsons Bay Territory; Kennicot.)

76. Helophilus integer nov. sp. ㅇ. Ex affinibus Helophili versicoloris; vitlis dorsalibus quatuor latiusculis huteo-pollino- 
sis, lineâ interject $\hat{\imath}$ nulla, latis abdominis fasciis praeter primam integris, pedibus luteis, femoribus posticis fusco-lituratis, tarsis posticis cum tibiarum apice nigris. - Long. corp. $4 \frac{3}{4}$ lin., Long. al. $3 \frac{5}{6}$ lin.

Praecedenti valde similis, sed pube totius corporis mullo breviore vittisque dorsalibus quatuor luteo-pollinosis latiusculis distinctissimisque diversus. Fascia scutelli basalis nigra. Fasciae luteae abdominis latae, prima anguste interrupta, reliquae inlegrae; segmenta singula praeter primum maculam subtriangulam ochraceo-pollinosam. cum margine postico contiguam habent; margo segmenti tertii anguste, quarti latius luteus. Pedes lutei; femora antica prope basim maculà nigrà notautur; femora postica prope basim maculam minutam nigricantem, supra lituram magnam nigram et prope apicem utrinque maculam fuscam habent; tibiae posticae prope basim fuscoannulatae, in apice nigro-fuscae; tarsi postici toti ex nigro fusci. (New York; Schaum.)

77. Helophilus laetus nov. sp. $\delta$ et ㅇ. Ex affinibus Helophili versicoloris, vittis dorsalibus quatuor et linedi interjecti tenuissimá huteo-pollinosis, fasciis abdominis latis, primá latius. sequentibus angustius interruplis, pedibus luteis, femorum anteriorum basi posticorumque annulo latissimo nigris, annulis tibiarum posticarum duobus tarsisque posticis ex nigro fuscis. - Long. corp. $4-4 \frac{1}{3}$ lin., Long. al. $3 \frac{1}{3}-3 \frac{1}{2}$ lin.

Duobus praecedentibus valde similis, sed ab Helophilo obsoleto pube breviore vittisque dorsalibus distinclissimis, ab Ilelophilo integro pube paulo longiore et lineà dorsali meliâ, ab utroque pedum pictura diversus. Frons foeminae ut in reliquis speciebus practer verlicem nigro-pilosa, maris infra pilis lulgis, supra nigris vestita. Vittac clorsales quatuor mediocres, distinetissimae ef linea media tenuissima. postice nomnihil ahbreviata luteo-pollinosae. Margo basilis sculclli niger. Fasciae luteite abdominis maris latae, prima lalius, sequentes duac anguste interruplae; foemina fascias minus litlas sed latius interruptas habet; margines poslici segmentorum singulorum, primo tamen excepto, lutei, maculâ medià subtriangulâ Inteo-pollinosi. segmenti secundi minutà, quarti in fasciam dilalalâ. Pedes lutei, femorum anteriorum basi posticorumpue annulo mediu latissimo infra interrupto, tibiarum posticarum apice tarsispue postiris totis nigris vel ex fusco nigris, anuloque tibianm posticarum subbasali fusco. - (New York, Schaum; New Wiscousin, Oslen. Sacken.) 
78. Helophilus divisus nov. sp. ․ Helophilo versicolori affinis, setâ antennarum nigrâ, vittis dorsalibus quatuor latiusculis et lined media luteo-pollinosis, fasciis abdominis angustissimis in lunulas binas dissolutis, pedilus luteis. femorum anteriorum dimidio basali. extremo tibiarum anticarum apice, ultimis duobus tarsorum anteriorum articulis, tibiarum posticarum triente apicali tarsisque posticis nigris. femoribus posticis maeter basin et apicem fuscis. - Long. corp. $4 \frac{1}{3}$ lin., Long. al. $3 \frac{5}{6}$ lin.

A praecedentibus tribus facie minus projectâ, setâ antennali nigrâ, abdominis lunulis angustis, alis cinereis pedumque piclurì differt. Pubes frontis nigra, supra longiuscula, verticis lutea. Pubes lutea in thoracis dorso perbrevis, in scutello modice longior. Villar dorsales quatuor latae et linea media latiuscula utrinque attenuata luteo-pollinosae. Margo basalis scutelli niger. Fasciae luteae abdominis angustissimae. late interruptae, ila ul singulae in lumblas duas modice curvas dissolutae sint; margines postici segmentormm secundi, fertii el quarti obsolete lutescentes. polline subcinereo fascialae. Pubes abdominis fere omnis nigra. Pedes lutei. postici obscuriores, femoribus practer basim et apicem ex nigro fuseis, in basi maculi minuti nigrà notatis; dimidium hasale femorum anteriorum nigrum; fibiarum anticarum apex farsorumque anteriorum articuli ultimi duo nigricantes: libiae posticae prope basim annulum subfuscum, trientem apiealem nigrun habent; larsi postici nigri. Alae cinereae. - (Districl Columbia; Osten-Sacken.)

79. Heloplilus hamalus nov. sp. P. Lx affimibus Helophili transfugi facie valde producth, unternis ochraceis, vilt is thoracis qualuor latinsculis, intermediis subcineruscentibus, lateralibus ex fusco ochraceis, abdomine aequali atro. segmento primo tribusque lunularum paribus albidis. - Inons. corp. $4 \frac{1}{4}$ lin. Long. al. $3 \frac{3}{4} \operatorname{lin}$.

Similis Helophilo transfugo. Facies ralde producta, subconica, genis nigris, vittà media nullâ. Antennae subochraceae. Frons nigricans, prope antennas polline vchraceo aspersia, nigro-pubescens. Viftae thoracis latiusculae quatuor ochraceo-pullinosic, intermediae cinerasceutes. Scutcllum testaceum. Abdomen aequale; segmeutum primum albido-cinereum; segmenta sequentia tria atra, opaca, singula lunulis binis albidis ornata, adversus marginem posticum subnitida; segmentum ullimum cinerco-pollinosum. Pedes ex luteo badii, femoribus nigro-maculatis et lituratis. libiis posticis fuscobiannulatis, tarsis anticis posticisque totis intermediornmoge apice 
ex fusco nigris. Alae cinereo-hyalinae, puncto stigmaticali sub. fusco. - (Hudsons Bay Territory; Kennicot.)

80. Pterallastes thoracicus nov. sp. $\delta$ et ㅇ. Niger, antennis fuscis, thorace confertim luteo-pollinoso et pube luteâ vestito, pedibus nigris, fenorum apice, tibiarum basi tarsisque posterioribus

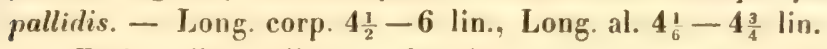

Facies albo-pollinosa, foeminae concava, maris subtuberculata. Antennae fuscae. Frons maris albo-pollinosa; triangulum verticale angustum. Frons foeminae mediocris, confertim luteo-pollinosa, maculâ magnà cum antennis contiguâ atrâ, nitidâ, vertice nigro. Thoracis dorsum et scutellum polline conferto luteo sparsa, luteo-pubescentia. Abdomen nigrum, nilidum, obsolete subcoerulescens, pallide pubcscens, pube in posticis tamen segmentorum ultimorum marginibus nigri. Pedes nigri, extremo femorum apice, tibiarum basi larsisque posterioribus pallidis, femoribus posticis permodice incrassatis. Alae cinereo-hyalinae, limbis venarum transversalium disci et triente apicali dilute niggro-cincreis, venulâ transversâ mediả obliquâ, a cellulae discoidalis basi longius quam ab apice remotâ. (Penusylvania; Osten-Sacken.)

Nola. Plerallastes formâ ac figurî totius corporis, praccipne capilis, et picturâ Myoleptam simulans. alas Helophili habet.

81. Pterallastes liluratus nov. sp. \&. Niger, fronte. farie, humeris, viltulis lateralibus thoracis, scutello pedibusque po. sterioribus dihute luteis. pedibus anticis nigro et luteo variis. -Long. corp. $5 \frac{2}{3}$ lin., Long. al. $4 \frac{2}{3}$ lin.

Niger, suboparus. Caput dilute luteum. occipite praeter marginem cincreo et opaco, genis atris et nitidis. Anlennae majuseulae, luteae. Thoracis dorsum polline luteo subcinerascens, opacum, vittulis duabus ufrinque abbreviatis atris el opacis, humeris vitulisque lateralihus abbreviatis luteis. Sculcllum luteum, margine basali nigricante. Abdomen nigrum, subopacum, pallide pubescens. Pedes antici nigri, femorum latere infero apiceque et libiarum basi luteis; pedes posteriores lutei, ultimo tarsorum articulo fusco. Alac ex ferrugineo fuscae, adversus marginem posticum diluliores, lilurâ longiludinali mediâ inde a basi usque ad venam Iransversam mediam perlinente limpidia; sligma obsoletissimum; venula transversa media subnormalis; venae longitudinalis primae pars dimidia basalis et vena longitudinalis quinta saturatius fusco-limbatae. - (Pennsylvania). 
82. Diden fuscipes nor. sp. $\delta$ et 9 . Aeneo-viridis, abdo. mine nigro, flavo fasciato, pedibus badiis, femorum basi, tibiis po. sticis tarsisque omnibus fuscis. - Long. corp. $5 \frac{1}{2}-6$ lin.. Long. al. $5-5 \frac{1}{2}$ lin.

Simillima Dideae Foersteri. sed colore pedum diversa. Antennae nigrae, basi arliculi tertii interdum rufâ. Frons prope an. tennas fusco-bimaculata. Fasciae flavae abdominis quatuor. prima in maculas duas ovatas usque ad laterales abdominis margines pertinentes divisa. sequentes duae per limbum angustum atrum a marginibus abdominis separatac et postice profunde excisae. quarta foeminae subinterrupta, maris in maculas duas dissolula. Hypopygium nigro-aeneum. Pedes badii, in speciminibus nuper exclusis ex badio ochracei, femorum basi nigro-fuscâ, tibiis posticis tarsisque omnibus fuscis. - Alae cinereo-hyalinae, imâ basi et stigmale fuscis. (Pennsylvania.)

83. Doros flavipes nov. sp. \&. Atro et flavo varius, pedibus praeter posticorum tarsos flavis, alis hyalinis. - Long. corp. $4 \frac{1}{6}$ lin., Long. al. $4 \frac{1}{3}$ lin.

Caput flavum, occipite nigro. albido-pollinoso. Vitla angusta frontis cum vertice alra. Primi duo antennarum articuli flavi, tertius ex nigro fuscus, setâ concolorc. Thorax aler, nitidus, dorso subaenescente, pube luleâ vestito et ulriuque vittâ laete flavâ ornato, pleuris maculas confluentes flavas gerentibus. Scutellum atrum, nitidum, Iuteo-pubescens, margine lacte flavo. Primum abdominis segmentum nigrum, modice nitens; segmentum sccundum atrum et opacum prope basim fasciam aequalem llavam, in apice fasciam nitidam nigram, interdum aurantiacomarginalam habet: segmenti tertii dimidium anterius fasciis duabus acqualibus, alterà basali lacte flavâ, alterâ atrâ et opací completur. posterius fotum nigrum et nitidum est; pictura segnentorum quarti et quinti similis est, fascià nitida tamen latiore et adjecto limbo marginis postici llavo; fascia basalis flava segmenti quinti praeter fines laterales postico segmenti praecedentis margine oblegitur. Veuter fasciis llavis et nigris allernantibus ornatur. Pedes lacle flavi, tarsis posticis practer articulos ultimos duos fuscis. Alac hyalinar, apicem versus subcinerascentes, venis fuscis, stigmale subfusco. - (Pennsylvania.)

84. Doros a equalis nov. sp. ơ. Arro et flevo varius, femoribus praeter apicem ex nigro fuscis, alis dilule subinfuscatis. costá late el nequaliter fusco-limbata. - I Long. corp. $4_{6}^{5}$ lin. Iong. a). $4 \frac{1}{6}$ lin. 
Caput flavum, triangulo verticali et occipite nigris, margine hujus albo-pollinoso. Lunula frontalis, antennae et genae nigropiceae. Thorax niger, pube lutescente et nigricante vestitus, dorso utrinque villâ et in margine punclis duobus confluentibus flavis ornato, praeterea viltis duabus obsoletioribus albido-pollinosis pictus; pleurae flavo bimaculatae. Scutellum lestaceum. Abdomen aequale, atrum, nitidum, fasciis tribus angustis flavis ornatum; fascia prima modice arcusta in segmento secundo media, secunda et tertia rectae, in segmentorum sequentium basi sitae, omnes anguste interruptae; fascia basalis segmenti quinti obtecla; margines postici segmentorum tertii et quarti flavi, segmentum quintum triangulum flavum gerens. Venter niger, fascis angustis tribus et margine postico segmenti quinti flavis. Femora anteriora lusca, in latere postico ex fusco nigra, in triente apicali flava; femora postica fusco-nigra, basi luteâ, apice flavo; tibiae flavae, apicali posticorum dimidio ex fusco ochracco; tarsi anteriores lutei, postici ex ochraceo fusci. Alae dilutissime subinfuscalae, costâ late et aequaliter fusco-limbatâ. - (Pennsylvania.)

85. Hyalomyia triangulifera nov. sp. o'. Cinerea, opaca, antennis pedibusque nigris, abdominis convexiusculi segmento primo maculisyue triangulis segmentorum tertii et quarti binis nigris. Long. corp. $2 \frac{1}{6}-2 \frac{1}{2}$ lin., Long. al. $1 \frac{1}{1} \frac{1}{2}-2 \frac{1}{4}$ lin.

Nigra, polline conferto cinerascente vestita, opaca. Frons modice angusta, nigra, orbitis cinerco-pollinosis. Facies et genae nigrae, interdum piceae, albido-pollinosae. Antenuae nigrae, in speciminibus quibusdam obscure fuscae. Proboscis nigra, palpis testaceis, apicem versus nigricantibus. Thoracis dorsum cinereum, lineis vittisque paulo obscurioribus obsoletissimis. Scutellum nigrum, obsoletius cinereo-pollinosum. Abdomen minus depressum quam in Iyalomyiis plerisque, cinereo-pollinosum, segmento primo tolo nigro, duobus sequentibus maculas trigonas binas nigras, marginibus singulorum posticis contiguas gerentibus. Pedes nigri, nonnumquam piceo-lilurati. Tegulae dilute subflavesentes. Alae hyalinae, costii lusci, venis luteis, apicem versus fuscis. - (New York; OstenSacken.)

Nolat. Segmenta abdominalia omnia prope marginem posticum setulis erectis instructa sunt; segmenta ultima tria praeterea setulas binas a margine antico minus remotas habent. In his rebus cum $X_{y}$ stis quibusdam species nostra congruil, sed alarum venis cum Hyalonyiis optime convenit. 
86. Xysta didyma nov. sp. ठ. Nigra, antennis pedibusque concoloribus; thoracis dorsum lateribus polline albido late limbatis et postice maculâ geminâ albo-pollinosâ notatum; abdomen polline albido aspersum, ita ut quum anus lumini ardvertilur nigro-fasciatum appareat. - Long. corp. 4 lin., Long. al. $3 !$ lin.

Nigra, opaca. Caput concolor; frons angusta, villâ mediâ nigrâ, orbitis et lunulà albo-pollinosis. Antennae nigrae; facies et genae albo-pollinosae. Proboscis nigra; palpi testacei. Occiput nigrum, inferiore orbitarum dimidio albo-pollinoso. Thorax niger, opacus, dorso obsolete cinereo-pollinoso, utrinque vittâ albo-pollinosâ marginatum et maculâ didymâ albo-pollinosâ, margini poslico contignå ornatum. Pleurae polline albido cinerascentes. Scutellum nigrum. Abdomen nigrum, polline albido cinereum, sed it a ut, si anus lumini advertilur, segmentum primum tolum, segmentum secundum praeter marginem anticum et vittulam mediam nigra appareant. in segmento tertio autem fascia paulo obsoletior, margini postico contigua et in segmento quarto macula obsoleta nigrae conspiciantur. Venter polline albido cinereus. Pedes toti nigri. Tegulae albae, valvulâ superiore sublutescente. Alae hyalinae, cellulà posteriore primâ clausâ, brevissime subpedunculatâ. - (Illinois.)

87. Himantostoma sugens nov. sp. $\sigma^{7}$. Nigra, nigrohirta, orbitis et facie albo-micuntibus, thorace polline ruro albido obscure cinerascente, dorsi vittis obsoletis subfusco-pollinosis, abdomine confertius albido-pollinoso, alis hyalinis. - Long. corp. $2 \frac{7}{12}$ lin., Long. al. $2 \frac{5}{\frac{5}{2}}$ lin.

Tota nigra, opaca, polline albido cinerea, nigro-pilosa. Vilta frontis angustae nigra; lunula frontalis, orbitae, facies et genae albopollinosae. Antennae nigrae, breves, per carinam separatae, setà brevissime pubescente adversus basim incrassatâ. Proboscis nigra, attenuata, dimidiam corporis longitudinem superans, palpis tenuibus concoloribus. Thorax leviter albido-pollinosus, obscure subcinerascens, dorsi vittis imperfectis obsoletisque et scutello praeter marginem subfusco-pollinosis. Abdomen subdepressum, nigro-pilosum, setis longioribus destitutum, polline albido confertius aspersum, lineà mediâ tenuissimâ subfusco-pollinosâ. Pedes nigri. Halteres fusci; tegulae ex albo sordide subflavescentes. Alae hyalinae, costâ fuscâ, venis ex ochraceo luteis, apicem versus fuscis; venula trans. versa media, a cellulae niscoidalis basi longius quam a fine distans, infra apicem venae longitudinalis primae posita est; venula transversa posterior ab utroque cellulae posteriores primae fine pari 
intervallo distat; ultimum venae quartae segmentum in angulum quadratum, breviter appendiculalum fractum est, ita ut cellula posterior prima pedunculo perlongo instrucla sit. (Illinois.)

Nota. Himantostoma corporis formà Xystam simulat, at figura faciei magis Hyalonyiae quam Xystae est. Ab utroque geneucre proboscide tenui el quam dimidium corpus longiora facie per carinam mediam nasutà et alarum venâ quartà angulo recto fractâ breviterque appendiculatî̀ differt.

88. Cistogaster divisa uov. sp. ठ․ Facie fronterue aureis, thoracis dorso scutelloque subaureo-pollinosis. abdominis testacei villi mediâ pedibusque nigris, alis cinereis. - Jong. corp. $2 \frac{3}{4}$ lin., Long. al. $2 \frac{1}{1}$ lin.

Frons aurea, vittâ angustà nigrà. Antennae fusco-nigrae, setâ concolore. articuli tertii basi ex ochraceo rufâ. Facies aurea, genis albo-micantibus. Occiput cinereum, albido-pilosum, orbiti oculorum albà. Thoracis dorsum polline ex aureo ochraceo, adversus marginem posticum minus conferto et pallidiore vestitum, lineis duabus intermediis, postice divergentibus et valde abbreviatis vittulisque duabus interruptis obscurioribus. Scutellum cum posteriore thoracis parte concolor. Pleurae et coxae polline albido dilute cinereae. Abdomen ex rufo testaceum, viltâ medià et basi segmenti primi nigris. Pedes nigri. Tegulae lavae. Alae cinereae, venis obscure luteis, adversus apicem et marginem posticum fuscis. - (Connecticut; Norion.)

89. Trichopoda radiata nov. sp. ठ大. Atra, opaca, abdomine purpureo-nigro, femornm basi obscure luted, alis ex fusco nigris, in paginâ superiore lacteo-radiatis. - Long. corp. $7 \frac{1}{4}$ lin., Long. al. $6 \frac{1}{4}$ lin.

Orbitae oculorum frontales et faciales auratac; vitta frontalis latiuscula atra. Antennae nigrae; facies testacea, interfum subfusca, flavido-pollinosa. Occiput albo-pollinosum. Thorax ater, opacus, in dimidio auteriore praeter fasciam vittulasque ordinarias quatuor aureo-pollinosas lineà concolore mediâ, antice abbreviatî ornatum; dimidium posterius lineis Juabus tenuissimis, interdum obsoletis flavo-pollinosis variegatum et utrinque vittulà albo-pollinosâ marginatum, adversus ınarginem posticum subnitidum. Pleurae albo-pollinosac. Abdomen valde depressum, purpureo-nigrum, opacum, polline lacteo subobsolete aspersum. Venter testaceus, vel ex testaceo piceus, apicem versus plerumque ochraceus. Coxae ex luteo testa- 
ceae, nigro-lituratae et polline albido indutae. Pedes nigri, femorum anteriorum basi angustius, posticorum latius obscure luteâ, libiis posticis supra nigro - pennatis. Alae ex fusco nigrae, margine postico et angulo axillari ex fusco cinereis, cellulâ costali strigisque cum venis longitudinalibus contiguis in superiore alarum paginâ co. lore lacteo pictis. - (District Columbia; Osten Sacken.)

Nota. Trichopodae formosae proxima, sed palpis testaceis, abdomine purpureo nigro femorumque basi luteâ distincta. Trí chop. formosa palpos nigros, abdomen obscure rufum et femora tota nigra habet.

90. Trichopoda trifasciata nov. sp. $ठ$. Nigra, subnitens, scutello antennisque ex rufo testaceis, abdomine minus depresso quam in reliquis speciebus, subcylindrico, fasciis segmentorum ultimorum trium flavescenti-pollinosis, interruplis, dimidio alurum anteriore ex fusco nigro, posteriore hyalino. - Long. corp. $4 \frac{1}{3}$ lin. Long. al. $4 \frac{1}{6}$ lin.

Orbitae oculorum auratae; vitta frontalis ex fusco nigra; antennae ex testaceo rufae, setâ concolore; facies praeter orbitas nigra, albido-pollinosa. Thorax ex fusco niger, subnitens, dimidio anteriore fasciâ, vittulis lateralibus latis. lineisque obsoletissimis duabus intermediis aureo-pollinosis ornato, dimidio posteriore unicolore nigro. Scutellum ex rufo testaceum, basi tamen piceâ. Pleurae polline albido rare aspersae. Abdomen ex piceo nigrum, nitens, angustum, subcylindricum, minus depressum quam in Trichopodis reliquis; in segmentis ultimis tribus prope marginem singulorum antiticum fasciae flavescenti-pollinosae, aequales et anguste interruptae conspiciuntur. Coxae ex luteo rufescentes, anticae aureo-pollinosae. Femora antica nigra, imâ basi et apice ex luteo rufescentibus, posteriora ex luteo rufa, annulo tamen latissimo nigro; tibiae nigrae, triente basali omnium ex luteo rufescente, posticis supra nigro-squamatis; tarsi nigri. Tegulae flavicantes. Alarum dimidium costale ex fusco nigrum, prope costam subfusco obsolete plagiatum, dimidium posterius hyalinum, adversus apicem alae cinerascens. - (Connecticul; Norton.)

91. Wahlbergia brevipennis nov. sp. ․ Capite, antennis, proboscide, palpis, thorace tolo pedibusque atris, abdomine obscure rufo, alis perbrevibus hyalinis, basi lutescente, venâ longitudinali quartâ angulatim flexâ, transversâ posteriore valde obliquâ. - Long. corp. $2 \frac{1}{3}$ lin., Long. al. $1 \frac{1}{2}$ lin. 
Wablbergiis europaeis valde similis, sed paulo minor; segmenti ventralis secundi basis tumida, brevissime nigro-spinulosa. Alae breviores quam Wahlb. melanurae Meig. et dimidiatae Zett. et veua transversa posterior magis obliqua quam in his; vena longiludinalis quarta angulatim flexa, inde ab angulo venam tertiam reclà pelens; cellulae submarginalis pedunculus brevior quam Wahlb. melanurae, at paulo longior quam Wablb. dimidiatae. - (Nebraska.)

92. Heteroneura spectabilis Loew o el 아. Flava, infra pallida, pleurarum vitlâ superâ, angulis segmentorum abdominalium singulomum posticis el hypopygis maris atris, libiarum posticarum basi ex fusco nigrâ, alis maculá permognâ apicali ex fusco nigrâ ornatis, venis transversis remotis. - Long. corp. $\delta 2 \frac{1}{4}$, \& $3 \frac{1}{3}$ lin., Long. al. $\sigma^{7} 2 \frac{1}{4}$. 우 $3 \frac{1}{6}$ lin.

Synon. Heteroneura spectabilis Loew, Wien. Entomol. Monatschr. IV. 82.

Heteroneurae flavae Meig. (luridae Hal.) affinis. Supra dilute flava, colore frontis et thoracis in testaceum vergente, infra pallida. Facies maris supra nigra, foeminae vittulis duabus fuscis inde ab antennarum basi decurrentibus variegata. Palpi magni, lati, albidi, apice interdum subochraceo. Anlennae pallidae, setâ tenui breviter pilosâ. Thoracis dorsum interdum utrinque fuscescenti-vittatum, vittis in scutelli angulos laterales pertinentibus. Scutellum planum, setis sex praeditum. Pleurae supra vittâ atrâ ornatae, in mare latiore quam in foeminâ. Anguli postici segmentorum abdominalium singulorum maculis magnis atris, interdum in viltam confluentibus picti. Hypopygium maris atrum. Pedes dilute flavescentes, coxis femorumque dimidio basali exalbidis, libiarum posticarum triente primo ex nigro fứsco. Alae subhyalinae, dilute lutescentes, adversus marginem posticum ex luleo subcinerascentes. in apice macula permagnà ex fusco nigrâ signatae; venula transversa minor in cellulâ discoidali mediâ collocata. - (Washington, Osten-Sacken; Pennsylvania.)

93. Heteroneura lat ifrons Loew \&. Dilute flavescens, genis, pleuris, coxis femorumque dimidio basali albicantibus, vittis thoracis lateralibus antice abbreviatis et vilta mediâ scutelli alris, alis cinereis, adversus costam et apicem ex fusco nigricuntibus, venis transversis approximrtis. - Long. corp. $1 \frac{2}{3}$ lin., Long. al. $1 \frac{1}{2}$ lin.

Synon. Heteroneura latifrons Loew, Wien. Entomol. Monatschr. IV. 83. 
Dilute flavescens, infra albida. Frons et facies latiores, quam in reliquis Heteroneuris, quae venulas transversas approximatas habenl. Anlennae saluratius flavac, setâ nigrâ breviter plumatà. In thoracis dorso utrinque vitha lateralis lalissima atra, antice valde ahbreviata cernitur. Scutellum subplanum, alro-vittatum, setulis minoribus quatuor setisque majoribus duabus instructum. Metanotum utrinque fusco-maculatum, maculâ mediâ fuscâ nounumquam arljectâ. Pleurae immaculatae. Abdomen flavescens, segmento quinto abbreviato atro. Tarsi posteriores dilute, antici plerumque paulo saluratius subfusci. Alae cinerascentes, adversus dimidium secundum coslae et apicem ex fusco nigricantes, venulis transversis modice approximatis. - (Washinglon; Osten.Sacken.)

94. Anthophilina terminalis nov. sp. $\delta$. Atra, nilida, fronte supra antennas antennisque ipsis, facie, halteribus, coxis pedibusque albidis, ultimo tarsorum articulo atro, alis hyalinis, dilutissime cinerascentibus. - Long. corp. 1 lin., Long. al. $1 \frac{1}{12}$ lin.

Atra, nitida. Caput nigrum; frons infra flavesceus, supra nigra et opaca, triangulo verticali magno, nitido. Primi duo antemnarum articuli dilutissime flavicantes, tertius albidus, albo-puberulus, seta nigrâ breviter pubescente. Facies albida, selâ mystacinâ utrinque unicâ. Palpi breves, pallidi; proboscis concolor. Coxae et pedes dilutissime flavicantes, ultimo tarsorum omnium articulo atro; femora antica infra setulas nonnullas habent, quarum ultima praecedentibus paulo validior est. Halteres albi. Alae hyalinae, subcinerascentes, venis Iutescentibus. - (Carolina; Zimmermann.)

95. Anthophilina tenuis nov. sp. $\delta$. Nigra, thoracis dorso scutelloque subcinerascentibus, capite cum antennis, humeris, pleuris, ventre pedibusque dilute flavicantibus, ultimo tarsorum articulo nigro. - Long. corp. $1 \frac{1}{4}$ lin., Long. al. $1 \frac{7}{12}$ lin.

Nigra, modice nitens, thoracis dorso, scutelloque obsoletissime cinerascentibus. Caput dilute flavescens, maculâ verticis occipiteque fere toto ex nigro fuscis, orbitis facialibus genisque albomicantibus. Antennae laete flavae, setâ nigricante, breviter pubescente. Seta mystacina utrinque solitaria. Pleurae cum humeris, venter pedesque dilute flavescentes, ultimo tarsorum articulo nigro, imả basi tamen exceptâ. Halteres flavicantes. Alae hyalinae, venis ex fusco luteis. - (Sitka; Sahlberg.)

96. Anthophilina variegata nov. sp. $\delta$ et 9 . Pallida, thoracis vittis dorsalibus quatuor subobsoletis, pleurarum vittâ superâ 
abdominisque fasciis fuscis, extremo tarsorum apice nigro, alis dilute cinerascentibus. - Jong corp. $1 \frac{1}{6}$ lin., Long. al. $1 \frac{1}{2}$ lin.

Pallida, opaca. Capui concolor, puncto verticali occipitisque maculâ geminà permagnâ fuscis. Autennae pallidac, articulo tertio nigro-pilosulo, in latere averso plerumque infuscato, setì nigrâ dislincle nigro-pubescente. Sela mystacina ulrinque unica. In thoracis dorso vittae qualuor subfuscae, saepe subobsoletae adsunt. Scutellum pallidum, haud raro praeter margines subfuscum. Pleurae supra vittam inlegram ex nigro fuscam habent. Metanolum subfuscum. Segmenta abdominalia singula postice fasciis fuscis, in marginibus abdominis nonnihil dilatalis ornanlur. Pedes pallidi, ex tremo articuli tarsorum ultimi apice nigro; femora antica infra setulas nonnullas habent, quarum ultima praecedentibus validior. IIalterum capilulum fuscum. Alae subhyalinae, cinerascentes, venis fuscis. - (District Columbia; Osten-Sacken.)

97. Ischnomyia vitlula nov. sp. $\sigma^{7}$ et + . Atru, modice nitens, tertio antennurum articulo praeter basim, facie cum genis, proboscide, palpis, pectore pedibusque albidis, alis angustis, limbo venae longitudinalis tertiue nigro, adversus alae apicem dilatato ornatis. - Long. corp. $1 \frac{1}{1} \frac{1}{2}-1 \frac{1}{4}$ lin., Long. al. $1 \frac{1}{2}$ lin.

Atra, modice nitens. Occiput nigrum, infra pallidum. Frons obscure fusca, marginibus lateralibus albo-pollinosis. Antennae nigrae, articulo tertio praeter basion albo, albo-pilosulo, selâ breviter pubescente nigrâ. Facies albida per lineam tenuissimam atram ab orbitis albo-pollinosis separata. Selulae mystacinae utrinquae duae minutae. Genae angustae albidae; proboseis et palpi concolores. In thoracis dorso plerumque vittulae duac pallescentes cernuntur. Scutellum nigrum, setis duabus instructum. Pleurae albidae, limbo tamen supero nigro. Pedes graciles, pallidi, setulis concoloribus femorum anticorum nonnullis. Halteres nigri. Alae longae, angustae; vena longitudinalis tertia utrinque colore nigro, postice aequaliter, antice apicem versus latius circumdatur; alae, ante hanc vittam hyalinae, postice cinereae et venarum limbis obsoletius nigricantibus variegatae sunt; vena longitudinalis secunda flexuosa; venula transversa media ab utroque cellulae discoidalis fine pari intervallo distat. - (Penusylvania; Osten-Sacken.)

Nota. Ischnomyia Anthophilinae proxima, ab hac alarum venå longitudinali secundà flexuosî, selulis mystacinis binis femorum. que anticorum setulis aequalibus distinguitur.

98. Hyadina gravida nov. sp. б. Ex nigro viridis, facie albo-pollinosî, abdomine obeso, punctulato, segmentis primis duobus abbreviatis, tertio permagno. - Long. corp. I lin., Long. al. I $_{6}^{\prime}$ liu. 
Caput nigrum, fronte virescenle subnitidâ, facie albo-pollinosâ. Antenuarum articuli primi duo nigri, tertius rufus, apicem versus infuscatus. Thorax ex nigro virescens, opacus, viltis cinereo-pollinosis duabus, obsoletis et postice valde abbreviatis. Scutellum planum, thoraci concolor. Abdomen ex nigro viride, nitidum, punclulatum, brevissime puberulum, segmentis primis duobus abbreviatis, tertio permagno, quarto majusculo semiorbiculari. Pedes nigri, genibus summis tarsorumque basi ex ferrugineo rufis. Halterum pedunculus luteus, capitulum nigricans. Alae subinfuscatae, venis nigris, segmentis ultimis duobus costae subaequalibus. - (Sitka; Sahlberg.)

99. Scatella sejuncta nov. sp. ㅇ․ Nigra, opaca, abdomine nilidissimo subvirescenle, tarsorum basi rufa; alae maculis quadratis nigris confertim variegalae, punctis nigris, venas non tangentibus in cellulis submarginali et posteriore primá inter maculas interjectis. - Long. corp. 1 lin., Long. al. $1 \frac{1}{6}$ lin.

Scat. quadratae Fall. et Seat. Stenhammari Zett. similliua, ab hac tarsorum basi rufâ, ab utrâque corpore paulo majore alarumque picturâ diversa. Maculae costales alarum inaequales quinque vel sex; inter venas longiludinales secundam et tertiam maculis quadratis puncta duo a venis remota interjecta sunt; inter venam tertiam et quartam puncta tria cum maculis alternantia cernuntur, a venâ tertiâ minus quam a quartâ distantia, tertio cum venâ tertiâ interdum contiguo. Halterum capitulum in speciminibus descriptis nigricat. - (Sitka; Sahlberg.)

100. Parydra varia nov. sp. $\sigma^{\top}$. Ex olvaceo aenescens, facie valde declivi, pedibus rufo et nigro variis, alis fuscis, dilutius variegatis et gultis quinque albidis notatis, vená longitudinali secundâ appendiculatâ. - Long. corp. $1 \frac{1}{3}$ lin., Long. al. $1 \frac{7}{12}$ lin.

Ex olivaceo aenescens. Facies valde declivis, supra polline al. bido subopaca. Antennae fuscae. Scutellum simplex, valde convexum, ex nigro virescens, nitidum. Abdomen obscure virescens, nitidum, breviter nigro - pubescens, lateribus ex cupreo aeneis. Pedes nigri, trochanteribus, femorum apice, tibiarum basi et apice tarsisque omnibus praeter apicem obscure rufis. Halteres lutescentes. Alae fuscae, lituris aliquot dilutioribus prope apicem gutlisque quinque, si lumen transmittitur, albicantibus variegatae, venà longitudiuali secundâ appendiculatà. - (Sitka; Sahlberg.)

Nota. Tibiis anticis totis rufis variat. 


\title{
Diptera Americae septentrionalis indigena.
}

\author{
Descripsit
}

I. L $\quad \boldsymbol{o} \quad \boldsymbol{e} w$.

Centuria quinta.

1. Chasmatonotus unimaculatus.

2. Bibio hirlus.

3. - inaequalis.

4. - nervosus.

5. - obscurus.

6. - lugens.

7. - variabilis.

8. - fraternus.

9 - abbreviatus.

10. - nigripilus.

11. - basalis.

12. - longipes.

13. Scatopse pygmaea.

14. Tipula fralerna.

15. - ternaria.

16. - pubera.

17. - macrolabis.

18. - serrulata.

19. - canadensis.

20. - latipennis.

21. - centrulis.

22. - angulata.

23. - tephrocephala.

24. Pachyrrhina nobilis.

25.

virescens.

$26 . \quad$ - lugens.

$27 . \quad$ - viltula.
28. Pachyrrhina unimaculata.

$29 . \quad$ - sodalis.

$30 . \quad$ - occipilalis.

31. - xanthostigma.

32. - gracilicornis.

33. Spilomyia hamifera.

34. - fusca.

35. Temnostoma obscura.

$36 . \quad-\quad$ aequalis.

37. - allernans.

38. Lepidomyia calopus.

39. Xylota bicolor.

40. - barbata.

41. - fraudulosa.

42. Chrysoloxum laterale.

43. - pubescens.

44. - ventricosum.

45. Microdon tristis.

46. - laetus.

47. - coarctatus.

48. Ceria abbreviata.

49. Empis laevigata.

50. - stenoplera.

51. - longipes.

52. - rufescens.

53. Rhamphomyia umbrosa.

54.

basalis. 
55. Rhamphomyia macilenta.

56.

57.

58.

59.

60.

61.

62. Hilara tristis.

63. - seriala.

64. - testacea.

65. Hormopeza brevicornis.

66. nigricans.

67. Gloma rufa.

68. - obscura.

69. Cyrtoma femorala.

70. - procera.

71. Tachypeza rapax.

72. - rostrata.

$73 . \quad$ - clavipes.

74. - pusilla.

75. Platypalpus aequalis.

76.

77. - pachycuemus
78. Plalypalpus lateralis.

79. apicalis.

S0. favirostris.

81. laetus.

82. Dolichopus splendidulus.

83. quadrilamellatus.

84. - palaestricus.

85. - dorycerus.

S6. - melanocerus.

87. Gymnopternus coxalis.

88. - meniscus.

59. Pelastoneurus abbreviatus.

90. - lamellatus.

91. - alternans.

92. Porphyrops longipes.

93. Cordylura praeusta.

94. - nana.

95. Telanocera ambigua.

96. Sapromyza decora.

97. Heteroneura melanostoma.

98. Opomyza lurida.

99. Ephydra subopaca.

100. Caenica spinosa.

1. Chasmatonotus unimaculatus, nov. sp. ot et + . Ater, alis concoloribus, maculâ marginis postici candidâ. - Long. corp. $\frac{3}{1} \frac{1}{3}$ lin., Long. al. 1 lin.

Caput atrum, oculis in utroque sexu per frontem latam nitidam separatis. Proboscis brevis nigra; palpi concolores, quadriarticulati; articulus primus brevis; articuli sequentes duo mediocres, aequales, secundus clavatus, tertio crassior; articulus quartus linearis, praecedenti paulo longior. Antennae nigro-fuscae, breves, in utroque sexu aequales; articulus basalis globosus; articuli flagelli quinque breviter pilosi, primus cylindricus, sequentes tres rotundatoovati, quintus ovatus. Thorax ater, dorso nitido, pleuris opacis. Scutellum concolor. Abdomen nigrum, subopacum. primis segmentis in foeminâ luridis; hypopygium maris globosum, concolor. Pedes nigri, femorum basi sordide lutescente tarsisque in speciminibus immaturis cinereis. Halteres nigri. Alae atrae, maculâ candidà sub- 
triangulari, a margine postico usque ad venam lertiam pertinente ornałae. - (New Hampshire; Osten-Sacken).

Nota. Chasmatonotus, artâ propinquilate cum Hydrobaeno conjunclus, differt lamen palpis longioribus et antennarum flagello in utroque sexu ex articulis quinque composito; thoracis dorsum rimâ tenui, postice in foveolam dilatalâ fissum est, unde nomen.

2. Bibio hirlus, nov. sp. ర大 el 오. Tolus niger, pilis longis sordide albicantibus villosus, alis subalbidis, venis validissimis fuscis, costae propinquis, costâ ipsâ et sligmate nigris.

ऽ. capile pedibusque fere tolis semper, thoracis dorso et scutello interdum nigro - villosis.

9. fronte, palpis pedibusque fere tolis nigro-pilosis. libiarum posticarum calcaribus lamelliformibus.

Long. corp. 4-4 $\frac{1}{3}$ lin.. Long. al. $3 \frac{1}{2}-3 \frac{1}{1} \frac{1}{2}$ lin.

Mas: Niger, nitens, pilis longis, sordide albicantibus villosus. Caput pilis longis nigris vestitum. Thoracis dorsum et scutellum plerumque pilis pallidis. interdum nigricantibus rel nigris villosa. Ultima abdominis segmenta nounumquam praeler pilos pallidos aliquot nigris instructa. Pedes nigri, in speciminibus quibusdam fere toti nigro-pilosi. in plerisque femora anteriora supra et postica in basi pallide villosa. Calcaria tibiarum anticarum valde inaequalia, posticarum brevia et valida. Alae albicantes, venis validissimis nigro-fuscis, costae propinquis, costâ ipsâ et stigmate nigris.

Foem.: Mari simillima, sed brevius pilosa, pilis palporum et frontis nigris, thoracis, scutelli abdominisque pallidis; pedum pili ut in mare colorati sunt, sed multo breviores. Calcaria tibiarum posti. carum compressa, lamelliformia, obtusa. - (California; Agassiz).

Nota. Bibioni albipenni Say affinis, sed pilis totius corporis confertioribus et multo longioribus alisque foeminae non cinereis facile dislinguitur.

3. Bibio inaequalis nov. sp. ‥ Ex badio teslucens, capite nigro. pedibus testaceis, calcari interiore tibiarum anticarum bre. vissimo, alis aequaliter ex luteo subfuscis. - Long. corp. $3_{6}^{5}$ lin.. Long. al. 4 lin.

Ex badio lestaceus, pilis brevibus pallidis vestilus. Caput ni. grum, antennis palpisque concoloribus. Metanotum nigro-fuscum. Venler ochraceus, postico segmentorum singulorum margine fusco. Pedes restarei, larsis anterioribus inde ab arliculi primi, posticis 
inde ab secuudi apice fusco-nigris, calcari interiore tibiarum anticarum omnium brevissimo. Alae totae aequaliter ex luteo subfuscae. renis posticis concoloribus, anticis cum cosłà et stigmate subfuscis. - (Sitka; Kolenati).

4. Bibio nervosu's nov. sp. ㅇ. Niger, coxis pedibusque rufis, trochanteribus, genibus, tibiis primisque duobus tarsorum articulis in apice, reliquis tarsorum articulis totis nigris, calcaribus tarsorum anticorum valde inaequalibus; alae ex subfusco cinereae, venis validis fuscis. cosiae propinquis, cosłâ ipsâ et sligmaíe nigrofuscis. - Long. corp. $3 \frac{1}{3}$ lin.. Long. al. 4 lin.

Niger, ventre et capite coucoloribus, pilis brevibus pallidis vestitus. Pedes cum coxis rufi; genua nigra: tibiae anticae praeter annulum medium nigrae, calcaribus valde inaequalibus; tibiae posteriores et primi duo tarsorum articuli in apice. arliculi farsorum reliqui toti nigri, imâ tertii basi tamen exceptà; calcaria tibiarum posticarum mediocria. Alae totae aequaliter ex fusco cinereae. venis fuscis. stigmale, costâ et renis costae propiuquis nigro-fuscis. - (California: Agassiz).

Nola. Proxime affinis est Bibioni xanthopo Wied., sed alis alarumque venis tibiarumque anticorum calcari interiore longiore diversus. -

5. Bibio obscurus nov, sp. f. Niger, nitidus, ventre coxisque concoloribus. pedibus rufis, tibiarum anticarum calcaribus valde inaequalibus, alis dilutissime subfuscis, costâ cum venis costue propinquis et cum stigmate angusto subfuscis. - Long corp. $4 \frac{1}{3}$ lin.. Long. al. $3 \frac{7}{\frac{7}{2}}$ lin.

Niger, nitidus, ventre coxisque concoloribus. pilis pallidis ve. stitus. Pedes rufi vel rufo-testacei, genibus nigris, tarsis apicem versus fusco-nigris; calcaria tibiarum anticarum valde inaequalia, posticarum parva. Alae inaequaliter, sed dilutissime subfuscae, venis posticis paulo obscurioribus, anticis cum costâ et stigmate angusto subfuscis. - (Hudsons Bay Territory; Kennicot).

Nota. A Bibione xanthopo Wied. coxis nigris, tibiis anticis minus latis, venis posticis alarum dilutioribus et stigmate angustiore differt.

6. Bibio lugens nov. sp. ㅇ. Niger, nitens, ventre concolore, coxis pedibusque rufis, tibiarum anticarum calcaribus valde incequalibus, alis nigro-fuscis adversus costam obscurioribus. imá 
basi sordide albicante, stigmate nigro. - Long. corp. $3 \frac{1}{\frac{1}{2}}$ lin.. Long. al. $3 \frac{1}{3} \operatorname{lin}$.

Niger, modice nitens, ventre concolore, pilis pallidis restitus. Pedes cum coxis rufi. apice tibiarum anticarum late. reliquarum anguste nigro, tarsis nigris, articulo primo prater basim et atticuli secundi basi rufis: calcaria tibiarum anticarum ralde inaequalia, posticarum mediocria. Alae nigro-fuscae, adrersus costam obscuriores. in imâ basi sordide albicantes; venae validae, poslicae fuscae, anticae cum coslà ct cum stigmate fusco-nigrae rel nigrae; ullimum renae quartac segmentum reclum. - (Winuipeg: Keunicot).

Nola. Bibioni basali valde propinquus. sed calcaribus tibiarum anticarum admodum inaequalibus, posticarum brevioribus, basi alarum obsolelius albicante et ultimo venae quartice segmento recto diversus.

7. Bibio variabilis nov. sp. $\sigma^{7}$ et ․ Niger, nitens, calcaribus tibiarum anticarnem subaequalibus, posticarum majusculis.

8. ruro lolus nigro-pilosus. plerumgue abdomine vel rolo vel praeter basim pallide piloso: libiae piceo-rufae, apicem versus nigrae; primi tarsorum articuli in apice, reliqui toli nigri: alae pure hyalinae, venis posticis pallidis, anticis cum costâ et sligmate nigro. fuscis.

I pilis brevibus pallidis restita: roxae mfae, posticae plerumque ex parle obscuriores: pedes rufi, genibus. libiarum apice tarsisque nigris, primis tribus tamen tarsorum arliculis praeler apicem rufis; alae subfuscae, adversus costam obscuriores, renis posticis subfuscis, unlicis cum costâ et stigmate nigro-fuscis.

Long. corp. 3- $3 \frac{3}{4}$ lin. Long. $3 \frac{2}{6}-3 \frac{3}{4}$ lin.

Nas: Niger, nilidus, coxis femoribusque concoloribus. tibiis anticis plerumque piceis, ante apicem nigricantibus, posterioribus piceo-rufis, apicem versus fusco-nigris, tarsorum articulis primis tribus in apice. sequentibus tolis nigris. Raro totus nigro-pilosus, plerumque abdomen vel totum vel praeter segmenta prima pallide pilosum. interdum pleurae et coxae etiam pallide pilosae. Alae pure hyalinae, venis posticis pallidis. anticis cum costâ et stigmate nigro-fuscis.

Foem: Nigra, modice nitens, pilis brevibus pallidis vestita. Coxac rufae, posticae plerumque ex parte obscuriores; pedes rufi. genibus et extremo tibiarum posteriorum apice ex fusco nigris, tibiianticis in basi et ante apicem fuscis vel fusco-nigris. tarsorum articulis primis tribus in apice, reliquis totis fusco-nigris. Alae sub. 
fuscae, adversus basim et angulum axillarem dilutiores, adversus costam obscuriores, venis posticis subfuscis, anticis cum costâ et stigmate nigro-fuscis. - (Sitka; Kolenati, Sablberg. - New Hampshire; Osten-Sacken).

8. Bibio fruteruus nov. sp. ơ et +. Viger, pedibus rufis, libiarum anticarum calcaribus subuequalibus, longinudine tarsorum posticorum ordinarià.

$\delta^{7}$. corpore, praeter oculos et palpos, albido-piloso, coxis nigris, alis dilutissime cinereo-hyalinis.

․ pilis brevibus pallidis vestita, thoracis dorso coxisque rufis, alis subfuscis.

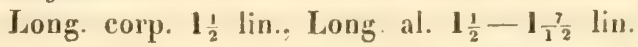

Mas: Niger, nitens, pilis longiusculis pallidis vestitus, pilis tamen oculorum, genarum palporumque nigris. Coxae concolores. Pedes ex testaceo ruf, genibus, tibiis anticis in apice et basi posterioribusque in extremo apice nigris. primis duobus tarsorum articulis in apice, reliquis totis nigris; calcaria tibiarum anticarum subaequalia, posticarum mediocria; tarsi postici non breviores quam in speciebus plerisque. Alae dilutissime cinereo-hyalinae, venis dilute subfuscis, stigmate saturate fusco. - (District Columbia; OstenSacken).

Foem.: Nigra, thoracis dorso rufo, pilis brevibus pallidis vestita. Coxae rufae, posticae anterioribus obscuriores. Pedes ex leslaceo rufi, notis iisdem nigris, quas pedes maris habent, tibiis tamen anticis interdum praeter annulum medium obscure rufum totis nigris. Alae ex cinereo subfuscae, adversus costam saturatius subfuscae, venis posticis subfuscis, anticis cum costâ et stigmate nigro-fuscis. - (District Columbia; Osten-Sacken).

Nota. Foemina interdum thoracis dorsum nigro bimaculatum habet.

9. Bibio abbreviatus nov. sp. $\sigma^{7}$ et $\%$. Niger, pedibus rufis, libiarum anticarum calcaribus subrequalibus, tarsis posticis brevioribus quam in speciebus affinibus.

$\delta$ corpore praeter raput totum albido-piloso, coxis nigris, alis pure hyalinis, venis postiris sine colore, anticis el costâ fuscis, stigmale nigro-fusco.

9. pilis brevibus pallidis vestita, thoracis dorso coxisyue rufis, alis subfuscis.

Long. corp. $1 \frac{1}{2}$ lin., Long. al. $1 \frac{1}{2}-1 \frac{7}{\frac{1}{2}}$ lin. 
Bibioni fraterno simillimus, sed tarsis posticis brevioribus certo distiuclus. Mas caput tolum nigro-pilosum, alas pure hyalinas et tibias posticas breviores ef paulo latiores quam Bibio fraternus habet, cum quo in reliquis notis ommibus plane congruit. Foemina praeter farsos posticos breviores a Bibionis fraterni foeminâ non differt. (District Columbia; Osten-Sacken).

10. Bibio nigripilus nov. sp. б. Niger, nigro-pilosus, coxis concoloribus, pedibus rufis, libiarum aricurum crelcaribus subaequalbus, longiludine tarsorum posticorum ordinaviâ; alae pure hyalinae, venis posticis sine colore. anticis et costa fuscis, stigmate nigro-fusco. - Long. corp. $1 \frac{1}{2}$ lin., Long. al. $1 \frac{1}{2}$ lin.

Inler Bib. fraternum el abbreviatum ruasi intermedius, tarsos posticos longrores illius cum alis hyalinis hujus conjungens, cum utroque corporis pedumque picturâ congruit, sed pilis totius corporis nigris ab utroque dillert. - (Winnipeg; Kenuicot)

Nota. Dilophus articulatus Say in viciniam Diloph. fraterni, abbreviati et nigropili referendus videtur; sed et Sayi et Wiedemanni descriptio vimis incerta et ambigua est, ut judicari possit, ad quem corum pertineal.

11. Bibio basalis nov. sp. ㅇ. Niger, coxis pedibusque rufis, calcaribus tibiarum anticarum subaequalibus, alis nigro-fuscis adversus costain obscurioribns, basi albida, stigmate et venis nigrofuscis - Long. corp. 3 lin., Jong. $3 \frac{3}{4}$ lin.

Niger, nitidus, rapile el thoracis dorso subopacis, pilis brevibus pallidis, adversus apicem abdominis nigris vestitus. Pedes cum coxis ruf, nigro-pilosuli, genibus et tibiarum apice nigris, tibiarum anticarum calcaribus subaequalibus, tarsis nigris, articulis primis duobus praeter apicen rufis. Alae nigro-fuscae, adversus coslam obscuriores, basi albidâ, venis omnibus et stigmale nigro-fuscis. (New Hampshire; Osten-Sacken).

12. Bibio longipes nov. sp $\sigma^{\pi}$ et ․ Macer, niger, nilichus, calcaribus libiarum anticarum valde inaequalibus.

万. roxae et pedes concolores; caput pilis nigris, reliquum corpus prallidis vestifum; pedes postici elongati, tibiis clavatis tarsorumque arliculis valde incrassatis; alae hyalinae, venis posticis dilutissime cinereis. anticis cum costâ et stigmate nigro-fuscis.

․ pilis brevilus pallidis vestila; thorax testaceo-rufus, plevumque nigro-maculatus: perles cum coxis testaceo-rufi, genibus: tibi. 
arum apice tarsisque (arliculi primi basi tamen exceptâ) nigris; alae dilute subcinerascentes, venis posticis dilule subfuscis, anticis cum costâ et stigmate ex fusco nigris.

Long. corp. $2 \frac{1}{6}-2 \frac{7}{1} \overline{2}$ lin., Long. al. $2 \frac{1}{4}-2 \frac{7}{1} \frac{7}{2}$ lin.

Mas: Bibionis gracilis mari sinillimus, tarsorum posticorum articulos singulos crassiores et alas non cinereas, sed pure hyalinas, venis posticis dilutioribus instructas habel; praeterea pili thoracis et scutelli, quos Bibio gracilis nigros habere solet, in hoc nostro Bibione longipede semper pallidi sunt. - Foemina a Bibionis gra cilis foeminâ pedibus posticis brevioribus, alis non ex cinereo sub. fuscis, sed dilutissime subcinerascentibus venisque posticis dilutioribus differt. - (District Columbia; Osten-Sacken).

13. Scatopse pygmaea nov. sp. 오. Nigra, modice nitens, alis hyalinis, venâ longitudinali secundâ brevi, furcâ tertiae mediocri, basim versus angustissimâ, apicem versus subilo dilatatâ. Long. $\operatorname{corp} . \frac{5}{1}^{\frac{5}{2}}$ lin. Long. al. $\frac{1}{2}$ lin.

Nigra, modice nitens, tarsis sordide albicantibus vel sulofuscis. Antennae breves, crassiusculae. Alae albido hyalinae, venis primis duabis et costâ inde a basi usque ad venae secundne finem subcinerascentibus, reliquis sine colore; vena secunda, primam longitudine paulo superans, dimidiâ alâ brevior est; venae terliae furca mediocris, sed pedunculo multo brevior, ramis prope basim valde approximatis, apicem versus subito divergentibus, anteriore recurvo, posteriore incurvo. - (District Columbia; Osteu-Sacken).

\section{Tipula fraterna nov. sp. 오. Antennae ochracecte, api-} cem versus subfuscae, flagelli articulis in basi atris; alae villatae, limbis venae quintae angustius obscuriusque, costae latius et paulo dilutius fuscis, vittâ mediâ cinerascente usque ad cellularum basalium finem pertinente et fasciá irregulari ulbidâ a costâ per cellulae discoidalis basim prope ad marginem posticum ductâ. - Long. corp. $6 \frac{1}{2}$ lin., Long. al. $8 \frac{5}{1} \frac{5}{2}$ lin.

Caput ex fusco cinereum, linế medià frontis et occipitis fuscâ. Rostrum ochraceum, lateribus infuscatis; palpi subfusci. Antennae laete ochraceae, apicem versus ex ochraceo subfuscae, flagelli articulis inde ab secundo in basi atris. Thoracis dorsum cinerascens, villis fusco-cinereis, subobsolete fusco margioatis, mediâ per lineam niğro-fuscam dissectâ. Abdominis lalera praeter basim late infuscala. Extremus femorum apex fuscus. Alae vittalae, limbis costae et venae quintae fuscis, illo latiore, sed extra cellulam subcostalem 
dilutiore, villâ mediâ subcinerascente usque ad venulam transversam mediam ductâ; fascia irregularis albiłla, anfe stigma costam attingen:, per cellulam discoidalem, per cellulac posteriotis quartae basim et per cellulam posteriorem quinlam fere ad posticum usque alae marginem extenditur. - (District Columbia; Osten-Sacken).

15. Tipula ternaria nov. sp. $\hat{o}$. Cinerco-nigra, posticis segmentorum abdominalium singulorum marginibus appendicibusque hypop'ygii luteis, antennis pulpisque nigris; alıe maculatae, maculà obscurá insigni in cellularum basalinm initio. - Long. corp. $6 \frac{1}{2}$ lin.. Long. al. 7 lin.

Cinereo-nigra, opaca. Capul concolor, rostro cum palpis nigro. Antennae breves, nigrae, secundo flagelli articulo badio. Dorsales thoraris villae nigrae. media e villis duabus et lineâ composita. Scutellum nigrum, lateribus albido-pollinosis; metanotum cinereonigrum. Pleurae cinereae. Abdomen cinereo-nigrum, margine segmentorum singulorum posico ex luteo ochraceo. Hypopygium magnum, nigro-fuscum, lamellâ supremâ nigrà, latiore quam longiore. appendicibus luleis. Pedes nigri, lemoribus praeter apicem luteis, libiarum basi ex fuico luteâ. Alae ex lusco cinereae, maculis nigricanlibus tribus, primâ cellularum basalium inilium tegente, maculisque albidis compluribus variegalae; cellulae posteriores praeter albidam primae ef quartae basin immaculalac et maculie albidae in postico alarum margine nullae. - (Iludsons Bay Territory; Kennirot).

16. Tipula pubera nov. sp. o. Testacea, vittis thoracis paulo obsruvioribus, corpore toto pilis solitis longioribus vestito; flagellum antennarum fusco-nigrum; alae marulatae, cellulis postevioribus omnibus allido-marginatis, venae longitudinalis secundae ramulo auteriore abbreviato. - Long. согр. 9 lin., Long. al. 10 lin.

Ex luteo teslacea vel ochracea, opraca, pilis longioribus, in vertice, rostro et palpis nigricantibus, in reliquo corpore pallidis restita. Caput totum concolor, ultimo palporum articulo anlennarumque flagello fuscis, primo tamen hujus articulo dilutiore. Vitlae thoracis relirgui corporis colore. paulo tamen saturatiore tinctae. Scutellum et metanotum immaculata. Abdomen lineae mediae subfuscae restigium et utrinque lineam subfuscam habet. Hypopygium permagnum, concolor, lamellâ infimât magnâ. in margine apicali pilis confertissimis subaureis babatà. Pedes ex luteo subfusci, feuorum tibiarumque apice et ullimis tarsorum articulis nigro-fuscis. Alae 
ex cinereo fuscae, maculatae, venae secundae ramulo anteriore abbreviato; macula obscura major in cellularum basalium initio nulla; stigma fuscum; basis venae secundae, venae transversales, vena longitudinalis quinta tola venarumque reliquarum apices fusco-limbatae; cellulae posteriores albido marginatae; cellulae axillaris primae margo maculâ et strigulâ albidis nolatus. - (California; Agassiz).

17. Tipula macrolabis nov. sp. of et . Testacea, tho. racis dorso cinereo, fusco-villalo, villâ mediâ per lineam cineream dissectâ; alae maculatae, maculà obscura majore in cellularum basalium inilio mulla, prope marginem anticum maculis obscuris tribus, adjectâ quaria obsoletiore. maculis albicantibus compluribus sparsis, cellula posteriore primá prope marginem albido-lituratâ. Long. corp. $6 \frac{1}{2}-6_{6}^{5}$ lin., Long. al. $7 \frac{1}{T}-7 \frac{1}{2}$ lin.

Teslacea, thorace vel toto cinereo, vel ex flavo cinereo, scutello, metanoto pleurisque flavicantibus. Caput cinereum, lineâ occipitis el frontis fuscâ. Ro-trum ex fusco lestaceum vel fuscum; palpi ex fusco nigri, basi fuscâ. Scapus antennarum luteus, flagellum ex luteo subfuscum vel fuscum, basi articulorum singulorum nigrâ. Vittae thoracis salurate fuscae, media per lineam latiusculam cineream dissecla. Abdomen maris ex luteo teslaceum, subfusco trilineatum. Abdomen foeminae multo obscurius colorem post mortem mutavisse videlur. Hypopygium maris permagnum, reliquo corpore obscurius. subbadium, lamellis lateralibus valde elongatis, linearibus, arcuatis et forcipis speciem efficientibus. Terebra foeminae mediocris, segmento basali brevi, ex basi latà subito altenuato, lamellis teunibus aculis. - Pedes lutei, femorum tibiarumque apice et larsis praeter basim fuscis. Alae maculatae, maculå obscurâ majore in cellularum basalium initio nullà; maculae fusco-nigrae subquatuor prope marginem anticum, primae duae quadrangulae in cellulà basali primâ sitae, teríia irregularis cum stigmate contigua, quarta praecedentibus obsoletior subapicalis; maculae albidae complures; cellularum posteriorum margines elutae, quartae et quinfae ex parte albidae; cellula axillaris prima prope marginem lituram vel maculam albidam, interdum obsoletam habet. - (Hudsons Bay Territory; Kennicot).

18. Tipula serrulala nov. sp. ㅇ. Thoracis villae dorsales fusco-marginalae; alue marulatae. maculis fusco-nigris duahus, alterá minare venae secundae basim legente, allerà cum stigmale conliguá. maculis albidis compluribus diffusis; nullis tamen in mur- 
gine postico; lamellae lerebrae infra serrulatae. - Long. corp. 10 $\frac{1}{3}$ lin., Long. al. $9 \frac{1}{2}$ lin.

Testacea, thoracis colore in ciucrem vergente. Caput concolor, palporum apice fusco. Scapus autennarum testaceus (lagellum deest). Thoracis villae dorsales ex testaceo fuscae, anguste fusco-marginalae, media per lineam obsoletiorem fuscam dissecta. Scutellum et melanotum immaculata. Abdomen vitlis tribus angustis fuscis piclum. Lamellae terebrac latiusculae, leniter recurvae, infra serrulalae. Femora lutea, apice subfusco; libiae et larsi ex luteo subfusci, apice illarum et ultimis horum articulis fusco-nigris. Alae fusco-cinereae, maculalae, naculis fuscis duabus, alterâ minore in venae secundae basi sitâ, alterâ irregulari cum sligmate concolore in unam connatì. maculis albidis compluribus diffusis, in margine postico famen nullis; cellular!n posteriorum prima in basi albida, quarta et quinta in basi et marginibus adversis elulae, reliquae immaculatae. - (Ifudsons Bay Territory; Kennicot).

Nota. Foeminam unicam Tipulae serrulatae, sordidam et mutilalam descripsi; a Tipulà tessellatâ. cui proxima. corpore minus robusto, alis dilutins el parcius maculatis, maculà obscurâ majore in cellularum basalium initio destilutis et pedibus longioribus graciliorihusque certe differt.

19. Tipula canadens is nov. sp. $\sigma$. Thorax ex cervino cinereus, villis cinereis fusco-marginatis, mediâ per villulam fuscam subfusiformem dissecta; alue subfuscae maculis subquatuor albidis variegatae. cellulis posterioribus praeter albidam primae et quartae basim immaculatis. - Long corp. 6 lit.. Long. al. 7 lin.

Ex luteo testacea. Caput cinereum, rostro luteo. supra sub. fusco. Palpi ex fusco nigri. Antennarum scapus luteus, flagellum ex ochraceo subfuscum, articulis praeter primum infra excisis, in basi nigris. Thoracis dorsum ex cervino cinereum, vittis cinereis fusco-marginatis; vitla media per vittulam subfusiformem fuscam dividitur. Pleurae ex fusco cinereae. Scutellum et metanotum ex fusco cinerea. Abdomen ex luteo testaceum, villis tribus aequalibus fuscis, segmentis ultimis fere totis nigro-fuscis. Hypopygium parvum lamellis superioribus minutissimis. rolundato-ovatis. Pedes fusci. femoribus adversus basim luteis. Alae subfuscae, adversus costam obsolete sublutescentes, maculis subquatuor albidis rariegatae; macula minuta in venae secundae basi et stigma fusca; cellularum posteriorum prima et quarta in basi albicantes. reliquae immaculatac. - (Hudsons Bay Territory: Kennicot). 
Nota. Tipula canadensis, Tipulae baliopterae proxima, antennas obscuriores, villam thoracis mediam vittulà fuscâ integrå dissectam, apicem abdominis juxta hypopygium non excavatum et superiores hypopygii lamellas mullo breviores habel.

20. Tipula lalipennis nov. sp. O'. Pallida, antennis nigroannulatis, thoracis dorso ex fusco ochraceo, vill is concoloribus fuscomarginatis; alce latae, ex luteo dilute subfuscae, maculis aliquot fuscis albidisque pluribus variegatae, maculà obscurá majore in cellulurum basalium initio mellâ, cellulis posterioribus praeter albidam primae basim cellulisque axillaribus immaculatis; lamella hypopygii suprema nigra, non longior quam latior. -- Long. corp. 5! lin., Long. al. $7 \frac{1}{2}$ lin.

Pallida vel dilute ocbracea. Caput concolor, vertice subcinerascente. Antennae ochraceae, apicem versus obscuriores, articulis flagelli simplicibus, basi primi nigricanle. reliquorum nigrâ. Rostrum luteum, lateribus obscurioribus. Palpi ochracei vel ex fusco ochracei, basi fuscâ. Thoracis dorsum fusco ochraceum; viltae concolores, fusco-marginatae; margines vittarum laleralium acquales, villae mediae postice atfenuati, antice valde dilatati. Pleurae ex flavo obsolete cinerascenles, immaculatae. Abdomen fusco univittatum. Hy. popygium magnum, appendicibus pendulis uullis instructum, lamellà suprenâ rotundâ, niğrâ. Femorum apex fuscus. Alae latae, ex luteo dilute subfuscae, adversus cosfam lulescentes, maculis saluratioribus paucis, albidis pluribus variegalac; basis venae secundae fusco-marginata; stigma fuscum; cellularum posteriorum prima in basi albicans, reliquae immaculatae; maculae albidae in cellulis axil. laribus omnino nullae; veuulae transversales basi alarum proximae infuscatae, sed macula obscura major in cellularum basalium initio nulla. - (New Hampslire; Osten-Sacken).

Nota. A Tipulâ hebete alis latioribus, antennarum apice obscuriore, pleuris omnino immaculatis et abdomine fusco viltato differt; hypopygium minus, appendicibus pendulis vel inflexis destitulumı, lamellâ supremâ non oblongâ et luteâ. sed rotundâ et nigrâ instructum diversitatem maris aperte demonstrat.

21. Tipula centralis nov. sp. $\sigma^{7}$. Olscure cinerea, villis thoracis concoloribus obsolete et subtiliter fusco marginatis, abdomine sordide testaceo, villis tribus et segmentis ultimis duobus nigris; alue ex rinereo fuscae, stigmale el macula in rence secundae basi nigro-fuscis, maculà minulà centrali cellulisque discoi- 
dali el posteriore quarta in basi albidis; hypopygium parvum, lamellis superioribus brevibus, truncalis. - Long. corp. 7 lin., Long. al. 8 lin.

Caput obscure cinereum, lineâ tenni occipitis el frontis fuscâ, lateribus rostri nigris. Palpi nigri. Scapus antennarum luteus, basi articuli primi fusca; primus flagelli articulus luteus, basim versus nigricans, reliquum flagellum fuscum, apicem versus vigrum, basi arliculorum singulorum alrâ. Thoracis dorsum ohscure cinereum, viltis concoloribus. subtiliter et obsolete fusco-marginatis, mediâ per lineam dilulius cinerean divisâ. Abdomen sordide testaceum. villâ mediâ, villis lateralibus obsolctioribus ultimisque duobus segmentis fusco-nigris. margine laterali ipso subalbicante. Ilypopygium parvum, lamellà supremà nigrâ, reniformi, lamellis superioribus parvis truncatis. Pedes fusco-nigri, femoribus adversus basim luteis, tibiarum basi fuscâ. Alae ex cinereo fuscae, stigmate, maculà obsoletâ contiguâ et maculâ alterâ renae secundac basim te. gente saturate fuscis, maıulà parvà albidâ in cellulae basalis secundae margine postico, basi venae secundae oppositâ, cellulis discoidali et posteriore quarti in basi obsolete albicantibus. - (Iludsons Bay Territory; Kennicot).

22. Tipula angulata nov. sn. ơ et ?. Lutea, thoracis dorso ex favo cinereo, vitlis cinereis, media postire valde altenuala et per lineam ex fluvo cineream divisâ: antennae luleae, articulis fagelli in basi nigris: alae maculatae, fasciâ albida sub-

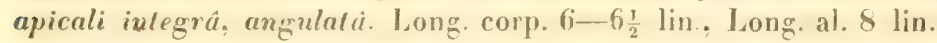

Caput ex luteo cinereum, lineâ occipitis el frontis tenuissimå fuscâ. rostro luleo. Palpi fusci vel ex luteo fusci. basi luteả. Antennac ex luleo ochraccae, arliculis flagelli practer primum in basi nigris. Thoracis dorsum ex flavo cincreum, vitlis cinereis', medià postice valde attenuatà et per lineam dilute cineream dissectât. Scufellum, melanotum et pleurae flavae. Abdomeu lulcum, viltà mediâ fuscà. Hypopygium mediocre, concolor, lamellà supremâ niğro-fuscâ. Terebra testacea, lamellis tenuibus acutis. Pedes lutei, femorum apice, tibiis apicem versus farsisque nigro-fuscis. Alae longae, fusco-cinereae. basim versus dilutiores, ante apieem fascià albidâ integrâ angulalà ornatac; macula fusca majuscula cellularum basalium inilium explet. - (Massachusets).

Nota. Foeminam possideo nuper exclusam. $5 \frac{3}{4}$ lin. longam, quae antennarum articulos in basi levissime lantum nigricantes, venac secundac ramulum anteriorem valie abbreviatum ef maculam 
fuscam in cellularum hasalium initio silam valde minutam habet. Utrum varietas Tipulae angulatae. an species diversa sit, dubito. - (New Hampshire; Osten-Sactien).

23. Tipula tephrocephala nov. sp. $\delta$. Lutea, cupite supra albido-cinereo, antennarum flagello nigro, basi articulorum singulorum pallidâ; alae cinereo-hyalinae, cellulâ rostali luteâ, sli. gmate fusro, maculâ cum stigmatis Lasi cohaerente albidâ. - Long. corp. $6 \frac{1}{3}$ lin., Long. al. $7 \frac{1}{2}$ lin.

Lutea. Caput supra albido-cinereum. Palpi subfusci. Antennarum scapus luteus, llagellum ex fusco luteum, articulo primo praeter apicem, reliquis in basi luleis. Vitt:e dorsales thoracis ochraceae, laterales anguslae, media e vittis duabus angustis, intervallo lato separatis composita. Abdominis segmenta singula prope marginem posticum lineam transversam fuscam habent, ultima fere tota fusca sunt. Hypopygium parrum compressum. Pedes Jutei. femorum tibiarumque apice et tarsis praeter basim fusco-nigris. Alae cinereo hyalinae, basi et cellulâ costali lutescentibus, sligmate fusco. maculâ albidà cum sligmatis basi contiguâ. inlerduns usque ad cellulae discoidalis basim extensâ. - (New Hamplshire; OstenSacken).

24. Pachyrrhina nobilis nov. sp. ․ Flava, villis thoracis atris nitidis. scutello et melanoto immaculalis, abdomine serie mediâ macularum nigrarum maculisque lateralibus candido-micantibus ornato, terebrấ brerissimâ oblusâ. - Long. corp. $4 \frac{2}{3}$ lin., Long. al. $6 \operatorname{lin}$

Caput flarum, opacum, rostro et scapo antennarum concoloribus, flagello antennarum nigro-fusco. Thorax flarus, pleuris, scutello et melanoto concoloribus, immaculatis. vitlis dorsalibus atris, nitidis. Abdomen flarum, serie mediâ macularum nigro-fuscarum maculisque lateralibus candido-micantibus: venter flarus, segmentorum anticorum margine postico et segmentis posticis fere totis candido-micantibus. Terebra flara, brevissima, obtusa. Pedes flavi, fenorum tibiarumque apice et tarsis totis fusco-nigris. Alae lutescentes, limbo apicis venarumque transcersalium limbis nigricantibus, stigmate fusco. - (New Hampshire; Osten.Sacken).

25. Pachyrrhina virescens nov. sp. $\sigma^{7}$. Flava, capite concolore immaculato, thorare in mortua ex viridi flavo, in vivâ viridi, pleuris el metanoto immaculatis, villis dorsalibus nigro et 
badio variis, lateralium parte anteriore exterius incisa. - Long. corp. $4_{6}^{5}$ lin., Long. al. $\mathcal{4}_{6}^{5}$ liv.

Caput aurantiacum, opacum, immaculatum, rostro paulo dilutiore. Scapus antennarum et primus flagelli arliculus flavi. articuli reliqui nigri, longiusculi, infra excisi. Thorax in vivâ viridis post mortem flavescif; viltae dorsales nigro et badio variae, prope laterales dorsi margines opacae, in reliquo dorso nilidae; vitla media antice subito dilatata; strigula flava inde a margine laterali thoracis in anteriorem vittarum lateralium partem ducitur. Pleurae immaculatae. Abdomen flavum, serie mediâ macularum fuscarum. Hypopygium flavum, lamellis supremis lanceolatis. Pedes flavi, femorum tibiarumque apice et tarsis totis ex fusco nigris. Alae cinereo-hyalinae, stigmate subfusco. - (District Columbia; OstenSackeu).

26. Pachyrrhina lugens nov. sp. ․ Atro et aurantiaco varia, fronte atro-bipunctut $\hat{a}$ et metanoto alro-vitlalo; alae infuscatae; terebra acuta. - Long. corp. $5 \frac{1}{2}$ lin. Long. al. $4 \frac{1}{1} \frac{1}{2}$ lin.

Caput anrantiacum; frons opaca, utrinque puncto atro ornata; triangulum occipitale atrum, subnitens, latum, angulo antico acuminato; facies aurantiaca, infra antennas punctum quadrangulare atrum gerens; rostrum aurantiacum, nitens. supra (margine antico famen excepto) atrum, in lateribus nigro-fuscum; palpi et anleunae nigrae. Collare aurantiacum, lateribus nigris. Thoracis vitlae dorsales latissimae, atrae, nitidae. Pleurae atrae, subnitidae, auronliaco maculatae. Scutellum atrum; metanotum aurantiacum, viltâ nediâ et maculâ posticâ atris. Abdomen aurantiacum; segmentum primum atrum; segmenta sequentia quatuor singula fasciâ postieâ alrâ opacà ornantur, quae latera versus attenuala est et in medio abdomine ilo dilatatur, ut cum fascià segrmenti pracedentis cohaereat; segmenta sextum et septimum aurantiaca, octavum excepto margine postico atrum, nitidum. Terebra atra, apicem versus picea, lamellis tenuibus acutis. Coxae atrae; trochanteres et femora lutea, haec apicem versus nigra; tibiae nigro-fuscae, apicem versus nigrae; pedes toti nigri. Alae infuscatae, triente apicali diluiiore, cellulà costali luteà, stigmate et venis nigris, limbo apicis venarumque transversalium limbis nigricantibus. - (New Hampshire; Oslen.Sacken).

27. Pachyrrhina vittula ō. Frons postica et occijut subnitida, vitta mediâ nigrâ; thoracis vittae dorsales nigrae. pleurue nigro-maculatae; abdomen nigro trivittatum, rittis lateralibus tenui- 
bus interruptis: alce cinerene, stigmate subfusco. - Long. corp. $5 \frac{1}{2}$ lin., Long. al. $6 \frac{1}{1 \frac{1}{2}}$ lin.

Caput flavurn; frous postice et occipul modice nitida, vitta mediâ usque ad marginem anticum frontis produclâ punclisque duo. bus frontalibus nigris; rostrum concolor, fusco quadriviltalum; palpi flavi; scapus anteunarum flavus, flagellum nigrum, articulis singulis infra leviter excisis. Collare utrinque nigro-maculatum; viltae dorsales nigrae, nitidae, nedia antire modice dilalala. Pleurae maculis fusco-nigris varicgatae. Scutcllum luteum. Metanotum lineâ mediâ fuscí et maculà posticâ luteâ pictum. Abdomen nigro-trívitfatum. vittâ mediâ integrà, vittis lateralibus tenuibus et interruptis. Iypopygium mediocre, laminà supremâ totà et infimae basi nigris, appeudicibus flavis, supremis lanceolatis. Pedes lutei, femorum libiarumque apice et tarsis totis ex fusco nigris. Alae cinereae, stigmate subfusco. - (Hudsons Bay Territory; Kennicot).

29. Pachyrrhina unimaculata nov. sp. హ. Lutescens, capite thoraceque oparis, villis hujus subochraceis et subfusco-marginatis: antennae lutene, arlirulis flagelli longiusculis, izde a secundo in brisi. ullimis tolis nigris; alae sublutescents. stigmate fusco. - Long. corp. $4 \frac{1}{4}$ lin., Long. al. $5 \frac{1}{6}$ lin.

Luteola, lateralibus thoracis marginibus pleurisque flavis. Caput opacum immaculatum, rostro concolore. Palpi nigro-fusci, articulo primo in basi, articulis reliquis in apice luteis. Aulennae dilute luteae, arliculis flagelli longis, basi secundi et sequentium leviter incrassalâ nigrâ, ultimis tolis nigris. Thoracis dorsum opacum, vittis obsoletioribus subochraceis, subfusco marginatis el medià per lineas duas subfuscas divisâ. Scutellum et metanotum immaculata. Ab. domen luteolum, nitidum, lateralibus segmentorum marginibus inaequaliter infuscatis. Hypopygium concolor. (Pedes desunt). Alae ex cinereo lutescentes. stigmate nigro-fusco. - (New York; OstenSacken).

29. Pachyrrhina sodalis nor. sp. ․ Caput praeter faciem et margines laterales frontis nilidum; antennarum flagellum nigrum, arliculis primis ex fusco rufis; thoracis dorsum nilidum, villis ex ochraceo fuscis; abdomen villât mediâ fuscâ et utrinque serie strigularum nigrarum variegatum; alae ex cinereo hulescentes, sligmate luteo, - Long. corp. $8 \frac{2}{3}$ lin., Long. al. $7 \frac{1}{6}$ lin.

Caput aurantiacum, praeter faciem et praeter marginem anticum et latera frontis nitidum. Rostrum concolor, in lateribus fusco- 
nigrum; palpi suhfusci, articulo quarto praeter basim lutescente. Antennae nigrae. scapo ochraceo, primo vel primis duobus flagelli articulis ex lusco rufis. Thoracis dorsum nitidum. villis latis ex fusco ochraccis. suturâ latera versus nigrâ. Scutellum et metano. fum ochracea, immaculala. Pleurae flavo et ochraceo variae. Abdomen viltâ mediâ aequali fuscâ et utrinque serie laterali słrigularum nigrarum variegatum. segmento ultimo fere toto nigro. Terebra barlia, lamellis tenuibus acutis. (Pedes desunt.) Alae ex cinereo lutescentes, cellula costali et stigmale luteis. - (Connecticut.)

30. Pachyrrhina occipitalis. nov. sp. ․ Occiput subnitens, nigro-fascialum : antennarum flagellum nigrum; thoracis dorsum nilidum. villis ex orhraceo fuscis; abdomen villa mediâ et utrinque strigulis subobsoletis fuscis variegalum: alae ex cinereo lutescentes. stigmale luteo. - Long. corp. $6 \frac{2}{3}$ lin., Long. al. $6 \frac{5}{6}$ liu.

Caput fiavum. opacum, occipite subnitente, nigro-vittato. Ro. strum conculor. laterihus infuscatis. Scapus antennarum flavus, flagellum nigrum. imâ articuli primi basi flavicante. Thoracis dorsum nilidum, villis modice latis ex ochraceo fuscis. Scutellum ochra. ceum; metanolum obsolete ochraceo vel subfusco vittatum. Pleurae flavo et ochraceo variae. Abdomen villa media et utrinque strigulis lateralibus subobsolelis ex nigro fuscis pictum. Terebra ex luteo testacea, Iamellis tenuibus acutis. Pedes lutei. femoribus apicem versus fuscis, tibiis tarsisque fusco-nigris. Alac ex cinereo lutescen. les, cellulâ costali et stigmale luleis. - (Hudsons Bay Territory; Kennicot.)

Nota. Pachyrrhinae sodali simillima. sed fronte et occipite nigro-fasciatis diversa.

31. Pachyrrlina xanthostigma, nov. sp. ठ \& $\&$. Ocrijut totum nitens, immaculatum; autennae flavae, adversus apicem obscuriores, articulis fagelli praeter primum in basi nigris: thoracis dorsum nilidum, villis ochraceis; abdumen viltâ mediâ tenui. interruplá, fuscâ el utringue slrigulis lateralibus nigris variegutum; alae ex cinereo sublutescentes, stigmate tuteo. - Long. corp. $6_{3}^{2}-$ 8 lin., long. al. $6 \frac{1}{3}-7$ lin.

Caput flavum, occipite concolore, nitido, immaculato. Rostrum concolor, nitidum, lateribus fuscis; palpi flavi. Antennae maris mediocres, articulis flagelli infia modice excisis; scapus et primus flagelli articulus flavi, reliquum flagellum ochraceum vel ex ochraceo subfuscum, basi articulorum singulorum nigrà. Thoracis dorsum ni- 
tidum, vittis dilute ochraceis, sulurâ utrinque in strigulam nigram excurrente. Abdomen vitlâ medià tenui, interruptâ, fuscâ, in foeminá valde obsoletâ et strigulis lateralibus nigris pictum Pedes flavi, extremo tibiarum apice tarsisque apicem versus ex fusco nigris. Alae ex cinereo lutescentes, cellulâ cosłali et stigmate luteis. - (Illinois.)

32. Pachyrrhina gracilicornis, nov. spec. o \& ㅇ. Occiput subopacum, immaculatum; antennae tenues, mediocres, in utroque sexu aequales, fuscae, scapo primisque flagelli arliculis flavis; thoracis dorsum nitidum, villis ex fusco ochraceis; abdomen villd media fuscâ et utringue strigulis lateralibus nigris variegatum;

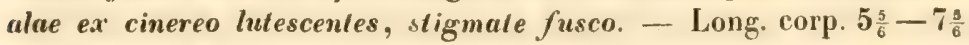
lin., Long. al. $6 \frac{5}{12}-6 \frac{1}{2}$ lin.

Caput flavum, opacum, occipite subopaco, immaculato. Rostrum concolor, nitidum, laleribus fuscis; palpi subfusci, arliculo ultimo fere toto et extremo pracedentium apice ochraceis. Antennae tenues, mediocres, in ulroque sexu aequales, fuscac, primo vel primis flagelli articulis et scapo flavis. Thoracis dorsum nitidum, vittis ex fusco ochraceis, mediâ per lineam flavicantem dissectâ. Scutellum lutescens; melanotum obsoletissime subluteo vittatum. Abdomen vittâ mediâ integrâ fuscâ et utrinque strigulis lateralibus nigris variegalum. Lamella hypopygii suprema et infimae basis nigrae, appendices flavae. Terebra lutea, apicem versus badia, lamellis tenuibus, acutis. Pedes lutei, extremo femorum tibiarumque apice infuscato, tarsis ex luteo fuscis, apicem versus nigro-fuscis. Alae ex cinereo lutescentes, cellulâ costali luteâ, stigmate fusco.

Nota. A Pachyrh. sodali el occipilali stigmate non luteo, sed fusco distinguitur.

33. Spilomyia hamifera, nov. sp. f. Tharace nigro et Aavo vario, abdomine flavo, marulà basuli subquadralá fasciisque segmentorum singularum binis nigris, alterâ basali el integrâ, alterá mediâ et interruplâ. - Long. corp, $7 \frac{1}{2}-8$ lin., Long. al. 7 lin.

Caput laete flavum, fronte et facie anguste nigro-viltatis; genae viltulâ fusco-nigrâ notatae; anteunae fuseae, in junioribus testaceac, margine arliculi terlii fusco. Vertex niger; occipul nigicans, orbitâ polline subalbido conspersâ. Thorax niger, flavo-varius; dorsum in margine antico maculas quatuor, in dimidio posteriore vittulas duas hamatas, inde $a b$ angulis posticis usque ad suturam pertiventes et lituras duas minutas, inversam literae $\mathrm{V}$ formam efficientes, colore 
flavo piclas oslendit; in pleuris praeter humerum maculae tres laete favae cernunlur, quarum ea, quae prope coxam anticam sita est, plerumque obsolescit. Scutellum flavum, margine basali interdum fusco vel nigro. Metanotum nigrum utrinque maculam flavam habet. Abdomen flavum; segmentum primum praeter angulos laterales nigrum; segmenta sequentia singula fascias binas angustas nigras habent, alteram margini antico contiguam et integram, alteram mediam et interruptam. Venter niger, margine segmentorum singulorum postico flavo. Pedes flavi, tibiis tarsisque anticis nigris. Alarum dimidium anterius fuscum, posterius hyalinum. - (Pennsylvania; Osten-Sacken.)

Nota. Spilomyiae genus cellulâ marginali clausâ a Milesiis, femoribus posticis dentatis a Temuostomis distinguitur.

34. Spilomyia fusca, nov. sp. o' et ㅇ. Nigro-fusca, jarie. thoracis maculis vitlulisque, sculelli margine et fasciis in abdominis apice tribus dilute sulphureis. - Long. corp. 6! -7 lin., Long. al. $5 \frac{1}{2}-6 \frac{7}{12}$ lin.

Caput dilute sulphureum, vertice: vittulâ faciei incompletâ et vittulà frontali supra abbreviatà nigro-fuscis; antennae fuscae, articulis duobus primis saepe nigris; occiput nigrum, orbitâ albopollinoså. Thorax ex nigro fuscus; dorsum in margine antico maculas quatuor, in dimidio posteriore lineas duas hamatas, inde ab angulis posticis usque ad suturam perinentes, et strigulas duas dimidiam circuli forman efficientes, colore dilute sulphureo pictas habet; in pleuris maculae tres dilute sulphureae cernuntur. Scutellum nigrofuscum, margine postico dilule sulphureo. Abdomen nigro-fuscum, breviler nigro-pilosum; segmenti secundi margo posticus angustissime flavescit; segmentum terlium limbum marginis postici aequalem et utrinque fasciae mediae initium loreve dilute sulphurea ostendit; segmentum quartum fasciam anguste interuptam et limbum marginis postici laliusculum sulphureos habet. IJypopygium maris tolum sulphureum. Venter ex nigro fuscus, incisuris dilute flavescentibus. Femora fusca, testaceo et sulphurco varia; tibiae auticae praeter basim sulphuream fuscae, posteriores sulphureae. apice tamen ochraceo; tarsi antici fusci, posteriores ochracei. Alae subhyalinae, in dimidio anteriore fusco-literatae. - (Pennsylvania; Osten-Sacken.)

35. T'e mиostoma obscura, nos. sp. ơ. Nigra, abdominis segmentis singulis flavo unifasciatis, facie subtuberculata. - Long. eorp. $4 \frac{1}{1} \frac{1}{2}$ lin., Long. al. $4 \frac{1}{2}$ lin. 
Caput tomento subaureo ornalum, vertice, maculà iriangulari supra antennas, vittâ latâ faciei genisque atris, antennis fuscis. Thorax ater, humeris, sulurâ, puncto utrinque supraalari minutissimo pleurarumque strigulâ flavo-pollinosis. Scutellum piceo-nigrum, subopacum. Abdomen alrum, modice nitens, segmentis singulis praeter primum fasciam aequalem, integram. modice arcualam. flavo-pollinosam, utrinque colore atro opaco limbatam gerentibus. Нуроруgium atrum, nitens. Pedes antici nigri, genibus luteis; pedes intermedii lutei, femoribus praeter apicem nigris, tibiarum apice obsolete subfusco, ultimis tribus tarsorum articulis fuscis; pedes postici lutei, femoribus praeter apicem et imam basim nigris, libiarum dimidio apicali et ullimis tribus tarsorun articulis fuscis. Alae cinereae, obsolete sublituratae. - (Saskalchevan; Kennicot.)

Nota. A Temnostomâ bombylanti, cui simillima, faciei tuberculo minuto quidem, sed manifesto differt.

36. Temnostoma aequalis, nov. sp. ơ. Nigro et flavo varia, segmentis abdominalibus singulis flavo bifascialis, fasciâ interjectâ nigrâ in ultimo segmento anguste interruptâ, pedibus anticis posteriorumque femoribus nigris. - Long. corp. $5 \frac{1}{2}$ lin., Long. al. $5 \mathrm{lin}$.

Caput tomento subaureo vestitum, lineâ fronlali, vittấ faciali genisque atris, antennis subfuscis; Iriangulum verlicale nigrum, infra flavo-pollinosum. Thorax ater, humeris, suturâ, puncto supraalari utrinque et vittulâ pleurarum flavo - pollinosis. Scutellum nigro-aeneum, nitidum. Abdomen nigrum, modice nitens, segmentis singulis praeter primum fascias binas flavo-pollinosas, integras et in laterali abdominis margine non contiguas gerentibus; fascia anterior segmentorum singulorum a margine antico intervallo atro opaco separatur et postice limbum atrum opacum habet; fasciae segmenti quarti per viltulam mediam flavo-pollinosam conjunguntur. Hypopygium piceum. Pedes antici nigri, genibus luteis; pedes posteriores lutei, femoribus praeter apicem nigris, ultimo tarsorum articulo fusco. Alac cinereae, obsoletissime lituratae. - (Fnglish River; Kennicot.)

37. Temnostoma alternans, nov. spec. ot et . Nigro et favo varia, segmentis abdominalibus singulis flavo bifasciatis, fascia interjectâ nigrá in ultimo foeminae et in duobus ullimis maris segmentis in maculas tres dissecta, femorum anteriorum basi, tibiis farsisque antiris nigris. - Jong. corp. $6 \frac{5}{\frac{1}{3}}-7 \frac{2}{3}$ lin. Long. al. $5 \frac{1}{3}$ $-6 \frac{1}{3} \operatorname{lin}$. 
Caput tomento subaureo vestitum, vertice, vittâ frontali infra abbreviatâ, vitlâ faciei inlegrâ genisque alris, antenuis luteis. Thorax niger, humeris, maculis utriuque binis in sulurâ silis, viltulà utrinque laterali inde ab angulo postico usque arl suturam pertinente et maculà posticâ triangulà tomento flavo teclis. Pleurae maculâ magnà Gavo-pollinosâ nolałae. Scutellum nigro-aeneum, nilidum. Abdomen atrum, opacum, segmentis singulis praeter primum fascias binas lacle llavas, ad latera abdominis conjunctas gerentibus; segmeulum secundum alriusque sexus fascias anteriorem angusle, posteriorem late interruplas habet; fascia anterior segmenti tertii in utroque sexu anguste interrupla est; posteriorem, quae in foeminâ angusle inlerrupla cernitur, mas inlegram et praeter latera cum anteriore bis conjunctam habet; segmentum quartum foeminae fasciam anteriorem anguste iuterruplam, posteriorem emarginatam habet; in mare hae fasciae latiores et praeter latera bis conjunctae sunt, ita ut fascia interjecta atra in maculas tres dissolvalur; segmentum quintum focminae similem picturam quam quartum maris babet. Iypopygiun luteum. Pedes lulei, femorum anteriorum basi ex fusco nigrà, libiis anticis pracler basim tarsisque anticis totis nigris. Alae in dimidio anteriore subfusco lituratae. - (Philadelphia.)

38. Lepidomyia calopus, nov. sp. ․ Nigra, squamulis albidis rare aspersa, basi libiarum tarsorumque arliculis primis duobus albis, alis nigro-maculatis. - Long. corp. $2 \frac{1}{2}$ lin.. Long. al. $2 \frac{1}{i \frac{1}{2}} \operatorname{lin}$.

Nigra, nudiuscula, subnilida. Frons plana, infra latior, lineå mediâ impressâ subobsoletà et utrinque maculis binis albido-pollinosis instructa. Antemae anguslae, faciei subaequales; articuli primi duo testacei, secundus primo paulo longior et supra fuscus; articulus tertius elongatus, niger, basi infra testaceà, setâ basalí, nudâ, fuscâ. Thorax cum sculello ef pleuris squamulis minutis albidis rare, sed aequaliter aspersus. Abilomen planum, lateribus et apice atho- جqquamulosis, disco squanulis destiluto. Pedes atri, nitidi, subcyanescentes, tibiarum basi primisque duobus larsorum arliculis albis; femora omnia crassa, infra duplici seric spinularum nigrarum armata; tibiae subclavalae, posticae modice arcuatac. Alae hyalinae, nigro-maculatae. (Cuba; Guudlach.)

Nota. Principales generis Lepidomyiae notae hae sunt: Corpus pro porlione breviusculum et latiusculum, modum, squamulis minutis aspersum. Facies in medio tuberculata. Antennae faciei aequales, articulo tertio duobus praccedentibus simul sumtis 
duplo longiore, aequali, setâ basali tenuissimâ, nudâ. Femora omnia valde incrassata et infra spinosa; tibiae et tarsi crassi. Cellnla alarum marginalis aperta; venula transversa media subnormalis; margo apicalis cellulae posteriores primae in medio sinuatus, angulo postico rotundato, antico acuto et prope al nıargineun alae ducto.

39. Xylota bicolor nov. sp. O'. Nigra, albido-pubescens, abdomine praeter segmenlum primum toto rufo, tibiarum anteviorum basi, primo tarsorum anlicorum primisque duobus intermediorum articulis albidis. - Long. corp. $5 \frac{1}{4}$ lin., Long. al. 4 lin.

Caput nigrum, albo-pollinosum, fronte valde projectâ. Antennae nigrae, articulo terlio rotundato ovato, paulo longiore quam latiore, setâ dilute ferrugineâ, apicem versus fuscâ. Triangulum verticale nigrum nitidum, pilis albidis vel ex flavo albidis vestitum. Thorax niger, obsoletissime aenescens, pube dorsi subflavicante, pleurarum albidâ. Scutellum thoraci concolor, pube exalbidâ vestitum. Primum abdominis segmentum nigrum, reliquum abdomen tolum rufum, fulvo-pubescens. Hypopygium concolor, fulvo-pilosum. Venter rufus, primo segmento tamen nigro. Peres nigri, albido pilosuli, coxis posticis inermibus, femoribus posticis modice crassis, libiarum anticarum basi. primo farsorum anticorum primisque duobus intermediorum articulis albidis. Alae cinereae, dimidio basali hyalino, stigmate fusco. - (Illinois; Osten-Sacken.)

Nota. Xylota bicolor a Xylotâ haematode Wied., quam eandem ac Xylotam pigram Fabr. esse persuasum habeo, oculis longius contiguis, pube tolius corporis longiore, secundo abdominis segmento immaculato, hypopygio non piceo, sed rufo, femoribus posticis minus incrassatis, tibiarum denique anticarum basi, primo tarsorum anticorum primisque duobus intermediorum articulis albidis differt.

40. Xylota barbala nov. sp. ‥ Latiuscula, thorace cupreoaeneo, abdomine cyaneo-nigro, nigro-pilosulo, segmento primo segmentorumque sequentium singulorum fasciâ chalybeâ, nitidâ, albopilosá, pedibus nigris, tibiarum posteriorum basi, libiis anlicis fere totis primisque tarsorum anticorum arliculis ex fusco testaceis. Long. corp. $5 \frac{1}{\frac{1}{2}}$ lin., Long. al. $5 \frac{1}{4}$ lin.

Caput latum, nigrum. Frons modice projecta, nigro-pilosa. Primi duo antennarum articuli nigri, tertius nigro fuscus, subrotundus, setâ nigrâ. Facies mediocriter excavata, albido-pollinosa. Barba 
albida, paulo longior quam in Xylotis plerisque. Thoracis dorsum obscure cupreo-aenenn, modice nilens, albido-pilosum; pleurae aeneo-nigrae, nitidae, albo-pilosae. Scutellum viridi áneum, albo-pilosum. Abdomen latiusculum, cyaneo-nigrum, subopacum, pilis brevissimis nigris vestitifum, segmento primo tolo chalybeo, nitido, albo-piloso; segmentum secundum fasciam chalybeam, nitidam, latissimam, subintegram, pilis albis vestitam babet; segmenta sequeulia duo singula prope marginem anticum fasciam similem, sed interruptam et minus latam gerunt. Pedes nigri, albido-pilosi; femora in apice nigro-pilosula. poslica non inerassata; tibiae anticae ex fusco teslaceae, tomento lateris antici subfulvo; tibiarum posteriorum basis et primi duo tarsorum anticorum articuli ex fusco teslacei, tarsi omnes infra fulvo-tomentosi. Alae cinereae, dimidio basali hyalino, sligmate nigro-fusco, venis nigris. - (Sitka.)

41. Xylota fraudulosa nov. sp. $\delta$ el 오. Nigro-viridis, abdomine flavo-quadrimaculalo, coxis posticis maris nec dentalis nec tuberculatis. - Long. corp. $3 \frac{2}{3}$ liu., Long. al. 3 lin.

Caput nigrum, froute foeminae aeneo-viridi; antennae fuscae, articulis primis duobus ex fusco nigris, basi selae nigricantis luteâ; frons modice prominens et facies modice excavata. Thorax aeneoviridis, nitens, vittis quatuor dorsalibus ex cupreo scoriaceis. Scutellum cum thorace concolor. Primum abdominis segmentum nitidum, subaeneum; sequentia duo atra, praeter margines laterales opaca, utrumque maculis binis flavis quadratis ornatum, quae maculae in mare cum marginibus lateralibus cohaerere, in foeminâ ab his separatae esse solenl; segmentum quarlum aeneo-viride, nitidum, in foeminâ interdum ex viridi scoriaceum; segmentum quintum foeminae et hypopygium maris cum segmento praecedente concolora. Venter flavus, segmento quarto ex nigro fusco. Pedes nigri, subvirescentes, genibus, tibiarum anteriorum basi, primis duobus vel tribus tarsorum anticorum tribusque intermediorum articulis dilute flavicantibus, intermediis tarsorum posticorum articulis haud raro fuscis vel subfuscis; femora postica valde incrassata; coxae posticae in utroque sexu inermes. Alae subhyalinae, ex fusco cinereae, stigmale subfusco. - (Illinois, Wisconsin; Osten-Sacken.)

Nota. Xylotae bifasciatae Meig. simillima, at paulo minor et pube breviore vestita est, nec setam antennarum totam nigram, sed in basi luteam habet. 
42. Chrysotoxum laterale nov. sp. ठ. Hedibus totis favis, alarum limbo costali fusco, aequali. - Long. corp. $5 \frac{1}{3}$ lin., Long, al. $5 \frac{1}{6}$ lin.

Antennarum articulus secundus primo longior, margine apicali testaceo; articulus tertius praecedentibus simul sumlis paulo longior. Oculi hirti. Laterales thoracis vitlae subinlegrae, vittulae albidopollinosae conspicuae. Scutellum flavum, fasciolà disci nigricante. Flavae abdominis fasciae mediocres, arcuatae, angustissime interruptae, cum limbo flavo marginis lateralis connexae; margo segmentorum singulorim posticus flavus, segmenti primi angustus, tertii latus, quarti valde dilalalus, quinti in maculam oblongam productus, ita ut inter hanc maculam et fasciam $Y$ inversum colore nigrum pictum sit. Hypopygium flavum. Media ventris segmenta singula fasciam arcuatam angusle interruptam et marginem posticum flavos habent. Pedes toli flavi. Alae cinereo-hyalinae, fusco costae limbo angnslo et aequali. - (Nebraska.)

Nota. A Chrysotoxo derivato Walk., cui affine, villâ thoracis laterali latiore, marginc abdominis flavo, picturâ ventris laetiore pedibusque totis flavis facile distinguitur.

43. Chrysotoxum pubescens Loew $c^{7}$ et 우 Pedibus totis flavis, alis adversus costam lutescentibus. - Long corp. 6 lin., Long. al. $5 \frac{7}{1} \frac{7}{2}$ lin.

Syn. Chrysoloxum pubescens Loew, Wien. Monatschr. IV, 84.

Secundus antennarum arliculus primo longior, tertius duobus praecedentibus simul sumtis in foeminâ subaequalis, in mare longior. Oculi hirti. Laterales thoracis vittae interruptae, vittulae albido-pollinosae conspicuae. Scutellum flavum, disco nigro. Flavae abdominis fasciae mediocres. arcuatae, interruptae, in angulis segmentorum posticis cum limbo marginis postici connexae; hi linbi in segmentis posterioribus latiores sunt quam in praecedentibus; limbus segmenti ultimi in maculam triangulam dilatatur, ita ut inter hane maculam et fasciam $\mathbf{V}$ inversum colore nigro inscriptum sit. Venter niger, segmentis postice flavo-marginatis, duobus intermediis in mare, ultimis tribus in foeminâ maculas binas ovatas gerentibus. Hypopygium flavum. Pedes flavi. Alae cinereo-hyalinae, adversus costam lutescentes. - (Illinois; Osten-Sacken.)

44. Chrysotoxum ventricosum nov. sp. \&. Oculis hirlis, sculello toto flavo, abdominis globosi fasciis mediocribus, modice arcuatis, a margine laterali et marginis postici limbo anguste se- 
parat is vel subseparatis, femorum anteriorum basi femoribusque posticis praeter apicem nigris, - Long, corp. 5 lin., Long. al. $5 !$ lin.

Tertius antennarum articulis duobus praecedentibus simul sumtis paulo longior. Oculi hirti. Laterales thoracis villae interruplae. Scutellum totum flavum. Abdomen globosum, fasciis mediocribus, modice arcualis, anguste inlerruptis, a margine laterali et a limbo marginis postici plerumque separatis, interdum per maculam luteam in postico segmenti angulo sitam cum ulroque conjunclis; poslicus segmenti primi margo limbum flavum aut nullum aut angustissimum habet; limbi segmentorum sequentium mediocres, ultimi in maculam triangulam dilatatus, per Y nigrum inversum a fasciâ separatam. Ullima tria ventris segmenta singula fasciam mediocrem, lalissine interruptam et limbum posticum flavos habent. Pedes flavi, basi femorum anteriorum femoribusque posticis excepto apice nigris. Alae cinereae, fusco costae limbo aequali. - (Washington.)

Nota. Chrysoloxum veulrícosum a foeminâ Chrysoloxi arcuali Linn. (horlensis Meig.), cui simillimum, basi abdominis nigropilosà facile distingnitur.

45. Microdon Mistis nov. sp. F. Niger, pallide pilosus, antennis longis fusro-nigris, fronte latissimâ, sculello billentalo, abdominis oblongo-ovati segmento paenullimo duobus praecedentibus simul sumtis subaequali. - Long. corp. $4 \frac{1}{2}$ lin., Long. al. $3 \frac{1}{2} \frac{1}{2}$ lin.

Caput aeneum nigrum, pilis ex flavo albidis vestitum, fronte latissimâ, aequali. Anlennae elongatae, nigro-fuscae, articulo primo lineari, tertio subaequali. in basi testaceo. Thorax aeneo-niger, obsolete cupreo-lineatus, pilis flavescentibus vestitus. Sculellum viridinigrum, albido-pilosum, planiusculum, apice emarginalo et ulrinque deute minuto concolore armatum. Abdomen oblongo-ovatum, punclatum, nigrum, segmento paenullimo duobus praecedentibus simul sumtis subaequali, basi marginibusque lateralibus llavo-pilosis pilisque albidis in disco ita dispositis, ut fascia late interrupta in postico segmenti tertii margine, plagae duae magnae separatae in segmento quarto duaeque minores subcontiguae in segmento quinto pilis albidis vestitae appareant. Venter flavo-pilosus, nigro-piceus, marginibus posticis segmentorum singulorum dilute llavicintibus. Pedes ni. gro-picei, femorum-basi, genibus el basali tibiarum posticarum dimiclio dilute testacejs; larsi nec dilatati nec incrassali. Alae cinereae, limbis venarum transversalium nigricantibus angustis, angulis posticis cellularum posterioris primae el discoidalis rolundalis, nou appendiculalis. - (Virginia) 
46. Microdon laetus nov. sp. $\delta$ et ㅇ. Laete viridis, chalybeo et violaceo splendens, oculis hirtis, fronte et facie angustis, ocellis a verlice remolis, antennis brevibus nigris, libiis maris favis, foeminae nigricantibus. - Long. corp. 4 lin., Long. al. $3 \frac{1}{2}$ lin.

Corpus gracile, laete viride, nilidum. Caput chalybeum; facies angusta, aequalis, pilis dilulissime flavis, prope antennas pilis nigris vestita. Antennae capite breviores, nigrae, articulo tertio primi longitudinem paulo excedente. Frons angusta, nigro-pilosa, in mare supra antennas coarclata, in foeminâ aequalis; ocelli in utroque sexu a vertice remoti. Thoracis dorsum chalybeo et cupreo splendens, plagâ discoidali cupreo-circumscriptà ornatum, nigro-pilosum, margine antico angulisque posticis tamen pallide pilosis. Scutellum nigropilosum, subconvexum, apice emarginato et utrinque denticulum nigrum gerente. Abdomen maris cylindricum, adversus apicem chalybescens; abdomen foeminae minus convexum, praeter margines fere tolum violaceum. Femora chalybea; tibiae maris descripti flavae, foeminae nigricantes el chalybeo micantes; tarsi utriusque sexus nigri. Alae cinereae, limbis nigricantibus venarum transversalium angustis, subobsoletis, angulis posticis cellularum posterioris primae et discoidalis rolundatis, non appendiculatis. - (Cuba: Gundlach.)

Nota. Microdon laetus Microdonti hrevicorni Lw. similis et affinis est, sed oculis hirtis, abdomine minus lato et tibiis multo gracilioribus differt.

47. Microdon coarctutus nov. sp. $\delta$ et 오. Gracilis, chalybeoviridis, modice nilens, oculis subnudis, fronle el facie angustis, ocellis a verlice remotis, antennis brevibus nigris, segmenti abdominalis secundi marginibus tunidis. - Long. corp. $3 \frac{1}{2}-4$ lin., Long. al. 3 lin.

Gracillimus. chalybeo-viridis, modice nitens, albirlo-pubescens. Frons aequalis, angusla, focminae paulo latior quam maris, ocellis a vertice remolis. Antennae nigrae, breves, articulo tertio praecedentibus simul sumtis paulo longiore. Thoracis dorsum aeneo-viride, subtilissime punctulatum et transversim aciculalum, vittis quatuor obscure cupreis. Scutellum ex viridi nigrum, apice emarginato et utrinque denticulo nigro instruclo. Abdomen maris cylindricum, obtusum, foeminae acutum; segmentum secundem paulo latius quam sequentia, disco depresso, marginibus lateralibus quasi tumidis. Alae cinereo-hyalinae, venarum transversalium limbis nigris, angulis posticis cellularum posterioris primae et discoidalis rotundatis, brevissime appendiculatis. (District Columbia; Osten-Sacken.) 
48. Ceria abbreviata nov. sp. §. Nigra, favo varia, pedunculo antennarum longo, abdominis cylindrici segmentis primis duobus solito brevioribus, costali clarum dimidio fusco. - Long. corp $4 \frac{1}{2}-4 \frac{3}{4}$ lin.. Long. al. $3 \frac{1}{2}-4$ lin.

Ceriae conopsoidi simillima. Nigra subopaca. Occiput nigrum; vertex praeter angulum ocelliferum flavus; frons flava, vitlâ nigrả; facies flava, vitlà tenui, lineâ transversâ genisque niggris. Antennae nigrae, pedinculo fusco, elongalo. Thorax niger, punctatus, humeris. maculâ ulrinque laterali minutâ pleurarumque maculà didymâ flavis. Scutellum flavum, basi nigrâ. margine apicali fusco. Abdomen cylindricum, praeler posticos segmentorum margines scrobiculatum, atrum, lateribus segmenti primi marginibusque posticis segmenlorum secundi et quarli latius, terlii angustius flavis. Нуроpygium atrum. Pedes interdum nigri, femorum basi fuscâ, genibus et imâ tibiarum basi flavis, saepius nigro-fusci inveniunlur, femorum basi et apice tibiarum tarsisque anlerioribus testaceis vel ex fusco testaceis. genibus tibiarumque basi flaris. Alae hyalinae, dimidio costali adversus basim dilutius, adversus apicem saturatius fusco. - (Penusylvania.)

Nota. Ceria abbreviala sceundum abdominis segmenlum multo brevius quan Ceria conopsoides hibet.

45. Empis laevigata nov. sp. o. Nitida, tola atra, nigropilosa; oculi contigui; halterum capitulum flavesrens; alue dilute subfuscae, stigmale paulo saluratiore, subosoleto: hypopygium clansum, filamento rentrali oblecto: venter ante hypopygium apophysi-

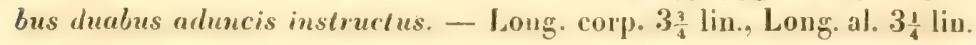

Tola alra. nitida, nigro-pilosa. Oeuli contigui. Antennae tenues, nigrac. Proboscis nigra, supra ex parte fusca, tibiis anlicis longior. Thoracis dorsum nigro-pilosum, polline cinerascenle obsoletissime aspersum. Scutellum convexum, praeter setas marginales sex nudum. Pleurae et coxae cinereo-pollinosae, subopacae. Abdomen nigro-pilosum. Hypopygium deflexum, clausum. filamento centrali obtecto. Venter ante hypopygium apophyses duas incurvas, pilis nigris barbatas habet. Pedes simplices. tenues, pilis brevibus setisque tenuibus nigris vestili. Iallerum capitulum flavesəens. Alac dilute subfuscae, stigmale subfusco, venis fuscis. (New IIamphire; Osten-Sacken.)

50. Eimpis stenoptera. nov. sp. on el f. Tenuis, nudiu. senla. opara, ex albo cinerascens. viltis quatuor thoraris sulfuscis; 
antennae nigrae; proboscis brevis; pedes graciles, fusci, femorum tibiarnmque basi hutet, tarsis nigris; alae anguslae, cinereo-hyalinae, venis nigro.fuscis, stigmale obsolelo. - Long. corp. $1 \frac{1}{1} \frac{1}{2}$ lin., Long. al, $2 \frac{5}{12} \operatorname{lin}$.

Tenuis, nudiuscula, opaca, ex albo cinerascens, abdomine foeminac minus albicante. Caput concolor. Oculi maris separati. Antennae tenuissimae, nigrae. Proboscis nigra, capite longior, sed femoribus anticis brevior. Thoracis dorsum subfusco quadrivittatum, vittis intermediis poslice, lateralibus antice valde abbreviatis. Hypopygium maris clausum, nigrum. lamellis inferis testaceis, filamento centrali oblecto. Coxae albido-cinereae, apicem versus dilute lutescentes. Pedes graciles. fusci, femorum basi et latere infero libiarumque basi luteis, tibiis apicem versus tarsisque totis nigris. Hal. teres dilute ffavescentes. Alae anguslae, cinereo-hyalinae, stigmate obsoleto, venis fuscis. - (New Hampshire; Osten-Sacken.)

51. Empis longipes nov. sp. すૅ. Flava, antennis gracilibus nigris, capite et dorso thoracis cinereis, hoc fusco-quadriviltato, abdominis villa mediá segmentorumque singulorum marginibus poslicis nigricantibus, tarsis nigris; hypopygium flavum, filamento centrali crassissimo, praeter basim obtecto; alae ex luteo cinereae, stigmate concolore, obsoletissimo. - Long. corp. $2 \frac{3}{4}$ lin., Long. al. $3 \frac{1}{4}$ lin.

Tenuis, mdiuscula, llavicans, supra obscurior. Caput nigrum, polline albo cinereum. Frons angustissima. Antennae tenuissimae, nigrae, stylo terminali mediocri. Proboscis primis duobus tarsorum anticorum arliculis simul sumtis subaequalis. Thorax lulescens; dorsum cinereum, opacum, villis qualuor anguslis fuscis, intermediis postice, lateralibus aulice valde abbrevialis, pilis minulis setisque nigris rarissimis. Scutellum lutescens. Abdomen nilidun, luteum, vittà mediâ segmenlorumque singulorum marginibus posticis nigricanlibus. Hypopygium mediocre, flavum, ringens, apice nigrobarbato, filamento centrali crassissimo, concolore, practer basim obtecto. Pedes longi, graciles, flavi, breviter nigro-pilosuli, tarsis ex nigro fuscis, arliculis primis in apice, reliquis lolis nigris. Alae ex luteo cinereac, venis ex fusco luleis, stigmate concolore, obsoletissimo. - (Lake George N. Y.; Osten-Sacken.)

52. Empis rufescens nov. sp. O. Flava, supra rufescens, capite cinereo, primis larsorum articulis in apice, reliquis lotis nigris; vculi subconligui; hypopyginm longiusculum, uscendens, filu- 
mento centrali longo, exserto; alae ex huteo rinerene. stigmate dilutissime subfusco. - Long. corp. $3 \frac{1}{\frac{1}{2}}$ lin., Long. al $3 \frac{1}{3}$ lit.

Flava, supra rufescens. Thorax subopacus, abdomen nitidum. Caput nigrum, polline albo cinereum. Oculi in fronte subcontigui. Antennae mrdiocres, validiusculae, articulis primis duobus rufis, tertio nigro, stylo terminali mediocri. Proboscis flava, tibiis anticis longior. Thoracis torsum pilis selisque raris nigris instructum. Hypopygium flavum, longiusculum, ascenden clansum. lamellis inferis elongalis, superis parvis, breviter ovatis, filamento centrali exserto, infero, tenui, arcuato, flivo. Pedes graciles, pilis setulisque brevibus nigris vestiti. flavi, articulis tarsorun primis duobus in apice, ultimis tribus tolis nigris. Alae ex luteo cinereae, venis fuscis, alversus costam et basim ex fusco luteis, sligmate dilutissime subtusco. - (New Ilampshire; Osten-Sacken.)

53. Rhamphomyia umbrosa nov. sp. o et ㅇ․ Nigva, nigro-pilosa; hypopygium parvum, ascendens, apice badio, filamento centrali mire incrassato, atro, praeter basim obfecto: alae ex fusco nigrae, Gasi hutescente. - Long. corp. $2 \frac{3}{4}$ lin., Long al. $3-3_{1}^{\prime} \frac{1}{2}$ liu.

Tola nigra, nigro-pilosa, supra polline cinereo leviter aspersa. Oculi conligui. Antennae mediocres, nigrae, articuli secundi margine apicali obsolete fusco, articulo tertio oblongo-lanceolato, slylo terminali brevissimo. Proboscis nigra, femoribus anlicis aequalis; palpi concolores. Abdomen compressum; hypopygium parrum, ascendens, clausum, nigrum, apicem versus badium; filamentum centrale inferum, crassissimum, atrum, nilidum, praeler basim oblectum. Pedes simplices, pilis selisque nigris insiructi. Halleres ex luteo subfusci. Alae ex fusco nigrae, basi lutescente, stigmate nigro; alae foeminae modice dilatalae. - (New Hampshire; Osten-Sacken.)

54. Rhamphomyia basulis nov. sp. 우. Cinerea, ventre, coxis pedibusque dilute lutescentibus, tibiis apirem versus tarsisque totis ex nigro fuscis, tibiis posticis breviter syuamato-cilialis; alae dilatalae, nigrae, basi hyaliná. - Long corp. $2-2 \frac{1}{12}$ lin., Long. al. $2 \frac{3}{6} \operatorname{lin}$.

Cinerea, opaca. Caput ex albo cinereum; antennae nigrae, longiusculae, anguslae, articulis primis duobus breviler nigro-pilosis, articulo terlio oblongo-lanceolato, stylo terminali mediocri. Proboscis fusca, femoribus anticis paulo brevior. Thoracis dorsum subfusco obsolete trivitlatum, pilis brevibus selulisque raris nigris instructum: Abdomen ex fusco cinereum, subnitens, ventre fere toto 
pallido; stylianales longiusculi, lineares. Coxae ef pedes dilule lutescentes; femora apicem versus obsolete subfusca; tibiae adversus apicem nigro-fuscae, posticae leviter compressae, utrinque pilis nigris modice dilatatis cilialae. Halteres exalbidi. Alae valde dilalatae, nigrae, basi hyalinâ, stigmate obsoletissimo - (New Hampshire; Osten-Sacken.)

55. Rhamphomyia macilent a nov. sp. ఫ־. - Cinerea, opaca, thorace obsoletissime villato, abdomine nigro, nitido, hypopygio parvo concolore, filamento centrali crasso, praeter basim obtecto; oculi se. parati; antennae longae, nigrae; pedes lutei, extremo libiarum apice infuscato, tarsis ex fusco nigris, femoribus infra nigro-setulosis; hallerum capilulum albicans; alae angustae, cinereo-hyalinae, stigmate subfusco, venis fuscis. - I.ong. corp. $2 \frac{5}{1} \frac{1}{2}$ lin., Long. al. $2 \frac{7}{3} \frac{1}{2} \operatorname{lin}$.

Macra, cinerea, opaca, nudiuscula. Caput concolor, oculis per frontem latam separatis. Antennae longae, tenues, nigrae, articulis primis duobus breviter nigro-pilosis, terlio sublineari, stylo terminali mediocri. Proboscis fusca, femoribus anticis brevior; palpi lutei, apice fusco. Thoracis dorsum vittis obscurioribus obsoletissimis vel nullis, pilis setisque nigris brevibus et raris. Abdomen nigrum, nitidum, supra pilis nigris, utrinque et infra pallidis vestilum. Hypopygium nigrum, parvum, lamellis omnibus brevibus, ovatis, breviler nigro-pilosis, flamento centrali crassissimo, prater basim obtecto. Coxae luteae, anticae basim versus subfuscae. Pedes lulei, breviter nigro-pilosi, femoribus infra nigro-selulosis, extremo tibiarum apice infuscato, tarsis ex fusco nigris. - Alae angustae, cinereo-hyaliuae, stigma!e subfusco, venis fuscis, basim versus lutescen. tibus. - (New Hampshire; Osten-Sacken.)

Nota. Focminam unam possideo, quae forlasse uxor Rhamphomyiae macilenlae est, sed a mare, quem descripsi, differt vitlis dorsalibus tribus distinctis et capitulo halterum fusco. Altera foemina cum hac congruit quidem, sed et coxas omnes practer apicem infuscatas et femorum apicem fuscum habet; tibiarum color jam inde a medio in fuscum abit. Pili pedum utriusque foeminae non differunt, nec alii sunt, quam quales in foeminâ ejus modi maris expeclaveris. Duae aliae foeminae ab eà, quam altero loco notavi, non recedunt nisi alis magis obscuratis pal. pisque nigro-fuscis. 
56. Rhamphomyia rustica nov.sp. ot et + . Capite, thorace non villato scutelloque cinereis, abdomine lutescente, segmentis vel posticis vel omnibus praeter marginem posticum piceis vel nigris; antennae favae, articulo tertio praeter basim nigro; coxae lulescentes, ravius excepto anticorum apice picene; pedes untici lutei, tarsis niguis; pedes postici in speciminibus maluris toli nigri. in immaturis ex parte, interdum maximá ex parte dilute lutescentes. ๙. oculi contigui; filamentum centrale hypopygii flexuosum, prope basim fractum.

‥ styli anales longinsculi. lineares.

Long. corjo. $2 \frac{1}{6}-2 \frac{1}{3}$ lin., Long. a1. $2 \frac{5}{1} \frac{5}{2}-2 \frac{7}{1} \frac{1}{2}$ lin.

Caput obscure cinereum, nigro-pilosum, oculis maris contiguis. Antennae graciliores, dilute flavescentes, articulo terlio praeter ba. sim nigro, stylo terminali mediocri. Proboscis fusca, coxis anticis paulo longior; palpi lulei, apice obscure fusco, inlerdum toli fusci. Thorax cinereus. vittis obscurioribus nullis, pilis selisque raris nigris. Sculellum concolor. Abdomen in speciminibus nuper exclusis luteolum, segmentis ultimis praeler marginen posticum piceis; specimina matura practer margines segmentorum singulorum posticos totum abdomen nigrum habent. Coxac plerumque lutescentes, non nunguam solo anticarum apice excepto piceae; pedes antici lutescenles, femorum basi, tibiarumque apice inferdum infuscatis. larsis semper nigris; pedes posticos specimina maluna tolos nigros, iumalura saepe maximâ ex parte lutescenles habenl, tibiarum apice tamen tarsisque semper obscuris. Halteres dilute flavescentes. Alae cinereo-hyalinae vel cincreae, venis fuscis el stigmale subfusco; ba. sis venae tertiae plerumque umbrù subfuscá circunfusa esl. - New Hampshire; Oslen-Sacken.)

57. Rhamphomyia luteiventris, nov. sp. đ̆. Cinerca, viltis thoracis tribus nigricantibus, abdomine supra nigro, infra dilute favicante, coxis pedibusque flavicantibus, tibiis anterioribus in apice subfuscis, posticis exceplà basi tarsisque omnibus nigris; oculi contigui; antennae nigrae, arliculo secundo fusco; probosris coxis anticis puulo longior; hypopygium nigrum, lamellis intermediis subovatis, superis lanceolatis, porrectis. filumento centrali flexuoso; alue cinereo-hyalinae. - Long. corp. $2 \frac{1}{4}$ lin. Long. al. $2 \frac{1}{4}$ lin.

Caput obscure cincreum. orulis conliguis. Antenne graciles, nigrae, articulis primis duobus breviler nigro-pilosis, secundo practer basion fusco, stylo terminali breviusculo. Proboscis fusca, coxis anticis paulo longior. Thorax cinereus, opacus, vitlis tribus nigris 
subobsoletis, pilis selisque raris nigris, Sculellum concolor. Abdomen supra nigrum, nitidum, ulrinque et infra dilule flarescens. Hypopygium mediocre, nigrum, ringens, lamellis intermediis subovatis, obtusis, superis lanceolatis, porrectis, omnibus nigro-pilosis, filamento centrali luteo, tenui, flexuoso, prope basim non fracto. Pe. des cum coxis dilute flavicantes, nigro-pilosi; tibiae anteriores in apice nonnihil fuscescunt; libiae posticae praeter basim et tarsi om. nes nigri. Halteres dilute flavicantes. Alae cinereae, venis fuscis, stigmate subfusco. - (New Hampshire; Osten-Sacken.)

Nota. A Rhamphomyiâ mutabili ventre pallido, coxis dilutiori-

bus et oculis maris conliguis differt.

58. Rhamphomyia nigricans nov. sp. ऊ. Tota nigra, opaca, nigro-pilosula, thorace el abdomine polline albido cinerascentibus; oculi conligui; proboscis mediocris; alae hyalinae, venis tenuibus fuscis, sligmate subobsoleto; hypopygium nigro-pilosum, filamento centrali flexuoso. - Long. corp. $1 \frac{1}{2}$ lin., Long. al. $1 \frac{1}{2}$ lin.

Tola nigra, antennis, proboscide, palpis, halteribus pedibusque concoloribus. Caput nigro-pilosum; oculi contigui; antennae tenues; proboscis coxis anticis longior. Thorax polline raro albido subcinerascens, vitlis tribus obscurioribus obsoletis, nigro-pilosus. Scutellum concolor. Abdomen polline conferliore albido aspersum, obscure cinerascens, nigro-pilosum. Hypopygium nigrum, nigro-pilosum, filamento centrali concolore, tenui, flexuoso. Pedes simplices, pilis selisque tenuibus nigris vestiti. Halteres nigri. Alae hyalinae, costâ venisque costae vicinis nigris, venis reliquis obscure fuscis, stigmate cinerascente, subobsoleto. - (New Hampshire; OstenSacken.)

59. Rhamphomyia hirtipes $\sigma^{\star}$. Nigra opaca, antennis, proboscide mediocri, halteribus, hypopygio pedibusque concoloribus; alae hyalinae, venis tenuibus fuscis, stigmate subobsoleto; pili et setulae corporis nigrae, pili breviusculi in lateribus abdominis et ventre dilutissime lutescentes, pili longiusculi in hypopygio et in tibiis posticis (harum basalibus tamen exceptis) paulo saluratius luteoli. - Long. corp. $1 \frac{1}{2}$ lin., Long. al. $1 \frac{1}{2} \mathrm{lin}$.

Minuta, nigra, opaca pilosula. Caput concolor, nigro-pilosum, oculis separatis. Antennae mediocres, nigrae; proboscis nigra, coxis anticis paulo longior; palpi nigri. Thorax nigro-pilosus, vittis tribus obscurioribus obsoletis, pleuris levissime albido-pollinosis. Abdomen opacum, pilis dorsalibus nigricantibus, lateralibus ventrali- 
pilis dorsalibus nigrieantibus. lateralibus ventralihusque dilutissime lutescentihus. Hypopygium concolor, subglobosum, pilis longiusculis luteolis instructum. filamento centrali obscuro. tenui. arcuato. Pedes toti nigri. pilis longioribus et confertioribus nigris vestiti; pili tibiarum posticarum reliquis longiores, prope tihiarum basim nigri, in tibiis reliquis sordide luteoli. Halteres nigri. Alae hyàlinae. costâ venisque primis nigris, reliquis ex nigro fuscis, stignale cinereo. subohsoleto. - (New Hampshire; Osten Sacken).

60. Rhamphomyia irregularis nov. sp. ㅇ. Albo-pollinosn. thorare obsolete bivittato, abdomine candido micante, pedibus totis nigris, alis albidis, cellulà discoidali maximâ. - Long. corp. $1 \frac{7}{12}$ lin. Long. al. $1 \frac{2}{3}$ lin.

Nigricans, confertim albo-pollinosa, nudiuscula. Caput concolor, antennis brevibus nigris. Proboscis nigra. cosis anticis paulo longior. Thoracis dorsum olssolete cinereo bivillatun, pilis selulisque rarissimis nigris. Scutellum concolor. Abdomen candido-micans, praeter basim albido-pilosam subnudum, extremo apice cum stylis analibus nigro. Pedes cum coxis nigri, brevissime nigro. pilosuli. Halteres albi. Alae albidae, venis validiusculis dilutissime llavicantibus. apicem versus paulo obscurioribus, costà et venae primae apice atris, stigmate subobsoicto; cellula discoidalis elongata, permagna; cellulae posteriores secunda et terlia parvae. (New Hampshire; Osten-Sacken).

Nota. Rhamphomyiam irreularem leucopterae uxorem esse crederen, nisi pili omnes multo breviores, pili abdominis omnes albidi alarumqque venae crassio:es essent.

61. Rhamphomyia candicans nov. sp. ㅇ. Ex cineren albicans, antemnis nigris, proboscide brevi, coxis pedibusque flavis, tibiis anterioribus adversus apicem, posticis praeter basim tarsisque omnibus ex fusco nigris; alae exalbidae. stigmate obsoleto. - Long. corp. 2 lin., Isong. al. $1 \frac{1}{1} \frac{1}{2}$ lin.

Ex cinereo albicans, opaca, nudiuscula. Caput concolor, antenuis mediocribus nigris. Proboscis nigra, coxis anticis longior. femoribus brevior. Thorax non villatus. pilis setulisque minutis. raris, nigris. Scutellum concolor. Abdomen albido-pilosum, adversus apicem subnudum. Coxae flavicantes, posticarum basi cinereâ. Pedes flavicantes, nigro-pilosuli setulisque nigris rare aspersi. tibiarum anteriorum apice infuscato. tibiis posticis tarsisque omnibus ex fusco nigris. Halteres albidi. Alae albidae, venis concolo. 
ribus, costâ et venae primae apice nigris, stigmale obsoleto. (New Hampshire; Osten-Sacken).

62. Hilara tristis nov. sp. ơ et + . Nigra, opaca, nigropilosa, halteribus pedibusque concoloribus, genibus testaceis, alis nigricantibus, metatarso antico maris modice incrassato. - Long. corp. 2 lin., Long. al. $2 \frac{1}{2}$ lin.

Tota nigra, nigro-pilosa, opaca, antennis, capite, hypopygio, halteribus pedibusque concoloribus, halterum pedunculo genibusque testaceis. Frons tota velutina. Thoracis dorsum polline rarissimo, dilute cinereo aspersum, villis tribus obscurioribus subobsoletis. Pedes graciles, pilis brevibus selisque raris nigris vestiti, melatarso maris antico modice incrassato, oblongo, praeter pilos ordinarios supra selulas tres vel quatuor gerente. Alae nigricantes, stigmate nigro. - (New Hampshire; Osten-Sacken).

63. Hilara seriata nov. sp. $\sigma$. Cinerea, nigro-pilosa, abdomine nigro, antennis nigris, palpis, halteribus, coxis pedibusque testaceis, tibiis anticis adversus apicem, reliquis praeter basim fuscis, tarsis ex fusco nigris; primus tarsorum anticorum articulus incrassatus; tibiae intermediae pilis longioribus erectis hirtae; alae cinereae, stigmate subnigricante.- Long. corp. $1 \frac{1}{4}$ lin., Long. al. $1 \frac{3}{4}$ lin.

Frons atra, vittulâ ab antennis ascendente nigrâ. Antennae nigrae; palpi testacei. Thorax cinereus, opacus, vittis nullis, pilis setulisque nigris in series regulares dispositis. Scutellum concolor. Abdomen nigrum, modice nitens, nigro-pilosum. Pedes cum coxis testacei, tibiis anticis adversus apicem, posterioribus praeter basim fuscis, tarsis omnibus ex fusco nigris; metatarsus anticus incrassatus, ovatus; tibiae intermediae pilis erectis el paulo longioribus hirtae. Halteres testacei. Alae cinereae, stigmate ex cinereo subnigricante. - (New Hampshire; Osten-Sacken).

Nota. Simillima Hilarae gracili, sed pili thoracis in series regulares dispositi tibiarumque intermediarum hirsulies differentiam demonstrant.

64. Hilara testacea nov. sp. ठ․ Obscure lutea, opaca, capite, abdominis fasciis, hypopygio et tarsis nigricantibus. breviter et rare nigro-pilosa, tibiis intermediis tamen infra pilos longiores gerentilus; metatarsus anticus incrassatus; alae cinereae, adversus costam lutescentes, stigmale subfusco. - Long. corp. $1 \frac{1}{3}-1 \frac{5}{12}$ lin., Long. al. 2 lin. 
Obscure lutea, opaca, pilis nigris lirevioribus rarioribusque vestita. Caput nigrum. polline alhido cinerascens. Antennarum articuli basales ex fusco lutei, tertius cum stylo niger. Palpi lutei. Abdomen fasciis basalibus segmenlorum singulorum nigricantibus, in segmentis primis plerumque obsoletis, cingulatum. Pedes reliquo corpore paulo dilutiores. Iarsis tolis fuscis, tibiarum posticarum apice interdum infuscato; metatarsus anticus incrassatus; libiae inlermediae infra pilis longis ins/ruclae. Halteres lutescenles. Alae cinereae, adversus costam lulescentes, stigmate subfusco. - (New Ilampshire; Osten-Sacken).

Nota. Cavendum ne cumı Iilarâ luteâ commisceatur, quae alas minus cinereas tibiasque intermedias infra breviter pilosas habet.

65. Hormopeza brevicornis nov. sp. o' et $q$. Obscura, farsorum anticorum articulis oblongis, longitudine decrescentibus. - tertio antennorum articulo globoso, alis exalbidis, stigmate nullo. Long. corp. $1 \frac{2}{3}-1 \frac{3}{4}$ lin., Long. al. $1 \frac{5}{6}$ lin.

Capul nigrum, oculis maris contiguis. Frons supra antennas nilida. Antennae brevissimae; articuli primi Juo breves, flavicaules; articulus tertius globosus, niger; slylus terminalis brevis, niger, articulo basali crasso, apicali tenui. Proboscis brevissima, crassa. oblusa, nigro-fusca; palpi minuli, recurvi, sordide albicantes. Thorax niger, cincreo-pollmosus, opacus, pilis pallidis veslilus. Scutellum concolor. Abdomen nitrum, nilidum, pallide pilosum, hypopygio concolore. Pedes fusci. coxarum apice, imá femorum basi genibusque plerumque luteis. Hallerum capitulum subfuseum. Alae exalbidae, venis pallidis, sligmate nullo. - (Yakon River; Kennicol).

66. Hormopeza nigricans nov. sp. ठ’. Nigra, tarsorum anticonum artimlis oblongis, longitudine decrescentibus, tertio antennarum articulo orali, alis rinerro-hyalinis, stigmate fusco. Long. corp. '2 $\frac{1}{\frac{1}{2}}$ lin. Long. al. $2 \frac{1}{1} \frac{1}{2}$ lin.

Tota nigra, pallide pilosa. Caput roncolor, oculis contiguis. Antenmae breves, nigrae, articulo tertio ovali, styli brevis articulo hasali crasso. apicali tenui. Proboscis hrevissima. crassa. obtusa. ex fuseo nigra: palpi minuli, recurvi. sordide albidi. Thoras cinereopollinosus. opacus. Sculellum concolo". Abdomen nigrum. nitidum. hypopygio roncolore. Perles nigri. exarum apice genibusque extremis luteis. Hallerum rapitulum ex fuseo nigrum. Alae cinereo-hyalinat. stigmate venisque fuseis. - (Vukon River: Kennicot). 
Nota. Hormopezae brevicornis et nigricans ab Hormopezâ ohliteratả distinguuntur farsorum anticorum structurâ, quos Zetterstedtius in Hormopezâ obliteratâ moniliformes esse affirmat. quum illae articulos eorum oblongos habeant. Ceteras notas, quas Zetterstedtius generi Hormopezae tribuit, iis esse constat, unde dubitatio nulla, quin in hoc genere ponendae sint

67. Gloma rufa nov. sp. ‥ Flava, supra mescens, cayite cinereo, antennarum articulo terminali et selâ nigris, tarsis apicem versus fuscis. - Long. corp. $2 \frac{1}{2}$ lin., Long. al. 3 lin.

Flava, supra rufescens, nigro-pilosa. Caput nigrum, polline albo cinereum, facie fere tolâ, proboscide palpisque flavis. Primi duo antennarum articuli breviusculi, flavi, nigro-pilosi; articulus tertius niger, ovatus, apice subacuto, setâ crassiusculâ concolore. Tarsi apicem versus fusci. Alae ex cinereo lutescentes, stigmate paulo saturatius tincto, venis ex fusco luteis, adversus basim et costam luteis. - (New Hampshire; Osten-Sacken).

68. Gloma obscura nov. sp. $\sigma^{\top}$. Nigra, halleribus, abdominis basi pedibusque ex testaceo flavis, ullimis duobus tarsorum articulis nigris. - Long. corp. $2 \frac{5}{12}$ lin., Long. al. $2 \frac{1}{1} \frac{1}{2}$ lin.

Nigra, nigro-pilosa. Caput concolor, proboscide fuscâ, palpis nigricantibus. Antennae nigrae, articulis primis duobus breviusculis. nigro-pilosis, tertio breviter ovato, selà crassiusculâ concolore. Abdomen nitidum, nigrum vel fusco-nigrum, basi utrinque ex testaceo flavâ, subpellucidâ. Coxae et pedes flavicantes, femoribus tibiisque posticorum apicem versus infuscatis, ultimis duobus tarsorum articulis nigris. Halteres flavescentes. Alae ex cinereo subfuscae, stigmate paulo obscuriore, venis fuscis. - (New Hampshire; OstenSacken).

69. Cyrtoma femorata nov. sp. ‥ Atra, thorace cinereopollinoso, tibiis posticis luteis, upicem versus atris, tertio antennarum arliculo lanceolato, femoribus posticis incrassatis. - Long. corp. $1 \frac{1}{2} \frac{1}{2}$ lin., Long. al. 2 lin.

Atra, antennis concoloribus, articulo tertio lanceolato. Thorax cinereo-pollinosus, subopacus; scutellum concolor. Pili thoracis et scutelli rari, nigri. Abdomen nitidum, pilis raris albidis aspersum, segmentis singulis in dimidio anteriore obsolete cinereo-pollinosis. Pedes longi, atri, nigro-pilosi, extremo coxarum apice genibusque extremis testaceis; femora postica incrassata; tibiae anticae validi- 
usculae, prope basim crassiores; tibiae posticae crassae, oblique truncatae, luteae, apicem versus nigrae. Halleres sordide albicantes. Alae ex fusco cinerea, venis fuscis, stignate obsoletiore subfusco. - (New Hampshire; Osten Sacken).

Nota. Nomeu generis apud Graecos nentrum est. sed ab usu, qui adhuc obtinuit apud diplerologos, nunc quidem cedere nolıi.

70. Cyrtoma procera nov. sp. ․ Atra, thorace cinereojollinoso, tibiis posticis luteis, apicem versus atris, tertio antennarum articulo lanceolato. femoribus posticis incrassutis. - Long. corp. $2 \frac{1}{6}$ lin., Long. al. $2 \frac{1}{4}$ lin.

Atra, antennis concoloribus, articuli tertii dimidio basali latiusculo et ovato, apicali tenui el subulato. Thorax leviter cinereopollinosus; scutellum concolos. Pili thoracis et scutelli nigri. Abdomen nitidum, pilis albidis aspersum. Pedes longi, atri, nigropilosi, coxarum apice genibusque luteis; femora postica incrassala; tibiae anticae validiusculae, basim versus vix crassiores; tibiae posticae crassae, oblique truncatae, luteae, apicem versus nigrae. Halteres sordide albicantes. Alae ex fusco cinereac, venis fuscis, stigmate obsoletiore subfusco. - (Sitka; Kolenati).

Nota. Speciei praecedenti similis, sed major antennarumque figurâ diversa.

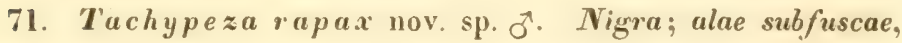
in basi albae, venulà transversâ basali posteviore instructae; femora untica nigro-maculata, infra pilis pallidis ciliata, tibiae intermediae infra prope apicem breviter excisae. - Long. corp. 1 $\frac{5}{12}$ lin.. long. al. $1 \frac{5}{1} \frac{-}{2}$ lin.

Simillima Tachypezae truncorum. Caput nigrum, subcinerascens; anteunae flavae, articulo tertio saepe fusco; palpi albi; pro. boscis nigra. Thorax niger, dorso et sculello subopacis, pleuris nilidis. Abdomen plerumque ex fusco nigrum, in speciminibus immaturis adversus basin sordide lutescens. Venter concolor, margine postico segmenti ullimi pilis longiuseulis nigris ciliato. Hypo. pygium uigrum nilidum, supra pilis brevissmis hirtum. Coxae flavae, anticae prope apicem maculâ rolundâ nigrâ notatae. 'Trochanteres antici llavi. infra nigri. Femora antica crassissima. llava. in latere posteriore prope apicem puncto el atomo, in lalero anteriore maculâ triangulâ basali, lineolis subtribus intermediis per puncta conjunctis ef puncto subapicali. omnibus nigris variegata. infra pilis pal- 
lidis, tenuibus et longiusculis ciliata. Femura intermedia crassa. flava. Femora postica fusca vel nigro-fusca, basi flavâ, latere supero ex flavo testaceo. Tibiae anticae crassae, fuscae, sed latere supero toto et infero praeter apicem dilutissime flavicantibus. Tibiae intermediae fuscae vel subfuscae, supra et iufra praeter apicem dilute flavicantes, ante apicem infra leviter excisae. Tibiae posticae dilute flavicantes, triente apicali nigro. Tarsi antici dilute flavicantes, articulo primo infra fusco, ultimis duobus nigris. Tarsi intermedii pallide flavicantes, articulis ultimis duobus nigro-fuscis. Tarsi postici ex nigro fusci-articulis primis duobus praeter apicem nigricantem exalbidis. Alae infuscalae, basi albidâ et venulà transversà basali posteriore manifestà; cellula posterior prima submarginali paulo latior; venae longitudinales terlia et quarta subparallelae, quartae apice tamen paulo recurvo. - (Illinois: Le Baron).

Nota. Foeminam possideo in marium supra descriptorum societate captam, quae coxas anticas immaculatas, femora antica tota flavicantia utrinque atomo subapicali nigro notata, femora intermedia minus crassa et fuscum posticorum colorem minus extensum habet quam mas, quocum in reliquis notis congruit.

72. Tachypeza rostrata nov. sp. J. Nigra, proboscide pedibusque flavis, femoribus posticis tibiisque omnibus ex parte flavis, harum intermediis infra prope apicem leviter excisis; alue subfuscae, in basi albae, venula basali posteriore instruclae. - Long. corp. $1 \frac{1}{2}$ lin., Long. al. $1_{\frac{1}{2}}^{\frac{5}{2}}$ lin.

Caput nigrum; antennae flavicantes, articuto terlio subfusco; palpi albi; proboscis flava, extremo apice nigro. Thoracis dorsum et scutellum nigra, subopaca; pleurae nigrae, nitidae. Abdomen ex fusco nigrum, basi dilutiore, hypopygio nigro, nitido, pilis longioribus non instructo. Pedes cum coxis flavi. Femora antica valde incrassata; intermedia crassa; postica tenuia et praeter apicem et basim fusca. Tibiae anticae modice crassae, supra et infra flavicantes, utrinque subfuscae; tibiae intermediae utrinque fuscae, supra flavicantes, infra subfuscae vel flavicantes et prope apicem levissime excisae; tibiac posticae basi lantum extremâ exceptâ fusco-nigrae. Tarsi dilute flavicantes, adversus apicem ex fusco nigri. Alae praeter basim albidam infuscatae, venulâ transversâ basali posteriore manifestâ sed brevi, venis longitudinalibus tertiâ et quartâ subparallelis. quartae apice tamen leviter recurvo. - (New Hanipshire).

73. Tachypeza clavipes nov. sp. ठ․ Atra, nitida, pedi. bus concoloribus, tibiarum anticarum apice valde incrassato; alae 
praeter basim albidam nigricantes, venulá transversâ basali posteriore instructae. - Long. corp. $1 \frac{1}{3}$ lin., Long. al. $1 \frac{1}{3}$ lin.

Caput nigrum; antennae nigro-fuscae; proboscis nigra; palpi albi. Thorax ater, nitidus, lineâ dorsi mediâ cinereo-pollinosâ. Abdomen fusco-nigrum, hypopygio atro, supra pilis brevibus nigris hirto. Coxae atrae, extremo apice piceo, anticae albo-pollinosae. Pedes atri, nitidi, tibiis anticis supra piceis tarsorumque posteriorum basi testaceâ. Femora antica modice incrassata, infra pilis longiusculis albis ciliata; tibiarum anticarum apex valde incrasstus. Femora intermedia posticis paulo crassiora, infra prope basim setulis aliquot nigris praedita; tibiae intermediae simplices. Halteres albi. Alae venulà transversâ basali posteriore instructae, praeter basim albidam nigricantes. liturâ obsoletâ cinerascente inde a basi usque in cellulam posteriorem secundam pertinente; venae longitudinales tertia et quarta subparallelae, apice quartae obsolete recurvo. - (Illinois; Le Baron).

Nola. Foeminae duae, unâ cum mare descriplo captae, eandem alarum picturam eundemque venarum cursum ostendunt, sed antennis praeter apicem infuscalum flavis. thoracis dorso toto polline cincreo leviter asperso et minus nitido, coxis omnibus dilute flavicantibus, femoribus anterioribus infra ef antice flavis, tibiis anterioribus fuscis supra flavicantibus, tibiis posticis praeter apicem nigrum et basim subfuseam flavicantibus, et tarsis anlerioribus praeter apicen pallidis diserepant. - In. certum est, utrum eadem alarum pictura eademque venarum configuratio has foeminas $\mathrm{cum}$ mare congregari jubeant, an valeat notarum reliquarum diversitas

76 Tachypeza pusilla nov. sp. ․ Nitida, atra, proboscide palpisque concoloribus, pleurarum maculí albicante mullà, pedibus luteo el nigro variis; alue cinereae, dimidio costali inde a venae terliae origine usque ad apicem infuscato. venuli transcersá basali posteviore nullî. - Long. corp. $\frac{1}{1} \frac{1}{2}-1$ lin. Long. al. ${ }_{6}^{5}$ lin.

Minuta, atra, nitida. Caput atrum, proboscide et palpis concoloribus. Primi duo antennarum articuli fusci; articulus terlius in speciminibus descriptis deest. Thorax tolus ater, nitidus, scutello, concolore. pleuris immaculalis. Abdomen latinsculum, atrum, nilidum. Coxae luteae. Pedes antici lutei, lemoribus tibisque suprat. tarsis totis nigro-fuscis. Pedes intermedii cum anticis concolores. tibris tolis tamen fusco-nigris, femoribus infra nigro-setulosis. Pedes postici praeter luteam femorum basim fusco-nigri. inci larsorum 
basi rarius luteâ. Halteres albidi. Alae latiusculae, subcinerascentes, dimidio costali inde a venae tertiae basi usque ad apicem infuscato, venis longitudinalibus tertiâ et quartâ parallelis, venulà transversâ basali posteriore nullả. - (Illinois; Le Baron).

Nota. Variat femoribus anticis supra minus infuscatis.

75. Platypalpus aequalis nov. sp. of et \&. Niger, nilidus, tharacis dorso polline cinereo, pleuris praeter plagam inferam polline albido opacis, pedibus fluvis, singulis tarsorum arliculis in apice nigris; antennae nigrae, articulo tertio lanceolulo; palpi testacei; cellulae alarum basales prima et secunda aeguales; vena longitudinalis sexta basim versus abbreviata. - Long. corp. $1 \frac{1}{4}$ lin., Long. al. $1 \frac{5}{6}$ lin.

Caput cinereun, fronte et facie albidioribus. Antenuae nigrae vel fusco-nigrae, articulo tertio lanceolato. Palpi teslacei, vel subfusci; proboscis nigra. Thoracis dorsum et scutellum polline cinereo opaca. Pleurae praeter plagan nigram inferam, inter coxas anticas et intermedias sitam, polliue ex cinereo albido aspersae. Abdomen nigrum, nitidum, veutre maris plerumque toto concolore, foeminae luteo, apicem versus nigro; hypopygium nigrum nitidum. Pedes cum coxis flavi, articulis singulis tarsorum in apice nigris, articulo ultimo tolo nigro; femora antica valde incrassata, intermedia anticis crassiora, infra praeter pilos longiores flavicantes setulis nigris ciliata; dens apicalis tibiarum intermediarum magnus. Alae ex cinereo sublutescentes, venis liteis, apicem versus paulo obscurioribus, longitudinali tertiâ apicem versus vix levissime incurvâ, quartae subparallelâ; cellulae basales prima et secunda aequales; venula transversa basalis posterior integra, sed adversus finem posteriorem tenuior; vena longitudinalis sexta adversus basim abbrevata. (Illinois; Le Baron).

76. Platypalpus trivialis nov. sp. ‥ Niger, nilidus, thoracis dorso polline cinereo, pleuris praeter plagam inferam polline albido opacis, pedibus favis, singulis tarsorum articulis in apice nigris; antennae nigrae, articulo tertio breviler ovato; palpi flavi; alarum cellula basalis prima brevior quam secunda; vena longitudinalis sexta basim versus non abbreviata. - Long. corp. $1 \frac{1}{4}$ lin., Long. al. 2 liu.

Caput cinereum, facie confertim albo-pollinosà. Antennae nigrae, articulo tertio breviter ovato. Palpi flavi; proboscis nigra. Thoracis dorsum et scutellum polline cinereo opaca. Pleurae prae- 
ter plagam vigram nitidam, inter coxas anticas et intermedias sitam, polline albido aspersae. Abdomen nigrum, nitidum, ventre concolore. Pedes cum coxis flavi, articulis singulis tarsorum in apice nigris; femora antica modice, intermedia valde incrassata et infra praeter pilos longiores flavicautes setulis nigris ciliata; dens apicalis tibiarum intermediarum magnus. Alac cinereo-byalinac, venis validis subfuscis, basim versus ex fusco lutescentibus, longitudinali tertià apicem versus incurvâ el cum quartâ convergente; cellularum basalium prima brevior quam secunda; venula transversa basalis posterior recta, integra et vena longitudinalis sexta basim versus non abbreviata. - (Maine, District Columbia; Osten-Sacken).

77. Platypalpus pachycnemus nov. sp. $\delta$. Niger, nitidus, thoracis dorso et scutello polline cinereo opacis; antennae fuscae, articulo tertio breviler ovato; pedes fusco et testaceo varii, tibiis anticis incrassatis; alue cinereae, venâ longitudinali tertiâ incurva, cellulá basali primâ longiore quam secunda. - Long. corp. $\mathbf{1}_{6}^{2}$ lin., Long. al. $1 \frac{3}{4}$ liu.

Caput ex nigro cinereum, facie confertim albo-pollinosâ. Antennae saturate fuscac, articulo tertio breviter ovato. Proboscis nigra; palpi fusci, albicantes. Thoracis dorsum polline cinereo leviter aspersum, subopacum, pallido-pilosulum. Sculellum concolor. Pleurae praeter plagam nitidam inferam albido-pollinosae. Abdomen totum nigrum, nitidum, ventre et hypopygio concoloribus. Coxae dilute testaceae, basim versus fuscae. Femora nigro-fusca, apice omnium posticorumque latere supero dilute testaceis; femora antica leviter, intermedia valde incrassata. Tibiae anticae incrassatae, fuscae, in basi et infra dilule testaceae; intermediae tolae fuscae, dente apicali magno; posticae ex testaceo flavesceules, extremo apice infuscato. Primus tarsorum anticorum articulus nigro-fuscus, reliqui testacei, apice singulorum fusco; tarsi intermedii. toti nigro-fusci; postici dilute testacei, articulis primis duobus in apice, sequentibus fere totis vel tolis fuscis. Alae cincreae: venis validis fuscis, in basi alarum lutescentibus, longitudinali tertià adversus finem incurvâ el cum quarlâ convergente. cellulà basali primà quam secunda breviore; venula transiersa basalis posterior completa; venae longitudinalis sextae segmentum primum subobsoletum. - (I)istrict Columbia; Osten-Sacken).

78. Platypalpus lateralis nov. sp. $\delta$ et . Ater, nitidus, thoracis marginibus lateralibus pleurisque albo-pollinosis, pedibus 
favis, ultimis tarsorum articulis in apice nigris; alae hyalinae, cellularum basalium primá et secundâ aequalibus. - Long. corp. $1 \frac{1}{4}$ lin., Long. al. $1 \frac{3}{4}$ lin.

Aler, nitidus. Capul ex nigro cinereum, subopacum. Antennae nigrae, arliculo tertio breviter lanceolato, in basi flavo. Proboscis atra; palpi albi. Margines thoracis laterales et pleurae praeter maculam inferam nitidam polline conferto albido opacae. Scutellum polline albido rariore aspersum. Abdomen atrum, nitidum, segmentis ultimis in foeminâ valde elongatis et minus attenuatis quam in Platypalpis plerisque. Pedes cum coxis flavi, primis tarsorum articulis in apice subfuscis, sequentibus fuscis, ultimo fere toto nigro; femora antica subincrassata, intermedia crassa, infra setulis nigris rarioribus ciliała; dens apicalis tibiarum intermediarum parvus Alae hyalinae, venis fuscis, adversus basim alarum lutescentibus, longitudinalibus tertiâ et quartâ apicem versus parallelis vel subparallelis; cellulae basales prima et secunda aequales; venula transversa basalis posterior subintegra, postice tenuior; vena longitudinalis sexta adversus basim non abbreviata. - (New Hampshire; Osten-Sacken).

79. Platypalpus apicalis nov. sp. ‥ Ater, nitidus, thoracis marginibus laleralibus pleurisque obsoletissime allido-pollinosis, pedibus flavis, femorum anticorum posticorumque apice supra maculâ oblongâ nigrâ notatis, ultimo tarsorum articulo nigro; alae hyalinae; cellulae basales prima et secunda aequales. - Long. corp. $\mathbf{1}_{\frac{1}{1}}$ lin., Long. al. $\mathbf{I}_{\frac{2}{3}}$ lin.

Ater, nitidus. Caput minus nitens, facie confertim albo-pollinosâ. Antennae nigrae, articulo tertio breviter ovato, basi anguste luteâ. Proboscis nigra; palpi albidi. Thoracis margines laterales et plcurae polline albido-cinereo obsoletissime aspersae, modice nitentes. Abdomen nitidum. Pedes cum coxis flavi, ultimo tarsorum articulo nigro, femoribus anticis posticisque in apice supra maculâ ovatâ nigrầ notatis; femora antica modice incrassata, intermedia anticis paulo crassiora, infra breviter nigro-ciliata; dens apicalis tibiarum intermediarum brevis. Alae hyalinae, venis fuscis. in basi luteis, lougitudinalibus tertiâ et quarlà parallelis; cellulae basalis prima secundae aequalis vel paulo longior; venula transversa basalis posterior completa; vena longitudinalis sexta basim versus abbreviala. - (Pennsylvania; Osten-Sacken).

80. Platypalpus flavirostris nov. sp. ot. Flavus, supra 'ufescens, nitens, capite cinereo, proboscide flavâ, ullimo antenna- 
vum articulo nigro, ultimo tarsorum articulo praeter basim fusco, dente apicali tibiarum intermediarum parvo. - Long. corp. $1 \frac{1}{3}$ lin., Long. al. $2 \frac{1}{1} \frac{1}{2}$ lin.

Flavus, supra rufescens, nitens, breviter flavo-pilosulus. Caput cinereum, facie albido-cinereâ. Primi duo antennarum articuli flavi; articulus tertius parvus, breviter ovatus, niger, seta concolore. Palpi dilute llavicantes; proboscis longiuscula, lutea, apice nigricante. Pleurae supra polline albo rarissimo leviter aspersae, infra maximâ ex parte nudae. Abdomen supra subfuscum, hypopygio nigro. Femora antica non incrassila, intermedia valde incrassata, infra selulis nigris ciliata; tibiarum intermediarum dens apicalis parvus; articulus ultimus tarsorum omnium praeter basim infuscalus. Alae sublutescentes, venis dilute luteis, longiludinali tertiâ apicem versus levissime incurvâ et cum quartì subconvergente. cellulis basalibus primâ et secundà aequalibus, venulà transverså basali posteriore incurvà et postice abbreviatâ, venae longí ludinalis sextae basi non obsolelâ. - (New Hampshire; OstenSacken).

81. Platypalpus laetus nov. sp. 오. Flavus, nitens. capite cinereo, proboscide nigrà, articulo ultimo antennarum et tarsorum nigricante, dente upicali libiarum intermediarum majusculo. - Long. corp. $1 \frac{1}{1 \frac{1}{2}}$ lin., Long. al. $1 \frac{2}{3}$ lin.

Flavus, nileus, breviter flavo-pilosulus. Caput sinereum, fronte et facie confertim albo-pollinosis. Primi duo antennarum articuli flavi; articulus tertius parvus, breviter ovatus. fusco-niger, seti nigrâ. Proboseis brevis, tota nigra; palpi albidi. Pleurae supra polline albo rarissimo leviter aspersae, infra maximà ex parte nudae. Slyli anales nigro-fusci. Femora antica modice incrassata, intermedia crassissima, infra setulis nigris ciliata; libiarum intermediarum dens apicalis majusculus; articulus ultimus tarsorum omnium nigricans. Alae sublutescentes, venis luteis, longitudivali tertiâ rectí, quartầ leviter rcurvâ et apicem versus cum tertià subconvergente, cellulî́t basali primâ quam secunda paulo breviore, venulâ transversâ basali posteriore rectâ et integrà, venae longitudinalis sextae basi obsoletâ. - (New Hampshire; Osten-Sacken).

82. Dolichopus splendidulus nov. sp. $\sigma^{\top}$. Aeneo-viridis. pedibus flavis. coxis articis tibiisgue posticis totis concoloribus. tarsis posticis antennisque tolis nigris, ciliis oculorum inferioribus tegularumque ciliis flavicantibus; femora postica pilis flavicantibus 
ciliata; ultimus tarsorum anticorum articulus dilalatus, ater. Long. corp. $2 \frac{1}{2}$ lin., Long. al. $2 \frac{5}{12}$ lin.

Aeneo-viridis, nitens. Facies ex aureo ocbracea. Antennae totae nigrae, mediocres, articulo tertio brevi. Lamellae hypopygii albae, nigro-limbatae. Coxae anticae nigro-pilosulae; femora postica prope apicem setâ solitarià instructa, infra pilis flavicantibus rare ciliata; tibiae posticae simplices; larsorum anticorum articuli primi quatuor lenues, longitudine decrescentes, flavi, subalbicantes, articulus terminalis compressus, modice dilatatus, ater. Alae cinereohyalinae, costà ad exitum venae longitudinalis primae breviter incrassalâ, venâ longitudinali quartà non fractâ. - (New Hampshire; Osten - Sacken).

Nota. A Dolichopo splendido, quem magnitudine non aequat, differt: tertio antennarum articulo breviore. ultimo tarsorum anticorum articulo paulo minore ciliisque femorum posticorum multo rarioribus.

83. Dolichopus quadrilamellatus $\sigma^{7}$ et ․ Aeneo-viridis, antennis brevibus nigris, articulo primo tamen infra flavo, ciliis oculorum inferioribus albis, tegularum cilis nigris, coxis anticis pedibusque pallide flavis, tarsis posterioribus inde ab articuli primi apice nigris, alis cinereo hyalinis, venâ longitudinali quartâ non fractâ.

ठ. tarsorum anticorum articulis decrescentibus, primis tribus tenuibus et dilute flavis, duobus ullimis depressis, modice dilatatis et atris.

․ tarsis anticis simplicibus, inde ab articuli primi apice nigris.

Long. corp. $3-3 \frac{1}{1} \frac{1}{2}$ lin., Long. al. $2 \frac{1}{1}-3$ lin.

Laete aeneo-viridis, nitens. Facies alba, in mare latiuscula, in foeminâ lata. Antennae breves, atrae, articulo primo praeter marginem superum flavo. Lamellae hypopygii luteae, lobatae et reduplicatae, ita ut duplices esse videantur, lobi secundi margine adusto, setulis aliquot incurvis nigris pilisque subtilibus albidis vestito. Coxae anticae flavae, nigro-pilosulae; femora postica prope apicem setam solitariam gerentia; tibiae posticae in utroque sexu simplices.

- (New York, Osten-Sacken).

84. Dolichopus palaestricus nov. sp. \% . Aeneo-viridis, pedibus favis, coxis anticis tibiisque posticis totis concoloribus, antennis tarsisque posticis totis nigris, ciliis oculorum inferioribus 
tegularumque ciliis flavirantibus, maris ultimo tarsorum anticom articulo valde dilatato. - Long. corp. $2_{6}^{5}$ lin. Long. al. $2 \frac{3}{6}$ lin.

Facies maris angusta. ex aureo ochracea. focminae lata. dilutius ochracea. Coxac anticae tolae flavae. nigro-pilosulae; coxae posteriores cinereae. Lamellae hypopygii albae. limbo marginali latiusculo, nigro. Pedes nari; femora postica prope apicem setit solitariâ, infra ciliis flavicanlibus instructa; tibiae posticae crassiusculac, in latere postico praeter trientem apicalem denudatae; larsorum anticorum articuli primi quatuor llavi, longitudine decrescentes, articulus ultimus duobus praecedentibus simul sumptis longior, compressus et eximie dilataius, ater, in latere posteriore candido-micans. Alac hyalinae, costâ ad venae primae exitum nonnihil incrassatâ, venà longiłudinali quartà non fractà. - (New Hampshire; Osten Sacken).

- Nota 1. A Dolichopo batillifero differt: ciliis femorum posticorum rarioribus tibiis posticis minus incrassatis et in latere posleriore longius denudalis, tarsis denique posticis totis nigris.

Nota 2. Foeminam possideo, alis subinfuscatis instructam, quam legitiman Dolichopi palaestrici uxorem esse suspicor.

85. Dolichopus dorycerus nov. sp. on. Viridi-aeneus, cupreo-micans, antennis praeter articulum primum nigris et setâ lamelliferâ instructis, cilis oculorum tegularumque nigris, pedibus luteis, tarsis praeter basim nigris, ultimis quatuor anticomm articulis brevibus et valde dilatatis. - I.ong. corp 3 lin., Long. al. $2 \frac{3}{4} \operatorname{lin}$.

Facies ex fusco ochracea. Antennae breves, articulo primo flavo, secundo subobsoleto, tertio minuto nigro, setâ tenui, lamellam ellipticam ferente. Lamellae hypopygii mediocres. sordide albidac. latius nigro-limbatae. Coxae anticae luteae, nigro-pilosae, posteriores nigrae. Pedes lutei; femora postica prope apicem setis binis armata; tibiac simplices, posticae non incrassatae, in latere posteriore maculis duabus ex nigro fuscis, alterâ subbasali, alterả apicali nolatae; primus tarsorum anticorum articulus practer apicem luteus, reliquis simnl sumtis longior, articuli sequentes perbreces, dilatati, atri; larsi posteriores inde ab arliculi primi apice nigri. Alae ex cinereo byalinae, adversus costam sublutescenles, angulo postico bilobo, venì longiludinali quartì non fractâ et costâ ad venae primae exitum le. viter incrassatâ. - (New Hampshire; Osten-Sacken).

S6. Dolichopus melanocerus nov. sp. J et antennis nigris, ciliis oculorum inferioribus albidis, tegularum ciliis 
nigris, coxis anticis perlibusque flavis, tarsis anterioribus inde ab articuli primi apice, poslicis totis tibiarumque posticurum apice nigris, vená longitudinali alarum quarlá non fractâ.

Ђ. facie ochraceâ, femoribus posticis ciliatis.

․ facie ex albo ochracea, femoribus posticis non ciliatis.

Long. corp. $2 \frac{7}{12}$ lin., Long. al. $2 \frac{1}{2}$ lin.

Antennae totae nigrae, articulo tertio maris oblongo-ovato. foeminae breviore. Lamellae hypopygii albae, anguste nigro marginatae. Coxae anticae nigro-pilosae et in basi nigricantes, posteriores ex nigro cinereae. Femora maris postica infra pilis rarioribus flavicantibus ciliata; tibiae maris posticae in latere posteriore ex parte pilis destitutae. Alae cinereo-hyalinae, venå longiludinali quartâ non fractâ; mas costam prope venae primae exitum nodatam habet. - (Canada; Couper).

87. Gymnopternus coxalis nov. sp. o. Aeneo-viridis, antennis totis nigris, lamellis hypopygii hunatis, flavicanlibus. coxis nigris, anticorum dimidio apicali pedibusque faris, tarsis inde al, articuli primi apice nigris, ullimo anticorum arliculo non depresso. - Long. corp. $1 \frac{1}{2}$ lin. Long. al. $1 \frac{1}{2}$ lin.

Facies albida, interdum dilutissime flavescens vel $x$ albo cinerascens. Frons albido-pollinosa. Lamellae hypopysii flavescentes, lunatae, angulo supero acuto, ciliis brevibus nigris. Tegulae nigrociliatae. Ordinariae tibiarum anticarum setulae apicem versus brevissimae. Alae cinereae. - (New York, Osten-Sacken).

88. Gymnopternus meniscus nov. sp. O’ et ․ Aeneoviridis, antennis totis nigris, lamellis hypopygii lunatis, favicantibus, coxis anticis pedibusque flavis, imâ illarum basi nigrâ, larsis anticis apicem versus subfuscis, posterioribus inde ab articuli primi apice fuscis. - Long. corp. $1 \frac{7}{\frac{1}{2}}$ lin., Long. al. $1 \frac{7}{\frac{7}{2}}$ lin.

A Gymnopterno coxali, cui simillimus, diflert magnitudine. coxis anticis praeter imam hasim flavis tarsisqne dilutioribus. (District Columbia; Osten-Sacken).

89. Pelastoneurus abbreviatus nov. sp. ơ el ㅇ․ Obscure viridis, selâ antennarum breviter phumatâ, ciliis oculorum inferioribus nigris, pedibus ex testaceo flavis, femoribus anterioribus interdum basim versus infuscatis, coxis omnibus nigris, lamellis hypopygii brevissimis, nigris. - Long. corp. $1 \frac{3}{2}$ lin., Long. al. $5 \frac{5}{12}$ lin.

Antennae rufae, apicem versus ex fusco nigrae, setâ breviter plumatâ. Facies maris albicans, foeminae obscure cinerea, supra et 
adversus latera obsolete albicans. Thoracis dorsum polline subfusco leviter aspersum, adversus marginem posticum minus opacum. Scutellum ex viridi chalybescens. Tegulae albidae, nigro-ciliatae. Lamellae hypopygii perbreves, sublunatae, nigrae. Coxae nigrae. Pedes flavi vel ex testaceo flavi, femorum posticorum apice nigro; tarsi posteriores praeter basim nigri, antici apicem versus fusci. Alae obscure cinereae, subnigricantes. - (New York, Osten-Sacken).

90. Pelastoneurus lamellatus nov. sp. $\delta$. Obscure viridis, posticâ thoracis parte et scutello violaceis, setâ antennarum longe plumatá, ciliis oculorum inferioribus nigris, pedibus flavis, coxis anticis concoloribus, basim versus nigricuntibus, lamellis hypopygii brevissimis nigris. - Long. corp. $1 \frac{1}{2}$ lin., Long. al. $1 \frac{3}{1} \frac{\mathrm{l}}{2}$ lin.

Antennae rufae, apicem versus ex fusco nigrae, setâ louge plumatâ. Facies albo-micans. Thoracis dorsum polline subfusco leviter aspersum, adversus marginem posticum obscure violaceum. Scutellum concolor. Tegulae albidae, nigro-ciliatae. Lamellae hy. popygii perbreves, sublunatae, nigrae. Coxae anticae flavae, albomicantes, adversus basim late nigricantes. Pedes flavi, apice femorum posticorum nigro; tarsi posteriores praeter basim nigri, antici apicem versus fusci. Alac obscure cinereae, subnigricantes. - (New York, Osten-Sacken).

Nota. A Pelastoncuro abbreviato distinguitur: colore thoracis et scutelli, setâ antennarum longius plamalâ, coxis anticis magnâ ex parte flavis et venis longitudinalibus alarum tertî̀ et quartâ intervallo latiore separatis.

91. Pelastoneurus alternans nov. sp. 오. Obscure viridis, villis thoracis allernis aeneis et ex caeruleo viridibus, setu antennarum breviler pubescente, cilies oculorum inferioribus albidis, coxis anticis pedibusque flavis. - Long. corp. $1 \frac{7}{12}$ lin.. Long. al. $1 \frac{1}{2}$ lin.

Antennae rufae. apicem versus nigrae. setâ breviter pubescenle. Facies quam in reliquis speciebus angustior, ohscure ciucrea. Tegulae albidae, nigro-ciliatae. Coxae anticae totae flavac, nigropilosac, vix obsolelissime albicantes. Tarsi inde ab arliculi primi apice ex fusco nigri. Alac obscure cincrene, subnigricantes. (New York, Osten-Sacken).

92. Porphyrops longipes nov. sp. ठ大. Viridis. facie albôn. coxis ex viridi nigris, pedibus anterioribus flavis, articulis tarsomum ultimis duobus nigris, pedibus posticis nigris, femorum basi 
tibiisque supra (basi tamen except (i) lestaceis, tibiarum apice tarsisque fuscis, exterioribus hypopygii appendicibus filiformibus. bipartilis. - Long. corp. $2 \frac{1}{1} \frac{1}{2}$ lin. Long. al. $2 \frac{5}{1} \frac{5}{2}$ lin.

Obscure viridis, nitens, lineis thoracis duobus obscurioribus. Facies angusta, alba. Antennae nigrae, ariiculo tertio lanceolato, setâ antennis paulo longiore. Occiput infra pilis confertis albis vesticum. Tegulae albido-cilialae. Appendices exteriores hypopygii testaceae, filiformes, bipartitae, pilis albidis subtiliter ciliatae. Coxae ex viridi nigrae, intermediae pilorum nigrorum fasciculo rigido armatae. Pedes antici dilute flavi, ultimis duobus tarsorum articulis nigris, primo reliquis simul sumptis fere longiore, in apice infra subdilatato. Pedes intermedii graciles dilute flavi, ultimis duobus tarsorum articulis nigris. Femora postica non incrassata, nigra, basi tamen lestaceâ; tibiae posticae crassiusculae, nigrae, apicem versus fuscac et supra praeter basim dilute testaceae vel flavac; tarsi postici crassiusculi, fusci, articulis ultimis duobus nigris. Alae cinereohyalinae, venâ longitudinali tertiâ apicem versus leniter recurvâ. quartả leniter flexâ. - (New Hampshire; Dsteı-Sacken).

93, Cordylura praeusta nov. sp. $\sigma^{7}$. Dilute flavescens, fronte et dorso saluratioribus, singulis abdominis segmentis anguste fusco marginatis, selà antennarum nigro-plumosä, alarum apice et venâ transversâ posteriore fusco-limbatis. - Long. corp. $3 \frac{1}{1}$ lin., Long. al. $2 \frac{3}{4}$ lin.

Dilute flavescens, nitida, pilis plerisque et setis omnibus nigris. Caput concolor, fronle ochraceâ, albo-pollinosâ, opacâ. facie praeter laiera exalbidâ, setâ mystacinâ utrinque unà. Antennae flavicantes, breviores, articulo tertio obtuso, setâ nigrâ et pilis nigris plumatâ. Scutellum setis duabus longis pilisque duobus minutis nigris instructum. Abdomen supra nigro-pilosum, utrinque et infra pilis tenuibus pallidis vestitum, segmentis singulis postice subtiliter fusco marginatis. Pedes dilute flavescentes, pilis omnibus setisque raris nigris. Alae ex cinereo sublutescentes, apice late, venâ Iransversâ posteriore anguste fuseo-limbatis. - (Canada; Couper).

94. Cordylura nana nov. sp. ‥ Atra, nitida, thoracis marginibus lateralibus et viltá mediâ latissimá cinereo-pollinosis, capite praeter superius occipitis dimidium pedibusque flavis, set $a$ antennarum nudâ, alis odversus costam nigricantibus. - Long. corp. 2 lin., Long. al. $1 \frac{3}{4}$ lin.

Caput flavum; antennae concolores, artieulo tertio obtuso, setâ 
tenui subnudi. Proboscis cum palpis pallida. Superius occipitis dimidium nigrum; vertex concolor, maculà geminà polline albido aspersâ. Thorax ater, nitidus; dorsi vitta latissima polline cinereo opaca, margines laterales polline albido-cinereo aspersi; pleurae infra polline albido cinereae. Abdomen atrum, nitidum, ventre pallido. Pedes cum coxis flavi, extremis posticorum genibus nigris. Alae cinereo-hyalinae, adversus costam ex cinereo nigricantes, ita ut cellula marginalis inde a venae primae fine reliquâ alà obscurior sit. - (Canada; Couper.)

95. Telanocera ambigua nov. sp. $\sigma$. Antennae elongatae, tenues, articulis ultimis duobus subaequalibus, selâ albo-plumosâ; alae nigroveticulalae, limbo costae et apicis nigro. - Long. corp. $2 \frac{7}{\frac{7}{2}}$ lin., Long. al. $2 \frac{1}{4}$ lin.

Corporis forma ac figura omnino Tetanocerae, sed caput et antenuae Sepedontis, ita ut quasi intermedia inter utrumque genus appareat. Ex fusco testacea, thorace et abdomine fusco punctulatis. Frons utrinque maculas binas nigras habet, quarum inferior juxta antennas sita est. Antennae longae, tenues, testaceae, apicem versus nigrae; articulus secundus tertio subaequalis, pilis rarioribus nigris instructus; articulus terlius obtusus; seta altra, hasim versus lulea, albo-plumosa. Facies prope antennas tuberculum laevigatum badium habet. Pedes testacei, tibiis anticis praeter basim, reliquis in apice nigris. Alae breviusculae, nigro-reticulatae, gullulis marginalibus nullis ita ut limbus costae et apicis niger. marginis postici ex nigro cinereus sit: vena transversa posterior valde arcuata. (Maine.)

96. Sapromyza decora nov. sp. f. Flavescens, maculis nigris variegata, alis fusco reticulatis. - I Jong. corp. $2 \frac{1}{6}$ lin., Long. al. $2 \frac{1}{4}$ lin.

Dilute flavescens, infra pallidior. Tertius antennarum arliculus triangulus, supra leviter excisus, setâ nigło-plumatâ. Frons praelè margines nigro-maculatos convexa, nitida, maculam geminam atram gerens. Genae ef occiput fusco-maculala. Thorax et abdomen maculis nigris, seriatim dispositis ornata. Femora singula infra maculâ nigrâ notata. Alae fusco-reliculatae, costâ et apice radiatis, disco et margine postico guttatis. - (Iake George N. Y.; Osten-Sacken.)

Nota. Capitis forma el praccipue antennarum simillima quibusdam Tetanoceris; hoc et peculiaris frontis figura causam praebent eximiam, ut haec species pro typo habeatur unius corum generum, in quae Sapromyzae discerpendae sunt. 
97. Heteroneura melanostoma nov. sp. $\sigma$. Dilulissime flnnesrens, facie et abdomine nigris, setâ antennarum subnudâ, venis transversis alarum approximatis - Long. corp. $1_{\frac{5}{2}}$ lin., Long.

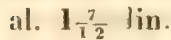

Dilutissime flavescens, pedibus tolis concoloribus. Facies nigra, opaca, supra dilute flave:cens. Sela antennarum subuda. Tho racis dorsum paulo saluralius flavescens, ulrinque albo marginatum. Pleurae dilute flavescentes, supra ohsolelius fusco-vittatae. Abdomen nigrum, nitidum. Alae hyalinae, plagâ apirali nigrâ; venae transversae approximatae ita ut anterior a cellulae discoidalis basi intervallo fere duplo latiore quam ab apice dislet. - (New Hampshire: Osten-Sacken.)

Nota. Ab Heteroneurâ albimanâ, cui propinqua, pedibus anticis tolis flavis facile distinguitur.

98. Opomyza lurida nov. sp. ठ et $q$. Iatea, metanoto plearisque ex nigro fuscis, abdomine nigro, pedibus dilute luteis, femorum posticorum annulo subapicali obsolelissime subfusro: ठ. hypo pygio nigro; ․ abdominis apice luteo.' - Long. corp. $1 \frac{2}{3}-1 \frac{3}{4}$ lin.. Long. al. $1 \frac{2}{3}$ lin.

Lutea. Caput concolor occipite ef superiore frontis dimidio fuscis, inferiore fronlis dimidio et antemnis ochraceis. Thoracis dorsum sordide luteum. adversus latera subfuscum; color scutelli ex luteo in fuscum vergens; pleurac obscure fuscae; metanolum ex fusco nigrum: abdomen nigrum. hypopygio maris concolore. summo apice in foeminâ luteo. Pedes dilute lutei, femoribus posticis ante apicem colore dilute subfusco obsolete ammulatis, libiis posticis praeler mediam parteun snepe subfuscis. Alae subhvalinae, maculà apicali an gustisque venularum transversalium limbis ex fusco nigris. - - (Sitka: Sallberg.)

Nota. Variat froutis dimidio superiore. occipite, metanoto plenrisque ex ferrugineo rafis.

99. Ephydra subopaca nov. sp. ठ et + V. Viridi-nenea, polline fusco-cinerco subopara, pedibus testaceis; peristomium foeminae setis longis, maris brevioribus el rarioribus ciliatum; hypopygium oblongum, convexum, subtilissime carinatum. - Long. corp. $1 \frac{1}{1} \frac{1}{2}-2$ lin., Long. al. $1_{\frac{1}{2}}^{\frac{7}{2}}-1 \frac{2}{3}$ lin.

Viridi-aenea, thoracis dorso el sculello interdum cupreis, polline ex fusco cinereo vel ex fusco ochraceo subopaca. Frons praeter margines laterales nitida. Antennae nigrae, pilo laterali arliculi tertii nullo, selâ breviter peclinatâ. Facies maris descripti polline con- 
ferto ochraceo, foeminarum albo tecta. Latera peristomii foemina setis longis nigris, mas brevioribus ef rarioribus ciliata luabet. Hypopygium oblongum, convexum, carinulâ medià lineari. Coxae testaceae ef cinerascentes, vel cinereac. Pedes lestacei, tibiarum apice fuseo, larsis ex fusco nigris; femora interdum supra ex cinereo glauca: femora postica in latere posteriore viltam denudatam, nilidam, badiam vel fuscam habent; tibiae posticae, supra selosulac, in triente apicali lineolà laevigatâ, badiâ vel fuscâ notantur: Alae cinereae vel fusco-cinereae, venis fuscis. - (Connecticut; Oslen-Sacken.)

Nola. Color pollinis faciei, quem in foeminis duabus album, in mare uno ochraceum observavi, variabilis esse videlur; alterum sexum faciem semper polline ochraceo, alterum albo aspersan hahere, veri simile non est.

100. Caenia spinosa nov. sp. \&. Aeneo-viridis, pedibus fuscotestaceis, alarum nigricanlium coslá nigro-selosâ, abdomine infru anum spinis duabus recurvis armato. -- Long. corp. $2 \frac{1}{4}$ lin., Long. al. $2 \frac{1}{4}$ lin.

Aeneo-viridis. Frons praeter latera et superius faciei dimidium nitida; dimidinu faciei inferius ochraceo-pollinosum, pilis nigris vestilum, peristomio setis longis nigris ciliato. Thoracis dorsum el scutellum polline subfusco aspersa, subnilida. Pleurae snpra polline ex ochraceo fusco. infra cinereo opacae. Singula abdominis segmenta in dimidio posteriore glaucescentia; infra anum spinae duac tenues. leviler recurvae conspiciuntur. Coxae polline albido cinereae. Pedes fusco-testacei, apicem versus fusci. Alac nigricantes, costâ setis validiusculis nigris armalá. - (Massachusets; Sanborn)

Ad calcem hujus centuriae liceat pauca a me crrata emendare ef tabulam secundum systematis ordinem dispositam earum specicrum addere, quas quinque hae centuriae complectuntur.

Species, quam Empidis pictae nomine (Ceul. III. 2h.) descripsi. jam a Wiedemanno Empidis spiloplerae nomine descripla est. Nomullis speciebus locus additus est .,New Wisconsin". qui ,Northern Wisconsin" esse debebat. 
Catalogus generum et specierum, quae insunt in quinque primis dipterorum centuriis.

\section{Culicidae.}

Corethra.

trivittata .... II. 1.

\section{Chironomidae.}

Chasmatonotus.

unimaculatus .. V. 1.

T anypus.

flavicinetus... I. 2 .

pinguis ..... I. 1 . tricolor ..... I. 3.

Ceratopogon.

albiventris ... I. 7. argentatus ... I. 5 . bimaculatus .. I. 6 . festivus ..... I. 13. longipennis . . I. 10. opacus .... I. I. 9. plebejus .... I. 11. rufus .... I. 12. setulosus .... I. 8 . trivialis ..... I. 4 .

\section{Blepharopteridae.}

Blepharoptera. capitata . . . IV. 43.

\section{Tipulidae.}

Dixa.

centralis ... III. 3 . fusca ..... III. 5 . marginata. . III. 1. notata..... III. 4 . terna ..... III. 2.

Holorusia. rubiginosa .. IV. 1.

Tipula. angulata ... V. 22. angustipennis. IV. 19. apicalis .... IV. 2 appendiculata . 1V. 20 . balioptera... IV. 15 bella. . . . . IV. 29 . caloptera . . IV. 30. canadensis .. V. 19. casta .... IV. 25. centralis ... V. 21. cincta .... IV. 24. discolor ... IV. 12. eluta .... IV. 27. fallax ..... IV. 10. fasciata ... IV. 6 . fragilis .... IV. 7 . fraterna .... V. 14. grata ..... IV. 11. hebes ...... IV. 18. infuscata ... IV. 26. ignobilis ... IV. 9. latipennis ... V. 20. longiventris . . IV. 5 . macrolabis .. V. 17. pallida . . IV IV. 16. pubera .... V. 16. septentrionalis IV. 4. serrulata ... V. 18. serta ..... IV. 14. speciosa . . IV. 22. strepens . . IV. 28. subfasciata .. IV. 13. submaculata . IV. 23. suspecta ... IV. 8. tephrocephala. V. 23. ternaria.... V. 15. tessellata ... IV. 3. umbrosa ... IV. 31. valida .... IV. 21 . versicolor. . IV. 17. Pachyrrhina.

abbreviata .. IV. 36. cireumscripta . IV. 38. eucera ... IV. 39. gracilicornis - V. 32. incurva ... IV. 32. lugens ... . V. 26. nobilis ... V. 24. occipitalis ... V. 30. pedunculata. . 1V. 33 . polymera . IV. 40. punctum ... IV. 34. sodalis ... V. 29. suturalis . . IV. 37. tenuis ..... IV. 41 . unifasciata . IV. 35. unimaculata. V. 28. virescens ... V. 25. vittula..... V. 27. xanthostigma . V. 31. Stygeropis.

sordida ... IV. IV. 42.

\section{Simulidae.}

Simulium.

quadrivittatum II. 2.

\section{Bibionidae.}

Bibio.

abbreviatus .. V. 9 . basalis ....V. 11 . fraternus ... V. 8 . hirtus .... V. 2 . inaequalis ... V. 3 . longipes.... V. 12. lugens..... V. 6 . nervosus ... V. 4 nigripilus ... V. 10 . obscurus ... V.5. variabilis ... V. 7 .

Dilophus.

longiceps ... I. 14.

serotinus ... I. 15

Scatopse.

pygmaea ... V. 13.

\section{Xylophagidae.}

Rachicerus.

obscuripennis. III. 6 . varipes .... III. 7.

Xylophagus. lugens .... III. 8. 
Subula. pallipes ... III. 9 .

Arthropeas. americana... I. 16 .

B olbom yia. nana.

II. 5 .

\section{Stratiomyidae.}

Pachygaster. pulcher . . III. 16. Nemotelus. acutirostris . III. 13. canadensis . . III. 12. crassus . . . III. 10. unicolor... III. 11.

0 x y c era. centralis ... III. 14. unifasciata . III. 15.

Metoponia. obscuriventris IV. 45. similis.... IV. 44 .

\section{Leptidae.}

Chrysopila.

foeda

I. 18 , rotundipennis . I. 19. velutina... I. 17.

Leptis.

costata... II. 4 . dimidiata ... III. 17. hirta.... I. 21 . ochracea ... II. 3 . terminalis ... I. 20 . scapularis . . I. 22 .

\section{Asilidae.}

Lep to gaster.

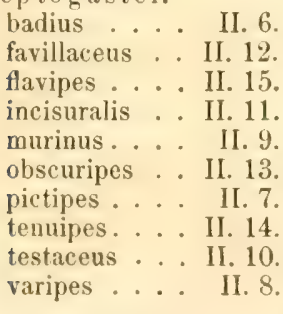

\section{Bombylidae.}

Bombylius.

atriceps ... IV. 49. haemorrhoicus IV. 46. pulchellus . . IV. 47. ravus .... IV. 50 .

validus ... IV. 48.

Systoechus.

candidulus . IV. 51 . vulgaris . . . IV. 52 .

Lordotus. gibbus ... IV. 53 .

Phthiria. notata.... III. 19. sulphurea .. III. 18. Geron. calvus.... IV. 54 subauratus . . IV. 55.

Sysiropus. macer .... IV. 56

\section{Syrphidae.}

Temnocera. megacephala . IV. 57.

L epidom y ia. calopus ... V. 38

Sericomyia. chalcopyga . . III. 20.

Spilomyia. fusca .... V. 34. hamifera ... V. 33 .

T emuos toma. aequalis... V. 36 . alternans ... V. 37. obscura ... V. 35 .

Tropidia. mamillata... I. 68 . Didea. fuscipes... IV. 82 . Spheg in a. infuscata .. III. 23. lobata .... III. 21. rufiventris... III. 22 .

Bac cha. capitata . . III. 25. cognata ... III. 27. lugens.... III. 24. obseuricornis . III. 26.

Doros.

aequalis ... IV. 84. flavipes ... IV. 83 .

Chrysochlamys. buccata... IV. 72 .

Chilosia. capillata . . IV. 65. comosa ... IV. 66. cyanescens . IV. 67. leucoparea . . IV. 69. pallipes . . . IV. 70 . plumata . . IV. 68 . tristis .... IV. 71 .

Chry sogaster.

latus .... IV. 59. nigripes . . . IV. 60 .

Orthoneura. pictipennis . IV. ¿S.

Trigly $p h u s$.

modestus . . IV. 62. pubescens... IV. 61.

Paragus. angustifrons . IV. 64. dimidiatus . IV. 63 .

$\mathrm{X}$ y lota.

barbata...V V. 40 .

bicolor ... V. 39 .

fraudulosa . V.41.

Pteralastes.

lituratus ... IV. S1. thoracicus . IV. 80 .

Helophilus.

divisus ... IV. 78 .

hamatus... IV. 79.

laetus .... IV. 77.

latifrons. . . IV. 73 .

integer ... IV. 76 .

obscurus ...IV. 74.

obsoletus ... IV. 75 .

Chrysotoxum.

laterale... V. 42 .

pubescens... V. 43 .

ventricosum. V. 44.

Microdon.

coarctatus... V. 47.

laetus .... V. 46 .

tristis .... V. 45 .

Ceria.

abbreviata . V. 48 .

Hybotidae.

Brachystoma.

binummus. II. 16 . nigrimana. . II. 17. serrulata ... I. 23.

Syneches.

albonotatus . II. 1S. pusillus ... I. 25. rufus.... I. 24.

S yndy as.

dorsalis .... I. 26 .

polita .... I. 27 .

Empidae.

Empis.

armipes... 1.32. 


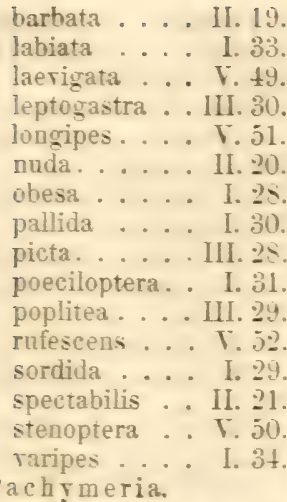

breris.... II. 2.2. pudica. ... I. 35.

Rhamphom yia.

angustinennis. I.55. aperta.... H. 27. basalis ... 1. 54 . brevis .... I. 52. candicans... V.61. clavigera... I. 53. conjuncta ... I. 56 . corvina... I. 51. erassinerris. I. 59. debilis .... I. 45 . dimidiata... I. 36 , exigua ... II. 32. frontalis... II. 28 . fumosa ... I. 39 . gilvipes.... I. 4 s. glabra.... I. 41 . gracilis .... I. 43 . hirtipes .... 1. 59. impedita ... II. 31 . incompleta . . III. 31 . irregularis .. Y. 60 . laerigata ... I. 37 . lencoptera... I. $6 \%$. limbata... I. 60 . liturata .... I. 61. longicauda .. I. 33. longicornis . I. 47. longipennis.. I. 46 . luctifera... 1. 50 . lugens..... II. 30 . lateirentris . . Г. 57. macilenta... mutabilis ... 11. 26 . nana .... I. 64 . nigricans ... T. jE peotinata I. 49 polita.... II. 29. priapulus ... I. 54 . pulehra... I. 40 . pulla .... I. 44 . pusio .... I. 63 . rava ... 11. 25. rustica ... T. 56. sellata ... I. 42 . soccata ... I. 67. sordida .... 1. 58 . testacea... II. 24. umbilicata. . I 65. umbrosa. . 1. 53. ungulata ... I. 66 . unimaculata. II. 33. vara..... 1. 57. rittata... II. 23. Hilara.

$$
\text { atra ..... II. } 42 .
$$

basalis ... II. 15 . breripila... II. 41 . femorata .. 11. 35 . gracilis .... II. 44 . Ieucoptera... II. 43 . Jutea ..... III. 33. macroptera . . III. 32. mutabilis ... II. 40 . nigriventris . II. 38 . seriata ... V.63. testacea ... V. 64 . tristis.... T. 62 . trivittata .. II. 39. umbrosa .. II. 34 . unicolor... II. 37 . velutina... II. 36 .

Hormopeza.

brevicornis . V. 65. nigricans ... T. 66 .

Gloma.

obscura ... Y. 68. rufa..... V. 67.

Crrtoma. femorata .. T. 69. halteralis ... II. 46 . longipes... II. 47 . pilipes.... II. 45 . procera... T. 70 .

\section{Tachydromidae.}

Stilpon. raripes ... 11. 58. Urapetis. pubescens... II. 57.
Platypalpus. aequalis... V. 75. apicalis ... I. 79 . debilis . . . III. 37. discifer ... III. 36 . flarirostris . . V. SO. laetus.... I. S1. lateralis... V. TS. mesogrammus III. 3 S. pachyenemus . V. T. trivialis ... Y. 76 .

Phoneutisca. bimaculata . III. 35 .

Tac bypeza. clavipes... V. 73. pusilla ... T. Tt. rapax ... T. 71. rostrata... V. T2.

Synamphotera. bicolor.... III. 31 .

Hemerodromia. defecta ... II. 55 . notata ... II. 53. obsoleta . . II. 52. scapularis . . II. 54 . ralida.... II. 51 . vittata.... II. 56 . Clinocera.

lineata ... II. 50 . simplex . . . II. 49.

\section{Dolichopodidae.}

Dolichopus.

albiciliatus . . II. 59 . dorycerus ... V. S5. fulvipes . . . II. 61 . melanocerus. T. $\$ 6$. palaestricus . T. $\$ 1$. praeustus . . II. 62 . quadrilamellatus $\mathrm{V} .83$. setosus ... II. 63 . socius ... II. 60 . splendidulas . V. \$2. Tachjtrechus. angustipennis. II. 64 . Gymopteruus. $\begin{array}{ll}\text { coxalis ... } & \text { T. } 87 . \\ \text { meniscus . . . } & \text {. } 88 .\end{array}$ Pelastoneurus. abbreviatus. . V. $\$ 9$. alternans ... V. 91. lamellatus... V. 90. Porpbyrops. longipes. ร. . 2? 
Chrysotus.

cornutus ... II. 65.

picticoruis

Sympycaus.

nodatus... II. 68 .

H ydrophorus.

parvus.

marginata... II. S1.
melampus ... II. 69. Allophyla.
Ilaevis.... II. 85. tener.... II. : 1 .

\section{Tachinidae.}

Tahlbergia. breripennis . . IV. 91. Hyalom yia. triangulifera . IV. 85.

Xysta. didyma ... IV. 86 .

Himantostoma. sugens ....IV.st.

Cistogaster. divisa... . IV. \&S.

Trichopoda. radiata ... IV. $\$ 9$. trifasciata. . IV. 90.

\section{Anthomyidae.}

Lispe. sociabilis .. II. 72 .

\section{Cordyluridae.}

Cordylura.

adusta.... III. 41. angustifrons. III. 45. bimaculata . III. 40 . cincta . . . III. 47. confusa . . . III. 43. cornuta .... III. 4 s. flavipes . . . III. 46 . gilvipes . . . III. 49. nana.... T. 94. pleuritica . . III. 42. praeusta ... V. 93. setosa.... III. 44. terminalis . . III. 39 .

H y drom yza. contluens . . III. 50.

\section{Helomyzidae.}

Helom z a. apicalis ... II. 86. latericia ... II. \$9. longipeunis . . II. 90. plumata .... II. 88. Scoliocentra.

fraterna.... III. 5l. helvola .... II. S0.

Anorostoma.

lepharoptera. armipes . . . II. $\$ 3$. leucostoma . . III. 53. lutea ... III. 5 ?. pubescens . II. 82 . tristis.... II. St.

\section{Sciomyzidae.}

Tetanocera.

ambigua... . V. 95. rotundicornis . I. 70. triangularis . I. 69 .

Sciomyza. Iuctifera... I. 71.

\section{Trypetidae.}

Trypeta. abstersa... II. 77 . alba ..... I. 72 albidipennis.. I. 73 . atra..... II. 74 . finalis .... II. $7 \mathrm{~s}$. geminata .. II, 75 . sarcinata ... II. 73 . timida . . . II. 76 . rernoniae... I. 74 .

\section{Lonchaeidae.}

Palloptera.

jucunda... . III. 55.
superba ... I. 75.
terminalis.

\section{Sapromyzidae.}

Sapromyza.

bispina

I. 79 cincta ..... I. S1. compedita... I. 76 . decora.... V. 96. fraterna.... I. 7. quadrilineata. I. 7 S. rotundicornis . III. 56 . stictica ... III. 5S. tenuispina... I. SU. umbrosa. . III. 5 i.

Pachycerina.

verticalis... I. $\$$.

La uxania.

albovittata . II. 79 .

femoralis ... I. 89 .

gracilipes ... I. 85.

manuleata... 1. 88.

muscaria ... I. 87 .

obseura ... I. 86 .

opaca .... I. $\$ 4$.

trivittata ... I. 90 .

rariagata ... I. \$3.

\section{Heteroneuridae.}

Heteroneura.

melanostoma . V.97.

latifrons. . . . IV. 93 . spectabilis . . IV. 42.

Anthophilina.

tenuis .... IV. 95 . terminalis . . IV. 94. rariegata . . IV. 96 .

Ischnom yia.

rittata....IV. 97 .

\section{Opomyzidae.}

Op om zza.

lurida.... T. 98.

\section{Ephydridae.}

Psilopa. nobilis.... II. 92.

Discocerina. leucoprocta.. I. 93 . orbitalis... I. 91. simplex ... I. 92. Hydrellia. formosa... I. 94.

Philygria. debilis.... I. 96. opposita... I. 95. Hy a dina. gravida... IV. 98.

Par ydra. abbreviata. . I. 97. varia ... IV.100.

Ephydra. subopaca... V. 99.

Scatella. obsoleta... 1. 98 . sejuncta... IV. 99 , 
Caenia.

formosa . . . III. 61

longula .... III. 64 . nigriceps . . . III. 63.

Geonyzidae.

Diastata. eluta .... III. 59 . pulchra ... I. 100 .

Diplocentra. helva ..... II.91.

\section{Drosophilidae.}

Amiota.

humeralis ... II. 93. leucostoma .. II. 94.

Drosophila. adusta..... II. 98. amoena ... II. 96. ampelophila . II. 99. dimidiata ... II. 95. punctulata. . II.100. terminalis . . III. 60 . tripunctata . . II. 97.

Oscinidae.

Crassiseta. costata ... III. 62 . nigricornis . III. 65 . Gaurax.

festivus .... III. 66 .

Hippelates.

nobilis ... III. 67. plebejus... III. 68 .

Oscinis.

atriceps ... III. 74. decipiens . . III. 76 dorsalis .... III. 72 . flaviceps ... III. 71. hirta..... III. 75 . longipes ... III. 77. nudiuscula . III. 70 . pallipes . . . III. 69 . subvittata . . III. 78. trigramma. . III. 80 . umbrosa . III. 73. variabilis ... III. 79 . Siphonella. cinerea .. . III. 81 . Chlorops. crocota ... III. 89. elzcera. . . III. 85. fossulata .. III. 82 .

grata ..... III. 92. melanocera . . III. 91. obscuricornis . III. 90. producta . . III. 96. pubescens . . III. 88. quinquepun-

ctata III. 94. Sahlbergi ... III. 95. sanguinolenta. III. 84. sulphurea . . . III. 83. trivialis . . . III. 87. unicolor .... III. 93. variceps . . . III. 86. versicolor . . . III. 97.

\section{Agromyzidae.}

Milichia. picta.... I. 99.

Odontocera. dorsalis ... III. 98 .

\section{Phytomyzidae.}

Phy tom yza.

Clematidis . III. 100.

Ilicis .... III. 99. 


\section{Diptera}

\section{Americae septentrionalis indigena.}

Descripsit

\section{H. $L \quad 0$ e w.}

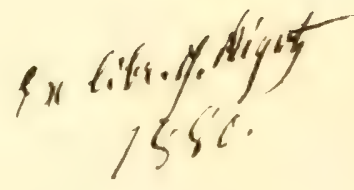

II.

B e rolini.

Typis A. W. Scbadii.

18651872. 


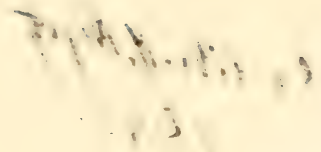




\title{
Diptera Americae septentrionalis indigena. Descripsit
}

H. L

\author{
C e n t u r i a s e $\mathrm{x}$ t a.
}

1. Ceratopogon genualis.

2. Slygeropis dimidiala.

3. - fuscipennis.

4. Stratiomyia quadrigemina.

5.

6. - unilimbata.

7. . senaria.

8. - lativentris.

$9 . \quad$ barbala.

10. - melastoma.

11. - obesa.

12. - quaternaria.

13. - apicula.

14. discalis.

15. nigriventris.

16. angularis.

17. - marginalis.

18. - nolala.

19. Odontomyia nigrirostris.

20.

21

2 .

28

28

24

2

2
27. Odontomyia pilimana.

28. - microstoma.

29. Clitellaria subulata.

30. Cyphomyia rubra.

31. marginata.

32. Oncodes pallidipennis.

33. Acrocera bimaculata.

34. Opsebius gagatinus.

35. Temnocera pubescens.

36. Vohucella apicalis.

37. - sexpunctata

39. Pipiza femoralis.

$39 . \quad$ - salax.

40. - nigribarba.

41. - fraudulenta.

42. calcarala.

43. Syrphus simplex.

44. - nigripes.

45. - praeustus.

46. - jactalor.

47. Mesogramma parvula.

$48 . \quad$ subannulata.

$49 . \quad$ - planiventris

$50 . \quad$ laciniosa.

51. - poecilogastra.

52. arcifera. 
53. Xylota pretiosa.

54. - pachymera.

55. - obscura.

56. - quadrimaculata

5\%. - subfasciala.

55. - angusticentris

59. Pteroptila decora.

60. zonala.

61. Eristalis Gundlachi.

62. - atrimanus.

63. - seniculus.

64. - atriceps.

65. - latifrons

66. - hirtus.

6\%. - obscumis.

65. - inornatus.

69. - melanostomus.

70 . pilosus.

71. Pipunculus fuscus.

72. - nitidiventris.

73. - cingulatus.

71. - subopacus.

$75 . \quad$ - nigripes.

76. Callomyra notata.
7. Callomyia divergens.

75. Platypeza velutina.

79. - flavicornis.

s0. - obscura.

61. - pallipes.

S.3. Platycnema imperfecta.

53. Diaphorus subsejunctus.

84. Psilopus castus.

\$5. - dorsalis.

86. Telanocera spinicornis

87. Eumetopia varipes.

55. Ephydra crassimana.

\$9. Drosophila flexa.

$90 . \quad$ - quinaria.

91. - bimaculata.

92. - obscuripennis.

93. Hippelates pallidus.

94. - convexus.

95. - flavipes.

96. Desmometopa tursalis.

97. Lobioptera lacteipennis.

95. Rhicnoëssa coronata.

99. Leucopis bella.

100. Sigaloëssa bicolor.

1. Ceratopogon genualis nov. sp. $\sigma$. Parvus, thoracis dorso et scutello fuscis. illo vittis duabus exalbidis postice confluen. tibus ornalo, abdomine nigro. segmentorum singulorum margine postico, ventre pedibusque dilute flavicantibus, femorum apice tibiarumgue basi nigris, alis aequaliter pilosis. - Long. corp. $\frac{1}{1} \frac{1}{2}$ lin.. Long. al. $\frac{5}{6}$ lin.

Caput fuscum, apice proboscidis palpisque nigris; antennae sub. fuscae. nigro-pilosae. Thoracis dorsum fuscum, vittis duabus albidis integris, postice late confluentibus. Scutellum et metanotum nigro-fusca. Pleurae dilute flaricantes. fusco-maculatae. Abdomen nigrum, forcipe concolore. margine postico segmentorum singulorum praeter ultima rentreque dilute flavicantibus. Pedes dilutissime flavicantes, genibus posticorum latius nigris, anteriorum angustius ni- 
gricantibus sive fuscis; femora postica subtus et tibiae posticae su. perne pilos aliquot perlongos pallidos gerunt. Halterum capitulum fuscum. Alae subcinerascentes, pilis longis aequaliter hirtae. (Cuba; Gundlach.)

2. Stygeropis dimidiala nov. sp. 2. Cinerea, vitlis tho. racis nigro-cinereis. mediâ per lineam dilute cineream divisâ, abdo. minis fasciâ media fuscâ, pleuris inter alas et halleres lateralibusque abdominis marginibus flavis; alae cinereae, stigmale subfusco. - Long. corp. $6-6 \frac{1}{3}$ lin., Long. al. $6 \frac{1}{1} \frac{1}{2}-6 \frac{1}{2}$ lin.

Cinerea. opaca. Caput nigro-cinereum, facie et frontis lateribus albo-pollinosis. Rostrum superne nigrum, lateribus luteis vel lufeo-fuscis. Palpi nigri. Antennae apicem versus valde attenuatae. nigrae, imâ flagelli basi et secundo scapi articulo rufis. Thorax cinereus. superâ pleurarum vittâ subfuscâ et plagâ magnâ inter alas et halteres flavâ. Abdomen cinereum, vittâ mediâ fuscâ. marginibus segnentorum singulorum lateralibus late. postico angustissime flavis. Primum terebrae segmentum breve. lamellae longae et tenues. Pedes fusci. femoribus adversus basim luteis, apice femo. rum tibiarumque et tarsis praeter basim nigris. Alae cinereae, venis fusco-nigris. stigmate subfusco. - (Hudson's Bay Territory; Kennicot.)

3. Stygeropis fuscipennis nov. sp. $\sigma$. Flavescens, capite thoraceque supra cinereis, alis ex ferrugineo fuscis, unguiculis dentatis. - Long. corp. ? lin., Long. al. $5_{\frac{7}{2}}$ lin.

Caput flavum, supra obscure cinereum. Rostrum concolor. superne cinerascens. Scapus antennarum ex rufo fuscus. flagellum nigrum. basi articulorum singulorum valde incrassatâ. Thorax flave. scens, dorsi vittis confluentibus cinereis. mediâ per lineam nigram divisà, pleuris cinereo maculatis. Abdomen speciminis descripti praeter basim flavam deest. Pedes multo graciliores quam in Stygeropidum genere esse solent. femoribus luteis apicem versus infuscatis, tibiis praeter apicem nigrum subfuscis. tarsis fusco-nigris. unguiculis dentatis. Alae ex ferrugineo fuscae. - (Illinois.)

4. Stratiomyia quadrigemina nov. sp. ऊ. Nigra. pilis sublutescentibus vestila: scutello praeter basim, maculis lateralibus segmenti abdominalis secundi et tertii magnis, a margine antico usque ad posticum pertinentibus. segmenti quarti triangulo medio sirigisque marginis postici lateralibus et segmenti quinti vittâ sub- 
aequali flavis; venter flavo et nigro fasciatus, fasciis anticis nigris utrinque valde abbreviatis. - Long. corp. $5 \frac{1}{3}$ lin., Long. al. $4 \frac{5}{1 \frac{5}{2}}$ lin.

Simillima Strat. Normae Wied., sed pilis totius corporis longioribus, facie multo convexiore pilis sublutescentibus, non albis ve stitâ, maculisque lateralibus segmenti abdominalis tertii multo majoribus diversa. - Nigra, pilis lutescentibus vestita. Caput totum concolor, facie valde convexâ, pilis longiusculis lutescentibus, sed prope oculos albicantibus vestitâ. Scutellum flavum. basi angulisque lateralibus nigris. Abdomen nigrum; segmenta secundum et tertium singula utrinque maculam lateralem subtriangulam flavam, inde a margine antico usque ad posticum pertinentem habent; segmentum quarlum utrinque in margine postico strigà flavâ notatur et maculà medià flavâ, longe triangulà instructum est; in segmento quinto vitta aequalis flava, antice paulo abbreviata conspicitur; praeterea margines laterales segmentorum flavi sunt. Venter flavo et nigro fascialus, fasciis anticis nigris valde abbreviatis. Femora nigra, apice lutescente, triente basali posticorum piceo; tibiae lutescentes, anteriores praeter basim et apicem plerumque subfuscae, posticae basi exceptâ subfuscae; tarsi lutescentes, articulis ultimis fuscis. Alae infuscatae. - (Connecticut; Norton.)

Nota 1. Nomen generis male fietum aptissime a Zellero in Hoplomyiam mulatum est; sed auctores recentiores plerique, familiam nomine omnino novo et inusitalo appellare nolentes, nomen a Zellero propositum rejiciunt; cum quibusdam eorum igitur nomen usitalum in Stratiomyiam vertere liceat.

Nota 2. Segmenta abdominis intermedia in plerisque speciebus marginis postici latera colore flavo limbata habent, ita ut fines laterales fasciae flavae seu maculae duae transversae adsint, quas strigas appellare ausus sum.

5. Stratiomyia normula nov, sp. 오. Nigra, albido-pilosa, capite concolore, maculâ frontis parvâ flavâ, scutello praeter basim, segmenti abdominalis secundi maculis lateralibus magnis, tertii angulis anticis extremis strigisque marginis postici lateralibus, quarti maculâ mediâ lineolisque transversis marginis postici lateralibus, vittá denique segmenti quinti, postice paulo latiore flavis vel viridibus; venter niger, fascià segmenti secundi posticâ posticisque segmentorum reliquorum marginibus flavis vel viridibus. - Long. corp. $4 \frac{1}{1} \frac{1}{2}$ lin., Long. al. 4 lin.

Ex affinibus Stratiomyiae normae, sed minor; facie totâ nigrâ, maculâ flavâ frontis minutâ, vittâ flavâ segmenti abdominalis quinti 
antice uon latiore, sed minus lalà pedibusque obscurioribus ab illâ facile distinguilur. - Nigra, albido-pilosa, in thoracis dorso pilis nigris internixtis, ita ut vittac et fasciae imperfectae et obsoletae appareant. Capul nigrum; lacies lota concolor, modice convexa; in fronte ante ocellos macula minuta subcordala flava conspicitur. Scutellum practer basim ef angulos laterales flavum vel viride. In abdominis segmento secundo utrinque macula magna subtrigona, in tertio ulrinque macula minula anguli antici et striga transversa marginis postici colore flavo rel viridi piclae sunt; sermentum quartum praeter angulorum anticorum apicem latera marginis postici tenuis. sime flavo vel viridi limbala habet et maculam mediam ejusdem co. loris, elongato-triangulam gerit; segmentum quintum villâ flavâ vel viridi, postice paulo latiore et integrâ, anlice abbreviatâ ornatur. Venter niger, fasciâ segmenti secundi posticà marginibusque posticis segmentorum sequentium flavis vel viridibus. Femora nigra, extremo apice lulescente; tibiae anteriores fuscae, posticae subfuscae, triente basali ommium dilute lutescente; tarsi lutei apicem versus fusci. Alae infuscatae. - (Nerv York; Osten-Sacken.)

Nota. Utrum haec species viva picturam viridem, ut opinor, an flavam habeat, ex speciminibus paucis exsiccatis difficile judicatur.

6. Stratiomyia unilimbata nov. sp. ㅇ․ Nigra, exalbidopilosa, capite concolore, maculà parva frontis maculisque lateralibus faciei flavis; srutello praeter basim. segmenti abdominalis secundi maculis lateralibus magnis, strigis latevalibus in margine postico segmenti terlii. segmenti yuarti limbo postico tenui, incerpuali et in medio in triangutum dilatulo, villi segmenti grinti latiuscula subaequali, angulis anticis denique segmentorum ultimorum trium favis vel ex viridi flavis; venter niger. fascid postica segmenti secundi segmentorumque reliquorum marginibus posticis favis vel ex viridi flavis. - Long. corp. $5_{\frac{1}{2}}^{\frac{7}{2}}$ lin, Long. al. $4 \frac{1}{2}$ lin.

Nigra, pilis exalbidis vel dilutissime lulescentibus vestita. Caput concolor; facies convexa, albo-pilosa, utrinque maculâ marginali flavà; in fronle macula minula subcorlata flava ante ocellos sita est. In thoracis dorso pilis dilute lutescentibus nigri intermixti, ita ut villac et fasciac incompletac et obsoletissimate fiant. Scutellum ex viridi flavum, basi angulisque lateralibus nigris. Abdomen nigrum; segmenfum secundum ufringue maculam magnam subfriangulam, segmentum tertium praeler angulos anticos exlremos utringue in margine postico strigam seu maculam transversan colore flavo 
vel ex viridi flavo tinctas habet; in segmento quarto praeter angulos anticos extremos et margines laterales ipsos limbus tenuis marginis postici inaequalis et in medio margine in triangulum dilatatus, in segmento quinto praeter angulos anticos villa latiuscula subaequalis, antice paulo abbreviata eodem colore pinguntur. Venter niger, fasciâ segmenti secundi posticâ marginibusque posticis segmentorum reliquorum flavis vel ex viridi flavis. Femora praeter apicem dilute lutescentem nigra; tibiae lutescentes, fusco-annulatae; tarsi lutescentes, apicem versus fusci. Alae infuscatae. - (Wisconsin.)

7. Stratiomyia senaria nov. sp. ఠ’. Nigra, pilis lutescentibus vestita, scutello praeter basim, maculis lateralibus segmenti abdominalis secundi mediocribus, segmentorum tertii et quarti strigis transversis in marginis postici lateribus sitis et vittâ segmenti quinti antice attenuat â flavis; veuter niger, fasciis segmentorum singulorum posticis, secundi latiore, reliquorum minus latis, flavis. Long. corp. $5 \frac{5}{12}$ lin., Long. al. $4 \frac{1}{3}$ lin.

Nigra, pilis lutescentibus vestita. Caput totum concolor, facie modice convexâ, albo-pilosâ. Scutellum praeter basim flavum. Abdomen nigrum; maculae laterales flavae segmenti secundi mediocres, triangulae; segmenta sequentia duo strigas transversas flavas in marginis postici lateribus habent; segmenti quinti vitta flava, postice latior et integra, antice paulo abbreviatur. Venter niger, fasciis segmentorum singulorum posticis flavis, secundi latiore quan reliquorum. Pedes lutescentes, femoribus praeter apicem extremum nigris. Alae infuscatae. - (Florida.)

8. Stratiomyia lativentris nov. sp. ‥ Nigra, pilis brevibus lutescentibus nigrisque vestita, facie praeter vitlam infra dilatatam, macula frontis, maculis duabus verlicis, margine occipilis laterali, scutello praeter marginem basalem, maculis lateralibus segmenti abdominalis secundi triangulis, strigulis tertii in marginis postici lateribus silis, quarti limbo postico et quinti viltâ latiusculâ subaequali flavis; venter flavus, fasciis difformibus nigris. - Long. corp. $6 \frac{1}{2}$ lin., Long. al. $5 \frac{1}{1} \frac{1}{2}$ lin.

Nigra, pilis minutis luteis et nigris vestita. Facies praeter vittam latam, infra subito dilatatam flava, pilis lutescentibus hirta. Frons nigra, maculâ mediâ rolundatâ maculisque duabus in verticis margine flavis, his in occiput nigrum continuatis; margines laterales occipitis flavi, superne nigri. Sculellum flavum, margine basali nigro. Abdomen latum, nigrum; maculae laterales flavae segmenti 
secundi mediocres, triangulac; strigae segmenti tertii, in marginis postici lateribus sitae, latiusculae; segmentum quartum marginem posticum totum inaequaliter flavo-limbatum habet, limbo medio in Iriangulum parvum dilatalo; villa flava segmenti quinti latiuscula, subaequalis, antice abbreviafa. Ventris llavi segmenta singula fascias basales nigras valde inaequales et difformes habent. Pedes ochracei, femoribus praeter apicem nigris. Alae infuscatie. - (Barnston, Lake Superior.)

Nota. Hacc species et sequentes duac abdomen latius et magis depressum quam pracedentes habent, a quibus praelerea primo antennarum articulo multo breviore dillerunt.

9. Stratiomyia barbata nov. sp. $\sigma^{7}$. Nigra, nigro-pilosa, faciei maculis lateralibus permagnis, ocripitis marginibus latevalibus, scutello praeter marginem basalem, maculis segmenti abdominalis secundi mediocribus, strigis transversis utrinque atlenuat is in lateribus marginis postici segmentorum sequentium duorum el maculâ magnà segmenli quinti, postice latiore flavis; venter niger, segmenlis singulis postice flavo-marginalis. - Long. corp. $6 \frac{1}{2}$ lin., Long. al. 5 lin.

Nigra, nigro-pilosa. Caput nigrum, praeter pilos aliquot fulvos in faciei lateribus tolum nigro-pilosum, faciei maculis lateralibus permagnis occipitisque margiuibus lateralibus totis flavis. Pili thoracis nigri, in antico dorsi triente plerique fulvi. Scutellum flavum, fulvopilosum, margine basali nigro et nigropiloso. Abdomen latum, nigrum; segmenti secundi maculae lalerales flavae mediocres, triangulae; segmenta sequentia duo in lateribus marginis postici strigis vel maculis transversis, singulis utrinque atteuuatis instructa; macula llava segmenti quinti magna, postice latior. Pili abdominis plerique fulvi, reliqui nigri. Venter niger, segmentis singulis postice flavomarginatis. Femora nigra, nigro - pilosa, apice extremo ochraceo; tibiae ochraceac, fusco-annulatae; larsi toti ochracei. Alae fuscae. - (California; Agassiz.)

Nota. Stratiomyiam foemineam e Californiâ allatam, inter hane speciem et sequentem quasi intermediam, propter formam nıculae flavae in segmento abdominali quinto et propter ventris picturam potius Stratiomyiae barbatae quam Stratiomyiae melastomae foeminam esse suspicor. Pictura abdominis eadem ac Strat. barbatae, sed strigis sive maculis transversis in margine postico segmenti quarti silis contiguis, non intervallo lato, ut in Stral. barbalat, separalis. Frons nigra. uigro-pilosa, fascii 
anticå flavâ, per lineam longitudinalem nigram dissectâ, cum faciei lateribus flavis continuâ et pilis fulvis vestitâ; puncta duo flava in vertice sita sunt, tertium ante ocellos. Facies flava, fulvo-pilosa, vittâ mediâ et triente infero nigris, pilis hujus nigris. Occiput nigrum, marginibus lateralibus totis maculisque duabus contiguis, cum punctis flavis verticis cohaerentibus, flavis. Pili thoracis plerique nigri, reliqui fulvi.

10. Stratiomyia melastoma nov. sp. $\delta$. Nigra, pilis plerisque nigris, reliquis fulvis, facie praeter lineam mediam et trientem inferum, occipitis marginibus lateralibus et lineolâ a summo vertice demissâ, scutello praeter marginem basalem, maculis segmenti abdominalis secundi mediocribus, strigis transversis in lateribus marginis postici segmentorum sequentium duorum et maculâ maximâ segmenti quinti, antice latiore et quinquangulâ flavis; venter flavus, fasciis basalibus nigris segmentorum singulorum angustis. Long. corp. $6 \frac{1}{2}$ lin., Long. al $5 \mathrm{lin}$.

Nigra, pilis nigris et fulvis vestita, his tamen rarioribus. Frons nigra, nigro-pilosa. Facies flava, fulvo-pilosa, lineâ mediâ et triente infimo nigris, hoc nigro-piloso. Occiput nigrum, marginibus lateralibus et lineolâ a vertice demissâ flavis. Pili thoracis plerique nigri, in dorsi triente antico, prope suturae fines et in angulis posticis fulvi. Scutellum praeler marginem basalem fulvum, fulvo-pilosum. Abdomen latum nigrum, pilis plerisque fulvis, reliquis nigris; maculae laterales flavae segmenti secundi majusculae, triangulae; strigae transversae in segmenti tertii margine postico flavae; strigae flavae segmenti quarti in limbum marginis postici integrum, bis dilatatum et ter sinuatum connatae; macula flava segmenti quinti per-. magna, quinquangularis, antice latior. Venter flavus, fasciis segmentorum singulorum basalibus nigris, tenuibus. Pedes ochracei, femoribus praeter apicem nigris et nigro-pilosis, tibiis imperfecte fuscoannulatis. - (California; Agassiz.)

11. Stratiomyia obesa nov. sp. ‥ Nigra, pilis longiusculis dilute hutescentibus vestita; caput flavum, antennis, fasciâ frontis occipitisque maculá nigris; scutellum flavum; anguli antici segmentorum abdominalium secundi, tertii et quarti, strigae laterales transversae secundi el tertii, limbus posticus quarli et segmentum quintum praeter limbum basalem et maculas duas difformes flava; pedes lutescentes. - Long. corp. $6 \frac{1}{4}$ lin., Long. al. $5 \frac{7}{12}$ lin.

Nigra, pube longiusculà dilute lutescente, in thoracis dorso ex- 
albidâ veslita. Caput flavo-luleum; frous superne fasciam nigram et nigro-pilosam habet, quae latera versus dilatatur et dentes breves tres ad verticis marginem emittit, inler quos maculae duae flavae conspiciuntur. Antennarum nigrarum basis maculâ minutâ vígro-fuscâ circumdatur; inter froutem et faciem utrinque macula lateralis fusca sita est. Facies viltà seu potius lineâ fuscâ notatur. Occiput maculam magnam discoidalem nigram babet, superne radios tres emittentem, ita ut margines laterales lati et marulae duae triangulae, cum verticis maculis connalac flavae sint. Thorax niger, angulis posticis et pleurarum limbo supero obsolete luteolis. Scutellum flavum. Abdomen nigrum, Jatiusculum et convexum; segmentorum secundi, tertii et quarti anguli antici flavi: segmentum secundum praeterea in marginis postici lateribus strigas seu maculas transversas flavas, appendiculam adversus seginenti basim directam emillentes habet; strigae flavae segmenti tertii longae et subcontiguae, ita ut limbum marginis postici subintegrum et bis dilata. tum constiluant; segmentum quarfum limbum marginis postici subaequalem flavum, prope latera subito attenuatum habel; segmentum quintum flavum, limbo marginis antici sinuoso maculisque duabus magnis difformibus nigris. Venter flavus, fasciis basalibus segmentorum singulorum nigris. Pedes lutescentes, femoribus infra fusco-lituratis. Alae infuscatae, apice decolore - (Illinois; Le Baron.)

12. Stratiomyia quaternaria nov, sp. $\sigma$. Nigra, scutello praeter marginem apicalem concolore; abdominis segnenta secundum el tertium utringue maculam subrolundat am flavam, inde a margine antico usque ad posticum pertineutem, segmenta reliqua margines laterales flaros habent; in segmento quinto praeterea macula triangula flava adest, e limbo marginis postici et viltâ merlià confecla. - Long. corp. 5 lin., Long. al. $3 \frac{3}{4}$ lin.

Nigra, capite toto scutelloque practer marginem apicalem concoloribus. Segmenta abdominis secundum et tertium utrinque maculâ magnâ subrotundałâ flavâ ornantur, quac inde a margine antico usque ad uarginem posticum extenditur; segmenti quarti margines laterales et fines laterales marginis postici tenuiler flavi. Segmentum quintum tenuiter flavo-marginatum et limbo postico cum vittâ antice angustiore et paulo ablireviatâ in maculam triangulam flavam confluentibus ornatum. Venter niger, segmentis secundo et tertio, illo praeter limbum marginis antici angustissimmu interruptum, hoc practer fasciam basalem utrinque subito altentatam el paulo abbreviatam. flavis; segmenta ullima duo marginem posticum 
flavum habet. Femora nigra, apice extremo dilute lutescente; tibiae anteriores praeler Irientem basalem fuscae, posticae subfuscae; larsi lutescentes, adversus apicem subfusci. Alae subinfuscatac, apice limpidiore. - (Illinois; Le Baron.)

13. Stratiomyia apicula nov. sp. $\sigma^{\top}$ et + . Nigra, scutello praeter marginem apicalem concolore; abdominis segmentum secundum alrinque macula magnà favi, inde a margine antici) usque ad posticum pertinente crnatur, terlium angulos anticos, margines laterales tenues strigasque transversas marginis postici flavas habet; quarli margines laterales tennes et marginis postici fines laterales extremi flavi; in segmento quinto praeter margines laterales flavos macula triangula flava adest, e limbo marginis postici et vittá media confecta. - Long. corp. $4 \frac{5}{6}-5 \frac{1}{2}$ lin., Isong. al. $4 \frac{1}{6}-4 \frac{7}{12}$ lin.

Nigra, capite toto concolore, fronte foeminae tamen ante ocellos maculam parvam flavam gerente; facies foeminae in utroque margine maculam sordide flavicantem habet, quae pilis confertis albis obtegitur, ita ut in speciminibus non detritis aegre observetur; margines laterales occipitis foeminae infra vel decolores, vel flavescentes reperiuntur. Scutellum praeter marginem apicalem nigrum. In secundo abdominis segmento utrinque macula lateralis flava inde a margine antico usque ad posticum pertinet; segmenlum tertium angulis anticis, marginibıs lateralibus et strigis transversis marginis postici flavis ornalur; segmentum quintum praeter margines laterales triangulum flavum, postice in limbum marginis diffluens habet. Venter niger; segmentum secundum flavum, limbo interrupto marginis antici nigro; segmenta reliqua postice flavo-limbata, ila ut fasciae latae, nigrae, postice emarginatae fiant, quarum prima in mare utrinque valde abbreviata, in utroque sexu per lineam longitudinalem flavam dividitur. Femora nigra, apice extremo dilute lutescente; tibiae anteriores praeter trientem basalem dilute lutescentem fuscae, posticae subfuscae, saepe triente apicali omnium dilutiore ita ut anteriores praeter annulum fuscum, posticae praeter subfuscum dilute lutescant; tarsi lutescentes, adversus apicem subfusci. Alae subinfuscatae, apice limpidiore. - (Illinois; Le Baron.)

Nota. Stratiomyia apicula simillima Strationyiac quaternariae, nec nisi picturâ abdominis diversa.

14. Stratiomyia discalis nov. sp. ‥ Nigra, sculello praetev marginem apicalem concolore: maculae laterales flavae segmentorum abdominalium secundi et tertii inde a margine antico usque 
ad posticum pertinentes, illius latiores lateribusque internis convexis. hujus minus latae et lateribus internis profunde sinuatis; segmenfum terlium praeter angulos anticos tolum nigrum; segmentum quintum praeler margines laterales favos lineam mpdiam flavam, tenuem et antice abbreviatam habet. - Long. corp. 5 lin., Long. al. $4 \frac{7}{7} \operatorname{lin}$.

Nigra, scuiello practer marginem apicalem concolore. Caput nigrum, maculì parvà ante ocellos flavâ, maculis marginalibus faciei marginibusque lateralibus occipitis sordide et obsolete flavicantibus. Maculae flavae segmenti abdominalis primi latae, inde a margine antico ad posticum usque perlinentes, lateribus inlernis rotundatis: maculac laterales flavae segmenti secundi, sicut primi, ab altero margine ad alterum pertinentes, sed minus latae. Lateribus internis profunde sinuatis; segmentum tertium praeter angulos anticos flavos totum nigrum; segmentum quintum praeter margines laterales flavos lineam mediam flavam, tenuem et antice valde abbreviatam babet. Segmenta venfris secundum et terlium flava, illius limbo basali sub. interrupto nigro, hujus fasciâ nigrâ latissimâ, sed utrinque subito attenuatâ et valde abbreviatà; segnenta sequentia nigra, margine postico tenuiter flavo. Pedes lutescentes, femoribus praeter apicen extremum nigris, tibiis fusco-annulatis, tarsis apicem versus fuscis. Alae subfuscae, apice vix limpidiore. - (Hassachuseits; Seudder.)

Nota. Stralioms ia foeminea, quam Le Baron misit, Stratiomyiam discalem esse persuasum baberem, nisi facies ejus convexior et abdomen pro portione longius esset. Latera interna macularum segmenti abdominalis secundi non rolundala vel convexa. sed paulo emarginata; linea flava segmenli quinli mullo latior quam in Stratiomyiâ discali et minus abbreviata; fascia nigra segmenli ventralis tertii utrinque subito abrupta et valde abbreviala, per lineam mediam flavam dissecta. - Long. corp. $5 \frac{3}{4}$ lin., Jong. al. $4 \frac{3}{4}$ lin. - (Illinois.)

15. Stratiomyia nigriventris nov. sp. ‥ Nigra, scutello praeter marginem apicalem concolore; froutis maculi parva, faciei maculis marginalibus, marginum occipilalium dimidio inferiore, segmentorum abdominalium secundi, terlii et yuarli angulis anticis strigisque transversis in margine postico sitis, marginibus lateralibus et vittâ aequali segmenti quinti flavis; venter niger. marginibus posticis segmentorum singulorum flavis. - Long. corp. 5 lin.. Long. al. $4 \frac{1}{3}$ lin.

Nigra. scutello praeter marginem apicalem concolore. Caput 
nigrum, maculâ frontis subcordatâ, maculis lateralibus faciei oblongis occipilisque marginibus infra late flavis. Abdominis segmenta secundum, tertium et quartum angulos anticos strigasque transversas tenues, in marginis postici laleribus sitas flavas lsabenl; in scgmento quinto praeter margines Jalerales vitta aequalis, antice paulo abbreviata flava est. Venter niger, segmentis singulis postice tenuiter flavo-marginatis. Pedes dilute lutesceutes, femoribus praeter apicem extremum nigris, tibiis anterioribus praeter trientem basalem et praeter apicem nigris, posticis nigro-annulatis, tarsis apicem versus fuscis vel subfuscis. Alae infuscatae. - (Nebraska.)

16. Stratiomyia angularis nov. sp. \&. Nigra, scutello praeter marginem apicalem concolore, frontis macula parvâ, faciei maculis marginalibus obsoletis, marginum occipitalium parte infeviore, abdominis marginibus lateralibus totis, segmentorum secundi et sequentium angulis anticis, tertii et quarli strigulis transversis tenuibus, in margine postico silis et vitlá aeguali segmenti quinti fluvis; venter flavus, fasciis basalibus segmenlorum singulorum nigris. - Long. corp. $5 \frac{2}{3}$ lin., Long al. $4 \frac{2}{3}$ liu.

Nigra, scutello praeter marginem apicalem concolore. Caput nigrum, inaculà frontis subcordatâ, maculis lateralibus faciei obsoletis occipitisque marginibus infra tenuiter flavis. Margines abdominis laterales ipsi flavi; segmenta secundum et tertium utrinque in angulo antico maculam rolundalam et in margiue poslico lineolam trausversam flavas babenl; segmentum tertium similiter piclum, sed maculis angulorum anticorum longioribus, lineolis transversis vero brevioribus; maculae segmenti quinti in limbum postice tenuiorem marginis lateralis elongatae, vilta media subaequalis, antice paulo abbreviata. Venter flavus, vittis basalibus segmentorum singulorum nigris, utrinque valde abbreviatis, secundi et quinti reliquis tenuioribus, illà interrupt $\hat{h}$, hac integrâ, segmentorum intermediorum utrinque subilo altenuatis. Pedes lulesceutes, femoribus practer apicem extremum nigris, tibiis praeter trientem basalem subfuscis, anticis fusco-annulatis, tarsis apicen versus fuscis. Alae infuscalae. - (Philadelphia.)

17 Stratiomyia marginalis nov. sp. ․ Nigra, sculello praeler marginem apicalem concolore, macula frontis parvà, faciei maculis marginalibus, marginum occipitalium parte inferâ, abdominis marginibus luteralibus totis, strigulis transversis brevibus in se- 
gmentorum secundi, tertii et quarti marginibus posticis. limbis lateralibus segmenti terlii postice minus latis, quarti et quinti subaequalibus. vitta denique segmenti quinti fluvis: venter flavus, fasciis basalibus segmentorum singulorum nigris, latis, utrinque subito abruptis et valde abbreviatis. - Long. corp. $5 \frac{2}{3}$ lin., Long al. $4 \frac{2}{3}$ lin.

Nigra, scutello praeter marginem apicalem concolore. Caput. nigrum, maculâ fronlis subcordatâ, maculis marginalibus facici occipitisque marginibus lateralibus infra tenuiter flavis. Abdominis segmentum secundum praeter margines laterales ipsos et praeter lineolas transversas perbreves, in lateralibus marginis postici finibus silas, totum nigrum; segmentum tertium margiues laterales antice latius, postice tenuius flavo-limbatos et lineolas transversas posticas paulo longiores habet; segmentorum reliquorum margines laterales subaequaliter flavo-limbati; vilta flava segmenti quinti postice paulo latior, antice modice abbreviala. Venter flavus, fasciis basalibus nigris segmentorum singulorum latis, utrinque valde abbreviatis et subito abruptis, segmenti secundi postice undatâ. quinti in maculas duas semirolundas fere disseclâ. Pedes dilute lutescentes, femoribus praeter apicem extremum nigris, tibiis anticis praeter trientem basalem fuscis, apice tamen dilutiore, tibiis posticis fusco-anuulatis, tarsis omnibus apicem versus subfuscis. Alae infuscalae, apice limpidiore. - (Philadelphia.)

18. Stratiomyia notata nov. sp. б. Nigra, scutello praeter apicem concolore, maculis transversis segmenti abdominalis secundi, strigis transversis segmentorum sequentium duorum, maculâ mediâ Iriangulâ in margine postico segmenti quarti et vittâ postice latiore segmenti quinti pallidis, - Long. corp. 4 lin., Long. al. $3 \frac{1}{2}$ lin.

Nigra, capite et scutello, apice tamen hujus excepto, concoloribus. Abdominis segmentum secundum ulrinque maculam transversam pallidam, cum margine postico contiguam, ab antico remotam habet; in segmento tertio anguli antici et marginis postici strigae laterales pallidae sunt; segmentum quarlum praeter strigas laterales in margine postico maculam triangulam colore pallido pictam babet; vitta pallida segmenti quinti postice latior, antice subacula et paulo abbreviata; abdominis margines laterales ipsi maximà ex parte flavi. Venter niger, fascià segmenti secundi posticâ pallidâ, latâ. in medio ventre usque ad basim segmenti pertinente, limbis pallidis marginis postici segmentorum sequentium singulorum tenuibus. Pe- 
des dilutissime lutescentes, femoribus practer apicem extremum nigris, tibiis fusco-annulatis, tarsis adversus apicem fuscis. Alae subinfuscatae, apice modice limpidiore. - (Nebraska.)

Nota. Utrum pictura abdominis vivae dilute flava, an viridis sit, ex specimine, quod supra descripsi, non liquet.

19. Odontomyia nigrirostris nov. sp. $\sigma^{7}$. Nigro et flavo varia, scutelli dentibus nullis, alarum cellulis submarginalibus duabus, posterioribus quinque. - Long. corp. $5 \frac{2}{3}$ lin., Long. al. $4 \frac{3}{4}$ lin.

Nigro et flavo varia, pube pallidâ vestita. Caput flavum; vittae laterales frontis nigrae, latae, antice abbreviatae, postice cum maculà nigrâ verticis cohaerentes; macula nigra faciei magna. Antennae nigrae, articulo primo quam secundus paulo longiore. Proboscis tota nigra, palpis concoloribus. Thoracis dorsum nigrum, angulorum posticorum margine pallide flavescente. Pleurae pallide flavescentes, nigro-maculatae; pectus nigrum. Scutellum muticum, pallide flavescens, basim versus nigrum. Abdomen latum, subplanum, atrum, angulis segmenti primi, maculis lateralibus secundi inde a margine antico ad posticum usque pertinentibus, strigis transversis in tertii et quarti marginibus posticis et ipso abdominis margine toto pallide flavescentibus. Venter totus pallidus. Pedes nigri, femorum omnium apice, tibiarum anteriorum dimidio priore, posticarum tarsorumque anteriorum basi dilutissime flavicantibus vel exalbidis. Alae pure hyalinae, venis validioribus ochraceis, longitudinali tertiâ ramulo instructâ, iła ut cellulae submarginales duae fiant; cellula discoidalis venas emittit tres, quarum ultima praecedentibus multo brevior est. (North Wisconsin; Kennicot.)

Nota. Cellularum posteriorum numerus in distinguendis Odontomyiis notam praebet, quâ maximopere confidas; minus certa nota cellularum submarginalium numero efficitur, cum in is speciebus, quae unâ tantum cellulâ submarginali utuntur, non raro accidat, ut vena tertia ramo instructa sit, aut ubi duae cellulae submarginales esse solent, hic ramus desit.

20. Odontomyia megacephala nov. sp. ठ․ Vividis, thoracis dorso praeter angulos posticos, scutello praeter apicem, abdominis vittâ latiusculâ, punctis quatuor in angulis anticis segmentomum tertii et quarti nigris: pedes badii, dimidio priore femorum virescente, tarsis praeter basim nigris; alarum cellulae submarginales duae, posteriores quinque. - Long. corp. $5 \frac{2}{3}$ lin., Long. al. $4 \frac{1}{2}$ lin. 
Odontomyiae Lefebvrei Macq. affmis. Caput permagnum; triangulum verticale nigrum, basi tamen viridi; oculorum areolae superae majusculac. inferae minutissimae; triangulum frontale minufum, nigrum. Primi duo antennarum articuli cylindrici, aequales. rufo-ferruginei; articulus tertius niger, infra ferrugineus, apice tamen toto nigro. Facies tota viridis, immaculata, non prominens, adversus oris aperturam valde recedens, convexa et obtuse carinala. Thoracis dorsum nigrum, angulis posticis riridibus. Pleurae totae virides; pectus cinereum. Scutelli dimidium basale nigrum, apicale viride. Metanotum nigrum. Abdomen viride, vittâ mediâ atrâ, adversus basim segmenti primi dilatatâ, in seggmentis secundo et ter. lio utrinque emarginatâ; praeterea anguli antici segmentorum tertii et quarti maculis parvis atris notantur. Venter totus viridis. Pedes badii vel rufo-ferruginei, femoribus anlicis praeter dimidium secundum, intermediis praeter trientem apicalem et posticis praeter apicem ex flavo virescentibus; apex tibiarum anticarum et tarsi omnes nigri, horum tamen articulo primo praeter apicem badio. Alae pure hyalinae, venis validioribus obscure ochraceis, longitudinali tertiâ ramulo instructâ, cellulà discoidali venas tres aequales emittente. - (California; Agassiz.)

21. Odontomyia varipes nov. sp. $\delta$. Viridis, thoracis dorso praeter angulos posticos, scutelli maculá basali trigonâ et abdomine praeter maculas laterales magnas et praeter segmenti quinti limbos nigris; pedes subbadii, femorum dimidio priore tibiarumque basi flavicantibus, tibiarum dimidio apicali tarsisque praeter basim fusco-nigris; alarum cellulis submarginalibus duabus, posterioribus quinque. - Long. corp. $5 \frac{1}{3}$ lin., Iong. al. $3 \frac{5}{6}$ lin.

Odontomyiae megacephalae affinis, sed capite minore et alià abdominis picturâ diversa. Triangulum verticale nigrum, basi tamen viridi: triangulum frontale minutum, nigrum. Primi duo antennarum articuli cylindrici, aequuales, primus fusco-niger, secundus rufo-ferrugineus; articulus tertius in specimine descripto deest. Facies viridis margine supremo nigro, non prominens, adversus oris aperturam valde recedens, obtuse carinata. Proboscis dilute flavescens, palpis concoloribus, labellis nigris. Thoracis dorsum nigrum, angulis posticis viridibus. Scutellum viride, maculâ basali nigrâ, late triangulà. Pleurae virides. maculâ mediocri dilute subfuscâ. Abdomen nigrum, angulis segmenti primi, maculis lateralibus secundi et tertii magnis, illius inde a margine antico ad posticum usque pertinentibus, hujus a margine antico fasciâ nigrà separatis. maculis minoribus subrotun- 
datis segmenli quarti, limbis deneque lateralibus et postico segmenti quinti viridibus. Venter tolus viridis. Femora dilute flavicantia. dimidio secundo anticorum, intermediorum triente ultimo posticorumque apice ferrugineo-rufis; tibiae ferrugineo-rufae. dimidio apicali anteriorum posticarum apice fusco-nigris; tarsi fusco-nigri, primo posteriorum articulo praeter apicem rufescente et imâ anticorum basi badiâ. Alae pure hyalinae, venis validioribus obscure ochraceis, longitudinali terliâ ramulo insłructâ, cellulâ discoidali venas tres aequales emittente. - (Carolina?)

22. Odontomyia binotata nov. sp. $\sigma$. Viridis, thoracis dorso praeter limbos laterales et praeter puncta duo disci, metanoto et vittâ abdominis nigris; alarum cellula submarginalis unica, posteriores quinque. - Long. corp. $5 \frac{1}{1} \frac{1}{2}$ lin., Long. al. $4 \frac{1}{2}$ lin.

Triangulum verticale nigrum, basi tamen viridi; Iriangulum frontale minutum, nigrum. Antennarum articulí primi duo cylindrici, subaequales, ex ferrugineo rufi. Facies tota viridis, non prominens, adversus oris aperturam valde recedens, modice convexa et obtuse carinata. Proboscis pallida, palpis concoloribus, labellis nigris. Thoracis dorsum nigrum, maculis duabus parvis disci marginumque lateralium limbis viridibus. Pleurae virides; pectus cinereo-nigrum. Scutellum totum viride; metanotum nigrum. Abdomen viride, vittâ adversus basim segmenti primi valde dilatatâ, in segmentis secundo et tertio profunde emarginatâ, punctisque duobus, in angulis anticis segmenti quarti silis nigris. Venter totus viridis. Pedes ex ferrugineo rufi, femorum dimidio priore tibiarumque basi flavescentibus, femorum anteriorum apice superne, tibiarum anteriorum apice toto tarsisque omnibus nigris, metatarsis tamen posterioribus praeter apicem anticorumque basi ex ferrugineo rufis. Alae pure hyalinae, venis validioribus ochraceis, longitudinali tertiâ sine ramulo, cellulà discoidali venas tres aequales emittente. - (Illinois; Le Baron.)

23. Odontomyia lasiophthalma nov. sp. $\sigma$. Nigra, viridi-varia, oculis valde pilosis, secundo antennarum articulo quam primus dimidio breviore, pedibus luteis, femoribus praeter apicem nigris; alarum cellula submarginalis unica, posteriores quinque. Long. corp. $4 \frac{1}{6}$ lin., Long. al. $3 \frac{1}{3}$ lin.

Caput nigrum; facies concolor, breviter conica, maculis duabus transversis, fasciam anguste interruptam constituentibus, duabusque minoribus in antico oris margine pallidissime flavicantibus. Oculi pilis longiusculis confertim vestiti. Primi duo antennarum articuli 
sordide lutei, apicem versus obscuriores, secundus dimidio et u!lra longior quam primus: articulus terlius in specimine descripto decsi Thoracis dorsum pilis sublutescentibus hirtum. nigrum. angulis pu. sticis ex flavo viridibus. Pleurac concolores. albido-pilosae, maculis duabus ex llavo viridibus, superiore majore et in anguli formam fracti, inferiore minore et oblongo-ovatâ. Scutellum nigrum, limbo latiusculo marginis ex flavo viridi. Abdomen nigrum, margine tolo maculisque utrinque tribus viridibus, maculis segmenti secundi majoribus et triangulis, ad marginem anticum usque non pertinentibus. tertii mediocribus et transversis, quarli strigiformibus. Venter 10. tus viridis. Pedes lutei vel ex luleo ochracei, femoribus practer apicem nigris. Alae hyalinae, venis crassioribus ochraceis, longitu. dimali tertia sine ramulo, celluli discoidali venas tres aequales emit. tente. - (New York; Calverly.)

Nota. Hace specics propter arliculum primum antemarum se. cundi longitudinem valde superantern infer Stratiomyias ei Odoniomyias quasi intermedia propter venam longitudinalem tertiam simplicem rectius ad Odontomyiarum quam Strationviarum genus referiur. Eandem ac Stratiomyiam vicinam Mar. quarti (non Odonfomyiam vicinam cjusdem) esse conjicerem. nisi Macquartus maculas laterales abdominis. quae in nostri specie virides sunt et ab antico segmeniomm margine fascia nigrâ separantur. in suâ rufas esse et inde a postico ad anti. cum usque marginem segmentorum singulorum pertinere affir. maret. -

24. Odontomyia inaequalis nov. sp. O' et R. Nigra, pleurarum maculis, scutelli margine apicali. abdominis marginc laterali segmentorumque singulorum limbo postico, ventre denique tole en flavo virescentibus. pedibus luteis, tursis praeter basim fuscis: alurum cellulae posteriones quatuor, submarginales plerumgne duate in terdum unick.

of capnet nigrum. inferiore fuciei dimidio flavo: limbi postici segmentorum abdominalium secundi. tertii el quarli latissime in cerrupli.

I caput flanum, occipitis disco. fasciis fronlis duabus el fociei macula triangula nigris: limbi postiri segmontorum abdominulinm omnes integri.

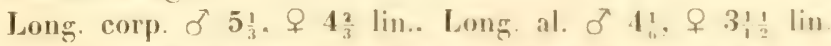

Mas. Caput nigrum, Caciei dimidio inferione inde ab antico oris angulo dilute flavo. Antennac nigrae. arliculis primis duobus 
fuscis, subtus badiis. Proboscis nigra; palpi dilute flavi. Thorax niger, lutco-pilosus, pleurarum maculis duabus, alterâ difformi supra coxas anticas, alterâ rotundà ante alas, flavis. Scutellum nigrum, limbo apicali lato dentibusque brevibus ex flavo virescentibus, extremo horum apice nigro. Abdomen nigrum, margine toto segmentorumque secundi, terlii et quarli limbis posticis late interruptis ex flavo virescentibus, his in segmento secundo in maculas subtriangulas dilatatis, in segmento quarto subobsoletis. Venter to. fus ex flavo virescens. Pedes lutei, tarsis inde ab articuli primi apice nigro-fuscis, articuli secundi basi tamen dilutiore. Alae pure hyalinae, venis validioribus ochraceis, longitudinali tertiâ in alâ alterâ simplice, in alterâ ramuli rudimento obsolelo instrucfâ, cellulâ discoidali venas duas emittente, quarum anterior prope basim tenuissima. - (Hudson's Bay Territory; Kennicot.)

Foemina. Caput flavum, occipite practer orbilas nigro; frons nigro quadrimaculala. maculis superis cum maculâ minutâ nigrâ verticis confluentibus, ita ut fasciam utrinque oculorum marginem prope attingentem constituant, maculis inferis oblique ductis, in mediâ fronte subcontiguis, utrinque marginem oculorum aftingentibus. Facies modice prominens, convexa, maculâ triangulà niğâ ornata. Proboscis nigra; palpi dilute flavi. Thoracis dorsum nigrum, subaureo-tomentosum, angulis posticis ex flavo virescentibus. Pleurae ex flavo virescentes, maculâ magnâ nigrâ. cuın colore nigro pectoris cohaerente. Scutellum nigrum, limbo apicali lato dentibusque parvis ex flavo virescentibus, extreno horum apice nigro. Abdomen nigrum, marginibus segmentorum singulorum lateralibus aequaliter, posticis subaequaliter ex flavo virescentibus. Venter totus ex flavo virescens. Pedes lutei (tarsi in specimine descripto desunt). Alae pure hyalinae, venis validioribus ocliraceis, longitudinali tertiâ ramulo instructâ, cellılà discoidali venas duas emiltente, quarum anterior prope basim tenuissima est. - (Hudson's Bay Territory: Kennicot.)

Nota. Mas et foemina, quos descripsi, eodem tempore a clarissimo Kennicot prope ..Fort Resolution" capti sunt; cum signa abdominum eorum adeo differant, diu dubius haesi utrum sexu tantum an specie eos differre existimarem; sed tantopere in ceteris notis congruunt, nt priorem opinionem amplecti permovear.

25. Odontomyia rufipes nov. sp. $\sigma$. Capite thoraceque tolis nigris. sculello abdomineque favis. basi tamen illius, hujus viltá 
segmentorumque singulorum fasciu basali ngris, pedibus rufis: alurum cellulae submarginales duae, posteriores quatuor. - J,ong. corp. 5 lin., Long. al. $3_{6}^{5}$ lin.

Capul lotum nigrum. Primi duo antenuarum articuli ex fusco nigri, subacquales; tertius in specimine descripto deest. Facies mn. dice prominens, convexa, obluse carinala, albo-pilosa. Proloseis nigra. Thorax totus niger, pilis longiusculis abidis. in pleuris allois birtus. Scutellum flavum. basi nigrâ. Abdomen flavum. vilfâ unrdiâ, in margine antico segmenti secundi dilatatâ. segmenlorumupue sequentium singulorum fascià basali integrâ nigris. Venter tolus flavus. Pedes ex ochraceo rufi; larsi postici speciminis descripli desunt. Alae pure hyalinae, venis validioribus ochraceis, longiludinali terliâ ramulo instructâ, cellulà discoidali venas duas emittente. - (Cuba; Gundlach.)

Nota. Colorem abdominis vivae viridem esse suspicor.

26. Odontomyia scalaris nov. sp. O. C'apile flavo. muculâ verticis et vilta faciei nigris, thouras donso nigro, limbo laterali lato inde ab humeris usque ad suluram perlinente angulisgue posticis flavis, pleuris faris nigro-marnlatis, scutello toto fluro. prdibus rufis; alarme cellulae submarginales duae. posteriores yun. tuor. - Long. corp. $4 \frac{11}{12}$ lin. Jong. al. $3 \frac{3}{4}$ lin.

Caput flavum, occipitis disco el maculât verticis dillormi nigris Primi duo antemnarum articuli fusco-nigri. subaequales: icrlius dext. Facies modice prominens, convexa, oblusissime carinata. albo-pilo sula, villâ mediâ nigrà. Thoracis dorsum nigruu. aureo-tomento. sum. marginis lateralis limbo lato. inde ab lumero usque arl sufu. ram pertinente. et angulo postico flavis. Plemae flavae. nicro-maculatac, albo-pilosulae. Pectus et metanotum nigra. Sentellum fofum flavum. Abromen flavum. villà media segmentorumune secundi et sequentium singulormm fascia antici nigris. Ventro tutus flavus. Pedes ex ochraceo rufi. tarsis poslicis apicem versus fusris. Alae pure hyalinae, venis validioribus ochraceis, longitudinali tertiti ramulo instructà. colluli discoidali venas duas emiltente. - (Cubia: Gundlach.)

Nota. Odontomyia rulipes et Odonlomyia sealaris forsitan mas et foemina ejusdem specici sunt. sed illa sculelli basim nigram. haec seutellum lotum flavum habet: in reliquis Odonfomyia rum specicbus omnibus. quas adhus observare liouil. smulalli piclura in utroque: sexu radem est. 
27. Odontomyia pilimana nov. sp. $\delta$ et $q$. Nigra. an. tennis rufis, thoracis dorso in urogue sexu aureo-tomentoso. abdomine viridi, villá medià nigrâ, pedibus luteis, anticorum posticorumque tibiis et metatarsis subtus pilosis; alarum cellulae posterio res qualuor, submurginalis unica.

$\sigma$ pilis thoracis brevioribus, quam in speciebus cognatis.

+ fronte prope ocellos luteo-bipunctali.

Long. corp. $4-4 \frac{7}{12}$ lin., Joug. $3 \frac{1}{12}-3 \frac{5}{\frac{5}{2}} \mathrm{lin}$.

Mas. Caput nigrum, facie pilis albis aspersâ, obtuse bicarinatâ. infra antenuas prominente, adversus oris aperturam recedente. Antennae rufae, extremo articuli tertii apice nigro. Proboscis crassa. nigra. Thorax totus niger; dorsum pube lutescente quam in specierum affinium maribus breviore et tomento aureo vestitum; pleurae albido.pilosae. Scutellum nigrum, dentibus et margine apicali virescentibus. Abrlomen viride, vittâ medià nigrâ, postice modicu dilatatâ. Pedes toti Julei; anticorum posticorumque tibiae et metatarsi subtus pilis longiusculis pallidis vestiuntur. Alae hyalinae venis validioribus lutesccntibus, longitudinali tertiâ ramulo instructâ. cellulà discoidali venas duas emittente. - (Illinois; Le Baron.)

Foemina. Mari simillima. Frons ante ocellos luteo bipunclata et utrinque maculâ aureo-tomenlosâ ornala. Orbilac posticac supra tomeuto aureo. infra albo obtectae. Thoracis dorsum confer; tim aureo-tomentosum, pleurae albo-pilosulae. Vitla nigra abdominis in segmentis tertio et quarto magis dilatala quam in mare. (lllinois; Le Baron.)

25. Odontomyia nicrostoma nov. sp. ․ Lutea, thoracis dorso praeter humeros angulosque posticos nigro, abdomine praeter limbos laterales latos, maculam segmenti quarti triangulam similemque quinti nigro, ventre tamen luteo, fusco-bivittato; cellula submarginalis unica, posteriores quatuor. - Long. corp. 5 lin., Long. al. $4 \frac{1}{6} \operatorname{lin}$.

Caput Iulescens; occipitis discus fuseo-maculatus; in fronte praeter maculam verticis Irilobam inlerdum fascia inlerrupla fusco-nigra conspicitur. Antennae fusco-nigrae, articulis primis duobus badiis vel fuscis, ultimis duobus articuli tertii segmentis stylum acutiusculum constiluentibus. Facies non prominens, modice convexa, pilis dilutissime flavicantibus vestita. Oris apertura parva; proboscis nigra, labellis subfuscis, palpis luteis. Thorax luteus, subaurco-tomentosus, dorso praeler humeros angulosque posticos nigro, pectore fusco-bimaculato. Scutcllum luteum, denlibus parvis, plerumque 
praeter basin nigris. Metanotum nigrum. lateribus lanen luteis Abdomen nigrum. limbis lateralibus latis el repandis maculisque friangulis duabus, allera in segmenti quarti. alleri in quinti apico. silis. lutescentibus; specimina immalura abdomen fere folmon ex fusen luleum, limbos lamen laterales maculasque driangulas sesmentorum quarti el quinti dilulius lu!escentes habeut. Venter dilut lulescens. villis duabus laleralibus lalissimis fuscis. Pedes lulei. Larsis posticis plerumque fere totis olscure fuscis, femoribus posterioribus inlerdum fusco-liluratis. Alae subhyalinae. leviter lutescentes. venis validioribus luteis, longibudiuali terlia simplici. cellula discoidali venas duas emillente. - (Massachusels; Samborn. - New lork: Calverly.)

Nola. lostrema duo segmenla lertii antennasum articuli in hat specie stylum satis acufum formanl. ul falcudum sit. andeunas cjus non dissimiles esse Clilellariarum antemnis. sed venarmm in alis decursus huic specici lormu deberi inler Odonlomyias demonstrat. Eandem prorsus rem in compluribus aliis Colonlo myis videmus, qualis inler europacas Odontomyia limbala. cujus foeminam Meigenius. Lac singulari antennamm formi de eeplus, nomine novo Clifellariac pacificac descripsil.

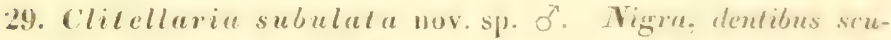
telli halleribusque albis, tarsis fuscis. primis duobus posterionum articulis albidis: alae hyalinae. Alimidio apicali infuscalo, adrersus marginem posticum dilutiore. cellulis subnurginalibus subhyalinis. long. corp. $3 \frac{1}{3}$ lin. Long. al. $3 \frac{3}{2}$ lin.

Tolat nigra, modice nitens. Capul coucolor: anlemnae nigrofuscae, basi et slylo mudiusculo nimpis; frous el facies afbo-pilosar: palpi nigri; oculi pilis conlerlis, in alin luminc nigris, in alio sub. fuscis vestiti, postice el infra albidu-pilosi. P’ili nigri vertich al ni gricanles thoracis lumine mulato colorem mulant. illi in sulafusram.

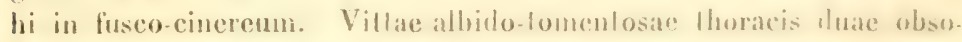
letissimae. Sendelli pili quam thoracis paule ohsenriores, donfer mediocres albidi. albido - pilosi. Ablomen breve. subrolumbun: in segmenlis tertio el quarlo pubes alloida maculas laterales transversas effecil; practerea macula mimula. in margine poslieo sesmenti

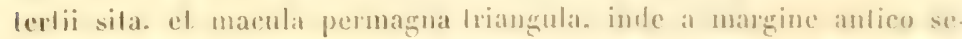

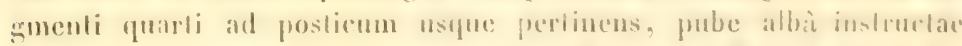
sunl; segmenlam quintum folmu albo-pubeseons. Venter niger, los. fus pube brevisimat albit aspersus. Peales nigri. Dresissime albu-pu

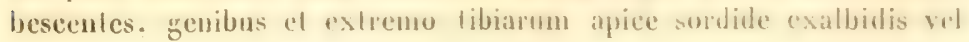


dilute subfuscis; tarsi antici fusci, infra dilutiores, posteriores exalbidi, articulis ultimis tribus subfuseis vel fuscis. Halteres albi. Alae hyalinae, dimidio apicali infuscalo, adversus marginem posticum diluliore, cellulis submarginalibus et limbo antico cellulae posterioris primae subhyalinis; cellula marginalis perhrevis, angustissima, fusca; apex cellulae costalis et cel!ula stignaticalis concolores. - (Virginia)

30. Cyphomyia rubra nov. sp. Ұ. Rufa, capite pedibusque

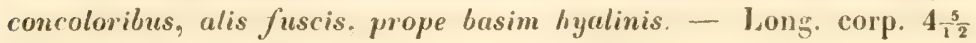
lin., Long. al. $4_{i}^{5}$ lin.

Rufa, nudiuscula, modice nitens. Caput concolor, fronte et posticâ oculorum orbitâ anguslis, aequalibus, hac albo-tomentosâ. Antenuae longae, totae nigrae. Facies albido-pilosula. Thoracis dorsum e colore rufo in badium vergens. lineis tribus niveo-tomentosis, mediâ postice admodum abbrevialâ, lateralibus interrup̣tis. Scutellum concolor, apice alho-lomentoso. Abdomen pube brevissimâ nigrâ, prope basiun longiore albidâ vestilum. maculis lateralibus albido-pilosulis segmentorum tertii el quarti obsoletissimis. Pedes rufi, tarsis ochraceis, apicem versus fuseo-nigris. Alae nigro-fuscae. basim versus hyalinae. - (Cuba: Gundlach.)

31. Cyphomyia marginala nov. sp. O' et f. Chalybea, thoracis viltis abdominisque maculis lateralibus albido-tomentosis, scutello, abdominis margine tolo femorumque dimidio apicali rufis.

$\delta$ praeter comentum albidum pilis longioribus nigris vestilus.

I fronte carinala et orbilà oculorum postica rufis.

Long. corp. $3-4 \frac{1}{6}$ lin, Long. al. $3-3 \frac{3}{4}$ lin.

Chalybea. Caput maris concolor; oculi superne pilis longis nigricantibus, postice et infra albicantibus vestiti; triangulum frontale albo-tomentosum: facies pilis brevioribus albis longioribusque nigris hirsuta. Caput foeminat rufum, occipite praeter orbitam et facie praeter margines chalybeo-nigris; oculi pilis brevibus plerisque albidis hirti; facies pilis albidis instructa; orbitac albo-tomentosae. Antennae maris breviores et tenuiores quam foeminac, rufae, articulo primo, raro articulis primis duobus, et apice nigris; antennae foeminae plerumque totae rufae, articulis primis et ultimis paulo obscurioribus. Thoracis dorsum tomento albicante trivittatum, in mare praeter hoc tomentum pilis longioribus nigris instruclum. Scutellum rufum vel rufo-testaceum pilisque nigris in mare longissimis, in foeminâ brevibus vestitum; dentes dilutiores. apicem versus albido- 
pilosis. Abdomen chalybeum, limbo marginali ruto in apice abdo. minis foeminae valde dilatato; pubes albida speciem maculanum lá teralium magnarum elficit in ullimis duobus maris. fribus focminas segmentis; reliqua pubes nigra, in fucmina brevissima in mare longa. basi tamen abdominis in utroque sexu longins albo-pilosi. Venter chalybeas, maris albo-pilosus, segmentis ultimis duobus rulo-marginatis, foeminae brevissme albo-pubescens, segmentis singulis praeler primum late rufo-marginatis. ultimo plermmone toto ruto. Pedes ruti vel ex rufo badii, femoribus basim versus libiisque practer imam basim nigris vel nigro-fuscis, farsis nigro-fuscis, arliculo tamen primo praeter apicen exalbido. Alac cinereo-hyalinac stigmate subfusco.

- (Cuba; Gundlach.)

Nola. Haec Cyphomyia tota corporis formi quibusdam Clilellaris similis est, sed co, quod antennae extremae non in slylum. nt in illis. eseunt ef quod vena intercalaris posterior ex secunda cellula basali orilur, eam vere ad Cyphomyias referri probaliur.

32. Oncodes pallidipennis nov. sp. I Vigro-fuscus. pube dilute lutescente vestitus, segmentorum abdominulium singulomum marginibus posticis tenuiter albis, alis hyatinis, renis exabiclis. Long. corp. ¿ L lin.. Long. al. $2 \frac{1}{4}$ lin.

Nigro-fuscus, pube dilute lulesecule veslifus. Thoracis calli anlesculellares testacei. Hargines poslici segmentornm abdominalium singulorum lenuiler albi. V'enter linsens, segmentis singulis posliec albido-marginalis. Pedes ex fusco teslacei. founoribus praeler apicem extremum fusco-nigris, farsis apiecm versus fuscis. Tegular sordide exalbidae, fusco-marginatae. Halteres nigri. pedumenlo pallido. Alae hyalinae, venis omnibus decoloribus. maculi stigmalirali nullà. - (Penusylvania; Osten-Sacken.)

Nola. Oncodes dispar Mace. tegulas flavicantes. halleres llavos el alas maculà slignalicali nigro-fuscá insignes label.

33. Acrorena bimaculala nov. sp. ot et f. Piceo-nignru. abdominis apire luteo-bimaculata. halleribus, flavis. alis requaliter et modice infuscalis. ecnis obscure fuse is, longitudinali secundie, prate-

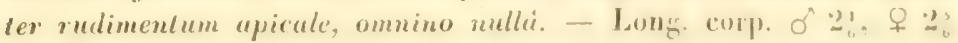
lin. Long. al. ơ 2⿺辶, $9: 3 !$ lin.

Piceo-nigra, pube brevi sublused veslila. Ialli humerales ple rumque testacei vel fuseo-testacei. antesculellanes interdum lestaceo.

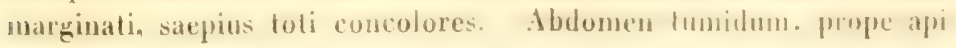


cem utrinque maculâ magnâ transversâ luteâ notatum. Venter píceus, segmentis singulis postice exalbido limbatis. Pedes pallide testacei, femoribus tibiisque plerumque magnâ ex parte luridis. Tegulae sordide exalbidae, fusco-marginatae. Halteres dilute tlavicantes. Alae modice et aequaliter infuscatae, venis validis, obscure fuscis, auxiliari tamen nigrâ; vena longiludinalis secunda praeter apicis rudimentum omnino deest; vena longitudinalis tertia furcata et transversae ambae perfectae, ut in speciebus plerisque. - (Distr. Columbia; Osten-Sacken.)

34. Opsebias gagutinus nov. op. ․ Nigerrimus, nitidus. pedibus halteribusque luteis, alis fusco-nigris, cellulá posteriore primà per venam transversum divisi. - Long. corp. $2 \frac{3}{4}$ lin., Long. al. $3 \frac{1}{\frac{1}{2}} \operatorname{lin}$.

Nigerrimus, nitidus, capite tboraceque pube longiusculâ subfuscâ, abdomine pube breviore el pallidiore vestitis. Coxac nigrac; pedes toti lutei. Tegulae mediocres, sordide lutescentes, pallide pilosae, margine extremo fusco. Halteres dilute lutescentes. Alae totae fusco-nigrae, venis nigris ut in Opsebio inflato directis, venâ famen transversâ anteriore obliquâ et adjectâ venâ alterâ transversî, quae cellulam posteriorem primam inter cellulae discoidalis finem et cellulae submarginalis secundae basim dissecat. - (Philadelphia; Osten-Sacken.)

Nota. Hoc genus dipterorum, cui Pithogastri nomen imposui

(Wien. entom. Monalschr. I. 34.), jam prins ab Achille Costî Opsebii nomine appellatum est.

35. Temnocera pubescens L,w. \&. Nigra, capite, thoracis dorso, pleurarum parte superiore abdominisque lasi lutescentibus, antennis subfuscis, alis cinereo-hyalinis, venis trunsversis totis, venis longitudinalibus auxiliari et tertia in summo apice fusco-limbatis. - Long. corp. 6 lin.. Long. al. $5 \frac{1}{2}$ lin.

Syn. Temnocera pubescens Loew Wien. ent. Honatschr. V.38.

Caput luteum, orbitâ oculorum posticâ albo-pollinosâ. Faciei pars inferior longe producia, acuminata, pilis brevibus nigris confertim vestita. Antennae subfuscae, supero articuli tertii margine exciso, setâ nigrâ et nigro-plumatì. Proboscis elongata, nigra. Frons utrimgue areuatim impressa, nigro-pilosa, pilis luteis rarioribus intermixtis. Thorax luteus, disco dorsali vitlis tribus Jatissimis confluentibus nigris obscuriore, pube lutescente confertissimâ obtectus, in marginibus lateralibus et postico setis nigris parce armatus. 
Pars superior pleurarum lutea et luteo-pubescens. inferion cum pectore nigra et uigro-pubescens. Sculellum inllatum, ante apicem non impressum. lutem, in disco pube nigrâ. in marginibus lutcit vestitum, in margine posico selis nigris derem pracdilum. Abdomeu nigrum, confertim nigro-pubescens, segmento prino el majorc secundi parte luteis et luteo-pubescentibus. Alae cinereo-Invalinac. basi dilute lutescente, venae longitudinalis secundae apice valde recurvo, hoc, apice venae auxiliaris venisque transversis totis trumi. ter fusco-limbatis. - (Cuba; Gundlach.)

36. Volucella apicalis nov. sp. o'. Luteo-testacea, abdominis basi pallidiore, apice obscuriore, obsoletissime scoriaceo. thoracis dorso scoriacen-vittato, ultimis tarsorum articulis nigris. apicali alurum dimidio nigro-nebuloso. - Long. corp. 33 lin.. Long. al. 3 lin.

Caput lutemm, facie longe productà, nitidà. antennis concoloribus, articulo tertio supra levissime concavo. Thorax luteo-testaceus, viltis dorsalibus quatuor scoriaceis, pectore piceo. Abulomen Inteo-testaceum, segmentis duobus primis, margine tamen poslico secundi excepto. pallidis, segmentis ullimis obsoletissime subscoriaceis. Pedes saturate lutei, articulo tertio tarsorum anticorum nigro-fusco. nltimis duobus tarsorum ommium ariculis nigris. Halteres albi. Nlac dilutissime sublutescentes. adversus costam Juteac. margine postico cincreo-limbato, venis dimidii apicalis late et indeterminate colore fusco-nigro limbalis. limbis venarmm longiludinalium secundae. Iertiac el quarlae eonfluentilus. - (Cuba: (iumblach.)

37. Volurella sexpunctula LW. б’ et 8. Lutea. nilens. pube fulvi vestila, pectore abdominisyue maculis lateralibus nigris, alae hyalinae, stigmate praeter basim fuscam lateo. - Ionis. corp. $3 \frac{3}{4}-4 \frac{5}{12}$ lin., Jous. al. $3 \frac{5}{12}-4 \frac{1}{3}$ lin.

Syn. Volucelle sexpunctata $\mathrm{L}_{\perp} \mathrm{w}$. Wien. ent. IIonatsche. I. 33.

Tota lutea. modice nitens. Oculi sublusco-pilosi. Frons pracler verticem nigro-pilosa. Facies modice producta. nitens, inlia antemnas leviter pollinosa. Iuberculo magno obtuso. Plenve concolores; peclus nigrum vel nigro quadrinaculalum. Segmenta abiluminalia singula pracler primum in margine postico utringue maruli nigrâ. margini laterali propinquà motantur: bae marulae in secturentis secundo el terlio laliores quam longiores suml at pleimuque frel fasciam posticam subbadiau conjungmulur: rarissime practerea segmenta secundum. Lestium el fuartum singula maculi media nigria 
instructa sunt. Pubes abdominis brevis, prope margines segmentorum singnlorum posticos uigra, reliqua pallida. Venter luteus, segmento quarto nigro-bimaculalo; in segmento venirali tertio utrius. que sexus et in quinto foeminae haud raro maculae binae nigrae minores conspiciuntur. Pedes lufei, tibiarum apice plerumque fusco vel nigro, ultimis tarsorum articulis semper nigris. Alae hyalinae. stigmatis lutei basi fuscà. - (Cuba; Gundlach.)

35. P'ipiza femoralis nov. sp. O’. Aeneo-nigra, pallide-pilosa, fascia segmenti abdominalis secundi anguste interruptâ. femorum apice, libiis tarsisque huteis, apice horum obscuriore; alue cinereo-hyalinae, stigmate ex ochraceo subfusco. - Long. corp. $3 \frac{1}{1} \frac{1}{2}$ lin., Loug. al. $3 \frac{2}{3}$ lin.

Aeneo-nigra, modice nitens, pallide-pilosa. Oculi breviter albopilosuli; facies pilis albis hirta. Antenvae majusculae, articulis basalibus duobus ex rufo ochraceis, tertio nigro, adversus basim obscure rufo, selâ nigrâ, prope basin pallidà. Fascia lutea segmenti abdominalis secundi lata et modice arcuala per lineam longitudinalem nigram dividitur et per limbum nigrum a margine laterali separatur. Pubes pallida abdominis brevis, adversus basim abdominis longior et albida, inter fasciam flavam et marginem posticum segmenti sccundi nigra. Femora praeler apicem luleum aeneo-nigra; tibiae luteae, posticac prope apicem plerumque obsolete fusco-annulatae; larsi lutei, articulo paenultimo posticorum nigro, reliquorum fusco, ultimo illorum fusco. horum ochraceo vel subfusco. Alae cinereo-hyaliuae, triente basali purius hyalino, stigmate ex ochraceo subfusco. - (Illinois; Osten-Sacken.)

39. Pipiza salax nov. sp. f. Nigro-aeneu, albido-pilosa. triangulo frontali, anteriore trianguli verticalis dimidio et postico oculorum margine nigro-pilosis; Antenune nigrae, sublus rufue; pedes nigri, genibus, libiarum anticarum basi, libiis intermedies praster annulum subapicalem fuscum tarsorumque anteriorum articulis primis luteis; alae praeter trientem basalem cinereae. - Long. corp. $3 !$ lin., Long. al. $2 \frac{2}{3}-2 \frac{3}{4}$ lin.

Nigro-aenea, modice nitens, albido-pilosa. Oculi pilis minutis nigris, infra pilis albis vestili. Triangulum frontale et triangulum verticale, vertice ipso famen excepto, nigro - pilosa. Autemae nigrae, subtus obscure rufae, articulo tertio oblonge ovato. Occiput albido-pilosulum, postico oculorum margsine nigro-cilialo. Abdomen breviter nigro-pilosum, segmento primo, segmentorum reliquorum 
marginibus lateralibus maculisque aenescentibus ordiuaris et postici segmenti quarti parte albido-pilosis. Hypopysum quan in reliquis specicbus multo longius. Pedes nirri. genibus. libiarum anlicarum friente vel dimilio basali. tibiis intermediis praeter anuulum subapicalem latissimum fusco-nigrum. primo farsorum anticorum primisque duobus inlermediorum articulis luteis, secundo tarsorum anlirorum articulo plerumune testacco; primms tarsorum posticorum articulas sequentibus paulo crassior. Alae practer trientem basalem purius liyalinum cinereae, stigmate subfusco. - (Pennsylvania: UstenSacken.)

40. Pipiza nigribarba nov. sp. ठ․ Nigro-aenea. albidopilosa, oculis, rrirngulo frontali et facie nigro-pilosis: antennat nigrue; pedes nigri. genibus. tibiarum anteriorum basi, tribus primis tarsorum intermediorum intermediisque reliquoram articulis luteis, primo tassorum posticorum articulo vulde incrassato: alue prater trientem basalem cinerascentes. rena. quae cellulam posteriorem primam cleudit. in angulum fractit. - Long. corp. $\frac{5}{12}$ lin.. Long. al. $3 \frac{1}{6}$ lin.

Nigro-aenea, modice nitens, albido-pilosa. Oculi pilis nigricanlibus confertissinis vestiti. Triangulum fromtale et trianguli verticalis dimidinn anterius nigro-pilosa. Antennae nizrae; artieulus fertius oblongus. Lalere inleriore basim versus obscure rufo. Facies nigro-pilosa. supuat practer latera pilis albis instrucla. (leciput breviter albido-pilosulum. postico oculorum margine nigro-cilialo. Pubes abdominis brevissima nigra, segmenli primi. marginm lateralium praeter angulos segmentorum singulorum anticos. et macularum aenescentium ordinariarum albida el longios. Hypopygium breve. Pedes nigri, grabus, imâ libiarum posticarmu basi el priore ante. riorum dinidio Inteis; larsi anlici fusci. apice arliculi primi el articulo secundo lutes, articulis ultimis duobus fusco-nigris: tarsi intermedii lutei. arliculis ultimis duobus nigris: larsurum poslicorum articulus primus valde incrassalus. niger, extremo apice lutco, articuli sequenles duo lulei. ultimi duo rum apice praceedentis nigri: tibiae poslicae supra pilis longinsoulis albis instructac. Alac prateter trientem basalem cincrascentes. stigmate subfusco of vena. qua cellula posterior prima claudifus. angulatim lraclit. - (New Yorti: Osten-Sarken.)

41. Pipizafraudulenta uos. sp. O. Nigro-aenea. albidupilose, aculis. triansulo frontali et facie nigro-pilosis, untenuae ni- 
grae; pedes nigri, genibus, tibiarum anteriorum basi, tribus primis tarsorum intermediornm intermedisque reliquorum arliculis luleis. primo tarsorum posticorum arliculo valde incrassuto; alce praetes. trientem basalem cinerascentes, vena, yuae cellulam posteriorem primnm claudit, flexa, non angulati. - Long. corp. $3 \frac{1}{3}$ lin., Long. al. $3 \frac{1}{12} \operatorname{lin}$.

Pipizae nigribarlae simillima, sed antemna tolae nigrae. tibiac posticae supra pilis longis nigris, non albis instructae, et vena ala. rum cellulam posleriorem primam claudeus llexa, non in angulum fracta. - (Illinois.)

42. Pipiza calcarata nov. sp. б. Aeneo-nigra, albido-pilosa, triangulo frontali et facie toli nigro-pilosis; untennae nigrae. subtus rufae. Pedes nigri, genibus, tibiis anterioribus praeter annulum anticarum intermediarumque dimidium basule, primis tribus anteriorum, secundo et tertio tarsorum posticorum arliculis luteis, coxis posticis calcaratis; alue praeter trientem basalem cinerascentes. - Long. corp. 31. lin., Long. al. $2 \div \frac{1}{2}$ lin.

Aeneo-nigra, modice niteus, albido-pilosa. Pubes oculorum albido-cinerascens, in lumiue alio nigricans vel nigra. Pili trianguli frontalis et facici omnes nigri. Antennae nigrae, subtus rufae, articulo tertio oblongo. Pili abrlominis brevissimi nigri, nurginem la. leralium macularumque aesescentium ordinariarum albidi et longiores. Pedes nigri, tibiis anticis praeter annulum nigro-fuscum, tibiarum intermediarum dimidio basali et extremo apice, primis tribus tarsorum anteriorum arliculis farsorumque posticorum articulis secundo et te:tio cmm apice primi luteis; coxae posticae apophysi calcariformi, adversus apicem dilatalâ et compressâ armalae; netalarsus posticus paulo incrassilus. Alac praeler trientem basalem cinerascentes, stiğmấe subfusco, venâ transversâ mediâ a cellulae discoidales basi et vená cellulam posteriorem primam claudeute ah alae margine intervallo minore separalis, quam in speciebus, quas supra descripsi. - (New York; Oslen-Sacken.)

43. Syrphus simplex I,w. Q. Chalybeus. pallide pubescens. antennis pedibusque nigris, tibiarum anteriorum basi g'enibusque poslicis lutescentibus, alarum dimidio basali pure hyalino, apicali nigro-cinerco. - Long. corp. $4 \frac{1}{4}-4 \frac{1}{3}$ lin. Long. al. $3 \frac{1}{2}-3 \frac{7}{12}$ lin.

Syn. Syrphus simplex Lw. WVien. ent. Monatschr. V. I0.

Capul nigro-chalybeum, nilidum. Facies albido-pollinosat. In. berculo parvo laevigalo. Oculi mudi. Antennac nigrae, articulo 
lertio ovato. Frons breviler nigro-pilosi, ulringue villuli marginali albido-pollinosà, a mediâ fronle usque ad faciem perlinente. Thu. rax el scutellum chalybea, nitida, pilis abbidis vestila. Abdomen albilo-pubescens. chalybeum. segmentorum singulorum parte postici obseuralí. opacâ. Venter chalyheus. nitidus. Pedes nigri, libiarum anteriorum basi genibusque posticis lutescentibus, melatarso postico subincrassalo. Tegulae exalbidae. Halteres sordide lulesentes. Alarum hyalinarum dimidium apicale nigro-cinereum, stigmale nigro. fusco; vena longiludinalis terlia subrecla. - (Cuba; Cundach.)

44. Syrphus nigripes nov. sp. ơ. Aeneo-viridis. nitens. cupile sculelloyue concoloribus: abdomen luteum. segmentorum secunli, tertii et quarti singulorum villi medici, illorum inlegri. hujus rentice abbreviata., ommium postice in limbum apicalem dilatali. nigri: pedes nigri, tibiarm anteriorum basi genibusyme posticis nigris. - Long corp. $4 \frac{1}{6}$ lin. I.ong. al. $3 \frac{5}{2}$ lin.

Aeneo-viridis. nilens, luleo-pilosns. Capul concolor. oculis nu. dis, verlice et froule nigro-pilosis, facie practer tuberculum parrum et praeler oris marginem polline lutescente aspersâ pilisque lulescentibus hirtâ; antennae fusco-nigrae. subtus olscure rufescentes, articulo tertio orato. Abdominis segmentum primum nigro-ieneum: segmenla sequentia tria lutea. limbo marginis poslici singulorum adversus lalera minns lalo et vittá mediâ. in segmento secundo latfiore, in quarlo antice abbrevialti. nispis: segmentum quintum loreve. nigrum. Hypopygum nigro-aeneum. Venter lutens. margine poslico segmentorum singulorum tciniter nigro. Pedes fusco-nigri, genibus et tibiarum anteriorum basi luteis vel testaceis. Alac practer basim subinfuscatae, stigmate fuseo. - (Cuba; Gundlach.)

45. Syrphus proenstus nov. sp. O. Chalybeus, maculis abdominis quatuor transressis luteis. alarum hyalinarme apice fuscolimbato. - Long. corp. $2 \frac{1}{2}$ lin., Long. al. $2 \frac{3}{4}$ lin.

Chalybeus. nitens, pube brevi exalbida vestitus. Oculi nudi. Frons violacea. marginibus lateralibus et linea longitudinali mediai albo-pollinosis. Antenuac luteo-testaceac. articulo primo longiusculo. secundo superne fusco. Iertio oblongo. superne el iu apice fuseo. setâ tenuissmi. Facies nigro-chalybea. albido-pollinosa. fuberulu fere nullo, vitla media demudati latà, utrinque limbo tenui. amron et purpureo splendente marginata. Thorax chalybeus. dorso villis albido-pollinosis quatuor interjectisque nigricantilus tribus ubsoleto variegato. Scutellum totum nigru.chalybeum. nilidust. Primum ab. 
dominis segmentum chalybeum, nilidum: segmentum secundum atro. purpureum. viltà basali es violaceo chalybeà, nilidâ. latera versus usque ad angulos posticos dilatatà; segmentum tertium atro-purpureum, marginibus lateralibus chalybeo-nitentibus maculisque luasalibus duabus transversis luteis; segmentum quartum atro-purpureum: dimidio anteriore modice nitido, marginibus lateralibus chalybeo.nitentibus maculisque basalibus duabus transversis luteis; segmentum quintum ex violaceo chalybeum, nitidum, apicem versus magis atropurpureum et minus nitens. Venter nigro-chalybeus, nitidus, fasciầ basali segmentorum tertii, quarti et quinti singulorum luteâ, aequali. Pedes lutei, apice femorum tibiarumque posticorum tarsisque omnium nigris, primo tamen tarsorum posteriorum articulo luteo. Alae hyalinac. apice fusco-limbato. stigmate ex luleo subfusco. - (Cuba: Gundlach.)

46. Syrphus jact at or Lw. J. Caput favum: thorax aeneus. maculis lateralibus auratis ornatus; scutellum farum; upex abdominis nigri. fasciis trilus integris flavis picti, nigro flavoque varius: pedes flavi. femoribus tibiisque posticorum late nigro-cinctis; alae fuscae. Iriente basali hyalino. - Long. corp. $4 \frac{5}{12}$ lin.. Long. al. $4 \frac{1}{3} \operatorname{lin}$.

Syn. Syrplus jactator Lw. Wien. ent. Monaischr. V. 40

Caput flavum, aureo-pollinosum, tuberculo faciali modice prominente vittulà nigrâ, fronte prope antennas puncto nigro notatis. Antennae laete ochraceae, arliculo tertio breviter ovato, superne fuscano, setà nigricante. Triangulum verticale nigrum, minulum. Thoracis dorsum aeneum, lineis tribus obscurioribus valde obsoletis piclum et utrinque maculà magnâ aureo-pollinosâ ornatum. Pleurae obscurius aeneae, maculà oblongâ ante alas demissâ et inferius alterâ minore contiguâ aureo-pollinosis. - Abdomen aequilatum, de pressum; segmentum primum minutum, nigrum; secundum et tertium nigra, fasciâ basali flarâ, integrâ, latera versus paulo latiore: in basi segmenti quarti fascia simillima conspicitur et in posteriore ejus parte maculae cuneatae tres adsunt. ila ut tridens niger. adversus marginem posticum directus cernalur; segmentum quintum obscurius ochraceum lineâ longitudinali nigrâ punclisque duobus obsoletissimis varium. Venter flavus, nigro-bifasciatus. Pedes flavi, posticorum femoribus et tibiis late nigro-annulatis. Tegulae flavidae. Halteres ochracei. Alae fuscae. prope marginem posticum paulo dilutiores. triente basali liyalino, ante renam longitudinalem quartam 
fulvescente, ad alac incisuram maculì fuscâ nolato: stigma elongalum fulvescens. - (Cuba: Gundlach.)

Nota. Pollen aurenm. faciem et maculas Hhoracis legens. nito. rem non emillit.

47. Mesogramma parvula nov. sp. d’ et $q$. Sulellum nigro-aeneum. flavo-marginalum: abdomen nigrum. fascia interrupta segmenti secundi, segmentorum duomem sequentinm linei media arcubusque binis et fascià intermuptâ segmenti yuinti flavis : perles postici praeter trientem basulem et extremum apicem femorum nigri. - Long. corp. $2 \frac{5}{12}-2 \frac{1}{2}$ lin.. Long. al. $2 \frac{1}{3}-2 \frac{5}{1}$ lin.

Aeneo-nigra. obscura. Antennae fuscae, infra sordide rufescenles. Thoracis dorsum praeter villam mediam glaucescentem olivaceo-bivithatum. Scutellum nigro-acneum, modice nitens, flavo-marginatum. Nacula flava supra coxas anticas in pleuris nulla. Abdomen nigrum, fasciâ aequali sed interruptà segrmenti secundi, lineà medià arcubusque binis. margini anlico adjacentibus segmenti tertii et segmenti quarti, fasciâ denique late interruptâ segmenti quinti, in mare tenuiore quam in foemina, flavis. Segmentum primum toium nitidum; segmentorum reliquorum pictura nigra praefer limbum latiusculum marginis postici segmentorum singulorum velulina. Pedes postici praeter trientem basalem et apicem extremm femormm nigri; tarsi anteriores ochracei vel ex ochraceo subfusci Alar cinereo-hyalinae, stigmate subfusco. - (Florida: Osten-Sacken.)

Nota. Syrphi quidam americani. corporis gracilitate et rapilis formâ Melithrepiis similes, sed triangulo verticali maris perlongo. ocellis utriusque sexus a verticis margine longe remotis et thorace lineâ medià albicaule vel glaucâ ornato a reliquo Syrphorum agmine diversi, Mesogrammarum genus consliluunt. in quo Syrph. Boscii Macq. cetypus Say. geminatus Say- mar. ginatus Say. politus Say. pulchellus Macf. et alii collocandi sunt.

48. Mesogramma subannulata nov. sp. ó et + . Sculellum nigrum. Inteo-pollinosum et flavo-marginalum: abdominis segmenta prima duo nigra, fascia secundi angusle inlerrupla flari: reliquum abdomen flavum. segmentorum tertii et quarli lineis longiludinalibus binis. marginis postici limbo anguste interrupto angu. lisque posticis late nigris: segmenlum quintum nigro-lrimarulatum. Annulus femorum posticorum subapicalis. Vibiarum posticarum an- 
mulus subbasalis et tarsi postici nigri, apice articuli primi et articulo secundo horum ferrugineis. - Long. corp. $2 \frac{5}{6}-2 \frac{1}{2} \frac{1}{2}$ lin., Long. al. $2 \frac{1}{2}-2 \frac{2}{3}$ lin.

Antenuae ochraceae, raro suprá subfuscae. Vertex nigro-acneus. Thoracis dorsum praeter lineam mediam albicantem oliraceo-bivitIalum. Scutellum aeneo-nigrum. polline conferto ocbraceo opacum. flavo-marginatum, albido-pilosulum. Pleurae supra coxas anticas maculà flarâ notatac. Abdomen flavum. nigro variegatum, maris aequale, foeminac oblongo-oratum; segmentum primum praeter angulos anticos marginesque laterales et anticum nigrum; segmentum secundum praeter fasciam aequalem inlerruptam flavam et praeter marginum lateralium dimidiun anterius nigrum; segmenta sequentia duo flava. singulorum lineolis mediis binis, marginis postici limbo angustissime interruplo angulisque posticis late nigris; segmentum quintum nigro-trimaculatum. Femora postica prope apicem annulum modice latum, fuscum vel nigricantem habent; tibiae posticae, prope basim latius sed plerumque obsoletius fusco-annulatae, haud raro prope apicem ansulo altero subfusco instructae sunt; tarsi postici fusci vel nigri, apice articuli primi articulisque sequenlibus duobus ochraceis. Alat cinereo-hyalinac. stigmate ex ochraceo subfusco. (Cuba; Gundlach.)

19. Mesogramma planiventris nov. sp. ․ Sculellum flavum, nigro-pilosum: abdominis segmenta prima duo nigra. angulis anticis primi et fascia requali secundi flavis; segmenta sequentir flava, tertii et quarti maculis binis mediis cuneatis et limbo postico auguste interrupto, ex angulis posticis antice producto nigris, seğmenti quinti maculâ unicâ nigrâ; tarsi postici fusci, articulis ultimis duobus nigris. - Long. corp. $2 \frac{2}{3}-2 \frac{3}{4}$ lin., Long. al. $2 \frac{7}{1} \frac{7}{2}$ lin.

Antennae ex rufo sordide ochraceae, supra fuscae. Vertex aeneo-niger. Thoracis dorsum praeter lineam mediam albicantem obsolete oliraceo-bivitlatum. In pleuris supra coxas anticas macula minuta albida. Scutellum totum flavum, pilis minutis nigris vestifum. Abdomen ovatum, valde depressum. planum; segmentum primum nigrum. margine antico tenuissimo angulisque anticis extremis flavis: segmentum secundum nigrum. fascià medià flavâ. aequali: segmenta sequentia duo flava, singulorum maculis binis mediis cu. neatis nigris et limbo nigro marginis postici anguste interrupto. aequali, sed ex angulis posticis segmenti antice producto; segmentum quintum praeter maculam mediam nigram totum flavum. Pedes flari, femoribus tibiisque posticorum non annulatis. tarsis posti- 
cis fuscis, articulis ultimis duobus nigris; tarsi anteriores ochracei. Alae hyalinae, stigmate ex luteo dilutissime subfusco. - (Florida: Osten-Sacken.)

50. Mesogramma laciniosa nov. sp. ․ Scutellum flavum, albido-pilosum: abdominis segmenta prima duo nigra, angulis anticis primi et fascic aequali secundi flavis: segmenta duo sequentia flava, singulorım limbo postico inceguali et anguste intermpto. lineis mediis binis antice in maculas triangulas dilatatis et utrinque macula oblongâ, inde a margine antico usque ad dimidium segmenti pertinente nigris: segmentum quintum flavum, maculis nigris quinque, duobus in angulis posticis, tribus in margine antico, harum mediâ per lineam nigram cum margine postico conjunctâ: tarsi po. stici nigri, apice articuli primi articulisque duobus sequentibus fuscis. - Long. corp. $3 \frac{1}{3}$ lin., Long. al. 3 lin.

Antennae rufo-ochraceac. Vertex aeneus. Thoracis dorsum praeter vitlam mediam glaucescentem olivaceo-birittalum. In pleuris supra coxas anticas macula flava nulla. Scutellum totum flarum. albido-pilosum. Primum abdominis segmentum nigrum, angulis anticis marginibusque lateralibus et antico flavis. Segmentum secundum fasciis duabus nigris, per fasciam aequalem flavam scparatis pictum; segmenta sequentia duo flava. singula praeter limbum marginis postici inaequalem, interruptum et nigrmm, lineis duabus longitudinalibus mediis, antice in maculam triangulam dilatatis et utrinque maculâ oblongâ, inde a margine anlico usque ad dimidium segmenti pertinente nigris variegata; segmentum quintum flavum, angulis posticis maculisque tribus marginis antici nigris: medià harum per lineam nigram cum margine postico conjunctà. Perles tlavi. femoribus tibiisque posticis non annulatis, tarsis poslicis nigris, apiec articuli primi et articulis sequentibus duobus fuscis vel fusco-ochraceis, tarsis reliquis ochraceis. Alae byalinae. sligmate dilutissime subfisco. - (Cuba; Gundiach.)

51. Hesogramma poecilogastra nov. sp. Q. Fintellum nigrum, favo-marginatum; abdomen nigro et faun variegatum, ilu ut anguli antuci segmenti primi. fascia secundi, linea media tertii et quarti, maculae denigue quaternae segmentorum ultimorum trium. externate sulquadratae et in angulis anticis segrmentorum singulnrum sitae. flavae sint: anmulus femorum posticorum subajicalis. tibiae posticae prater imam basim et trientem apicalem. tarsigue po- 
stici nigri, apice tamen arliculi primi el articulo secundo horum ferrugineis. - Long. corp. $2 \frac{2}{3}-2_{0}^{5}$ lin.. Long. al. $2_{6}^{5}$ lin.

Verlex nitidissimus, laete violaceus. Thoracis dorsum praeter lineam mediam albido-glaucam viltis duabus olivaceis, fusco-marginatis instructum. Macula flava supra coxas anticas in pleuris nulla. Primum abdominis segmentum vigrum, angulis anticis late flavis; segmenlum secundum fascias duas nigras, fasciâ flavâ, aequali et integrâ separatas habe!; in segmento tertio linea longitudinalis media postice subdilatata et maculae quatuor marginem anticum altingentes colore flavo pictae sunf; maculae externae in angulis anticis sitae et dimidio segmento breviores formam quadrangulam habent; maculae internae quam externae fere duplo longiores et bilobae sive reniformes sunt, dimidio anteriore subtriangulo, posteriore rotundalo. Pictura segmenti quarli eadem ac tertii; color niger limbi postici utriusque segmenti interdum in ferrugineum mutatur. Segmentum quintum maculis quatuor flavis ejusdem formae, ac segmenta praecedentia, variegatum, sed lineâ medià flavâ nullâ. Femora postica prope apicem annulo latiusculo nigro cinguntur; tibiac posticae praeter imam basim et praeter trientem apicalem nigrae sunt; tarsi postici nigri apicem arliculi primi et articulum secundum ferrugineos habent. Alae subhyalinae, colore dilutissime fusco cinereo tinctae, stigmate fusco. - Cuba; Gundlach.)

52. Mesogramma arcifera nov. sp. ঠ et $q$. Scutellum nigrum, flavo-marginalum; abdominis segmentum primum nigrum, margine basali flavo; in segmenlis sequentibus duobus lineolae longitudinales binae lineam mediam flavam includunt et utrinque macula velutina, plerumque per limbum piceum marginis postici cum lineolâ proximâ conjuncta conspicilur; segmenlum quintum maculis tribus velutinis variegatum; femora anteriora subfusco-liturata; pedes postici praeter basim et apicem femorum nigri, annulo tibiarum subobsoleto fusco. - Long. corp. $2 \frac{1}{3}-2 \frac{5}{12}$ lin., Long. al. $2 \frac{1}{3}-$ $2 \frac{7}{12} \operatorname{lin}$.

Antennae subfuscae vel ferrugineae, articulo tertio infra, primis duobus praeler marginem superum lutescentibus. Vertex utriusque sexus obseure aeneus. In thoracis dorso praeter vittam mediam glaucescentem uirinque vilta olivacea apparet. Scutellum nigro. velutinum. flavo-marginatum. Macula flava supra coxas anticas in pleuris nulla. Primum abdominis segmentum nigrum, margine antico flavo. Segmentum secundum praeter arcus duos flavos nigrum, limbo marginis postici subnitido et magis piceo, lineâ mediâ et 
utrinque maculâ magnâ cum limbo marginis postici confluente nigro-velutinis. Segmenta tertium et quartum singula praeter lineolas binas longitudinales nigro-velutinas, antice dilatatas et marginem anticum prope attingentes, utrinque maculam magnam nigro-velutinam, plerumque per limbum marginis postici nigro-piceum vel piceum cum lineolâ proximâ conjunctam habent. Segmentum quintum maculis tribus nigro-velutinis variegatum. Femora antica supra prope apicem lituram subfuscam sive nigricantem, interdum obsoletam habent; femora intermedia praeter hanc lituram subapicalem liturâ obsoletiore subbasali notantur; tarsi anteriores ex flavo subfusci; pedes postici nigri, dimidio priore apiceque femorum et imâ tibiarum basi flavis, annulo medio obsoleto et extremo tibiarum apice plerumque fuscis. Alae cinereo-hyalinae, stigmate subfusco. - (Cuba; Gundlach).

53. Xylota pretiosa Lw. ठ․ Laete viridi-aenea, nitidissima, abdomine chalybeo maculis quatuor pallide flavis ornato, tibiis anterioribus posticarumque triente basali tarsisque omnibus albido-flavis, horum articulis tribus ullimis nigris. - Long. corp. 5 lin., Long. al. $\mathbf{4}_{\frac{1}{2}}^{\frac{5}{2}}$ lin.

Syn. Xylota pretiosa Loew Wien. ent. Mlonatschr. I. 39.

Facies viridi-aenea, albido-pollinosa. Aniennac nigrae, articulo tertio subrotundo, setâ concolore. Frons viridi-aenea. albido-pollinosa. Triangulum verticale angustum, ex viridi chalybeum. nitidum, parce nigro - pilosulum. Ocelli a margine occipitali remoti. Thorax laetissime viridi-aeneus, adversus marginem posticum subchalybeus, utrinque pube brevissimâ albidâ, inter alas pube nigrà vestitus. Scutellum chalybeum. Abdomen lacte chalybeum; segmenlum secundum maculis duabus pallide flavis ornatum, quarum angulus posterior usque ad lateralem abdominis marginem producitur; pars posterior hujus segmenti nigro-violacea, opaca: segmentum tertium maculis duabus transversis pallide flavis, fasciam in medio segmento late interuptam formantibus et pone has maculas colore nigro-violaceo pictum est, ipso lamen margine apicali chalybeo. Venter pallide flavescens, segmento primo chalybeo, ultimo violaceo. Trochanteres cum imâ femorum basi pallide flavescentes. Femora viridi-aenea, apice extremo anteriorum pallide flavescente: femora postica modice incrassata, ante apicem infra in dentem obtusissimum Merodontum more dilatata, in latere inferiore et in dentis margine nigro-spinosa. Tibiae anteriores pallidissime flaveseentes, subalbidae; tibiae posticae incurvae, triente hasali albido. medio 
- nigro-violaceo. apicali nigro; tarsi colore tibiarum tincti, articulo tertio fusco, ultimis duobus nigris. Tegulac albae, margine ciliisque nigris. Halleres dilute flavescentes. Alae cinereo hyalinac, adversus apicem praulo obscuriores, stignate renisque nigris. - (Cuba: Poey.)

54. Xylota pachymera nov. sp. +. Nigro-chalyben, maculis huteis abdominis vel quatuor, vel duabus, raro nullis: antennae fusco-nigrae, articulo tertio oblongo: facies carinata: femora postica immodice incrassata; apex tibiarum posticarum in dentem productus. - Long. corp. $4 \frac{1}{3}$ lin., Long. al. $3 \frac{7}{\frac{1}{2}}$ lin.

Caput nigro-chalybenm, frontis fasciâ mediâ et facie carinatâ albido-pollinosis. Antennae fuseo - nigrae, articulo terlio oblongo. Thorax chalybeo-niger, nitens, dorsi magis aenescentis vittis duabus approximalis pube confertiore vestitis. Abdomen nigro-chalybeum, interdum magis aenescens, segmenti sccundi maculis duabus oblongis luteis, margines segmenti non attingentibus, raro obsoletis; segmenli tertii dimidium anterius nitidum, interdum maculis duabus parvis luteis variegatum, dimidium poslerius nigrum et subopacum; segmenta sequentia toła nitida, nigro-chalybea, rarius nigro-aenea. Venter luteus, segmentis ultimis aeneis. Femora nigro-chalybea, postica mire incrassata; tibiae anteriores praeter basin exalbidam fusco-nigrae, posticae praeter basim albidam nigrae, valde arcuatae, apice subtus in dentem producto; tarsi antici albidi, postici nigro. fusci, ultimis duobus omnium articulis nigris. Alae nigro-cinereae, stignate fusco. - (Cuba; Gundlach.)

55. Xylota obscura nov. sp. 오. Obscure aeneo-viridis; tertius antennurum articulus rufo-ferrugineus, setâ nigrâ; pedes nigri. femoribus posticis vix incrassatis, tibiarum basi dilute lutescente, primis duobus tarsorum anteriom arliculis rufo-ferrugineis. - Isong. corp. $4 \frac{3}{4}$ lin., Long. al. $4 \frac{1}{6}$ lin.

Xylotae triangulari Zett. similis. Caput nigrum, fronte nonnihil prominente el facie modice excavatà. Antemnae majusculae, articulis primis duobus nigro-fuscis, tertio rufo-ferrugineo, rotundo, setâ totâ nigrà. Thorax obscure aeneo-viridis, maculis bumeralibus albido-pollinosis nullis. Scutellum concolor. Abdominis latiusculi segmentum primum nigrum, nitidum; segmentum secundum, praeter maculas duas magnas subtriangulas aeneo-micantes et pilis pallidis vestitas, nigrum, nigro-pitosum. subopacum; in segmento tertio maculae similes in fasciam coalescunt; segmentum quintum aeneum et 
tolum nitidum, limbo tamen marginis postici magis nigro; segmenfum quintum nigrum. nilidum. Venter tolus scoriaceo-niger. Pedes nigri, femoribus posticis levissime incrassatis, libiarum omnium basi dilute lutescente, apice tibiarum posticarum in dentem non producto, primis duobus tarsorum anleriorum arliculis rufo-forrusineis vel rufo-fuscis, larsis posticis tolis nigris, sublus pallife fonch. tosis. Alae subhyalinae. practer basim fusco-cinereae. stigmale fusco, venâ transversâ anteriure longà el valde obliquà. - (Red River; Kennicot.)

56. Xylota quadrimaculata nov. sp. do el q. Obscure aeneo-viridis, abdomine luteo-quadrimarulato, tertio antennarum articulo obscure ferrugineo, seli toli nigra: pedes nigri, tibiis anterioribus posticarmmque basi luteis, tarsorum articulis ultimis duobus nigris. tertio fusco, religuis huteis. tarsorum tamen posticorum adversus basim subfuscis: tibiarum posticnrnm apex in dentem non moductus; covae posticae maris tuberculatae. - Long. corp. 4 $4 \frac{3}{4}$ lin., Long. al. $3 \frac{7}{1}-4$ lin.

Caput nigrum, fronle modice promineste el facie nonnihil excavalá polline conferto albido obtectis. Primi duo anteunatum ar. ticuli nigri, tertius ferrugincus, ovalus. sctâ totâ niĝ̣à. Thorax fo. lus aenco-viridis, nilidus, non villalus. Sculcllum rum thorate concolor. Primum abdominis segmenlum nitidum. subaencum; sermen. tam secundusu flavo-bimaculalum. fascià anticà el vilti media atris. fasciâ posticâ fusco-nigrâ vel nigrà; segmentum terlium similiter píetum, fascià anlicà minus latâ el saepe minus niegrà. prostira laliuru et magis nigrâ; maculac flavac segnentorum secundi el lerlii in foeminat minores quam in mare. sacpe ex parle aul folac aencale: segmentum quarfum aeneo - nigrmm, nilidum. in mare siepe acneopicenus. Coxac posticae maris nee dentalae nes luberculatac femora praeter apiecm acneo-nigra. postica modiec incrassala; libiar anteriores luteac, ante apicem obsulelissime infuscalac, posticie nigrofuscae, friente basali dilutissime lutesecnte, apice in dentem nun produclo; tarsorum arliculi primi duo lulei, posticormm basin ver sus subfusci, tertius fuseus, ullimi duso nigri. Alac sublyalimar, ex fusco cinereae, sligmale fuseo. - (Illinois; Le Baron)

Nota 1. Propter similifudinem Nylotac quadrimaculalac cum Dyloti frandulosi diagnosin hujus. yuam in Cemlur. V. Il jro. posui, in secpuentem emendare velis: Iylota framalulasu a

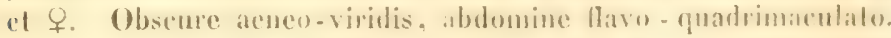
setac anlemalis hasi lutea, coxis posticis maris noe doutali 
nec tuberculatis, tibiis fere totis nigro-fuscis, tarsis posticis nigris, articulis primis tribus nigro-fuscis. - Long. corp. $3 \frac{2}{3}$ lin , Long. al. 3 lin.

Nota 2. Xylota ejuncida Say, quae antennas dilutius pictas, femora postica miuus valida, coxas posticas maris tuberculatas et arliculos primos tres tarsorum omnium luteos habet, a specic nostrâ facile distinguitur.

57. Xylota subfasciata nov. sp. ơ et $\sigma^{\circ}$ Obscure aeneoviridis; abdominis segmenta secundum et tertium lutea, villâ tenui, fascià singulorum posticâ (secundi angustâ, tertii latâ) nigris, marginibus lateralibus nigro-aeneis; antennae totae nigrae, set $\hat{a}$ concolore; pedes nigri, tibiarum basi tarsorumque anteriorum arliculis primis duobus luteis; tibiarum posticarum apex in dentem non productus, angulo tamen infero acutiusculo; coxae posticae maris dentatae. - Long. corp. 4-4 $\frac{3}{4}$ lin., Long. al. $3 \frac{5}{6}-4 \frac{1}{3}$ lin.

Xylolae quadrimaculalae simillima, sed antennis totis nigris, maculis luteis abdominis majoribus el vittâ nigrâ tenuiore separatis, tibiis obscurioribus posticarumque apice subtus acutiore diversa. Foeminae abdomen maculas luteas minores, interdum ex parte, rarissime tolas aenescentes habet. - (Red River; Kennicot.)

58. Xylota angustiventris nov. sp. $\delta$. Aeneo-nigra, abdomine angusto, maculis segmenti secundi duabus oblongis luteis; frons valde prominens; antennae fusco-nigrae, selâ nigrâ; pedes nigri, tibiarum basi primisque tribus tarsorum anteriorum articulis luteis; coxae posticae dentatae. - Long. corp. $4 \frac{1}{1} \frac{1}{2}$ lin., Long. al. $4 \frac{1}{6}$ lin.

Aeneo-nigra. Frons valde prominens, praeter maculam prope antennas sitam, albido-pollinosa. Antennae fusco-nigrae, majusculae, articulo tertio breviter ovato, setâ totâ nigrâ. Facies valde excavata, nigro-pilosa. Abdomen minus latum quam in speciebus reliquis, aeneo-nigrum, segmentis secundo et tertio postice late opacis, secundo praeterea maculis duabus oblongis luteis ornato. Pedes nigri, basi libiarum omnium primisque tribus tarsorum anteriorum articulis dilutissime lutescentibus vel exalbidis; coxae posticae dente minuto armatae; femora postica nonnihil incrassata; tibiarum posticarum apex in dentem non productus. Alae praeter trientem basalem infuscatae, adversus marginem posticum mullo limpidiores. stigmate fusco, venâ transversâ anteriore obliquissimâ. - (Illinois; Le Baron.) 
59. Pteroptila decora nov. sp. I et $\delta$. Nigra. antenis ferrugineis supra fuscis, maculis flave-tomentosis norem in dorso thoracis et sex in abdomine, pedibus tuteis vel ex lulco hudiis. femorum posticorum dimidio secundo subfusco vel fusco, larsis prueter basim nigris, alarum dimidio anteriore fusco, busin versus ex fusco huteo, celluti costali dilute hutescente. - Long. corp. $1 \frac{2}{3}-$ $6 \frac{1}{6}$ lin., Long. al. $33 \frac{1}{2}-\frac{7}{1^{2}}$ lin.

Nigra. Caput concolor; margines oculorum postici limbo llavotomentoso cincti. Frous flavo-?omentosa, vertice et villi medii nigris. Antennae ferrugincac, articulo terlio breviter ovato, supra nigro-fusco. Facies flavo-tomentosa, vittà medià et ulrinque vittuli latiore genarum uigris. Thoracis dorsum maculis llavo-lumenlosis novem variegalum, duabus in margine antico, qualuor in suturi transversali tribusque sulcohaenentibus in margine postico sitis. Scutellum piceum, rarius testaceum, basim versus nigrum. Abdumen maculis flavo-tomentosis sex orratum, dubus subarcuatis in segmento primo binisque majusculis in tertio et quarto. Hypopygium maris badium. Pedes lutei vel ex luteo barlii, secundo femorun posticorum dimidio subfuseo vel fisco, sed exfremo lemorum apice semper dilutiore, farsorum anticulis ultimis quatuor vel tribus nigris. Alac hyalinae, dimidio anleriote fusco, adversus basint ex fusco testaceo vel luteo, celluli costali dilutissime lutescente. (Cuba; Gundlach.)

Nota. Pteroptida Eristalidi prosima esl, sed faccile separatur pi lis minutissimis totam alaruin superficien implentibus. Cum Pteroptilae corporis picturî quibusdam Milesiis simillimac sint. nonnullae a seriptoribus in Milesiarum genere posilac sunt.

60. P'teroptila zonata nov. sp. Oे. Nigra, opaca. faciei latcribus albido-pollinosis, maculis anticis duabus, sulurie transtersu margineque postico tharacis et fascia abelominis basali albielo- - lomentosis, fascid segmenti abdominalis secundi lividie. segmentorum sequentium singulornm, fasciis busulibus flaco-tomerntosis. hypopygin fawo-pollinoso, alis hyalinis, cellulis sligmaticali. marginali al sub marginali praeter simum hujus nigricuntilus. - Longr. corp. (i. lin.. Long. al. $5 \frac{1}{2}$ lin.

Nigra, opaca. Caput concolor, marginibus lateralilus fronlis el facie prateler villam mediam albitlo-pollinosis. Antennte nigrae. allticulo tertio ovato. Thoracis dersum maculas duas manginis antici,

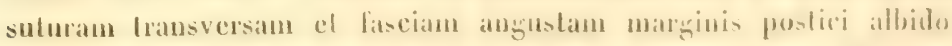
tomeulosas habed. Seulellum lividum. basim versus niğrum. Primum 
abdominis segmentum praeter basim albido-tomentosum; segmentum secundum fasciâ lividâ, anguste interruptâ, latera versus valde dilatatâ sed ante margines laterales subito abruptâ et margine postico vitellino ornatum; segmenta sequentia duo singula fasciâ angustâ basali flavo-tomentosâ et margine postico vitellino instructa. $11 y$ popygium polline vitellino confertissime aspersum. Pedes vitellini, femoribus anticis totis, femorum intermediorum basi femoribusque posticis praeter trientem apicalem nigris, his infra nigro-setosulis, reliquâ omni pedum pube pallidâ. Alae pure hyalinae, venis omnibus fusco-nigris, cellulis stigmaticali, marginali et submarginali nigricantibus, sinu hujus tamen hyalino. - (Mexico; a Germaro olim mihi data.)

61. Eristalis Gundlachi nov. sp. $\delta$ et 우. Niger; frons nigro-pilosa; anlennae rufae, setâ nudá; fasciae thoracis tres, media flavicans, reliquae glaucescentes; pili in priore dorsi dimidio flavi, in posteriore nigri; scutellum flavum et flavo-pilosum; abdominis segmenta secundum et tertium praeler villam inaequalem mediam flava, margine postico singulorum dilutius flavo; segmenti guarli margo posterior favus; alae hyalinae. -- Long. corp. $4 \frac{1}{3}-$ $\mathbf{4}_{\frac{7}{1} \frac{7}{2}}$ lin., Long. al. $3 \frac{2}{3}-3 \frac{1}{1} \frac{1}{2}$ lin.

Mas. Niger, opacus. Vertex obscurus, nigro-pilosus. Oculi pube confertâ nigrâ vestili. Facies pallide pollinosa pilisque pallidis vestita, vittâ mediâ et viltâ utrinque genarun latiore nigris, nitidis. Antennae obscure rufac sive ex ferrugineo rufae, setâ nudâ. Thoracis dorsum margines anticum el posticum glaucescentes fasciamque suturalem flavicantem gerens, in dimidio anteriore pilis flavicantibus, in posteriore nigris vestitur. Sculcllum flavo-ochraceum, flavo-pilosum, pilis famen aliquot nigris inier flavos dispersis. Primum abdominis se rgmeulum nigrum, imâ basi glaucescente angulisque lateralibus flavo-ochraceis; segmenta secundum et tertium flavo-ochracea, vittâ medià alrâ per marginem segmenti secundi flavum interruptâ, adversus marginem segmeuti secundi sensim, tertii subito latiore; segmentum secundum prope margines laterales praeter angulos anticos et prope marginem posticum pilis nigris vestitum; segmentum tertium lotum nigro-pilosum, pilis tamen longioribus in marginibus lateralibus ipsis flavicantibus; in segmento tertio maculae duae parvae, vittae arrae adjacentes, nitent; segmentum quartum nigrun, imâ basi et margine postico flavo-ochraceis, fasciâ paulo ante medium segmenlum sitâ aeneo-nitidâ, anguste interruptâ. Hypopygium nigrum, nitidum. Venter flavus, segmento ultimo ni- 
gro. Pedes nigri, genibus, tibiarum anlicarum dimidio priore. libiis intermediis practer apicem, farsorum intermediorum articulo primo cum basi secundi pallide flavicantibus, metalarso antico sordide luteo vel subfusco. Alac pure hyaliuac, venis fusco-nigris.

Foemina. Mari simillima, sed pube totius corporis breviore. Frons pallide pollinosa, supra obscurior. lineis tribus opacis. mediâ longiore usque ad antennarum basim non pertinente, lateralibus valde abbrevialis. Vitta media segmenti abdominalis secundi lalior. ante marginem posticum in fasciam transversam dilatata el cum limbo nigro marginis lateralis conjuncla. Vitta atra sermenti qualti mullo latior quam in mare, postice in fasciam usque ad latera segmenti ductam dilatiala; fascia nitida bujus segmenti ter inferrupla est. ita ul in medio segmento fasciolae duae abbreviatae et in ulropue latere macula triangula nitore insignes conspiciantur. Fascia nitida segmenti quarti paulo latior, sed angustius interupta quam in mare. Segmentum quintum nitidum, nigrum vel piccum. Religua omuia ut in mare. - (Cuba; Gundlach.)

Nota. Hanc speciem Macquarti Eristal. cubensem esse crederem, nisi frontem foeminae pilis flavicanlibus vestilam esse dicerel; species enim nostra frontem totam nigro-pilosam habet.

62. Eristalis atrimanus nov. sp. F. Niger: frons polline lutescente uspersa, nigro-pilosa, villi lati nigrat; antennae nigrae. sela muda: margo thoracis anticus subcinerascens, fascia suturalis et strigula utringre obligua flarescentes; pili in anteriore dorsi dimidio flavi, in posteriore nigri; maculae duac subcontiguae in segmento sccundo favo-ochraceae: margines segmentorum abdominalium secundi, terlii et quarti flavi; alae cinereo-hyalinae, renis disci colore dilute subfusco circumfusis. - Long. corp. 4! lin.. Long. al. $3 \frac{2}{3}$ lin.

Niger, opacus. Frontis villa media nigra. lata. inlegra. nigropilosa. latera polline lutescente obtecta el pilis pallidis vestila. (Muli hirti. Antennae nigrae, seti nudi, nigro-fuscâ. Facies, practer vittam median et utringue genarum vittam nigras, albo-pollinosa et albo-pilosa. Thoracis dorsum marginem anticum cinerascentem. lasciam vero suluralem et ubinque strigulam ab alae basi oblique alversus marginem posticun ductam lulescentes habel: dimilium an. terius dorsi davo-pilosum, posterius nigro-pilusum. Sembellum flavoochracenm, pilis plerisyue flavis. reliquis nigris. P'rumum abdominis seguenlum nigrum. angulis laleralibus flavis. In segromento seeundo maculae duac flavae, transverse ovalae. margini aulico oppo. 
sitae, parvo intervallo scparatae conspiciuntur. Segmenta secundum, tertium et quartum margines posticos flavos habent. In utroque margine laterali segmenti tertii macula Iriangula, in segmento quarto fascia late interrupta, tenuis, sed latera versus dilatata aeneo splendent. Segmenfum quintum nigrum, nitilum. Pedes nigri, tarsis totis concoloribus, genibus, tibiarum anticarum triente basali intermediarumque dinidio priore pallide flavicantibus. Alae cinereohyalinae, venis disci colore dilute fusco circumfusis. - (Cuba; Gundlach.)

63. Evistalis seniculus nov. sp. 万. Niger; frons tola et facies praeter villam atram albo-pollinosae et albo-pilosae; antennae obscurne rufac, seti nudá; fascia suturalis thoracis et strigulı utrinque obliqua flavescentes; pili in anteriore dorsi dimidio flavi, in posteriore plerique nigri; scutellum flavum, nigro-pilosum; abdominis segmentum secundum praeler villum mediam angustam flavum; segmentum terlium maculis duabus et margine postico flavis instrurlum; segmenti quarti murgo posticus flavus; alae subhyalinue, ex cinereo dilutissime subfuscae, venis disci el dimidii apicalis plevumque colore subfusco dislinctius circum/usis. - Long. corp. $4 !$ lin., Long al. $3 \frac{1}{3}$ lin.

Nicer, opacus. Vertex obsemus, nigro-pilosus. Frous tota polline albo obtecta et albo-pilosa; oculi hirti. Antennae obscure rufae vel rufo-ferrugineae, selâ uudâ. Facies albo-pollinosa et pilis albis vestita, viltâ mediâ et utrinque vittâ genarum nigris, nitidis. Thoracis dorsum, in dimidio anteriore llavo-pilosum, in posteriore pilis flavis et nigris vestitum, fasciam suluralem et utrinque strigulam ab alae basi oblique adversus marginem posticum ductam flavicantes habet; margines anticus et posticus non glaucescunt. Scutellum flavo-ochraceum, nigro-pilosum. Primum abdominis segmentum nigrum, angulis lateralibus extremis flavis. Segmentum secundum flavum, vittâ mediâ subangustî, antice paulo latiore alrâ. Segmeutum terlium praefer marginem posticum flavum maculis duabus semiovalibus flavis instructum, neque fasciam neque maculas nitidas habet. Segmentum quartum marginem posticum flavum et in utroque margine laterali maculam triangulam aeneo-nitentem habet. Нуроруgium nigrum, nitidum, pallide pilosum; reliquac abdominis partes ıigrac pilis nigris, flavae pallidis vestiuntur. Pedes nigri, genibus, libiarum anticarum triente basali, intermediarum dimidio primo ef metalarso intermedio pallide flavicantibus, imâ metatarsi antici basi lutcâ. Alae subhyalinae, ex cinereo subfuscac, venis disci et dimi- 
dii apicalis plerumque colore dilute subfusco distinctius circumfusis. - (Cuba; Gundlach.)

64. Eristalis atriceps nov. sp. 万’. Niger, nitidus; cepul tolum concolor, antennis obscure rufis, seta muli instructis; scutelhum et maculae duae segmenti abdominulis secundi badia: margines postici segmentorum secundi, tertii et quarli pallide flavi; alae hyalinae, costâ prater trientem apicalem fusco-limbati. - Long. corp. $4 \frac{1}{3}-4 \frac{5}{1} \frac{5}{2}$ lin., Long. al. $3{ }_{6}^{5}$ lin.

Niger, nitidus, Caput tolum concolor, facie practer vittas ordinarias polline albido levissime aspersâ pilisque rarioribus albidis vestità. Frons, oculi et vertex nigro-pilosi. Antennac ex ferrugineo rufae, setà nudâ. Thoracis dorsum pilis ochraceis vel rufoochraceis vestitum, angulis posticis et fasciâ ab alà allerâ ad alteram pertinente nigro-pilosis. Pleurae et cosae nigro-pilosae. Scutellum badium, nigro-pilosum, margine ipso pilis ochraceis vestito. Segmentum abdominale secundum. utrinque maculam subfriangulam badiam gerens, dimidium posterius opacum, marginem poslicum pallide flavum habet. In segmento tertio ante marginem posticum flavum fascia subopaca et magis nigra cernitur. Segmentum yuartum praeter marginem flavum nitet. Hypopygium nigrum, nilidum. Pili abdominis conferti, nigri, in segmento primo el in dimilio priore secundi rufo-ochracei vel vulpini, in marginibus anticis segmentorum sequentiun pallide lutescentes, in hypopygio longiores et rariores. plerique albidi, reliqui nigri. Venter nimer, nilidus, pilis longis pallidis vestilus, margine postico segmentorum singulorum sordide albicante. Pedes nigri et nigro-pilosi, femoribus posticis non dilatittis, femorum apice, tibiis primisque duobus tarsorum arliculis ex ferrugineo rufis, genibus tibiarumque basi dilute flavescenlibus, tibiis anticis adversus apicem superne fuscis, posticis nitro-inumblis. Alae byalinae, venis nigris, costâ praeter trientem apjealem luscolimbatâ, limbo ubi vena tertia oritur usque ad venam quartam dilatato. - (New Ilampshire; Osten-Sacken)

65. Eristalis latifrons nov. sp. ơ et + . Niger. mollire nilens. tolus pallide-pilosus: antenuae fuscue. setci mudi luted: srutellum testaceum: maculae duae segmenti abdominalis scrundi abbtrigonae testuceae, margo posterior pallidus; margines postici segmentorum sequentium pallidi, antici pallide pollinosi: pedes nigri, genibus, tibiis praeter apicem tarsorumque intrrmediom basi pul- 
lide flavescentibus; oculi maris contigui, foeminue fronte latissima separati. - Long. corp. $5 \frac{1}{4}-5 \frac{1}{3}$ lin., Long. al. $4 \frac{1}{6}-4 \frac{1}{2}$ lin.

Niger, modice nitens, totus pube longiusculâ pallidâ vestitus. Oculi maris contigui, vertex subopacus, frons nitida, lateribus albopollinosis. Frons foeminae latior quam in specielus praecedentibus, albido-pollinosa, maculis nigris verticis duabus nitidis et vittâ nigrâ, supra obsoletiore, infra latiore et nitidâ. Antemnae nigro-fuscae vel fuscae, setâ nudâ, dilute subfuscâ vel sordide luteâ. Oculi pilis pallidis hirti. Facies lala, albido-pollinosa, viltâ mediâ nigrâ valde dilatalâ, ab antennarum basi remotâ, oris marginem prope attingente. Genae nigrae, nilidae. Abdominis segmentum primum practer basim glaucescens. Segmentum secundum inaculas duas subtriangulas teslaceas, lato intervallo separatas et adversus margines laterales valde dilatalas, fatsciam subinterruptam velutinam fusco-nigram el maryinem posticum pallidum habet. In segmento terio margo anticus pallide pollinosus, posticus pallidus reperiunlur; practerea in mare fascia velutina fusco-nigra, interrupla et utringue valde abbreviala conspicilur. Margines segmenti quarti simili modo ac tertii picti sunt. Hypopygium maris et segmentum abdominale ultimum foeminae nigra, nitida. Venter piceus vel piceo-niger, segmentis anticis miuus obscuris, marginibus segmentorum singulorum omnibus pallidis. Pedes nigri. femoribus posticis non dilatatis, femorum apice tibiisque pallide flavicantibus, tibiarum anticarum posticarumque triente apicali et intermediarum apice nigris, metatarso intermedio praeter apicem flavescente. Alae hyalinac, venis dilute fusco-ochraceis rel ochraceis; in alis forminae sub stigmate nubecula ex luteo dilute fusca adest. - (Matamoras; Osteu-Sackeu.)

66. Eristalis hirtus nov. sp. ठ․ Niger, pilis longiusculis lutescentibus vestitus; oculi lirti; antennae nigrae, setâ pilosá: facies lutea, pilis luteolis hirta, villa mediâ, margine oris genisque nigris; thorax unicolor; scutellum luteum, prima tria abdominis segmenta velutina, maculis dubus magnis subtrigonis secundi luteis, fasciâ biarcuali subinterruptà terlii laevigali, utriusque margine postico tenuiter flavo; segmentum quarium et hypopygium modice nitida, margine postico illius tenui flavo; pedes nigri, pallide pilosi, femoribus posticis gracilibus, tibiis intermediis praeter apirem, reliquarum dimidio busali primisque duobus tarsorum intermediorum articulis pallide favicantibus; alue pure hyalinae. - Long. corp. $5_{\frac{1}{4}}^{\frac{3}{3}}$ lin., Long. al. 5 lin.

Niger, pilis longiusculis lutescentibus vestitus. Oculi hirti. An- 
tennac nigrae, selì pilosì. Facies lutco-testacer, polline dilute lutescente aspersa pilisque confertis concoloribus hirta; villa media tenuis, margines oris et genac nigrae; luberculum facici parvum. Thorax unicolor, modice nitens. Scutellum luteum. P'rima tria abdominis segmenta nigro-velutina; in secundo praeter marginem postieum tenuiter flavum maculae duae magnae substriangulae luteae conspiciuntur; terlium praeter marginem tenuissimum flarum fasciam biarcuatam levigatam et subinlerruptam habet. Sermentum quartum, postice tenuissime flavo-marginalum, et hypopygium modice nitent. Pubes abdominis dilute lutescens, in segmento quarto et in hypopygio longior quam in segmentis praccelentibus, in segmentorum tertii et quarti partibus nigro-velulinis nigra. Pedes nigri, pallide pilosi, femoribus posticis gracilibus; femorum apex. tibiac intermediae praeter apicem, reliquae practer dimidium apicale et primi duo tarsorum internediorum articuli pallide flavescentes. extremo tamen horum apice fusco. Alae pure hyalinae, venis nigro-fuscis, auxiliari, longitudinali primâ, spuriâ et quintâ fusco - testaceis, stigmate minutissimo subfusco. - (California; Agassiz.)

67. Eristalis obscurus nov. sp. o'. Aeneo-niger, nitens. pube longinsculâ dilute lutescente cinerea vestitus: frons luta, supra nigro-pilosa; oculi hirti; antennae rufo-ferrugineae, articulis primis duobus nigris, setâ pilosí; facies praeter villas ordinarias flavo-testacea, albo-pollinosa et albo-pilosa; scutellum badium. adversus basim nigrum; abdominis segmenta singula prater primum fascia posticà atrâ, non emarginati el margine postico tenuissime flavo instructa; pedes nigri, femorum omnium apice posticorumque basi, tibiarum anticarnm posticarumque triente basali, tibiis intermediis praeter apicem primisque duobus tarsorum omnium arliculis pallide favicantibus; alae pure hyalinae, venis disci fusco-limbatis. - Long. corp. 5-5 $\frac{1}{2}$ lin., Jong. al. $4 \frac{1}{3}-4 \frac{2}{3}$ lin.

Eristali dimidiato similis. Aeneo-niger. nitidus. pube longiusculâ dilute lutescenti-cinereâ vestitus. Frons lata coneolor, supra nigro-pilosa, maculà marginis antici medià testaceì, marginibus lateralibus antice albo-pollinosis. Facies flavo-testacea vel testacea. albo-pollinosa et albo-pilosa. vittâ medià nigrâ, raro piceì, margine oris genisque semper nigris. Primi duo antennarum articuli nigri, tertius rufus vel rufo-ferrugineus, raro obscure fuscus. setì pilosà. Thoracis dorsum unicolor, neque villatum neque fasciatum. Scutellum piceum vel badium, adversus basim semper aeneo - nigrum. Primum abdominis segmentum glaucum. albido-pilosum. Segmen- 
tum secundum fascias duas velutinas, per fasciam nitidam, latera versus valde dilatatam separalas et marginem posticum flavum habet. In segmentis sequentibus singulis praeter marginem tenuissimum flavum fascia postica atra, in segmento tertio velutina, in reliquis duobus modice nitens conspicitur. Pubes abdominis in posteriore segmentorum singulorum dimidio nigra, in anteriore maximâ ex parte cinerascens. Pedes nigri, pallide pilosi, femoribus posticis gracilibus, adversus basim flavis; apex femorum omnium, tibiarum anticarum posticarumque triens basalis, tibiae intermediae, apice tamen excepto, et primi duo tarsorum omnium articuli pallide flavicantes, hrorum secundo apicem versus nigricante. Alae pure hyalinae, venis nigris, discalibus fusco - limbatis, stigmate et imâ alarum basi fuscis. - (Red River; Kennicot.)

68. Eristalis inornatus nov. sp. ㅇ. Subaeneo-niger, nitens, pube longinscula lutescente vestitus; frons lata, prope ocellos nigro-pilosa, vertice tamen ipso pilis luteis instructo; oculi hirti; antennae mfo-ferrugineae, articulis primis duobus nigris, setâ pilosá; facies praeter viltas ordinarias flava, sed polline dilute lutescente pilisque concoloribus aspersa; scutellum totum testaceum; abdominis segmenta singula praeter. primum fusciâ posticá atrâ, secundum et tertium emarginatâ et vehtiná, seynentia subnilidá, et margine postico tenuissime flavo instructa. Pedes nigri, extremo femorum apice, tibiarum anticarum posticarumque dimidio basali, tibiis intermedis praeter trientem apicalem tarsorumque intermedio. rum articulo primo pallide favicantibus; alae hyalinae, venis disci colore subfusco late circumfusis. - Long. corp. $6 \frac{1}{\frac{1}{4}}$ lin., Long. al. $4 \frac{5}{6}$ lin.

Subaeneo-niger, nitens, pube longiusculâ lutescente vestitus. Frons lata, concolor, pilis confertis luteis, prope ocellos nigris instructa, lateribus antice luteo-pollinosis, margine antico supra anteunas testaceo. Oculi hirti. Facies quam Erist. obscuri longior et tuberculo minore instructa, polline dilute lutescente obtecta pilisque concoloribus vestita, vittû mediâ lenuiore genisque nigris. Primi duo antennarum ariculi nigri, tertius rufo-ferrugineus, selâ pilosâ. Thorax unicolor, modice nitens, totus luteo-pilosus, pilis tamen pleurarum dilutioribus. Scutellum testaceum, luteo-pilosum. Primum abdominis segmentum glaucum, segmenta reliqua nilida, marginibus posticis secundi, tertii et quarli tenuibus flavis. In segmento secundo fasciae duae nigro - velutinae apparent, altera margini antico adjacens et latera versus attenuata, altera cum margine postico con- 
tigua et emarginala. Segmentum terlimm fasciis similibus, anticit tamen multo tenuiore instructum est. Ultima duo abdominis segmenta tota nitida, prope marginem posticum purius nigro-lincta. Pili abdominis plerique nigri, in segmento primo albidi, in dimidio anteriore segmenti secundi et adversus angulos anticos segmentorum intermediorum pallide lutescentes. in segmentis ultimis pallidi cum nigris mixti. - Pedes nigri, pallide pilosi, femoribus posticis gracilibus; apex femorum, tibiac anticae et posticae in dimidio basali. tibiae intermediae praeter apicem tarsorumque intermediormm articulus primus cum imâ secundi basi pallide flavescentes. Alac hyalinae, venis nigro-fuscis, adversus basim alarum testaceis, discalibus colore dilute subfusco latissime circumfusis, sligmate minuto nigrofusco. - (Red River; Kennicot.)

Nota. Specimen. quod descripsi, abdomen lacsum el detritum habel, ita ut de pubis colore recte judicare difficile sit.

69. Eristalis melanostomus nov. sp. ơ el ㅇ. Niger. scutello flavo, pilis longis favis vestilus, facie, thoracis dimielio poste. riore, lateribus segmentorum abdominalium primi et secundi, angulis anticis tertii, hyponygio maris et ultimo segmento abdominis foeminae nigro-pilosis; pedes nigri, nigro-pilosi, tibiarum anteriomem basi testacei, tarsis posterioribus rufo-ochraceis.

$\sigma$ dimidium posterius segmenti abdominalis secundi et segmentum terlium praeter marginem posticum pilis vulpinis vestila: alae totae hyalinae.

오 alae hyalinae, maculà media nigrai permagnâ.

Long. corp. $5 \frac{7}{1}-6 \frac{1}{2}$ lin., Long. al. $4 \frac{3}{4}-6 \mathrm{lin}$.

Syn.? Eristalis flavipes var. $\beta$. Walker List III. 6:3:3.

Niger, pilis Jongis, plerisque flavis vestitus. Oculi utriusque sexus nigro-pilosi, vittâ medià confertius pilosi, maris conligui, foeminae fronte latâ separati. Frons tota flavo-pilosa. Antennae nigro-fuscae, articulo secundo saepe subfusco vel testaceo selâ brevissime pilosâ. Facies atra, nitida, niģro-pilosa. supra polline flavescente leviter aspersa pilisque flavescentibus instructa. Thorax opacus, dimidio anteriore dorsi pleurisque flavo-pilosis, posleriore dorsi dimidio nigro-piloso, marginibus lateralibus in focmina. postico in ulroque sexu, in foeminà tamen latius quam in mare. flaro-pilosis. Scutellum flavum, confertissime flavo-pilosum. Abdomen ulriustue sexus nitens; abdomen foeminae llavo-pilosum. lateribus sugmenti primi et segmenti secundi, angulis anticis segmenti tertii el segmento ultimo nigro-pilosis; abdomen maris latera segmentorum basalium. 
angulos anticos segmenti tertii el hỷpopygium nigro-pilosa, segmentum primum et secundi dimidium anterius praeter latera, marginem posticum segmenti tertii et segmentum quartum flavo-pilosa, segmenti secundi dimidium posterius et segmentum tertium praeter angulos anticos et praeter marginem posticum pilis vulpinis vestita habet. Venter niger, nilidus, nigro-pilosus. - Pedes nigri, confertim nigro-pilosi, tibiarum anleriorum basi fuscâ, tarsis anticis fusconigris, reliquis rufo-ochraceis, apicem versus infuscatis. Alae maris totae pure hyalinae, foeminae maculà mediâ nigrâ permagnâ insignes. - (Minnesota, Oregon; Osten-Sacken.)

70. Eristalis pilosus nov. sp. of et . N Niger, pilis longis flavis confertim vestitus; oculi nigro-pilosi; antennae nigrae, setâ undâ; facies nigra; thorax unicolor, opacus; scutellum luteum; prima duo abdominis segmenla opaca, secundum utrinque maculâ dilute lutescente, modice nilente instructum; segmentum tertium nitidum, maculis duabus opacis, in fasciam abbreviatam confluentibus; segmenta ultima duo aeneo-nigra, nitida, maculá minutâ triangulâ, margini antico paenullimi propinquâ, opacâ; pubes in disco abdominis vulpina, in lateribus mediis nigra, reliqua flava; pedes nigri, nigro-pilosi, femoribus posticis gracilibus; alae pure hyalinae, venis fusco-nigris, discalibus in foeminae alis colore nigricante circumfusis. - Long. corp. $5 \frac{1}{2}-6 \frac{1}{2}$ lin., Long. al. $4 \frac{1}{3}-5 \frac{1}{2}$ lin.

Niger, pilis longis flavis, interdum pallescentibus vestitus. Caput nigrum, flavo pilosum; facies concolor, praeter vittam mediam latissimam polline flavicante levissime aspersa; oculi utriusque sexus nigro-pilosi, maris contigui, foeminae fronte latâ separati; antennac nigrae, setâ nudâ. Thorax unicolor, opacus, pilis omnibus flavis. Scutellum dilute luteseens, confertissime flavo-pilosum. Abdominis segmenta prima duo opaca; sccundum utrinque maculam subrotundatam, dilutissime lutesecutem, modice nitidam et marginem posticum sublevigatum habet. In segmento tertio nitenie maculae duae opacae inter se conjunctae fasciam valde abbreviatam constituunt. Reliqua segmenta aeneo-nigra sunt et praeter maculam minutam triangulam, prope marginem segmenti quarti sitam, nitent. Pili abdominis flavi, in medio abdomine vulpini, adversus anum interdum pallidi, in angulis posticis segmenti secundi et in marginibus lateralibus segmenti tertii, hujus tamen angulis exceptis, nigris. Pedes nigri, nigro - pilosi, femoribus posticis gracilibus, imâ tibiarum basi fuscà. Alae pure hyalinae, venis fusco-nigris, discalibus in foeminae alis colore nigricante circumfusis. (Groenland; Möschler.) 
71. Pipunculus fuscus nov. sp. ठ․ Nigro-fuscus; antennae totae nigrae, articulo terlio brevi, otusiusculo; facies albo-pollinosa; frons nigra; abdomen atrum, velutinum, segmenti primi margine postico cinereo-pollinoso, segmentorum sequentium singulorum laevigato et nilido, segmento quinto fere toto nilido. - Long. corp. $2 \frac{1}{6}$ lin., Inong. al. $2 \frac{3}{4}$ lin.

Nigro-fuscus. Oculi rufi. Antennae nigrae, articulo tertio brevi. obtusiusculo. Facies albo-pollinosa. Triangulum frontale practer margines polline fuseo aspersum. Thoracis dorsum fusco-pollinosum. opacum, adversus marginem posticum subuitens. Scutellum nigrun. nitidum. Metanotum et primum abdominis segmentum, practer basim atıam, cinereo-pollinosa; reliquum abdomen atrum, velutinum, fasciâ posticâ segmentorum singulorum laevigatâ, nitidâ, segmenti secundi imperfectâ el anlice cinereo-limbatâ, quarti mediocri, quinli latâ, sexti valde dilatatâ, ita ut hoc segmentum praeler fasciam anlicam late interruptam totum nitidum sit. Pedes rufo-lestacei. femoribus, practer basim imam el praeter apicem exfremum. farsorumque apice nigris. Alae cinereae, sligmale fusco. - (Maryland: Osten-Sacken.)

72. Pipunculus nitidiventris nov. sp. O. Nigro-rinereus; antennae fusco-nigrae, articuli terlii apice breviter amminato; fucies et frons albo-pollinosne; abdomen nigrum, nilens. segmento primo praeter basim, lateribus angulisyne posticis segmen-

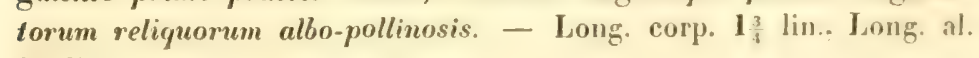
2. lin.

Nigro-cinereus. Antennac nigro-fuscae, arliculi terlii apice breviter acuminato. Facies et frons albo-pollinosac. Thoraris dorsun polline albido-cinereo, in rlisco fusco-cincreo opacum. Sculellum nigrum, modice nilens. Mctanolum albido-pollinosum. Ablomen lotum nigrum, nitidum; segnentum primum practer basim albidopilosum; secundum polline cinereo levissime aspersum. ila ul minus niteal quam sequentia. Ialeribus et nargine poslico fere tofo allidopollinosis; segmentum tertium villam ciucreo-pollinosam. antive dilalalam, postice obsoletan label; lalera. anguli postici el marginis postici fines in segmentis $3-5$ polline albido legrmblur; segmentum sextum margines laterales et angulos posticos alho-pollinosos habel. Pedes rufo-lestacei, femoribus praeler iman basim el extrmmm apicem nigris, libiis posticis fuscis. larsormm apice nignon - (I)istr. Columbia; (Oslen-sacken.) 
73. Pipunculus cingulatus nov. sp. ơ. Cinereo-niger; antennae tolae nigrae, articulo terlio brevi, obtusiusculo; facies et frons albo-pollinosae: abdomen nigrum, nilidum, segmento primo albo-pollinoso, reliquorum singulorum fascia basali obscure cinereopollinosâ lateribusque albo-pollinosis. - Long. corp. $1 \frac{5}{6}$ lin., Long. al. $2 \frac{1}{12} \operatorname{lin}$.

Cinereo-niger. Antennae totae nigrae, articulo tertio brevi, obtusiusculo. Facies et frons albo-pollinosae. Thoracis dorsum polline fusco-cinereo opacum; pleurae polline albido-cinereo aspersae. Sculellum nigrum, modice nitens. Metanotum albo-pollinosum. Segmeutum abdominale primum albo-pollinosum, maculâ mediâ atrâ; reliquum abdomen nigrum, nilidum, lateribus albido-pollinosis, segmentorum singulorum fasciâ tenui basali obscure cinereo-pollinosâ. Femora practer apicem nigra; tibiae nigro-fuseae, triente basali omnium anteriorumciue apice rufo-testaccis; tarsi rufo-testacei, apicem versus fusci, articulo ullimo nigro vel nigro-fusco. Alae subfusco-cinereae, stigmate fusco. - (Distr. Columbia; Osten-Sacken.)

74. Pipunculus subopacus nov. sp. ㅇ. Fusco-niger: antennae nigrae, arliculo tertio in aculeum candidum producto; facies albo-pollinosa: frons nigra; abdomen subnitidum, segmento primo praeter basim, reliquis adversus latera et angulos posticos subolsolete exalbido - pollinosis. - Long. corp. $1 \frac{2}{3}$ lin., Long. al. $1 \frac{3}{4}$ lin.

Fusco-niger. Antennae nigrae, articuli tertii apice in aculeum longum candidum producto. Facies albo-pollinosa. Frons nigra. Thoracis dorsum polline fusco-cinereo leviter aspersum, subopacum; pleurae polline exalbido cinereae. Metanotum albido - pollinosum. Abdomen fusco-nigrum, subnilidum, segmento primo praeter marginem basalem, reliquis adversus latera et adversus angulos posticos exalbido-pollinosis. Pedes rufo-tesiacei, femoribus praeter apicem nigris, tibiis fuseo-annulatis, apice tarsorum nigro; primus tarsorum posticorum articulus brevior et quam in reliquis speciebus paulo crassior. Alae cinereo-hyalinae. sligmate fusco. - (Washington; Osten-Sacken.)

75. Pipunculus nigripes nov. sp. ठ․ Fusco-niger; antennae totae nigrae, articulo tertio breviter acuminato; facies et frons albo-pollinosae; abdomen, praeler hypopygium, lotum opacum, segmento primo albido-pollinoso, sequentibus tribus atris, velutinis, fasciâ singulorum posticâ late interruptâ albo-pollinosâ. - Long. corp. $1 \frac{1}{6}$ lin., Long. al. $1 \frac{1}{2}$ lin. 
Fuseo-niger. Anlenuae tolae nigrae. arliculi lertii appe breviter acuminalo. Facies el frons albo-pollinosae. Thoracis dorsum et scutellum fusco-pollinosa, subopaca. Abdomen folum opacum: segmentum primum praeler basim albo-pollinosum; segmenla serpuentia tria afra. velutina, fascia singulorun postica obscure cincreo-pollinosâ, lalera versus laliore ef albo-pollimsai; segmenlum quinturn fusco-pollinosum, subnitidum. lateribus albido - pollinosis. Hypopygium nigrum nilidum. Pedes nigri, genibus pallidis. lassorum basi nigro-fuscå. Alae cinerascenles. stignale fuseo. - (Pennsylvania; Osten-Sacken.)

76. Callomyia notata nov. sp. O. Ara, relutina. Ihuraris maculis glanco-aeneis abdominisque strigis lateralibus glantis ulbupollinosis, ventre pedibusque pallidis, halteribus nigris, alun ruevis longitudinalibus tertiri et quarti apricem ressus perfecte puralle-

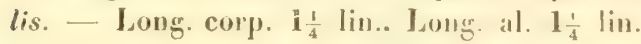

Caput nigrum; antennac fusco-nigrac, articulo tertio atculo. 'Thorax ater, opacus, pectore cincreo, lrienle anlico dorsi fere tolo, nigro-aeneo, adversus humeros albido-polliurso maculisque duabus permaguis posticis glaucis, confertius albo-pollinosis. Abdomen atrum, velutimm, segmento primo ulrinque puncto. sequenlibus tribus siugulis utrinque strigâ sive maculì Iransversì albu-pollinosà. lacte glaucescente ornalis, strigis segmenti lertii per marginem pusticum tenuissime album conjunclis. Venler lolus pallidus. Pedes cum coxis pallidi, femosum dimirio apicali, libiis posticis practer apicem, imâ libiarum anleriorum basi tarsorumpue omnium apice nigricanlibus. Halleres alri. Alac purissime hyalinac, renis nigris. longitudinalibus tertiâ ef quarlát adversus apiecu perfecte parallelio. - (Penusylvania: Osten-Saclien.)

77. Callomyia divergens nov. sp. S. Ilra. relutina. muculis thoracis abicantibus, ventre, pedibus halleribuspue pallidis. ulurum renis longitudinalibus terlid el quarli aprem etersus dierergenlibus. - Long. corp. 5 lin., Long. al. I lin.

Capul nigrum; antennae fuscac, arlioulo lerlio arulo. Thurax aler. opacus. maculis dorsi humeralibus posticistue duabus albirantibus. Abdomen alrum. velulimm. immarulalum. ventre toto pallido. Pedes cam eoxis pallidi. Larsorum apice paulo obsomiore. Jalleres

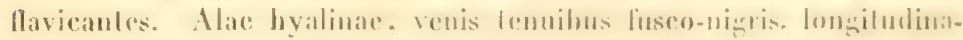
libus forlia el quarti apioem versus divergentibus. - (Pemestra niat; Usten-Sacken.) 
78. Plalypeza velutina nov. sp. ㅇ․ Atra, antennis, pedibus halteribusque concoloribus; alae purissime hyalinae, venne longitudinalis quartae ramulo anteriore valde arcuato, posteriore longinsculo, venâ Iransversâ posteriore margini alae valde approximatâ. - Long. corp. $1 \frac{1}{3}$ lin., Long. al. $1 \frac{2}{3}$ lin.

Caput nigrum, opacum, antennis, palpis et proboscide concoloribus. Thorax tolus niger, opacus. Abdomen alrum, velutinum, immaculatum. Pedes nigri, tarsis anterioribus praeter apicem posticorumque laleribus luridis. Halteres nigri. Alae purissime hyalinae, venis nigris, longitudinalis quartae ramulo anteriore valde arcuato, posteriore longiusculo, venâ transversâ posteriore alae margini valde approximatâ. - (Pennsylvania; Osten-Sackẹn.)

Noła. A Platypezâ atrâ Fall., cui simillima, cellularum posteriorum secundâ paulo majore, tertiâ modice breviore et cellulâ anali pro portione paulo longiore distinguitur.

79. Platypeza flavicornis nov. sp. đ. Atra, antennis flavis, pedibus fuscis, halteribus nigris; alae pure hyalinae, venae longitudinalis quartae ramulo anteriore leviter arcualo, posteriore brevissimo, venâ transversâ posteriore a margine alae longe remotâ. - Long. corp. $1 \frac{1}{4}$ lin., Jong. al. $1 \frac{1}{3} \mathrm{lin.}$

Praetel anum obsolete cinerascentem tola atra et velulina. Antennae et palpi llavicanles. Pedes fusci, femoribus omnibus libiisque posticis maximâ ex parte uigris, tibiis anlicis tarsisque pallidis. Halteres nigri. Alae hyalinae, venis nigro-fuscis, venae longitudinalis quartae ramulo anteriore leviter arcualo, posteriore perbrevi, venà transversâ posteriore ab alae margine valde remotì. - (Pennsylvania; Osten-Sacken.)

80. Platypeza obscura nov. sp. F. Aira, antennis nigris, pedibus halteribusque nigro-fuscis, angulis anticis segmentorum abdominalium singulorum cinereis; alae pure hyalinae, venue longitudinulis quartae ramulo anteriore valde arcuato, posteriove brevissimo, venû transversâ posteriore margini alce cpproximat $\hat{a}$. - Long. corp. $1 \frac{1}{6}$ lin., Long. al. $1 \frac{1}{4}$ lin.

Caput nigrum, antennis palpisque concoloribus. Thorax niger, opacus. Abdomen atrum, velutinum, angulis anticis segmentorum secundi, tertii, quarti et quinti segmentoque sexto toto cinereis. Pedes nigro-fusci, femoribus omnibus tibiisque posticis maximâ ex parte nigris, extremo tibiarum apice, tarsis anierioribus praeter apicem tarsorumque posticorum latere extremo pallidioribus. Halteres 
nigro-fusci. Alae hyalinae, renis nigro-fuseis, longitudinalis quartae ramulo anteriore valde arcuato, posteriore brevissimo, venti transversâ posteriore alae margini valde approximatâ. - (Pennsylvania; Osten-Sacken.)

S1. Platypeza pallipes nov. sp. ․ Cinerea, abdomine nigro-fasciato, antennis pedibusque dilute lutescentibus. - Long. corp. $\nu_{\frac{1}{1}}^{\prime}$ lin., Long. al. $2 \frac{1}{4}$ lin.

Dilute cinerea, opaca. Caput concolor, fronte fere tolì ex fusero cinereâ; antennae, proboscis et palpi dilute lutescentes. Calli luumerales pleurarumque maculae lutesentes; dorsi villae fuseae qualuor; mediae approximatae. adversus marginem anticum dorsi obsolescentes. postice valde ablrevialae; laterales lreves. antice admodum, postice modice abbreviatae. Latera segmenti abolominalis primi lutescentia; reliquum abdomen cincreum. fasciis poslicis segmentorum singulorum atris et maculì minutâ alrâ in margine antico segmenti secundi, cum fasciâ alrâ cohacrente. Coxae ef pedes dilute. lulescentes, femoribus posticis prope apicem superne. larsis poslicis practer basim subinfuscatis. Halteres lulescentes. Alac majusculae. cinereo-hyalinae, venis fuscis, longitudinalis quartac ramulo auleriore satis arcuato, posteriore longiusculo, venâ transversà posteriore margini alae modice approximalâ. - (Dislr. Columbia: Oslen. Sacken.)

Nota. Plalypeza pallipes valde similis est Platypezae consobrinae Zell., sed differt alis limpidioribus et veni transversi posteriore magis perpendiculari alacque margini minus approximatâ.

82. Plalyenema imperfect a nov. sp. O’ el . Nigra. pedibus simplicibus, alarum venà transversî anteriore nulli. - Long. corp. $\frac{3}{4}$ lin., Jong. al. $\frac{3}{4}-\frac{5}{6}$ lin.

Caput nigrum, antennis concoloribus, palpis latiusculis exalbidis vel dilutissime flavicantibus. Thorax cum sculello niger. Abdomen nigro-fuscum, marginibus posticis lenuissimis et ventre lolo pallidis. Pedes simplices. Alie cincreo-hyalinac, veni transversi anteriore destitutae, venis praeter costalem, auxiliarem el lonsiludinalem primam decoloribus. - (Washinzlon; Ostensarken.)

\$3. Diaphorus subsejunctus nov. sp. ot. Latel rividis. coxis anticis pedibustue flavis, riliis hallerum pallidis. oculis maris fronte angustissima lineari separatis. - Jong. corp. $1 \frac{1}{3}-1 \frac{3}{12}$ lin.. Long. al. $1 \frac{1}{4}-1 \frac{1}{3}$ lin. 
Caput nigro-viride; frous angustissima, linearis. cinerea; facies angusta. nigro - cinerea; antennae parrae, nigrae. Tboracis dorsum viride sive ex caeruleo viride. leviter albo-pollinosum, modice nitens. Scutellum cum dorso thoracis concolor. Pleurae nigricantes. albo-pollinosae. Abdomen viride sive aureo - viride. Cosae anticac flavae. posteriores nigricanles. apice tamen flavo. Pedes flavi, tarsis anticis apicem versus saturatius. posterioribus dilutius infuscatis. nttimo omnium articulo nigro. Cilia halterum pallida. Alae cine-

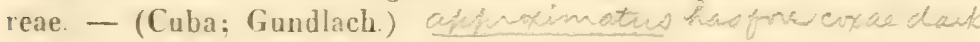

54. Psilopus castus nov. spec. ठ․ Late viridis, nitidus. pleuris concoloribus albo-pollinosis, primis duobus antennarum articulis, coxis anticis. poslicarum apice pedibnesque flavis. Iarsis maximá ex parte nigris. ciliis halterum pallidis, hypopygio minu-

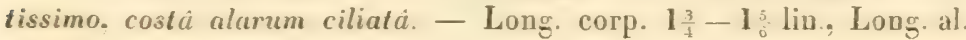
$1 \frac{5}{6} \operatorname{lin}$

Caput chalybeum, vertice virescente, facie albo-pollinosà. nudù: antennae perparvae, articulis primis duobus flavis, tertio nigro. Thorax laete viridis. dorso leriter pollinoso. nitido. antice cacrulescente. pleuris polline confertiore aspersis, subopacis. Scutellum caeruleum sice riridi-caeruleum, setis duabus praeditum. Abdomen aureo - riride. levissine albo-pollinosum. imâ segmentorum singulorum basi cupreo-purpureâ; hypopygium nigrum. minutissimum, appendicibus solitis brevibus. hadiis. Corae anticae flavae. albo-pollinosae. pilis minulis albis et prope apicem setulis aliquot albis vestitae: coxac posteriores nigricantes. apice flavo. setulis albis. Pedes graciles flari. bresissime nigro-pilosuli, praeter seriem setarum nigrarum in postico femorum internediorum latere pilis setisque longioribus destituti: tarsi inde $a b$ articuli primi apice nigri. primo anticorim articulo subfusco. intermediorum flavo, posticorum nigro-fusco. Cilia halterum pallida. Alae cinereo-hyalinae, venis nigris, costà breviter nigro-cilialà. - (Cuba: Gundlach.)

S5. I'silopus dorsalis nov. sp. O. Flavus, capite praeler. antennas. proboscidem et palpos, thoracis plagà dorsali antice altenuatà sculelloque viridi-caeruleis, segmentis abdominalibus singulis postice, anticis angustissime. posticis late viridibus. pedibus nudinsculis, tarsis fuscis, ciliis halterum pallidis, costâ alurum dilule lu. rescentium cilialu. - Long. corp. $2 \frac{1}{1} \frac{1}{2}$ lin., Long. al. 2 lin.

Caput ex viridi cacruleum, albo - pollinosum, facie planâ noı pilosà; duobus prinis antenuarum arliculis, proboscide palpisque 
flavis. Thorax flavus. plậâ dorsali latissimâ antice altenuatî ex cacruleo viridi pleurarumque polline albo aspersartmm maculâ subobsolelâ caerulescenle. Sculellum viridi-caerulenm. setis duabus instructum. Abdomen flarum; segmenfum primum postice anguste fusco-marginatum: secundum prope basim fusco-fascialum marginem posticum fusco-limbatum et ex parte viridi-micanlem labet: uterque segmenti tertii margo fusco-limbalus. limbo postici tamen maguà ex parte viridi-micante; segmentum quartum, similiter pictum. limbum utrumque paulo latiorem et posticum latius viridi-splendentem habel: segmenta reliqua singula prope basim nigricantia prope apicen late riridi micant. Pedes cun coxis flari. nudiusculi. pilis setisque longioribus destituti, tarsis praeter basim fuscis. Cilia halterum pallida. Alae ex cinereo sublutescentes. costà pilis erectis subtiliter ciliatâ. - (Cuba; Gundlach.)

86. Tetanocera spinicornis nor. sp. ․ Ex cinereo fusca, fusco-vittata. antennarum articulo secundo bispinoso. selà plumalá. facie genisque longe descendentibus albo-pollinosis, alis fusco-reticu. latis. - Long. corp. $2 \frac{1}{2}-2 \frac{7}{2}$ lin. Long. al. $2-2 \frac{1}{1} \frac{1}{2}$ lin.

Caput flarum: frons unicolor, opaca, nec rittata, nec maculata. fossulà longitudinali mediâ paulo obscuriore. Antennae concolores, articulo primo brevissimo, secundo lato supra spinis duabus nigris armato. tertio quam secundus paulo breviore acuto. selà concolore plumalà. Facies subplana et genae lonzissime demissae albo-pollinosae, vittâ ab infero oculorum angulo usque ad marginem oris pertinente subfuscà. Thoras fuscus. polline albido cinerascens, dorso utrinque late albilo-limbato et ritlis angustis fuscis quatuor, mediis in scutellum productis ornato: pleurae fusco-rittatae. inter tegulas et halteres maculà ovatâ atrâ signatae. Abdomen fuscum. polline albido cinerascens, fusco-puuctatum et fusco quinque-viltalum. vilti intermedià angusta et inlegrâ. reliquis latioribus et subinterruptis. Pedes ex flavo teslacei, femorum maculis. tibiarum apice et ultimis duobus vel tribus tarsorum articulis nigris. Alac fusco-reticulatac, guttis ninoribus minus limpidis et irregulariter disjeclis, majoribus limpidioribus et in faseias leviter arcuatas tres. primå tamen obso. letiore, dispositis. - (Cuba; Gundlach.)

57. Eumelopia varipes nov. sp. of. Nigra. Thorace smtelloque virescentibus. femoribus nigris, tibiis testaceis. - Long. corp. 2 lin., Lin. al. $\mathbf{1}^{2}$ lin.

Eumetopiae rufipedi simillima, sed maculà alarum apicali ma- 
jore venisque longitudinalibus terliâ et quartâ magis convergentibus. pedibus denique obscurioribus differt. Caput fuscum, opacum, vertice et superiore occipitis parte virescentibus, nitidis, marginibus lateralibus frontis confertius albo-pollinosis, antennis et facie nigris. Thorax viridi-niger, nitidus. Scutellum concolor. Abdomen nigrum, adversus basim magis virescens et nilidius, adversus apicem subopacum. Femora nigra, antica viridi-nigra, nitida, reliquis paulo crassiora; extremus apex femorum omnium flavo-testaceus; tibiae flavotesfaceae, posticae praecedentibus obscuriores, apice fusco; tarsi nigro-fusci, basi dilutiore. Alae hyalinae, maculâ apicali permagnà nigrâ. - (Cuba; Gundlach.)

88. Ephydra crassimana nov. sp. ठ․ Tota aeneo-viridis, polline dilute cinerascente aspersa, subopaca, metatarso antico incrassato. - Long. corp. $2 \frac{1}{2}$ lin., Long. al. $2 \frac{1}{2}$ lin.

Obscure aeneo-viridis, polline dilute cinereo subopaca, pube setulisque longiusculis nigris vestila. Facies polline conferto cinereo aspersa, margine oris pilis longis rigidis ciliato. Antennarum seta breviuscula, praeter basim incrassatam albida, supra breviter pilosa. Frons aeneo-riridis utrinque serie setarum nigrarum instructa, marginibus lateralibus opacis. Hуроpygium majusculum, appendicibus apicis duabus minutis stiliformibus. Pedes cum corpore concolores, validi, tarsis crassioribus quam in Ephydris plerisque, primo tarsorum anticorum articulo incrassalo, unguibus magnis. - (Mexico.)

89. Drosophila flexa nov. sp. ठ'. Ex luteo latericia, capite pedibusque luteis, alarum venis transversis nigro-limbatis, venarum longitudinalium primae, secundae et tertiae singularum apice puncto majore nigro, quartae minore notato. - Long. corp. $1 \frac{1}{3}-$ $1 \frac{5}{6}$ lin., Long. al. $1 \frac{1}{3}-1 \frac{5}{6}$ lin.

Ex luteo latericia. Caput luteum, fronte primisque duobus antennarum ariiculis flavis. Pedes lutei. Alae ex luteo subfuscae, adversus costam paulo saturatiores; venac transversae nigro-limbatae, posterior flexa; apex venae longitudinalis primae nigro-notatus, secundae et tertiae nigro-circumfusus, quartae obsolete nigro-limbatus. (Cuba; Gundlach.)

90. Drosophila quinaria nov. sp. ठ et 오 Lulescens, thoracis dorso et scutello ex luteo latericiis, abdomine macularum nigrarum seriebus quatuor picto, alarum venis transversis venarumque longitudinalium secundae, tertiae et' quartae singularum apice nigro.limbato. - Long. corp. $\mathbf{1}_{\frac{5}{2}}^{\frac{5}{2}}$ lin., Jung. al. $1 \frac{1}{2}$ lin. 
Lulescens; thoracis dorsum et sculellum sublatericia; villa frontalis sordide aurantiaca; terlius antemarum articulus dilutissime fu. scescens; palpi flavicantes. Abdomen macularum nirrarum seriebus qualuor variegatum. Pleurae, coxae pedesque dilulissine lutescentes. Alae lutescentes, venis ex lnteo fuscis, apicem versus fuscis. transversis anguste nigro-limbatis, longitudinalium secundae. tertiae et quartae singularum apice nigro-circumfuso. - (New York; OstenSacken.)

Nota. A Drosophilâ tripunclatâ, cujus alae simili modo pictae sunt, abdominis picłırâ distinguilur.

91. Drosophila bimaculata nov. sp. ‥ Pallide flavescens. thoracis dorso el sculello sublatericis: palpi magni, nigrricantes; abdomen nigrum, opacum, ima basi et segmento secundo pallidis, maculà tamen mediâ hujus nigrdi alae sub̉hyalinae, maculis duabus magnis nigris, costae contiguis. - Long. corp $1 \frac{3}{4}$ lin., Long. al. $1 \frac{1}{4}$ lin.

Dilute flavescens, opaca. Caput concolor, occipitis maculis duabus indeterminatis fuscis; frons satis angusta; facies non carinata; palpi magni, exserti, nigricantes. Thoracis dorsum et scutellum sublatericia. Abdomen nisrum, opacum, basi segmenti primi et segmento secundo pallidis, hoc maculâ mediâ nigrâ et utrinque ma. culâ obsolete nigricante variegato. Pedes toti dilute flavicantes. Alae cinereo-hyalinae, basi et cellulâ marginali sublutescentibus maculisque duabus magnis nigris, costae contiguis ornalae. - (Cuba; Gundlach.)

92. Drosophila obscuripennis nov. sp. Ђ. Obscure latericia, infru dilute lutescens, palpis magnis abdomineque atris, opacis, alarum dimidio anteriore nigro, inter venas transversas tamen eluto, venâ transversâ posteriore late nigro-limbatâ. - Long. corp. $1 \frac{1}{2}$ lin., Long. al. $1 \frac{1}{2}$ lin.

Caput lutescens, fronte modice latâ, obscure latericiâ, palpis magnis, exsertis, atris. Thoracis dorsum et sculellum obscure latericia, opaca; pleurae lulescentes. Abdomen atrum, opacum, basi anguste luteâ. Pedes toti dilute lutei. Halterum capitulum fuscum. Alarum dimidium posterius cinereum, venâ transversâ posteriore latissime nigro-limbatâ; dimidium anterius ex fusco nigrum, fasciolà inter venas transversas silâ costamque fere attingente et ipso alarum apice elutis. - (Cuba; Gundlach.) 
93. Hippelates pallidus nov. sp. ․ Flavescens, abdomine apicem versus fusco, calcari tibiarum posticarum longissimo. Long. corp. $1 \frac{1}{3}$ lin., Long. al. $1 \frac{1}{4}$ lin.

Flavescens, pube albidâ vestitus, triangulo verticali concolore, nitido, usque ad anticum frontis marginem produclo. Articuli antennarum basales flavi; tertius deest. Setae thoracis perpaucae nigricantes. Scutellum majusculum. superne plauum, setis duabus magnis apicalibus nigris. Basis abdominis flava; segmenta tria ultima marginesque laterales segmenti praecedentis ex nigro-fusca. Pedes pallidi, calcari nigro tibiarum posticarum longissimo. Alae hyalinae, venis subfuscis, prope basim alarum lulescentibus. - (Cuba; Gundlach.)

94. Hippelates convexus nov. sp. $\delta$ et ․ Niger, nitidus, capite flavo, triangulo verticali nigro, nitidissimo, abdominis basi fuscâ; pedes lutei, femoribus praeler apirem, tibiis posticis praeter basim nigris, tarsis omnibus, basi tamen except $\hat{a}$, fuscis. - Long. corp. $\frac{3}{4}-\frac{5}{6}$ lin, Long. al. $\frac{3}{4}$ lin.

Niger, nitidissimus. Caput flavum, occipite nigro; triangulum verticale magnum, nigrum, nitidissimum; antennae flavae, articulo tertio magnâ ex parte nigro. Scutellum breve, convexiusculum. Abdomen nigrum, nitidum, basi fuscâ vel sordide luteå. Pedes cum coxis anticis lutei, femoribus omnibus praeter basim nigris. tarsis praeter basim, posticis saepe totis fuscis. Halteres dilute flavicantes. Alae hyalinae, venis fuscis. - (Cuba; Gundlach.)

95. Hippelates flavipes nov. sp. $\sigma^{\circ}$ et 우. Aler nitidus, capite, praeter occiput et praeter triangulum frontale, abdominis basi, coxis pedibusque flavis, alis hyalinis. - Long. corp. $\frac{3}{4}-\frac{1}{1} \frac{1}{2}$ lin., Long. al. $\frac{3}{4}-\frac{5}{6}$ lin.

Ater, nitidissimus. Caput flavum, proboscide, palpis antennisque concoloribus, tertio harum articulo interdum superne leviter nigricante, occipite et triangulo verticali nitidissimo atris. Basis abdominis flava. Pedes cum coxis dilute flavi, tarsorum apice interdum paulo obscuriore. Halteres flavicantes. Alae hyalinae, venis pallidis, costâ et venâ longitudinali primâ dilutissime subfuscis. (Cuba; Gundlach.)

96. Desmometopa tarsalis nov. sp. ठ et 9 . Atra, nitida, primo tarsorum anticorum primisque duobus reliquorum articulis ochraceis, halteribus lutescentibus, alis albido-hyalinis, venis pallidis, costâ nigro-fuscá. - Long. corp. $\frac{1}{1} \frac{1}{2}-1$ lin., Long. al. $\frac{5}{6}$ lin. 
Atra, nitida. Caput afrum, antennis. proboscide palpisque to. tis concoloribus; frons aterrima. opaca. Iriangulo verticali, marginibus lateralibus villulisque duabus tenuissimis nigris. Thoracis dorsum et scutellum polline cineree levissime aspersa. Pedes atri, primo tarsorum anlicorum primisque duobus reliquorum articulis ex rufo ochraceis. Halleres lutescentes, capilulo supra interdum obscuriore. Alae albido-hyalinae, venis pallidis, longitudinalium tertiac et quartae apicibus modice sed perspicue convergentibus, costâ nigro-fuscâ. - (Cuba; Gundlach.)

Nota. Agromyza M atrum Meig. cum proxime cognatis genus proprium constituit, cui Desmometopae nomen imponere placuit.

97. Lobioptera lacteipennis nov. sp. ठ et ㅇ. Atra.ni. tida, halteribus lutescentibus, alis albidis, venis concoloribus, longitudinalibus terliâ et quartá valde convergentibus. - Long. corp. $1 \frac{1}{6}-$ $1 \frac{1}{4}$ lin., Long. al. I- I $\frac{1}{4}$ lin.

Atra, nitida. Caput cum antennis, proboscide et palpis totum concolor, fronte subopacà. Thoracis dorsum et scutellum ex viridi atra. Abdomen subopacum, segmento ultimo toto laleribusque praecedentium nitidis. Halteres lutescentes. Alae albidae, venis concoloribus, costâ dilutissime lutescente; segmentum ultimum venae longitudinalis quartae leviter arcuatum et cum venâ tertià couvergens. ita ut cellulae posterioris primae ostium angustissimum sil. (Cuba; Gundlach.)

98. Rhicnoëssa coronala nov. sp. ㅇ․ Cinerea, thorace obsolete fusco-lineato, fronte aurantiacà, ulrinque albo-marginatá, tertio antennarum nigrarum arliculo sublus rufo, coxis anticis favicantibus, coxis posterioribus pedibusque nigris, - Long. corp. $1 \frac{1}{4} \mathrm{lin}$. Long. al. $1 \frac{1}{4}$ lin.

Occiput nigro-cinercum, albo-pollinosum. Frons aurantiaca, triangulo verticali cinereo, limbis lateralibus lunulique frontali albis. Primi duo anteunarum arficuli n̂igri, tertius supra niger, subtus flavus s. rufus; facies et genae latissimae subflavescentes, albo-pollinosae; setulae mystacinae tenuissimae et minutissimae; palpi exalbidi. Thoracis dorsum ex fusco cinereum. lineis quatuor magis fuscis obsoletissimis. Scutellum concolor. Pleurac cinereac, supra late fusco-limbatae. Abdomen obscure cinereum, lateribus segmentorumque ultimorum marginibus posticis albido-cinereis. Coxac anticae flavicantes, albo-pollinosae, posticae nigrae; pedes nigri, exlremo femorum apice tibiarumque basi luteo-testaceis, basi tarsorum intermediorum fuscâ. - (Georgia; Osten-Sacken.) 
99. Leucopis bella nov. sp. ․ Albida, thorace fusco-bivit. lato, primo abdominis segmento proter margines atro, segmentis sequentibus singulis punctum minutum atrum in mediâ basi, secundo praeterea utrinque maculam alram gerentibus. - Long. corp. $\frac{1}{1} \frac{1}{2}-$ 1 lin., Long. al $\frac{1}{1} \frac{1}{2}$ lin.

Albicans, opaca. Vitta fronlalis concolor, utrinque nigro-marginata. Antennae nigrac, albido-pollinosae. Palpi nigri; proboscis flava. Thoracis dorsum villis duabus integris. adversus marginem posticum modice convergentibus ornatur. Abdomen candicans; segmentum primum praeter margines atrum, opacum; segmenta secundum, tertium et quartum, singula in mediâ basi puncto atro notantur, praeler quod secundum utrinque maculam rotundam atram gerit. Pedes nigri, albo-pollinosi, genis tarsisque flavicantibus, extremo horum apice paulo obscuriore. Alae lacteae, venis dilute subfuscis. - (Cuba; Gundlach.)

100. Sigaloëssa bicolor nov. sp. ․ Alra, antennis et fa. cie luteis, humeris, scutello, pleuris pedibusque fluvis. - Long. corp. $\frac{7}{12}-\frac{2}{3}$ lin., Long. al. $\frac{1}{1} \frac{1}{2}$ lin.

Caput atrum, nitidum, facie luteâ genisque angustis candidomicantibus; antennae luteae, setâ confertius sed brevissime plumulatâ. Thoracis dorsum nitidum, margine laterali humerisque flavis. Scutellum totum flavum. Pleurae flavae. lineâ longitudinali mediâ atrâ. Abdomen globosum, ałrum, opacum, apice extremo subfusco aut sordide luteo. Pedes cum coxis toti flavi. Halterum capitulum ex nigro fuscum. Alae hyalinae, leviter sublutescentes, venis luteis ut in Astiis directis, adjeclâ tamen venulâ transversâ posteriore, apici venae longitudinalis primae oppositâ. - (Cuba; Gundlach.)

Nota. Sigaloëssa ab Astiâ (Asteiâ Meig.). cui proxima, alis venâ transversâ posteriore instructis distinguitur. 


\title{
Diptera Americae septentrionalis indigena.
}

\author{
Descripsit
}

H. L

C e n t u r a septim a.

1. Tanypus scapularis.

2. - humeralis.

3. - thoracicus.

4. - bellus.

5. - pusillus.

6. - hirtipennis.

7. - pilosellus.

8. Macrocera formosa.

9. Sciophila bimaculata.

10. Sargus elegans.

11. - lucens.

12. - tricolor.

13. - pleuriticus.

14. Chrysonotus nigricornis.

15. Euparyphus tetraspilus.

16. - brevicornis.

17. - stigmaticalis.

18. - bellus.

19. Stratiomyia maculosa.

$20 . \quad$ - laticeps.

$21 . \quad$ picipes.

22. Midas rufiventris.

23. - luteipennis.

24. - xanthopterus.

25. - simplex.

$26 . \quad$ venosus.
27. Echthodopa pubera.

28. Pygostolus argentifer.

29. - dives.

30. - pictus.

31. Plesiomma funesta.

32. - leptogastra.

33. - indecora.

34. macra.

$35 . \quad$ unicolor.

36. Diogmites platypterus.

37. - discolor.

35. - ternatus.

39. - misellus.

40. - bilineatus.

41. - angustipenris.

42. - hypomelas.

43. - umbrinus.

41. Mirrostylum galactodes.

45. Scleropogon pictus.

46. Stenopongon modestus.

17. - inquinatus.

18. consanguinens.

49. Iatipennis

50. - longulus.

51. Ospriocerns Aercides.

52. Rhosilamenthus. 
53. Dizonias phoenicurus.

54. bicinctus.

55. Sphegeus chalcoprocius.

56. Dicolonus simplex.

57. Lasiopogon bivittatus.

58. Heteropogon gibbus.

59. Cyrtopogon chrysopogon.

60. marginalis.

61. melanopleurus.

62. Holopogon seniculus.

63. Ablautus trifarius.

64. Baccha parvicomis

65. - notata.

66. Ocyptamus longiventris.

67. - conformis.

68. latiusculus.

$69 . \quad$ scutellatus.

70. Microdon incequalis.

71. Dalmannia nigriceps.

72. Myopa clausa.

73. Oncomyir abbreviata.

74. - loraria.

75. Zodion nanellum.

76. Atrichia longurio.
77. Dolichopus pugil.

78. - terminalis.

79. - detersus.

80. - platyprosopus.

81. - saroles.

82. Gymnopternus phyllophorus

\$3. Paraclius claviculalus.

84. Tachytrechus binodntus.

85. Euthera tentatrix:

86. Crabala platycnema

87. - angulata.

88. - maculosn

89. - nebulosa.

$90 . \quad$ - placida.

91. Lauxanin flaviceps.

92. Ephydra obscuripennis.

93. Drosophila multipnnctata.

94. Gaurax anchora.

95. Phora clavata.

96. - microcephala

97. - pachyneura

98. - incisuralis.

99. - nigriceps.

100. - scalaris.

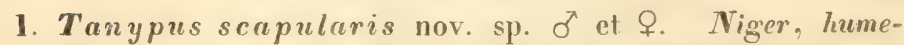
ris pleurarumque dimidio superiore albidis, pedibus albo ef nigrro variis, alis nudis, maculd centrali atrâ. venas transversas includente ornatis. paenullimo tarsorum articulo brevi, obcordalo.

$\delta$ abdomine albo et nigro annulato, tibiis anticis primoque tarsorum anticorum articulo, apice tamen utriusque excepto, albis.

오 abdomine toto nigro, pedibus anticis prater femorum basim nigris.

Long. corp. $1 \frac{1}{2}-1 \frac{2}{3}$ lin., Long. al. $1 \frac{1}{4}-1 \frac{1}{3}$ lin.

Caput albidum, occipitis disco piceo-nigro. Antennae foeminae breves, fuscae; maris antennarum articulus primus niger, flagellum subfuscum. Thorax maris niger et opacus, foeminac piceo-niger et subnitidus; humeri, collare et pleurarum dimidium superius in 
utroque sexu albida. Scutellum cum thorace concolor. Abdomen maris nigrum. segmentis primis duobus tolis. margine postico tertii. quarto praeter basim et sexti dimidio posteriore albis; foeminae abdomen totum nigrum. Femora omnia in ulroque sexu praeter basim albidam nigra vel piceo-nigra; tibiae et tarsi antici foeminae concolores, maris albidi, apice tamen libiarum et larsis inde ab articuli primi apice nigris; tibiae posteriores albidae, basi latissime. apice late nigris; farsi posteriores nigri, articulo primo practer apicem albido; articulus paenultimus tarsorum onnimm in ufroque sesu perbrevis, obcordatus. Halteres exalbidi. Alae nudac. subhyalinae. maculâ minutâ nigrâ, venas transversas includente el puncto nigro in venae quintae anastomosi. - (Washington: Osten-Sacken.)

Nota. Foemina variat tibiis intermediis praeter annulum alhidum nigris.

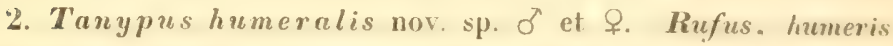
pleurarumyue dimidio superiore albidis, pectore et melanolo fuscis. pedibus nigro et albo variis, alis nudis, maculi centrali atri. venas transversas includente ornatis, paenultimo tarsorum articulo brevi. obcordalo.

o abdomine albo et nigro annulato. tibiis anticis praeter apicem albis.

Q abdomine toto nigro. tibies anticis tolis nigris.

Long. corp. $1 \frac{1}{3}-1 \frac{2}{3}$ lin. Long. al. $1 \frac{1}{4}-1 \frac{1}{3}$ lin.

Caput albidmm. disco occipitis fusco. Anlennac fuscac. flagello antennarum maris dilutiore. Thorax rufus. in mare opacus. in foe minâ subnitidus et plerumque colore panlo saturatiore timclus: col. lare, humeri et superius pleurarum dimidium in utroque sexu albida. in foeminâ tamen colore minus puro piela. Pectus et metanotum nigro-fusea. Abdomen maris nigrum. segmentis primis duobus, tortii et quinti apice, quarto et sexto practer basim albis. Femora omnia in utroque sexu praeter basim albidam nism vel piceo-nigra; tibiae anticae forminac concolores, maris pracler apicem nigrum albidae; tibiae intermediae foeminac plerumpue nigrae raro ammlo fusco cinctae; tibiae intermediar maris albidae. hasi ef apice nigris: tibiae posticac in utrogue sexu practer basim et apicem albidac: tarsi antici nigri. articulo primo in ulroupe sexu praeter apirrm albo, in mare práterea articuli secundi basi sarpe lubescenlo: larsi posteriores maris ef foeminar artieulos primos duos alhos. apier nigro ornatos, reliquos articulos tolos nigros habenl: arliculus parnultimus tarsorum omnium brevis. obrordalus. Alar mudace subhya- 
linae, maculâ minutâ nigrâ, venas transversas includente, et puncto nigro in venae quintae anastomosi. - (Cuba; Riehl.)

3. Tanypus thoracicus nov. sp. ठా. Rufescens, nitidus, flagello antennarum, scutello et abdomine praeter basim segmentorum singulorum nigrofuscis, pedibus lutescentibus, tibiarum apice tarsisque praeter basim nigris, arliculo quarto brevi, tarsorum posteriorum obcorduto, alis nudis, subhyalinis, venis transversis fuscis. - Long. corp. $2 \frac{1}{4}$ lin., Long. al. $1 \frac{1}{2}$ lin.

Caput ex luteo rufescens, primo antennarum articulo concolore vel rufo-fusco, flagello pilisque flagelli fuscis. Thorax rufescens, nitidus, humerorum colore in luteum vergente, scutello nigro-fusco, metanoto rufescente vel subfusco. Abdominis segmenta singula colore fusco-nigro inaequaliter variegata, ita ut plerumque basi solà exceptâ tota nigra sint. Pedes dilute lutescentes, femorum anticorum tibiarumque omnium apice extremo nigro; farsorum anticorum articuli ultimi quatuor cum primi triente apicali nigri; tarsi posteriores inde ab articuli secundi apice nigri; paenultimus tarsorum omnium articulus brevis, tarsorum posteriorum obcordatus. Halteres albidi. Alae nudae, subhyalinae, venis transversis fuscis. - (Washinglon; Osten-Sacken.)

4. Tanypus bellus nov. sp. ¿’ et ㅇ. Pallide flavescens, vittis thoracis et metanoto rufis, pleuris et pectore rufo et fusco variegatis, abdomine nigro-annulato, tarsis adversus apicem et extremo tibiarum apice nigris, paenultimo tarsorum articulo simplici, alis nudis, subhyalinis, venis transversis fuscis. - Long. corp. $1 \frac{1}{3}-1 \frac{1}{2}$ lin., Long. al. $1 \frac{1}{4}-1 \frac{1}{3}$ lin.

Caput pallidum vel dilute lutescens, occipitis disco rufo-ferrugineo; antennae foeminae pallidae, apicem versus nigricantes; antennae maris subfuseac, articulis basali et apicali nigris, pilis dilulissime subfusçis. Thoracis dorsum pallide flavescens, vittis tribus rufis, mediâ poslice valde abbreviatâ et per lineam tenuissimam pallidam divisâ, lateralibus antice valde abbreviatis. Scutellum pallide flavescens. Metanotum rufum vel ex rufo ferrugineum, saepe linể mediâ fuscâ notatum. Pleurae rufo et fusco variae. Abdomen pallidum, fasciis segmentorum singulorum basalibus nigris vel fuscis, segmentorum ultimorum latioribus. Pedes breviter pilosi, pallide flavescentes vel subalbidi; extremus tibiarum apex niger; tarsi antici inde ab articuli primi apice nigri, articuli tamen secundi basi in mare pallidâ; tarsorum posteriorum articuli primi duo praeler apicem ex- 
Irenum pallidi, reliqui nigri, basi lamen tertii in mare pallidâ; ar. ticulus paenultimus farsorum omnium simplex, sublinearis. Halteres albidi. Alae nudae, subhyalinae, venis transversis fuscis vel nigris. - (Washington; Osten-Sacken.)

5. T'anypus pusillus nov. sp. ô et $\Varangle$. P'allidissime favescens, thoracis villis et metanoto ex ochraceo rufis, segmentorum ab. dominalium singulorum fasciis basalibus fuscis, in foemina obsolet is vel nullis, pedibus albidis, extremo libiarum apice tarsisque adver. sus apicem nigris, paenultimo tarsorum articulo simplici, alis ииdis, subhyalinis, venis transversis subfuscis. - Long. corp. $\frac{3}{4}-1 \frac{1}{12}$ lin., Long. al. $\frac{3}{4}-\frac{5}{6}$ liu.

Tanypo bello simillimus, sed longe unor et dilutius pictus. Caput pallidum, occipilis disco rufo. Antennae fuscae, maris pilis dilute subfuscis vestilae, foeminae basiu versus pallidac. Thorax pallide flavescens, vittis tribus rufis, mediâ postice valde abbreviatí et plerumIque per lineam flavicantem divisà, lateralibus autice valde abbreviatis. Metanolum pleurarumque dimidium superius rufa, pleurae interdun. fere lotae rufae. Scutellum flavescens. Abdomen maris exalbidum, annulis segmentorum singulorum basalibus fuscis; abdomen foeminae plerumque lotum albidum vel pallide flavescens, interdum maculis lateralibus subfuscis, raro segmentorum singulorum anuulis subfuscis. Pedes breviter pilosi, albidi; exiremus tibiarum apex niger; tarsorum pictura eadem ac Tanypi belli. Halteres albidi. Alae nudae, subhyalinae, venis trausversis subfuscis vel fuscis. - (Washinglon; Osten-Sacken.)

6. Tranypus hirtipennis nov. sp. ․ Tolus juscus, alis subconcoloribus confertissime pilosis, venis transversis nigris, omnibus tarsorum articulis linearibus. - I Long. corp. $\mathbf{1}_{4}^{3}-\mathbf{1}_{6}^{5}$ lin. . Long. al. $2 \frac{1}{12}-2 \frac{1}{6} \operatorname{lin}$.

Fuscus, antennis, segmentorum abdominalium singulorums margine postico femoribusque praeter apicem dilutioribus, palpis obsenrioribus; tarsi pro portione longi, apicem versus obscure fusci, articulis omnibus linearibus, longitudine decreseentibus, ullimo quam paenullimus longe breviore. Alae cinereo-fuscae, pilis lougis fuscis confertissime vestilac, venis in Tanyporum speciebus solitis, transversis uigris, reliquis subfuscis, longitudinali tertiâ prope alae apicem in marginem excurrente. - (Maine.)

7. T'anypus pilosellus nov. sp. ․ Testaceus vel subfu. scus, pallide pilosus, thoracis dorso praeter viltas, sculello pedibus. 
antennisque pallidissimis, his pilis longis instructis et apicem versus nigricantibus, alis confertim pilosis, subcinereis, cellulis basalibus brevibus. - Long. corp. $\frac{1}{2}$ lin., Long. al. $\frac{7}{1 \frac{1}{2}}-\frac{2}{3}$ lin.

Minutus, opacus, testaceus vel ex testaceo subfuscus. Antennae mediocres, pallidae, apicem versus nigricantes, pilis perlongis pallidis vestitae, articulo ultimo non incrassato. Thoracis dorsum praeter vittas solitas plerumque albicat. Scutellum pallidum. Pedes et halteres exalbidi. Alae confertim pilosae, subcinereae, margine costali sublutescente, cellulis basalibus brevibus. - (District Columbia; Osten-Sacken.)

8. Macrocera formosa nov. sp. o et + Pallide fava, abdomine nigro-annulato, alarum hyalinarum maculis duabus (alterâ minore el basali, alterâ majore et costae mediae contiguâ) fasciisque duabus confuentibus (alterâ subapicali, alterâ apicali) nigricantibus. - Long. corp. 2 liu., Long. al. $2 \frac{1}{4}$ lin.

Pallide flava. Antennae perlongae concolores, apicem versus subfuscae. Vittae thoracis obsoletissimae aut nullae. Margo segmentorum abdominalium singulorum posticus niger; tria ultima segmenta in mare plerumque tota nigra, forcipe anali tamen flavo. Pedes dilutissime flavi, apice femorum posteriorum nigro, tibiarum posticarum fusco, tarsis subfuscis, apicem versus obscurioribus. Alae hyalinae in apice et in apicali marginis postici dimidio pilis longioribus aspersae, maculis et fasciis nigricantibus eleganter variegatae; prope basion macula minuta, in mediâ alâ macula major subtriangula, inde a costâ usque ad veoam longitudinalem quintam pertinens cernuntur; apex alae fasciis duabus, alterâ subapicali arcuatâ, alterâ apicali, per costae venarumque limbos inter se conjunctis ornatur. - (New-York; Osten-Sacken.)

9. Sciophila bimaculala nov. sp. ․ Ochracea, antennarum flagello margineque segmentorum abdominalium singulorum postico nigris, alarum triente apicali et maculâ posticâ ex fusco cinereis, venarum transversalium limbis obscure fuscis. - Long. corp. $2 \frac{1}{1} \frac{1}{2}$ lin., Long. al. $2 \frac{5}{6}$ liu.

Tota ochracea, nigro - pilosa. Caput concolor, maculâ minutâ ocellos approximatos includente, palpis antennarumque flagello nigris. Thoracis vittae reliquo thorace paulo obscuriores, obsoletae, media duplicala. Singula abdominis segmenta praeter ultimum postice nigro-marginata. Tibiarum seiulae breves et tenues; tarsi apicem versus infuscali. Alat brevissime pubescentes, subhyalinae, 


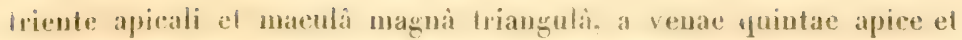
margine postico inclusa. ex lusco cinercis; veua longitudinalis prima in costan exeurrens prope apicem venulan transversam. a cellulae submarginalis internac apice el basi aeque distantem emittit; venulac transversae obseure tuseae el fusco-limbalac: furcula venae lougitudinalis guartac duplicem pedunculi longitudinem superal venae yuintae fureula pedunculo subaequalis. - (English River; Kennicot.)

10. Siargus elegans nov. sp. Oे et 우. L'allidus. maruli apicali dorsi, scutelli disro et melanoto ex nigro viridibus, abdomine nigro-fasciato. alarum dimidio basali pure hyalino, apicali obsolete infuscato. - Long. corp. $3 \frac{1}{1}-4$ lin. Long. al. $3 \frac{1}{2}-4$ lin.

VIas. Pallide luteolus. nitens, pube dilute lulescenie vestitus. Caput concolor, oculis magnis conliguis. occipile nigro. Lriangulo verlicali obseure aeneo-viridi ef luteo-piloso. triangulo fronlali tumido, albo pilinque pallidis hirto; antemat luleolae; margo inferus lacici nigro-piceus. Thorax laete luteolus, viltà inde a callo lıumerali usque ad hasim alarum pertinente exalbidi el macula apicali dorsi obsenre aeneo-viridi. Sculellum praefer marginem et melanotum practer lalera obscure aenco-viridia. Segmentum abdomimale sceundum utrinque maculì laterali nigrâ. segmenta sequentia tria singula fascià latà nigrâ notantur, lasciâ segmenti terlii plerumque integrâ, lasciis quarti et quinti interruptis. Pedes pallidi, femoribus posticis proje basin obsolete subfusco-ammalis. Alae hyalinae, limidio apicali levissime subinfuscato. - Klorida; Massachnsetis; New-York.)

Foemina. Frons modice laba, nigro-chalybea dimidio anteriore albo, rrangulo verlicali longo, aeneo-viridi. Ahdominis semmenta secundum, tertinm, fuartum ef quintum nigro-lasciala, laseiis omminn latis. secundi el lertii interuplis, reliquorum integris. In reliquis notis cum mare congrua. - (New-Kork; Calverly.)

11. Sargus lucens nov. sp. J゙. Viridis, nitidissimus, oculis contignis, abdomine basim versus valde angustato, nigro-cupreo, segmentorum singuloram apice fulvo-lomentoso, antennis pedibusque? luteis, tarsorum posticorum apice fusco, alis fuscis. - Long. corp. $6-6_{t j}^{1}$ lin. Lous. al. $5_{t j}^{1}$ lin.

Oculi magni, conligni; triangulum verlicale angुastissimum. valde elongatum, obscure aenco-viride; friangulum fronlalo lumidum, Ieslaceum, nigro-pilosum; antemae luteae, arliculis primis duobus nigro-pilosis; facies obscure aeneo-viridis. prope antennas lutea, foli 
nigro-pilosa; proboscis pallida; occiput nigrum. Thorax viridis, nitidissimus, pube flavescente vestitus, callo humerali minuto, lineâ marginali, callo antescutellari lateribusque metanoti luteis. Scutellum totum cum thorace concolor. Abdomeu basim versus valde attenuatum, nigro-cupreum, nitidum, segmentorum singulorum apice fulvo-tomentoso. Pedes cum coxis lutei, tribus ultimis tarsorum posticorum articulis fuscis vel nigris. Halteres lutei, capitulo fusco. Alae fuscae, basim versus paullo dilutiores. - (Cuba; Gundlach.)

Nota. A Sargo laterali Macq. triangulo verticali longiore pleurisque viridibus differt.

12. Sargus tricolor nov. sp. ㅇ. Viridis, nitidus, infimo frontis triente albo, antennis, thoracis lineâ laterali, callo antescutellari, metanoti lateribus, scutelli margine, pedibus abdomineque luteis, primo hujus segmento fere tolo, maculis lateralibus secundi fasciisque latis terlii, quarti et quinti violaceis, alis dilutissime ex luteo subfuscis. - Long. corp. 4 lin., Long. al. $3 \frac{1}{3}-3_{\frac{5}{12}}$ lin.

Frons angusta, viridi-aenea, triente infimo subtumido, albo, prope antennas ex luteo testaceo. Antennae luteae, articulis primis duobus breviter nigro-pilosis. Facies obscure testacea, nigro-pilosula, adversus oris aperfuram nigricans. Thorax aureo-viridis, nitens, callo humerali, lineâ laterali, callo antescutellari, scutelli margine lateribusque metanoti luteis. Abdomen ex latericio luteum, segmento primo praeter margines anticum posticumque, secundi maculis lateralibus, tertii, quarti et quinti fasciis latis violaceis. Venter totus ex latericio luteus. Pedes cum coxis lutei, tarsis posticis apicem versus infuscatis. Alae sordide sublutescentes vel ex luteo dilutissime subfuscae. - (Cuba; Gundlach.)

Nota. Frons angusta foeminae oculos maris contiguos esse demonstrare videtur.

13. Sargus pleuriticus nov. sp. ․ Er chalybeo viridis, nilidus, abdomine violaceo, frontis triente infimo, antennis, facie, pleuris pedibusque luteis, alis modice infuscatis, adversus basim dilutioribus. - Long. corp. $4 \frac{1}{6}$ lin., Long. al. $3 \frac{1}{1} \frac{1}{2}$ lin.

Frons angusta, ex chalybeo viridis, nitida, triente infimo sublumido, dilute luteo, superne albido. Antennae saturate luteae, articulis primis duobus breviter nigro-pilosulis. Facies lutea, pilis pallidis vestita. Thoracis dorsum praeter callos humerales et antescutellares ex chalybeo viride, nitidissimum; pleurae totae luteae; pectus, scutellum et metanotum ex chalybeo viridia, hujus lateribus 
Inteis. Abdomen violaceum, postico segmenti primi margine chalybeo; venter concolor. Pedes cum coxis dilute lutei, tarsis posticis plerumque totis fuscis femorumque omnium apice interdum obsolet subfusco. Alae modice infuscatae, basim versus hyalinae, cellulis stigmaticali et marginali fuscis. - (Cuba; Gundlach.)

14. Chrysonotus nigricornis nov. sp. \&. Chalybeus, thorace scutellogue virescentibus, abdominis disco violaceo, facie, antennis pleurisque nigris, frontis fasciâ lineisque lateralibus thoracis albis, pedibus dilute lutescentibus, alis subhyalinis, dilutissime subinfuscatis. - Long. corp. $2 \frac{5}{6}-2 \frac{1}{1} \frac{1}{3}$ lin., Long. al. 3 lin.

Frons lala, planiuscula, viridi-chalybea, violaceo-splendens, prope antennas fasciâ angustâ albâ ornala, infra hanc fasciam nigra. An. tennae nigrae, arliculis primis duobus ex parte obscure testaceis vel fuscis. Facies nigra; proboscis dilute lutescens. Thoracis dorsum ex chalybeo viride, nitidissimum, scutello et metanoto conco. loribus, lineis lateralibus albis. Pleurae cum pectore nigrae. Abdomen latiusculum, chalybeum, disco violaceo. Venter totus obscure violaceus. Coxae praeter apicem nigrae. Pedes dilute lutescentes, ultimis tarsorum posticorum articulis modice infuscatis. Alac subhyalinae, levissime colore subfuseo tinctae, venis ex luleo subfuscis. - (District Columbia; Osten-Sacken.)

15. Euparyphus tetraspilus nov. sp. ㅇ. Niger, flavo-maculatus, capite nigro, pedibus pallidis, femoribus praeter apicem et annulo tibiarum posticarum nigris, stigmate dilutissime flavicante,

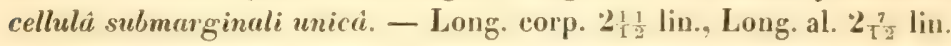

Caput nigrum, maculis minutis flavis in postico verticis margine duabus, in fronte quatuor; orbitarum posticarum dimidio inferiore, marginibus lateralibus faciei et infimâ parte marginum frontalium albo-pollinosis. Primi duo anteunarum articuli nigri; lertius in specimine descripto deest. Thorax niger; dorsum lineis longitudinalibus duabus, prope ad suturam ductis, et utringue callo humerali macnlâque cuneatâ, ex angulo postico productâ, flavo-variegatum; pleurarum margo superus flavus ante alam in maenlam dilatatur. Sentellum nigrum, dentibus flavicantibus. Abdomen nigrum, maculis disci rotundis quatuor et apicis unầ semirotundà flavis; praeterea margo lateralis segmentorum tertii et quarti prope angulos posticos singulorum flavus est. Venter folus niger. Pedes pallidi vel dilutissime lutescentes, femoribus praeter apicem nigris, libiis posticis nigro-annulatis. Alae pure hyalinae, stigmate venisque validiori- 
bus dilutissime flavicantibus, venâ longitudiuali ferdî̀ simplici. (New York; Osten-Sacken.)

16. Euparyphas brevicurnis nov. sp. T. Nigro et flavo variegralus, capilc scutellogie favis, pedibus luteis, libiis posticis tarsisque fuscis, primo tamen tarsorum posteriorum articulo pallido, stigmate subfusco, cellulà submarginali unicà. - Long. corp. $2 \frac{1}{3}$ lin., Long. al. $2 \frac{1}{4}$ lin.

Caput flavum, vertice rufescente; occiput praeter orbitas et practer maculam triangulam, a verticis margine demissam, nigrum; in fronte praeter maculam nigram verticis utrinque macula lateralis atra et lineola media nigra conspiciuntur; facies praeter vitfulam mediam nigram vittas laterales lalas nigras, polline albo obtectas habet. Thorax niger; dorsum aureo-tomentosum, vittis duabus po. stice nonnihil abbreviatis, utrinque callo humerali et maculi cuneatâ. ex angulo postico productâ, flavo-variegatum. Pleurae albopilosulae superne vittam integram, postice latiorem et maculam mediam llavas gerunt. Scutellum favum. dentibus concoloribus. Abdomen nigrum, margine lolo segmentorumque lertii et quarti maculis lateralibus, in angulis posticis silis. flavis. Venter flavus, nigrovarius. Pelles cum coxis lutescentes, tibiis posticis praeter annulum subbasalem angustum farsisque omnibus fusco-nigris, primo-tamen tarsorum posteriorum articulo pallido. Alae hyalinae, stigmate renisque validioribus subfuscis, venâ longitudinali tertii brevi, simplici. - (District Columbia; Osten-Sacken.)

17. Euparyphus stigmat icalis nov. sp. ㅇ. Niger, favo-varius, capite flavo, pedibus luteis, tarsis anticis fere tot is, posterioribus inde ab articuli secundi apire nigro-fuscis, cellulis subnarginalibus duabus. - Long. corp. $2 \frac{3}{4}$ lin., Long. al. $2 \frac{2}{3}$ lin.

Caput flavum, superne rufescens. occipite praeter orbitas, puncto verticis, frontis lineà mediâ maculisque duabus transversis, supra antennas fasciam lalam constituentibus, villis denique faciei tribus nigris. Orbitarum posticarum dimidium inferius, margines laterales faciei et marginum frontalium pars infera polline candido legunlur. Antennae longiusculae, nigrae. Thorax niger; dorsum lineis duabus subintegris, intervallo lato separatis, vitla utrinque laterali ab humero usque ad sufuram pertinente et maculâ cuneatâ ex angulo postico productâ, flavo-variegatum; pleurae vittâ superâ intergrâ et maculâ mediâ flavis instructac. Scutellum nigrum, apice dentibusque flavicantibus. Abdomen nigrum, margine ipso maculisque utrin- 
que tribus, in angulis postieis segmentorum secundi, tertii et puarti sitis, flavis. Venter flavus. marulis laferalibus sesmentorum singulorum fuscis. Pedes cum coxis Intei. lemorum posteriorm dimidio secundo tibiisque posticis fusco-lituratis, farsis anticis practer basim articuli primi, posterioribus inde ab arliculi secundi apice nigro-fuscis. Alae hyalinac, stigmate venisque validioribus fuscis, costî tamen el venà auxiliari luteis. venâ longiludinali tertiâ ramulo instructâ. — (District Columbia; Osten-Sacken.)

18. Euparyphus bellus nov. sp. \&. Niger. flavo-varius, capite nigro, pedibus pallidis, femoribus prater apicem nigris, stigmate sine colore, cellulis submarginalibus duabus. - Long. corp. $2_{2}^{\frac{1}{2}}$ lin., Long. al. $2 \frac{5}{12}$ lin.

Caput nigrum, vittis lateralibus frontis supra abbreviatis, maculis duabus in postico verticis margine et orbilarum posticarum dimidio inferiore flavis, his, marginibus laleralibus faciei et infimat marginum frontalium parle albo-pollinosis. Antenuae mediocres, nigrae. Thorax niger; dorsum lincis duabus intervallo lato separatis. callo humerali maculâque cuneatà ex angulo postico productà flavis variegatum; pleurarum margo superus flavus cum maculî flavâ ante alam cohaeret. Scutellum nigrum. margine apicali dentibusque flavicantibus. Abdomen nigrum; segmentum tertium maculis flavis quatuor, binis rotundis in disco, binis minoribus in angulis posticis. oruatur; in segmenfo quarto maculae duas subrolundae flavae conspiciuntur. cun limbo inaeyuali flavo marginis postici. inter has maculas late interupto, connexae; somentum quintum maculam apicalem flavam, semirotundam. antice cmarghinalan gerit. Venter totus niger. Pedes pallidi. vel dilutissime lutescentes, femoribus praeter apicem nigris, libiis posticis anguste et obsolete fusco-annulatis. Alac pure hyalinae, venis validioribus lulesecntibus. Iongitudinali tertia ramulo instruclá. stigmate sive colore. - (Massachusctls; Sauborı.)

Nota. Eupreryphs masculus ex ểdem provinciâ allatus caput practer frontem triangulam flavam lotum nigrum. Jorsi lineas flavas postice value abbreviatas. maculas flavas in angulis posticis segmenti tertii fere nullas et marginem posticum segmenti quarti non flavum, sed concolorem liabet; in reliquis vero nolis cum foeminâ Euparyphi belli oplime congruit. ita ut eun Euparyphum bellum esse declarare non dubitarem. nisi venarum e cellulầ discoidali emissarum prima, quae in Eupurypho bello praeter imam basim ounino evanescit, tola acoualiter comspicua esset. 
19. Stratiomyia maculosa nov. sp. ․ Nigra, capile, scutello abdomineque flavis, segmentis hujus secundo nigro-bimaculato, tertio et quasto quadrimaculatis, quinto nigro, vilta mediâ maculisque duabus cum vittâ cohaerentibus flavis. - Long. corp. $5 \frac{5}{6}$ lin., Long. al. $5 \frac{1}{3}$ lin.

Latiuscula, subobesa. Caput flavum, orbità oculorum posticâ latâ, totâ concolore; occiput praeter margines laterales et praeter maculas duas a vertice demissas nigrum; vertex niger, maculis duabus subquadratis flavis, cum maculis occipitis confluentibus; facies a fronte lineâ transversà nigrâ distinguitur et lineâ longitudinali nigrâ dividitur; genae nigrae. Thorax niger, pilis luteis vestitus. Scutellum flavum. Abdomen latum, flavum; segmentum primum fere totum nigrum; in segmento secundo maculae duae permagnae nigrae inde a margine antico, ubi cohaerent, ad marginem posticum usque pertinent; segmentum tertium maculis, sive potius vittulis quatuor obliquis nigris, ex limbo antico nigro prope ad marginem posticum ductis ornatur; pictura segmenti quarli omnino eadem; segmentum quintum nigrum, vitlâ latiusculâ maculisque duabus cum vittâ cohaerentibus flavis. Venter flavus, segmentorum singulorum margine basali nigro. Femora nigra, apice luteo; tibiae et tarsi lutescentes. Alae ex luleo subfuscae, cellulis submarginalibus duabus, posterioribus quatuor. - (California.)

20. Stratiomyia laticeps nov. sp. ㅇ․ Nigra, capite, scutello praeter basim, abdominis maculis transversis utringue tribus et apicali triangulâ viridi-flavis, pedibus testaceis. - Long. corp. $6 \frac{2}{3}$ lin., Long. al. 5 lin.

Caput latum, ex viridi flavum; orbitae posticae oculorum latae tolae flavae; discus occipitis niger; frontis latae dimidium superius piceo-nigrum, sed ita ut color niger antice sinu prope ad ocellos ascendente emarginatus sit et in verticis margine puncta duo viridiflava includat; supra antennas lineola transversa nigra, in facie vitta angusta nigra couspiciuntur. Antennae nigrae, breviores quam in congeneribus plerisque, articulo tertio primis duobus simul sumtis longiore. Thorax niger, pilis subaureis vestitus. Scutellum ex viridi flavum, basi anguste nigrâ. Abdomen nigrum, maculis utrinque tribus transversis, quae in segmentorum secundi, tertii et quarti marginibus posticis silae sunt, et maculà segmenti ultimi triangulari ex flavo viridibus. Venter ex flavo virescens, fascià segmentorum singulorum basali atrâ, primi tenui, secundi interruptâ. Pedes lutei, colore femorum in fuscum, tibiarum in luteum vergente. Alac 
ex cinereo lutescentes, venis validioribus ex fusco luteis. cellulis submarginalibus duabus, posterioribus quatuor. - (Hudson's Bay Territory; Kennicot.)

Nota. Picturam abdominis in mortuâ ex flavo viridem in vivâ laete viridem esse persuasum habeo. Walkeri strat. Nymphis a specie nostrà femoribus uigris distincta videtur.

21. Stratiomyia picipes. nov. sp. $\delta$ et 오. Nigra, facie maeter trientem infimum et vittam, scutelli dimidio apicali, segmentorum abdominalium secundi et tertii strigis transversis angulisque anticis, quarti angulis anticis et limbo postico cum viltâ mediâ an-

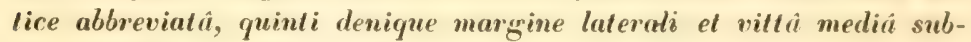
integrâ flavis, pedibus badiis.

$\sigma^{7}$ orbitâ oculorum posticâ tenuissimâ, infra flavescente.

$\&$ orbitâ oculorum posticâ lat î praeter trientem supremum flavâ, fronte nigrâ, flavo-quadrimaculat $\hat{u}$.

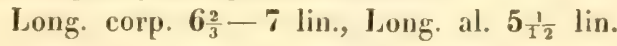

Nigra. Autennae nigrae, longae, articulo tertio quam primi duo simul sumti paulo longiore. Facies praeter vittam latiusculam et praeter trientem infimum flava. Frons foeminac nigra, nigro-pilosa, supra antennas maculis duabus transversis majoribus, in vertice duabus minoribus, postice in occiput productis ornata. Postica oculorum orbita in mare tenuissima, infra flavescens, in foemina lata et praeter trientem supremum flava. Occiput nigrum. Thorax niger, maris pilis fere ommibus lutescentibus, foemiua pallidis et nigris vestitus. Scutellum nigrum, dimidio apicali flavo. Abdomen nigrum; segmentum primum practer angulos anticos utrinque strigam transversam, in margine postico sitam colore flavo pictam hibbel; segmenti tertii pictura eadem, strigis tamen transversis longioribus; segmentum quartum practer angulos anticos fasciam posticam villamque mediam antice abbrevialam llavas habet; in segmento quinlo praeter margines laterales ipsos vilta llava, antice modice dilatata ef mediocriter abbreviata conspicilur. Venter niger, segmento primo utrinque maculâ flavâ notalo, segmentis sequentibus singulis practer margines lalerales fasciâ apicali flavî ornalis, fasciâ ultimi in maculan triangularem dilatalâ. Pedes ex badio picei, tibiarum tarsorumque colore in luteum vergente. Alac cellulis marginalibus duabus, posterioribus quatuor. - (English River, Kennicot; Canada, Couper.)

Nota. Variat femoribus ante apicem infra fusco-lituratis. 
22. Midas rufiventris nov. sp. $\sigma^{\top}$. Niger, abdomine rufo, alis aequaliter fuscis. - Long. corp. 12-13 lin., Long. al. 11 lin.

Caput cum antennis nigrum, fronte et facie albo-pilosis. Thorax niger, opacus; dorsum polline olivaceo-fusco aspersum, lineis duabus lato intervallo separatis marginibusque lateralibus dilutius pollinosis. Scutellum concolor. Pleurae cinereo-pollinosae, nigro-pilosulae. Abdomen aurantiaco-rufum, nitens, obsolete roseo-micans, segmentorum marginibus lateralibus ipsis nigris; pili segmenti primi nigri. Venter aurantiacus, segmento primo segmentique ultimi marginibus lateralibus et postico nigris. Hypopygium nigrum, nigropilosum. Pedes nigri, nigro-pilosuli, femorum anteriorum colore in piceum vergente. Alae aequaliter fuscae. - (California; Agassiz.)

23. Midas luteipennis nov. sp. 주 et ㅇ. Aler, antennis, pedibus pilisque totius corporis concoloribus, thorace et primo abdominis segmento opacis, reliquo abdomine purpureo-nigro, modice nitenle, alis luteis, adversus marginem posticum latissime cinerascentibus. - Long. corp. 9-9 $\frac{1}{2}$ lin., Long. al. $7 \frac{1}{2}-8 \frac{1}{2}$ lin.

Caput modice nitens, atrum, atro-pilosum; antennae tolae atrae: orbita facialis oculorum superne anguste albido-pollinosa. Thorax totus ater, opacus, atro.pilosulus, viltis dorsalibus plerumque omnino obsoletis, inlerdum subobsoletis ef quam inlerstitia minus atris. Scutellum concolor. Primum abdominis segmentum atrum, opacum atro-pilosum; reliquum abdomen nudiusculum, modice niteus, colore purpureo-atro, in violaceum vergente piclum. Venter concolor; in exemplis nuper exclusis segmentorum singulorum basis picea, in maturis venter totus rufo-piceus, violaceo-micans. Hypopygium atrum. atro-pilosum. Pedes toli atri, modice nitentes, atro-pilosuli. Halteres nigri. Alae luteae, adversus marginem posticum latissime ex fusco cinerascentes, venis luteis, in colore cinerascente tenuissime luteo-limbatis. - (New Mexico; Capt. Pope.)

Nota. Mares duo, reliquis paulo majores, alarum venas in colore cinerascente subfusco-limbatas habent.

24. Midas xanthopterus nov. sp. $\delta$ et . Ater, opacus, antennis, pedibus pilisque totius corporis concoloribus, alis ex anrantiaco ochraceis, oprecis, cellularum subcostalis, marginalis et submarginalis apicibus nigris, marginis postici limbo et apice extremo nigricantibus. - I ong. corp. $10 \frac{1}{2}-12 \frac{1}{2}$ lin., Long. al. $10 \frac{2}{3}-11 \frac{1}{2}$ lin.

Ater. opacus, antennis, pedibus pilisque totius corporis concoloribus. Pedes conferlissime pilosi Halteres atri. Alae latiusculae, 
opacae, ex aurantiaco ochraceae, alult̂, cellulae costalis basi apicibusque cellularum subcostalis, marginalis el submarginalis nigris, marginis postici limbo subaequali ef extremo apice nigricantibus: nitidis. - (New Mevico; Capt. Pope.)

25. Midas simplex nov. sp. O’. Aler, opacus, antennis pedibus pilisque totius corporis concoloribus, alis ex orhruceo huteis. nitidis, adversus marginem posticum et apicem lalissime ex fusco nigricantibus. - Idong. corp. $1 \frac{2}{3}$ lin., Long. al. $9 \frac{1}{1} \frac{1}{2}$ lin.

Ater, opacus, antennis, pedibus pilisque totius corporis conco loribus. Abdomen subnitidum, hypopygio concolore, nigro-piloso. Pedes pilis multo rarioribus vestiti quam Mid. xanthopteri. Halteres atri. Alae ex ochraceo luteae, nitidae, adversus marginem posticum et apicem latissime ex subfusco nigricantes, venis luteis. in colore nigricante saturatius limbalis. - (New Mexico; Capt. Pope.)

26. Midas venosus nov. sp. d'? Niger, pallide pilosus, antennis concoloribus, segmentorum abdominalium fascies posticis ef femorum posticonum tibiarumque postirarum dimidio basali dilute favicantibus. alis cinereo-hyalinis. fusco-venosis, cellulis posterioricus secundâ el quartí confuentibus. - Long. corp. circa $8 \frac{1}{4}$ lin.. Long. al. 6 liv.

Niger, pallide pilosus. Frontis et faciei latera pallide tomentosa. Antennac nigrae. Thoracis dorsum pallide tomentosum. vittis tribus denudatis. nigris. Segmentorum abdominalium singulorum margines postici colore dilute flavicante limbati; limbus scgmenti secundi utrinque annulo ovato nigro notatus. (Ullima abdominis segmenta desunt). Pedes niģri, imâ tibiarum intermediarum basi et femorum posticorum tibiarumque posticarum dimidio basali dilute flavicantibus vel exalbidis. Pili pedum maximà ex parte pallidi, in femorum posticorum dimidio apicali. in tibiarum posticarum apice et in tarsis omnibus nigri. Halteres fusci. Alace cinereo-hyalinae, venis fuscis tenuiter sublusco-limbalis, venulà inter cellulas posteriores secundam et quartam nulli. - (New Mexico: Capt. Pope.)

27. Echlhodopa pubera nov. sp. of et ㅇ. Nigra. mystace pilisque totius corporis dilute flaricantibus, dimidio basali libiarum rufo. - Long. corp. $6 \frac{1}{2}$ lin., Long. al. $\sigma \frac{13}{4}$, 오 $5 \frac{5}{12}$ lin.

Mas. Niger, modice nitens, tibiarum posticarum basi, anterio- 
rum dimidio basali ex luteo rufis. Facies et occiput ochraceo-pollinosa. Mystax et pili totius capitis flavi. Primus antennarum articulus secundo paulo longior, tertius primis duobus simul sumtis paulo brevior; stylus terminalis crassus, brevis obtusissimus, biarticulatus. Pleurae praeter pilos maculis aliquot ochraceo-pollinosis instructae. Totius corporis pubes et pedum setae flavae; coxae anticae pilis confertis flavis vestitae. Halteres lutei. Alae nigro-cinereae, adversus angulum posticum albae, venis nigris, inde a basi usque ad mediam alam anguste nigro-limbatis.

Foemina. Mari simillima, sed robustior, abdomine latiore, polline faciei, occipitis et pleurarum, quemadmodum pube et pilis totius corporis multo pallidioribus, alis majoribus, subaequaliter nigro-cinercis, adversus angulum posticum paulo-dilutioribus, sed non albis. - (Nebraska; Heyden.)

Nota. Echthodopa a Dioctria non differt, nisi triente infimo faciei convexo et mystace denso vestito, femoribus denique posterioribus et tibiis omnibus praeter pilos setis brevibus, sed validis instructis. Antennarum forma, alarum venae et pubes tibiarum posticarum omnino eaedem atque in Dioctriâ.

28. Pygostolus argentifer nov. sp. $\delta$. Niger, ultimis duobus abdominis segmentis argenteo-pollinosis, lumine non reflexo atris; alae infuscatae, basi hyalina, venularum transversalium limbis nigricantibus, liturâ costali fusco-nigrâ. - Long. corp. 4 lin., Long. al. $3 \frac{1}{2}$ lin.

Niger. Caput concolor, fronte polline subfusco, facie subochraceo aspersis; mystax albus, prope oris marginem fulvescens, setis paucis, dilute subfuscis. Antennae nigrae, articulo tertio breviusculo et validiusculo, stylo terminali dimidiam articuli tertii longitudinem modice superante. Thoracis dorsum nigrum, obsoletissime vittatum. Abdomen vigrum, nitidum, maculis marginum lateralium albido-pollinosis, segmentis ultimis duobus totis pulchre argenteopollinosis, lumine non reflexo atris et opacis. Pedes badii, femoribus praeter apicem nigris. Alae infuscatae. triente basali hyalino, liturâ costali stigma includente fusco-nigrâ limbisque venarum transversalium nigricantibus. - (District Columbia; Osten-Sacken.)

Nota. Pygostolus a reliquis Dasypogoninorum generibus, quorum tibiae anticae calcare armatae sunt, abdomine depresso et in mare adversus apicem latiore fasilline distinguitur; facies lata, non tuberculata; thorax gilbbus; abdomen utrinque maculis marginalibus albido-pollinosis ornatum; abdominis ma- 
ris segmenta ultima duo albo-vel argenteo-pollinosa; pedes validi. tibiis posticis clavatis, tarsis posticis crassis; alae longae. fusco vel nigro-variegatae. cellulis posterioribus omnibus apertis.

29. Pygostolus dives, nov. sp. $\delta$ et 오 Niger. segmentis ultimis duobus abdominis maris albo-pollinosis; alae pulchre nigrovariegatae, triente basali hyalino: terlius antennarum articulus duplicem styli longitudinem paulo superans. - Long. corp. $\sigma^{\top} 4 \frac{1}{3}$, 오 $5 \frac{1}{6}$ lin., Lons. al. $0^{7} 3 \frac{2}{3}$, . $4 \frac{5}{6}$ lin.

Mas. Niger. Caput concolor, faciei margine infero albido-pollinoso; mystax rarus, albus, setis prope oris marginem validis, fuscis; antennae nigrae, stylo terminali dimidiam articuli tertii longitudinem prope allingente. Thoracis dorsum nigrum, opacum, obsolete vittatum. Abdomen scoriaceo-nigrum, nitidum, marginum lateralium maculis minutis albo-pollinosis, segmentis ultimis duobus totis albo-pollinosis, lumine non reflexo concoloribus. Pedes badii vel ex rufo picei, femoribus maximâ ex parte niğric. Alae nigrovariae, triente basali, imâa tamen basi et cellulà anali exceptis, byalino.

Foemina. Thoracis dorsum nigrrofuscum, opacum, lineâ mediâ postice abbreviatâ, limbis lateralibus postice lalioribus et scutello cinereis. Abdominis maculae laterales majores quam maris, segmenta ultima non pollinosa. Alae circa venas transversis nigrolimbatas hyalinae, ita ut fascia media postice dilutior, limbus latus apicis et puncta interjecta quatuor colore nigro picta sint. In reliquis foemina cum mare congruit. - (California; Agassiz.)

30. Pygostolus pictus. nov. sp. S. Niger; alae pulchre nigrovariegatae, triente basali hyalino; terlius antennarum articulus tenuis, piceus. quadruplici styli longiludine. - Long. corp. $5 \frac{1}{3}$ lin., Long. al. $5 \frac{1}{4}$ lin.

A foeminâ Pygosłoli divitis, cui simillima, foemina $\boldsymbol{P}^{\prime}$ ygostoli picti notis sequentibus dignoscitur. Antennac paulo longiores, articulo tertio mullo tenuiore, nigro - fusco, apicem versus plerumque rufescente, stylo apicali multo breviore. Thorax multo convexior, limbis cinereis dorsi lalioribus. Pictura alarum simillima. sed minus obscura - (District Columbia; Osten-Sacken.) 
31. Plesiomma funesta, nov. sp. ơ et 오 Alra, alis con. coloribus, pedibus aut rufis aut nigris, stepe anterioribus rufis, posticis vero nigris. - Long. corp. $8 \frac{3}{4}-13$ lin., Long. al. $7 \frac{2}{3}-10$ lin.

Syn. Plesiomma funesta Loew, Wiener Mlonatschr. V. 35.

Caput fusco-atrum, opacum. Mys!ax setis novem vel decem validis, ad oris marginem positis, in basi rufis, in aypicc nigris constans. Aniennarum articuli prini duo fusci, nigro-pilosi, sceundus primo longior, tertius autecedentibus simul sumtis aequalis, in margine superiore nigro pilosus; stylus terminalis aculus. Macula flavopollinosa, oculo contigua, ulringue inler faciem et frontem cernitur. Setae occipitis nigrae, margo lateralis flavo-pollinosus. Thoracis opaci color inlerdum nonnihil in fuscum vergens; pili minuli thoracis et setae, quae in posteriore ejus parte exstant, nigricantes. Pleurae fusco-nigrac, opacae; spiracula alba. Sculellum afrum, opacum, setis duabus apicalibus nigris. Abdomen elongatum, satis tenue, atrum, modice iantummodo nilens, lreviler nigro-pilosum. Coxae fusco-atrae. Pedes nigri, antici saepissime, anleriores haud raro, omnes rarissime rufi vel badii. Setae in fenorum apice, in tibiis et in larsis obscure rufae rel fuscae. Alae nigrae, lactissime chalybeo-splendentes. - (Cuba; Poey, Gundlach.)

32. Plesiomma leplogestra, nov. sp. б. Canut ochraceum, antennis, pulpis et proboscide luteis; thoracis dorsum ochraceum, villis tribus nimris, medià antice eximie dilatala: pleurae cinereae; abdomen teme. ex ochraceo fuscum: pedes lutei, anteriorum femoribus superne, posticorum femoribus tibiisque fere tolis nigrofuscis; alae aequaliter infuscatae. - Lons. corp. $7_{4}^{1}$ lin., Long. al. $5 \frac{1}{4} \operatorname{lin}$.

Congeneribus plerisque gracilior. Caput pallide ochraceum; occiput nigrum. polline dilule circeo confertim aspersum, cilis postocularibus tenuibus, pallidis. Antennac luteae. articulo secundo superne, tertio prope basim fuscis, stylo terminali acuto, nigro; articuli primi duo et margo superior articuli tertii nigro-pilosi. Setae mystacinae circiler sex, pallidae. Palpi dilute utescentes, pallide pilosuli; proboscis ex luteo testacea. In dorso thoracis viltae nigrae tres, interstiliis ocluraceo-pollinosis separatae conspiciuntur, quarum media antice mire dilatalur; margo lateralis dorsi polline ochraceo tegilur, humeri ef collare colore ochraceo linguntur. Pleurae cinereae, albirlo-pollinosac. Metanolum fuscum, polline exalbido aspersum. Scutellum nigricaus, praeter margines laterales ochraceopollinosum. Setae in dorso thoracis et in scutello omnes nigrae. 
Abdomen tenue, colore fusco adversus margines posticos segmentorum singulorum ef adversus latera abdominis in ochraceum vergente. Pubes abdominis brevissima, vulpina. Iypopygium cum abdomine concolor pilisque vulpinis vestitum. Pedes tenues, lutei vel ex luteo testacei. setis ex ochraceo rufis intructi; femora anteriora superne pracles apicem, poslica praeter annulum apicalem nigrofusca, omnia in apice extremo puncto nigro-fusco nolata; tibiae posticae fuscac, basim versus badiae vel subtestaceas; tarsi apicem versus obscure fusci. Halteres lutei. Alae aequaliter infuscatae, cellulis tamen costali et subcostali paulo saturatius tinctis; venae nigro-fuscae. - (Cuba; Gundlach.)

33. I'lesiomma indecora, nov. sp. 우. C'aput ochraceum, antennis rufo-ochraceis, proboscide badia; thoracis dorsum villis tribus nigricantibus, mediù antice subferruginề, valde dilatatâ; pleurae nigro-marulalae: abdomen ex ferrugineo fuscum; pedes ex ochraceo rufi: alae fuscae, adversus costam luteo-fusrrie. - Long. corp. 9 lin., Long. al. $7 \frac{5}{12}$ lin.

Caput ochraceum, fronte adversus verticem minus angustatâ, quam in IDles. funestá el leptogastrú, occipitc obscuriore, ochraceopollinoso, ciliis postocularibus validis, ochraceo-rufis. Anlemnae ochracco-rufae; articuli primi duo et maruo superus arliculi tertii pilis ochraceo-rufis, apicem versus fuscis, vestiti; stylus terminalis breviusculus, acutus. Selae mystacinae circiler sex. ochraceo-rufae. Palpi lutescentes, ochraceo-pilosuli. Proboscis badia. In thoracis dorso vittae tres nigricantes, interstitiis ochraceo- vel subaureo-pollinosis separatae conspiciunlur; vitta media antice practer margines laterales obsolete rubeseit et utrinque colore rufo-ferrugineo eximie dilatatur; margo lateralis dorsi ochraceo-pollinosus; humeri rufoochracei; collare fuscum. Pleurae subobsolete nigro-maculatae. Scutellum et metanotum ochraceo-pollinosa. Selae thoracis et scutelli ochraceo-rufae, adversus apicem nigrae. Aldomen ferrugineofuscum, adversus apicem obscure badium, pube brevi vulpinà vestitum. Pedes ex ochraceo rufi, setis omnibus concoloribus. femoribus anterioribus superne leviter fusco-lituralis. Halteres rufo-ochracei. Alae fuscae, adversus costam luteo-fuscae, venis obscure luteis. adversus apicem et marginem posticum nigro-fuseis. - (Cuba; Gundlach.) 
34. Plesiomma macra, Loew ठ․ Ochracea, thorace villis tribus nigris signalo, alis fuliginosis, cellulis posterioribus elutis. - Long. corp. $6 \frac{1}{3}$ lin., Long. al. $4 \frac{5}{12}$ lin.

Syn. Plesiomma macra Loew, Wien. ent. Monatschr. V. 35.

Pallide ochracea, parce et breviter ochraceo-pilosa et setosa, pilis et setis in poste:iore thoracis parte, in ahdomine toto, in pedibus posticis et in pedam anteriorum femoribus fuscanis. Femora anteriora, abdominis segmenta ullima duo et hypopygium fuscana. Caput latiusculum, vertice minus angusto quam in congeneribus plerisque. Vittae thoracis nigrae, postice acuminatae marginemque non altingentes, laterales antice abbreviatae. Pleurae albo-pollinosae. Abdomen gracile, segmentis intermediis paulo tenuioribus. Trochanteres puncto nigro nolati. Halteres pallide ochracei. Alae fuscanae, cellulae discoidalis dimidio apicali cellulisque submarginalibus et posterioribus elutis. - (Cuba; Poey.)

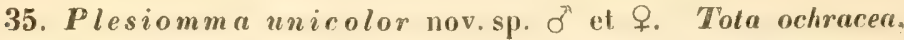
marginibus posticis segmentorum abdominalium ullimorum interdum leviter infuscalis; alae fusco-nigrae, cellularum discis elutis. -Long. corp. 8-9 lin.. Long. al. $6 \frac{1}{3}-7$ lin.

Tota ochracea. Frous adversus verticem minus angustata quam in Plesionmis esse solet. Setae mystacinae plures et subliliores. in duplicem seriem disposilae. Pili in thoracis dorso longiores. Ungues praeter imam basim uigri. Setae tolius corporis ochraceae; pubes brevis in intermediis abdominis segmentis maximâ ex parte nigra, reliqua ochracea. Alae latiusculae, fusco-nigrae; disci cellularum singularum (costali tamen et subcostali exceptis) eluti, nigrocinerei. - (New Mexico; Capt. Pope.)

36. Diogmiles platypterus, nov. sp. ơ. Niger, alis totis concoloribus, thorace praeter viltas dorsales nigro-fusco, antennis pedibusque testaceis, facie subochracei, mystace pallido. - Lons. corp. $7 \frac{2}{3}-8$ lin., Long. al. $7 \frac{5}{12}$ lin.

Niger. Occiput fusco-pollinosum, pilis setisque nigris instruclum. Frons polline ex ochraceo fusco aspersa, pilis pancis, brevibus, nigris. Antennae testaceae, arliculis primis duobus nigro-pilosis, secundo quam primum longiore. Facies ochraceo-pollinosa. Mystax pallidus, setis circiter sedecim ad viginti compositus. Palpi nigri, nigro-pilosi. Oculorum areolae perparvae, aequales. Thoras praeter vittas dorsales ordinarias nigras totus nigro-fuscus, opacus, nudiusculus, pilis brevibus setisque omnibus nigris. Scutellun con- 
color, setis marginalibus Juabus nigris, Abdomen nigrum, basim versus, subopacum, apicem versus nitidum, setis in lateribus segmenti primi pilisque brevibus ommium segmentorum nigris. Hypopygium nigrum, nilidum, nigro-pilosum. Coxaenigro-fuscae. Pedes luteo-leslacei, breviter nigro-pilosi, posticorum femoribus tibiisque in extremo apice, ullimis duobus vel tribus farsorum ommium arliculis tolis reliquorumyuc apice nigris. Halleres subfusei, capitulo plerumque lutescente. Alac latae, nigrae, adversus angulum posticun panlo dilutiores. - (Illinois; Osten-Sacken.)

Nola. Diogmites, Saropogonibus affines, a plerisque cellulâ posteriore quarti clausâ. ab ommibus capile laliore el magis discilormi, abdomine ef pedibus multo longioribus gracilioribusque discernmintur.

3\%. Diogmites discolor nov. spec. ơ et ㅇ. Ex subfusco ochraceus, thurace nigro-bilineato, abdomine angusto. maris praeter segmentoram singuloram angulos posticos et margines laterales fere ioto nigro, foeminae fuscro, alis lulescenti-hyalinis, adversus marginem posticum et upicem cinereis rel fusco-cinereis. celluli anali et angulo postico pube microscopica non plane distitutis. - Long. corp. $7 \frac{1}{2}-11$ liu., Long. al. $6 \frac{1}{3}-8 \frac{2}{3}$ lin.

Es subfusce ochaceus. Capul dilute ochraceopollinosum. Setae oceipilis fuscae vel nigrae. Primi duo antemnarum articuli nigro-pilosi. Mystax stramineus. Palpi nigri, nigro-pilosi, interdum pilis nigris el fuscis hirli. Thorax ex subfuseo ochraceus, pilis per. brevibus selisque omnibus uigris; lilla media dorsi angusla, aequalis, nigra. lincà longiludinali subfuseâ dissecta; vitlac lalerales subfuscae. Abdomen maris lenue, nigrum, brevissime nigro-pilosum, Iriente basali segmenti secundi subfusco, latera versus albido-pollinoso. angulis posticis segmentorum secundi. terlii el quarti albopollinosis. Ilypopygimm nigrum, nigro-pilosm. Abdomen foeminae fuscum, latera versus nigrum, segmentis ultimis lribus plerumque to. lis, reliquis adversus manginem posticum et basi segmenli secundi subfuseis, hae segmenlorumrjue sequentium angulis posticis albo-pollinosis; pili abdominis brevissimi nigri. prope apteem luteo-rufi, in apice ipso diluliores. Schate segmenti abdominalis primi in utroque sexu subfuscac. Pedes lutei, larsis apicem versus setisque ommibus nigris. Alae luleo-hyalinat, adversus appeem el marginem posticum cinereac vel fusco-cincence, cellula anali el angulo postico pube microscopiâ non prorsus deslilutis. celluli tamen anali practer apicem 
extremum et praeter strigam obsoletam uudâ. - (Penusylvania; Osten-Sacken.)

Nota. Variat hypopygio maris ex parte piceo - rufo, abdomine foeminae praeter apicem nigro femoribusque utriusque sexus apicem versus subfuscis.

38. Diogmites ternatus, nov. sp. $\delta$. Uchraceus, thoracis dorso subaureo-pollinoso, atro-triviltato, villá mediá in prothoracem continuatâ, alis lutescenti-hyalinis, adversus apicem et marginem posticum cinereis, cellulae analis plağa magna microscopice puberulâ.

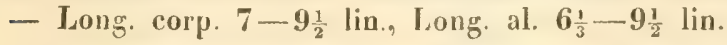

Species valde variabilis. Ochraceus, abdomine praeter margines segmentorum subfusco, interdum toto subfusco. Caput ochraceo- vel subaureo-pollinosum, fasciâ verticis fuscâ vel subfuscố, non raro omnino obsolelâ. Selae occipilis et verticis subfuscae vel nigrae. Primi duo antennarum articuli nigro-pilosi, raro pilis pallidis vestiti. Mystax stramineus. Palpi rufi vel badii, plerumque pilis nigris, saepe nigris et subfuscis, interdum omnibus subfuscis vel lutescentibus hirti. Thoracis dorsum polline subaureo aspersum, pilis brevibus setisque nigris instructum, atro-trivillatum, vitlâ mediâ fere semper in prothoracem continuatâ, integrâ vel per lineam longitudinalem ochraceam dissectà, vittis lateralibus antice valde abbreviatis, anguste interruptis. Setae, quae in lateribus segmenti abdominalis primi exstant, nigrae. Pedes luteo-teslacei vel subbadii, tarsis apicem versus setisque omnibus nigris. Alae hyalinae, fere semper lutescentes, adversus apicem et marginem fosticum cinereae vel fusco-cinereae, cellulac analis plagâ magnâ microscopice pubescente. - (Cuba; Poey. Gundlach: Louisiana, Schaum.)

39. Diogmites misellus, nov. sp. of. Ochraceus, vittis thoracis tribus atris, colore medine adversus marginem anticum thoracis in subfuscum mulato, alis hyalinis, adversus apicem et marginem poslicum cinerascentibus, pube microscopicâ in cellulà anali

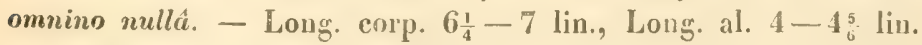

Ochraceus. Facies dilute flavescens, mystace sframineo. Palpi rufi vel badii, pilis lutescentibus vel subfuscis instructi. Selae occipitis et verticis subfuscae vel nigrae. Pili antennarum nigri, in articulo secundo interdum infra sulffusci. Thoracis dorsum pilis setisque nigris instructum, atro-trivittatum, colore vittae mediae adversus marginem anticum in subfuscum vel rufescentem vergente, vittis lateralibus antice eximie abbreviatis, anguste interruptis. Ab- 
dominis segmenta praeter margines omnes subfusea; setae laterales segmenti primi pallidac. P'edes luteo-testacei. larsorum apice setisque omnibus nigris. Alne pure hyalinae, adiversus apicem et marginem posticum cincrascentes, pube microscopicâ in cellulâ anali omnino nullâ. (Distriet Columbia; Osten-Sacken.)

Nota. A Diogme ternato corpare minore, Horacis pilis Iongioribus et villa medià antice semper rufescenle, alarum denique cellulât anali pube microseopica omnino distitula facile dignoseitur.

40. Diogmites bilinealus, nov. sp. ㅇ. Ex ochraceo-subfuscus, thorace fuscu-bilineato, abdomine ru/escente, angulis posticis segmentorum singuloman albicantibus. alis hyalinis, adversus apicem et marginis postici dimidium apicale cinereis, pube microscopicti in celluld anali et in angulo postico omnino mulla. - Joug. corp. It $-11 \frac{1}{2}$ lin. Long. al. 9 lin.

Ex ochraceo subfusens. Caput dilule ochraceo-pollinosum; setae occipitis et verticis fuseae vel nigrae. Primi duo antennarum articuli nigro-pilosi. Mystas stramineus. Palpi rufi vel badii, basi plerumque nigrâ, pilis nigris et fuscis hirti. Thoracis dorsum ex ochraceo subfuscum, polline dilute ochraceo leviter aspersum, pilis perhrevibus selisque omnibus nigris; vil: a media acqualis nigro-fusca, lineà ex achraceo subfuseà dissectan, ila ut lineis duabus nigro-fuscis componatur. Abdomen latius quam in specicbus pracmissis, rufescens, apicem versus fuscim; anguli postici ef margines laterales segmentorum singr: orum albo-polinosi, strigà ubliçui nigrà a colore refescente distincti. Pedes ex luteo leslacei. Larsis apicem versus setisque omnibus nigris. Alae lulescenli-hyalinae, adversus apicem et marginis postivi dimidium apjeale cinceae vel fusco-cinereae, pube microscopicá in cellulà anali el in angulo postico omnino mullà. (Cuba; Biehl.)

11. Diommites angustipennis nov. sp. F. E.x cinereo ochracens, viltis thoracis tribus obscure olvaren-fuscis, abdomine prater segmentorum angulos posticos et margines laterales olivaceo-fusco, alis anguslis hyalinis, redrersus apricum et mareninem postirum cinereis. limbis angustis venarum in marginem posticum cxcurrentinm el marginis postici ipsins pube microscopici destitutis. lyalinis. - Long. corp. $9 \frac{3}{6}-10$ lin. Long. al. 8 lin.

Ex cinereo pallide ochraceus. Capul ochraceo-pollinosum. Setae occipitis et verlicis subfuscae vel nigrae. Primi duo antenna- 
rum articuli nigro-pilosi. Mystax stramineus. Palpi rufi vel badii, pilis subfuscis hirli. Thoracis dorsum polline ex cinereo dilute ochraceo aspersum, pilis perbrevibus setisque omnibus nigris, vittis tribus subintegris, obscure olivaceo-fuscis ornatum; vitta media postice nonnihil atteuuata, plerumque lineâ longitudiuali pallide ochraceâ dissecta; vilłae laterales utrinque valde attenualae, acułae, subinterruptae; in villâ mediâ saepe lineae duae nigrae, in vittis lateralibus maculae binae nigrae conspiciuntur. Abdomen subfuscum vel ex olivaceo subfuscum, angulis posticis marginibusque lateralibus segmentorum singulorum polline exalbido vel dilute ochrascente aspersis, a colore subfusco maculâ obliquâ nigrâ distinctis. Setae laterales segmenti primi subfuscae. Pedes badii, larsis apicem versus setisque omnibus nigris. Alae angustae, hyalinae, dilute sublutescentes, adversus apicem et marginem posticum cinereae vel fuscocinereae, venarum in marginem poslicum excurrentium et marginis postici ipsius limbis angustis hyalinis et pube microscopicâ distitutis, venarum longitudinalium secundae, tertiae et quarlae apicibus non limbatis. - (Kansas; Matamoras.)

42. Diogmites hypomelas, nov. sp. ․ Ochraceo-rufus, opacus, vittis thoracis et femorum, abdominis maculis lateralibus, apice et ventre nigris, pilis setisque totius corporis pallidis. Long. corp. $8 \frac{5}{6}-10 \frac{1}{3}$ lin., Long. al. $7-7 \frac{5}{6} \mathrm{lin}$.

Ochraceo-rufus; opacus, pilis setisque totius corporis dilute flavicantibus. Caput ochraceo-pollinosum. Antennae ochraceo-rufae, articulo tertio minus lato quam in speciebus plerisque. Palpi ochraceo-rufi. Thoracis dorsum polline dilute ochraceo aspersum, nigrotrivitlatum, vittâ mediâ divisâ, lateralibus antice eximie abbreviatis. Pleurae fere totae nigrae, leviter ochraceo-pollinosae. Segmenta abdominalia ultima tria vel qualuor, reliquorum anguli antici et venter nigra. Pedes es ochraceo rufi, femoribus superne nigro-vittatis. Alae subhyalinae, colore ex subfusco lutescente tiuctae, adversus apicem et marginem posticum fusco - cinereae, cellularum posteriorum quartâ in ipso alae margine clausâ, tertiâ minus latâ quam in congeneribus. - (New Mexiko; Capt. Pope.)

43. Diogmiles umbrinus, nov. sp. O' et 오. Robustus, fermugineus, thorace imperfecte nigro-viltato, pilis selisque coxarum raro omnibus, semper ex parte nigris, alis subfusco-fygalinis, adversus apicem et marginem posticum fusco-cinereis, cellulà anali et angulo postico pube microscopicâ non omnino destitutis. - Long. corp. $9-10 \frac{2}{3}$ lin., Long. al. $7 \frac{1}{6}-8$ lin. 
Reliquis speciebus brevior et robustior, ferrugineus, opacus. frons et facies ochraceo-pollinosae. Antennarum pili nigri, longiores et numero plures quam in speciebus reliquis. Mystax dilute flavicans. Palpi badii, nigro-pilosi, sacpe pilis nigris et subfuscis hirti. Setae verticis et occipitis nigrae, in occipsitis dimidio inferiore sacpe fuscae vel subfuseac. Thoracis lorsum villis tribus imperfectis nigro-fuscis vel nigris variegatum, medià lineis duabus parallelis et postice valde abbreviatis composità, lateralibus e maculis binis intervallo lato separatis constantibus. Pili thoracis nigri, in prothoracis lateribus saepe subfusci vel pallidi; selae omnes nigrae. Color abdominis, plerumque in rufo-ferrugineum vergens, latera versus in nigrum mutatur; anguli postici segmentorum polline dilute ochrasente vel exalloido aspersi. Setae segmenti primi nigrae; pili abdominis breves, nigri, in apice abdominis foeminae saepe vulpini vel pufu-ochracei. Hypopygium ferrugineum vel piceum, nigro-pilosum. Coxae ferrugineac, pilis setisque plerisque subfuscis, reliquis nigris, rarius omnibus nigris. Pedes fusci vel badii, genibus tarsorumque basi testaceis, setis omnibus nigris. Alae ex subfusco hyalinae, adversus apicem el marginem posticum late fusco-cinereae. celluâa anali et angulo postico pube microscopicá non plane distilis. - (New-York; Osten-Sacken. - Illinois.)

Nota. A speciehus praccelentibus omnibus corporis stalurâ robustiore et colore obscure fermgineo, ab omnibus praeler Diogm. platypterum pilis setisque coxarum vel ex parte, vel omuibus nigris ditfert.

44. Microstylum galactodes. nov. sp. ó et ㅇ․ Nigrum vel nigro-piceum, leviter albo-pollinosum, alis albido-hyalinis, lumine Iransmisso practer margines et apicem lacteis, setis mystacinis qua-

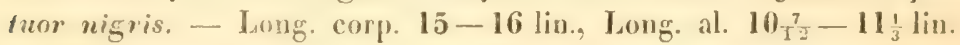

Nigrum vel nigro-piceum, polline albo leviler aspersum, faciei modice lalae pleurarumpue polline conferliore, seymentis abdominalibus ultimis quatuor foeminae et ventre utriusque sexus polline destitulis, nilidis. Pili tolius corporis perbreves, nigri; setae medioeres, concolores. Setac mystacinae qualuor validue, nigrae. IIypopygium maris badium, breviter nigro-pilosum. Pedes simplices, nigro-picei, polline nullo aspersi. Halleres nigro-picei, capilulo superne sordide lutco. Alac albido-lyyalinate, lumine transmisso practer marginis anlici dimidiun apicale, praeter trieulem apicalem alac et praeler limbum latissimum marginis postici lacteac. colore tamen lacteo in alis foeminte minus late dilluso quam in alis maris et in- 
terdun satis obsoleto; venae alarum lutene; cellula posterior prima ante alae marginem clausa et pedunculata. - (New Mesico; Capt. Pope.)

45. Scleropogon pirlicornis, nov. sp. ․ Rufescens, pilis selisque rigidis, dihulissime hulescentibus vel exalbidis vestitus, capile praeter oris margines, aniennaram articulo secundo cum basi tertii, villis dorsalibus thoracis tribus. pleurarum maculis, scutello, abdominis fasciis latis, femorum anlicorum viltis, posteriorum latere antico tibinsque posticis fere tolis nigris. - I Jong. corp. 10 lin., Long. al. $7 \frac{1}{3}$ lin.

Rufescens, subopacus. pilis et selis rigidis dilutissime lutescentibus vel exalbidis vestitus, setis tamen verticis et froutis pilisque brevibus in thoracis dorso magnâ ex parle fuscis vel nigris. Caput praeter latera oris nigrum, subochraceo-pollinosum. Anlennac rufae, articulo secundo et basi tertii nigris, apice extremo lujus et stylo terminali fuscis. Palpi nigri. Vitlae dorsales thoracis nigrae tres acquales, laterales antice valde abbreviatae. Scutellum nigrum. Pleurac nigro-maculatae. In abdominis segmentis primis quinque singulis fascia hasalis latissima nigra, in segmento sexto viltate nigrae tres conspiciuntur, ante marginem posticum inter se confluen. tes; segmentum septimum similiter picłum ac sextum, viltâ famen media in lineam allenuata; segmenlum octavum breve, practer maculam basalcm nigrum. Veuter rufus, margine postico segmenti septimi el segmento oclavo ni.ris vel nigro-piceis. Pili abdominis breviusculi, segmeulorum ultimorum resupinati. Pedes rufi; femora antica nigro-liturata, liturâ antirà latiore; femorum posteriorum latus anticum nigrum; tibiac posticae nigrae, latere inferno praeter trientem apicalem rufo. Alae breriusculae, leviler infuscatae, venis fuscis, transversî medià fusco-limbatâ; cellularum posteriorum prima et quarta clausae et pedunculalae, lertia valde dilatala. - (California.)

Nota. Scleropogones in notis plerisque cum Stenopogonibus couveniunt, sed ab his facie et fronte eliam anguslioribns. tertio antennarum articulo breviore et slylum longiorem gerente, alarum cellulâ posteriore primà ante marginem alae clausâ et tertiâ eximie dilatatì discrepant.

46. Stenopognon modestus nov. sp. ․ Cinereus, mystace, barbâ setisque thoracis stramineis, pedibus cinereo-nigris, genibus tarsisque badiis, alis requaliter fuscis. - Long. corp. 13-14 lin.. Jong. al. 9 lin. 
Cinereus, opacus. Mystax et pili totius eapilis straminei. Antennae nigrae. Thoracis dorsum vix obsoletissime vittalum, pilis brevissimis nigro-fuscis selisque stramineis instrucium; humeri badii. albido-pollinosi. Abdomen nigro-cinereum, adversus apicem nigrum et nitidum, pilis brevibus stramineis vel exalbidis, in segmentis ultimis duobus resupinalis vestitum. Pedes cinereo-nigri, genibns farsisque badiis, mullisetosi, selis femorum plerisque pallidis, libiarum tarsorumque plerisque nigris. Alac aequaliter fuscae, venis nigrofuscis, collulà posteriore quartà aperti. - (North Red River: Kennicol.)

47. Stenopogon inquinalus, nov. sp. of el Q. E.x subfusco-cinereus, mystace, brabi setisque thoracis stramineis, antennis, humeris abdomineque testaceo-rufis, macalis laleralibus abdominis femoribusyue magna ex parte nigris, alis dilute subfussis, cellula posteriore quarta aperta; segmenta abdominalia ultima tris foeminae fusca. - Long. cosp. $12 \frac{1}{2}$ lin., Long. al. $8 \frac{5}{6}-9$ lin.

Ex subfuseo cinereus, opacus. Mystax el pili folius capitis straminei. Anteunae rufae, apice arliculi rertii el stylo nigro-fuscis. Palpi fusci, vel ex parte rufi. Thorax obsolete vittatus, pilis brevissimis nigro-fuscis setisque stramineis instructus; humeri rufi. subluteo-pollinosi. Abdomen ex rufo testaceum vel lalericium. Iateribus segmentorum nigris. plerum(que famen practer angulos posicicos; segmenta abdominalia ultima tria foeminac fusca. Pubes abdominis brevis, straninea. Pedes ex testaceo rufi, femoribus manna ex parte nigris, multiselosi, selis plerisque pallidis, in pedum posticorum tibiis et larsis fere ommibus nigris. Alac aequaliter ex cinereo fuscac, venis fuseis, cellulâ posteriore quartî apertì. - (Nebraska; Heyden.)

48. Stenopogon consanguineus, nov. sp. ó et L. Ochraceus, thorace praeter humeros nigro. polline conferto lutescente opaco, lateribus segmentorum abdominstium femorumque rillis nigris, alis subfuscis, costa venisgne proximis ochrareis, cellula submarginati secundi breviusculd, posteriore grarti unte marginem alae clausi. - Long. corp. $\sigma 7,7,7 \frac{3}{4}$ lin., Long. al. $\sigma^{7} 43$, 우 $5 \frac{2}{3} \operatorname{lin}$

Ochracens. Caput nigrum, sed polline conferto, dilutissime llavicante aspersum. Antenne nigrae. Myslax el pili lolius rapitis straminei. Thorax praeler humeros niger, sed polline lutescente confertim obtectus, opacus, dorso pilis brevibus selisque stramineis 
vel exalbidis instructo. Abdomen ochraceum, lateribus segmentorum nigris, margiuibus tamen posticis plerumque exceptis. Pedes ochracei, femoribus nigro-viltatis, setis omuibus stramineis vel lutescenlibus; tibiac posticac interdum infra fuscae. Alae subfuscae, costâ venisque cosiae proximis, auxiliari tamen exceplà, ochraceis, cellukarum posteriorum discis plerumque clutis, cellula posteriore quartâ anie marginem alac clausâ; alae maris breviores quam foemince et cellula submarginali breviore instructac. - (Nebraska; Heyden.)

49. Stenopogon latipenuis, nov. sp. ․ Ochraceus, capile, prolhorace, pleurarum maculis, villis dorsulibus thoracis tribus et metanoto nigris, sed polline lutescente obtectis. alis latinsculis subfuscis, costâ venisque proximis ochraceis, cellulà subuarginuli secundà brevinsculâ, , - Long corp. $9 \frac{1}{4}$ lin., Long. al. $6 \frac{1}{4}$ lin.

Praecedenti simillimus sed major et robuslior, fronte paulo angustiore, alis latioribus femoribusque validioribus. Antennae nigrae. Thorax ochraceus, prothorace, pleurarum maculis, melanoto viltisque dorsalibus tribus nigris, polline conferto lutescente oblectis, opacis. Aldomen folum ochraceum, segmentorum ultimorum marginibus posticis interdam nigricantibus. Coxae posticae ochraceae, nigro-maculalae. Pedes toli vchracei, pilis setisque ommibus lutescentibus. Alae latiusculac, subfuscae, costâ venisque cosłae proximis ochraceis, cellulâ submarginali sccundâ breviusculâ, posteriore quartâ ante marginem alae clausâ. - (New Mexico; Capl. Pope.)

50. Stenopogon longulus, nov. sp. $\delta$ el ㅇ. Uchraceus, thorace praeter hameros nigro, hutescenti-pollinoso, opaco, segmentorum abdominalium lateribus femorumque viltis nigris, alis infuscalis, costâ venisyue fuscis, cellula submarginali secundà longiusculà, posteriore quarta prope ad marginem alae clansâ. - Long. corp. $\mathrm{S}_{\frac{2}{3}}-10$ lin., Long. al. $6 \frac{1}{6}-6_{2}^{1}$ lin.

Stenopogoni consangumeo similis, sed major el gracilior. Abdomen pro portione longius. Alae longiores et colore saluratius fusco tinclae; costa et venae fuscae; cellula submarginalis secunda longior, posterior quarta in ipso alae margine vel prope ad marginem clausa; alae maris alis foeminae aequales. - (New Mexico; Capt. Pope.) 
51. Ospriocerus Aeacides, nov. sp. ठౌ. Ater, rlis concoloribus, abdomine praeter segmentum primum, ventrem el lypopygium rufo. - Long. corp. 6 $6_{5}^{3}$ lin. Long. al. $5 \frac{1}{\frac{1}{2}}$ lin.

Ater, opacus; abdomen rufum, segmento primo, marginibus litleralibus segmentorum sequentium, ventre toto el hypopygio atris. Facies et occipul albido-pollinosa. Pili breves, in parte rufi abdominis rufi, in reliquo cospore nigri; selac ommes nigrae. Halleres et alae nigrae. - Ab Ospriocera Aeaco Wied., quocum Ospriocerum spathelatum Bell. conjungendum esse suspicor, alis paulo angustioribus et abdominis segmento secundo praeter margines lalerales rufo dignoscilur. - (California; Agassiz.)

Nota. Osprioceri, Stenopogonibus proxime affines, ab his lorliu antennarum articulo longiore et stylo terminali ommino obsoleto discrepant; cellula posterior quarla ante alae marginem clausa; color corporis niger, abdominis tamen maximâ ex parte rufus.

52. Uspriocerus Rhadamanthus, nov. sp. đ. Niger, alis magnis concoloribus, abdomine latericio, scgmenlis primo et secundo praeter marginem posticum hujus, segmentornm seyuentium maculis lateralibus, ventre toto et hypopygio nigris; thoracis alorsum plesumque latericium. plaghi magnà nigrâ, interdum totum nigrum. Long. corp. 10 lin., Long. al. $8_{\frac{7}{1}}$ lin.

Niger, opacus. Facies et occiput albo-pollinosa. Thoracis dorsum in exemplis plerisque latericium vel rufo-lestaceum. plagi permagnâ nigrâ, in quibusdam tolum fusco-nigrum vel niggrum. Plenrae, pectus et scutellum semper tola nigra. Segmenta abdominis prima duo nigra, fasciâ posticá secundi latericia; segruenta sequenlia praeter hypopysium latericia, maculis lateralibus singulorum semiovalis nigris, angulos posticos nou atlingenlibus; venter totus niger. Pili breves in parle latericia ablominis lulescentes, in reliquo corpore nigri; setae omnes nigrae. Pedes nigri, erenibus, tibiis larsisque nigro-piceis. Halteres nigri. Alac magnae, multo laliores quam in Ospriocero Aeaco Wied., nigrae. - (New Mexico; Capl. Pope.)

53. Dizonias phoenicurus, nov. sp. o'. Niger, pedibus alisque concoloribus, abdominis dimidio basuli fasciis duabus albidlopollinosis ornato. apiculi cum hypopygio rufo, mystace et barbe totis nigris. - Long. corp. $\mathrm{S}_{3}^{2}-9 \mathrm{lin}$, Long. al. $7_{6}^{5} \mathrm{lin}$.

Niger, opacus. Caput concolor, facici lateribus, fronte orbitis- 
que occipitalibus albido-pollinosis; frons nigro-selosa; antennae nigrae, articulis primis duobus nigro-pilosis; mystax setosus, totus niger; palpi fusco-nigri, nigro-pilosi; proboscis nigra, apice piceo; barba nigra; occipitis dimidium superius selis sordide et dilutissime lutescenlibus, inferius nigris hirtum. Thorax niger, pilis brevibus selisque omnibus nigris. Segnenta abdominis prima tria nigra, margine postico lertii ex auranliaco rufo et fasciâ bisali secundi et tertii singulorum albido pollinosà, in medio abdomine emarginatâ, adversus latera abdominis modice dilatatâ; reliquum abdomen ex aurantiaco rufum. segmenlo tertio practer maculam mediam segmentorumque sequentium marginibus laleralibus nigricantibus. Hypopygium ex aurantiaco rufum. Venter cinereo-niger. Abdominis pubes brevis, in segmentis primis et in ventre nigra, in reliquo abdomine rufa; segmenti primi lalera nigro-pilosa; hypopygium pilis luteis vestitum. Coxae nigrae, pilis validis, exalbidis et nigris instructae. Pedes nigri, genibus piceis, pilis brevibus setisque nigris. Halteres lutei. Alae nigrae. - (Tamaulipas.)

Nota. Dizoniarum species adluc engilae omnes colore nigro alarum abdominisque fasciis duabus aibido-pollinosis. postice emarginatis, prope basim segmenti secundi et segmenti tertii silis, excellunt. it at colore et picturâ facilius quam partium fabricâ dignoscantur. Caput modice latum, minus disciforme quam in generum propinquorum spccicbus; vertex levissime depressus; fuberculum occllare modice convexum; primus antennarum arliculus brevis, secundus brevissimus, tertius valde elongalus, tennis, superne nudus, slylo apicali obtuso et obsoleto instruclus. Frons et facies modice latae; tuberculum faciei modice convexum, sed longum, ita ut antennarum basim prope attingat, totum mystace rigido hirtum. Abdomen cylindricum, apicem versus non allenualum. Pedes validi, tibiis anlicis non calcaratis, posticis non clavatis. Alac latiusculae: rami venac longiludinalis tertiae valłe diraricati; cellula posterior prima apicem versus angustata; cellula discoidalis longa; cellularum posteriorum tertia lalissima, quarta ante marginem alae clausa.

54. Dizonires bicinctus, nov. sp. ठ․ Tolus ater, pedibus alisque concoloribus, abdomine fasciis duabus albido-pollinosis ornato, pilis setisque totius corporis nigris, hypopygii tamen maximá ex parte albis. - Jong. corp. $11_{\frac{1}{2}}-12$ lin., Long. al. $9 \frac{3}{4}$ lin.

Totus ater, opacus. Caput concolor, fronte, faciei lateribus or- 
bitisque occipilalibus exalbido-pollinosis. setis frontis et occipitis. mystace, barbâ palporumque pilis nigris: antennae nigrae, articulo secundo et basi tertii piceis vel rufo-pices. Thoracis dorsum nigrum. marginibus lateralibus albidopollinosis. Pili hreves el setae ommes thoracis nigrac. Abdomen airum. opacum. sogmenturum se. cundi et tertii singulorum fascià basali exalbido-pollinosi, in medio abdomine excisì ef adversus margines laforales morlice dilatatâ. Pubes abdominis brevis, nigra: segmenti primi latera et secundi anguli antici pilis longioribus nigris, margo posticus segmenti ultimi et hypopygium exalbidis vestiunlur. Venter niger. Pedes cum coxis nigri. genibus piceis, pilis hrevibus setisque omnibus nigris. Halleres lutei, basi pedunculi nigrâ. Alac nigrae. - (New Mexiko; Capt. Pope.)

No a. A Dizon. quadrimaculata Bell. coxis anlicis nigro-pilosis ef hypopygio albo-piloso recerlit.

55. Sphageus chalcoproctus, nov. sp. ․ Budius, colore pedum in luteum vergente. thorace nigro, dorsi maculis quatuor et margine aureo-pollinosis, ullimis abdominis segmentis nilidissimis. colorem laete coccinetun resplendentibus. alis fuscis, dimidio antico praeter trientem rpicalem lubeo. - Lons. corp. $9 \frac{3}{4}$ lin. Long. al. $7 \frac{2}{3} \operatorname{lin}$.

Capui auren-pollinosum. mystace, barbà, pilis reliquis setisque ommibus ochraceis. Aulennarum arficulus primus rufo-luteus seeundus fiscus, tertius rufus, plerumque prope basim superne nigricans. Primus palpurum arliculus nioro-fucus, secumbus luteo-rufus. Thorax niger, humeris marginibusque laleralibus el postico ex badio rutis, pilis selisque ommibus ochraceis; dorsi mangines laberales. maculae duae triangulares prope humeros silae ef villulac duac posticae polline conferto aureo tegunfur; color niger dorsi interdum lineis duabus temissimis badio-rufir in villas fres dividilur. In pleuris maculae quatuor subaure-pollinosac conspiciunlur, in metanoto duac. Scutellum badio-rufum, aureo-pollinosum, maculì basali nigrà notalum et selis marginalibus o hraceis instructum. Abdomen lacle badiun, segmento primo toto maryinibusque pocticis reliquorum tenuissime nigris. segmentis ullimis qualuor nitidissimis. colorem lacte coccineum resplendentibus; anguli postici segmenti primi et anguli antici segmentorum proxime sequentium trimm conferlim albido pollinosi. Setac. quae in segmenti primi lateribus exstant, et pili totius abdominis ochracei. Pedes ex badio lutei; femora anlica basim versus fusca et infra confertim nigro-spinosa: femora inter- 
media infra praeter apicem et in medio latere antico spinis congestis nigris horrent. Setae pedum pleraeque ochraceae, reliquae nigrae; pili breves, maximâ ex parte ochracei, adversus femorum omnium tibiarumque posticarum apicem et in primis farsorum posticorum articulis maximâ ex parte nigri. Alae luleo-fuscae. dimidio antico praeter trientem apicalem lutco. - (Cuba; Gundlach.)

Nota. Sphageus a Bathypogone, cum quo corporis formâ ac figurâ congruit, notis sequentibus discrepat: 1. facie convexâ, sed non tuberculatâ; 2 . tertio antennarum articulo multo longiore et stylo apicali olısoleto; 3. cellularum posteriorum tertiâ minus dilatatâ, non jan longe ante marginem alae, sed in margine ipso clausâ venarumque longitudinalium nullâ abbreviatâ; 4. spinis validis femorum anteriorum in areas cougestis.

56. Dicolonus simplex, nov. sp. \&. Niger, nitens, luteohirtus, occipitis lateribus, fronle, primis duobus antennarum articulis palpisque nigro-pilosis, alis cinereis. - Long. corp. $5 \frac{5}{13}$ lin., Long. al. 4 lin.

Totus niger, nitens, pilis confertis luteis vestitus. Facies praeter tuberculum et orbitae occipitales luteo-pollinosae; frons cum tuberculo antennas ferente harumque articuli primi duo nigro-pilosi; mystax luteus, pilis supremis et lateralibus aliquot nigris; palpi nigri, nigro-pilosi; occiput luteo-pilosum, lateribus tamen nigro-pilosis. Extremus abdominis apex praeter luteos pilis aliquot nigris instructus. Pedes toti nigri, luteo-pilosi, setis tenuibus concoloribus. Alae cinereae, cellulis basali secundâ et anali anguloque postico alae praeter apicem, cellulâque denique discoidali limpidioribus. - (California; Agassiz.)

Nota. Dicolonorum corpus confertim pilosum, setis paucis ef quam pili vix validioribus instructum, formâ ac figurâ Laphriam simulat. Caput parvum, thorace minus latum, facici tuberculo et frontis margine antico, autennas ferente, convexis; antennarum articulus primus longus, secundus mediocris, tertius sublinearis, primis duobus simul sumtis aequalis, in margine superiore pilo uno alterove iustructus; stylus terminalis antennarum brevis, crassissimus et obtusissimus. Pedes mediocres, tibiis anticorum non calcaralis, femoribus tibiisque posticorum modicc clavatis, tarsorum articulis omnibus brevibus, subglobosis. Alarum cellulae posteriores omnes aperlae, prima apicem versus anguslata, tertia non dilatata; vena transversalis media cellulac discoidalis basi approximata. 
57. Lasiopogon biviltatus, nov. sp. o'. Niger, polline cinereo-fusco aspersus, viltis thoracis duabus tenuibus nigris, intervallo lato distantibus. alarnem venula transversâ medià ultra cellulam discoidalem mediam promoti. - - Long. corp. 4 liu., Long. al. $3 \frac{7}{12}$ lin.

Totus niger. Mystax, palporum, antennarum, frontis verticisque pili nigri; barba exalbida. Thoracis dorsum polline ex cinereo subfusco aspersum, vittis duabus angustis nigris, lato intervallo separatis, antice divergentibus ef subabbreviatis notatum. nigro-pilosum. Scutellum concolor, nigro-pilosum. Pleurae cincreo-pollinosae, exalbido-pilosae, pilis ante alas et ante halteres nigris. Abdomen nigrum, nitidum, segmento primo fere tolo, segmentorumque reliquorum marginibus posticis et lateralibus late cinereo-pollinosis. Pili abdominis longiusculi, sordide exalbidi; margo posticus segmenti primi latera versus setis aliquot nigris instructus. Venter nigro-cinereus, exalbido-pilosus. Hypopygium magnum, nigrum, nitidum, nigro-pilosum. Pedes toli nigri, selis omnibus pilisque tarsorum, tibiarum trientisque femorum apicalis nigris. reliquis femorum pilis sordide exalbidis. Alae cinereo-hyalinae, venis fusco-nigris, transversà medià a cellulac discoidalis basi paulo Jongius quam ab apice remotâ. -- (California).

55. Het eropogon gibbus, nov. sp. \&. Niger, capite. thorace praeter villas dorsales angulisque posticis segmentorum abdominalium primorum quahur albido-pollinosis: alae hyalinae, limbo costali et dimidio apicali nigricantibus. - Long. corp. 6 lin., Long. al. $6 \frac{\mathrm{l}}{\mathrm{l}} \mathrm{lin}$.

Caput polline exalbido vel dilute flavesente aspersums: oceiput obscurius, pilis albis setisque albis et nigris insiructum: pubes fronlis allsa; setae prope ocellos nigrae. Primi duo antennarum articuli rufi vel badii, nigro pỉlosi, secundus infra setâ perlongâ nigrâ instruetus; articulus tertius tenuis. niger; stylus terminalis perlongus. tenuissimus. Mystax albus vel dilutissime lutescens, infra longior, pilo uno allerove nigro in margine oris. Palpi plerumque nigro-pilosi. interdum pilis albidis ef nigris hirti. Barba alba. Thorax albido-pollinosus, vittis dorsalibus tribus latis, medià nigrâ, aequali, poslice valde abbreviati, lateralibus fusco-nigris, inaequalibus, subinterruptis; humeri ef pleurae plerumque rnfescentes. Pili thoracis albi, dorsi lamen plerique nigri; setae ommes nigrar. Abdomen nigrum, nudiusculum, pilis perbrevibus nigris instructum. lateribus pilos longiores albos gerentibus et plerumque ex badio rufis; 
segmenta prima quatuor angulos posticos polline exalbido vel lulescente obtectos et interdun margines posticos colore ex badio rufo tinctos habeut. Venter rufescens, exalbido-pollinosus, pilis albis, adversus basim multo Iongioribus vestilus, apicem versus niger. Pedes badii. femorum, libiarun tarsorumque apicibus plermmque nigris; pubes maximâ ex parte alba, in tiłbarum apice et in tarsis nigra; femora prope apicem setis paucis, plerisque nigris instructa; tibiae multisetosae, setis fere omubus albidis vel dilute lutescentibus, reliquis nigris; tarsorum setac nigrae. Halteres lutei. Alae longae, apicem versus attenuatae, hyalinae, venis nigris, cellulis costalibus et dimidio apicali alarum nigricantibus, cellulâ tamen discoidali totâ et cellulis posterioribus quartâ et quintâ adversus basim dilutioribus. - (Pennsylvania; Osten-Sacken.)

59. Cyrtopogon chrysopogon, nov. sp. ठ et + Niger, tibiarum basi late lutea, alis hyalinis, apicem versus leviler cinerascentibus, mystace maris confertissimo, toto aureo, foeminae tenui, praeter pilos interiores nigro. - Long. corp. $5 \frac{1}{4}-5_{4}^{3}$ lin., Long. al. $3 \frac{7}{13}-4 \frac{1}{6}$ lin.

Niger. Caput concolor, luteo-pollinosum. Frons et occiput nigro-pilosa. Antennae nigrae, articulis primis duobus nigro-pilosis. Mystax maris conferlissimus, tolus dilute aurcus, pilorum marginalium uno alterove nigro; mystax foeminae multo tenuior, pilis interioribus aureis, externis nigris. Barba candida. Thoracis dorsum polline vel sordide sublutescente, vel subfusco opacum, viltis nigris, mediâ duplici, lateralibus inaequalibus variegatum, margine laterali inaequaliter atro, nitido. Scutellum nigrum, nitidum, imâ tantum basi pollinosâ. Thoracis dorsum et seutellum nigro-pilosa. Pleurae polline dilutius lutescente instructae, albo-pilosae. Abdomen tolum nigrum, nitidum, albo-pilosum, maris adversus apicem superne cum hypopygio tolo nigro-pilosum; anguli postici segmentorum secundi, tertii, quarti et quinti niveo-pollinosi. Venter niger, albido-pilosus. Pedes nigri, nitidi, tibiarum triente basali in foeminâ, dimidio basali in mare luteo; femora albo-pilosa. apice tamen omnium nigropiloso, setis omnibus nigris; tibiarum pili et setae omnes nigrae; ima articulorum tarsalium basis lutea; tarsi antici maris graciliores quam foeminae, articulis ultimis quatuor in latere interiore pulchre candido-ciliatis. Halteres albidi. Alae pure hyalinae, adversus marginem posticum et adversus apicem cinerascentes, venis nigris, in imâ alarum basi ochraceis, transversis saepe tenuissime et obsoletissime fusco-limbatis. - (Massachusetts; Packard.) 
60. Cyrtopogon marginalis, nov. sp. ․ Niger, antennis praeter basim et apicem rufis, femorum apice, tibiis tarsisque badiis, abdomine fasciis quatuor albido-pollinosis ornato, alis praeter apicem cinerascentem hyalinis. - Long. corp. $5_{\frac{1}{1} \frac{1}{2}}-\mathbf{5}_{6}^{1}$ lin., Long. al. 4-4 $\frac{1}{1 \frac{1}{2}}$ lin.

Niger. Caput concolor, pilis frontis plerisque nigris, occipitis plerisque albis. Primi duo antennarum articuli nigri, albo-pilosi; articuli secundi apex et articulus tertius rufi, extremo apice hujus et stylo fuscis. Pili mystacis plerique nigri. reliqui albi. Barba tota alba. Thoracis dorsum fusco-pollinosum, vittis subobsoletis magis nigris variegatum, albo-pilosum, humeris, callis duobus lateralibus angulisque posticis nigris, nitidissimis, nigro-pilosis. Pleurae albido-pollinosae et albo-pilosae. Scutellum nigrum, nitidum, albopilosum. Abdomen nigrum, nitidum, segmentis secundo, tertio, quarto et quinto singulis fascià posticâ albido-pollinosâ ornatis, ipso tamen margine postico praeter latera nigro et nilido. Margines postici segmentorum et latera abdominis albo-pilosa, reliquum dorsum nigro-pilosum. Venter niger, nitidus, totus albo-pilosus. Femora nigra, imâ basi et apice badiis, pilis longis albis, infra lutescentibus, in extremo apice nigris vestita. Tibiae badiae, apice fusco, superne pilis albis, infra nigris, omnibus perlongis et confertis hirfac. Tarsi badii, colore articuli primi in luteum vergente, pilis articulorum basalium plerisque albis, reliquorum nigris. Setae tibiarum tarsorumque omnes nigrae. Alae pure hyalinae, venis nigro-fuscis; cellulae marginalis et submarginalis prior adversus apicem, submarginalis posterior tota cinerascenles. - (Massachusctts; Sanborn.)

61. Cyrtopogon melanopleurus nov. sp. ․ Niger, tibiis tarsisque praeter apicem rufo-piceis, alis hyalinis, adversus apicem cellulae analis et in triente apicali nigricantibus. - Long. corp. $4 \frac{1}{2}-5 \frac{1}{3}$ lin., Long. al. $3 \frac{5}{T^{\frac{5}{2}}}-4_{\frac{1}{2}}^{\frac{1}{2}}$ lin.

Niger. Capul concolor, fronte et superiore occipitis dimidio nigri-pilosis. Antennae nigrae, articulis primis duobus nigro-pilosis. Mystax practer pilos externos nigros dilute lulescens. Barba alba. Thoracis dorsum polline subfusco opacum, nitgro-pilosum, vittis nigricantibus, mediâ duplici, lateralibus in maculas binas dissolutis variegatum, margine laterali denulato, nitido. Pleurae nigrae, nilidae, supra polline ex subfusco luteo aspersae, albo-pilosae, fasciculo pilorum nigrorum ante halteres. Scutellum nigrum. nitidum, nigro-pilosum. Abdomen nigrum, nitidum, segmentorum secundi, tertii, quarti et quinti marginibus poslicis adversus latera albido- 
pollinosis. Pili abdominis exalbidi; pubes brevis in medio dorso. praesertim in segmentis posticis, plerumgue ex parte nigra. Femora nigra, pilis exalbidis vel sublutesceutibus, superne et adversus apicem plerisque nigris vestita. Tibiae batiae vel ex rufo badiae, apice nigro, nigro-pilosie. Tarsi badii, articulorum singulorum apice plerumque, articulo ultimo semper nigro, breviler nigro-pilosi. Setae tibiarum tarsorumque omnes nigrae. Alae cinereo-hyalinae, venis fusco-nigris; cellula analis adversus apicem nigrieans, venâ, quâ a cellularum posteriorum ultimâ separatur, colore obscuriore circumfusâ; cellulae subcostalis apex, cellula marginalis praeter basim, cellulae submarginales, cellulae basalis primae apex, cellulae discoidalis margo anticus et apex extremus, cellulae denique posteriores primae tres nigricantes, tertiae tamen harum angulo postico excepto; venae transversae colore saturatiore limbatae. - (Hudsons Bay-Territory; Kennicot. - White Mountains; Scudder.)

62. Holopogon seniculus, nov. sp. ot et 우. Totus ater, praeter caput et thoracis dorsum polline exalbido opaca nitidus, albo-pilosus, alis purissime hyalinis. - Long. corp. $2 \frac{2}{3}-2 \frac{3}{4}$ lin.g Long. al. $2-2 \frac{1}{2}$ lin.

Ater nitidus. Caput et thoracis dorsum polline albido aspersa, opaca, lineâ tamen mediâ et disco hujus obscırioribus. Mystax et pili totius corporis in mare nivei, in foeminâ albi vel dilutissime sublutescentes, hi in abdominis dorso brevissimi, in reliquo corpore toto perlongi. Pedes toti atri. Halleres dilute flavi. Alae purissime hyalinae, venis ex luteo subfuscis. - (Nebraska; Heyden.)

63. Ab̆lautus trifarius, nov. sp. ㅇ. Ex subfusco cinereus, abdomine trifariam nigro-maculato, alis puve hyalinis. - Long. corp. $3 \frac{1}{4}$ lin., Long. al. $2 \frac{3}{4}$ lin.

Ex subfuseo cinereus, opacus. Caput concolor; setac verticis subfuscae; primi duo antennarum articuli brevissimi, nigri, superne pilis brevioribus fuscis, infra longioribus ochraceis instructi; mystax totam faciem usque ad basim antennarum legens, densissimus, al. bus, pilis validioribus prope oris aperturam nigris; barba alba. Thoracis dorsum pilis setisque sordide, sed dilute lutescentibus vestitum, obsolete nigro-vittatum, vittâ mediâ per lineam cineream divisâ et postice valde abbreviatâ, lateralibus interruptis. Scutellum cum thorace concolor, planum. margine setis confertis lutescentibus instructo. Abdomen polline albo-cinereo aspersum, opacum, triplice serie macularum nigrarum, ad marginem anticum segmentorum sin- 
gulorum positarum ornatum, apice ipso toto nigro. Pubes albida abdominis mediocris, rara, resupinata, in segmenti secuudi lateribus longior; litera segmenti primi setis aliquot lutescentibus praedita, reliquum abdomen selis omnino destitutum. Pedes badii. tibiis tarsisque multo dilutioribus, confertim albido-pilosi, toli setis rigidis, sordide lutescentibus vel dilutissime subfuseis linti, farsorum setis ex parte nigris. Alae pure hyalinae, venis nigris. - (California; Agassiz.)

Nota. Ablaulus, novum Dasypoguninorum genus, Anarolio et Rhadino proximum, ah illo antennis multo brevioribus, facie planâ et thorace non jubalo, ab hoc fronte non dilatalâ. ocu. lorum areolis aulicis quam reliquac majoribus alarumque cellulâ posteriore quarlâ aperti differt. Thorax et pedes valde setosi, pulvilli uulli; abdomen anguslum, apicem versus altenuatum, praeter latera segmenti primi selis nullis instructum, pube mediocri, rarâ, resupinalâ vestilum; cellulae posteriores alarum omnes apertae.

64. Baccha parvicornis $\mathrm{I}_{\mathrm{W}} \mathrm{W}$. $\sigma^{\prime}$. Obscure mellea, thorace aenescente, alarum hyalinurum morgine antico et macula apicali nigris. - Long. corp. 4 lin. Jong. al. 3 lin.

Syn. Baccha parvicornis Lw. Wien. ent. Monatschr. V. 4 .

Obscure mellea. thorace el scutello nitore aureo et cupreo lacte resplendentibus. Caput flavum, maculà fronlis minutâ nigrâ, antennis proximi. Abdomen compressum, genitalibus paulo majoribus, quam in hujus generis speciebus esse solent. Pedes mellei, apice tarsorum posticorun subfusco. Alae pure hyalinae: limbo tenui costae, inde a renae auxiliaris fine usque ad finen venae Jongitudinalis primac ducto et maculà apicali. inde a costî ipsî usịue ad venam longitudinalem tertiam pertinente nigris. - (Cuba; Gundlach.)

65. Baccha notata, nov. sp. đ. Ocharace, lriangulo verticuli et puncto frontali atris. thoracis disco praeter limbos laterales ex fusco ochraceo, vividi-villato, abdomine fusco-lineato, alis infuscatis, adversus costam ex fusco lutescentibus. - long. corp. 1 lin., Long. al. 3 ! lin.

Caput luteum, occipite cinceo; triangulum verticale alrum; frons opaca. nigro-pilosula, maculà mimulâ alrâ nolata: lunula frontalis nitens, prope antennas nigra. Anfeunac ochraceac. Facies pallide ochracea. subdiaphana. fola nitida. Thorax ochraceus; dorsum practer limbos laterales latos ex fuseo ochraceum, lineis mediis 
duabus postice abbreviatis vittisque lateralibus duplicatis virescentibus. Scutellum ochraceun; metanotum aeneo-nigrum; pectus nigro-maculatum. Abdomen ochraceum, lineis longitudinalibus fuscis ornatum; hypopygium aeneo-nigrum. Pedes ochracei, femorum posticorum triente apicali tibiisque posticis praeter anuulum subbasalem latissimum subfuscis. Alae infuscatae, adversus costam ex fusco lutescentes, cellulis marginali et submarginali apicem versus colore fuscano paulo saturatius linctis. - (Cuba; Gundlach.)

66. Ocyptamus longiventris, nov. sp. of et f. Aeneoniger, facie utriusque sexus lateribusque frontis foeminae antice flavis, abdomine angusto, subaequali, maris ex fusco nigro, foeminae plerumque badio et nigro-anнulato, alis nigris, sinu subtriangulari apicis subhyalino, margine postico et angulo axillari elutis. - Long. corp. $5 \frac{1}{5}$ lin., Long. al. $4 \frac{1}{3}$ lin.

Similis Ocyptamo fuscipenni Say, sed major alarumque picturâ diversus. Caput flavum; frons maris tota nigro-aenea; frons foeminae flava, sed vittâ aeneo-nigrâ, antice attenuatâ, superne froutem totam tegente. Antennae nigrae, articulis primis duobus et basi inferâ tertii interdum testaceis. Thorax aeneo-niger, modice nitens. Scutellum concolor. Abdomen elongatum, tenue, subaequale; abdomen maris plerumque totum fusco-nigrum vel purpureo-nigrum, opacum, apice tamen segmentorumque marginibus posticis subnitidis et violaceo-splendentibus; abdomen foeminae colore magis in rufum vergente pictum, minus opacum, segmentis singulis ante apicem fasciâ nigrâ instructis et in margine postico magis violaceo-splendentibus. Pedes pallide flavicantes, femoribus anterioribus adversus apicem subfuscis, posticis fuscis, tibiis anticis adversus apicem fuscis, posticis tarsisque omnibus nigro-fuscis. Alae nigrae, sinu apicis magno subtriangulo hyalino, inde a venâ longitudinali tertiâ usque ad marginem posticum pertinente; margo posticus ipse et angulus axillaris eluti. (Washington; Osten-Sacken.)

67. Ocyptamus conformis, nov. sp. ‥ Aeneoniger, frontis chalybeae lateribus antice et facie flavis, thoracis viltis et abdomine violaceis, hujus fasciis tribus atris, alis nigris, sinu subtriangulari apicis hyalino, maculâ centrali et angulo axillari elutis. - Long. corp. $4 \frac{2}{3}-4 \frac{3}{6}$ lin., Jong. al. $4 \frac{1}{6}$ lin.

Caput flavum; frons chalybea, marginibus lateralibus antice flavis. Antennae nigrae, paulo majores quam Ocyplami longiventris. articulis primis duobus et basi inferâ tertii saepe testaceis. Thorax 
aeneo-niger, dorso obsolele violaceo-villato. Scutellum concolor. Abdomen ex chalybeo violaceum, polline allido tenuissime aspersum, apice saturatius violaceo, segmentis secundo, tertio et quarto ante apicem fascià opacà atrâ, postice emargiuatâ ef antice in lineam productà ornatis. Pedes anteriores pallide flavicantes. femoribus libiisque apicem versus subfuscis. tarsis nigro-fuscis; pedes postici uigro-fusci, fenorum basi dilule flavicante, tibiis basim versus flavotestaceis. Alae nigrae, silu apicis magno subtriangulo, inde a venâ longitudinali tertiâ usque ad marginem posticum pertinente pure hyalino, macula centrali el anculo axillari elutis, subhyalinis. (Cuba; Gundlach.)

68. Ocyplamus laliusculus, nov. sp. \&. Niger, abdomine latinsculo, nigro-purpureo, alis totis nigris. - Long. corp. $3 \frac{1}{6}$ lin., Long. al. $3 \frac{1}{6}$ lin.

Niger, modice uitens. Frons tola chalybea. Facies exalbida, vittulâ subfuscâ, saepe obsoletà. Aulennae nigrae, articulis primis duobus flavis. Scutellum aeneo-nigrum vel aeneo-piceum. Abdomen latiusculum, depressum, aequale, nigro-purpureum, mediâ segmentorum singulorum parte purius nigrâ et magis opacâ. Pedes anteriores lutei, femoribus tibiisque adversus apicem, tarsis praeter basim nigro-fuscis: pedes postici fusco-nigri, femorum basi genibusque luteis. Alae tolae aequaliter nigrae, adversus marginem posticum paulo dilutiores. - (Cuba; Gundlach.)

69. Ocyptamus scutellatus, nov. sp. F. Niger, scutello Aavo, abdomine latiusculo, rufescente, alis nigris, Iriente apicali

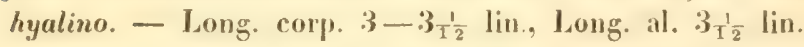

Niger, modice nitens. Caput flavum, vittì fronlis nigrâ, opacâ. superne frontem tolam tegente. infra subito attenuatî et nitidâ. Antennae nigrae, articulis primis duobus el basi inferâ tertii luteis. Thoracis dorsum utrinque in margine maculis binis minutis flavis nolatum, alterà ante alas, alterâ in angulo postico. Scutellum totum flavum. Abdomen latiusculum, depressum aequale, latericio-rufum, segmento primo segmentorumque reliquorum fasciis latis fuscis. Pedes anteriores lutei, femoribus prope apicem superne tarsorumque apice fuscis; pedes postici nigro-fusci, femorum dimidio priore, genibus tarsorumque basi luteis. Alae nigrae, triente apicali hyalino, angulo axillari el alulâ subelutis. - (Cuba; Richl.) 
70. Microdon inaegualis, nov. sp. of. Aeneo-viridis, abdomine nigro-piloso, chalybeo, segmento ultimo lateribusque segmentorum praecedentium violaceis, hypopygio fulvo, pedibus chalybeis, ultimo tarsorum articulo luteo. - Long. corp. $4 \frac{3}{4}$ lin., Long. al. $4 \frac{1}{4}-4 \frac{1}{3} \operatorname{lin}$.

Aeneo-viridis, nitens. Frons nigro-pilosa utrinque dilatatur, ita ut oculi in mediâ fronte intervallo multo minore quam in vertice et prope antennas distent. Antennae nigrae, articulis primis duobus chalybeo-nitidis, primo et ultimo subaequalibus. Facies pilis exalbidis vestita. Proboscis cum palpis nigra. Thorax pube fuliginosâ vestitus, maculis aliquot cupreis aliisque violaceis, omnibus tamen subobsoletis variegatus. Scutellum cum thorace concolor, nigro-pilosum, breve, sed latum, dentibus duobus brevibus, nigris, lato intervallo separatis. Abdomen latiusculum, segmentis tribus primis chalybeis, latera versus purpureo-violaceis, ultimo toto purpureo-violaceo; segmentum primum perbreve, secundum paulo longius, tertium, praecedentibus duobus et quartum praecedentibus tribus simul sumtis longiora. Hypopygium fulvum, pube brevi, dilute luteâ vestitum. Pedes chalybei, nigro-pilosi, ultimo tarsorum articulo luteo, adversus basim infuscato. Alae limpidae, venis nigris, dimidii apicalis plerisque fusco circumfusis. - (Cuba; Gundlach.)

Nota. Microd. inaequalis Microd. trochilo Walk. affinis est, sed pilis abdominis nigris, non pallide flavis, distinguitur.

71. Dalmannia nigriceps, nov. sp. $\sigma^{\Uparrow}$ Nigra, faciei parte mediâ, humeris, scutello praeter basim, segmentorum, abdominalium secundi, tertii et quarti marginibus posticis viltulâque quinti flavis, pedibus laele flavis, femoribus anticis praeter apicem, femorum posticorum annulo subapicali farsisque omnibus nigris. - Long. corp. 3 lin., Long. al. $2 \frac{3}{4}$ lin.

Nigra, modice nitens. Caput cum antennis concolor, facie parte mediâ, anticâ oculorum orbitâ et postico genarum margine pallide flavis. Thorax pilis pallidis vestitus; calli humerales flavi, maculâ rotundâ nigrà notati. Scutellum praeter basim nigram flavum, pallide-pilosum. Primum abdominis segmentum totum nigrum; segmentum secundum postice anguste flavo-limbatum, limbo in medio margine postico in trianguli formam dilatato; pictura segmenti tertii et quarti simillima, triangulo tamen in tertio longius producto et acutiore quam in secundo, in quarto fere ad marginem anticum pertinente; segmentum quintum vittulà flavâ, utrinque nonnihil abbreviatâ ornatum. Venter pallide flavus, triangulo basali nigro. 
Coxae nigrae. Pedes flavi; femora antica praeter trientem apicalem superne nigra, subtus nigricantia; femora postica annulo subapicali latiusculo nigro ornata; tarsi omnes toti nigri. Halteres flavi. Alae subfuscae, basim versus dilutioies. - (Virginia; Oslen-Sacken.)

72. Myopa clausa, nov. sp. б'. Rufa, farie flavicante, alarum immaculatarum cellulà posteriore prima clausi - Long. corp. $3 \frac{7}{12}$ lin., Long. al. $2 \frac{1}{1} \frac{1}{2}$ lin.

Caput vesiculosum, genis latissimis, dilute flavescens, superiore occipilis dimidio et fronte rufo-fermgineis. Primus antennarum articulus fuscus. secundus ex ochraceo dilute subfuscus. tertius cum setâ ochraceus. Thorax ex ferrugineo rufus, dorso obscuriore, vittâ medià maculisque duabus nigricantibus. Abdomen rufum, segmentis ultimis duobus reliquorumque angulis posticis leviter albido-pollinosis. Pedes rufi, tibiarum basi tarsisque lutescentibus. Alac modice infuscatae, basim versus sordide lutescentes, cellulà posteriore primâ clausâ. - (Maine.)

73. Oncomyia abbreviata nov. sp. ot et f. Nigra, thorace abdomineque cinereo-pollinosis, antennis rufis, pedibus fere totis testaceis, secundo proboscidis segmento quam primus breviore. - Long. corp. $2 \frac{7}{1} \frac{7}{2}$ lin., Long. al. 2 lin.

Nigra, polline dilute cinerascenle subopaca. Caput dilute flavicans, fronte sordide lutescente. alversus verlicem fuscâ. Antennae rufae vel rufo-teslaceae, superne leviler subfuscae. Secundum proboscidis segmentum primo brevius. Thoracis dorsum subaequaliter cinereo-pollinosum, nec vittis confertius pollinosis. nec lineis denudatis instructum. Abdomen cinereo-pollinosum. Pedes ex luteo testacei, femorum anticorum apice superue nigro. reliquorum infuscato, tibiis tarsisque apicen versus uigro-fuscis. Alae leviter infuscatae, venis obscure fuscis, adversus basim ferrugincis vel ex ferrugineo luteis. - (Washington; Osten-Sacken.)

Nota. Occemyiae nomen, a R. Desvoidy male compositum, in

Oncomyiam mulari necesse est

74. Oncomyia lovaria, nov. sp. ot el f. Nigra, leviter exalbido-pollinosa, antennis nigris, infra rufis, pedibus maxima ex parle nigris, secundo proboscidis segmento primi longitudinem panlo superante. - Long. corp. $1 \frac{3}{4}-2 \frac{1}{4}$ lin., Jong. al. $1_{15}^{\frac{5}{2}}-1 \frac{3}{4}$ lin.

Nigra, leviter albido-pollinosa, modice nitens. Caput dilute llavicans, facie albo-micante, fronte sordide rufescente. adversus ver- 
ticem nigro-fuscâ vel nigrâ; antennae nigrae, lateribus adversis praeter marginem superun et praeter apicen, aversis in margiue infero rufis. Proboscidis segmentum secundum primo paulo longius Occiput nigrum. In dorso thoracis lineae tres, polline denudata difficillime conspiciuntur. Pedes nigri, genibus femorumque posticorum basi scmper, coxis anticis, femorum anticorum tibiarumque omnium basi primisque farsorum omnium articulis plerumque testaceis. Alac cinereae vel dilutissime infuscatae, imâ basi lulescente. (New Hampshire; Oslen-Sacken.)

75. Zodion uanellum, nov. sp. P. Perparvum, nigro-cinereum, abdomine nigro, opaco. lateribus et lineâ longiludinali medici segmenti sexti cinereo-pollinosis, segmentis sexto et septimo testaceis. - Long. corp. $1 \frac{1}{3}$ lin., Long. al. 1 - $1 \frac{1}{1} \frac{1}{2}$ lin.

Perparvum, nigro - cinereum. Occiput nigricans; frons aurautiaca, prope verticem fusca; antennae fuscae, in lateribus adversis praeter apicem rufac; facies et genae dilute flavicantes; hae angustiores, oculi pro portione majores quam in reliquis speciebus. Thorax nigro-cinereus, pleuris paulo dilutius tinctis; viltae dorsales nigrae, angusle interruptae, utrinque ahbreviatac. Segmenta abdominalia prima quatuor superne nigra, opaca, marginibus posticis angustissime, lateribus lale cinereo-pollinosis; segmentun quintum brevissimum, fusco-testaceum; segmentum sextum testaceum, levissime pollinosum, subnitidum; septimum polline omnino distitutum, nitidum, testaceum, apice tamen nigro; valvula ventralis majuscula. Pedes subfusci, coxis, femorum apicibus tibiarumque basi pallide testaceis. Halferes albidi. Alae cinereo-hyalinae, venis nigris. (Washington; Osten-Sacken.)

76. Atrichia longurio, nov. sp. ơ. Nigra, subopaca. hu. meris, sculello pedibusque testaceis, alis cinereo-hyalinis. - Long. corp. 4 lin., Loug. al. $3 \frac{1}{2}$ lin.

Nigra, opaca. Articulus tertius antennarum ex fusco rufescens. latere externo obscuriore. Calli humerales et scutellum sordide lutea vel testacea. Pedes cum coxis ex luteo subfusci, imà coxarum basi et tibiarum tarsorumque apice saluratc fuscis. Abdomen tenue, clongatum, hypopygio ex fusco rufeseente. Alae cinereo-hyalinae. venis fuscis. - (Mexiko; Mus. Berol.)

Nota. Scenopinidarum genus novum, corpore elongato, tenui. pedibus gracilibus alarumque cellulà posteriore primâ longe a margine clausâ insigne, Atrichice nomine, a celeberrimo Schrankio Scenopinis imposito, appelavi. 
77. Dolichopus pugil, nov. sp. ठ'. Aeneo-viridis, antennis praeter apicem nigrum ochraceis, pedibus cum coxis anticis posterionumque apice luteis, tibiarum anticarum apice pilis conferlis nigris fasciculato, ultimo tarsorun anticorum articulo dilatulo. Long. corp. $2 \frac{3}{4}$ lin., Long. al. $2 \frac{5}{12}-2 \frac{1}{2}$ lin.

Aeneo-viridis, nitens. Frons subchalybea, modice nitens. Antennae ex rufo-lutea vel ochraceae, apicali articuli tertii dimidio nigro. Facies ochracea. Cilia oculorum inferiora lutescentia. Lamellae hypopygii maguae, latae, albae, tenuiter nigro-limbatae. margine apicali setis longis nigris ciliato. Coxae anticae luteae, nigropilosulae, posteriores cinereae, apice extremo luteo. Femora lutea, postica infra pilis longissimis nigris ciliata et ante apicen seti unica instrucla. Tibiae luteae; apex anticarum leviter subincrassalus et pilis confertissimis nigris fasciculatus; poslicae prope apicem liturâ fusco-nigrâ notatae. Tarsi antici pallidi, apice articuli primi subiutcrassato et nigricante, articulo ultimo compresso-dilatato, nigro; tarsorum intermediorum arliculi primi tres in apice, reliqui toti nigri; tarsi postici nigri. Tegulae pallidae, nigro - ciliatae. Alae ciuereohyalinae, costà prope venae primae finem incrassalâ, venâ lougitudinali quartâ non fractâ. - (Canada.)

78. Dolichopus terminalis, nov. sp. ठ. - Viridis, nitens, antennis rufis. ciliis oculorum inferioribus et fucie angusti albis, legularum ciliis nigris, coxis pedibusque dilute flavicuntibus, femoribus posticis non ciliatis, tarsis posticis inde ab articuli primi apice ultimoque tarsonum anticorum articulo nigris. - Long. corp. $2 \frac{1}{4}-2 \frac{1}{3}$ lin., Long. al. $2 !-2 \frac{1}{4}$ lin.

Viridis, nitens. Frons obscure viridis. Antennae rufae, dimidio apicali arliculi tertii nigro-fusco. Facies angusta, albo-pollinosa. Cilia oculorum inferiora albida. Thoracis dorsum polline ex cinereo subfusco aspersum, modice nitens. Hypopygium viridi-nigrum. lamellis ovatis albis, limbo mediocri nigro. Coxae et pedes pallide flavicantes; femora postica non ciliata; tihiarum posticarum latus interius aequaliter pilosum; tarsi simplices, anticorum articulus terminalis leviter subcompressus, niger; tarsi posteriores inde al articuli prini apice nigri. Cilia legularum nigra. Alae cincreo-hyalinae, basim versus subangustatae, angulo axillari non prominente. costâ ad venae primae insertionem non incrassatî et venâ longitudinali quartâ non fractâ. - (Genesseo, New-York; Osten-Sacken.) 
79. Dolichopus detersus, nov. sp. $\delta$. Viridis, nitidissimus, pedibus lolis nigris, posticorum femoribus nigro-cilialis, facie inferioribusque oculorum ciliis albis, alis hyalinis, costâ ad nervi primi finem in uodulum incrassata. - Long. corp. $2 \frac{1}{6}$ lin., Long. al. $1 \frac{1}{1} \frac{1}{2}$ lin.

Viridis, nitidissimus. Frons concolor. Antennae nigrae. Facies angusta, alba. Cilia inferiora oculorum alba. Incisurae abdominis tenuiter nigrae. Hypopygium nigrum, lamellis subrolundatis nigricantibus, late nigro-limbalis. Pedes toti nigri; femora postica pilis longis nigris ciliala; tibjae posticae subinerassatae, latere interiore practer apicem uudo. Cilia tegularum nigra. Alae ex cinereo hyalinae, venis nigris, costâ ad venae primae insertionem iu nodulum incrassatâ. - (Saratoga; Osten-Sacken.)

80. Dolichopus platyprosopus, nov. sp. ठ․ Viridis, antennis tegularumque riliis nigris, oculornm ciliis inferioribus et facie latâ albis, pedibus favis, femoribus postucis pallide ciliatis, $t i$ biarum posticarum apice, tarsis anterioribus inde ab articuli primi apice posticisque tolis nigris. - Long. corp. $2 \frac{1}{4}$ lin., Long. al. $2 \frac{1}{4}$ lin.

Viridis, nitidus. Anteunae nigrae, articulo primo infra rufo. Facies lata, albo-pollinosa. Inferiora oculorum cilia albida. Нypopygium viridi-nizrum, lamellis ovatis albis, tenuiler nigro-limbalis. Coxae anticae flavae, praeter setas apicales nigras tenniter albo-pilosulae; coxae posteriores cinereae, apice tamen flavo. Pedes flavi; femora postica iufra ciliis pallidis, modice longis instructa. Apex tibiarum posticarum niger, latus interius fere totum nudum; tarsi omnes simplices, anteriores inde ab articuli primi apice, postici toti nigri. Alae cinereo-hyalinae, costâ ad venae primae finem in nodulum incrassatâ, venâ longitudinali quartâ non fractâ. - (Hudson's Bay Territory; Keunicot.)

81. Dolichopus sarotes. nov. sp. ơ. Viridis, modice nitens, antennis rufis, oculorum ciliis inferioribus et facie albis, coxis pedibusque flavis, tarsorum anticorum articulis primis duobus elongatis, reliquis brevibus. praeter basim tertii nigris, tertio et quarto superne confertim nigro-barbatis. - Long. corp. $2 \frac{1}{2}-2 \frac{5}{\mathrm{~T}}$ lin., Jong. al. $2 \frac{5}{6}-2 \frac{1}{2} \frac{1}{2}$ lin.

Viridis, modice nitens. Frons ex viridi subchalybea, nitens. Antennae rufae, articulo tertio breviter ovato, apicem versus infuscato. Facies angusta, albido-pollinosa. Cilia inferiora oculorum 
albida. Thoracis dorsum viridi et chalybeo variegatum, polline cinereo aspersum, modice nitens. Scutellum chalybescens. Pleurae ex glauco cinercac. Ilypopygium viridi-nigrum. lamellis ovatis albis, tenuissime nigro-limbatis. Coxae flavae, intermediac nigro-lituratae. Pedes flavi; femora postica non ciliata; tibiae posticae totae flavicantes, latere interiore toto aequaliter piloso; firsorum anticorum articuli primi duo clongali. ila ut simul sumti tibiarum Iongitudinem aequiparent, articuli ultimi tres breves practer basim tertii nigri, terlius et quarfus superne pilis confertis nigris barbati; tarsi posteriores inde ab articuli primi apice fusci, apicem versus fusco-nigri. Alae pro portione magnae, latiusculae, cinereo - hyalinac. costà ad venae primae insertionem obsoletissime subincrassatô, venâ longitudinali quartà non fractâ. angulo axillari valde prominente. - (Illinois; Le Baron.)

52. Gymnopternus phigllophorus, nov. sp. o'. Nigroviridis, nileus, ciliis oculorum inferioribus tegulurumque ciliis nigris, alis nigricantibus, pedibus luteis, antennis praeter apicem fuscum rufis, seli tenui, elongalì, lamellam nigram ferente. - Long. corp. $1_{\frac{5}{12}}^{\frac{5}{2}}$ lin., Long. al. $1 \frac{1}{2}$ lin.

Frons nigro-viridis, modice nitens. Anteunac rufae, articulo tertio ovali, apicem versus fusco, selà elongatâ, tenui, niọrà. lamellam magnam concolorem ferente. Facies obscure ochracea, opací. Cilia inferiora oculorum nigra. Thoracis dorsum nigro-viride, polline subfusco leviter aspersum, modice nitens. Abiomen obscure viride. nitens. Hypopygium majusenlum, nigrum, lamellis lunalis. dilute lutescentibus. Coxac luteae, posteriores obsenre cincreo-maculatae. Pedes lutei, tarsis ommilsus inde ab articuli primi apice obscurioribus, anticis subfuscis, posterioribus fuscis. Tegulate pallidae, nigro-ciliatae. - (Lake Gcorge; Osten-Sacken.)

83. Paraclius claviculatus, nov. sp. $\sigma^{\top}$. Aeneo-viridis, pedibus favis, facie albidâ, antennis mufis, articulo tertin praeter basim nigro, sela brevissime pubescente, apicem versus modice incrassatit. - Long. corp. 1! lin. Long. al. 1! lin.

Frons chalybed nitens. Antennae rufae articulis primis duobus superne. terlio practer basim nigris; seta antennalis nisra, longiuscula, brevissime puberula, apice modice incrassato. Facies albopollinosa. Cilia inferiora oculorum albida. Thoracis dorsum ex viridi chalybescens, villâ medià obseure cupreo-aeneà et utrinque maculì atrâ. Seupllum cum dorso thoracis roncolor. Pleurac ex 
glauco cinereae. Abdomen aeneo-viride. Hypopygium longiusculum, subsessile, nigrum, lamellis fuscis, e basi latiore longe attenuatis, nigro-pilosis. Coxae anticae totae, posteriores in apice flavae. Pedes flavi, posticorum femoribus et tibiis in apice extremo fuscis, tarsis anterioribus praeter basim imam nigro-fuscis, posticis totis nigris. Cilia tegularum nigra. Alae obscure cinereae, subnigricantes, ultimâ venae quartae parte minus arcuatim ductâ quam in congeneribus plerisque. - (New Rochelle N. Y.; Osten-Sacken.)

84. Tachytrechus binodatus, nov. sp. $\delta$. Viridi-aeneus, antennis pedibusque luteis, setâ antennali perlongâ, tenuissimâ, binodatâ, tarsis praeter basim nigris. - Long. corp. $3 \frac{1}{6}$ lin., Long. al. $2 \frac{5}{12} \operatorname{lin}$.

Frons viridi-aenea, subopaca. Antennae luteae, articulo secundo subobsoleto, tertio minuto, subrolundo, adversus apicem nigro-fusco; seta antennalis perlonga et tenuissima, lamellis duabns, alterâ mediâ, alterâ apicali, illâ totâ, hac praeter basim candidam atris instructa. Facies subaurea, angustissima, infra paullo dilatata. Cilia oculorum inferiora lutescentia. Thoracis dorsum et scutellum viridi-aenea, nitida. Pleurae et abdomen ex aeneo viridia, polline sublutescente aspersa, modice nitentia. Hypopygium ex chalybeo viride, lamellis mediocribus fusco-nigris. Pedes cum coxis anticis lutei, posticorum femoribus tibiisque in apice extremo nigris. Femora antica valida, utrinque pilis lougiusculis nigris vestita; femora intermedia tenuia, infra nudà; femora postica ante apicem selâ unicâ instructa. Tibiae anticae infra et supra nigro-setosae; tibiae intermediae elongatae, praeter setas ordinarias apicem versus setulis confertis nigris praedilae. Tarsi omnes simplices, praeter basim luteam nigri, antici eximie, intermedii valde abbreviati, postici tibiis sub. aequales. Tegulae pallidae, nigro-cilialae. Alae breviusculae, cinereae, adversus costam obscuriores, venâ transversâ posteriore eximie arcuatâ. - (Saratoga; Osten-Sacken.)

85. Euthera tentatrix, nov, sp. \&. Nigra, thoracis dorso vittis albo-pollinosis ornato, capite pedilusque subfulvis, orbitis tamen, occipitis dimidio superiore, tibiis tarsisque nigris; alne hyalinae, basi venarumque initiis saturate fulvescentibus, margine costali fasciisque duabus nigris. - Long. corp. $2 \frac{3}{4}-2 \frac{5}{6}$ lin., Long. al. $2 \frac{1}{4}-2 \frac{1}{3}$ lin.

Nigra, nitida, nigro-pilosa. Caput ex ochraceo fulvum, frontis lateribus orbitisque facialibus nigris, nitidis, albo-pollinosis, inter 
antennas famen et oculos polline omnino destitutis. Primus antennarum articulus ex ochraceo rufus. secundus badius, tertius niger; sela antennalis biarticulata, breviuscula, badia. Palpi ex ochraceo fulvi. Occipitis dimidium superius fere totum nigrum. In thoracis dorso vitlae quatuor polline albo aspersne conspiciunlur, intermediae lato intervallo separatae, laterales ohsoletae. Scutellum et abdomen ovale polline albo levissime aspersi. Femora ex ochraceo fulva, tibiae et tarsi nigri. Alae hyalinae. imâ basi venarumque longitudinalium parte basali salurate fulvescentibus. reliquis venarum parlibus nigris; vitta costalis angusta, fasciae duae et alula praeter basim nigrae; vena longiludinalis quinta anguste nigro - limbala. (New-York; Osten-Sacken.)

Nota. Euthera novum Tachinidarum genus constituit, insigne oculis nudis, facie nudâ et carinalâ, antennis linearibus facie longioribus et sełâ nudâ instruclis, alarum venâ longitudinali tertiâ rectâ et cellulâ posleriore primì truncatâ, longe ab alae margine clausà. Selae frontales et myslacinac breres et tenues; abdomen ovatum, margine postico segmenti terlii et segmento quarto sefas mediocres gerentibus.

s6. Calobata platycnema, nov. sp. ㅇ. Lutea, libiis nigro-fuscis, compresso-dilatatis, alis nigro-trifasciatis. - Long. corp. $3 \frac{1}{2}$ lin., Long. al. $3 \frac{5}{12}-3 \frac{1}{2}$ lin.

Lutea. Frons ferruginea, nigro-maculala. Antennae nigrae, arliculo lertio oblongo - ovalo, setâ tenui, nudí. Clypeus fuseus, lalus, sed non prominens. Proboscis crassa; palpi fusci. Thoracis dorsum opacum, pleurae nitidae. Scutellum et abdomen obscurius lutea vel subfusca, terebrâ semper nigro-piccâ vel nigrâ. Pedes anlici lutei, tibiis modice compressis et primo farsorum articulo praeter apicem nigro-fuscis; femora intermedia obscure lutea. apicem versus subfusca et annulo latiusculo pallido ornata; femora postica fusca, triente basali et annulo subapicali latiusculo pallidis; tibiae posteriores fusco-nigrae, compresso-dilatafac. adversus basim et adversus apicem tenuiores; tarsi posteriores sordide lutei vel dilute subfusci. Alae subhyalinae, apice, fasciâ mediâ latissimâ et fasciâ subbasali angustâ nigris, cellulâ posteriore primà anguste apertâ, anali valde elongatâ. - (New Granada.)

87. Calobata angulata. nov. sp. o et f. Nigra, metanoto, pleuris abdomineque subchalybeis, cupite latericio, femorum posteriorum annulo subapicali obliguo. posticorum basi tarsisque an- 
ticis praeter basim albis, alis nigro-Irifasciatis, cellulâ anali elongatâ. - Loug. corp. $3 \frac{7}{12}$ lin., Long. al. $3 \frac{5}{12}$ lin.

Caput latericium, opacum, maculà mediâ frontis nigrâ. Antennae nigro-fuscae, articulis basalibus lutescentibus, terminali oblongoovato, setâ tenui, nudâ. Clypeus latus, sed nou prominens, sordide latericius vel fuscus; proboscis percrassa, palpis fuscis. Thoracis dorsum opacum, nigricans, humeris sordide latericiis. Metanolum, pleurae et abdomen subchalybea, modice nitentia. Pedes nigri, femoribus anticis nigro-fuscis, posterioribus adversus apicem fuscis et ante apicem annulo obliquo albo ornatis, posticorum basi albâ, tarsis anticis albis, dimidio tamen basali articuli primi nigro. Alae subhyalinae, fasciâ mediâ latissimâ, maculam majusculam elutam includente et fasciâ subbasali angustâ nigris; cellula posterior prima anguste aperta, analis valde elongata. - (New Granada.)

88. Calobata maculosa, nov. sp. $\sigma^{\top}$ et + . Chalybea, capite rufo, alis pure hyalinis, fasciis tribus et apice nigris, cellula anali mediocri. - Long. corp. $3 \frac{1}{2}$ lin., Long. al. $3 \frac{1}{3}$ lin.

Chalylica. Caput rufum, fronte opacâ et immaculatâ. Anten. nae ex ochraceo rufae, articulo iertio rotundato - ovato, setâ tenui, nudâ. Clypeus modice latus, prominens; proboscis crassa. Thoracis dorsum ex chalybeo nigrum, opacum, in exemplis illaesis vittis fasciisque glaucescentibus variegatum. Pleurae chalybeae, albidopollinosae. Abdomen chalybeum. Coxae chalybeo-nigrae, albo-micantes; pedes antici nigri, femorum annulis duobus lutescentibus, altero basali, altero subapicali, primisque duobus tarsorum articulis, apice secundi excepto, albis; femora intermedia lutea, apice ipso et annulo subapicali nigris, adjecto interdum annulo subbasali latissimo. obsoleto, subfusco; femora postica lutea, annulis duobus, altero subbasali latissimo et altero subapicali angusto apiceque ipso nigris; tibiae posteriores cum tarsis nigrae, primo tamen tarsorum posticorum articulo praeter trientem apicalem albo. Alae pure hyalinae, apice fasciisque tribus nigris, fasciâ subbasali angustissimâ, intermediâ latiusculâ, difformi, guttulam hyalinam, in cellulae discoidalis apice sitam includente, tertiâ mediocri, arcuatâ; cellula posterior prima anguste aperta, cellula analis mediocris, non elongata. (Cuba; Gundlach.)

89. Calobata nebulosa, nov. sp. ठ. Rufescens, abdomine ex nigro-chalybeo, setâ antennarum subnudâ, clypeo prominente, femoribus posticis luteis, femoribus anticis tibiisque omnibus fusco- 
nigris, basi tarsonum omnium albâ, apice nigro. alarum disco levi-

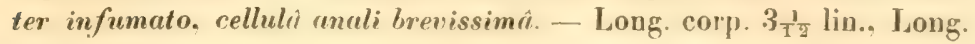
al. $2 \frac{2}{3} \operatorname{lin}$.

Caput rufum. fronte immaculati, opacâ, fasciis tamen lateralibus subnitidis, obsoletissime albido-pollinosis. Antennae ex fusco ochraceae, articulo tertio ovato, setâ mediocri, breviter puberulâ. Clypeus modice latus, prominens; proboscis crassissima. Thorax rufescens, modice nilens. Abdomen ex nigro chalybescens. appendicibus inferis hypopygii pallidis. Coxae rufescentes. Pedes antici fusco-nigri, tarsis albis, inde ab articuli secundi apice nigris; femora posteriora lutea, anumlo subapicali nigricante obsoletissimo: tibiae posteriores fusco-nigrae; tarsi posteriores nigri, articulo primo practer apicem albo. Alae hyalinae, apicem versus obsoletissime cinerascentes, in disco leviter infumatae; cellula posterior prima anguste aperta, cellula analis perbrevis. - (Florida.)

90. Culobata placida. nov. sp. ‥ Rufo-testucea, set̂̀ antennarum plumata. clypeo prominente, pedibus unticis nigris, tarsis tamen proeter apicem albis, pedibus posterioribus lnteis, alis subhyulinis, maculà subrotundatá fuscà. permagná notatis, cellulà anali brevi. - Long. corp. 3 lin.n Lons. al. $2 \frac{2}{3}-2 \frac{3}{4}$ lin.

Caput ex luteo rufum. Froms immaculata. opaca, viltis lateralibus laliusculis subnifidis, polline alto leviler aspersis. Antenna ex ochraceo rufae vel subfuscae, articulo tertio ovato, sctá breviter plumalâ. Clypeus modice latus, prominens. Abdomen subfuscum vel fuscum, terebrá semper nigrâ. Coxac ex fusco luteae; pedes autici fusco-nigri. femoribus basim versus Intescentibus. articulis primis duobus tarsorum albis; pedes posteriores sordide lutei, tibiis tarsisque obscurioribus. Alac sublyyalinae, adversus apicem obsolelissime cinerasceutes, maculâ permagnâ subrotundalâ. ex nigro fuscâ ornatae; cellula posterior prima anguste aperta. cellula analis perbrevis. - (Cuba: Fundlach.)

91. Lauxania flaviceps. nov. sp. ठ'. Nigra, nitida. rapite cum antennis luteo. tertio harum articulo ovato. set ì subnudî. alis hyalinis. - I, ong. corp. $1 \frac{1}{3}$ lin. Inong. al. $1 \frac{2}{3}$ lin.

Nigra. nitida. Caput Inteum. ocellorum regione viltulisque lateralibus frontis infra abbreviatis. nigris. Antennae luleac. articulo tertio ovato, selâ subnuda. Facies subtumida. nitens: genae latissimae. Pedes ex fusco nigri. genibus ef extremo libiarum apiec llavesentibus, vel sordide exalbidis. Halteres alli. Alar hvalinar. 
venis pallidis, in ipso alarum apice cinereis. - (District Columbia: Osten-Sacken.)

92. Ephydra obscuripes, nov. sp. $\delta$ et 오 Obscure viridis, abdomine glauco - viridi, omnino opaco. pilo laterali in terfio antennarum articulo nullo, facie albo-pollinosa, margine oris in mare pilis rarioribus brevioribusque, in foemina confertioribus longioribusque vestito, pedibus totis obscuris. - Long. corp. 2-2 $\frac{1}{\frac{1}{12}}$ lin.. Long. al. $2 \frac{1}{6}$. lin.

Obscure acneo-viridis. Frons plerunque concolor, raro chalybescens, marginibus lateralibus polline fusco vel fusco-einereo aspersis; opacis. Antennac nigrae, pilo laterali articuli tertii nullo, setâ - superne breviter pubescenic. Facies albo-pollinosa, margine tamen summo, inter antenuas sito fusco-pollinoso; oris margo in mare pilis rarioribus tenuioribusque. in foeminâ confertioribus validioribusque ciliatus. Pleurae ex viridi glaucescentes, polline pallido tectae. opacae. Dorsum thoracis polline fusco aspersum, subopacum. Scutellum aeneo-viride, modice nitens. Abdomen ex glauco viride. totum opacum, rolore marginis postici segmentorum singulorum plerumque magis in einereum vergente; ultimum segmentum abdominis maris praccedenti aequale vel paulo longius; hypopygium parvum. Pedes virides, opaci, tarsis nigris. Alae obscure cinereae.

- (Massachusetts; Osten-Sacken.)

93. Drosophila multipunctala. nov. sp. つౌ. Lutescens pectore pedibusque pallidissimis, alis hyalinis, punctis subtredecim nigris in utrágue alta. - Long. corp. $\frac{3}{4}$ lin., Long. al. $1 \frac{1}{4} \mathrm{lin}$.

Lulescens, capite cum antennis concolore, abdomine praeter basim subfusco, pectore, ventre pedibusque pallidissimis. Alae hyalinae, levissime cinereo-nebulosae, nigro-punctatae; in utrâque alâ puncta marginalia quatuor, tria majora in apicibus venarum longitudinalium primae, secundae et tertiae, quartum minutissimum in apice venac longitudinalis primae, conspiciuntur; vena transversa minor puncto nigro includitur, cui in venâ longitudinali tertiâ duo minutissima praemissa, tria majora, apicali hujus venae non compulato, postposila sunt; vena transversa posterior punetis duobus subconfluentibus nigris, in utroque fine collocatis notatur; punctum denique nigrum in segmento paenultimo venae longitudinalis quartae, adversus apicem nigrieantis, adest. - (District Columbia; OstenSacken.) 
94. Gaurax anchora, nov. sp. 8 et $q$. Flavus, thoracis maculis duabus et vittâ in scutellum productâ, metanoto et abcomine praeter basim, marines laterales et apicem atris. - Long. corp. 1 1/6-1 1/4 lin., Lons. al. 1 1/6 lin. Flavus, nitens. Caput cum antennis concolor, setâ antennarum et verticis puncto nigris. Thoracis dorsum praeter vittam atrom, in scutellum productam maculis duabus atris, ad marginem anticum sitis notatur, quae cum vittâ cohaerent, ita ut anchorae forma efficiatur. Netanotum atrum. Abdomen atrum, basi, marginibus lateralibus et apice flavis, extremo tamen terebrae apice atro. Pedes dilute flavicantes, tibils tarsisque anticorum subfuscis, fuscis vel nigro-fuscis, posticorum tibits in dimidio basali plerumque infuscatis vel fuscis. Alae hyalinae. - (New York; Osten Sacken.)

Nota 1. Vitta atra thoracis interdum linea tenui flavâ dividitur; pedum pictura valde variat.

Nota 2. Osten-Sackenius larvas hujus speciel gregatim chrysalidem Cecropiae folliculo inclusam devorantes observavit.

95. Phora clavata, nov. sp. 5 et q. Migerrima, modice nitens, setis frontis omibus sursum versis, antennis rufis, palpis luteis, alis hyalinis, costâ brevissime ciliatâ, venarum validarum secundâ simplici, tibiis intermediis superne setis binis, reliquis unicâ ar:atis. Long. corp. 1 1/3-1 1/2 1in., Iong. 1. 1 1/3- 1 5/12 Iin.

Crassa, nigerrima, modice nitens. Frons lata, convexiuscula, punctata, setis omnibus sursum versis. Antennae ex ochraceo rufae; palpi latiusculi, lutei. Apex abdominis, praesertim maris, magis nitens, quam reliquum corpus. Pedes antici sordide testacei, Pusco liturati; pedes postici nigri vel nigro-picei, genibus testaceis; femora postica latissina; tibiae 
intermediae superme prope basim setas binas, reliquae unicam gerentes. Hal teres nigri. Alae hyaline, costâ nigrâ brevissime ciliatâ; venorum validarum secunda simplex, apice dilatato; venarum tenuium prima prope basim eximie flexa. (District Columbia; Osten Sacken).

Nota. Faec species Phorae femoratae prosima est, sed antennarum palporumque colore facile distinguitur.

96. Phora mierocephala, nov. sp. . Migra, opaca, capite parvo, setis frontalibus omibus sursum versis, antennis palpisque fusco-nigris, alis cinereo-hyalinis costâ breviter ciliatâ, venarum validarum secundâa furcatâ, tibiis internediis superne setulis binis, reliquis unich amatis. - Lon. 1 2/3 lin., Long. al. $15 / 6-111 / 12$ lin. 
Tenuis, nigra vel fusco-niera, basi abdominis saepe sordidissime lutescente. Caput parvum; frons lata, brevis, subconvera, setis omibus sursum versis. Antennae nigrae, palip nigro-fusci. Pedes nigro-picei, trochanteribus, genibus, tibils tarsisque ex fusco testaceis; femora nostica reliquis paullo crassiora; tiblae intermediae superne prope basim setas binas, reIiquae setulam unicem gerentes. Halteres exalbidi. Alae cinereo-hyalinae, venis omibus saturate fuscis, costâ breviter ciliatâ; venarum validarum secunda furcata, tenuium prima prope basim Ilexa, quarta omino obsoleta. - (District Columbia; Osten-Sacken.)

Nota. Foeminam Phorae, venâ secundà simplici instructam posideo, quae in reliquis notis omnibus cum Phorâ microcephalá mire congruit, ita ut eam varietatem singularem hujus esse persuasum habeam.

97. Phora pachyneura, nov. sp. ․ Iigra, opaca, antennis palpisque concoloribus, setis fronatalbus omibus sursum versis, facie nitida, alis cinereis, costâ brevissime ciliata, venarum validarum secunda crassissimä, furcata. - Long. corp. $13 / 4$ lin. Long. al. 1 11/12-2 lin.

Modice crassa, nigra, abdomine opaco, thorace et fronte subopacis, facie nitida. Caput parvum, nigrum, antennis palpisque concoloribus; frons lata, brevis, subconvexa, setis omnibus sursum versis. Pedes nigro-picei, eenibus luteis, femoribus posticis modice latis; tibiae intermediae superne prope basim setulis duabus, anticae unicâ minutissimâ instructae, posticae inermes. Halteres nigrii. Alae cinerae, costâ brevissime ciliata; venae validae nigro-fuscae, secunda crassima, furcata; venae tenues subfuscae, apicem versus subtiliores et dilutiores, prima prope basim flexa. quarta subobsoleta et valde abbreviata. - (Russian Ancrica.)

98. Phora incisuralis, nov. sp. +. Nigra, 
humeris, pleuris, primo abdominis semento, segmentorum reliquorum singulorum marginae postico pedibusque, flavescentibus, setis frontalibus omnibus sursum versis, antennis palpisque rufoochraceis, alis subhyalinis, costâ brevissime et subtilissime ciliatâ, venarum validarum secundâ fureata. - Long. corp. 1 1/3 lin., Long. a.1. $15 / 12$ lin.

Caput nigrum; frons lata, subplana, nitida, rare et subtilissime punctulata, setis omnibus, sursum versis; antennae rufo-ochraceae, latere externo obscuriore; palpi laetius ochracei lati. Thoracis dorsum, scutellum et metanotum nigra, subnitida. Humeri flavescen- 
tes; pleurae flavae, nigro-maculatae. Abdomen nigrum, opacum. segmento primo fere toto, segmentorumque reliquorum marginibus posticis luteis. Venter practer apicem flavesccns. Pedes cum coxis dilute lutescentes; femora postica value lata. apice nigro; tibiac anticae superne setularum serie, intermediae prope basim setis binis instructae; tibiae posticae in latere externo serie setularum armatae. Halteres dilutissime flavicantes. Alae hyalinae. coslì brevissime et subtilissime ciliatà, venis subfuseis, validarun secundâ furcatâ, tenuium ullimâ reliquis subtiliore et pallidiore. auxiliari valde abbreviatâ. - (Washington; Osten-Sacken.)

99. Phora nigriceps, nov. sp. ऽ et $q$. Flava, capile nigro, antennis concoloribus, setis anticis frontis deorsum rersis, pulpis flavis, anticis abdominis segment is saepe fere totis religuorumque lateribus fuscis vel nigris. alis subhyalinis, ciliis costae longiusculis, venarum validarum secunda furcatâ. - Long. corp. $1_{T_{2}}-$ $1 \frac{1}{6}$ lin., Long. al. $1 \frac{1}{6}-1 \frac{1}{4}$ lin.

Flavescens, thoracis colore saepe in rufum, interdum in badium vergente. Caput nigrum; frons lata, subconvexa, subliliter punctulata, lineâ longitudinali subtilissime exsculptî, setis anlicis deorsum versis. Antennae nigrae, in immaturis fuscae; palpi flavi. Pleurae infra alas et inter coxas posteriores plerumque nigro-lituratac. Metanolum plerumque fuscum vel nigricans. Abdomen in exemplis immaturis totum luteum, in maturis segmenta prima praeter margines posticos fere tota segmentorumque reliquorum latera fusca habet. Pedes pallide flavicantes, extremo femorum posticorum apice nigro, tibiis anticis mulicis, reliquis superne serie setularum brevium subciliatis. Halteres pallidi. Alae subhyalinae, dilutissime ex cinereo sublutescentes, ciliis costae mediocribus, venis fuscis. validarum secundâ furcatà, tenuium quartâ iutegrà et perspicuà. - (Washing-
ton; Osten-Sacken)

100. Phora scalaris. nov. sp. O et t. Flana. capte mum antennis el palpis concoloribus, murgine postico segmenti ulslominalis primi anguste, religurorum singulorum margine postico of lateribus lutissime nigris. setis anticis frontis deorsum versis. alis subhyalinis, ciliis costae mediocribus. renumum ralidurnem serundi furcala. - Long. corp. $1_{\frac{1}{3}}^{\frac{1}{3}}-1$ lin. Loug. al. 1 $1 \frac{1}{1}-1$ lin.

Flavescens. thoracis colore interdum sublatericio. Caput cum antennis et palpis flavescens. Frons lata, subconvexa. subliliter punctulata, lineâ longritadinali tenuissina laevigatio. selis andieis deor- 
sum versis. Pleurae immaculatae. Metanotum flavescens. Abdomen luteum vel ochraceum, segmenti primi margine postico anguste segmentorumque reliquorum marginibus lateralibus et postico latis. sime nigris. Pedes pallide flavicantes, femorum posticorum apice nigro, tibiis omnibus superne serie setularum brevium subciliatis. Halteres pallidi. Alae subhyalinae, ex cinereo dilutissime sublutescentes, ciliis coslae mediocribus, venis fuscis, validarum secundâ furcatâ, tenuium quarlâ integrâ et perspicuâ. - (Cuba; Pocy, Gundlach.) 




\title{
Diptera Americae septentrionalis indigena.
}

\author{
Descripsit
}

\section{H. L $\quad \boldsymbol{o} \quad \boldsymbol{e} \boldsymbol{w}$.}

C e n t u r i o c t a va.

1. Dixa clavata.

2. Longurio testacers.

3. Dilophus dimidiatus.

4. Nothomyia scutellata.

5. - calopus.

6. Nemotelus carbonarius.

7. Pangonia rusa.

8. Lepidoselaga recta.

9. Thereua comata.

10.

11. Psilocephala longipes.

12.

13.

14.

15.

16.

17.

18. Exoprosopa gazophylax.

19.

20

21

22.

23.

24

25.

26. melampodia.

munda.

laticornis.

melanoprocta.

costalis.

rufuentris.

decora.

trabalis.

sordida.

cubana.

bifurca.

Agassizii.

nubifera.

parva.
27. Anthrax proliosciden

28. - pertusa.

29. - flavipes.

30. - Ceyx.

31. - fuliginosa.

32. - palliatu.

33. - diagonalis.

34. sagata.

35. - curta.

36 - parvicornis.

3\%. - bigradata.

38. - nigricauda.

39. - scrobiculata.

40. - stenozona.

41. adusta.

42. - molitor.

43. - mucorea.

44. Hemipenthes seminigra.

45. Argyromoeba Delita.

$46 . \quad$ - slellans.

47. obsoleta.

48. - pauper.

49. - euplases.

50.5 contigua

51. Plons limbala.

52. Temnoreva purpurascens. 
53. Scenopinus albidipennis

54. Empis distans.

55. - violacea.

56. - suavis.

57. - superba.

58. Asyndelus ammophilus.

59. - appendiculalus

60. Hydrophorus aeslumm.

61. Gymnochaeta alcedo.

62. Pyrellia centralis.

63. - setosa.

64. Loxocera pectoralis.

65. - pleuritica.

66. Psila lateralis.

67. bivillata.

68. collaris.

69. dimidiata.

70. - sternalis.

71. - levis.

72. Chyliza apicalis.

73. Hydrellia conformis.

74. Scatella mesogramma.

75. Hippelates dorsalis.

76. Oscinis carbonariu.
77. Oscinis dorsulis.

78. Siphonella reliculata

79. Elliponeura debilis.

80. Rhicnö̈ssa albula.

81. - parvula

52. Phyllomyza nilens.

83. Agromyza selosa.

84. - simplex.

85. - virens.

86. - magnicornis.

87. - angulata.

88. - melampyga.

89. - coronala.

$90 . \quad$ - longipennis.

91. - marginata.

92. - parvicornis.

93. - neplis.

94. Lobioptera indecora.

95. - leucogastra.

96. Leucopis simplex.

97. Cacoxenus semilutens.

98. Trigonomelopus villatus.

99. Phytomyza nervosa.

100.

genualis.

1. Dixa clavata, nov. sp. $\sigma^{\prime}$ et $\mathcal{T}$. - Alarum costa, vena auxiliaris tola, venarum longiludinalium prima praeter apicem, secunda et tertia in basi favae; venae religuae fuscae et anguste fusco.limbatae; apex tibiarum posticarum valde incrassatus, ater. Long. corp. $2 \frac{1}{12}$ lin., Long. al. $2 \frac{5}{12}-2 \frac{1}{2}$ lin.

Caput atrum, palpis concoloribus; frons lata. nitidissima, utrinque tenuiter flavo-marginala; proboscis fusco-nigra; antennarum scapus flavus, flagellum praeter basim flavam fuscum. Thoracis dorsum opacum, flavescens, vitlis tribus fuscis, quarum media lineâ tenui pallidâ dividitur. Scutellum fusco-testaceum. Metanotum nigrum, marginibus tamen lateralibus et antico flavo-testaceis. Pleurae vittis alternantibus fusco-nigris et flavidis pictae. Abdomen nifidum, sordide nigro-cinereum. Pedes flavi; coxae anticae praeter apicem fuscae; femorum omnium apex ater; tibiarum anteriorum 
apex angustissime, posticorum latius aler, hic valde incrassatus: tarsi adversus apicem nigri. Halteres flavi. Alae hyalinae, margine apicali el cellulae analis dimidio basali infuscatis; costa et vena longitudinalis prima practer apices, vena auxiliaris tola et venarum quartae et quinlae basis flavae; venae reliquae fusco-nigrae et colore fusco-nigro tenuiter limbalae, venulae tamen transversalis limbo latiore. - (Lenox, Massachuselts; Osten-Sacken.)

2. Longurio testaceus, nov. sp. \%. - Testaceus, vittis thoracis fusco-fermuineis, obsolelius nigro-marginatis, alis cinereohyalinis. venis quintà et septimâ fusco-limbatis. - Long. corp. $14 \frac{1}{2}$ $-14 \frac{3}{4}$ lin., Long. al. 11 lin.

Caput ex ferrugineo testaceum vel ochraceum, latiusculum. breve, oculis mannis, fronte aequali, rostro quam caput breviore. crassinsculo. palpis mediocribus concoloribus, antennis longitudinem capilis paulo superantibus, ex ferrugineo ochraceis. pilosis. articulis flagelli decem, inferis globosis, sequentibus tenuioribus longioribusque. Thorax polline pallido opacus, villis ordinariis ex fusco ferrugineis, interiore tamen lateralium margine, ubi ad suturam accedit, lineolâ alrâ notato. Scutellum el melanotum cerina, illud longius fluam latius, hoc fusco-maculatum. Abdomen longissimum, tenue, testaceum, modice nitens, marginibus segmenti ultimi integris: hypopyrii longiusculi el non incrassali lamella supera profunde cmarginata, forceps magnus, articulo basali simplice, terminali reflexo, permagno, foliaceo. Pedes longi. terues, ex fusco lutei, fe. moribus tibisque in apice nigris, larsis apicem versus fuscis. Halleres pallidi. Alae cinereo-hyalinae, cellulâ costali sublutescente. venis costali, auxiliari et longitudinali primà subfuseis, reliquis nigro-fuscis, longifudinalibus quinlà el septimâ margineque axillari fusco-limbatis, stigmatis dimidio anteriore subfusco, posteriore decolore. - (Massachusetls; Osten-Sacken.)

Nota. Longurio. genus novum in Tipulinorum numerum adscri bendum, capite pro portione minulo el antennarum perbrevium flagello articulis decem composito insignis est. Rostrum capite reliquo brevius, crassum; palpi mediocres, articulo ultimo quam antecedens paulo Iongiore: abdumen lenue, longissimum; hypopygium non incrassatum, similius Limnobiae quam Tipulae hypopygio, forcipalum. articulis terminalibus forcipis magnis. foliaceis. 
3. Dilophus dimidiatus, nov. sp. ㅇ. - Niger, capite elongato, halteribus et alis concoloribus, thorace toto pedumque anteriorum coxis el femoribus, apice horum excepto, rufis. - Long. corp. $2 \frac{5}{6}$ lin., Long. al. $2 \frac{7}{12}$ lin.

Caput angustum, valde elongatum, nigım. Thorax totus rufus, scutello et metanoto concoloribus, pectine priore fusco, subinterrupto. Abdomen tolum nigrum. Coxac posticae nigrae, anteriores rufae, colore articuli secundi in fuscum vergenle. Pedes nigri, femoribus anterioribus praeter apicem nigrum rufis, libiis anticis prope basim, in medio et in apice spinosis. - (New Vork; Osten-Sacken.)

Nota. Dil. dimidiatus a Dil. spinipede Say femoribus posticis nigris, non rufis, a Dil. thoracico Say scutello et metanoto rufis, non nigris discrepat.

4. Nothomyia scutellata, nov. sp. ठ et \&. - Obscure viridis vel ex viridi chalyben, nilida. antennis pedibusque nigris, tarsorum tamen posteriorum basi late albidâ, sculello spinis perbrevibus instructo praeter basim halleribusque flavis. - Long. corp. $2 \frac{2}{3}-2 \frac{3}{4}$ lin., Long. al. $2 \frac{5}{1} \frac{5}{2}-2 \frac{1}{2}$ lin.

Caput nigro-viride vel nigro-chalybeum, nitidum, occipite antennisque nigris. Thorax totus viridis, nitidus, dorsi colore saepe in chalybeum vergente. Scutellum praeter basim viridi.chalybeum flavum, dentibus perparvis concoloribus armatum. Abdomen planum, nigro-chalybeum, modice nitens, ventre concolore. Pedes nigri, tarsorum posteriorum articulo primo exalbido, in extremo apice leviter infuscato, articulo secundo vel dilutius vel suturatius subfusco, interdum praeter apicem sordide exalbido. Halteres flavi. Alae subinfumatae, cellulis stigmalicali et ınarginali subfuscis, venis validioribus fuscis; vena longitudinalis tertia simplex, ramulo antetiore destituta. - (Cuba; Gundlach, Poey.)

Nota. Nothomyia, novum Sarginorum genus corporis formâ ac figurâ inter Microchrysam et Oxyceram intermedium, cum illâ colore metallico. cum hac ultino antennarum articulo minuto ovato el scutello spinis duabus armato congruit, ab utrâque cellulâ submarginali unicâ discrepat; oculi maris subcontigui; frons foeminae subangustala antice valde dilatala est; ocelli in triangulum subaequilaterum dispositi; posteriores alarum cellulae quinque. - Oxyceram metallicam Wiedemanni Nothomyiam esse certissime credo. 
5. Nothomyia calopus, nov. sp. ․ - Vividis, nitida, scutello concolore, abdominis disco violaceo, antennis pedibusque nigris, femorum omnium triente apicali tibiarumque intermediarum dimidio secundo ex rufo ochraceis, primis duobus tarsorum posteriorum articulis flavescenti-exalbidis. - Long. corp. $2 \frac{1}{4}$ lin., Long. al. $2 \frac{1}{6}$ lin.

Caput viride, modice nitens, antennis vigris. Thorax tolus viridis, valde nitens. Scutellum concolor, spinis duabus mediocribus nigris armatun. Color abdominis nitidissimi pulchre violacens ad. versus margines in chalybeum, in marginibus ipsis in viridem abit. Venter viridis vel aeneo-viridis, modice nitens. Pedes nigri, femorum omnium triente apicali tibiarumque intermediarum dimidio ullimo colore ex rufo ochraceo pictis, farsorum posticorum articulis primis duobus exalbidis vel dilute flavescentibus. Halteres flavi. Alae cinereo-hyalinae, venis validioribus fuscis, cellulis stigmaticali et marginali ex luteo subfuscis. - (Cuba; Gundlach.)

6. Nemotelus carbonarius, nov. sp. $\delta$ ef \&. - Nudus, ater, nitidus, antennis concoloribus, fronte immaculat $\vec{u}$, lineâ laterali pallida thoracis nullà, femoribus praeter apicem flavescentem atris, tibiis anterioribus subfuscis, posticis atris, basi et extremo omnium apice flavesrentibus. - Long. corp. $1 \frac{2}{3}$ lin., Long. al. $1 \frac{7}{\frac{1}{2}}$ lin.

Nemotelo unicolori simillimus, sed paulo minor et thoracis li. neâ laterali pallidâ nullâ diversus. Halteres superne subfuscai. Oculi maris subcontigui. - (Lenox, Massachusetts; Osten-Sacken.)

7. Pangonia rasa, nov. sp. ㅇ. - Cinerea, breviter albo-pilosa, abdomine fusco, segmentorum singulorum limbis posticis cinereis, proboscide capilis longiludinem paulo superante, palpis el antennarum basi luteis, pedibus fusco-testaceis; alae cineveo-hyalinae. cellulis posterioribus omnibus aperlis. - Long. corp. $5 \frac{1}{2}$ lin., Long. al. $4 \frac{3}{4} \operatorname{lin}$.

Cinerea, opaca, breviter albo-pilosa. Caput tolum cinereum; frons aequalis, lineis impressis duabus inde ab ocellis ad mediam usque frontem ductis. Antennae tenues; arliculi primi duo sordide lutei vel ex subfusco lulei, bicrissime nigro-pilosuli; articulus tertius non dentatus, fusco-niger, imâ basi fusco-ferrugineâ. Proboscis capitis longitudinem paulo superans, fusco-nigra, labellis crassiusculis. Palpi recti, tenues, acuti, lutei. leviter albo-pollinosi, articulo primo albo-piloso, secundo fere tolo nigro-pilosulo. Thoracis dorsum colore schislaceo trivitlalum. Sculellum concolor. Abdominis color fuscus, adversus latera. angulos posticos et marginem posti- 
cum segmentorum singulorum in latericio-testaceum vergens; pili abdominis breves, in partibus fuscis omnes nigri, in dilutius pictis omnes albi. Femora fusco-testacea, breviter albo-pilosa; tibiae anteriores concolores vel paulo obscuriores, posticae fuscae, omnes brevissime nigro-pilosulae; tarsi fusco-nigri, nigro-pilosuli, imâ basi fusco-testaceâ. Halteres fusci. Alae cinereae, venis fuscis, auxiliari et secundae basi dilutioribus, stigmate subfusco, cellulâ submarginali secundâ non appendiculatâ, cellulis posterioribus omnibus apertis. - (Northern Wisconsin; Kennicol.)

8. Lepidoselaga recta, nov. sp. ․ - Antenuae el frontis pars inter has et callum frontalem sita ochraceae. - Long. corp. $3 \frac{1}{2}$ lin., Long. al. 3 lin.

A Lepidoselagâ lepidotâ Wied., cui valde similis est, differi antennis dilutius ochraceis, fronlis parte ante callum nigrum sitâ ex subfusco ochraceâ, libiis omnibus etiam crassioribus, termino iuter colorem nigrum alarum et apicem dilutiorem magis recto, pilis denique aeneo-micantibus longioribus tenuioribusque. - (New Granada.)

Nota. Quem Hadri lepidoti marem descripsit Bellardius Sagg. I. 75., is jure ad Lepidoselagam rectam refertur, sed foemina ad Jepidoselagam lepidotam Wied. videtur pertinere. Fijus I.epidoselagae lepidotae exempla quum a Wiedemanno ipso nominata viderim tum ex insulâ Cubâ advecta possideo. Prorsus eandem esse, hanc atque Haematopotam crassipedem Fabr. Antl. 108. 4. arbitror. Nam si Fabricii verba, vel potius foeminae typicae descriptionem in Wiedemanni Auss. Zweifl. I. 220. 10. propositam consulueris, certissimum videbis esse, partem frontis ante callum sitam colore eodem nigro nitere, quo reliquum caput utitur. At in Lepidoselagâ reclâ haec capitis pars est ochracea. Fabricii igitur Haematopotae crassipedis descriptionem nullo modo in hanc speciem quadrare fateberis. Nec quo minus ea cum Lepidoselingâ lepidotâ conjungatur, Wiedemanni verba prohibent, in quibus obscurior alae pars ab apice limpido rectâ separari dicitur. Nam aliarum Haematopotarum colores et picturas spectans jure suo ita loqui poterat, quum in Dipterorum exoticorum libro, alarum signis scilicet deceplus, hanc speciem inter Haematopotas relinquerel. Quodsi ea, quae Wiedemannus in Dipt. Exot. latine scripsit, cum iis comparas, quae in posteriore Wiedenanni libro leguntur, patebit specimen Haematopotae hujus Fabricianum per tempus inter 
haec duo opera interjectum non denuo a viro doclo esse inspectum. Itaque nec nimis mirum, quod in ejus opere seriore post Haematopotan crassipedem Fabricii brevi intervallo Tahanus lepidolus descriptus est. nec inde demonstres haec duo nomina ad diversas species esse revocanda. Quin eo facilius Wiedemannus in errorem induci potuil, quod specimen Haematopolae crassipedis originarium detritum et squamulis illis laele metallicis, quibus bona Lepidoselagae lepidotae exempla mire ornantur, plane erat spolialum. Quod ita esse ex comparatione verborum Fabricii cum Wiedemanıi verbis abunde liquet.

9. Thereua comata. nov. sp. 3. - Nigra, capitis thorarisgue colore in fuscum vergente. segmentorum abdominalium singulorum margine postico albido, tibiis tarsorumque basi fuscis; alae subfuscue, fusco variegulae, cellulà posteriore quarta in ipso alae margine clausà. - Long. corp. 5-5 $5_{\mathrm{T}^{\frac{1}{2}}}$ lin., Long. al. $3_{\mathrm{T}^{\frac{5}{2}}}-3 \frac{1}{2}$ lin.

Nigra, pilis longis nigris et flavo-cinereis vestila. Caput polline flavo-cinereo obduclum, occipitis tamen dimidium inferius albopollinosum; pili verticis et frontis nigri, faciei nigri et flavo-cinerei, occipitis fere ommes flavo-cinerei; setulae occipitales nigrae. Anteunae mediocres, uigrae, basi articuli terlii obscure rufâ; arti. culus primus sequentibus simul sumptis aequalis, praeter setas ordinarias infra pilis longis flavo-cincreis instruclus; slylus terminalis brevis. Thoracis dorsum opacum, fusco-nigrum, lineis duabus obsoletis dilutius fuscis. praeter setas ordinarias nigras pilis longioribus nigris brevioribusque dilutissime flavo-cinereis vestitum. Scutellum concolor. Pleurae cinereac, pilis longis dilute flavo-cinereis instructae, fasciculo pilorum ante alarum basim nigro. Abdomen nigrum, subopacum, nigro-pilosum, pilis in segmento primo. in segmentorum sequentium lateribus et in ventre loto flavo-cinereis; margines postici segmentorum onmium pallide flavo-pilosuli, margines ipsi luteo-albidi, segmenti tamen primi niger. Femora nigra, superne pilis flavo-einereis, infra pilis longis nigris. in femoribus anterioribus conferlioribus, in posticis rarioribus validioribusque instructa. Tibiae badiac, extremo apice fusco; tarsi nigri. dimidio priore articuli primi et basi secundi badiis. Selae numerosae pedum nigrae. Alae dilute sub. fuscae, adversus marginem posticum cinereac, fusco-nebnlosae. venis transversis ommibus colore fusco-nigro late circumfusis; venae fusco-nigrae; cellula posterior quarla in alae margine clausa. (Califoruia; Agassiz.) 
10. Thereua candidata, nov. sp. $\sigma^{\star}$ - Cinerea, albopilosa, capite toto abdomineque niveis, tertio antennarum arliculo testaceo, pedibus dilute luteis, femoribus praeter apicem nigris; alae hyalinae, venis luteis, stigmate obsoleto, cellulâ posteriore quartá apertâ. Long. corp. 4 liu., Long. al. $3 \frac{1}{2}$ liw.

Caput totum albo-pollinosum et albo-pilosum, setis occipilis nigris. Anteunae mediocres, tenues; articulus primus tertio subaequalis, nigricans, albo-pollinosus, praeter setas ordinarias nigras infra pilis albis instructus; articulus secundus fuscus, albido-pollinosus; articulus terlius fusco-testaceus, basi et extremo apice saturate fuscis; stylus terminalis mediocris, acutissimus. Proboscis dilute subfusca; palpi lutescentes, pilis longis albis instructi. Thorax nigricans, polline albido cinerascens, totus albo-pilosus, setis tamen ordinariis nigris. Scutellum concolor. Abdominis color niger polline pilisque confertis albis obtectus. Hypopygium fusco-ferrugineum, albo-pilosum. Pedes dilute lutescentes; femora praeter apicem nigra, polline pilisque albis instructa; ultimi duo tarsorum articuli nigro-fusci. Halterum pedunculus nigro-fuscus, capitulum praeter basim nigram albidum. Alae hyalinae, venis luteis, stigmate obsoleto, cellulà posteriore quartâ clausâ. - (Northern Wisconsin, Kennicot.)

11. Psilocephala longipes, nov. sp. ․ - Nigra, pedibus concoloribus, capite lolo, thoracis vittis dorsalibus, pleuris abdominisque fasciis albidis; alae cinereo-hyalinae, venis praeter basim fusco-limbatis, cellulâ posteriore quarta late apertâ. - Long. corp. $3 \frac{5}{6}$ lin., Long. al. $3 \frac{1}{3}$ lin.

Caput totum albidum, froute concolore, admodum angustatâ. Antennae mediocres, tenues, nigrae; articulus primus albo-pollinosus, quam tertius brevior, setulis nigris, brevibus et paucis instructus; articulus tertius acutus, stylo terminali pro portione longiusculo. Proboscis fusca; palpi concolores, breves. Occiput albo-pilosum, superne setis nigris hirtum. Thoracis dorsum albidum, opacum, vittis tribus latis nigris, opacis, integris. Scutellum fuscum, basi nigrâ. Thoracis dorsum et scutellum praeter setas ordinarias nigras pilis brevibus ex flavo albicantibus vestita. Pleurae et coxae totae albicantes. Abdomen nigrum, breviter nigro-pilosum; segmenta prima tria singula limbo postico albo, latera versus in maculas breviter albo-pilosas dilatalo ornantur; segmentum quintum totum albicat. Pedes longi, tenues, toti nigri, femoribus maximâ ex parte breviter albo-pilosulis. Halleres fusci. Alae latiusculae, ci- 
nereo-hyalinae, venis fusco-nigris, practer basim subobsolete fuscolimbatis, stigmale tenui fusco, cellulât posteriore quartà late apertả. - Cuba, Gundlach.)

12. I'silocephala melampodia, nov. sp. \&. - Nigra. pedibus concoloribus, capile, thoracis villis dorsulibus, pleuris, abdominis fasciis imperfectis segmentigue secundi margine postico albis, frontis angustae dimidio superiore opace nigro; alae cinereo-hyalinae, cellula posteriore guarta lute aperti. - Long. corp. $4 \frac{1}{2}$ lin.. Long. al. $3 \frac{5}{6}$ lin.

Caput albicaus; frontis angustae dimidium superius nigrum, opacum. Autennae mediocres, validae, nigrae; articuli primi duo polline albo leviler aspersae, nigro-selosae; articulus tertius latiusculus, modice acutus, stylo terminali pro portione majusculo. Occiput confertim albo-pilosum, superue nigro-setosum. Proboscis nigra; palpi majores, fusci. adversus apicem nigri, parce albo-pilosi. Thoracis dorsum albicans, vittis tribus latissimis schislaceo-nigris, opacis; praeler setas ordinarias nigras thoracis dorsum pilis minutis, plerisque albis, reliquis nigris vestilum. Scutellum schistaceo-nigrum, albido-pilosum, setisque ordinariis nigris armatum. Pleurae albo-pollinosac et albo-pilosae. Abdomen nigrum, nilidum, breviler nigro-pilosum. segmento tamen primo subopaco et pilis longioribus albis vestito; segmenti secundi marso posticus albidus, ulringue in maculam albido-pilosam dilalatus; segmenti tertii margo posticus concolor. sed maculae latera!es albidac ut in segmenlo praecedenle; seğmenlum quartum tolum nigrum; segmenta sequentia duo maximâ ex parte polline albo aspersil, ila ut in utroque fascia albicans, lata, sed interrupta conspicialur. Pedes toti nigri, femoribus fere tolis albido-pilosulis. Halteres fusci. Alae cinereo-hyalinae, venis et stigmate lenui nigro-fuscis, venis transversis obsoletius subfusco-lim. batis, cellulà posteriore quartâ late aperlâ. - (Illinois, OstenSacken.)

13. Psilocephala munda, nov. sp. +. - Vigra, mudius. cula, capile, thoracis lineis duabus, segmentorum abdominalium secundi el tertii marginibus posticis, quinti et sexti maculis lateralibus albis, fronte lati praeter trientem anticum nigra et nitida; alae hyalinae, cellulá posteriore quarli ante alae marginem clausâ. Long. corp. $3 \frac{1}{T^{2}}-4_{\frac{1}{2}}$ lin., l.ong. al. $2 \frac{3}{6}-3 \frac{5}{12}$ lin.

Nigra, nilida. nudinseula. Caput polline conferto niveo, in occipitis disco rariore vestitum: frons lata. practer tricuten anticum 
niveum nigra et nitida. Antenuae breves, nigrae, articulis primis duobus leviter albo-pollinosis, tertio fusco-nigro; articulus primus tertio brevior, nigro-setosulus; stylus terminalis brevis, acutus. Proboscis fusco-nigra; palpi concolores, pilis mediocribus et raris albis vestiti. Occipitis pili breviusculi, albi, setulae nigrae. Thoracis dorsum nigrum, nitidum. lineis duabus confertim albo-pollinosis ornatum, latera versus polline rariore albo aspersum. Scutellum nigrum, leviter albo-pollinosum. Selae thoracis et scutelli nigrae, pili brevissimi albi, in medio dorso nigri. Pleurae albo-pollinosac, pilis mediocribus albis. Abdomen nigrum, nilidum, breviter nigropilosum, segmento tamen primo albo-piloso; segmentorum secundi et lertii margo posticus tenuiler albus, latera versus latius albo-limbatus; segmentum quintum maculis duabus albo-pollinosis obliquis, in medio segmento fere contiguis ornatum; segmentum sextum maculis duabus similibus, sed duplo brevioribus instructum. Pedes graciles, nigri, tibiarum anticarum basi, tibiis posterioribus praeter apicem iarsormmque posteriorum basi badiis. Halteres nigro-fusci, capiluli dimidio superiore albo-pollinoso. Alae hyalinae, stigmate venisque fusco-nigris, his tamen in basi alarum dilute subfuscis; cellula posterior quarta prope marginem alae clausa. - (Wisconsin, Kennicol.)

14. Psilocephala laticornis, nov. sp. +. - Nigro-cinerea, opaca, fronte angust i concolore, abdomine nigro, segmentorum secundi, terlii et quarli marginibus posticis, quinti, sexti et septimi maculis lateralibus ex favo albidis; alae cinereo-hyalinae, cellula posteriore quartâ in ipso alae margine clausâ, vel angusle apertá.

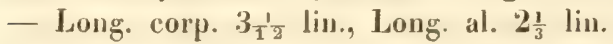

Nigro-cinerea, opaca. Caput concolor, totum opacum, frontis angustae colore magis in fuscum, adversus antennas in purius cine. reum vergente. Anteunae brevissimae, articulis primis duobus nigris, levissime albo-pollinosis, breviter nigro-setosis, articulo tertio fusco-nigro, brevi, latissimo, acuto, stylo terminali mediocri, acuto. Proboscis crassa, dilute subfusca; palpi parvi, ochracei, subnudi. Thoracis dorsum obsolete cinereo-bilineatum. Abdomen nigrum, nitidum, nigro-pilosum, segmento primo nigro-cinereo, opaco, albo-piloso; segmentorum secundi, tertii et quarti margines postici ex flavo albidi, latera versus latiores, illorum integri, hujus interruptus; segmenta quintum, sextum et septimum singula utrinque maculå magnå ex havo albidâ ornala. Pedes nigri, femorum apice, tibiis metalarsisque pracler apicem tesiaceis. Alae cinereo-hyalinae. ve- 
nis et stigmate fuscis, cellulâ posteriore quarlà vel angusle apertâ. vel in margine alae clausâ. - (Cuba; Gundlach.)

15. Psilocephala melanoprocta, nov. sp. ఠ. - Cinerea, capite, lineis dorsalibus duabus et abdomine polline confertiore al. bidis, antennis et hypopygio majusculo nigris el nigro-hirtis; alae cinereo-hyalinae, venis et stigmate fuscis, cellula posteriore quartâ clausâ. - Jong. corp. $?^{7} \frac{7}{2}$ lin., Loms. al. $22_{6}^{5}$ lin.

Caput confertim albo-pollinosum, genis et occipite albo-pilosis, setis tamen occipitis nigris. Antennae breves; articuli primi duo nigri, levissime albo-pollinosi, nigro-selosi; articulus tertius fusconiger, latiusculus, modice acutus, primis duobus simul sumptis longior; stylus terminalis mediocris, aculus. Proboscis nigra; palpi concolores, albo-pilosi. Thorax nigricans; dorsum subnitidum, polline albido levissime aspersum, lineis duabus confertim albo-pollinosis ornatum, setis ordinariis omnibus pilisqne in anteriore thoracis dimidio plerisque nigris, pilis reliquis albis; pleurae confertius albo-pollinosae, albo-pilosae. Scutellum nigricans, albo-pollinosum, pilis albis setisque ordinariis nigris instructum. Abdominis color niger polline conferto albo in colorem cinereo-album mulatur; segmentorum secundi, tertii el quarti singulorum margo posticus albidus; pili abdominis rariores, modice longi, albi. Hypopygium majusculum, atrum, nitidum, folum nigro-pilosum. Pedes nigri; anticorum femora albo-pilosa, tibiarum basis fusca; posteriorum femora albo-pilosula, tibiae practer apicem inaque tarsorum basis fuscac. Halleres fusco-nigri. superiore dimidio capiluli lurido, confertim alto-pollinoso. Alae cinerco-hyalinae. sligmate venisque nigrofuscis, his tamen in alarum basi dilutioribus; cellula posterior quarta prope marginem alae clausa. - (Maine. Hudsons Bay Territory; Kennico1.)

16. Psilocephala costalis, nov. sp. +. - Nigra, pedibus concoloribus. tarsis tibiisque anticorum incrassatis, fronte angusti. atrá el nitidâ, primo antennarum arliculo elongzato, celluli alarnm

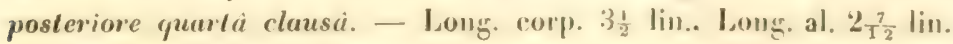

Nigra, nudiuscula. Caput nigrum; frons angusta. nitida: or. bita facialis et orbitac fronlalis pars inlima late albae. reliqua frous utrinque tenuissime albo-marginata; antemae longiuseulae, nigrae: articulus primus sequentibus simul sumptis paulo longior; nigro-setosus; articulus tertius apicem versus modice attenualus. Apertura oris permagna: proboscis fusco-nigra; palpi concolores. pilis longis 
albis vestiti. Thorax quinque - villatus, vittis externis et mediå atris, interjectis albido-schistaceis, marginibus adversis albis. Abdomen nigrum, breviler nigro-pilosum, segmento primo albo - piloso, secundo et tertio postice albido-limbatis, quinto utrinque maculâ albidà notato. Pedes toti nigri, libiis tarsisque anticorum distincte incrassatis; femora ex parte albido-pilosula. Alae cinereo subhyalinae, apice paulo saturatius cinereo, venis et sligmate nigris, cellulis costalibus et marghinali nigricantibus, venâ transversâ medià et venae quartae segmento paenultimo nigro-sublimbatis, cellulâ posteriore quartâ prope alae marginem clausâ. - (California; Agassiz.)

17. Psilocephala rufiventris, nov. sp. ․ - Nigra, abdomine rufo, alis cinereo-bifasciatis. - Long. corp. $3 \frac{3}{4}-3 \frac{5}{6}$ lin., Long. al. $2 \frac{3}{4}$ lin.

Ex Psilocephalae piclipeunis affinibus Nigra, nudiuscula, ab. domine rufo. Caput albido-pollinosum, dimidio superiore frontis angustac nigro, modice nitido. Antennae tenues; articuli primi duo fusci, superne fusco-nigri, setulis brevissimis nigris instructi; articulus tertius niger, aequalis, truncatus, stylo terminali brevissimo. Thorax niger; vitlis lateralibus duabus atris, opacis. Abdomen rufum, segmento lamen primo vigro. Femora nigra, apice extremo testaceo; tibiae anticae validiores quam in congeneribus plerisque, fusco-testaceae, apicem versus et infra fusco-nigrae; tibiae posteriores fusco-testaceae, posticae in apice fusco-nigrae; tarsi antici validi, subincrassati, nigri; tarsi posteriores graciles, nigri, articulo tamen primo et basi secundi fusco-testaceis. Alae cinereo-hyalinae, in limidio apicali cinereo-bifasciatae, venis et stigmate fusco-nigris, cellulis costalibus et marginali, hujus apice excepto, cinereo-infumatis, cellulâ posteriore quartâ longe ab alae marginc clausâ. - (Nebraska )

18. Exoprosopa gazophylax, nov. sp. 우. - Alae cinereue, cellulis submarginalibus quatuor, costali et marginali totis, submarginali praeter basin et apirem et basali primâ fere tolâ nigris, venis transversis colore nigro late circumfusis, excepta tamen venâ inter cellulas submarginales posteriores sitâ. - Long. corp. 6 $\frac{1}{8}$ lin., Jong. al. $8 \frac{1}{3}$ lin.

Foemina descripta pilis fere omnibus destituta, nigra, opaca, sculello, abdominis lateribus segmentorumque singulorum marginibus posticis rufis. Femora rufa; tibiae badiae, apicem versus nigrac, posticae confertissime nigro-setosac; larsi toti nigri. Alac 
magnae, cinereac; cellulac submarginales qualuor. quales in Exoprosopâ Cerbero Fabr. et similibus; cellulae coslalis el marginalis ex fusco nigrac, illius basi saluratius nigrâ; cellula submarginalis nigra, basi tamen et apice latissime cinereis: cellula basalis prima fere lota nigricans, limbo venac quartac dilutiore; vena interealaris el venae transversales omnes, eâ, quae inler cellulas submarginales posteriores posita est, solí exceptâ, colore nigro late circumfusae; venae longitudinales quarta et quinta ante apicem maculâ minulâ nigrâ notałae. - (California.)

19. Exoprosopa decora, nov. sp. ․ - Alue nigrae, cellulis submarginalibus tribus, harum exterioribus praeter basim, fa. sciâ Iransversâ irregulari inde a margine postico prope ad renam longitudinalem secundam perlinente gullisque duabus (alterâ in cellulne posterioris secundae, allerd in anguli postici apice sitâ) hynlinis. - Long. corp. $5 \frac{1}{2}$ lin. Long. al. $6 \frac{1}{12}$ lin.

Nigra, facie, scufello, abdominis lateribus et ventre rufis. Pili thoracis plerique nigri, prothoracis subfulvi. Abdominis margines nigro-pilosi, pilis tamen albis in angulis anticis segmenti secundi; abdominis dorsum pilis brevibus nigris, corpori adpressis instructum, quasi nigro-tomenlosum, si tale vestimentum corporis tomenlum appellare licel; anguli postici segmenti tertii albo-tomentosi; segunenta sequentia praeter pilos nigros pilis brevibus albidis aspersa. Pedes fusco-nigri, femoribus anticis tibiisque omnibus dilutioribus, tarsis anticis tenuissimis. Alae atrae, opacae; cellulae submarginalis tres, exteriores hyalinae, basi superioris angustius, inferioris lalius atrí; faseia transversa hyalina, maculis duabus majoribus duabusque minoribus composita, inde a margine postico usque in cellulae submar. ginalis primae basim pertinet; praeterea guttulae duae limpidae in alae margine postico adesse solent, altera in celluli posteriore secundâ, alterâ in angulo postico, ubi vena longiludinalis ultima in marginen excurrit. - (Wisconsin, Kennicol.)

20. Exoprosopa trabalis, nov. sp. 4. - Nigru. luleo-pilosa, antennis pedibusque concoloribus; alae cinereo-hyalinae, triente costali inde a basi usque ad cellulae submarginalis secundae inilium limbisque anguslis venarum trunstersalium nigro-fuscis. cellulis submarginalibus tribus, cellulî posterinre primá ante marginem alae

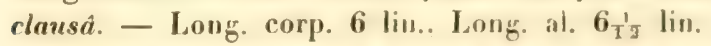

Nigra, opaca. seutelli apice badio. Capul concolor, nigropilosum et luteo-tomentosum. Antennae articulis duobus primis nigro- 
pilosis. Thorax praeter setas aliquot nigras totus luteo-pilosus. Abdominis latera pilis dilute luteis, in angulis posticis segmentorum siugulorum pilis nigris vestita. Abdominis dorsum praeter pilos lu. lescentes raros nigro-lomentosum, faciis basalibus angustis segmentorum secundi et quarti albido-, tertii, quinli et sexti dilute luteotomentosis, segmento ultimo toto albo-tomentoso. Pedes nigri. Alac cellulis submarginalibus tribus instructite el cellulâ posteriore primå longe ab alae margine clausâ insignes, cinereo-hyalinae, triente anlico inde ab alae basi usque ad cellulae submargiualis secundae basim nigro-fuseo, venis transversalibus omnibus colore saturatius nigro-fusco anguste limbalis. - (Jalapa.)

21. Exoprosopa sordida, nov. sp. ठ et 우 - Nigra, scutello, abdominis maculis lateralibus et ventre rufis, luteo-pilosa, abdomine fasciis latis luleo-tomentosis cinclo; alae cinereae, cellulis submarginalibus tribus, triente costali usque ad cellulae submarginalis secundae basim venisque basalibus cellularum posteriorum ullimae et paenultimae fusco-limbatis. - Long. corp. $6 \frac{1}{4}-6 \frac{5}{6}$ lin., Long. al. $6 \frac{2}{3}-7 \frac{7}{T^{2}}$ lin.

Exopr. fasciatae Macq. similis, sed alarum colore multo dilutiore. Nigra, opaca, luteo-pilosa. Caput nigrum, antennis et proboscide longiusculâ concoloribus, marginibus oris luteis. Thoracis anguli poslici et scutellum rufa. Abdominis segmenta priora plerumque utrinque rufo-maculata, marginibus lateralibus praeter angulos posticos luteo-pilosis; margines laterales segmentorum reliquorum fere toli nigro-pilosi; fasciae dorsales abdominis latitudine allernant, latiores dilule luteo-tomentosae, angustiores nigro-tomentosae. Venter sordide rufus, saepe praeter basim segmenlorumque reliquorum margines posticos piceo-niger, dilute luteo-tomentosus, tomento tamen segmenti quinti praeter marginem posticum nigro. Pedes piceo-nigri, femoribus tomento luteo vestilis. Alae cinereae. triente costali usque ad cellulae submarginalis secundae basim fusco, venâ longiludinali quintâ usque ad cellulam posteriorem ultimam et cellulae hujus venâ basali cum proximâ parłe venae, quà cellula discoidalis a cellulà posteriore paenullimâ distinguitur, colore fusco limbatis: cellulae submarginales tres. - (Matamoras; Tamanlipas.)

22. Exoprosopa cubana, nov. sp. $\sigma$ et + . - Nigra, scutello, abdominis maculis lateralibus et ventre rufis, primo antenna. rum arliculo et facie luteis; luteo-pilosa, abdomine fasciis latis luten-tomentosis cincto; alae cinereae, cellulis submarginalibus tribus 
instructae, dimidio costali usque ad cellulae submarginalis secundae basim nigro-fusco, venis basalibus cellularum postcriorum ultimae et paenultimae late, secundue angustissime nigro-limbatis. - Long.

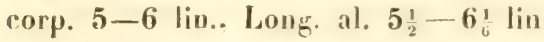

Pracedenti similis, sed major. proboscide loreviore. facie et primo antemarum articulo luteis, pilis tolius corporis ahdominisque tomenlo suturatius tinelis. alis denique latius nigro-fuscis facile distinguilur. - Nigra, opaca. Facies dilute lutea: primus articulus antennarum suturatius luteus vel testaceus. interdum subfuscus. nigro-pilosus; proboscis non prominens. Abdominis maculae laterales rufae in speciminibus integris ommino obsoletae: fasciae nigro - to. mentosae duae primae latáe. latera versus valde altenuatae. Venter ex ochraceo rufescens, luteo-tomentosus. tomento tamen segmenti quinti fere ommi nigro, segmentis sequentibus plerumgue olsscurioribus. Pedum color niger, sed in femoribus et tibiis fere totis sub lomento subfulvo latet. Alae cincreae. cellulis submarginalibus tribus el cellulâ posteriore primâ angustissime tantum aperlâ: dimidium costale usque ad cellulae sumarginalis secundac basim nigrofuscum; venac basales cellularum posteriorum ullimae et paenulimae colore saturate uigru-fusco balius circumfusae. venà basali secundac lenuissime et sulobsolete fusco-limbata. - (Cuba; Gundach.)

23. Exoprosopa bifurca, nov. sp. +. - Nigra, sculello abdominisque maculis lalevalibus obsolelis rufis. supra pilis luleis. infra albis vestita, abdomine fasriis latis luteo-lomentosis rimeto. ventre toto albo-tomentoso: alae cinerene. cellulis sulmurginalibus tribus instructue, cellutis costali et subcostali fuscis, marginalis triente medio fusco-nigro. basali prima subfusca. - Long. corp. $6 \frac{1}{4}$ lin., Long. al. $6 \frac{3}{4}$ lin.

Nigra, opaca. Caput praeter margines lutros oris roncolor, fronte praeler pilos nigos et facic pallide tomentosis: antemae nigrae; proboscis modice prominens. Tluoracis dorsum luteo-pilosum; pili pectoris et pleuratum plerique albidi. Soutellum rufum. Ab. dominis maculae laterales rufae in specimioibus illaesis obsoletac vel subobsolelae; in dorso abdominis fasciae latiludine allernanl. lafiores luteo-tomentosae, angustiotes nigro-tomentosar. Venler lotus albo-tomentosus. Pedes toti nigri. Alae rinerrac. cellulis suburarginalibus tribus; cellula costalis fusca. extremo apice nipro-fusco; cellula subcostalis tota et marginalis inde a venae secuudae origine usque ad imam cellulac submarginalis secundac basim fusco-nigrae: cellula basalis prima eodem colore, sed dilutiore tincta; cellulae 
posterioris primae dimidium basale obsolete infumatum; cellula po. sterior tertia ad marginem alae minus dilatata quam in proximc affuibus. - (California, Agassiz.)

24. Exoprosopa Agassizii, nov. sp. ‥ - Exopr. bifur. cae proxima, sed venis basalibus cellularum posteriorum ultimae ef paenultimae latissime, secundae anguste rolore fusco-nigro limbutis diversa. - I Jong corp. $6 \frac{1}{6}$ lin., Long. al. $6 \frac{2}{3}$ lin.

Corporis formâ ac figurâ Exopr. bifurcae simillima et, nisi specimine unico el valde detrito fallor, pilis et fomento ul in illâ tinctis vestila. Alarum pictura paulo diffusior, cellulae submarginalis dimidio basali, cellulâ basali primâ totâ et cellulae posterioris primae dimidio priore fusco-nigris, venis basalibus cellularum posteriorum ultimae et paenullimae colore fusco-nigro late circumfusis, secundae angusle limbatâ; cellula posterior terlia ad marginem alae magis dilatala, quam in Exopr. bifurcà. - (California, Agassiz.)

25. Exортоs ора nubifera, nov. sp. ठ. -- Nigra, opaca, facie luteâ, scutello el abdomine tolo praeter busim et fasciam mediam rufis, luteo-pilosa, abdominis fasciis alternis nigro et pallidotomentosis, harum primâ et tertiá albicantibus, reliquis luteis; ala. rum pictura qualis Exopr. fascipennis Say, sed dilutior et apice cellulae marginalis tolo hyalino; cellulae submarginules tres. -

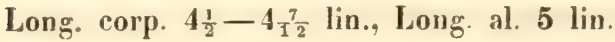

Exoprosopae fascipenni Say proxima. Nigra, opaca, luteo-pilosa. Caput pro portione majus quam illius, nigrum, facie surdide lutescente; antennae nigrae, articulo basali subtus obscure luteo; proboscis paulo prominens. Thorax luteo-pilosus; discus dorsi 10mento luteo et albicante vestilus; pleurac prope coxas posteriores albo-tomentosae. Scutellum rufum, imâ basi nigrâ et albo-tomentosà. Abdomen rufum, segmento primo et vittâ mediâ, prope ad marginem posticum segmenti quarti pertinente nigris; segmenti primi margines laterales et anguli antici segmenti secundi luteo-pilosi, reliqui abdominis margines pilis nigris instructi; fasciae dorsales alternae nigro-tomentosae et pallescentes, harum prima et tertia albidae, reliquae luteae; segmenta duo ultima albido-pollinosa. Venter rufus, totus albido-tomentosus. Pedes nigri. Alae cinereo-hyalinae, ut in Exopr. fascipenni Say, sed colore dilutiore, ex cinereo in nigrum vergente tinctae, et cellulae marginalis apice toto cinereohyalino, non nigro; cellulae submarginales tres; cellula posterior tertia ad marginem alae valde dilatata. - (Cuba, Gundlach.) 
26. Exoprosopa parva, nov. sp. б. - Nigra, opaca, fa. cie et pedibus ex huteo badiis, thorace luteo-piloso, plerisque tumen pleurarum pilis albidis: alae hyalinae, cellulis submarginalibns tribus instructae, cellulis costuli, subcostali el marginali (hujus apice excepto) nigricantibus, venis transversis ommibus et venae longitudinalis serundae apice colore nigro lale circumfusis. - Long. corp. $3 \frac{1}{2}$ lin., long. al. $3 \frac{1}{3}-3 \frac{5}{12}$ lin.

Color corporis nigricans, opacus. Caput concolor, facie ex luteo badiâ, plerumque ex parte fascâ; antennae nigrae, arliculis duobus primis breviter nigro-pilosis, tertio e basi crassâ subito atteuuato; proboscis non prominens. Pili thoracis plerirue lutescentes, pleurarum magnâ ex parte albidi; lomentum in reliquo llioracis dorso luleum. Scutellum nigrum. Abdomen valde detritum fasciis alternis nigro et pallido-tomentosis cinctum fuisse videlur. Pedes ex Juleo badii, larsis adversus apicem nigris. Alae hyalinae, subcinerascentes. cellulis submarginalibus tribus; cellulae costalis, subcostalis, marginalis (hujus apice excepto) et basalis prima cum alae et cellularum basalium reliquarum initio fusco-nigrae; venae transversae omnes et longitudinalis secunda ante extremum apicem colore saluratius nigro late circumfusae. - (Cuba; Gundlach.)

27. Anthrax proboscidea, nov. sp. ․ - I'roboscis duplicem capilis longiludinem aequans: alue longae, hyalinae. margine costali nigro-fusco. venis transversis omnibus, venae longitudinalis secundae et ramuli antici tertiae apicibus colore fusco-nigro limba. tis, fascia denique maculis ejusdem coloris composila inde a veni transversa posteriore usque ad venae longiludinalis primae apicem pertinente. - Long. corp. $4_{12}^{\frac{3}{2}}$ lin., Long. al. $4_{i}^{\text {s lin. }}$

Corpus in specimine descripto plane delritum, nigerrimum. nitidum, segmentorum abdominalium singulorum marginibus posticis angustissime rufis. Caput concolor, facie prominente sed ubtusâ. rufo-testaceat; antennae breves, articulis aequalibus. primis duobus rufo-testaceis, tertio nigro, rolundo, subito in stylum temem, articulis antennae simul sumtis paulo longiorem coeunte. Proboscis elongala, duplici eapitis longiludine vis brevior. Pedes badii, tarsis apicem versus nigris. Alate longae el pro portione minus latae. hyalinae; basis usque in celiularum basalium inilium ex fuseo nigra; cellulae costalis et subcostalis praeter hujus apicem ex nigro fuscae; venae transversales omnes, et venae longitudinalis secundae pars terminalis colore fusco-nigro limbatae; practer hos limbos fascia irregularis fusco-nigra, a venâ transversi posteriore usque ad 
venae primae apicem pertinet et punclum fusco-nigrum extremo apici ramuli anterioris venae tertiae imposilum est. - (Sonora; Schott.)

28. Anthrax pertusa, nov. sp. ơ. - Anthraci fenestratae Fall. affinis, tertio untennarum articulo conico, pilis et tomento corporis maximâ ex parle albis vel exalbidis; alae hyalinae, fasciis duabus postice paulo abbreviatis nigro-fuscis, alterâ basali latiusculâ et subaequali, alterà obliquâ, antice valdie dilatatâ el maculam hyalinam inchudente. - Long. corp. $4 \frac{1}{2}$ lin. Long. al. $4 \frac{1}{2}$ lin.

Caput nigrum, facie et triente antico frontis luteis; frons practer pilos nigros et facies albido-tomentosae, oris margine antico pilis brevibus nigris instructo; proboscis non prominens; articuli antennarum duo primi obscure lutei et nigro-pilosi, tertius niger et conicus. Thorax niger, opacus, tomento et pilis exalbidis, prope collum sublutescentibus. Scutellım rufum, basi nigrà. Abdomen nigrum, maculis lateralibus magnis rufo-testaceis, apice et ventre luteis; abdominis margines albo-pilosi, in angulis posticis segmenti tertii et in segmentis quinto et sexto totis nigro-pilosi. Pedes ex luteo testacei, tarsis nigris. Halteres albi. Alae hyalinae, colore nigro-fusco bifasciatae; fascia prima subbasalis, latiscula et aequalis inde a costâ usque in angulum posticum pertinet, sed ibi marginem non attingit; dimilium anterius secundae valde dilatatum maculam hyalinam, in quâ vena transversa anterior et basis ramuli antici venae tertiae sitae sunl, includit, dimidium vero posterius angustum et recurvum cellulam discoidalem cellularumque posteriorum tertiam et quartam percurrit; cellula costalis et alae basis con lore subfusco tinguntur. - (New Mexico.)

29. Anthrax flaviceps, nov. sp. 오 - Nigra, opaca, tomento et pilis fere omnibus luleis, capile praeler verlicem et occiput luteo; alae venula appendiceâ a cellula discoidali in cellulam posteriorem tertiam porrecta instructae, fusco-cinereae et praeter apicem et marginem posticum fusco-nebulosae. - Long. corp. $6 \frac{2}{3}-$ 6 $\frac{3}{4}$ lin., Long. al. $7 \frac{2}{3}-7 \frac{3}{4}$ lin.

Nigra, opaca. Caput luteum, vertice et occipite nigris, fronte et facie praeter pilos nigros illius luteo-tomentosis, margine tamen antico oris pilis brevilus nigris instructo; proboscis non prominens; primus antennarum articulus luteus vel badius, confertim nigro-pilosus; articulus secundus niger, pilis brevioribus nigris hirtus; articulus tertius in specimine utroque deest. Thorax fulvo-pilosus. 
Scutellum praeter basim rufum. Abdomen totum nigrum, marginibus lateralibus fulvo-pilosis, pilis tamen nigris in segmentorum singulorum angulis posticis. Abdominis dorsum totum luteo-fomentosum, latera versus pilis luteis et in segmentorum ultimorum marginibus posticis pilis nigris instructum. Venter niger, segmentorum marginibus posticis pallidis el pilis luteis aspersus. Pedes testacei, femorum anticorum dimidio basali, tibiis anlicis praeter basim, tibiis reliquis adversus apicem larsisque ommibus totis nigris. Alae ex fusco-cinereac, basi usque in cellulam discoidalem et dimidio costali usque ad venae terliar anastomosim inaequaliter fuscis, venâ basali cellulae posterioris secundae venisque in marginem posticum excurrentibus pracler singularum apicem colore fusco late circumfusis; venae similiter atque in Anthr. Alcyone Say ductae, venula enim appendicea a cellulâ discoidali in cellulam posteriorem tertiam missa, haec cellula vero integra, non ut in Anthr. Alcyone in partes duas divisa. Venula adventicia inlerdum deest. interdum in venam intercalarem excurrit. - (Tamaulipas.)

30. Anthrax Cey.x, nov. sp. б' - Nigra, opaca. tomento pilisque plerisque huteo-fuscis, pilis reliquis nigris; alue venuld adventicia a cellula discoidali in posteriorem tertiam porrertâ instmaclae; dimidium busale fere totum et costale praeter apirem nigra. hujus triente medio in fuscum vergente, reliqua ala cinereo-hyalina, limbis nigris venurum omnium latis subconfuentibus. - Long. corp. 6 lin.. Long. al. $7 \frac{1}{4}-7 \frac{1}{3}$ lin.

Anthraci Alcyoni Say simillima, sed corporis colore et vestimento obscuriore, alis lalioribus. cellularum posteriorum discis limpidioribus et cellulâ posteriore tertià integrâ diversa. Facies magis conica, pilis omnibus nigris, flavis prorsus nullis. Pili thoracis non lutei. sed luteo-fusci. in marginibus lateralibus et prope alarum basim magnâ ex parle nigri. Abdominis pili nigri minus rari. pili reliqui et tomentum fulvo-fusca. Venter nigro-fuscus. Alae nigrae, apice et dimidio posteriore praeter cellulas basales et angulum axillarem cinereo-hyalinis, venis tamen omnibus late nigro-limbatis: dimidii coslalis Iriens medius fuseus, venà lransversâ medià et imâ venae secundae basi alro-marginalis. Pedes quam Anthracis Alcyonis Say obscuriores. Larsis anticis tenuioribus ol longioribus. - (Virginia.) 
31. Anthrax fuliginosa, nov. sp. ఫ઼. - Nigra, opaca, tomento pilisque fere omnibus luteis, capite praeter occiput ventreque tolo laete luteis, pedibus saturatius luteis; alae fusco-et nigronebulosae, apice et margine postico nigro-cinereis, cellulae discoidalis dimidio secundo praeter marginem apicalem dilutiore, venâ appendiceâ nullâ. - Long. corp. $5_{6}^{\frac{1}{-}}$ lin., Long. al. $6 \frac{1}{2}$ lin.

Iterum species Anthr. Alcyoni Say simillima, sed cellula discoidali minus inaequali venulam appendicean non emittente, cellulà posteriore tertiâ inlegrâ venisque in alae apicem excurrentibus colore nigro non marginatis. - Nigra, opaca, scutello abdominisque maculis lateralibus rufis. Caput laete luteum, vertice summo et occipite nigris; pili frontis plerique nigri, in antico ejus triente magnà ex parte lutei; facies breviler luteo-pilosa, oris margine antico pilis brevibus nigris instructo. Proboscis vix prominens. Primus antennarum articulus laete luteus, pilis nigris subtilioribusque luteis vestitus; articuli reliqui nigri, terminalis conicus. Pili thoracis admodum detriti omnes lutei fuisse videntur. Scutellum rufum, basi nigrâ. Abdomen longiusculum, segmentis anticis utrinque rufo-maculatis; pili pauci et tomentum, quae in abdomine restant, praeter pilos aliquot nigros in segmentorum posticorum marginibus posticis, lutea. Venter dilute luteus et pilis luteis aspersus. Pedes saturate lutei, extremo tibiarum apice tarsisque nigris. Alae similiter atque Anthr. Alcyonis Say nigro. et fusco-nebulosae, colore tamen fusco in basi alarum et circa venam longitudinalem quintam latius diffuso; limbus latissimus marginis postici et apex alae nigrocinerei, venarum ibi excurrentium apicibus colore nigro non limbatis; cellulae discoidalis dimidium alterum praeter marginem apicalem dilutius cinereum. - (California.)

32. Anthrax palliala, nov. sp. ‥ - Nigra, opaca, pilis et tomento luteo-fuscis, thoracis dorso maximá ex parte nigro-piloso segmentorumque abdominalium ultimorum marginibus posticis pilos nonnullos nigros gerentibus; facies in conum productu et tertius antennarum articulus conicus; pedes suturate luteo-testacei; alae dimidiatim nigrae, termine coloris nigri subaequali et valde obliquo. - Long. corp. 5 lin., Long. al. 5 lin.

Anthraci fulvo-hirtae Wied. proxima. Nigra. opaca. scutello concolore. Caput nigrum, facie conicâ praeter vittam mediam saturate luteâ; pili frontis et faciei nigri, tomentum ex luteo in subfuscum vergens. Proboscis non prominens. Antennae nigrae, artieulo primo infra obscure luteo, nigro-piloso, articulo tertio conico. 
Pili thoracis fusco-lutei, in disco dorsi fere omnes, in pleuris non pauci nigri; tomentum dorsi ex fusco luteum. Praeler paucos et tenues nigros in segmentorum angulis posticis et in ultimorum matginibus posticis, pili abdominis omnes ex fusco lutei; tomentum in reliquo abdomine cum pilis concolor, in disco segmenti ultimi albidum. Venter niger, pilis et tomento raro luteis. Pedes luteo-testacei, tarsis apicem versus nigris. Alae byalinae, dimidio basali nigro; terminus coloris nigri subaequalis, valde obliquus, subrectus, antice vix levissime concavus, postice distinctius convexus a venae auxiliaris apice ad ultimum anguli axillaris trientem tendit. - (IIlinvis, Osten.Sackeu.)

33. Anlhrax diagonalis, nov. sp. ․ - Tola nigra, opaca, pedibus concoloribus, tomento et pilis plerisque luteis, angulis tamen posticis segmentorum abdominalium ullimorumque marginibus posticis nigro-pilosis; facies in conum producta et tertius antennarum arliculus conicus; alae dimidiatim nigrae, termino coloris nigri valde obliquo, in media alà perspicue gradalo. - Long. corp. $5_{\frac{1}{3}}^{\frac{5}{2}}$ lin., Long. al. $5 \frac{5}{\mathrm{~T} / \mathrm{I}}$ lin.

Anthraci fulvo-hirtae Wied. et pallialae m. affuis. Tola nigra, opaca, capite pedibusque concoloribus. Facies in conum producla et frons praeter pilos uigrus tomento luteo vestitae. Antennae nigrae, articulis primis duobus breviter nigro-pilosis, tertio conico, basi crassiore quam in specie praecedente. Pili et fomentum thoracis et scutelli nigri omnia lutea fuisse videntur. Latera abdominis luteo-pilosa, segmentorum singulorum anguli postici ultimorum. que margines postici nigro-pilosi; abdominis dorsum maximâ ex parte luteo-tomentosum; venter niger, tomento obscuro vestitus. Alae hyalinae, dimidio basali nigro; terminus coloris nigri valde obliquus, subrectus, in cellulà posteriore primâ distinctissime, in quarłâ obsoletius gradatus, a venae auxiliaris apice ad angulum axillarem mediun tendil, ubi color niger valde diluitur. - (California.)

34. Anthrax sagata, nov. sp. ठ"? - Tota alra, opaca, pedibus concoloribus, pilis prothoracis omnibus el plevisque pleurarum luteis, hurum reliquis brevibusque dorsi nigris; sculellum et abdomen nigro-tomentose, segmento hujus primo in lateribus pilis salurate huteis vestilo, antepaenultimo exalbido-tomentoss, paenullimo et ultimo confertius exalbido-pilosis; alae dimidiatim nigrae. - Long. corp. $4 \frac{1}{1} \frac{1}{2}$ lin., Long. al. $5 \frac{1}{4}-5 \frac{1}{3}$ lin.

Tota nigra, opaca. pedibus concoloribus. Caput deest. Pro- 
thorax Inteo-pilosus; pleurae pilis luteis et nigris vestilae, fasciculo tamen pilorum supra halteres tolo saturate luteo; thoracis dorsum et scutellum tomento et pilis nigris instructa. Abdomen nigro-tomentosum, tomento segmenti quinti albicante; latera segmenti primi saturate luteo-pilosa, secundi, tertii et quarti nigro-pilosa, reliquorum cum margine postico ultimi pilis confertis exalbidis instructa. Alae dimidiatim nigrae; terminus coloris nigri obliquus, levissime bisinuatus, sinu anteriore inde a venae auxiliaris apice usque in cellulae posterioris tertiae basim pertinente, posteriore hinc usque ad marginem alae ducto, ita ut angulus axillaris totus, extremo apice solo excepto, niger sit. - (Matamoras.)

Nota. Anthr. sagata utrum Anthr. fulvo-hirtae Wied. an celeri Wied. magis affinis sil, caput amissum dijudicari vetal.

35. Anthrax curta, nov. sp. ठ․ - Tota aterrima, opaca, pedibus concoloribus; caput sphaericum; prothorax, segmentum ab. dominale primum totum segmentague tria ultima magná ex parle albo-pilosa; anguli quatuor thoracis fulvo-pilosi; reliquum corpus tomento et pilis nigris vestitum; alae dimidiatim alrae. - Long. corp. $4 \frac{2}{3}$ lin., Loug. al. $4 \frac{7}{12}$ lin.

Aterrima, opaca. Caput concolor. sphaericum, facie non prominente; frons adversus verticesn valde angustata, pilis brevissimis nigris et lomento nigro-vestita; tomentum faciei nigro, albo et subfusco varium; antennae nigrae, articulis duobus primis confertim nigro-pilosis; proboscis non prominens; occiput niveo-tomentosum, prope verticem breviter albo-pilosum. Thorax pilis brevibus nigris et tomento atro insignis; prothorax albo-pilosus: humeri et anguli postici fulvo-pilosi; margo posticus pilis brevibus fulvis aspersus. Scutellum atro-tomentosum et nigro-pilosum, margine postico fulvotomentoso. Primum abdominis segmentum tolum niveo-pilosum; segmenta secundum, tertium et quartum atro-tomentosa, adversus margines lalerales et in his ipsis confertim atro-pilosa; segmenta tria ultima in medio dorso nigro-tomentosa, adversus latera tomento niveo instructa, marginibus niveo-pilosis. Venter atro-fuscus, segmenlis duobus primis tomento niveo, reliquis tomento atro praeditis. Pedes toti atri, libiis posticis superne confertim selulosis. Alae hyalinae, dimidio basali atro; terminus coloris atri, in alae dimidio anteriore leviter concavus, a venae auxiliaris apice oblique usque per cellulam posteriorem quartam et hine, margini postico parallelus in angulum axillarem ducitur, ubi color ater dentem reduncum emittit. - (California.) 
36. Anthrax parvicornis, nov. sp. ठ. - Fusco-nigra. opaca, pilis et tomento ex luteo subfuscis. pedibus ex luteo testaceis; antennue breves. artirulis aequalibus; proboscis elongata; alae dimidiatim nigrae, termino coloris nigri obliguo et gradato. Long. corp. $4_{I^{5}}^{5}$ lin., Long. al. $4_{\frac{5}{2}}^{\frac{5}{2}}$ lin.

Fusco-nigra, opaca. Caput sphaericum, nigrum, lateribus faciei non productae luteis. Frons lata et facies nigro-pilosae el tomento fusco-luteo aspersae. Antennae parvae, fuseo-nigrac, articulis aequalibus, terminali sphacrico, in stylum tenuem, quam articuli tres simul sumbi longiorem subito coarctato. Proboscis elongala, dupli. cem eapitis longiludinem lese aequans. Pili thoracis ex luteo subfusci. in pleuris dilutiores, in dorso magnâ ex parle nigri; tomen. tumi dorsi ex fusco luteum. Scutellım praeter basim nigram obscure rufum. tomento fusco-luleo obtectum et in margine postico pilis nounullis nigris instruclum. Apex ablominis el venter fuscotestacei; segnentum frimum et lalera secundi pilis luteo-fuscis vestila, religums abdominis margo nigro-pilosus: fomentum in medio dosso maximâ ex parte nigrum latera versus et in tribns ultimis aboiominis segurentis fusco-luteum. Pili ventris plerique nigri. Pedes salurate lutei vel luteo-testacei, tarsis nigris. Alae hyalinae, dimidio basali niggro. venâ lransversâ mediâ el venâ basali cellulae posterioris quartae dilutius limbatis; lerminus coloris nigri obliquus el gradalus, a venae auxiliaris apice usque per cellulam posteriorem quarlam Juctus, hinc margine postico parallelus in angulum axillarem lendens deliqueseil; celiula analis usque ad extremum apicem infuscata. - (Illinois; ()sten-Sacken.)

37. Anthra.t bigradata, nov. sp. ठ․ - Nigra, opaca, thorace utringue villt allo-pilosi oruato; alae dimidiatim nigrae, termino coloris nigri obliguo, bigradato in anteriore, undulato in posteriore alae dimidio. - long. corp. $3 \frac{1}{3}$ lin., Long. al. $3 \frac{7}{\mathrm{~T}_{2}}$ lin.

Anthraci maurae Jinu. affinis. - Nigra, opaca. Capul conco. lor, sphaericum: frons el facies nigro-pilosae el lomento luteo adspersae; antennarum articuli duo primi fusei et nigro-pilosi. tertius niger et e basi intrassatâ in stylum altenuatus; proboscis paulo promineus, labellis crassiusculis. Thoracis dorsum tomento fusco-luteo vestilum, marginibus laleralibus confertissime albo-pilosis, margine antico pilis nigris et luteis instructo; pleurae pilis nigris et fuscoluteis hirtac. Tomenlum scutelli nirri fusco-luteum. Abdominis margines in segmentis duobus primis luleo-pilosi. in segmentis re. liquis pilos rariores nigros gereules; segmentum primum pilis erec- 
tis albis vestifum, margine tamen postico subfusco-tomentoso; segmenla secundum latera versus, quarlum praeter marginem posticum, sextum el septimum fere tota tomento luteo, in angulis anticis segmenti quarti albicante, indula; reliquum abdomen maximâ ex parte nigro-tomentosum. Venter niger, luteo-tomentosus et pilis nigris aspersus. Pedum color fusco-niger. Alae hyalinae, dimidio basali nigro, venâ transversâ mediâ et inâ venae secundae basi dilutius limbatis; terminus coloris nigri valde obliquns a venae auxiliaris apice perpendiculariter usque ad venam longitudinalem secundam et a secundå iterum perpendiculariter ad quartam demittitur, ita ut gradus duo fiant; inde a fine posteriore venae transversae mediae leviter undulatus marginem alae in triente ultimo anguli axillaris attingit. - (Cuba; Gundlach.)

38. Anlhrax nigricauda, nov, sp. +. - Nigra, flavo.pilosa, in capite, in gualuor ultimis abdominis segmentis praeter latera, in pectore, in ventre et in pedibus totis pili omnes et tomentum nigra; alae hyalinae, levissime infuscalae, cellulis costali et busali primầ nigris. - Long. corp. $5 \frac{1}{2}$ lin.. Long. al. $5 \frac{1}{2}$ lin.

Anthraci fulvianae Say affinis, nigra, pilis longiusculis flavis vestita. Caput nigrum, pilis et tomento concoloribus. Quatuor ultima abdominis segmenta pilis et tomento nigris instructa, lateribus tamen flavo-pilosis. Pectus nigro-pilosum. Venter niger, pilis omnibus et tomento fere omni concoloribus, reliquo tomento albicante. Pedes nigri, pilis, setulis et tomento omni concoloribus. Alae hyalinae, colore ex fusco-cinereo leviter tinclae, imâ basi cellulisque costali et basali primâ nigris, venulâ transversâ mediâ et venae longitudinalis secundae basi nigro-limbalis. - (Massachusetts; Scudder.)

39. Anthrax scrobiculata, nov. sp. ot. - Nigra, abdominis fasciis duabus subapicalibus nigro-tomentosis segmentorumque tertii, quinti et sexti lateribus nigro-fasciculatis: caput nigro-pilosum, tomento nigro et luteo instructum, fronte adversus verticem eximie angustala ; alae hyalinae. - Long. corp. $5 \frac{3}{4}-5 \frac{1}{1} \frac{1}{2}$ lin., Long. al. $5 \frac{3}{4}$ lin.

Ex Anthr. flavae Meig. affinibus. Nigra, lateribus segmentorun abdominalium secundi et tertii rufis. Caput concolor, globosum, nigro-pilosum, tomento nigro et luteo tectum; frons adversus verticem admodum angustata foveà modice concavå, mediae fronti im. positâ insignis; antennae nigrae, articulis primis duobus nigro-pilo- 
sis; facies in conum non producta; proboscis non prominens. Thorax totus pilis saturate luteis instructus. Scutelli margo tomentum subfulvum gerens. Abdomen confertim luteo-pilosum, segmentorum terlii, quinti et sexti lateribus et ultimi margine postico nigro-pilosis; tomentum abdominis fere omne nigrum, in segmentis paenultimo et antepaenultimo confertius, ita ut fasciae vigrae fiant. Venter niger, pilis plerisque luteis, tomento maximâ ex parte nigro. Pedes nigri, pilis, setis et tomento nigris, femorum tamen tomento partim luteo; tibiae posticae setis confertissimis ciliatae. Alae hyalinae, imâ basi fuscâ, cellulâ costali dilute subfuscà. (Illinois.)

40. Anthrax stenozona, nov. sp. \&. - Nigra, pedibus et imâ alarum basi concoloribus; pili albi, in lateribus segmentorum abdominalium tertii, quinti et sexti nigri; tomentum in abdominis dorso nigrum, in segmentorum secundi et terlii basi anguslissime, in quarli paulo latins album, in paenultimi et ullimi basi exalbidum.

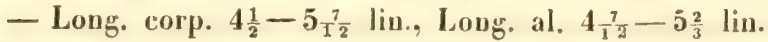

Nigra. Caput rotundum, totum concolor; frons modice lata, nigro-pilosa, adversus antennas albo-tomentosa; facies pilis rarioribus uigris et tomento conferto albo vestita; antennae nigrae, articulis primis duobus nigro-pilosis, tertio e basi globosâ in stylum tenuem producto; proboscis non prominens. Thorax albo-pilosus: tomentum dorsi nigrum, in margine postico album. Scutellum pilis albis et nigricantibus instructum, nigro-tomentosum, marginibus lateralibus albo-tomentosis. Abdominis latera in segmentis duobus primis et in quarti basi pilis albis, in reliquis segmentis pilis nigris vestita; tomentum abdominis reliqui nigrum, in segmentorum sceundi, tertii et quarti basi album ita ut in illis singulis fasciae singulae tenuissimae albae, in boc fascia paulo latior appareant; basis segmentorum paenultimi et ultimi polline exalbido instructa el anus utrinque tomento longiore albo fasciculatus. Ventris segmenta duo prima tota, tertii triens posticus, quartum praeter punctum nedium et reliqua praeter imam singulorum basim albo-tomentosa. Pedes nigri; tibiae posticae superne sefulis concoloribus subadpressis crebris ciliatae; femorum lomentum exalbidum, apicem versus nigrum; tibiac nigro-lomentosae, postieac tamen superne fomento albo aspersie. Alae pure hyalinae, imâ basi nigro-fuscî, venis nigris. - (Illinois.) 
41. Anthrax adusta, nov. sp. +. - Nigra, fronte, duobus primis antennaram articulis, segmentorum abdominalium tertii, quinti et quarti lateribus anoque nigro-pilosis, reliquo corpore fulvopiloso, abdomine fasciis fulvo-tomentosis ornato, imi alarum basi et cellula costuli ex nigro fuscis. - Long. corp. $6 \frac{1}{6}-6_{\frac{5}{2}}^{5}$ lin., Long. al. $6 \frac{1}{3}-6 \frac{1}{2}$ liu.

Nigra, caput rotundatum, lotum concolor; frons angusta. nigro-pilosula, adversus antennas tomento ex aureo fulvo vestita. Antennae nigrae, articulis duobus primis nigro-pilosis, tertio e basi globosâ in stylum tenuem producto; facies confertissime fulvo-tomentosa: occiput tomento breviore fulvo tectum; proboscis non prominens. Pili thoracis ex auren fulvi; fomentum concolor, in dorsi disco maximà ex parte nigrum; scutellum superne fomento nigro, in marginibus lateralibus aureo-fulvo instructum. Lalera sesmentorum abdominalium tertii. quinti et sexti pilis nigri fasciculala, margines laterales abdominis reliqui fulvo-pilosi; anus pilis nigris lirtus: fomentum in abdominis dorso nigrum, segmentis praeter primum siugulis fasciâ fulvo-tomentosâ oruatis; ventris segmenta duo prima fota, terlium in triente postico, reliqua praeter singulorum basim fulvo-tomeulosa. Pedes nigri, femoribus tibiisque confertissime fulvo-tomentosis. Alıe ciucreo-hyaliuae, imâ basi et cellulâ costali nigro-fuscis, cellulà basali primâ cellularumque adjacentium marginibus plerumque levissime infuscatis, iuterdum subfuscis. - (Cuba; Gundlach.)

42. Anthrax molitor, nov. sp. †. - Nigra, pilis albidis et tomento albido vestila, lateribus segmentorum abdominalium quinti et sexti nigro-pilosis, marginibus posticis secundi et tertii, anticis quinti et sexti nigro-tomentosis, alis hyalinis. - Loug. corp. $5 \frac{5}{6}$ lin., Long. al. $5 \frac{1}{2}$ lin.

Nigra. Caput globosum, concolor, albido-tomentosum, tomento frontis nigro-pilosulae sublulescente; antennarum nigrarum articuli duo primi pilis nigris et albis instructi, tertius e basi globosâ in stylum mediocrem attenuatus; proboscis non prominens. Thorax pilis albidis et tomento albido vestilus; discus dorsi detrili praeter tomentum albidum tomento raro nigro instructus fuisse videtur. Scutellum albido - tomentosum, prope basim tomento nigro vestitum. Abdomen albido-tomentosum, segmentorum secundi et tertii limbo postico latius, quinti et sexti margine antico angustius nigro-lomentosis; lalera abdominis albido-pilosa, in segmentorum quinti ef sexti angulis anticis pilis nigris hirlat. Veuter praeter basim nigram se. 
gnentorum quinti et sexti conferlim albo-tomentosus. Pedes nigri; color tomenti prope femorum b:sim allidus adversus apicem per lutescentem in nigrum mulatur; tibiae posticae superne setulis subadpressis conlertim ciliatae. Halteres albi. Alae hyalinae, imả basi sublutescente; cellulà costali cinerascente. - (California.)

43. Anthrax mucorea, nov. sp. f. - Nigra. occipite et facie candido-tomentosis, reliqui corporis pilis et tomento sublutescentibus, disco thoracis et scutelli. segmentorum abdominalium trium primorum limbo postico latius. yuinti et sexti margine antico

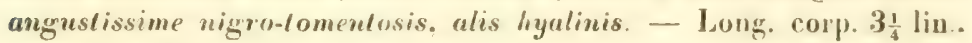
Long. al. $3 \frac{1}{4}$ lin.

Nigra. Capul globosum, concolor: frous laliuscula. nigro-pilosa; tomentum frontis sublutescens, faciei album. occipitis candidissimum; duo primi anlennarum articuli pilis nigris et rarioribus albis hirti. tertius e basi globosâ in slyfum mediocrem attenuatus; proboscis non prominens. Pili thoracis pallide lutescentes; tomenfum in dorsi disco nigrum. in margine postico dilute luteum. in pleuris albidum. Scutelum nigro-tomentosum, margo tamen totus tomento dilute luteo instructus. Pili in abdominis laleribus pallide lutescentes. admixtis paucis obscuris in segmenti tertii angulis posticis; tomentum abdominis lutescens, in dimidio posteriore segmentorum primi, secundi et tertii. et in imâ quinti ef sexti basi nigrum. Venter totus pallido-tomentosus. Pedes nigri; femorum et tibiarum fomentum fere omne pallidum; tibiae posticie superno setulis subadpressis confertim cilialae. Alac liyalinas. imâ basi ex fusco sublutescente. cellulâ costali leviter cincriscente: venae tertiae ramulus anterior in extremo apice subincurvus. - (Nebraska.)

44. Hemipenthes seminigra, nov. sp. \&. - Hemip. morioni Linn. simillima. sed lateralibus thoracis marginibus luteo-pilosis, alarnm parle hyalinâ minus lata el celluli posteriore primâ apicem versus magis angustati. - Long. corp. $\$ \frac{1}{4}$ liw.. Long. al. $4_{1 \frac{5}{3}}^{\frac{5}{2}}$ lin.

Nigra, pilis plerisque concoloribus. Thoracis dorsum in marginibus lateralibus et antico pilis dilute luteis. in diseo pilis nigris vestitum, tomento luten levissime aspersum. Scutellum nigro-pilasum, maryine obsolete luteo-tomentoso. Pili segmentorum abdominalium primi el secundi ommes, terlii el quarti praeter latera ex albido-lutescentes, quinti et sexti omnes nigri, ullimi maximà ex parte pallidi; tomentum abdominis nigrum, segmentorum singulorum 
marginibus posticis segmentisque ultimis tolis tomento tenui luteo leviter aspersis. Pedes nigri, luleo-lomentosi, anteriorum genibus tibiisque fuscis, pilis raris setisque nigris. Alae dimidialim nigrae, termino coloris nigri inde a cellulae analis apice per quatuor gradus inaequales oblique usque ad venae primae finem ducto; cellula posterior prima anguste aperta. - (Saskatchevan; Kennicot.)

Nota. Hemipenthes morio et seminigra propter pulvillos ab Anthracibus, propter stylum anteunarum simplicem ab Argyromoebis separandae, proprium genus, cui Hemipenthis nomen imposui, constiluere debent.

45. Argyromoeba Delila, nov. sp. ð. - Arg. Simsoni Wied. proxima, insignis alarum venis plane eodem modo ductis, sed vestimento totius corporis dilutiore alarumque maculis minoribus et discretis destincta. - Long. corp. $7 \frac{1}{6}$ lin., Long. al. $7 \frac{1}{4}$ lin.

Alarum venis, cum venis Arg. Simsonis congruentibus, ab Argyromoebis reliquis discrepat; ab Arg. Simsone pilis totius corporis dilutioribus alarumque maculis multo minoribus et omnibus dissitis facile distinguitur. - (California.)

46. Argyromoeba stellans, nov. sp. ठ'. - Alae nigromaculatae, maculis dimidii anterioris majoribus et confluentibus, dimidii posterioris quatuor et tolidem apicis perparvis et dissilis, venulis appendiceis qualuor praeter solitas, unicâ venae longitudinalis secundae, duabus ramuli anterioris venae tertiae, unicâ venae inter cellulas discoidalem et posteriorem terliam silae. - Long. cor'p. $5 \frac{1}{3}$ lin., Long. al. $5 \frac{1}{3}$ lin.

Affinis Arg. Oedipo Fabr., similior Arg. Plutoni Wied. - Nigra, pilis nigris rarioribusque albis vestita. Latera segmenti abdominalis primi praeter angulos posticos albo-pilosa, reliqui abdominis margines nigro-pilosi, pilis albis in segmentis tertio et quarto crebro admixtis; margines postici segmentorum secundi, tertii, quinti et sexti albo-tomentosi. Pedes nigri, femoribus fuscis. Alae hyalinae, nigro-maculatae, praeter venulas appendiceas omnibus fere Argyromoebis communes a cellulà discoidali venulae rudimentum in cellulam posteriorem tertiam porrigitur; simile rudimentum a venâ longitudinali secundâ in cellulam submarginalem primam demittitur et duo, prius sursum, posterius deorsum directum e venae tertiae ramulo anteriore nascuntur; basis alarum nigra; dimidium anterius maculis majusculis nigris variegatum, quarum ea, quae in veuâ trans. versả sitâ est et quae praecedunt nonnihil confluunt, reliquae duae 
discretae sunt; in dimidio posteriore maculae quatuor perparvae in venis sitae et punctum in venâ intercalari cernuntur; apex maculis quatuor minutis ornatus, quarım unâ in venae terliae ramulo anteriore inter appendiculas jacet. duae in venâ secundâ, reliquae pone apicem venae primae locum habent. - (Oregon.)

47. Argyromoeba obsoleta, nov. sp. $\widehat{\sigma}$. - Pilis nigris varioribusque albis vestila, margine postico segmentorum abdominalium serundi. tertii. quarti et quinti tomento albo quadrimaculato, segmento ultimo tolo albo-tomentoso; alae cinereae, in basi et adversus costam nigrae, in dimidio posteriore punclis duobus nigris notatae. venarum appendiculis proeter Argyromoebarum ordinarias nullis. - Long. corp. $4 \frac{7}{T^{2}}$ lin., Long. al. $5_{4}^{3} \mathrm{lin}$.

Nigra, pilis nigris rarisque albis vestita. Latera segmentorum abdominalium primi albo-pilosa, angulis tamen posticis exceptis; margo posticus segmentorum abdominalium secundi, tertii, quarli et quinti singulorum maculis quaternis albo-tomentosis ornatus; segmenfum ultimum praeter maculam minutam mediam tolum albo-tomentosum. Venter niger, nigro-pilosus. Pedes nigri. Alae longae. cinereae, venarum appendiculis praeter duas ordinarias nullis, adversus basim et costam colore nigro, circa venas transversas saturatiore tinctae, in dimidio posteriore maculis sive punctis duobus nigris notatae, altero in venâ, quâ basis cellulac posterioris quarlae a cellulà discoidali distinguitur, allero in ramulo venae terliae anteriore; vena inter cellulas discoidalem et posteriorem quartam saluratius cinereo-limbata. - (Nissouri.)

48. Argyromoeba pauper, nov. sp. б. - Nigra, pilis nigris rarioribusque albis nestita, pilis in lateribus segmenli abdominalis primi et tomento in segmentorum singulorum marginibus posticis albis: alae hyalinae, cellula rostali cum maculis contiguis subtribus nigrî, vená inter cellulas basalem secundam et posteriorem quartam latius, venulis transversis reliquis tenuissime nigro-limbatis. - Long. corp $3 \frac{1}{5}$ lin., Long. al. $3 \frac{1}{2}$ lin.

Nigra, pilis nigris rarioribusque albis vestita. Latera se abrominalis primi albo-pilosa; margines segmentorum omnium tomento albo. in specimine descripto valde detrito instructi. Venter niger. Pedes nigri, tibiis anterioribus fuscis, posticis superne minus confertim ciliatis. Alae cinereo-hyalinae; cellulae costalis color niger cum maculis subłribus nigris, primâ in ipsà alae basi. secundà in basi cellulae marginalis et tertiâ in venâ transversâ mi- 
nore, colıaeret; vena, quâ cellula basalis secunda a posteriore quartâ separalur, nigro-limbala; venulae transversales reliquae tres colore nigricante tenuissime limbalae; venarum appendiculae praeter solilas duas nullae. - (Illinois.)

49. Argyromoeba euplanes, nov. sp. ठ․--Atra, fasciis thoracis duabus angustis duabusque abdaminis latioribus candido-tomentosis, harum ultimâ interruptâ, alarum dimidio anteriore atro, posteriore hyalino. - Long. corp. $5 \frac{1}{12}$ lin., Long. al. $6 \frac{1}{6}$ lin.

Tota atra. Frons latiuscula. nigro-pilosa, polline albido levissime aspersa. Facies pilis albis ef nigris hirla. Collum albo-pilosum; pili in reliquo thoracis dorso nigri; tomentum praeter fascias duas tenues candido-pollinosas, quarum altera in suturâ transversâ. altera in margine postico sita est, nigrum. Scutellum pilis et tomento nigris vestitum. Pili pleurarum candidi. Abdominis segmentum primum folum cum angulis anticis secundi et latera segmenti quinti candido-pilosa; segmentum primum fasciâ candido-tomentosâ in medio margine altenualâ, segmentum quinłum fasciâ paulo latiore et in medio segmento interruptâ ornanlur; reliquum abdomen pilis nigris et tomenlo vigm instrucctum. Venter totus niger et nigro-pilosus. Pedes nigri; tibiae posticae superne setulis rarioribus instruclae. Alae longae, dimidio anteriore atro, posteriore hyalino: terminus coloris alri áb alae basi rectâ usque in imam cellulae posterioris quartae hasim ductus, leviter convexus usque ad cellulae discoidalis apicem pergit, ita ut haec praeter basim hyalina sit; hinc per gradus duos subaequales ad venam longitudinalem secundam accedens huic parallelus ultra procedit et marginem in ipso alae apice attingit; venae appendiculis nullis praeter duas solitas instructae. - (Cuba; Gundlach.)

50. Argyromoeba contigua, nov. sp. ㅇ․ - Nigra, pilis nigris rarioribusque albis vestila, abdominis fasciis albo-tomentosis. alarum dimidio anteriore nigro, posteriore hyalino, ramulo anteriore venae teriae non appendiculato. - Long. corp. $2 \frac{1}{6}$ lin., Long. al. $3 \mathrm{lin}$.

Nigra, pilis nigris rarioribusque albis vestita. Frons nigro-pilosa; facies pilis nigris et candidis instructa. Thoracis dorsum nigro-pilosum, pilis albis in margine antico crebro intermixtis. Pili pleurarum et segmenti abdominalis primi candidi; reliquum abdomen nigro-pilosum; tomeutum valde detritum, quod restat fere omne nigrum, adversus latera segmentorum quarti et quinti candi- 
dum. Pedes nigri Alarum dimidium anterius nigrum, posterius hyalinum; terminus coloris nigri inde a cellulae analis apice per cellulae posterioris quartae basim usque ad venam longitudinalem quartam duclus, hane venam usque ad cellulae discoidalis finem sequitur; hine per gradus duos subaequales ad venam longiludinalem secundam promolus, cum lac venâ alae apicem pretit. miculà famen inajusculâ nigrà in cellulac submarginalis primae apice adjectà; venae tertiae ramulus anterior appendiculâ, in Aryromocbarmm genere solitâ, destitutus. - (Virginia.)

51. Ploas limbata, nov. sp. F. - Cinereu. sculello conco. lore, pilis albidis, dihute favicantibus et raris nigris vestita; alae cinereo-hyalinne, venis transrersis fusco-limbalis. - Long. corp. 4 lin., Long. al. $3 \frac{3}{4}-3 \frac{5}{6}$ lin.

Totat cincrea el opaca; seulellum comrolor, apice non emarginato; thorax non viltalus. Pili corporis plerique albidi, abdominis lutescentes, in segmentorum singulorum marginibus posticis nigri. Pedes ni ro-fusci. lomento "xalbido cinerascentes, nigro-setosuli. Halteres albi. Alae cinerco-hyalinae, venis fuscis, transversalibus colore fusco limbatis. - (New-Mexico.)

52. Temnocera purpurascens, nov. sp. ठ․ - Nigra. scutello primisque duobus abdominis segmentis purpuruscentibus, ultimo hujus segmento et ventre saturate chalybeis, capile thorarisque dorso pube pallidâ, reliquo corpore pube nigrâ vestilis; alae hyalince, ma-

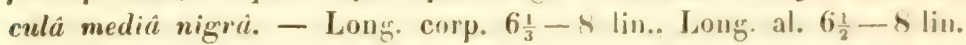

Caput nigrum. fronte et facie practer genas stramincis, orbiti occipitali pallide pollinosâ; pubes froulis, faciei, oculorum et orbitae occipilalis pallida, oecipitis reliqui nigra; genae mudae. Antennae subfuscae, arliculo primo et setâ plumatí piceo-nizrris. Thorax niger. nitens; dorsi pubes pallide flavescens, pleurarum pectorisque nigra. Scutellum planum, purpurascens sive ex picro purpurasecens. inerme, pube nigrâ instruclum. Alodomen lalum. sublepressum. nitens, nigro-pubescens, segmento ultimo saturalissime clablybeo sive ex purpureo chalybeo, praccedentibus purpurascentibus. Venter salurate chalybens, nigro-pubescens. Pedes nigri el nigro-puberuli. tibiis practer apicem rufis, adversus imam basim infuscalis. Hallerum capitulum album. Alae lon-iusculac. hyalinae, macula magnà nigrà. coslae mediae contigua el venas transvorsas includente; venae ante hanc maculam magnà ex parte ochraceo-ferrngineas, in maculâ ipsà el in ultimo alae dimidio lusco-nigrae. costà tamen venisque 
longitudinalibus primis tribus prope maculam ochraceo-ferrugineis. - (Hayti: Uhler.)

53. Scenopinus albidipennis, nov. sp. ఠౌ. - Niger, halterum capitulo albo, femoribus omnibus tibiisque posticis praeter apicem nigris, hoc pedumque posteriorum tibiis el tarsis omnibus testaceis, alis albicantibus. - Long. corp. $1 \frac{1}{2}$ lin., Long. al. $1 \frac{1}{4}$ lin.

Niger, capite thoraceque subopacis, abdomine nitido, intermediis hujus segmentis albo-marginatis. Antennae nigrae. Femora nigra, extremo apice testaceo; tibiae anteriores testaceae, posticac nigrae, apice tamen teslaceo; tarsi omnes teslacei. Halterum pedunculus niger, capitulum album. Alae albo-hyalinae, venis primis tribus totis luteis, reliquis subfuscis, in alarum basi lutescentibus. (Cuba, Gundlach.)

54. Empis distans, nov. sp. ㅇ. - Nigra, alis nigricantibus, venâ longitudinali terliâ crassâ, a costâ lato intervallo distante, libiis anticis femoribusque posterioribus utrinque, tibiis posterioribus superne pennatis. - Long. corp. $1 \frac{2}{3}$ lin., Long. al. $2 \frac{2}{\frac{1}{2}} \operatorname{lin}$.

Nigra. Antennae concolores, tenues, longiusculae. Proboscis nigra, labro apicem versus teslaceo, coxas intermedias allingente, labellis linearibus. Thorax ex cinereo niger, opacus, viltis obsoletis pilisque raris, omnibus nigris instructus; pili ante balteres nigri. Scutellum concolor, pilis apicalibus duobus instructum. Abdomen purius nigrum, nilidum, brevissime nigro-pilosulum. Pedes graciles, ex piceo nigri; tibiae anticae praeler basim femoraque posteriora utrinque pennala; tibiae posteriores superne aequaliter pennatae, in. fra pilis ordinariis brevissime ciliatae. Halteres sordide lutei, in colorem fuscum vergentes. Alae nigricantes, cellulis costali et marginali obscurioribus, venis nigris; vena longitudinalis terlia reliquis crassior, a costâ longe distans, all hanc ramulum subperpendicularem mitlit, ita ut cellula subcostalis secunda triangulum aequilaterum formet; cellula discoidalis majuscula; vena longitudinalis quarta, inde a cellulae discoidalis basi tenuior, apicen versus leviter reflexa est. - (Georgia, Pöppig; Mus. Berol.)

55. Empis violacea, nov. sp. б". - Chalybea, nitida, pedibus pennatis, alarum hyalinarum basi, limbo costali el cellulue discoidalis limbo nigris. - Long. corp. $1 \frac{3}{4}$ lin., Long. al. $2 \frac{1}{6}$ lin.

Chalybea, nitida, pilis tenuibus nigris vestita. Caput ex chalybeo nigricans; oculi contigui; articuli antenuarum primi duo ob- 
scure testacei, articulus tertius breviusculus, ovatus, niger. stylo aequali instructus; proboscis hrevis, labro capitis longitudinem paulo vincente, piceo. Thoracis dorsum ex chalybeo virescens; pleurae nigro - piceae, opacae, ante alarum basim chalybeae et nitidae: pili ante halteres nigri. Color abdominis ex chalybeo-aeneus, in apice abdominis in violaceum mutalus. Hypopygium parvum, clausum, nigrum el nigro-pilosulum, segmento ultimo ventris fornicato et pilis nigris vestito suffultum; lamellac laterales breves; lamella supera dissecta; penis opertus, apicem versus lenuissimus. Pedes nigro-picei, nigro-pilosi, anteriorum femoribus in triente apicali tibiisque praeter apicem, posticorum genibus tarsorumque omnium articulis secundo et tertio cum apice extremo primi et cum imâ quarti basi dilute lutescentibus; tibiae anteriores superne pilis ordinariis, apicem versus pilis compressis ciliatae; metatarsi anteriores superne breviter pennati; pedum posticorum tibiae et femora compressa. illae superne pennatae, infra pilis confertis cilialae, haec utrinque pennata. Halteres nigro-fusci. Alae pure hyalinae, basi limbisque costae et cellulae discoidalis latissimis nigris, ita ut praeter triangulum inde a margine axillari usque ad venam quartam pertinens et praeter maculam cellulae discoidalis, antico hujus margini contiguam, cellulae posteriores primae tres hyalinae sint, primae tamen dimidio basali reliquarumque basi exceptis. Vena longitudinalis tertia praeter ramulum anteriorem, perpendicularem et subrecurvum, ramulum alterum brevem in cellulam posteriorem primam mitlit, a venâ transversâ mediâ et ab alae apice aeque distantem; cellula di. scoidalis lata, oblique truncala; vena longitudinalis quarta et vena intercalaris tenues, ante alae marginem evanescenles. - (Mexico, Deppe; Mus. Berol.)

56. Empis suavis, nov. sp. ․ - Nitida, laete chalybea, thoracis dorso praeter marginem posticum vividi, antennis halteribusque nigris, alis pure hyalinis. - Long. corp. $1 \frac{1}{6} \mathrm{lin.}$, Long. al. $\mathbf{1}_{\frac{7}{1}} \operatorname{lin}$.

Frons et facies ex chalybeo virides, nitidae; occipul chalybeum, modice nitens. Antennae nigrae, articulo primo longiusculo, tertio ovato, setá eo breviore; proboscis capite paulo longior. Thoracis dorsum viride, nitidun, margine postico chalybeo. Scutellum chalybeum. Pleurae piceo-nigrae, ante alarum basim virides el nitidae. Abdomen crassiusculum, laete chalybeum, nitidum. Femora picea, extremo apice luteolo; tibiae lutescentes, apicem versus paulo obscuriores, posticarum apice fusco; tarsi antici fusci, articulis in- 
termediis lutescentibus, primo incrassato; tarsi posteriores dilute lutescentes, articulis ultimis nigro-fuscis. Halteres nigri. Alae purissime hyalinae, venis fuscis; venae longitudinalis quariae segmentum primum omnino obsoletum; pars hujus ultima et vena intercalaris tenuissimae, dilutius pictae et ante marginem alae deliquescentes; vena longitudinalis sexta valde abbreviata; venae longiludinalis tertiae ramus anterior perpendicularis et rectus. - (Mexico, Deppe; Mus. Berol.)

57. Empis superba Lw. ð.- - Aeneo-viridis, abdominis apice chalybeo, alis, antennis pedibusque nigris, femoribus tamen anticis femorumque posteriorum annulo latissimo subapicali luteis. - Long. corp. $1 \frac{1}{1} \frac{1}{2}$ lin., Long. al. $2 \frac{1}{2}$ lin.

Syn. Empis superba Lw. Wiener ent. Monatschr. V. 36. 8.

Facies aeneo - nigra. Proboscis aequalis capiti et thoraci conjunctis, fusca. Antennae nigrae, articulis primis duobus nigro-pilosis, primo subelongato, stylo apicali albido. Oculi contigui. Thorax et scutellum viridi-aenea, nitida, pilis brevibus nigris hirta. Pleurae fusco-nigrae, opacae, callo subalari minuto et maculà mediâ coeruleo-viridibus, ante halteres fuscos nigro-pilosae. Abdominis color pyritosus, adversus apicem in laetissime cupreum, in apice ipso in chalybeum vergens. Pedes nigri, pilis brevibus concoloribus confertim vestiti, tibiis primoque tarsorum anticorum articulo modice incrassatis, femoribus anticis praeter summum apicem luteis femoribusque posterioribus annulo latissimo subapicali luteo cinctis. Alae nigrae, venae longitudinalis tertiae ramulo anteriore rectâ ad costam ascendente. - (Cuba, Poey.)

58. Asyndetus ammophilus, nov. sp. 0 . - Glauco-viridis, opacus, capite argenteo, libiis pallide flavicantibus, posticis praeter basim nigris, tarsis nigris, articulis tamen duobus primis anticorum flavicantibus, primo incrassato, secundo abbreviato, glo. boso et selâ validâ armato. - Long. corp. $1 \frac{1}{6}-1 \frac{1}{4}$ lin., Long. al. $1 \frac{1}{6}-1 \frac{1}{4}$ lin.

Laete viridis, tomenlo conferto albo glaucus et opacus. Caput concolor; facies et frons latissimae, confertissime argenteo-pollinosae; antennae nigrae, arliculo tertio parvo, setâ dorsali nudâ. Palpi nigri, nigro-setosuli; orbita infera albo - ciliata. Scutellum nudum, setis duabus instructum. Abdomen breviter nigro-pilosum, segmentorum primi et secundi lateribus pilos longiores albos gerentibus; hypopygium immersum setulis quatuor validis instructum. Coxae 
virides, albido-pollinosae, anticae pilis nonnullis nigris instructae: femora viridia, leviter albo-pollinosa, opara, extremo apice pallide flavescente; tibiac anleriores lotae pallide flavescentes, posticae praeter trientem basalem nigrac; larsi antici breves. arliculis duobus primis pallide flavicanlibus, primo incrassato. secundo abbrevialo, globoso, setâ validâ armato et superue subfusco, articulis reliquis nigris; larsi posteriores nigri, imâ intermediorum basi dilute flavicante. Tegulae albae el albo-ciliatae. Alae hyalinae, levissime cinerascentes, venis nigris, in imâ basi fuscis. - (Newport, Rhode Island; Osien-Sacken.)

Nota 1. Foeminae duae simul cum maribus Asynd. ammophili et Asynd. appendiculati captae, his simillimae, inter se non differunt, nisi facie alterius verius aequali et tolâ paulo latiore. alterius supra quam infra latiore ef totí paulo angusliore; illam Asynd. ammophili, hane Asynd. appendiculati foeminam esse persuasum habeo. Palpi foeminarum majores quam marinm. nigri. polline albo et setulis nigris aspersi; facies supra oris aperturam binodata, qualis in Diaphororum foeminis esse solet; pedes simplices, ut in maribus picti, tarsis tamen anticis praeter dimidium basale articuli primi nigris; tibiae posticae utriusque focminae cum tibiis Asynd, appendiculati concolores.

Nota 2. Diaphori genus in Americà septentrionali numerosas easque diversissime constructas species complectilur, quas si ac. curatius examinamus, in complura minora genera dividendas esse palefiet, Omnes enim eae, quas in Monogr. of N. A. Dipt. Part. Il. in genere Diaphoro collocavi, eà re insignes sunt, quod marium tarsi saltem antici pulvillis elongatis munili sunt eấfue notâ a Chrysotis recedunt. Duae species. quam alteram modo descripsi, alteram proxime describam, totâ corporis conformalione. Diaphoris genuinis similes sunt et eà quoque re cum is rongruunt, quod hypopygium quatuor setis validis armatum ferunt. sed pulvillis elongatis carent; ceterum venâ tertiâ longitudinali ad secundam eximie admota, extremâ quartae venae longiludinalis parte (quemadmodum in Diaphoro interruplo Monogr. of $\mathbf{N}$. N. Dipt. Part. II. tab. 6. fig. $29 e$ videmus) interruptâ el venâ transversâ posteriore pariter alque in hac specie mire ad alae radicem accedente insigniuntur. Ad has duas species excipiendas Asyudetum genus condidi. Cui Diaphorus interruptus. quoniam venarum in alis decursu prorsus eodem utitur, inseri poteril. sed quum pulvillos productos habeat. gregem peculiarem hac ipsà pulvillorum natura signatum constituat necesse erit. 
59. Asyndetus appendiculatus, nov. sp. б. - Glaucoviridis, opacus, capite argenleo, tibiis pallide flavicanlibus, posticis praeler dimidium basale nigris, tarsis nigris, articulo primo unticorum flavo, non incrassalo, secundo appendicibus duabus favis in-

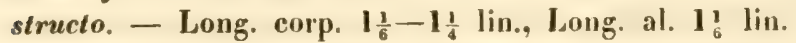

Praecedenti persimilis, sed facie paulo angustiore larsorumque anticorum fabricâ diversus; primus horum arliculus flavus, simplex, non incrassatus; articuli reliqui nigri; articulus secundus in apice appendicibus duabus dilute flavicantibus instructus, alterâ longiore, pedunculatâ, balteriformi, alterâ breviore, subclavatâ et in hamulum apicalem altenuatâ; articuli tres ultimi superne pilis brevibus resupinatis vestiti, tertius et quartus subincrassati, singuli quam articulus terminalis paulo breviores. - (Newport, Rhode Island; OstenSacken.)

60. Hydrophorus aestuum, nov. sp. $\delta$. - Viridis, albopollinosus, facie tolâ albâ, genis latis. - Long. corp. $1 \frac{1}{3}-1 \frac{3}{12}$ lin., Long. al, 2 lin.

Viridis, thoracis dorso obsolete cupreo-vitlato et in disco leviter cinereo-pollinoso, reliquo corpore polline albo, in pleuris confertiore, asperso. Caput confertissime albo-pollinosum, genis lalis et facie totâ albis. Setulae capitis, thoracis et scutelli nigrae; pu bes totius corporis alba. Pedes tenues, nigro-setosuli; femora an tica modice incrassata, infra duabus spinularum seriebus instructa; tibiae anticae spinularum ereclarum serie unà armatae, spinulâ ultimâ reliquis majore et validiore. Tegulae albo-ciliatae. Alae byalinae, leviter subcinerascentes, venis nigris, longitudinalibus tertiâ et quarłâ apicem versus modice convergentibus. - (Newport, Rhode Island; Osten-Sacken.)

Nota. Ab Hydrophoro inaequalipede, cui proxime accedit, nisi genis latioribus non differt.

61. Gymnochaeta alcedo, nov. sp. $\sigma$ et ㅇ․ - Nitens, vi. ridis vel chalybeo-viridis, capite albido-pollinoso, vittâ frontali antennisque nigris, tertio harum articulo quam in congeneribus longiore, superne convexo, pedibus nigris. - Long. corp. $4 \frac{1}{2}-4_{\frac{T}{2}}$ lin., long. al. $4 \frac{1}{12}-4 \frac{1}{6}$ lin.

Nitens, viridis vel chalybeo-viridis. Capitis color viridis praeter occipitis dimidium superius et praeter latera frontis sub tomento conferto albido plane latet; oculi confertissime pilosi; frons maris quam foeminae paulo angustior; vitta frontalis nigra; se- 
tarum froutalium series simplex infra antennarum basim contiunata, in foeminâ adjeclis setis duabus lateralibus validis; palpi ochracei. Thoracis dorsum levissime albido-pollinosum, ita ut in margine antico vilfarum quatuor albidarum initium appareat, scapulis marginibusque lateralibus tomento confertiore aspersis. Pleurae concolores, albido-pollinosae. Segmenta abdominalia secundum et tertium singula setis dorsalibus bis binis armata. Pedes nigri. Tegulae albidae. Alae cinereo-hyalinae, spinà costali nullâ. - (Massachusetls; Osten-Sacken.)

Nota. Hanc speciem propter corporis colorem Gymuochaetis, Nemoraeis proxime affinibus, ascripsi; a Gymmochaetis in Europå viventibus tertio antennarum arliculo longiore et superne convexo differt.

62. Pyrellia centralis, nov. sp. $\delta$ et 우 - Viridis vel chalybea, alarum venâ transversâ mediâ nigro-limbatâ. - Long. corp. $2 \frac{3}{4}-2 \frac{1}{1} \frac{1}{2}$ lin., long. al. $2 \frac{5}{12}$ lin.

Nitida, raro viridis, plerumque chalybea, thoracis maculis dorsalibus, scutello et abdomine saepe violaceis. Antennae et facies rufae; palpi concolores; genae piceae, pallide-pilosae; frous maris linearis, foeminae modice lata, in utroque sexu nigra, prope antennas haud raro rufa, orbitis albo-pollinosis, supra tamen nudis, nitidis, nigris vel nigro-chalybeis. Thoracis dorsum praeter margines laterales et posticum macrochelis nullis instructum; sligma prothoracis nigrum. Setae validae in abdominis apice nullae. Pedes picei vel piceo-nigri, femoribus subaenescentibus. Tegulae exalbidae, tenuissime fusco-marginatae. Alae cinerco-hyalinae, venae longitudinalis quarlae parte ultimá ad alae marginem valde approximată, venâ transversâ mediâ nigro-limbatâ. - (Cuba; Gundilach.)

63. Pyrellia selosa, nov. sp. \&. - Chalybea vel viridi-chalybea, facie, antennis, palpis pedibusyue nigris, thoracis dorso tolo macrochetis instructo. - Long. corp. $3 \frac{1}{3}$ lin.. long. al. 3 lin.

Nitida, obscure chalybea, raro ex chalybeo virescens. Caput nigrum, albido-pollinosum. Dorsum thoracis totum macrochetis et pilis longioribus quam in Pyrelliis plerisque instructum, prope marginem anticum leviter albo-pollinosum, ita ut villarum albidarum initia conspiciantur. Stigma prothoracis fusco-nigrum. Macrochetae in abdominis apice mediocres. Pedes nigri. Tegulae exalbidae vel dilutissime subfuscae, margive concolore. Alae cinereo-hyalinae, venae longitudinalis quartae parte ultima margini alari non approximatà. - (Illinois; Osten-Sacken.) 
64. Loxocera pectoralis, nov. sp. \&. - Rufescens, lined mediâ, scapulis margineque laterali thoracis et pleurarum dimidio superiore tolo nigris. - Long. corp. $2 \frac{1}{1} \frac{1}{2}-3$ lin., long. al. $2 \frac{5}{2}$ lin.

Rufescens. Caput luteum, maculis occipitalihus duabus, angulis verticis, triangulo ocellari magno, faciei dimidio superiore et tertio antennarum articulo nigris. Pleurarum dimidium superius cum scapulis et cum dorsi marginibus lateralibus nigrum, nitidum; linea dorsalis media nigra, sed minus nilens. Metanolum maculâ mediâ nigrâ notalum. Abdomen adversus basim piceo-nigrum, in apice piceum. Pedes cum coxis lulei. Alae subhyalinae, apice et liturâ paenultimum venae quartac segmenlum el venam transversam posteriorem includente fuscis, apicibus venarum quartae et quintae divergentibus. - (Washington; Osten-Sacken.)

65. Loxocera pleuritica, nov. sp. ơ et $\nmid$. - Rufescens. vittâ mediâ trienteque antico thoracis el maculâ pleurarum subhumerali nigris. - Long. corp. ơ $2 \frac{1}{1} \frac{1}{2}$, 우 $3 \frac{1}{6}-3 \frac{1}{3}$ lin., Long. al. $2 \frac{1}{2}-2 \frac{2}{3}$ lin.

Rufescens. Caput luteum, fronte rufà vel subbadiâ, occipitis dimidio superiore, angulis verticis, triangulo ocellari magno, faciei dimidio superiore et tertio antennarum articulo nigris. In dorso thoracis praeter trientem anticum nigrum vitta media uigra semper, macula minula nigra utrinque prope adjecla plerumque cernuntur. Pleurac inler coxam anlicam et scapulam nigrae, praeterea tolae rufescentes. Melanotum totum nigrum. Abdomen adversus basim in mare angustius, in foeminâ latius piceo-nigrum, in ultimo segmento focminae piceum. Pedes cum coxis lutei. Alae subhyalinae, apice et lilurâ paenultimum venac quartae segmentum et venam transversam posteriorem includente fuscis, apicibus venarum quartae et quintae divergentibus. -- (Connecticut, Nortun; New York, Osten-Sacken.)

Nota. Loxocerae hic descriptae, ut Lox. cylindrica Say, tertium antennarum articulum perlongum, setâ tenui et distincte pubescente instructum habent, qualis in Loxocerâ albiselâ reperitur.

66. Psila lateralis Lw. $0^{\Uparrow}$ et 오. - Flava, articulo tertio antennarum, puncto verlicis, muculis duabus occipitis, callis humeralibus, vitta latâ pleurarum et abdomine atris; alae basim versus dilutissime lutescentes, apicem versus leviter cinerascenles. - Long. corp. $1 \frac{3}{4}-1 \frac{5}{6}$ lin., long. al. $1 \frac{2}{3}-1 \frac{3}{6}$ lin.

Synon. Psila lateralis Loew, Wiener Monatschr. IV. 81. 
Caput flavum, occipite nigro-bimaculato et ocellis maculâ parvâ nigrâ inclusis; duo primi antennarum articuli concolores, terlius latiusculus et praeter basin flavam ater; seta antennalis dilute flavescens, breviter albo-pilosa; palpi atri; setae verticis nigrae. Thoracis dorsum flavum, callis humeralibus atris. Pleurarum dimidium superius atrum, stigmate tamen prothoracis flavo. Scutellum et metanotum flava, hoc utrinque maculâ nigrâ notatum. Setae solitae thoracis et scutelli nigrae. Abdomen tolun atrum. Pleurarum dimidium inferius cum pectore et cum pedibus totis dilutissime flavescens. Alae leviter cinerascentes, basim versus dilutiores et obsolete lutescentes; venae luteac, in alarum dimidio apicali subfuscae. - (Washinglon; Osten-Sacken.)

67. Psila biviltata, nov. sp. Oे et q. - Flava, arliculo tertio antennarum, triungulo frontali, maculis duabus occipitis, limbis lateralibus thoracis cum vilfá superâ pleurarum confluentibus et abdomine atris; alae basim versus dilutissime lulescentes, apicem versus rinereae, venis lale fusco-limbatis. - Long. corp. $1 \frac{3}{4}$ lin., long. al. $1 \frac{2}{3} \operatorname{lin}$.

Caput flavum, maculis occipitis duabus permagnis et triangulo angusto frontis inde ab ocellis fere usque ad marginem anticum pertinente atris; duo primi antennarum articuli concolores, tertius ater, quam in specie praecedente multo angustior; seta antennalis dilute flavescens, breviter albo-pilosa; palpi alri; setae verticis nigrae. Thoracis dorsum flavum, marginibus lateralibus antice latissime, postice minus late atro-limbatis; pleurarum dimidium superius totum atrum, stigmate prothoracis concolore. Scutellum et metanotum flava, hoc utrinque maculà maguà nigrâ notatum. Selae solitae thoracis et scutelli nigrae. Abdomen totum atrum. Pleurarum dimidium inferius cum pectore et cum pedibus totis dilute flavescens. Alae cinereae, in imâ basi dilutiores; venae fusco-nigrae, late fusco-limbatae, dimidio priore costae, venis auxiliari et longitudinali primâ cum basi secundae flavis. - (Connecticut; OstenSacken.)

68. Psila collaris, nov. sp. $\sigma^{7}$. - Fluva, thoracis marginibus antico el lateralibus, pleurarum villà lutissimá, metanoto toto abdomineque utris; alae omnium dilutissime lutescentes, cellula discoidali latiuscula. - Long. corp. $\mathbf{I}_{\mathrm{T}_{2}}^{\mathrm{s}}$ lin., Long. al. $1 \frac{1}{3} \mathrm{lin}$.

Thoracis dorsum flavum. marginibus antico ef lateralibus latissime atro-limbatis: sculellum flavum; metanotum totum pleurarum- 
que dimidium superius atra, stigmate tamen prothoracis flavo. Setae solitae thoracis et scutelli nigrae. Abdomen totum atrum. Pleurarum dimidium inferius cum pectore et cum pedibus totis dilutis. sime flavum. Alae hyalinae, vix dilutissime lutescentes, venis luteis, cellulâ discoidali quam in congeneribus paulo latiore. - (Connecticut; Osten-Sacken.)

69. Psila dimidiala, nov. sp. ․ - Flava, selis capitis, thoracis et scutelli concoloribus, abdomine atro: alae dilute lutescentes. - Long. corp. $2 \frac{1}{4}$ lin., long. al. 2 lin.

Ex rufo flava. Caput concolor, palporum apice nigro; seta antennalis subfusca, brevissime pubescens; setae solitae verticis, thoracis et scutelli luteac. Metanofum praeter latera et abdomen totum nigra. Pedes toti flavi. Alae dilute lutescentes, venis luteis. - (Red River; Kennicot.)

70. Psila sternalis, nov. sp. ơ. - Nigra, selis solitis et pube brevi pallidis, capite luleo, arliculo tamen tertio antennarum, puncto verticis el disco occipilis atris, pectore pedibusque dilutissime flavescentibus; alae hyalinae, vix levissime lutescentes. - Long. corp. $1 \frac{5}{6}$ lin., long. al. $1 \frac{3}{4}$ lin.

Nigra, subvirescens, pube setisque ordinariis pallidis. Caput flavum, disco occipitis, puncto verticis et tertio antenuarum articulo atris; seta antennalis alba, basim versus flavescens, breviter albo-pilosa; palpi toti flavi. Pleurae ex nigro piceae, triente infimo cum pectore et cum pedibus totis dilute flavescente. Alae byalinae, obsolete lutescentes, apicem versus dilutissine cinerascentes, venis luteolis. - (Middle States; Osten-Sacken.)

71. Psila levis, nov. sp. ․ - Alerrima, antennis tolis, facie praeter vittam mediam et fronte praeter triangulum angustum usque ad marginem anticum pertinentem et praeter verlicem obscure luleis, pedibus dilutissime flavicantibus; alae hyalinue, dilute lutescentes. - Long. corp. $1 \frac{2}{3}$ lin., long. al. $1 \frac{3}{4}$ lin.

Aterrima, nitidissima, pube pallidâ, setis solitis subfuscis vel fuscis. Caput saturate lateum, occipite toto, vertice, frontis trian. gulo anguslo fere usque ad marginem anticum pertinente et marginum lateralium dimidio superiore, faciei denique vittâ infra dilatatâ atris; antennae saturate luteae, selâ dilute flavicante et perspicue albo-pubescente; palpi nigri. Coxae et pedes flavicantes. Alae majusculae, basim versus magis angustatae quam in congeneribus 
plerisque, hyalinae, dilutissime lutescentes, venis luteis. - (NewHampshire.)

72. Chyliza apicalis Lw. C’ et ㅇ․ - Lutea, palpis. pleurarum villâ superá lateribusgue abdominis el melanoli nigris, alae hyalinae, apice, venae longiludinalis quartae segmenlo paenullimo et vena transversá posteriore dilute fusco-limbatis. - Long. corp. $2 \frac{1}{4}$ lin., long. al. $2 \frac{1}{6}$ lin.

Syn. Chyliza apicalis Loew, Wien. Monatschr. IV. 82.

Colore lacte luteo, in vitellinum vergente tincta, infra pallidior, modice nitens, pube brevi totius corporis pallidâ, selis tamen verticis, thoracis et sculelli nigris. Antennae fotae Juteae. setâ concolore, brevissime pubescente; palpi atri; foveae antennales interdum infra infuscatae et occiput interdum nigro-bimaculalum. Pleurae vittà superâ alrà ornalae; netanotum utrinque nigro-maculatum. Abdominis latera late nigra. Pedes dilutius lutei, femoribus posterioribus apicem versus saluratius tinetis, posticis nonnumquam ante apicem annulo subfusco cinctis. Alae hyalinae, vix levissime cinerascentes, venis fuscis, in imâ tantum alarum basi luteis; apex alarum late fusco-marginatus; vena transversa posterior cum paenultimo (in speciminibus aliis cum paenultimo et antepaenultimo) venae quartae segmento colore dilute subfusco limbata. - (Washington; Osten-Sacken.)

73. Hydrellia conformis, nov. sp. ô el ․․ - Glauco-cinerea. facie non carinatá pallide ochraceâ, untennis pedibusque nigris, primo tarsornem articulo rufo. - Long. corp. $\mathbf{I}_{\mathbb{T}^{\frac{1}{2}}}$ lin., long. a). $1 \frac{1}{3}$ lin.

Hydrelliae scapulari proxime affinis. Tola polline albido leviter aspersa, ex viridi-glauco cinerea, opaca. Facies non carinala, pallide ochracea; palpi concolores; antennae nigrae, radiis setae quinque vel sex; lunula frontalis cinereo-pollinosa. Humeri cum reliquo thoracis dorso concolores. Segmentum ultimum abdominis maris duobus praecedentibus simul sumtis aequale. Pedes nigri, femoribus glaucescentibus, genibus extremis et primo tarsorum articulo rufis, reliquis borum articulis nigro-fuscis, in imâ basi interdum obsolete rufescentibus. Alae cinereo-hyalinac, segmento costae tertio dimidiam secundi longitudinem modice excedente. - (Newport, Rhode Jsland; Osten-Sacken.) 
74. Scalella mesogramma, nov. sp. ․ - Albo-cinerea, villâ thoracis fuscà; alae dilute cinerascentes, albido-guttatae, venis nigris, transversis validioribus el obsolete nigro-limbatis. Long. corp. $1 \frac{1}{6}-1 \frac{1}{3}$ lin., long. al. $1 \frac{1}{6}-1 \frac{1}{4}$ lin.

Albo - cinerea, opaca. Caput concolor, proboscide et antennis nigris, his albido-pollinosis; setulae in oris margine et in facie rariores. In thoracis dorso vitla fusca conspicitur, antice integra, postice liueà albo-cinereâ divisa et paulo abbreviata. Pedes toti nigri, coxis, femoribus libiisque polline albo cinereis. Alae cinerascentes, gutlis difformibus albido-hyalinis, venis nigris, transversalibus validioribus, anguste et obsolete nigro-limbatis. - (Newport, Rhode Island; Osten-Sacken.)

75. Hippelates dorsalis, nov. sp. ㅇ․ - Luteus, vittis thoracis tribus confluentibus cinereo-nigris, segmentis abdominalibus prater primum singulis fascia basali atrâ, in maculas tres dilalatâ ornatis. - Long. corp. $1, \frac{1}{2}$ lin., long. al. 1 lin.

Luteus. Caput concolor; discus occipitis niger; ocelli maculâ subtriangulâ nigrâ circumdati, triangulo ocellari reliquo luteo. Apex antennarum infuscatus. Viltae thoracis tres latissimae, confluentes, posticae abbreviatae, polline lutescente cinerascentes et opacae. Abdominis segmentum primum obsolete fusco-trimaculatum; segmenta reliqua singulâ fascià basali nigrâ, ter in triangulum dilałatâ oruantur. Pedes dilute lutescentes. Halteres albidi. Alae hyalinae, levissime cinerascentes. - (Cuba; Gundlach.)

76. Oscinis carbonaria, nov. sp. ot. - Alra, modice nitens, triangulo ocellari magno et nitidissimo, genibus, libiarum apice tarsisque albido-testaceis, halleribus albidis, alis nigricantibus. - Long. corp. $\frac{3}{4}$ lin., long. al. $\frac{3}{4}$ lin.

Atra, modice nitens. Caput opacum, antennis, proboscide palpisque concoloribus; frons lata, holosericea, triangulo ocellari magno, aequilatero, superne margines fronlis fere attingente, nitidissimo; facies infra modice recedens. Thoracis dorsum polline fusco-cinereo levissime aspersum, subopacum. Abdomen nitidum, colore nonnihil ex atro in viridem vergente. Pedes nigri, genibus testaceis, extremo tibiarum apice tarsorumque articulis primis albido-testaceis, interdum sordide albidis, ultimis horum articulis nigris. Halteres ex flavo albidi. Alae ex cinereo nigricantes, venis fusco-nigris, tertiâ et quartâ parallelis, ultimo hujus segmento quam cellulâ discoidalis longiore, primo costae segmento secundum et secundo tertium superante. - (Jistrict Columbia; Osten-Sacken.) 
Nota. Oscinis carbonaria Oscin. variabili similis est. sed magnifudine corporis, fronte latiore, Hhoracis dorso leviter cinereopollinoso et costae segmento inter renas secundan et tertian interjecto breviore vere distinguitur.

ta
77. Oscinis dorsatis. nov. sp. o et 9. - Luteu, tertio antennurum articulo maximà ex parte, macula occipilali et melanoto atris, thoracis dorso vel tolo luteo, vel imperfecte cinereo-vittato, vel proeter scapulas et mangines laterales cineveo, larsis anticis reliquorumgue apice fuscis. - Long. corp. I lin., long. al. $\frac{1}{1} \frac{1}{2}$ lin.

Lutea, opaca. Caput flavum; frous lata, modice prominens, triangulo ocellari latissimo, brevi, lutescente, subopaco; antennac mediocres, articulis duobus primis luleis. terlio maximâ ex parte nigro, infra tamen semper luteo; sela anlennalis nigra et nigro-pubescens; facies brevis, modice recedens; genae anguslae; palpi dilute flavi; proboseis lutea, stipilis apice plerumque nigro, labellis modice elongatis. Thoracis dorsum luteum, polline subochraceo leviter aspersum, saepe vittis tribus obsoletis nigricantibus, lateralibus angustis, mediâ latâ et anlice eximie abbreviali variegatum, in speciminibus quibusdam praeter scapulas et margines laterales totum nigro-cinereum. Scutellum subplanum, luteum; metanotum atrum. Abdomen vel luteum. vel fuscum, basi tamen semper luteâ. Pedes dilutius lutei, tibiis posticis superne fusco-lituratis, tarsis anlicis tolis reliquorumque apicibus fuscis. Ilalleres albi. Alae cinereo-hyalinae, venis uigro-fuscis. Iongitudinalibus terliâ el quartì parallelis. - (Newport, Rhode Island; Osten-Sacken.)

78. Siphonella reliculat thoraceque tomento albo lineato-reticulatis. - Long. corp. $\frac{5}{6}-\frac{1}{12}$ lin., long. al. $\frac{1}{1}-1$ lin.

Nigra. Caput concolor; frous lala; riangulum ocellare magnum, lineis duabus longitudinalibus abbido-polliuosis in partes tres divisum; margines laterales frontis albido-pollinosi et nigro-maculati; reliqua frons lineis qualuor albido-pollinosis picta. Antennac ex ferrugineo ochraceae. margine apicali arliculi lertii interdum infuscato; facies infra producta; genae latiusculae, piceo-nigrae, orbiti tamen albido-pollinosá. Proboscis piceo-nignra. Thoracis dorsum polline albido et punctis interjectis nigris, in series longitudinales subconfluentibus reticulatum. Pleurae maculis aliquot parvis albidopollinosis ornalac; pectus inmaculalum. nilidum. Scutellum con- 
vexum, opacum. Abdomen piceo-nigrum, adversus basim sordide piceum. Pedes nigro-picei, trochanteribus, genibus, extremo tibiarum apice tarsisque luteis. Halteres fusco-nigri. Alae hyalinae, venis dilute subfuscis, secundâ brevi, segmentis ultimis tertiae et quartae parallelis. - (Cuba; Gundlaclr.).

79. Elliponeura debilis, nov. sp. $ð$. - Lutea, thorace nigro-villato, pedum posticorum tibiis et tarsis dilutissime subfuscis. - Long. corp. $\frac{1}{2}-\frac{7}{12}$ lin., long. al. $\frac{2}{3}$ lin.

Lutea. Caput subdepressum, concolor, occipitis maculâ nigrâ; triangulum ocellare magnum, latum, luteum, oculis tamen maculâ uninutâ nigrâ circumdatis; reliqua frons et facies angusta dilulius flavae; antennae luteae, breves, arliculo tertio rotundo, supra maculâ nigrâ nolato; oris aperlura ampla; proboscis brevis, retracta, flava, palpis concoloribus; genae angustae. Thoracis dorsum puncto humerali vittisque nigris pictum; vitta media latiuscula, postice valde abbreviata; viltae laterales subintegrae, utrinque paulo abbreviatae, ante suturam in maculam dilatafae; inter vitlam lateralem et alae basim lineola nigra interjecta est. In pleuris inter coxas anteriores macula triangula nigra conspicitur. Pedes dilute flavi, posteriorum tibiis praeter basim et tarsis plerumque subfuscis. Halteres dilute flavescentes. Alae hyalinae, levissime subcinereae, venis primis tribus leviler recurvis, validioribus, fuscis, venâ quartà leviter incurvâ, tenuissimâ, quintâ quam quarta paulo validiore, venulâ transversâ mediâ ad cellulae submarginalis basim valde approximatâ, transversâ posteriore nullâ. - (District Columbia; Osten-Sacken.)

Nota. Elliponeura, novum Oscinidarum genus, propter costam perpaulo ultra finem venae tertiae pertinentem inter Chloropina numeranda est; capite subdepresso, venis alarum primis tribus recurvis et venâ transversâ posteriore nullâ a reliquis horum generibus distinguitur.

80. Rhicnoёssa albula, nov. sp. ठ大 et \&. - Alba, pilis se. tulisque totius corporis concoloribus, fronte, antennis, tibiis tarsisque pallide luteis, horum apice nigro. - Long. corp. $1 \frac{1}{4}$ lin., long. al. $1-1 \frac{1}{6}$ lin.

Color cinereus, in segmentorum abdominalium marginibus posticis lutescens, in toto corpore sub tomento conferto albo latens. Vertex et occiput concolora, reliquum caput album, fronte tamen praeter margines laterales et antennis dilute lutescentibus, tertio horum arliculo saepe prope setae basin fusco. Pedes dilute lutescen- 
tes, femoribus praeter apicem, interdum etiam praeter basim cinereis et albo-pollinosis, ullimo tarsorum posteriorum articulo nigro, paenultimo nonnumquam subfusco. Alae albidae, venâ costali nigro-fuseâ, venis reliquis decoloribus. Pubes et setulac totius corporis albae. - (Newport, Rhode Island; Oslen-Sacken.)

81. Rhicnö̈ssa parvula, nov. sp. $\delta$ et $\mathcal{f}$. - Cinerea. pilis setulisque totius corporis nigris, fronte praeter verlicem lutê, facie albo-pollinosâ, genibus, tibiarum anticurum apice primisque duobus vel tribus tarsorum omnium arliculis dilule lutesrentibus. Long. corp. $\frac{1}{1} \frac{1}{2}$ lin., long. al. $\frac{1}{1} \frac{1}{2}$ lin.

Cinerea, opaca, pilis setulisque omuibus nigris. Vertex et occiput concolora; frons practer verficem lutea, utrinque albido-marginata; antennae nigro-fuscae, infra dilutiores; facies et genae dilute lutescentes, albo-pollinosae; palpi exalbidi. Pedes cinereo-nigri, genibus, tibiarum anticarum apice primisque duobus, rarius tribus primis tarsorum articulis lutescentibus. Alae albido-hyalinae, venâ costali atrâ, venis reliquis nigro-fuscis. - (Newport, Rhode Island; Osten-Sacken.)

82. Phyllomyza nitens, nov. sp. ठ'. - Nitida, alra. hal. teribus pedibusque concoloribus, larsis luteis, vená transversá posłeriore alarum nullâ. - Long. corp. $\frac{2}{3}$ lin., long. al. $\frac{7}{12}$ lin.

Atra, nilida. Caput concolor; frons atro bolosericea; triangulo ocellari nitido, ad anticum usque frontis marginem producto; lertius anteunarum articulus rolundus, magnus, multo tamen minor quam in mare Phyllomyzae securicornis Fall.. selâ brevissime puberulâ instructus. Facies nitida, concava. Palpi permagni, atri; proboscis fusca, geniculata, usque ad palporum apicem perlinens. labellis linearibus ad mentum usque reflexis. Pedes atri, tarsis praeter apicem extremum luteis. Halteres nigri. Alae cinereo-byalinae, costâ venisque tribus primis nigris, reliquis fere sine colore; vena transversa posterior deest, ita ut cellulae discoidalis ef posterior secunda in unam confluant, a cujus basi vena transversa mediat intervallo minuto distat. - (Penusylvania; Osten-Sacken.)

83. Agromyza setosa, nov. sp. \&. - Nigra, subopaca. thoracis dorso ante suturam setis iustructo. halleribus favis, alis cinereo-hyalinis, venis fusco-nigris, cellula discoidali brevi. - I.ong. corp. $1 \frac{2}{3}-1 \frac{3}{4}$ lin., long. al. 2 lin.

Tota nigra, subopaca, nigro-pilosa. Frons lata, selis longiori- 
lus validioribusque quam in Agromyzis plerisque inslructa. Antennae nigrae adversus basin fuscae vel ex fusco ferrugineae, setà omnium brevissime puberulâ. Thoracis dorsum, in congeneribus ante scutellum plerumque setas nullas praeter laterales gerens, ante suturam mediam setis duabus instructum. Pedes nigri, genibus ex. tremis obsolete fuscis. Alae cinereo-hyalinae, venis fusco-nigris, costali inde a primae apice modice incrassatâ; cellula discoidalis brevis, ita ut ultimum venae quintae segmentum antepaenultimo paulo longius sit; vena transversa media a cellulae discoidalis basi intervallo duplo majore quam ab apice distat. - (District Colum. bia; Osten-Sacken.)

84. Agromyza simplex, nov. sp. б. - Nilida, alva. pedibus halleribusque concoloribus, cellulâ discoidali brevi. - Isong. corp. $1-1_{\frac{1}{1}} \frac{1}{2}$ lin., long. al. $I_{6}^{\prime}$ lin.

Nitida, atra. Caput totum concolor, frontis holosericeae triangulo ocellari nitido, marginibus lateralibus subnitidis. Abdomen latiusculum, nitidissimum. Pedes et halteres toti nigri. Alae hyalinae, leviter cinerascentes, venis nigris, costali inde a venae primae apice incrassalâ; cellula discoidalis brevis, ita uf venae quintae segmenta ullima duo aequalia sint; venae transversae approximalie. posterior obliqua. - (Middle States.)

85. Agromyza virens, nov. sp. $\sigma$ et ㅇ. - Nigro-viridis, nilida, capite, pedibus halleribusque alris, alis latis, venis subfuscis, apicem versus obscurioribus. - Long. corp. $1 \frac{1}{3}-1_{6}^{5}$ lin., long. al. $1 \frac{2}{3}-1 \frac{3}{4} \operatorname{lin}$.

Agromyzae aeneiventri Fall., ab Americà septentrionali non alienae simillima, sed laetius splendens. Caput totum atrum, triangulo ocellari mediocri, aculo, modice nitente, orbitis frontalibus ansustis, subnitidis. Thorax ex viridi niger'; scutellum concolor. Abdomen obscure viride, terebrâ foeminae latå, atrâ. Pedes et halte res atri. Alae hyalinae, levissime cinerascentes, longiores et latiores quam in Agromyzâ aeneiventri, venis dilutioribus sed similiter dispositis, transversâ tamen posteriore ab alae margine minus remotả et a mediâ minore intervallo separatå; cellula discoidalis la. tior quam in Agromyzâ aeneiventri. - (Pennsylvania; OstenSacken.)

86. Agromyza magnicornis, nov. sp. ठ․ - Nigra, capite concolore, lunulâ frontali et proboscide sulphureis, antennis 
magnis, thorace albido-pollinoso utrinque sulphuren-limbato, abdo. mine nigro nilido, segmentorum marginibus sulphureis, pedibus nigris, genibus tamen sulphureis; alae hyalinae, segmento ultimo venae quartae quam paenultimum paulo longiore. - Long. corp. ${ }_{6}^{5}$ lin., long. al. $\frac{1}{1} \frac{1}{2}-1$ lin.

Caput nigrum, frontis subopacae lunulâ sulphurei. albo-micante; antennae atrae, majusculae, porrectac: proboscis sulphurea. palpi nigri. Thoracis dorsum et scutellum polline albido leviler aspersa, subcinerascentia, opaca, illud limbis lateralibus latiusculis sulphureis ornatum. Abdomen atrum, nitidum, marginibus segmentorum singulorum lateralibus et postico anguste et aequaliter sulphureis. Pedes nigri, genibus extremis sulphureis, tibiis tarsisque nigro-fuscis. Halteres sulphurei. Alae byalinae vix cineraseentes. venis fuscis, in imâ basi sulphureis; cellula discoidalis brevis; ullimum venae quintae segmenlum paenultimo paulo lougius; vena Iransversa media in cellulam discoidalem mediam inserta; vena transversa posterior obliquior, quam in Agromyzis esse solet. - (Pennsylvania; Osten-Sacken.)

87. Agromyza angulata, nov. sp. 오. - Alra. nitida, lunulâ frontali albo-pollinosâ, antennis parvis fusco-nigris, linề in utroque thoracis margine laterali tenuissima, ante alarum basim in pleuras demissâ et margine postico segmenti abdominalis ultimi fluvis, pedibus nigro et huteo-variis, ultimis duobus venue quintue segmentis aequalibus. - Long. corp. $\frac{1}{1} \frac{1}{2}$ lin., long. al. $1_{6}^{\prime}$ lin.

Atra, nilida. Frons opaca, triangulo ocellari marginibusque lateralibus subnitidis, lunulâ albo-pollinosâ; antennae parvae. niggro. fuscae; proboscis flava: palpi nigri. Thoracis dorsum levissime cinereo-pollinosum, nitidum, utrinque lineâ tenuissimâ flavâ. iude a callo humerali usque ad alarum basim pertinente ef hine in pleuras demissâ ornatum. Segmenti abdominalis ullimi marı̣o posticus anguste et dilute flavus. Fensora nigra, extremo apice flavo; libiae anticae testaceae, praeter basim et apicem plerumque infuscalae: tibiae posteriores nigro-fuscae, basi tamen et apice singularum te. staceis; tarsi testacei, posteriores non raro fusco-testacei. Ilalleres albi. Alae hyalinae, venis dilute subfuscis, in ima basi sulphurcis. cellulâ discoidali parvâ, segmentis venae quartae paenullimo el anlepaenultimo aequalibus, ultimis duobus venae quintae subaequalibus. - (Pennsylvania; Osten-Sacken.)

Nota. Marem possideo, qui a foemina frontis colore magis in fusco-nigrum vergente, triangulo ocellari marginibusque latera- 
libus non nitentibus ef polline albo lunulae minus conferto differt, sed in reliquis notis omnibus cum eâ optime congruit, ita ut de eâdem specie dubitare vix liceat.

88. Agromyza melampyga, nov. sp. ठ et ㅇ. - Flava, occipile praeter marginem, thoracis vittis, metanoto et extremo abdominis apice nigris. - Long. corp. $\frac{3}{4}-\frac{5}{6}$ lin., long. al. $1-1_{\frac{1}{1} \frac{1}{2}}$ lin.

Flava, fere sulphurea, abdomine paulo saluratius tincto. Occiput excepto margine tolum nigrum, reliquum caput totum flavum, antennis, proboscide palpisque concoloribus. Thoracis dorsum nigro-vilfatum, vittâ mediâ aequali, postice subito abruptâ et per lineam tenuissimam flavam dissectâ, viltis lateralibus per suturam flavam divisis, antice abbreviatis et obtusis, postice subintegris et acutis. Pleurae infra fusco-bimaculatae. Metanotum, terebra foeminae et hypopygium maris atra, nitida. Pedes flavi, tibiarum tarsorumque colore in luteum vel dilutissime subfuscum vergente. Alae hyalinae, venis fuscis, cellulâ discoidali brevi, ultimo venae quintae segmento paenultimum paulo superante, paenultimo el antepaenultimo venae quartae subaequalibus. - (District Columbia; OstenSacken.)

89. Agromyza coronata, nov. sp. ठ大 et \&. - Nitida, atra, occipile, antennis palpisque concoloribus, religuo capite, thoracis limbis lateralibus imâque alarum basi sulphureis; alae cinerascentes, venis nigris, cellulà discoidali minulâ, cellulis basalibus secundâ el prinıâ confuentibus. - Long. corp. $\frac{2}{3}$ lin., long. al. $\frac{3}{4}$ lin.

Caput laete sulphureum, occipite et triangulo ocellari atris, superiore frontis dimidio utrinque atro-marginato; antennae mediocres et palpi atri. Thorax et abdomen atra, nitida, marginibus tamen lateralibus illius laete sulphureis. Pedes toti atri. Halteres sulphurei. Alae cinereo-hyalinae, imâ basi sulphureâ, venis omnibus fusconigris; cellula discoidalis minuta; vena transversa media in cellulâ discoidali mediâ collocata, vel a basi paulo latius distans; primum venae longiludinalis quartae segmentum plane obsolelum, ita ut cellula basalis secunda cum primâ conjugatur. - (Cuba, Riehl; Pennsylvania, Osten-Sacken.)

90. Agromyza longipennis, nov. sp. ․ - Modice nitens, nigra, occipite antennisque concoloribus, reliquo capite luteo, pedibus luteo et nigro variegatis; alae longae, hyalinae, segmentis ultimis duobus venae quintae subaequalibus. - Long. corp. $1 \frac{1}{6} \mathrm{lin}$. long. al. $1 \frac{1}{4}$ lin. 
Caput luteum. occipile el triangulo ocellari nigris, frontis dimidin superiore utrinque nigro-marginato; antennae nigrae, articulis primis duobus praeter marginem superum ferrugineis; proboscis lutea, palpi concolores. Thorax niger. leviter cinereo-pollinosus, subopacus. Abrlomen minus latum, longiusculum, nigrum, modice nitens. Coxae nigrae, Irochanteribus tamen anteriorum luteis; femora atra. apice omnium lale luteo. Tibiae anticae subfuscae, basi late luteâ, tibiae posteriores fuscae, in imâ basi lufescentes; tarsi anlici subfusci, posteriores fusci. Alae longae, subangustae, hyalinae. venis fusco-nigris, in imà basi sulpliureis, costâ nigrâ; cellula discoidalis subbrevis, segmenla igilur ultima duo venae quintae subaequalia; vena transversa media ab utroque cellulae discoidalis fine aequali intervallo separala: segmentum primum venae quarlae subob. soletum. - (I)istrict (Olumbia; Osten-Sacken)

91. Agromyza marginata, nov. sp. ठ․ - Atra, nilida, frontis marginibus lateralibus, thoracis lineis lateralibus, segmentorum abdominalium marginibus posticis halleribusque sulphureis, pedibus nigro et sulphureo-variegatis; alae rinereo-hyalinae, ultimo venae quintae segmento quam paenultimum modice longiore. Long. corp. $\frac{3}{4}$ lin., long. al. $\frac{5}{6}$ lin.

Alra, nilida. Caput concolor; frons holosericea. ulringue late sulphureo-marginala, lriangulo ocellari nitido; anlennae totae atrae; genae pallide sulphurcae. peristomin lamen nigro: proboseis sulphurea, palpi nigri. Thora utrinque lineâ marginali sulphureâ. ad basim alarum dilatala ortulus. Scutellum tolum afrum et nilidum. Abdomen comcolor. margine postico scgmentorum singulorum anguste el acqualiter sulphmpos. Coxae nigrae, anticie apicem versus dilutiores; dimilium basale femorum omnium nigrum, apicale sulphureum; tibiac anlicae subfuscae, adversus basim lale sulphureat. reliquae fuscae vel fusco-nigrae, in imá basi dilutiores; Iarsi nigrofusci, antici dilutiores, adversus basim subsulphureac. Halleres sul. phurei. Alae cineren-hyalinae, venis nigris, in imà basi sulphureis; cellula discoidalis brevis. ita ut ultimum venae quinlae segmentum paenullimo modice sit longius; vena transversa media aequali intervallo ab utroque cellulae discoidalis termino distans. - (I)istrict Columbia; Osien-Sacken.)

92. Agromyza parvicornis. nov. sp. ơ et ㅇ. - Atra, vitida. fronte opacá nigro-fuscâ, antennis ferrugineis, pedibus nigro et lurido variis, halleribus albis; alae latiusculae, venis testa. 
ceis, quintae segmento ultimo quam paenultimum mullo breviore. Long. corp. $1-1 \frac{1}{12}$ lin., long. al. $1 \frac{1}{6}-1 \frac{1}{4}$ lin.

Atra, nitida, nigro-pilosa. Caput concolor, fronte practer triangulum ocellare et praeter angulos verticis opacâ. ex nigro fuscà. Antennae parvae, ferrugineae, articulis primis duobus saepe flavo. ferrugineis, raro tolae flavo-ferrugineae. Genae angustae, setulae mystacinae parvac; proboscis subfusca vel lutea; palpi nigri. Pedes nigri, genibus lurido-testaceis, libiis saepe nigro-fuscis, tarsis lurido-testaceis, apicem versus fuscis, posterioribus quam antici obscurioribus. Halteres albi. Alae latiusculae, cinereo-hyalinae, venis testaceis vel dilute subfuscis, cellulâ discoidali mediocri, segmentis venae quartae paenultimo et antepaenultimo subaequalibus, ultimo venae quintae quam paenultimum multo breviore. - (Wa. shington; Osten-Sacken.)

93. Agromyza neptis, nov. sp. ठ大 el ㅇ․ - Alra, nitida, fronte opacâ, antennis mediocribus nigris, pedibus nigro et luteo variis, halleribus albis, alarum venis teslaceis, in imâ basi sulphureis, quintae segmento ullimo quam paenullimum paulo breviore. Long. corp. $\frac{3}{4}$ lin., long. al. $\frac{1}{1} \frac{1}{2}$ lin.

Praecedepti simillima, sed multo minor, fronlis colore in fuscum non vergente, antennis pro portione majoribus et totis nigris, segmentis denique venac quintae ultimis duobus minus inaequalibus sine dubio diversa. - (District Columbia; Osten-Sacken.)

94. Lobioptera indecora, nov. sp. ․ - Opaca, nigra, pedibus halleribusque concoloribus, alis saturale cinereis. - Long.

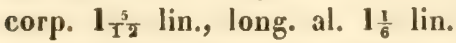

Lobiopterae ludenti Wahlb. proxima. Nigra, opaca, nigro-pilosa, capite thoraceque polline cinereo leviter aspersis, abdomine non pollinoso et minus opaco. Frontis lalae lunula angustissima testacea. Antennae et proboscis nigrae, palpis concoloribus; setarum validarum series peristomii usque ad faciem mediam pertinens. Pedes el halteres toti nigri. Alae subhyalinae, salurate cinereae, venis ex fusco nigris, cosłâ nigrâ. - (Nebraska.)

95. Lobioptera leucogastra Lw. ${ }^{7}$. - Nigra, pedibus halteribusque concoloribus, abdomine praeter segmentum primum niveo, alis albidis. - Long. corp. $1 \frac{1}{3}$ lin., long. al. $1 \frac{1}{6}$ lin.

Syn. Milichia leucogastra Lw., Wien. Ent. Monatschr. V. 43.20.

Nigra, subopaca, nigro-pilosa, thorace polline subfusco obsolete asperso, abdomine praeter segmentum primum polline candidissimo 
confertim vestito. Frons modice lata, lunulà angustissimà concolore. Antennae et proboscis nigrae, palpis concoloribus. Pedes et halteres toli nigri. Alae albo-hyalinae, venis ex luteo dilute subfuscis, costâ obscuriore. - (Cuba; Poey.)

96. Leucopis simplex, nov.sp. Ђ. - Nigricans, tota polline albo conferlissime aspersa, antennis palpisque atris, pedibus nigris, basi el apice tibiarum primisque yuatuor tursorum arliculis luteis. - Jong. corp. $\frac{3}{4}$ lin., long. al. $\frac{3}{6}$ lin.

Color corporis niger polline conferto albo aequaliter obtectus, abdomen immaculatum. Antennarum palporumque color ater. Femora nigra; tibiae fusco-nigrae, in basi latius, in apice minus late luteae; tarsi lutei, ultimo tamen singulorum articulo nigro-fusco. Halteres albidi. Alae hyalinae, venis fuscis. - (New York; OstenSacken.)

97. Cacoxenus semiluteus, nov. sp. б’ et $9 .-$ Ex luteo cinereus, antennis, apice scutelli, abdomine pedibusque saturate lu. teis. - Long. corp. $\frac{1}{1} \frac{1}{2}$ lin., long. al. $\frac{1}{1} \frac{1}{2}$ lin.

Color capitis et thoracis nigricans polline luteo opacus fit et in luten-cinereum mulatur. Frons lata, lunulà angustissimå concolore; antennae salurate luteae, articulo tertio subfusco vel in margine supero infuscato. Color lutescens scutelli adversus basim in colorem thoracis abit. Abdomen tolum saturate luteum vel luteotestaceum. Pedes cum abdomine concolores. Halteres exalbidi. Alae hyalinae, subcinerascentes, venis ex luteo testaceis. - (Cuba; Poey.)

98. Trigonometopus villat us, nov, sp. ‥ - Pallidus, fere exalbidus, antennis, maculis occipitis duabus, dorsi villis lateralibus latissimis lineisque duabus intermediis, scutello denique praeter lineam mediam subfuscis. - Long. corp. 1 $\frac{3}{6}-1 \frac{6}{6}$ lin., long. al. $1+\frac{1}{2} \operatorname{lin}$

Color totius corporis fere exalbidus, in stramineum vergens. Antennac breves, subfuscae, lateribus adversis pallidioribus, articulo tertio obtuso. Frons in dimidio anteriore obsolete subfusco-bivit. tala, praeter setas ordinarias pilis brevibus nigris, prope marginem anticum crebrioribus, in reliquâ fronte valde raris instructa. Occiput utrinque maculà magnâ ex ferruginco subfuscâ nolatum. Thoracis dorsum polline albo obsolete aspersum utrinque villam latissimam integram, ex ferrugineo subfuscam et in areâ interjeclà lineas duas obsoletiores subfuscas gerit. Scutellum ex ferrugineo subfuscum, lineã tamen mediâ exalbidâ. Abdomen in vivo totum 
exalbidum esse suspicor, in mortno dimidium anterius segmenlorum singulorum praeter primum nigrum video. Pedes toli exalbidi. In alis vitta integra dilute fusco-cinerea, venarum tertian et quartam includens et nubecula venac secundae finem obumbrans conspiciunfur; alarum triens anticus dilute ex cinereo lutescens, posticus cinereus; venae in triente antico dilutissime lutescentes, sed finis secundae el venae reliquae totae fuscae; segmentum ultimum renae quartae non appendiculatum. - (Georgia.)

99. Phylomyza nervosa, nov. sp. ㅇ. - Cinerea, capile marginibusque laterulibus thoraris favis, tertio antennarum articulo palpisque atris, pedibus teslaceis, apicem versus fuscis. alis nigrocinereis, venis fuscis, omnibus praeler quartam ralidissimis. long. corp. $1_{6}^{1}-1 \frac{1}{4}$ lin. long. al. $1 \frac{1}{3}$ lin.

Cinerea, opaca. Caput flavum, occipite praeter margines el maculâ ocellos includente nigris; tertius antennarum arliculus majusculns, ater; palpi atri. Thoracis margines laterales cum pleurarum margine supero flavescentes. Scutellum cinereum, opacum. Metanotum et abdomen nigra, subopaca, ultimo hujus segmento postice flavo-marginalo. Coxae et pedes luteo-lestacei, femoribus posticis ante apicem fusco-lituratis, tibiis infuscatis, apicem versus ob. scurioribus, tarsis totis saturate fuscis. Halteres dilute flavicantes. Alae nigro-cinereae, venis nigro.fuscis, omnibus praeter quartam lenuiorem validissimis. - (District Columbia; Osten-Sacken.)

100. Phytomyza geuualis, nov. sp. ․ - Obscure cinerea, opaca, capite favo, tertio antennarum articulo palpisque atris. pedibus nigris, coxis anticis, coxarum posteriorum apice genibusque flavis, alis hyalinis levilev cinerascentibus, venis tribus primis reliquas crassitie et obscuritate vincentibus. - Long. corp. $\frac{3}{4}-\frac{5}{6}$ lin., long. al. $\frac{1}{1} \frac{1}{2}$ lin.

Obscure cinerea, opaca. Caput flavum; occiput nigrum, infra late flavo-marginatum; ocelli maculâ parvâ nigrâ inclusi; margines laterales frontis albicantes. Articulus tertius antennarum et palpi atri. Thoracis dorsum utrinque lineâ flavâ, propter tenuitatem obsolefâ pictum. Scutellum totum cinereum. Abdomen nigrum, modice nitens, marginibus posticis segmentorum primi et secundi tenuissime, ultimi anguste flavis. Pedes tenues, nigri, coxis anticis totis, posteriorum apice genibusque omnibus flavis. Alae hyalinae, subcinerascentes, imâ basi flavicante, costâ venisque tribus primis quam reliquae validioribus et subfuscis, his fere decoloribus. (District Columbia; Osten-Sacken.) 


\title{
Diptera Americae septentrionalis indigena.
}

\author{
Descripsit
}

H. L $\quad \boldsymbol{o} \quad \boldsymbol{e} w$.
C e n t u r i a n o n a.

1. Ditomyia enzona.

2. J'lesiastina tristis.

3. laula.

4. Asyudylum coxale.

5. Macrocera hissula.

6. clara.

7. - inconcinna.

8. Platyura divaricala.

9. - diluta.

10. - mendica.

11. mendosa.

12. - melusoma.

13. Empheria balioplera.

14. - didyma.

15. - nepticula.

16. I'olylepta fragilis.

17. Sciophila omensta.

18. - oblruncala.

19. - appendiculata.

20. - biseriata.

$21 . \quad$ tantilla.

22. Lasiosoma yuadralula.

23. Endicrana obumbrata.

24. Syntemna polyzona.

25. Boletina tririncta.

26. Phlhinia tanypus.
27. Giaphyroptera melaena.

28. decora.

29. - opima.

$30 . \quad$ sublunala.

31. oblectubilis.

32. Leja sovorcula.

33. - abbreviala.

34. Acnemia psylla.

35. Docosia dichroa.

36. Rymosia filipes.

37. Trichonta vulgaris.

38. - foeda.

39. Zygomyia ignobilis.

40. - ornata.

41. Epirypla pulicaria.

42. Mycothera paula.

4:3. Mycelophila exslincla.

44.

bipusedula.

45. - mutica.

46. - inculla.

47. pinguis

48. - scrularis.

49. - Trichonola

50. - fallax.

51. - sigmoides.

52. - quatuornotula 
53. Myceiophila polita.

55. monochaeta.

56. Sciara sciophila.

57. - ochrolabis.

58. Trichosia hebes.

59. Dilophus breviceps.

$60 . \quad-\quad$ obesulus.

61. - tibialis.

62. Xylophagus longicornis.

63. - rufipes.

64. abdominalis.

65. P'tolina fasciala.

66. - majussula.

67. Oncodes costatus

6s. Obsebins sulphuripes.

69. Thereua albiceps.

70. - flavicincla.

71. gilvipes.

72. - strigipes.

73. Psilocephala variegala.

74 - sculellaris.

$75 . \quad$ erythrura.

76. Gieron macropterus.
77. Geron vilripennis

78. - albidipennis.

79. Myiolepla varipes.

so. Oithoneura usluluta.

81. Callomyia lalpula.

82. - tenera.

83. Platypeza anthrax.

54. Sanrropus carbonifer.

85. Coenosia tricincta.

66. Schoenomyza chrysostoma.

57. Cordylura gracilipes.

85. - inermis.

59. - scapularis.

90. - glabra.

91. - munda.

92 - latifrons.

93. - gagatina.

94. - aculicornis.

95. - megacephala.

96. - albibarba.

97. Loxocera collaris.

98. - fallax.

99. Chyliza notala.

100. Mycelaulus longipennis.

1. Dit omyia euzona, nov. sp. б'. - Lulea, abdomine nigro-fascialo, alarum fasciis tribus difformibus subfuscis, primà sub. basali et incompletâ, ultima apicem alae explente. - Long. corp. 3 lin., long. al. $3_{\frac{1}{2} 2}$ lin.

Ditomyiae fasrialue Heig. similis, lutea, capite concolore. Scapus antennarum dilute luteus, flagellum nigrum, hujus lamen articulo primo in basi luleo; palpi nigri. Dorsi viltae laterales plerumque lineâ nị̂ro-fuscà circumscribuntur'; praeterea inierdum linea subtilissima media colore fusco tingitur. Scutellum praeter basim nigro-fuscum. Pleurae fuseo-maculatac, uraculâ supra halteres majore nigro-fuscâ. Abdominis sçgmenla singnula fasciâ posticâ nịgrâ, in medio abdomine el in abdominis marginibus lateralibus valde dilatalâ ornautur; forceps analis nigro-fuscus, apicem versus niger. Coxae et pedes lutescentes. Halteres lutei. Alae subcinerascentes, 
colore fusco-cinereo trifasciatae; fascia prima prope basim alac a costà orieus usque in cellulam basalem primam pergit, ubi obsolescit vel plane evanescit; fascia secunda utrumque alae marginem atlingit, anlicum ante cellulae subcoslalis apicem. posticum ubi vena paenultima excurrit; fascià terlia alae apes lale expletur. - (D)islricl Columbia: Osten-Sacken.)

Nota 1. Quod ad Mycetophilidarum in genera dintribulionem altinct, monographiam Mycetophilidarum Europacorum a Winnertzio conscriplam, quantum fieri potuil, serquatus sum. (yos ut possem, generibus, in quibus constiluendis vir oculalissimus Europacis tantum speciebus usus est, ex parle saltem latiores fines tribuere sum coactus. Praecipuan venarum in alis decursûs et jubclionis, quippe quae notas et facillimas et certissimas praebeant, rationem habendam putavi. Frontis vero et palporum structuram minns curandam censui; nam in speciminibus unicis et exsiccatis saepe tam incerto cognoscitur, ut facile in errorem inducamur. Neque ocellorum numerum et dispositionem nimis grande momentum habere opinor; quum enim in speciebus maxima inler se propinquitale junctis ocellorum disposilio diversa sil, in generibus constituendis eam patet non esse magni pouderis; nu. merus autem eorum, qui in unicis iisque exsiccatis speriminibus saepe prorsus nullo modo extricatur, pariter ad genera designanda parum idoneus videlur. Sed ubicunque in rebus gravioribus species, quas descripsi, a speciebus Europaeis, cum quibus in eodem genere posilae sunt, differunt, discrimina diligenter notare non neglexi.

Nota 2. Nomina, quibus venas ef rellulas alarum dislinxi. recte intelligel, qui memor est Mycetophilidas vena longindinali secundâ carere et seclorem marginalem rum sectore submarginali in unum coaluisse; hic jgitur, si vena longiludinalis terlia simplex est. unam cellulan marginalem. sin vona longitudinalis lertia ramum antice emillit, duas efficit cellulas mangiuales, quas post venam longitudinalem terliam cellula posterior prima sequilur.

2. Plesiastina tristis, nov. sp. F. - Tola nigro-fuscu. pleuris dilutius fuscis, apice abdominis luteo, alis obscure cinereis vel subnigricantibus. - Long. corp. $2_{-\frac{7}{2}}^{7}$ lin. lons. at. $2 \frac{2}{3}$ lin.

Caput nigrofuscum, vertice antenuarumque llagello purins ni. gris. Thorax nitens, nigro-fuscus, pleuris el melanoto dilulius fuscis. Aldomen fusco-nigrum vel nigrum, nigro-pilosum, segmento 
ultimo ejusque appendicibus luteis. Pedes cum coxis saturate fusei, trochanteribus tamen genibusque extremis sordide exalbidis. IIalteres nigri, pedunculi dimidio basali luteo. Alae saturate cinereae vel subnigricantes, cellulâ posteriore secundâ quam pedunculus longiore. - (District Columbia; Osten-Sacken.)

3. Plesiastina lauta, nov. sp. ठ․ - Pallide flava, verlice. antennarum flagello, thoracis vittis abdomineque praeter segmentorum singulorum margines nigro-fuscis, alis dilute cinerascentibus. - Long. corp. $2 \frac{1}{3}$ lin, long. al. $2 \frac{5}{T} 2$ lin.

Dilute flavescens. Antennarum flagellum fusco-nigrum; vertex maximâ ex parte fuscus. Thoracis dorsum nitens; lascia media nigro-fusca, adversus marginem anlicum dilutior, lineâ pallidâ obsolete divisa; villae laterales fusco-nigrae. Pleurae immaculatae. Al.domen dilute llavescens, marginibus segmentorum singulorum omnibus pallidis; venter totus dilute flavescens. Pedes dilule flavescentes, tarsis apicem versus nigricantibus, tibiarum calcaribus nigris. Halteres pallidi. Alae dilute cinerascentes, colore cinereo adversus apicem et adversus marginem posticum paulo saluratiore; cellula posterior secunda quam pedunculas paulo brevior vel perlunculo aequalis. (New-York.)

4. Asyndulum coxale, nov. sp. ․ - Nigrum coxis pedibusque flavis. trorhanteribus tamen el larsis nigricantibus, alis ciuereo-hyalinis, adversus apicem el adversus marginem posticum paulo saluralius cinereis. - Long. corp. $2 \frac{1}{2}$ lin., long. al. 2 lin.

Nigrum, capite. antennis et proboscide concoloribus. Pili to tius corporis nigri. Mesolhoracis margo auticus latera versus anguste flavus. Scutelli latera lutescentia. Abdomen totum nigrum, hypopygio concolore. Pedes sordide flavi, trochanteribus, calcaribus libiarum tarsisque subnigris. Halteres ex luteo subfusci, capitulo superne nigrofusco. Alae subhyalinae, colore ex fusco cinereo leviter linctae, adversus apicem et adversus dimidium apicale marginis postici paulo saturatius cinereae; vente alarum nigro-fu. scae, similiter atque in Asyndylo femorali Mcig. ductae. - (Hudsons-Bay Territory; Kennicott.)

5. Macrocera hirsula, nov. sp. ठ․ - Lutea, nigro-pilosa, abdomine apicem versus nigro, alarum cinerearum maculà mediâ fuscâ, fasciâ subapicali apiceque frusco-cinereis. - Long. corp. "2 ${ }^{7}{ }^{7}$ lin., long. al. $2 \frac{1}{2}$ lin. 
Lutea, tota pilis nigris quam in speciebus reliquis Iongioribus vestita. Vertex subfuscus; antemae pro portione modice Ionura. sesquialteram corporis longiludinem vix superantes. apicem versus nigricantes, Thoracis villae dorsales pleurarumque maculae subfuscae. Ablomen apicem versus nigrum; hypopygium fuscum. Coxae dilute lutescentes, nigro-pilosae. posteriores in apice fuscae. Perles dilute lutei, larsis subfuscis. Halteres pallidi. Alae colore ex luteo ciuerco levissime tinclae, adversus apicem ef adversus marginem posticum pilis longioribus instructae, maculâ centrali majusculì fuscá, fascia subapicali inlegrà el apice ex rinereo fuscis: apex ve. nae longitudinalis primae non incrassalus; ramulus anterior venae longiludinalis tertiae perlongus et procumbens. - (District Columbia; Osten-Sacken.)

6. Macrocera clara, nov. sp. o et 우 - Gracilis. dilute lutea, basi segmentorum abrlominalium singulorum fusrit. alis liyalinis, fascia media antice abbreviata et postice deliguescente. maruli

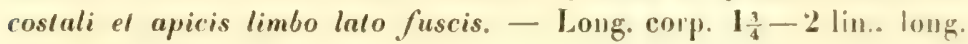
al. $2-2 \frac{1}{4} \operatorname{lin}$.

Gracillima, dilute lulea, nudiuscula, pilis folius rorporis palli dis. Antennac praeter basim luteam fuscae, teunes. perlongae. ma. ris quadruplicem, foeminae triplicem corporis fongitudinem fere aequiparenles. Thorax immaculatus. Abdomen pilis longiorihus pallidis vestitum, segmentis singulis alversus banim fuscis. Coxae et pedes dilute lulescenles, tarsis apicem versus subluscis IIalleres pallidi. Alae hyalinae, in apice ol in apieali marginis postici dinidio pilis longioribus aspersae; apex venae longiludinalis primae incrassatus et fuscus macula fuscâ cum vena longiludinali tertio conjungilur; in mediâ alâ fascia angularis fusca exslat. quate ante ve. nam longitudinalem tertiam subito priermupilur, postice sero sub. obsoleseens cum venâ paenultima marginem petit: apex alac limbo lato fusco ornatur; ramulus anterior venae longiludinalis ertiar breviusculus, obliquus, pallidus. - (Districl Columbia; Osten. Sacken.)

7. Macrocera inconcinna. nov. sp. ‥ - Luleu. alis rinereis, maculi centrali fusci pictis. apice venue longiludinalis pri. mae incrassato. - Long. corp. I! lin.. long. al. 2 lin.

Lutea. nudiuscula, viltis thoracis abdominisque fasciis ex luteo subfuscis, obsoletissimis. Antennae practer basim nigrae, sesquial. teram corporis longitudinem superantes. Pedes dilute lutesceutes, 
larsis nigrofuscis. Haltcres lutei. Alae ex subfuseo cinereac, adversus apicem et adversus marginem poslicum pilis longioribus vestitac et colore paulo saturatius cinereo tinclae; apex venae longitudinalis primae incrassalus; ramulus anterior venae longitudinalis tertiac brevis, sed obliquus; in modiâ alâ macula majuscula subfusca. inde a lineâ longiludinali fuscâ cellulae sulımarginali primae inscriplâ usque ad venam antepaenultimam pertinens conspicitur; praclerea maculac subfuscate cuncalae vestigium in cellulâ basali ap. parel. - (District Colnmbia: Osten-Sacken.)

S. Platyura divaricala, nov. sp. o'. - Lulca. ullimo abdominis segmento fusco, hypopygio nigro, alsum parte apicali fuscâ, extremo tamen apice dilutiore, ramulo anteriore venae terline perpendiculari et cellulà posteriore secundâ quam in Platyurâ sublerminali Say mullo latiore. - Long. corp. $\mathbf{I}_{\frac{7}{1} \frac{7}{2}}$ lin., long. al. $I_{-\frac{7}{2}} \operatorname{lin}$.

Lutea Antennarum flagellum breviusculum, fuscum. Segmentum ullimum abdominis fuscum, bypopygium lotum fusco-nigrum. Alae sublulescentes. triente apicali ex cinereo fusco, extremo apice cincreo; vena auxiliaris paulo ante cellulae marginalis initium in costam exit: ramulus anterior venae longitudinalis tertiae perpendicularis; cellula posterior secunda apicem versus magis dilalatur quam in Platyura subterminali Say et quam in reliquis speciehus hic enumeratis. - (Georgia.)

9. Platyura diluta, nov. sp. $ఠ$ et 오. - Lutea, segmento abdominali ullimo maris hypopygrioque fuscis, alis fascia subapicali, postice abbrevialâ, dilule fuscá pictis, ramulo anteriore venae ter. tiae obliquo. - Loug. corp. $2 \frac{1}{2}$ lin., long. al. $2_{\frac{1}{2}}^{\frac{1}{2}}$ lin.

Lutea. Antennarum flagellum breviusculum, fuscum vel subfuscum. Ima hasis segmentorum abdominalium singulorum plerumque subfusca; hypopsgium maris cum nltimo abdominis segmento salurate fuscum. Pedes dilutissime lulescentes. Tarsis nigricantibus. Halıeres pallidi. Alae lutescentes, viltâ subapicali postice abbreviati dilute subfuscâ; ramulus anterior venac longitudinalis tertiae obliquus. sed brevis. - (District Columbia; Osten Sacken.)

Nota. Haec nostra Platyuru dilula a Platyura subterminali Say distinguitur alarum fascià ab apice minus remolà, dilutiore cf postice magis abbreviatà; praeterea vena longiludinalis tertia Platyurae subterminalis ramulum perpendicularem, Platyurae nostrae obliquum enillit. 
10. Platyura mendica, nov. sp. L. - Lutea. sesmentorum abdominalium singulorum basi subfuscit. alis aequaliter subcinereis. veni auxiliari paulo ante cellulue marginalis basim in costam e.tcurrente, venae terliae ramulo anteriore longinsculo. obliguo. Long. corp. $1 \frac{1}{2}$ lin., long. al. $1 \frac{1}{2}$ lin.

Lutea, pedibus dilutioribus, tarsis nigricantibus. Antemnarmm flagellum breviusculum. fusco-nizrum. articulis duobus vel tribus primis dilulissime luleis. Segmenta abdominalia singula adversus basim subfusca. Halteres paltidi. Alac aequaliter el dilule luteo-cinereac. venis fuscis; vena auxiliaris paulo ante venac tertiae inilium costam petit; venae longitudinalis tertiae ramulus anterior longiusculus el obliquus; cellula marginalis secunda longa ef latiusurula. - (Nerv-York; Osleu-Sacken.)

11. Platyura mendosa. nov. sp. $\delta$ - Iulea. alis dilute Inteo-cinereis, vente longitudinalis tertice apice colore saturalius cinereo rircumfuso, vend auxiliari perbrevi. - Long. corp. 1!' liu.s long. al. $1 \frac{1}{1} \frac{1}{2} \operatorname{lin}$.

Iutea, colore abdominis in subfuscum vergente, tarsis nigricantibus. Antennae adversus basim luteac, adversus apicem fuscae. Halleres pallidi. Alae dilute luteo-cinereae. adversus costam magis lutescentes. venis luteis. costali et longiludinalis tertiae apice obscurioribus, hoc nubeculà cinereâ circumfuso; vena auxiliaris perbrevis longe anle venae tertiae basim cum costa conjungilur; venae longitudinalis quartae basis a venulà transversâ intervallo minore quam in Platyuris plerisque distat; ramulus anterior venae longiludinalis tertiae obliquus; cellula marginalis secunda perlonga, sed angusla. - (I)istrict Columbia; Osten-Sacken.)

12. Platyura melasoma, nov. sp. +. - Vigra. halleribus pedibusque dilute luteis, alis ex luten cineruscentibus, apice tamen adversus costam subfusco, venula transversi subrostali nulli. Long. corp. 3 lin., long. al. $2 \frac{2}{2}$ lin.

Nigra. Mesolhoracis margo anticus latera versus marginesunue laterales anguste lutei. Sculellum nigro-fusem, luteo marçinatum. Abdomen nigrum et nigro-pilnsum. colore segmenti primi in fuscum vergente. Pedes cum coxis dilute lutescentes, libiis modice obscurioribus, larsis nigricantibus. Alac sublugalinae. dilute luteocinereae. appice saluratius cinereo, adversus costam subfusco; venae ex luteo subfuseae, costalis obscurior; vena auxiliaris, reliquis tenuior et-pallidior, ibi in coslam excurrit ubi vena lerlia incipit, cum veni 
longiłudinali primâ venulà transversâ nullâ conjungilur; cellularum marzinalium prima anguste aperla, altera pro portione longa: ramuIus anterior venae longiludiualis lertiac longiusculus ef obliquus. (District Columbia; Osten-Sacken.)

13. Empheria balioplera, nov. sp. \&. - Magna, alarum cellulâ marginali primá quam cellulae posterioris secundae pedunculus longiore, venulâ transversâ subrostali prope basim cellulae mar. ginali primae inserta. - Long corp. $3 \frac{1}{6}$ lin., long. al. 3 lin.

Istea vel sordide lutea, pilis totius corporis nigris. Caput. paulo obscurius; antemuac rufo-ferrugineac, apicem versus nigrac; palpi nigri. Abdomen exempli descripti contusum, ita ut discernere nequeam, num segmenta singula postice nigro-marginata sint. Color tibiarum quam femorum impurior; larsi nigricantes. Alae ex cinereo lulescentes, adversus costam luleac; vena costalis ultra ve. nae longitudinalis tertiae finem paululo producta; venula lransversa subcoslalis prope basim in cellulam marginalem prinam inserta; haec cellula permagna. quam cellulac posterioris secundae pedunculus longior'; macula fusca, inde a veni auxiliari usque ad venam longiludinalem quartam pertinens, venulam fransversam subcosia. lem, venae tertiae segmentum primum veuulamque transversam ordinariam excludit et in venâ quarlà usque ad ccllulae posterioris secundac basim producitur. ita ut pedunculus hujns cellalae fuscolimbatus sil; renae tortiae ramulus anterior, quo cellularum marginalium prima a secundâ distinguilur, maculâ parvâ fuscâ circumdatur; apex a!ac ut in Empheriis plerisque lale fuscus; anguli postici dimidium apicale fere totum fuscum, extremo lamen ejus apice excepto. - (Illinois: Le Baron.)

14. Empheria didyma, nov. sp. \&. - Majuscula, alarum rellulá marginali primâ guam cellulae posterioris serundae pedun. rulus multo breviore, venulâ Iransversâ subcostali ab ulrogue ejus termino pari intervallo separalâ. - Long. corp. $2 \frac{5}{6}$ lin., long. al. $2 \frac{2}{3} \operatorname{lin}$.

Synon. Scioplila bimaculata Loesw, Centur. VII. No. 9.

Lutea. Flagellum antennarum fusco-nigrum; palpi nigri. Alıdominis segmenlum primum margine postico lateribusque exceptis nigro-fuscum; in segmentorum intermediorum marginibus posticis maculac binae transversae nigrae conspiciunlur. Tarsi apirem versus nigricantes. Halteres lutei. Alae dilute cinerascentes, adversus costam obsolete sublutescentes; vena coslalis ultra venae longiludi. 
16. Polylepta frugilis, nov. sp. Q. - Nigro-fusca, antennarum basi, coxis pedilusque praeter larsos pallide flavis, alis ri. nereis, venà muxiliari ubi venulam subcostalem emiltit subito abruptâ, cellulâ marginali primâ majusculâ, duplo longiore quam latiore. - Long. corp. 2 lin., long. al. $1 \frac{1}{1} \frac{1}{2}$ lin.

Nigro-fusca, polline albido levissime aspersa, subopaca. Antell. nac fusco-nigrae, imâ flagelli basi scapoque luteis, primo tamen hujus articulo superne fusco Palpi pallide lutescentes. Coxae et pedes dilute flavicantes. lassis praeter imam basim fusco-nigris. Hal. teres pallidi. Alae subh alinae. colore ex fusco cinereo dilute tinctae; venae fuscae; vena coslalis venam longitudinalem tertiam non transgredilur; cellula marginalis prima majuscula el duplo fere longior quam latior est; anticus ejus margo venulâ transversâ subcostali in partes aequales dividitur; vena auxilioris, inde ab alae basi usque ad venulam Iransversam subcostalem valida. hic subito finem habel; venula transversa ordinaria brevitate excellit; cellulae posterioris secundae pedunculus, quam cellula ipsa paulo brevior, duplicem cellulae marginalis primae longitudinem satis excedit; cellulae posterioris quartae basis ab alae basi paululo longius abest quam cellulae posterioris primae hasis. - (Massachusetts.)

17. Sciophila onusta, nov. sp. ․ - Lutea. antennarum flagello, viltis thoracis duabus latissimis segmentorumque abdominalium dimidio posteriore fusco-nigris. - Long corp. $1 \frac{5}{6}$ lin., long. al. $1 \frac{1}{1} \frac{1}{2}$ lin.

Lutea, pilosula, pilis validioribus nigricantibus. reliquis pallidis. Caput concolor: vertice subfusco; scapus antennarum dilute luteus, flagellum fusco-nigrum, articulis primis plermmque dilute luteis; palpi subfusei. Thoracis dorsum vittis duabus lalissinis fusco-nigris, antice abbreviatis piclum; praeterea in antico dorsi margine interdum vittae mediac intium subfuscum conspicitur. Discus scutelli subfuscus. Pleurae maculis subfuscis obsolete variegatae. Di. midium apicale segmentorum abdominalium singulorum fusco-nigrum. Coxae et pedes dilute flavicantes, larsis fuscis. Alae aequaliter cinereae, venis fuscis; vena auxiliaris, quae in costan excurrit venisque reliquis tenuior et pallidior est, adversus finem validior et fusca fit; cellula marginalis prima majuscula, margine antico venulà transversâ subcostali in partes subaequales diviso et quam margo posticus modice longiore; pedunculus cellulae posterioris secundae sesquialteram cellulae marginalis primae longiludinem fere aequiparat; peduaculus cellulae posterioris quartae quam venae quartae 
segmentum primum paululo hrevior. - (District Columbia; OstenSacken.)

18. Scioptila obtruncata, nov. sp. d. - Nigro-fusca. antennarum basi. humeris, abdominis fusciis pedibusque luteis. alarum venà auxiliari imperfecti et celluli marginali prima majuscula. - Long. corp. $1 \frac{2}{3}$ lin.. long. al. $1 \frac{3}{4} \mathrm{lin}$.

Coput fusco-nigrum, dimilie inferiore facioi dilutins fusco. Infenvac fusco-nigrae. scapo tamen primisquo flyglli arliculis difule luteis; palpi lutei. Thorax nigro-fusens, pilis nigris instruclus. humeris late luteis. margine laterali exalhido vel dilutissime lutescente: sculellum nigro-fuseum; pleurarum dimidium superius sordide lutescens, inferius fuscum. Segmenta abdominalia primum. sextum el septimum tota nigra. reliqua pracler fasciam apicalem singstorum lutea. Hypopygium parvum. luteum. Pili abdominis nigri. Coxae el pedes dilute lutescentes. tarsis fuscis. Halteres pallidi. Alac leviter et aequaliter cinerascentes, venis fuscis; vena auxiliaris paulo ultra venulam transversam subcostalem pergit. ubi subito finem ha. bet; cellula marginalis prima majuscula, margine antico quam poslicus modice longiore et venulâ transversi subcostali in partes aequales diviso: cellulae posterioris secundae pedunculus cellulam ipsam aequat: primum venae longitudinalis quartae segmentum a primo quintae segmento longifudine paulo superalur. - (District Columbia; Osten-Sacken.)

19. Sciophila appendiculata. nov. sp. ठ́. - Dilule lutea. antennarum flagello praeter basim abdomineque praeter segmentorum marginem postirnm fusco-nigris. alornm cellula marginali prima parva. quam reliqua ala distinctius cinereti. hypopyeso luten. appendicibus duabus atris instructo. - Lang. corp. $1_{\frac{7}{3}}$ lin.. long. al. $1 \frac{7}{1 \frac{\pi}{2}} \operatorname{lin}$.

Caput luteum. palpis concoloribus. colore verticis in fusmm vergente. Antennae fusco-nigrae. seapon tamon primisque flagerlli articulis luleis. Thorax dilute luteus. dorso paulo sotmatius timelo. nigro-piloso. Abdomen fusco-nigrum. segmenform singulorum malgine postico luteo-limbato. parmultimo tamen segmento vel toto ni-

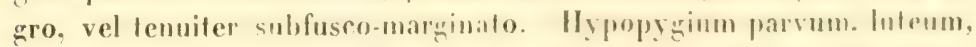
appendicibus laleralibus linearibus, alris et nigroppilosis. Coxae et perles dilulissime lulescentes, tarsis nimro-fuscis. Ialleres pallidi. Alae hyalinac. adversus apicem et marginem posticum leviter cinerascentes, cellulà submarginalj primâ saturalius cinercâ. venis fuscis: 
vena anxiliaris, adversus basim tenuior et dilulius picta, in costam excurrit; cellula marginalis prima parva, margine antico quam posticus longiore; ab hujus cellulae apice venula transversa subcostalis longius quam a basi remota cst; pedunculus cellulae posterioris secundae triplicem cellulae marginalis primae longiludiuem excedit, cellulae ipsius longitudinem vix aequat; primum venae longitudinalis quartae seguentum primo venae quarlae segmenlo paulo brevius est. - (New-York.)

20. Sciophila biseriata, nov. sp. $\sigma^{7}$ - Lutea. verlice ma. culisque pleurarum subfuscis, abdominis segmenlis singulis ulrinque maculâ laterali fusco-nigvá pictis, alis aequaliter ex luteo cinereis, venis fuscis, cellula marginali primâ magná. - Jong. corp. $2 \frac{6}{6}$ lin., long. al. $2 \frac{7}{\frac{7}{2}}$ lin.

Dilute lutea, verticis tamen colore in fuscum vergente. (Anlemnae et palpi speciminis unici desiderantur.) Thoracis dorsum nigro-pilosum. Plenrae colore subfusco bimaculatae. Abdomen nigro-pilosum; segmenta singula praeter primum utrinque maculâ triaugulari fusco-nigrâ, ex angulo anlico fere ad marginem posticum usque productâ ornantur. Pedes dilute lutescentes, tarsis apicem versus nigro-fuscis. Alae colore ex luteo einereo acqualiter tinctae et venis ex luteo fuscis instructae; vena auxiliaris in costam excurrens in alâ dextı́a ante apicem extremum subobsolela fit; cellula marginalis prima permagna marginem anticum postico panto longiorem, venulâ transversâ subcostali in partes subaequales divisum habet; pedunculus cellulae posterioris secundae quam cellula ipsa brevior, ad duplicem rellulae posterioris primae longitudinem prope accedit; primum venae longiludinalis quartae segmentum primo quintac segmento subaequale. - (Red River; Kennicott.)

21. Sciophila tantilla, nov. sp. \&. - Pallide lutescens, capile. antennarum fagello praeter basim. Thoracis dorso praeter humeros et praeler margines lateralrs, abdomine denique fere tolo fusco-nigris, alis hyalinis. - Iong. corp. $1 \frac{1}{6}$ lin., long. al. $1_{4}^{\frac{1}{4}}$ lin.

Pallide lutescens. Caput nigrum, palpis, antennarum scapo primisque flagelli articulis pallidis, reliquo flagello fusco-nigro. Thoracis dorsum nigrum, nitidum, humeris lale et marginibus lateralibus anguste pallidis; melanotum fusco - viltalum. Abdomen speciminis descripti mutilatum; segmenta prima fusco nigra, basi singulorum pallidâ. Pedes cum coxis pallidi, tarsis practer basim fuscis. Alae byalinae, adversus apicem et marginem posticum vix cinera 
scentes, venis validioribus fuscis. Ienuioribus ex luleo subfuscis: vena auxiliaris costam petit; cellula marginalis prima parva, margine antico quam postirus longiore; cellula posterior secunda latiuscula, basi quam in reliquis specicbus minus aculà. quam pedunculus brevior, qui fere quadruplicen cellulac marginalis primae longiludinem aequiparal; primum venae longiludinalis quintae srgmentum quam primum quarlae molice longius - (Nebraska.)

22. Lasiosoma quadralula, nov. sp. ‥ - Lulea, anlennis, capite abdomineque nigro-fuscis, alis cinereis, cellulà marginali primâ minutá, cellulae posterioris quarlue pedunculo el venâ auxiliari subaequalibus. - Long. corp. $1 \frac{1}{2}$ lin., long. al. $1_{\frac{5}{2}}$ lin.

Lutea, pilis pallidis vestita. Caput nigro-fuscum. antennis praeter basim rufam concoloribus, palpis dilule luteis. Thoracis dorsum non vithatum; metalhoracis color in fuscum vergens. Abdomen fusco-nigrum, margine postico segmentorum singulorum latera versus plerumque sordide lutescente, exlremo abdominis apice luteo. Pedes cum coxis lutei, tarsis basi exceptà nigro-fuscis. Halleres lutei. Alae latae, dilute cinerascentes, venis validioribus fuscis. Ienuioribus ex fusco luteis; cellula marginalis prima minuta, quadrata, margine antico venulì transversâ subcostali in partes acquales diviso; pedunculus renae posterioris quartae venae auxiliari aequalis vel subaequalis. - (Maine.)

Nota. Lasiosoma quadralula a Lasiosomi pallipede Say cui alfinis, thorace non fusco, alarum venis saturatius linelis. venuli transversâ subcostali non in cellulae marginalis primae basim inserlâ el pedunculo cellulae posterioris quarlac quanı vena anxiliaris non longiore differt.

2:3. Eudicrana obumbrata, nov. sp. Q. - I'allide lutesrens, antennarum Angello, vertice el ocripile nigro-fusris. abdomine nigro, segmentis tertio. quarto, quinto at sexto trifariam flaro-marulatis. alis leviter cinerascentibus, apire el mangine postico suluratius cinereis. - Long. corp. $22_{6}^{s}$ lin., long. al. $2 \frac{1}{2}$ lin.

Caput nigro-fuscum, inferiore faciei dimidio. genis palpisyue dilule luteis. Scapus antennarum luteus, flagellum fuseo-nigrmm. Thoracis dorsum, scutellum ef metanolum lutea, pilis longionilus validioribusque nigris, hreviorihus tenuioribusque fuscis instructa. Pleurae pallide futescentes. prope coxas punctis lineolistgue nigris subreticulalae. Abdomen nigrum. segumentis primis duobus of ul. timo immaculatis, reliqui- trilariam nisro-maculatis; appentices amales 
breves, luteae. Coxae pallide lutene, pilis validioribus nigris tenuioribusque pallidis vestitae. Pedes pallide lutescentes, tibiaum calcaribus tarsisque fuscis. Halteres pallidi. Alae subcinereae, apice et marginis postici limbo saluratius cinerris; vena auxiliaris paulo ante collulae marginalis primae apicem in costam excurril; cellulae posterioris secundae pedunculus quam cellula marginalis prima brevior; collula posterior quarta propius ad alae basim accedit quam prima. - (New-York; Osten-Sacken.)

Nota. Eudicruna, novum Sciophilinorum genus, corporis formâ ac fignrâ Plntyuram simulat. Ocelli laterales oculis adjacen!, intermedius plane obsoletus. Pedes lenues, tibiarum setulis medio. cribus, calearibus longis. Alae magnae, sed modice lalae, pube quam in Lasiosomis fere longiore vestilae; vena costalis venam longitudinalem tertiam transgreditur; vena auxiliaris in costam excurrit et venulâ transversâ cum venà longitudinali primâ conjungilur; cellula basalis pro portione brevis, marginalis prima longa; cellulae posteriores secunda ef quarla perlongae, basim versus valde acuminalae; vena anguli postici prima subobsoleta; secundi conspicua, validiuscula, quam in reliquis sciophilinorum generibus longior; terlia seu spmia longa, sed subobsoleta.

24. Syntemna polyzona, nov. sp. ठ. - Lulea, segmenlis abdominalibus singulis postice nigro fasciatis. - Long. corp. $1 \frac{1}{1} \frac{1}{2}$

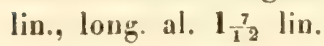

Lacte lutea, nitida, luteo.pilosa. Caput concolor, facie palpisque palidioribus, antennis apicem versus subfuscis. Ocelli tres, in lineam transversam dispositi, majusculi, intermedio tamen quam laterales minore, maculâ nigrâ inclusi. 'Thoracis dorsum unicolor', vix levissimo fasciarum vestigio; pleurae pallidissime flavescentes. Abdomen laete luteum, segmentis singulis postice nigris, ila ut fasciae septem aequales appareant. Hypopygium breve, luteum, appendicibus adversus apicem nigro-fuscis. Coxae pallide favescentes, apicali trochanterum margine fusco. Pedes dilute flavicantes, tibiarum colore in subfuscum, tarsorum in fuscum vergente; tibiae anticae setis lateralibus destilulae, intermediae brevibus instructae; tibiae posticae in specimine descripto desunt. Halteres flavescentes, capituli basi dilute subfusca. Alae ex cinereo lutescentes, lalae, angulo postico rolundato, cosłâ venisque longitudinalibus primâ et tertiâ ex luteo subfuscis, reliquis luteis; vena auxiliaris ante venac longitudinalis tertiae initum in venam longitudinalem primam 
excurril, ita ut cellula basalis sesquialteran cellulae subcostatis longitudinem aequiparel. - (Middle slates.)

Nota. A Synlemua morosâ Winn.. unici hujus generis specie adlue eogniti. nostra speries ocello intermedio quam laterales minore, tibiis anticis setas laterales nullas gerentihus. vena anxiliari breviore, rellula basali longiore cellulisquo posteriorihus secundâ et quartá brevius pedunculalis diflert.

25. Bolelina tricinrla, nov. sp. o' el $q$ - Alra, nilida. luteo-pilosa, fasciis abdominis tribus: halteribus, coris pedibusque favis, tarsis praeter basim fusris. - Long. corp. $1_{\mathrm{T}^{7}}^{\frac{7}{2}}$ lin., long. al. $1 \frac{7}{12} \operatorname{lin}$.

Nitida, nigra, luteo-pilosa. Caput concolor: antennac fusco-nigrae. srapo et flagelli basi testaceís vel subfuscis; palpi llavicantes. Abdomiris segmenta secundum, tertium ef quartum faseià posticâ flavâ ornafa. Venter praeter segmenla tria ullima llavus. Ilypopygium maris parvum; lamellae anales foemisae pallidac. Coxae col pedes flavescentes, trochanteribus fusco-maculatis, tibiarum calcaribus subtestaceis vel sordide lufescentibus. tarsis practer basim fuseis; tarsi antici maris graciles, focmina tumescentes. Halteres llavicantes. Alae fusco-cinereat venis validioribus fuscis, tenuioribus subfuscis. - (Wiskousin; Maryland.)

26. Phthinia tanypes, nov sp. of el $9 .-$ Gracillima, thorace ferrugineo, hallerum cupilulo abdomineque nigro.fuscis, segmenlis hujus adversus basim dilutioribus. hypopygio maris lamellisque analibus foeminae pallidis, alis subfuscis. - lons. colp. $3-3-3 \frac{1}{4}$ lin.. long. al. $2-2 \frac{1}{6}$ lin.

Gracilima. pedihus temuisimis, valde elongalis. Capul luteum vel dilute subfuscun, vertice el superiore occipitis dimidio ex ferrugineo fuscis. Antennac pilosae, fuscar. scapo tamen ef ima llatgelli basi dilute flavicantibus. Palpi flavi, appicen versus interdum subfusci. Thorax opacus, ex ferrugineo fuscus, pleuris dilulioribus. dorso non viltalo, lumeris el lineâ baterali inde al, humeris usque ad alarum basim ducla albido-pollinosis. Abulomen lenue, perlonsum. nigro-fuscum, segmentis singulis adversus basim pletumuge dilutius pictis. Hypopygium maris parvum. exallidum vel dilule llatescens; lamellac anales foeminate exalbidac. Coxace el pedes faricanles, femoribus tamen practer dimbdum basale, libiis totis farsisque in speciminibus maluris plerumque obsrurioribus. Hallorum pedunen. 
lus pallidus, capitulum fusco-nigrum. Alae colore saturate cinereo vel fusco-cinereo tinctae, venis nigro-fuscis. - (New-York; OstenSacken.)

27. Glaphyroptera melaena, nov. sp. Ђ. - Alra, nitida, facie, basi antennarum intermediisque ventris segmentis luteis, palpis, halleribus tolis, coxis pedibusque dilulissime lulescentibus, alarum fasciâ lalà subapiculi el lilurâ iuler venum longiludinalem ultimam el venam axillarem silâ nigricantibus. - Long. corp. $1 \frac{1}{2}$ lin., long. al. $1 \frac{5}{6}$ lin.

Atra, nitida, pilis lutescentibus veslita. Caput concolor, facie lamen luteâ; antennae nigrae, scapo primoque flagelli articulo luteis; palpi dilute lutescentes. Pleurae prope humeros triangulo exalbido notalae. Pili abdominis lotescentes; hypopygium alrum, nigro-pilosum. Coxae et pedes pallide flavesceutes, femorum posticorum apice nigro, tibiarum posticarum apice postice infuscato; ultimi larsorum articuli fusci; tarsi postici quam tibiae paulo breviores. Alae pro portione longae, Lyalinae; prope apicem fascia lala perpendicularis nigro-fusca, adversus posticum alae marginem dilutior et inter venam longiludinalem ultimam et venam axillaren litura nigro-fusca conspiciuntur. - (New-York.)

Nota. Glaphyroptera melaena Gilaphyropterae ventrali Say simillima est; hujus halteres non tolae exalbidae sunt, sed capitulum nigrum habent.

28. Glaphyroptera decora, nov. sp. +. - Lulea, pleurarum maculà posticà villulàque melunoti nigro-fuscis, fasciis abdominis nigris, alis prope apicem subobsolete fusco-fasciatis. - Long. corp. $1 \frac{3}{4}$ lin., long. al. $1_{\frac{7}{2}}^{\frac{7}{2}}-1 \frac{2}{3}$ lin.

Lutea, capite concolore. Antenuarum flagellum praeter basim subfuscum vel fuscum; ocelli laterales colore nigro circumscripti, distinctissimi; ocellus intermedius nullus. Thoracis dorsun utrinque prope alae basin maculà puncliformi fusco-nigrâ nolalum, pilis validioribus nigricantibus tenuioribusque lutescentibus vestitum. Discus scutelli fuscus. Metanoti vittula media lusca, lubera lateralia nigro-fusca. Segmenta abdominalia sextum et septimum tola atra, reliqua lutea et singula postice fascià atrâ ornata; fascia segmenti primi minus lata et interrupta, fasciae segmentorum reliquorum integrae ef aequales. Ventris lutescentis segmenta duo ultima atra. Coxae et pedes lulescentes, apice femorum posticormm nigro. libiarum calcaribus luteis tarsisque fere totis nigro-fuseis. Alae ex lu- 
teo cinereae, adversus costam et basim magis lutescentes, renis va. lidioribus fuscis, tenuioribus ex luteo fuscis; prope apicem alae fascia perpendicularis subfusea, adversus marginem posticun deliquescens conspicitur et reua lougitudiualis ullima postice lilurâ sub. fuscâ adumbratur. - (Georgia.)

29. Glaphyroptera opima, nov. sp. J et racis dorso maculis duabus laterulibus permagnis alvis ornato, metanolo cum tuberibus lateralibus atro, abdomine nigro, angulis lamen anticis segmentorum singulorum et hypogygio maris luteis, alarum fasciá subapicali, macula centrali et litura venam ultimam adumbrante fusris. - Long. corp. $1 \frac{1}{1} \frac{1}{2}$ lin., long. al. '2 $\frac{1}{\frac{1}{2}}$ lin.

Caput luteun, vertice et occipitis dimidio superiore fuscis; antennae fuscae, scapo priurisque flagelli arliculis luteis; palpi foti lutei. Thorax luteus, scutello concolore; dorsum nitidum, utrinque maculà ingenti ovatâ atrâ ornatum, ita ut practer trientem auticum et praeter vittam mediam totus ater sit; metanotum cum tuberibus lateralibus atrum, in speciminibus immaturis interdum fusco-nigrum. Pili thoracis lutei vel subfusci, ubi colore atro pictus est nigri vel nigricantes. Abdomen magis nigrum; basis segmenti secundi dilute lutea; segmenta sequentia angulos anticos colore dilute luteo tinctos habent, ita ut fasciae basales lutescentes, in medio abdowine interruptae vel valde anguslatae appareant; hypopygium luleum et pilis dilute lutescentibus instructum; venter tolus pallide luteus. In maribus quibusdam abdominis pictura lutea in sulphuream vel virescentem mulatur. Foeminae abdomen similiter pictum alque maris, anticis tamen segmentorum singulorum angulis minns late luteis. Coxae et pedes pallide lutescentes, extremo femorum posticorum apice nigro tarsisque praeter basim nigro-fuscis. Halteres pallidi. Alae dilute cinereae, venis fuscis; fascia subapicalis fusca adversus costam modice dilalalur, adversus marginem posticum dilutior fit; marula fusca, in ima cellulae posterioris primae basi sila, venam longiludinalem tertiam paulo transgreditur; vena longiludinalis ultima liturà fuscâ postice adumbralur. - (Counecticut; Norton.)

30. Glaphyroptera sublunata, nov. sp. \&. - Iuter, segmentorum abdominalium singulorum fascia postica nigra utringue abbrevialà, alarum fascié subapicali tenui arcuati et lituri renam longitudinalem ultimam adumbrante fuscis. - Long. corp. 2?! lin., long. al. $2 \frac{1}{4}$ lin.

Lutea, pilis lutescentibus vestita. Caput concolor; ocelli sin- 
guli colore nigro tenuiter circumscripti, intermedius valde minutus; antennae apicem versus subfuscae; palpi dilute lutei. Thoracis dorsum utrinque prope alae basim maculâ punctiformi nigrâ nolatum. Metathorax adversus marginem inferum plerumque subfuscus. Abdominis segmentum primum postice tenuiter nigro-limbatum; in segmentorum qualuor sequentium margine postico fascia nigra adversus latera subito angustata et longe a margine laterali abbreviata conspicilur; fascia nigra segmenti sexti angusla, latera versus paulatim attenuata; segmentum septimum breve, totum luteum. Venfor dilute luteus. Coxae et pedes dilute lutesecntes, extremo apice femorum posticorum nigro, tibiarum calcaribus luteis, tarsis praeter basim nigro-fuscis. Alae lutescentes, venis fuscis, adversus basim ex parte lutescentibus; prope apicem fasciâ tenui arcuatâ, postice paulo abbreviatà ornantur et vena longitudinalis ultima postice liturâ fuscâ adumbratur. - (New-York; Osten-Sacken.)

Nota. Plalyuram foemineam possideo, quam Platyurae sublunalae varietatem esse suspicor. Paulo minor est; fasciae nigrae abdominis tenuiores sunt; fascia subapicalis alarum latior et integra est; apex denique anguli postici colore dilute subfusco tingitur.

31. Glaphyroptera oblectabilis, nov. sp. \&. - Lutea, antennis adversus apicem nigricantibus, femorum posticorum apice nigro, singulis abdominis segmentis postice fasciâ nigrâ, in medio abdomine triangulariter dilatatâ ornatis, alarum fasciâ subapicali latiusculâ, maculâ centrali et anguli postici apice fuscis. - Long. corp. $1_{\frac{1}{2}}^{\frac{5}{2}}$ lin., long. al. $1 \frac{1}{2}$ lin.

Lutea, capite toto concolore. Palpi et antennae dilute lutescentes, hae apicem versus nigricantes. Ocelli nigri. Thorax totus unicolor, pilis luteis, validioribus tamen plerumque fuscis instructus. Fascia postica nigra segmenti abdominalis primi in medio abdomine modice dilatatur; fasciae nigrae segmentorum sequentium in trian. gulum usque ad marginem anticum producuntur; segmentum sextum fere totum nigrum vel nigro-fuscum; segmentum septimum breve, cum extremo abdominis apice colore luteo tinctum. Venter luteus, segmento sexto nigro, in speciminibus immaturis fusco. Pedes pallide lutescentes, apice femorum posticorum nigro, calcaribus tibiarum luteis et tarsis apicem versus subfuscis. Halteres pallidi. Alae ex luteo dilute cinereae, adversus costam paulo distinctius lutescentes; fascia latiuscula subapicalis, integra et leviter arcuata, macula centralis in basi cellulae posterioris primae sita et apex 
anguli postici colore fusco tinguntur. - (Niddle States; OstenSacken.)

32. Leja sororcula, nov. sp. ठ - Dilutissime lutescens, antennis praeter scapum, thoracis dimidio posteriore femorumque posticorum apice nigris, abdominis segmentis quatuor primis postice fusco-marginatis, quinto et sexto tolis nigris; apex alarum fuscus; cellula posterior securda dimidiam primae longiludinem fere aequiparans, in basi angusle aperta. - Long. corp. $1 \frac{1}{6}-1 \frac{1}{6}$ lin., long. al. $1 \frac{1}{4}-1 \frac{1}{3}$ lin.

Pallidissime lutescens, pilis pallidis vestita. Caput concolor, vertice tamen et occipitis dimidio superiore nigro-fuscis. Scapus antennarum pallidus, flagellum practer basim pallidam arliculi primi nigrum. Thoracis dimidium posterius tolum nigrum, sed ita ut color niger in medio dorso latius procedal quam in lateribus, ubi paulo ante alarum basim finilur. Segurentum abdominale primum in margine postico fasciolà nigrâ, utrinque valde abbreviatå piclum est; in margine postico segmenti secundi fascia difformis nigro-fusca conspicitur, quae in lateribus abdominis subilo usque ad marginem anticum dilatala est; fascia nigro-fusca in segmenti terlii margine postico utrinque modice abbreviatur; segmentum quintum fasciam obsoletiorem fuscam gerit; segmenta quintum et sextum lola nigra. Hypopygium luteum, appendicibus tamen obscurioribus et apice nigro-piloso. Pedes cum coxis pallidi, femorum posticorum apice nigro; setae tibiarum nigrae, calcaria lutea; tarsi anteriores inde ab articuli primi apice, postici praeter articuli primi basim fusci. Alae ex luteo dilute cinerascentes, apice minus late fusco, ita ut ramulus anterior venae longitudinalis quartae extra colorem nigrum initium habeat; vena longitudinalis ultima poslice obsoletissime colore subfusco adumbratur; cellula posterior secunda. in basi angustissime aperta, quam cellulae posterioris primae dimidium vix brevior est. - (New-York.)

33. Leja abbreviata, nov. sp. ․ - Dilutissime lutescens, antennis adversus apicem, thoracis viltis confluentibus, untice valde abbrevialis, metalhorace tolo femorumque posticorum apice nigris, abdominis segmentis singulis postice subfusco-marginatis; apex alarum late fuscus; cellula posterior secunda quam primae dimidium

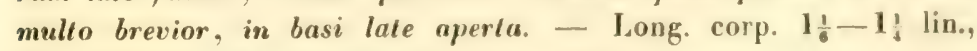
long. al. $1 \frac{1}{4}-1 \frac{1}{3}$ lin.

Pallidissime lutescens, pilis pallidis vestita. Capul concolor, 
vertice et superiore occipitis dimidio nigro-fuscis. Antennae pallidae, scapo adversus apicem nigricante. Thoracis dorsum vittis tribus nigris, postice confluentibus, antice subsejunctis et maximopere abbreviatis pingitur. Scutellum nigrum; metathorax cum tuberibus lateralibus colore nigro-fusco tingitur; idem color basion alarum cingit. Abdomen speciminis immaturi vestigium tantum fasciarum fuscarum ostendit. Pedes a pedibus Lejae sororculae non differunt, nisi tarsis posticis totis fuscis. Alae ex luteo dilule cinerascentes, apice late fusco, ita ut ramulus anterior venae longitudiualis quartae totus in colorem nigrum immersus sit; vena longitudinalis ultima pustice distincte colore fusco adumbratur; cellula posterior secunda, in basi late aperta, quam cellulae posterioris primae dimi. dium multo brevior est. - (Middle States.)

Nota. Lejae abbreviatae exempla matura eandem, quan Leja sororcula habet, picturam habere suspicor; alarum apex latius fuscus, ramulus anterior venue longitudinalis quartae brevior et validior, basis denique cellulae posterioris secundae latius aperta Lejam abbrevialam a sororcula certo distingunt.

34. A cnemia psylla, nov. sp. ô. - Nigra, halterum capitulo concolore, coxis pedibusque flavescentibus. - Long. corp. $1 \frac{1}{4}$ lin., long. al. $1 \frac{1}{6}$ lin.

Nigra, nitida, pilis pallidis, adversus apicem abdominis obscurioriuus vestita. Caput concolor, antennis fusco-nigris, adversus basim dilute subfuscis vel luteis. Hypopygium majusculum, nigrofuscum. Coxae et pedes flavescentes, trochanteribus puncto nigro notatis, tibiarum calcaribus flavis, tarsis subfuscis. Halterum pedunculus flavescens, capitulum nigrum. Alae cinerascentes, venis validioribus fuscis, tenuioribus dilute subfuscis. - (Maryland.)

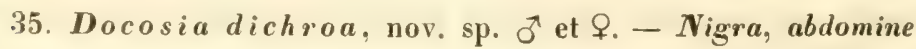
rufo, hypopygio maris cum ultimis duobus abdominis segmentis ni-

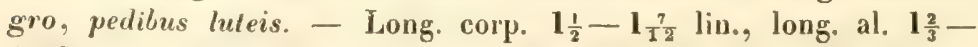
$1 \frac{3}{4}$ lin.

Caput nigrum; antennae concolores; palpi fusci vel subfusci. Thorax totus ater et nitidus. Abdomen foeminae tolum ex ochraceo rufum, maris segmenta duo ultima et bypopygium atra. Pedes cum coxis ex ochraceo lutei, tarsis anticis inde ab articuli primi apice, posterioribus totis fuscis. Halleres lutei. Alae hyalinae, venis longitudinalibus primâ et tertiâ cum venulâ transversâ ordinariâ, venulà transversâ subcostali et venâ costali nigris. - (District Columbia; Osten-Sacken.) 
36. Rymosia filipes, nov. sp. ․ - Ex ochraceo testarea. segmentorum abdominalium singulorum fasciâ posticâ fuscri. in medio abdomine dilatalà. - Long. corp. '23 lin., long. al. $2{ }_{6}^{2}$ lin.

Ex ochraceo lesticea, opaca. Caput concolor; antenna longae, tenues, fuscae, scapo et imâ flagelli basi lutescentibus; palpi lutei vel ex luteo testacei. Setac thoracis et scutelli nigrae. Abdominis segmenta primum et ultimum fere tola fusca, relifua sin. gula postice fasciâ fuscâ, in medio abdomine valde dilalatâ instructa. Hypopygium luleum, quam ultimum abdominis segmentum paulo brevius; penis exsertus; lamellae terminales breves; lanceolatae, sursum directae, nigro - pilosulae. Coxae sordide lutescentes, pilis brevibus setisque nigris. Pedes tenues, perlongi. sordide lutescentes, tibiarum colore in subfuscum vergente, calcaribus tibiarum tarsisque nigro-fuscis. Alae ex luleo cinereae, adversus costam sordide lutescentes. - (Connecticut; Norton.)

37. Trichonta vulgaris, nov. sp. $\delta$ et 오. - Flavescens, antennis praeter basim, fronte, vittis thoracis tribus. pleuris, scuteilo, metanoto et abdomine fuscis, segmentis hujus singulis, primo tamen excepto, postice flavido-fasciatis, pedunculo cellulae posterioris quartae et primo venae quartae segmento aequalibus. - Long. corp. $1 \frac{2}{3}-1 \frac{3}{4}$ ! in., long. al. $1 \frac{9}{1}-1 \frac{3}{3}$ lin.

Caput fuscum, fronte pilis brevibus pallidis cinerascente: anlennae nigro-fuscae, scapo primisque duobus vel tribus flagelli articulis luteis; palpi dilute lutei. Thoracis dorsum flavescens, vittis tribus fuscis interdum confluenlibus, lateralibus antice valde abbrevialis, intermediâ integrâ et adversus anticum marginem dorsi valde dilatatâ; pili el selulae thoracis omnes dilulissime flavescentes. Pleurae fuscae, inter coxas anticas et humeros flavae. Scutellum metanolumque fusca. Abdomen fuscum, segmentis singulis praeter primum postice flavo - fasciatis. Segmentum sextum maris orcultum; hypopygium mediocre nigrum. Segmentum sextum foeminae breve, plerumque adversus basim fuscum, interdum tolum flavescens: vaginae appendices superae minulae et flavescentes vel lulescenles, lamellae inferae majusculae et nigrae. Coxae et pedes dilute flavicantes, larsis adversus apicem subfuscis; articuli tarsorum quatuor ultimi in foeminâ infra levissime tumidi. Halleres pallidi. Alae cinereae, adversus coslam sublulescentes, venis validioribus nigrofuscis, tenuioribus subfuscis; cellula posterior quarta propius ad alac basim ascendens quam in Trichontis plerisque. ita ut pedunculum primo venae quartae segmento aequalem habeat. - (Maryland; District Columbia, Osten-Sacken.) 
38. Trichonta foeda, nov. sp. ㅇ. - Fusca, antennarum basi, facie, thoracis dorso praeter viltas ordinarias, halteribus, coxis pedibusque flavis, segmentis ubdominalibus singulis udversus basim sordide lutescentibus, pedunculo cellulae posterioris quartae quam primum venae quartae segmentum mullo longiore. - Long. corp. $1 \frac{3}{6}$ lin., long. al. $1 \frac{3}{4}$ lin.

Caput nigro-fuscum, facie tamen flavescente; antennae nigrofuscae, scapo primisque flagelli articulis flavis vel luteis; palpi lutescentes, articulo primo et extremo articuli ultimi apice plerumque fuscis. Thoracis dorsum flavicans, vittis tribus nigro-fuscis, lateralibus antice valde abbreviatis, intermediâ integrâ et adversus marginem anticum thoracis dilatatâ. Pubes brevis dorsi certo luminis situ magnâ ex parte pallescens; setulae omnes nigrae. Metanotum et scutellum fusca, hoc setulis marginalibus nigris instructum; pleurae fuscae vel subfuscae. Abdominis fusci segmenta singula adversus basim sordide lutescunt vel flavicant. Coxae et pedes pallide flavicantes, tarsis adversus basim nigro-fuscis. Halteres pallidi. Alae cinereae, adversus costam sublutescentes, venis validioribus fuscis, tenuioribus subfuscis; cellula posterior quarta quam in congeneribus plerisque brevior, ita ut extrema ejus basis ab alae radice aequali intervallo quam basis cellulae posterioris secundae distet. - (Middle States.)

39. Zygomyia ignobilis, nov. sp. ㅇ․ - Fusca, ventre, coxis pedibusque flavis, alis immaculatis. - Long. corp. $1 \frac{1}{3}$ lin., long. al. $1 \frac{1}{3}$ lin.

Fusca, subopaca, pilis brevibus appressis dilute flavicantibus vestita, setulis tamen in posticâ dorsi parte et in scutelli margine nigris. Caput concolor; seapus antennarum luteus vel ochraceus, articulo basali superne, terminali in extremo apice fuscis; flagellum fusco-nigrum, imâ tantum articuli primi basi luteâ. Lamellae anales fuscae, venter flavescens. Coxae et pedes dilute flavescentes; femora antica superne obsoletius, posteriora saturatius subfusco-vittata; apex horum fuscus; tarsi subfusci. Halteres pallidi. Alae immaculatae, ex cinereo sublutescentes, venis validioribus fuscis, tenuioribus subfuscis. - (Middle States.)

40. Zygomyia ornata, nov. sp. ठ ris antennarumque basi luteis, coxis pedibusque pallide flavicantibus, alarum maculà centrali et fasciá subapicali fuscis. - Long. corp. $1 \frac{1}{6}-1 \frac{1}{4}$ lin., long. al. $1-1 \frac{1}{1 \frac{2}{2}}$ lin. 
Parva, fusca vel nigro-fusca, opaca, pilis brevibus dilute lutescentibus vestita, setis tamen in posticâ thoracis parte et in scutello nigris. Caput concolor; antennae nigro fuscae, scapo et flagelli basi luteis; palpi dilutius lutei. Humeri sordide lutei vel ochracei. Hypopygium maris parvum, subimmersum, luteum; appendices anales foeminae ex subfusco lutei. Coxae et perles dilutissime flavescentes vel albicantes; femora intermedia in extremo apice, postica paulo latius nigricantia; tibiarum posteriorum apex nigricans; tarsi praeter basim subfusci. Halteres exalbidi. Alae cineraseentes, costam versus sublulescentes, maculâ centrali usque ad costam pertinente et fascià subnormali, ex cellulae costalis apice demissâ et adversus marginem posticum alae deliquescente fuscis. - (Pennsylvania).

41. Epicypta pulicaria, nov. sp. ㅇ. - Nigra, modice ni. tens, coxis pedibusque pallide Ravicantibus, antennis tarsisgue fuscis; alae cinereae adversus costam lutescentes. - Long. corp. $1 \frac{1}{4}$ lin., long. al. $1 \frac{1}{6}-1 \frac{1}{4}$ lin.

Nigra, modice nitens, pube brevi appressâ nigricante vestita. Caput concolor, palpis luteis, anteunis fuscis, harum tamen scapo plerumque et imâ flagelli basi interdum rufis. Coxae et pedes pallidissime flavescentes, tibiarum calcaribus tarsisque anticis fuscis, tarsis posterioribus subfuscis; tibiae intermediae infra setis binis instructae. Halteres albidi. Alae ex luteo cinereae, cellulâ costali totâ et priore cellulae marginalis dimidio luteis. - (Penusylvania.)

42. Mycothera paula, nov. sp. 우 - Parva, alarum maculà centrali, fasciâ et limbo apicali fuscis, cellulà posteriore quartâ perbrevi. - Long. corp. $1 \frac{1}{1} \frac{1}{2}$ lin., long. al. 1 lin.

Caput fusco-nigrum, opacum, facie fuscà; antennarum scapus cum tribus vel quatuor primis antennarum articulis luteus, reliqui flagelli articuli nigro-fusci; palpi lutei. Thoracis dorsum ex ochraceo testaceum, interdum colore subfusco obsolete trilasciatum, marginibus lateralihus leviter albido-pollinosis; pubes dorsi brevis, lutea, adversus margines laterales exalbida; setac nigrae. Scutellum ex ochraceo testaceum, setis marginalibus nigris instructum. Coxae et pedes pallidissime flavicantes, femorum posticorum tibiarumque posticarum extremo apice fusco, tarsis praeter iman basim fusconigris. Alae cinereo-hyalinae, maculâ centrali et fascia inde a cellulae costalis apice subnormaliter demissâ et adversus marginem posticum deliquescente fuscis, apice late cinereo-limbato; cellula posterior quarta brevissima. - (Middle States.) 
43. Mycetophila exstincta, nov. sp. ㅇ. - Obscura, alis macula centrali obsolelissime cinerea pictis, tibiis intermediis infra

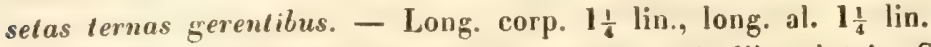

Caput fuscum, opacum, facie et partibus oris dilute luteis. Scapus antennarum flavus, flagellum nigricans, imâ tamen basi interdum flavâ. Thorax fuscus, subopacus, humeris et angulis posticis luteis. Scutellum totum nigro-fuscum. Abdominis segmenta quinque prima fusca, venter et abdominis apex flavi, lamellis tamen terminalibus paulo saturatius tinctis. Coxae pedesque pallide flavescentes, extremo tantum femorum posticorum apice fusco, tarsis subfuscis; tibiae intermediae infra setis ternis armatae; tibiae posticae apicem versus modice crassiores; tarsi pro portione tenues, primo posticorum articulo reliquis quatuor simul sumtis subaequali. Venae alarum luteae, in maculâ centrali obsoletissimâ fuscae. - (Middle States; Osten-Sacken.)

44. Mycetophila bipunctata, nov. sp. ㅇ. - Obscura, abdominis cingulis pallidis nullis, alis maculâ centrali fuscâ pictis, tibiis intermediis infra setas binas gerentibus, primo tarsorum posticorum articulo reliquis quatuor simul sumtis vix breviore. Long. corp. $1 \frac{1}{6}$ lin., long. al. $1 \frac{1}{6}$ lin.

Caput fuscum, opacum, facie et partibus oris dilute luteis. Scapus antennarum flavus, flagellum nigricans, imâ tamen basi interdum flavâ. Thorax nigro-fuscus, humeris luteis. Scutellum et abdomen nigro-fusca, extremo hujus apice et ventre flavis. Coxae pedesque pallide flavescentes, extremo tantum femorum posticorum apice fusco, tarsis subfuscis; tibiae intermediae infra setis binis instructae; tibiae posticae apicem versus modice crassiores; \{arsi pro portione tenues, primo posticorum articulo reliquis quatuor simul sumtis aequali. Alae maculâ centrali parvâ, saturate fuscâ notatae. - (Wisconsin.)

45. Mycetophila mutica, nov. sp. 오. - Thorax ex luteo rufus, abdomen obscurum; alae maculà centrali minutâ fuscâ piclae; tibiae intermediae infra setis nullis instructae. - Long. corp. $\mathbf{1}_{1^{\frac{5}{2}}}$ lin., long. al. $1 \frac{1}{2}$ lin.

Caput ex luteo rufescens, fronte subcinerascente, facie et partibus oris dilute luteis. Scapus antennarum pallide flavescens, flagellum dilute subfuscum. Thorax ex luteo rufescens, opacus. Scutellum concolor. Abdomen fuscum, segmentis quatuor ultimis latera versus late luteis. Cosae et pedes dilute flavicanles, tarsis 
gracilibus subfuscis, anticis duplicem tibiarum longitudinem attin. gentibus, primo posticorum articulo reliquis quatuor simul sumtis paulo longiore; tibiae intermediae infra setis destitulae, posticae apicem versus permodice crassiores. Alae maculâ centrali saturate fuscâ pictae. - (Middle States; Osten-Sacken.)

46. Mycetophila inculta, nov. sp. \&. - Fusra, nilens, hu. meris segmentorumque abdominalium singulonum marginibus posticis pallidis, pube in thoracis dorso brevissimâ, alis maculạ rentrali fuscâ pictis, tibiis intermediis infra setas binas gerentibus. primo tarsorum posticorum articulo tribus sequentibus simul sumtis subaequali. - Long. corp. $1 \frac{1}{1} \frac{1}{2}$ lin., long. al. $1 \frac{1}{1} \frac{1}{8}$ lin.

Caput badium, facie et partibus oris luteis; antennae ex luteo subfuscae, scapo et imâ flagelli basi luteis. Thoracis dorsum ba. dium, nitens, pube lutescente brevissimâ et appressâ vestitum. prope marginem posticum setis nonnullis nigris instructum. Plenrae fuseae. Scutellum ex badio fuscum, nigro-setosum, puncto medio luteo notatum. Abdomen fuscum vel nigro-fuscum. segmentis singulis praeter primum postice limbo pallide luteo, utrinque in triangulum dilatato marginatis. Lamellae anales majusculae, basim versus subfuscae, adversus apicem ochraceae. Coxac et pedes pallide lu. tescentes rel flavicantes, femorum posticorum apice nigro-fusco, tarsis subfuscis pro portione tenuibus, primo posticorum articulo articulis tribus sequentibus subaequali; tibiae intermediae infra setis bius armatae; tibiae posticae apicem versus modice crassiores. Alarum venae luteae, macula centralis mediocris et saturate fusca. margo apicalis cum marginis postici dimidio apicali tenuiter et obsolete cinerascens. - (Middle States; Osten-Sacken.)

47. Mycetophila pinguis, nov. sp. ․ - Robusta. ochracea, nitens, viltis thoracis confuentibus, sculelli angulis abdominisque segmentis praeler murgines fusco-nigris; alae maculis duabus. fuscis ornatae, alterâ centrali, alterá subapicali latissimá, ex cellu. lae marginalis apice in cellulam posteriore in primam demissit: tarsi antici subincrassati, tibiae intermediae infra sei is ternis instructue. tibiae posticae adversus apicem valde inrrassatae. - Jong. corp. 2 lin., long. al. $1 \frac{1}{1} \frac{1}{2}$ lin.

Robusta, ochracea, nitens. Color frontis in badium verge?ns; antennae praeter scapum et praeter imam flacelli basim subfuseac. Thoracis dorsum villis tribus nigris inter se conlluentibus pictum, intermedià postice abbreviatâ, lateralibus antice valde ahbrevialis et 
lato intervallo a margine laterali dorsi separatis; pubes dorsi brevissima lutescens, in vittis nigris maximâ ex parte nigricans; setae in marginibus lateralibus et in postico nigrae. Scutellum praeter angulos nigros ochraceum, setis nigris instructum. Pleurarum dimidium anterius ex ochraceo badium, dimidium posterius et metanotum fusca. Abdominis segmentum primum totum nigro-fuscum; segmentorum reliquorum margines anticus et posticus minus late, laterales lalissime ochracei; eodem colore apex abdominis et venter tincti sunt. Pedes cum coxis ex ochraceo lutei, validi, femorum posticorum lalissimorum apice nigro; tibiae intermediae infra setis ternis armatae; tibiae posticae apicem versus admodum incrassatae; tarsi antici fusco nigri, distincte sed modice incrassati; tarsi posteriores validiusculi, adversus apicem fusci; primus tarsorum posticorum articulus articulis tribus sequentibus subaequalis. Alae colore saturate fusco-bimaculatae; macula centralis mediocris; macula subapicalis lata, ex cellulae marginalis apice in cellulam posteriorem primam subnormaliter demissa usque ad posticum hujus marginem non pertinet, sed umbram obsoletissime cinerascentem longius emiltit; venae alarum fuscae, adversus basim luteae; cellulae marginalis apex ab extremo alae apice latius remotus, quam in Mycetophilis plerisque. - (English River, Kennicott; Maine.)

48. Mycetophila scalaris, nov. sp. $\delta$ et 우 - Lutescens, vittis thoracis confluentibus, scutelli angulis, segmenti abdominalis primi margine postico, segmentorum trium sequentium maculis binis permagnis (interdum confluentibus) segmentisque quinto et sexto praeter margines posticos totis nigro-fuscis; alae maculá centrali fuscâ et maculâ subapicali subfuscâ ornatae, hac dilutâ, anguslâ et ex cellulae marginalis apice oblique in cellulam posteriorem primam ductâ; larsi antici foeminae non incrassati; tibiae intermediae infra setis ternis instructae; tibiae posticae adversus apicem mediocriter incrassatae. - Long. corp. $1 \frac{1}{2}-1 \frac{7}{12}$ lin., long. al. $1 \frac{7}{\frac{1}{2}}-$ $1 \frac{2}{3} \operatorname{lin}$.

Caput luteum; antennae subfuscae, scapo et flagelli basi dilute lutescentibus. Thoracis dorsum ex ochraceo luteum, modice nitens, vittis tribus fuscis, rarius fusco-nigris, inter se confluentibus pictum; fascia intermedia postice semper, antice haud raro abbreviata; fasciae laterales antice late abbreviatae et ab lateribus dorsi remolae; pubes dorsi vix mediocris, lutescens; setae paucae nigrae. Scutellum luteum, angulis lateralibus setisque marginalibus nigris. Pleu- 
rarum dimidium anterius ex ochraceo luteum, dimidium posterius et metanotum fusca. Segmentum abdominale primum luteum, margine postico nigro-fusco, nonnumquam in maculas duas diviso; segmenta tria sequentia lutea, singula utrinque maculâ permagnâ nigro-fuscâ notala, ita ut pictura scalaris appareat; segmenta quintum et sextum nigro-fusca, margine postico illius angustius, hujus latius luteis; apex abdominis et venter lutei. Pedes cum coxis pallide flavicantes, validi, femorum posticorum apice nigro, tarsis apicem versus subfuscis; femora postica valde dilatata; tibiae intermediae infra setis ternis praeditae; tibiae posticae validae, apicem versus mediocriter incrassatae; larsi postici breviusculi et validiusculi. ar. ticulo primo articulis reliquis simul sumtis aequali. Alae fusco-bimaculalae; macula centralis vix mediocris; macula subapicalis dilutior, angusta, inde ab extremo cellulae marginalis apice oblique in cellulam posteriorem primam ducta, cujus marginem posticum non attingit; infra hanc maculam venae longitudinales colore cinerascente obsoletissime adumbrantur; venae alarum subfuscae, adversus basim lutescentes, in speciminibus dilutius pictis fere totae sordide lutescentes. - (Middle States.)

Nota. In speciminibus nonnullis vittas thoracis incompletas et subobsoletas pleurarumque dimidium posterius et metanotum dilute subfusca video.

49. Mycetophila trichonota, nov. sp. б. - Nigro-fusca, subopaca, humeris, scutello praeter angulos segmentorumque abdominalium singulorum margine postico pallidis, thoracis dorso dilute lutescente, pube quam in speciebus plerisque longiore setulisyue nigris vestito; alae maculis duabus fuscis ornalae, altera centrali, alterá subapicali ex cellulae marginalis apice arcuatim in cellulam posteriorem primam ducta; tibiue intermedine infra setis binis instruclae. - Long. corp. $1_{\frac{3}{2}}$ lin., long. al. $1_{\frac{1}{2}}$ lin.

Caput fuscum, opacum, facic tames et partibus oris dilute luteis; antennae fusco-nigrae, scapo et flagelli basi pallide flavicantibus. Thorax nigro-fuscus, subopacus, humeris, angulis poslicis et puncto ante scutellum sito luteis; pubes dorsi longior quam in speciebus plerisque, lutescens, setulis nigris crebro intermixtis. Scutellum luteum, angulis lateralibus nigro-fuscis, setis nigris. Abdo. men nigro-fuscum; segmentorum singulorum margines lalerales et posticus tenuiler et dilute luteo-limbati. primum tamen segmentum totum nigro-fuscum; extremus abdominis apex cum bypopygio parvo et venter dilute lutei. Pedes cum coxis pallide flavescentes, femo- 
rum posticorum apice nigro; tibiae intermediae infra setas binas gerentes; tibiae posticae validae, apicem versus mediocriter incrassatae; tarsi antici nigro-fusci, posteriores apicem versus subfusci; primus tarsorum posticorum articulus reliquis quatuor simul sumtis aequalis, Alae fusco-bimaculatae; macula centralis majuscula; macula subapicalis dilutior, subangusta. ex cellulae marginalis apice ob. lique in cellulam posteriorem primam decurrit, sed marginem posticum hujus non attingit; infra maculam subapicalem venae longitudinales nubeculâ cinerascente obsolete adumbranlur; venae alarum fuscae, adversus basim et in postico alarum dimidio sordide Iutescentes. - (District Columbia; Osten-Sacken.)

50. Mycetophila fallax, nov. sp. ठ'. - Nigro.fusca, subopaca, humeris, scutello praeter angulos segmentorumque abdominalium singulorum margine apicali pallidis, thoracis dorso pube lon. giusculâ dilute lutescente setulisgue nigris vestito; alae maculis duabus fuscis ornatae, alterâ centrali, allerâ subapicali ex cellulae marginalis apice arcuatim per cellulam posteriorem primam ductâ; libiae intermediae infra setis ternis instructae. - Long. corp. $1 \frac{1}{2}$ lin., long. al. $1 \frac{1}{2}$ lin.

Simillima Mycetoph. trichonolae, sed vena longitudinalis alarum prima longior et cellulae marginalis apex ab extremo alae apice minus remotus; alarum macula centralis major, subapicalis latior, saturatior et usque ad marginem posticum cellulae posterioris primae pertinens, ita ut semifasciae similis sit; tibiarum intermediarum selae inferae non binae, sed ternae.-- Middle States; OstenSacken.)

51. Mycetophila sigmoides, nov. sp. $\sigma^{t}$ - Dilute, lutescens. thorace abdomineque fusco-variis, femoribus omnibus infra maculâ subfuscâ notatis, tibiarum calcaribus praeter apicem nigrum exalbidis; in alis praeter maculam centralem fuscam series macularum trium fuscarum literam $\mathbf{S}$ refert, quarum prima reliquis multo major ex apice cellulae marginalis per cellulam posteriorem primam ducitur. - Long. corp. 2 lin., long. al. $1 \frac{1}{1} \frac{1}{2}$ lin.

Dilute lutescens, modice nitens. Caput concolor, frontis colore in subfuscum vergente; antennae nigro-fuscae, scapo et imâ flagelli basi dilute lutescentibus. Thoracis dorsum fusco-trivittatum; fascia intermedia postice abbreviata; fasciae laterales ab dorsi margine laterali remotae et antice valde abhreviatae; pubes thoracis brevis, lutescens, setae paucae nigrae. Scutellum dilute Juteum, angulis 
lateralibus fuscis, setis marginalibus nigris. Pleurae fusco-maculatae; netanotum tolum fuscum. Abdomen pallide lulescens, in spe. cinine descripto corrugalum, ita ut de picturå fuscå certum dicere nequeam; segmentum quintum pracler marginem poslicum colore nigro-fusco pictum est, segmentum sextum adversus basin infuscatum; extrenus abdominis apex cum hypopycio parvo et venter dilute lutescunt. Pedes cum coxis pallide flavescentes: femora omnia prope basim infra maculá oblongâ subfuscâ vel nigricante volala; femorum posticorum apex niger; tibiae posteriores minus validae, apicem versus paulo incrassatae, in apice extremo colore nigro tinctae; libiae intermediae infa setis binis longiorilus armatae, setâ terliâ breviore ante has saepe adjectà; tibiarum calcaria exalbida vel pallide lutescentes, apice singulorum abrupte nigro; tarsi tenues, subfusci, primo posticorum articulo arliculis tribus sequentibus simul sumtis aequali. Alae praeter maculam centralem fuscam serie trium macularum fuscarum, in formam literae $S$ positarum ornantur; macula prima, reliquis duabus multo najor et semifasciae hamatae similis, ex cellulae marginalis apice per cellulam posteriorem priman ducilur, cujus marginem posticum paulo transgreditur; maculae secunda et terlia perparvae, singulae vinis longitudinalibus sequentibus impositae sunt; venae alarum luteae. - (Middle Slates.)

52. Mycetophila qualuornolata, nov. sp. ㅇ. - Iutescens, thoracis viltis, sculelli angulis abdominerue praeler segmen. torum singulorum margines posticos nigro-fuscis: alae maculii centrali fuscá el semifascia hamalá subapicali ornalae, praeterea maculis duabus subfuscis notantur, altera transversa in celluli posteriore lertiâ silâ, alterâ rolundalâ, majore el obsoletiore in postico alae angulo; tibiae intermediae infra setâ unici instructae. - Long. corp. $2 \frac{1}{12}$ lin., long. al. $2 \frac{1}{\frac{1}{2}}-2 \frac{1}{6}$ lin.

Validiuscula, lutescens, subopaca. Caput sordide luteun. colore frontis magis fusco; antennae nigro-fuscae, scapo lamen et thagelli basi luteis. Viltae dorsales thoracis thes nigro-fuscae; villit intermedia antice valde dilatata, postice altenuata ef abbreviata: vitlae laterales antice valde abbrevialae el usque ad marginem dorsi dilatatae. Pubes dorsi lutescens, setac nigrae. Pleurae cum metanoto nigro-fuscae. Sculellum luteum, angulis lateralibus nigro-fuscis, setis marginalitus nigris. Abdomen nigro-fuscum, modice nitens, segmento ultimo praeter basim, segmentorum reliquorum marginibus posticis, segmenti secundi vittâ medià segmentorumque ter- 
tii et quarti imâ basi luteis; lamellae anales ochraceae, adversus ba. sim obsolete subfuscae. Pedes cum coxis pallide flavicantes; apice femorum posticorum nigro; tibiae intermediae infra setâ unicâ in. structae; tibiae posticae pro portione tenues, apicem versus paulo crassiores; larsi subfusci, graciles, primo poslicorum articulo quam articuli tres sequentes simul sumti breviore. Macula centralis alarum majuscula, saturate fusca; macula subapicalis fusca, hamala, ex cellulae marginalis apice per cellulam posteriorem primam ducta, cum maculà transversali dilutiore, in cellulâ posteriure tertiâ sitâ speciem fasciae in cellulâ posteriore secundâ late interruptae et poslice modice abbreviatae praebet; praelerea macula majuscula rolundata, dilute cinereo-fusca infra maculam centralem et prope marginem posticum alae sita conspicitur. - (Maryland.)

53. Mycetophila polita, nov. sp. đ. - Atra, nitens, humeris segmentorumgue abdominalium duorum ultimorum fasciis luteis; alae praeter maculam centralem fuscam semifasciâ latiusculâ fuscâ, inde a cellulue costalis apice demissâ ornantur; tibiae intermediae infra setis ternis instructae. - Long. corp. $1 \frac{1}{6}$ lin., long. al. $1 \frac{1}{4}$ lin.

Atra, nitida. Caput concolor, facie tamen et partibus oris luteis; antennae fusco-nigrae, scapo et imâ flagelli basi dilute lutescentibus. Humeri angulorumque thoracis posticorumque apex extremus lutei. Segmentum abdominale quintum fasciâ basali luteâ, in medio abdomine dilatatâ pictum; in segmento sexto praeter fasciam basalem vitta media lutea est; extremus abdominis apex cum hypopygio minuto dilute luteus. Pedes cum coxis pallide flavescentes, femorum posticorum margine supero et apice nigris; tibiae in. termediae infra setis ternis instructae; tibiae posticae apicem versus paulo crassiores. Alae fusco-bimaculatae; macula centralis parva; macula altera inter hanc et alae apicem intermedia, latiuscula, semifasciae similis, non ex cellulae marginalis sed ex costalis apice usque ad marginem posticum cellulae posterioris primae demissa, modice obliqua; infra hane maculam et infra cellulae marginalis finem venae longitudinales singulae colore cinereo subobsolete adumbrantur. - (New-York; Osten-Sacken.)

54. Mycetophila monochaeta, nov. sp. $\delta$ et $9 .-$ Obscura, opaca; in alis cinereis praeter maculam centralem fuscam macula magna subfusca, in venâ longitudinali terliâ sita conspicitur, quae cum fuscedine dilutiore confluit, quâ cellulae costalis apex el cellu- 
lae marginalis dimidium apicale linguntur; tibiae intermediae infra selá unicâ instructae. - Long. corp. $1 \frac{1}{3}-1 \frac{1}{3}$ lin., long. al. $1 \frac{1}{2}-$ $1 \frac{2}{3} \operatorname{lin}$.

Fusco-nigra. Caput concolor, opacum, partibus oris subfuscis; antennarum flagellum fusco - nigrum, imâ basi articuli primi saepe lutescente; scapi articuli plerumque praeter apicem. rarius toti lutei. Thoracis dorsum opacum, latera versus albido-pollinosum humerisque plerumque testaceis. Lamellae anales foeminae et hypopygium parvum maris lutea. Pedes cum coxis pallide flavescentes, femoribus posticis minus dilatatis, libiis larsisque tenuioribus quanı in Mycetophilis plerisque. tibiis intermediis infra setâ unici instrnctis et primo tarsorum posticorum arliculo articulis reliquis simul sumtis aequali. Alae cinereae, fusco-bimaculatae; macula centralis mediocris; macula subapicalis major et dilutior, inter maculam centralem el alae apicem intermedia, in venâ Iongitudinali terliâ sila est et cum fuscedine obsoletiore confluit, quâ apex cellulae costalis et cellulae marginalis dimidium apicale tinguntur: venae alarum fuscae. - (District Columbia; Osten-Sacken.)

55. Mycetophila procera, nov. sp. ठ․ - Reliquis specie. bus major et ab omnibus cellulae posterioris quartae figura, quae Dynatosomae est, diversa: alae praeter maculam centralem fuscam serie macularum fuscarnm irregulari, inde a cellulae marginalis apice usque in angulum posticum pertinente pinguntur ef in marginis postici triente apicali colore subfusco adumbrantur. - Iong. corp. $2 \frac{1}{2}$ lin., long. al. $2 \frac{7}{12}$ lin.

Caput ex ferrugineo sordide luteum; antennae fusco-nigrae. scapo et flagelli basi luteis. Thorax luteus, villis tribus dorsalibus, scutelli angulis, pleurarum maculis et metanoto toto nigro-fuscis; dorsum pube brevi lutescente pilisque longioribus nigris vestilum; setae ordinariae thoracis et scutelli nigrae. Abdomen fusconigrum. segmentorum singulorum margine postico angustius. marginibus lateralibus latius luteis segmentisque secundo et tertio practerea villâ latiusculâ luteâ variegatis. Pedes cum coxis lutescentes. tenuiores. femorum posticorum apice nigro; tibiae intermediae infra setis quaternis vel quinis armalae; tarsi longi, tenues, primo posticorum articulo articulis reliquis simul sumtis vix longiore. Alae praeter maculam centralem fuscam serie inconcinna macularum fuscarum. inde a cellulå marginalis apice usque in angulum posticum pertinente pictae et in marginis postici triente apicali colore subfuseo limbalae; venae alarum validae; cellula posterior (quarta apicem versus latior quam in Mycetophilis esse solet. - (New.York; Osten-Sacken.) 
Nola. Hanc speciem, quamquam cellulam alarum posteriorem quartam Dynatosomae gerit, propter venam auxiliarem abbreviatam inter Mycetophilas numerari.

56. Sciara sciophila, nov. sp. $\sigma^{\top}$ et 9 . - Nigra, palpis halterumque capitulo concoloribus, thorace nitido, humeris sordide luteis; pedes pallide lutescentes, trochunteribus tarsisque nigro-fuscis; alae nigricantes, semihyalinae, venae longitudinalis primae segmentis subaequalibus, cellulae posterioris secundae basi infra apicem cellulae costalis sitâ, cellulâ posteriore quartâ non pedunculalâ. - Long. corp. ठ大 $1 \frac{2}{3}, \& 1 \frac{1}{1}-2 \frac{1}{4}$ lin., long. al. $1 \frac{1}{1} \frac{1}{2}-2 \frac{1}{3}$ lin.

Nigra. Caput concolor, subopacum, dimidio superiore faciei palpisque in speciminibus immaturis fuscis, in maturis nigris; antennae fusco-nigrae, secundo scapi articulo plerumque primoque flagelli arliculo interdum lutescentibus. Thoracis dorsum modice nitens, nudiusculum, nigerrimum, humeris sordide luteis. Scutellum et metanotum cam thoracis dorso concolora. Pleurae fusco-nigrae. Abdomen maris nigrum, subopacum, nigro-pilosum, hypopsgio magno concolore instruclum; abdomen foeminae fusco-nigrum, opacum, nigro-pilosulum, lamellis terminalibus subrotundatis nigris. Coxae et pedes dilute lutescentes, femoribus adversus apicem levissime, tibiis in extremo apice distinctius infuscalis, Irochanteribus tarsisque nigro-fuscis. Halteres nigri, basi lamen pedunculi luteâ. Alae nigricantes, semipellucidae, venis validioribus nigro-fuscis, tenuioribus subfuseis; segmenta venae longitudinalis primae subaequalia; cellulae posterioris secundae pedunculus cellulae ipsi aequalis, prope a basi cellulae posterioris tertiae oritur; cellulae posterioris quartae pedunculus plane nullus; apex cellulae marginalis ab extremo alae apice intervallo aequali vel paulo minore distat, quam cellulae posterioris tertiae apex. - (District Columbia; Osten-Sacken.)

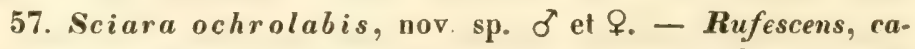
pite praeter faciem, thoracis vittis halterumque capitulo nigris, abdomine fusco, hypopygio maris dilute lutescente; pedes lutescentes, trochanterum apice tarsisque praeter basim nigro-fuscis. Alae subhyalinae, colore ex cinereo subfusco leviter tinctae, venae longitudinalis primae segmentis subaequalibus, cellulae posterioris secundae basi infra apicem cellulae costalis aut paulo propius ad alae apicem sit $\hat{a}$. - Long. corp. $\delta 1 \frac{1}{4}-1 \frac{1}{3}$, \& $1 \frac{1}{2}-2$ lin., long. al. $1 \frac{1}{3}-$ $1+\frac{1}{2}$ lin.

Caput nigrum, facie vel fuscâ vel rufescente; palpi fusci; scapus 
antennarum dilute lutescens, flagellum fusco-nigrum, basi tamen plerumque lutescente. Thoracis dorsum, sculellum et melanotum rufescentia, pleurae luteae; vitlae dorsales thoracis tres fusco-nigrae. media postice et laterales utrinque abbrevialac. omnes saepe dilutiores et imperfectac, laterales interdum plane obsoletae. Alodomen fuscum, opacum. Hypopygium maris majusculum, dilute lulescens vel exalbidum, articulormm terminalium lateribus adrersis alris. I,amellae anales foeminae subrolundalae. fusco-nigrae. Coxac el pedes pallide lutescentes, trochanterum apice nigro, larsis practer basim lutescentem nigro-fuscis. Halterum pedunculus pallidus. capitulum nigrum. Alac subbyalinae, colore ex cincreo subfuseo leviter tinclae, venis validioribus fuscis, lenuioribus subfuscis: segmenta venae longiludinalis primae subacqualia; cellulae posterioris sceundae pedunculus tenuissimus, cellulae ipsi subrequalis. vix propius ad cellulae posterioris quartae quam ad cellulae marginalis hasim ori. tur; pedunculus cellulae posterioris quartac vix ullus: cellulae marginalis apex et apex cellulae posterioris tertiac ab extremo alac apice intervallo subaequali separantur. - (New-York; Edwards.)

58. Trichosia hebes, nov. sp. 오 - Nigra, capite hallerumque capilulo concoloribus; alae nigricantes, semihyalinae. segmentis venae longiludinalis primae aequalibus vel ultimo paenultimum paulo superante, vená longitudinali terliá apicem versus non incurvâ. - Long. corp. $1_{\frac{1}{1}}^{\frac{3}{2}}$ lin., long. al. $1 \frac{1}{4}-1 \frac{1}{3}$ lin.

Nigra. Caput concolor, facie, palpis antennisque fuseo-nigris, basi harum dilute fusca vel sordide lutescente. Thoracis dorsum modice nitens, humeris luteis. Scutellum et melanolum concolora; pleurae fusco-nigrae. Abdomen nigrum vel fusconigrum. nigro-pilosulum, lamellis analibus rotundalo ovalis. concoloribus. Pedes ex luteo subfusci. tibiis posticis fuscis. Iarsis fusro-nigris. IJallerum pedunculus pallidus, eapilulum nigrum. Alae nigricantes. smipellucidae, venis validioribus nigro-fuscis. Icunioribus subfuscis, collulae posterioris primae dimidio apicali. relluli posteriore secundà tolâ et cellulà posteriore tertià adversus apicem pilis Iongiorihus aspersis; segmenta venae longitudinalis primac aequalia. vel ullimum pacnultimo paulo longius; vena longiturlinalis tertia recta, apicem versus non incurva; basis cellular posterioris secundac infra apicem cellulae costalis sita; cellulac posterioris fuartae pedunculus perbrevis. - (New-York; Edwards.) 
59. Dilophus breviceps, nov. sp. +. - Rufo-lestaceus. capite abdomineque nigris, femoribus luleis, tibiis fuscis, tarsis nigris; alue subhyalinae. leviter ex huleo cinerascentes, stigmate majusculo subfusco. - Long. corp. $1 \frac{2}{3}-2$ lin., long. al. $1 \frac{3}{4}-2$ lin.

Caput breve, nigrum. Color thoracis rufo-testaceus, pleurarum in luteum vergens, melanoti interdum subfuscus. Abdomen nigro. fuscum, ventre fere toto sordide lutescente. Femora lulea; tibiae fuscae, in speciminibus minus maluris dilutius tinctae, spinis anticarum acutis; larsi tenues, toti nigri, anteriorum basi interdum testaceâ. Halteres nigri. Alae subhyalinae, levissime ex cinereo lutescentes; praeter costae dinidium apicale venae costae proximae luscae, reliquae dilute lutescentes; sligma majusculum, subfuscum. - (New-Hampshire.)

60. Dilophus obesulus, nov. sp. ㅇ․ - Niger, nitidus, humeris rufis, coxis femoribusque luleis, tibiis tarsisque nigris; alae hyalinae, subalbicantes, stigmate nigro. - Long. corp. $1 \frac{2}{3}$ lin.. long. al. $2 \div$ lin.

Robuslus, niger, nilidissimus. Capul concolor, subopacum, breviusculum, sed quam caput speciei praecedentis paulo longius. Humeri rufi et pleurae obsulete rufo-maculatac. Venter lotus niger. Coxae luteae, trochauleribus tamen fuscis vel fusco-nigris; fenora lutea; tibiae fusco-nigrae, anticae in speciminibus immaturis prope basim et ante apicem badiae; larsi tenues, toti nigri. Halteres nigri. Alae hyalinae, obsolete albicantes; costa in dimidio apicali et venae costae proximae ex cinereo subfuseae, in speciminibus immaturis saepe pallidissimae, venae reliquae sine colore; sligma majusculum, nigrum. - (District Columbia; Usten-Sacken.)

61. Dilophus tibialis, nov. sp. Q. - Niger, nitidus, coxis anlicis et femoribus ex luleo rufis, libiis tarsisque nigris, illis quam in speciebus simililus validioribus; alae cinereae, stigmate fusco. Long. corp. $2 \frac{1}{6}-2 \frac{1}{3}$ lin., long. al. $2 \frac{1}{3}-2 \frac{1}{2}$ lin.

Niger, uitidus. Caput concolor, non elongatum. Humeri puncto rufo vel badio obsolete notali. Coxae anticae luteo-rufae, tro. chanteribus nigris, posteriores cum trochanteribus nigrae; femora luteo-rufa, apice omnium posteriorumque basi nigris vel nigro-fuseis; tibiae nigrae, validiores quam in speciebus praecedentibus, posteriores basim versus minus attenuatae; larsi tenues, nigri. Alae colore ex cinereo in dilutissime subfuscum vergente leviter tinctae, costâ venisque costae proximis fuscis vel nigrofuscis, aliquis dilulissime subfuscis, stigmale fusco. - (Silka.) 
rales, quinto praeter murgines laterales el posticum rufis: pedes rufi; alae nigro-variegalae. - Long. corp. $6 \frac{1}{3}$ lin., long. al. $4 \frac{1}{2}$ lin.

Niger, abdomine pracler basim et apicem rufo. Frons polline cinereo opaca, triente antico convexo, laevigalo, nitido. Facies aterrima, opaca, superne maculis duabus candido-pollinosis ornata. Antennae nigrae, articulo primo brevi et rassiusculo; palpi alri; proboscis lulea. Thoracis dorsum praeter margines laterales opacum et polline latescenti-cinereo, in vittarum interstitiis confertiore pilisque brevibus, dilule lulescentitus aspersum. Scutellum et metano. tum concolora. Pleurae leviter albo-pollinosae, nitidae. Abolominis segmenta secundum, tertium, quartum et quintum ex aurantiaco rufa, marginitus lateralihus omuium et margine postico quinti nigris, reliquorum incisuris fuscis; reliquum abrlonen nigrum et nitidum. Piclura ventris simillima, segmento tamen quinto fere toto nigro. Pedes rufi, tibiarum hasi non infuscalâ, duobus ullimis larsorum anticorum articulis nigro-fuseis; tarsi posteriores in specimine descripto desunt. Halteres flavi. Alae subcinereae, apice et margine postico latissime cinereo-limbalis; venae fusco-nigrae; inde a stigmate fusco-nigro fascia lata fusco-nigra usque in insam cellulae posterioris quartae basim dimiltitur; vena transversa posterior colore nigro-fusco latius et venarmm longitudinalium segmenta ullima eodem colore angustius marginata sunt. - (Texas.)

Nota. Xylophagus abdominalis similis et affinis est $\boldsymbol{X}_{\boldsymbol{y}}$ lophago cincto, sed primus antennarum arliculus brevior, faciei maculae caudidae majores, thoracis dursum magis pollinosum, tibiae adversus basim non infuscalae, cellulae posteriores alarum breviores et ultima venarum longitudinalium segmenta distinctius colore nigro fusco limbata differentiam demonstrant.

65. Ptiolina fasciata. nov. sp. J. - Cinevea, pallide pilosa, thoracis dorso nigro-villato, abdomine nigro-fascialo. - Long. corp. $2 \frac{1}{2}-2 \frac{7}{12}$ lin., long. al. $2 \frac{1}{12}$ lin.

Cinerea, opaca, pilis mediocribus ei pube tolius corporis exalbidis, vel dilutissime lutescentibus. Antennae nigrae, articulis duobus primis subnudis. Facies nuda. Palpi nigri, breviter albidopilosi. Thoracis vittae dorsales nigrae opacae; vilta media, adversus anticum thoracis marginem cinerascens et postice abbreviala, lineå mediâ non divisa; vittae laterales, utrinque abbreviatae et suturâ cinereà disseclae, postice maculâ nigrâ prope alae basim adjeclâ geminalae. Scutelli cirerei margo niger. Abdominis segmentum primum, praeter marginem posticum, nigrum; segmenta reliqua 
singula fasciâ basali nigrâ in medio abdomine dilatatâ. latera versus valde atlenuatâ ornantur. Peles quam in speciebus plerisque breviores et validiores; femorum apex extremus luteolus; color in tibiarum basi luteus adversus apicem per fuscum in nigrum abit. Pili femorum breviusculi, tibiarum pubes hrevissina. Halferum ca. pitulum nigrum, pedunculus fuscus. Alac cincreae. Lasim versus sublutescentes, sligmate subfusco, cellulis submarginali secundâ longâ. discoidali parvâ, posteriore securdâ petiolalâ. - (IIudsons-Bay Terrilory; Kennicolt.)

66. Pliolina majuscula, nov. sp. б. - Nigro-cinerea. thoracis dorso et sculello nigro-pilosis. alis cineveis. stigmate et renis nigris, cellula discoidali apertà. - Long. corp. 22-3 lin.. Iong. al. $2 \frac{7}{\mathrm{~T}}-2 \frac{2}{3} \operatorname{lin}$.

Nigro-eincrea, opaca. Antemae nigrae, articulis duobus primis breviter nigro-pilosis, stylo apicali adversus apicem altenuato. Facies nuda. Palpi magni, nigri, arliculo primo of basi secundi albidopilosis, reliquâ articuli secundi parte nigro-pilosâ. Nenlum et occipilis dimidium inferius albido-pilosa, superior hujus margo et vertex nigro-pilosi. Thoracis dorsum nigro-vittatum; vitta media latiuscula, lineà tenui cinerascente divisa, antice modice attenuala. postice valde abbresiata; vittae laterales, utrinque abbreviatae el sulurâ cinereâ disseclae, postice maculâ nigrâ prope alae lasim arljectâ geminanfur. Abdomen breviter nigro-pilosum, segmentum lamen primum segmentorumque sequentium latera pilis longis exalbidis instructa. Pedes breviusculi, validi, nigri, genibus dilute lutescentibus. libiis anterioribus ex luteo subfuscis. apicem versus nigris; femora pilis brevibus plerisque nigris, infra longioribus. prope basim exalbidis, prope apicem nigris vestila; tibiarum tarsorumque pubes brevissima nigra. Ilallerum eapitulum nigrum, pedunculus fuscus. Alae cinereae, venis nigris coloce ex cinereo in nigricantem vergente obsolete limbatis. stigmale cellularumque basalium primae et serundae apice fusco-nigris, cellulis submarginali secundì pedunculo aequali. discoidali et posteriore fertiâ in unam confluenlibus. venâ transversả posteriore, praeter initium breve e venac interealaris basi excurrens, omnino nullà. - (Hudsons-Bay Terrilory: Kennicott.)

67. Oncodes costatus. nov. sp. O’. - Niger. segmentis abdominalibus singulis postice albo-manginatis, costi et venis alarum fuscis, dimidio apicali costae incrassalo. - I,ong. corp. 22! lin., long. al. $2 \frac{5}{12}$ lin. 
Nitidus, ex piceo niger, stigmatc prothoraris picco-marginato, scutello praeter basim pedibusque piceis, tarsis tamen apicen versus nigris. pulvillis et empodio concoloribus. Abdominis segmenta singula postice fascià albâ. tenui et aequali ornantur. Segmentum ventrale primum nigrum, postice albo-fascialum; segmenta reliqua alba. singulorum fasciâ basali nigrâ. angustà quidem sed latera versus salis dilatatâ. Tegulae sordidissime exalbidac, fusco-marginatac. Alae subhyalinae adrersus basim coloris subfusci vesligium ostendunt; costa et venae saturate fuscac; dinidium apicale illius incrassalum; venae transversalis dimidium posterius obsoletum. - (Massachusetls; Sanborn.)

68. Opsebius sulphuripes, nov. sp. \&. - Nigerrimus, nilidus, halleribus pedibusque exalbidis vel dilutissime Ravicantibus, alis nigrn-fuscis, cellula posteriore primâ per venam Iransversam

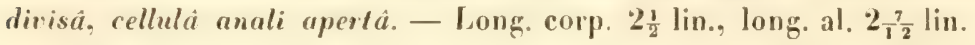

Nigerrimus. nilidus. Oculi conferlim nigro-pilosi, pilis tamen in inferà oculurum parte dilutius quam in parte superâ linctis. Antennac luteae. Sligmata prothoracis badio-marginala. Thoracis dorsum, scutellum el ahdomen albido-pilosa. Pedes exalbidi vel dilutissime flavicantes. subtiliter allido-pilosi. Tegulae mediocres, hyalinae. Halteres dilutissime flavicantes. Alae nigro-fuscac, adversus apicem el marginem posticum dilutiores; venae fusco-nigrae; vena transversa minor perpendiculariler demitlitur; cellula posterior prima per venam alteram transversam, ut in Opsebio gagalino, inler cellulae discoidalis finem et cellulae submarginalis secundae basim dissecatur; cellula posterior tertia. quae in Opsebio gagatino quartac basim transgreditur, in specie nostrâ eam non allingit, ila ut cellula posterior tertia brevior sit quam quarta; cellula analis. in Opsebiis gagatino el inflato longe ab alae margine clausa, in Opsebio sulphuripede aperta est. - (Sharon-Springs. New-York. - OstenSacken.)

Nota. Ut ab Opsebio sulphuripede distinguatur. Opsebii gagatini diagnosi in calce addendum est: ..cellulà anali clausâ".

69. Therena albiceps, nov. sp. $\sigma^{7}$ et 오. - Cinerea, albopilosa, capile toto niveo, antennis nigris, pedibus subfuscis, femoribus. tibiarum apice tarsisque adversus apicem nigris; alae hyalinae, venis et sligmale fuscis, cellulà posteriove quartâ vel in ipso alue margine clausi, vel anguste apertâ; segmenta abdominalia foeminae serundum, terlium et quartum late nigro-fasciala, fasciis villà albida disseclis. - Long. corp. 4-1 $\frac{7}{\frac{7}{2}}$ lin., long. al. $3-3_{\frac{5}{1}}^{\frac{5}{2}}$ lin. 
Caput utriusque sexus lotum albo-pollinosum et albo-pilosum. setis occipitis nigris, callo frontali foeminae nullo. Antemae mediocres, nigrae; arliculus primus tertio suloarqualis, allo-pollinosus, praeter selas ordinarias nimas pilis allis inslunclus: stulus terminalis mediocris, acutus. Proboscis fusea; palpi subfusci. comferlim albopollimosi ef pilis albis vestiti. Thorax nigrieness. polline alloido rineraseens, folus albo-pilosus, selis tamen ordinariis nigris: viltae dorsales tres obscurius cinereace in mare minus dislinetar, in for. mina magis conspicuae. in illo interstitis olsolelis albicantibus. in liac latioribus et ex albido lutescentibus separanfur. Scutellum concolor. Abdomen maris totum alho-pollinosum et confertim alho-pi. losum; abdomen focminae nigrum. polline conferlo albo otsleclum. segmentis tamen secundo. tertio et quarlo praeter fascian singulorum posticam, latera versus usque in angulos anlicos dilalatam polline conferto albo destilutis, ita ut in lis sermentis fisciac latissimac fusconigrae, latera versus valde anguslalae appareant. quas villa merlia minus confertim albido-pollinosa, in sermento serundo plerumque obsoleta, dissecat: ima segmenti quinti basis fusca: margines postici segmentorum quarli, quinli et sexti anguste fusci; segmenlum octavum lotum atrum et nitidum; pili longiores in forminac abdomine albi. breves et erecti in posteriore abdominis dimidio nigri. Pedes ex luteo subfusci; femora practer apicem exlremum nigra, polline pilisque albis: tibiae anticae adversus apicem lale, posleriores angusle fusco-nigrae; larsi fusco-nigri, basi anticorum angusle. posleriorum latius subfuscat. Hallerum pedunculus sordide lutens, capitulum lotum fusco-nigrum. Alae hyaliuac: renae nigrofuseae. in alarum basi dilutissime subfuscae; venae auxiliaris tota 1 costalis usque and cellulae marginalis finem dilutissime subfuscac; sligma nigro-fuscum: cellula posterior quarta vel in ipso alac marciue clausa. vol anguste aperta. - (British America, Seudder; Red Riscr, Kennicoll.)

Nota. Thereua olbireps a Therenat cumblala pedibus. alarum venis stigmateque obscuriorilus ef hallorum capilulo tolo fusco. nigro, non albo ef infra nigro. facile distinguifur: diversum an. tennarm colorem certam ambarum dillerentiam non pracbere. specimina Thereune camdidalae nuper milii nussa. Juorum au. temnae lotae nigrae sunl. demumslant. Foemina Therene candidarae alis minus hyalinis. sublutesculibus a mare dillerl: practerea frontis dimidium superius polline conferto rimanomo ols. tegilur el abdominis segmenta pracler primum el septimmm nigres. faseiata sunt. 
70. Thereua flavicincta, nov. sp. ठా. - Nigra, antennis concoloribus, segmentorum abdominalium marginibus posticis, hypopygio pedibusque luteis, albido-pilosa, pilis tamen frontis plerisque, verticis omnibus et non paucis in thoracis disco dorsali nigris; hal. terum copitulum nigrum; alae hyalinae, stigmate venarumque transversalium limbis angustis fuscis, cellulâ posteriore quartâ clausâ. - Long. corp. $4 \frac{3}{2}-4 \frac{2}{3}$ lin., long. al. $4 \frac{1}{4}-4 \frac{1}{3}$ lin.

Nigra, opaca, albido-pilosa. Pili verlicis omnes frontisque pili plerique nigri. Antennae nigrae, mediocres; articulus primus cinerascens, practer setas ordinarias nigras infra pilis albis vestitus; articulus terlius quam primus paulo longior, in imâ basi plerumque rufus. Facies confertim albo-pilosa; in genis albo-pilosis pili prope oculos nigricant. Thoracis dorsum polline luteo-cinereo levissime aspersum, ita ut vittarum inlerstitia obsolete cinerascentia conspiciantur, sed color niger reliqui dorsi in ciscreum non mutetur; pilis albidis dorsi pili numerosi nigri admiscentur'; pili pleurarum et scutelli omnes albi; setae ordinariae thoracis et scutelli nigrae. Primum abdominis segmentum totum nigrthm; segmenta reliqua omnia postice luteolimbata, ultimorum tamen limbis in medio abdomine interruptis. Venter nigricans, segmentis singulis, primo tameu excepto, postice late luteo-marginatis. Hypopygium luteum, superne fuscum. Pili abdominis omnes albidi. Pedes lutei vel ex subfusco-lutei, femoribus albo-pilosis. Halterum pedunculus luteus, capitulum totum fusco-nigrum. Alae hyalinae, venis fuscis, adversus basim dilutissime subfuscis, stigmate venarumque transversalium limbis angustis fuscis, cellulâ posteriore quartâ ante margiıem alae clausà. - (Northern Wisconsin, Kennicott; White Mountains, Scudder.)

71. Thereua gilvipes, wov. sp. ․ - Cinerascens, antennis nigris, callo frontis cordato, thoracis villis nigro-fuscis, intermediá lineam atram includente, vittarum interstitiis subochraceis, abdomine atro et nitido, adversus apicem salurate badio, segmentis singulis poslice ochraceo-limbalis, pedibus luteis, nlarum venis omnibus fuscolimbatis. - Long. corp. $5 \frac{3}{4}$ lin., long. al. 4 lin.

Callus frontalis ater, nitidus, cordatus, supra attenuatus, usque ad ocellos pertinens. Frons ipsa supra callum polline ex ochraceo fusco, infra callum luleo tecta, praeter callum breviter nigro-pilosa. Occipitis dimidium superius luteo-vel ochraceo-pollinosum, nigrosetosum; reliquae capilis partes confertim albo-pollinosae et praeter pilos nigricantes prope oculorum angulum inferum pilis confertis albis vestitae. Antennae mediocres nigrae; articulus primus cinerasiens, terio vix brevior, praeter sctas ordinarias inf a pilis aliquot 
albis aspersus. Thoracis dorsum opacum, nigro-pilosum, viltis tribus nigro-fuscis pictum, quarum inlermedia lineâ longitudiuali atrâ dividilur; vittarum interstitia polline subochraceo, dorsi latera polline luteo-cinereo obtecta. Pleurae albido-pollinosae et albo-pilosac. Scutellum subochraceo-pollinosum, maculâ tamen basali fusco-polli. nosa. Primum abdominis segmenlum albido-cinereum; reliqunm abdomen nilidum, atrum, adversus apicem obscure badium, margine postico segmentorum singulorum lacte ochraceo, in segmentis secundo, tertio, quarto et quinto singulis cum fascia ochraceo-pollinosâ. latera versus dilatatâ, confluente; segmenta tria prima parce albido-pilosa, reliqua pilis erectis nigris hirta. Venter opacus. lutes. cinereus, adversus apicem subbadius, segmentorm marginilus posticis dilute luteis, segmentis tribus primis albido-pilosis, reliquis nigro-pilosis. Pedes lutei. Lasis apicem versus nigro-fuscis: femora praeter pilos nigros pilis albidis aspersa. Halterum pedunculus Intrus. capitulum fusco-nigrum. Alae cinereac, venis fuscis. colore nigrofusco anguste limbatis, adversus basim alarum dilutioribus ef non limbatis; sligma nigro-fuscum; cellula posterior quarla ante marginem alae clausa. - (Massichuselts; Sanborn.)

Nota. Thereuan gilvipedem ut alterum sesum cum Thereni favicinctâ conjungere propler diversam alarum picluram mon ausus sum; num merito separatae sint. quibus vivas observandi occasio datur, videant.

72. Thereua strigipes, nov. sp. +. - Nigricans, callo frontali magno, supra levissime attenuato et ad ocellos usque perti. nente, thoracis dorso praeter pilos nigros tomento lutescente asperso, abdomine nigro et fere toto nitido, segmentorum marginibus posticis luteis; pedes sordide lutei, femoribus nigris intermediis adversus basim posticisque infra sordide luteis; alae rinereae, venis nigrofuscis et anguste fusco-limbalis, stigmate nigro-fusco. celluli posteriore quarta in ipso alae margine clausit. - Long. corp. $4_{\mathrm{I}^{\frac{5}{2}}} \mathrm{lin.}$. long. al. $3 \frac{1}{3}-3 \frac{5}{1} \frac{1}{2}$ lin.

Nigricans. Callus frontalis ater, nilidus, magnus, supra vix attemuatus. usque ad ocellos pertinens; frons ipsa polline ex ochraceo subfusco obtecla el praeter callum nigro pilosa; occipilis dimi. dium superius ochraceo-pollinosum. setis nigris pilisque luteis vesti. tum; reliquae capilis parles albo-pollinosae et albo-pilosar, pilis tamen prope marginem inferum oculorum fuscis vel nigricantibus. Antennae mediocres, nigrae; articulus primus cimerasenens, tertio aequalis. praeler setas ordinarias nigras infra albo-pilosus; ima basis articuli tertii 
rufscens. Thoracis dorsum sordide nigrum, opacum. polline nullo aspersum vel polline in specimine mediocriter conservato tanfum detrito, pilis nigris et tomento raro lutescente instructum. Scutel. lum pallide-pilosum. Setae thoracis el scutelli nigrae. Pleurae nigricantes, polline albo dilute cinereac, albo pilosae. Abdomen nigrum, nitidum. adversus basim subopacum, segmentorum marginibus posticis jutcis, primi tamen segmenti margine excepto; segmenla tria prima pilis albidis, primum confertioribus. secundum et tertium raris inslructa; pili segmentorum reliquorum breves, erecti, nigri. Femora antica nigra, infra sordide testacea; femora intermedia sordide lutea, adversus apicem nigra: femora postica nigra, infra sordide lutea; tibiae sordide luteac, extremo apice nigro-fusco; tarsi nigro-fusci, articulo primo praeter apicem sordide luteo. Colorem pedum, quem sordide luteum appellavi, melius fortasse ex luteo in subfuscum vergentem nomi navissem. Halterum pedunculus luteus, capitulum fusco-nigrum. Alae cinereae, stigmate venisque nigro fuscis, venis transversis latius, longifudinalibus anguslius et obsoletius fusco-limbatis, cellulâ posłe. riore quarlå aperlâ. - (English River; Kennicott.)

73. Psilocephala variegata, nov. sp. $\sigma^{7}$. - Cinerea, opaca, pilis albidis, in thoracis dorso et adversus abdominis apicem pallide flavesrentibus vestila; antennue breves, nigrae, arliculo primo incrassalo; pedes lutei, femoribus, tibirum "pire tarsisque apicem vorsus nigris; alae sordide albicantes. non pelluridae, stigmate nigrofusco-venarumgue limbis fuscis variegatue. - Long. corp. $4 \frac{3}{4}$ lin., long. al, $3 \frac{1}{6}$ lin.

Cinerea. opaca. Caput albo-pollinosum et albo-pilosum, fronte tamen et facie nudis; selae in supero occipitis margine luteac. Antennae nigrae, breves, articulo primo iucrassato, praeter setas ordinarias nigras infra pilis nonnullis luteis aspersa. Thoracis dorsum non viltalum, pilis ex albido dilute flavescentibus vestitum. Scutellum concolor, pilis confertis pallidissime flavescentibus instruclum Setae ordinariac thoracis et scutelli nigrae. Pleurae polline exal. bido dilute cinereae, albo-pilosae. Abdomen totum pollinosum et opacum, marginilus poslicis segmenti secundi latiore, segmenti terlii angustiore pallide lulescentibus; pollinis color ex albido in flavidocinereum vergens, mulato lumine ante segmentorum secundi. tertii et quarti marginem posticum purius albicat. Venter cinereus, marginibus poslicis segmentorum secundi et tertii sordide lutescentibus. Pili abdominis exalbidi, adversus abdominis apicem pallidissine flavescentes. Hypopygium mediocre, nigrum, lamellis tamen late luteo 
marginatis, pallide pilosum. superne polline dilute cincrascente aspersum. Pedes ex subfusco lutei; femora niz-a. albo-pollinosa ef pilis albis vestila; libiarum apex tarsigue praeler hasim luseo-nigri. Halterum pedunculus sordide Julescens, capiluhum iufra nigrum. superne fuscum. Alae non pellucidae. sordide albicantes; venar nigro. fuscae; vena costalis usque ad rellulae matginalis fuem. vena anxiliaris tola. venae longitudinalis tertiae hasis ef venae ommes in ala. rum triente basali dilutiores; stigna fusco-nigrum: venar transversales fusco-limbatae; venarum longitudiualium apices obsoletins colore fusco circumfusi; posticus alarum margo leviter cinerascens: collula posterior quarta aperta. - (Canada.)

74. Psilocephala scutellaris, nov. sp. Q. - Nigra. fronlis macula rhomboidali aterrima et opact. scutello fulvo. alis rincreo-trifasciatis. - Long. corp. $4 \frac{7}{12}$ lin., long. al. $22_{6}^{3}-2 \frac{1}{1} \frac{1}{2} \operatorname{lin}$

Nigra, subnuda, modice nitens. Frontis dimidium superius nilidissimum; in media fronte macula rlomboidalis magna. aterrima et omnino opaca; anlerius frontis dimidium el facies loresis-ima leviler albo-pollinosa. Antennac longiusculae, fusco-nizrae. arfirulo primo subfusco et breviter nigro-piloso, tertio subacquali. slylo terminali minuto. Palpi fusco-nigri, nigro-pilosi; proboseis concolur. Oecipitis dimidium superius setis nigris, inferius pube bresi albicante instruelum; zenac breviler nigro-pilosulae. Thoraci- dorsum subnudum, pilis brevissimis appressis. plerisque lulescenlibus parce aspersum et levissme albido-pollinosum. ita ul viltae verius nigrae fres latissimae. interstitiis paulo confertius albo-pullinosis di-linclae conspieiantur, quarum intermedia poslice admodum abbreviatur. Setac laterales dorsi brevissimae, nigrae; setae ante sculellum mullac. Sculellum ex fulvo rufum, opacum, praeler selas qualuor brevissimas nigras nudum. Abdomen anguslum, nigrum. nitens. adrersus basiun subopacum, margine postico segmenli secundi lalius albido. marginibus posticis segmenti primi el tertii angustius el sordide exallidis. Spinarum corona cum extremo genitalium apire rufa. Primum abdominis segmentum el latera segmenti secumdi treviter albopubescentia; reliquum abdomen pilis hrevissimis nigris, in posteriore ab. dominis dimidio erectis instructum. Pedes tenurs. elonsnti. snbundi. nigri; extremus fenorum apex subfuscus; tihiae anticas modice compressae, superne subfuscae: tibiac infermediar lolat sub. fuseac; tarsi anlici compresso-dilatali. nigri; larsi posteriores lemues et simplices, nigri, intermediorum articulo primo pracler apicem. posticorum arliculo primo cmm basi arliculi secomdi colore sordide 
subfusco, valde diluto tinctis. Halterum pedunculus luteo-rufus, capilulum nigro-fuscum. Alae breves, hyalinae, levissime cinerasceutes, cellulâ costali subfuscà fasciisque tribus cinereis, quae, si alae oblique asspiciantur, nigricant; cellula posterior quarta angusta et longe ab alae margine clausa. - (District Columbia; OstenSacken.)

75. Psilocephala erythrura, nov. sp. రా. - Nigricans, polline albo, in abdomine confertissimo pilisque albis vestita, scutelli dimidio apicali aterrimo, hypopygio rufo, alis colore nigricante trimaculatis. - Long. corp. $2 \frac{1}{2}$ lin., long. al. $2 \frac{1}{1} \frac{1}{2}$ lin.

Nigricans, albo-pollinosa et pilis albis vestita. Antennae fuscac; facies brevis. Scutelli dimidium apicale aterrimum, holosericeum. Setge ordinariae thoracis el scutclli nigrae. Abdomen polline conferto candidissimo oblectum. Iypopygium ex luleo rufum, pilis lutescentibus hirfum. Femora pracler apicem sublutescentem nigra; libiae ex subfusco sordide lutescentes, anlicae subcompressae et infra nigro-fuscae; tarsi antici modice compressi, nigri; tarsi posteriores ex subfusco sordide et dilule lutescentes, adversus apicem nigro-fusci. Alae hyalinae, leviter cinerascentes et colore nigricante trimaculatae; macula prima, reliquis obsoletior et minor in apice cellulae posterioris secundae sita est; macula secunda fasciae postice abbrevialae, a cellulae costalis apice ad normam demissae similis est; macula tertia, apici alae propinqua, maculis duabus, alterâ in cellularum submarginalium priore, alterâ in posteriore sitâ, componitur; cellula posterior quarta ante marginem alae clausa. - (Middle Slates.)

76. Geron macroplerus, nov. sp. o.- Opacus, niger, supra pilis lutescentibus, infra albis veslitus, abdominis lateribus antice dilute lutescentibus, femoribus tibiisque prater apicem luteis; ulae magnae, obscure cinereae, stigmate fusco, cellulà sub. marginali secundâ longâ, venâ transversâ posteriore abliquâ ế le. viler flexa. - Long. corp. $2 \frac{1}{3}$ lin., long. al. $2 \frac{3}{4}$ lin.

Niger, opacus, corporis formâ ac figurà Geronti calvo similis. Antemne nigrae, articulis duobus primis brevissime nigro-pilosulis. Pili verticis nigri, occipitis dilute sublutescentes, menti albidi. Thoracis dorsum et scutellum pilis lutescentibus et tomento rarissimo subaureo vestita; dorsi margines laterales et humeri latissime cinerei. Pleurae albo-pollinosae et albido-pilosae. Lalera segmentorum abdominalium primi, secundi et tertii cum primis ventris segmentis dilute lutea. Pili abdominis longi, lutescentes, in abdominis apice 
magnå ex parte nigri vel nigricantes, in ventre omues albidi. Coxace fusco-nigrae. Pedes lulei, lenornm apice late nigro-fusco, extremo tibiarum apice fuseo farsisque practer anteriorum basim nigro-fuscis. Halterum pedunculus fusco-niger, adversus apicem dilute luteus: capilulum luteum, superne nigrofuscum. Alae magnae, obscure cinereae, basi panlo dilutiore, venis of stigmate fuscis, Cellula sulbmarginalis secunda longa, ila ut duo ultima venae fongiludinalis tertiae segmenta subaequalia sint; vena transiersa posterior modice obliqua et levissime tanlum flexa. - (Genesseo: New. Iork.)

77. Geron vilvipennis, nov. sp. 万. - Opuesus, aler, supre pilis hueis et tomento tenui subaurco vestitus. infra pilos albidos squamulasque candidas gevens. mystare candido, breribus antennarum pilis nigris; pedes nigri, tibiis anticis adrersus basim, posterioribus prater apicem piceis: alue pure hyalinae. stigmate dilutissime lutescente, celluli submarginali secundi perbrevi et maximopere

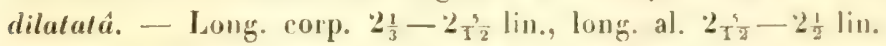

Aterrimus, opacus. Oculi contigui. Fronlis pili breves, lutescentes, prope antennas candidi. Facies albo-pollinosa et candido. pilosa. Antennae nigrae, arliculis duobus primis breviter nigro-pilosis; pili verlicis nigri, occipilis lutei, menti albidi. Thoracis dorsum et sculellum tola atra et opaca, pilis luteis et tomento rarissimo subaureo vestita. Pleurae albo-pollinosae, pilis albis et tomento candido instru. etae. Abdomen atrum, opacum, pilis luleis et tomento brevisimo subaureo, lateribus el ventre polline albido dilute cinereis. pilis albidis el tomento candido praeditis. Pedes nigri. tibiis anticis adversus basim piceis, tibiis posterioribus practer apreem nigro-fuscum rufo-piceis, posticis tamem plerumgue quam intermediate obscuriuribus. Halleres havi. Alae pure hyalinae. stigmate dilulissime sub. lutescente, cellula submarginali sccumbi perbueri el maximopere dilatatâ, ita ut extremus venae longitudinalis tertiace apex paulo longius ab apice funam a basi rami anterion is obsil; vena transtersa posterior obliqua et distinete billexa - (Midulle siates.)

Nota. In Geronte subaruto describendo (Cent. IV. 55) exem. plorum mentionem feci, quorum tibiar piceo colore essent. Sed exempla integriora naclus. ea nou ad Gerontem subauratum, sed ad Gerontem vilripennem referenda esse intellexi; ideo forontis subaurali diagnosis ita corrigalur necesse est, 11 sit:

Gerou subauratus, ơ et f. - Opacus, ater, supra. pilis lutescentibus et tomento tenui subaureo vestitus, infra pilos syamulasque candidas gerens, mystace candide. brevibus anlennarum 
pilis nigris; pedes toli nigri; alae cinereo-hyalinae, stigmate subfusco, cellulà submarginali secundâ brevi el valde dilatatá. Long. corp. $1 \frac{3}{4}-2$ lin., long. al. $1 \frac{3}{4}-2$ lin.

78. Geron albidipennis, nov.sp. ठౌ.-- Ater, opacus, supra pilis exalbidis, infra albis vestitus; pedes nigri; alae pure hyalinae, leviter albicanles, sligmate decolore, venae longiludinalis tertiae segmento paenultimo duplicem ultimi longitudinem aequiparante, venâ Iransversa posteriore levissime flexá. - Long. corp. $1 \frac{1}{2}$ lin., long. al. $1 \frac{1}{2}$ lin.

Ater, opacus. Oculi contigui. Antennae nigrae, arliculis duobus primis conferlim albo-pilosulis. Facies candido-pilosa. Pili occipitis albi, prope verticem et in hoc ipso lutescentes. Thoracis dorsum et scutellum lota alra et opaca, pilis ex albo sublutescentibus et tomento raro subaureo vestita, margine tamen antico dorsi vere albo-piloso. Abdomen alrum pilis exalbidis et tomento rarissimo subaureo aspersum, lateribus late et veutre toto albo-pollinosis, pilis albis et tomento conferto candido instructis. Pedes nigri, tibiis intermediis fusco-nigris. Halteres flavi. Alae pure hyalinae, leviter albirantes; sligua sine colore; cellula submarginalis secunda valde dilatata el perbrevis, ila ut segmentum paenultimum venae longitu. dinalis terliae duplicem ultimi longitudinem assequatur. - (California: Agassiz.)

79. Myiolepta varipes, nov. sp. ․ - Nigra, antennis, lateribus segmenti abdominalis primi, segmento secundo praeter margines laterales et viltam. libiis intermediis prapler annulum nigrum, tibiarum reliquarum basi tarsisque posticis ex rufo luteis, horum tamen articulis duobus ullimis nigris. - Jong. corp. $3 \frac{7}{1^{\frac{2}{2}}}-3 \frac{2}{3}$ lin., long. al. $3 \frac{2}{3}$ lin.

Myioleplae luteolae Gme l. simillima. Nigra, nudiuscula. Frons ulrinque maculâ albido-pollinosâ ornata. Anlenuae ex luteo rufae, setâ concolore, articulo primo basin versus badio. Facies concava, peristomio valde producto, fasciâ superâ, marginibus lateralibus et vittulâ ad peristomium decurrente albo-pollinosis. Thoracis dorsum aenescens, pilis brevibus appressis lutescentibus vestitum, marginis anlici limbo lato albido-pollinoso, in medio margine late interruplo. Sculellum aeneo-nigrum, breviter luteo-pubescens. Abdomen nigrum, lateribus segmenti primi scgmentoque secundo luteis, hujus vittâ mediâ lalâ marginibusque lateralibus nigris. Pedes nigri, extremo femorum omninu apice, libiarum ommium trente basali interme. 
diarumque apice, tarsorum denique posteriorum articulis tribus primis luleis. Halleres dilule lulei. Alate cinereo-livalinat. adversus lasim dilute lutescentes. maculà subfuscà inde a cellulae costalis apice usque ad cellulate discoidalis basim pertineule. ipso alae apice dilutius subfusco. - (Virginia.)

so. Orthoneura ustulata, nov. sp. +. - Ex chalybeo ri. ridis: nilida, segmentorum abdominalinm secundi et tertii margine postico opaco et nigro; antennae rufie, arliculo terlio rotundato: alae cinereae, plaga subapicali nigricante. - Long. corp. $2 \frac{5}{\frac{5}{2}}-\frac{2}{\frac{7}{2}}$ lin., long. al. $2 \frac{1}{6}-2 \frac{1}{3}$ lin.

Ex chalybeo viridis. nilida, pedibus tolis concoloribus. Faciei dimidium superius valde concavum et polline albo aspersum, inferius valde promineus. Antennae rufac, inà basi fuscâ; arliculus tertius rolundus, marginibus supero et apicali fusco-limbatis. Thoracis dorsum et scutellum seabriusenla et minus nitida. Abdomen nitidum, segmentorum secundi ef tertii marginibus posticis el vitli latiusculâ inde a basi abdominis usque in segmentum quartum perlinente alris et opacis. Hallerum pedunculıs lutescens, capitulum nigrun. Alae cinereate, venis nigris; stigma nigro-cincreum: plaza subapicalis colore nigricante difluse tineta. sed ila ul vena coslalis el venac longiludinales dilutius limbatae siol. - (New Jersey).

Nota. In speciminibus immaluris segmenta abdominalia secundum et terlium plerumpue practer margines et prater vilfan colore sordide luteo tinctae sunt et apex alarum minus nigricat.

81. Callomyia talpula, nov. sp. Q. - Mlva, holosericer, hallerum copilulo concolore. fronte nitidissimci. pedibus lutescentibus, alarum venis longiludinalibus tertia el quarli dirergentibus.

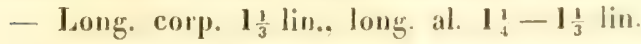

Frons atra, nilidissima. Antennae nigrae. arliculo lertio longo. aculissimo, selá terminali longiludinem arliculi tertii paulo exerdente. Palpi nigri. Oceipul alrum. opacum. Thorax lolus alcrrimus, holosericeus. Abdomen conrolor, extromo lasmen apier cinereo. Pedes cum coxis pallide flavi. fomoribus tibiisque poslicorum apicem versus dilute subfuseis. farsormm anteriorum apice larsispue postiris practer basim fuscis. Tegulae dilule Mavescentes; hallerum pedunculas luleus, capitulum nigum. Alae purissime fyalinae. ve. nis longiludinalibus tertià ef quarta apicon versus divergentibus. (New IIampshire.) 
52. Callomyia tenera, nov. sp. ㅇ. - Atra, fronte et facie chalybeis, nitidis, thoracis dorso ex chalybeo glaucescente, abdomine strigis lateralibus magnis gluncis ornato, pedibus pallidis, halteribus nigris, alarum venis longitudinalibus tertiâ el quartâ parallelis. Long. corp. $1 \frac{1}{6}$ lin., long. al. $1 \frac{1}{6}$ lin.

Frons chalybea, nitens, vertice tamen summo et occipite atris et opacis. Antennarum arliculi duo primi fusci, tertius niger, acutus, quam seta terminalis paulo brevior. Facies brevis, chalybea. Thoracis dorsum et scutellum in specimine descripto e nigro chalybea, subnitida, glaucescentia, illius limbo laterali inde ab humero usque ad alae basim atro et opaco. Abolomen atrum, velulinum, segmenlis quinque primis singulis utrinque strigâ sive maculâ transversà albo-pollinosà, laete glaucescente ornatis, maculis segmenti primi lato intervallo inter se distantibus, segmentorum reliquorum maculis in medio abdomine fere contiguis. Pedes cum coxis pallidi, femorum dimidio apicali, tibiis posticis, tarsorum anteriorum apice tarsisque posticis praeter basim subfuscis. Halteres atri. Alae purissime hyalinae, venis longitudinalibus tertià et quartâ parallelis. - (New York; Osten-Sacken.)

Nota. Callomyia tenera in multis cum Callomyiâ nolatâ con. gruit, ita ut illam, si magnitudine aequaret, hujus foeminam esse conjectarem.

83. Platypeza anthrax, nov. sp. $\delta$. - Atra, antennis, pedibus halleribusque nigris, ultimo abdominis segmento cinereo; alae cinereo-hyalinae, venae longitudinalis quartae ramulo anteriore leviler arcualo, cellulâ posteriore secundâ longà sed angustâ. Long. corp. $1 \frac{5}{\frac{5}{2}}$ liu., long. al. $1 \frac{2}{3}$ lin.

Caput nigrum, opacum, antennis palpisque concoloribus; facies breviler nigro-pilosula. Thorax ater, opacus, pleuris fusco-nigris. Sculellum et abdomen alra, opaca; segmentorum abdominalium secundi et tertii margines postici subtilissime rufescentes, segmentum ultimum obscure cinereum, maculâ basali atrâ, minutâ et subtriangulà pictum. Pedes nigri vel fusco-nigri, genibus extremis pallidis. Halteres nigri. Alae hyalinae, leviter cinerascentes, venis fuscis; vena transversa minor ab alae basi latius remota, quam in Platypezis velutinâ et obscurâ, ita ut intervallum inter venas transversas duplicem longitudinem intervalli, quod inter venam Iransversam minorem et cellulae discoidalis basim interjectum est, paulo superet; ramulus anterior venac longitudinalis quartae leviter curvatus, posterior mediocris; cellula posterior secundâ longa, sed an- 
gusta; cellula analis quam in Platypezâ relueliná et in Plutypezá obsrurâ modice longior. - (New York: Osten-Sarken)

84. Saucropus carbonifer, nov. sp. $0^{-1}$ - Pallide fanes, marulâ magnâ ante srutellum, pleurarum marulis el melanoto nigris, segmentis abiominalibus secundo el tertio nigro-fasriatis, artirulo ultimo larsorum antirorum dilatato, atro. - Long. corp. '2 ${ }_{1}^{\prime}$ lin.. long. al. 2 ! lin.

Flarus, antennis concoloribus. Facies angustissima, alha. Orcipitis dimidum superius nigricans. Thoracis dorsum aute sculel. lum maculâ magnâ semirulundâ nigrî, polline albo áspersâ nolatum. Melanolum tolum nigrum, leviter albido-pollinosum. Pleurae nigromaculatae. Tegulae pallide flavesecules, albido cilialae. Segmentum abdominale secundum triente apicali excepto nigrum; segmentum tertium fasciâ basali nigrâ, in medio abromine valde angustalâ vel iuterruplâ ornatum. Ilypopygium majusculum. luteum. Podes gracillimi, nudiusculi, pallide llavescentes; tarsi tenuissimi, anticorum articulo prenultiono albo, articulo ultimo depresso, dilatalo. atro. Alac ex cinereo sublutesceutes, venis fuscis, cellulae posterioris primae dimidio apicali sulsito dilatalo. - (New York; OstenSacken.)

85. Coenosia tricincla, nov. sp. J. - Tola lulea, nilens. thoracis viltis abdominisque fasciis tribus nigro-fuscis. - Long. corp. $2 \frac{1}{6}$ lin., long. al. '2 lin.

Lutea, nitens. Caput concolor; frons opaca, adversus verticem latior; antennae dilute lutescentes, arliculo tertio breviusculo, selit subnudà, adversus apicem nigricante et valde altenuatå; sela my. stacina utrinque unica nigra; proboscis et palpi dilule lutescentes. In thoracis dorso conspicimfur vitlae lres nigro-fuscae, intermedia postice valde ahbreviala, laterales plerumque imperfectae, hand rars subfuscae vel plane obsoletac. Sculelli setae duac. Segmenla ab. dominalia secundum, tertium el quartum postice colore nigro-fusco limbalae; segmenfum secundum plerumque practerea lincoli longiludi. nali fusco nigrà signalum. I'llimum ventris segmentum infegrum. Iy. popygium luleum, parvum. subimmersum. Pedes dilule lutescentes. Alae latae, subhyalinae, Ieviler sublutescentes. - (New IIampshire)

86. Schoenomyza chrysostoma, nov. sp. o'. - C'ineren. frontis dimidio anteriore niceo, supra punclo triangulari altrrimo 
excisum, farie aterrimâ. opacâ, margine oris fulon-limbato. - Long. corp. $1-1_{\frac{1}{2}}$ lin., long. al. $1-1_{\frac{1}{12}}$ lin.

Cinerea. Occiput et superius frontis dimidium concolora: inferius frontis dimidium niveum, margo tamen superus coloris nivei puncto triangulari aterrimo excisus. Facies aterrima, opaca. oris aperlurâ fulvo-limbatâ; genae ex aureo ochraceae. Viltae thoracis et maculae ahdominis paulo ohscurius cinereae, valde obsolelae. Pedes nigri. genibus extremis fuscis. Alae hyalinae subalbicantes, venis transversis vix obsoletissime cinereo-limbatis. - (New Hamp. shire.)

87. Cordylura gracilipes, nov. sp. ․ - Gíracilis, atra. nilida, capite praeter superius occipitis dimidium, villa thorncis et scutelli media, pleuris totis, coxis pedibusque dilutissime Ravicantibus, alis hyalinis, apice levissime infuscato. - Long. corp. $2 \frac{1}{3}$ lin., long. al. $2 \frac{1}{6}$ lin.

Capul ex alho dilutissime flavesiens. proboscide et palpis conroloribus, fronte luteà. leviler albo-pollinosâ. maculâ parvâ ocellos includente et superiore occipilis dimilio atris; anlennac breves exalbidae, setâ practer basim nigricante, pilis subtilissimis plumatâ. Thoracis dorsum atrum, nitidum, vittâ latissimâ luteâ, antice modire alubreviałâ. Scutellum atrum. nitiłum, viltulâ lutescente dimidialum. Metanofum atrum, nilidum, polline albido levissime aspersum. Pleurae tolac ex albo dilutissime flavescentes. Abdomen tofum atrum et nitidum. Pedes graciles, ex albo dilutissime flavescentes, coxis larsisque concoloribus, setas paucas et tenues subfuscas gerentes; femora antica infra prope basim setis rigidis ternis vel quaternis armala: femora po-teriora selis nullis instructa. Alae hyalinae, dilute sublutescentes, costâ venisque costae propinquis luteis, venis reliquis ex luteo subfuscis; apex alarum cinereus vel dilute sul,fuscus. - (New Ilampshire.)

Nota. Cordylura gracilipes simillima est Cordylurae adustae. sed diflert: selâ antennarum plumatâ, femoribus intermediis inermibus, pleuris totis exalbidis tarsisque pallidis.

88. Cordylura inermis, nov. sp. +. - Alra, nilida, ropile rum antennis. probosride el pulpis (lateralibus tamen fronlis marginibus, verlice et ocripitis dimidio superiore exceptis), pleuris praeter villulam sub alarum busi silam, roxis pedibusque pallide flavescentibus, setâ antennarum breviler pilosulâ, alis subluyalinis. Long. corp. '2 - 2' lin.. long. al. $2-2 \frac{1}{1} \frac{1}{2}$ lin. 
Atra, nilida. Capul dilute flaveseens, proboscide, palpis anlennisque concoloribus. setâ harum breviter pilosulà. non plumalâ; frons: lutea, albido-pollinosa, utrinque nigro-marginala: macula minula ocellos includens, verticis margo posticus et occipitis dimidium superius atra. Thoracis dorsum, scutellum el metanolum atra el nitida. Pleurae dilute flavicantes, vittulâ atrâ inde a metanofo usquuc in medias pleuras pertinente piclae. Abdomen folum atrum it nitidum. Coxae dilute tavescentes. Pedes concolores. Fraciles. setis lorngioribus plane nullis instıucti, tarsis subfuscis. Alae liyalinae, aequaliter et dilutissime ex cinereo sublutescentes. - (New Ilampshire.)

Nota. Similis el Cordylurae adustue et Cordylurae sracilipedi. ab utrâque frontis marsinibus lateralibus niçris, pedibus sclalon-iores nullas gerentibus, thoracis dorso tolo alro discrepat; ab hac praeterea seta antennarum non plumata. sed breviter pilosulà et pleurarum vitlulâ alrâ distinguitur.

89. Cordylura scapularis, nov. sp. O. - Alra. nitida. capite cum antennis, proboscide et palpis (fronte praeter margincs laterules, verlice occipitisque dimidio superiore exreplis). scrupulis. pleuris totis, coxis pedibusque dilutissime farescentibus. setis longioribus hornem tenuibus. femorum anticorum ternis r.pl quatrnis. femonum posticorum uullis. setâ antennarum plumalà, alis hyalinis. apice ex cineveo subfusco. - Long. corp. 3 lin.. lons. al. $2 \frac{1}{2}$ lin.

Atra, nitida. Capul ex alto dilute flavescens, proboscide, palpis anteunisque concoloribus, selả antennali nigrà et nigro-plumald̀. Frous nigra, opaca, leviter albo-pollinosa. marginibus lateralibus dilute flavis; occipitis dimidium superius cum vertice atrum. Thu. racis dorsum practer scapulas. scutellum et metanolum atra el nitida. Pleurae lotae ex albo flavescentes. Abrlomon lotum alrum ef nilidum. Coxae dilute flavescentes. Pedes concolores; setate longiores fuscae vel fusco-nigrae; femora anlica prope basim infra selis teruis armata, femora posteriora selis uullis inslructa. Alac hyalinae. ex cinereo dilute lutescentes, apice ex cincreo dilute subfusco. (English River; Kennicott.)

Nola. Cordylurae pleurilicae non absimilis. oced differt: sulac anlennalis basi minus incrassatà. fionle praeler margines laterales nigrâ, scapulis pallidis, villuli atrì pleurarmu nullide pedibus gra. cilioribus, selis pedum lenuibribus of in infero femorum antico.

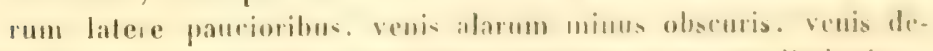
nique transtersis latiore interallo distantilus el non limbilis. 
90. Cordylura glabra, nov. sp. ㅇ․ - Atra, nilida, capile rum antennis, proboscide et palpis (fronte praeter marginem anli. cum, vertice et occipitis dimidio superiore exceptis), pleuris tolis, coxis pedibusque dilute favescentibus, femoribus anlicis infra selas circiler senas, intermediis unicam, posticis binas ferentibus, alis hye. linis, leviter cinerascentibus, venis transversis lato intervallo distanlibus, posterioris limbo et apice alae dilute subfuscis. - Long. corp. $3 \frac{5}{\frac{5}{2}}$ lin., loug. al. $2 \frac{3}{6}$ lin.

Alra, nitida. Caput dilute flavescens, proboseide, palpis antennisque concoloribus, setà harum nigricante, pilis longis plumalà. In foveà ovali prope peristomii marginem anticum linea transversa atra cernitur. Frons atra, opaca, levissime albo-pollinosa, marginibus lateralibus nigris et polline confertiore vestilis, margine antico latius aurantiaco. Occipitis dimidium superius cun vertice atrum. Thoracis dorsum, scutellum el metanotum alra ef nitida. Pleurac dilute flavescentes, maculà ovatà fuscâ, infra basim alarum sitâ. Abdomen totum alrum et nitidum. Coxae diltute flavae. Pedes concolores; femora antica infra setis circiter senis, intermedia prope apicem singulà et postica binis instructa. Alae hyalinae, dilute lulescenti-cinereae, adversus costan purius sublutescentes, venis transversis longe inter se distantibus, intermedià subincrassatâ, posleriore et alac apice colore dilute subfusco limbatis. - (New Hampshire.)

Nota. Prope accedit ad Cordyluram pleuriticam et ad Cordyluram scapularem, sed ab utrâque lineâ peristomio inscriplâ niegrâ dislinguitur. A Cordylurâ pleuriticâ praeterea differt setac antennalis basi minus incrassatâ, fronte praeter margines atrâ, alis apicem versus paulo latioribus venisque transversis laliore intervallo separatis, venâ denique longitudinali sextâ minus abbreviatâ A Cordylura scapulari autem distinguitur corpore majore, frontis piclurâ, scapulis alris, pedibus pedumque setis validioribus, majore harum numero venâque transversâ posteriore nou limbalâ.

91. Cordylura munda, nov. sp. ㅇ. - Alra, nitida, capile cum antennis et proboscide (vertice tamen et superiore ocripitis dimedin exceptis), pleuris tolis, coxis pedibusque dilute favescentibus. selá alarum plumatâ, alis hyalinis, apice late venisque transuersis

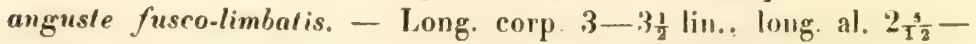
$2 \frac{1}{2} \operatorname{lin}$.

Atra, nitida. Caput dilute flavescens, proboscide palpis antennisque concoloribus, setâ harum nigricante el pilis longis uigris plu. malâ. Vertex niger, occipitis dimidium superius atrum. Thoracis 
dorsum, sculellum el melanotum atla el nilida. Pleurae lolac dilutissime flavescentes. Abdomen lotum illum of nithdum. Cosac dilute flavescentes; pedes roncolores; selae plerarque funcae. femoribus anticis infra subquaternas tenuiores, posticis unican breviorem. sed validiorem el nigrum ferentibus. Alae hyalinae. dilute lutescenticinereae. adversus costam purius nublutescontes. venis transersis longe inter se distantibus et anguste fusco-limbatis. ipso abarum apice late fuscu. - (Iludsons Bay Terrilory. Font Resolution; Kenuicolt.)

Nota 1. Varial fiontis triente supremo nigricanle. - fonneclicul; Dassell.)

Nola 2. Cordylurae pleuriticae similima est, ilit ut de ditlereuliâ specifica dubitare possis. quam lamen pleuris totis llavicantibus; segmentis venae longiludinalis quatae pracultimo el antepaenutimo minus inaequalibus. veni transversi ninore di. stincte fusco-limbatâ. septimo abdominis segmento minus lato "l setis pedum tenuioribus dilulioribusque salis demomslratam esse opinor. A Cordylura glabra haec nostra Cordylura mundu alis pro portione brevioribus el minus lalis. vená fransversa fuscolimbalâ et septimo abdominis segmento minus lato facile distinguitur.

92. Cordyluralatifrons, nov. sp. P. --.. Robustu, nigra. capile cum proboscide, palpis et anlennis concolore. selci harum plu. matá. fronte latissima maeter margines laterales obsrure rufesrente. pedibus badiis, femoribus anticis praeler upicem intermerliisque busim versus nigris, alis ex subfusco lutescentibus. - Long. 101p. $3 \frac{1}{2}$ lin., long. al. $2 \frac{7}{12}$ lin.

Robusta, nigra. Capul cuncolon, fronle lalissima praeler margines laterales obscure rufescente. Antemate totae nigrae. articulo tertio oblongo, apice subrotundato et seli concolore plamalis. fiaries et genac albo-pollinosie. Oris margo latcralis setis paucis ni. gris instructus, mystacinâ reliquis longiore el validionce. Probuscis fusco-nigra; palpi nigri al nigro-pilosi. Dimilium inforius occipritis albido-pilasum. Thoracis dorsam obsolete albido pollimosum, humeris lamen el villâ media polline confertu nblectis: pili rari nigri, selae concolores. Sulcllom parce nigro-pilosulum selisque qualuor nigris praedilum. Platue alloido-pollinosac. praeter setas ordinarias nigras pili- raris lenuissmingue altidis aspersae. Ablomen nigrum. nitidum. nigro pilos-um, sen̆mento-

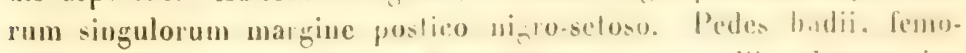
ribus anticis praeter apicem femoribusque internediis adversus bat. 
sim nigris; pedum pili nigri, femoribus tamen anterioribus infra palide pilosis; setae numerosae omnes nigrae. Alac ex colore dilute subfusco lutescentes, adversus costan el adversus basim di. slinctius lutescentes, venis luteis adversus apicem fuscis, transversis non approximatis. -- (Middle States).

93. Cordylura gagatina, nov. sp. 万. - Alra, nilida. moboscide. palpis antennisque concoloribus, setâ harum plumatâ. sculelli selis duabus nigris, tibiis tarsisque piceis, alis dilutissime subfusris. - Long. corp. $2{ }_{6}^{1}-2 \frac{1}{4}$ lin., long. al. $1 \frac{2}{3}-1 \frac{3}{4}$ lin.

Parva, atra, valde nitens. Caput fotum concolor, facie tamen confertissime albo-pollinosâ; antennac fuseo-nigrae, articuli secundi apice albo-pollinoso, articulo terlio ovato. setâ plumalâ concolore; genac angustae; praeter setam mystacinam selae paucae et breves in oris margine latcrali. Proboscis fusco-nigra; palpi of el nigropilos. Thoravis dorsum polline nullo aspersum, nitidissimum, sctis pilisque rarissimis nigris. Scutellum pilis aliquot brevibus nigris setisque duabus nigris instructum. Pleurae leviter albo-pollinosae; setae ordinariae nigrae, pili sulutiles albidi Abdomen subobsolete albido-pollinosum, nitidım. nigro-pilosum, segmentorum singulorum margine postico setas raras et tenues nigras gerente. Lobi segmenti ventralis ultimi magni, ovali, infra albido-pilosi. Coxae nigrae, pilis pallidis selisque nigris vestitae. Pedes picei vel badii, femoribus tamen practer extremum apicem nigris, libiarum anlicarum colore magis in testareum, posticarum magis in fuscum vergenle; selae rariores, onues nigrae; pili breves, nigri, femoribus tamen infra pilus longiores pallidos ferentibus. Alie colore dilute subfusco leviler linclae, venis ex luteo subfuscis, adversus basim dilutioribus el magis lulescintibus. Lansversis non approximatis - (Canada.)

91. Cordylura acuticornis, nov. sp. 9. - Gracilis, cinevea. abdomine magis nigro. fromle luteâ. facie palpisque allis. untemnorum nigrarum articulo tertio infra acutangulo setique valida submudi, coxis pedibusque luteis, alis subhyalinis dilute lutescentibus.

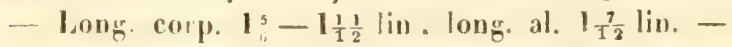

Gracilis. cincra. opaca. Occipul cinereo-nigrum, opacum; frons lala, lutea; facies et genae albae: anlennae majusculae, nigrae, articuli tertii angulo infero acuto, setâ validâ, subuudâ, concolore. Praeter selam myslacinam nigram in margine laterali oris setulae paucae pallidae, quam illa mullo breviores ef lenuiores comspiciuntur. Thorax tolus cum metamolo, pleuris el seutello acqualiter cinereus el 
opacus. splis pilisque raris nigris instuructus. Selar sculelli quatung nigrae, apicales tenues et perbreves Abrlomen ex cinereo nigri. rans. subnitidum. Coxae dilitute lutescentes. posteriores artversus basim subfusrae, omnes pilis el setis albidis hirlae. Pedes loti lutri, breviler nigro-pilosuli. femoribus tanfun infora pilis pallidis aspersis; setae temues nizrae. Alac byalinae. colore sublutescente leviter tiuclar.

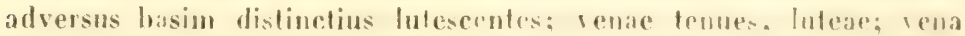

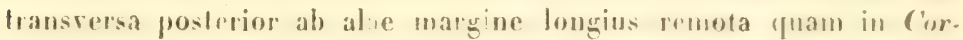
dyluris plerisque, ila ut ullimum smae quantace sesmenlum duplicem paenultimi longiludinem excedal. - (IImlsons bay Terrilory: Kennicolt.)

95. Cordylura megacephala. nov. sp. Q. - Rohusta. rinereo-nigna opaca. pilis setisyue lotins corporis nigris: capul magnum. maximâ ex parte rufo-ferruginenm. facie brevi. gentis lutissi. mis, sefâ antennarum nuda: peates badii rel es luleo subfusci. frmoribus nigris: alne rinereae. rellulis subrostali el marginali dibule subfusris. - I oong. corp. $22_{6}^{5}-2 \frac{1}{1} \frac{1}{2}$ lin., long. al. $2 \frac{5}{T^{\frac{2}{2}}}$ lin.

Robusta, cinereonigra. opaca, pilis ommitus selisune numerosis folius corporis nigris. Caput magnum, obscure rufo-ferrugincum. oparnm. frontis latae marginibus linteralibus. triangulo ocellari orcipitisque dimidio superiore cinereo-nigris. fulemar obscure rufoscentes; articulus lertius oblongus. apice rofundato: sela nigra. nuda. lenuis, basali tamen triente subito et valde incrassalo. Faries bre vis; oris apertura ascendens. margine laterali setis validis instrurlo: Eenae adversus mentum longe demissae Proboseis alma, labrollis fuscis: palpi ex lufor subfusci. adversus aprom nigri. nigro-selosi. Srulelli setae sex. Abrlomen breve. Coxae ef femora nigar fre mora antica crassa: fibian badiar vel ex lulou subfuscion larsi comcolores. adversus apicem fusci. Hae rinereare renis fuscis. obsolelissime subfuscolimbatis. collulis subostali ot marginali subfosis. (District Columbia; (Dsten-sirkin.)

96. Cordylura albibarba. 110v. sp. d. - Intere. orripilis dimidio superiore. thoracis dorso prater margenes laterales. scutelli disco abdomineque preter hypopysinm, fuscis. alarum apice renisque

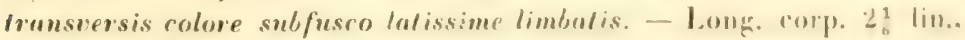
long. al. $2 \frac{1}{6}$ lin.

Simillima Scalinae. Iulfa. Frons lata. salurale lutea. Interl. nae nigro-fuscae, artionlis duobus primis intra rufescentibur. ardiculo

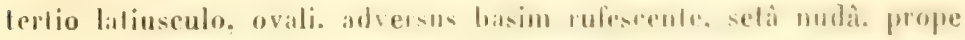


basim rufâ. Facies ex luteo albicans; genae latae concolores; setae mystacinar binar sulaequales nigrae. adjeclis setulis aliquot minutis nigris. Palpi albi et albo-pilosi. Occipitis dimidium inferins albopilosum. Thoracis dorsum fuscum, polline luteo aspersum. subopacum. pilis et setis tenuibus nigris, marginibus lateralious late luteolimbalis. Srutellum fuscum, lutco-marginalum. pilis brevibus setisque qualuor nigris instructum. Pleurae lutene, obsolete nigro-ma. culatae. albo-pollinosae: selae ordinariae nigne; pili rari, tenuissimi, in suprriore pleurarum dimidio nigricantes, in inferiore pallidae. Abdomen fuscum, nitens, segmenlis sexto et septimo cum hypopygio luteis; lobi segmenti abdominalis ultimi magni, ovati, !ntei. Coxae anticae albidae et albo-pilosae; coxae posteriores dilute lutessentes, pilis concoloribus hirtae, in latere exteriore setam unicam nisram gerentes, posticorum apice praetcrea pilis nonnullis brevibus nigris asperso. Pedes Intescentes, tibiis intermediis adversus basim tarsisque anticis adversus apicem levissime infuscatis, tarsis poslicis obscurioribus. Selae pedum paucae, lenues, nigrae; pili breves, in femorum basi el margine infero pallidi, reliqui nigri. Alae quam scalinarum breviores et laliores, subbyalinae, colore ex lutescente cinereo leviter tinclae; venarum color fuscus adversus basim per subfuscum in luteum mutatur; venac transversae colore subfusco late limbatae; apex cellularum marginalis et submarginalis late, cellulae posterioris primae angustius colore subfusco, in margine apicali cellulae submarginalis evanescente, linclus. - (New Hampshire.)

97. Loxorera collaris, nov. sp. of et ㅇ․ - Ex luteo rufa, antennis longissimis praeter busim nigris, thoracis margine antico latissime et abdomine fere toto atris, alis aequaliter luleo-rinereis. - Long. corp. $\delta 1 \frac{5}{6}$, of $2 \frac{7}{12}$ lin., long. al. $1 \frac{5}{6}-2$ lin.

Caput luteum, superne rufum. occipitis dimidio superiore et friangulo ocellari permagno, ad anticum usque frontis marginem perlinente atris et nilidis. Margines laterales faciei albo-pollinosi, vitla media nitida, salurate fusca vel nigra. Antenuac lon. gissimae, nigrae, articulis primis duobus cum basi tertii luteo-rufis, sctâ pillide flavescente, breviter pubescente, dimidiam anlennae longiludincu vix attingente. Thorax rufus, dorsi tamen triente antico atro. Abdominis color ater adversus latera et marginem anticum segmenti secundi in mare obsoletius, iu foemina distinctius in rufum mulatur. Pedes dilute lutei, femoribus adversus lrasim 
pallidioribus. extremo tarsorum apice fusco. Alae tolae aequaliter rx luteo cinereac. - (District Columbia: Osten-Sarken.)

95. Loxocera fallat. nov. sp. Q. - Ira. nilida. rapile praeter occipilis dimidiun superius et prater frongulum ocellure

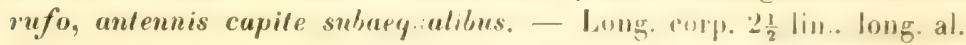
$2-2 \frac{1}{1} \mathrm{i}$ lin.

Atra, nilidissima. Frons rufa. Triangulo ocellari nigro. antice valde atlenualo, marginem fiontis anticum lere attingente. Antennae breves. capili subaequales. nigrae. duobus tamen primin articulis el imit tertii basi rufis; seta antennarmm exalbida. breviler pubescens, tertio antennarum arliculo longior. Facies ex rufo lutea. vittâ mediâ nigrâ. adversus peristomium valde aftenuali. Orripitis dimidium superius atrun, inferius cun genis luteum. Pedes dilule lutei. Halteres albidi. Alae cincrascenles. ina basi dilutissime lla. vescente, venis fuscis. - (Canada.)

Nota. Loxocera fallax. anlennarum fỉzurâ intes Loxoceras et Psilas intermedia, corporis picturi his propinguior est, sed capitis formâ cum illis congruit, ita uf aptius Lovorevis quam Psilis aduumerelur; a Chylizis rapilis formâ ae figurâ el ultimo venae quarlae segmento incurvo magis quam a P'silis el a Loxoceris genuinis recedit.

99. Chyliza nolata, nov. sp. Q. - Alra. capile, lhoracis viltulis dorsalibus, maruli magna pleuravum. srulello. pedibusque luteis, apice tamen femorum posticorum nigro, alarum reni trans. versâ posteriore angustius, margine apicali latius nigro-limbatis. -

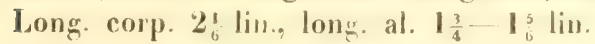

Atra, pube brevi pallidâ vestila. Capul flavmu: antenuac concolores, selâ teuni, pallidi. brevisime pulescente; froms lutea; di. midium superius oceipilis praeler margines nigrum. Thoracis dorsum puncto humerali ofseure luteo villulisque qualuor luteis motatum. intermediis anguslis of obsoletis. lateralibus latis ef a sutura ad angulum posticum ductis. Seutellum Intemm. Melanotum atrum. Pleurae afrae. maculì magnâ luteâ. coxis intermediis rontignầ or. nalae. Abdomen fotum atrum. Pedes cum coxis Ravi. femoribus tamen posticis amulo subapirali laliusculo. fusco-nigro conclis. Alac cinereo-hualimae. venae longitudimalis quarlate segmento pacmullimo et venâ transversi posteriore angusle. margine apoirali lalius nigrolimbatis. - (District Columbia: Osten-Sacken.) 
100. Mycetaulus longipennis, nov. sp. $\delta$. - Rufo-testaceus, pectore. melanoto et abdomine nigris, pedibus luteis; alae longae, celluâa cosłali subfuscâ el maculâ apicali nigro-fuscá. - Long. corp. $1 \frac{1}{2}$ lin., long. al. $1 \frac{2}{3}$ lin.

Rufo-testaceus. Caput concolor, occipite nigro-fusco vel piceo, antennis luleis. Macula in thoracis margine antico silâ. pectus, metanotum el abdomen totum nigra. Pedes lutei, tibiarum posticarum basi tarsorumque apicibus nigro-fuscis. Halteres albidi. Alae quam Mycetauli bipunctati longiores et pro portione minus latae, hyalinae, cellulâ costali subfuscâ, cellulâ subcostali angustissimâ fusco-nigrâ et maculâ apicali fusco-nigrâ. - (Hudsons Bay Territory; Kennicott.) 


\title{
Diptera Americae septentrionalis indigena.
}

\author{
Descripsit
}

\section{H. L $\quad \boldsymbol{o} \quad e \quad w$.}

\section{Centuria decima.}

1. Dixa venosa.

2. Tipula praecisa.

3. Ctenophora angustipennis.

4. Odontomyia arcuata.

5. - plebeja.

$6 . \quad$ - nigerrima.

7. Stratiomyia insignis.

$8 . \quad$ constans.

9. Clitellaria lata.

10. Nemotelus glaber.

11. Hermetia clirysopila.

12. Chrysops gigantulus.

13. Atherix varicornis.

14. Chrysopila modesta.

15. Triptotricha lauta.

16. Leptis incisa.

17. Oncodes melampus.

18. - engonalus.

19. Eulonchus tristis.

20. Midas tenuipes.

21. Dioctria resplendens.

22. Echthopoda formosa.

23. Leptogaster brevicornis.

24. Blux bellus.

25. Pygostolus aemulator.

26. Diogmites symmachus.
27. Mirrosiylum morosum.

28. Stenopogon brevinsrulus.

$29 . \quad$ - univillatus.

30. - obscuriventris.

31. - gralus.

32. Callinicus calcuneus.

33. Heteropogon phoenicurus.

34. - laulus.

35. Discocephula calva.

36. Thereua melanoneura.

37. - fucata.

38. Xestomyza planiceps.

39. Aphobantus revinus

40. Leptochilus modestus.

41. Bombylius semirufus.

42. - albicapillus.

43. Sparnopolius brevicornis.

44. Ploas atralula.

45. - nigripennis.

46. - obesula.

47. Phlhiria egerminans.

48. Allocolus Ehourdsii.

49. Spilomyia longicornis.

50. Brachypalpus frontosus.

51 cycrogaster.

52. Myiolepla nigra. 
53. Myiolepta aerea.

54. - strigilata.

55. Helophilus polygrammus.

56. Microdon baliopterus.

57. Ceria tridens.

58. Pipunculus subvirescens.

59. fuscialus.

60. Drapet is unipila.

61. - gilvipes.

62. - divergens.

63. Paraclius pumilio.

64. Pelastoneurus furcifer.

65. Hydrophorus cerutias.

66. Gymnosoma filiola.

67. Blepharopeza adusla.

68. Homalomyia femorata.

69. tetracantha.

70. Coenosia nivea.

71. - calopyga.

72. - modesta.

73. Schoenomyza dorsalis.

74. Cordylura vittipes.

75. lutea.

76.
77. Cordylura capillata.

78. Blepharoptera discolor.

79. pectinula.

80. Sciomyza tenuipes.

81. - trabeculata.

82. Sapromyza macula.

83. Lauxania eucephala.

84. Notiphila pulchrifrons.

85. Drosophila obesa.

86. sigmoides.

87. Hippelates pusio.

88. - eulophus.

89. Crassisela eunola.

90. Opeliophora straminea.

91. Siphonella latifrons.

92. Chlorops procera.

9.3. - Gundlachi.

94. - confluens.

95. - microcera.

96. - pulchripes.

97. - allernata.

98. - nigricans.

99. - maculosa.

100. - mellea.

1. Dixa venosa, nov. sp. o. - Nigra, rostro, thoracis dorso praeter vittas tres confluentes nigras pleurarumque villâ superâ flavis; alae immaculalae, cinereae, venis validiusculis fuscis el cellulae submarginalis secundae basi quam in affinibus latiore. - Long. corp. $1 \frac{1}{3}-1 \frac{3}{1}$ lin., long. al. $1 \frac{1}{2}-1_{T^{2}}^{\frac{7}{2}}$ lin.

Caput nigrum, antennis palpisque concoloribus, rostro dilute flavo. Thoracis dorsum subnudum, opacum, practer vittas tres or. dinarias nigras flavum; scutellum nigrum; pleurae vittà fusco-nigrà pictae, superne late flavae, infra sordide fuscac vel subfuscae. Abdomen totum nigrum. Femora lutescenlia, antica apicem versus magis fusca, apex omnium niger; tibiarum color praeter apicen nigrum ex luteo in subfuscum vergens; tarsi fusco-nigri. Halterum capilulum nigro-fuscum. Alae plane immaculatae, cincreae, venis fuscis quam in speciebus similibus validioribus et cellulà submarginali secundâ adversus basiu solito latiore. - (Texas; Belfrage.) 
2. Tipula praecisa, nov. sp. $\sigma^{\pi}$ et 오- Lutea, thoracis vittis dorsalibus subfuscis, mediâ divisâ, omnibus saluratius marginatis, abdominis villâ fuscâ. angustâ sed uequali; alae subfuscue. fasciâ lunatâ ante stigma sitâ et per cellulae discoidalis basim usque in cellulam posteriorem quartam pertinente albido-hyalinat.

ऽ. hypopygium mediocre concolor, clausum, lamellis rolundatis non prominentibus.

ㅇ. terebrae lamellae superae apicem versus non attenualae. oblique truncatae et leviler emarginatae.

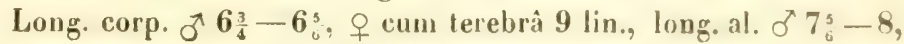
오 $8 \frac{5}{6}-9 \mathrm{lin}$.

Lutea. Caput concolor, occipite el fromte pleurumque cinerascentibus. Palpi lutei, adversus apicem fusco-nigri. Antrmas simplices; scapus luteus; flagellum nigrun, arliculis primis practer basim singulorum paulo crassiorem ex luleo fuscis, rarius luteis. primo haud raro toto luteo. Thoracis dorsum plermmue cinerascens, vittis distinctissimis cinereofuscis, omnibus undique colore saluraliore marginatis et mediâ per lineam lutescentem dimidiata. Abdominis vitta media fusca, angusta sed aequalis, inde a basi abdominis usuue ad marginem posticum segmenti septimi pertinens; ablominis villae laterales obsoletiores et dilutius fuscae, in mare angustiores et plerumque subintegrae, in foeminâ latiores sed valde interruptae, ita ut plerumque tantum maculae obsolelac, late inter se distanles conspiciantur. Hypopygium maris concolor, mediocre, clausum, lamellis rotundatis non prominentibus. Terebra focminae fusca vel luteofusca, lamellis inferis longiusculis et modice oblusis, superis modice latis, adversus apicem non altenualis, ipice ipso oblique truncalo et leviter emarginato. Pedes ex luteo subfusci, femoribus tibiisque in apice paulo saturatius tinctis. Halterum capitulum fuscum pedunculus lutescens. Alae dilute subfuscae, stigmate fusco; ante stigma fascia lunata albido-hyalina inde a costâ usyue in cellulam posteriorem quartam pertinens conspicitur. - (California; II. Edwards.)

3. Ctenophora angustipennis. nov. sp. ơ. - Antennis quadrifariam pectinatis instructa, rufa, capite, dorsi marginibus lateralibus, scutello angulis lateralibus exceptis. pleuris praeter vittam luteam, metanolo abdominisyue villa nigris; pedes luteo-rufi. femorum tibiarumque apice et tarsis anterioribus nigris. tursis posticis laete vilellinis inde ab articuli terlii apice nigris. - L.ong. corp. $7 \frac{1}{6}$ lin., long. al. 7 lin. 
Ctenophorae vittatae Meig. proxima. Caput totum nigrum. Palpi laete lutei, articulo terminali fusco. Anténnae radiis modice longis et subaequalibus quadrifariam pectiuatae. Scapi articulus primus niger, secundus luteus, adversus basim nigro-fuscus; articulus primus flagelli luteus; infra prope basim lobo majusculo, prope apicem radiis duobus brevioribus, illo et his adversus apicem infuscatis instructus; reliqui llagelli articuli fusco-nigri. Collare praeter latera nigra laete luteum; thoracis dorsum rufum, callo humerali luteo, marginibus laleralibus et maculâ oblongâ, ab incisurâ usque ad marginem posticum pertinente nigris. Scutellum nigrum, augulis lateralibus luteis. Pleurae praeter vitlam luteam et metanotum totum nigra. Abdomen rufum, vittâ integrâ nigrâ, in segmeutorum singulorum margine postico valde dilatatâ piclum; venter concolor, segmentorum singulorum marginibus posticis flavis. Hypopygium similiter atque in Ctenophorâ vittalâ constructum, rufum, lamellis lateralibus majusculis luteo-rufis, lamellâ superâ fuscâ, profunde excisà, ita ut utrinque in dentem compressum producta sit. Pedes ex luteo rufi, femorum tibiarumque apice tarsisque anterioribus nigris, primo horum articulo basim versus fusco, tarsis posticis laete vitellinis, inde $a b$ articuli tertii apice nigris; femora postica non incrassata. Halteres lutei, Alae angustae, ex luteo subfuscae, sligmate parvo fusco. - (California.)

4. Odontomyia arcuata, nov. sp. ㅇ․ - Vividi-flava, occipite praeter orbitam, vertice, frontis fascia inaequali, antennis praeter basim, thoracis dorso abdomineque nigris, maculis lateralibus hujus in medio abdomine fere coëuntibus et ventre lolo flavis; pedes lutei; alarum cellulae submarginales duae, posteriores yualuor. - Long. corp. $5 \frac{1}{2}$ lin., long. al, $4 \frac{1}{4}-4 \frac{1}{3}$ lin.

Caput pallide flavum, facie oblusâ immaculatâ. Occiput praeter orbitam nigrum. Triens supremus frontis niger, in margiue postico obsolete luteo-bipunctatus; practerea in fronte fascia inaequalis nigra, e maculis duabus magnis et interjectâ liturâ composita conspicilur. Antennae nigrae, basi ex rufo badiâ. Thoracis dorsum praeter callos humerales et praeler angulos posticos nigrum, lomento aureo, adversus latera confertiore vestitum. Scutellum flavum, basi nigrâ, dentibus apicalibus parvis, subapproximatis, apicem versus nigris. Pleurae totae immaculatae, viridi-flavae, in vivâ sine dubio virides. Abdomen vigrum; segmenta secundum, tertium et quartum siugula utrinque maculâ triangulâ flạvâ, vel viridi-flavâ, autice con. cavâ et angulo acuto usque ad mediun fere abdomen pertinente 
ornata; margines laterales et posticus segmenti quinti flavi, lifurâ tamen transversâ nigrâ huic plerumque inseriptì; segmentum sextum flavum. Venter totus flavo-viridis vel viridis, immarulatus. Pedes lutei, tarsis inde ab arliculi primi apice fusco-nigris. Alae pure hyalinae, venis validiorihus ochraceis, longitudinali tertiâ ramulo instructâ, cellulâ discoidali venas duas emittente. - (California; H. Edwards.)

5. Odontomyia plebeja, nov. sp. ठ઼. - Nigra, capite scutelloque praeter extremum apicem et dentes concoloribus. abdomine viridi, viltâ latâ atrâ picto, pedibus tolis luteis; antenuae ex rufo fuscae; alae pure hyalinae, venis validioribus luleis, rellulis posterioribus quatuor, submarginalibus duabus. - Long. corp. $4_{1 \frac{3}{2}}^{3}$ lin., long. al. $3 \frac{1}{3} \mathrm{lin}$.

Nigra. Caput tolum concolor, facie ante oculos vix prominenle. Antennae ex rufo fuscae; lateribus adversis magis in rufum vergentibus. Thorax plane immaculatus, dorso pilis dilute luteis vestito, pleuris praeler marginem superum albido-pilosis. Scutcllum nigrum, extremo apice dentibusque luteis. Abromen lacte viride, vitlâ latâ et subaequali atrâ, fere ad posticum usque segmenti quinti marginem pertinente pictum. Perles toti lutei. apice tarso. rum non obscuriore. Halterum capilulum viride. Alae pure lyyalinac, venis validioribus luteis, venà longitudinali tertiâ ramulo instructâ, cellulà discoidali venas duas emillente, quarum aulerior prope basim valde obsoleta est. - (Connecticul; Norton.)

6. Odontomyia nigerrima, nov. sp. ․ - Atra. mulius. cula, scutelli dentibus, femorum tibiarumque apice. basi denigue tibiarum et tarsorum testaceis, segmentorum abdominulium secundi. tertii et quarti marginibus posticis adversus latera et quinti toto lutescentibus; facies tumida, mire prominens: primus untennurum articulus quam secundus satis longior: alurum venae valialioves fu. scae, cellulae posteriores quainor el submarginales duae. - Lang. corp. 4 lin., long. al. $3 \frac{1}{2}$ lin.

Atra, nitida, nulliuscula, breviler albo-pubescens. (aput con. color, fossula longitudinali froulis ulringue testaceo-marginatà. Facies mire prominens, tumida. oblusa. mareinilus laleralihus or is valde dilatatis. Proboseis nigra, stipile temui, capilulo longo el crassissimo. Antennae tenurs. nigrae. articulo primo sesubialleram secundi longitudinem aequiparante. Scutellum totum nigrmu, dentibus ex fusco testaceis. Margines postici segmenlorum abdomina- 
lium secundi, tertii et quarti adversus latera abdominis colore lutescente tinclae, ita ut fascise tres angustae, latissime inlerruplae conspiciantur; margo posticus segmenti quinti tolus lutescit. Vellter aler, disco latissime, inaequaliter et sordide lutescente. Hanc abdominis picturam in speciminibus vivis totam viridem esse suspicor. Pedes nigri, femorum apice, tibiarum basi et extremo apice primoque tarsorum articulo praeter apicem fuscum luteo-testaceis. Alae hyalinae, venis validioribus nigro-fuscis, costali tamen et lon. gitudinali terliâ adversus apicem subfuscis, venâ longitudinali ter. tiâ ramulo instructâ, cellulâ discoidali venas duas emiltente. (Middle States.)

7. Stratiomyia insignis, nov. sp. $\sigma^{7}$. - Nigra, luteo-pilosa, scutelli dimidio apicali segmentorumque abdominalium secundi, terlii et quarti maculis lateralibus flavis, secundi inlegris, tertii et quarti viltâ obliquà nigrâ in maculam triangularem et in strigam obliguum dissectis; praeterea margo posticus segmenti quarli puncto pavo et segmentum quintum viltulâ flavâ ornantur. - Long. corp. $5 \frac{1}{2}-6$ lin., long. al. $4 \frac{1}{2}-5$ lin.

Nigra, capite toto scutellique dimidio basali concoloribus. Pubes in abdominis disco nigra, in reliquo corpore lutea. Secundum abdominis segmentum utrinque maculam majusculam triangularem flavam gerit; segmentorum tertii et quarti maculae laterales flavae, majores quam segmenti primi et minus triangulares, non integrae, sed vittâ obliquà nigrâ dissectae, ita ut praeter angulum anticum segmenti striga obliqua, arcuatim ex angalo postico adversus marginem anticum ascendens colore flavo picta sit, quae in segmento tertio adversus finem satis dilatatur; margo posticus segmenti quarti puncto flavo, segmentum quinlum villulâ angustâ flavâ notantur. Segmentum ventrale secundum praeter maculam basalem nigram totum flavum; segmentum tertium et quartum nigra, fascià apicali utriusque flavâ, latiusculâ, latera versus usque ad marginem anticum segmenti dilatatâ; segmentum quintum nigrum. tenuiter flavomarginatum. Pedes lutei, femoribus tamen praeter apicem nigris, tibiis anuulo angusto nigro-fusco cinctis, tarsis apicem versus fuscis. Alae infuscatae. - (California; H. Edwards.)

Nota. Propter similem abdominis picturam Stratiomyiam insignem marem Stratiomyiae maculosae (Cent. VII. 19.) esse persuasum haberem, nisi facies et scutellum hujus tota flava essent. 
8. Stratiomyia constans, nov. sp. ठ et + . - Stratiomyine mulabili Fbr. proxima, sed antennarum apex minus acuminatus; maris abdomen superne argenteo-lomentosum; segmenta abdominalia foeminae secundum utrinque flavo-maculutum, terlium quam in Stratiomyiâ mulabili multo latius flavo-marginatum, quartum vero po. stice multo angustius flavum. - Long. corp. $\delta 5-4 \frac{1}{2}$, 우 $4_{6}^{5}-5$ lin., long. al. ot $3 \frac{3}{1 \frac{1}{2}}-3 \frac{2}{3}$, \& $4-4 \frac{1}{1} \frac{1}{2}$ lin.

Corporis formâ ac figurâ antennarumque fabricâ Stratiomyiae mutabili Fabs. simillima, apice tamen antennarum minus acuminato. Thoracis dorsum in mare pube albâ. in foeminâ tomento lenui albido aspersum. Vlargo laleralis dorsi in mare flavo-trimaculalus, maculâ primå in lumero, secundâ in sulurae initio laterali et ter. tiâ in angulo postico sitis; in foeminâ maculae prima et secunda in vitlam latam ab humero usque ad suluram pertinentem confluunt. Scutellum semper totum flavum. Abdomen maris tolum tomento niveo, argenteo - micante veslitum, nigrum, undique angusle flavomarginatum; segmentum secundum postice fasciâ lale interruptâ flavà, adversus latera abdominis latiore ornatum; segmentum lertium fasciâ simili, sed minus late interruptâ picłum. Abdomen foeminae nigrum, tomento lutescente obsolele aspersum, anguste flavo-marginatum; segmentum secundum utrinque in angulo postico maculit transversali flavâ pictum; segmenta tertium et quartum singula postice fasciâ latiusculâ flavâ cinguntur, fasciâ tamen segmenli terlii quam in foeminâ Stratiomyiae mutabilis nullo latiore. fasciâ quarti vero quam in hac multo angustiore. Venter ulriusque sexus niger, segmentis singulis postice flavo-marginatis, colore flavo in segmentis duobus primis valde dilalato. Pedes ex rufo-lutei. IIallerum capitulum lacte viride. Alarun forma, venae et color a Straliomyia mutabili vix differunt. - (Texas; Belfrage.)

Nota. In maribus vivis abdomen colore non flavo. sed laele viridi pictum esse persuasum habeo; relipuam maris picluram el picturam foeminae in vitâ etiam viridem esse suspicor.

9. Clitellaria lata. nov. sp. Of el ㅇ․ - Lata. nigra, scutelli dentibus adversus apirem halleribusque albidis. thorace of srutello maris oculisque utriusque sexus nigro-pilosis: antenua breres. articulo tertio obscure rufo-ferrngineo, slylo terminali subuudo. Long. corp. $4 \frac{1}{2}-5$ lin., long. al. $4-4 \frac{1}{2} \frac{1}{2}$ lin.

Lata, nigra, opaca. Oculi maris contigni, conferlim nigro-pilosi; frontis triangulum anticum polline pallido obtectum; pili menti pilique plerique faciei nigri, reliqui faciei pili pallidi. Oculi foemi- 
nae fronte latâ disjuncti, brevius nigro-pilosi; reliquum caput praeter pilos nigros, qui in mediâ fronte, in vertice et in mento ex. stant, pilis brevibus albis tomentosum; orbita postica oculorum lata, tomento subargenteo vestita. Antennae utriusque sexus breves, nigrae; articuli duo primi nigro-pilosi; articulus tertius crassus, sordide rufo-ferrugineus, apicem versus obscurior; stylus terminalis pilis nigris, paucis et brevibus aspersus. Thorax maris nigro-pilosus; dorsum tomento dilute lutescente leviler aspersum, sed ita ut vitta media utrinque valde attenuala et villae laterales e maculis binis compositae omni tomenlo destitutae sint. Pleurae foeminae breviter nigro-pilosae; dorsum thoracis pilis nigris plane nullis, sed praeter vitlas tomento confertiore albo vestitum. Scutellum maris nigro-pilosum, latera versus tomento dilute lutescente obsolete aspersum, foeminae totum albo-tomentosum; dentes scutelli in utroque sexu adversus apicem albicant. Abdominis segmenta secundum et tertium latera versus, quartum adversus latera et marginem posticum, quintum praeter marginem anticum tomento albido vestita. Pedes toti nigri. Halteres albidi. Alae maris dilute nigricanles, foeminae cinereae vel nigro - cinereae, venis et stigmate nigris. (California; H. Edwards.)

10. Nemotelus glaber, nov. sp. ․ - Nudus, nitidus, ater, thoracis dorso et scutello obsolete virescentibus, fronte immaculat $\hat{a}_{\text {, }}$ laterali thoracis lineâ tenuissimâ albicanle, femoribus tibiisque atris, tarsis albis, anticorum articulis duobus ultimis posteriorumque ullimo fuscis, halterum capitulo superne nigro. - Long. corp. $1 \frac{2}{3}-$ $1 \frac{3}{4}$ lin., long. al. $1 \frac{7}{\mathrm{~T}}-1 \frac{2}{3}$ lin.

Nudus, nitidus, ater. Frons lata, immaculata. Antennae fusco. nigrae, adversus basim sordide rufescentes. Facies in conum majusculum acutum producla. Thoracis dorsum et scutellum ex atro obsolete virescentia; linea lateralis thoracis tenuissima, exalbida. Pedes atri, genibus tantum extremis sordide albicantibus tarsisque albis, articulis tamen duobus ultimis anticorum reliquorumque articulo ultimo fuscis. Halteres albidi, capitulo superne nigro. Alae albicantes, venis validioribus pallidissimis, reliquis omnino decoloribus. - (Texas; Belfrage.)

11. Hermetia chrysopila, nov. sp. 우 - Nigra, subopaca, antennis adversus basim latissime rufis, maculâ frontis ulringue laterali, verlice, scutelli dimidio apicali, extremo femorum apice, tibiis tarsisque tolis laete luteis; thoracis villula media postice ab- 
breviata, margines laterales et posticus, scutelli dimidium apicale. pleurarum fascia, abdomen denique praeter segmentorum singulorum margines anticos tomento aureo ornata; alae ferrugineae, dimidio posteriore et apice nigro-fuscis. - Long. corp. $4_{4}^{3}-5$ lin., long. al. $4 \frac{1}{4}$ lin.

Nigra, subopaca. Caput concolor, pube pallidà vestilum. Antennae nigrae, dimidio basali fere toto rufo. Vertex practer tulerculum ocellare tolus luteus; in anteriore fronlis parte utringue macula lateralis lutea. Humerus uterque maculâ parvà rolundatâ ex. albidâ notalus. In dorso thoracis praeter vittulam median postice admodum abbreviatam margines laterales inde a scapulis usque ad basim alarum et margo posticus totus, in pleuris fascia normaliter demissa tomento conferto aureo teguntur. Scutelli dimidium basale nigrum, apicale laete luteum et tomento aureo vestitum. Abdomen praeter segmentorum singulorum angulos posticos et marginem basalem aureo-tomentosum, tomento adversus segmentorum margines posticos longiore et confertiore. Pedes laete lutei, femoribus tamen apice excepto nigris. Alarum dimidium costale inde a basi usque ad ultimum alae trientem ferrugineum; reliqua ala nigro-fusea. adversus incisuram axillarem multo dilutior. - (Texas; Belfrage.)

12. Chrysops gigantulus, nov. sp. ㅇ. - Ochraceus, thorace cinereo, polline suborhraceo et pilis hutescentibus vestito, callis frontis et faciei, tertio antennarum articulo praeter imame basim, proboscide, genibus, extremo ibiarum apice tarsisque praeter busim nigris; alae immaculatae, ex subfusco cinereae, coslae limbo et ima basi luteis. - Long. corp. $5_{\frac{7}{12}}$ lin., long. al. $4 \frac{5}{6}$ lin.

Caput laete ochraceum; calli ordinarii capitis atri et nitidi. frontalis rotundus, verticalis triangularis, faciales mediocres et fasciolâ atrâ inter se conjuncti. Antemnae saturate lutcae; articulus secundus brevior quam in congeneribus plerisque, ita ul trientem articuli primi vix excedat; articulus tertius quam duo primi simsul sumti longior, ater, imâ basi salurate luleá. Proboscis nigra. palpi saturate lutei. Thoracis dorsum et scutellum obscure cinerea, polline subochraceo, in vitfarum dorsalium interstitiis confertiore aspersa et pilis lulescentibus vestila. Pleurae laelius cinereae. polline albid, adversus pleurarum marginem superum in ochraceum mutato instructae et luteo-pilosae. Abdonen praeter segmenti primi basim cineream ochraceum, ventre toto concolore. Pili alodominis plerigue nigri, in marginibus lateralibus magni ex parte lutei. Venter luteopilosus, segmentis tamen tertio et sequentibus in medio abdomine 
nigro-pilosis. Pedes lutei, genibus, extremo tibiarum apice tarsisque nigris. basi harum exceptâ. Alae immaculatae, ex subfusco cinereae, cellulà costali et stigmale luteis; in alarum basi venae omnes luteae sunt; praeterea venae auxiliaris et longitudinalis prima totac, longiludinalium secundae el quintae segmenta prima sextaeque initium colore luteo tincta sunt; venae reliquae nigrae; cellula submarginalis secunda appendiculata, qualis in Haematopotis et in Tabanis quibusdam reperitur. - (California; H. Edwards.)

13. Atherix varicornis, nov. sp. ㅇ. - Nigra, cinereo. pollinosa, primo articulo antennarum, palpis. pedibus halteribusque luteis. alis aequaliter nigro-cinereis. - Long. corp. 3 lin., long. al. $2 \frac{5}{6}$ lin.

Nigra, cinereo-pollinosa, opaca. Caput concolor, superne pilis nigris, infra pilis pailidis instructum; primus antennarum articulus mediocriter incrassatus, saturate luteus, superne paulo obscurior; articuli sequentes alri; palpi lutei, nigro-pilosi. Thoracis dorsum et scutellum nigro-pilosa; pleurarum pili pallidi. Abromen superne nigro-pilosum, imâ tamen basi et lateribus pallide pilosis. Coxae nigrae, pallide pilosae. Pedes obscure lutei, femoribus anticis prope basim superne nigro-lituratis tarsisque omnibus adversus apicem nigris. Halteres lutei. Alae aequaliter nigro-cinereae, stigmate fusco. (California; H. Edwards.)

14. Chrysopila modesta, nov. sp. $\delta$ et 우 - Lurida, superne tomento dilute flavescente veslita; pedes pallidi, femorum po. sticorum dimidio apicali tarsisque omnibus adversus apicem infuscatis; alae subhyalinae, stigmate nigro-fusco, lato, sed brevi. - Long. corp. of $2 \frac{1}{2}$, \& 3 lin., long. al. $2 \frac{1}{2}-2 \frac{7}{2}$ lin.

Caput cinereum, pallide pilosum, fronte foeminae fusco-maculatâ. Palpi breves, non recurvi, fusco-nigri, albido-pilosuli. Antennae lutescentes vel ex luteo subfuscae, articulo primo plerumque nigrofusco et ultimi apice infuscato. Thorax luridus, thoracis vittis, pleurarum maculis confluentibus et scutello praeter marginem fuscis. Pili et tomentum thoracis dilutissime flavicant. Abdomen maris nigricans, segmentorum singulorum margine apicali, segmenti secundi dimidio basali et segmento primo toto luteis; abdomen foeminae ex luteo luridum, segmentorum singulorum margine postico dilutius luteo, segmentis ultimis praeter marginem posticum nigro-fuscis. Coxae luridae vel fuscae, pallide pilosae. Pedes dilute lutescentes, dimidio apicali femorum posticorum subfusco vel fusco, tarsis om- 
nibus adversus apicem fuscis. Halterun capitulum nigro-fusinm. Alae hyalinae, rix levissime cinerascentes. umbrâ paulo dislinclius cinerascente inter stigma ct cellulae subnarginalis sceundac basim: venae fuscae, lougiludinalis secundae apex valde recurvus: sligma fusco-nigrum, majusculum, sed breve. - (Texas; Belfrage.)

15. Triptotricha lauta, nov. sp. ․ - Lutea vel subbalia. alis ex luteo subfuscis, venis colore nigricante non limbatis. - Long. corp. $6 \frac{3}{4}$ lin., long. al. $5 \frac{1}{2}$ lin.

Triplotrichae rufuthorari Say simillima. Iutea vel subbadia, colore thoracis saluratiore. Caput nigrum, fronte et facie cineroopollinosis, antenuis luteis, tertio tamen harum articulo alro. Abdomen macularum nigrarum serie oruatum. Alae ex luteo subfuscae, basin versus saturalius lutescentes, limbis nigricantibus venarum nullis. - (California; H. Edwards.)

Nola. Leptidarum genus, cui Triptotrichae nomen imposui. a Leptide, cui proximum est, corpore glabro, thorace minore. ih. domine latiore el cellulâ posteriore quartì ante marginem alac clausì distinguitur.

16. Leptis incisa, nov. sp. ․․ - Nigricans, palpis, antennis coxisque conooloribus, segmentis abdominulibus singulis postice anguste luleo-marginatis, pedibus fusco el huteo variegatis, alis nigrocinereis. - Long. corp. $3 \frac{3}{4}$ lin., long. al. $3 \frac{2}{3}$ lin.

Nigricans. Caput concolor, occipile cinereo-pollinoso, finte et facie polline subfusco aspersis. Pili rigilli in supremo ocripitis triente frontisque pili plerique nigri; reliqui capitis pili pallidi: antennae totae nigrae; palpi nigri et nigro-pilosi. Thorax polline cinereo aspersus, opacus; vittae dorsales nigricantes. intermedia lineà cinereâ divisa: dorsum thoracis et scutellum pilis longiusculis nigg is vestita; pilorum pallidorum fasciculus ante halleres. Abromen nigrum, pallide pilosum, segmentis singulis postice tenuiler luteo. marginatis. Coxae nigrae, cinereopollinosac pallide pilosae. Femora antica nigro-fusca, basi latius el apice anguslius luteis; femora posteriora lutea et fusco-lifurata: libiae sordide luteac adversus apicem subfuscae; tarsi fusco-nigri, adversus basim sordide lutri rol subfusci. Halteres lutei. Alac aequaliter nigro-cinereace adversus basim obsolete el sordide sublulescentes. sligmate fuscos. - (California; H. Edwards.) 
17. Oncodes melampus, nov. sp. 저을 - Niger, humeris, tegularum margine. pedibus totis alarumque venis concoloribus, segment is abdominalibus postice albo-limbat is, segmentis ventralibus albis, singulis fasciâ basali nigrâ ornatis. - Long. corp. $2 \frac{2}{3}$ lin., long. al. $2 \frac{1}{1} \frac{1}{2}$ lin.

Niger, pilis exalbidis, nonnihil sublutescentibus vestitus. Humeri cum reliquo thorace concolores. Abdominis segmenta singula postice albo-limbata, limbo segmenti primi angustissimo, limbis secundi et tertii angustis et aequalibus, segmentorum sequentium modice latioribus et minus aequalibus; venter albus, segmenlo primo praeler basim nigro, fasciis basalibus segmentorum reliquorum nigris, latera versus latioribus el prope abdominis marginem subito dilatatis. Pedes toti nigri. Halteres fusco nigri; tegulae exalbidae, nigro-marginatae. Alae hyalinae, levissime cinerascentes, venis omnibus nigris. - (California; H. Edwards.)

18. Oncodes eugonatus, nov. sp. Oౌ. - Niger, segmentis abdominalibus postice albo-limbatis, pedibus piceo-nigris, femorum tibiarumque apire harumque parte inferâ melleis, alis hyalinis, venis costali longitudinalibusque duabus primis nigris, reliquis pallidis. Loug. corp. $2 \frac{7}{1}$ lin., long. al. $2 \frac{1}{4}-2 \frac{1}{3}$ lin.

Niger, pilis exalbidis, nonnihil sublutescentibus vestitus. Humeri cum reliquo thorace concolores. Abdominis segmenta singula postice latius albo-marginata; venlel alhus segmento primo praeter basim nignro, segmeutorum reliquorum imâ basi nigrâ, colore tamen nigro prope abdominis marginem subito valde dilatalo. Pedes piceonigri; femorum apex melleus; tibiae superue piceo-nigrae, infra melleac, apice toto melleo; primus tarsorum articulus praeter apicem nigrum melleus. Halteres nigri; tegulae exalbidae, nigro-marginatae. Alae pure hyalinae, quam in specie praecedente pro porlione breviores, venis costali longiludinalibusque duabus primis minus validis, fusco-nigris, venis reliquis pallidis. - (Texas; Belfrage.)

19. Eulonchus tristis, nov. sp. ठ․ - Viridis, scutello abdomineque sordide purpureis, antennis et proboscide lolis nigris, pedibus nigro et albo variegatis. - Long. corp. $4 !$ lin., long. al. $3 \frac{5}{6} \operatorname{lin}$,

Caput viride, nitidum, antennis totis et proboscide nigris, palpis fusco-nigris, tuberculo ocellifero quam in Euloncho smaragdino Gert. etiam majore, cyaneo-nigro. Thorax aeneo-viridis, pleurarum dimidio inferiore coxisque cyaneis, colore dorsi prope scutellum 
in violaceo-purpureum vergente. Scutelli et abdominis color violaceo-purpureus modice nitens, ventris ex chalybeo viridis et nilidior. Pedes nigri, femoribus in apice, tibiis in basi late et superne fere ad apicem usque albidis. Tegulae albidae; halleres dilutissime flavescentes. Corpus pilis confertis lutescentibus. in abdomine rarioribus. brevioribus dilutioribusque instructum. Alae byalinae, colore sub. fusco dilutissime tinclae. - (California; II. Edwards.)

20. Midus tenuipes, nov. sp. ఫ̋.-Ater, nitidus, pilis capitis, thoracis et segmenti abdominalis primi flaris. hypopygio. pedum anteriorum tibiis et tarsis rufis, posticorum ex ru/o fuscis; libine posticae non calcaralae; alae nigricantes, venis longiludinalibus quartâ in primam el nullâ nisi ultimâ in marginem posticum excurventibus. - Long. corp. $\delta_{\frac{1}{4}}$ lin., Iong. al. $5_{6}^{5} \mathrm{lin}$.

Niger, nilens. Caput pilis erectis flavis hirtum. Proboscis brevis. labellis non incrassalis. Antennae mediocres, nigrae, arlirulis duobus primis nigro-pilosis. Thoracis dorsum subopacum. flivopilosum. pilis in specimine deseripto practer humeros. vittas quatuor valde abbrevialas et marginem posticum detrilis. Pleurae nitilissimae, prope coxas anticas el infra alis flavo-pilosae. Abdomen nifidum, margine postico segmentorum singulorum nigro-piceo: segmentum primum confertius flavo-pilosum; segmenta reliqua pilis raris aspersa, in abdominis lateribus et in ventre maxima ex parte flavis, in reliquo abdomine plerisque el in ultimis segmentis omnihus nigris. Hypopygium ex badio rufum, nigro-pilosum. Femora nigra, apice rufo-teslaceo. postica non incrassata. infra spinis rariorihus a'mata. Tibiac anteriores cum tarsis rufae. libiae posticae non ral. caratae et leviter arcuatae, rufo-fuscae vel fuscae. imâ basi et exIremo apice dilutioribus; tarsi postiri fusco-rufi. Ilalleres nigri. Alae nigricanles, basim versus dilutiores; venac nigrae, in basi alarum lestaceae, ipsà famen costâ exeeptâ: vena longitudinalis quarta in venae longitudinalis primae apicem excurrit. ita ut enllula posterior prima aute marginem alae clausa sil: cellulae posteriores secunda et quarla confluunt. ita ut praeter longitudinalem ultimim vena nulla in marginem posteriorem alae exenrrat. - California: H. Edwards.)

Nota 1. A. Mida venoso, cui affinis. fasciis flavis abdominis nullis, alis obscurioribus et cellulà posteriore primà clausi facillime distinguitur.

Nota 2. Si rationem probamus. quà Midas genus a peritissimo Ferstaeckero in minora genera dinsolutum est. haec nostra species 
secundum totam corporis formam nulli alii quam Leptomidae inseri potest; discrepat tamen leviter venarum in alis decursu, qui talis est. quali Cephalocera utilur. Ex is speciebss, quas in Cent. VII proposui, Midas venosus jure ad Leplomidam numeratur, reliquae in proprio Midae genere sunt retinendae.

21. Dioctria resplendens, nov. sp. Ђ゙. - Nigro-viridis splendida, mystace confertiore rufo, alis nigris. - Long. corp. $2 \frac{5}{6}$ lin. - long. al. $2 \frac{3}{4}$ lin.

Nigro-viridis, nitens, pilis rufis vestita, pilis tamen ventris et pedum colore ex rufo in ochraceum vergente tinclis. Mystax rufus, quam in congeneribus plerisque confertior. Echthopodam simulat, sed femora postica setis nullis instructa Dioctriam produnt. Thoracis dorsum non viltalum, tolum aequaliter splendens. Alae pro genere latiusculae, nigrae. - (California; H. Edwards.)

22. Echthopoda formosa, nov. sp. $\sigma^{\prime}$. - Nigra, mystace fulvo, palpis et hypopygio majusculo nigro-pilosis, tibiis praeter trientem ultimum luteis. - Long. corp. $8 \frac{1}{2}$ lin, long. al. $6 \frac{1}{2}$ lin.

Nigra, libiis fulvo-luteis, anteriorum trieute apicali poslicarumque apice etiam latius nigris. Mystax et frontis occipilisque pili fulvi, menti et proboscidis flavescentes, palporum nigri. Antennae tenues, nigrae, articulis duobus primis pilos ex fulvo fuscescentes gerentibus. Facies pro portione angustior quam in Echthopodâ $\mu u$. berâ, fulvo-tomentosa. Thoracis dorsum tomento et pilis fulvis vestitum. Scutellum fulvo-pilosum. Pleurae practer pilos luteos maculis aliquot luteo-pollinosis instructae. Pili abdominis nitentis perbreves, in lateribus fulvi, in dorso nigri. Hypopygium quam Echthopodae puberae majus, nigrum et nigro-pilosum. Femora nigra, luteopilosa, antica inermia, posteriora in latere antico spinis nigris prae. dita. Tibiae ex fulvo luteae, anteriorum triente apicali posticarumque apice latius nigris; spinae in tibiarum parte nigrâ omnes, in luteâ pleraeque nigrae. Tarsi nigri, pilis spinisque nigris instructi. Halteres sordide lutei vel subfusci. Alae nigro-cinereae, adversus angulum posticum albae; venae nigrae inde a basi usque ad mediam alam anguste nigro-limbatae. - (Pennsylvania; Auxer.)

23. Leptogaster brevicornis, nov. sp. ․ - Opacus, thorace ex latericio fusco, abdomine fusco, segmentis secundo, tertio et quarto luteo-annulatis; antennae luteo-testaceae, articulo tertio ovato, quam stylus terminalis paulo breviore; pedes luteo-testacei, 
annulo femorum posticorum subapicali tibiisyue posticis prapter frien. tem basalem fuscis, annulo tamen harum subapicali lutentestacen: alae subhyalinae, colore lutesrenti-cinereo leviter tinctue, rellulis submarginali secunda el posteriore secundi mire elongalis, posteviore guartâ sessili vel subsessili. - Long. corp. 5 lin., long. al. 33 lin.

Facies ex stramineo albicans; setae mystacis paucar, albac. Anteunae luteo-testacene, articulo tertio quam in speciebus plerisque breviore, ovato, stylo terminali quam articulus ipse paulo lou. giore. Thorax ex latericio fuscus, vitlis tamen dorsalibus obscurioribus, polline exalbido aspersus. Abdomen fuscum, smbutidum, adversus basim polline cinerascente opacum; segmenta sccundum, tertium el quarlum singula annulo subapicali luleo ornala; practerea annuli obsoletiores sordide lutei et in abdominis dorso interrupti in segmentorum tertii, quarti et quinti basi conspiciunlur: in segmento secundo annuli medii vestigium obsoletum observalur. Pedes ex luteo testacei; femora postica ante apicem anuulo fusco magis conspicuo, femora reliqua obsoleliore ef minus perfecto cingunlur; triens basalis tibiarum posticarmm pallidus, utrinque lineà fuscii pictus, quae adversus mediam tibiarum partem, quam paulo transgreditur, valde dilatatur; trientis secundi el tortii color lutro-testaceus, in rufum vergens, annulo lanen subapicali latissimo, plerum. que incompleto, fusco. Alae sublsyalinae, colore ex cinerco lute. scente leviler tinctae; venae fusco-nigrae, transversalis unedia reliquis validior; cellulae suhmarginalis secunda et poslerior secunda mire elongatae, ita ut illa triplicem pedunculi longitudinem excedat vel quadruplicem fere attingat et hujus basis a cellulat discoidalis apice intervallo duplo latiore quam a venà transversali mediâ disjuncla sit; cellula posterior quarta sessilis vel subsessilis; cellula analis apicem versus nec angustata, nec dilatata. - (Texas; Belliage.)

Nota. Leptogaster brevirornis colore el piclurà rorporis vena. rumque in alis dispositione ad Leplogastrum farillaceum (Cent. II. 12) proxime accedil, sed arliculus tertius antemarum illius ovalus ol quam stylus paulo brevior, hujus vero longe acuminatus el sty longior est; praeterea cellulae submarginalis secunda el posteriou secunda in illo eliam longiores sunt.

24. Blaxbellus, nov. sp. o el ㅇ. - Fuscus, opacrus, abdomine rufo et nitido; pedes rufi. femoribus. Jibiis tarsornmyre ar. liculis singulis adversus apicem nigro-fuscis.

б. facies el frons candidissimne et thoracis dorsum antire maculis duabus candido-pollinosis ornatum; alue nigro-fuscae, ante apicem maculà parvá elutâ, costae contiguà nolatae. 
․ facies et frons fusco-pollinosae, illa tamen adversus margines polline exalbido aspersa; thoracis dorsum totum fuscum; alae nigrofuscae, maculâ parvâ, ante apicem costae contiguâ cellularumgue singularum disco elutis.

Long. corp. $2 \frac{1}{\frac{1}{2}}-3 \frac{7}{\frac{7}{2}}$ lin., long. al. $2 \frac{1}{2}-2 \frac{5}{6}$ lin.

M as: Frons et facies polline candidissimo, fere argenteo-micante confertim tectae, illa nuda, haec pilis perpaucis tenuissimisque albis aspersa; mystax simplex, exalbidus. Antennae totae nigrae, articulis duobus primis aequalibus, tertio fusiformi praecedentibus simul sumtis paulo longiore, stylo terminali lineari, aculo, articulis duobus primis simul sumtis breviore. Thorax fuscus, opacus, dorso vittis tribus nigro-fuscis et antice maculis duabus magnis candido-pollinosis ornato. Pleurae polline ex ochraceo subfusco aspersae, polline tamen vittae mediae et coxarum anticarum posticarumque albicante. Abdomen tolum aequilatum, modice convexum, laevigatum, rufum, marginibus lateralibus segmentorum singulorum albo pollinosis. Hypopygium parvum, rufum vel ex rufo badium. Pedes rufi; femora anteriora adversus apicem latissime, postica minus late nigro-fusca; tibiae anteriores adversus apicem fuscae, posticae nigro-fuscae; articuli singuli tarsorum omnium adversus apicem nigro-fusci. Pedes postici elongali, libiis subclavalis tarsisque validissimis. Halteres magni, flavi. Alae nigro-fuscae, adversus angulum axillarem paulo dilutiores, maculâ parvâ elutâ, inter costam et basim cellulae submarginalis secundae sitâ; cellula posterior quarta apicem versus valde angustata et cellula analis clausa.

Foemina: Frons fusco-pollinosa; facies albido-pollinosa, in disco tamen polline subfusco instructa. Thoracis dorsum maculis candido-pollinosis, quibus mas ornatur, plane destitutum. Alae ut in mare nigro-fuscae, sed colore nigro-fusco, quae in alis maris conspicilur, in cellularum singularum disco late eluto. In reliquis mari simillima. - (Texas; Belfrage.)

Nota. Ex illis Americae septentrionalis Dasypogoninis, quibus apex tibiarum anticarum spinâ armatus est et omnes alarum cellulae posteriores apertae sunt, tria genera constituantur necesse est. Ac primum eorum Dioctria octopunctata Say format. Schinerus quidem in Annalibus societ. zool. et botan. Vindobon. (Schriften d. Wiener zool. bot. Gesellsch. XVI. 1846) me arguit hanc speciem, quae jure ad Dioctrias referatur, Dioctriam esse injuriâ negavisse; at vir do. ctissimus, si minus leviter rem examinasset, hoc affirmare non esset ausus; scilicet diligentius inspectis Musei Wiedemanniani exemplis tibias anticas spinâ terminali muniri certo vidisset. Taraclicus igitur 
hoc genus nominetur, cujus civis ipsa ista Dioctria octopunctala est. Has autem generis notas maxime insignes habemus: 1) apicem tibiarum anticarum spinâ armalum; 2) universam capitis formam Dioctriis similem, praesertim mystacis, proboscidis, antennarum; 3) abdomen valde convexum ubique setis destitutum. pilis brevissimis obsitum et punclatum; 4) tibiarum posticarum apicem incrassa. tum et farsos posticos robustissimos; 5) cellulas alarum posteriores omnes late apertas.

Alterum horum Dasypogoninorum genus illud est, quod in Cent. VII. Pygostoli nomine condidi ef notis breviter indicatis firmavi. Quum, quod Schinerus recte vidit, in nominc fingendo neglexerim ab Halidajo jam Hymenopterorum genus Pygostolum esse appellatum, pro meo Pygostolo "Nicocles" ponendum esl, quo nomine Jaennickeus jam speciem quandam Mexicanau descripsit. Hoc genus a Macquarti Brachyrhopala (Dipt. exot. Suppl. II.) non dif. ferre Schinerus opinatur. At in eo mire errat. Nam quum Brachyrhopalae abdomen breviter clavatum i. e. sub apicem undique anbilu auclum sit, in Pygostolis s. Nicoclibus abdomen sensim et distincle quidem latescit, sed ubique planissimum manet, quam conformationem quis unquam clavatam dicel? Videtur Schinerus descriplionem Bra. chyrhopalae apud Macquarlum non ad finem usque perlegisse: aliter enim videre debebat, Brachyrhopalae abdomen breviler clavalum (abdomen à courte massue) adsignari, quale Pygostolus plane non habet; quid quod ipsum Brachyrhopalae nomen hane naluram ab. dominis denotat? Et quam causam habuerit Schinerus perpetuo .. Brachyrhopola6" scribendi, explicent alii. Macquartus practerea de facie nudá, mystace simplici, antennarum slylo subobsolefo. venula traus. verså in primo cellulae discoidalis triente posila loyuilur. Num potuissel ila describere Pygostoli (Nicoclis) tolam faciem pilosam. myslacem ideo non simplicem, slylum antemurum dislinclisimum. venulam transversam in ultimo cellulae discoidalis triente vel aseo ultra collocatam? Denique Brachyrhopalae larsi antici robuslissimi sunt, pedes postici non elongati; Pygostolus pedes posticos habul elongatos cum tarsis mire robustis. quum pedum anticormm con. formatio sit ordinaria. Tanta diseriminum series Brachyrhopralum et Pygostolum in unum genus conjungi certissime vetat!

Tertium horum Dasypogoninorum geuus id est. quod Blax milii audit. A Taractiro praeler capul latius depressiusque distin. guitur antennarum brevitate ef formâ longe aliâ. quippe quarum articulus primus non sil secundo multo longior. sed eàdem "um eu 
longitudine, et tertius non sil linearis, sed fusiformis cum stylo non incrassato et obtuso, sed lineari et acuminato. His notis adde thoracem gibbosiorem, abdomen paulo planius et punctis destitutum, venam denique transversam mediam insigniter adversus cellulae discoidalis finem promotam. Quem venae transversae locum Blax cum Pygostolo communem habet; atque antennarum ratione magis inter se congruunt quam cum Taractico. Ne vero Blax cum $\boldsymbol{P} \boldsymbol{y}$ gostolo confundatur, abdominum forman comparare satis est; Blacis enim abdomen prorsus eâdem ubique latitudine manet multoque minus est deplanatum.

25. Pygostolus a mulator, nov. sp. $\sigma^{7}$ - Niger, segmentis abdominalibus duobus ultimis randido-pollinosis, paenultimo bis latiore quam longiore; alae pulchre nigro-variegalae, triente basali hyalino; tertius antennarum articulus duplicem styli longiludinem vix aequi-

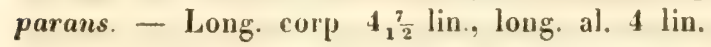

Pygostolo divili (Cent. VII. 29) simillimus sed abdomine longiore et adversus apicem minus dilatato distinctus, ita ut segmentum paenultimum hujus duplo, illius fere quadruplo latius quam longius sit. Praeterea mystax confertior, longior et multo obscurior quam Pygostoli divitis est. A Pygostolo picto (Cent. VII. 30) tertio an. tennarum articulo minus tenui et stylo terminali longiore differt. (California; H. Edwards.)

Nota. Cur pro Pygostolo in posterum nomen Nicoclis usurpandum sit, in verbis ad speciem praecedentem scriptis declaravi. Hic vero ut Pygostoli nomine pergerem, eà re impulsus sum, quod, si aliter facerem, consensus cum nominibus earum specierum, quas in Cent. III. descripsi, turbaretur.

26. Diogmites symmachus, nov. sp. ơ et ㅇ․ - Diogmilae bilineato mire similis, sed minor el alis minus latis facile distinctus. - Long. corp. 8-9 lin., long. al. $6 \frac{1}{4}-7 \frac{\pi}{4}$ lin.

A Diogmite bilineato (Cent. VII. 40) difficillime distingueretur, nisi minor esset et alas minus latas aliterque colore cinereo pictas haberet. Hic color in Diogmitae bilineati alis cellulam submarginalem totam, cellulam posteriorem primam inde ab alae margine usque ad basim cellulae submarginalis secundae cellulasque posteriores secundam et tertiam practer inam basim totas explet; in hac nostrà specie color cinereus in cellulâ submarginali secundâ marginem posticum, in cellulis posterioribus primâ et secundà utrumque marginem non attinget nisi prope alae marginem, in cellulâ vero posteriore terliâ 
a marginibus omnibus limbo hyalino separatur; in Diogmilae bilineali cellulâ posteriore quartà macula cuneala, cum margine apicali subcohaerens, in Diogmilae symmachi litura oblonga a marginibus omnibus limbis hyalinis aequaliler separata conspicitur; in illius cellulà posteriore quintâ macula magna trigona, cum margine alae cohaerens, in hujus eâdem cellulà macula trigona ab alae márgine limbo hyalino separata observatur; angulus axillaris Dingmilae bilineat $i$ vestigium picturae cinereae nullum, Diogmitae symmachi lituram cum margine alae parallelam ostendit. Cellula posterior tertia Dio. gmitae symmachi propter alas minus latas minus lata est quam Divgmitae bilineati. - (Texas; Belfrage.)

27. Microstylum morosum, nov. sp. 주 et 우. - Alrum, alis pedibusque concoloribus, capite thoraceque exalbido-pollinosis. polline tamen in dorso thoracis praeter margines rarissimo, barba. mystace, selis in posticis thoracis angulis et in coxis exalbidis. selis reliquis omnibus nigris.

ơ abdomine toto nigro.

I segmentis abdominalibus tertio, quarto et quinto praeter latera. sexto adversus basim rufis.

Jong. corp. $17 \frac{1}{2}-18 \frac{1}{2}$ lin., long. al. $13 \frac{1}{2}-14 \mathrm{lin}$.

Mas: Totus niger. subopacus, pedibus totis alisque concoloribus. Caput albido-pollinosum, occipitis polline practer orbitas rariore: palpi, duo primi antennarum articuli. frons et dimidium superius occipitis pilis selisque nigris instructa; reliqui occipitis pili et mystax albidi. Thorax albido-pollinosus, polline dorsi praeter margioes multo rariore; prothorax superne nigro-setosus, infra exalbido-pilosus; me. solhoracis dorsum subnudum, pilis brevissimis nigris instructum, sed in angulis posticis pube confertiore exalbida vestifum; setae dorsi rarae et pro portione breves, angulorum proticorum albidae. reliquate nigrae. Setae marginales scutclli nigrac; selarum series quae ante halteres conspicitur, exalbida. Abdomen levissime albido-pollinosum. adversus basim et margines laterales polline modice confertiore ad. spersum; pili abdominis perbreves nigri, adversus latera abdominis albidi; latera segmenti primi selis nigris et pallidis armati, reliquum abdomen setis destitutum; Hypopygimm nigrum et nigro-pilusmm. Coxae albido-pollinosae el albido-pilosae. Pedes brevissime nigro. pilosi, femoribus tamen posticis fere totis intermedisume magni as parte albido-pilosis: selae pedum pro portione breves. nigrae. P'ul. villi fusco-nigri. Ilalleres dilute luleseentes. Alac fotae aequaliter 
nigrae, cellulâ posteriore primâ ante marginem alae clausà el ibi breviter pedunculalà.

Foemina: A mare, cui simillima, diflert capitis, thoracis coxarumque polline dilule sublutescente, segmentis abdominalibus terlio, quarto et quinto praeter latera et sexto adversus basim rufis, quatuor ultimis denique non pollinosis, sed nitidis. - (Texas; Belfrage.)

Nota. Maxima haec est species inter Asilidas intra Faunae Americae septentrionalis fines alhuc detectos. Quam si cum Microstylo galactode (Cent. VII.94) excipis, nulla alia ibi e genere Microstylorum inventa est. Schinerus quilem imperii Mexicani cives: Dasypogonem Lucasi Bell., quadrimaculatum Bell. et spathulatum Bell. inter Microstyla ponendos esse censet (Schriften der Wien. zool. bot. Gesellsch. XVI. 702). Sed in eo fallitur; nam primi duo ad genus Dizoniam, terlius ad Ospriocerum perlinet, et ne unus quidem eorum affinitate aretiore cum Microslylis con. jungilur. Microst. galactodes et morosum viciniora sunt Microstylis orbem antiquum incolentibus quam illae species, quarum alteram ex Brasilià apportalam Macquartus Microslyli longipedis nomine, alteram ex eâdem regione oriundam Walkerus Dasypogonis (Microst.) magnifici nomine descripsit.

28. Stenopogon breviusculus, nov. sp. б et 우 - Capile et thorace fuscis, ochraceo-pollinosis, corpore toto pilis sel isque luteis vel lutescentibus instructo: antennte nigrae, articulo primo rufo; abdomen et perles ex luteo rufa, villa illius femoribusque omnibus superne nigris; alae cinereo-hyalinae. - Long. corp. $7 \frac{1}{2}-8 \mathrm{lin.}$ long. al. $4 \frac{2}{3}-5 \frac{1}{4}$ lin.

Capilis thoracisque color nigro-fuscus, praeter villas dorsales thoracis polline ochraceo obtectus: primus antennarum articulus et calli humerales rufi, articulus secundus illarum et pleurae ex rufo fuscescentes. Ablomen maris tolum opacum, foeminae apicem versus nitens, viltâ rufâ in foeminâ latiore quam in mare, in ulroque sexu adversus basim abdominis in segmentis singulis magis dilalala; venter et hypopygium tola rufa. Pedes rufi, femoribus superne, apice tamen excepto, nigris; focmina libiae posticae plerumque in latere externo practer basim nisricantes. Pili totius corporis lutei; setae omnes concolores. Alae hyalinae, venis fuscis, maris vix levissime, foeminae distincte cinerascentes.

(California; H. Edwards.) 
29. Stenopogon univittatus, nov. sp. ․ - Niger, capite thoraceque polline subfusco aspersis. abdominis villá latá, ventre pedibusque rufis, femoribus anlicis posticisque praeter apicem "t tibiarum posticarmm apice nigris; mystax lutens; frons nigro-pilosa: tharacis dorsum prueter latera pilis et selis nigris vestilum; reliqui corporis pili et selae dilute lutescentes; alae cinereo-hyalinae. l.ong. corp. $\delta \frac{1}{2}$ lin., long. al. $6_{6}^{1} \mathrm{lin}$.

Niger, antemnis tolis concoloribus, capite thoraceque polline fusco-ochraceo vel subfusco instructis; hujus villa inlermedia duplex el nigra, vittae laterales obsoletae. Abdomen nitidum, viltâ tatâ. paulo ante marginem posticum segmenti secundi incipiente cl aut anum usque pertinente venlreque toto rufis. Pedes rufi, cosis oms. nibus. femoribus anticis posticisque practer apicem el tibiarum posticarum apice nigris; lemora intermedia superne interdum lilura nigricaule uolata. Froms nigro-pilosa; Horacis dorsum practer latera antice pilis confertis nigris, pustice selis confertis nigris vestilnm: reliqui corporis pili et selac ommes lulescentes; mystax paulo situralius luteus. Alae cinereae. fere fusco-cinereae, adversus angulum posticum dilutiores; venae alarum nigrae. - (California; H. Edwards.)

30. Stenopogon obscuriventris. nov. sp. ․ - Niger. ventre concolore, capitis thoracisyue polline hutescente, abdominis cinereo; mysta.r luteus; pili in verlice et in thoracis dorso praeter latera et prueter marginem posticum nigri; corpus reliquum pilis setisque lutescentibus instructum: pedes nigri. femorum anteriorum apice, tibiarum basi tarsisyue ommibus rufis, singulis horum arfirulis apicem versus nigris; alae cineren-hynlinae. - Long. corp. $9_{3}^{2}$ lin.. long. al, $6_{\frac{1}{\frac{1}{2}}} \operatorname{lin}$.

Niger, antemnis totis concoloribus. capile thoraceque pulline ex subfusco ocbraceo vel fere dilute subfusco, abdomine polliur magis cinereo et adversus anum valde raro aspersis. Venter totus niger. Pedes nigri. femorum anteriorum apice. tibiarmm anteriormu dimidio basali posticarumque trienle primo rufis. larsis ex badio rufis, articulorum singulorum apice obscuriore. Thoracis villac dorsales fusco-nigrae. laterales subobsoletac. intermedia postice abbre. viata. pilis selisque nigris instructa. Reliqui corporis pili lutei selaeque omnes concolores. Alae cinereo-lıyalinac, venis nigris. (California; II. Edwards.)

31. Stenopogon grolus. uns. sp. ot. - Niger, polline tho. vacis fusco-ochraceo. mysture. pilis setisque totius corporis unlpinis. 
dorsi tamen dimidio anteriore praeter latera nigro-piloso: vitfa lata abdominis rufa; pedes rufi vel ex luteo rufi, femoribus anticis poslicisque praeter apicem, litur $\hat{a}$ femorum intermediorum tibiarumque posticarum dimidio apicali nigris; alne nigricantes, triente basali praeter limbum costae albo, - Long. corp. 10 lin., long. al. $6_{\frac{1}{1}}^{7}-$ $6 \frac{2}{3}$ lin.

Niger, antennis totis concoloribus, capite thoraceque polline ex fusco ochraceo aspersis, sed ita ut vitla intermedia thoracis practer lineam mediam polline dilutiore omni destituta, atra et opaca sit et vitlae laterales minus confertim pollinosae fusco-nigrae appareant. Abdomen totum nitidum, vittâ lalâ, in segmento secundo incipiente et ventre fere toto rufis. Hypopygium nigrum vel piceo-nigrum. Pedes rufi vel ex luteo rufi, coxis omnibus, femoribus anticis posti. cisque praeter apicem, femorum intermediorum liturâ superâ tibiarumque posticarum dimidio apicali fere toto nigris. Pili frontis et forcipis analis nigro-fusci; thoracis vitla intermedia cum interstitiis, quibus a vittis lateralibus distinguilur, pilis nigris instructa; mystax ex fusco vulpinus; pili reliqui corporis laetius vulpini, setae concolores. Alae nigricantes, venis fusco-nigris, triente basali praeter limbum costae albo. - (California; H. Edwards.)

32. Callinicus calcaneus, nov, sp. $\delta$ et $\mathcal{T}_{\text {. }}-$ Rufus, nitidus, thoracis abdominisque colove magis in laete badium vergente, polline capitis, humerorum pleurarumque laete ochraceo. vittis thoracis nigris; alae fuscae, lumine certo violareo-micantes, adversus costam saturate sed sordide luteae. - Long. corp. $6 \frac{2}{3}-9 \frac{3}{4}$ lin., long. al. $5 \frac{1}{2}-8$ lin.

Fx badio rufus, thorace modice, abdomine lactius nitente. Caput praeter callum ocellos ferentem polline laete aureo-ochraceo vestitum. Antennae ex luteo rufae, articulo tertio nigro, infra et in imâ basi plerumque luteo-rufo; stylus terminalis mediocris, crassus, niger, articulo terminali perparvo, subulato. Proboscis cum palpis uigra. Thoracis vittae dorsales nigrae, in exemplis illaesis omnes polline cinereo aspersae, intermedia duplex; humeri polline aureo-ocbraceo confertim obtecti, margines laterales dorsi obsoletius ochraceo-pollinosi. Pleurae nigro-maculatae, inaequaliter ochraceo-pollinosae. Metanolum nigrum, callis tamen lateralibus confertim et laete ochraceo-pollinosis. Basis segmenti abdominalis primi semper nigra; segmentorum reliquorum margines postici plerumque colore nigro vel nigricante limbati. margines laterales semper paulo latius nigri; anguli postici segmenti primi laele ochraceo-pollinosi; margines po- 
stici segmentorum secundi. tertii et quarti latera versus albo-polli. nosi. Venter nitidus rufus, segmentis singulis fascia basali pallido. pollinosâ et fascià alterì apicali fusco-nigrí. in medio abdomine maculam pallide pollinosam gerente ornatis. Pedes toti rufi vel luteo-rufi; metatarsus posticus varus. latere interiore concavo, oxteriore convexo. Pili totins corporis breves, in thoracis dorso $\mathrm{ot}$ in abdomine brevissimi, ochracei; selarum color in vulpinum vergens. Alae fuscae. adversus costam et in imâ basi sordide lutear. ubi fuseae sunt certo lumine violaceo micantes: venae nigro-fuscar. prope costam sordide luteae, in imi basi purius luteae. - California: H. Edwards.)

Nota. Callinicus. novum Dasypogoninorum genus. corporis figurâ Diogmilae similis. a quo tibiis anticis non calcaratis facillim. distinguitur. Caput modice latum. facie latâ. totả leviler consrxi. mystace rigido, usque ad antennarum basim pertinente. prope oris aperturam longiore: anfennae mediocres. articulo tertio primis duobus simul sumtis paulo longiore, stylum mediocrem crassiusculum gerente. Thorax mediocris, convexus. dorso pilis brevissimis. advervsus marginem posticum setis validioribus instructo. Abdomen apicem versus non attenuatum, modice convexum. Pedes longin. sculi, validi, leviter pilosi, libiis poslicis adversus apicem non rrassioribus. Alarum cellulae posteriores prima et quarta late apertap.

3:3. Heteropogon phoenicurus. nov. sp. $\sigma$ et + . - Niger, abdominis apice rufo. tibiis tarsisque badiis vel ex rufo broliis. alarum dimidio basali praeter imam basim hyalino, apicali nigro -Jong. corp. $4 \frac{1}{2}-5 \frac{3}{4}$ lin.. long. al. $4 \frac{1}{3}-5_{T^{5}}^{5}$ lin.

Mas: Niger. segmenti abdominalis quinti margine postico. st. gmenlis sequentibus totis et hypoprerio saturale rufis. libiis tarsicque badiis rel ex rufo badiis. his adversus apicem fusco-nigris vel nigris. Frons polline fusco-cinereo aspersa. opaca. vigro-pilosa. Anlennar nigrae, quam in speciebus curopaeis etiam temiores et stylo longiore instructae. Facies polline rinereo opara; pars inferior mystaris om nino nigra, superior e pilis nigris el exalbitis mixla. his adversus basim interdum dilule sublutescentibus. Palpi nigri el nigro-pilosi. Orbitae occipitalis selae longae, nigrac: ocriput totum cum mento el cum proboscidis basi pilis perlongis albis confertissime veslilum. Thoracis dorsun subopacum, praeter villas tres ordinarias latissimas polline dilute lutescente, interdum fere exalbido aspersum. tolum albo-pilosnm. setis lamen scapularihus setisque supra alarum basiu nigris. Pleurae et sculellum albo pilusa: mateo hujus utrimpue seta 
unicâ nigrâ, raro albâ instructus. Pili in abdominis dorso brevissimi, nigri, inde a margine postico segmenti quinti fulvo-rufi, in hypopygio majusculo longiores et dilutiores; margines lalerales abdominis pilis longis albis vel dilutissime sublutescentibus vestiuntur, qui adversus apicem abdominis valde decrescunt et colorem pallidum in rufo-fulvum mutant. Venter cinereus, pilis Jongis albidis vestitus. Femora atra, breviter nigro-pilosa, in basi utrinque, infra tamen latius pilis longis albis hirta, nigro-setosa, intermedia infra prope apicem pilis confertis nigris barbata. Tibiae badiae vel rufo-badiae, extremo apice omnium modice saturatius tincto; anticae breviter albo-pilosae et nigro-setosae, setis tamen, quas in latere postico gerunt, omnibus albis; tibiae intermediae albo-pilosae, ante medium infra fasciculo conferto pilorum nigrorum instructae et ibi undique nigro-pilosae, in latere postico setis albis, in antico nigris, vel nigris et albis armalae; setae tibiarum posticarum omnes, pili maximâ ex parte nigri sunt. Tarsi badii vel rufo-badii, extremo articulorum singulorum apice fusco-nigro, articulis ultimis fere totis nigris; setae tarsorum nigrae, metatarsi antici ex parte albae; pili tarsorum nigri, melatarso tamen antico superne pilis albis confertim vestito. Halteres lutei. Alarum dimidium prius hyalinum, imâ basi usque ad venulam humeralem nigrâ; dimidium apicale nigrum, basi cellulae submarginalis primae, apice basalis primae et cellulis discoidali et posterioribus quartâ et quintâ dilute subfuscis; venulae transversales venarumque anastomoses colore saturatius nigro circumfusae.

Foemina: Mari simillima, sed diversa pilis tolius corporis modice brevioribus, femoribus intermediis infra prope apicem non nigro-barbatis, tibiis intermediis fasciculo pilorum nigrorum carentibus et totis aequaliter albo-pilosis, pilis albis melatarsi antici denique brevioribus et multo rarioribus. - (Texas; Belfrage.)

34. Heteropogon lautus, nov. sp. бో et 9 . - Niger, thorace cinereo, tibiis tarsisque rufis vel rufo badiis.

5. alae totae pure hyalinae; tarsi antici superne confertim albo-pilosi.

우. alae pure hyalinae, imâ basi usgue ad venulam humeralem nigrá, venis transversalibus venarumque anaslomosibus colore nigricante anguste marginatis.

Long. corp. $4 \frac{1}{2}-5 \frac{2}{3}$ lin., long. al. $4 \frac{5}{12}-5 \frac{5}{\frac{5}{2}}$ lin.

Niger, tibiis tarsisque rufis vel ex rufo badiis, apice illarum el articulis singulis horum adversus apicem paulo saluratius tinctis. Caput polline conferto exalbido obtectum, opacum, pilis albis setisque 
albidis vestitum, setis tamen inferis mystacis. pilis palporum om. nibus antennarumque plerisque, selâ denique validà. quà antennarum articulus secundus infra instructus est, nigris. Thorax totus polline conferto opacus et cinereus, pleurarum scapularumque colore magis in albidum, reliqui dorsi et sculelli magis in fusco-cinereum vergente. Pili thoracis omnes alti, selae nigrae, in postico dorsi margine et in margine sculelli exalbidae. Abdominis segmenta sex prima nigra. nitida, brevissime nigro-pilosa. singulorum margine postico angulisque. posticis polline albido-cinereo adspersis et brevissime pallide pilosis: segmenta duo ultima et hypopygium parrun ex rufo badia; adversus basim abdoninis segmentorum latera pilis longis albis instructa. Venter cinereus. pilis longis albis vestilus. Femora superne fere fola breviter nigro-pilosa. pilis reliquis allis, adversus femorum basim multo longioribus; setae femorum pleraeque nigrae. paucae albidac. Tibiae albo-pilosae selisque nigris et albidis armalae. Tarsi antici toti superne confertim candido-pilosi, intermedii el postici nigropilosi, illi adver'sus imam basim, hi paulo latius pilis albis parre aspersi; larsorum selae nigrae, metatarsi antici pleraerjue exalbidar. Halleres lutei. Alae tolae purissime hyalinae, imâ tantum basi usquo. ad venulam axillarem cinerascente.

Foemina: Mari similis, sed pollen frontis, faciei, dorsi el scutelli in fuscum vergil; setae marginales scutelli nigrae sunt: ahdonen plerumque totum nigrum rarius adversus apicem ex nigro olısolete rufescit; margo posticus segmentorum singulorum pollinis cinerascentis pilorumque pallidornm vestigium vix ostendil; tarsi antiri supernc pilis confertis candidis nullis instructi sunt: alarmu hyalinarum ima basis ad renulam humeralem usque nigra est el remulae transversales venarumque anaslomoses colore nigricante anguste adumbranlur. - (Texas; Belfrage.)

35. Discocephala calva. nov. sp. Q. - Fusca, rinereovaria, abdomine clavato, pedibus budiis. femoribus. tibiis tarsorumene articulis singulis adversus apirem nigris. alis anguslis aequaliter nigro-fuscis. - Long. corp. 3 lin. long. al $22_{3}^{2} \mathrm{lin}$.

Capul nigro-fuscuns. opacum; faries polline allon levissime aspersa. antico tamen oris margine polline confertiore sublulesconte vestilo: pili mystacini prope oris marginem perpauci, albi; occipul cum „enis confertim albo-pollinosum pilisque albis birtum. Antemas el proboscis nigrae; palpi rufo-badii. pilis exalbidis inslructi. Thuraris dorsum nudum, opacum, fuscum, villis ordinariis male delerminalis nigro-fuseis. maculi utringue baterali maculisque pluribus grope mar. 
ginem posticum sitis polline albo laete cinereis. Pleurae, melanotum et scutellum albo-pollinosa, basi tamen hujus fuscâ. Abdomen clavatum, nudum, subopacum, nigro-fuscum, segmentorum singulorum margine postico angustissime angulisque posticis latius albido-pollinosis. Coxae nigro-fuscae, polline albido cinereae. Pedes ex rufo badii, femoribus adversus apicem superne, tibiarum apice toto tarsorumque arliculis singulis praeter basim nigris. Pili et setae pedum rariores, albicantes, in tibiarum posticarum apice et in tarsis ex parte fuscescentes. Alae angustae,aequaliter nigro-fuscae. - (Texas; Belfrage.)

36. Thereua melanoneura, nov. sp. ठ․-Nigra, albo-pollinosa, pilisque albis vestila, primis duobus antennarum articulis superne, fronte lateribusque faciei nigro-pilosis, thoracis dorso praeter albos pilis nigris instructo, alis hyalinis, stigmate tamen venisque omnibus tolis nigris. - Long. corp. $3 \frac{1}{3}$ lin. - long. al. $2 \frac{2}{3}$ lin.

Psilocephalae variegalae Lw. similis. Nigra, polline albo adspersa pilisque albis vestita. Vertex, frons et latera faciei nigropilosa; facies, genae et occiput confertim albo-pilosa. Antennae nigrae; articuli duo primi polline minus conferto cinerei, supernc nigro-pilosi, infra albo-villosi selisque aliquot nigris instructi. Thoracis vittae dorsales lalissimae, polline rariore quam interstitia vestitae, nigro-cinereae. Pili in thoracis dorso ex parte nigri, setae ordinariae omnes nigrae. Abdomen polline confertissimo candido ornatum pilisque candidis vestitum, segmento secundo postice anguste, duobus sequentibus anguslissime albo-marginatis. Venter concolor, polline tamen minus candido segmentorumque secundi sequentiumque marginibus posticis latius exalbidis. Pedes nigri, tibiis praeter apicem tarsorumque basi ex luteo rufis; femora albo-villosa; setulae pedum omnes nigrae. Halteres nigri, pedunculo subfusco. Alae hyalinae, stigmate venisque omnibus usque ad imam alarum basim nigris. venulis transversis colore nigro peranguste limbatis, cellulâ posteriore quartâ in ipso alarum margine clausà vel angustissime apertâ. - (Califoruia; H. Edwards.)

Nota. Mas, quem supra descripsi, anteriorem venae tertiae ramulum in utràque alà simili modo, atque in Hrematopotis observatur, appendiculatum habet.

37. Thereua fucata, nov. sp. ot el + . - Thoracis villae dorsales nigrae et nitidae, viltarum interstitia ochraceo-pollinosa; segmenlorum abdominalium singulorum apex, venter tolus pedesque colore ex luteo in badium vergente tincti; alae praeter limbum co- 
stalem fuscum fasciis tribus arcuatis nigro-fuscis ornatae. - Iong. corp. 4 lin., long. al. $3 \frac{1}{6}$ lin.

Caput nigrum, polline ochraceo, in facie dilutiore et in occipitis dimidio inferiore in cinereum vergente obtectum; callus frontalis foeminae ater, nitidus, cordatus, utrinque frontis marginem attingens et superne ad ocellos usque pertinens. Pili capitis ochracei, in fronte foeminae fere omnes, in fronte maris prope oculos nigri: setae occipitis nigrae. Antennae mediocres, ex melleo subliadiar. articulo tamen tertio praeter imam basim nigro; articuli duo primi pilis setisque nigris hirli; articulus primus cylindricus, non incrassatus, tertio subaequalis. Thoracis dorsum nigrum, nitidum. nigropilosum, vittarum tamen interstitis marginibusque lateralibus polline ochraceo confertim obtectis, his et antico dorsi margine ochracen. pilosis. Sculellum ochraceo-pollinosum et pilis ochraceis aspersum. Setae ordinariae thoracis et scutelli nigrae. Pleurae polline altescente cinereae, pallide pilosae. Abdomen foeminae nigrum. nitidum. sesmentis singulis, primo ultimoque exceptis, postice fascia obsure luteả, latera versus dilatałâ marginatis. Abdomen maris fasciis similibus, sed latioribus pictum, adversus apicem tolum obscure luleum. Venter utriusque sexus luteus. Coxae nigrac, polline exalbido cinerascentes, pilis pallidis selisque nigris hirtae. Pedes ex lutro sulbbadii, tarsis adversus apicem nigris; femora postica maris superne nigra, anteriora prope basim nigro-liturata. Hallerum pedunculus luteus, capitulum nigro-fuscum. Alae subhyalinac. costâ fusco-marginatâ, venulis transversis venarumque longiludinaliun apicilus colore nigro-fusco late limbatis, ita ut fasciae tres inaequales. arcuatae ol antice abbreviatae appareant; stigma ni.ro.fuscum; cellula posterior quarta clausa. - (California; H. Edwards.)

38. Xestomyza planiceps, nov. sp. R. - Nigricans. cineren. pollinosa, opaca, tibiis larsomumque basi huescentibus. alarum rosta rolore nigricante, venulis transversis colore nigm limbulis. - 1.ong. corp. 5 lin., long. al. $3 \frac{1}{2}$ lin.

Nigricans, cinereo-pollinosa, opaca. ('apul comcolor. depressum. infra alho-pollinosum et pilis alhis veslitum. Frons lala. plana. antice modice prominens, nigro-pilosa; oceipul selulis nigris piliscyue albidis instructum. Antennae nigrae: articulus pritums inlindricus. elongalus, modice crassus, selis pilisque plerisque nigris, pilis religuis albicantibus hirtus; articulus secundus miunlus. globosus. nigro-setosulus; articulus terlius perbrevis, conicus, slylo terminali crasso el obluso praedilus. Thoracis durum el sculellum pilis Inngiurihus 
setisque tenuibus nigris ef pilis hrevioribus pallidis vestifa; pleurae albido-pilosae. Abdomen breviler nigro-pilosum. segmento tamen primo fere toto segmentorumque secundi et tertii laterilus pallide pilosulis: margo posticus segmenli abdominalis secundi albus; segmentum octarum polline destitutum. atrum et nitidum. Venter totus cinereo-pollinosus el opacus. segmentorum singulorum margine postico lutescente: pili in ventris dimidio anteriore albidi, in po. steriore nigri. Pedes nigri, tibiis practer apicem tarsorumque basi lutescentibus. Hallerum pedunculus luteus, capilulum nigro-fuscum. Alac subbyalinac, venis nigris, Iransversalibus omnibus anguste nigrolimbalis, costâ colore fusco-nigro latius limbalì; stịma nigrum: cellula posterior quarta late aperta: cellula posterior prima venula fransversali advenliciâ in parles duas dividilur, quarum prior alterius longitudinem excedil: prope ultra hane venulam e venâ longitudi. nali terliâ ramnlus hrevis in cellulam posteriorem primam demiltitur; lic ramulus et vena adventicia ipsa similiter ac venae transversales ordinariac colore nigro adumbrantur; num hac venulae adventiciac in omnibus $\boldsymbol{X}$ estomyzae planicipilis speciminibus adsint ex unico specimine non liquet. - (California; H. Edwards.)

39. Aphoebantus cervinus, nov. sp. ㅇ. - Superne tomento cervino. infra albo vestitus: alae cinereo-hyalinue, cellula subcostali inde a cellulae submarginalis primae basi subfusca. - Long. corp. $3 \frac{2}{3}$ lin., long. al. $3 \frac{1}{2}$ lin.

Caput magnum. globosum. Frons modice lata. adversus verticem angustior, nigro-pilosa. Facies albo-pilosa. Antennae breves. nigrae, arliculis duobus primis superne breviter nigro-pilosis, articulo tertio e basi globosâ subito attenualo el stylum brevem aculumque ferente. Thoracis dorsum ef sculcllum tomento cervino conferlim vestila; sctae dorsi nigrae. laterales tamen ante alas cervinac; margo denudatus scutelli niger, selis numerosis nigris instructus. Plcurae albopollinosae et candido-tomentosac. Abdomen tomento conferto cer. vino obtectum, segmento tamen primo pilis erectis pallidioribus hirtum; segmenta reliqua pilis nigris parce aspersa, in margine postico singulorum longioribus el minus raris. Venter albo-tomentosus. Femora nigra. tomento albo, apicem versus per luteum in cervinum mutalo vestita; tibiae anteriores luteae, posticae subfuscae, omnes cervino-tomentosae; tarsi fusci. primis anteriorum arliculis practer apicem luteis; femora infra et tibiae undique setis rarioribus, lutcis vel fuscis instrucla; apex metatarsi postici setâ pro portione longâ armatus. Halleres dilute lulesconles. Alae longae, modice latac. 
cinereo-hyalinae, celluli subcostali inde a cellulate submarginalis primae basi ad apicem usque subfuscà; venae nigrae: vena transversalis media in cellulam discoidalem mediam inserta; prope cellulae posterioris tertiae basim appendicula brevis in cellulam discoidalem excurrit. - (Texas; Belirage.)

Nola. Aphoebantus, novum Bombylidarum genus, ab Argyra. moebis Mespero Rss., Letoi Wied. similibusque. quibuscum corporis figurà et vestitu congruit, tertio antennarum articulo stylum brevem et aculum gerente diserepat; vena longitndinalis secunda lertiam Bombylinorum more prope basim emitlit, non ledta longius a bani secundam, ut in Anthrecinis esse solet; renula transversalis media a cellulate discoidalis basi longius romola est quam in Argyramobeb, cum quibus cellulâ submarginali secundî appendiculatâ pulvillisque distinctis convenit.

40. Leplochilus modestus, nov. sp. of et 오. - Niger, albopilosus, tibiis luteis; tomentum corporis maxima ex parte album, in disco thoracis et in sculello revimum. in abdomine nigro-, revino. el albo-variegalum; alae hyalinae. - Long. corp. 3-3 $3 \frac{2}{3}$ lin., long. al. $2 \frac{2}{3}-3$ lin.

Niger, opacus. Caput concolor, margine tamen oris nitente. exalbido vel lutescente. Oculi maris ante ocellos contigui; vertex nigro-pilosus; frontis pars antica magna, convexa, albo-pilosa. Frons foeminae lata, pilis nigris, ad:ersus antenuas albis instrucla; fomentum fronlis album, adversus verticem in cervinum vergens. Anlennae latius inler se distantes, breves, nigrae; articuli duo primi albo-pilosi. tertius e basi bulbilormi subilo attenuatus et stylo brevi aculisimorque instruelus. Facies modice projecta, albo-pilosil pilis ori prosimis plerumeque saturatius tinctis, in foemina non raro ferrugincis vel fuseis, interdum nigris. Proboscis nigra, palpis concoloribus. Thoracis tomentum album, in disco dorsi et in seulello rervinum: pili thoracis albi, in thoracis dorso praeter marginem anlicum magni ex parte fusci, vel fusco-nigri; selae dorsi pleraeque luleae. Sintellum lumidum, margine oblusissimo, atro et nitido, in appice sentelli valde impresso. Abdomen maris pilis longroribus albis, foeminate brevioribus vestitum, segmenli ultimi margine pustico in mare praeterea pilis longis fusco nigris instructo; tomentum abdominis in foeminâ nigro-, cervino- et albo-varium, in mare minus conspicuum et praeter segmentorum sinsulorum margines posticos, ubi album est, fere totum nigrum fuisse videlur. Ilypopygium maris subtumidum, clausum, albo-pilosum. Femora nigra; tibiae luteae vel ex 
luteo lestaceac: tarsi fusci. adrersus basim luteo-testacei. Femorum tibiarumque setae rarae. sordide luteae. Hallerum pedunculus pallidus. capilulum superne nigro-fuscum. Alae pure hyalinae. venis fusco-nigris. - (Texas: Belfrage.)

Nota. Leplochilus ab Aphoebanto, cui corporis formà proximus. distinguifur facie adrersus oris marginem magis prominente. aperturâ oris multo longiore, proboscide elongatà labellis tenuibus instructâ. cellulà submarginali secundà non appendiculatà et pulvillis omnino nullis. Diversam scutelli formam nolam polius speciei quam generis esse suspicor. Anlcnuarum situs ef figura alarumque vonac, appen. diculà cellulae submarginalis secundae exceptà. in ambobus generibus uon differunt.

41. Bombylius semirufus. nor. sp. ol el f. - Ater. atro. pilosus, pedibus, halteribus tegulisque concoloribus, abdominis lale. ribus inde a segmenti secundi margine laterali medio, apice inde a segmenti quindi limbo postico rufo-pilosis; alae cinereo-hyalinae. basi atria. - Loug. corp. $4 \frac{3}{4}-5$ lin., long. al. $5 \frac{1}{3}-5 \frac{1}{3} \operatorname{lin}$.

Bombylio haemorroico Lw. similis et affinis. Ater, antennis. proboscide, pedibus. halleribus. legulis alarumque cinerco-hyalinarum hasi concoloribus. Pili rapitis el thoracis atri. breves. Scutellum fusco-nigrum. atro-pilosum. Abdomen atro-pilosum. lateribus tamen inde a segmento secundo medio el disco iude a segmenti quinti limbo postico confertim rufo-pilosis; viltula media abdominis tomento raro rufo aspersa. in mare valde obsoleta. in speciminibus detritis omnino nulla. Color abdominis, uhi pilis rufis instructum est, in sordide latericium abit. - (Hayti: P. R. Uhler.)

42. Bombylius albicapillus. nov. sp. $\delta$ el 8 . - Aler. oparus, tertio antennarum articulo adversus busim dilatato. occipite pilis longiusculis albis instructo. veliquo corpore pilis albis. subfuscis et nigris restito; pedes testacei, femoribus anlicis adversus basim. reliquis infra nigris; alae cinereo-hyalinae, triente anlico maculisgue septem nigris, - Long corp. $33_{6}^{5}-4$ lin.. long. al. $4 \frac{2}{3}-5$ lin.

Bombylio fraterculo Wied, aflinis. picturâ alarum Bombylio pygmaeo Fbr. similis. Aler, opacus. Oculi maris contigui, foeminae late remoti. Frons tomento ex luteo subfusco pilisque nigris instructa. Antennae nigrae, articulis duobus primis longe nigro-pilosis, terlii dimidio basali modice dilatato. Facies conica, nigro-pilosa, pilis tamen prope oris aperturam fere omnibus subfuscis. Proboscis nigra. Horace el abdomine simul sumtis paulo brevior. Mentum 
albo-pilosum. Occipitis dimidium superius pilis longiusculis. in mare candidis, in foemina exalbidis confertim vestilum. Pili in thoracis dorso dilute lutescentes certo lumine albi, ante alas el in thoracis angulis posticis vere candidi apparent; inter humeros et alas villa. super alas fasciculus pilorum nigrorum conspiciunlur: practerea in posteriore thoracis dimidio et in scutello prarler pilos dilute lute. scentes pili aliquot longiores nigri exstant. Pleurarum el pectoris pili albidi. Tomentum abdominis subfuscum; pili longions in ss. gmentorum singulorum margine postico nigri, in angulis posticis segmentorum terlii quartique el in abdominis apice multo confertiores: latera segmentorum primi cum angulis anticis secundi el quinti cum angulis anticis sexti albo-pilosa; reliqui abdominis pili lutescentes. in medio abdomine in subfuscum vergentes. certo lumine albo-micantes. Pedes testacei; femora nigro-pilosa, antica in dimidio priore. reliqua infra nigra. Halteres nigri. Tegulae nigro-marginatae el albido-eiliatae. Alae cinereo-hyalinae. triente antico el maculis septem nigris. - (Califoruia; H. Edwards.)

43. Sparnopolius brevicornis, nov. sp. ‥ - Totus niger. luteo-pilosus et tomento subfulvo vestilus, fronte, duobus primis antennarum articulis segmentorumque abdominalium ultimorum marginilus posticis nigro-pilosis. farie opacâ. - Long. corp. $2 \frac{1}{2}$ lin.. long. al. $2 \frac{1}{2}$ lin.

Tofus niger, opacus, pilis luteis et tomento subfulvo vestitus. Caput concolor. Antennae nigrae, quam Sparnopoli fulvi Wied. breviores crassioresque, articulis duobus primis pilis longis nigris confertim hirtis, articulo tertio breviler lanceolato. Facies polline cincrascente leviter aspersa, opaca, practer pilos paucos luteos mar. ginum lateralium omnino nuda. Proboscis cum palpis nigra. Se. gimenlorum abdounalium trium vel qualuor, raro luorum ultimorum margines postici pilis longioribus validioribusque nigris obsiti. IIalteres dilute lutei. Alae cinereo-hyalinae, venis fuscis, prope hasim lutescentibus, auxiliari tota lutescente. - (Texas; Belfrage.)

44. Ploas atratula. nov. sp. f. - Nigra. corpore loto praeter scutellum nitidum opaco, alis nigris adversus marginem po.

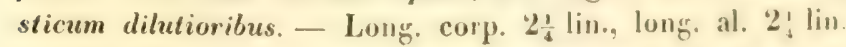

Parva, nigra, opaca, ventre concolure, pilis longioribus nigris brevioribusque exalbidis vestita. Pili frontis el antennarum omnes nigri. Scutellum atrum nitidum, apice non impresso. Pedes toti nigri. Hatteres lutei, capitulo infra subinfuscallo. Alac nigrac, ad. 
versus apicem et marginem posticum dilutiores; cellulae submarginales Ires, ut in Ploadibus plerisque. - (California; H. Edwards.)

45. Ploas nigripennis, nov. sp. +. - Nigra, abdomine tamen praeter basim el vittam e maculis triangulis segmentorum singulorum compositam laevigato et nitido, halleribus luteis, alis nigris adversus marginem posticum dilutioribus. - Long. corp. $4 \frac{3}{4}$ $-4 \frac{5}{6}$ lin., long. al. $4 \frac{1}{3}-4 \frac{5}{1} \frac{5}{2}$ lin.

Nigra, opaca, pilis nigris et dilute flavescente-cinereis vestila. Sculellum opacum, apice vix levissime impresso, in detrilâ nitido. Primum abiominis segmenfum totum opacum; in segmento secundo utrinque macula lsansversalis laevigata et nitida, margini postico contigna conspicitur; in segmentis sequentibus hae maculae valde dilatantur, ita ut nihil opacum sit nisi segmentorum singulorum limbus anlicus, in medio abdomine in maculam magnam triangularem dilatatus. Venter cinereus et cinereo-pilosus. Pedes toti nigri. Halteres lutei, capitulo infra fusco. Alae nigrae, adversus apicem et marginem posticum dilutiores; cellulae submarginales tres. - (Cali. fornia; H. Edwards.)

46. Ploas obesula, nov. sp. ơ et ㅇ. - Nigra, opaca, abdomine adversus apicem nigro-viridi et nitido, halteribus nigris, alis nigris adversus marginem posticum dilutioribus. - Long. corp. $3 \frac{3}{4}$ $-4 \frac{1}{6}$ lin., long. al. $3 \frac{7}{\frac{7}{2}}-3 \frac{3}{4}$ lin.

Nigra, opaca. Abdomen adversus apicem nigro-viride, et nitidum; in speciminibus detritis interdum basis sola vel segmenta duo prima reliquorumque singulorum basis et macula media triangula opaca sunt, ita ut suspicer in speciminibus illaesis fortasse abdomen totum polline alro aspersum et opacum esse. Antennae nigrae, articulo primo valde incrassato, nigro-piloso; caput reliquum pilis longis nigris vestitum, superiore lamen occipitis dimidio, praeler pilos nigros in posticâ oculorum orbitâ, pilis luteis vel fulvescentibus instructo. Thoracis dorsum luteo-vel fulvescenle-pilosum, margine tamen laterali pleurisque nigro-pilosis. Abdomen superne pilis lutescentibus, in margine laterali et in ventre nigro pilis longis nigris hirtum. Pedes toti nigri, eoxis confertius, femoribus parcius nigropilosis. Alae nigrae, adversus apicem et marginem posticum dilutiores; cellulae submarginales tres. - (California; H. Edwards.)

47. Phthiria egerminans, nov. sp. б. - Ex luteo fusca, opaca, thoracis villis abdomineque nigris, hujus segmentorum singulorum margine postico luleo; alae maculis nigris, parvis et deformibus 
variegatae, venis longitudinalibus quarti el quintî prope marginem alae furcatis. - Long. corp. $2 \frac{5}{12}-2 \frac{1}{2}$ lin.. long. al. $2 \frac{7}{1} \frac{7}{2}$ lin.

Color corporis niger polline conferlo in luteo-fuscum mutatur. Pili totius corporis albidi. vix dilute lutescentes, in facie, fronte el vertice subrufestentes. Caput lutesceus, triangulo ocellari. frontis dimidio antico occipitisque disco nigricanlibus; anlennar nigrae. articulo tertio lato et superne pilosulo. Proboscis nigra: palpi tenues concolores. Thoracis vitlae dorsales latae, nigrae. opacac, mmmes anlice modice abbreviatae, intermedia linể tenui subluscả divisa et postice eximie abbreviata. Abdomen nigrum, opacum, segnentis singulis postice anguste et acqualiter luteo-marginatis. Pedes ex luteo subfusci, femoribus maximâ ex parte, tibiarum apice larsisque totis nigris. Halteres albidi. Alae hyalinae, totae maculis parvis deformibus nigro-fuscis variegatae; venae praeter basim alarum, ubi pallescunt, nigrae; vena longitudinalis secunda leviter undulala. venae tertiae ramulus anterior prope basim appeadice recurrente instructus; venae longiludinales quarta et quinta prope marginrm alae furcatae, interjectâ tamen venâ intercalari simplici; vena. ưuì cellula discoidalis a cellulà posteriore quartâ distinguilur, venulam appendiciam in illam emittit. - (California; II. Edwards.)

48. Allocotus Edwardsii, nov. sp. q. - Niger, abdomine macularum albarum serie ornato, pedibus fuscis, alis hyalinis. Long. corp. 3 lin., long. al. '2 $\frac{5}{5}$ lin.

Niger, nitens. Caput totum concolor; occipul albo-pollinosum; frous praeter trientem anticum et verticem polline exalbido aspersa et pilis brevibus nigricantibus inslructa; in facie ulrinque macula minuta candido-pollinosa. Thoracis dorsum subopacum; villae tres obscuriores, latae, iutegrae, obsoletissime cinereo-pollinosae; vittarum inlerstitia angusta, confertim albo-pollinosa; margo laleralis dori polline conferto candido obtectus et pube candidi vestilus: pleurac nudae, vitidae, vittà candido-polliuosá ornatae. Scutellum basim versus albo-pollinosum, adversus apicem polline destitutum et nitens. Abdomen nigrum, nitidum, pilis nigris, mire brevibus instructum. ila ut nudum appareat; segnentum primum in margine postico maculam transversam albam, in angulis lateralibus pollen randidum pilosque tenues candidos gerit; margo posticus segmenti secundi arl. versus latera abdominis tenuiler albo-limbatus et in medio abdomine maculà triangulari albâ ornafus; piẹtura allua segmentorum reliquorum fere eadem, sed ita ut in segmento singnulo quod sefuitur macula minor et limbus tenuior sint, quam in segmento priore; seguentum 
septimum immaculatum, obsoletissime albido-pollinosum. Venter totus niger. Pedes fusci, larsis apicem versus nigris. Halleres nigri, pedunculo fusco. Alae hyalinae, venis nigris, stigmate nullo. (California; H. Edwards.)

Nota. Novum Bombylidarum genus, cui Allocoti nomen im. posui, a reliquis Bombylidarum generibus notis bis distinguitur.

Corpus cylindricum, nudum. Caput sphaericum, fronte tamen prominente. Autennae breves, approximatae; articulus tertius duobus primis simul sumtis aequalis, apice oblique truncalo, stylo plane obsoleto. Oculi permagni; ocelli tres minuti. Oris apertura perlonga, usque ad antennarum basim pertinens; genae lineares. Proboscis in oris aperturam inclusa, marginem anticum paulo superans. Alarum venae similiter atque in Sparnopolio ductae, apice tamen venae longitudinalis secundae magis recurvo, cellulâ submarginali secundå cellularumque posteriorum secundâ et tertiâ longioribus, venulà denique transversali mediâ a cellulae discoidalis basi longius remotâ. Pulvilli distincti; ungues simplices.

49. Spilomyia longicornis, nov. sp. ot et ㅇ․ - Nigra, maculis vittulisque thoracis, scutelli margine abdominisgue fasciis

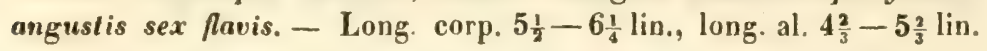

Spilomyiae salluum Fbr. simillima, Nigra, flavo-varia. Oculi maris contigui; trianguli verticalis dimidium superius nigrum, inferius flavum; frons flava, maculâ triangulari nigrâ supra antennas. Frons foeminae flava, vittà adversus verticem attenualâ et vertice ipso nigris. Antennae nigro-fuscae, saepe ex parte, raro totae rufo. piceae, articulis duobus primis quam Spilomyiae saltuum longioribus, setå luteâ. Facies utriusque sexus flava, vittâ mediâ et utrinque strigulà ab oculis oblique ad peristomium ductâ nigris. Thoracis dorsum in margine antico maculas quatuor, in dimidio posteriore vittulas duas hamatas, inde ab angulis posticis usque ad suturam pertinentes et prope marginem posticum lituras vel strigulas duas obliquas, inversam literae $\mathrm{V}$ formam efficientes, colore flavo pictas gerit. In pleuris praeter humerum et callum subalarem maculae quinae flavae conspiciuntur, quam in Spilomyia saltuum majores, ita ut tres inter halteres et coxas intermedias sitae in fasciam obliquam coalescant. Margo scutelli flavus. Abdominis segmenta secundum, tertium et quartum fasciis binis angustis flavis, per marginem lateralem flavum inter se conjunctis ornanlur, quarum anterior in segmento secundo latera versus modice dilatatur, anteriores in segmentis tertio et quarto colore nigro angustissime interrumpuntur. 
Hypopygium maris flavum; segmentum abdominale quintum foeminae nigrum. Pedes flavi, anticorum tibiis praeter basim tarsisque totis nigris, femoribus posticis colore subfusco lituratis, tarsis posterioribus libiarumque posticarum apice ochraceis. Alae subhyalinae, in dimidio anteriore fusco-lituratae. - (Massachusetts, Osten-Sacken; Pennsylvania, Sabborn; Texas, Belfrage.)

50. Brachypalpus frontosus, nov. sp. ot et 우 - Niger, albido-vel dilutissime lutescente-pilosus, thoracis dorso et sculello aenescentibus, fernorum apice tibiarumque basi luteis, femoribus posticis incrassalis, tibiis posticis valde incurvis, in mare infra dente armatis. - Long. corp. 5-6 lin., long. al. $4 \frac{2}{3}-5 \frac{1}{6}$ lin.

Niger, nitidus, pilis albidis vel dilutissime lutescentibus vestitus. Oculi maris breviter contigui. Frons maris tota albido-vel sublutescente-pollinosa, foeminae lata, fasciâ mediâ inaequali et subobsolelâ albido-pollinoså. Antennae nigro-fuscae, articulis duobus primis iıterdum rufo-piceis, setâ luteâ. Facies valde concava, peristımio modice producto, faciei Plocotae apicatae Meig. non dissiuilis. utrinque fasciis binis albido-pollinosis, superiore subhorizontali. inferiore ad peristomiun oblique demissâ. Thoracis dorsum et scutellum nigro-aenea, illud vittis cupreo-purpurascentibus, intermediâ duplici, lateralibus antice valde abbreviatis subobsolete pictum. Abdomen nigrum vel scoriaceo-nigrum, nitidum, pube omni pallidâ. Perles nigri, extremo femorum apice tibiarumque basi flavescentibus: tibiae intermediae saepe subfuscae vel rufo-testaceae, basi tameu navâ et annulo subapicali nigro semper exceptis; tarsi anteriores adversus basim plerumque picei vel rufo-picei. Femora poslica incrassata, maris quam foeminae crassiores; tibiae posticae incurvae. maris infra dente armatae, foeminae muticae. Halteres dilute favicantes; tegulae exalbidae. Alae cinereo-hyalinae, adversus apicem distinctius cinereae; veuae luteae, prope apicem et marginem posticum fuscae, transversales fusco-limbatae; stigma luteum et apex cellulae costalis subfuscus. - (District Columbia; Osteu-Sacken.)

51. Brachypalpus cyanogaster, nov. sp. ㅇ. - Nigev, albo-pilosus, abdomine violaceo, peristomio mive producto. - Long. corp. $5 \frac{1}{3}$ lin., long. al. $5 \frac{1}{6}$ lin.

Niger nitidus, albo-pilosus. Caput concolor, fronte modice pro. minente et peristomio mire producto. Antennae fusco-nigrae, articulis duobus primis longiusculis, tertio obliquo. Thoracis dorsum et scutellum aeneo-nigra. Abdomen quam in Brachypalpis plerisque 
latius et brevius, laete violaceum, albo-pilosum, segmento tamen tertio praeter margines laterales nigro-piloso et segmenti quarti disco praeter pilos albos pilis brevioribus nigris vestito. Pedes toti nigri et albo-pilosi; femora postica valida, sed non incrassata, prope apicem infra subexcisa et setulis rigidis nigris instructa. Halterum pedunculus fuscus, capitulum dilute flavicans; tegulae albae. Alae cinereohyalinae, adversus apicem saturatius cinereae, cellulâ costali apicem versus et stigmate toto dilute infuscatis, venis fusco-nigris, transversalibus tenuiter fusco-limbatis. - (Pennsylvania; Auxer.)

Nota. Speciem hanc, corporis formâ ac figurâ inter Criorrhinas et Brachypalpos quasi intermediam, propter femorum posticorum fabricam Brachypalporım generi inserui; facie infra mire productâ. ita ut Chilosiae personatae Lw. similis sit, ab utroque genere distingui et genus novum constituere potest.

52. Myiolepta nigra, nov. sp. ㅇ,-- Nigra, nitida, pube albâ vestila, tarsorum posteriorum arliculis tribus primis sordide lutescentibus, alis infuscatis. - Iong. corp. $3 \frac{1}{3}$ lin., long. al. 3 lin.

Nigra, nitida, tota albo-pubescens. Frons utrinque maculâ albido-pollinosâ notata. Antennae fusco-nigrae. Facies concava, peristomio valde producto, nitida, fasciâ superâ, marginibus lateralibus et utrinque vittulâ oblique ad peristomium demissâ albo-pollinosis. Margo anticus thoracis polline albo aspersus. Pedes nigri; articuli Ires primi tarsorum posteriorum sordide lutescentes vel sordide albidi, posteriorum tamen colore saturatiore et adversus basim tarsorum in subfuscum vergente picti. Halteres dilute flavescentes; tegulae albae. Alae infuscatae, adversus marginem posticum cinereae, basim versus hyalinae. - (Pennsylvania; Auxer.)

53. Myiolepta aerea, nov. sp. ․ - Viridi-aenea, nitens, margine antico frontis, tertio anntennarum articulo fere toto, tibiarum basi et apice extremo, tarsis denique praeter articulos duos ultimos rufis, alis lutescentibus. - Long. corp $3 \frac{1}{1} \frac{1}{2}$ lin., long. al. $3 \frac{1}{2}$ lin.

Viridi-aenea, nitens, pube brevi flavescente vestita. Frons utrinque maculâ albo-pollinosâ notata et supra antennas rufo-marginala. Duo primi antennarum articuli nigro-fusci, articulus tertius quam in Myioleptis nigrâ et varipede major, vere rotundus, sordide rufus, adversus marginem superum late fuscescit; seta antennarum lulea. Facies concava, praeter vittulas albido-pollinosas, ab oculorum margine antico ad peristomium modice productum oblique demissas tola nitida. Margo anticus thoracis polline albo leviler aspersus. 
Apex extremus femorum, tibiarum triens basalis ef summus apex cum tribus primis tarsorum omnium articulis rufi. Halteres dilute flavicantes; tegulae albidae. Alae sublutescentes, stigmate venisque luteis, his prope apicem et prope marginem posticum fuscis. (Illinois; Le Baron.)

54. Myiolepta strigilata, nov. sp. o et $9 .-$ Ex nigro aenescens, modice nitens, lota pilis brevibus rigidis appressis albidis vestita, antennis, tibiis tarsorum anticorum basi tarsisque posticis praeter articulos duos ullimos rufo-ferrugineis, terlio antennarum articulo ovato, - Long. corp. $2 \frac{6}{6}-3 \frac{1}{2}$ lin., long. al. $2 \frac{3}{T^{3}}-3 \frac{1}{3}$ lin.

Nigro-aenea, modice nitens, pilis brevibus rigidis appressis albis vestita. Vertex maris ater, nitidus; frons et facies polline dilute lutescente confertissime vestitae, maculâ tameu lunatâ supra antennas. tuberculo faciei genisque atris et nitidis; dimidium inferius faciei utrinque maculâ permagnâ luteâ pictum. Frons et facies foeminae atrae et nitidae, haec in dimidio inferiore utrinque maculå obliquà luteâ picta; bae maculae et fascia bisinuata infra antennas sita albido- vel sublutescente-pollinosae; reliqua facies non pollinosa. Antennae ex ferrugineo rufae, adversus basim saturatius tinctae, articulo terlio ovato et setâ concolore instructo. Venter polline albido cinereus et breviter albo-pilosus. Femora nigra, extremo tantum apice rufu-luteo; tibiae ex ferrugineo rufae, adversus basim magis in luteum vergenies, anticae adversus apicem nigricantes, posticae in medio fuscae; tarsi antici nigri, adversus basin rufi, postici rufi, duobus ultimis articulis nigris. Alae dilutissime lutescentes, sed apicem versus cinereae et fascià mediâ obsoletius cinerascente utrinque abbreviatâ notatae. - (Texas; Belfrage.)

55. Helophilus polygrammus, nov. sp. ․ - Niger, capite pedibusque fere totis concoloribus, thoracis dorso cinerascente, lineis longitudinalibus atris ornato, abdominis segmentis secundo, tertio et quarto singulis semifasciis angustis albis, in illo mediocriter, in his valde arcuntis ornato. - Long. corp. $4 \frac{1}{2}$ lin., long. al. 4 lin.

Niger, praeler frontem maximà ex parte nigro-pilosam pilis dilute lutescentibus vestitus. Capul concolor, polline dilute cinerascente, in facie confertiore aspersum, vilti tamen mediả hujus polline omnino destilutâ, atrâ et nitidà. Thoracis dorsum modice nilens, cinerascens, lineis longitudinalibus octo nigris variegatum; lineae intermediae aequales, parallelae, postice valde abbreviatae; proximac utrinque deliquescentes; sequentes antice abbreviatae, adversus sulu. 
ram dilatatae et suturâ ipsâ inlerruptae; extremae obliquae, inde a postico thoracis margine prope ad suturam ductae. Scutellum lutescens, adversus basim nigrum. Abdomen nigrum, lateribus segmenti secundi flavis: segmentum primum cinerascens; segmenta tria sequentia semifasciis angustis albo-pollinosis, in segmento secundo modice, in tertio et quarto valde arcuatis ornata. Pedes nigri, genibus omnibus tibiarumque anteriorum basi testaceis, tibiarum posticarum dimidio basali badio. Halteres albidi. Alae hyalinae, levifer tantun cinerascentes, stigmate nullo.

(California; H. Edwards.)

56. Microdon baliopterus, nov. sp. $\sigma^{7}$ et 우. - Ex speciebus, quae corpore tenui antennisque brevibus excellunt, fusco-aeneus, modice nitens; fronte, thorace el scutello cupreo-micantibus, abdo. minis colore ex aeneo subviresrenle, latera versus in cupreum vergente; antennis pedibusque testaceis, tertio illarum articulo femorumque dimidio basuli fere lolis nigro-fuscis; alis hyalinis, venis plerisque colore fusco-nigro latissime circumfusis. - Long. corp. $3 \frac{3}{4}$ $-4 \frac{1}{2}$ lin., long. al. $3-3 \frac{1}{3}$ lin.

Microdontibus coarctato (Cent. V. 47) et laeto (Cent. V. 46) affinis, ex fusco aeneus, modice nitens. Frons cupreo-resplendens, pube dilute flavescente vestila; facies et occiput albo-pubescentia. Oculi subnudi. Antennae breves, saturate testaceae; articulus tertius duobus primis simul sumtis paulo brevior, praeter basim fusco-niger. Thorax cupreo-micans, vittis purpurascentibus dorsi subopacis; pubes dorsi subaurea, pleurarum alba. Scutellum cupreo-micans et subaureo-pubescens. Color abdominis ex aeneo subvirescens, adversus margines laterales in mare obsoletius, in foeminâ distinctius in cupreum vergens; margo apicalis segmenti ultimi in mare plerumque luteus. Abdomen subareo-pubescens, lateribus tamen adversus segnentorum singulorum basim pube albâ, apicem versus pube nigrâ irstructis. Pedes saturate testacei vel ex fusco rufi, femorum dimidio basali semper magnà ex parte fusco-nigro, tarsis interdum fuscis. Alae cinereo-hyalinae, venulis transversalibus venarumque anastomosibus colore fusco-nigro latissime circumfusis. (Texas; Belfrage.)

57. Ceria tridens, nov. sp. §־. - Nigra, favo-varia, vittis nigris faciei tribus, intermediâ integrâ. lateralibus abbreviatis, pedunculo antennas ferente elongato, costali alarum dimidio fusco. Long. corp. $4 \frac{1}{2}$ lin., long. al. $3 \frac{2}{3}$ lin. 
Ceriae abbreviatae (Cent. V. 48) persimilis, nigra, subopaca. Occiput cum vertice nigrum, posticâ tamen oculorum orbitâ prope verticem maculis duabus flavis ornatâ. Frons flava, vittâ nigrâ. Facies flava; praeter lineam Iransversalem tenuissimam genae, vilta media latiuscula et utrinque vittula abbreviata, ab antennarum basi oblique demissa nigrae sunt. Antennae nigrae, pedunculo elongato fusco, adversus basim luteo insidentes. Thorax niger, punctatus, humeris, utrinque macula laterali et lineolâ, pleurarum de. nique maculâ trilobà favis. Scutellum flavum, basi nigrå. Abdomeu cylindricum, praeter posticos segmentorum margines subtiliter scrobiculatum, nigrum; segmenta duo prima quam in Ceriâ abbreviatá longiora, duo ultima breviora, ila ut abdominis formâ ac figurâ ad Ceriam vespiformem et similes propius quam ad Ceriam abbreviatam accedal; latera segmenti primi flava; segmenta reliqua postice flavofasciala, fascia segmenti secundi latera versus modice latiore, segmenti quarti in medio abdomine eximie dilatatâ; practerea in segmento quarto semifasciae duae Iunatae, polline luteo aspersae conspiciuntur. Hypopygium nigrum. Femora anteriora nigra, basi latius flavâ, apice angustius luteo; femora postica flava, annulo sub. apicali latissimo nigro; libiae luteae, posticae prope apicem nigrolituralae; tarsi anteriores lutei, articulis intermediis nigro-fuscis, tarsi postici toti nigro-fusci. Alae hyalinae, dimidio costali adversus basim dilutius, arlversus apicem saturatius fusco. - California; H. Edwards.)

Nola 1. Diagnosi Ceriae abbreviatae Cent. V. 48, ut facilius a Ceriâ tridente distinguatur, addere velis: ,vittâ nigrâ faciei simplice et angustä".

Nota 2. Ceriae abbrevialae specimen masculum e Floridà allatum in thoracis dorso utrinque supra alarum basim lineolam flavam, qualem Ceria tridens geril, breviorem tamen et minus distinctam habet.

58. Pipunculus subvirescens, nov. sp. б. - Niger nitidus, thoracis dorso abdomineque subvirescentibus, puncto humerali, halleribus, genibus tarsorumyue basi pallidis, alarum hyalinarum venâ longitudinali secundà brevi, stigmale nullo. - Long. corp. $1 \frac{1}{3}$ lin., loug. al. $1 \frac{7}{\frac{7}{2}}$ lin.

Capnt nigrum, fronte et facie candido-pollinosis; antennae nigrae, articulo tertio longe acumiuato et apicem versus candido-micante. Thorax niger, dorso subvirescente et nitido, puncto humerali pallido et margine Interali iude ab humeris usque ad alas anguste, sed con. 
fertim albo-pollinoso. Scutellum atrum, nitidissimum, valde convexum. Abdomen ex nigro subvirescens, modice nitens, hypopygio magno nigro. Pedes nigri, extremo femorum apice tibiarumque basi dilute lutesceutibus, tarsis sordide luteis, adversus apicem nigris. Halteres dilute lutei, pedunculo tamen fusco. Alae hyalinae, vix levissime cinerascentes, stigmate nullo; venae tenues nigrae, longitudiualis secunda perbrevis, transversalis media aequali intervallo a cellulae discoidalis basi et apice separata. - (Texas; Belfrage.)

59. Pipunculus fasciatus, nov. sp. ठ઼. - Opacus, niger, halteribus antennisque concoloribus, tertio harum arliculo obtuso, segmentis abdominalibus singulis postice cinereo-fascialis, genibus luteis, alis cinereis, stigmate fusco, venula transversali mediâ a cellulae discoidalis apice longius quam a basi remotâ. - Long. corp. $1 \frac{2}{3}$ lin., long. al. $1 \frac{1}{1} \frac{1}{2}$ lin.

Niger, opacus. Caput concolor, fronte et facie leviter albidopollinosis, orbitis posticis late polline albo aspersis; antennae nigrae. articulo terlio brevi et obtuso. Thoracis dorsum polline ex fusco cinereo opacum; scutellum minus pollinosum et subnitidum, fortasse detrilum; pleurae et metanotum albido-pollinosa. Segmentorum abdominalium singulorum basis atra et opaca; reliqua segnenti primi pars confertius alho-pollinosa, segmentorum reliquorum polline cinerascente, adversus latera abdominis albicante leviter aspersa ef minus opaca. Hypopygium mediocre, nigrum. Pedes nigri, extremo femorum apice tibiarumque basi luteis vel ex rufo luteis. Halteres toti nigri. Alae cinereae, basim versus purius hyalinae, stigmate fusco; venae nigrae, transversalis media a cellulae discoidalis apice latius quam a basi remota. - (Texas; Belfrage.)

60. Drapetis unipila, nov. sp. $\%$. - Atra, nitida, tibiis tarsisque magnâ ex parte fuscis vel badiis; thoracis dorsum pilis aliquot longioribus nigris aspersum; tibiae posticae in triente primo pilo longiore instructae. - Long. corp. $\frac{1}{1} \frac{1}{2}-1$ lin., long. al. $1 \frac{1}{6}-1 \frac{1}{3}$ lin.

Atra, nitidissima. Antennae concolores, articulo tertio brevi et ovato. Palpi fusco-nigri. Thoracis dorsum breviter cinereo-pilosulum pilisque aliquot longioribus nigris aspersum. Abdomen atrum, segmento secundo praeter marginem apicalem saepe et basi segmenli tertii interdum sordide albidis. Trochanteres ex rufo badii. Femora praeter apicen rufescente-badium atra, antica adversus basim valde incrassata, postica tota modice crassa, intermedia non incrassala; femora omuia infra in imà basi pilo unico instructa, postica tamen 
tenuiore et difficilius conspicuo; praeterea femora antica ufrinque, femora intermedia tantum antice pilum subapicalem, femora postica vero in latere anteriore pilos duos longos. alterum subapicalem, alterum ab apice paulo longius remolum gerunt; libiae anteriores praeter basin rufo-badian plerumque saturate fuscae setulisque apicalibus instructae, posticae badiae vel rufo-badiae, superne practer basiun et apicem saepe fuscae et ibi pilo longo, multo latius ab apice quam a basi remoto armalae; apex tibiarum posticarum dilalatus, ita ut tarsus nou in apice ipso, sed paulo ante extremum tibiae apicem insertus sit. Tarsi anteriores nigro-fusci, adversus basim saepe rufo-badii, postici rufo-badii; articulo ultimo semper nigro-fusco, tribus praecedentibus interdum fuscis. Halteres albidi. Alae byalinae. venis ex luteo dilute subfuscis; venae longitudinales prima et secunda modice et aequaliter arcualac, tertia paulo ante apicem alae in costam excurreus, tota levissime undata et adversus apicem levilir incurva, quarta leviter undata et tertiae subparallela; cellula basalis posterior anteriore multo longior. - (Texas; Belfrage.)

61. Drapetis gilvipes, nov. sp. Ј.- Atra, nitida, palpis, coxis perlibusque luteis; thoracis dorsum prater latera et marginem posticum pilis longioribus nullis aspersum; alue cinereae, venis fuscis, longitudinalibus primâ el secunda levissime arcuatis, terliâ subrertá et adversus apicem cum quartá parallelâ. - Long. corp. $\frac{2}{3}$ lin., long. al. $\frac{3}{4}$ lin.

Atra, nitidissima. Antennae concolores, quam in specie prae. cedente breviores; articulus tertius bevis et rotundato-ovatus; seta perlonga. Palpi sordide lutescentes. Thoracis dorsum pube brevi nigricante vestitum, praeter latera et marginem poslicum pilis longioribus nigris nullis instructum. Pleurae polline omnino nullo adspersae, nitidissimae. Abdomen alrum et nitidum. segmentis secundo, tertio et quarto in specimine descripto sordide exalbidis, postico tamen singulorum margine atro; in speciminibus maturioribus forsitan abdomen fotum atrum. Pedes cum coxis saturate lutei, melatarso postico larsorumque onnium apice luscis vel fusco-nigris. Femora intermedia validiuscula sed non incrassata, femora reliqua modice et aequaliter incrassata. Tibiac anteriores setulis apicalihus armatae; tibiarum posticarum apex simplex. Halteres exalbidi. Alae cinereae, venis saturate fuscis; venae longiludiuales prima et secumia fantum levissime arcuatae, lertia subrecta et paulo aute extremum apicem alac in costam excurrens, quarta tertiae subparallela, non undata, triente tamen apicali segmenti ultimi levissime recurvo: cellula basalis posterior anteriore longior. - (Texas; Belfrage.) 
62. Drapetis divergens, nov. sp. ơ et ㅇ. - Atra, nitida, verlice thoracisque dorso pube albá confertius vestitis, palpis albidis. pedibus luteis, tarsis tamen infuscatis; alae hyalinae, venis longitudinalibus primâ subrectâ, secundâ valde arcual $\hat{a}$, lertiâ et quartî valde divergentibus, illa leviler flexâ et longe ante apicem in costam excurrente, hac levissime recurvâ et marginem paulo pone apicem attingente. - Long. corp. $\frac{1}{2}-\frac{9}{5}$ lin., long. al. $\frac{2}{3}$ lin.

Atra, nitida. Antennae breves, nigrae, articulis duobus primis semper minus nigris, plerumque fuscis. in speciminibus minus maturis saepe subfuscis vel rufis. Palpi modice lati, albidi. Pubes et pili verticis albicantes. Thoracis dorsum pube brevi el subappressâ albâ confertius vestitum et supra alas pilis aliquot dilute lutescentibus. lumine transmisso nigricantibus praedilum. Abdomen atrum et nitidum, in speciminibus minus maturis adversus basim exalbidum, postico tamen margine segmentorum singulorum semper atro. Coxae anticae totae, posteriores practer basim luteae. Pedes lutei, tarsis fere totis fuscis vel subfuscis; femora postica intermediis et antica posticis crassiora, omnia pilis longioribus destiluta praeter intermediorum pilum subapicalem; tibiarum anteriorum setulac apicales nullae; apex tibiarum posticarum simplex. Halteres albidi. Alae hyalinae, venis adversus basim lutescentibus, adversus apicem sub. fuscis vel fuscis; rena longitudinalis prima tantum adversus finem leviter recurva, secunda valde arcuata, ita ut secundum costae segmentum tertio brevius sit; vena longitudinalis tertia leviter flexa, priore scilicet dimidio magis recurvo quam apicali, ita ut longe ante extremum apicem alae angulo satis acuto cum costâ conjuncta sit; venae longitudinales tertia et quarta apicem versus valde divergentes; cellula basalis posterior anteriore multo longior. - (Texas; Belfrage.)

63. Paraclius pumilio, nov. sp. $\sigma^{7}$ et 우. Viridis, nitens, set $\hat{a}$ antennarum subnudâ: pedes nigri, trocharleribus, tibiis anterioribus totis posticarumque dimidio basali superne, tarsorum denique anteriorum basi pallide flavicantibus; alae cinereo-hyalinae, segmento primo costae non incrassato. - Long. corp. $1 \frac{1}{4}-1 \frac{1}{3}$ lin., long. al. $1-1 \frac{1}{6} \operatorname{lin}$.

Viridis, nitens. Frons cinereo-pollinosa, obsoletissime aenescens. Antennae nigrae, setâ concolore subnudà. Facies maris adversus os valde angusla, exalbido-pollinosa; facies foeminae paulo latior et polline magis cinerascente oblecta; cilia oculorum inferiora alba. Thoracis dorsum saepe ex viridi subaenescens, utrinque in suturae 
initio laterali maculâ confertim candido-pollinosâ ornatum. Pleurą nigrae, albo-pollinosae. Hypopygium maris valde elongalum, nigrum: lamellae mediocres, ovatae, pallidac, adversus apicem late fusconigrae, margine pilis paucis nigris ciliato. Coxae nigrae, anticae in apice sordide pallescentes, albo-pollinosae et nigro-pilosae. Trocluanteres cum imă femorum posticorum basi pallide flavicantes, fere exalbidi; femora nigra; tibiae anteriores totae pallide flavescentes. posticae nigrae, dimidio basali superne pallido; tarsi antici inde ab articuli primi apice, intermedii jam ab arliculi hujus dimidio et postici toti nigri. Halteres et tegulac albicantes, cilia harum nigra. Alae cinereo-hyalinae. veuis nigris; apex cellulae posterioris primae eximie angustatus; primum costae segmentum non incrassatum. ('Texas; Belfrage.)

64. Pelastoneurus furcifer, nov. sp. ठ - Obscure viridis, thoracis dorso nigricante et postice plerumgue violareo resplendente: antennae sordide rufae, articulo tertio adversus apicem nigro; cilia oculorum inferiora nigra; coxae anticae, apex coxarum posteriorum et pedes flavesrentes; alae nigricantes; lamellae externae hypopygii furalae, nigrae. - Long. corp. 2 lin., long. al, 2 lin.

Frons fusco-pollinosa, vertice marginibusque lateralibus polline destitutis violaceis. Antennae sordide rufae, articulo terlio adversus apicem late fusco-nigro. Facies pro portione lata, maris vix an. gustior quan foeminae, polline fusco, adversus latera et superne albido aspersa. Cilia inferiora oculorum nigra. Thoracis dorsum ex viridi nigrum vel nigro-caesium, in parte posticâ plerumque violacco-resplendens et adversus angulos posticos aenescens vel cupreo-micans. Abdomen obscure viride. Hypopygium maris valide elongalum, nigrum; lamellae externae magnae, furcatae. nigrae. parte externâ breviore, latiore et pilis longioribus validioribusque nigris ciliałâ, parte internâ longiore et lineari; lamellae internae parvae, tenues. fuscae, in apice pilis longis ramulosis instructae. Halteres et tegulae flavicantes, ciliis harum nigris. Alae nigri. cantes. - (Texas; Belfrage.)

65. Hydrophorus cerutias, nov. sp. J. - I.aele viridis antennarum elongatarum arliculus terlius infra dente valido instructus; alae cinereo-hyalinae. - Long. corp. 2 lin., long at. 2 lin.

Caput nigrum, occipitis dimidio inferjore pilis confertis luteis vestito. Antennac nigrae, quam in congeneribus multo longiores; articulus tertius elongatus, in dimidio apicali infra excisus, ila ut 
ante hanc incisuram dente valido instructus sit; sela antennarum terminalis, brevis, nigra, apice tamen subtilissimo albicante. Thoracis dorsum praeter partem posticam polline dilute subfusco leviter aspersum, obscurius viride et minus nitens. Postica dorsi pars, scutellum et abdomen laetissime viridia et splendidissima. Pubes abdominis albida. Pedes nigri, femoribus viridi-micantibus. Alae cinereo-hyalinae, inmaculalae, venis nigro-fuscis, in basi alarum partim ex luteo subfuscis. - (Texas; Belfrage.)

66. Gymnosoma filiola, nov. sp. ర大 el ․․ - Gymnosomae rotundat ae L. simillima, sed minor, antennis paulo brevioribus abdomineque purius rufo diversa. - Long. corp. 2 lin., long. al. $1 \frac{2}{3}$ lin.

Quam Gymnosoma rotundata L. minor; anlennae paulo breviores, fusco-nigrae, articulo tertio adversus basim latius rufo; abdomen lolum purius rufum; anguli laterales verticis in mare, margines laterales frontis toti in foeminâ nigri et nitidi. Maculae nigrae abdominis in foeminå semper majores quan in mare sunt; valde dilatatas, quales in Gymnosomae rolundatae foeminâ saepe observan. tur, numquam vidi. Reliqua in utrâque specie plane congrua. (Texas; Belfrage.)

67. Blepharopeza adusta, nov. sp. ठ․ - Nigra, antennis pedibusque concoloribus, thoracis marginibus lateralibus et postico, scutello abdominisque lateribus rufis; alae cinereo-hyalinae, basi tamen curn alula et legulis nigrâ. - Long. corp. $4 \frac{1}{3}-5$ lin., long. al. $4 \frac{1}{2}-4 \frac{1}{1} \frac{1}{2}$ lin.

Nigra. Caput concolor, albo-pollinosum, facie ex parte sordidissime albicante, fronte adversus verticem polline rariore aspersâ et plerumque sordide rufescente; vitta frontalis pro portione angusta, fusca vel ferruginea; palpi luridi vel sordide rufescentes. Thoracis dorsum leviter albo-pollinosum, lineis quinque subobsoletis nigris piclum, humeris, marginibus lateralibus et maculâ bilobâ ante scutellum sitâ rufis, margine postico interdum toto rufo. Pleurae nigrae, in speciminibus immaturis superne fere totae rufae, in maturis fere tolae nigrae. Scutellum rufum. Abdominis segmentum primum tolum nigrum; segmenta reliqua singula utrinque maculâ permagnâ rufâ ornata. Pedes toti nigri, tibiis posterioribus in nuper exclusis praeter apicem et basim fuscis. Tegulae nigrae. Alae cinereo-hyalinae, basi el alulâ nigris. - (California; H. Edwards.)

Nota. I arvae Blepharopezae aduslae in erucis Spilosomae aerene viventes observatae sunt. 
68. Homalomyia femorata Lw. O. - Nigra, pedibus concoloribus, thorace et scutello leviler cinereo-pruinosis, abdomine depresso praeter basim, vittum mediam segmentorumque prenullimi et antepaenultimi maculas binas albo-pollinoso; femora postira adver. sus apicem incrassala ibique pilis aliquot longissimis instructa; alue hyalinae, venis transversis valde approximalis. - Long. corp. $2 \mathrm{lin.}$. long. al. $1 \frac{3}{4}$ lin.

Syn. Homalomyia femorata L w. Wien. ent. Monatschr. V. 42. Is.

Oculi fronte lineari nigrâ. subtilissime albo-marginatâ stparati Facies tenuiter albo-pollinosa, selà myslacinà utrinque unicâ mediocri armata; orbitae angustae, candido-micantes. Antennae nigrae. articulo secundo selulam validiorem gerente, articulo terlio oblongo et marginem oris prope attingente. Thorax et scutellum polline albo-cinereo leviter aspersa, subopaca, non vittala. Abdominis segmentum primum valde abbreviatum et segmentum secundum nigra, angulis tamen posticis hujus albido-pollinosis; segmenta reliqua confertius albido-pollinosa, vittâ mediâ maculisque segmenti tertii et quarti binis magis nigris. Pedes toti nigri; femora postica subincurva, ante apicem modice iucrassata ibique in latere inferiore pilis quinque vel sex longissimis instructa; tibiae intermediae simplices infra subtiliter pubescentes, practer setas apicales et selan praeapicalem setis omnino destiturae; tibiae posticae in latere anteriore pilis longis nigris cilialae. Tegulae albidae, inferior superiore major. Alae hyalinae, leviter cincrascentes, venis tertiâ quarlâque adversus apicem levissime couvergentibus, ita ut ultimum venae quartae segmentum quadruplicem paenullimi longitudincm ferme attingat. - (Cuba; Gundlach.)

69. Homalomyia tetracantha, nov. sp. ot. - Nigra. abdomine convexiusculo confertim cinereo-pollinoso el vilta angusti atrá ornato, tibiis omnibus ex fusco-rufis. alis subfuscis: pectus pone coxas anticas spinis duabus rectis instructum et coxte intermediae spind validiore aduncâ armatae. - Long. corp. $2 \frac{7}{\frac{7}{2}}$ lin., long. al. $2 \frac{1}{2} \operatorname{lin}$

Nigra. Oculi fronte angustâ atrît, ulrinque tenuiter albo-marginatà separati. Antennae nigrae, articulo secundo setuli validiore instructo, articulo tertio oblongo. Facies cinerea. orbitis albo-micantibus. Thoracis dorsum nitidum. polline subfusco aspersum. sed laterali margine lalissime albo-pollimoso. Scutellum cinereo-pollino. sum, disci tamen polline in subfuscum vergente. Pectus pilis perbrevibus instructum. pone coxas anticas spinis duabus colongatis 
rectis armatum. Abdomen quam in congeneribus plerisque minus depressum, confertion cinereo-pollinosum et viltâ angustâ nigrå ornatum. Hypopygium pro portione magnum. Cosae piceo-nigrae, inlermediae spinâ aduncâ armalae. Femora piceo-nigra vel picea, apice extremo dilutius tinclo; femora intermedia valida, in triente apicali sensim attenuata, infra setis prope basim raris, apicem versus confertioribus brevioribusque instructa. Tibiae ex fusco rufae vel testaceae, anticae reliquis semper fusciores, intermediae simplices, triente apicali vix obsoletissime incrassato, infra pube brevissimâ, in triente apicali paulo longiore vestitae. Tarsi nigri, simplices. Tegulae lutescentes, inferior superiore major. Halteres dilute flavescentes. Alae subfuscae, basi luteâ; venae longitudinales tertia et quarta adversus apicem modice convergentes; venae transversales latius inter se distantes, ita ut segmentum ultimum quartae duplicem paenultimi longitudinem non aequiparet. - (Middle States; Osten-Sacken.)

Nota. Homalomyia lelracantha, Homalomyiis apricae Hal., insigni Lw. et obesae $\mathbf{L}$ w. propter pectoris coxarumque intermediaruın spinas affinis est; ab Homalomyiä obesâ, cui simillima, vix differt, nisi fronte angustiore et colore dilutiore pedum.

70. Coenosia nivea, nov. sp. Ђ. - Nivea, antennis proeter basim nigricantem, palpis pedibusque pallide favicantibus, abdomine immaculato. - Long. corp. $1 \frac{1}{4}$ lin, long. al. $1 \frac{1}{6}$ lin.

Color capitis et thoracis nigricans, sed tomento confertissimo niveo obtectus. Abdomen ovatum, album, adversus apicem nigricans, totum niveo-pollinosum, immaculatum. Anfennae dilutissime lutescenles, adversus imam basim nigricantes, mediocres, setâ tenui, breviter pubescente vel subnudâ, adversus basim paulo validiore. Palpi dilutissime flavescentes. Pedes pallide flavescentes, tenues, tarsis gracilibus, adversus apicem subinfuscalis, articulo terminali nigro-fusco, pulvillis majusculis. Tegulae albae. Alae cinereo-hyalinae. - (Pennsylvania; Osten-Sacken.)

71. Coenosia calopyga, nov. sp. $\sigma^{7}$ - Albido-cinerea, antennis totis, palpis pedibusque dilute flavis, abdomine ovalo, adversus basim albicante et subpellucido, praeter villam et macularum solitarum series in segmentis terlio et quarto utrinque maculâ permagná piceo-nigrâ ornato. - Long. corp. 1 $\frac{5}{1}$ lin., long. al. $1 \frac{1}{4}$ lin.

Color capitis nigricans polline albo in albido-cinereum mulatur; orbita prope autenuas plerumque flavescit, margo anticus frontis in- 
terdum. Facies candida. Antenuae totae dilute flavae, mediocres, paulo tamen quam Coenosine nicene longiores; seta tenuis, adversus imam basim modice incrassata, pilosa; palpi dilute flavescentes. Color thoracis et scutelli nigricans polline albido obtegitur, ita ut in albido-cincreum abeat; pictura in lhoracis dorso uulla. Abdomen valde convexum, breviter ovatum, adversus basim subpellucidum et exalbidum, adversus apicem ex fusco nigricat, sed polline albo albido-cinereum redditur; ima abdominis basis et vilfula media usque ad marginem posticum segmenti tertii pertinens fuscae vel subfuscae sunt; in segmentis tribus ultimis maculae binae fuscae. in segmento secundo dilutiores, in quarto nitidae conspiciunlur; segmenta tertium el quartum praeterea ulrinque maculà nitidissimà nigro-piceâ, margini autico appositâ oruantur. Pedes dilute flavicantes. Tegulac albae; alae hyalinae. - (Pennsylvania; Osten. Sacken.)

72. Coenosia modesta, nov. sp. ō. - Parva, pallidissime favescens, antennis totis, palpis pedibusque concoloribus, thoracis villâ latissimâ antire abbreviatâ, scutello et melanoto cinereis, segmentis abdominalibus praeter primum fusco-bipunctalis. - Long. corp. $1 \frac{1}{6}$ lin., long. al. $1 \frac{1}{\frac{1}{2}}$ lin.

Pallidissime flavescens. Caput concolor, vittà frontali lactius flavâ et occipilis dimidio superiore cinerascente. Sela mystacina utrinque unica nigra; in oris margine laterali pili nigri nulli. Thoracis dorsum vitłà latissimâ nigricante, polline albo aspersả et antice modice abbreviatâ ornatur. Eodem colore sculellum praeter marginem et metanotum tincla sunt. Abdominis segmenta quartum et terlium punctis binis nigro-fuscis notantur; in segnento secundo puncta duo dilutius fusca, saepe valde obsoleta conspiciuntur. Pedes toti dilute flavescentes. Tegulae albidae; alae hyalinae. venis dilute lutescentibus. - (Washington; Osten-Sacken.)

73. Schoenomyza dorsalis, nov, sp. ot et ․․ - Schoenomyzae argyrostomae Cent. IX. \$6. simillima, sed pasto major et pictura thoracis distinctiore diversa.

5. anterius frontis dimidium niveum, superne prencto aterrimo, utrinque in lineam atram excurrente excisum: facies tola fulva.

․ anterius frontis dimidium albirans: facies tota pallide fatvescers.

Long. corp. 1:-1! lin.. long. al. $1 \frac{1}{6}-1 \frac{1}{3}$ lin.

Cinerea. Dimidinm superius frontis in mare fuscum, dimidium 
inferius niveum et superne puncto triangulari aterrimo excisum, quod utrinque in lineam aterrimam, colorem fuscum a niveo distinguentem dilatatur. Foeminae frons fusca, vel ex cinereo fusca, adversus marginem anlicum albicans. Facies maris aureo-fulva, foeminae pallide flavescens. Thoracis dorsum lineis inaequalibus fuscis variegatum. In reliquis notis Schoenom. chrysostomae et litorellae valde similis. - (District Columbia; Osten-Sacken.)

Nota. Schoenomyzae genus variarum familiarum ostendit nolas, unde aegerrime dicatur, cui earum adjicienda sit, quum, in quacunque ponas, natura aliena satis facile cognoscatur. Mihi ipsi nondum contigisse, ut cerlum ei locum tribuerem, non diffiteor. Nunc Anthomyidarum familiam praetuli, quia suspicor in eâ potius quam in aliâ ullâ Schoenomyzas quaesitum iri.

74. Cordylura viltipes, nov. sp. б. - Nigra, villá frontali primisque duobus antennarum articulis subrufis, harum articulo tertio lrevi, fusco-nigro, selâ. breviter plumata instructo, pedibus flavis. femoribus tamen superne nigris. - Long. corp. $2 \frac{7}{12}$ lin., long. al $2-2 \frac{1}{1} \frac{1}{2}$ lin.

Nigra, polline exalbido leviter aspersa, modice nitens. Caput flavescens, occipite praeter marginem inferum, triangulo ocellari orbitisque frontalibus nigris, vittâ fronlali rufâ. Primus antennarum articulus ex rufo fuscus, secundus ex rufo luteus, tertius fusco-niger, brevis, apice rolundato. Seta mystacina utrinque unica perlonga, sed tenuis; praeterea seta altera mystacinae aequalis, sed tenuior in margine laterali oris. Palpi pallide flavescentes vel exalbidi. Selac capitis nigrae; pubes in occipitis dimidio inferiore pallida. Thoracis dorsum non vittatum, setis longis pilisque raris nigris instructum. Setae abdominis nigrae, pili in segmentis primis pallidi, in posticis nigri. Alae colore ex fusco cinereo dilutissime tinctae, venis longitudinalibus tertiâ et quartâ adversus apicem parallelis, ultimo quartae segmento subrecto. Coxae flavescentes, intermediae tamen adversus basim et posticae maximà ex parte nigrae. Pedes flavescen. tes, femoribus omnibus supcrne nigris vel fusco-nigris; femora antica infra pallide-pilosa, adversus apicem pilis quatuor validioribus nigris instructa. - (Sitka; Kolenati, Sahlberg.)

75. Cordylura lutea, nov. sp. ․ - Tola sordide lutea, arliculo tertio antennarum brevi praeter basim el antennarum setâ phumatâ nigris, incisuris abdominis nigricantibus, setis scutelli duabus, mystacinâ ulrinque unicâ. - Long. corp. $2 \frac{3}{4}$ lin., long. al. $2 \frac{1}{2}$ lin. 
Sordide lutea vel subtestacea, polline exalbido leviter aspersa. opaca. Frons modice lata, concolor vel colore purius luteo tincta. orbilis angustissinis confertius exalbillo-pollinosis, selis lateralibns longis, sed tenuibus. Primi duo antennarum articuli lutei, secundus setulâ longâ instructus, articulus fertius practer basim luteam niger, brevis, apice rofundato: sela antennarum nigra, conferlim ni. gro-plumala, adversus apicem nuda. Sela mystacina utrinque unica et setula unica brevior in margine laterali oris. Thoracis dorsum non vitlatum. Setae scutelli duae. Abdominis incisurae nigricantes; terebra exserta nigro-fusca, infrá tamen adversus basim lute. scens. Pedes toti sordide lutei, setis longis nigris inslructi; frmora antica infra non spinosa, sed setas quinque vel sex tenues ferentia. Alae tołae sordide lulescentes, venis luteo-fuscis, longitudinalibus lertià quartâque apicem versus parallelis, ultimo quartae segmento subrecto. - (Sitka; Kolenati.)

76. Cordylura fulvibarba, nov. sp. б. - Nigricans. sed confertim luteo-pollinosa, opaca, pedibus totis luteis, mento pilis perlongis fulvis barbato et hypopygio utrinque fassiculum pilornm ful. vescentium perlongum gerente. venâ lonġitudinali serundâ prope api. cem breviter appendiculata. - Long. corp. $3 \frac{1}{2}$ lin. long. al. $3 \frac{1}{6}$ lin.

Cordylurae hirco Zelt. simillima, sed alarum cellulâ posteriore primâ inlegrâ femorumque anteriorum fabricâ dislincta. Nigricans, sed polline luteo, in thorace confertiore quan in abdomine aspersa. ita ut ille vere opacus, hoc subopacum sit. Caput lutenm; occiput, excepto margine infero, nigricans, polline lulescente vestitum: frons modice lata, vitta tamen latissima, rufa; triangulum ocellare obscurum, exalbido-pollinosum; orbilae fronlales angustac, superius obscurae, totae exalbido-pollinosae. Antennarum articulus primus-fuscus. secundus dilute lutescens; articulum tertium, qui in specimine descripto deest. oblongum et setâ nudâ. ut in Cordylurà hirro Zelt.. instructum esse conjectare audeo. Setae mystacinae utrinque sub. terne, longitudine descrescentes, adjectis pilis minoribus. Palpi spatulati, pallide lutescentes, subtiliter albido-pilosuli. Mentum pilis longissimis, demissis, fulvis confertissime harbalum. Thoracis dorsum non vitlafum. Setae sculelli quatuor. Abdomen pallide pilo. sum, segmentis lamen ultimis alversus marginem posticum el hypopygio toto nigro-setulosis; hypopygii pars infera utringue fasciculo conferto pilorum fulvescontium perlongo el sursum direclo inslructa. Coxae anticae luteae, imâ tanlum basi nigricanle, posteriores nigrae et luleo-pollinosae. Pedes loti lutei; femora antica incrassala. sed 
simplicia, infra non excisa et praeter trientem ultimum confertissime et subaequaliter nigro - spinulosa; tibiae anticae modice incurvae, praeter basim infra breviter nigro-spinulosae; femora intermedia simplicia, dimidio priore infra non exciso, apice infra nigro-setoso et imâ basi infra setam pallidam gerente; pedes postici toti simplices. Alarum pars postica et apex cinerascentes, venis nigro-fuscis; pars antica praeter apicem dilutissime lulescens, venis luteis; venae ut iil Cordylurâ hirco Zett. duclae et vena longitudinalis secunda, ut in illâ, appendiculam brevissimam prope apicem emittens, sed venae transversales extraordinariae, quibus cellula posterior prima in mare Cordylurae hirci Zett. in tres partes dividitur, in Cordylurae fulvibarbae mare nullae. - (Hudsons-Bay Territory, For't Resolution; Kennicot.)

77. Cordylura capillata, nov. sp. ․․ - Tola fusco-nigra, modice nitens, oculis valde convexis, setis laterulibus frontis perlongis et in latera vergentibus, antennarum nigrarum articulo terminali rotundato - ovato et setấ validâ nudâ instructo, libiis anticis subincurvis et infra spinulâ apicali evectâ armatis, alis suturate cinereis, nigro-venosis. - Long. corp. $2 \frac{1}{2}$ lin., long. al. $2 \frac{3}{4}-2 \frac{5}{6} \mathrm{lin}$.

Cordylurae glaucescenti Lw. simillima, sed colore corporis minus glauco abdomineque pilis nigris longioribus rigidioribusque vestito diversa. Tota fusco.nigra, modice nitens, polline dilutissime cinereo, fere exalbido leviter aspersa, dorsi marginibus lateralibus et vittà mediâ obsoletissimâ, scutello, plenris denique et metanoto paulo confertius pollinosis. Oculi valde couvexi. Frons lata; vitla frontalis nigro-fusca, antice dilutior, prope antennas plerumque lu. tescens; orbitae frontales latae, setis longis nigris, in latera directis instructa. Antennae breviusculae, tolae nigrae, arliculo terminali rotundato ovato, setâ concolore validâ, sed apicem versus valde attenuatâ. Setae mystacinae tenues. Palpi mediocres, fusci, adversus basim lutescentes. Thoracis dorsum praeter setas ordinarias fere nudum. Setae scutelli quatuor. Abdomen pilis nigris, quam in speciebus proxime cognatis longioribus rigidioribusque vestitum. Pedes graciles, selis paucis tenuibusque armati; femora antica modice incrassata, infra praeter pubem longiusculam pallidam setas duas nigras in trieute basali ferentia; tibiae anticae leviter incurvae, apice infra spinulâ erectà armato. Alae saturate cinereae, fere nigro-cinereae, venis omnibus fusco-nigris, longitudinalibus tertiâ et quartâ apicem versus parallelis.

(New Hampshire.) 
78. Blepharoptera discolor, nov. sp. ‥ - Lutea, abdomine nigro, exabido-pollinoso. - Lang. corp. 2 lin., long. al. 22' lin.

Parva, sordide lutea. Frons el antennae rufae, vel ex ochraceo rufae; tertius harum articulus rotundus, adversus basim saepe subfuscus; seta antennalis nuda, nigra. Oculi mediocres, rolundi. Seta mystacina utrinque unica mediocris. Scutellusn practer selas quatuor ordinarias nudum, modice convexum. Pleurat tolae nudae. setâ unicâ armatae. Abdomen tolum nigrum, sed polline albido glaucescens. Pedes dilutius lutei, tarsis omnibus fuscis. vel fusconigris. Alae sublutescentes, venis ex Iuteo fuscis, selulis costae mediocribus et raris. - (New Hampshire.)

Nota. Blepharoptera discolor 우 a Blepharopteri lutea of differt pilis thoracis rarioribus scutelloque breviore et convexiore, ita ut illam hujus foeminam esse suspicari non liceat.

79. Blepharoplera peclinata, nov. sp. $\sigma$ et 9. - Cineven. capile el hypopygio parvo maris huteis, pedibus testaceis, antennu rum articulis duobus primis rufis, lerlio rufo-fusco. vel nigro-fusco. alis cinerascentibus. - Long. corp. $1 \frac{2}{3}-1_{6}^{5}$ lin., long. al $1 \frac{1}{4}-2 \mathrm{lin}$.

Caput luteum, occipitis dimidio superiore cinereo; antennarum articuli duo primi rufi, tertius rufo-fuscus vel nigro-fuscus, setầ con colore; seta mystacina utrinque unica. valde longa; probo-cis fusca; palpi lutei. Thorax cinereus, colore dorsi plerumque ex cinereo modice in lulescentem vergente. Pleurae supra coxas intermedias setâ unica instructae, inter hanc setam et basim alarum pilis paucis brevisoimis nigris et setulâ nigrâ aspersae, infra suturam longitudinalem confertius nigro pilosulae. Scutellum setio quatuor validis armatum, praeterea nudum. Abdomen cinereum, nigro-pilosum, segmentorum secundi, tertii et quarti marginibus posticis anguste. quinti latius luteis vel rufescenti-luteis, raro totum cinereum; hypu. pygium maris parvum, lutescens vel rufescenti-luteum. Pedes a luteo testacei; femora superne fuscescentia. anlica posticanue inlerdum praeter apicem fere tota fusca; tarsi apicen versus fusci, interdum nigri; apex metatarsi antici maris infra dilatatus. Halteres llavicantes. Alae ex luteo cinereae, stigmate lutescente et custi setis pro portione longis pectinati; venae transversales reliquis magis nigrae et plerumque colore nigricante obsolete circumlusac. (Texas; Belfrage.)

80. Sciomyza tenuipes, nov. sp. б. - C'inerea, opaca: caput sordide luteum, frontis villis tribus antice ubbrevialis occipile- 
que cinereis; alae adversus marginem posticum cinerascentes, adversus anticum dilute subfuscae, venis transversis fusco-limbatis. Long. corp. $1_{\frac{7}{2}}^{\frac{7}{2}}-1 \frac{2}{3}$ lin., long. al. $1 \frac{3}{4}-1 \frac{5}{6}$ lin.

Quam species pleraeque gracilior, cinerea, opaca, praeter setas ordinarias nigras breviter nigro-pilosa. Caput sordide luteum, vittis frontis tribus antice modice abbreviatis occipiteque cinereis et opacis. Antennae setâ subnudå instructae, ferrugineae vel ex ferrngineo rufae. articulo primo fusco, tertio plerumque praeler basim infuscato. Palpi rufi, setâ apicali nigrâ instrucli. Thoracis dorsun fusco-bilineatum et pleurae superne late fusco-vitlatae. Segmenta abdominalia singula postice albido-cinerea. Hypopygium minutum. Coxae anticae lutescentes, posteriores saturatius tinctae. Pedes longiores tenuioresque quam in congeneribus plerisque; antici nigri, genibus anguste luteis; posteriores subfusci vel fusco-testacei, femoribus apice excepto fuscis vel fusco-nigris. Alae costam versus dilute subfuscae, adversus marginem poslicum magis cinerascentes; venae fuscae, transversales fusco-limbatae; ultimum venae longitudinalis quartae segmentum saepe appendiculam fusco-limbatam in cellulam posteriorem secundam emiltit. - (Middle Stales; OstenSacken.)

81. Sciomyza trabeculata. nov. sp. О઼. - Cinerea, opaca, capile coxisque anticis lutescentibus, pedibus anticis nigris, posterioribus testaceis. femorum dimidio basali et annulo subapicali, tibiarum apice et duobus ultimis tarsorum articulis nigris; alarum cinereo-hyalinarum cellulae submarginalis, basalis prima. posterior prima et discoidalis fasciolis transversalibus nigris pictue. - Long. corp. $1 \frac{1}{2}$ lin., long. al. $1 \frac{1}{2}-1 \frac{7}{T^{2}}$ lin.

Cinerea, opaca. Frons lutea, antice subnitida et utrinque inter antennam et oculum maculâ minutâ nigrâ notala, superne villis tribus valde abbreviatis polline dilutissine lulescente opacis; facies exalbida; occipitis dimidium supcrius cinereum. Antennae ferrugineae vel ex ferrugineo fuscae, articulo tertio breviter ovato, setâ subnudâ. Proboscis lutea, basim versus nigra; palpi pallidi. Coxae anticae luteae, posteriores saturatius linctae; pedes antici nigri, geniculis extremis testaceis; pedes intermedii ex luteo testacei, femorum basi et annulo subapicali, tibiarum apice duobusque ultimis tarsorum articulis nigris; pedum posticorum pictura fere eadem, sed femorum basis saturatius et multo latius nigra, ita ut femora prae. ter annulum tota nigra sint. Alae cinereo-hyalinae, stigmate et cellulae marginalis dimidio apicali suturatius cinereis, venis nigris; ve- 
nulae tıansversales et appendicula a venâ longiludinali quartâ in cellulam posteriorem secundam demissa colore nigro limbatae; praeterea fasciolac transversae cinereo-nigrae couspiciuntur in cellulà submarginali quinque, in basali primà una, in posteriore primá quatuor et duae in cellulâ discoidali, hae interdum interruplae vel imperfeclae. - (Texas; Belfrage.)

82. Sapromyza macula, nov. sp. $\delta$ et 9 . - Iutescens, opaca, mucula faciei atrâ, thoracis villis dorsalibus quatuor pleurarumgue binis fuscis, pedibus exallidis, tibiis posterioribus annulo subbasali nigro pictis, alis immaculatis. - Long. corp. $1 \frac{3}{4}-1 \frac{1}{2}$ lin.. long. al. $1 \frac{1}{2}$ lin.

Dilute lutescens. opaca. Caput concolor, faciei maculâ rołundà, aterrimâ et opacâ. Antennae luteae, articulo tertio ovato et setâ breviter plumatâ instructo. Thoracis dorsum vittis quatuor angustis sulufuscis vel fuscis pictum, praeter bas villas leviter albido-pollinosum; pleurae fusco-bivitlatae. Scutellum planum, selis quatuor inslructum faciisque duabus ante marginem apicalem coëuntibus subfuscis: interdum plane obsolelis variegatum. In abdomine praeter macularum nigrarum seriem mediam segmenta intermedia adversus littera abdominis nigricant. Hypopygium magnum, dilute lutescens. Pedes exalbidi, libiis posterioribus annulo subbasali nigro. superne plerumque interrupto ornatae. Alae immaculalae. colore ex cinereo lutescente levissime tinctae, venis concoloribus. - (Texas; Belfrage.)

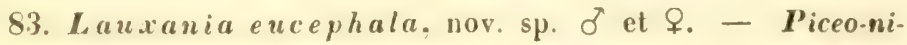
gra, leviter cinereo-pollinosa. abdominis basi semper, thoracis parte postica cum scutello plerumque rufis vel ex luteo rufis; capul luleum, frontis villis tribus antice abbreviatis nigris et faciei maculis sex nigris; antennse luteae, articulo terlio elongato, selâ subnuda. - Long. corp. $1 \frac{5}{6}-2 \frac{1}{12}$ lin., long. al. $1 \frac{1}{1} \frac{1}{2}-2 \frac{1}{2} \frac{1}{2}$ lin.

Reliquis speciebus robustior et magis obesa, piceo-nigra. Caput luteum, maculis lameu occipitis duabus permagnis uigris, in fasciam connatis. Frons nitida, villis tribus nigris antice abbreviatis a verlice demissis, intermediả cunealâ, lateralibus acqualibus. Antennate tolac luteae; articulus tertius quam articuli duo primi simul sumti duplo longior; sela subtilis, subnuda, nigra, in imâ basi lulea. Prope antennas macula parva nigra utrinque oculis adjacet; maculae duae subrotundac nigrae in mediâ facie locum habent et genae maculâ unicâ nigrà pictae sunt. Proboscis fusca; palpi lutei. Thoracis dorsum polline cinerascente aequaliter aspersum adversus 
latera et marginem posticum plerumque rufescit. Scutellum subplanum, raro piceo-nigrum, plerumque rufum vel ex luleo rufum. Abdomen adversus basim semper sordide rufum vel luteo-rufum, non raro fere lotum rufo-luteum. Pedes ex luteo vel ex rufo testacei, tarsis anticis in speciminibus plerisque obscurioribus, femoribus omnibus semper maximâ ex parte nigris. Halteres exalbidi. Alac immaculatae, totae colore dilute lutescente tinctae. - (Texas; Belfrage.)

84. Notiphila pulchrifrons, nov. sp. ð. - Nigricans; frons alra, marginibus lateralibus et triangulo frontali albis, lineâ tamen cuneatâ atrâ huic inscriptâ; thoracis dorsum et abdomen albido-pollinosa, illud nigro-villatum, hoc nigro-fasciatum; pedes nigri, extremo femorum apice, tibiarum basi tarsisque posterioribus rufis. horum apice tarsisque anticis totis vel maximâ ex parte fuscis. - Long. corp. $1 \frac{1}{1} \frac{1}{2}-1 \frac{1}{6}$ lin.. long. al. $1 \frac{1}{3}$ lin.

Parva, nigricans. Frons alra, opaca, utrinque anguste albo. marginata; triangulum frontale acutum, usque ad anticum fronlis marginem perlinens, polline confertissimo exalbido vel dilute subcinerascente obtectum et lineâ longiludinali cuneatâ atrâ pictum. Antennae nigrae, articulo tertio adversus basim late rufo; setae radii circiter decem. Lunula frontalis albo-pollinosa. Thorax polline albido vel albido-cinereo vestitus, vittis dorsalibus nigris vel fusconigris, duabus intermediis usque ad apicem scutelli ductis, sed in scutello fuscis et interdum subobsoletis; pleurae fusco-vittatae. Abdomen albe-pollinosum, fasciis basalibus segmentorum fusco-nigris, latis et interruptis. Pedes nigri, extremo femorum apice, tibiarum basi tarsisque posterioribus luteo-rufis, horum apice fusco; tarsi antici interdum toli nigro-fusci, plerumque superne praeter imam articuli primi basim nigro-fusci et infra praeter articulum ultimum rufi, in speciminibus immaturis articulo terminali excepto fere toti rufi. Alae ex subfusco cinereae, immaculatae. - (Texas; Belfrage.)

85. Drosophila obesa, nov. sp. ठૅ et ㅇ. - Helvola. peclore pedibusque exalbidis, fronte latissimâ praeter setas verticis urinque setis tribus validis armatá; alae cinereae, cellulis costali et marginali subfuscis, venarum longitudinalium secundae tertiaeque apicibus colore fusco-nigro latissime circumfusis et venula transversali posteriore colore fusco-nigro limbatâ. - Long. corp. 2 lin.. long. al. '2 lin.

Magna, obesa, lota helvola, pectoris pedumque colore in exal- 
bidum vergente. Capul latum, concolor, opacum; frons latissima, tola breviter nigro-pilosa et practer setas verticis ulringue selis tribus validis nigris instructa, duabus superis reclinatis, infimà inclinalâ. Tertius antennarum articulus ovatus; seta antenuarum pilis longis superne circiter octo et infra sex plumata. Thoracis dorsum breviler nigro-pilosum, marginibus lateralibus et postico setas validas nigras gerentibus. Plcurarum dimidium superius nudum, inferius pilis minutissimis nigris aspersum selisque duabus validis nigris praeditum. Scutellum magnum, semicirculatum, planum, nudum, setis marginalibus quatuor validis. Hetanotum nitidum. Abdomen subuitidum, breviter nigro-pilosum. Alae latae, saturatius cinereae, cellulis costali et marginali subfuscis; adversus cellulae marginalis el submarginalis finem color alarum in fusco-nigrum sensim mutatur. ila ut ala ibi latissime, sed indelerminate colore fusco-nigro marginata sit; venula transversalis posterior colore fusco-nigro limbata, a venulâ transversali medià longe remota. - (Texas; Belfrage.)

86. Drosophila sigmoides, nov. sp. ․ - Lutea. thoraris villis dorsalibus el pertore in subfuscum vergentibus; alae ex cinereo subfuscae, adversus costam fuscae. extremo cellulae costalis apice, venularum transversalium limbis venarumgue longitudinalium secundae, tertiae et quartae apice extremo atris, venulà transversali

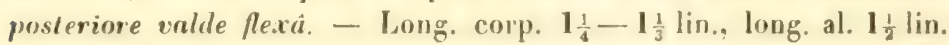

Lutea, thoracis vittis dorsalibus et pectore colore magis in subfuscum, vel in latericium vergente linctis. Pili et setae totius corporis lutescentes vel fuscescentes, transmisso lumine nigricantes. Frons practer setas ordinarias verticis utrinque setis tribus instructa, duabus superis reclinatis, infimå inclinatâ, intermedia minuta. Scutellum planum, longius quam latius, praeter setas quatuor marginales nudum. Abdomen apicem versus plerumque leviter infuscatum, lateribus tamen semper latissime lutescentibus. Alae longae et angustae, ex cinereo subfuscae, adversus costam saturatius fuscae; extremus apex cellulae costalis ater el ima basis cellulae marginalis nigricans; venarum longitudinalium secundae, terliae ef quarlae apices atri et colore nigro angustissime limbati; venae transversales anguste atro-limbitac, late distantes, posterior in formam literae $S$ flexa. - (Texas; Belfrage.)

87. II ippelates pusio, nov. sp. ㅇ. - Aler, nitidus, fronte praeter marginem anticum nigri. triangulo verticali alro et niti. dissimo. abdominis basi ex fusco lutescente; peiles lutei, femoribus 
tamen praeter apicem nigris. - Long. corp. $\frac{2}{3}-\frac{3}{4}$ lin., long. al. $\frac{2}{3}$ lin.

Hippelatae couvexo Lw. simillimus, a quo apice trianguli verticalis acutiore, tibiis posticis totis luteis et calcari pro portione majore instructis distinguilur. Capul nigrum, fronlis margine antico luteo, facie interdum nigro - testaceâ, plerumque nigrâ. Antennae fuscae, infra et adversus basim rufae vel luteae, interdum luteae, supero tantum margine articuli tertii subfusco. Thorax ater el nitidus; scutellum convexiusculum concolor. Abdomen atrum, basi tamen lutescente et margine apicali segmenti ultimi exalbido vel dilute lutescente. Coxae nigrae, extremo apice obsolete rufescente; femora nigra, apice latius luteo; tibiae omnes cum tarsis totis luteae. Halteres albidi. Alae hyalinae. - (Texas; Belfrage.)

Nota. Hippelates pusio variat fronte latâ nigrà femoribusque fere tolis luleis, tantum adversus basim nigricantibus.

88. Hippelates eulophus, nov. sp. $\delta$ et 오. - Sordide luteus, nigro-vuriegatus, selâ antennarum crassisimá alrâ. - Long. corp. $\frac{1}{1} \frac{1}{2}-1$ lin., long. al. 1 lin.

A congeneribus adhuc cognitis setâ antennarum valde incrassatâ diserepans Crassise tam mentitur. Capul luteum: triangulum verticale concolor, vitidum, marginem anticum frontis fere attingens; occiput nigro-bimaculatum. Antennae luleae, externo articnli tertii latere superne nigro-marginato, setâ atrâ, compressâ et confertissime nigro-pubescente. Thoracis dorsum sordide luteum, vittis duabus nigris, postice abbreviatis piclum. Pleurae ex rufo luteae. Scutellum subplanum, luteum. Abdomen maris nigrum, segmenti antepaenultimi lateribus, segmento ultimo toto et hypopygio sordide rufescentibus; abdomen foeminae forlasse immaturae luteum, viltâ medià, segmentorum singulorum margine postico et maculâ utrinque laterali nigris. Pedes lutei; tibiae anticae nigro-fuscae, posticae subfuscae; tarsi antici et postici toti intermediorumque articuli duo ul. timi nigroffusci. Halteres albidi. Alae cinereae, venis validiusculis fuscis. - (Texas; Belfrage.)

Nota. Piclura thoracis valde variabilis esse videlur; vittac dorsales interdum valde latae, interdum angustae et subobsoletae sunt; in uno specimine praeterea lineam mediam nigricantem observavi.

89. Crassiseta e unota, nov. sp. 우. - Sordide lutea, capite favo, antennis, triangulo verticuli occipitisque dimidio superiore 
atris, thoracis dorso nigro-trilineato abdomine, tibiis anticis posticisque et tarsis omnibus fuscis. - Long. corp. $\frac{3}{4}-1$ lin., long. al. $1-1 \frac{1}{12}$ lin.

Capul flavum; triaigulum verlicale latum, frontem mediam paulo transgrediens, atrum et nitidum, angulis tamen superis favis. Antennae cum setà incrassatâ tołae atıae; occiput atrum, infra flavum. Thorax ex rufo luteus, dorso lineis tribus nigris, in margine autico subcobaerentibus picto. Scutellum luteum, breviusculum et convexum, setulis duabus nigris instruclum. Abdomen saturate fu. scum, adversus basim paulo dilutius pictuan. Pedes lutei vel ex rufo lutei; tibiae anticae practer imam basim nigro-fuscae; larsi omnes nigro-fusci. Halteres exalbidi. Alae cinereo-hyalinae, (Tesas; Belfrace.)

90. Opeliophora straminea, nov. sp. 우 - Dilute sulphurea, triangulo verticali concolore, thoracis viltis mufescentibus, intermediae margine antico luteraliumque marginibus externis nigro. fuscis, metanoto, fasciis basalibus segmentorum abdominalium et terebrá subulatâ nigris. - Long. corp. cum terebrà $1_{\frac{1}{1} \frac{1}{2}}$ lin.. long. al. $\frac{1}{1} \frac{1}{2}$ lin.

Pallide sulphurea, opaca. Caput praeter maculam didymam nigram in occipitis disco et practer punctum nigrum ocellos iscludens tolum concolor, formâ ac figurâ Liparae simile. Frous lalis. sima, nigro-pilosula, Iriangulo verticali male delerminato majusculo et concolore, margine antico promineute sed obtusissimo. Antennae breves, articulo tertio mediocri, subrotundo, adversus apicem fusco, setâ pallidâ, tenui, subnudà. Oculi non magni, subrolundi. breviter sed confertissime pilosuli. Facies modice recedens et infra pilis aliquot vigris instructa. Genae lalissimae. Oris apertura pro portione parva; proboscis el palpi dilute flavicantes. Vittac thora. cis latiusculae, rufescentes, margine antico intermediae latius nigro, lateralium marginibus externis angustius nigro-fuscis: strigulae supra alas sitae totae fusco-nigrae. Scutellum convexum, pilis bresibus setulisque apicalibus nigris. Pleurae maculis duabus mediocribus nigris pictae, alterâ mediâ, allerâ supra coxas poslicas silà; praelerea iuter coxas anteriores macula magna mellea observatur. Meta. nolum tolum nigrum et nitidum. Abdominis segmenta secundum. tertium, quartum et quintum singula fascià basali angusti nigrà, latera versus paulum dilatałâ cinguntur; segmentum quintum prarce. denti longius, sextun et septimum brevia. octavum in terebram corneam subulatam atram transmutatum. Tarsi apicem versus fusci. 
Halteres albidi. Alae hyalinae, venis pallidissimis; vena costalis usque ad alae apicem pertinet, ubi cum longiludinali quarlâ connectitur; veuae longitudinales terlia el quarta apicem versus rectae et vere parallelae; venulae transversales non approximatae. - (Texas; Belfrage.)

Nota. Novum Oscinidarum genus, cui Opetiophorae nomen imposui, cum Liparâ in multis congruit, ab hac et reliquis Oscini daru $\mathrm{m}$ generibus segmento abdominali ultimo foeminae in terebram subulataın corneam mutato discrepat.

91. Siphonella latifrous, nov. sp. of el \&. - Nigra, polline dilute cinerascente leviter asporst. anlennis, proboscide pedibusque concoloribus. fronte latissimá ef facie brevi lutescentibus, venis alcrum subcinerascentium validiusculis el fuscis. - Long. corp. $1 \frac{1}{12}$ 1 lin., long. al. $1-1 \frac{1}{12}$ lin.

Nigra, polline dilute cinerascente leviter aspersa, subopaca. Caput valde depressum; frons latissima, plana, sordide lulescens; triangulum verticale brevissimum, nigrum. polline dilute cinerascente opacum. Antennae nigrae, setâ concolore. Facies brevissima et genae dilute lutescentes, margine tamen laterali oris et occipite toto nigris. Apertura oris amplissima; proboscis geniculata nigra. Pedes nigri, genibus anticorum, rarius omnium angusle subfuscis vel ex fusco luteis. Halleres albi. Alae subcinereae, venis validiusculis fuscis, longitudinali quartâ paulo ante extremum apicem in marginem alae excurrente. - (Texas; Belfrage.)

92. Chlorops (Centor) procera. nov. sp. o. - Nigra, capite flavo, superiore occipitis dimidio, triangulo verticali et limbo supero ultimi antennarum articuli nigris; pedes flavi, tibiis posticis praeler apicem et imam basim nigris, libiarum intermediarum apice calcur incurvum gerente. - Long. corp. $1 \frac{1}{2}$ lin., long. al. $1 \frac{1}{3}$ lin.

Chloropi (Centori) Cereris Fall. persimilis, sed gracilior. Caput flavum, fronte quam in Cblorope Cereris minus latâ, triangulo verticali el dimidio superiore occipitis nigris; antennae dilute luteae, articulo tertio superne late nigro-marginato; seta praeter basim luteam in specimine descripto deest. Thoracis dorsum rugulosum, nigrum, utrinque lineâ tenui flavâ marginatum, humeris nigro - piceis; pleurarum dimidium superius piceum, adversus marginem superum dilutius pictum, dimidium inferius dilute flavum, nigro-bimaculatum. Scutellum rugulosum, piceum, imâ basi et apice flavis. Abdomen tolum nigrum el nitidum. Coxar dilute flavae; pedes sa- 
turatius flavi (antici desunt): tibiae intermediae adversus apicem pilis nonnullis longioribus, dilute flavescentibus et in apice ralrare incurvo nigro instructae; tibiae posticac praeter apicem ef imam basim fusco-nigrae; duo primi tarsorum posteriorum articuli flavi. reliqui desunt. Halteres albi. Alae cinereo-hyalinae.- (connceticut.)

\section{Chlorops (Diplotoxa) Gundlachi. nov. sp. ‥-} Flava, tertio antennarum articulo subrofundo et atro. viltis thoracis nigris et nilidis. alarum venis longitudinalibus secunda et tertià recuvvis, transversalibus valde approximatis, - Long, corp. 1 lin.. long. al. $\frac{5}{6}$ lin.

Flava. alarum venis Chloropi (Diplotoxae) versicolori (C'cnl. III 97.) subsimilis. Frons lata, breviter nigro-puherula; triangulum verticale majusculum, subaequilaterum, antice acutum. luteum vel lu. teo-lastaceum, maculâ ocellos includente et apice autico nigris. Oculi mediocres; genae latiusculac. Duo primi antennarum arliculi fusci vel subfusci; articulus tertius ater, subrolundus: sela albida. basi crassiusculâ fuscâ. Vittae dorsales thoracis nigrae, nitidae; lıumeri puncto nigro notati. Plenrae luteae, margine lamen supero et viltâ media flavis, maculis duabus infra vittam lestaceis vel subfu. scis, raro nigro-fuscis. Scutellum dilute flavescens, convexum. Alodomen luteum. immaculatum. Pedes flavi. tarsis alversus apicem nigris. Halteres albi. Alae hyalinae. venis nigro-fuscis. longitudinalibus secundà leviter et terliâ valde recurvis; venulae transversae valde approximatae. ita ut segmenfum paenullimum venae quartae partem sextam segmenti ultimi prope aftingat et paenullimum venac quintae ultimum paulo superet; segmentum ultimum venae quarlae rectum et ut in Chloropibus plerisque valde attenuatum. (Cuba; Gundlach.)

94. Chlorops (Diplotoxa) confluens. nov. sp. ơ et \&. Flava, antennis, triangulo verticali majusculo, thosacis dorso pacter margines laterales et abdomine praetcr latera et apicem nigris. long. corp. 1-1 $\frac{1}{3} \mathrm{lin}$. long. al. $\frac{5}{6}-1 \frac{1}{4} \mathrm{lin}$.

Diploloxae Gundlachi I, proxime affuis. Coput Havum. occipilis dimidio superiore nigro; triangulum verlicale acquilaterum. nagnum, ila ut marginem anticum fronlis fere altingal. nigrum. nitidum, latera versus minus levigatum. Antennae nigrae; articulus tertius subrofundalus, in latere interiore interdum adversus hasim rufescens. Palpi tlavi. Thoracis dorsum nigrum. nitidum. laleribus inaequaliter flavo-marginalis; pleurae flavae, infra nigro-bimaculatae. 
Abdomen nigrum, subopacum, marginibus lateralibus, apice et ven. tre toto flavis. Pedes flavi vel sordide flavi, extremo tarsorum apice subfusco. Halteres exalbidi. Alae subcinerascentes, venis fuscis. longitudinalibus secundâ et lestiâ recurvis, segmento ultimo quarlae subliliore, venulis transversis valde approximatis. - (Texas; Belfrage.)

95. Chlorops (Diplotoxa) microcera, nov. sp. \&. - Lu. tea, thoracis dorso prater margines laterales cinereo et opaco. ab. dominis colore in fuscum vergente; capul luteum, triangulo verliculi mediocri, opaco, concolore, ante ocellos nigricante, antennis parvis luteis, articulo tertio minuto, rotundo, adversus apicem an. gustius vel latius nigro; alarum venae longiludinales secundâ et tertia modice recurvae, transversales valde approximatae. - Long. corp. $\frac{3}{4}-\frac{5}{6}$ lin.. long. al. $\frac{5}{6}$ lin.

Parva. lutea, thoracis dor'so practer margines laterales sordide lutescentes toto cinereo et opaco. Caput subdepressum, dilute luteum; in superiore occipitis címidio macula triangularis nigra conspicitur, quae antice cum puncto nigro, ocellos includente cohaeret et postice utrinque marginem lateralem occipilis attingit; triangulum verticale mediocre opacum, luteum, ante ocellos plerumque nigricans. Antennae parvae, luteae, articulo tertio minuto, rolunio, adversus apiccm nigro interdum tolo nigro, setâ nigrâ instructo. Pleurae nigro-maculatae. Scutellum dilute luteum, angulis laterali. bus nigricantibus. Metanolum saturate fuscum vel fusco-nigrum. Color abdominis ex fusco-luteus. Pedes lutei, tibiis posticis superne obscuratis, tarsis omnibus fuscis. Halteres albi. Alae cincreo-hyalinae, venis longitudinalibus secundâ et tertiâ modice lantum recurvis, ultimo quartae segmento tenui, sed quam ultimum quintae segmentum non tenuiore, venulis transversalibus valde approximatis. - (Texas; Belfrage.)

96. Chlorops (Diplotoxa) pulchripes, nov. sp. ठ․Nigra, thoracis dorso cinereo-pollinoso, capite praeter occiput flavo, pleuris pedibusgue rufis et nigro-variegatis; triangulum verticale atrum el nitidum, magnum, longius quam latius, fossulâ longiludinali insigne; tertius antennurum articulus ovatus et obtusus. Jong. corp. $1_{\frac{1}{1}}^{\frac{1}{2}}-1 \frac{1}{6}$ lin., long. al. $1 \frac{1}{4}-1 \frac{1}{3}$ lin.

Caput flavum, fronte quam Chloropis (Diplotoxae) versicoloris minus latâ et magis prominulâ; triangulum verticale magnum, longius quam latius, antice suboblusum, fossulà longitudinali excava- 
tum, alrum et nitidum. Occiput nigrum, margine infero et superne utrinque maculà setulam, lateralem verticis feronte, favis. Antennae longiusculae, articulo tertio ovato. supra vix levissime exciso: latera adversa antennarum plerumque rufa. articulo primo el apice tertii nigris, latera aversa vero nigra. articulo tamen tertio adversus basim infra rufo; sela antennarum alba, basin versus flava: clypeus niger; proboscis et palpi llavesecnles. Thoracis dorsum nigrum. ad. versus nargines lalerales sordide rufescens, folum polline cinerascenle opacum. Scutellum nigrum. arlversus margines sordide rufescens, polline cinerascente aspersum. Pleurae obscure rufae vel subbadiae, nigro-maculalae el rillulâ longiludinali dilute flavâ pictae. Abdomen nigrum, nilidum Pedes cum coxis rufi; ima femorum omnium basis nigra; praeterea femora antica anuulo subapicali vigro ornantur, cujus vestigium obsoletum in femoribus posterioribus vis observatur; tibiae anticae practer basim nigrae, inter. mediae tolae rufae vel obsolete fusco-aunulalae, posticae anuulo lato nigro cinctae; tarsi antici fere toti tarsorumque po-teriorum apex nigri. Halteres albi Alae cincreo-byalinae, venis longitudiualihus secundà et tertià arcuatim recurvis, ultimo quartac segmento valde. attenuato venisque transversalibus admodum approxinatis. - (Texas; Belfrage.)

Nota. Ne specimina bujus speciei Chloropis (Diplotorre) rersicoloris sprcimina esse putes, ad lrianguli verticalis forman ef figu. ram in utrâyue specie plane diversam diligenter attendas necesse est. Color et pictura Diplotoxurum nimis variabiles sunt, yuam ut specierum distinguendarum ansam semper certam praebeant.

97. Chlorops (Diplotoxa) alternata, nov. sp. o’ et ․․ Rufescens, capile pleurarumque vilta pallide fluris. thoracis dorso opaco, viltis duabus cinereis, villi interjerta medici sculdlogne fuscis. abdomine fusco-nigro, alurum venis longitudinalibus secundi et terfiâ valde recurvis et venulis transversis valde approximatis: antennae valde elongatae, artirulo tertio sublineari. - Long. corp. $I_{6}^{\frac{1}{6}}$ lin.. long. al. $1 \frac{1}{3}$ lin.

Cum Chlorope (Diploloxa) versicolose (Cent. III. 97.). a quà antennis multo longioribus facile dislinguilur, religuis notis ommibus, practer venas longiludinales alarum secundam et tritim fantulum levius arcuatas, ommino congruil. Duo primi anlennarmm anticuli quam in hac specie vix longiores, fusci, infra ef in latoribus adversis rufi; articulus tertius clongalus, sublinearis, adversus basim modice latior, basi rufà, apice latissime nigro: sela antrunarmm alba, 
basim versus flava. Abdomen fusco-nigrum et nitens, extremo apice plerumque rufescente, ut in speciminibus detritis Chloropis (Diploloxae) versicoloris non raro observatur. - (Texas; Belfrage.)

98. Chlorops (Diploloxa) nigricans, nov. sp. ơ el ․․ Nigra, vel fusco-nigra, thoracis dorso cinereo-pollinoso, pedibus fusris, tertio antennarum arliculo lineari, alis nigro-cinereis, venis longitudinalibus secundâ et tertiâ levissime arcuatis. - Long. corp. $1 \frac{1}{3}-1 \frac{5}{12}$ lin., long. al. $1 \frac{1}{3}$ lin.

Reliquis speciebus gracilior, nigra vel fusco-nigra. Caput concolor, frontis triente antico et vittulâ faciei infra abbreviatâ luteis. Facies albo-pollinosa, adversus oris aperturam modice recedens. Triaugulum verlicale atrum, nitidum, majusculum, superne oculis contiguum, lateribus convexis, ita ut antice subobtusum sit. Antennae longissimae; articuli duo primi breves, fusci, lateribus adversis plerumque tolis rufis; articulus tertius mire elongatus, linearis, niger, basi tamen rufâ; seta alba, basim versus lutea. Thoracis dorsum et scutellum polline exalbido cinerasentia, vittâ mediâ illius adversus marginem anticum minus pollinosâ et saturatius nigrâ, vittis lateralibus plane obsoletis. Peles fusci, coxis anticis, femoribus anterioribus tarsorumque omnium basi colore magis in rufoteslaceum vergente tinclis, tibiis anticis, tarsis anlicis totis reliquisque praeter basim nigricantibus; femora postica quam in speciebus reliquis crassiora. Halteres albi, pedunculo nigrieante. Alae nigrocinereae, venis nigro-fuscis, validiusculis, ultimo quartae segmento tenuiore; venae longitudinales secunda et tertia leviter tantum arcualae, tertia et quarta apicem versus valde divergentes; venulae transversales admodum approximatae. - (Texas; Belfrage.)

Nota. Haec species ad Ectecephalae figuram prope accedit, sed reliquis notis plerisque cum Diplotoxis congruit, ita ut his adnumeranda sit, quamvis tertio antennarum articulo valde elongato. - Diplotoxae adhuc cognitae apte in tres tribus dividuntur; tribus prima Diplotoxas Gundlachi, confluentem et microceram complectitur, quae tertium antennarum articulum rotundum habent; tribus secunda Diplotoxas versiculorem et pulchripedem, in quibus ovatus est, continet; Diplotoxae alternata et nigricans, quarum antennae articulo tertio elongato instructae sunt, tribum tertiam constituunt. 
99 Chlorops (Anthracophaga) maculosa, nov. sp. ठ et ․ - Pallide lutescens, antennis ochraceis. harnm apice. palpis, trianguli verticalis angulo antico marginibusque lateralibus. thoracis vitlis, pleurarum maculis, metanoto abdomine praeter segmento. rum singulorum margines posticos, femorum basi el annulo tibiarum denique posticurum annulo nigris. - Lons. corp. $1 \frac{1}{5}-1 \frac{1}{2} \mathrm{lin.}$ long. al. $1 \frac{1}{4}-1 \frac{1}{3}$ lin.

Dilute lutescens. nigro-varia. Triangulum verticals luteum. opacum, marginibus lateralibus el angulo antico nigris et nilidis: punctum ocellare nigrum. Antennae saturatius luteae vel rufae. articulo tertio majusculo, ovato. superne et adversus apicem fusco-nigro, selâ albâ, adversus basim lıteâ. Oculi mediocres rolundatoovati. Facies subperpendicularis et genae latae pallidae. Proboscis lutea; palpi majusculi et clypei latera atra. Occiput maculà medià nigrâ, superne breviter tridenlatâ et utrinque maculà obsoletà sub. fuse variegatum. Thoracis dorsum puncto humerali nigro vitlisque ordinariis nigris pictum, sed folum polline exalbido aspersum. ila ul opacum sit et viltae cinereo-nigrae appareant. Scutellum convexum, praeter setulas marginales pilis brevibus nigris iustructum. Stigma prothoracis nigrum et nitidum; pleurarum maculae nigrae. pectorales interdum fuscae. Abdomen fusco-nigrmm, segmentis singulis postice pallide marginatis, apice segmenti ultimi latius lutescente. Pedes lulei; femma pallidiora, basi et anmulo lato nigris; tibiate posticae annulo lalissimo nigro ornalae: larsi antici fere toti reliquorumque articuli ultimi nigro fusci. Alae hyalinae. levissime cinrascentes, venis dilute subfuscis, longitudinalibus tertic̀ et quartâ modice convergentibus. - (Texas; Belfrage.)

Nota. A Chlorope (Anthracophaga) sanguinolentia (Cent. III. 84.), cui proxime affinis, praeter colorem corporis pedumgque picturam, tertio antennarum articulo palo minore. alarum venis minus validis pallidioribusque, longitudinalibus tertià et quartà magis divergentibus differt.

100. Chlorops mellea, nov. sp. O el T. - Luteu, villis dor. sulibus thoracis et metanoto nitidis, vel rufescentibus, vel fresis. vet nigris; triangulum verticale luteum, permagnum, usque ad marginem anticum frontis pertinens, fossula longiludinali cacavatum; gence latissimae. - Long. corp. $1_{3}^{1}-1_{3}^{\prime}$ lin., long. al. $1_{\frac{1}{2}}^{\frac{1}{2}}-\mathbf{I}_{\frac{1}{3}}^{\prime}$ lin.

Praeter oculos. thoracis viltas dorsales el melanotum tota di. lute lutea, vel ex luteo mellea. Caput latum, frontis margiue an- 
tico modice prominente. facie adversus oris marginem recedente, oculis mediocribus ovatis genisque, latissimis; Iriangulum verticale permagnum. in verlice oculis subcontigunum, antice ad marginem usque frontis pertinens, nilidum. fossulâ longiludinali excavatum ef pilis brevissimis nigris parce aspersum. Tertius antennarum articulus mediocris et subrotundus. Thoracis dorsum nitens; vittae dorsales ef melanotum vel rufescentia, vet fusea. vel fuseo-nigra: pleurae immaculata, rarissime obsolete nigro-maculatae. Segmenta abdominalia singula adversus marginem posticum in speciminibus plerisque colore dilutissime subfusco tincta. Alae byalinae, leviter cinerascentes; venae pallidae, vel dilutissime luridae, longitudinales tertia et quarta divergentes, transversales modice approximatae. (Texas; Belfrage.)

Operi meo, cujus decima centuria terminum facit, novas Americae septentrionalis Dipterorum species complectenti pauca, quibus alia explicentur, alia corrigantur, addenda esse censeo.

Ea igilur genera, quae in his centuriis condidi, omnia notis idoneis munivi. Genera tamen Diplocentra et Amiola excipienda sunt, quae ideo notis carent, quod quum secundum centuriam conscriberem, spes mihi erat, ut alterum, „Dipterorum Africae australis" volumen ante quam haec centuria ederetur. Quod quum non factum sit. hic monere satis est Diplocentram non differre a genere, quod Macquartus injuriâ, quoniam aliud genus jam antea eodem nomine appellatum erat, Curtonotum appellavit. Amiotam referri ad Drosophilam alboguttatam Wahlb. aliasque hujus generis species, in quibus cellula secunda basalis non confluit cum cellulâ discoidali, ex ipsâ Amiotae humeralis descriptione in Cent. II. No. 93. abunde colligitur; genus Phortica, quod paulo serius Schinerus instituit, non aliud est quam haec mea Amiota.

Quod ad genera in Mycelophilidarum familiâ tractata attinet, necessaria omnia in Winnertzii Monographiâ Mycetophilidarum europaeorum (Schriften d. Wiener zool. bot. Ges. 1S63) insunt. De Dolichopodidarum generibus altera Dipterorum in Americâ septentrionali viventium monographia (Monographs of the Diptera of 
North America P. II.) consulenda est, et de Helomyzidis in actis entomologorum Silesiae (Zeilschrift für Entomologie, Jahrgang 1859.) satis docui. Chloropes demum, postquam prima harum cenfuriarum apparuil, in iisdem actis (Zeitschrift für Entomologie 1866) in minora genera divisi; ut vero aequabilitas quaedan servaretur, in reliquis centuriis a genere dividendo abstinui; sed in decimâ non tantum singulis Chloropum speciebus ea genera adseripsi. quibus quaeque inserenda esset, sed eliam in indice generali indicavi, ad quae genera species in prioribus centuriis decriplae pertinerent.

Sunt praeterea nonnulla genera, quae aut prius aut aliis locis condideram. Fortasse nou erit inutile commemorare, quae sinl ea et ubi constituta sint.

Itaque Triglyphus constitutus est in Okenii Iside (Isis von Oken) 1840 ;

Arthropeas in Ephemeridibus entom. Stetinensibus (Stettiner entom. Zeitung) 1850 ;

Bolbomyia in Loewii Faunâ succino inclusâ (Der Berusteiı und die Bernsteinfauna) 1850 ;

Synamphotera in Giebelii Annalibus scientiae naturalis (Zeitschr. f. d. gesammten Naturwissenschaften) 1856 ;

Cacoxenus in Fntomologicis menstruis Vindebonensibus (Wiener entom. Monatschrifi) 1\$58;

Stilpon in Loewii Supplementis novis (Neue Beilräge Thl. IV.) 1859 ;

Rhicnoëssa in Ephemeridibus entom. Berolinensibus (Berliner entom. Zeitschrift) 1865.

Rhachiceri genus, quod Halidajus condidit et Walkerus in Dipterorum catalogum (List of Dipterous Insects) recepil, unsquam quantum scio, notis cerlis stabilitum est. Sed ab omnibus Xylo. phagidarum generibus facile eo distinguitur, quod tertius antennarum ejus articulus non modo annulalus est, sed etiam annulis bene inter se discretis conslal, ac numerus horum annulorum in mare major est quam in foeminâ et numerum, quem reliqui Xylophagidae in articulo terminali exhibent, longe superat. (Quum Rhachiceri species in Europâ quoque delecla sit, alio loco copiosius the hoc genere agam.

In duobus generibus ea nomina secutus sum, quibus plerique auctores usi sunt aut utuutur, quum tamen alia secundum vetustatis legem revocanda sint. Ilaguje pro Anthophilina Anthomyza. pro Platypalpo Tachydromia dici debebat. Quầ vero de causâ nomini 
Pygostolo nomen Nicocles substituendum esset, in notâ ad Blacem bellum Cent. X. No. 24. additâ declaravi.

Nonnulla generum nomina emendatione indigent; quae cum tam levis sit, ut formae verborum non nimis mutentur, in indice generali nomina cmendata scribere non dubitavi. Itaque pro Rymosia Rhymosiam, pro Rachicero Rhachicerum, pro Argyromoebâ Argyramoebam, pro Dalmanniâ Dalmaniam legis. Mesogrammam in Mesograptam mulavi, quia illud nomen jam plantarum generi cuidam tributum erat. Denique Anthracis nomini, quo diplerologi ut foeminino usi sut, masculinum sexum restitui, et Cyrloma, quum nequaquam foemininum sit, neutris adscripsi.

Ut etiam systematis, quod mihi sequendum videbatur, mentio fiat, hoc commemoro in familiis circumscribendis et collocandis me eum ordinem, quem in Monographiis Dipterorum Americanorum (Monographs of the Diptera of North America P. I.) explanavi, secutum esse. In Dipterorum acalypterorum grege difficultas generum et familiarum circumscribendarum tam varia est ac tanta, ut studio solum diligentissimo superari eam posse spes sit. Ea causa est, quod de Rhicnoëssa genere quid certum et verum sit, intelligere non valui, et quoniam aliquis ei locus concedendus erat, in familia Agromyzidarum locum adsignavi. Id genus similitudinem quandam Phycodromidarum habere negari nequit; at recedit ab is diversissimo venae auxiliaris situ, quare si iis inserere Rhicnoëssam maluissem, meliorem ei locum inventum esse vix credideris. Pariter de Trigonomelopi villati loco maxime dubius haereo. Nam ut ex descriptione liquet, a Trigonomelopo frontali Meig. notis conformationis insignibus tantopere differt, $u t$ in idem genus redactis aperte vis quaedam inferri videatur. Ac major fere dubitatio est, num Trigonometopum in Heteroneuridarum familiam excipere velis.

Speriebus quibusdam nomina institui, quae quia aliis eorundem generum speciebus imposita erant, retineri non possunt. Duabus jam nomina mutata sunt. Nam Sciophila bimaculata Cent. IX. No. 9. quum Roserus aliam civem Europaeam ila appellaverit, nunc Empheria didyma audit, quo nomine et copiosius et secundum utrumque sexum in Cent. IX. No. 14. descripta est; frustra igilur illud nomen in indice generali quaeras. Deinde Midae rufiventris nomen Gerslaeckerus in Midaidarum monographiâ propter speciem a Macquarto ita nominatam cum Midâ ventrali commutavit.

Praeterea ex Psilocephala laticorni Psilocephala platycera, ex Rhamphomyia lugenti Rhamphomyia luctuosa, ex Phytomyza Ilicis Phytomyza ilicicola faciendar sunt. 
Denique haec, quae vel calamus meus vel Iypotheta peccavit, corrigas precor:

Cent. III. No. 97. initio descriptionis pro ,corporis picturâ" le. gendum est ,corporis color"6.

Cent. IV. No. 20. pro "Satkatchevan" leg. "Saskalchevan".

Cent. IV. No. 43. pro "Blepharoplera" leg. "Blepharocera".

Cent. IV. No. 89. pro, ,purpureo nigro" leg. "purpureo-nigro".

Cent. V. No. 3.3. in adnotatione pro ,clausât" leg. ,non clausât". Cent. KX. No. 77. pro "Oscinis dorsalis" leg. "Oscinis dorsata". 
Catalogus generum et specierum, quae insunt in dipterorum americanorum centuriis.

\section{Culicidao. \\ Corethra. trivittata . . . . II. 1 . \\ Chironomidae.}

Chasmadonotus. unimaculatus... V. 1. Tan y us.

bellus.... VII. 4 flavicinctus .. I. 2 hirtipennis . . VII. 6 . humeralis ... VII. 2. pilosellus ... VII. 7. pinguis ..... I. 1 . pusillus ... VII. 5. scapularis . VII. 1. thoracicus .. VII. 3 . tricolor..... I, 3.

Ceratopogon.

alhiventris ... I. 7. argentatus ... I. 5 . bimaculatus .. I. 6 , festivus ...... I. 13. genualis ... VI. 1. Jongipennis. . I. 10. opacus ... I. 9 . plebejus ... I. 11 . rufus ...... I. 12 . setulosus ... I. 8 . trivialis ..... I. 4 .

\section{Blepharoceridae.}

Blepharocera. capitata .. IV. 43.

\section{Tipulidae.}

I) ixa.

centralis ... III. 3 . clavata ... VIII. 1. fusca.... III 5 . marginata .. III. 1 . notata ... III. 4 . terna ..... III. 2 . venosa ....X. X. 1. L ongurio. testaceus ... VIII. 2. Holorusia. rubiginosa .. IV. 1. Tipula. angulats ... V. 22 angustipennis IV. 19. apicalis ... IV. 2. appendiculata IV. 20 balioptera . IV. 15. bella ... IV. 29. caloptera . IV. 30. canadensis . V. 19. casta ... IV. 25. centralis .. V. 21. cincta... IV. 24. discolor... IV. 12. eluta .... IV. 27. fallax ... IV. 10. fasciata ... IV. 6 . fragilis ... IV. 7 . fraterna... IV. 14. grata ... IV. 11. hebes .... IV. 18. infuscata . IV. 26. ignobilis ... IV. 9. latipennis ... V. 20. longiventris . IV. 5 . macrolabis . V. 17. pallida ... IV. 16. praecisa ... X. 2. pubera ... V. 16. septentrionalis IV. 4. serrulata ... V. 18. serta .... IV. 14. speciosa . . IV. 22. strepens ... IV. 28. subfasciata .. IV. 13. submaculata. IV. 23. suspecta ... IV. 8. tephrocephala V. 23. ternaria $1 !$. V. 15. tessellata ... IV. 3. umbrosa ... IV. 31 . valida.... IV. 21. versicolor . IV. 17.

Pachyrrhina.

abbreviata .. IV. 36 . circumscripta IV. 38. eucera . . IV. 39. gracilicornis - V. 32 . incurva ... IV. 32 . lugens ... V. 26. nobilis ... V. 24 . occipitalis .. V. 30 . pedunculata . IV. 33. polymera . . IV. 40. punctum ... IV. 34 . sodalis .... V. 29. suturalis ... IV. 37. tenuis .... IV. 41 . unifasciata . IV. 35. unimaculata V. 28. virescens .. V. 25. vittula ... V. 27. xanthostigma. V. 31 .

Stygeropis. dimidiata ... VI. 2. fuscipennis . VI. 3. sordida ... IV, 42 . Ctenophora. angustipennis . . X, 3 .

\section{Simulidae.}

Simulium. quadrivittatum II. 2 . Mycetophilidae.

Ditomyia. euzona .... IX. 1. Plesiastina. lauta .... X. 3 . tristis .... X. 2. 
As yndulum. coxale.... IX. 4.

Macrocera.

clara...... IX. 6 . formosa .... VII. 8. hirsuta ... IX. 5 . inconcinna . IX. 7.

Platyura. diluta .... IX. 9. divaricata ... IX. 8. melasoma . IX. 12. mendica . . IX. 10. mendosa ... IX. 11. Empheria.

balioptera . . IX. 13. didyma ... IX 14. nepticula . IX IX. 15. Polylepta. fragilis.... IX. 16. Sciophila.

appendiculata IX. 19. bimaculata . VII. 9. biseriata . . IX. 20. obtruncata.. IX. 18. onusta .... IX. 17 . tantilla.... IX. 21 .

Lasios oma. quadratula. . IX. 22. Eudicrana. obumbrata. IX. 23.

Syntemna. polyzona .. IX. 24. Boletina. tanypus . . IX. 26.

Glaphyroptera. decora .... IX. 28. melaena ... IX. 27. oblectabilis . IX. 31 . opima ... I. IX. 29. Leia. sublunata .. IX. 30. abbreviata .. IX. 33. sororcula . IX. IX. 32. Acnemia. psylla .... IX. 34.

Docosia. dichroa .... IX. 35.

Rbymosia. filipes ... IX IX. 36 .

Trichonta. foeda .... IX. 38 . vulgaris ... IX 37. Zygomyia. ignobilis . . IX IX. 39. oruata .... IX. 40.
Epicypta. pulicaria... IX. 41.

Hycothera. paula ... IX. IX. 42.

Ilycetophila. bipunctata. IX. 44. exstincta . IX IX. 43 . fallax .... IX. 50. inculta .... IX. 46. monochaeta . IX. 54 . mutica ... . IX. 45. pinguis ... IX. 47. polita .... IX. 53. procera ... IX. 55. quatuornotata IX. 52. scalaris ... IX 48. sigmoides . IX. 51. trichonota. IX. 49.

Sciara.

ochrolabris . 1X. 58 . sciophila . IX. 57.

Trichosia.

hebes .... IX. 58 .

\section{Bibionidae.}

Bibio.

abbreviatus .. V. 9. basalis .....V. 11 . fraternus ... V. 8 . hirtus :... V. 2. inaequalis ... V. 3. longipes . . . V. 12. lugens ..... V. 6. nervosus ... V. 4. nigripilus ... V. 10 . obscurus ... V. 5 . variabilis ... V. 7.

Dilophus.

breviceps .. IX. 59. dimidiatus . . VIII. 3. longiceps ... I. 14 obesulus . . IX IX. 60 . serotinus ... I. 15 tibialis .... IX. 61 . Scatopse. pygmaea ... V. 13.

\section{Xylophagidae.}

Rhachicerus. obscuripennis III. 6. varipes... III. 7. X y lophagus. abdominalis . IX. 64. longicornis . IX. 62 .
Jugens .... III. 8 .

rufipes .... IX. 63 . Subula.

pallipes ... III. 9 .

Arthropeas.

americana ... I. 16 .

B olbomyia.

nana..... II. 5.

\section{Stratiomyidae.}

Metoponia.

obscuriventris IV. 45. similis ... IV. 44 .

Sargus.

elegans .. VII. 10.

lucens ....VII. 11.

pleuriticus . VII. 13.

tricolor ... VII. 12

Chry son otus.

nigricornis. VII. 14.

Notbom yia.

calopus ... VIII. 5. scutellata .. VIII. 4.

0 x y e era.

centralis ... III. 14. unifasciata .. III. 15.

Euparyphus.

bellus ... VII. 18. brevicornis. . VII. 16. stigmaticalis . VII. 17. tetraspilus . VII. 15.

Odon tomyia.

arcuata... X. 4.

binotata .. VI. 22 .

inaequalis .. VI. 24.

lasiophthalma VI. 23.

megacephala . VI. 20.

microstoma. VI. 28.

nigerrima .. X. 6 .

nigrirostris . VI. 19.

pilimana ... VI. 27.

plebeja ... X. X.

rufipes ... VI. 25.

scaluris...V VI. 26.

varipes .... V1. 21

Stratiom yia.

angularis ... VI. 16. apicula . . VI. 13. barbata... VI. $y$ constans ... X. 8 . discalis.... VI. 14. insignis .. X. 7 . laticeps .. VII. 20. lativentris . VI. 8 . 


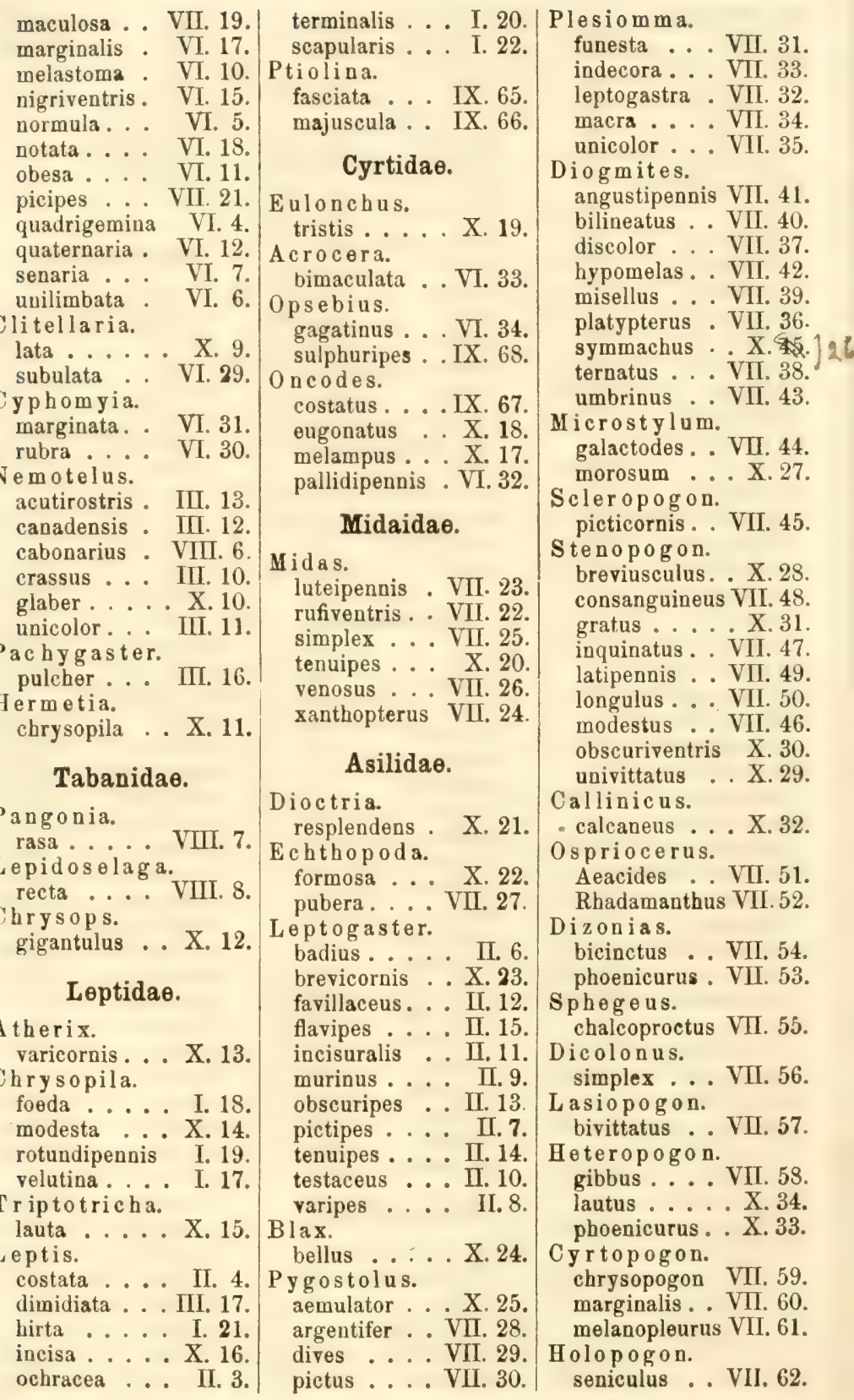


Ablautus. trifarius .. VII. 63.

Discocephala. calva ... X. 35.

\section{Thereuidae.}

Psilocephala. costalis ... VIII. 16. erythrura . IX. 75. laticornis .. VIII. 14. longipes . VIII. 11. melampodia VIII.12. munda ... VIII. 13. melanoprocta VIII. 15. rufiventris. VIII. 17. scutellaris. IX.74. variegata.. IX.73.

Thereua.

albiceps ... IX.69. candidata . VIII. 10. comata ... VIII.9. flavicincta.. IX.70. fucata... X. 37 . gilvipes ... IX.71. melanoneura. . X. 36 . strigipes . IX. IX.

Xestomyza. planiceps . X. X.38.

\section{Bombylidae.}

Exoprosopa. Agasizii .. VIII. 24. bifurca .. VIII.23. cubana... VIII. 22. decora ... VIII. 19. gazophylax . VIII. 18. nubifera... VIII. 25. parva ... VIII. 26. sordida ... VIII. 21. trabalis ... VIII. 20.

Anthrax.

adusta...V VIII. 41. bigradata . . VIIL. 37. Ceyx ... VIII. 30. curta ... VIII. 35. diagonalis . VIII.33. flaviceps .. VIII.29. fuliginosa . VIII.31. molitor .. VIII. 42. mucorea . VIII.43. nigricauda . VIll. 35. palliata ... VIII.32. parvicornis . V111.36. pertusa .. VIIL. 28. proboscidea. VIII. 27. sagata... VIII. 34. serobiculata VIII.39. stenozona. VIII. 40.

H e mipe $\mathrm{n}$ thes. seminigra . VIII.44.

Argyramoeba. contigua . V VIII. 50. Delila ... VIII.45. euplanes . VIII.49. obsoleta...VVIII.47. pauper .. V VII.4s. stellans ... VIII. 46.

Aphoebantus.

cervinus ... X. 39 .

Leptochilus.

modestus ... X. 40.

Bombylius.

albicapillatus . X. 42 . atriceps ... IV. 49 . haemorrhoicus IV. 46. pulchellus . . TV. 47. ravus .... IV. 50 . semirufus . X. 41 . validus ... [V. 48 .

Sy stoecbus. candidulus . IV. 51. vulgaris . . IV. 52 .

Lordotus. gitbus ... IV. 53 .

Sparnopolius. brevicornis . X. 43 .

Ploas.

atratula ... X. 44. limbata...V V1ll.51. nigripennis $\mathrm{X} .45$. obesula .. X. 46 ,

Alloc otus. Edwardsii . X. X. 48 .

Phthiria. egerminans . X.47. notata... III. 19. sulphurea .. III. 18.

\section{Geron.}

albidipemis . IX. 78 . calvus ... IV. 54 . macropterus. IX.76. subauratus . IV.50. vitripennis. IX.77.

Systropus. macer

\section{Syrphidae.}

Temnocera.

megacephala. IV. 57. pubescens . VI. 35. purpurascens VIII.52. Volucella.

apicalis .... VI. 36 . sexpunctata. VI. 37.

Lepidom y ia. calopus ... V. 38.

Sericomyia. chalcopyga . . III. 20.

Spilomyia. fusca .... V.34. hamifera ... V.33. longicornis . X.49.

Temnostoma. aequalis... V.36. alternans .. V.37. obscura ... V.35.

My io lepta.

aerea ... X.53. nigra ... X. 52 . strigilata .. X. X.54. varlpes . . IX.79.

Tropidia. mamillata... I. 68 .

Didea.

fuscipes... IV. 82 .

S phegina. infuscata... III. 23. lobata ... III.21. rufiventris . . 111.22.

Baccha.

capitata ... 111.25.

cognata . . 111.27. lugeus ... 111.24. notata... VII. 65. obscuricornis 111.26. parvicoruis . VII.64.

Oc y p tau us. conformis . VII.67. latiusculus . VIl.6. longiventris . V11.66; scutellatus . V VIl.69.

Doros.

aequalis ... IV.84. flavipes... 11.\$3.

Chrysochlamys. buceata... 11.7.2

Chilosia.

capillata .. IV.65. comosa . . 11.66.

IV. 56. cyanesceus. IV.67. 
leucoparea . IV. 69. pallipes ... IV. 70 . plumata... IV. 68. tristis .... IV. 71.

Chrysogaster.

latus .... IV. 59. nigripes ... IV. 60 .

Orthoneura.

pictipennis . IV. 58 . ustulata ... IX. 80 .

Triglyphus.

modestus ... IV. 62 . pubescens .. IV. 61 .

Pipiza.

calcarata ... VI. 42.

femoralis ... VI. 38.

fraudulenta. . VI. 41.

nigribarba . . VI. 40.

salax ... VI. 39.

Sy rphus.

jactator ... VI. 46.

nigripes . . . VI. 44.

praeustus . . VI. 45.

simplex... VI, 43.

Mesograpta.

arcifera ... VI. 52.

laciniosa .. VI. 50 .

parvula .... VI. 47.

planiventris . VI. 49.

poecilogastra. VI. 51.

subannulata . VI. 48.

Paragus.

angustifrons . TV. 64.

dimidiatus . IV. 63 .

Brachypalpus.

cyanogaster. X.51. frontosus ... X. 50 .

Xylota.

angustiventris VI. 58 . barbata ... V. 40 . bicolor ... V. 39 . fraudulosa .. V. 41 . obscura ... VI. 55 . pachymera .. VI. 54 . pretiosa ... VI. 53 . quadrimaculata VI. 56. subfasciata . VI. 57.

Pteralastes.

lituratus .. IV. 81. thoracicus . IV. 80 .

Helophilus.

divisus ... IV. 78.

bamatus ... IV. 79 .

laetus .... IV. 77.

latifrous ... IV. 73. integer . . IV. 76 . obscurus ... IV. 74. obsoletus . IV. 75 . polygrammus . X. 55 .

Pteroptila.

decora ... VI. 59. zonata ... VI. 60 .

Eristalis.

atriceps .... VI. 64 . atrimanus... VI. 62. Gundlachi .. VI. 61 . hirtus .... VI. 66. inornatus . . VI. 68 . latifrons ... VI. 65. melanostomus VI. 69. obscurus ... VI. 67. pilosus .... VI. 70. seniculus ... VI. 63.

Chrysotoxum. laterale.... V. 42. pubescens .. V. 43 . ventricosum - V. 44. Microdon.

baliopterus . X. 56 . coarctatus .. V. 47. inaequalis . VII. 70. laetus .... V. 46 . tristis .... V. 45 .

Ceria.

abbreviata . V. 48. tridens ... X. 57 .

\section{Myopidae.}

Dalmania.

nigriceps ...VII. 71 . M y p a. clausa...VVII 72.

oncom yia. abbreviata . VII. 73. loraria ... VII. 74. Zodion. nanellum ...VII. 75 .

\section{Pipunculidae.}

Pipunculus.

cingulatus .. VI. 73 . fasciatus . . X. 59 . fuscus ...VVI. 71 . nigripes ... VI. 75 . nitidiventris . VI. 72. subopacus .. VI. 74. subvirescens . X. 58 .

\section{Scenopinidae.}

Scenopinus.

albidipennis VIII. 53.

Atrichia.

longurio .. VII. 76.

\section{Platypezidae.}

Callom yia.

divergens . . VI. 77.

notata ... VI. 76.

talpula ... IX. 81 .

tenera.... IX, 82 .

Plat yeza.

anthrax ... IX. 83. flavicornis . VI. 79. obscura ... VI. 80 . pallipes . . VI. 81 . velutina ... VI. 78 .

Platyenema.

imperfecta . VI. 62.

\section{Hybotidae.}

Brachystoma.

binummus . II. 16 . nigrimana .. II. 17. serrulata ... I. 23 .

Syneches.

albonotatus . . II. 18. pusillus ... I. 25 . rufus .... I. 24 . Sy adyas.

dorsalis .... I. 26. polita .... I. 27.

\section{Empidae.}

Empis.

armipes ... I. 32 . barbata.... II. 19 distans ... VIII. 54. labiata .... I. 33 . levigata ... V. 49. leptogastra . . III. 30 . longipes ... V.51. nuda .... II. 20 . obesa .... I. 28 . pallida ... I. 30 . picta ... III. 28. poeciloptera - I. 31 . poplitea ... III. 29. rufescens ... V. 52. sordida ... I. 29. spectabilis .. II, 21 . 
stenoptera.. V.50.

suavis . . VIII. 56 . superba ...VVIII. 57.

varipes .. I. 34

violacea ... VIII. 55

Pach y weria.

brevis... II. 22 .

pudica... I. 35

Rhamplom y ia.

angustipenuis

I. 55 .

aperta...

basalis.

II. 27.

brevis ....

candicans.

clavigera.

conjuncta .

corvina ..

crassinervis

debilis....

dimidiata

exigua

V. 54

frontalis ..

fumosa

I. 52 .

V. 61 .

I. 53 .

I. 56 .

I. 51 .

I. 59 .

I. 45 .

I. 36 .

II. 32 .

II. $2 \mathrm{~s}$.

gilvipes ...

glabra...

gracilis

hirtipes ...

impedita . .

incompleta.

irregularis .

levigata ...

leucoptera. .

limbata

liturata

longicauda

longicornis

longipennis .

luctifera...

lugens.

luteiventris

macilenta

mutabilis

nana....

nigricans

pectinata..

polita ....

priapulus . .

pulchra ...

pulla....

pusio ...

rava....

rustica

sellata.

I. 39.

I. 48 .

I. 41 .

I. 43.

V. 59.

II. 31 .

III. 31.

V. 60 .

I. 37.

I 62.

I. 60 .

I. 61 .

I. 38 .

I. 47 .

I. 46 .

I. 50 .

II. 30 .

V. 57 .

V. 55 .

II. 26.

I. 64 .

V.58.

I. 49

II. 29 .

I. 54 .

I. 40 .

I. 41 .

I. 63 .

II. 25 .

V. 56 .

soccata

I. 42 .

sordida

1. 67 .

I. 58 . umbilicato

II. 24.

I. 65

umbrosa .. V. 53.

ungulata ... I. 66 .

unimaculata. II. 33.

vara

1.57

vittata

II. 23 .

II ilara.

atra.... II. 42.

basalis ... II. 45.

brevipila... II. 41 .

femorata... II. 35.

gracilis . . U. 44.

leucoptera .. II. 43.

lutea ..... III. 33.

macroptera. . III. 32.

mutabilis ... II. 40.

nigriventris . II. 38 .

seriata ... V. 63 .

testacea ... V.64.

tristis ... V. 62 .

trivittata . . II. 39.

umbrosa

II. 34 .

unicolor

II. 37.

velutina .. II. 36

Horinopeza.

brevicornis .

V. 65

nigricans . . V. 66 .

Gloma.

obscura ... V. 68 .

rufa ... V.67.

Cyrtoma.

femoratum . V. 69.

halterale... II. 46 .

longipes .. II. 47.

pilipes .... II. 48 .

procerum... V. 70.

\section{Tachydromida $\theta$.}

Stilpon.

varipes ... II. 5 S.

Irapetis.

divergens . X $\mathrm{X} .62$.

gilvipes.... X. 61 .

pubescens . II. 57 .

unipila ... X. 60

Platypalpus.

aequalis ... V. 75.

apicalis ... V.79

debilis ... III. 37 .

discifer... 111. 36 .

flavirostris . V. 80 .

laetus ... V. 81 . lateralis

mesogrammis III. 38 . pachycnemus $\div \mathrm{V} .77$

trivialis ... T.76.

Phoneutisca.

bimaculata . III. 35

Tachy peza.

$\begin{array}{lll}\text { clavipes } & \text {. V. } 73 . \\ \text { pusilla . . V V. } 74 . \\ \text { rapax . . . V. } 71 . \\ \text { rostrata } & \text { V. } & \text { V. } 72 .\end{array}$

S y $n$ a m p botera.

bicolor... III. 34.

Il emerodromia.

defecta... II. 55 .

notata ... II. 53 .

obsoleta . . II. 52 .

scapularis . II. 5t.

valida ... 11. 51.

vittata ... II. 56 .

Clinocera.

lineata... II. 50 .

simplex ... II. 4:4.

\section{Dolichopodidae.}

Do I ichopus.

albiciliatus . . [T. 59 .

detersus . VII. 7y.

doryïerus . V. Si.

fulvipes .. II. 61 .

melanocerus . V. 86 .

palaestricus . T. 84. platyprosopus VIl. So. praeustus . II. 62 . pugil ... VII. 77. quadrilamellatus V. S3. sarotes... VII. \$I. setosus... II. 63 . socius ... II. 60 . splendidulus . Y. 82. terminalis. VII. 78.

G ymnopternus.

coxalis .... V. S7.

meniscus . . V. 85 .

phyllophorus VII. 52.

Paraclius.

claviculatus VII. \$3. pumilio ... X. 63 .

Pelastoneurus.

abbreviatus . V.89.

alternans . . T.91.

furcifer . . X. 64.

lamellatus . V. 90.

Tachytrechus.

angustipennis II. 6 t. binodatus . VII. 84 . 
Porplfyrops. longipes ... V. 92 .

Diaphorus. subsejunctus . VI. 83.

Asyndetus.

ammophilus VIII. 58. appendiculatus VIII.59.

Chrysotus. cornutus ... II. 65 . picticornis . . II. 66 .

Sympyenus. nodatus ... II. 68 .

Hydrophorus. aestuum .. VIII. 60. cerutias ... X. 65. parvus .... II. 67.

Saucropus. carbonifer . IX IX. 84. Psilopus. castus .... VI. 84. dimidiatus . II. 70. dorsalis ... VI. 85 . melampus . II. 69. tener... . II. 71.

\section{Tachinidae.}

Blepharopeza. adusta .... X. 67.

Gymnochaeta. alcedo .... VIII. 61.

Euthera. tentatrix .. VII. 85.

Wahlbergia. brevipennis. IV.91.

Hyalomyia. triangulifera . IV. 85.

Trichopoda. radiata .... IV. 89 . trifasciata. . IV. 90.

Xysta. didyma .... IV. 86 .

Himantos toma. sugens .... IV. 87. Cistogaster. divisa.... IV. 88. Gymnosoma. filiola . . . X. X. 66 .

Muscidae.

Pyrellia. centralis . . VIII. 62. setosa ... VIII. 63.

Lispe. Anthomyidae. sociabilis II. 72 .
Homalomyia.

femorata...

X. 68 . tetracantha - X.69. Coenosia.

calopyga ... X. 71. modesta ... X. 72 . nivea.... X. 70. tricincta ... IX. 83.

Schoenomyza. chrysostoma. IX. 86. dorsalis ... X. 73 .

\section{Cordyluridae.}

Cordylura.

acuticornis . I IX. 94. adusta . . . . III. 41. albibarba ... IX. 96. angustifrons . III. 45 . bimaculata . . III. 40 . capillata ... X. 77. cincta ... . III. 47. confusa ... III. 43. cornuta ... III. 48 . flavipes... . III. 46 . fulvibarba . X X. 76. gagatina ... IX. 93. gilvipes ... III. 49. glabra .... IX 90. gracilipes . IX IX. 87. inermis ... IX IX. 88 . latifrons ... IX. 92. lutea .... X. 75 . megacophala. IX. 94. munda .... IX. 91 . nana ..... V. 94 pleuritica... III. 42 . praeusta ... V. 93 . scapularis . IX. 89. setosa . . . III. 44 . terminalis . I III. 39. vittipes.... X. 74 . H y drom y za. confluens ... III. 50.

\section{Helomyzidae.}

Hel om yza.

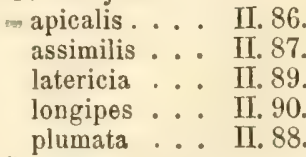
Scoliocentra.

fraterna ... III.51. Eume topia. helvola... II. 80 .
Anorostoma. marginata. II. 81 . All ophyla. levis .... ПI. 85 .

Blepharoptera. armipes ... II. 83 . discolor ... X. 78 . leucostoma.. III. 53. lutea ..... III. 52. pectinata ... X. 79 . pubescens .. II. 82 . tristis ... II. 84 .

\section{Sciomyzidae.}

Tetanocera.

ambigua ... V. 95 . rotundicornis. I. 70. spinicornis . . VI. 86. triangularis - I. 69.

Sciomyza.

luctifera ... I. 71. tenuipes ... X. 80 . trabeculata.. X. 81 .

\section{Psilidae.}

Loxocera.

collaris ... IX. 37 . fallax .... IX. 98 . pectoralis . VIII. 64 . pleuritica . . VIII. 65.

Psila.

bivittata . . VIII. 67. collaris ... VIII 68. dimidiata . VIII. 69. lateralis . . . VIII. 66. levis ..... VIII. 71. sternalis . VIII. 70. Chyliza.

apicalis ... VIII. 72. notata ... IX. IX. 99.

\section{Micropezidae.}

Calobata. angulata ... VII. 87. maculosa . VII. 88. nebulosa . . VII. 89. placida ... VII. 90. platycnema . VII. 86.

\section{Ortalidae.}

varipes .... VI, 87. 


\section{Trypetidae.}

Trypeta.

$\begin{array}{lr}\text { abstersa ... } & \text { II. } 77 . \\ \text { alba ... } & \text { I. } 72 . \\ \text { albidipennis } & \text { I. } 73 . \\ \text { atra..... } & \text { II. } 74 . \\ \text { finalis ... } & \text { II. } 78 . \\ \text { geminata... } & \text { II. } 75 . \\ \text { sarcinata... } & \text { II. } 73 . \\ \text { timida ... } & \text { II. } 76 . \\ \text { Vernoniae .. } & \text { I. } 74 .\end{array}$

\section{Lonchaeidae.}

Palloptera. jucunda .. III. 55.
superba . .
terminalis 75.
III. 54.

\section{Sapromyzidae.}

Sapromyza.

$\begin{array}{ll}\text { bispina... } & \text { I. } 79 . \\ \text { coneta } \ldots . . & \text { I. } 81 . \\ \text { compedita } & \text { I. } 76 .\end{array}$

decora .... V. 96.

fraterna ... I. 77. macula .... X. 82. quadrilineata. I. 78. rotundicornis III. 56 . stictica.... III. 58. tenuispina .. I. 80. umbrosa ... III. 57.

Pachycerina. verticalis... I. 82.

Lauxania.

albovittata . . П. 79 . eucephala .. X. 83 . femoralis ... I. 89 . flaviceps . . VII. 91. gracilipes .. I. 85. manuleata .. I. SS. muscaria ... 1.87. obscura ... I. 84. trivittata ... I. yo. variegata... I. 83.

\section{Heteroneuridae.}

Heteroneura. melanostoma V. 97. latifrons ... IV. 93. spectabilis . IV. 92.

Anthophilina.

tenuis.... IV. 95 . terminalis. . IV. 94. variegata .. IV. 96.

Is chnomyia. vittata... TV. 47.

Trigonome topus. vittatus . . VIII.9s.

Opomyzidae.

Op o m yza. lurida.... V.98.

\section{Piophilidae.}

M ycetaulus. longipennis . IX. 100.

\section{Ephydridae.}

Notiphila. pulchrifrons . X. S4. Psilopa. nobilis .... II. 92.

Discocerina. lencoprocta . I.93. orbitalis ... 1.91. simplex ... I. 92.

Il y drellia. conformis . VIII. 73. formosa ... I. 94 .

Philygria. debilis .... 1.96. opposita ... I. I5.

Il yadina. gravida.... IV.98. Parydra. abbreviata .. I.97. varia ... IV. 100. Ephydra. crassimana. VT.88. obscuripes . VII.92. subopaca . V V.99.

Scatella. mesogramma VIII. $7 . t$. obsoleta ... 1.98. sejuncta ... IV. 39. Caenia.

spinosa . . . V. 100.

\section{Geomyzidae.}

Diastata. cluta .... . III. 59 pulchra ... . 1. 100. Diplocentra. helva.

\section{Drosophilidae.}

Amiota.

humeralis . II. 93. leucostoma. II. 94.

I) rosophila.

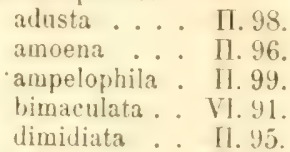

Hexa.... VI. 89. multipunctata VII. 9:. obesa ... X. 85 . obscuripennis V1.9\%. punctulata . . II. 100 . quinaria ... VI.90. sigmoides . X X.86. terminalis .. III. 60 . tripunctata . II. 97.

\section{Oscinidae.}

\section{Crassiseta.}

costata... III. 62.

eunotia... X. 89

formosa ... III. 61 .

longula .. III. 64

nigriceps . . III. 63 .

nigricoruis . III. 65.

Gaurax.

anchora ... VII. 9t.

festivus ... III. 66 .

Ui ppelates.

convexus... VI.94. dorsalis . V11I. 75 . eulophus... X. 88 . Havipes . . VI.95. nobilis ... III. 67. pallidus .. V V. 93. plehejus . . III.68. pusio ... X. 87 .

Oscinis.

atriceps ... III. 74. carbonaria VIII. 76. decipiens . 11I. 76 . dorsalis . . III. 72. dorsata... 1111.77. favicens... III. 71. hirta ... III. 75. longipes . . III. 77. nudiuseula . III. 70 . pallipes ... HH. (69. subvittata. . III. if. trigramma . 111.80. umbrosa . . III. 73. variabilis . . III. 79 . 
Opetiophora. straminea.. X. 90. Siphonella. cinerea.... III. 81. latifrons ... X. 91. reticulata V VIII. 78.

Chlorops.

(Centor.)

procera.... X. X. 92.

(Haplegis.)

fossulata. . . III. 82.

(Anthracophaga.)

encera .... III. 85.

maculosa . X X.99.

sanguinolenta III. 84.

(Diplotoxa.)

alternata ... X. 97.

confluens... X. X4.

Gundlachi . . X. 93.

microcera .. X.95.

nigricans... X. 98.

pulchripes . X X. 96.

versicolor . III. 97.

(Chlorops.)

crocota ... III. 89. melanocera. III. 91 . mellea ... X. 100. obscuricornis III. 90. producta ... III. 96. pubescens . . III. 88. quinquepunctata III.94. Sahlbergi . III. 95. sulphurea .. III. 83 . unicolor... III. 93. variceps . . III. 86. (Chloropisca.)

grata ... III. 92. trivialis ... III. 87.

Elliponeura. debilis ... VIII. 79 .

\section{Agromyzidae.}

Rhicnoëssa. albula .... VIII. 80 . coronata . VI. 98. parvula ... VIII. 81.

Lobioptera.

indecora... VIII. 94. lacteipennis . VI. 97. leucogastra . VIII. 95.

Milichia.

picta .... I. 99 .

Cacoxenus. semiluteus . VIII. 97.

Lencopis. bella ..... VI. 99. simplex . . V VUI. 96.

Desmometopa. tarsalis ... VI. 96. A grom y za.

angulata . VIII. 87. coronata . VIII. 89. longipennis . VIII. 90. maguicornis VIII 86. marginata . VIII. 91. melampyga . VIII. 88. neptis . . . VIII. 93. parvicornis . VIII. 92. setosa... VIII. S3. simplex ... VIII. 84. virens . . VIII. 85. Odontocera. dorsalis... III. 98. Phy llom yza. nitens .... VIII. 82.

\section{Phytomyzidae.}

Phy tom yza.

Clematidis . III. 100. genualis . VIII. 100. Ilicis ... III. 99. nervosa . . VIII. 99.

\section{Asteidae.}

Siga loüssa.

bicolor ... VI. 100.

\section{Phoridae.}

Phora.

clavata .. VII. 95. incisuralis . . VII. 98. microcephala VII 96. nigriceps . VII. 99. pachyneura . VII.97. scalaris . VII, 100. 






(

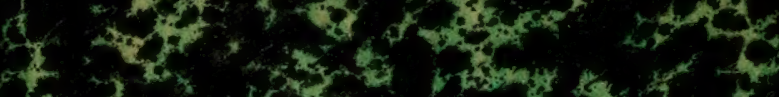

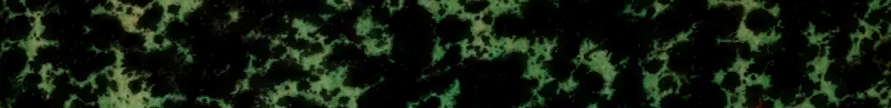

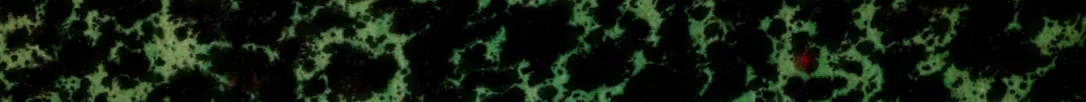
to

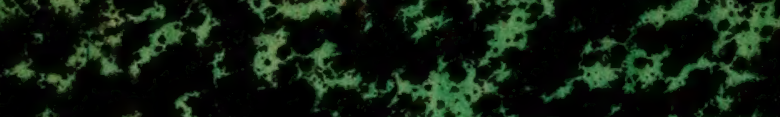

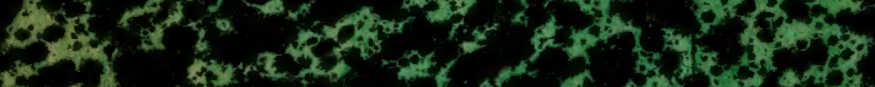
(

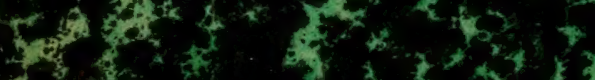

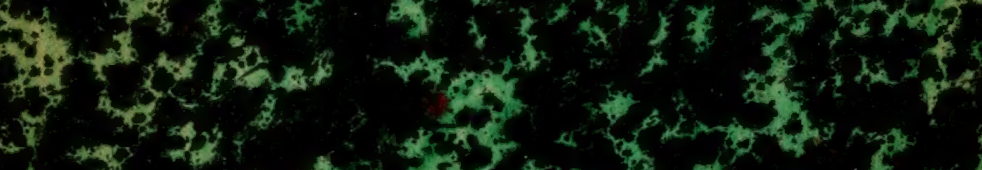

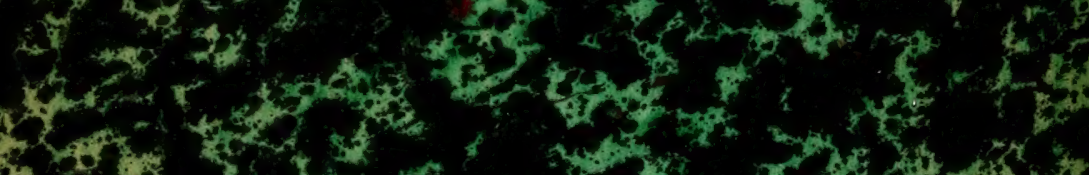

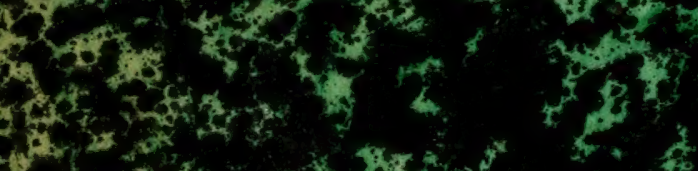

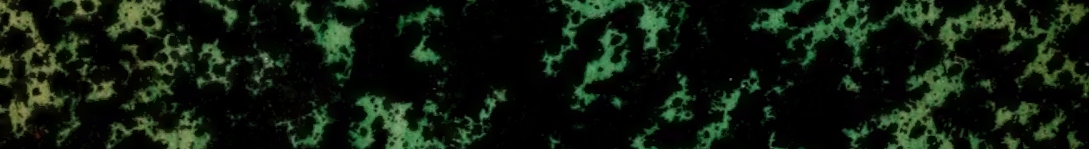
Yon

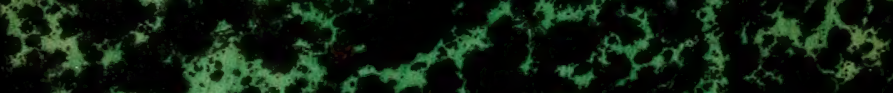

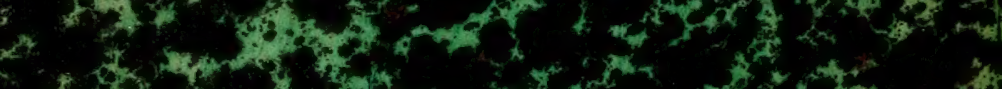

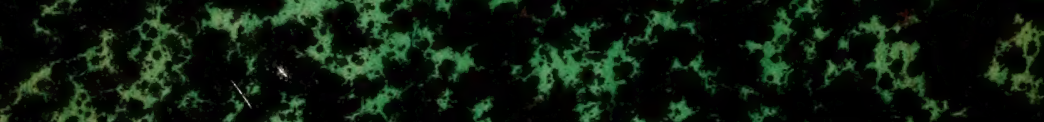

(1)

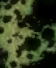
(2) (.) (1) 
35

$-43$

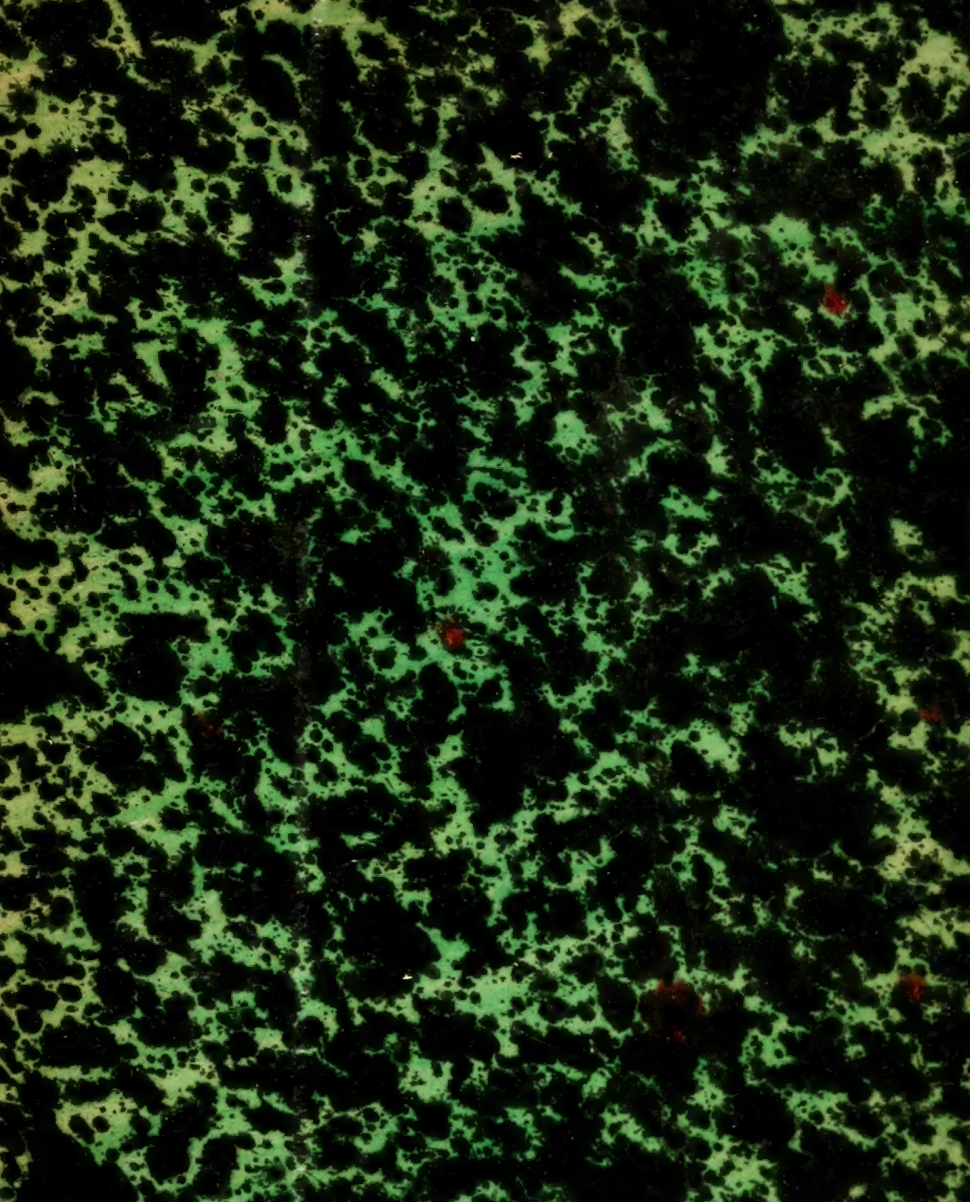

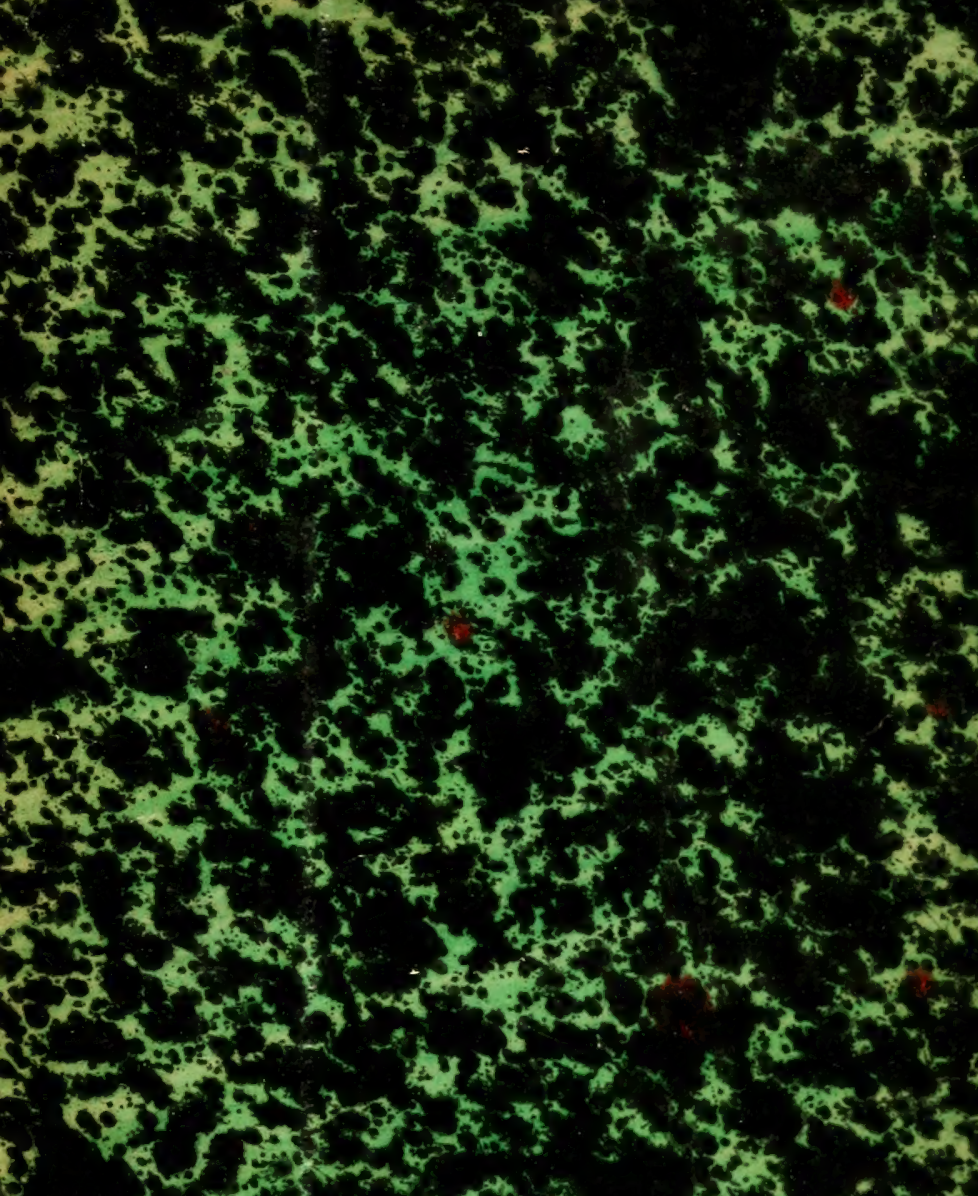

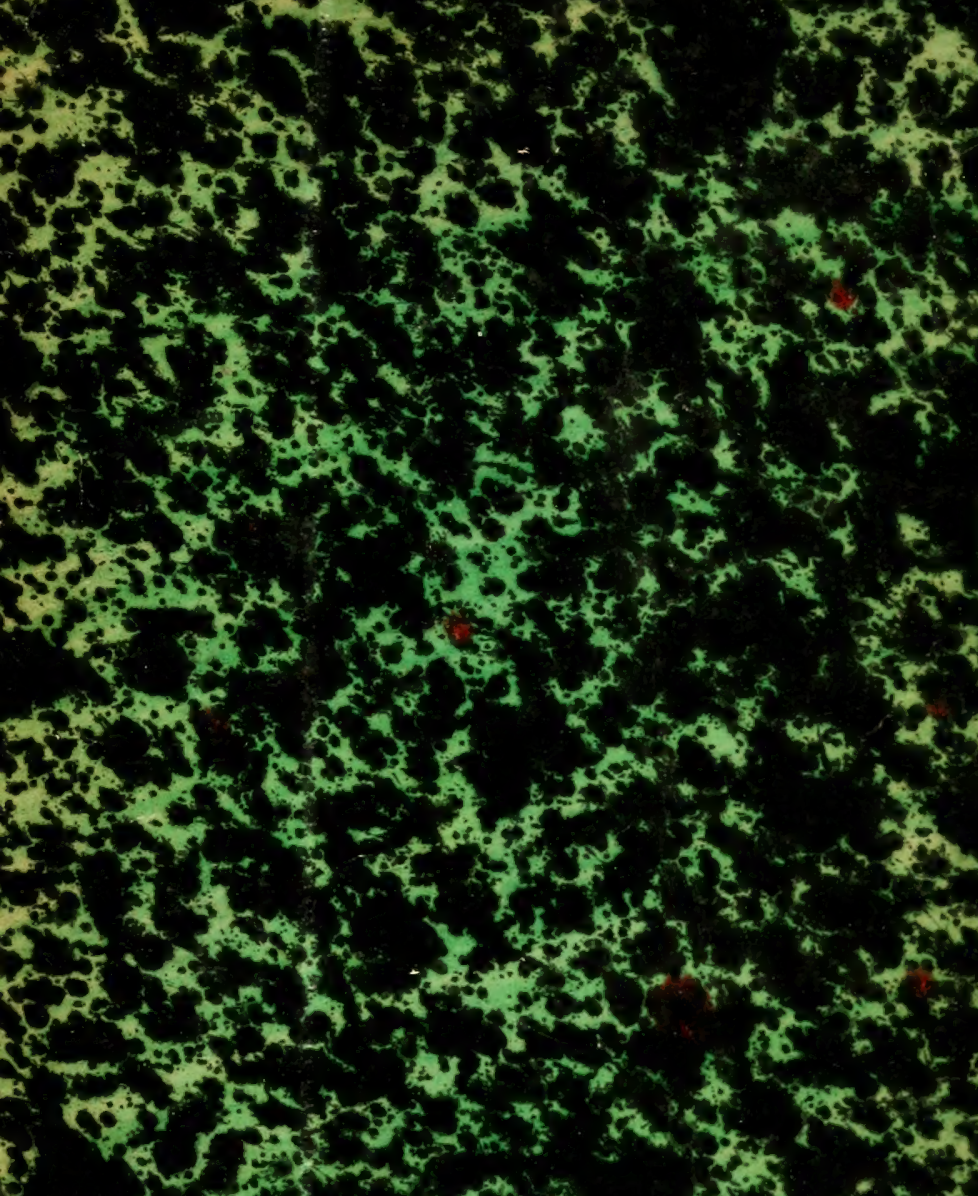

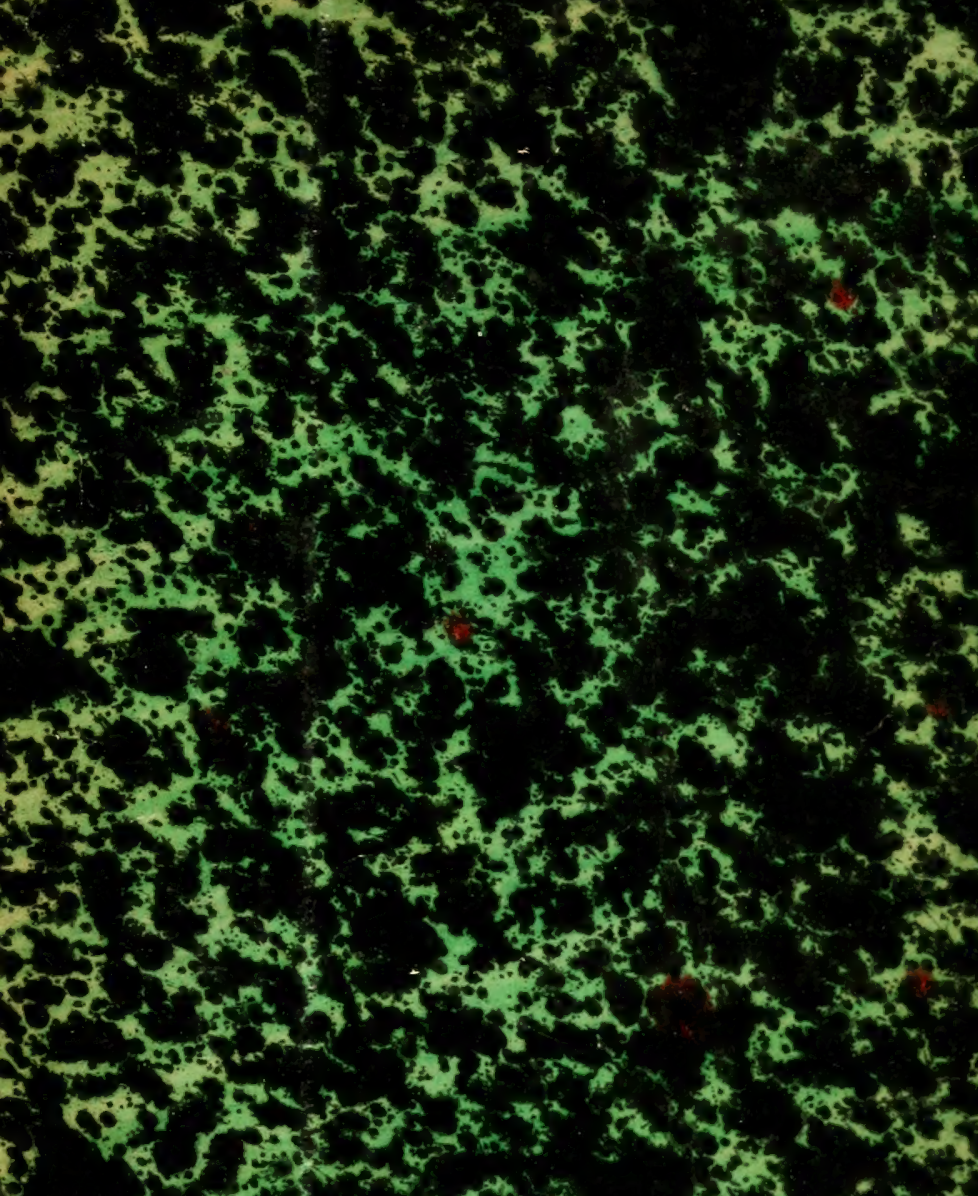

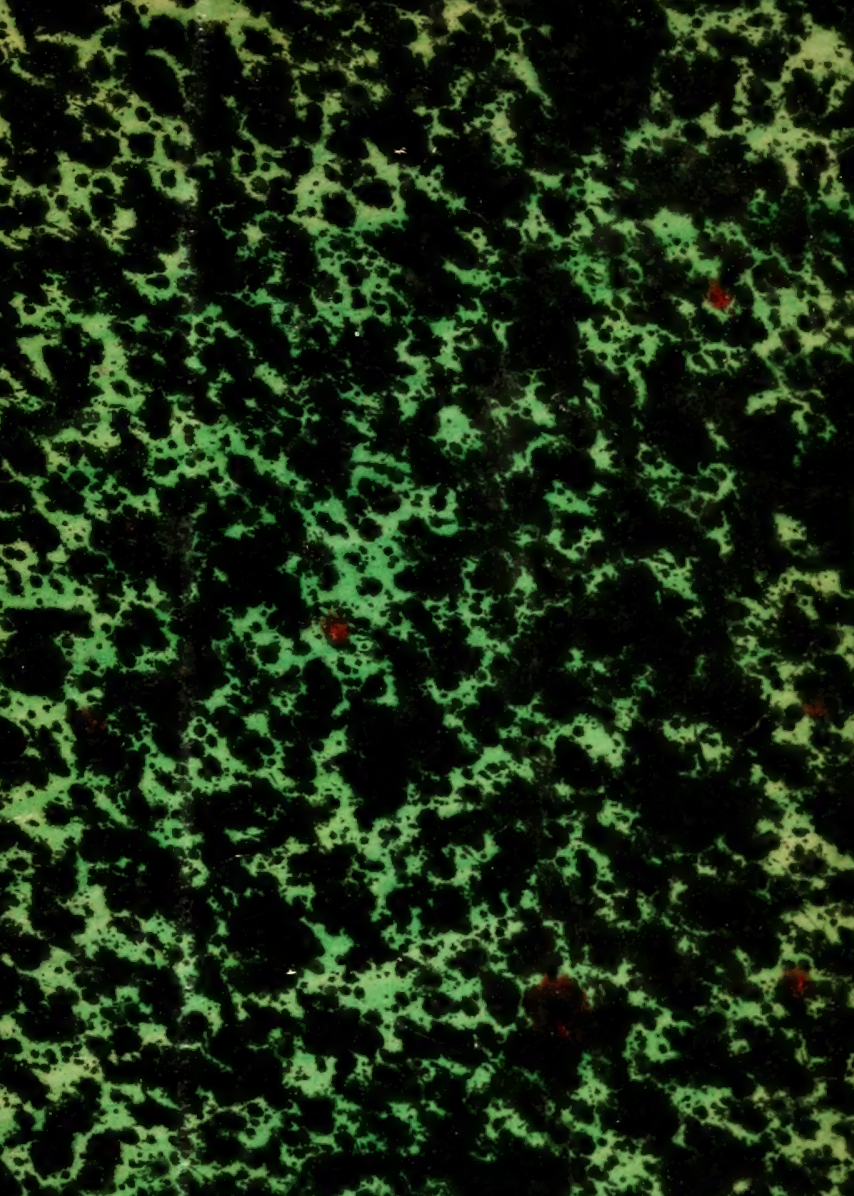

6. 013

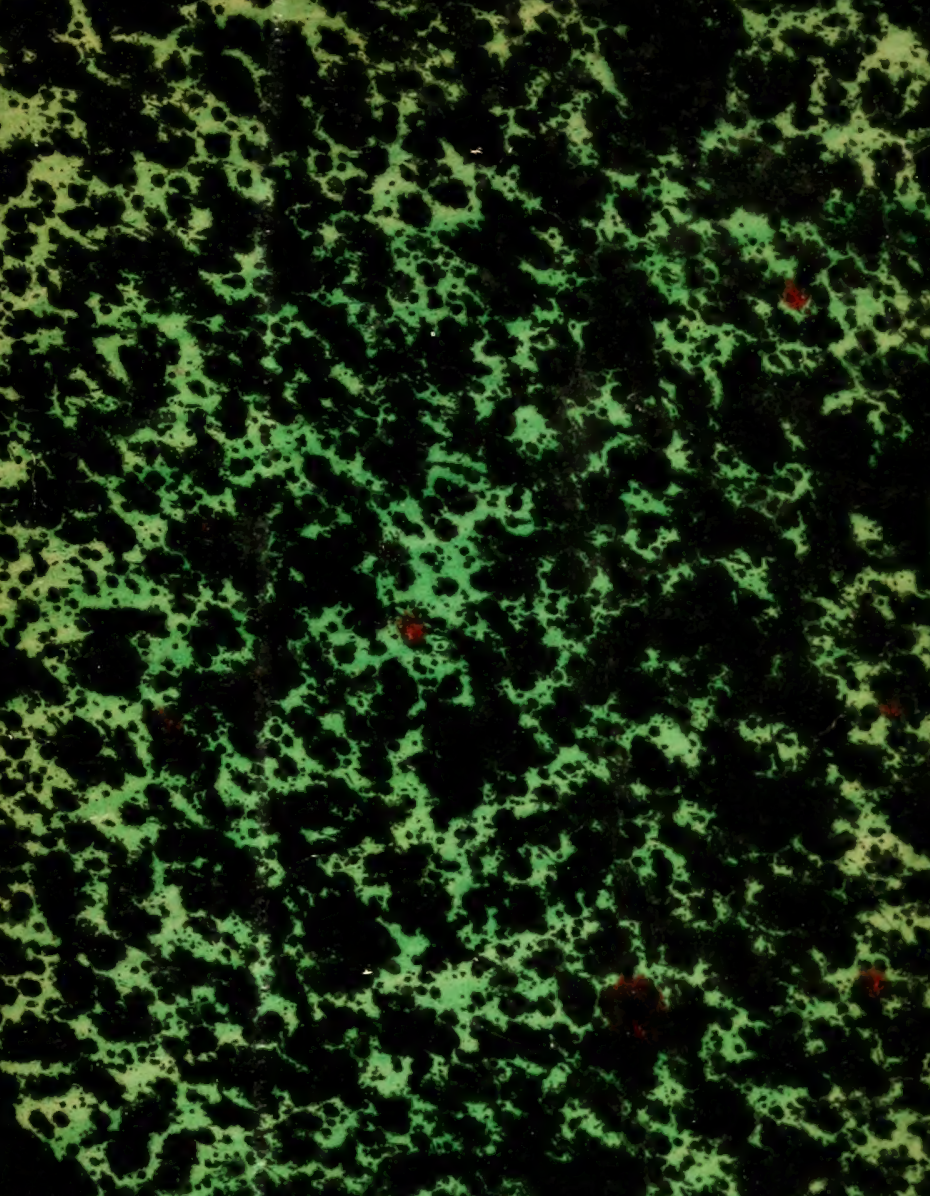

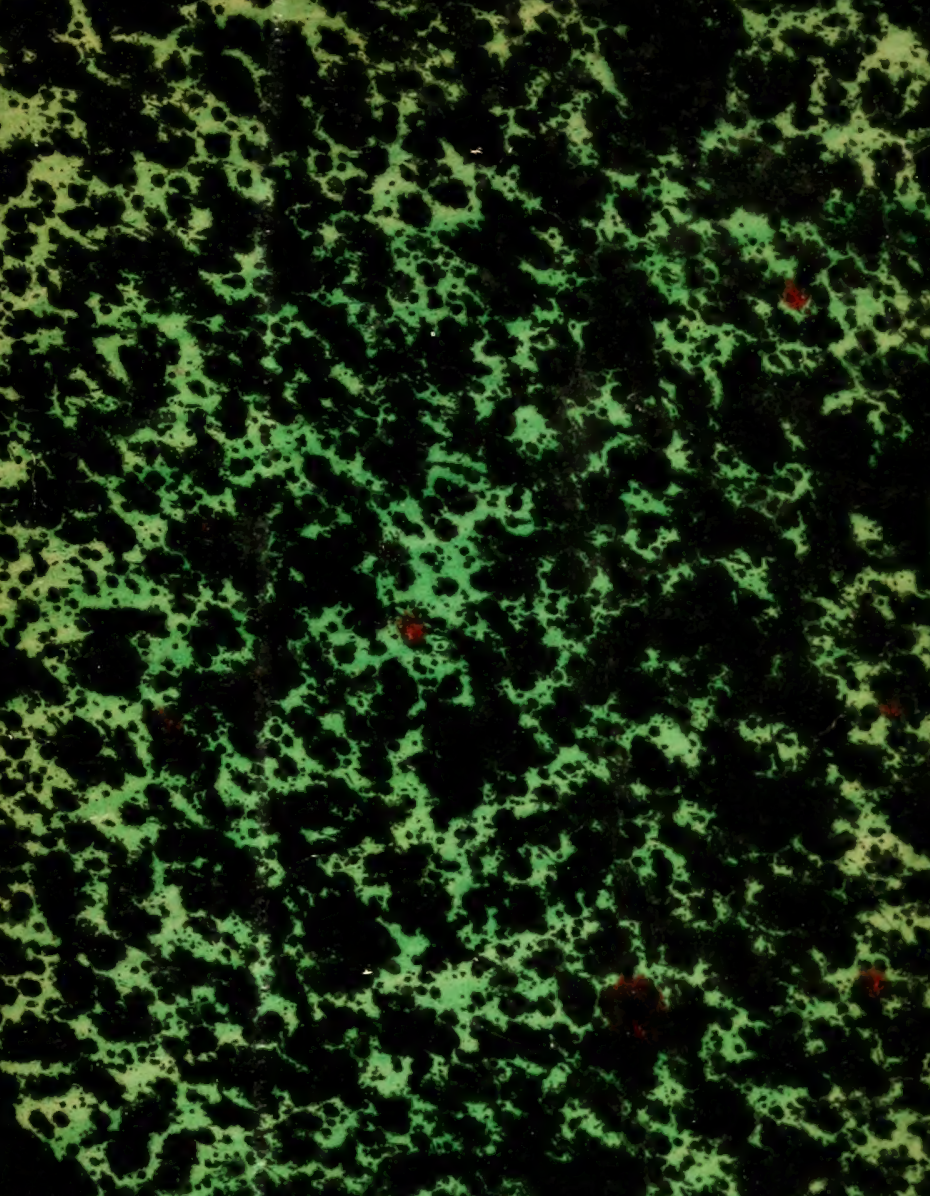

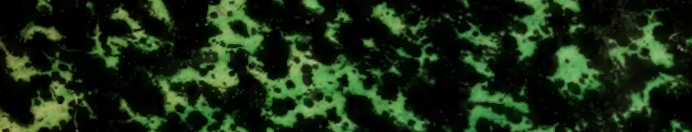

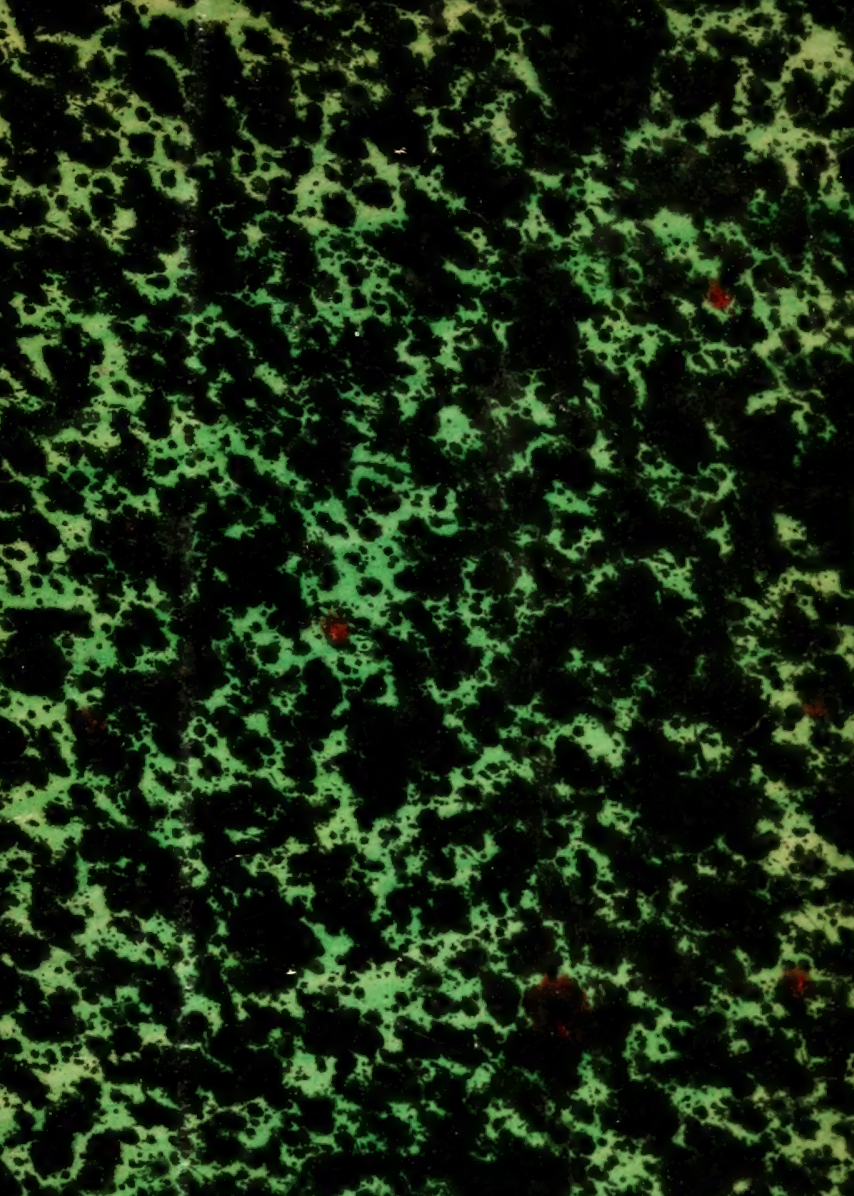

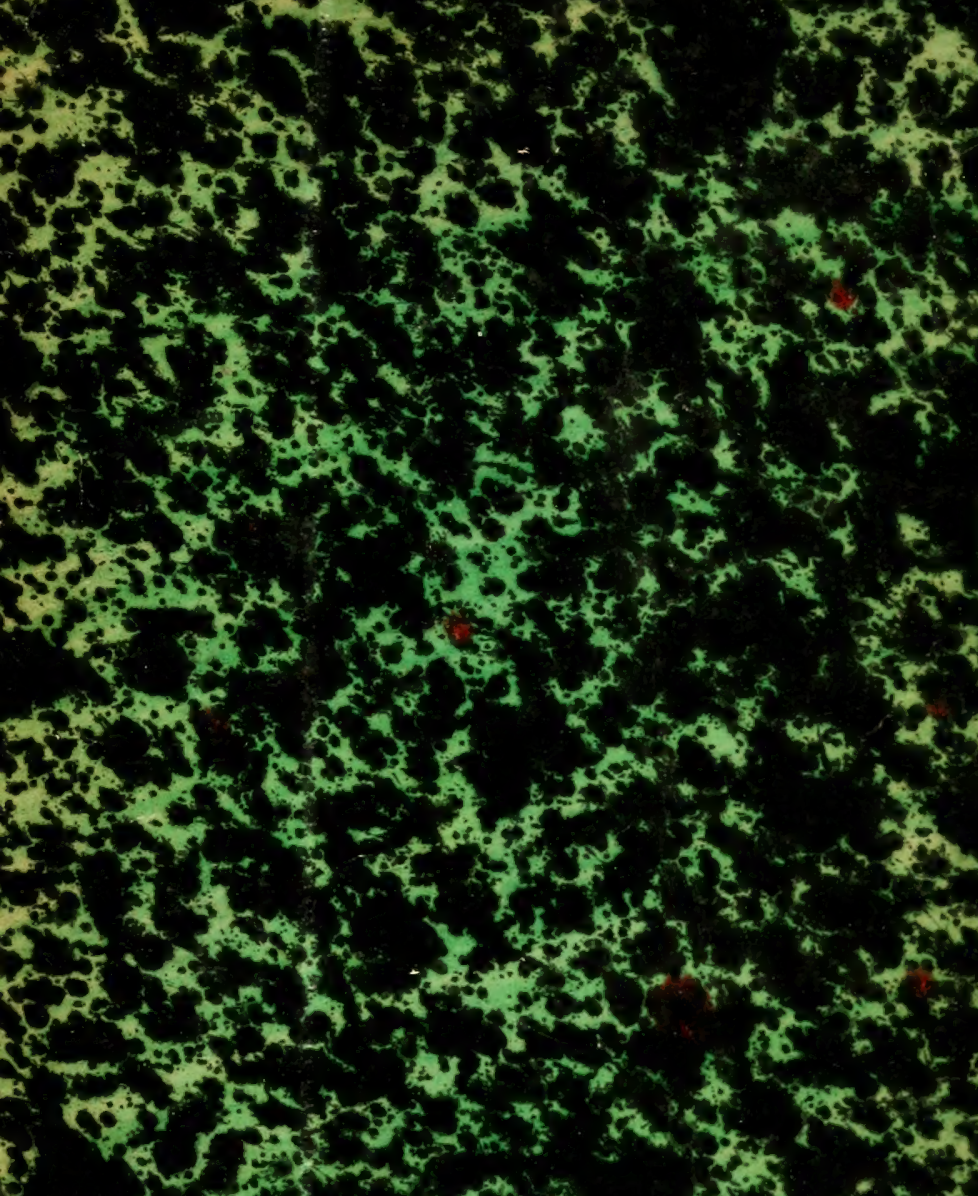

3.

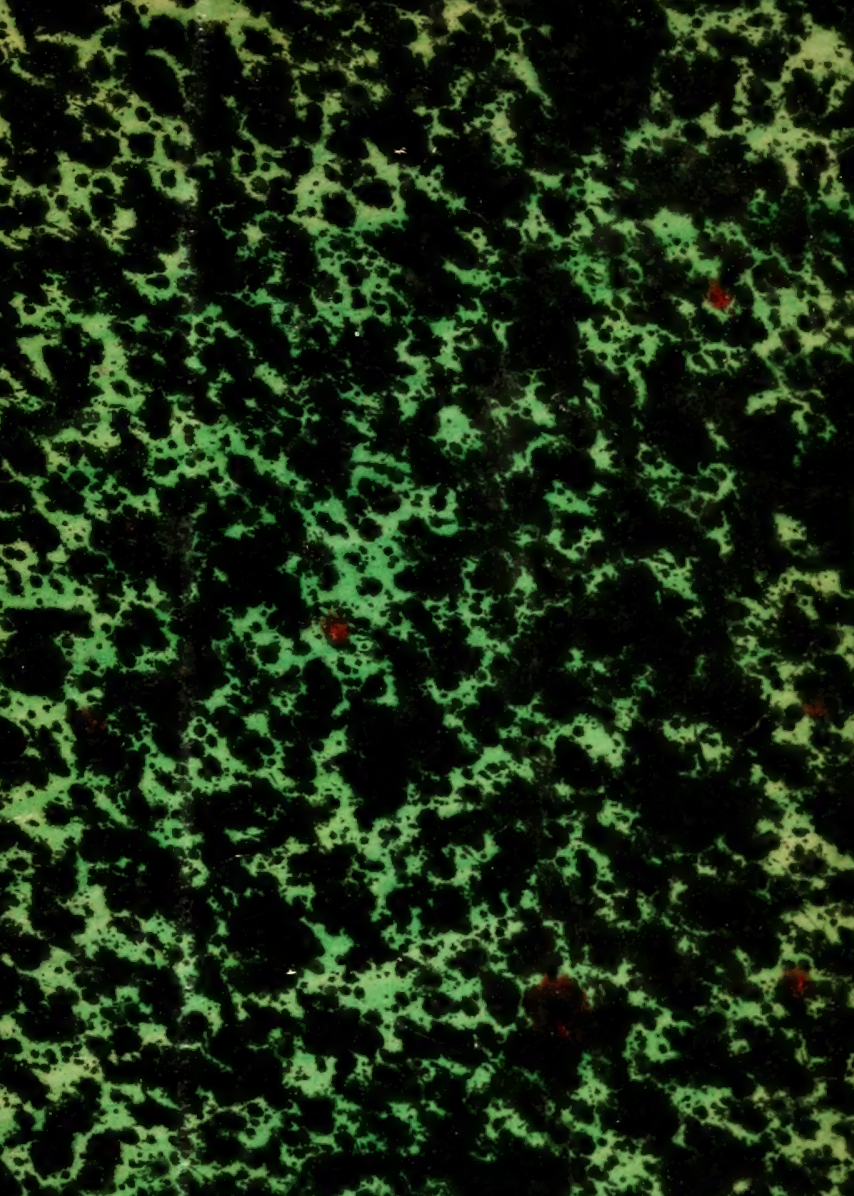

(1)

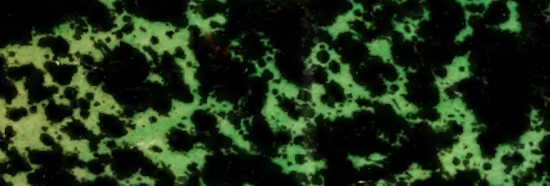

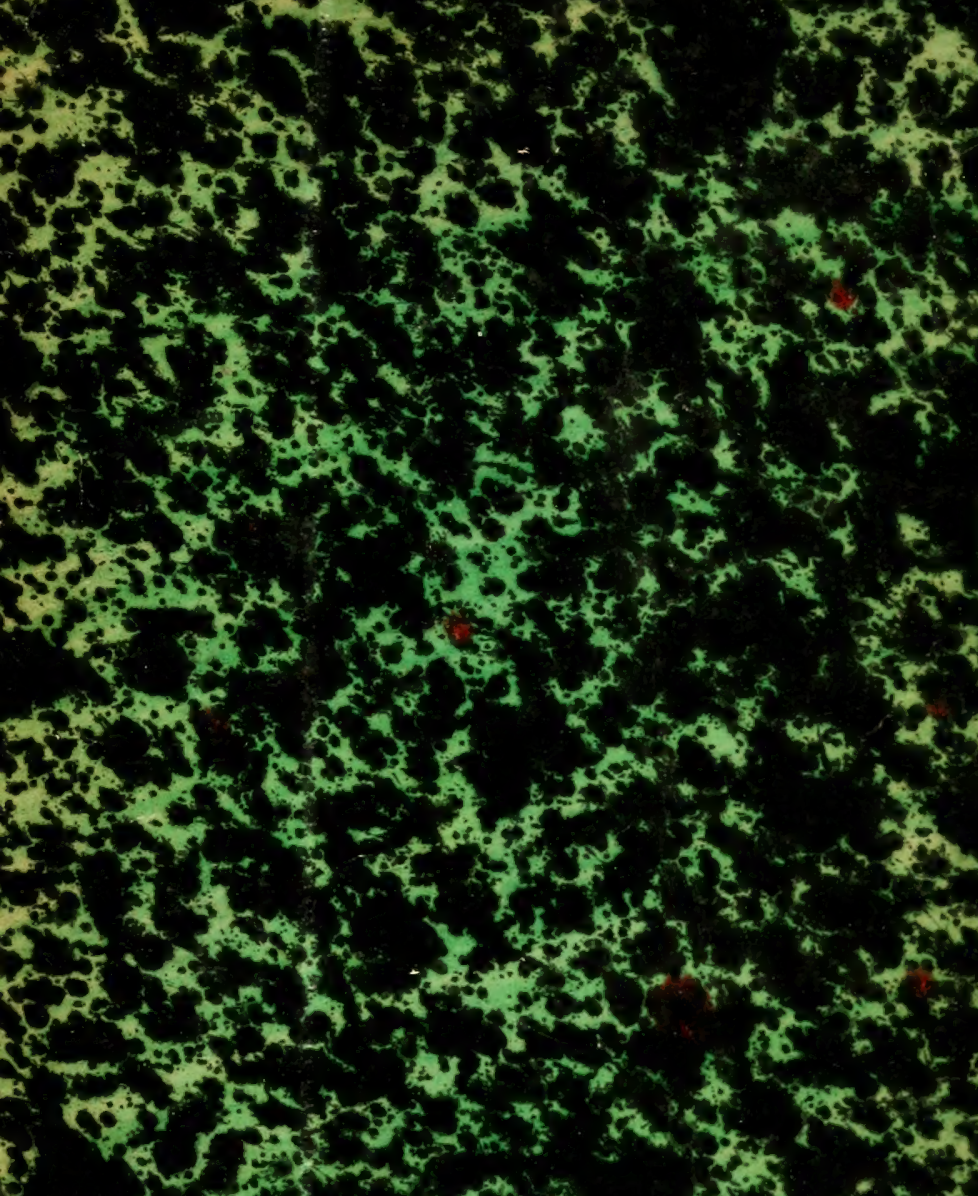

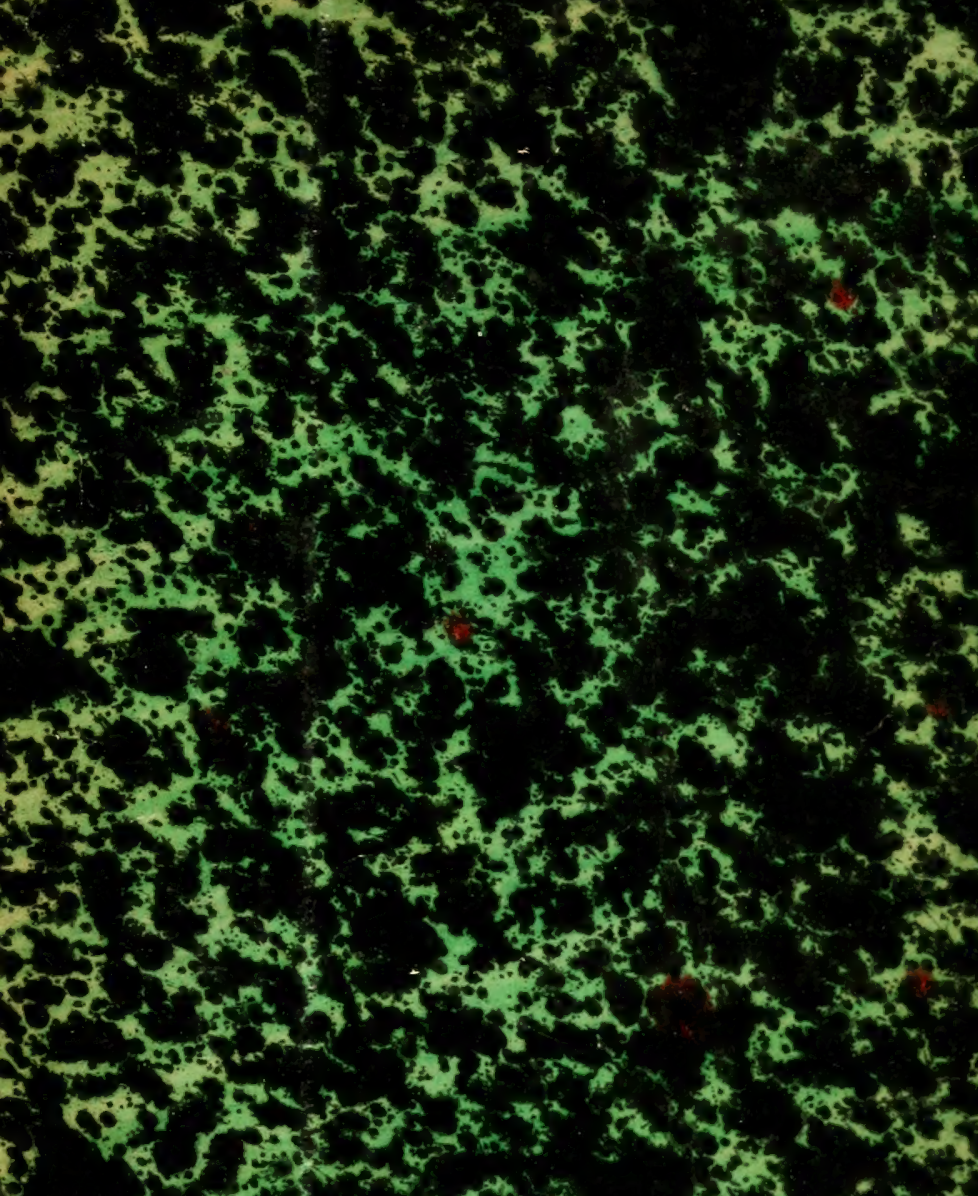

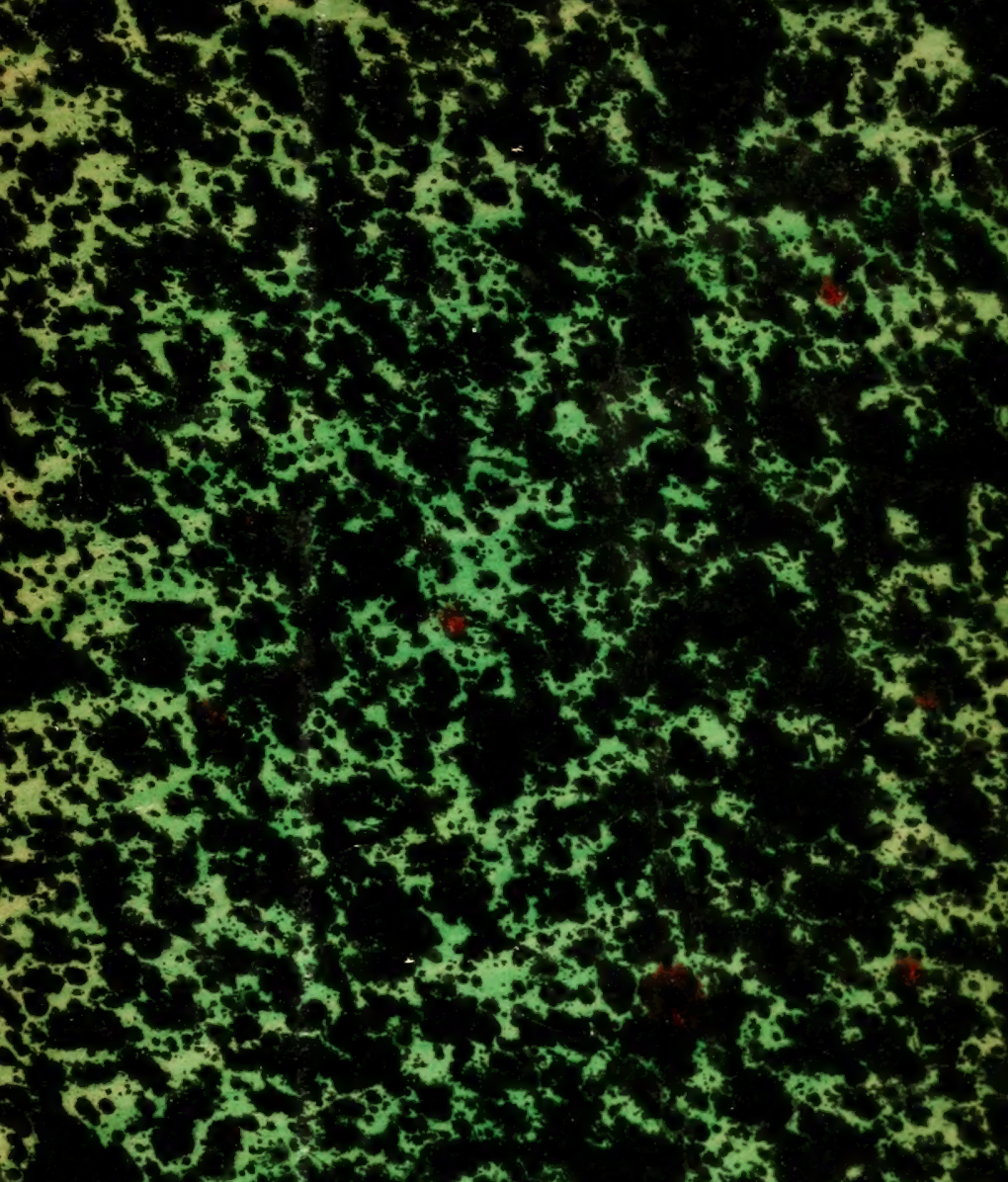

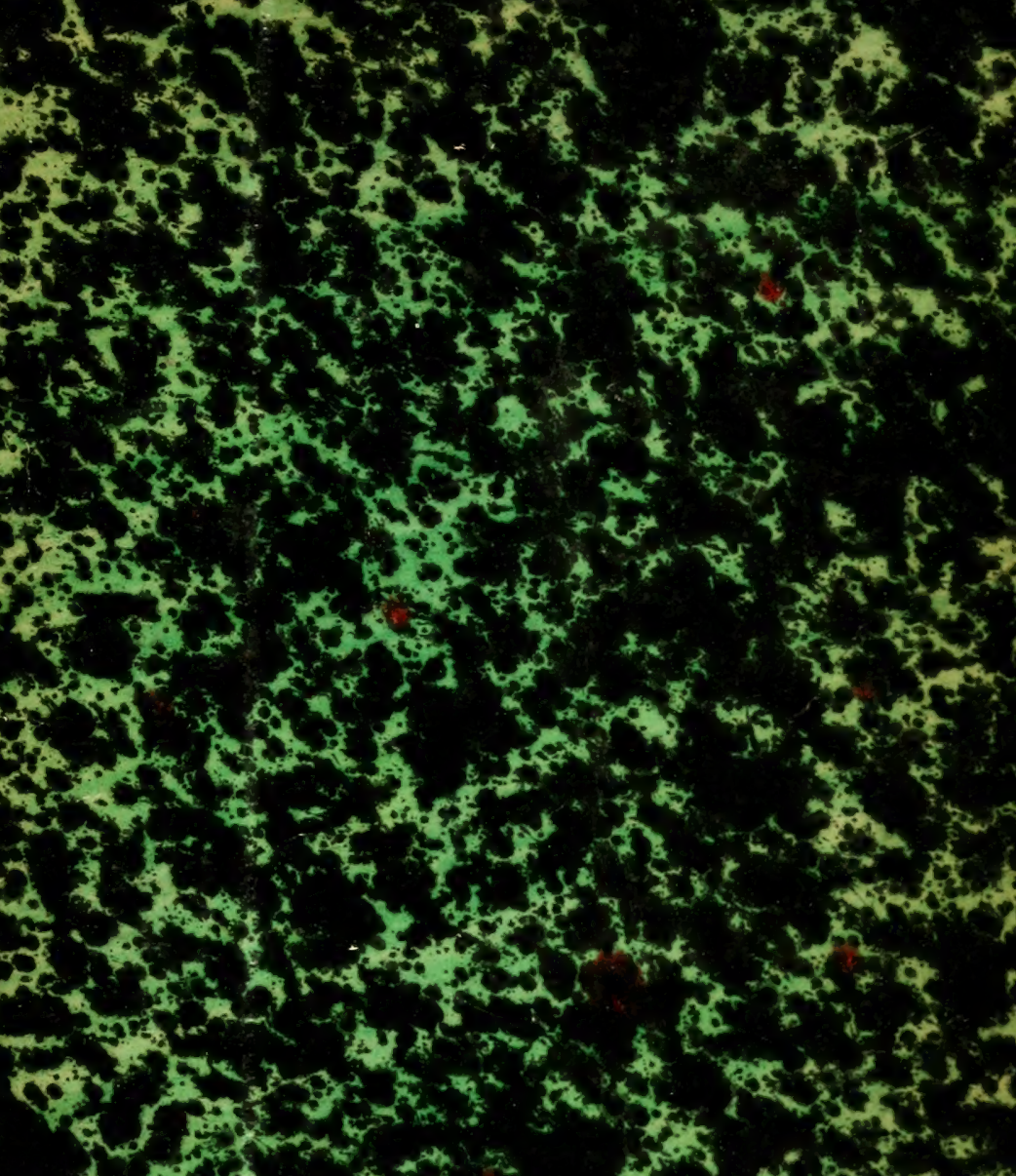

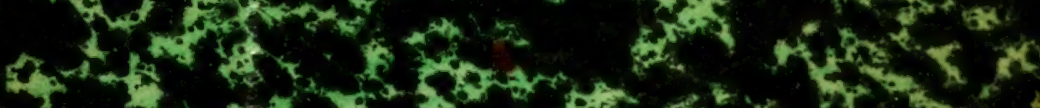

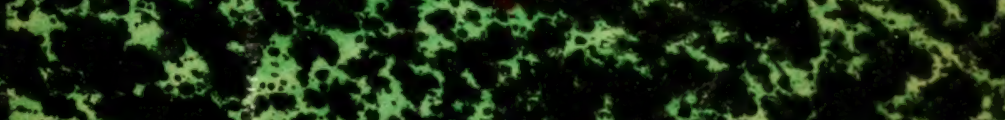
-

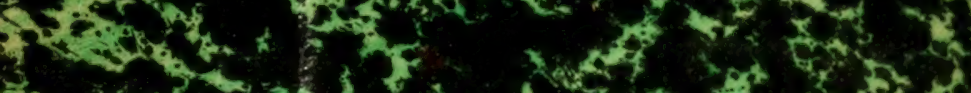

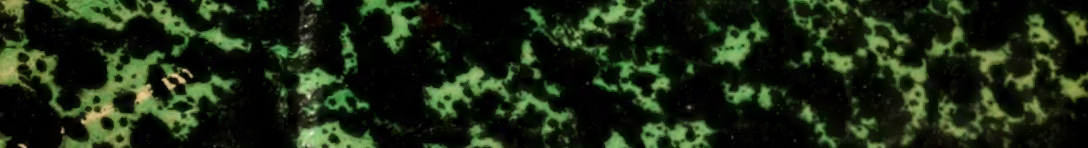

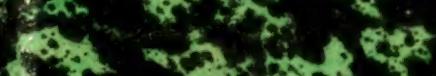

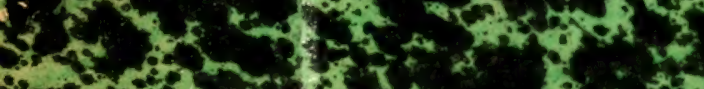

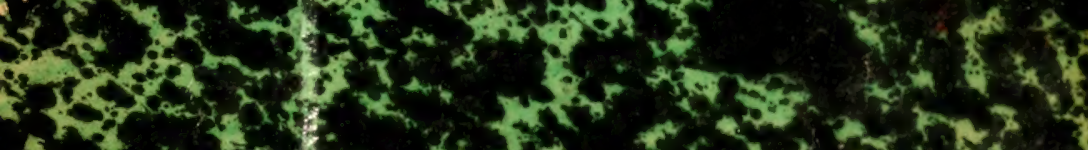

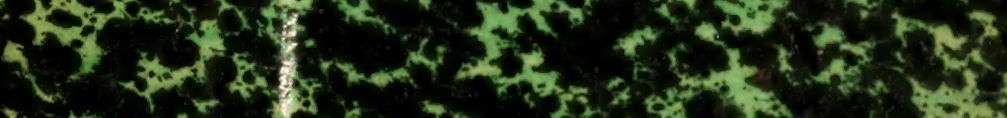

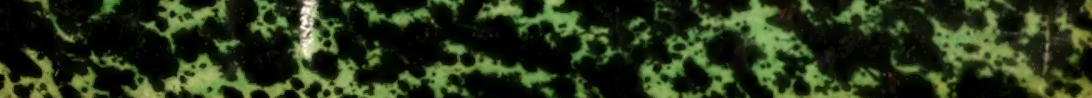




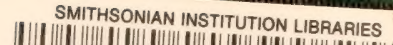

